\title{
ANÁLISIS PALEOBIOLÓGICO DE LOS UNGULADOS DEL PLEISTOCENO SUPERIOR
}

28: DE LA MESETA NORTE 


\title{
UNIVERSIDAD DE SALAMANCA
}

\author{
FACULTAD DE CIENCIAS \\ DEPARTAMENTO DE GEOLOGÍA \\ ÁREA DE PALEONTOLOGÍA
}

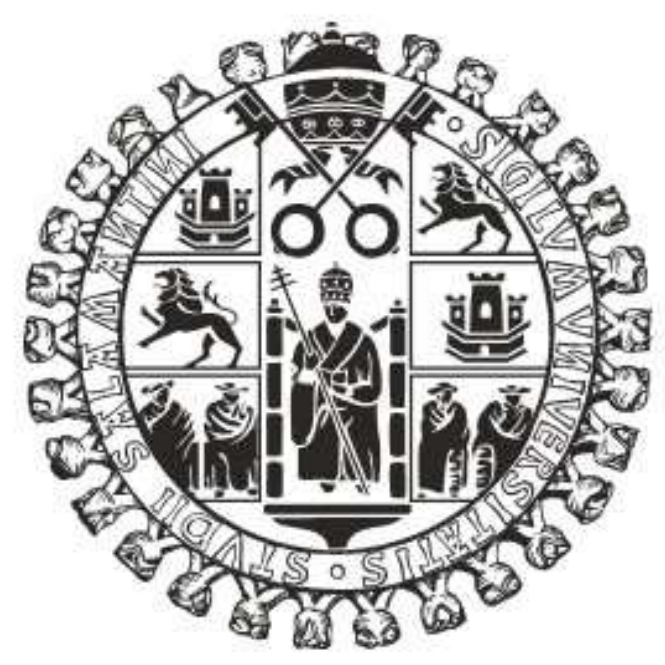

\section{Análisis paleobiológico de los ungulados del Pleistoceno Superior de la Meseta Norte}

\section{TESIS DOCTORAL}

\author{
DIEGO ARCEREDILLO ALONSO
}

SALAMANCA 2015

Directores:

Dr. Jorge Civis Llovera

Departamento de Geología

Universidad de Salamanca
Dr. Jan van der Made

Departamento de Paleobiología

Museo Nacional de Ciencias Naturales 
Memoria para optar al grado de Doctor que presenta D. Diego Arceredillo Alonso, dirigida por el Dr. Jorge Civis Llovera, catedrático de la Universidad de Salamanca y el Dr. Jan van der Made, investigador titular del Departamento de Paleobiología del Museo Nacional de Ciencias Naturales.

Salamanca 2015
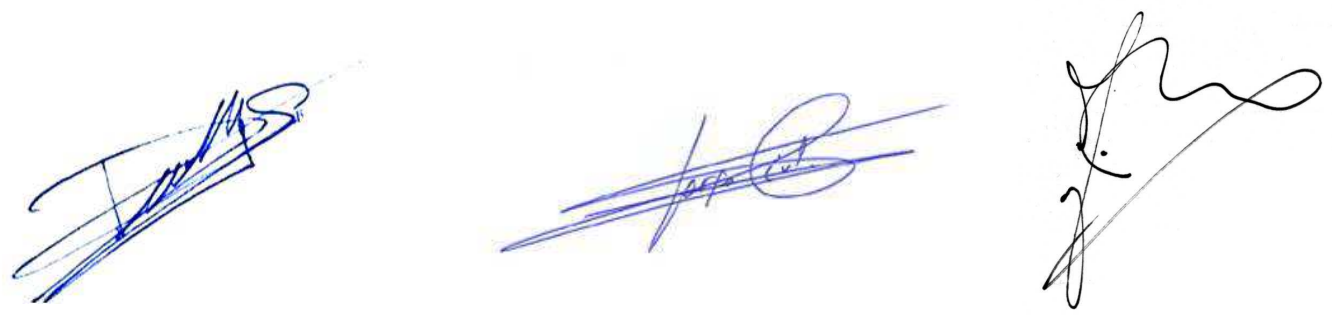

Fdo: Diego Arceredillo Alonso Fdo: Jorge Civis Llovera Fdo: Jan van der Made 
"Las huellas son fósiles de seres vivos, mientras que todos los demás fósiles son reliquias de los muertos"

Richard Swann Lull 
Esta Tesis supone culminar una importante etapa personal y profesional. Es lógico imaginar que una persona con una formación científica oriente su vida profesional a la investigación, sin embargo, la gente que me conoce sabe que este proyecto supone mucho más que un mero título académico. Más allá de todo esto, este trabajo no es sólo un logro individual sino más bien colectivo, el de un equipo del que formo parte desde hace muchos años y cuya pasión es leer este gran libro que es la historia de nuestras raíces. No sólo mis directores y compañeros son parte de este proyecto; sino que los amigos que he ido haciendo en este largo camino me han aportado la energía suficiente para no abandonar, siendo sus consejos, su apoyo y sus ánimos el recurso fundamental que me ha hecho seguir hacia adelante.

En primer lugar, quiero agradecer a mi director Jorge Civis Llovera su apoyo durante todos estos años, la tranquilidad que me ha demostrado durante este recorrido y las facilidades que me ha dado en todo momento. A mi otro director, Jan van der Made, por la formación que me ha proporcionado, por sus consejos y por sus conocimientos que son la base de este estudio.

Un agradecimiento especial merecen los directores del Proyecto Atapuerca: Juan Luis Arsuaga, Eudald Carbonell y José María Bermúdez de Castro, por haber hecho realidad uno de mis sueños de infancia, excavar en los yacimientos de Atapuerca y poder participar en este proyecto. Por supuesto, a mis mentores de la Universidad de Salamanca: María Valle, José Ángel González, Francisco Javier Sierro, Abel Flores, María Rosario Rivas y María Ángeles Bárcena, gracias por vuestra ayuda. Agradezco especialmente a Carlos Díez, Marta Navazo, Pilar Utrilla, Guillermo Molero, Carmen Cacho, Sergio Ripoll, José Alfonso Moure Romanillo y Germán Delibes su esfuerzo y dedicación, que permitieron, tras la excavación de estos yacimientos, recuperar los restos que hoy forman parte de este trabajo.

Agradezco profundamente el apoyo, el cariño y la paciencia que, los compañeros que he tenido más cerca durante estos años, me han demostrado continuamente. Gracias Carlos por haber confiado siempre en mí, por haberme dado esta oportunidad y por la paciencia que has demostrado formándome ya que me han permitido madurar tanto a nivel personal como profesional. A José Miguel Carretero por su apoyo, su interés y por facilitarme el acceso al material que custodia, sin él no hubiera sido posible la realización de parte de este trabajo. Hay que reseñar que muchas de las personas que empezaron siendo mis compañeros de trabajo se han convertido en verdaderos amigos, con las que se pueden compartir experiencias, alegrías y penas. A Marta Navazo, por sus consejos y su apoyo, así como por las largas conversaciones que hemos tenido durante todo este tiempo, que han hecho que pueda continuar en muchas ocasiones. A Marcos Terradillos, ambos hemos compartido el comienzo y el final de nuestros proyectos, su experiencia ha sido tenida en cuenta en este texto. A Javier Marcos, por ser un ejemplo de perseverancia. Por supuesto, a mis compañeros de las áreas de paleontología y arqueología: Felipe, Epi, Paola, Rebeca, Laura, Elena, Amalia, Ana Delia y María.

Son muchos los equipos con los que he colaborado y en los que he hecho muchos amigos, de todos ellos he podido aprender algo. A mis compañeros del Museo de la Evolución Humana: Celia, Silvia, Laura, Miguel Ángel, Andrés, Sergio y Raúl; pero sobre todo a Rodrigo Alonso por su apoyo y ayuda, un verdadero amigo durante estos años. A mis amigos del CENIEH: Mario, Emiliano, Guillermo, Eduardo, Isidoro, Alfonso, Joseba, Teo, Marina, María, Elena, Pilar, Laura, Mani y Claudia por apoyarme en mis malos momentos. Especial es mi agradecimiento y reconocimiento a Asier Gómez, un "tercer director", su apoyo, sus consejos, sus opiniones y su ayuda han sido pilares básicos de esta tesis. Por supuesto a mis amigos del Proyecto Fonelas: Guiomar, Alfonso y Pepe. Gracias por darme la oportunidad de colaborar de ese gran proyecto y por hacerme ver que escuchar es sinónimo de aprender. Y al equipo de Arlanpe, ese pequeño gran proyecto, ejemplo de constancia y perseverancia de que con poco se pueden alcanzar grandes cosas.

A lo largo de estos años he podido realizar mi trabajo gracias a la colaboración de muchas instituciones. Gracias a Pepa Barreiro, del Museo de Ciencias Naturales; a Santiago 
Martínez, del Museo de Segovia; a Jesús Rodríguez, del Centro Nacional de Investigación sobre Evolución Humana; a Juantxo Agirre, de la Sociedad de Ciencias Aranzadi; a Jesús Altuna y Koro Mariezkurrena, del Centro de Custodia de Materiales Arqueológicos y Paleontológicos de Guipúzcoa; a Iñaki García y Diego Gárate, del Arkeologi Museoa de Bilbao; a Isabel Rábano, del Museo Geominero; a Vicente Baldellou, del Museo de Huesca; a Juan Pastor, de la Universidad de Valladolid; a Marian Arlegui, del Museo Numantino; a Marta Negro, del Museo de Burgos y a Aurora Martín del Museo de la Evolución Humana.

En este mismo sentido, he tenido el placer de trabajar en instituciones extranjeras en las que he podido aprender y desarrollar mi trabajo. Gracias a Ernst Vitec y Andrea Larnhof, del Naturhistorisches Museum de Viena; a Jean Philip Brugal, de la Maison Méditerranéenne des Sciences de l'Homme, de l'Université d'Aix-en-Provence; a Thierry Aubry, del Parque Arqueológico do Vale do Côa; a Stéphane Madeleine y Jean Jacques Cleyet, del Musée National de Préhistoire de Francia; y a Beto Pérez, de la Fundación de Historia Natural Félix de Azara. Asimismo, me gustaría agradecer de todo corazón a D. Bluth su trabajo, sin él no estaría aquí.

Me gustaría agradecer especialmente a Eduardo Cerdá la oportunidad de trabajar en Sierra Activa. Ese periodo despertó en mí la pasión por la divulgación. Agradecerle la oportunidad de conocer a las personas que hoy forman parte tanto de su equipo como del de la Fundación Atapuerca: David, Alberto, Sergio, Susana, Rosi, Vanesa, Fani, Tai, Raquel, Nuria, Lorena (s), Belén, Carolina, Iván, Bea, Elena y Virginia, habéis pasado de compañeros a amigos. En el mismo sentido, me gustaría dar las gracias al equipo de la Fundación Atapuerca por seguir contando conmigo en el proyecto divulgativo, gracias Eva, Verónica, Patricia, Fortu, José María y Eudald.

Un agradecimiento especial a mis amigos farmacéuticos por todos esos grandes momentos: Valle, Luis, Raúl y Ángel, muchas gracias. A mis compañeros de "equipo", ese grupo que me ha hecho descubrir una gran afición y con los que he podido compartir tantas experiencias, que me han ayudado a seguir adelante en tantas ocasiones. A Puchi, Iñaki, Álvaro, Pepe, Charly, Nuria, Vanesa, Bea, Celia, Jaime, Sergio, Santi y Carolina. Espero que sigamos teniendo tan buenos momentos como los que hemos tenido hasta ahora. Mis amigos son para mí una parte fundamental. Los "buhardilleros" han sido la verdadera gasolina que ha permitido mover el motor de este trabajo. La paciencia que han demostrado escuchándome y la mayor parte de las veces aguantando las largas charlas, para ellos interesantísimas, no me cabe duda, sobre los ungulados, merecen una mención de honor en este apartado. Luis, Juanma, López, Bruno, Gon, Charly, Javo, Pere, Iñaki, Minguito, Viti, Andrés, Ramiro, Motores, Pablo, Marcos, Jouve, Carlos, Virginia, Esther, María, Raquel, Rosa, Cris, Ceci, Marina, Elena, Lisis, Clara y Marta, gracias de todo corazón.

Finalmente quiero agradecer a mi familia y especialmente a mis padres, a mi hermano y a mi abuela su apoyo e interés constante por mi trabajo, por no dejarme abandonar y que pueda seguir cumpliendo mis sueños. Y por supuesto, al motor de mi vida, Audrey, mi amiga, mi compañera, mi presente y mi futuro. Gracias por escucharme, por animarme, por cuidarme, por entenderme y por quererme. Esta tesis está dedicada a ti, je t'aime.

Seguramente se me olvida alguien, sois muchos los que habéis hecho posible este trabajo. A todos los que estáis y a los que no estáis....gracias.

Este trabajo ha sido realizado gracias a una beca de Formación de Personal Investigador de la Junta de Castilla y León. Además he participado en los proyectos de investigación: "El Pleistoceno y Holoceno en la Sierra de Atapuerca: Paleobiología y Paleoeconomía de las poblaciones humanas III y IV" (CGL2006-13532-C03-03 y CGL200912703-C03-01) dirigidos por José María Bermúdez de Castro; y he percibido ayudas para estancias de investigación en el extranjero de la Universidad de Salamanca y la Unión Europea. 


\section{Índice}




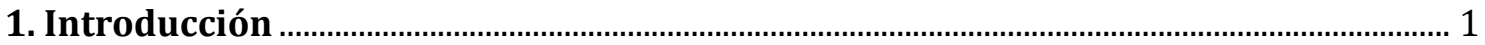

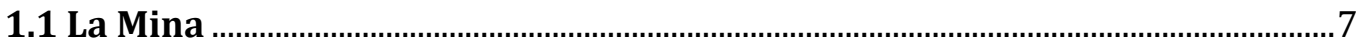

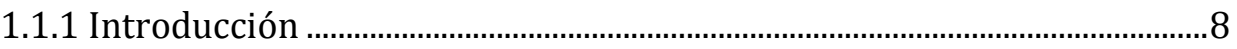

1.1.2 Geología y estratigrafía .......................................................................................8

1.1.3 Restos fósiles ......................................................................................................

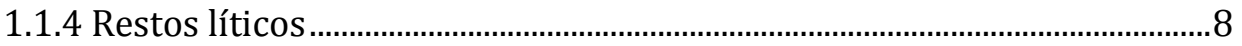

1.1.5 Datación.............................................................................................................

1.2 La Cueva de Valdegoba ................................................................................................

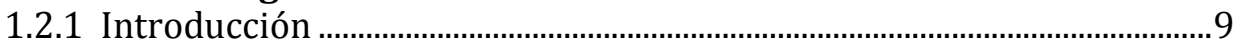

1.2.2 Geología y estratigrafía ....................................................................................

1.2.3 Restos fósiles ........................................................................................... 10

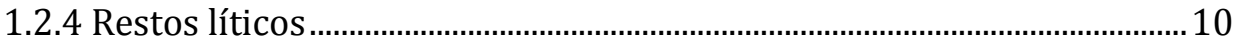

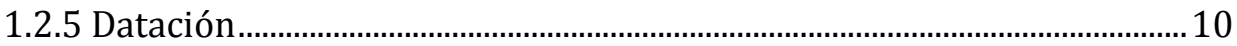

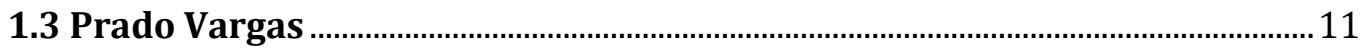

1.3.1 Introducción ................................................................................................. 11

1.3.2 Geología y estratigrafía ............................................................................. 11

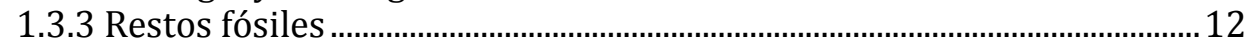

1.3.4 Restos líticos ................................................................................................. 12

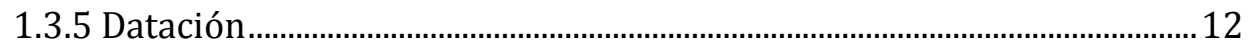

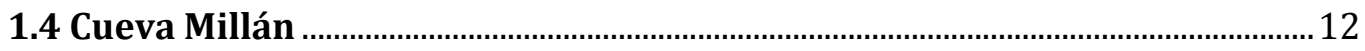

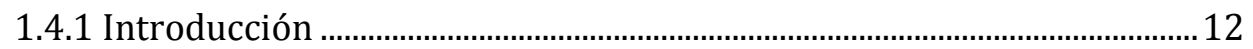

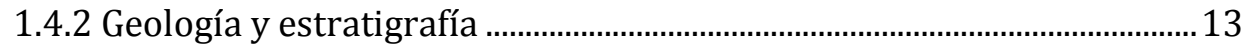

1.4.3 Restos fósiles ............................................................................................ 13

1.4.4 Restos líticos ................................................................................................ 14

1.4.5 Restos polínicos.......................................................................................... 14

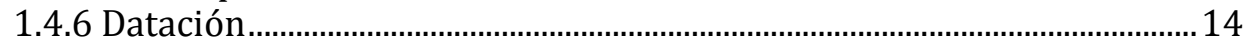

1.5 La Cueva del Búho / Cueva de la Zarzamora ......................................................... 14

1.5.1 Introducción ............................................................................................... 14

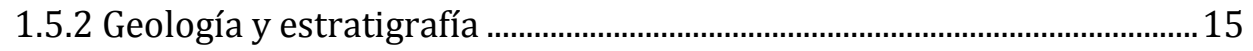

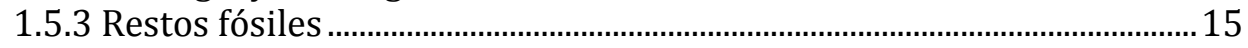

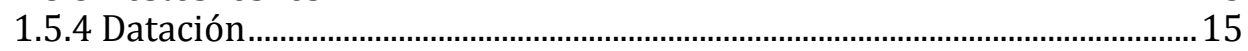

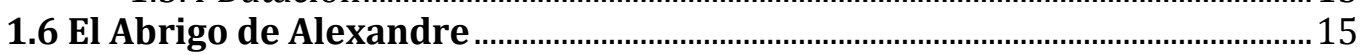

1.6.1 Introducción ............................................................................................ 15

1.6.2 Geología y estratigrafía ................................................................................... 16

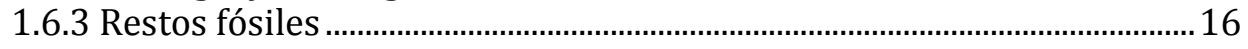

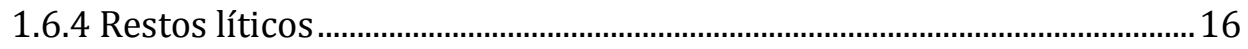

1.6.5 Datación................................................................................................................16

1.7 El Abrigo de Vergara .......................................................................................... 17

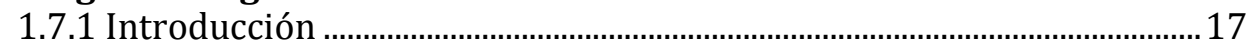

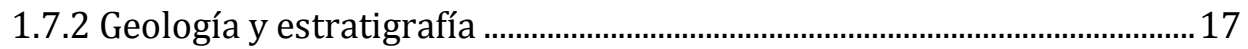

1.7.3 Restos fósiles .............................................................................................. 18

1.7.4 Restos líticos ................................................................................................... 18

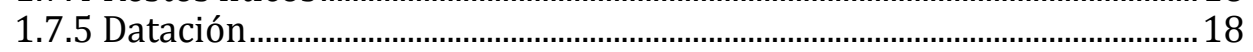

1.8 La Peña de Estebanvela ................................................................................... 18

1.8.1 Introducción ................................................................................................. 18

1.8.2 Geología y estratigrafía ............................................................................. 19

1.8.3 Restos fósiles .................................................................................................. 20

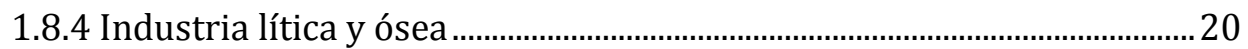

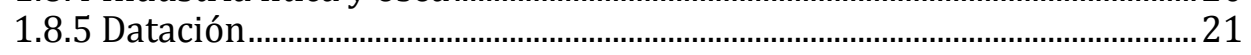

1.9 La Peña de Mudá …………………………………………………………….... 21

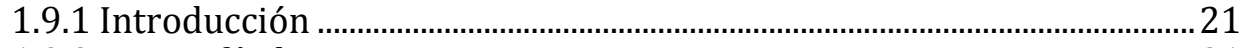

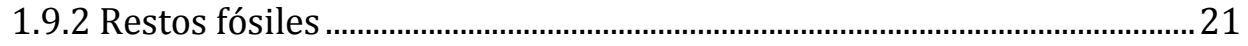

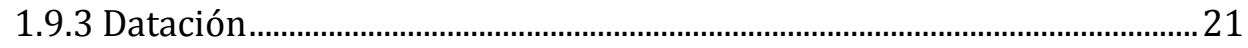

2. Objetivos

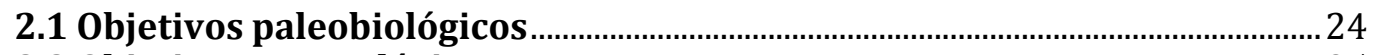

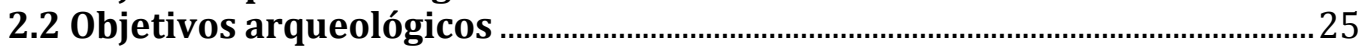

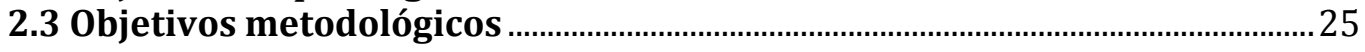




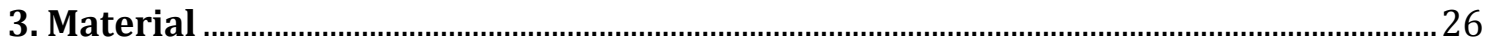

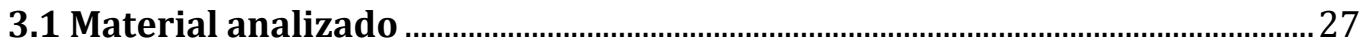

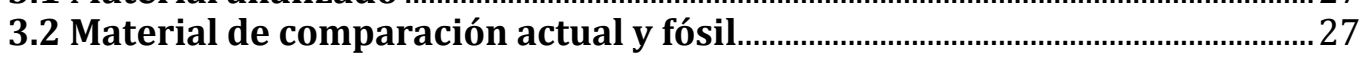

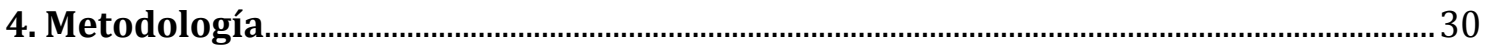

4.1 Paleontología sistemática..................................................................................... 31

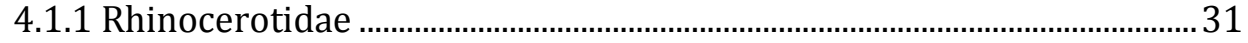

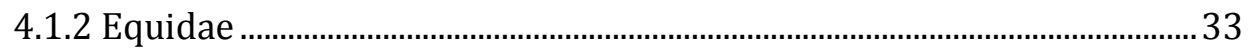

4.1.3 Suidae, Cervidae y Bovidae.............................................................................. 39

4.1.4 Número Mínimo de Individuos ...................................................................... 43

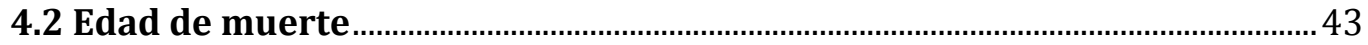

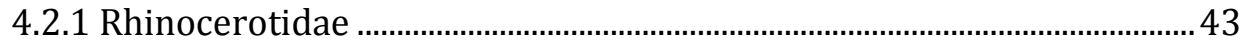

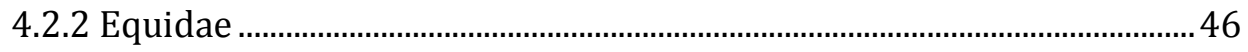

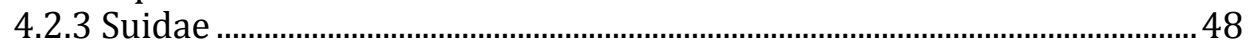

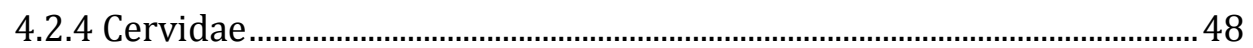

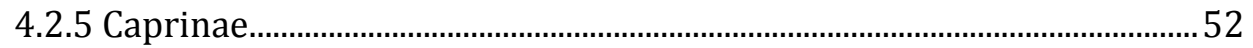

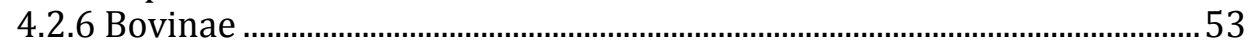

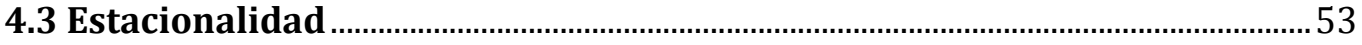

4.4 Bimodalidad y dimorfismo sexual …………………………………………....... 53

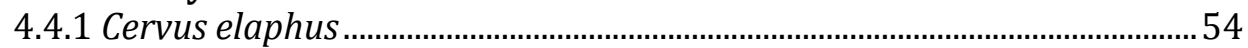

4.4.2 Rupicapra pyrenaica ......................................................................................... 55

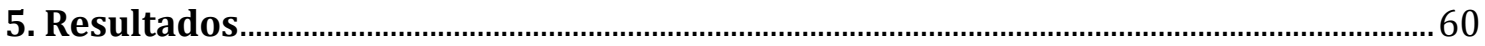

5.1 Stephanorhinus hemitoechus............................................................................... 61

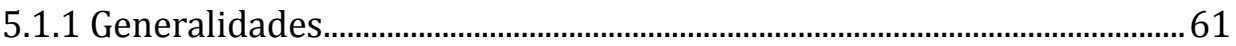

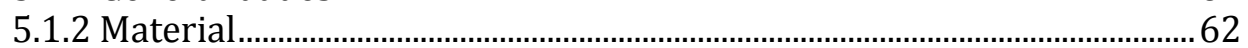

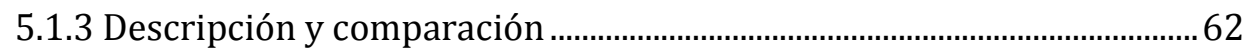

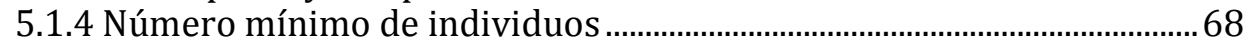

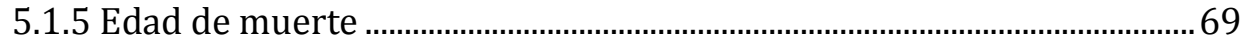

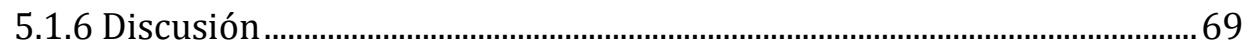

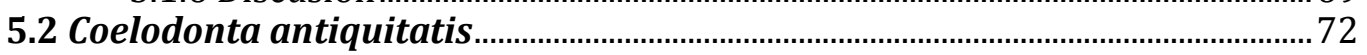

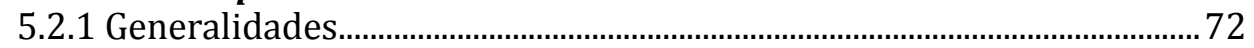

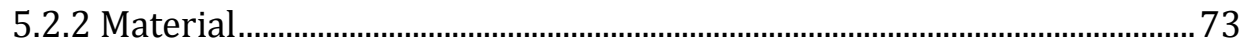

5.2.3 Descripción y comparación ......................................................................... 73

5.2.4 Número mínimo de individuos .................................................................... 74

5.2.5 Edad de muerte ........................................................................................... 74

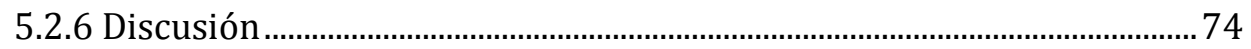

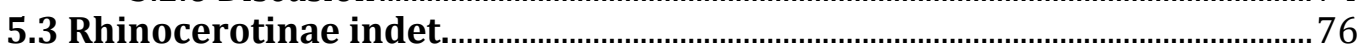

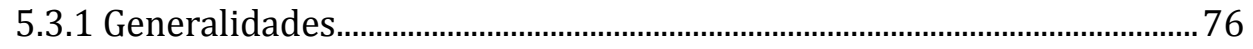

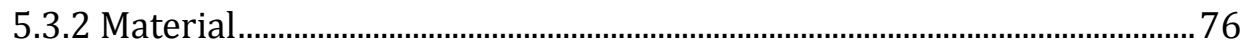

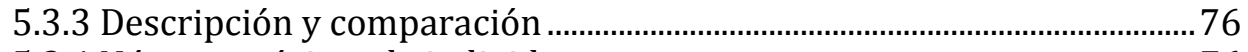

5.3.4 Número mínimo de individuos ......................................................................... 76

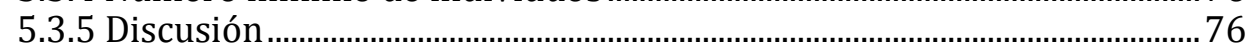

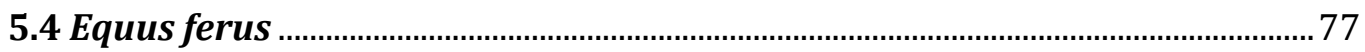

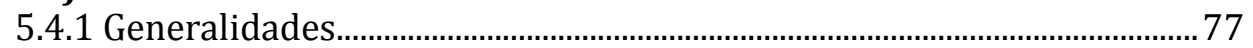

5.4.2 Material....................................................................................................... 78

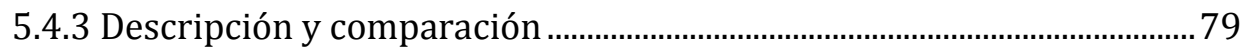

5.4.4 Número mínimo de individuos ....................................................................... 99

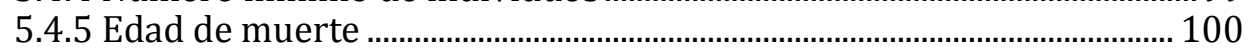

5.4.6 Discusión.................................................................................................. 106

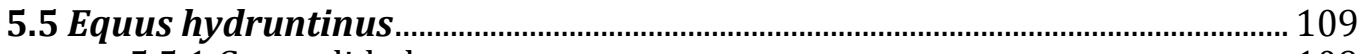

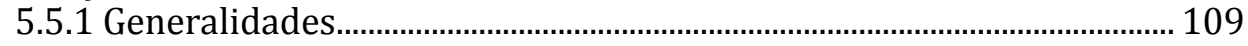

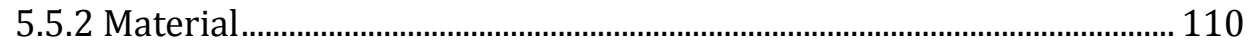

5.5.3 Descripción y comparación ..................................................................... 110

5.5.4 Número mínimo de individuos ..................................................................... 117

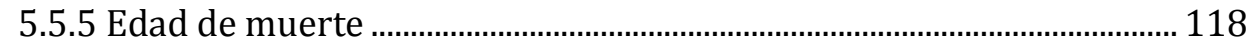

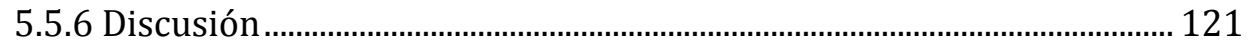

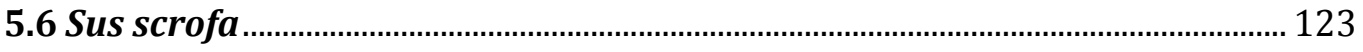




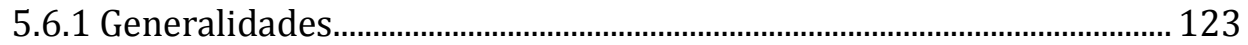

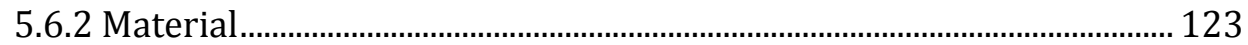

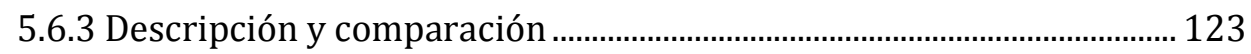

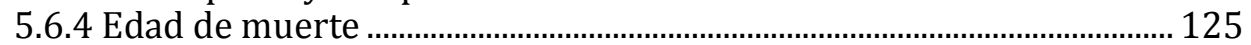

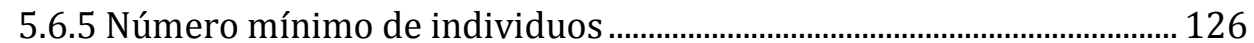

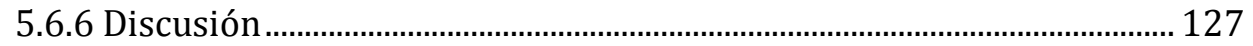

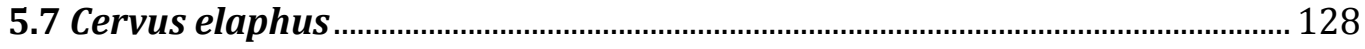

5.7.1 Generalidades............................................................................................ 128

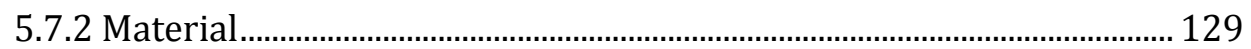

5.7.3 Descripción y comparación ........................................................................ 130

5.7.4 Edad de muerte ....................................................................................... 143

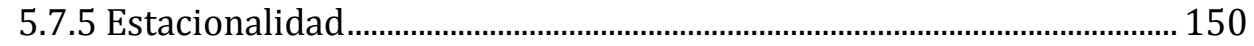

5.7.6 Bimodalidad y dimorfismo sexual ............................................................ 151

5.7.7 Número mínimo de individuos ................................................................. 153

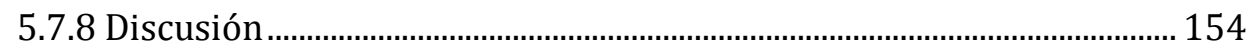

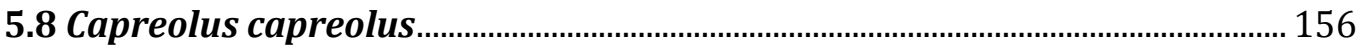

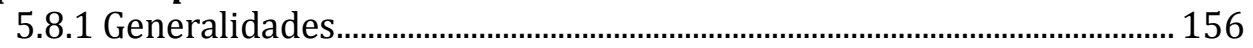

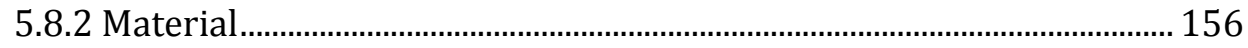

5.8.3 Descripción y comparación .................................................................... 156

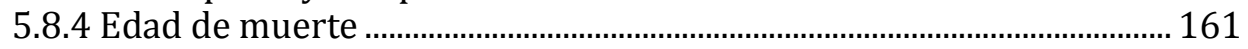

5.8.5 Número mínimo de individuos ……………………………………………….... 161

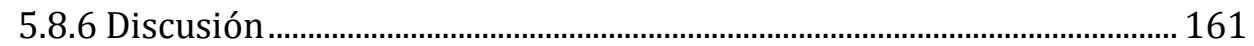

5.9 Rupicapra pyrenaica ……………………………………………………….... 164

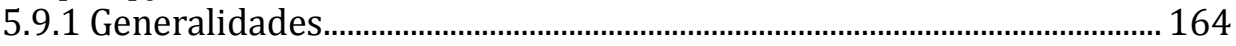

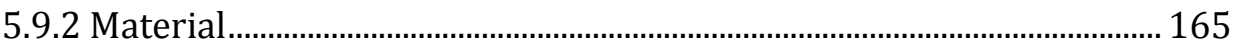

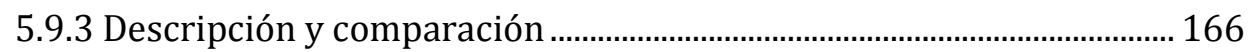

5.9.4 Edad de muerte ................................................................................................ 184

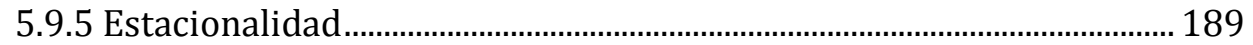

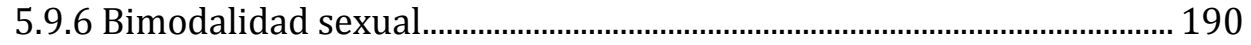

5.9.7 Número mínimo de individuos ................................................................ 196

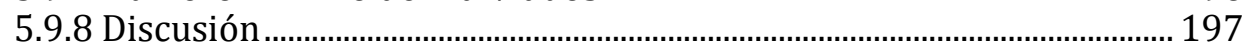

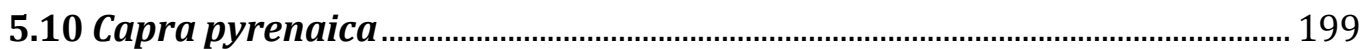

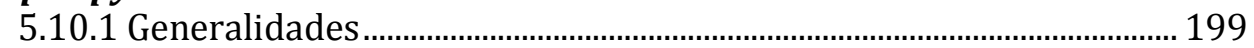

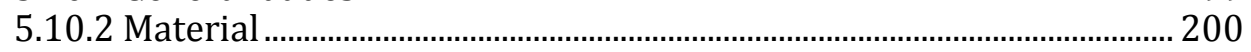

5.10.3 Descripción y comparación.......................................................................... 200

5.10.4 Edad de muerte............................................................................................. 216

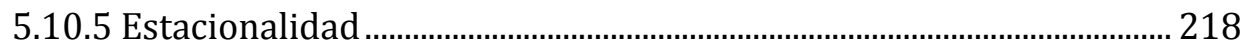

5.10.6 Número mínimo de individuos................................................................. 219

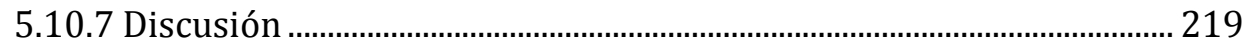

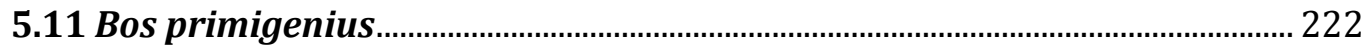

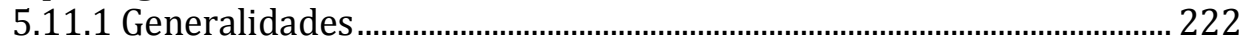

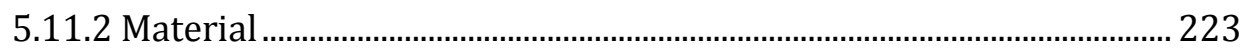

5.11.3 Descripción y comparación...................................................................... 223

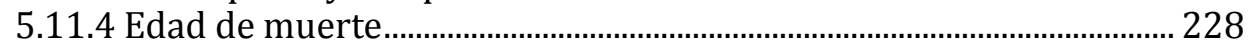

5.11.5 Número mínimo de individuos................................................................... 228

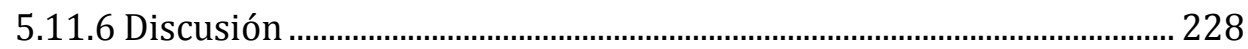

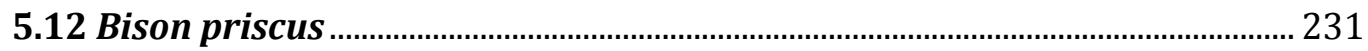

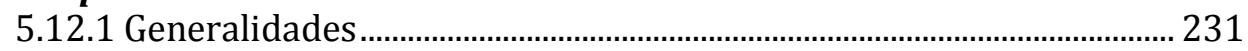

5.12.2 Material .................................................................................................... 231

5.12.3 Descripción y comparación..................................................................... 231

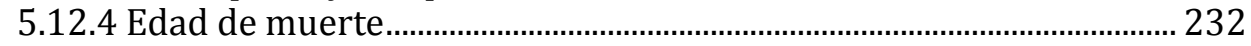

5.12.5 Número mínimo de individuos................................................................... 232

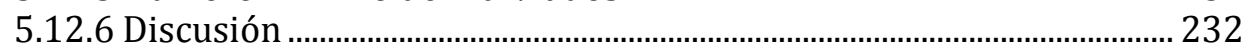

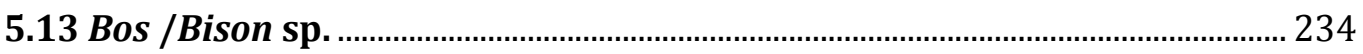

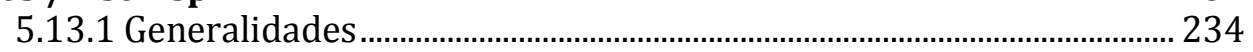

5.13.2 Material ............................................................................................................ 234

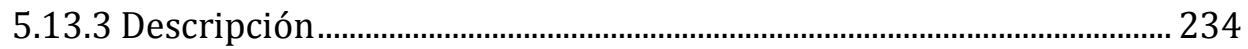

5.13.4 Número mínimo de individuos.................................................................. 238 


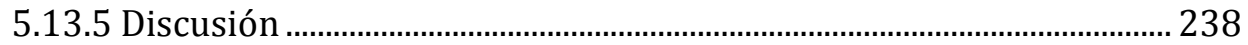

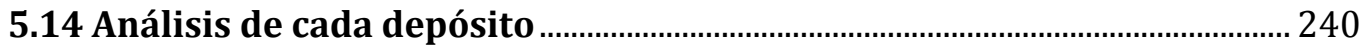

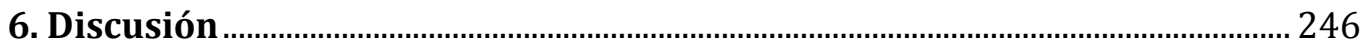

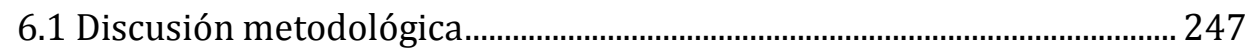

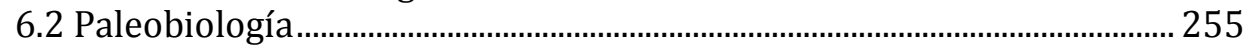

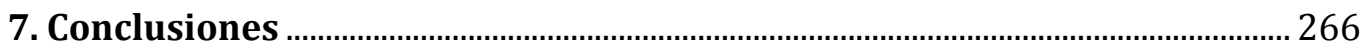

7.1 Conclusiones paleontológicas ................................................................... 267

7.2 Conclusiones relativas a cada uno de los yacimientos estudiados ....... 267

7.3 Conclusiones metodológicas.............................................................................. 269

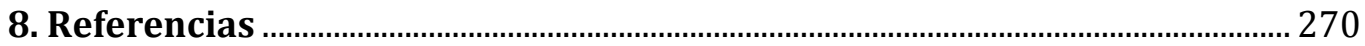

9. Résumé: Analyses Paléobiologiques des ongulés du Pléistocène Supérieur

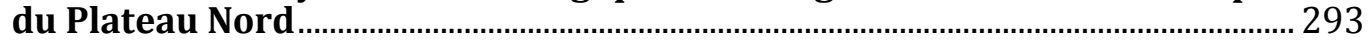


Tabla I.1.1. Resumen de los depósitos estudiados. 22

Tabla III.1.1. Material empleado de cada yacimiento estudiado y en cada capítulo 27

Tabla IV.2.1. Grupos de edad y edad relativa obtenida a partir del desgaste de las piezas de $C$. antiquitatis.

Tabla IV.2.2. Fases de desgaste y edad relativa obtenida a partir del desgaste de las piezas superiores de $C$. antiquitatis.

Tabla IV.2.3. Edad de muerte en Equus ferus relacionada con el desgaste de los dientes yugales inferiores y superiores. 48

Tabla IV.2.4. Edades de erupción dental en Equus ferus. 48

Tabla IV.2.5. Variables morfológicas tomadas en los caninos superiores de C. elaphus ..... 50

Tabla IV.2.6. Edades de erupción dental de los artiodáctilos estudiados (en meses)...........51

Tabla IV.2.7. Altura máxima de la corona estimada para los artiodáctilos a partir del material fósil.

Tabla IV.2.8. Rangos de edad estimados en cada una de las especies estudiadas 52

Tabla IV.3.1. Biología de la reproducción de las especies estudiadas.. 53

Tabla V.1.1. Medidas tomadas en los dientes de S. hemitoechus .63

Tabla V.1.2. Medidas tomadas en los astrágalos de S. hemitoechus. 68

Tabla V.1.3. Número mínimo de individuos de S. hemitoechus. 68

Tabla V.1.4. Rangos de edad de los individuos de S. hemitoechus identificados. .69

Tabla V.2.1. Premolares y molares de $C$. antiquitatis 73

Tabla V.2.2. Rangos de edad de los individuos de C. antiquitatis identificados . .74

Tabla V.4.1. Medidas tomadas en los incisivos deciduales de E. ferus .80

Tabla V.4.2. Medidas tomadas en los molares deciduales inferiores de E. ferus. .81

Tabla V.4.3. Medidas tomadas en los molares deciduales superiores de E. ferus .82

Tabla V.4.4. Medidas tomadas en los incisivos y caninos inferiores de E. ferus .83

Tabla V.4.5. Medidas tomadas en los premolares inferiores de E. ferus .84

Tabla V.4.6. Medidas tomadas en los molares inferiores permanentes de E. ferus.. 87

Tabla V.4.7. Medidas tomadas en los incisivos y caninos superiores permanentes de $E$. ferus .88

TablaV.4.8 Medidas tomadas en los premolares y molares superiores permanentes de $E$. ferus.

Tabla V.4.9. Índices registrados en la dentición de los E. ferus estudiados y otros caballos euroasiáticos. 91 
Tabla V.4.10. Medidas tomadas en las tibias, calcáneos y astrágalos de E. ferus de la Cueva de Valdegoba.

Tabla V.4.11. Medidas tomadas en metacarpos y metatarsos de E. ferus de la Cueva de Valdegoba 95

Tabla V.4.12. Medidas tomadas en las falanges proximales de E. ferus de la Cueva de Valdegoba 98

Tabla V.4.13. Medidas tomadas en las falanges medias de E. ferus de la Cueva de Valdegoba. 98

Tabla V.4.14. Medidas tomadas en las falanges distales de E. ferus de la Cueva de Valdegoba. 99

Tabla V.4.15. Número mínimo de individuos de E. ferus. 100

Tabla V.4.16. Edad de muerte y rango estimado a partir de los dientes permanentes de $E$. ferus de Valdegoba. 101

Tabla V.4.17. Caracteres morfológicos observados en los incisivos de Equus ferus de Valdegoba. 103

Tabla V.4.18. Caracteres morfológicos observados en los incisivos de Equus ferus de Cueva Millán 104

Tabla V.4.19. Edad de muerte y rango estimado a partir de los dientes permanentes de $E$. ferus de Cueva Millán. 104

Tabla V.4.20. Edad de muerte y rango estimado a partir de los dientes permanentes de $E$. ferus de la Peña de Estebanvela 106

Tabla V.4.21. Edad de muerte y rango estimado a partir de los incisivos de E. ferus del nivel 1A de la Peña de Estebanvela. 106

Tabla V.5.1. Medidas tomadas en los incisivos deciduales y permanentes de Equus hydruntinus 110

Tabla V.5.2. Medidas tomadas en los molares deciduales inferiores y superiores de $E$. hydruntinus.

Tabla V.5.3. Medidas tomadas en los premolares y molares inferiores permanentes de $E$. hydruntinus.

Tabla V.5.4. Medidas tomadas en los premolares y molares superiores permanentes de $E$. hydruntinus.

Tabla V.5.5. Índices registrados en la dentición de los E. hydruntinus estudiados y otros caballos euroasiáticos.

Tabla V.5.6. Medidas tomadas en astrágalos de E. hydruntinus... 115

Tabla V.5.7. Medidas tomadas en los metacarpos y metatarsos de E. hydruntinus...

Tabla V.5.8. Medidas tomadas en falanges medias de E. hydruntinus..

Tabla V.5.9. Número mínimo de individuos de E. hydruntinus 
Tabla V.5.10. Alturas de las coronas y rangos de desgaste en los dientes yugales del $E$. hydruntinus de la Cueva de Valdegoba

Tabla V.5.11. Alturas de las coronas y rangos de desgaste en los dientes yugales del $E$. hydruntinus de Cueva Millán

Tabla V.5.12. Alturas de las coronas y rangos de desgaste en los dientes yugales del $E$. hydruntinus de Estebanvela. 120

Tabla V.6.1. Medidas tomadas en los dientes de S. scrofa 124

Tabla V.6.2. Medidas tomadas en el radio de S. scrofa de la Cueva de Valdegoba.. 124

Tabla V.6.3. Medidas tomadas en las falanges de S. scrofa 125

Tabla V.6.4. Número mínimo de individuos de S. scrofa. 126

Tabla V.7.1. Medidas tomadas en los incisivos deciduales de C. elaphus. 131

Tabla V.7.2. Medidas tomadas en los molares deciduales inferiores de C. elaphus 131

Tabla V.7.3. Medidas tomadas en los molares deciduales superiores de C. elaphus. 132

Tabla V.7.4. Medidas tomadas en los incisivos permanentes de C. elaphus 133

Tabla V.7.5. Medidas tomadas en los premolares inferiores de C. elaphus. 134

Tabla V.7.6. Medidas tomadas en los molares inferiores permanentes de C. elaphus....... 136

Tabla V.7.7. Medidas tomadas en los caninos superiores de C. elaphus 137

Tabla V.7.8. Medidas tomadas en los premolares superiores de C. elaphus. 138

Tabla V.7.9. Medidas tomadas en los premolares superiores de C. elaphus. 140

Tabla V.7.10. Medidas de los radios del Cervus elaphus de Valdegoba 141

Tabla V.7.11. Medidas tomadas en los metápodos 141

TablaV.7.12. Medidas tomadas en los astrágalos 142

Tabla V.7.13. Medidas tomadas en las falanges proximales y medias de C. elaphus. 143

Tabla V.7.14. Medidas tomadas en las falanges distales de Cervus elaphus. 143

Tabla V.7.15. Variables morfológicas registradas en los caninos superiores del Cervus elaphus de Valdegoba 144

Tabla V.7.16. Variables métricas tomadas en los caninos superiores del Cervus elaphus de Valdegoba. 144

Tabla V.7.17. Alturas y edades dentales estimadas en el Cervus elaphus de la Cueva de Valdegoba. 145

Tabla V.7.18. Variables morfológicas tomadas en los caninos superiores del Cervus elaphus de Prado Vargas. 
Tabla V.7.19. Variables métricas tomadas en los caninos superiores del Cervus elaphus de Prado Vargas.

Tabla V.7.20. Alturas y edades dentales estimadas en el C. elaphus de Prado Vargas ..... 147

Tabla V.7.21. Variables morfológicas registradas en los caninos superiores del Cervus elaphus de Cueva Millán 148

Tabla V.7.22. Variables métricas tomadas en los caninos superiores del Cervus elaphus de Cueva Millán. 148

Tabla V.7.23. Alturas y edades dentales estimadas en el C. elaphus de Cueva Millán ........ 148

Tabla V.7.24. Alturas y edades dentales estimadas en el Cervus elaphus de la Cueva del Búho 149

Tabla V.7.25. Caracteres morfológicos y métricos de los caninos superiores del Cervus elaphus. 152

Tabla V.7.26. Número mínimo de individuos de Cervus elaphus 153

Tabla V.8.1. Medidas de los incisivos y caninos deciduales y permanentes del C. capreolus de la Cueva de Valdegoba. 157

Tabla V.8.2. Medidas tomadas en los premolares y molares deciduales y permanentes de C. capreolus. 158

Tabla V.8.3. Medidas de los incisivos y caninos deciduales y permanentes del C. capreolus de la Cueva de Valdegoba 159

Tabla V.8.4. Medidas tomadas en los astrágalos del C. capreolus de Valdegoba... 159

Tabla V.8.5. Medidas tomadas en las falanges del C. capreolus de Valdegoba 160

Tabla V.8.6. Número mínimo de individuos de Capreolus capreolus. 161

Tabla V.9.1. Medidas tomadas en los caninos e incisivos deciduales de R. pyrenaica....... 167

Tabla V.9.2. Medidas tomadas en los molares deciduales inferiores de R. pyrenaica ....... 168

Tabla V.9.3. Medidas tomadas en los molares deciduales superiores de R. pyrenaica ..... 169

Tabla V.9.4. Medidas tomadas en los incisivos y caninos inferiores permanentes de $R$. pyrenaica 170

Tabla V.9.5. Medidas tomadas en los premolares inferiores de R. pyrenaica .. 171

Tabla V.9.6. Medidas tomadas en los molares inferiores permanentes de R. pyrenaica.. 172

Tabla V.9.7. Medidas tomadas en los premolares superiores de R. pyrenaica 174

Tabla V.9.8. Medidas tomadas en los molares superiores permanentes de R. pyrenaica 175

Tabla V.9.9. Medidas tomadas en las escápulas del Rupicapra pyrenaica de la Cueva de Valdegoba. 176

Tabla V.9.10. Medidas tomadas en los húmeros del Rupicapra pyrenaica de la Cueva de Valdegoba. 176 
Tabla V.9.11. Medidas tomadas en los radios de R. pyrenaica . 178

Tabla V.9.12. Medidas tomadas en los metacarpos y metatarsos de R. pyrenaica 178

Tabla V.9.13. Medidas tomadas en las patellas del Rupicapra pyrenaica de la Cueva de Valdegoba. 180

Tabla V.9.14. Medidas tomadas en las tibias del Rupicapra pyrenaica de la Cueva de Valdegoba 180

Tabla V.9.15. Medidas tomadas en los astrágalos de R. pyrenaica 181

Tabla V.9.16. Medidas tomadas en los calcáneos del Rupicapra pyrenaica de la Cueva de Valdegoba. 181

Tabla V.9.17. Medidas tomadas en las ulnas del R. pyrenaica de la Cueva de Valdegoba 182

Tabla V.9.18. Medidas tomadas en las falanges proximales y medias de R. pyrenaica ..... 183

Tabla V.9.19. Medidas tomadas en las falanges distales de R. pyrenaica.. 184

Tabla V.9.20. Edad dental estimada en los $\mathrm{D}_{4} \mathrm{y} \mathrm{M}_{1}$ del $R$. pyrenaica de la Cueva de Valdegoba 184

Tabla V.9.21. Edad dental estimada en el R. pyrenaica de Prado Vargas. 187

Tabla V.9.22. Edad dental estimada en el R. pyrenaica de Cueva Millán. 187

Tabla V.9.23. Resultados previos Test Wilcoxon/Mann-Whitney en las extremidades del R. p. parva de la muestra moderna 190

Tabla V.9.24. Resultados obtenidos tras aplicar los tres métodos a la extremidad anterior de la muestra moderna. 191

Tabla V.9.25. Resultados obtenidos tras aplicar los tres métodos a la extremidad posterior de la muestra moderna 192

TablaV.9.26. Estadística descriptiva e Índice de dimorfismo sexual para el k-medias de la muestra de la Cueva de Valdegoba (Vb) comparada con la muestra moderna (Md). 194

Tabla V.9.27. Resultados del K-medias en la muestra de $R$. pyrenaica de la Cueva de Valdegoba. 195

Tabla V.9.28. Diferencias en el dimorfismo sexual de los R. pyrenaica actuales y los de la Cueva de Valdegoba 195

Tabla V.9.29. Número mínimo de individuos de Rupicapra pyrenaica 196

Tabla V.10.1. Medidas tomadas en los incisivos deciduales de C. pyrenaica 201

Tabla V.10.2. Medidas tomadas en los molares deciduales inferiores de Capra pyrenaica de la Cueva de Valdegoba 202

Tabla V.10.3. Medidas tomadas en los molares deciduales superiores de C. pyrenaica... 202

Tabla V.10.4. Medidas tomadas en los incisivos permanentes de C. pyrenaica 203

Tabla V.10.5. Medidas tomadas en los premolares inferiores de C. pyrenaica. 205 
Tabla V.10.6. Medidas tomadas en los molares inferiores permanentes de C. pyrenaica 207

Tabla V.10.7. Medidas tomadas en los premolares superiores de C. pyrenaica. 209

Tabla V.10.8. Medidas tomadas en los molares superiores permanentes de Capra pyrenaica

Tabla V.10.9. Medidas tomadas en los húmeros, radios, tibias y calcáneos de Capra pyrenaica

Tabla V.10.10. Medidas tomadas en los metápodos de C. pyrenaica 212

Tabla V.10.11. Medidas tomadas en los astrágalos de C. pyrenaica 213

Tabla V.10.12. Medidas tomadas en las falanges proximales y falanges medias de $C$. pyrenaica.

Tabla V.10.13. Medidas tomadas en las falanges distales de C. pyrenaica. 215

Tabla V.10.14. Edad dental estimada en los $\mathrm{D}_{4}, \mathrm{M}_{1}$ y $\mathrm{M}_{2}$ de $C$. pyrenaica 216

Tabla V.10.15. Número mínimo de individuos de Capra pyrenaica .... 219

Tabla V.11.1. Medidas tomadas en los dientes de Bos primigenius. 226

Tabla V.11.2. Medidas tomadas en los metápodos de Bos primigenius... 226

Tabla V.11.3. Medidas tomadas en las tibias de Bos primigenius 227

Tabla V.11.4. Medidas tomadas en los astrágalos de Bos primigenius. 227

Tabla V.11.5. Medidas tomadas en los calcáneos de Bos primigenius 228

Tabla V.12.1. Medidas tomadas en Bison priscus. 232

Tabla V.13.1. Medidas tomadas en los incisivos deciduales y permanentes de Bos/Bison sp.

Tabla V.13.2. Medidas tomadas en los molares deciduales inferiores de Bos/Bison sp... 235

Tabla V.13.3. Medidas tomadas en los molares deciduales superiores de Bos/Bison sp. 235

Tabla V.13.4. Medidas tomadas en los premolares de Bos/Bison sp. 236

Tabla V.13.5. Medidas tomadas en los metápodos y calcáneos de Bos/Bison sp. 237

Tabla V.13.6. Medidas tomadas en las falanges de Bos/Bison sp 237

Tabla V.14.1. Resumen de los resultados obtenidos en cada yacimiento 242

Tabla 5.14.2. Número mínimo de individuos y porcentajes de tallas en los depósitos del Paleolítico Medio y Superior 244 
Figura I.1.1 Situación de los yacimientos estudiados en este trabajo

Figura IV.1.1 Terminología empleada en la dentición de 1, 2 y 3) Rhinocerotidae; y 4 y 5 ) Equidae. 1) Premolar superior. 2) Tercer molar superior. 3) Molar inferior. 4) Premolar inferior. 5) Premolar superior..

Figura IV.1.2 Medidas tomadas en el material dental de los rinocerontes. 1) Premolar superior. 2) Tercer molar superior. 3) Premolar inferior .................................................................. 33

Figura IV.1.3. Medidas tomadas en los astrágalos de los rinocerontes.

Figura IV.1.4. Medidas tomadas en el material dental de los équidos. 1) Premolar superior. 2) Premolar inferior. 3) Incisivo. * Todas las medidas excepto IA, IL, Prefl. L. y Postfl. L. se han tomado también en la altura media de la corona...

Figura IV.1.5. Medidas tomadas en el postcráneo de los équidos. 1) Metacarpo II. 2) Metacarpo III. 3) Metacarpo IV. 4) Tibia. 5) Metatarso II. 6) Metatarso III. 7) Metatarso IV. 8) Calcáneo. 9) Astrágalo. 10) Falange proximal. 11) Falange distal. 12) Falange media

Figura. IV.1.6. Terminología empleada en los artiodáctilos. 1) Cuarto premolar inferior. 2) Tercer molar inferior. 3) Cuarto premolar superior. 4) Primer molar superior. + Los asteriscos indican las crestas que van por delante o por detrás de las cúspides principales. * Indica la precrista en la dentición superior y la precristida en la inferior. ${ }^{* *}$ Indica la postcrista en los dientes superiores y la postcrístida en los inferiores. Dichos términos van precedidos del prefijo correspondiente a cada cresta (ej. para - precrista, para-postcrista.

Figura IV.1.7. Medidas tomadas en los incisivos, caninos, premolares y molares de los artiodáctilos. 1) Incisivo. 2) Molar superior. 3) Premolar superior. 4) Molar inferior. 5) Premolar inferior. Las dimensiones DTa, DTp y DTpp se toman a nivel basal, no en la superficie oclusal. 40

Figura IV.1.8. Medidas tomadas en los huesos postcraneales de los artiodáctilos. 1) Escápula. 2) Húmero. 3) Radio. 4) Ulna. 5) Metacarpo. 6) Patella. 7) Tibia. 8) Astrágalo. 9) Calcáneo. 10) Metatarso. 11) Falange proximal. 12) Falange media. 13) Falange distal

Figura IV.2.1. Fases de desgaste observadas en los dientes yugales superiores de $C$. antiquitatis (tomado de Álvarez-Lao, 2007).

Figura IV.2.2. Cambios morfológicos que el desgaste produce en la superficie oclusal de los incisivos de Equus ferus y su edad correspondiente...

Figura IV.2.3. Medidas tomadas en la dentición de los perisodáctilos y artiodáctilos para la estimación de la edad de muerte. 1) Dientes yugales superiores e inferiores de Equus ferus. 2) Caninos superiores de Cervus elaphus. 3) Molares deciduos y permanentes de Rupicapra pyrenaica

Figura IV.2.4. Cambios morfológicos y el desgaste asociado observados en los caninos superiores de C. elaphus (d'Errico y Vanhaeren, 2002).

Figura IV.4.1. Medidas tomadas en los huesos postcraneales de los artiodáctilos para estimar el dimorfismo sexual. 1) Húmero. 2) Radio. 3) Metacarpo. 4) Fémur. 5) Tibia. 6) Metatarso. La variable SDD ha sido tomada en el mismo punto que la SD. Las medidas GL, SD, BD, DM y DL del metatarso son similares a las del metacarpo 56 
Figura V.1.1. Diagramas bivariantes de los premolares inferiores: DTa (diámetro transversal anterior) y DTp (diámetro transversal posterior). S. kirchbergensis de Kirchberg, Bilzingsleben, Mobach, Steinheim, Ehrigsdorf, Taubach, Gimbsheim, Eich. $S$. hemitoechus de Bilzingsleben, Neumark Nord, Steinheim, Ehringsdorf, Taubach, Gimbsheim, Eich (datos aportados por J. van der Made) y Cueva del Búho. Coelodonta antiquitatis de Chlum, Steinheim, Ehringsdorf, Belvedère,. Ariendorf, Backleben, Heldrungen, Kahla, Gimbsheim, Eich (datos tomados de Van der Made, 2010), Lezika y Labeko Koba S. hundsheimensis de Voigtsted, Süssenborn, Soleilhac, Mosbach, Mauer, Ceyssaguet, Soleinac (datos aportados por J. van der Made). 64

Figura V.1.2. Diagramas bivariantes de los molares inferiores permanentes: DTa (diámetro transversal anterior) y DTp (diámetro transversal posterior). S. kirchbergensis de Kirchberg, Bilzingsleben, Mobach, Steinheim, Ehrigsdorf, Taubach, Gimbsheim, Eich. $S$. hemitoechus de Bilzingsleben, Neumark Nord, Steinheim, Ehringsdorf, Taubach, Gimbsheim, Eich, datos aportados por J. van der Made) y Cueva del Búho. $S$. hundsheimensis de Voigtsted, Süssenborn, Soleilhac, Mosbach, Mauer, Ceyssaguet, Soleinac (datos aportados por J. van der Made). Coelodonta antiquitatis de Chlum, Steinheim, Ehringsdorf, Belvedère, Ariendorf, Backleben, Heldrungen, Kahla, Gimbsheim, Eich (datos tomados de Van der Made, 2010), Lezika y Labeko Koba 65

Figura V.1.3. Diagramas bivariantes de los molares superiores permanentes: DTa (diámetro transversal anterior) y DTp (diámetro transversal posterior). S. kirchbergensis de Bilzingsleben, Mobach, Steinheim, Ehrigsdorf, Taubach, Gimbsheim, Eich y Neumark Nord. S. hemitoechus de Bilzingsleben, Neumark Nord, Majolicas, Murr, Ehringsdorf, Gimbsheim, Eich (datos aportados por J. van der Made), Cueva Millán y la Peña de Mudá. $S$. hundsheimensis de Mauer, Süssenborn, Soleinac, Mosbach y Voigtsted (datos aportados por J. van der Made). Coelodonta antiquitatis de Bad Frankenhausen, Ehringsdorf, Ariendorf y Eich (datos aportados por J. van der Made), Lezika y la Peña de Mudá. 66

Figura V.1.4. Diagramas bivariantes de los molares superiores permanentes: DTa (diámetro transversal anterior), DTp (diámetro transversal posterior) y DAPb (diámetro anteroposterior basal). S. kirchbergensis de Bilzingsleben, Mosbach, Steinheim, Ehrigsdorf, Taubach, Gimbsheim, Eich y Neumark Nord. S. hemitoechus de Bilzingsleben, Neumark Nord, Majolicas, Murr, Ehringsdorf, Gimbsheim, Eich (datos aportados por J. van der Made), Cueva Millán, Peña de Mudá y la Cueva de Valdegoba. S. hundsheimensis de Mauer, Süssenborn, Soleinac, Mosbach y Voigtsted (datos aportados por J. van der Made). Coelodonta antiquitatis de Bad Frankenhausen, Ehringsdorf, Ariendorf y Eich (datos aportados por J. van der Made), Lezika y Labeko Koba.....

Figura V.1.5. Diagrama bivariante del astrágalo: Lm (longitud mínima) y Lint (longitud medial). Stephanorhinus kirchbergensis de Bilzingsleben, Ehringsdorf y Taubach, Stephanorhinus hemitoechus de Bilzingsleben, Ehringsdorf, Taubach (datos aportados por J. van der Made) y la Cueva de Valdegoba. Coelodonta antiquitatis de Zasuhino, Chlum, Wannen y Heringen (datos aportados por J. van der Made). 67

Figura V.3.1. Rhinocerotidae indet. proveniente del yacimiento de Prado Vargas (sigla VA). 1. VA.D-4.75 - Fragmento de esmalte de diente indeterminado . .76

Figura V.4.1. Diagramas bivariantes de los premolares inferiores: DAP (diámetro anteroposterior) y DT (diámetro transversal). E.f.torralbae de Atapuerca, Pedraza, Las Yedras, Torralba, Pinilla del Valle, Cova Negra y Transfesa. E.f.antunesi de la Carihuela. E.f.mosbachensis de Mosbach y L'Arago. E.f.taubachensis de Taubach. E.f.casarensis de Los Casares. E. stenonis de Atapuerca, Saint Vallier, Senéze, Venta Micena, Huélago y Baza 1. E. hydruntinus de la Carihuela, Abri Suard, Arcy y Prolom (Eisenmann y Baryshnikov, 1994; Maldonado, 1996).

Figura V.4.2. Diagramas bivariantes de los molares inferiores permanentes: DAP (diámetro anteroposterior) y DT (diámetro transversal). E.f.torralbae de Atapuerca, 
Torralba, Pinilla del Valle y Transfesa. E.f.antunesi de la Carihuela. E.f.mosbachensis de Mosbach y L'Arago. E.f.taubachensis de Taubach. E. stenonis de Chatillon Saint. E. hydruntinus de la Carihuela, Arcy y Prolom (Eisenmann y Baryshnikov, 1994; Maldonado, 1996)......

Figura V.4.3. Diagramas bivariantes de los premolares superiores permanentes: DAP (diámetro anteroposterior), DT (diámetro transversal) y PL (longitud del protocono). E.f.torralbae de Atapuerca, Villacastín, Las Yedras, Torralba, Pinilla del Valle, Cova Negra y Transfesa. E.f.antunesi de la Carihuela y Salemas. E.f.mosbachensis de Mosbach y L'Arago. E. hydruntinus de la Carihuela, Bourgeois Delaunay, Combe Grenal, La Ferrasie, Saint Germain la Riviere, Agios Georgios, Abric Romani, Arcy y Prolom (Eisenmann y Baryshnikov, 1994; Maldonado, 1996). 90

Figura V.4.4. Diagramas bivariantes de los molares superiores permanentes: DAP (diámetro anteroposterior), DT (diámetro transversal) y PL (longitud del protocono). E.f.torralbae de Atapuerca, Villacastín, Torralba, Pinilla del Valle y Cova Negra. E.f.antunesi de la Carihuela. E.f.mosbachensis de Mosbach y L'Arago. E. hydruntinus de la Carihuela, Bourgeois Delaunay, Combe Grenal, La Ferrasie, Fontarnaud, Pair non Pair, Agios Georgios, Binagady y Prolom (Eisenmann y Baryshnikov, 1994; Maldonado, 1996)...

Figura V.4.5. Diagramas bivariantes de los terceros metacarpos: BD (anchura epífisis distal), GL (longitud máxima), BDa (anchura articular distal), IR (índice de robustez). E.f.torralbae de Torralba, Pinilla del Valle, Atapuerca, Solana de Zamborino y Las Yedras. E.f.antunesi de la Carihuela, Salemas, Fontahinas y Jöao Ramos. E.f.mosbachensis de Mosbach, Achenheim y Lune Viel .E.f.germanicus de Pain non Pair. E.f.gallicus de Solutre y Saint Germain de la Riviere. E. stenonis de Chatillon Saint Jean. E.f.przewalskii actual (datos Maldonado, 1996).

Figura V.4.6. Diagramas bivariantes de los terceros metatarsos: BD (anchura epífisis distal), GL (longitud máxima) y BDa (anchura articular distal), IR (índice de robustez). E.f.torralbae de Torralba, Pinilla del Valle, Atapuerca, Solana de Zamborino y Las Yedras. E.f.antunesi de la Carihuela, Salemas, Fontahinas y Jöao Ramos. E.f.mosbachensis de Mosbach, Achenheim y Lune Viel . E.f.germanicus de Pain non Pair. E.f.gallicus de Solutre y Saint Germain de la Riviere. E. stenonis de Chatillon Saint Jean. E.f.przewalskii actual (datos de Maldonado, 1996) 96

Figura V.4.7. Desgaste en los dientes yugales y rangos de edad observados en los incisivos del Equus ferus de la Cueva de Valdegoba 102

Figura V.4.8. Desgaste dental en las piezas permanentes del Equus ferus de la Peña de Estebanvela 105

Figura V.51. Desgaste en los dientes yugales del Equus hydruntinus de la Cueva de Valdegoba.. 118

Figura V.5.2. Desgaste en los dientes yugales del Equus hydruntinus de la Peña de Estebanvela. 120

Figura V.7.1. Diagramas bivariantes de los premolares inferiores: DAP (diámetro anteroposterior) y DT (diámetro transversal). C. elaphus de Atapuerca (TG, TE) (Van der Made, 1999), Abric Romaní (Sánchez, 1990), Majolicas (Domingo y Alberdi, 2004), Fate, Manie, Madonna (Psathi, 2003), Mendandia (Alay-Ruiz, 2006), Prince Cave (Arellano Alonso, 2004), Combe Grenal (Guadelli, 1987), La Ferrasie (Delpech, 1984), Lazaret, Orgnac, Bau l'Aubesier, Bianche St. Vaast, Tournal (Magniez, 2010), Vaufrey (Delpech, 1988), Jarama VI, Buraca Escura, Lezika y Abauntz. Dama dama de Atapuerca (TG y TE) (Van der Made, 1999) y Maltravieso. Rangifer tarandus de Atxuri, Arlanpe, Urtiagako Leizea, Armotxe y Aitzbitarte IV. Megaloceros giganteus de Atapuerca (Van der Made, 1999). 
Figura V.7.2. Diagramas bivariantes de los molares inferiores: DAP (diámetro anteroposterior) y DT (diámetro transversal). C. elaphus de Atapuerca (TG, TE) (Van der Made, 1999), Abric Romaní (Sánchez, 1990), Majolicas (Domingo y Alberdi, 2004), Mendandia (Alday-Ruiz, 2006), Fate, Manie, Madonna (Psathi, 2003), Prince Cave (Arellano Alonso, 2004), Combe Grenal (Guadelli, 1987), La Ferrasie (Delpech, 1984), Lazaret, Orgnac, Bau l'Aubesier, Bianche St. Vaast, Tournal (Magniez, 2010), Vaufrey (Delpech, 1988), Jarama VI, Buraca Escura, Lezika y Abauntz. Dama dama de Atapuerca (TG y TE) (Van der Made, 1999) y Maltravieso. Rangifer tarandus de Atxuri, Arlanpe, Urtiagako Leizea, Armotxe y Aitzbitarte IV. Megaloceros giganteus de Atapuerca (Van der Made, 1999) 137

Figura V.7.3. Diagramas bivariantes de los molares inferiores: DAP (diámetro anteroposterior) y DT (diámetro transversal). C. elaphus de Atapuerca (TG, TE) (Van der Made, 1999), Abric Romaní (Sánchez, 1990), Majolicas (Domingo y Alberdi, 2004), Mendandia (Alday-Ruiz, 2006), Fate, Manie, Madonna (Psathi, 2003), Prince Cave (Arellano Alonso, 2004), Combe Grenal (Guadelli, 1987), La Ferrasie (Delpech, 1984), Lazaret, Orgnac, Bau l'Aubesier, Bianche St. Vaast (Magniez, 2010), Vaufrey (Delpech, 1988), Jarama VI, Lezika y Abauntz Dama dama de Atapuerca (TG y TE) (Van der Made, 1999) y Maltravieso. Rangifer tarandus de Bolinkoba, y Armotxe. 139

Figura V.7.4. Diagramas bivariantes de los molares superiores: DAP (diámetro anteroposterior) y DT (diámetro transversal). C. elaphus de Atapuerca (TG, TE) (Van der Made, 1999), Abric Romaní (Sánchez, 1990), Majolicas (Domingo y Alberdi, 2004), Mendandia (Alday-Ruiz, 2006), Fate, Manie, Madonna (Psathi, 2003), Prince Cave (Arellano Alonso, 2004), Combe Grenal (Guadelli, 1987), La Ferrasie (Delpech, 1984), Lazaret, Orgnac, Bau l'Aubesier, Bianche St. Vaast, (Magniez, 2010), Vaufrey (Delpech, 1988), Jarama VI, Buraca Escura, Lezika y Abauntz. Dama dama de Atapuerca (TG y TE) (Van der Made, 1999)

Figura V.7.5. Desgaste en los dientes yugales del Cervus elaphus de la Cueva de Valdegoba. Datos obtenidos con el modelo de desgaste y erupción. 145

Figura V.7.6. Comparativa entre los dos modelos de estimación de la edad de muerte en los Cervus elaphus de la Cueva de Valdegoba 146

Figura V.7.7. Comparativa entre los dos modelos de estimación de la edad de muerte en los Cervus elaphus de Prado Vargas. 147

Figura V.7.8. Comparativa entre los dos modelos de estimación de la edad de muerte en los Cervus elaphus del nivel 1A de Cueva Millán 148

Figura V.7.9. Desgaste en los dientes yugales del Cervus elaphus de Cueva Millán. Datos obtenidos con el modelo de desgaste y erupción. 149

Figura V.7.10. Desgaste en los dientes yugales del Cervus elaphus de la Cueva del Búho. Modelo de desgaste y erupción. Comparativa entre los dos modelos de estimación... 150

Figura V.7.11. Estacionalidad general y por rangos de edad del Cervus elaphus de la Cueva de Valdegoba. 151

Figura V.7.12. Caninos superiores de Cervus elaphus de la Cueva de Valdegoba. 1) Vb-sp2339. 2) Vb-sp-2286. 3) Vb-sp-2279. 4) Vb-sp-2283. 5) Vb.06.L13.Dad.85-90. 6) Vb-sp2268. 7) Vb-sp-3178. 8) Vb.06.J12.Cc.70-75. 9) Vb.06.L13.Ad.65-70. 152

Figura V.7.13. Caninos superiores de Cervus elaphus de: 1 y 2) Cueva Millán y 3) Prado Vargas. 1 y 2) CM86.1A.8J. 3) PV06.45.H31.208. 152 
Figura V.9.1. Dientes inferiores del $R$. pyrenaica de la Cueva de Valdegoba que presentan una columna accesoria. 1) Vb-sp-1995 - $\mathrm{D}_{4}$ izquierdo: cara bucal. 2) Vb-sp-1884 - $\mathrm{M}_{1}$ derecho: cara lingual. 3) Vb-sp-1885 $-\mathrm{M}_{1}$ derecho: cara lingual. 4) Vb-sp-1886 $-\mathrm{M}_{2}$ derecho: cara lingual. 5) Vb-03 M3 $32-\mathrm{M}_{3}$ derecho: cara lingual. 6) Vb.03.M3.18 $-\mathrm{M}_{3}$ derecho: cara lingual. 168

Figura V.9.2. Diagramas bivariantes de los molares inferiores permanentes: DAP (diámetro anteroposterior) y DT (diámetro transversal). $R$. pyrenaica de Orgnac 3 , Le Portel (Fernández y Crégut-Bonnoure, 2007), Erralla, Arlanpe, Jarama VI. R. rupicapra de Abric Romani (Sánchez, 1990), Nacimiento (Álferez et al., 1980 - 1981), Abauntz, Lezika, Lezikako Koba (Castaños et al., 2009), La Riera (Straus et al., 1986), Le Gras (Fernández y Crégut-Bonnoure, 2007) 173

Figura V.9.3. Diagramas bivariantes de los molares superiores: DAP (diámetro anteroposterior) y DT (diámetro transversal). R. pyrenaica de Arlanpe, Jarama VI, Buraca Escura, Arago, Portel (Fernández y Crégut-Bonnoure, 2007), Abri Marcq (Rivals, 2002) y Salemas (Álferez et al., 1980 - 1981) 175

Figura V.9.4. Diferencias observadas en las escápulas, húmeros, radios, tibias, astrágalos y calcáneos de: 1) R. rupicapra ( 9 actuales $(1,3,5,7,9$ y 11). 2) R. pyrenaica ( O actuales (2, $4,6,8,10$ y 12$)$. 177

Figura V.9.5. Diferencias observadas en metacarpos y metatarsos de: 1) R. rupicapra ( 9 actuales $(1,3) .2$ ) $R$. pyrenaica ( P actuales $(2,4)$.

Figura V.9.6. Desgaste en los dientes yugales del Rupicapra pyrenaica de la Cueva de Valdegoba. Datos obtenidos con el modelo de desgaste y erupción 186

Figura V.9.7. Comparativa entre los dos modelos de estimación de la edad de muerte en el Rupicapra pyrenaica de la Cueva de Valdegoba 186

Figura V.9.8. Comparativa entre los dos modelos de estimación de la edad de muerte en el Rupicapra pyrenaica de Prado Vargas.

Figura V.9.9. Desgaste en los dientes yugales del Rupicapra pyrenaica del nivel $1 \mathrm{~A}$ de Cueva Millán. Datos obtenidos con el modelo de desgaste y erupción 188

Figura V.9.10. Comparativa entre los dos modelos de estimación de la edad de muerte en el Rupicapra pyrenaica del nivel 1A de Cueva Millán 188

Figura V.9.11 Estacionalidad general y por rangos de edad del Rupicapra pyrenaica de la Cueva de Valdegoba (Vb) y Prado Vargas (PV). 189

Figura V.9.12. Estacionalidad general y por rangos de edad del Rupicapra pyrenaica de los niveles $1 \mathrm{~A}$ y $1 \mathrm{~B}$ de Cueva Millán. 190

Figura V.10.1. Diagramas bivariantes de los premolares inferiores: DAP (diámetro anteroposterior) y DT (diámetro transversal). C. pyrenaica de Arlanpe, Buraca Escura, Jarama VI, Abric Romani (Sánchez, 1990), Tournal y Le Portel (Crégut-Bonnoure, 1992b). C. ibex de Adaouste (Rivals, 2006). H. cedrensis de l'Arago, les Cèdres (Rivals, 2006) y Bau de l'Aubesier (Rivals y Blasco, 2008). H. bonali de l'Arago (Rivals, 2006) y les Cèdres (Rivals, 2006) 204

Figura V.10.2. Diferencias observadas en los $\mathrm{P}_{3}$ de: 1) Ovis (actual). 2) Capra (Cueva de Valdegoba). 3) Hemitragus (l'Escale). 4) Saiga (actual) 205

Figura V.10.3 Diferencias observadas en los $\mathrm{P}_{4}$ de 1) Ovis (actual). 2) Capra (Cueva de Valdegoba). 3) Hemitragus (l'Escale). 4) Saiga (actual). 206 
Figura V.10.4. Diferencias observadas en los $\mathrm{M}_{1}$ y $\mathrm{M}_{2}$ de 1) Ovis (actual). 2) Capra (Cueva de Valdegoba). 3) Hemitragus (l'Escale). 4) Saiga (actual) .......................................................... 206

Figura V.10.5. Diferencias observadas en los $\mathrm{M}_{3}$ de 1) Ovis (actual). 2) Capra (Cueva de Valdegoba). 3) Hemitragus (l'Escale). 4) Saiga (actual)..

Figura V.10.6. Diagramas bivariantes de los molares inferiores permanentes: DAP (diámetro anteroposterior) y DT (diámetro transversal). C. pyrenaica de Abric Romani (Sánchez, 1990), Tournal, Le Portel (Crégut-Bonnoure, 1992b), Buraca Escura y Jarama VI. C. ibex de Adaouste y Petralona (Rivals, 2006). C. caucasica de Kozarnika, Koudaro I y III, Ortvala (Fernández y Crègut-Bonnoure, 2007), Sakajia, Tsutskhavati, l'Arago, Le Portel, Baume Moula-Guercy, Saint Marcel y Dzudzuana (Rivals, 2006). H. cedrensis de Les Cèdres, Bau de l'Aubesier y Rigabe (Rivals, 2006). H. bonnali de l'Escale y l'Arago (Rivals, 2006)208

Figura V.10.7. Diagramas bivariantes de los premolares superiores: DAP (diámetro anteroposterior) y DT (diámetro transversal). C. pyrenaica de Abric Romani (Sánchez, 1990), Tournal, Le Portel (Crégut-Bonnoure, 1992) y Buraca Escura. C. ibex de Adaouste (Rivals, 2006). C. caucasica de l'Arago (Rivals, 2002), Kozarnika y Koudaro I y III (Fernández y Crègut-Bonnoure, 2007). H. cedrensis de Les Cèdres, Bau de l'Aubesier y Bolomor (Rivals, 2006; Rivals y Blasco, 2008). H. bonnali de l'Escale (Rivals, 2006)......... 208

Figura V.10.8. Diagramas bivariantes de los molares superiores: DAP (diámetro anteroposterior) y DT (diámetro transversal). C. pyrenaica de Abric Romani (Sánchez, 1990), Tournal, Le Portel (Crégut-Bonnoure, 1992), Jarama VI y Buraca Escura. C. ibex de Adaouste (Rivals, 2006). C. caucasica de l'Arago (Rivals, 2002), Kozarnika, Koudaro I y III, Ortvala (Fernández y Crègut-Bonnoure, 2007) y Sakajia (Rivals, 2006). H. cedrensis de Les Cèdres, Bau de l'Aubesier y Bolomor (Rivals, 2006; Rivals y Blasco, 2008). H. bonnali de l'Escale (Rivals, 2006).

Figura V.10.9. Polimorfismo observado en las alas metastilares del $\mathrm{M}^{3}$. 1) Vb-sp-2652. 2) Vb-sp-2650. 3) PV06 45 H32 76 3. 4) PE.02.E11.NIII.6. 5) Vb-sp-2635. 6) Vb-sp-2662 ... 211

Figura V.10.10. Desgaste en los dientes yugales de la Capra pyrenaica de la Cueva de Valdegoba. Datos obtenidos con el modelo de desgaste y erupción 216

Figura V.10.11. Comparativa entre los dos modelos de estimación de la edad de muerte en la Capra pyrenaica de la Cueva de Valdegoba 217

Figura V.10.12. Estacionalidad general y por rangos de edad de Capra pyrenaica en la Cueva de Valdegoba 218

Figura V.11.1. Diagramas bivariantes de los molares inferiores: DAP (diámetro anteroposterior) y DT (diámetro transversal). Bos primigenius de Mendandia (Alday Ruiz, 2006), Biache-Saint-Vaast (Auguste, 1995), Bau de l'Aubesier (Fernández, 2001), Livernon (Slott-Moller 1990), Abri Marcq (Crégut-Bonnoure, 1993) y Chinchon 2 (Crégut-Bonnoure, 1992c). Bison priscus de Nestier (Clot y Marsan, 1986), Jaurens, I'l skaya (Guèrin y Valli, 2000) y Marcamps (Slott-Moller 1990) . 223

Figura V.11.2. Diagramas bivariantes de los premolares superiores: DAP (diámetro anteroposterior) y DT (diámetro transversal). Bos primigenius de Biache-Saint-Vaast (Auguste, 1995), Bau de l'Aubesier (Fernández, 2001), Livernon (Slott-Moller 1990), Chinchon 2 (Crégut-Bonnoure, 1992c) y Combe Grenal (Guadelli, 1987). Bison priscus de Jaurens (Guérin y Valli, 2000), Marcamps (Slott-Moller 1990), I'l skaya (Guérin y Valli, 2000) y Ënlène (Lalande, 1986) 224

Figura V.11.3. Diagramas bivariantes de los molares superiores permanentes: DAP (diámetro anteroposterior) y DT (diámetro transversal). Bos primigenius de Biache-SaintVaast (Auguste, 1995), Bau de l'Aubesier (Guadelli, 1987; Fernández, 2001), Livernon 
(Slott-Moller 1990), Chinchon 2 (Crégut-Bonnoure, 1992c) y Combe Grenal (Guadelli, 1987). Bison priscus de Jaurens (Guérin y Valli, 2000), Marcamps (Slott-Moller 1990), I'l skaya (Guérin y Valli, 2000) y Ènlène (Lalande, 1986). 225

Figura VI.1.1. Variación del tamaño del protocono (PL) de la dentición superior dientes yugales centrales $\mathrm{P}^{3}$ a $\mathrm{M}^{2}$ ). Valores medios. Especies: Ear: Equus caballus arcelini. Ea: E. caballus antunesi. Ega: E. caballus gallicus. Ege: E. caballus germanicus. Ecfa: E. caballus cf. antunesi. Ec: E. caballus casarensis. Ecft: E. caballus cf. torralbae. Et: E. caballus torralbae. Eta: E. caballus taubachensis. Ech: E. caballus chosaricus. Epv: E. caballus pivetaui. Em: E. caballus mosbachensis. Ef: E. ferus. Yacimientos: QY: Le Queroy. MZ: Mezine. JR: Joao Ramos. SGR: St. Germain la Riviere. SO: Solutre. J: Jaurens. F: Fontahinas. SA: Salemas. AR: Arcy. ABR: Abric Romani. CR: La Carihuela. CG: Combe Grenal. CA: Los Casares. Q: La Quina. PP: Pair non Pair. R: Remagen. LY: Las Yedras. CN: Cova Negra. VC: Villacastín. ATE: Atapuerca Trinchera Elefante nivel 9. W: Weimar. T: Taubach. CH: Toungouze. S: Abri Suard. AL: yacimientos ingleses antewürnienses. PV: Pinilla del Valle. ATG: Atapuerca Galería. SZ: Solana Zamborino. LAM: Achenheim loess medio. E: Ehringsdorf. F1: La Fage. TO: Torralba. LAI: Achenheim loess inferior. Hoxn: yacimientos ingleses del Mindel Riss. A: l'Arago (datos y terminología tomada de Maldonado, 1996; gráfico 24). VB: la Cueva de Valdegoba. CM: Cueva Millán. CB: la Cueva del Búho. PE: la Peña de Estebanvela. 257

Figura VI.1.2. Variación de la longitud de los metápodos (GL) en Equus ferus. Especies: Ep: Equus caballus przewalskii actual. Ear: E. caballus arcelini. Ea: E. caballus antunesi. Ega: E. caballus gallicus. Ege: E. caballus germanicus. Ecft: E. caballus cf. torralbae. Ef: E. ferus. Yacimientos: QY: Le Queroy. MZ: Mezine. JR: Joao Ramos. SGR: St. Germain la Riviere. SO: Solutre. J: Jaurens. F: Fontahinas. SA: Salemas. AR: Arcy. CG: Combe Grenal. Q: La Quina. PP: Pair non Pair. R: Remagen. LY: Las Yedras (datos y terminología tomada de Maldonado, 1996; gráfico 24). VB: la Cueva de Valdegoba... 258

Figura VI.1.3. Variación de la longitud de los metápodos (GL) en E. hydruntinus. Yacimientos: PP F: Pair non Pair nivel F. PP D: Pair non Pair nivel D. Ro: Romanelli. AG: Agios Georgios. RB: Roter Berg. MG: Montgaudier. LAM: Achenheim loess medio (datos y terminología tomada de Maldonado, 1996; gráfico 24). VB: Cueva de Valdegoba 259

Figura VI.1.4. Variación de tamaño en el ciervo, Cervus elaphus, tomando la anchura del primer lóbulo (DTa) del $\mathrm{M}_{3}$, la anchura proximal (BP) de las falanges proximales y la longitud lateral del astrágalo (GLl). Los datos de la Cueva de Valdegoba, Cueva Millán, la Cueva del Búho y la Peña de Estebanvela se han añadido a las tablas de Van der Made (2011b) y Van der Made et al., (2014) 260

Figura VI.1.5. Variación de tamaño en el corzo, Capreolus capreolus, tomando la anchura del primer lóbulo (DTa) del $\mathrm{M}_{3}$. Los datos de la Cueva de Valdegoba se han añadido a las tablas de Van der Made et al., (2014). Datos y terminología tomada de Van der Made et al., 2014; figuras 2 y 6. Los yacimientos están ordenados de más moderno (arriba) a más antiguo (abajo). 261 
Lámina V.1.1. Stephanorhinus hemitoechus provenientes de los yacimientos de la Cueva de Valdegoba (sigla Vb), Cueva Millán (sigla CM), Cueva del Búho (sigla TCB) y la Peña de Mudá (sigla Q). 1) CM86.1A.9F - dentición superior izquierda $\left(\mathrm{P}^{3}-\mathrm{M}^{3}\right)$ : 1.a vista oclusal. 2) TCB - 174b - dentición inferior derecha $\left(\mathrm{P}_{2}-\mathrm{M}_{2}\right)$ : 2.a vista oclusal. 3) Vb-sp-235 - $\mathrm{M}^{3}$ derecho: 3.a vista oclusal; 3.b vista bucal. 4) Vb-sp-3201 - $\mathrm{D}_{2}$ derecho: 4.a vista oclusal; 4.b vista lingual. 5) Vb-sp-239 - $\mathrm{P}_{3 / 4}$ izquierdo: 5.a vista oclusal; 5.b vista bucal. 6) 540Q - $\mathrm{P}^{4}$ derecho: 6.a vista oclusal; 6.b vista lingual. 7) TCB-238 - D³ derecho: 7.a vista oclusal; 7.b vista bucal. 8) Vb-sp-238 - D2 derecho: 8.a vista oclusal; 8.b vista lingual. 9) Vb-sp-244 $\mathrm{P}^{3 / 4}$ : 9.a vista oclusal; 9.b vista lingual. 10) $539 \mathrm{Q}$ - $\mathrm{M}^{2}$ izquierdo: $10 . \mathrm{a}$ vista oclusal; $10 . \mathrm{b}$ vista lingual. 11) 542Q - M ${ }^{3}$ izquierdo: 11.a vista oclusal; 11.b vista lingual. 12) Vb-sp5689 - Astrágalo derecho: 12.a vista anterior; $12 . b$ vista posterior. 71

Lámina V.2.1. Coelodonta antiquitatis provenientes de los yacimientos de La Mina (sigla LM) y La Peña de Mudá (sigla Q). 1) 05.40.LM.738 - $\mathrm{P}_{3}$ izquierdo: 1.a vista oclusal; 1.b vista lingual; 1.c vista bucal. 2) 05.40.LM.759 - $\mathrm{M}_{1}$ izquierdo: 2.a vista oclusal; 2.b vista lingual; 2.c vista bucal. 3) 59Q - $\mathrm{P}^{3}$ derecho: 3.a vista oclusal; 3.b vista lingual; 3.c vista bucal. Nota: los restos procedentes de Mudá, en concreto las figuras 3.b y 3.c presentan, en su base, una anomalía debido a que esta pieza se encontraba incluida en un molde de escayola, lo que ha impedido realizar las fotografías de una forma más aceptable. 75

Lámina V.4.1. Equus ferus provenientes de los yacimientos de la Cueva de Valdegoba (sigla Vb), Cueva Millán (sigla CM), Cueva del Búho (sigla TCB) y La Peña de Estebanvela (sigla PE). 1) Mandíbula NIII derecha - vista oclusal. 2) Vb-sp-187 - $\mathrm{dI}_{1}$ derecho, cara lingual. 3) PE02.E11.NII - Serie dental $\left(\mathrm{P}^{3}-\mathrm{M}^{3}\right)$, vista oclusal. 4) Vb-138 - $\mathrm{D}_{3-4}$ derecho, vista oclusal. 5) Vb-173 - D 3 -4 izquierdo, vista oclusal. 6) CM86.1A.6F - I1 derecho, cara lingual. 7) Vb-sp-218 - Canino inferior, vista lingual. 8) Vb-sp-217 - Canino superior, vista lingual. 9) Vb-251 - Metacarpo II derecho. 10) Vb-sp-5618 - Metacarpo III derecho. 11) Vb-253 - Metatarso IV derecho. 12) Vb-249 - Metatarso II derecho. 13) Vb-178 Metatarso III izquierdo. 14) Vb-253 - Metacarpo IV derecho. 15) Vb-190 - Falange proximal izquierda. 16) Vb-194 - Falange media derecha. 17) Vb-203 - Falange distal. 18) Vb-208 - Calcáneo derecho. 19) Vb06.n2.113.Aa-Ad.90-95.1 - Húmero derecho. 20) Vb91.MN8.T10.4 - Astrágalo derecho. 21) TCB-734 - Tibia izquierda 108

Lámina V.5.1. Equus hydruntinus provenientes de los yacimientos de la Cueva de Valdegoba (sigla Vb), Cueva del Búho (sigla TCB), Cueva Millán (sigla CM) y La Peña de Estebanvela (sigla PE). 1) PE.02.F12.G12.N1.5.21 - dI derecho, cara lingual. 2) Vb - 117 $\mathrm{D}_{2}$ derecho, superficie oclusal. 3) Vb-sp-229 - $\mathrm{D}_{3-4}$ derecho, superficie oclusal. 4) Vb-163 $\mathrm{D}^{3-4}$ derecho, superficie oclusal. 5) Vb-sp-232 - $\mathrm{I}_{2}$ izquierdo, cara lateral. 6) $\mathrm{Vb}-94-\mathrm{P}_{3-4}$ derecho, superficie oclusal. 7) Vb-sp-281 - $\mathrm{M}_{1-2}$ derecho, superficie oclusal. 8) Vb-104 - $\mathrm{M}_{3}$ izquierdo, superficie oclusal. 9) Vb-7 - $\mathrm{P}^{2}$ derecho, superficie oclusal. 10) Vb-sp-255 - P3-4 derecho, superficie oclusal. 11) $\mathrm{M}^{1-2}$ izquierdo, superficie oclusal. 12) Vb-42 - $\mathrm{M}^{3}$ izquierdo, superficie oclusal. 13) Vb-261 - metacarpo II izquierdo. 14) Vb-247 - metacarpo IV izquierdo. 15) Vb-sp-6299 - metacarpo III derecho. 16) Vb-110 - metatarso II izquierdo. 17) Vb-sp-114 - falange media derecha. 18) Vb-207 - astrágalo derecho. 19) Vb-sp-4628 metatarso IV derecho. 20) TCB-192 - falange media derecha. 21) TCB-74 - astrágalo derecho 122

Lámina V.6.1. Sus scrofa provenientes de los yacimientos de la Cueva de Valdegoba (sigla Vb), Prado Vargas (sigla PV) y la Cueva del Búho (sigla TCB). 1) Vb-sp-3053 - $\mathrm{D}_{2}$ derecho: 1.a vista oclusal; 1.b cara lingual; 1.c cara bucal. 2) Vb-sp-3177 - $\mathrm{D}_{4}$ izquierdo: 2.a vista oclusal; 2.b cara lingual; 2.c cara bucal. 3) TCB-502 - $\mathrm{P}_{3}$ izquierdo: 3.a vista oclusal; 3.b cara lingual; 3.c cara bucal. 4) TCB-199 - $\mathrm{M}^{2}$ izquierdo: 4.a vista oclusal; 4.b cara lingual; 4.c cara bucal. 5) PV06.N4.G30.80 - Falange proximal derecha cara dorsal. 6) Vb-sp-5674 Falange media cara dorsal 126

Lámina V.7.1. Cervus elaphus provenientes de los yacimientos de la Cueva de Valdegoba (sigla Vb), Prado Vargas (sigla PV), Cueva Millán (sigla CM), Cueva del Búho (sigla TCB) y La Peña de Estebanvela (sigla PE). 1) Vb-sp-2302 - dI ${ }_{1}$ izquierdo: cara lingual. 2) Vb-sp- 
$2905-\mathrm{D}_{2}$ izquierdo: cara lingual. 3) Vb-sp-2875 - $\mathrm{D}_{3}$ derecho: cara lingual. 4) Vb-sp$3009-\mathrm{D}_{4}$ izquierdo: cara bucal. 5) $\mathrm{Vb}-\mathrm{sp}-2668$ - D2 izquierdo: cara lingual. 6) Vb-sp3010 - $\mathrm{D}^{3}$ derecho: cara lingual. 7) Vb-sp-2970 - D4 derecho: cara lingual. 8) TCB-213 - $\mathrm{I}_{2}$ izquierdo: cara lingual. 9) Vb-sp-3063 - $\mathrm{P}_{2}$ izquierdo: cara lingual. 10) Vb-sp-2961 - $\mathrm{P}_{3}$ derecho: cara lingual. 11) Vb-sp-2963 - $\mathrm{P}_{4}$ izquierdo: cara lingual. 12) PV06 45 H32 73 - $\mathrm{M}_{1}$ izquierdo: cara bucal. 13) PV06 45 H31 $88-\mathrm{M}_{2}$ izquierdo: cara bucal. 14) TCB $268-\mathrm{M}_{3}$ derecho: cara bucal. 15) Vb-sp-3001 - $\mathrm{P}^{2}$ izquierdo: cara lingual. 16)Vb-sp-3128 - $\mathrm{P}^{3}$ izquierdo: cara lingual. 17) Vb-sp-3085 - $\mathrm{P}^{4}$ izquierdo: cara lingual. 18) Vb-sp-3158 - $\mathrm{M}^{1}$ derecho: cara lingual. 19) CM86 1A 6I - M² izquierdo: cara lingual. 20) Vb-sp-3175 - M ${ }^{3}$ derecho: cara lingual. 21) Vb sp 5338 - Radio derecho. 22) CM.86.1A.10F - Tibia izquierda. 23) Vb sp 5564 - Calcáneo derecho. 24) Vb-sp-5372 - Metacarpo. 25) Vb-sp-5251 Metatarso. 26) TCB447 - Astrágalo derecho. 27) PE07.E8.NII-III.6.43 - Falange proximal derecha. 28) Vb06.M13.Ad.100-105.3 - Falange media izquierda. 29) TCB203 - Falange distal derecha 155

Lámina V.8.1. Capreolus capreolus proveniente del yacimiento de la Cueva de Valdegoba (sigla Vb). 1) Vb-sp-1029 - $\mathrm{P}_{3}$ derecho: cara lingual. 2) Vb-sp-3038 - $\mathrm{P}_{4}$ derecho: cara bucal. 3) Vb-sp-3056 - $\mathrm{M}_{1}$ derecho: cara bucal. 4) Vb-sp-3065 - $\mathrm{M}_{2}$ derecho: cara bucal. 5) Vb-sp$1028-\mathrm{M}_{3}$ derecho: cara bucal. 6) Vb-sp-3041 - $\mathrm{P}^{2}$ derecho: cara lingual. 7) Vb-sp-3046 - M1 derecho: cara lingual. 8) Vb-sp-3049 - $\mathrm{M}^{2}$ derecho: cara lingual. 9) Vb-sp-3055 - $\mathrm{M}^{3}$ derecho: cara lingual. 10) Vb-sp-2578 - Mandíbula $\left(\mathrm{P}_{4}-\mathrm{M}_{3}\right)$ izquierda: cara bucal. 11) Vbsp-2348 - $I_{2}$ izquierdo: cara lingual. 12) Vb sp 1584 -Canino permanente izquierdo: cara lingual. 13) Vb-sp-2582 - Mandíbula $\left(\mathrm{P}_{3}-\mathrm{M}_{2}\right)$ izquierda: cara bucal. 14) Vb-sp-3713 Calcáneo izquierdo. 15) Vb.91.6.M6.T1-2 - Astrágalo izquierdo. 16) Vb-sp-5368 Metatarso. 17) Vb-sp-5719 - Falange media anterior izquierda. 18) Vb-sp-5710 - Falange media posterior izquierda. 19) Vb-sp-5710 - Falange distal 163

Lámina V.9.1. Rupicapra pyrenaica provenientes de los yacimientos de la Cueva de Valdegoba (sigla Vb), Prado Vargas (PV), Cueva Millán (sigla CM), Abrigo Alexandre (sigla AL) y La Peña de Estebanvela (sigla PE). 1) Vb-sp-5921 - Mandíbula $\left(\mathrm{P}_{2}-\mathrm{M}_{3}\right)$ derecha: cara bucal. 2) Vb-sp-319 - Mandíbula $\left(\mathrm{D}_{2}-\mathrm{D}_{4}\right)$ derecha: cara bucal. 3) 97.13.AL.10C.15.162 - D2 izquierdo: cara bucal. 4) Vb-sp-5535 - Maxilar ( $\left.\mathrm{P}^{2}-\mathrm{M}^{3}\right)$ derecho: superficie oclusal. 5) Vb.89.K13.Dc.T10.1 - Radio izquierdo. 6) Vb-sp-1908 - Maxilar (D2 - D4) izquierdo: superficie oclusal. 7) Vb-sp-5730 - $\mathrm{dI}_{2}$ izquierdo: cara lingual. 8) Vb-sp-2045 - Canino permanente izquierdo: cara lingual. 9) Vb-sp-1505: $\mathrm{I}_{1}$ izquierdo: cara lingual. 10) Vb-sp1778 - Canino decidual izquierdo. 11) Vb-sp-4741- Pelvis izquierda. 12) Vb-sp-3506 Calcáneo izquierdo. 13) PE.02.F9.G9.NI.6 - Astrágalo derecho. 14) Vb.87.M13.T3. 6 - Fémur derecho. 15) Vb-sp-4738 - Escápula derecha. 16) Vb-sp-4853 - Falange distal derecha. 17) Vb-sp-3502 - Ulna derecha. 18) Vb-sp-3763 - Patella izquierda. 19) Vb-sp-5119 Metacarpo izquierdo. 20) Vb-sp-3224 - Metatarso derecho. 21) Vb-sp-4573 - Falange proximal derecha. 22) PV06.N4.H31.87 - Falange proximal derecha. 23) CM.86.1C.72 Falange media derecha. 24) Vb-sp-4989 - Falange media izquierda. 25) Vb-sp-5163 Húmero derecho. 26) Vb-sp-5216 - Tibia izquierda... 198

Lámina V.10.1. Capra pyrenaica provenientes de los yacimientos de la Cueva de Valdegoba (sigla Vb), Prado Vargas (PV), Cueva Millán (sigla CM) y La Peña de Estebanvela (sigla PE). 1) Vb.91.K13a.8.99 - $\mathrm{dI}_{2}$ izquierdo: cara lingual. 2) $36-\mathrm{D}_{2}$ izquierdo: cara lingual. 3) Vb-sp-921 - $\mathrm{D}_{3}$ derecho: cara lingual. 4) Vb-sp-5923 - $\mathrm{D}_{4}$ izquierdo: cara bucal. 5) Vb-sp-2699 - $\mathrm{P}_{2}$ derecho: cara bucal. 6) Vb-sp-2561 - $\mathrm{M}_{1}$ izquierdo: cara bucal. 7) Vb-sp6026 - $\mathrm{M}_{2}$ izquierdo: cara bucal. 8) Vb-sp-1027 - $\mathrm{M}_{3}$ izquierdo: cara bucal. 9) Vb-sp-1430 $\mathrm{D}^{2}$ izquierdo: cara lingual. 10) Vb-sp-2476 - $\mathrm{D}^{3}$ derecho: cara lingual. 11) Vb-sp-590 - $\mathrm{D}^{4}$ derecho: cara lingual. 12) PV.06.45.G30.387 - $\mathrm{I}_{1}$ izquierdo: cara lingual. 13) CM.861A.8C Canino izquierdo: cara lingual. 14) Vb-sp-2530 - $P_{3}$ izquierdo: cara lingual. 15) Vb.89.L13.Cd.8.10 - $\mathrm{P}_{4}$ derecho: cara bucal. 16) Vb-sp-2538 - $\mathrm{M}^{2}$ izquierdo: cara lingual. 17) Vb-sp-2635 - $\mathrm{M}^{3}$ derecho: cara lingual. 18) Vb-sp-2775 - $\mathrm{P}^{2}$ derecho: cara lingual. 19) Vb-sp-905 - $\mathrm{P}^{3}$ izquierdo: cara lingual. 20) Vb-sp-901 - $\mathrm{P}^{4}$ derecho: cara lingual. 21) Vb-sp5915 - M1 izquierdo: cara lingual. 22) Vb.06.M13.Ad.65.70.3 - Falange media posterior izquierda. 23) Vb-sp-5781 - Falange proximal anterior izquierda. 24) Vb-sp-4549 - Falange 
proximal posterior izquierda. 25) Vb-sp-5795 - Falange media anterior izquierda. 26) CM.86.1A.10F - Falange distal izquierda. 27) Vb-sp-5572 - Húmero izquierdo. 28) PE.07.B7.NVI.10.1433 - Astrágalo derecho. 29) Vb-sp-3254 - Radio derecho. 30) Vb-sp5879 - Metacarpo inmaduro izquierdo. 31) Vb-sp-5566 - Metacarpo derecho. 32) Vb-sp5842 - Ulna derecha. 33) Vb-sp-6289 - Calcáneo izquierdo. 34) Vb-sp-5675 - Tibia izquierda 221

Lámina V.11.1. Bos primigenius proveniente de los yacimientos de la Cueva de Valdegoba (sigla Vb) y la Cueva del Búho (sigla Q). 1) Vb-sp-292 - M1-2 derecho: 1.a cara bucal; 1.b cara lingual. 2) Vb-sp-288 - M3 izquierdo cara lingual. 3) 6647Q - Astrágalo izquierdo. 4) Vb-sp-303 - P4 derecho: 4.a cara lingual; 4.b cara mesial. 5) Vb-sp-289 - $\mathrm{M}^{3}$ izquierdo cara lingual. 6) Vb89.L13.Ca.T6.1 - Metacarpo derecho. 7) Vb-sp-5578 - Tibia derecha: 7.a superficie articular distal; 7.b cara anterior. 8) Vb06.N2.J12.Ca-Cb.85-90.6 - Metatarso derecho: 8.a cara anterior; 8.b superficie articular proximal. 9) 6420Q - Metacarpo izquierdo. 10) Vb-sp-4687 - Calcáneo derecho 230

Lámina V.12.1. Bison priscus proveniente de los yacimientos de la Cueva del Búho (sigla Q) y de la Cueva de Valdegoba (sigla Vb). 1) Vb-sp-4678 - Tibia derecha: 1.a cara anterior; 1.b superficie articular distal; 1.c cara lateral. 2) Vb-sp-4870 - Metacarpo izquierdo: 2.a cara anterior; 2.b cara posterior. 3) 6645Q - Astrágalo izquierdo. 4) 6639Q - Metatarso izquierdo: 4.a superficie articular proximal; 4.b cara anterior. 233

Lámina V.13.1. Bos/Bison sp. provenientes de los yacimientos de la Cueva del Búho (sigla Q) y de la Cueva de Valdegoba (sigla Vb). 1) Vb-sp-5642- Cuernos. 2) Vb-sp-2300 Incisivo decidual derecho: 2.a cara lingual; 2.b cara bucal. 3) Vb-sp-3027 - $\mathrm{D}_{3}$ derecho: 3.a cara bucal: 3.b cara lingual. 4) Vb-sp-1323 - $\mathrm{D}_{4}$ derecho: 4.a cara bucal; 4.b cara lingual. 5) Vb-sp-1324 - D ${ }^{3}$ derecho: 5.a cara lingual; 5.b cara bucal. 6) 6631Q - Metacarpo izquierdo. 7) 6611Q - Mandíbula ( $P_{2}-P_{3}$ ) derecha, cara lingual. 8) 6515Q - Tibia izquierda. 9) 6644Q - Astrágalo derecho. 10) Vb-sp-4685 - Falange proximal derecha. 11) 6414Q - Calcáneo izquierdo. 12) Vb-sp-4681 - Falange distal izquierda. 13) Vb-sp-4676 - Falange media izquierda 
1. Introducción 
El estudio de los ungulados en yacimientos arqueopaleontológicos es un tema tratado desde los primeros estudios de yacimientos arqueopaleontológicos. Su análisis nos proporciona gran información a dos niveles fundamentales: a nivel paleontológico y a nivel arqueológico. A nivel paleontológico ofrece información paleobiológica de especies, en algunos casos ya extintas, y datos paleoecológicos de gran interés como la composición de los grupos, las interacciones entre diferentes taxones o su presencia y/o ausencia en determinados periodos. La integración de estos datos con otros como los paleopalinológicos nos permiten conocer cómo podrían ser los ecosistemas en un periodo concreto y si los hábitats o los nichos de estas especies pueden haber cambiado con el tiempo. A nivel arqueológico, muchos depósitos son de origen antrópico, lo que hace que estos análisis, integrados con estudios tafonómicos, reflejen interesantes datos sobre los cazadores-recolectores, los periodos de ocupación de las cavidades, las preferencias cinegéticas de sus ocupantes o su relación con otros predadores.

El poblamiento de la Meseta Norte, durante el Paleolítico Medio y Superior, ha sido un tema muy discutido desde principios del siglo XX. La relativa ausencia de depósitos se puede explicar por varias razones, debido probablemente a causas climáticas o bien a diferentes procesos geológicos (Van der Made, 2011, 2014) o por qué no a una relativa falta de estudios y prospecciones en esta zona (Delibes y Martín, 2006), en comparación con las regiones próximas como Asturias, Cantabria y el País Vasco, ha llamado la atención de los investigadores. Sin embargo, en el primer tercio del siglo XX, la labor de nombres ilustres como el Abate Breuil, Hernández Pacheco y los padres Ibero y Carballo sacó a la luz las primeras evidencias de ocupaciones en este territorio. Un buen inventario de nombres aparece en la obra de Obermaier "El hombre fósil", empleada como libro de cabecera por los investigadores durante muchos años. Sin embargo, y por desgracia, muchos de los restos que aparecen en estas obras (Breuil, 1918 - 1919; Obermaier, 1925) se han perdido o las excavaciones no fueron realizadas siguiendo una metodología adecuada por lo que en muchos casos son difíciles de asignar a un periodo concreto. Los estudios llevados a cabo en esta región abarcan tres periodos culturales: el Paleolítico Inferior, el Medio y el Superior. Este trabajo se centra en los yacimientos con fósiles de ungulados de la Meseta Norte que se encuentran en la Comunidad Autónoma de Castilla y León, en concreto los circunscritos al Pleistoceno Superior que abarcan parte del Paleolítico Medio y la mayor parte del Paleolítico Superior.

\section{El Paleolítico Medio en la Meseta Norte}

Dentro del Paleolítico Medio, podemos hablar de depósitos al aire libre y sitios en cuevas o abrigos rocosos. Los primeros son los más abundantes y se encuentran repartidos por las provincias de Burgos, Valladolid, Segovia y Soria, siendo Ucero I el único depósito a cielo abierto localizado en ésta última. La mayor concentración, con unos 43 sitios, se encuentra en el Páramo de Corcos, en el límite de las provincias de Burgos, Valladolid y Segovia y que, además, han sido asignados al límite con el Paleolítico Inferior (Díez y Rodríguez, 2009). En Segovia hay referencias confusas en relación a hallazgos en Pradales y Honrubia de la Cuesta y se han localizado unos pocos restos en Cuéllar. Otro gran conjunto se encuentra en el entorno de la Sierra de Atapuerca (Burgos). Los más de una treintena de yacimientos (Navazo, 2006) localizados, gracias a las prospecciones realizadas por la Universidad de Burgos, completan las lagunas que aparecen en las cavidades de la sierra. La provincia de Burgos se conforma como la zona con mayor volumen de depósitos de este tipo en toda la Meseta. Al margen de los reconocidos en el entorno de Atapuerca, se han localizado yacimientos en el Valle del Ebro, las Merindades, en los valles de los ríos Urbel, Arlanza, Arlanzón y Pico. También se incluyen en este tipo las terrazas fluviales de Villagonzalo - Arenas, Villatoro, Ubierna, Villalonquejar, la Moneda, Villimar, Villacienzo y Cortés. Ninguno de estos depósitos ha proporcionado restos fósiles (Díez y Rodríguez, 2009).

Los yacimientos en cueva están bien representados, destacando de nuevo la provincia burgalesa con cinco depósitos: la Cueva de Valdegoba (Díez et al., 1988-1989; Quam et al., 
2001), Prado Vargas (Torres et al., 1989; Navazo et al., 2005), La Mina (Díez et al., 2008), Cueva Millán y La Ermita (Moure Romanillo et al., 1982; Moure Romanillo et al., 1983). Todos ellos han proporcionado tanto restos líticos como fósiles, completando y mejorando la información obtenida en los yacimientos al aire libre. En la provincia de Palencia destacamos los depósitos de Cueva Corazón, Villanueva 1 y la Cueva de Guantes. La primera, descubierta en 1978 y estudiada por las Universidades de Valladolid y la Complutense de Madrid, ha aportado un rico conjunto óseo y lítico (Díez Martín et al., 2011; Sánchez Yustos et al., 2011). Los otros dos, Villanueva 1 y la Cueva de Guantes, están siendo intervenidas actualmente por un equipo del Centro Nacional de Estudios sobre la Evolución Humana (CENIEH) (Rodríguez com. pers.).

Una breve mención merecen los yacimientos del Cañón de Río Lobos (Burgos - Soria). Sus abrigos y cavidades ya aparecen en las citas del Abate Breuil y de Hugo Obermaier a principios del siglo pasado. En sus textos citan sitios como los de Arganza o el abrigo del Barranco (Obermaier, 1925). Hoy en día, muchos de estos yacimientos y las piezas recuperadas en ellos no se han podido localizar. En la misma zona, en el año 2004, el Área de Prehistoria de la Universidad de Burgos, excava en la Cueva de la Máquina o el Polvorista, sin encontrar restos de ocupación paleolítica (Navazo com. pers.).

\section{El Paleolítico Superior en la Meseta Norte}

El Paleolítico Superior, periodo que comprende en Europa cronologías que van desde los 40.000 hasta los 9.500 años, no ha proporcionado tantos yacimientos. En muchos casos, existen problemas a la hora de adscribir cronológicamente los depósitos sobre todo por la falta de dataciones absolutas y por la reutilización de las cavidades en periodos posteriores como el Neolítico y la Edad del Bronce (Díez y Rodríguez, 2009). Estos depósitos podrían clasificarse según Díez y Rodríguez (2009) en cinco grandes grupos: yacimientos al aire libre con uso como taller, yacimientos al aire libre con representaciones artísticas, yacimientos en cueva con asentamientos, yacimientos en cueva con representaciones artísticas y, yacimientos en cueva con asentamientos y manifestaciones gráficas.

En el primer grupo, sitios al aire libre con un uso como taller, podríamos incluir el yacimiento vallisoletano del Palomar (Mucientes) (Delibes de Castro y Díez Martín, 2006) y los burgaleses del Valle de las Orquídeas (Mosquera et al., 2007) y Fuente Mudarra (Cardeñuela de Río Pico). Ninguno de ellos ha proporcionado restos fósiles, hallándose únicamente instrumentos líticos de factura muy homogénea (Díez y Rodríguez, 2009; Navazo com. pers.).

El segundo grupo, yacimientos al aire libre con representaciones artísticas, es más reducido. En él se incluyen el yacimiento de Domingo García (Santa María de Nieva, Segovia) (Ripoll y Municio, 1999), Siega Verde (Villar de la Yegua, Salamanca) y el hallazgo de Villalba de Almazán (Soria), la Placa de Villalba (Jimeno y Fernández, 1988). El primero y que, además, presenta las representaciones más abundantes y en mejor estado, comprende un área de más de $40 \mathrm{~km}^{2}$. Se han identificado grabados en los que destacan caballos, cabras, bóvidos, perros, ciervos, antropomorfos y zoomorfos (Díez y Rodríguez, 2009). La pieza aislada de Villalba, la Placa, apareció sin un contexto estratigráfico claro. En ella aparecen grabados, por las dos caras, ocho caballos y dieciocho cabras. Su asignación magdaleniense se debe a la tipología de las figuras (Jimeno y Fernández, 1988).

El grupo con mayor representación es el tercero, los yacimientos en cueva con asentamientos. Díez y Rodríguez (2009) incluyen en este grupo los yacimientos burgaleses de El Níspero (Orbaneja del Castillo), La Blanca y El Caballón (Oña), La Aceña (Lara), El Portalón y el Mirador (Ibeas de Juarros). Por otra parte, en Soria, destacamos los abrigos de Alexandre y Vergara (Deza) (Utrilla et al., 1999). Los restos de El Níspero se encuentran muy fragmentados aunque han sido asignados a ciervos, cabras y caballos. El yacimiento de La Blanca ha proporcionado restos en mal estado de cabras, ciervos, caballos y linces. 
En El Caballón se ha recuperado un importante conjunto arqueológico y un bastón de mando, ya desaparecido, del que únicamente se conserva un dibujo con lo que parece ser el grabado de una cabeza de rumiante. En La Aceña (Obermaier, 1925) se ha identificado una colección fosilífera muy escasa y además, la localización tanto de los restos como del abrigo es desconocida (Díez y Rodríguez, 2009). En campañas recientes, en la Sierra de Atapuerca, se han localizado niveles de transición entre el Pleistoceno y el Holoceno en los yacimientos de Portalón (Pérez Romero, 2009), Cueva del Silo y en la Cueva de El Mirador (Díez y Rodríguez, 2009), aunque en este último faltan por realizar dataciones más precisas de los niveles inferiores del sondeo comenzado en el 2002. En León incluimos los depósitos de El Espertín, La Uña, La Cantera y El Castro. Los restos recuperados en ellas no son muy abundantes y han aparecido muy fragmentados (Delibes de Castro y Díez Martín, 2006). En los abrigos sorianos de Alexandre y Vergara se han recuperado pocos restos y bastante fragmentados.

Dentro de los depósitos en cueva con manifestaciones artísticas destacamos tres, dos en Burgos y otro en Segovia. Los burgaleses se localizan en la zona norte y son la Palomera (Cueva de Sotoscueva) y la Cueva de los Moros o Penches (Barcina de los Montes) (Hernández Pacheco, 1917; Corchón et al., 1988 - 1989). La cavidad Segoviana, La Griega, se encuentra en Pedraza (Corchón, 1997). La Palomera, dentro del complejo kárstico de Ojo Guareña, presenta, en la llamada Sala de las Pinturas, 93 representaciones de uros, ciervos, antropomorfos, triángulos negros, bastoncillos y un posible mamut (Díez y Rodríguez, 2009). En Penches, descubierta por los jesuitas de Oña, se han identificado siete cabras, un équido, un bóvido y un posible antropomorfo esquemático (Corchón, 1988 - 1989). Estos depósitos, salvo la Sala de las Pinturas de Ojo Guareña (Corchón et al., 1996), no han proporcionado dataciones absolutas, aunque su cercanía a otros yacimientos magdalenienses y su semejanza, en cuanto al estilo, con otras figuras de la región cantábrica permiten asignarlas al Paleolítico Superior aunque algunos investigadores sugieren una asignación postpaleolítica (Diez y Rodríguez, 2009). La cueva de La Griega presenta un importante conjunto de grabados de animales entre los que destacan caballos, ciervos, uros, jabalíes, osos, felinos, peces, motivos geométricos y antropomorfos (Corchón, 1997). Su cronología se ha determinado por motivos estilísticos y se emplaza en el Solutrense y el Magdaleniense inferior (Díez y Rodríguez, 2009).

En el último grupo, el más completo ya que abarca asentamientos en cueva o abrigo con representaciones artísticas, sólo se incluye un depósito, la Peña de Estebanvela. Aparte de la colección de fósiles de ungulados, se ha recuperado un importante conjunto de industria lítica y ósea, y 35 elementos artísticos que incluyen plaquetas y cantos de piedra así como motivos decorativos que comprenden figuras geométricas abstractas.

Las pinturas y grabados rupestres en la Meseta Norte son muy abundantes, encontrándose tanto al aire libre como en abrigos y cuevas. Muchos de ellos no han sido muy difundidos y su acceso y por lo tanto su estudio no es sencillo. Para conocerlos mejor, ya que en esta introducción sólo hago referencia a los más conocidos, es interesante consultar los trabajos de Corchón et al., (1988 - 1989) y Altuna (2002) y las referencias que allí aparecen.

Por último, aunque su descubrimiento no es reciente, las primeras referencias datan de 1864, destacamos la Peña de Mudá (Mudá, Palencia). Sus fósiles no han sido estudiados hasta hace pocos años (Álvarez-Lao, 2007). A pesar de la ausencia de dataciones absolutas, las especies identificadas lo sitúan en alguna de las fases frías del Pleistoceno Tardío.

\section{Antecedentes en el estudio de la fauna de la Meseta Norte con especial referencia a los ungulados}

El estudio de los ungulados del Pleistoceno Superior de la Meseta Norte ha ido parejo al análisis de otros restos arqueopaleontológicos, quizás más "mediáticos", como los homínidos, los carnívoros o la industria lítica (Cacho et al., 2006; Navazo et al., 2005; 
Quam et al., 2001). El análisis de los restos fósiles de este grupo puede dividirse en dos periodos: los primeros años del siglo XX y a partir de la década de los años 70 del siglo pasado. En el primer periodo, caracterizado por las primeras incursiones de prehistoriadores en la región, destacan los trabajos y descubrimientos de investigadores como el Abate Breuil, Hugo Obermaier, el Padre Saturio y varios religiosos anónimos de los Monasterios de Silos y de San Salvador de Oña. El inventario que realizaron a principios de siglo (Obermaier, 1925) fue la base para los prehistoriadores posteriores. La metodología empleada en estos primeros años, basada fundamentalmente en los vaciados arqueológicos, es decir en una selección de piezas concretas, ha hecho que muchos de los yacimientos no se hayan podido localizar y que los pocos restos que aún se pueden encontrar aparezcan fuera de contexto lo que impide asignarlos a una época concreta.

Todo esto cambia a partir de los años 70 del siglo pasado, cuando se introduce la metodología arqueológica moderna. Con ella entra en escena el trabajo multidisciplinar, integrando varias disciplinas y especialidades que dan importancia a todo el registro para poder entender e interpretar los descubrimientos. La bibliografía de este periodo se podría dividir en dos tipos bien diferenciados. Por una parte, los estudios generales en los que se presentan los depósitos, incluyendo localización, geología, estratigrafía y listados faunísticos (Moure Romanillo y García Soto, 1983; Molero et al., 1989; Torres et al., 1989; Díez, 1990; Utrilla y Blasco, 2000; Quam et al., 2001; Navazo et al., 2005; Cacho et al., 2006; Díez et al., 2008; Sala et al., 2009) y estudios más concretos que se centran en algún grupo determinado. Así por ejemplo, destacamos los trabajos, en los depósitos burgaleses de la cuenca del Arlanza, de Pérez Legido y Cerdeño (1992) y Álvarez et al., (1992) sobre los macromamíferos; y los de Roselló Izquierdo (1992) sobre la ictiofauna. Muchos de estos trabajos, exceptuando los que se refieren a una especie en concreto como Cerdeño (1987), que describe el rinoceronte de Cueva Millán y lo asigna a Dicerorhinus hemitoechus, no presentan descripciones muy detalladas, centrándose fundamentalmente en el número de restos, número mínimo de individuos y unas medidas básicas. La ictiofauna, por otra parte, incluye también un análisis de la estacionalidad y compara las especies recuperadas con las recogidas en otros yacimientos del norte peninsular donde estos restos son más abundantes. Otro yacimiento en el que se realizan estudios más detallados es el de la Cueva del Búho. En este depósito se ha llevado a cabo un análisis general de los carnívoros por parte de Íñigo et al., (1998) y dos más concretos, uno sobre el rinoceronte y otro sobre los bovinos, permitiendo determinar la presencia en este sitio de Stephanorhinus hemitoechus (Íñigo, 1995) como de dos taxones de gran bóvido: Bos primigenus y Bison priscus (Sala et al., 2010). Con respecto a los ungulados, la Cueva de Valdegoba, junto con Prado Vargas y la Peña de Estebanvela son los yacimientos que presentan trabajos más detallados. Así, en el primero hay referencias sobre los équidos (Arceredillo, 2008b), la edad de muerte de los artiodáctilos (Arceredillo y Díez, 2009) y el dimorfismo sexual de los rebecos (Arceredillo et al., 2011). En Prado Vargas se han realizado análisis generales de este grupo (Arceredillo, 2010) y sobre la edad de muerte de los ciervos (Arceredillo y Díez, 2010). Los ungulados de la Peña de Estebanvela han sido estudiados por Yravedra (2006) y Arceredillo (2013), presentando el primero una lista faunística detallada y el segundo un análisis más exhaustivo del material.

Por otra parte, en los últimos años, se han identificado grupos que no habían sido descritos en la Meseta Norte en el Pleistoceno Superior como el rinoceronte lanudo Coelodonta antiquitatis (Álvarez-Lao, 2007) y géneros que no habían sido localizados en la Península Ibérica en el Pleistoceno como Hemitragus (Van der Made et al., 2003; Rivals y Blasco, 2008). Asimismo, ha habido avances en la clasificación de algunos taxones muy representativos como Equus caballus (Maldonado, 1996). Este autor analizó la evolución de esta especie y asigna el material de parte de los yacimientos ibéricos a las diferentes subespecies conocidas en ese momento. Algo similar ocurre con E. hydruntinus, especie poco conocida por la escasez de fósiles pero mejor estudiada ya gracias a trabajos como el de Davis (1980) y Maldonado (1996).

Una de las especies más comunes a mediados del Pleistoceno Superior y que pervive hasta nuestros días es el sarrio Rupicapra (Altuna, 1972). Tradicionalmente, esta especie 
ha sido considerada en los yacimientos ibéricos como R. rupicapra (Altuna, 1972; Alférez et al., 1980-1981) ya que por aquel entonces sólo se reconocía la existencia de esta especie. Sin embargo, tras la publicación de Nascetti et al., (1985) se acepta la presencia de dos especies distintas: $R$. pyrenaica y $R$. rupicapra, la primera presente en el suroeste de Europa y la segunda distribuida por el resto de Europa y el Cáucaso. A pesar de esto, los trabajos que hablan de $R$. pyrenaica son aún muy escasos (Cardoso, 1996; Fernández, 2001; Rivals, 2002; Moigne et al., 2006; Magniez, 2010). Esta nueva clasificación hace que sea necesario revisar el material de esta especie ya que no sólo afecta a la asignación taxonómica sino también a los datos empleados en los análisis posteriores. Esta información afecta a las épocas de partos, lactancia, celo y gestación; así como a las tasas de desgaste y a las fechas de reemplazamiento y erupción dental (Couturier, 1938; PérezBarbería, 1994). Algo similar ocurre con la cabra montés Capra pyrenaica. Tradicionalmente, los restos de este caprino ibérico han sido incluidos en la especie Capra pyrenaica. Sin embargo, se ha observado, en algunas referencias, el taxón Capra ibex como en el yacimiento burgalés de La Blanca (Delibes de Castro y Diez Martín, 2006). Crégut Bonnoure (1992b) define ciertos criterios diagnósticos en la dentición inferior de ambos caprinos que serán empleados posteriormente. Cabe señalar que dichos restos son abundantes en los yacimientos analizados, justificando su revisión.

Algo parecido ocurre con los uros y bisontes, Bos primigenius y Bison priscus. Muchos de sus restos se asignan normalmente a Bos/Bison sp. debido a la ausencia de material diagnóstico como los cuernos y el tercer molar inferior. Sin embargo, existen trabajos en los que se intenta discriminar entre ambos géneros y que emplean material postcraneal (Schertz, 1936; Bibikova, 1958; Brugal, 1984; Buitrago, 1992; Gee, 1993; Álvarez-Lao, 2007; Sala et al., 2010). En nuestros depósitos, los criterios observados por estos investigadores no pueden ser empleados en la mayor parte de los restos ya que aparece muy fragmentado. Los criterios que aparecen en Jaubert et al., (1994) nos permiten tener en cuenta piezas dentales distintas al tercer molar inferior por lo que su uso es de gran interés en los yacimientos arqueopaleontológicos.

Por lo general, el registro de ungulados en los yacimientos con registro arqueopaleontológico del Pleistoceno Superior de la Meseta Norte constituye la mayor parte del material recuperado en los mismos. Salvo la Cueva del Búho, La Mina y la Peña de Mudá, el resto de los depósitos ha tenido un origen fundamentalmente antrópico (Utrilla et al., 2006; Díez, 2006; Díez et al., 2008; Yravedra, 2013), aunque es cierto que hay referencias del uso ocasional por parte de carnívoros de mayor o menor tamaño (Torres et al., 1989; Navazo et al., 2005; Díez, 2006). Los análisis tafonómicos y los estudios arqueozoológicos realizados en estos yacimientos han permitido conocer tanto el origen de estas acumulaciones como las actividades realizadas en ellos. Sin embargo, estos trabajos no aportan datos sobre los periodos de ocupación ni sobre una posible selección de las presas por edades o sexos. Por esta razón, y debido al gran volumen de material obtenido, la correcta identificación de los taxones, la determinación de la edad de muerte, la estacionalidad y el dimorfismo sexual aportan importantes datos sobre las ocupaciones.

El emplazamiento y la situación junto con el escaso número de yacimientos localizado ha planteado una serie de incertidumbres a los investigadores, considerando está región como un lugar aislado y deshabitado en comparación con regiones próximas. Los recientes descubrimientos así como la obtención de estas grandes colecciones nos permiten proponer los periodos en los que ocupaban las cavidades o si fueron utilizadas de manera contínua $\mathrm{o}$ en determinadas estaciones. Por otra parte, la estacionalidad puede relacionarse con los comportamientos sociales y migratorios de las especies identificadas, ayudándonos a comprender la ocupación de un determinado lugar en una estación concreta. Asimismo, su análisis puede ayudarnos a conocer las preferencias cinegéticas de las dos especies que poblaron este territorio en el Pleistoceno Superior, Homo neanderthalensis y Homo sapiens, conocer si discriminaban entre especies, edades y géneros, y si ocupaban el territorio y las cavidades con la misma intensidad y en el mismo periodo del año. Asimismo, el gran volumen de material recuperado también nos puede ayudar a conocer si el tamaño de estas especies ha cambiado con el tiempo y si esto podría 
influir en las pautas de caza de estos dos grupos humanos. Los estudios previos de estos yacimientos han sido llevados a cabo de manera independiente por diversos grupos de investigación (Moure Romanillo y García Soto, 1982; Díez et al., 1988-1989; Navazo et al., 2005; Utrilla et al., 2006; Álvarez -Lao, 2007; Cacho et al., 2006). Un análisis global de los mismos puede ofrecernos una imagen más detallada y obtener conclusiones generales tanto de las ocupaciones, intensidad o de las preferencias de los grupos humanos que habitaron este territorio en el Pleistoceno Tardío. Para abordar este estudio analizamos los restos fósiles de los ungulados recuperados en nueve yacimientos de la Comunidad Autónoma de Castilla y León: la Mina, la Cueva de Valdegoba, Cueva Millán, Prado Vargas, la Cueva del Búho, el Abrigo de Alexandre, el Abrigo de Vergara, la Peña de Estebanvela y la Peña de Mudá (figura I.1.1) (tabla I.1.1). Pasamos, en los siguientes apartados, a describir brevemente cada uno de los depósitos.

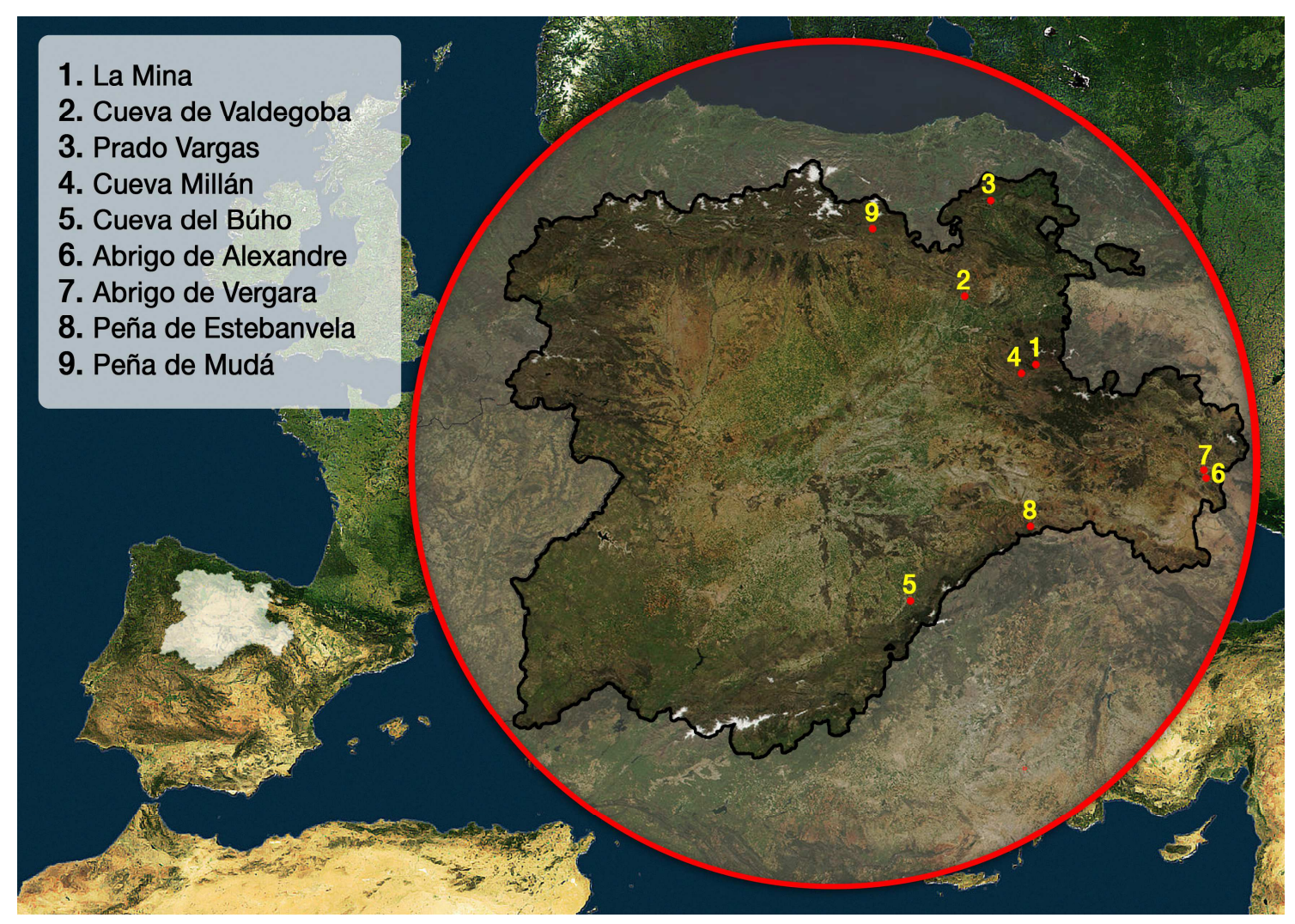

Figura I.1.1. Situación de los yacimientos estudiados en este trabajo.

\subsection{La Mina}

\subsubsection{Introducción}

El yacimiento de La Mina es uno de los tres depósitos situados en el curso medio del río Arlanza. Se localiza en el término municipal de Hortigüela (Burgos), a 970 metros sobre el nivel del mar, en un valle transversal del río Arlanza, por donde discurre el río Valparaíso (Díez et al., 2008). La cueva se interviene por primera vez en 2006 por el equipo del Dr. Carlos Díez de la Universidad de Burgos. Se realizaron cuatro sondeos donde se confirmó que el depósito estaba completamente revuelto. Identifican una pequeña matriz de arcillas con indicios de dos ocupaciones paleolíticas (Díez et al., 2008). 


\subsubsection{Geología y Estratigrafía}

La cavidad se enclava en el Sector Oricedo. En su estructura hay evidencias de un fuerte diaclasado que se manifiesta en el desarrollo de la cueva con direcciones de galería E-O (dominantes) y NO-SE secundarias junto con su conjugada NE-SO. La cueva tiene un desarrollo de 105 metros, terminando en un sumidero de 2 metros. Tanto la anchura como la altura varían entre uno y dos metros (Díez et al., 2008).

No se ha podido establecer una secuencia estratigráfica clara ya que el depósito ha sido objeto de continuas reactivaciones kársticas e intervenciones de furtivos (Díez et al., 2008). A pesar de ello, se pudieron identificar dos posibles conjuntos, que sin llegar a ser definidos como niveles sensu stricto, pueden darnos una idea de las posibles ocupaciones de la cavidad. El primero incluye 55 restos óseos rodados con mordeduras de carnívoros. Este grupo no ha proporcionado ningún resto arqueológico. La mayor parte de los fósiles corresponden a diáfisis fragmentadas de herbívoros de talla media a grande. El segundo agregado está representado por 493 fósiles y cuatro piezas líticas. También se han recuperado coprolitos de carnívoros y huesos digeridos.

\subsubsection{Restos fósiles}

Se han identificado 19 taxones en los 548 restos de asignación pleistocena recuperados (Díez et al., 2008). Los micromamíferos incluyen: Eurotestudo sp., Oryctolagus cuniculus, Lepus sp. e Hystrix sp. Los macromamíferos comprenden: Ursus arctos, Canis sp., Vulpes vulpes, Panthera sp., Lynx pardina, Felis sylvestris, Crocuta crocuta spelaea, Meles meles, Coelodonta antiquitatis, Equus ferus, Equus hydruntinus, Sus scrofa, Cervus elaphus, Rupicapra pyrenaica y Bos/Bison sp.

En este trabajo cambiamos la asignación del rinoceronte, incluyendo los restos en Coelodonta antiquitatis en lugar de en Stephanorhinus hemitoechus (Díez et al., 2008).

\subsubsection{Restos líticos}

Las materias primas se componen de sílex y cuarcita fundamentalmente. El sílex presenta características macroscópicas similares a las de La Ermita y Cueva Millán, salvo una lasca laminar que parece realizada con material alóctono. Se han recuperado núcleos con explotación ortogonal, muy agotados, cuchillos de dorso natural, lascas levallois, varios denticulados, una punta retocada de cuarcita y una raedera lateral recta sobre dorso natural. Debido a que los útiles han sido recogidos en un sedimento removido su adscripción cultural es difícil de definir. Teniendo en cuenta los procesos tecnológicos se podrían asignar al Pleistoceno Superior (Díez et al., 2008).

\subsubsection{Datación}

La metodología empleada fue la racemización de aminoácidos. Se llevó a cabo a partir de un diente de rinoceronte. El resultado reveló una edad aproximada de 52,5 Ka. BP. (Díez et al., 2008). El resto de taxones identificados, como los osos, zorros, caballos, ciervos, o cabras no nos permite aportar más información sobre el rango de tiempo representado. Debido a que el depósito está revuelto y a que la datación se ha obtenido a partir del diente del rinoceronte, únicamente se analizan los restos de este taxón. 


\subsection{La Cueva de Valdegoba}

\subsubsection{Introducción}

El yacimiento de la Cueva de Valdegoba se encuentra situado a $28 \mathrm{~km}$ al noroeste de la ciudad de Burgos, a $930 \mathrm{~m}$ sobre el nivel del mar y a 35 por encima del curso alto del río Urbel (Díez, 1990; Díez et al., 1989; Quam et al., 2001; Arceredillo, 2008a). Pertenece al municipio de Huérmeces, aunque las localidades más importantes de la zona son Montorio y Santibáñez de Zarzaguda. La cueva es conocida desde 1980 gracias a los trabajos realizados por el grupo espeleológico burgalés Edelweiss (Díez, 1990). Se realizaron cuatro campañas de excavación entre 1987 y 1991, y en el año 2006 se llevó a cabo un sondeo para acometer estudios sobre materias primas y paleovegetación por parte de la Universidad de Burgos.

\subsubsection{Geología y Estratigrafía}

El yacimiento se abre en un afloramiento de calizas turonenses (Cretácico Superior) en el borde más meridional de la orla Mesozoica de la cordillera Cantábrica (I.G.M.E., 1970) (Díez et al., 1988-1989). Éstas asoman cerca de la localidad de Huérmeces, sobre los depósitos terciarios de la Cuenca del Duero, siguiendo una orientación $135^{\circ} \mathrm{N}-140^{\circ} \mathrm{E}$ y un buzamiento de $38^{\circ}$. A los pies de la entrada, el río Urbel se encajona para posteriormente abrirse en la llanura terciaria de la Cuenca del Duero. La cueva está situada en el borde $\mathrm{N}$ del afloramiento y al E del cañón del río, en un farallón subvertical, al pie del cual aparecen depósitos de gran pendiente (Díez et al., 1988-1989; Quam et al., 2001).

El sistema kárstico es de tipo pluvial, con alimentación autóctona por infiltración gravitacional de agua superficial, facilitada por la gran cantidad de diaclasas existentes en la zona. El complejo está formado por tres cavidades, constituyendo en la actualidad un karst muerto. De las tres, la que presenta registro arqueopaleontológico es la mayor de ellas y se encuentra en posición central (Díez, 1990; Díez et al., 1988-1989). La entrada da paso a un vestíbulo orientado hacia el valle, con morfología de abrigo y donde se encuentra la mayor altura de la cueva. En el extremo SW se abre una galería ascendente en dirección N-S que se va cerrando progresivamente. Las dimensiones de la cueva no son muy grandes, presentando una longitud de $21 \mathrm{~m}$, una anchura máxima de 14 y una mínima de $6 \mathrm{~m}$ cuya altura varía entre los 4 a $5 \mathrm{~m}$ en la entrada y 0,5 $\mathrm{m}$ en el fondo (Díez 1990).

Buena parte de los depósitos aparecen alterados debido a reactivaciones y a la acción de furtivos (Díez, 2006). La cueva se encuentra parcialmente rellena por arcillas y cantos dispersos, los cuales llegaron a colmatar la cavidad y que posteriormente fueron vaciados por erosión y removidos por la acción de clandestinos (Díez, 1990). Sólo una de las catas realizadas permitió el levantamiento de una columna litoestratrigráfica apta para obtener resultados geológicos ya que en ella los materiales se encontraron in situ. Esta secuencia fue desarrollada por J. Jordá (Quam et al., 2001), diferenciando 8 niveles que de muro a techo son los siguientes:

Nivel I: Concreción estalagmítica basal. Estéril.

Nivel II: $40 \mathrm{~cm}$ de arcillas rojas con limos y arenas con un subnivel de concreción carbonatada. Estéril.

Nivel III: $10 \mathrm{~cm}$ de arcillas marrones con limos y arenas. Concreción estalagmítica en la superficie. Estéril.

Nivel IV: Arcillas marrones con bloques calizos de espesores no superiores a $50 \mathrm{~cm}$. Erosión visible en la superficie. Industria lítica y fósiles.

Nivel V: $20 \mathrm{~cm}$ de arcillas marrones con numerosos bloques calizos. Contacto erosivo con el nivel IV. Industria lítica, fósiles de fauna y homínidos. 
Nivel VI: Brecha caliza cubierta por al menos $20 \mathrm{~cm}$ de bloques calizos, instrumentos líticos y fósiles. En continuidad con el nivel V. Sólo la cementación de la brecha permite su diferenciación.

Nivel VII: Una concreción estalagtítica laminar cierra el nivel 6. Esta concreción se encuentra unida en diversos puntos a las paredes y el techo. Presenta material arqueológico. Es un reflejo claro del punto de colmatación que llegó a tener la cavidad.

Nivel VIII: $60 \mathrm{~cm}$ de arcillas en contacto con el nivel VII. Contiene una mezcla de materiales Paleolíticos y Holocenos así como restos humanos. Esta mezcla refleja una alteración por parte de furtivos.

\subsubsection{Restos fósiles}

Las excavaciones llevadas a cabo desde 1987 han proporcionado un importante conjunto de restos faunísticos que incluyen primates, carnívoros, perisodáctilos, artiodáctilos, aves, roedores y lagomorfos. Los macromamíferos incluyen: Homo sapiens, Homo neanderthalensis, Ursus arctos, Ursus spelaeus, Canis lupus, Vulpes vulpes, Crocuta crocuta, Panthera pardus, Felis silvestris, Lynx pardina, Meles meles, Lutra lutra, Martes sp., Stephanorhinus hemitoechus, Equus ferus, Equus hydruntinus, Sus scrofa, Cervus elaphus, Capreolus capreolus, Rupicapra pyrenaica, Capra pyrenaica, Bos primigenius, Bison priscus y Bos/Bison sp. (Díez et al., 1989). Los micromamíferos incluyen: Sorex sp., Neomys sp., Oryctolagus cuniculus, Microtus nivalis, Microtus arvalis-agrestis, Pliomys lenki, Apodemus cf. sylvaticus, Arvicola sp., Marmota cf. marmota, Hystrix cf. vinogradovii y Castor fiber. La avifauna comprende: Anas sp., Aegypius monachus, Falco tinnunculus, Columba sp., Athene noctua, Alectoris sp., Coturnix coturnix, Turdus sp., Pyrrhocorax graculus (Díez et al., 1989).

Los restos más destacables, ya que son los únicos descubiertos hasta el momento en Castilla y León, corresponden al homínido Homo neanderthalensis. De esta especie se ha recuperado un fragmento mandibular que conserva nueve piezas dentarias, una falange y dos metatarsos. También se han obtenido diversos restos adscritos a Homo sapiens que nos indican una ocupación holocena de la cavidad (Díez et al., 1988-1989).

En este trabajo se reasignan los restos del rebeco a la especie Rupicapra pyrenaica y se incluyen parte de los restos de gran bóvido al uro Bos primigenius y al bisonte Bison priscus.

\subsubsection{Restos líticos}

La industria lítica es abundante, unas 2500 piezas, producidas principalmente a partir de sílex y cuarcita, aunque también aparecen piezas fabricadas a partir de arenisca y cuarzo. El material proviene de afloramientos próximos al yacimiento. Las cuarcitas se encuentran en el río Urbel, y el sílex procede tanto del río, en forma de bloques neógenos, como de nódulos cretáceos del afloramiento donde se encuentra la cueva (Díez et al., 1988-1989; Quam et al., 2001). Abundan los núcleos centrípetos, las extracciones longitudinales, las raederas y los denticulados (Díez, 2006).

\subsubsection{Datación}

Se han llevado a cabo varios tipos de dataciones. Las primeras, realizadas por James Bischoff sobre varias costras estalagmíticas mediante series de Uranio, aportaron datos poco concluyentes. Se tomaron tres muestras: una en la costra estalagmítica basal del nivel I y otras dos en la brecha superficial del nivel VII (Arceredillo, 2008a). La primera aportó una fecha $>350 \mathrm{Ka}$ y las otras dos no ofrecieron datos concluyentes ya que aparecieron contaminadas con torio detrítico (Díez, 2006), dando por tanto, cronologías más antiguas, $95 \pm 8$ Ka y $73 \pm 5$ Ka. Por otra parte, el equipo de Trinidad Torres, en 2005, mediante 
racemización de aminoácidos, consiguió obtener fechas a partir de varios restos óseos del nivel IV: 121,86 Ka BP; del nivel V: 72,59 y $138 \mathrm{Ka} \mathrm{BP;} \mathrm{y} \mathrm{del} \mathrm{nivel} \mathrm{VI:} \mathrm{93,26} \mathrm{Ka,} \mathrm{106,02} \mathrm{Ka}$ (Díez et al., 2014). Por último, dos huesos del nivel V fueron enviados a la Universidad de Oxford (ORAU). Uno no pudo datarse y otro, mediante el protocolo de ultrafiltración, aportó un dato no calibrado de 48,400 \pm 3,300 BP (OxA-21970) (Dalen et al., 2012).

\subsection{Prado Vargas}

\subsubsection{Introducción}

La cueva de Prado Vargas se encuentra en la Merindad de Sotoscueva, a escasos 500 metros de la localidad de Cornejo, en el norte de Burgos (Torres et al., 1993; Navazo et al., 2005). Forma parte del complejo kárstico de Ojo Guareña, configurándose como una antigua surgencia, hoy en día inactiva, situada a 20 metros por encima del curso actual del río Trema. Esta cueva se sitúa en un paso natural entre la región Cantábrica y la Meseta Norte y presenta una morfología de abrigo natural (Torres et al., 1989).

Su potencial paleontológico se conoce desde los años 70 del siglo pasado. Fue entonces cuando el grupo espeleológico Edelweiss encuentra un cráneo de Ursus spelaeus que deposita, posteriormente, en el Museo Provincial de Burgos. Éste es analizado por Trinidad Torres que, tras un estudio previo, decide realizar una intervención única en 1986. Durante esta campaña se abrieron cuatro catas para definir la estratigrafía y observar su correlación, recuperándose diversas piezas líticas y fósiles (Torres et al., 1989; Navazo et al., 2005). La actividad se reanudó en 2006 por parte de la Universidad de Burgos, bajo la dirección de Marta Navazo y Carlos Díez, con la reapertura de la cata en la zona más próxima a la entrada y una en el exterior, próxima a la boca. Durante esta intervención se recogió gran cantidad de material lítico así como restos óseos y dentarios.

\subsubsection{Geología y Estratigrafía}

La cueva se abre en los materiales carbonatados del Cretácico Superior del flanco nororiental del sinclinal de Villarcayo y más concretamente en el sector denominado "zona plegada del río Trema", al pie de un pequeño escarpe calcáreo, cerrando un prado de fuerte pendiente y poca extensión (Torres et al., 1989; Díez y Rodríguez, 2009). Se trata de una cavidad de poco desarrollo, escasos 120 metros, según una galería rectilínea interrelacionada con una diaclasa (Torres et al., 1989), con una dirección NW-SE (Navazo et al., 2005) y una serie de pequeñas ramificaciones de dirección NW-SE. La cueva se divide en tres secciones bien diferenciadas: 1) cerca de la salida con una longitud de 30 metros y una altura máxima de $3 ; 2$ ) un pasillo de 6 metros de longitud; y 3) la parte final con 50 metros de recorrido y 2 metros de altura en su parte más elevada (Navazo et al., 2005). La cueva se abre al valle por medio de una fuerte pendiente aluvial que termina en el río Trema, a cuyo nivel se abren los actuales sumideros del río.

Durante la campaña de 1986 se estableció la estratigrafía de los depósitos. En este trabajo se ha analizado el material de la cata alfa, que se encuentra en su mayor parte en el nivel 4. Torres et al., (1989) identifica cinco niveles que de techo a muro son los siguientes:

Nivel 1: Tierra suelta y removida. Estéril.

Nivel 2: Material fino con cantos calcáreos. Material arqueológico in situ. Se recuperan varios fragmentos de cerámica de origen altomedieval y los restos de un artiodáctilo joven (cordero o cabra).

Nivel 3: Paquete de arcilla roja compacta de 40-50 cm de espesor. Estéril. 
Nivel 4: Material arcilloso mezclado con gravilla, grava y arena calcáreas. En este nivel aparece casi todo el material arqueológico y paleontológico.

Nivel 5: Compuesto por gravilla y arena gruesa calcárea. Estéril.

\subsubsection{Restos fósiles}

Las campañas llevadas a cabo han aportado pocos restos. La mayor parte aparece muy fragmentado y su identificación resulta en ocasiones imposible. Los sedimentos han sido cribados pero aún no se han analizado por lo que el registro tanto de micromamíferos como de avifauna aún no ha sido estudiado. Los macromamíferos incluyen: Canis lupus, Panthera pardus, Ursus spelaeus, Rhinocerotidae indet., Equus ferus, Sus scrofa, Cervus elaphus, Capreolus capreolus, Rupicapra pyrenaica, Capra pyrenaica y Oryctolagus sp.

En este trabajo se añade al inventario realizado por Torres et al., (1989) y Navazo et al., (2005) el resto de rinoceronte y se reasigna el rebeco a la especie Rupicapra pyrenaica.

\subsubsection{Restos líticos}

Predominan las lascas, destacando una pequeña porción de núcleos y la presencia de, al menos, dos buriles. Las materias primas empleadas fueron el sílex, la cuarcita, la caliza silicificada y la lutita (Navazo et al., 2005). La mayor parte de este material se localizó en la cata cercana a la entrada de la cueva, siendo rara en la cata interna (Torres et al., 1993, Navazo et al., 2005; Navazo y Díez, 2008).

\subsubsection{Datación}

La técnica empleada para datar el yacimiento fue la racemización de aminoácidos. Para ello se utilizó un $\mathrm{P}_{2}$ derecho de caballo (Navazo et al., 2005). Los resultados reflejaron una cronología próxima a los 46,4 Ka.

\subsection{Cueva Millán}

\subsubsection{Introducción}

El abrigo de Cueva Millán se encuentra en el término municipal de Hortigüela, a escasos 50 kilómetros de la ciudad de Burgos y a $985 \mathrm{~m}$ sobre el nivel del mar (Díez et al., 2008). Se sitúa en un pequeño valle transversal, tributario del río Arlanza, en un lugar conocido como "Los Riscos del Estillín" (Moure Romanillo et al., 1983; Álvarez et al., 1992; Roselló Izquierdo, 1992), formado por grandes cortados que se hacen menos pronunciados conforme descendemos hacia el curso fluvial (Moure Romanillo et al., 1983).

La primera referencia la realiza Martín Merino (1978), miembro del grupo espeleológico Edelweiss de la Diputación Provincial de Burgos. En ella habla de Cueva Millán como "...poseedor de un extraordinario taller de sílex" (Moure Romanillo et al., 1982; Moure Romanillo et al., 1983). Antes de las excavaciones llevadas a cabo por un equipo de la UCM, miembros del Colectivo Arqueológico Salense visitan la cavidad recuperando 1.165 piezas líticas en superficie (Díez et al., 2008). Miembros del Departamento de Prehistoria de la Universidad Complutense de Madrid, tras una visita previa donde recogieron abundante material lítico en superficie, deciden llevar a cabo una serie de intervenciones en el yacimiento. Éstas se realizaron en cuatro campañas, tres de 
ellas de forma consecutiva en 1980, 1981 y 1982 (Moure Romanillo et al., 1983; Álvarez et al., 1992) y la última en el año 1986 (Pérez Legido y Cerdeño, 1992).

\subsubsection{Geología y Estratigrafía}

El yacimiento se encuentra en el curso medio del río Arlanza, el cual comunica la Sierra de la Demanda con el terciario de la Meseta. Sigue una dirección oeste salvo en la zona de Hortigüela, donde toma una dirección sur al formar un ancho valle y encajarse en un desfiladero (Díez et al., 2008). Tanto Cueva Millán como La Ermita y La Mina participan de similar ambiente geomorfológico y paisajístico: espacios abiertos y valles, laderas generalmente pronunciadas con abundancia de riscos y paredes verticales, y gran desarrollo de zonas altas, en general amesetadas (Díez et al., 2008). El abrigo se abre en las calizas cretácicas del Turoniense Inferior que afloran en esta zona cercana a localidad de Hortigüela (Álvarez et al., 1992).

La estratigrafía se definió a partir de los cortes presentes en cinco cuadrículas situadas en diferentes zonas del abrigo. Fue realizada por el equipo de Enrique García Soto durante la primera campaña de excavaciones. La secuencia es bastante sencilla debido a la poca alteración de los depósitos. Se definieron cuatro unidades/niveles sedimentológicos (Moure Romanillo et al., 1983; Álvarez et al., 1992):

Nivel 1: Superficial muy delgado, formado casi en su totalidad por sedimentos vegetales. Presenta material lítico y fósiles.

Nivel 1a: Nivel con la mayor potencia de toda la secuencia, formado por arcilla blanquecina y pequeños cantos uniformes de caliza. Con fósiles y material lítico.

Nivel 1b: Arcilla amarillenta con cantos calizos de mayor tamaño que los del nivel precedente. Arqueológicamente fértil.

Nivel 1c: Arcilla roja y cantos calizos grandes más que 1a y 1b. Arqueológicamente fértil.

\subsubsection{Restos fósiles}

Las excavaciones llevadas a cabo durante las cuatro campañas han aportado un importante conjunto de fósiles. A pesar de ello, sólo una pequeña parte ha podido ser identificada (Álvarez et al., 1992) debido al elevado grado de fragmentación de los mismos (Díez et al., 2008).

La colección de micromamíferos se compone de: Ortyctolagus cuniculus, Myotis myotis, Castor fiber, Eliomys quercinus, Pliomys lenkii, Microtus arvalis/agrestis, Microtus nivalisminuta, Pitymys duodecimcostatus, Arvicola cf. terrestris y Apodemus sp. Los macromamíferos incluyen: Canis lupus, Vulpes vulpes, Mustela nivalis, Stephanorhinus hemitoechus, Equus ferus, Equus hydruntinus, Cervus elaphus, Capreolus capreolus, Rupicapra pyrenaica, Capra pyrenaica y Bos/Bison sp. Destaca la abundancia del conejo, seguido de los artiodáctilos, los perisodáctilos y por último de los carnívoros. Capra es el género que cuenta con mayor número de restos identificados, seguida por el ciervo, el rebeco y el caballo (Pérez Legido y Cerdeño, 1992; Díez et al., 2008). El mayor número de restos y de individuos se encuentra en el primer nivel, algo lógico si tenemos en cuenta que es la zona más ampliamente excavada (Pérez Legido y Cerdeño, 1992). La bibliografía no deja clara la presencia y/o ausencia de determinadas especies como Equus hydruntinus y Capreolus capreolus ya que en unas publicaciones aparecen y en otras no. E. hydruntinus no se menciona en el análisis llevado a cabo por Pérez Legido y Cerdeño (1992) tras la revisión del material de macromamíferos, mientras que Díez et al. (2008) sí que lo cita. Por otra parte, Moure Romanillo et al. (1983) y Álvarez et al., (1992) indican la presencia de corzo pero ni Pérez Legido y Cerdeño (1992) ni Díez et al., (2008) los nombran en sus revisiones. 
Son importantes los restos correspondientes a la ictiofauna (279 restos), de la que se han podido identificar tres especies: Salmo trutta, Anguila anguila y Chondrostoma polylepis (Moure Romanillo et al., 1983; Álvarez et al., 1992). Asimismo, Esteban et al. (1990) cita la presencia de la rana ibérica, Rana iberica.

En este trabajo se ha reasignado la especie Rupicapra rupicapra que aparece en Pérez Legido y Cerdeño (1992) y en Díez et al. (2008) a R. pyrenaica.

\subsubsection{Restos líticos}

Se han recuperado un total de 1.165 piezas en superficie. La materia prima utilizada es autóctona y está compuesta fundamentalmente de sílex y cuarcita. El hecho de encontrarse la cadena operativa completa, indicios de reciclado del material, dobles pátinas y diversos sistemas operativos sugiere un aprovechamiento intensivo de las materias primas (Díez et al., 2008). En los tres niveles subsiguientes, la industria parece ser bastante homogénea tanto en composición como en distribución. Además del sílex y la cuarcita, se han recogido piezas de cuarzo, arenisca y caliza (Moure Romanillo et al., 1983). Destacan las raederas, las escotaduras retocadas y los denticulados en los tres niveles (Moure Romanillo et al., 1983; Díez et al., 2008).

\subsubsection{Restos polínicos}

El análisis polínico detectó la presencia de tres especies de árboles: el pino, Pinus sp., el roble, Quercus sp., y el abedul, Betula sp.; y de ocho herbáceas entre las que destaca Ninphaceae (Moure Romanillo et al., 1983).

\subsubsection{Datación}

Las fechas se obtuvieron a partir de la técnica del ${ }^{14} \mathrm{C}$ (Moure Romanillo et al., 1983, Díez et al., 2008). Fueron tomadas en fragmentos de hueso de los niveles 1a y $1 \mathrm{~b}$ (Moure Romanillo et al., 1982; Moure Romanillo et al., 1983). La muestra calibrada del nivel 1a aportó unas fechas de 43.130 - 41.290 calBP. y la del 1b 43.010 - 41.250 calBP. Estas cronologías sitúan el depósito en un periodo comprendido entre el OIS2 y el OIS3.

\subsection{La Cueva del Búho / Cueva de la Zarzamora}

\subsubsection{Introducción}

Los yacimientos cuaternarios de la Cueva del Búho y de la Cueva de la Zarzamora (Perogordo, Segovia) se encuentran a escasos 2 kilómetros al SO de la capital segoviana, junto a uno de los afluentes del arroyo Tejadilla (Molero et al., 1989; Maldonado, 1996; Sala et al., 2009; Sala et al., 2010).

Los primeros trabajos que se realizaron en estas cavidades corrieron a cargo de Guillermo Molero y de su equipo (Iñigo et al., 1998; Sala et al., 2009). Dichas intervenciones se llevaron a cabo en tres zonas anexas: la Cueva del Búho, la Cata Exterior, situada sobre el suelo de una antigua galería colapsada, y la Cavidad Anexa (ahora Cueva de la Zarzamora). En 2008, un equipo formado por especialistas de la Universidad Complutense y del Centro Mixto UCM-ISCIII de Evolución y Comportamiento Humanos reanudó los trabajos en esta cavidad encontrando niveles fértiles solamente en la Cueva de la Zarzamora (Sala et al., 2009, 2010) cuyo material está aún en estudio. Este depósito ha 
sido interpretado por Sala (2012) como un cubil de hienas por la presencia de individuos juveniles y coprolitos de esta especie así como por la gran cantidad marcas de carnívoros.

\subsubsection{Geología y Estratigrafía}

Estas cavidades se abren en la vertiente norte del Sistema Central, en un afloramiento de calizas y dolomías (dolomías de Castrojimeno) (Alonso, 1981; Sala, 2012) del Cretácico Superior (Santoniense) pertenecientes a la Sierra de Guadarrama. Dichos materiales aparecen cortados por el sistema fluvial del arroyo Tejadilla. La actividad de las hienas y la acción de la escorrentía ha impedido en muchos casos la realización de una columna estratigráfica completa. A pesar de esto, se han identificado varios niveles en la Cueva de la Zarzamora (Sala, 2012) que de techo a muro son:

Nivel 1-2: $45 \mathrm{~cm}$ de potencia. Material detrítico de composición carbonática que llega prácticamente al techo. Además de cantos de dolomía, engloba fósiles de macrovertebrados y coprolitos de hiena. La mayor parte de los fósiles presentan una concreción carbonatada. La nomenclatura es debida a que en un primer momento se establecieron como dos niveles pero estudios posteriores no justificaron la subdivisión.

Nivel 3: $30 \mathrm{~cm}$ de potencia. Bloques angulosos y tabulares de dolomía alterada, englobados en una matriz de cristales de dolomita. Rico en fósiles.

Nivel 4: $15 \mathrm{~cm}$ de potencia mínima. Arcillas plásticas, homogéneas y estériles.

\subsubsection{Restos fósiles}

La actividad predadora de las hienas ha producido una mezcla importante de restos fósiles, encontrándose los niveles removidos como consecuencia tanto de la actividad de estos depredadores como de la acción erosiva de las aguas dentro del sistema kárstico. Los macromamíferos identificados en este depósito incluyen: H. sapiens, Canis lupus, Vulpes vulpes, Meles meles, Crocuta crocuta spelaea, Panthera cf. pardus, Lynx sp., Stephanorhinus hemitoechus, Equus ferus antunesi, Equus hydruntinus, Sus scrofa, Cervus elaphus, Bos primigenius y Bison priscus. Los micromamíferos presentes son: Myotis sp., Oryctolagus cuniculus, Lepus capensis, Erinaceus europaeus, Crocidura cf. rusula, Microtus cf. cabrerae, Microtus duodecimcostatus, Apodemus silvaticus, Castor fiber y Eliomys quercinus (Molero et al., 1989; Iñigo, 1995; Maldonado, 1996; Iñigo et al., 1998 y Sala et al., 2010).

\subsubsection{Datación}

La datación por radiocarbono de un fósil del nivel 1-2 aportó una fecha de $32.510 \pm 240$ años BP, aunque según Sala (2012) este dato hay que tomarlo con cautela ya que no se pudo repetir aplicando el protocolo de pretratamiento por ultrafiltración debido a la ausencia de colágeno. Otra fecha se ha obtenido en la cata exterior, en el nivel 2. De nuevo, a partir del radiocarbono, se ha obtenido una fecha de $>44.400$ años BP (Sala, 2012).

\subsection{El Abrigo de Alexandre}

\subsubsection{Introducción}

Este abrigo se localiza en la ladera sur de la Peña del Manto, en el paraje denominado Fuentes de San Roquillo, en la margen izquierda del río Henar en el término de Deza (Soria) (Utrilla et al., 2000). Se encuentra a 960 metros sobre el nivel del mar y se abre a unos 500 metros por encima del Abrigo de Vergara (Utrilla et al., 2006). 
Este abrigo fue descubierto en 1995 por Vicente Alexandre, un vecino de la localidad soriana de Deza (Utrilla et al., 2006). Tras los pertinentes permisos, Pilar Utrilla llevó a cabo una campaña de excavaciones en 1997 (Utrilla et al., 2006). La intervención consistió en la realización de un sondeo para extraer muestras palinológicas y sedimentológicas. Además, se tomaron muestras para realizar los primeros análisis radiocarbónicos. Los escasos restos de fauna, restos líticos y la relativa abundancia de útiles retocados les llevaron a suponer su utilización como lugar de hábitat (Utrilla et al., 2000).

\subsubsection{Geología y Estratigrafía}

El abrigo se sitúa en una zona de tobas calcáreas y estromatolíticas que presentan una estructura fibrosa donde, además, pueden encontrarse facies de rápidos y cascadas. En general, estos depósitos presentan una karstificación posterior, la cual origina precipitación de carbonato laminar. El origen de la unidad parece situarse en el drenaje de los relieves mesozoicos cuyas aguas carbonatadas precipitan debido a cambios bruscos de temperatura (Utrilla et al., 2000). El abrigo es muy profundo, casi una cueva. Las precipitaciones de aguas carbonatadas sobre los depósitos han permitido su conservación. Se detectaron tres niveles en el sondeo (Utrilla et al., 2006):

Nivel I: Tierra grisácea, suelta, con lajas horizontales en su base. Arenas y limos con gravas subredondeadas. Unos $20 \mathrm{~cm}$ de espesor medio.

Nivel II: Tobas rojas o blancas procedentes de la disgregación del techo. Dividido en dos subniveles: Ila: con tobas rojizas en matriz arcillosa y $20 \mathrm{~cm}$ de espesor; IIb: con tobas blancas y $50 \mathrm{~cm}$ de potencia.

Nivel III: Textura fina y color gris oscuro en un sedimento rojizo muy compacto. Único nivel fértil. Subdividido en tres subniveles: IIIa: limos rojos con carbones dispersos; IIIb: lentejón gris oscuro con cantos angulosos y cenizas. Con industria lítica, carbones y escasos restos de fauna; y IIIc: rojizo, textura arenosa, con cantitos redondeados.

\subsubsection{Restos fósiles}

Se limitan a unos pocos fragmentos dentales de un équido y a un diente de $R$. pyrenaica. En este trabajo se reasigna el diente de Cervus elaphus que aparece en Utrilla et al., (2000) al rebeco $R$. pyrenaica.

\subsubsection{Restos líticos}

A pesar de que sólo se llevó a cabo un sondeo, la colección de industria lítica es importante. El conjunto incluye raspadores, buriles, puntas de dorso y láminas (Utrilla et al., 2000). La factura permite descartar el abrigo como lugar de talla, proponiendo un uso como lugar de habitación (Utrilla et al., 2006).

\subsubsection{Datación}

Se dató un carbón proveniente del subnivel IIIb. Aportó una cronología de $15.370 \pm 110$ BP (Utrilla et al., 2000; 2006). Estas fechas sitúan el abrigo en las últimas fases del Pleistoceno Tardío. 


\subsection{El Abrigo de Vergara}

\subsubsection{Introducción}

El abrigo se abre en la ladera oeste de la Peña del Manto, un farallón calizo sobre la actual carretera que conecta Deza con Cihuela (Soria) (Utrilla et al., 1999; 2006). Se encuentra a escasos 120 metros por debajo del Abrigo Alexandre y a 860 metros sobre el nivel del mar.

Este depósito fue descubierto por Daniel Vergara en el curso de unas prospecciones arqueológicas que realizaba la Universidad de Salamanca por la zona. Se llevaron a cabo dos campañas de excavación en los años 1996 y 1997 dirigidas por Pilar Utrilla y Fernanda Blasco, siendo la primera de las intervenciones un sondeo de urgencia (Utrilla et al., 2000). Los trabajos revelaron una utilización del lugar como taller, dadas las características tecnotipológicas que ofrecían los materiales (Utrilla et al., 2000).

\subsubsection{Geología y Estratigrafía}

Tanto el Abrigo de Vergara como el Abrigo Alexandre se encuentran situados en la misma zona de tobas calcáreas (Utrilla et al., 2000) por lo que la explicación de la geología y de la estratigrafía es similar y se encuentra en el apartado homólogo del Abrigo de Alexandre.

El yacimiento se encuentra en la parte central del corredor rocoso que bordea la parte inferior de la Peña del Manto, debajo de una gran pared rocosa en extraplomo. Esto ha permitido la conservación de una pequeña parte del depósito. En origen, esta visera pudo ser mayor a juzgar por los grandes bloques presentes en la ladera y que se atribuyen a la visera original del abrigo.

El depósito arqueológico es pequeño, presentando unos escasos 4 metros de longitud, 1 metro de anchura y alrededor de 1 metro de potencia. Se han documentado cinco niveles que de techo a muro son (Utrilla et al., 1999; 2000):

Nivel a: Nivel masivo de arenas con arcillas y limos de color marrón grisáceo que va de amarillento a oscuro. Máximo espesor cercano a los $30 \mathrm{~cm}$ (hacia el interior de la pared) y el menor de 15 (en el borde de la cata). Escasos restos líticos, sobre todo restos de talla. Se han identificado dos subniveles: a2: nivel de arenas con arcillas y limos de naturaleza lenticular pero rico en nódulos de carbonatos. Situado en la zona central y desplazado hacia un lado. a3: nivel de lajas de entre 15 y $20 \mathrm{~cm}$ de longitud.

Nivel b: Cantos con fracción fina gruesa de color amarillo rojizo, de alrededor de $25 \mathrm{~cm}$ de espesor. Recubre un gran bloque caído de la visera. Restos de industria en su base, cerca de la conexión con el nivel c.

Nivel c: Limos con escasas fracciones gruesas de $20 \mathrm{~cm}$ de potencia máxima. En la base presenta grandes bloques caídos de la visera. Contacta gradualmente con el nivel inferior, buzando hacia el interior del abrigo. Se separa del d por un nivel de plaquetas calizas.

Nivel d: Limos de color marrón grisáceo con una potencia media de $12 \mathrm{~cm}$. Rellena una cubeta excavada en el nivel inferior. Cantos no muy abundantes, angulosos y alterados por la acción del fuego en condiciones reductoras. Es el nivel más fértil. Se han identificado dos subniveles: $1 \mathrm{~d}$ : limoarcillas con arenas de color marrón amarillento y con varios cantos angulosos. 2d: limos de color marrón con pocos cantos. Hay varias lajas planas y abundantes plaquetas caídas del techo. El nivel buza hacia el interior del abrigo y alcanza un espesor máximo de $27 \mathrm{~cm}$. Presenta industria lítica y escaso restos de fauna.

Nivel e: Arenas y arcillas de distribución muy homogénea de color ocre-rojizo, muy compacto y duro, sin ninguna piedra ni cantos. Presenta fracciones finas de color amarillo 
rojizo, con algunos cantos y gravas más abundantes hacia la base. Conforme se avanza en profundidad el nivel se vuelve más granuloso y van apareciendo calizas de aristas angulosas. Sin registro arqueológico aunque en su base aparecieron partículas de carbón vegetal.

\subsubsection{Restos fósiles}

Son escasos, han aparecido muy fragmentados y se han recuperado en el nivel d (Utrilla et al., 2000; 2006). La mayor parte son restos dentarios de herbívoros: Equus ferus y Cervus elaphus. Por otra parte, también se recuperaron los restos de un bivalvo: Pecten maximus.

\subsubsection{Restos líticos}

El conjunto lítico es abundante y diverso. 7.390 piezas fueron recuperadas, de las cuales 7.189 corresponden a restos de talla y otras 181 a piezas retocadas. La mayor parte aparecieron en el contacto de los niveles "c" $y$ " $d$ ".

Predominan las microlascas y las microláminas. En el nivel "a" y "b" destacan las microlascas (Utrilla et al., 2000; 2006). En los dos niveles con mayor concentración de útiles (c y d) se han identificado raspadores, perforadores, buriles, piezas de dorso, puntas de la gravette, microgravettes, piezas con truncadura, armadura mediterránea, denticulados, raederas, raclettes, piezas con muesca, hojitas retocadas y hojitas de dorso (Utrilla et al., 2000; 2006).

La materia prima es, fundamentalmente, sílex autóctono, obtenido en los depósitos Oligocenos y en las margas de limonita de la Cuenca Miocena de Almazán a la cual pertenece la cuenca del río Henar (Utrilla et al., 2000; 2006).

\subsubsection{Datación}

Se dataron tres de sus niveles a partir del método del ${ }^{14} \mathrm{C}$. En el nivel "b" se fechó un hueso, revelando una edad de $7.800 \pm 50 \mathrm{BP}$. En este caso hay que indicar que el Laboratorio encargado de realizar las dataciones expresó sus dudas por la baja concentración de colágeno de la pieza (Utrilla et al., 2000).

En el nivel "d" y más concretamente en el subnivel " $2 \mathrm{~d}$ " se dató un diente de caballo, dando una fecha de $14.000 \pm 100$ BP. Por último, un carbón recuperado en el nivel "e" arrojo una fecha de $>38.750$ B.P. (Utrilla et al., 2000; 2006). Esta última fecha parece proceder de un rellenado de una cubeta por lo que parece no encontrarse in situ (Utrilla et al., 2000).

\subsection{La Peña de Estebanvela}

\subsubsection{Introducción}

El abrigo rocoso de la Peña de Estebanvela (Peña de la Grieta) se encuentra en el borde más meridional del sector SE de la Cuenca del Duero (Cacho et al., 2003), a escasos 1.000 metros de la localidad de Estebanvela al noroeste de la provincia de Segovia. Se encuentra a 1.085 metros sobre el nivel del mar y a 20 metros sobre el curso actual del río Aguisejo, uno de los afluentes del Riaza (Jordá, 2006a). 
El yacimiento se descubre a raíz de la redacción de la Carta arqueológica de la Provincia de Segovia en 1992. El equipo prospector dirigido por Fernando López Ambite recupera diversos materiales del Paleolítico Superior en un abrigo colmatado en la margen derecha del río Aguisejo. El yacimiento recibió, en un primer momento, la denominación de Estebanvela 3. El equipo de investigación actual asignó el nombre de La Peña de Estebanvela, cambiando el topónimo de "Peña de la Grieta" para poder diferenciarlo de otros yacimientos peninsulares que ya presentaban el mismo nombre. En 1998 se solicitó el primer proyecto de investigación a la Dirección General de Patrimonio y Promoción Cultural de la Consejería de Educación y Cultura de la Junta de Castilla y León, concediéndose el proyecto de investigación: "El poblamiento de la cuenca alta del Duero durante el Paleolítico Superior y Epipaleolítico" que posteriormente pasó a denominarse "El Pleistoceno Superior Final y la transición al Holoceno en las estribaciones de la Sierra de Guadarrama" (Cacho et al., 2003).

\subsubsection{Geología y Estratigrafía}

El yacimiento se encuentra enclavado en el extremo meridional del sector SE de la Cuenca del Duero, en el borde S del corredor de Aranda de Duero-Burgo de Osma (Jordá, 2006a), en contacto con el extremo nororiental del Sistema Central representado por la sierra de Ayllón. Hacia el oeste se encuentra la sierra de Honrubia-Pradales y hacia el este la cuenca de Almazán. El abrigo se abre en los paraconglomerados del Mioceno de la cuenca del Duero (Jordá, 2006a). El encajonamiento cuaternario del río Aguisejo ha dado lugar a un pequeño cañón cuya margen derecha presenta un ligero ensanchamiento que es donde se encuentra el yacimiento.

La cavidad a la cual pertenece el abrigo se ha generado a consecuencia de la karstificación de un tramo paraconglomerático que lateralmente pasa a ser arenosolutítico, con la matriz arcillosa sustituida parcialmente por una carbonatación secundaria que aparentemente puede considerarse como un cemento (Jordá, 2006a). La cueva resultante tiene una profundidad de unos 6 metros observables, presentando pequeñas cúpulas y paredes irregulares. Se encuentra totalmente colmatada por depósitos subhorizontales de diferente naturaleza. Se han identificado seis unidades sedimentarias en el corte exterior (Jordá, 2006a):

Nivel 0: 0-50 cm de fragmentos de roca de naturaleza conglomerática englobados en una matriz de color naranja claro. Colmata completamente el abrigo, encontrándose en contacto con los conglomerados del techo.

Nivel I: 40-140 $\mathrm{cm}$ de conglomerados, arenas y arcillas de color anaranjado de base irregular. Presenta un ligero buzamiento hacia el oeste y varios subniveles interestratificados. El primero de ellos está formado por $25-100 \mathrm{~cm}$ de arcillas rojas con limos y arenas finas y medias que engloban cantos autóctonos. Alternan con arenas y lutitas. Este primer subnivel es estéril. El segundo, con una potencia comprendida entre 25 y $40 \mathrm{~cm}$ está formado por lutitas, arenas y gravas. Ocasionalmente, contiene cantos y gravas autóctonos. En los últimos 10-15 cm se observan alternancias de materiales finos de color rojo laminados con arenas gruesas y gravas de color gris. Este subnivel presenta material óseo y lítico.

Nivel II: $18-50 \mathrm{~cm}$ de lutitas arenosas de color gris, con cantos y bloques cuarcíticos autóctonos y clastos de pizarra alóctonos muy angulosos de claro origen antrópico. Hay intrusiones del nivel anterior provocadas por procesos de crioturbación. En la zona interna y hacia la base aparecen arenas y gravas finas que lateralmente pasan a limos rojizos orientados hacia el interior del abrigo. Hacia el exterior tiene cantos y gravas autóctonos. Este nivel es rico en material arqueológico.

Nivel III: 35-40 cm de depósito de color marrón rojizo y marrón claro. Formado por arenas finas y limos con escasez de arcillas. Tiene cantos y gravas autóctonos a techo. Con material arqueológico abundante. 
Nivel IV: $25-30 \mathrm{~cm}$ de conglomerado con matriz lutítica anaranjada. Tiene gravas, cantos, cuarcitas y cuarzos. En su interior aparecen laminaciones alternantes de diferente granulometría, producto de una arroyada difusa junto con carbonataciones secundarias. Hacia techo hay un paquete rojizo formado por un conglomerado granocreciente de matriz arenosa-limosa, muy carbonatada de unos $10 \mathrm{~cm}$ de espesor. Por debajo aparecen arenas finas con limos de colores ocres y amarillentos con cantos autóctonos. Apenas contiene restos arqueológicos.

Nivel V: $30 \mathrm{~cm}$ de arenas limosas marrones con cantos y bloques autóctonos. Presenta bloques de conglomerado. Apenas contiene restos arqueológicos.

Nivel VI: $<40 \mathrm{~cm}$ de arenas y gravas con arcillas de color rojo oscuro con cantos autóctonos. La parte inferior presenta grandes bloques de conglomerado.

\subsubsection{Restos fósiles}

La Peña de Estebanvela es un yacimiento con una gran riqueza taxonómica. Se han identificado 51 taxones hasta el momento. Éstos abarcan grupos como primates, avifauna, lagomorfos, roedores, carnívoros, ungulados, ictiofauna, malacofauna y herpetofauna.

Este yacimiento ha aportado un importante conjunto de restos humanos asignados a Homo sapiens. Todos ellos son postcraneales y destacan las costillas, los húmeros, los metacarpos, las tibias, los fémures y los coxales. Se han identificado al menos dos individuos (Trancho et al., 2006). En cuanto a los macromamíferos destacan: Canis lupus, Vulpes vulpes, Felix silvestris, Lynx pardina, Equus ferus, Sus scrofa, Cervus elaphus, Capreolus capreolus, Rupicapra pyrenaica y Capra pyrenaica.

Los micromamíferos incluyen: Oryctolagus cuniculus, Eliomys quercinus, Arvicola sapidus, Microtus arvalis-agrestis, Microtus oeconomus, Microtus duodecimcostatus, Apodemus sylvaticus, Chionomys nivalis, Talpa sp., Sorex minutus, Erinaceus europeus, Crocidura russula, Plecotus auritus-austriacus, Plecotus autriacus, Barbastella barbastellus, Myotis myotis y Rhinolophus ferrumequinum (Sesé, 2013). Asimismo, también se ha recuperado una importante fauna aviana que comprende: Aquila sp., Alectoris rufa, Perdix perdix, Coturnix coturnix, Hirudo rustica, Anthus campestris, Emberiza citrinella, Petronia petronia, Turdus sp. y Corvus monedula (Sánchez Marco, 2013). También se ha identificado un importante conjunto malacológico de procedencia tanto mediterránea como cantábrica: Theodoxus fluviatilis, Melanopsis sp., Helicella unifasciata, Jaminia quadridens, Candidula camporroblensis, Vallonia costata, Gastropoda indet., Littorina obtusata, Trivia árctica, Columbella rustica, Nassarius reticulatus, Cyclope neritea y Pecten maximus (Jordá, 2006b; Aparicio, 2013). Los restos ictiológicos corresponden en su totalidad a Salmo trutta (Perea y Doabrio, 2013). Se han identificado también varios restos de reptiles y anfibios (Sanchiz et al., 2013): Timon lepidus, Rhinechis scalaris, Malpolon monspessulanus, Vipera latasti, Coronella sp., Epidalea calamita y Alytes sp.

En este trabajo no se ha identificado corzo aunque sí que es citado por Yravedra (2006 y 2013) y se han asignado los restos del rebeco a la especie Rupicapra pyrenaica.

\subsubsection{Industria lítica y ósea}

El sílex es la principal materia prima del yacimiento, presentando una gran variedad de tipos. Aparecen también cuarzos, cristal de roca, cuarcitas y calizas. Entre los instrumentos destacan los rapadores, raederas, perforadores, hojas de dorso, truncaduras, hojas retocadas y buriles (Cacho et al., 2006). Junto con la industria lítica se han encontrado útiles en hueso como azagayas, punzones, espátulas y agujas. Por otra parte, se han recuperado adornos y arte mueble como algunas conchas o caninos de ciervo perforados y plaquetas de esquisto y pizarra decoradas con motivos geométricos y faunísticos, también placas de arenisca con perforaciones (Cacho et al., 2006). 


\subsubsection{Datación}

Hasta el momento se han realizado 16 dataciones radiocarbónicas empleando el método AMS, salvo en una en la que se utilizó el sistema radiométrico tradicional (Jordá Pardo y Cacho, 2013). El nivel I ha aportado un rango de fechas entre 12.700 y 13.580 calBP., el nivel II entre 13.610 y 13.800 calBP., el nivel III entre 14.290 y 15.010 calBP, el nivel IV entre 14.810 y 15.210 calBP. y el nivel V entre 17.610 y 17.840 calBP.

\subsection{La Peña de Mudá}

\subsubsection{Introducción}

La Peña de Mudá se encuentra en el norte de la provincia de Palencia, en la localidad de Mudá. La primera cita corresponde a Prado (1864). Este investigador recupera varios dientes de rinoceronte, un canino de oso y otros restos que no asigna a ningún taxón (Álvarez-Lao, 2007). Unos años más tarde, Calderón (1876) asigna los restos de rinoceronte a Stephanorhinus merckii. Está zona presenta una gran cantidad de cavidades por lo que el emplazamiento del depósito original no está muy claro. Recientemente, Álvarez-Lao (2007) en su tesis sobre los macromamíferos indicadores de clima frío revisa el material de rinoceronte, asignando uno de los dientes a la especie Coelodonta antiquitatis.

\subsubsection{Restos fósiles}

El material es escaso. Predominan los grandes herbívoros con taxones como Stephanorhinus hemitoechus, Coelodonta antiquitatis, Equus ferus y Bos/Bison sp. Los restos de carnívoros se limitan a unos pocos dientes de oso. Álvarez-Lao (2007) sugiere una posible mezcla de material desde su depósito en el Museo Geominero. Esto parece corroborado por la gran diferencia en la fosilización que presentan los rinocerontes con respecto al resto de taxones. Por este motivo sólo se analizan los restos de los rinocerontes.

\subsubsection{Datación}

La asociación de especies lo sitúa en alguna de las fases del Pleistoceno Superior final. El rinoceronte lanudo se encuentra, en la Península Ibérica, restringido casi en su totalidad a la zona cantábrica durante este periodo. Sin embargo, Álvarez-Lao y García (2006) asignan los restos recuperados en el yacimiento asturiano de La Parte (Pleistoceno Medio), a C. antiquitatis. Debido a esto, y a la espera de estudios posteriores no podemos precisar una edad concreta para este depósito. 
Tabla I.1.1

Resumen de los depósitos estudiados

\begin{tabular}{|c|c|c|c|c|}
\hline Yacimiento & Provincia & Ungulados identificados & Cronología & Referencia \\
\hline La Mina & Burgos & Coelodonta antiquitatis & $52,5 \mathrm{Ka}$ & Díez et al., (2008) \\
\hline Cueva de Valdegoba & Burgos & $\begin{array}{l}\text { S. hemitoechus, E. ferus, E. hydruntinus, S. scrofa, C. elaphus, C. } \\
\text { capreolus, Rupicapra pyrenaica, Capra pyrenaica, B. primigenius, B. } \\
\text { priscus }\end{array}$ & Nivel V: $48.400 \pm 3.300 \mathrm{BP}$ & Dalen et al., 2012 \\
\hline Prado Vargas & Burgos & $\begin{array}{l}\text { Rhinocerotidae indet., E. ferus, S. scrofa, C. elaphus, R. pyrenaica, C. } \\
\text { pyrenaica }\end{array}$ & 46,4 Ка & Navazo et al., (2005) \\
\hline \multirow{3}{*}{ Cueva Millán } & \multirow{3}{*}{ Burgos } & $\begin{array}{l}\text { S. hemitoechus, E. ferus, E. hydruntinus, C. elaphus, R. pyreniaca, C. } \\
\text { pyrenaica }\end{array}$ & Nivel 1A: $43.130-41.290$ calBP & Moure- Romanillo et al., (1983) \\
\hline & & E. ferus, C. elaphus, R. pyrenaica, C. pyrenaica & Nivel 1B: $43.010-41.250$ calBP & Moure- Romanillo et al., (1983) \\
\hline & & E. ferus, C. elaphus, R. pyrenaica, C. pyrenaica & Nivel 1C: $\sin$ datos & Sala (2012) \\
\hline Cueva del Búho & Segovia & $\begin{array}{l}\text { Stephanorhinus hemitoechus, Equus ferus, E. hydruntinus, Sus scrofa, } \\
\text { Cervus elaphus, Capreolus capreolus, Bos primigenius, Bison priscus }\end{array}$ & $\begin{array}{l}\text { Nivel 1-2: } 32.510 \pm 240 \text { BP. Nivel } \\
\text { Nivel II: }>44.400 \text { BP. }\end{array}$ & \\
\hline Abrigo de Alexandre & Soria & E. ferus, R. pyrenaica & Nivel IIIb: $15.370 \pm 110$ BP & Utrilla et al., (2006) \\
\hline Abrigo de Vergara & Soria & E. ferus, C. elaphus & Nivel d: $14.000 \pm 100 \mathrm{BP}$ & Utrilla et al., (2006) \\
\hline \multirow{4}{*}{ Peña de Estebanvela } & \multirow{4}{*}{ Segovia } & E. ferus, E. hydruntinus, S. scrofa, C. elaphus, R. pyrenaica, C. pyrenaica & Nivel I: 12.700 - 13.580 calBP & Jordá Pardo y Cacho (2013) \\
\hline & & E. ferus, E. hydruntinus, C. elaphus, $R$, pyrenaica, C. pyrenaica & Nivel II: 13.610 - 13.800 calBP & Jordá Pardo y Cacho (2013) \\
\hline & & E. ferus, E. hydruntinus, C. elaphus, R. pyrenaica, C. pyrenaica & Nivel III: 14.290 - 15.010 calBP & Jordá Pardo y Cacho (2013) \\
\hline & & C. elaphus, R. pyrenaica, C. pyrenaica & Nivel IV: 14.810 - 15.210 calBP & Jordá Pardo y Cacho (2013) \\
\hline Peña de Mudá & Palencia & S. hemitoechus, C. antiquitatis & Sin datos & Álvarez-Lao (2007) \\
\hline
\end{tabular}




\section{Objetivos}


Este trabajo trata de aportar datos sobre los ungulados del Pleistoceno Superior de la Meseta Norte, en concreto de la Comunidad Autónoma de Castilla y León. Este periodo abarca el Paleolítico Medio y el Superior, que se caracterizan por la presencia de dos especies: Homo neanderthalensis y Homo sapiens. Los ungulados pueden aportarnos información sobre los recursos alimenticios de estas dos especies y su comparación establecer diferentes estrategias de ocupación y de obtención de los recursos. Para conseguir esta meta se han establecido tres tipos de objetivos: paleobiológicos, arqueológicos y metodológicos.

Los objetivos paleobiológicos incluyen tanto la identificación, a nivel taxonómico, como el análisis de la bimodalidad y del dimorfismo sexual. En primer lugar se realiza la identificación, a nivel taxonómico y anatómico, de los restos de ungulados y, posteriormente se lleva a cabo una estadística básica que nos permite la comparación con otras especies similares del mismo periodo. De esta manera adaptamos las listas faunísticas a las nuevas clasificaciones y nos permiten comparar nuestros taxones con especies que, hasta este momento, no habían sido recuperadas en los yacimientos del Pleistoceno Tardío de esta región. Asimismo, el análisis de la bimodalidad y del dimorfismo nos permitirá conocer si el tamaño entre sexos ha cambiado a lo largo del tiempo.

Los segundos, los objetivos arqueológicos, incluyen la determinación de la edad de muerte, de los periodos de acumulación (estacionalidad) y del ratio sexual (proporción entre hembras y machos). Estos análisis parten de una correcta identificación de las especies ya que tanto el comportamiento social como los patrones biológicos cambian significativamente entre especies del mismo género. La consecución de los objetivos, tanto paleobiológicos como arqueológicos, nos permitirá, junto con otras disciplinas, inferir el origen y los periodos de acumulación así como las preferencias alimentarias de cada una de las especies de homínidos y compararlas posteriormente.

Por último, los objetivos metodológicos. En este trabajo se testan una serie de métodos estadísticos que nos permiten identificar cada taxón y conocer tanto la edad de muerte como la bimodalidad y el dimorfismo, eliminando la incertidumbre que introducen las metodologías que emplean datos basados en taxones actuales.

A modo de resumen, se presentan de forma esquemática los diferentes objetivos a conseguir en cada uno de los apartados.

\subsection{Objetivos paleobiológicos}

La meta a conseguir en dicho apartado consiste en revisar los restos de los ungulados de los yacimientos del Pleistoceno Tardío de Castilla y León, adaptando dicha clasificación a los últimos cambios taxonómicos y descubrimientos. Con esta finalidad seguimos los siguientes pasos.

- Presentar el material identificable de cada yacimiento.

- Describir morfológicamente los diferentes elementos recuperados.

- Mostrar la estadística básica de los elementos descritos.

- Justificar la asignación específica en función de los caracteres morfológicos observados.

- Conocer la bimodalidad y el dimorfismo sexual en aquellos individuos cuyos restos permitan la separación de sexos. 


\subsection{Objetivos arqueológicos}

A partir de la información obtenida previamente, y que nos permiten emplear datos procedentes del comportamiento social y datos biológicos de cada taxón, intentaremos concretar las preferencias alimenticias de las poblaciones que ocuparon la cavidad. Con este motivo intentamos:

- Establecer la edad de muerte en aquellos individuos en los que sea posible.

- Determinar la estacionalidad de la acumulación de los taxones en los que se ha podido conocer la edad en meses.

- Relacionar el comportamiento social de cada taxón con los periodos de ocupación de las cavidades.

- Comparar los datos obtenidos en los yacimientos del Paleolítico Medio con los registrados en los depósitos del Paleolítico Superior.

\subsection{Objetivos metodológicos}

Con la finalidad de alcanzar los objetivos anteriores se desarrollan una serie de métodos que permitan por un lado asignar correctamente el material a un taxón, conocer la edad de muerte y determinar la bimodalidad y el dimorfismo sexual. Estos modelos intentan:

- Evaluar los caracteres morfológicos que nos permitan discriminar entre taxones semejantes.

- Desarrollar un nuevo modelo para determinar la edad de muerte en el que se sustituyan las variables que emplean datos tomados en poblaciones actuales por datos provenientes de poblaciones fósiles. Comparar este método con los precedentes.

- Comparar distintos métodos estadísticos para determinar el sexo en poblaciones con poco dimorfismo sexual. 
3. Material 


\subsection{Material analizado}

Los restos provienen de los yacimientos datados en el Pleistoceno Superior de la Meseta Norte, en concreto de los localizados en la Comunidad Autónoma de Castilla y León, y que han aportado material fósil. Los restos procedentes de los yacimientos burgaleses de la Cueva de Valdegoba, Prado Vargas y La Mina se encuentran depositados en la Universidad de Burgos; los restos de Cueva Millán en el Museo Provincial de Burgos; el material de la Peña de Estebanvela en el Museo de Segovia; los fósiles de los abrigos sorianos de Vergara y Alexandre en el Museo Numantino de Soria y los restos de Mudá en el Museo Geológico y Minero en Madrid. No se analiza el material del yacimiento burgalés de la Ermita debido a que las colecciones no estaban accesibles por la renovación del Museo Arqueológico Nacional; tampoco los fósiles de las cuevas palentinas de Guantes y Cueva Corazón debido a que aún están en estudio; y los restos de los depósitos leoneses de el Espertín, la Uña, la Cantera y el Castro ya que se encuentran muy fragmentados. Por otra parte, los fósiles de los depósitos de la zona de Oña (Burgos) y de los diferentes yacimientos del Cañón de río Lobos (Burgos - Soria) recuperados a principios del siglo XX no se han analizado debido a que no se pueden incluir en un contexto en concreto.

El estado de conservación de las piezas no siempre ha permitido su identificación y por lo tanto su análisis. Presentamos el material empleado en cada apartado (tabla III.1.1).

Tabla III.1.1

Material empleado de cada yacimiento estudiado y en cada capítulo

\begin{tabular}{lccccccc}
\hline & \multicolumn{2}{c}{ Paleontología sistemática } & \multicolumn{2}{c}{ Edad de muerte } & Estacionalidad & \multicolumn{2}{c}{ Dimorfismo sexual } \\
\cline { 2 - 8 } La Mina & Craneal & Postcraneal & Dental & Postcraneal & Dental & Dental & Postcraneal \\
\cline { 2 - 8 } Valdegoba & 7 & & 2 & & & & \\
Prado Vargas & 4151 & 1668 & 461 & & 160 & 9 & 105 \\
Millán & 35 & 20 & 10 & 2 & 4 & 1 & \\
Búho & 167 & 90 & 50 & & 13 & 2 & \\
Alexandre & 76 & 38 & 22 & & 4 & & \\
Vergara & 1 & & & & & & \\
Estebanvela & 19 & & 13 & & & & \\
Muda & 129 & 59 & 1 & & & & \\
\hline
\end{tabular}

\subsection{Material de comparación actual y fósil}

Se han realizado comparaciones empleando el material depositado en varias instituciones científicas. Dicho material es fundamentalmente postcraneal ya que el dental estaba incluido en mandíbulas y maxilares por lo que la toma de medidas diagnósticas, que no variaran con el desgaste, no se podía realizar. Otros datos se han tomado de fuentes bibliográficas que incluyen especies provenientes tanto de yacimientos ibéricos como del resto de Europa.

Los ejemplares actuales proceden de las siguientes instituciones:

Cervus elaphus: Museo Nacional de Ciencias Naturales (Madrid), Museo Anatómico de la Universidad de Valladolid (Valladolid), Naturhistorisches Museum Wien (Viena).

Capreolus capreolus: Museo Anatómico de la Universidad de Valladolid (Valladolid).

Rangifer tarandus: Sociedad de Ciencias Aranzadi (San Sebastián), Centro de Custodia y Gestión de las Colecciones de Materiales Arqueológicos y Paleontológicos de Guipúzcoa (San Sebastián), Museo Anatómico de la Universidad de Valladolid (Valladolid), Naturhistorisches Museum Wien (Viena).

Rupicapra rupicapra: Naturhistorisches Museum Wien (Viena). 
Rupicapra pyrenaica: Nacional de Ciencias Naturales (Madrid), Sociedad de Ciencias Aranzadi (San Sebastián), Centro de Custodia y Gestión de las Colecciones de Materiales Arqueológicos y Paleontológicos de Guipúzcoa (San Sebastián).

Capra pyrenaica: Nacional de Ciencias Naturales (Madrid).

Capra ibex: Naturhistorisches Museum Wien (Viena).

Bison bonasus: Nacional de Ciencias Naturales (Madrid), Naturhistorisches Museum Wien (Viena).

Hemitragus jemlaicus: Naturhistorisches Museum Wien (Viena).

Saiga tatarica: Naturhistorisches Museum Wien (Viena).

En cuanto a las especies fósiles, los yacimientos donde se recuperaron y la bibliografía empleada es la que sigue:

Stephanorhinus hemitoechus: Bilzingsleben, Neumark Nord, Steinheim, Ehringsdorf, Taubach, Gimbsheim, Eich (Van der Made, 2010); Majolicas (Cerdeño, 1990).

Stephanorhinus kirchbergensis: Kirchberg, Bilzingsleben, Mosbach, Steinheim, Ehrigsdorf, Taubach, Gimbsheim, Eich (Van der Made, 2010).

Stephanorhinus hunsheimensis: Voigtsted, Süssenborn, Soleilhac, Mosbach, Mauer, Ceyssaguet, Soleinac (datos aportados por J. van der Made).

Coelodonta antiquitatis: Bad Frankenhausen, Chlum, Wannen, Heringen, Steinheim, Ehringsdorf, Belvedère, Ariendorf, Backleben, Heldrungen, Zasuhino, Kahla, Gimbsheim, Eich (Van der Made, 2010); Lezika, Labeko Koba (Arkeologi Museoa, Bilbao).

Equus ferus torralbae: Atapuerca (TG), Villacastín, Pedraza, Las Yedras, Solana de Zamborino, Torralba, Pinilla del Valle, Cova Negra, Transfesa (Eisenmann y Baryshnikov, 1994; Maldonado, 1996).

Equus ferus antunesi: la Carihuela, Fontahinas, Jöao Ramos, Salemas (Maldonado, 1996).

Equus ferus mosbachensis: Mosbach, Achenheim, Lune Viel, l'Arago (Maldonado, 1996).

Equus ferus taubachensis: Taubach (Maldonado, 1996).

Equus ferus casarensis: Los Casares (Maldonado, 1996).

Equus ferus germanicus: Pair non Pair (Maldonado, 1996).

Equus ferus gallicus: Solutre y Saint Germain de la Riviere (Maldonado, 1996).

Equus stenonis: Atapuerca, Saint Vallier, Senéze, Venta Micena, Chatillon Saint Jean, Huélago, Baza 1 (Eisenmann y Baryshnikov, 1994; Maldonado, 1996)

Equus hydruntinus: la Carihuela, Bourgeois Delaunay, Combe Grenal, La Ferrasie, Saint Germain la Riviere, Agios Georgios, Fontarnaud, Pair non Pair, Binagady, Abric Romani, Abri Suard, Arcy y Prolom (Eisenmann y Baryshnikov, 1994; Maldonado, 1996).

Sus scrofa y Sus strozii: Saint Vallier (Faure, 2004).

Cervus elaphus: Atapuerca (TG, TE) (Van der Made, 1999); Abric Romaní (Sánchez, 1990); Majolicas (Domingo y Alberdi, 2004); Mendandia (Alday-Ruiz, 2006); Fate, Manie, Madonna (Psathi, 2003); Prince Cave (Arellano Alonso, 2004); Combe Grenal (Guadelli, 1987); Vaufrey, La Ferrasie (Delpech, 1984); Lazaret, Orgnac, Bau l'Aubesier, Bianche St. Vaast, Tournal (Magniez, 2010); Vaufrey (Delpech, 1988); Jarama VI (revisión realizada en la Universidad de Burgos); Buraca Escura (Parque Arqueológico do Vale do Côa (Portugal); Lezika y Abauntz (Arkeologi Museoa, Bilbao).

Dama dama: Atapuerca (TG, TE) (Van der Made, 1999); y Atapuerca (TE) (Centro Nacional de Investigación sobre Evolución Humana CENIEH, Burgos).

Rangifer tarandus: Atxuri, Arlanpe, Urtiagako Leizea, Bolinkoba, Armotxe, Aitzbitarte IV (Arkeologi Museoa, Bilbao). 
Haploidoceros mediterraneus: Cova del Rinoceront (Sanz et al., 2014); y Lunel Viel (Croitor et al., 2008).

Rupicapra pyrenaica: Orgnac 3, l'Arago, Le Portel (Fernández y Crégut-Bonnoure, 2007); Abri Marq (Rivals, 2002); Salemas (Álférez et al., 1980-1981); Jarama VI (revisión realizada en la Universidad de Burgos); Buraca Escura (Parque Arqueológico do Vale do Côa (Portugal); Erralla y Arlanpe (Arkeologi Museoa, Bilbao).

Rupicapra rupicapra: Abric Romani (Sánchez, 1990); Nacimiento (Álferez et al., 19801981); Abauntz, Lezika, Lezikako Koba (Castaños et al., 2009); La Riera (Straus et al., 1986); y Le Gras (Fernández y Crégut-Bonnoure, 2007).

Capra pyrenaica: Abric Romani (Sánchez, 1990); Tournal, Le Portel (Crégut-Bonnoure, 1992b); Buraca Escura (Parque Arqueológico do Vale do Côa, Portugal), Jarama VI (revisión realizada en la Universidad de Burgos); y Arlanpe (Arkeologi Museoa, Bilbao).

Capra caucasica: Kozarnika, Koudaro I y III, Ortvala (Fernández y Crègut-Bonnoure, 2007); Sakajia, Tsutskhavati, Le Portel, Baume Moula-Guercy, Saint Marcel, Dzudzuana (Rivals, 2006); y l'Arago (Rivals 2002 y 2006).

Capra ibex: Adaouste y Petralona (Rivals, 2006).

Hemitragus cedrensis: l'Arago, les Cèdres, Rigabe, Bolomor (Rivals, 2006); y Bau de l'Aubesier (Rivals y Blasco, 2008).

Hemitragus bonali: l'Escale, l'Arago (Rivals, 2006); y les Cèdres (Rivals, 2006).

Bos primigenus: Mendandia (Alday Ruiz, 2006); Biache-Saint-Vaast (Auguste, 1995); Bau de l'Aubesier (Fernández, 2001); Livernon (Slott-Moller 1990); Abri Marcq (CrégutBonnoure, 1993); Chinchon 2 (Crégut-Bonnoure, 1992c); y Combe Grenal (Guadelli, 1987).

Bison priscus: Nestier (Clot y Marsan, 1986); Jaurens, I'l skaya (Guérin y Valli, 2000); Marcamps (Slott-Moller 1990); y Ėnlène (Lalande, 1986).

En el apartado dedicado al dimorfismo y a la bimodalidad sexual se han empleado varios ejemplares actuales como grupo control. Todos ellos corresponden a restos postcraneales de Rupicapra pyrenaica parva. Las instituciones en las que se ha recogido este material son el Museo Nacional de Ciencias Naturales (Madrid): machos: 14292/U.Z.A.1982.06.03.02(2),14253.U.Z.A.1982.06.04.01(3),14267/U.Z.A.1982.06.05.01( 3),14267/U.Z.A.1982.06.30.04(12),14264/U.Z.A.1982.08.10.01(16),14254/U.Z.A.1982.0.1 0.02(17),14271/U.Z.A.1982.08.11.01(19),14265/U.Z.A.1982.08.24.01(21),14283/U.Z.A.19 82.12.17.03(28),14256/U.Z.A.1982.12.21.05(31),14261/U.Z.A.1983.01.26.01(35),14287/ U.Z.A.1983.06.01.01(36),14269/U.Z.A.1983.06.09.04(47),14293/U.Z.A.1983.06.09.05(48); hembras:14288/U.Z.A.1982.06.04.02(4),14282/U.Z.A.1982.06.30.03(11),14292/U.Z.A.198 2.08.10.03(18),14279/U.Z.A.1982.08.08.01(13),14280/U.Z.A.1982.08.25.01(23),14290/U. Z.A.1982.08.25.02(24),14291/U.Z.A.1982.12.16.01(25),14283/U.Z.A.1982.12.17.01(26),1 4285/U.Z.A.1982.12.21.03(29),14278/U.Z.A.1983.06.02.03(39),14289/U.Z.A.1983.06.03.0 1(40),14258/U.Z.A.1983.06.03.03(42),14286/U.Z.A.1983.06.09.02 (45) la Sociedad de Ciencias Aranzadi (San Sebastián): machos 674, 619.13; hembras: 673,11; y añadimos la Colección Particular Altuna-Mariezkurrena: macho: A-138. 


\section{Metodología}


La metodología empleada en este trabajo combina una serie de procedimientos para cada uno de los capítulos. La elección de una terminología y unos criterios métricos adecuados son fundamentales para poder llevar a cabo la determinación de los taxones en el primer caso y la caracterización de la especie en el segundo. Una buena elección hace que el trabajo llevado a cabo pueda ser comparado por otros investigadores, haciendo de esta forma el estudio útil y con una prolongación en el tiempo.

\subsection{Paleontología sistemática}

En este apartado presentamos los criterios descriptivos y morfométricos empleados tanto en las piezas dentales como en los restos postcraneales.

\section{Material dental}

Las terminologías que describen la superficie oclusal de los dientes son diversas. Por un lado, nos encontramos con la nomenclatura propuesta por Osborn - Gregory en 1907. En la dentición superior, las cúspides principales se identifican con los prefijos proto (anterolingual), para - (anterolabial), meta - (posterolabial) e hipo - (posterolingual). En la cara lingual se desarrollan una serie de cúspides secundarias, los estilos, que generalmente son tres: el parastilo (anterolabial), el metastilo (posteriolabial) y el mesostilo (entre ambos). Por otra parte, pueden aparecer también otras cúspides secundarias; una entre el protocono y el paracono, el paracónulo; y otra entre el protocono y el metacono, el metacónulo. En los molares inferiores los prefijos son similares pero el sufijo cambia de - cono a - cónido: el protocónido (bucal), el paracónido (anterolingual) y el metacónido (posterolingual). Rara vez presentan cúspides accesorias, aunque, en ocasiones, pueden tener un mesocónido, posterior al hipocónido; y un entoconúlido cercano al entocónido. De estas cúspides parten crestas que delimitan depresiones denominadas valles o fosas cuyo nombre depende de las cúspides y de la dirección de la que parten. Por otra lado, Vandebroek $(1961,1969)$ propuso una terminología completamente diferente que se basa en la comparación con los dientes adyacentes apareciendo "econo" en lugar de paracono, "epicono" en vez de protocono, "distocono" por el metacono. En este trabajo empleamos la terminología propuesta por Osborn.

\section{Material postcraneal}

La terminología aparece en varios atlas morfológicos (Barone, 1966; Pales y García, 1981).

\subsubsection{Rhinocerotidae}

La nomenclatura empleada en los rinocerontes es la propuesta por Guérin (1980) y los criterios métricos aparecen en Van der Made (2010) (figura IV.1.1, 2 y 3).

Las medidas tomadas en el material dental son las siguientes (figura IV.1.2): DAP: diámetro anteroposterior máximo. DAPb: diámetro anteroposterior basal tomado en la zona de contacto de la raíz con la corona. DAPo: diámetro anteroposterior oclusal. DTa: diámetro transversal del lóbulo anterior DTp: diámetro transversal del lóbulo posterior. H: altura máxima de la corona. Hci: distancia entre el borde más bajo de la corona hasta el cíngulo existente en la cara lingual. Hli: altura desde el borde más bajo de la corona hasta el valle lingual 


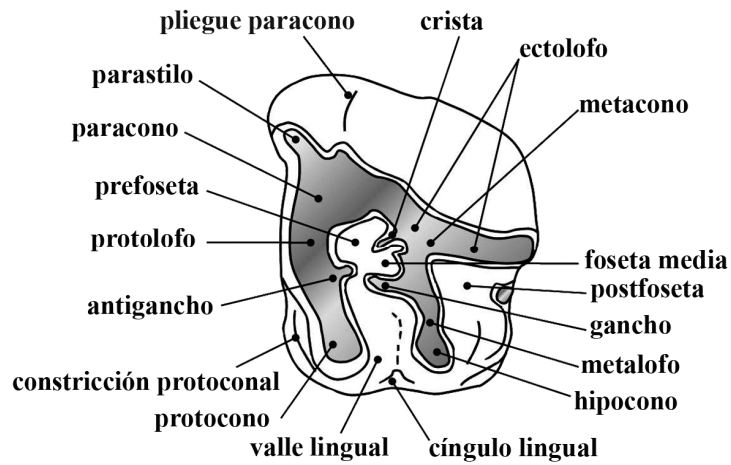

1.

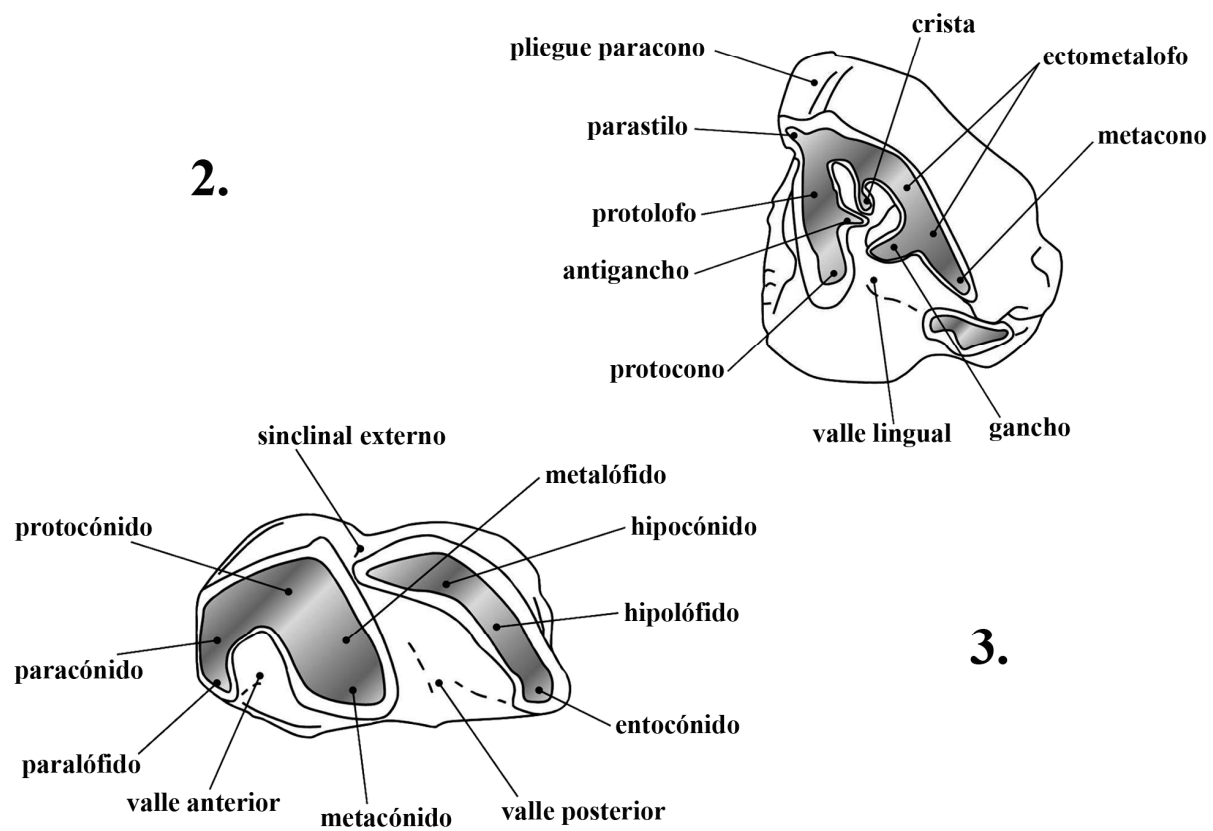

4.
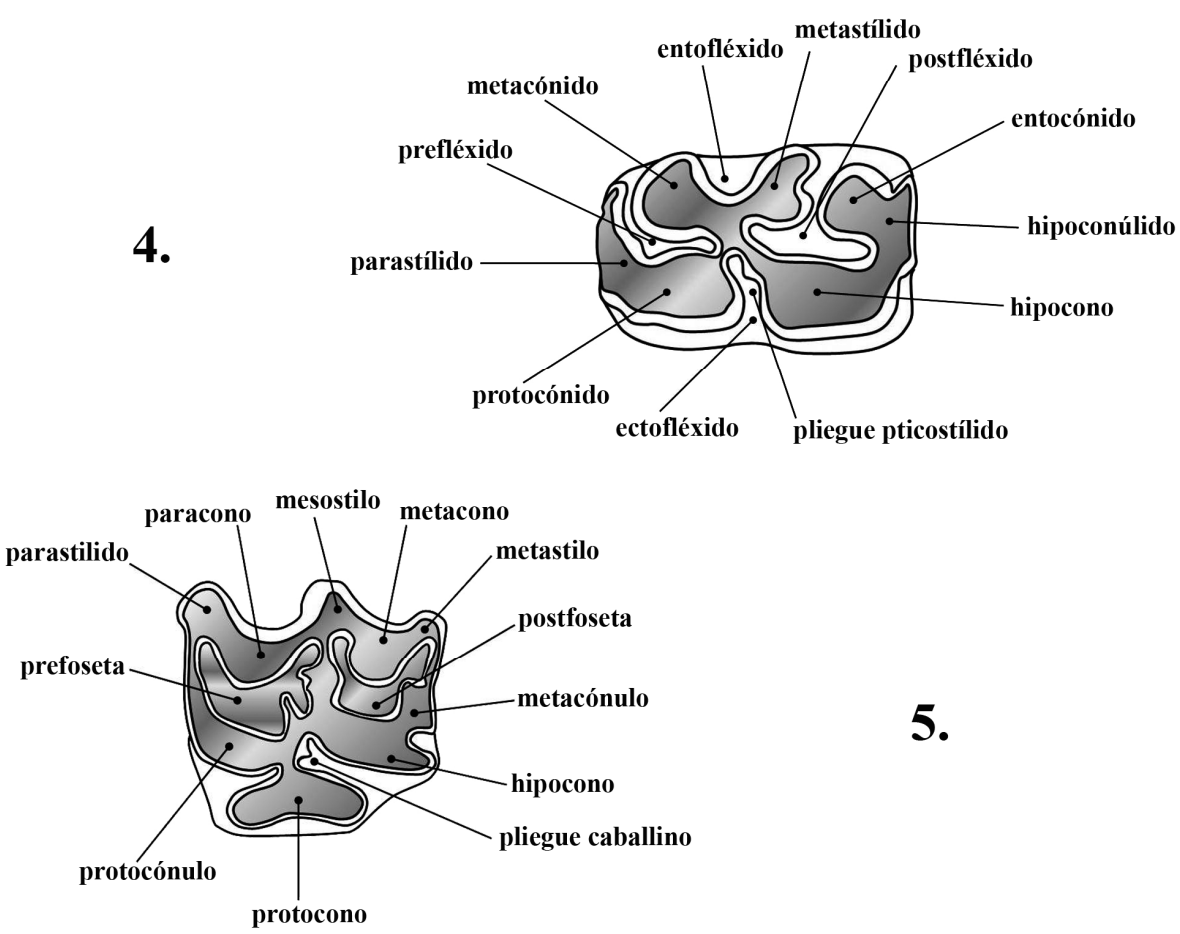

5.

Figura IV.1.1. Terminología empleada en la dentición de 1, 2 y 3) Rhinocerotidae y, 4 y 5) Equidae. 1) Premolar superior. 2) Tercer molar superior. 3) Molar inferior. 4) Premolar inferior. 5) Premolar superior. 


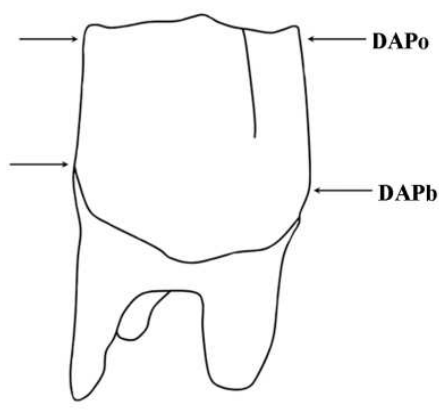

1.a
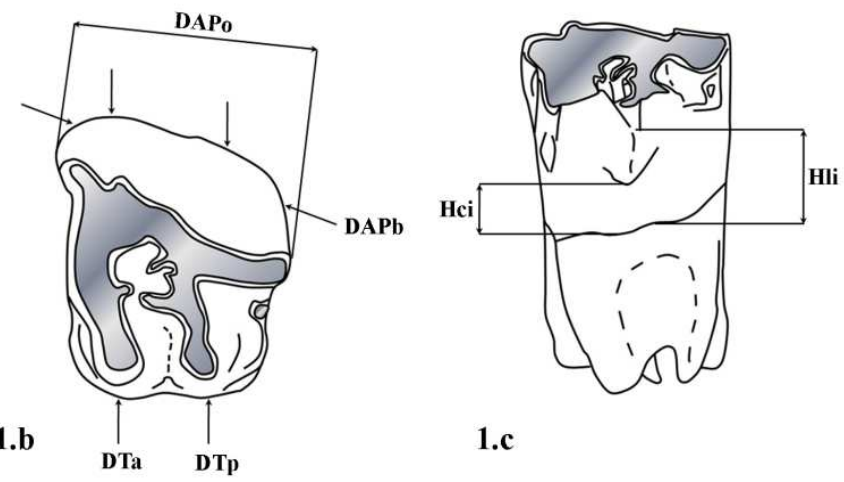

1.c
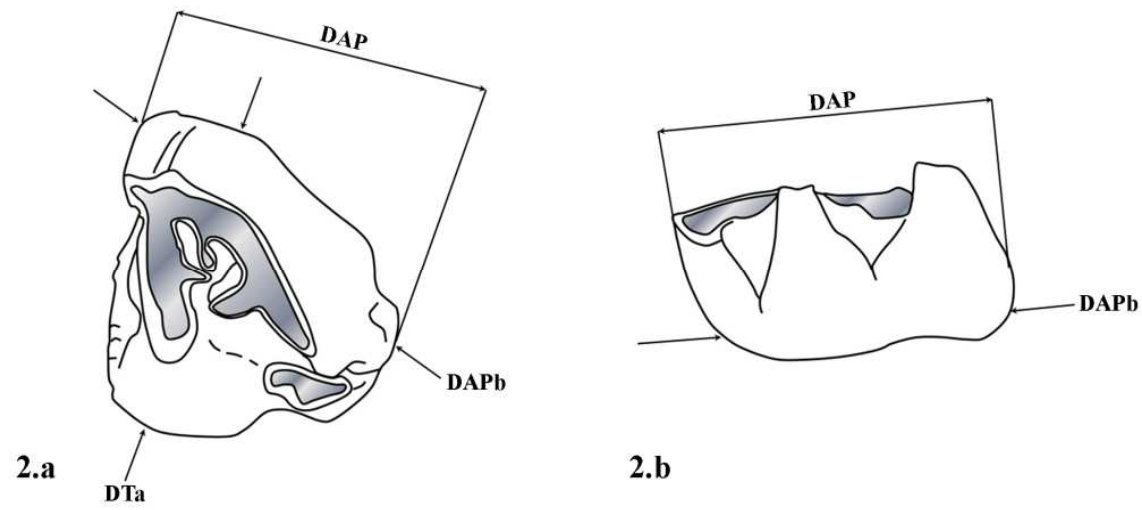

2.b

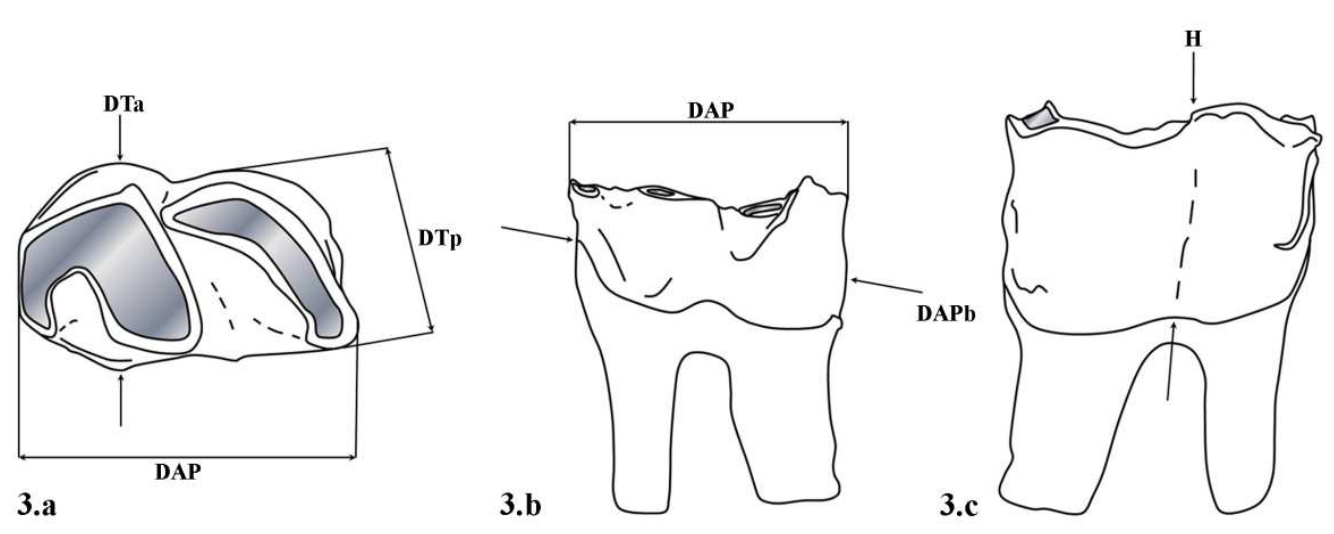

Figura IV.1.2. Medidas tomadas en el material dental de los rinocerontes. 1) Premolar superior. 2) Tercer molar superior. 3) Premolar inferior.

El material postcraneal es escaso, habiéndose recuperado únicamente un astrágalo. Las medidas recogidas son las siguientes (figura IV.1.3): DAPdf: diámetro anteroposterior de la superficie articular distal. DT: diámetro transversal máximo. DTdf: diámetro transversal de la superficie articular distal. DTpf: diámetro transversal de la tróclea. DTtl: diámetro transversal de la región articular. Lext: longitud tomada en la cara lateral. Lint: longitud tomada en la cara medial. Lm: longitud mínima, tomada en la zona media. Rint: diámetro de la tróclea. $\mathbf{R m}$ : diámetro mínimo de la tróclea.

\subsubsection{Equidae}

La terminología y las medidas empleadas en esta familia aparecen en Eisenmann et al., (1988) (figura IV.1.1, 4 y 5). 

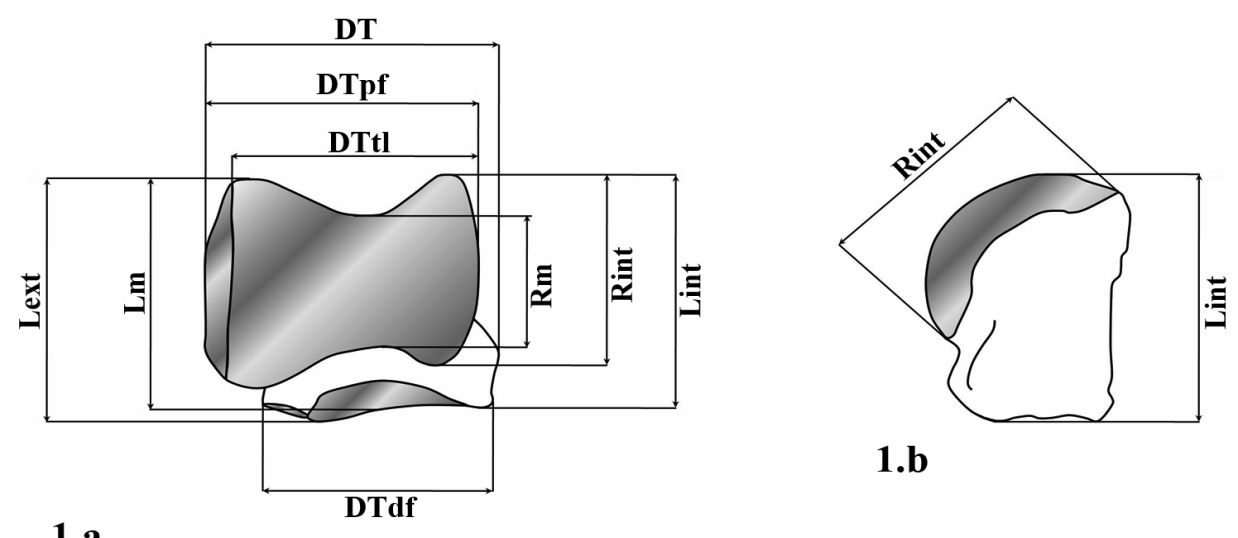

1.b

1.a

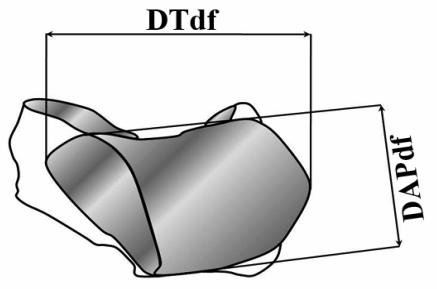

1.c

Figura IV.1.3. Medidas tomadas en los astrágalos de los rinocerontes.

Las medidas tomadas en los restos dentales son las siguientes (figura IV.1.4): DAP: diámetro anteroposterior máximo. DAP 1/2: diámetro anteroposterior en la altura media de la corona. En el caso de E. ferus se establece en $4 \mathrm{~cm}$ y en el caso de E. hydruntinus en 3 cm. DT: diámetro transversal máximo. DT 1/2: diámetro transversal en la altura media de la corona. En el caso de E. ferus se establece en $4 \mathrm{~cm}$ y en el caso de E. hydruntinus en $3 \mathrm{~cm}$. DTa: diámetro transversal del lóbulo anterior. Tomado desde el pilar del paracono al pilar del protocono en la dentición superior; y desde el pilar del paracónido al pilar del protocónido en la inferior. DTp: diámetro transversal del lóbulo posterior. Medida desde el pilar del metacono al pilar del hipocono en los dientes superiores; y desde el pilar del hipocónido en la dentición inferior. H: altura máxima de la corona. IA: diámetro transversal del infundíbulo en los incisivos superiores e inferiores. IL: diámetro mesiodistal del infundíbulo en los incisivos superiores e inferiores. KL: longitud del doble bucle en la dentición inferior. PL: longitud del protocono en la dentición superior. PL 1/2: longitud del protocono en la altura media de la corona. Postfl. L: longitud del postfléxido en la dentición inferior. Prefl. L: longitud del prefléxido en la dentición inferior.

Las medidas empleadas en el material postcraneal son las que siguen (figura IV.1.5):

Metacarpo II (figura IV.1.5: 1a, 1b): BP: anchura máxima de la epífisis proximal. DP: profundidad máxima de la epífisis proximal. GL: longitud máxima del hueso.

Metacarpo III (figura IV.1.5: 2.a, 2.b, 2.c): BD: anchura máxima de la epífisis distal. BP: anchura máxima de la epífisis proximal. DAF: diámetro máximo de la faceta anterior del cuarto carpal. DAT: diámetro máximo de la faceta articular del tercer carpal. DAS: diámetro de la faceta articular del segundo carpal. DD: profundidad máxima de la epífisis distal. DM: profundidad máxima del cóndilo medial. DL: profundidad máxima del cóndilo lateral. DPA: profundidad faceta articular. DPF: diámetro de la faceta posterior del cuarto carpal. GL: longitud máxima del hueso. GLm: longitud medial. SD: anchura mínima de la diáfisis. SDD: profundidad mínima de la diáfisis.

Metacarpo IV (figura IV.1.5: 3.a, 3.b): BP: anchura máxima de la epífisis proximal. DP: profundidad máxima de la epífisis proximal. 


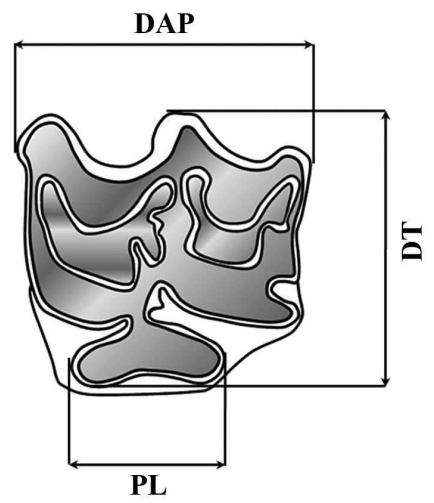

1.a
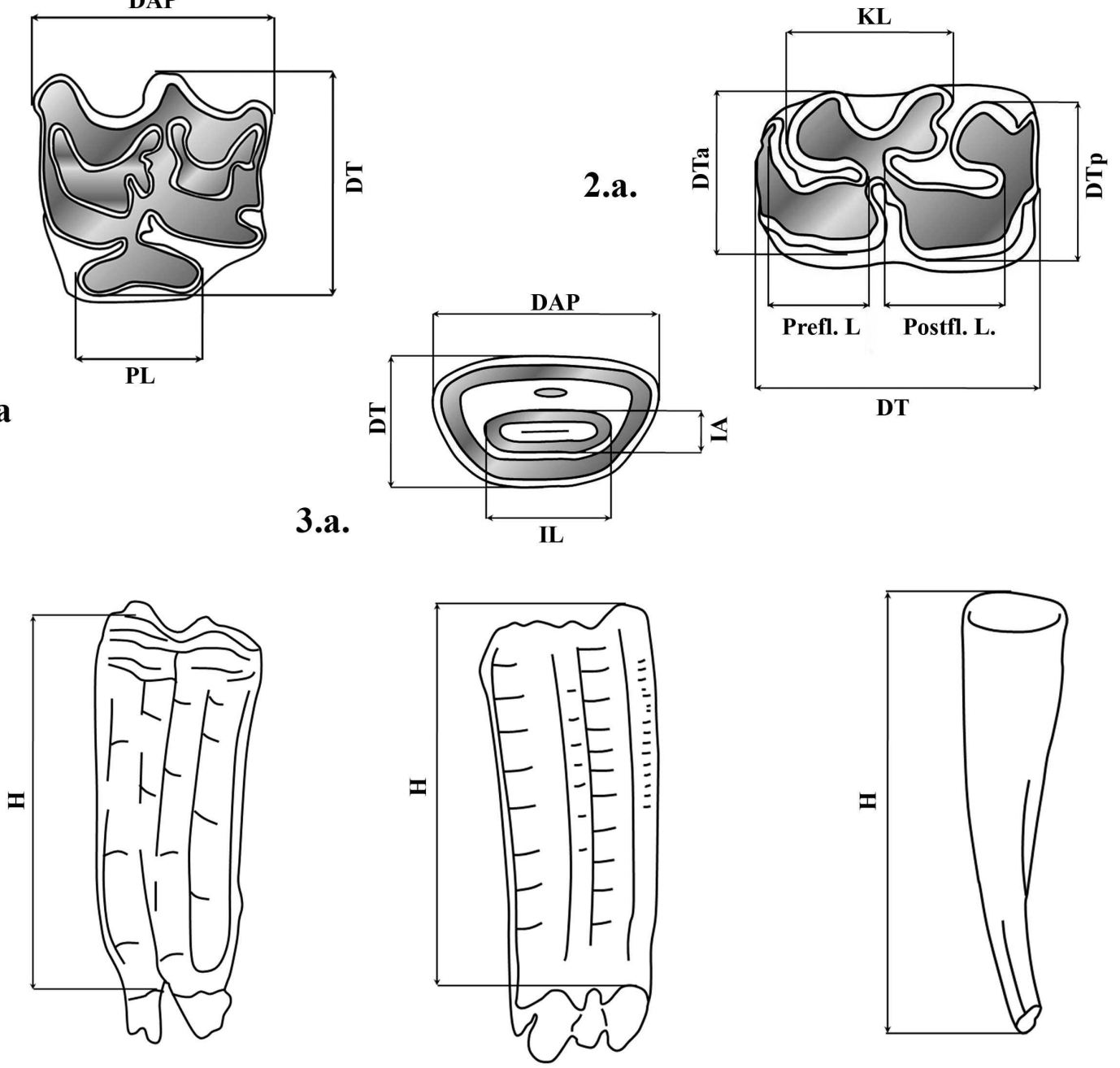

1.b.

2.b.

3.b.

Figura IV.1.4. Medidas tomadas en los dientes de los équidos. 1) Premolar superior. 2) Premolar inferior. 3) Incisivo. *Todas las medidas excepto IA, IL, Prefl. L y Postfl. L. se han tomado también en la altura media.

Tibia (figura IV.1.5: 4): BP: anchura máxima de la epífisis proximal. DP: profundidad máxima de la epífisis proximal.

Astrágalo (figura IV.1.5: 9.a, 9.b, 9.c): BT: anchura de la tróclea. DD: profundidad articular distal. DM: profundidad media máxima. GB: anchura máxima. GL: longitud máxima del hueso.

Calcáneo (figura IV.1.5: 8.a, 8.b): BD: anchura máxima de la epífisis distal. BP: anchura máxima de la epífisis proximal. DD: profundidad máxima de la epífisis distal. DP: profundidad máxima del extremo proximal. GL: longitud máxima del hueso.

Metatarso II (figura IV.1.5): BP: anchura máxima de la epífisis proximal. DP: profundidad máxima de la epífisis proximal.

Metatarso III (figura IV.1.5: 6a, 6.b, 6.c): BD: anchura máxima de la epífisis distal. BP: anchura máxima de la epífisis proximal. DD: profundidad máxima de la epífisis distal. DL: profundidad máxima del cóndilo lateral. DM: profundidad máxima del cóndilo medial. DP: profundidad de la superficie articular proximal. GL: longitud máxima del hueso. GLm: longitud medial. SD: anchura mínima de la diáfisis. 

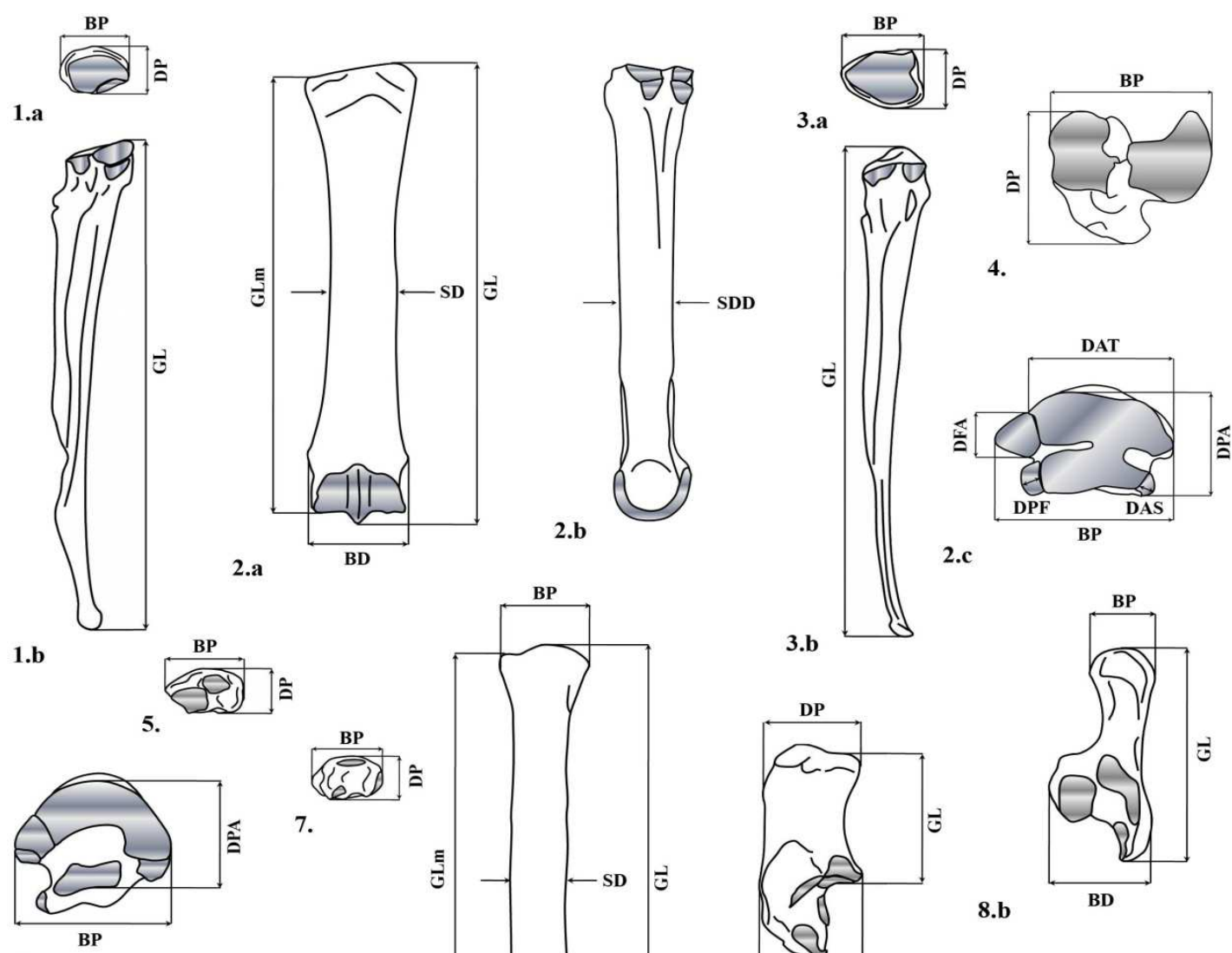

6.a
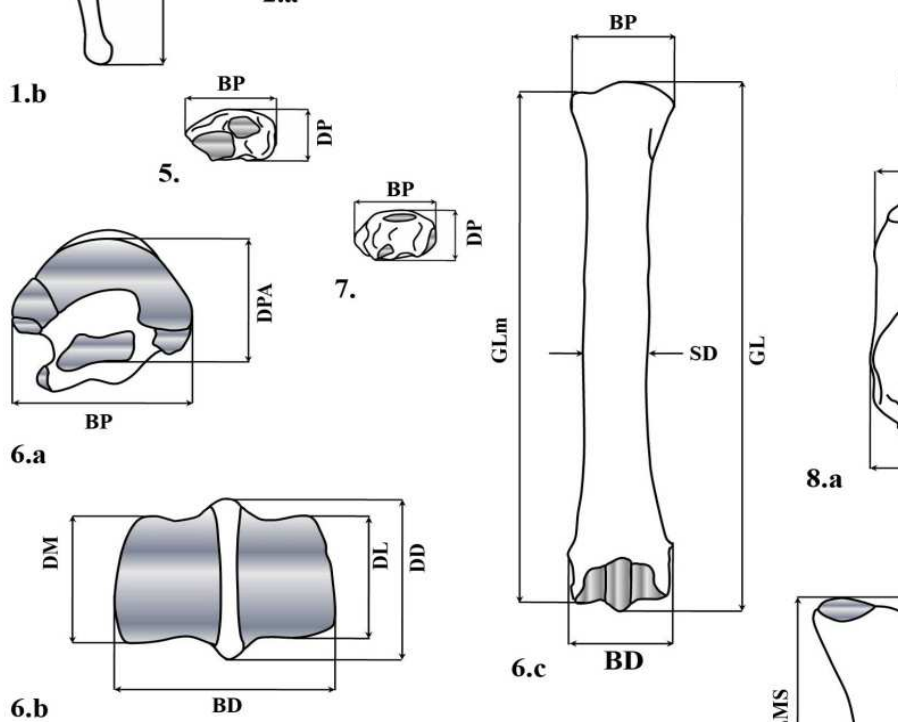

3.b

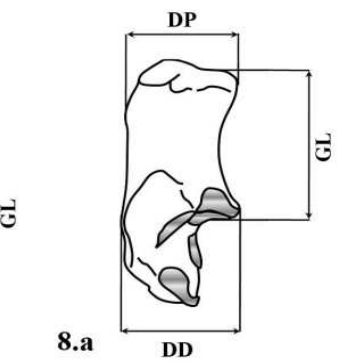

8.b

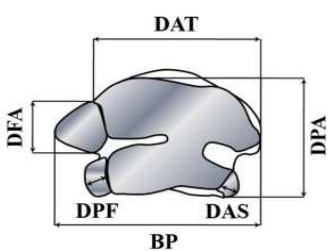

2.c

4.
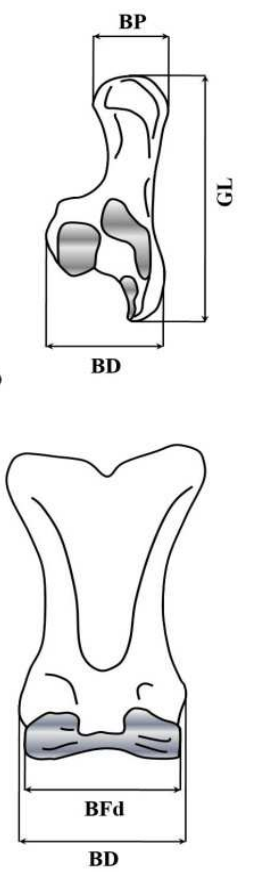

$10 . \mathbf{b}$

0.a
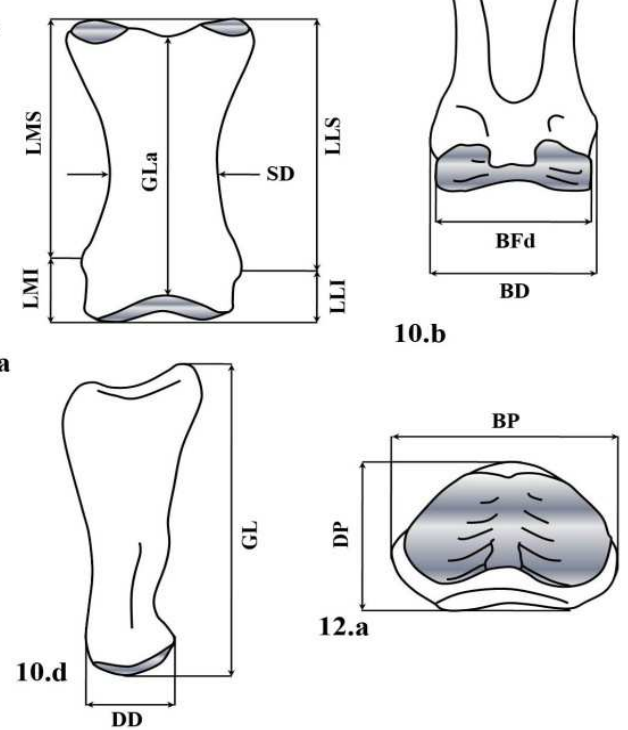

9.a

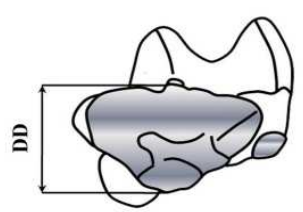

$9 . \mathbf{b}$
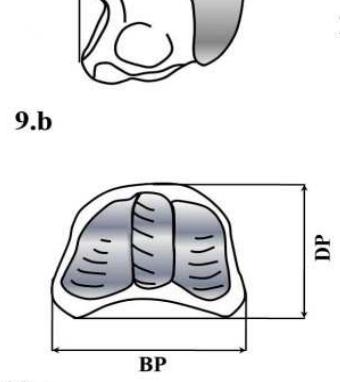

10.c
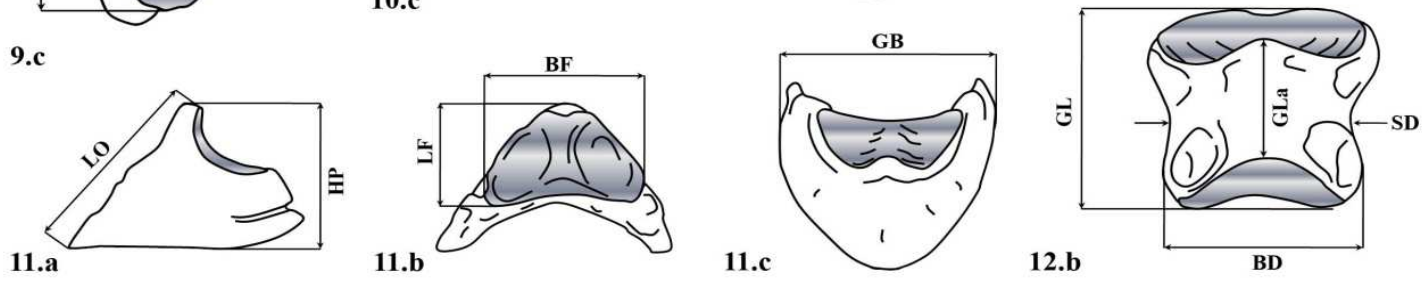

Figura IV.1.5. Medidas tomadas en el postcráneo de los équidos. 1) Metacarpo II. 2) Metacarpo III. 3) Metacarpo IV. 4) Tibia. 5) Metatarso II. 6) Metatarso III. 7) Metatarso IV. 8) Calcáneo. 9) Astrágalo. 10) Falange proximal. 11) Falange distal. 12) Falange media. 
Falange proximal (anterior y posterior) (figura IV.1.5: 10.a, 10.b, 10.c, 10.d): BD: anchura máxima de la epífisis distal tomada en las tuberosidades laterales. BFd: anchura articular distal. BP: anchura máxima de la epífisis proximal. DD: profundidad máxima epífisis distal. DP: profundidad máxima de la epífisis proximal. GL: longitud máxima del hueso. GLa: longitud anterior. LLI: longitud desde la infratuberosidad lateral. LLS: longitud desde la supratuberosidad lateral. LMI: longitud desde la infratuberosidad medial. LMS: longitud desde la supratuberosidad medial. SD: anchura mínima de la diáfisis.

Falange media (anterior y posterior) (figura IV.1.5: 12.a, 12.b): BD: anchura máxima de la epífisis distal. BP: anchura máxima de la epífisis proximal. DP: profundidad máxima de la epífisis proximal GL: longitud máxima del hueso. GLa: longitud anterior. SD: anchura mínima de la diáfisis.

Falange distal (anterior y posterior) (figura IV.1.5: 11.a, 11.b, 11.c): GB: anchura máxima. HP: altura máxima. LD: longitud anterior. LF: profundidad articular. LO: longitud del borde posterior de la superficie articular hasta el borde anterior del hueso.

\section{Índices}

Los criterios métricos son los más empleados para separar la gran cantidad de subespecies de équidos presentes en Europa durante el Pleistoceno (Maldonado, 1996). Los utilizados en este trabajo son los siguientes:

Índice del postfléxido (IPF): relaciona la longitud del postfléxido con el diámetro anteroposterior de la superficie oclusal.

$$
\mathrm{IPF}=\frac{100 \times \text { Postfl. L. (longitud del postfléxido) }}{\text { DAP }}
$$

Índice del doble bucle (IDB): relación entre la longitud del doble bucle y la superficie oclusal en los dientes inferiores.

$$
\mathrm{IDB}=\frac{\text { DAP superficie oclusal } \times 100 \times \mathrm{KL}}{\text { DAP }}
$$

Índice del protocono (IP): relaciona la longitud del protocono con el diámetro anteroposterior de la superficie de oclusal.

$$
\mathrm{IP}=\frac{100 \times \mathrm{LP}}{\mathrm{DAP}}
$$

Índice de robustez (IR): relaciona la anchura mínima de la diáfisis con la longitud total del hueso.

$$
\mathrm{IR}=\frac{\text { SD diáfisis } \times 100}{\text { GL longitud total }}
$$



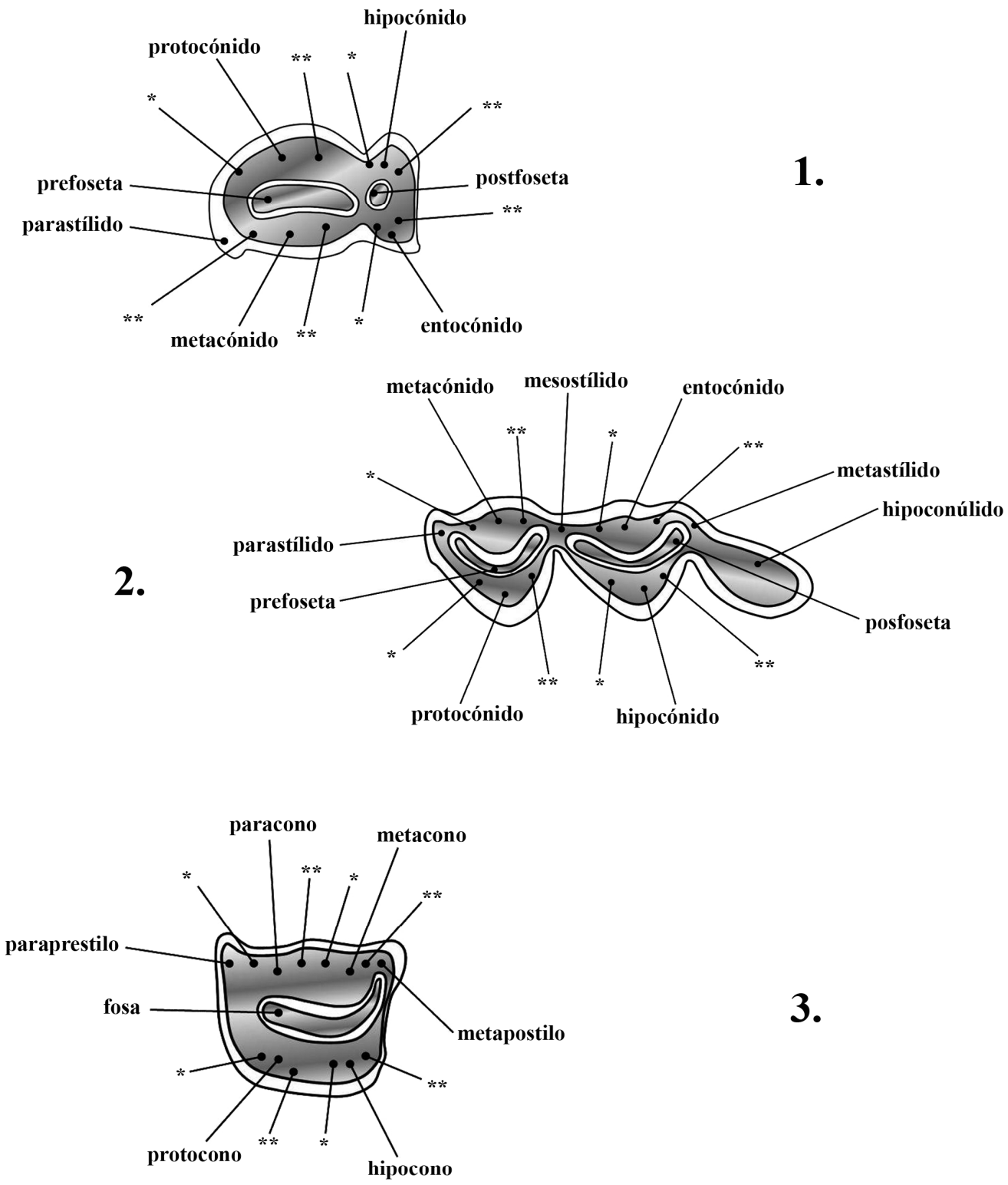

3.

4.

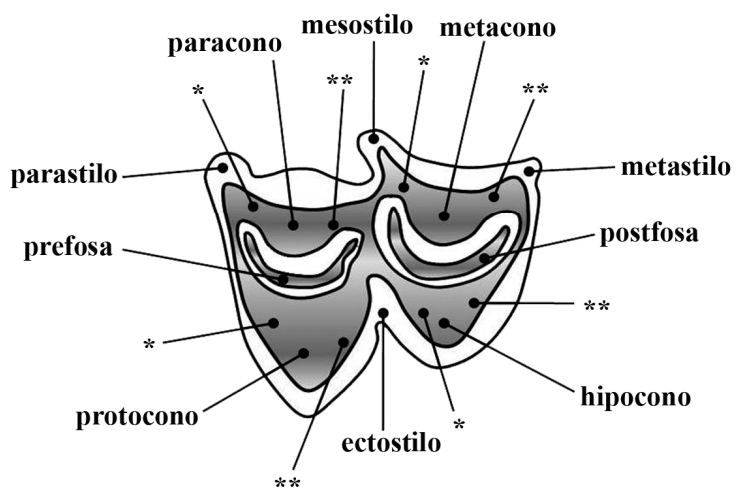

Figura. IV.1.6. Terminología empleada en los dientes de los artiodáctilos. 1) Cuarto premolar inferior. 2) Tercer molar inferior. 3) Cuarto premolar superior. 4) Primer molar superior. ${ }^{+}$Los asteriscos indican las crestas que van por delante o por detrás de las cúspides principales. * Indica la precrista en la dentición superior y la precristida en la inferior. ${ }^{* *}$ Indica la postcrista en los dientes superiores y la postcrístida en los inferiores. Dichos términos van precedidos del prefijo correspondiente a cada cresta (ej. para- precrista, para postcrista). 


\subsubsection{Suidae, Cervidae y Bovidae}

La terminología es la empleada por Van der Made $(1989,1996)$ (figura IV.1.6). A la hora de realizar las mediciones utilizamos dos criterios. En los dientes se ha seguido el modelo de Van der Made $(1989,1996)$ (figuras IV.1.7) y en el material postcraneal los criterios de Von den Driesch (1976) y Sala et al., (2010) (figuras IV.1.8).

En el material dental las dimensiones empleadas son (figuras IV.1.7): DAP: diámetro anteroposterior máximo. DAPb: diámetro anteroposterior basal tomado en la zona de contacto de la raíz con la corona. DLL: diámetro bucolingual de los incisivos y caninos. DT: diámetro transversal máximo. DTa: diámetro transversal del lóbulo anterior. Tomado desde el pilar del paracono al pilar del protocono en la zona basal de la dentición superior. Medido desde el pilar del paracónido al pilar del protocónido en la dentición inferior. DTb: diámetro transversal basal. DTp: diámetro transversal del lóbulo posterior. Medido desde el pilar del metacono al pilar del hipocono en los dientes superiores. Tomado desde el pilar del entocónido al pilar del hipocónido en la dentición inferior. Tomada en la región basal, en la unión de la corona y la raíz. DTpp: diámetro transversal del hipoconúlido del tercer molar inferior. H: altura máxima de la corona. Ha: altura del lóbulo anterior en los molares en la en la cara lingual en el caso de los inferiores y del lado bucal en los superiores. Hdist: altura de la corona de los incisivos y caninos en el extremo distal. Hla: altura de la corona de los incisivos y caninos en el lado labial. Hli: altura de la corona del incisivo en la cara lingual. Hmes: altura de la corona del incisivo en el extremo mesial. Hp: altura del lóbulo posterior de los molares en la cara bucal en los superiores y en la lingual en los inferiores.

Las medidas registradas en los restos postcraneales son (figura IV.1.8):

Escápula (figura IV.1.8: 1): BG: anchura de la cavidad glenoidea. GL: longitud de la cavidad glenoidea. La medida incluye el reborde de la cavidad. GLP: longitud máxima del processus articularis.

Húmero (figura IV.1.8: 2): BD: anchura máxima de la epífisis distal. BT: anchura máxima de la tróclea.

Radio (figura IV.1.8: 3.a, 3.b, 3.c): BD: anchura de la epífisis distal. BFd: anchura de la cara articular distal. BFp: anchura de la cara articular proximal. BP: anchura de la epífisis proximal. DD: profundidad mínima de la diáfisis. DP: profundidad de la epífisis distal. GL: longitud máxima del hueso. SD: anchura mínima de la diáfisis.

Ulna (figura IV.1.8: 4.a, 4.b): BPC: anchura máxima del la superficie articular proximal. DPA: profundidad a través del processus anconaeus. LO: longitud del oleocraneon. SDO: profundidad mínima del oleocraneon.

Metacarpo III + IV (figura IV.1.8: 5.a, 5.b, 5.c): BD: anchura máxima de la epífisis distal. BP: anchura máxima epífisis proximal. DD: profundidad de la epífisis proximal. DP: profundidad de la epífisis distal. GL: longitud máxima del hueso. PL: profundidad del cóndilo lateral. PM: profundidad del cóndilo medial. SD: anchura mínima de la diáfisis.

Patella (figura IV.1.8: 6.a, 6.b): BM: anchura máxima. DM: profundidad máxima. GL: longitud máxima.

Tibia (figura IV.1.8: 7): BD: anchura máxima de la epífisis distal. DD: profundidad máxima de la epífisis distal. SD: anchura mínima de la diáfisis.

Metatarso III + IV (figura IV.1.8: 10): BD: anchura máxima de la epífisis distal. BP: anchura máxima de la epífisis proximal. DD: profundidad de la epífisis distal. DP: profundidad máxima de la epífisis distal. GL: longitud máxima del hueso. PL: profundidad del cóndilo lateral. PM: profundidad del cóndilo medial. SD: anchura mínima de la diáfisis. 


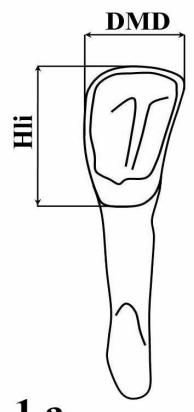

1.a

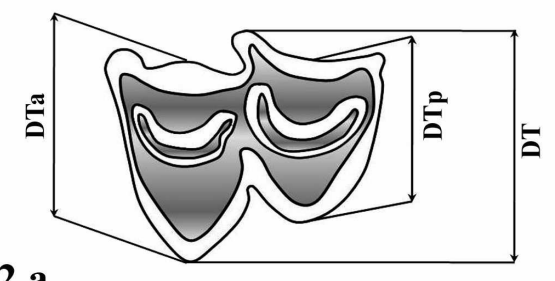

2.a

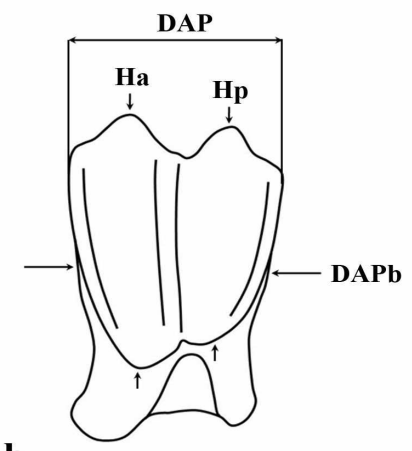

2.b

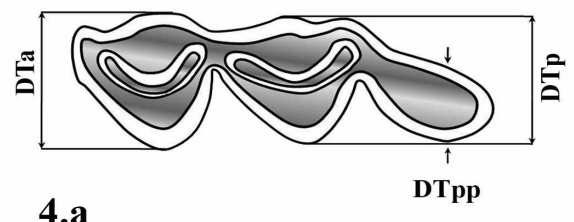

4.a

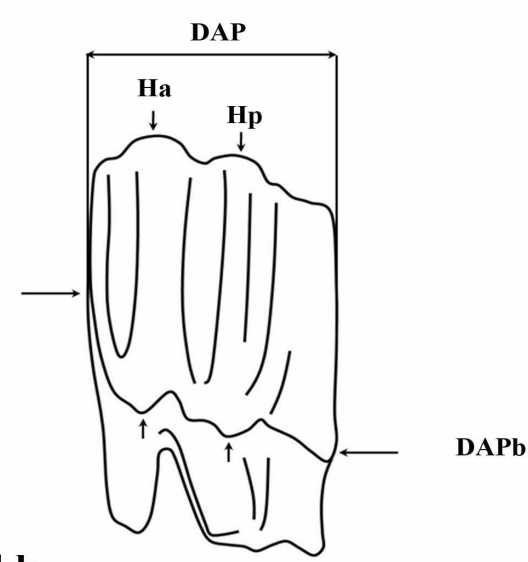

4.b

Figura IV.1.7. Medidas tomadas en los incisivos, caninos, premolares y molares de los artiodáctilos. 1) Incisivo. 2) Molar superior. 3) Premolar superior. 4) Molar inferior. 5) Premolar inferior. Las dimensiones DTa, DTp y DTpp se toman a nivel basal, no en la superficie oclusal.
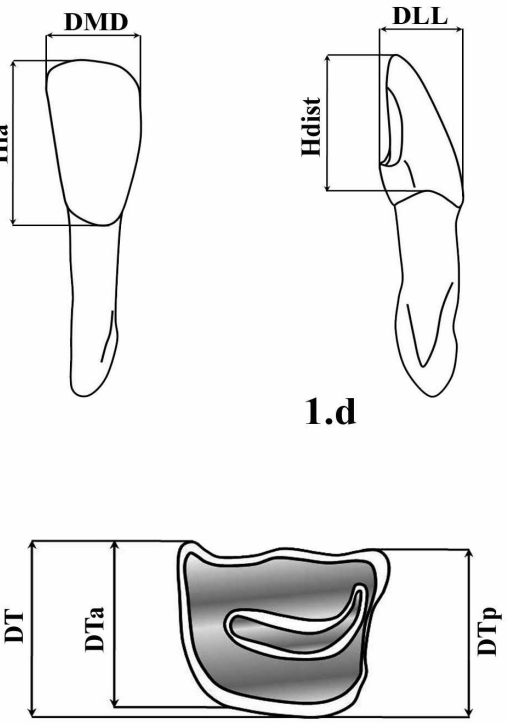

3.a

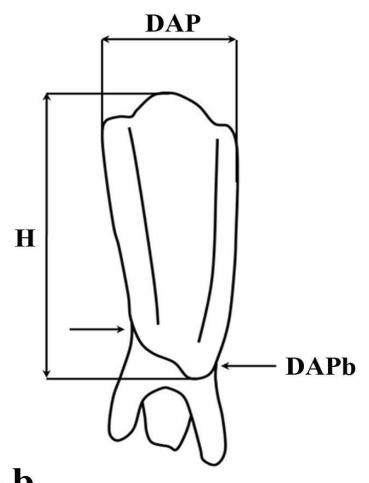

3.b

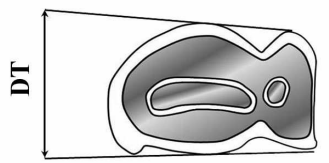

5.a

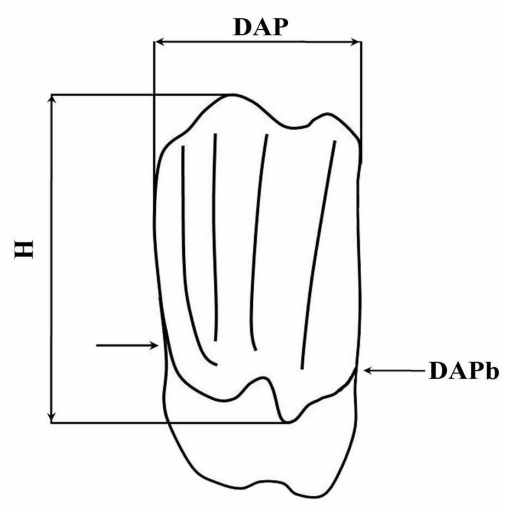

5.b 


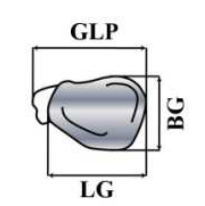

1.

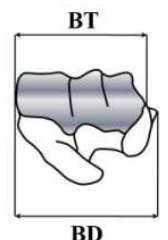

2.
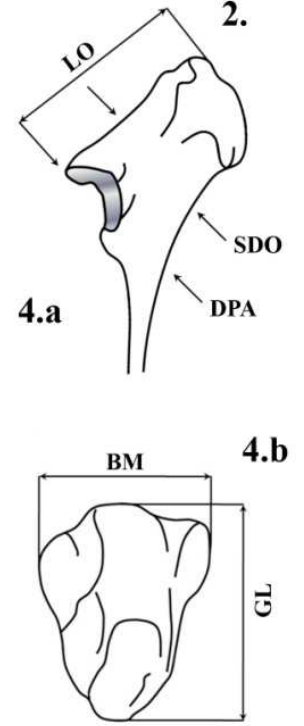

6.a

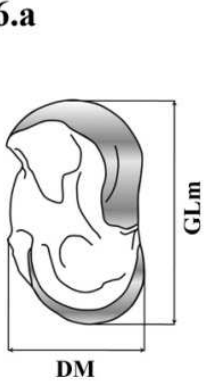

8.a

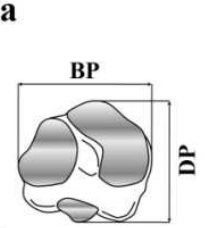

10.

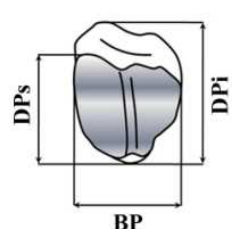

12.a

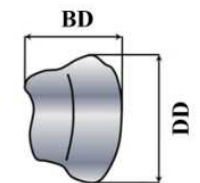

12.b

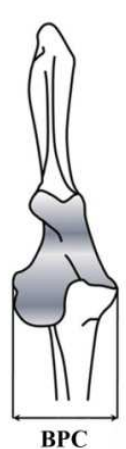

8.b

11.a

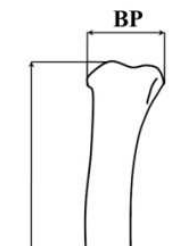

ลิ

3.b
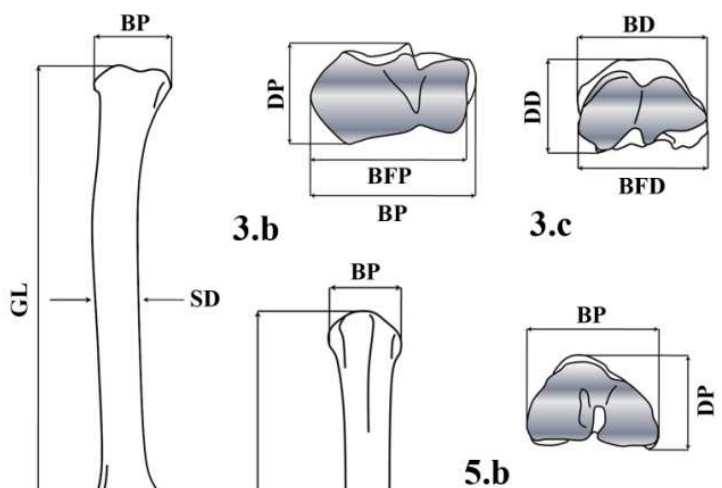

บ) $\longrightarrow-$ SD

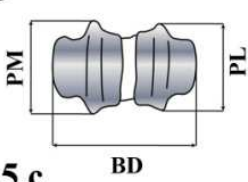

(1) [11

गे

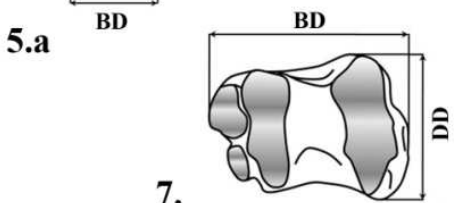

7.
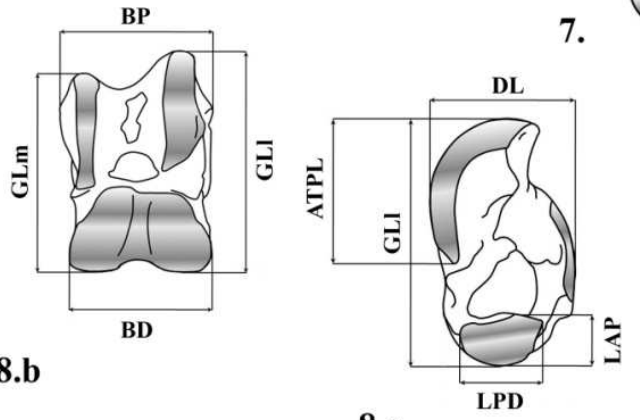

8.c
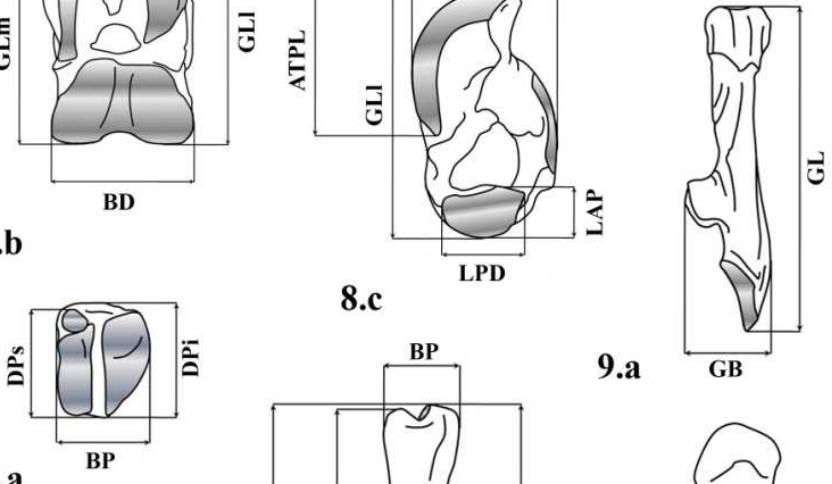

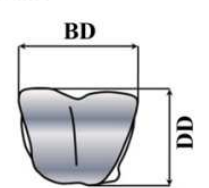

11.b

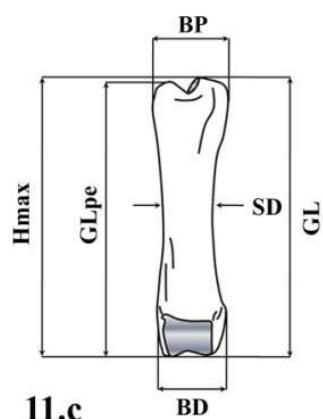

9.a
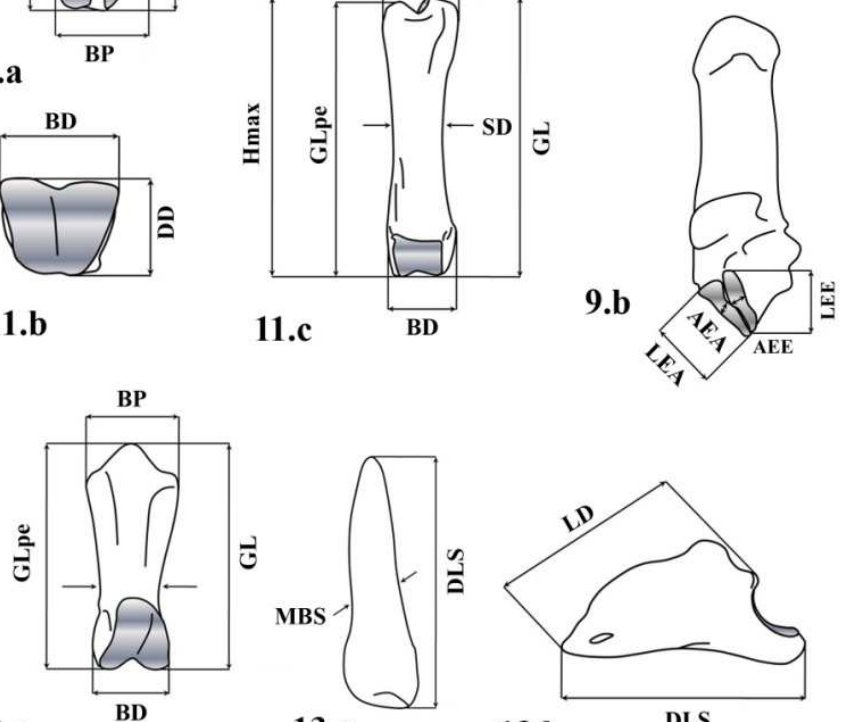

12.c

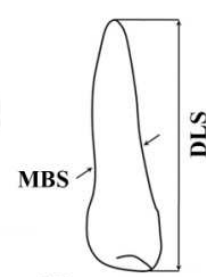

13.a

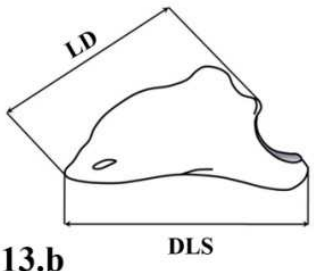

Figura IV.1.8. Medidas tomadas en los huesos postcraneales de los artiodáctilos. 1) Escápula. 2) Húmero. 3) Radio. 4) Ulna. 5) Metacarpo. 6) Patella. 7) Tibia. 8) Astrágalo. 9) Calcáneo. 10) Metatarso. 11) Falange proximal. 12) Falange media. 13) Falange distal. 
Astrágalo (figura IV.1.8: 8.a, 8.b, 8.c): ATPL: altura de la tróclea próximo-lateral. BD: anchura máxima de la epífisis distal. BP: anchura máxima de la epífisis proximal. DM: profundidad del extremo medial. DL: profundidad del extremo lateral. GLm: longitud máxima del extremo medial. GLl: longitud máxima del extremo lateral. LAP: longitud anteroposterior de la faceta articular lateral del calcáneo. LPD: longitud próximo - distal de la faceta articular lateral del calcáneo.

Calcáneo (figura IV.1.8: 9.a, 9.b): AEA: anchura de la superficie articular externa para el astrágalo. AEE: anchura de la superficie articular externa para el escafocuboides. GB: anchura máxima. GL: longitud máxima. LEA: longitud de la superficie articular externa para el astrágalo. LEE: longitud de la superficie articular externa para el escafocuboides.

Falange proximal (figura IV.1.8: 11.a, 11.b, 11.c): BD: anchura máxima de la epífisis distal. BP: anchura máxima de la epífisis proximal. DD: profundidad de la epífisis distal. DP: profundidad máxima epífisis proximal. DPi: profundidad de la epífisis proximal en la región de inserción muscular. DPs: profundidad de la superficie articular proximal. GL: longitud de la mitad axial. GLpe: longitud de la mitad abaxial. Hmax: longitud máxima del hueso. SD: anchura mínima de la diáfisis.

Falange media (figura IV.1.8: 12.a, 12.b, 12.c): BD: anchura máxima de la epífisis distal. BP: anchura máxima de la epífisis proximal. DD: profundidad de la epífisis distal. DPi: profundidad máxima de la epífisis proximal. DPs: profundidad de la superficie articular proximal. GL: longitud de la mitad axial. GLpe: longitud de la mitad abaxial. Hpost: longitud del hueso tomada en la cara posterior. SD: anchura mínima de la diáfisis.

Falange distal (figura IV.1.8: 13.a, 13.b): DLS: longitud máxima de la cara solar. LD: longitud de la superficie dorsal. MBS: anchura en la región media de la cara solar.

Asimismo, y debido a la semejanza morfométrica existente entre los géneros de grandes bóvidos, Bos y Bison, se han empleado diversas referencias bibliográficas que nos permiten diferenciarlos: Schertz (1936), Bibikova (1958), Altuna (1972), Brugal (1984), Jaubert et al., (1990), Buitrago (1992), Gee (1993), Álvarez-Lao (2007) y Sala et al., (2010). También se han utilizado varios índices que permiten, a nivel métrico, discriminar entre ambos géneros. Dichos índices se aplican sobre el astrágalo y el calcáneo y han sido desarrollados por Bibikova (1958) y aparecen en Sala et al., (2010).

\section{Índices}

En el astrágalo se han utilizado:

Índice de la faceta articular para el calcáneo: relaciona la longitud y la anchura de la cara que articula con el calcáneo.

$$
\mathrm{IFAL}=\frac{\text { longitud próximo distal (LPD) }}{\text { longitud anteroposterior (LAP) }} \times 100
$$

Índice de la tróclea distal: compara las anchuras de la tróclea distal del astrágalo.

$$
\mathrm{AMTD}=\frac{\text { anchura mesial de la tróclea distal (AMD) }}{\text { anchura lateral de la tróclea distal (ALD) }} \times 100
$$


En el calcáneo se han calculado:

Índice de las longitudes de las superficies articulares externas para el astrágalo y el escafocuboides: relaciona las longitudes de ambas caras articulares.

$$
\mathrm{ILAE}=\frac{\text { longitud superficie articular externa para el astrágalo (LEA) }}{\text { longitud superficie articular externa para el escafocuboides (LEE) }} \times 100
$$

Índice de las anchuras de las superficies articulares externas para el astrágalo y el escafocuboides: relaciona las anchuras de ambas caras articulares.

$$
\text { IAAE }=\frac{\text { anchura superficie articular externa para el astrágalo (AEA) }}{\text { anchura superficie articular externa para el escafocuboides (AEE) }} \times 100
$$

\subsubsection{Número Mínimo de Individuos}

Para determinar el número mínimo de individuos se han empleado las piezas más frecuentes y el grado de desgaste ya que, en algunos casos, la erosión indica la pertenencia a individuos diferentes. Los inmaduros, que incluyen aquellos sin la dentición permanente completa, se han determinado a partir de la última pieza decidual en caer (tablas IV.2.1, 4 y 6); mientras que los maduros a partir de la última pieza permanente en emerger. A partir de la edad de muerte, y teniendo en cuenta también la pieza más frecuente, se han estimado los ejemplares infantiles, juveniles, adultos y seniles. Los rangos de edad para determinar estos últimos aparecen en las tablas IV.2.2 y 8.

\subsection{Edad de muerte}

La naturaleza de algunos yacimientos arqueopaleontológicos hace difícil, y en ocasiones imposible, establecer el agente de acumulación o definir la combinación de diferentes agentes (Twiss, 2008). Afortunadamente, hay algunos depósitos donde la asociación de objetos y los caracteres presentes en los huesos pueden apuntar a un agente primario de acumulación (Klein et al., 1984). Uno de los métodos más utilizados en arqueología es el estudio de la edad de muerte. Los modelos empleados en este análisis se basan tanto en la morfología como en las medidas tomadas en las piezas dentales.

\subsubsection{Rhinocerotidae}

Dentro de esta familia los trabajos realizados son escasos, predominando sobre todo los llevados a cabo en el rinoceronte lanudo Coelodonta antiquitatis (Borsuk-Bialynika, 1973; Álvarez-Lao, 2007). En el género Stephanorhinus destacamos, por ejemplo, los trabajos Fortelius y Solounias (2000) y que fueron empleados por Kahlke y Kaiser (2011) en $S$. hundheimensis. Sin embargo, estos modelos no son aplicables a $S$. hemitoechus debido fundamentalmente a las diferencias en el espesor del esmalte (Van der Made, com. pers.). El método empleado en el rinoceronte de las estepas es sencillo, basándose en el desgaste y la erupción dental. Al no estar registradas las edades de erupción en esta especie se definen unos rangos de edad relativa que abarcarían desde ejemplares infantiles a adultos-viejos (Álvarez-Lao, 2007): los infantiles incluirían el material decidual; los jóvenes los dientes deciduales con desgastes marcados y las piezas permanentes germinales; los adultos los dientes permanentes con desgastes marcados $\mathrm{y}$, los viejos aquellos dientes con desgastes máximos. 


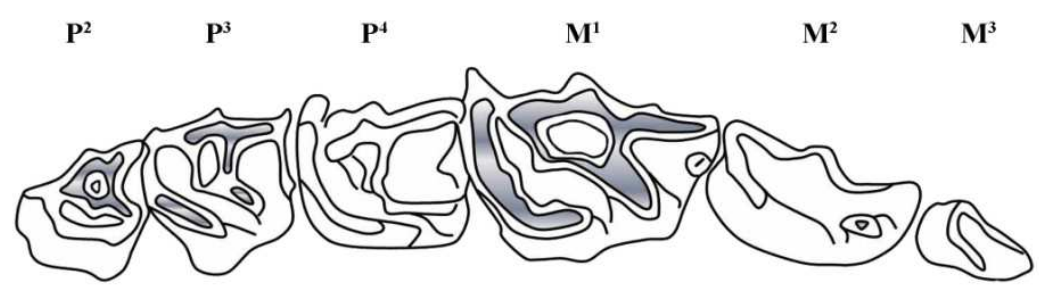

Fase 1

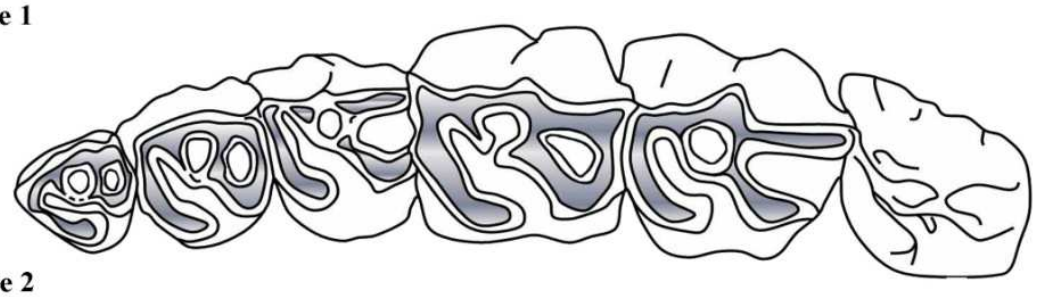

Fase 2

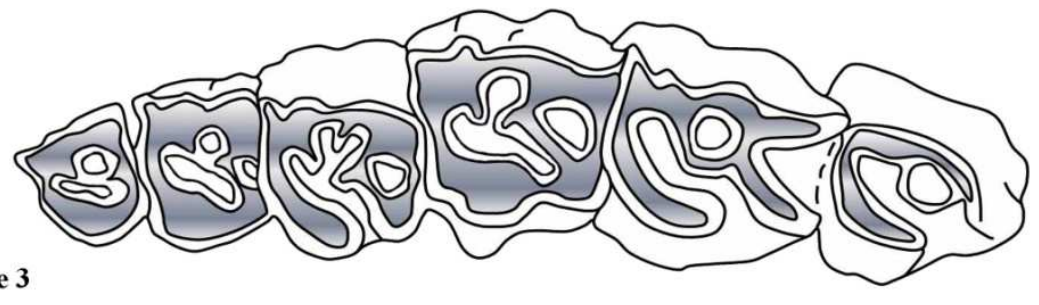

Fase 3

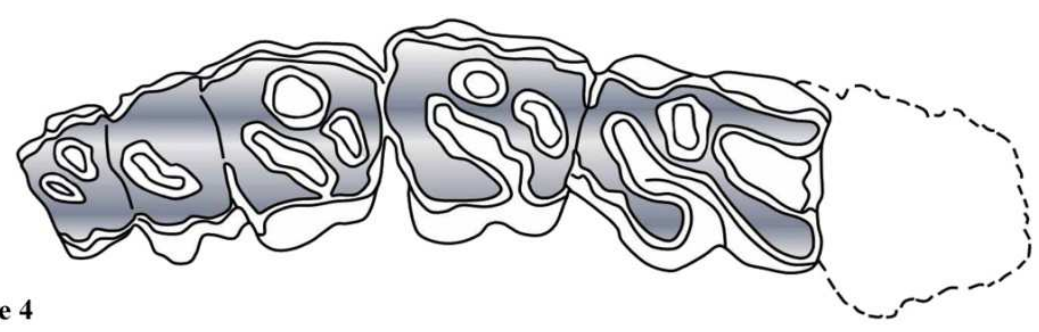

Fase 4

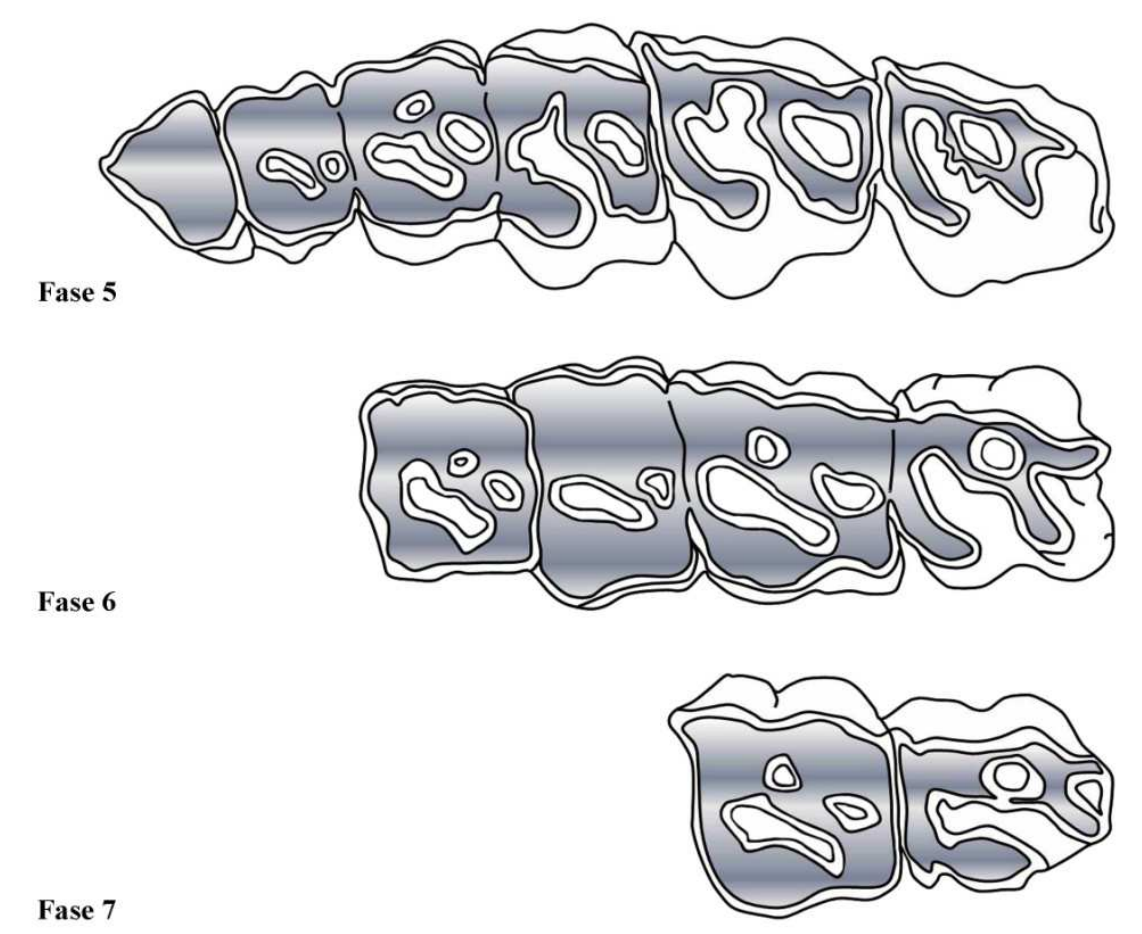

Figura IV.2.1. Fases de desgaste observadas en los dientes yugales superiores de $C$. antiquitatis (tomado de Álvarez-Lao, 2007). 
Tabla IV.2.1

Grupos de edad y edad relativa obtenida a partir del desgaste de las piezas de $C$. antiquitatis

\begin{tabular}{ccc}
\hline $\begin{array}{c}\text { Grupos de } \\
\text { edad }\end{array}$ & Características & Edad relativa \\
\hline I & Dentición decidual hasta la pérdida del tercer decidual & Joven \\
II & Dentición permanente hasta que comienza la erosión del M3 & Joven - Adulto \\
III & Erosión del M3 hasta 1/3 de la corona & Adulto - Viejo \\
IV & Erosión del M3 hasta $1 / 2$ o más. Los premolares pueden estar & Viejo \\
\hline
\end{tabular}

* Datos tomados de Álvarez-Lao (2007).

Las referencias son más abundantes en Coelodonta antiquitatis. Existen trabajos centrados en el estudio de las líneas de crecimiento de los cuernos, en la fusión de los huesos craneales y en el análisis tanto del desgaste como de las líneas de cemento de los dientes. En este sentido, Borsuk-Bialynika (1973) emplea, fundamentalmente, la fusión de los huesos craneales y hace una breve mención de las piezas dentales, definiendo cuatro rangos dependiendo de su erupción y grado de desgaste (tabla IV.2.1).

Tabla IV.2.2

Fases de desgaste y edad relativa obtenida a partir del desgaste de las piezas superiores de C. antiquitatis

\begin{tabular}{|c|c|c|}
\hline $\begin{array}{l}\text { Fase de } \\
\text { desgaste }\end{array}$ & Características & $\begin{array}{c}\text { Correlación } \\
\text { Borsuk-Bialynika } \\
(1973)\end{array}$ \\
\hline 1 & $\begin{array}{l}\text { Deciduales: recién perdidos } \\
\mathrm{P}^{2}-\mathrm{P}^{3} \text { : ligera erosión } \\
\mathrm{M}^{1} \text { : erosión más avanzada } \\
\mathrm{P}^{4} \text { y } \mathrm{M}^{2} \text { : emergiendo }\end{array}$ & $\begin{array}{c}\text { Grupo II } \\
\text { (Adulto - Joven) }\end{array}$ \\
\hline 2 & $\begin{array}{c}\mathrm{P}^{2}-\mathrm{P}^{3} \text { y M} \mathrm{M}^{1} \text { : postfoseta aislada, valle anterior abierto } \\
\mathrm{P}^{4} \mathrm{y} \mathrm{M}^{2} \text { : ligera erosión } \\
\mathrm{M}^{3} \text { : casi emergido }\end{array}$ & $\begin{array}{c}\text { Grupo II } \\
\text { (Adulto - Joven) }\end{array}$ \\
\hline 3 & $\begin{array}{c}\mathrm{P}^{2}-\mathrm{P}^{3} \text { : valle anterior aislado } \\
\mathrm{M}^{1} \text { : valle anterior en ocasiones aislado } \\
\mathrm{P}^{4} \text { : postfoseta aislada } \\
\mathrm{M}^{3} \text { : comienza el desgaste }\end{array}$ & $\begin{array}{c}\text { Grupo III } \\
\text { (Adulto - Viejo) }\end{array}$ \\
\hline 4 & $\begin{array}{c}\mathrm{P}^{4} \text { : valle anterior cerrado } \\
\mathrm{P}^{2} \text { y } \mathrm{P}^{3} \text { : atrición interdental evidente. Pueden haber perdido } \\
\text { parte de las fosas } \\
\mathrm{M}^{2} \text { : postfoseta cerrada o casi cerrada }\end{array}$ & $\begin{array}{c}\text { Grupo III } \\
\text { (Adulto - Viejo) }\end{array}$ \\
\hline 5 & $\begin{array}{c}\mathrm{P}^{2} \text { y } \mathrm{P}^{3} \text { : puede haber perdido todas sus isletas } \\
\mathrm{M}^{1} \text { : atrición interdental } \\
\mathrm{M}^{2} \text { : postfoseta aislada } \\
\mathrm{M}^{3} \text { : se diferencia el metalofo del ectolofo }\end{array}$ & $\begin{array}{l}\text { Grupo III - Grupo IV } \\
\text { (Adulto - Viejo) }\end{array}$ \\
\hline 6 & $\begin{array}{c}\mathrm{P}^{2} \text { y } \mathrm{P}^{3}: \text { dejan de ser funcionales } \\
\mathrm{M}^{2} \text { y } \mathrm{M}^{3} \text { : atrición extrema } \\
\mathrm{M}^{2}: \text { valle anterior cerrado } \\
\mathrm{M}^{3} \text { : ectolofo y y metalofo completamente diferenciados }\end{array}$ & $\begin{array}{l}\text { Grupo IV } \\
\text { (Viejo) }\end{array}$ \\
\hline 7 & $\begin{array}{c}\mathrm{P}^{4} \text { : desaparecido } \\
\mathrm{M}^{1} \text { : residual o desaparecido } \\
\mathrm{M}^{2} \text { : isletas muy reducidas o cercanas a desaparecer } \\
\mathrm{M}^{3} \text { : ectolofo y metalofo unidos, aislando la postfoseta }\end{array}$ & $\begin{array}{l}\text { Grupo IV } \\
\text { (Viejo) }\end{array}$ \\
\hline
\end{tabular}

* Datos tomados de Álvarez-Lao (2007).

Por otra parte, Álvarez-Lao (2007) utiliza los elementos más frecuentes, los dientes, y a partir de una amplia colección de referencia desarrolla un modelo que permite establecer la edad a partir del grado de desgaste de las superficies oclusales y de la atrición observada en el esmalte presente en las caras anterior y posterior de la línea premolar- 
molar (tabla IV.2.2) (figura IV.2.1). Por último, correlaciona sus datos con los grupos de edad creados por Borsuk- Bialynika (1973). Asimismo, Kirillova y Shidlouskiy (2010) establecen una metodología que añade el estudio de las capas de cemento del primer molar superior y las líneas de crecimiento observables en los cuernos nasal y frontal. Estos autores establecen como grupo de comparación a los rinocerontes blancos, indicando, al final, que los resultados de ambos métodos y del análisis del grado de desgaste de las piezas son similares.

En este trabajo se emplea el modelo de Álvarez-Lao (2007) ya que los restos recuperados son fundamentalmente dientes.

\subsubsection{Equidae}

Se han identificado dos especies, Equus ferus y E. hydruntinus. En el primero, E. ferus, se ha empleado una metodología morfométrica, observando los cambios en la forma de la superficie oclusal de los incisivos (Sisson y Grossman, 2001) y el desgaste de la corona en los dientes yugales (Eisenmann et al., 1988). En los casos en los que no se han podido medir las coronas, se han empleado las edades de erupción dental (Sisson y Grossman, 2001). En el segundo taxón, E. hydruntinus, se ha seguido únicamente un modelo métrico.

\section{Incisivos}

En estas piezas se han analizado los cambios morfológicos que el desgaste produce en la superficie oclusal (Sisson y Grossman, 2001) (figura IV.2.2). Los rangos de edad obtenidos no reflejan una edad exacta pero se han utilizado para los contrastar resultados obtenidos en los dientes yugales.

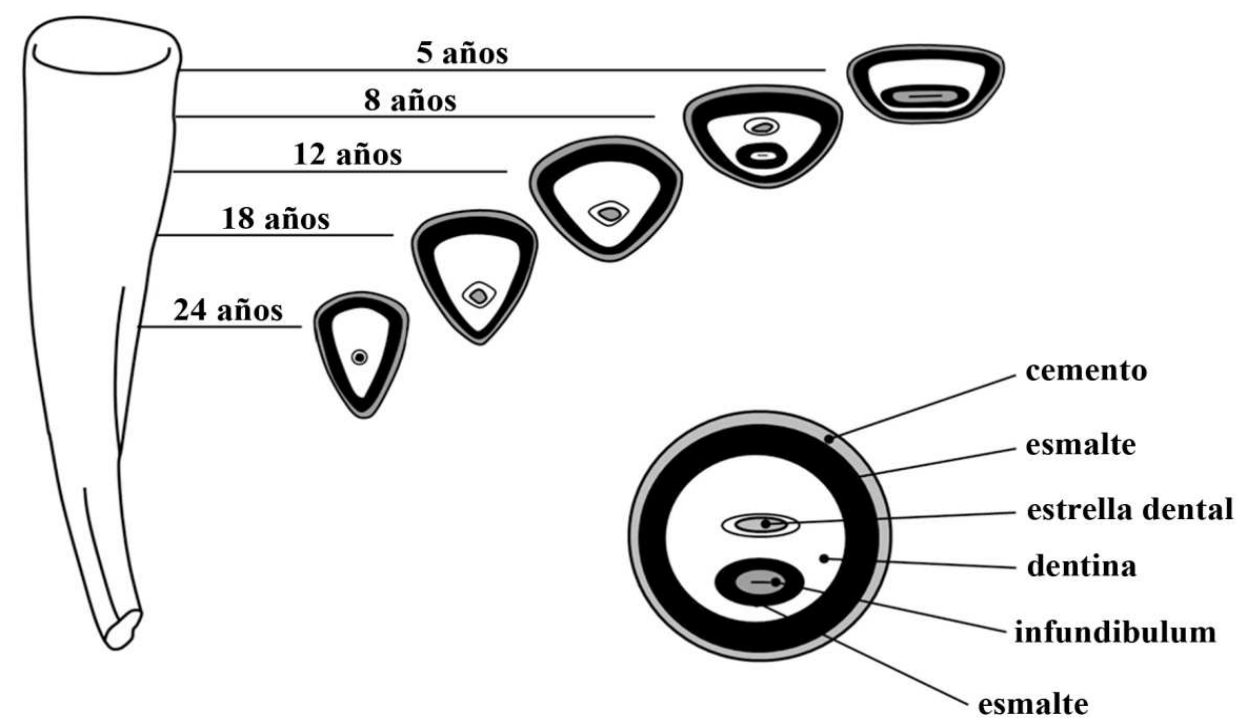

Figura IV.2.2. Cambios morfológicos que el desgaste produce en la superficie oclusal de los incisivos de Equus ferus, y su edad correspondiente.

\section{Dientes yugales}

En los dientes yugales, premolares y molares inferiores y superiores, se emplea una metodología métrica, tomando la altura de la corona como la principal variable. La altura máxima de la corona (AMC) para E. ferus ha sido tomada de Levine (1979) que la sitúa en $100 \mathrm{~mm}$, y es válida tanto para los premolares como para los molares inferiores y superiores. Por otro lado, la AMC de E. hydruntinus, se ha establecido en $90 \mathrm{~mm}$, 
modificando las observaciones de Arceredillo y Díez (2009) correspondientes a los actuales Equus asinus, que la situaban en los $80 \mathrm{~mm}$.

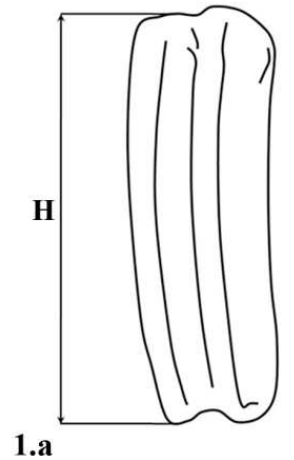

.a

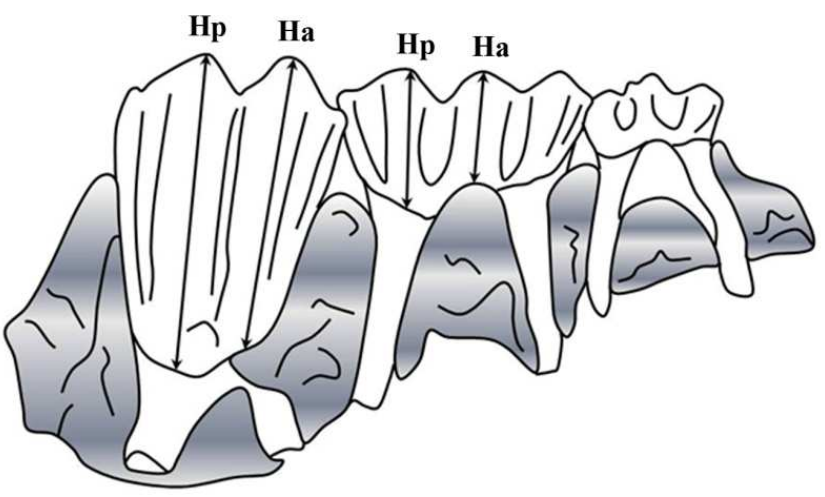

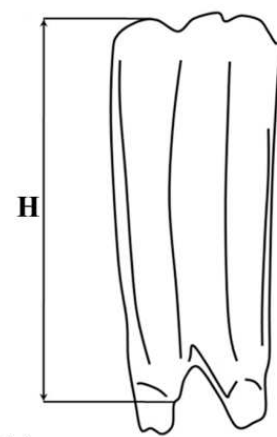

1.b

2.a

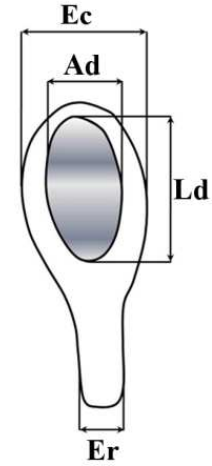

2.b

Figura IV.2.3. Medidas tomadas en la dentición de los perisodáctilos y artiodáctilos para la estimación de la edad de muerte. 1) Dientes yugales superiores e inferiores de Equus ferus. 2) Caninos superiores de Cervus elaphus. 3) Molares deciduos y permanentes de Rupicapra pyrenaica.

La altura de la corona (figura IV.2.3) se ha tomado de la raíz al parastilo en los dientes superiores; y desde el borde anterolingual al parastílido en los inferiores (Eisenmann et al., 1988). A la hora de procesar la información, en E. ferus se han empleado las tablas desarrolladas por Levine (1979) que relacionan el desgaste de la corona con la edad de muerte (tabla IV.2.3). En los casos en los que no se ha podido medir la altura de las coronas se emplea la erupción dental (tabla IV.2.4) para obtener una edad mínima (Montané et al., 1949; Sisson y Grossman, 2001; Fernández y Legrenge, 2003).

Por otra parte, E. hydruntinus, no aporta los suficientes restos como para poder relacionar un desgaste con una edad en concreto; y tampoco podemos utilizar una especie actual como E. asinus para conocer los rangos de desgaste. Debido a esto, la solución que aportamos consiste en dividir la corona sin desgaste en cuatro partes, representando cada una de ellas un rango de edad relativa: 1) Poco o nada desgaste ( $\leq 25 \%$ de la altura máxima de la corona); 2) Desgaste moderado (25-50 \% de la altura máxima de la corona); 3) Desgaste marcado (50-75 \% de la altura máxima de la corona) y 4) Desgaste máximo ( $\geq$ $75 \%$ de la altura máxima de la corona). Las dos primeras corresponderían a individuos juveniles ya que partimos de la erupción del $\mathrm{M}_{1}$; y las otras dos a ejemplares adultos que ya tendrían toda la dentición permanente emergida. 
Tabla IV.2.3

Edad de muerte en Equus ferus relacionada con el desgaste de los dientes yugales inferiores y superiores

\begin{tabular}{|c|c|c|c|c|c|c|c|c|c|c|c|c|c|}
\hline Edad & $\mathbf{P}_{2}$ & $\mathbf{P}_{3}$ & $\mathbf{P}_{4}$ & $\mathbf{M}_{1}$ & $\mathbf{M}_{2}$ & $M_{3}$ & Edad & $\mathbf{P}^{2}$ & $\mathbf{P}^{3}$ & $\mathbf{P}^{4}$ & $\mathbf{M}^{1}$ & $\mathbf{M}^{2}$ & $\mathbf{M}^{3}$ \\
\hline años & \multicolumn{6}{|c|}{ altura en mm } & años & \multicolumn{6}{|c|}{ altura en mm } \\
\hline $1-2$ & & & & $91-83$ & & & $1-2$ & & & & & & \\
\hline $2-3$ & & & & $91-89$ & $86-83$ & & $2-3$ & $65-70$ & & & $92-89$ & $88-89$ & \\
\hline $3-4$ & $60-59$ & 81-82 & & 89-81 & 86-82 & $77-70$ & $3-4$ & $68-70$ & $81-80$ & $85-83$ & $89-80$ & $89-86$ & $80-82$ \\
\hline 4-5 & $59-55$ & 82-78 & $80-79$ & 81-72 & $82-76$ & 77-78 & 4-5 & $70-68$ & $80-76$ & $85-81$ & $80-73$ & $86-80$ & $82-83$ \\
\hline $5-6$ & $55-49$ & $78-69$ & $79-73$ & $72-64$ & $76-70$ & $78-71$ & $5-6$ & $65-60$ & $76-70$ & $81-74$ & $73-66$ & $80-74$ & $82-75$ \\
\hline $6-7$ & $49-43$ & $69-60$ & $73-65$ & 64-56 & $70-63$ & 71-64 & $6-7$ & $60-54$ & $70-63$ & $74-65$ & $66-59$ & $74-67$ & $75-65$ \\
\hline 7-8 & $43-38$ & $60-52$ & $65-56$ & $56-49$ & 63-57 & 64-58 & $7-8$ & $54-48$ & $63-57$ & $65-58$ & $59-53$ & $67-60$ & $65-55$ \\
\hline $8-9$ & $38-33$ & $52-45$ & $56-48$ & $49-44$ & 57-50 & 58-51 & $8-9$ & $48-42$ & $57-50$ & $58-51$ & $53-48$ & $60-53$ & $55-48$ \\
\hline $9-10$ & $33-28$ & 45-39 & $48-42$ & 44-38 & $50-44$ & 51-46 & $9-10$ & $42-37$ & $50-45$ & $51-45$ & $48-43$ & $53-48$ & $48-42$ \\
\hline $10-11$ & $28-24$ & 39-34 & $42-37$ & 38-33 & 44-39 & $46-42$ & $10-11$ & $37-32$ & $45-40$ & $45-41$ & $43-40$ & $48-42$ & $42-37$ \\
\hline 11-12 & $24-20$ & $34-30$ & $37-33$ & $33-29$ & $39-35$ & $42-37$ & $11-12$ & $32-28$ & $40-36$ & $41-37$ & $40-36$ & $42-39$ & $37-33$ \\
\hline $12-13$ & $20-17$ & $30-28$ & $33-31$ & $39-26$ & $35-32$ & $37-33$ & $12-13$ & $28-24$ & $36-33$ & $37-35$ & $36-33$ & $39-35$ & 33-31 \\
\hline $13-14$ & $17-15$ & $28-25$ & $31-30$ & $26-24$ & $32-29$ & $33-29$ & $13-14$ & $24-20$ & $33-30$ & $35-32$ & $33-30$ & $35-33$ & $31-29$ \\
\hline 14-15 & $15-12$ & $25-23$ & $30-28$ & 24-22 & $29-27$ & $29-26$ & 14-15 & $20-18$ & $30-27$ & $32-30$ & $30-27$ & $33-31$ & $29-27$ \\
\hline $15-16$ & $12-10$ & $23-22$ & $28-27$ & $22-21$ & $27-24$ & $26-24$ & $15-16$ & $18-16$ & $27-25$ & $30-28$ & $27-25$ & $31-29$ & $27-25$ \\
\hline $16-17$ & $10-8$ & $22-20$ & $28-27$ & $21-20$ & $24-23$ & $24-23$ & 16-17 & $16-14$ & $25-22$ & $28-27$ & $25-24$ & $29-28$ & $25-24$ \\
\hline $17-18$ & $8-6$ & 20-19 & $28-27$ & $21-20$ & $23-22$ & $23-22$ & 17-18 & $14-13$ & $22-20$ & $27-26$ & $24-23$ & $28-27$ & $24-23$ \\
\hline 18-19 & 6-5 & 20-19 & $28-27$ & $20-19$ & $22-21$ & $22-21$ & 18-19 & $13-11$ & $20-19$ & $26-25$ & $23-22$ & $27-27$ & $23-22$ \\
\hline $19-25$ & $5-4$ & $19-10$ & $27-10$ & $19-10$ & $21-10$ & $21-10$ & $19-25$ & $11-5$ & $19-10$ & $25-10$ & $22-10$ & $27-10$ & $22-10$ \\
\hline
\end{tabular}

* Datos tomados de Levine (1979).

Tabla IV.2.4

Edades de erupción dental en Equus ferus

\begin{tabular}{|c|c|c|c|c|c|c|c|}
\hline \multirow{2}{*}{\multicolumn{2}{|c|}{$\frac{\text { Dentición decidual }}{\text { (semanas) }}$}} & \multicolumn{6}{|c|}{ Dentición permanente } \\
\hline & & & (meses) & & (meses) & & (meses) \\
\hline $\mathrm{dI}_{1}$ & Nacimiento/Primera semana & $\mathbf{I}_{\mathbf{1}}$ & 30 & $\mathbf{P}_{2}$ & $26-32$ & $\mathbf{P}^{2}$ & $28-34$ \\
\hline $\mathbf{d I}_{2}$ & 4-6 semanas & $\mathbf{I}_{2}$ & 42 & $\mathbf{P}_{3}$ & $30-34$ & $\mathbf{P}^{3}$ & $38-42$ \\
\hline $\mathrm{dI}_{3}$ & 6-9 semanas & $\mathbf{I}_{3}$ & 54 & $\mathbf{P}_{4}$ & $40-44$ & $\mathbf{P}^{4}$ & $45-50$ \\
\hline $\mathbf{D}_{2}$ & Nacimiento/primeras dos semanas & C & $48-60$ & $\mathbf{M}_{1}$ & $10-12$ & $\mathbf{M}^{1}$ & $10-12$ \\
\hline $\mathbf{D}_{3}$ & Nacimiento/primeras dos semanas & & & $\mathbf{M}_{2}$ & $20-26$ & $\mathbf{M}^{2}$ & $20-26$ \\
\hline $\mathbf{D}_{4}$ & Nacimiento/primeras dos semanas & & & $\mathbf{M}_{3}$ & $40-50$ & $\mathbf{M}^{3}$ & $40-50$ \\
\hline
\end{tabular}

* Datos tomados de Sisson y Grossman (2001).

\subsubsection{Suidae}

El material que permite la estimación de la edad en Sus scrofa es muy escaso, limitándose a varias piezas deciduales. Por este motivo, se emplean las edades de erupción dental observadas por Rolett y Chiu (1994) para estimar una edad mínima (tabla IV.2.6).

\subsubsection{Cervidae}

En esta familia se han analizado los cambios morfométricos que afectan a los caninos superiores y el desgaste de las coronas de los molares inferiores y superiores de Cervus elaphus. La erupción dental se utiliza en el corzo, Capreolus capreolus.

\section{Caninos superiores}

En estas piezas se emplea el modelo de d'Errico y Vanhaeren (2002). Estos autores desarrollan una serie de ecuaciones que permiten estimar la edad de muerte métricamente, observando una serie de cambios morfológicos en función del desgaste. Sin 
embargo, previa a la determinación de la edad hay que establecer el sexo ya que estas ecuaciones son diferentes para machos y hembras.

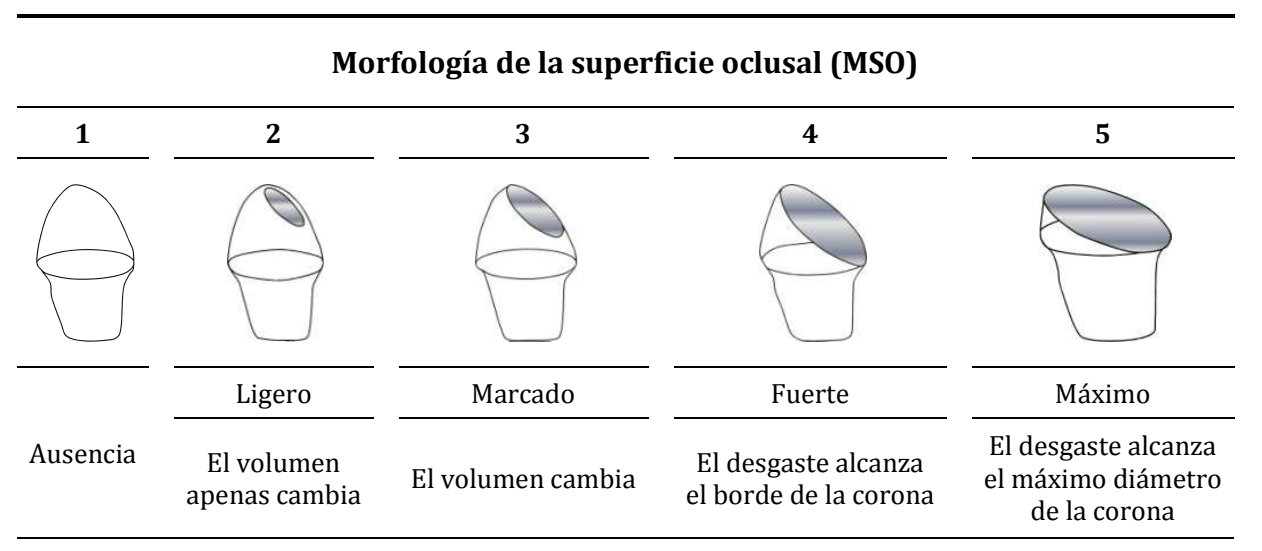

Morfología de la raíz (MR)

Casi cerrada

Morfología de la cavidad pulpar (MCP)

Visible

Morfología del lóbulo disto-lingual (MLD)

Presente

Figura IV.2.4. Cambios morfológicos y el desgaste asociado observados en los caninos superiores de C. elaphus (d’Errico y Vanhaeren, 2002).

A nivel morfológico se registran cuatro variables que incluyen cinco estados de desgaste dental (DD), tres etapas de desarrollo de la raíz (DR), el estado de calcificación de la cavidad pulpar (CP) y la desaparición por desgaste del lóbulo disto-lingual-cervical (DLC) (prominencia localizada en el borde posterior del borde lingual de la corona (Greer y Yeager, 1967) (figura IV.2.4). Estas variables se correlacionan con un valor numérico asignado según el grado de desgaste (tabla IV.2.5). 
Tabla IV.2.5

Variables morfológicas tomadas en los caninos superiores de C. elaphus

\begin{tabular}{|c|c|c|c|c|c|c|c|c|c|}
\hline \multicolumn{5}{|c|}{ Machos } & \multicolumn{5}{|c|}{ Hembras } \\
\hline MSO & MR & MCP & MLD & $\begin{array}{c}\text { Edad } \\
\text { (años) }\end{array}$ & MSO & MR & MCP & MLD & $\begin{array}{c}\text { Edad } \\
\text { (años) }\end{array}$ \\
\hline 1 & 1 & 0 & 0 & $2-4$ & 1 & 1 & 0 & 0 & $2-4$ \\
\hline 1 & 2 & 0 & 0 & $2-4$ & 1 & 2 & 0 & 0 & $3-5$ \\
\hline 1 & 3 & 0 & 0 & $5-7$ & 1 & 3 & 0 & 0 & $3-6$ \\
\hline 2 & 1 & 0 & 0 & $3-6$ & 2 & $1 / 2$ & 0 & $0 / 1$ & $4-8$ \\
\hline 2 & 2 & 0 & 0 & $4-8$ & 2 & $1 / 2$ & 0 & $0 / 1$ & $4-10$ \\
\hline 2 & 3 & 0 & 0 & $4-5$ & 2 & 3 & 1 & $0 / 1$ & $6-10$ \\
\hline 2 & 3 & 1 & $0 / 1$ & $6-7$ & 3 & 3 & 0 & $0 / 1$ & $4-13$ \\
\hline 3 & 3 & 0 & 0 & $6-11$ & 3 & 3 & 1 & $0 / 1$ & $8-19$ \\
\hline 3 & 3 & 0 & 1 & $7-14$ & 4 & 3 & $0 / 1$ & 0 & $6-14$ \\
\hline 3 & 3 & 1 & 1 & $7-14$ & 4 & 3 & 1 & 1 & $9-20$ \\
\hline 4 & 3 & 0 & 0 & $0-13$ & 5 & 3 & $0 / 1$ & $0 / 1$ & $13-20$ \\
\hline 4 & 3 & 0 & 1 & $9-13$ & & & & & \\
\hline 4 & 3 & 1 & $0 / 1$ & $10-14$ & & & & & \\
\hline 5 & 3 & 1 & $0 / 1$ & $10-16$ & & & & & \\
\hline
\end{tabular}

* MSO: morfología de la superficie oclusal. MR: morfología de la raíz. MCP: morfología de la cavidad pulpar; MDL: morfología del lóbulo disto - lingual (figura IV.2.4). Datos tomados de d'Errico y Vanhaeren (2002).

El modelo métrico requiere, como el morfológico, sexar previamente las piezas ya que las ecuaciones que se emplean están desarrolladas para cada sexo (d'Errico y Vanhaeren, 2002). Estos autores miden siete variables, localizadas tanto en las coronas como en las raíces: AC: anchura de la corona. AD: anchura del desgaste. AR: anchura de la raíz. EC: espesor de la corona. LC: longitud de la corona. LD: longitud del desgaste. LR: longitud de la raíz. Y: edad en meses (figura IV.2.3).

\section{Machos}

$$
Y=300,13+(-16,80 \mathrm{LC})+(9,18 \mathrm{LD})+(-6,99 \mathrm{LR})+(-12,74 \mathrm{AC})+(7,64 \mathrm{AR})+(-3,93 \mathrm{AD})
$$

\section{Hembras}

$$
\mathrm{Y}=222,09+(-10,83 \mathrm{LC})+\left(\frac{5,14 \mathrm{LD} \times \mathrm{AD}}{2}\right)+\left(\frac{-5,75 \mathrm{AC} \times \mathrm{EC}}{2}\right)
$$

\section{Dientes yugales}

En el caso de Cervus elaphus se emplean dos modelos métricos. La elección de este tipo de procedimientos en detrimento de los modelos morfológicos radica en que evita en muchos casos la subjetividad del investigador a la hora de interpretar los datos ya que permite un análisis no destructivo e invasivo (Levine, 1982, 1983; Hillson, 2005).

El primer modelo emplea dos ecuaciones desarrolladas por Klein et al., (1984), una aplicable a los dientes deciduales y la otra a los permanentes. En dichas ecuaciones se incluyen variables como: AGEe: edad erupción de un diente permanente. AGEpel: edad máxima del animal. AGEs: edad de caída de una pieza decidual. CH: altura de la corona del diente que queremos analizar y CHo: altura de la corona de una pieza sin desgaste. 


\section{Dentición decidual}

$$
\mathrm{AGE}=\mathrm{AGEs}-2 \mathrm{AGEs} \frac{\mathrm{CH}}{\mathrm{CHo}}+\mathrm{AGEs} \frac{\mathrm{CH}^{2}}{\mathrm{CHo}^{2}}
$$

\section{Dentición permanente}

$$
\text { AGE }=\text { AGEpel }-2(\text { AGEpel }- \text { AGEe }) \frac{\mathrm{CH}}{\mathrm{CHo}}+(\text { AGEpel }- \text { AGEe }) \frac{\mathrm{CH}^{2}}{\mathrm{CHo}^{2}}
$$

Las variables AGEe, AGEpel y AGEs se han tomado de la especie actual, estableciéndose la edad máxima (AGEpel) en 192 meses (Klein et al., 1984); y las edades de caída (AGEs) y erupción dental (AGEe) siguiendo las observaciones de Azorit et al., (2002) (tabla IV.2.6). Por otra parte, la variable $\mathrm{CHo}$, se ha tomado de la población fósil. En la Cueva de Valdegoba se ha recuperado una importante colección de piezas sin desgaste. De esta forma evitamos una parte de los errores que podrían deberse a la aplicación de datos provenientes de poblaciones actuales (tabla IV.2.7). Estas alturas (CHo) se han tomado en la cara lingual (figura IV.2.3), haciendo una media entre la del lóbulo anterior (Ha) y la del posterior (Hp) (tabla IV.2.7).

Tabla IV.2.6

\begin{tabular}{|c|c|c|c|c|c|c|c|}
\hline & S. scrofa & C. elaphus & C. capreolus & R. pyrenaica & C. pyrenaica & B. taurus & B. bonasus \\
\hline$I_{1}$ & $12-16$ & 14-15 & $5-6$ & 13-15 & 15 & $18-24$ & $22-26$ \\
\hline $\mathbf{I}_{2}$ & $18-27$ & $17-18$ & $7-9$ & $25-28$ & 30 & $24-30$ & $30-31$ \\
\hline $\mathbf{I}_{3}$ & $7-12$ & $19-25$ & $8-11$ & $36-39$ & $35-46$ & 36 & $35-40$ \\
\hline C & $7-12$ & $19-25$ & $8-12$ & $36-46$ & $48-57$ & $42-48$ & $38-44$ \\
\hline $\mathbf{P}_{2}$ & $14-17$ & $27-30$ & $12-13$ & $25-29$ & $30-33$ & $24-30$ & $27-28$ \\
\hline $\mathbf{P}_{3}$ & $14-16$ & $27-30$ & $12-13$ & $25-29$ & 25 & $18-30$ & $28-29$ \\
\hline $\mathbf{P}_{4}$ & $14-18$ & $27-30$ & $12-13$ & $25-29$ & 25 & $30-36$ & $37-40$ \\
\hline $\mathbf{M}_{1}$ & $4-6$ & 6 & $4-5$ & $2-3$ & $2-3$ & 5-6 & 6-9 \\
\hline $\mathbf{M}_{2}$ & $12-14$ & $15-16$ & $5-7$ & $9-13$ & 13 & $12-18$ & $16-18$ \\
\hline $\mathbf{M}_{3}$ & $21-33$ & $42-44$ & $12-13$ & $22-25$ & $25-30$ & $24-30$ & $27-43$ \\
\hline
\end{tabular}

Edades de erupción dental de los artiodáctilos estudiados (en meses)

* Datos tomados de: S. scrofa (Rolett y Chiu, 1994). C. elaphus (Klein et al., 1984). C. capreolus (Daujeard, 2008). R. pyrenaica (Pérez-Barbería, 1994). C. pyrenaica (Vigal y Marchordom, 1985). B. taurus (St. Clair, 2005). B. bonasus (Wegrzyn y Serwatka, 1984).

Tabla IV.2.7

\begin{tabular}{|c|c|c|c|c|c|c|c|c|c|c|c|c|c|c|}
\hline & \multicolumn{2}{|c|}{$\mathbf{D}_{4}$} & \multicolumn{2}{|c|}{$\mathbf{M}_{1}$} & \multicolumn{2}{|c|}{$\mathbf{M}_{2}$} & \multicolumn{2}{|c|}{$\mathbf{M}_{3}$} & \multicolumn{2}{|c|}{$\mathbf{M}^{1}$} & \multicolumn{2}{|c|}{$\mathbf{M}^{2}$} & \multicolumn{2}{|c|}{$\mathbf{M}^{3}$} \\
\hline & $\mathbf{n}$ & $\overline{\mathbf{x}}$ & $\mathbf{n}$ & $\overline{\mathbf{x}}$ & $\mathbf{n}$ & $\overline{\mathbf{x}}$ & $\mathbf{n}$ & $\overline{\mathbf{x}}$ & $\mathbf{n}$ & $\overline{\mathbf{x}}$ & $\mathbf{n}$ & $\overline{\mathbf{x}}$ & $\mathbf{n}$ & $\overline{\mathbf{x}}$ \\
\hline C. elaphus & 6 & 13,7 & 4 & 21,2 & & & & & 2 & 21,8 & 4 & 21,3 & 2 & 22,7 \\
\hline R. pyrenaica & 3 & 15,0 & 3 & 23,0 & 5 & 23,7 & 4 & 24,5 & 5 & 21,3 & 5 & 23,6 & 7 & 23,3 \\
\hline C. pyrenaica & 2 & 12,3 & 3 & 36,0 & 4 & 40,5 & 1 & 51,6 & & & & & & \\
\hline
\end{tabular}

Altura máxima de la corona estimada para los artiodáctilos a partir del material fósil

* Datos tomados de la Cueva de Valdegoba.

Debido a los errores que podrían generarse a la hora de incluir las ecuaciones anteriores, se desarrolla un modelo que emplea únicamente las edades de erupción y desgaste dental. Sin embargo, la gran variabilidad en las edades de erupción de alguna de las piezas impide usar este modelo en aquellas que van más allá de la erupción del $\mathrm{M}_{2} \mathrm{y}$ del $\mathrm{M}^{2}$ ya que la edad obtenida puede verse afectada en varios meses (Moran y 0' Connor, 1994). Un último paso consistiría en comparar ambos métodos para ver si los resultados 
que obtenemos a partir del modelo que proponemos podrían sustituir a las ecuaciones de Klein et al., (1984).

En el corzo, C. capreolus, debido a la ausencia de material sin desgaste y a la escasez de restos, se emplea un modelo basado en la erupción dental. Los datos provienen de las observaciones de Daujeard (2008) y aparecen en la tabla IV.2.6.

\subsubsection{Caprinae}

En esta subfamilia, tanto en el género Rupicapra como en Capra, se ha empleado, sobre los dientes yugales, el modelo métrico descrito en la familia Cervidae. Se implementan las ecuaciones de Klein et al., (1984) y posteriormente se comparan dichos resultados con el método que utiliza únicamente la erupción y el desgaste dental. La edad máxima (AGEpel) de Rupicapra pyrenaica se ha estimado en 300 meses y la de Capra pyrenaica en 216 (Klein et al., 1984). Las edades de caída y erupción dental en Rupicapra se han tomado de PérezBarbería (1994) y las de Capra de Vigal y Marchordom (1985) (tabla IV.2.6). Las alturas máximas de la corona sin desgaste ( $\mathrm{CHo}$ ) se han tomado del material de la Cueva de Valdegoba (tabla IV.2.7).

El modelo, con el que comparamos las ecuaciones de Klein et al. (1984) en Rupicapra, se ha desarrollado de la siguiente manera. En primer lugar se reúnen las mandíbulas de cada una de las especies descritas y que presenten al menos dos piezas dentales. En segundo lugar, se miden las alturas de las coronas sin desgaste. Normalmente, este dato proviene de dientes aislados. En tercer lugar, se divide dicha altura en cuatro rangos de desgaste. A continuación, ya en las mandíbulas, se compara la altura de las coronas, de las piezas que hemos medido previamente sin desgaste, con las de los dientes adyacentes, de los que conocemos la edad de erupción. De esta forma, obtenemos un rango de alturas que se encuentran entre la erupción de la pieza anterior y posterior. Por último, obtenemos el número de piezas que se encuentran en un rango en concreto.

Tabla IV.2.8

Rangos de edad estimados en cada una de las especies estudiadas

\begin{tabular}{|c|c|c|c|c|c|c|c|c|}
\hline \multicolumn{9}{|c|}{ Especie } \\
\hline & \multicolumn{2}{|c|}{ Equus caballus } & \multicolumn{2}{|c|}{ Sus scrofa } & \multicolumn{2}{|c|}{ Cervus elaphus } & \multicolumn{2}{|c|}{ Capreolus capreolus } \\
\hline & Erupción & Estimada & Erupción & Estimada & Erupción & Estimada & Erupción & Estimada \\
\hline & \multicolumn{2}{|c|}{ (meses) } & \multicolumn{2}{|c|}{ (meses) } & \multicolumn{2}{|c|}{ (meses) } & \multicolumn{2}{|c|}{ (meses) } \\
\hline \multirow[t]{2}{*}{ Infantil } & \multicolumn{2}{|c|}{$\left(M_{1}\right)$} & \multicolumn{2}{|c|}{$\left(M_{1}\right)$} & \multicolumn{2}{|c|}{$\left(M_{1}\right)$} & \multicolumn{2}{|c|}{$\left(M_{1}\right)$} \\
\hline & $10-12$ & $<11$ & $4-6$ & $<5$ & 6 & $<6$ & $4-5$ & $<4,5$ \\
\hline \multirow[t]{2}{*}{ Juvenil } & \multicolumn{2}{|c|}{$\left(M_{1}-C_{i}\right)$} & \multicolumn{2}{|c|}{$\left(\mathbf{M}_{1}-\mathbf{M}_{3}\right)$} & \multicolumn{2}{|c|}{$\left(M_{1}-M_{3}\right)$} & \multicolumn{2}{|c|}{$\left(\mathbf{M}_{1}-\mathbf{P}_{2-4}\right)$} \\
\hline & $(10-12)(48-6$ & $11-54$ & $(4-6)(21-33)$ & 5-27 & $6-(42-44)$ & $6-43$ & $(4-5)(12-13)$ & $4,5-12,5$ \\
\hline \multirow[t]{5}{*}{ Adulto } & \multicolumn{2}{|c|}{$\left(C_{i}\right)$} & \multicolumn{2}{|c|}{$\left(M_{3}\right)$} & \multicolumn{2}{|c|}{$\left(M_{3}\right)$} & \multicolumn{2}{|c|}{$\left(P_{2-4}\right)$} \\
\hline & $48-60$ & $>54$ & $21-33$ & $>33$ & $42-44$ & $>43$ & $12-13$ & $>12,5$ \\
\hline & \multicolumn{2}{|c|}{ Rupicapra pyrenaica } & \multicolumn{2}{|c|}{ Capra pyrenaica } & \multicolumn{2}{|c|}{ Bos taurus } & \multicolumn{2}{|c|}{ Bison bonasus } \\
\hline & Erupción & Estimada & Erupción & Estimada & Erupción & Estimada & Erupción & Estimada \\
\hline & \multicolumn{2}{|c|}{ (meses) } & \multicolumn{2}{|c|}{ (meses) } & \multicolumn{2}{|c|}{ (meses) } & \multicolumn{2}{|c|}{ (meses) } \\
\hline \multirow[t]{2}{*}{ Infantil } & \multicolumn{2}{|c|}{$\left(M_{1}\right)$} & \multicolumn{2}{|c|}{$\left(M_{1}\right)$} & (M & & (M & \\
\hline & $2-3$ & $<2,5$ & $2-3$ & $<2,5$ & $5-6$ & $<5,5$ & $6-9$ & $<7,5$ \\
\hline Juvenil & $\left(\mathbf{M}_{1}\right.$ & & $\left(\mathbf{M}_{1}\right.$ & & (M) & & $\left(\mathrm{M}_{1}\right.$ & \\
\hline & $(2-3)(36-46)$ & $2,5-41$ & $(2-3)(48-57)$ & $2,5-52,5$ & $(5-6)(42-48)$ & $5,5-45$ & $(6-9)(38-44)$ & $7,5-41$ \\
\hline Adulto & (C) & & (M & & (C & & (C & \\
\hline & $36-46$ & $>41$ & $48-57$ & $>52,5$ & $42-48$ & $>45$ & $38-44$ & $>41$ \\
\hline
\end{tabular}

* Se indican los dientes que determinan el comienzo y el fin del rango. La edad de erupción indica la fecha a la que emergen los dientes que hemos utilizado para el análisis; y la estimada, la edad de referencia a partir de la cual hemos establecido los rangos de edad. La edad estimada se ha establecido calculando la media del rango de erupción para de esta forma reducir los errores por exceso y defecto. 


\subsubsection{Bovinae}

En este caso, y debido a la falta de piezas dentales sin desgaste, empleamos las fechas de erupción dental para obtener una edad mínima del ejemplar. En el caso del género Bos se han utilizado los datos observados por St. Clair (2005) para Bos taurus; y para el género Bison, las fechas establecidas por Wegrzyn et al., (1984) para Bison bonasus (tabla IV.2.6).

Para facilitar la comprensión de las edades de muerte, se han establecido tres rangos de edad en función de las edades de erupción dental: infantil, juvenil y adulto. Así, un individuo infantil sería aquel que presenta únicamente la dentición decidual; el juvenil estaría representado por aquellos individuos que presentan desde el $\mathrm{M}_{1}$ erupcionado hasta el último diente permanente emergido (independientemente de cuál sea); y por último, los adultos serían aquellos que tienen su dentición permanente completamente erupcionada (tabla IV.2.8). En aquellas especies en las que el rango de erupción de las piezas permanentes sea muy amplio, se establece la media de la misma, para así, reducir el error por exceso o defecto.

\subsection{Estacionalidad}

El modelo social y el comportamiento de las diferentes especies analizadas muestra un patrón general, aunque existen muchas excepciones no sólo a nivel específico sino también en función de la distribución de las diferentes poblaciones en el territorio. El punto de partida de este estudio se encuentra en la edad de muerte, aunque este análisis no se puede llevar a cabo en todas las especies ya que en algunos casos, como en los équidos, los resultados de la edad se obtienen en años. En los artiodáctilos se ha podido determinar a partir de los resultados obtenidos con las ecuaciones de Klein et al., (1984) ya que las edades se registran en meses.

Para poder llevar a cabo este estudio y con la finalidad de obtener más información acerca de las preferencias alimenticias de los grupos que ocuparon las cavidades estudiadas, es importante conocer la biología de las especies identificadas. Entre estos datos destacan la época de partos, la madurez sexual, la época de celo, el periodo de gestación y de lactancia (tabla IV.3.1). De esta forma, podremos conocer, hipotetizar o explicar el por qué se consumen más ejemplares en unas estaciones que en otras.

Tabla IV.3.1

Biología de la reproducción de las especies estudiadas

\begin{tabular}{|c|c|c|c|c|c|c|}
\hline \multirow{2}{*}{ Especie } & \multirow{2}{*}{ Gestación } & \multirow{2}{*}{ Partos } & \multirow[t]{2}{*}{ Lactancia } & \multicolumn{2}{|c|}{$\begin{array}{c}\text { Madurez sexual } \\
\text { (meses) }\end{array}$} & \multirow[t]{2}{*}{ Celo } \\
\hline & & & & Macho & Hembra & \\
\hline S. scrofa & & Noviembre - Abril & & 12 & $10-18$ & Septiembre-Noviembre \\
\hline C. elaphus & 235 días & Mayo - Junio & 4-5 meses & $24-36$ & $12-24$ & Septiembre-Octubre \\
\hline C. capreolus & Diciembre - Mayo & Abril - Mayo & & 14 & 14 & Julio-Agosto \\
\hline R. pyrenaica & Diciembre - Abril & Mayo & 4 meses & $12-24$ & $12-48$ & Noviembre-Diciembre \\
\hline C. pyrenaica & 23-24 semanas & Abril - Mayo & & & & Noviembre-Diciembre \\
\hline
\end{tabular}

* Datos tomados de: S. scrofa (Sáez-Royuela, 1987; Hayssen et al., 1993; Rossell, 1998; Herrero, 2002; Markina et al., 2003; Fernández-Llario y Mateos-Quesada, 2005; Santos et al., 2006). C. elaphus (Hayssen et al., 1993; Stiner, 1994). C. capreolus (Braza et al., 1998; Mateos-Quesada, 1998). R. pyrenaica (Hayssen et al., 1993; Pérez-Barbería, 1994; Dalmau, 2005). C. pyrenaica (Vigal y Fandos, 1989; Fandos et al., 1992; Hayssen et al., 1993; Alados y Escós, 2003).

\subsection{Bimodalidad y dimorfismo sexual}

En muchas especies de ungulados hay partes esqueléticas que nos permiten una distinción clara entre sexos. Estas son, por ejemplo, las astas en los cérvidos (tamaño, 
forma, presencia/ausencia), la morfología de los huesos de la pelvis o también la de algunas piezas dentales como los caninos en los équidos, los suidos o también en los cérvidos. Las diferencias que en forma (dimorfismo) y tamaño (bimodalidad: distribución bimodal de medidas) presentan estas piezas hacen que sexar individuos a partir de ellas no requiera de un volumen de material importante. Sin embargo, es complicado, en ocasiones, encontrar estas piezas en los yacimientos, apareciendo, por lo contrario, materiales de difícil asignación sexual. Por ello, es necesario desarrollar un modelo que permita emplear este material para poder conocer tanto el sexo como el ratio sexual de las especies recuperadas.

En este trabajo se han empleado dos modelos aplicados a dos especies diferentes. El primero de ellos, el desarrollado de d'Errico y Vanhaeren (2002) que, además de permitir conocer la edad de muerte, también permite determinar el sexo a partir de los caninos superiores en el C. elaphus. El otro modelo se aplica a materiales que no presentan diferencias tan claras, los restos postcraneales. Sin embargo, este material encierra un problema fundamental que es la necesidad de disponer de un volumen muy importante de restos para que los resultados sean claros, por lo que únicamente ha podido ser aplicado a una especie, al rebeco R. pyrenaica.

\subsubsection{Cervus elaphus}

El ciervo de la Península Ibérica presenta un gran dimorfismo sexual (Carranza, 2011), al igual que la mayoría de las especies de cérvidos de latitudes medias. Estas diferencias se observan fundamentalmente en la presencia y/o ausencia de astas y en el peso "in vivo" del animal (Carranza, 2011). Asimismo, se ha observado una importante influencia de la latitud en el tamaño de esta especie, tanto en Europa como en la Península Ibérica. Así, los individuos que habitan en el norte, en bosques templados, tienden a ser más pesados y a presentar unas astas de mayores dimensiones que los ejemplares más meridionales, que habitan en un bosque mediterráneo. Estas diferencias son más marcadas en los machos, por lo que el dimorfismo sexual es más acusado en las poblaciones del norte de la península. Se observa, por lo tanto, una importante influencia del ambiente en las dimensiones corporales y en el tamaño de las astas, algo también relacionado con la densidad poblacional (Azorit et al., 2002, 2003; Fierro et al., 2002; Carranza, 2011). Este dimorfismo sexual influye notablemente tanto en la ecología como en el comportamiento social de esta especie (Carranza, 2011).

El análisis del dimorfismo y de la bimodalidad en el registro arqueológico de esta especie ha sido llevado a cabo por varios autores. Un estudio detallado fue realizado por Mariezkurrena y Altuna (1983). Estos autores aplicaron, a una muestra arqueológica, un test de apreciación de la diferencia de las medias independientes, llegando a la conclusión de que los metacarpos de los machos son mucho más robustos que los de las hembras debido al peso de las astas. Asimismo, recalcan que dicho método sólo puede aplicarse a grandes registros. Otros trabajos que emplean material postcraneal son los de Jéquier (1963) y Lemppeanau (1964). Jéquier (1963) utiliza el astrágalo, uno de los huesos más abundantes del registro, para intentar sexar los restos de diversos yacimientos. Sin embargo, los resultados obtenidos no suelen ser satisfactorios ya que no se pueden diferenciar bien aquellos que pertenecen a individuos jóvenes y adultos. También, utilizó piezas más dimórficas como el atlas, el axis o la pelvis, esta última también estudiada por Lemppeanau (1964).

\section{Caninos superiores}

En este trabajo empleamos los caninos superiores debido al escaso material postcraneal recuperado. Determinar el sexo a partir de estas piezas es relativamente sencillo ya que son morfométricamente muy diferentes entre machos y hembras y por ello seguimos el modelo de d'Errico y Vanhaeren (2002). 
En vista bucal y lingual, los caninos de los machos son más anchos que los de las hembras. La corona tiene una forma globular en los machos jóvenes, tendiendo a hacerse más triangular en los ejemplares adultos. Por lo contrario, las coronas de las hembras jóvenes son apuntadas, volviéndose más o menos rectangulares en los individuos de más edad. Además, presentan una protuberancia disto-lingual en la base de la corona que no tienen los machos. Las raíces de los caninos, en los machos, tienen forma cuadrada o trapezoidal mientras que las de las hembras tienen forma rectangular o en "V".

Asimismo, estas piezas presentan diferencias en cuanto a su tamaño, encontrándose, fundamentalmente, en la anchura (AR) y en el espesor de la raíz (ER) (d'Errico y Vanhaeren, 2002) (figura IV.2.3). Normalmente, la anchura es siempre más del doble del espesor en los machos y menor en las hembras.

\subsubsection{Rupicapra pyrenaica}

Los caprinos son un recurso fundamental en la alimentación de los homininos del Paleolítico Medio y Superior. Los criterios que se han empleado, tradicionalmente, para sexar sus restos se basan en el análisis de los núcleos óseos y de la pelvis así como de la primera vértebra cervical y la parte trasera del cráneo (Boessneck, 1969; Prummel \& Frisch, 1986; Fernández y Monchot, 2007). Sin embargo, la ausencia de estos restos en el registro ha hecho que en los últimos años hayan aparecido una gran cantidad de modelos estadísticos que permiten, con bastante exactitud, sexar a los caprinos a partir del material postcraneal.

El dimorfismo sexual en el sarrio es menos acusado que en otros ungulados poligínicos (García-González y Barandalla, 2002) por lo que es necesario, en muchas ocasiones, la combinación de caracteres para poder diferenciar los sexos (Ponti, 1992). Los datos actuales se centran principalmente en el aspecto externo del animal. Así, los machos, por ejemplo, presentan mayor masa corporal y un cuello más ancho. Sus cuernos tienen un perímetro basal más grande, son más ganchudos y se encuentran poco separados en la base del cráneo, aunque presentan una longitud más o menos similar a los de las hembras. El pelaje de los machos en invierno es más contrastado, sobre todo en la época de celo (Pérez-Barbería y Pérez-Fernández, 2009). Las hembras, por otra parte, presentan una masa corporal menor, un hocico más afilado y más largo, un cuello más largo que ancho (Pflieger, 1982), y unos cuernos más separados en la base del cráneo, con un perímetro basal menor y menos ganchudos. La efectividad de estos métodos depende de la edad del ejemplar y de la época del año.

Los individuos jóvenes tienen poco marcados estos caracteres y el pelaje del cuello, diferente en invierno y verano, les hace aparentar diferentes dimensiones. Si tenemos en cuenta la longitud del cuerpo y el peso, existen pocas diferencias entre machos y hembras con un 30\% favorable a los machos en el caso del peso (Pérez-Barbería et al., 2010). Sin embargo, estas diferencias presentan excepciones y, aún más, si tenemos en cuenta las diferentes subespecies (García-González y Barandalla, 2002). Así, por ejemplo, variedad cantábrica es la subespecie que presenta mayor dimorfismo en los cuernos (GarcíaGonzález y Barandalla, 2002; Pérez-Barbería et al., 2010).

Debido a la escasez de material actual y paleontológico, y por el elevado grado de solapamiento que existe entre los sexos, esta especie no ha sido utilizada en estudios de dimorfismo y bimodalidad sexual, siendo el único el realizado por Arceredillo et al., (2011). El método que se presenta está dividido en dos partes. En la primera seleccionamos una población de referencia sobre la que tomar las medidas. El material moderno pertenece en su totalidad a la subespecie Rupicapra pyrenaica parva. La muestra incluye únicamente individuos adultos con el tercer molar erupcionado (22-25 meses). Esto permite tener controlada la edad de los diferentes ejemplares lo que hace que el estudio sea más exacto. Además, el sexo de cada uno de los individuos analizados de la población actual es conocido. 


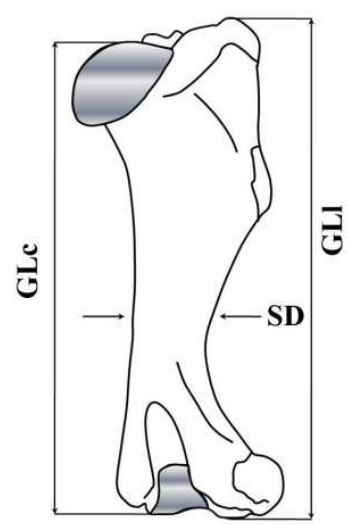

1.a
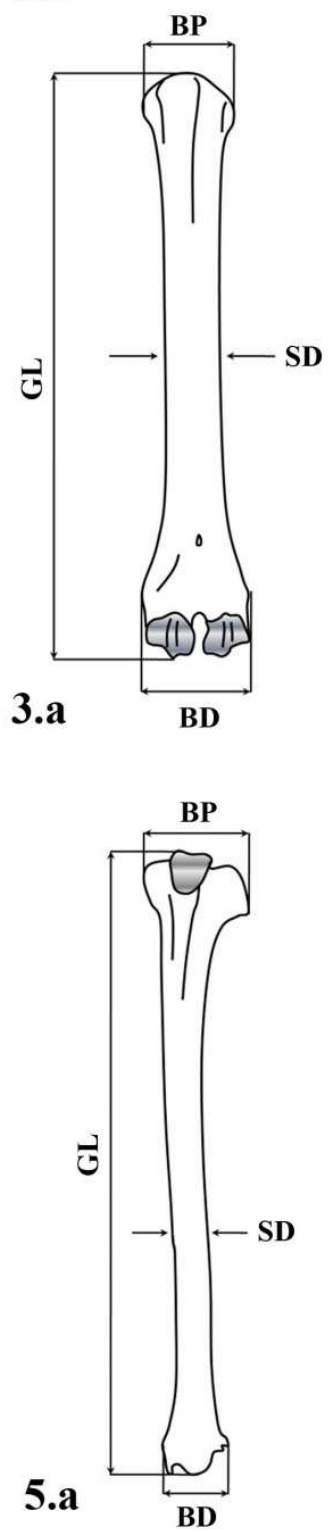

ิิ

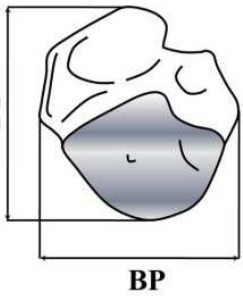

1.b

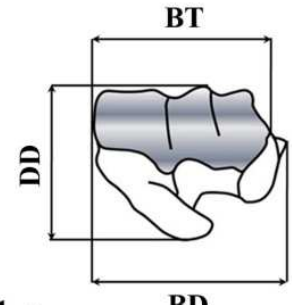

1.c

BD

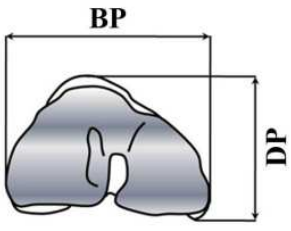

3.b

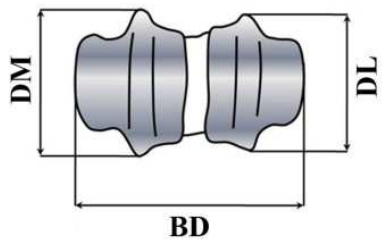

3.c

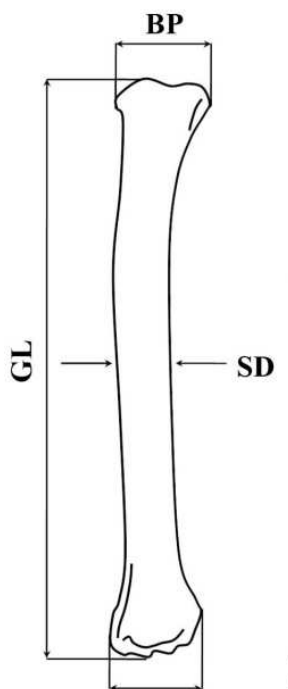

2.b

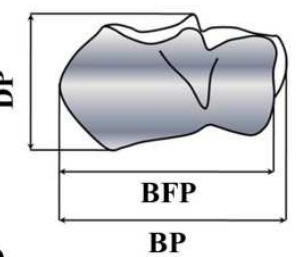

ลิ

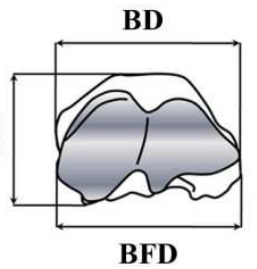

2.c

2.a

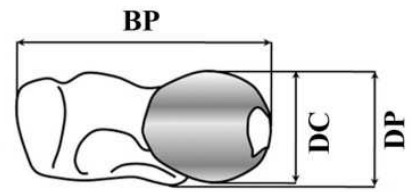

4.b

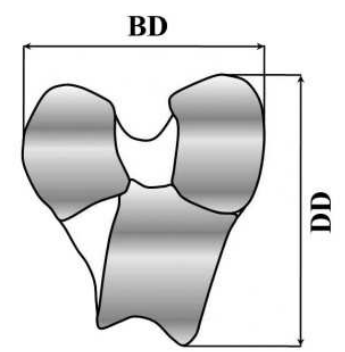

4.c

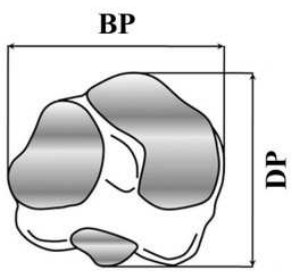

6.

5.b

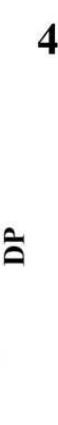

4.a

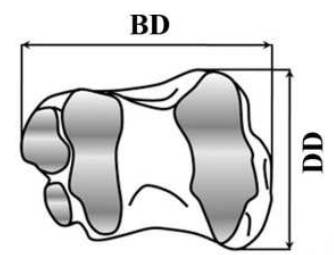

5.c

Figura IV.4.1. Medidas tomadas en los huesos postcraneales de los artiodáctilos para estimar el dimorfismo sexual. 1) Húmero. 2) Radio. 3) Metacarpo. 4) Fémur. 5) Tibia. 6) Metatarso. La variable SDD ha sido tomada en el mismo punto que la SD. Las medidas GL, SD, BD, DM y DL del metatarso son similares a las del metacarpo. 
Se han tomado una serie de medidas siguiendo los criterios de Von den Driesch (1976), todas en milímetros. Dichas variables aparecen en la figura IV.4.1, y son las siguientes:

Húmero (figura IV.4.1: 1.a, 1.b, 1.c): BD: anchura de la epífisis distal. BP: anchura de la epífisis proximal. BT: anchura máxima de la tróclea. DD: profundidad de la epífisis distal. DP: profundidad de la epífisis proximal. GLc: longitud desde la cabeza del húmero. GLl: longitud máxima del extremo lateral. SD: anchura mínima de la diáfisis. SDD: profundidad mínima de la diáfisis.

Radio (figura IV.4.1: 2.a, 2.b, 2.c): BD: anchura de la epífisis distal. BFd: anchura de la cara articular distal. BFp: anchura de la cara articular proximal. BP: anchura de la epífisis proximal. DD: profundidad de la epífisis distal. DP: profundidad de la epífisis proximal. GL: longitud máxima del hueso. SD: anchura mínima de la diáfisis.

Metacarpo III + IV (figura IV.4.1: 3.a, 3.b, 3.c): BD: anchura máxima de la epífisis distal. BP: anchura máxima epífisis proximal. DD: profundidad de la epífisis distal. DM: profundidad del cóndilo medial. DL: profundidad del cóndilo lateral. DP: profundidad de la epífisis proximal. GL: longitud máxima del hueso. SD: anchura mínima de la diáfisis.

Fémur (figura IV.4.1: 4.a, 4.b, 4.c): BD: anchura máxima de la epífisis distal. BP: anchura máxima de la epífisis proximal. DC: profundidad de la cabeza del fémur. DD: profundidad de la epífisis distal. DP: profundidad de la epífisis proximal. GL: longitud máxima del hueso. GLc: longitud desde la cabeza del fémur. SD: anchura mínima de la diáfisis.

Tibia (figura IV.4.1: 5.a, 5.b, 5.c): BD: anchura máxima de la epífisis distal. BP: anchura máxima de la epífisis proximal. DD: profundidad de la epífisis distal. DP: profundidad de la epífisis proximal. GL: longitud máxima del hueso. SD: anchura mínima de la diáfisis.

Metatarso III + IV (figura IV.4.1: 6): BD: anchura máxima de la epífisis distal. BP: anchura máxima epífisis proximal. DD: profundidad de la epífisis distal. DP: profundidad de la epífisis proximal. DM: profundidad del cóndilo medial. DL: profundidad del cóndilo lateral. GL: longitud máxima del hueso. SD: anchura mínima de la diáfisis.

Una vez seleccionados los huesos, y con el fin de conocer qué variables presentan diferencias significativas entre los sexos, se aplica el Test de Wilcoxon/Mann-Whitney, una prueba no paramétrica que permite contrastar la hipótesis de igualdad de las medianas de dos poblaciones. Se ha utilizado dicho modelo en lugar de la test de Student debido a que no se supone normalidad de la muestra. Posteriormente, se aplican estudios multivariantes a aquellas variables que han proporcionado los mejores resultados en el análisis univariante. El empleo de muchas variables supone manejar una gran cantidad de datos. La síntesis de estos datos es lo que hacen los métodos multivariantes. Dichos métodos pueden dividirse en dos grupos. En el primero se incluirían aquellos que reducen las variables empleadas a una o unas pocas, permitiendo comparar e interpretar mejor estos datos (análisis de componentes principales). Un segundo conjunto sería aquel que reúne nuestros datos en grupos o clusters, éstas serían las técnicas de clasificación (análisis cluster, análisis discriminante). Estos modelos provienen de diferentes estudios empleados tradicionalmente sobre caprinos fósiles (Altuna, 1978; Mariezkurrena y Altuna, 1983; Monchot, 1999; Fernández y Monchot, 2007; Van Asperen, 2010). Por último, el método, que proporcione mejores resultados en la muestra moderna, se aplica a la muestra de rebecos fósiles de la Cueva de Valdegoba.

Los análisis estadísticos empleados en este estudio son los siguientes:

\section{Análisis de componentes principales}

El análisis de componentes principales (ACP), desarrollado por Pearson en 1901, es un método muy empleado en estadística, cuyo objetivo es reducir la dimensionalidad de un 
conjunto original de datos. Para este propósito, describe la variación producida por la observación de $p$ variables aleatorias, transformándolas en un conjunto reducido de variables (componentes principales), siendo cada de ellas una la combinación lineal de las variables originales (Rencher, 2002). Estas variables (CP) son obtenidas en orden de importancia, de tal forma que la primera explica la mayor parte de la variación de las variables originales; la segunda expondría la mayor parte de la variación no explicada por la primera componente. El objetivo de este método es ver si las dos o tres primeras variables explican la mayor parte de la variación producida por las $p$ variables originales, reduciendo, de esta forma, la dimensionalidad de los datos y evitando la pérdida de información relevante (García-Pérez, 2008b).

En este trabajo se consideran dos técnicas diferentes: el ACP clásico y el ACP robusto. Mientras que el clásico se basa en la matriz de covarianza; el robusto usa una matriz de covarianza robusta, la cual hace que los resultados sean menos sensibles a las observaciones extremas o "outliers". Finalmente, en estos dos análisis, los valores que se han perdido han sido sustituidos por las medias específicas del sexo.

\section{Análisis cluster}

El análisis cluster (AC) es una metodología empleada para clasificar datos (Kaufman y Rousseeuw, 1990), agrupando $n$ objetos en $g$ grupos mediante una medida de la distancia existente entre las observaciones y un algoritmo de clasificación (Rodríguez, 1997), de tal forma que los datos de estos grupos sean lo más similares entre sí y los grupos lo más diferentes posible unos de otros.

En este estudio, se tienen en cuenta dos técnicas diferentes: los métodos aglomerativos jerárquicos (Agglomerative Hierarchical methods) (MAJ) y los métodos de división óptima (Optimal Paritioning Methods) (MPO).

Con los métodos aglomerativos jerárquicos, cada individuo, que empieza como una variable aislada, termina agrupándose con los individuos más cercanos, formando clusters que sucesivamente se combinan hasta que se consigue un gran cluster que representa todo el conjunto de datos. El resultado es un dendograma, que permite ver el cluster final de una forma clara. En este estudio hemos considerado válidos aquellos dendogramas en los que la primera división consiste en dos rangos que incluyen al menos tres individuos. Para aplicar dichos métodos, hay que tener en cuenta qué distancia matemática va a ser empleada para, posteriormente, aplicar el proceso aglomerativo. En este estudio se utiliza la distancia Euclidea:

$$
\mu=\left(x_{u 1} ; x_{u 2}, \ldots, x_{u p}\right) \text { у } w=\left(x_{w 1}, x_{w 2}, \ldots, x_{w p}\right)
$$

y que se expresa de la siguiente forma:

$$
\sum_{i=1}^{p}\left(x_{u i}-x_{w i}\right)^{2}
$$

En el proceso aglomerativo se han utilizado tres técnicas: "complete", "average" y "ward". La elección del método "complete" se debe a que es el más utilizado. Esta técnica, conocida también como la del "vecino más lejano", indica que los clusters $A$ y $B$ están unidos si la distancia entre ellos es:

$$
\max _{u \in A, w \in B}\{d u w\}
$$

donde $d_{u w}$ es la distancia entre los individuos de $A$ y $B$. En el método "average" la distancia entre los clusters es: 


$$
\delta_{A B}=\frac{1}{n_{A} n_{B}} \sum_{u \in A} \sum_{u \in B} d_{u w}
$$

siendo $n_{a}$ y $n_{b}$, respectivamente, el número de individuos de los clusters $A$ y $B$. Finalmente, con el método "Ward" los grupos se crean siguiendo un proceso iterativo: si en un paso se tienen $d$ clusters, siendo la suma de los cuadrados dentro del k-th cluster:

$$
k=1, \ldots, d, \sum_{i=1}^{n_{k}}\left(x_{i k}-\bar{x}_{k}\right)^{2}
$$

en el siguiente paso es elegida la unión de clusters para la que la suma de los cuadrados dentro del cluster sea la mínima.

En lo que atañe al método de división (partitioning method), el proceso consiste en dividir el conjunto de datos original en $c$ grupos o clusters. En este trabajo, se utiliza el algoritmo k-medias, un método iterativo cuyo objetivo es el reparto de $n$ observaciones en $k$ clusters y cada observación en un cluster con medias más cercanas (Kaufman y Rousseeuw, 1990). En otras palabras, este método intenta minimizar la suma de los cuadrados desde el centro de un cluster por lo que los individuos se van moviendo de un cluster a otro hasta que se obtiene el resultado óptimo.

En este estudio, se fuerza el algoritmo para considerar $\mathrm{k}=2$ clusters (los machos $\mathrm{y}$ hembras), considerando dos técnicas: k-medias clásico, cuando los centros del cluster son las medias; y el k-medias robusto: cuando los centros del cluster son las medianas. Hay que ser conscientes de que el programa, normalmente, asigna al azar los centros de los dos clusters, a menos que se los proporcionemos. Esto podría provocar problemas en los resultados, sobre todo cuando el programa se utiliza repetidamente. Sin embargo esto es una excepción a la norma. Como propusieron (Hammer y Harper, 2006) se ha repetido el método varias veces con el fin de saber si había alguna contradicción en los resultados. Sin embargo, otros autores sugieren proporcionar estos centros desarrollando un análisis aglomerativo hierático con medias conjuntas (Venables y Ripley, 2002).

\section{Análisis de mixturas (mixture analysis)}

Este método, desarrollado por Pearson en 1894, se basa en la asunción de que la muestra proviene de la mezcla de $c$ posibles grupos. Así, se asume que las observaciones proceden de la mezcla de $c$ distribuciones.

$$
P_{1} f_{1}+\cdots+p_{c} f_{c}
$$

En este caso se considera que $\mathrm{c}=2$, asumiendo que tanto machos como hembras estén representados en la muestra, aunque este método puede ser utilizado para discriminar entre un mayor número de grupos. Pearson consideró una mezcla de dos distribuciones normales:

$$
p_{1} \frac{1}{\sigma 1 \sqrt{2 \pi}} e^{-\frac{1}{\sigma_{1}^{2}}(x-\mu 1)^{2}}+\left(1-p_{1}\right) \frac{1}{\sigma_{2} \sqrt{2 \pi}} e^{-\frac{1}{\sigma_{2}^{2}}\left(x-\mu_{2}\right)^{2}}
$$

y usó el método de los momentos, desarrollado por él mismo, para estimar cinco parámetros del modelo, y no el método más útil de la máxima semejanza (method of máximum likelihood) desarrollado por R. A. Fisher. Hoy en día, este último es el método más empleado en el análisis de mixturas, el cual es aplicado con el algoritmo de máxima expectación (ME) (Dempster et al., 1977), el cual será el más aplicado en este estudio. El método ME intenta encontrar la máxima semejanza o la máxima estimada a posteriori. 


\section{Resultados}




\subsection{Stephanorhinus hemitoechus}

Orden Perissodactyla Owen, 1848

Familia Rhinocerotidae Gray, 1821

Subfamilia Rhinocerotinae Gray, 1821

Género Stephanorhinus Kretzoi, 1942

Especie Stephanorhinus hemitoechus (Falconer, 1868)

\subsubsection{Generalidades}

Los rinocerontes aparecen en Europa al principio del Oligoceno, hace unos 33 millones de años, asignándose sus fósiles, en un primer momento, al género Rhinoceros, posteriormente a Dicerohinus y por último a Stephanorhinus, cuyos primeros representantes aparecen en el Mioceno Tardío. Este género junto con Coelodonta son los dos rinocerontes presentes en Europa durante el Pleistoceno (Van der Made, 2010). Ambos son morfológicamente muy uniformes, lo que hace que su asignación pueda resultar en ocasiones complicada (Van der Made, 2005).

El primer género, Stephanorhinus, aparece representado en el Pleistoceno por cuatro especies: S. etruscus, $S$. hundsheimensis, $S$. kirchbergensis y $S$. hemitoechus. Sus diferencias, tanto morfológicas como métricas, presentan un gran solapamiento, lo que ha hecho que a lo largo de los últimos años establecer unas relaciones de parentesco sea complicado.

Los dos primeros taxones, $S$. etruscus y $S$. hundsheimensis, fueron asignados en primer lugar (Loose, 1975) a la especie Dicerorhinus etruscus, entrando en la línea D. etruscus etruscus - D. etruscus brachycephalus de Guérin (1980). Más tarde, Fortelius et al., 1993 les incluye a ambos en el género Stephanorhinus y asigna la mayor parte del material de D. $e$. brachycephalus a S. hundsheimensis. Por otra parte, S. etruscus, de la que tiene se tiene clara su aparición, no se sabe cuando pudo desaparecer debido a la dificultad a la hora de identificar parte de sus restos y por la dudosa datación de alguno de los yacimientos en los que aparece (Van der Made, 2010). Por esta razón, la línea S. etruscus - S. hundsheimensis no está del todo clara ya que $S$. hundsheimensis presenta, en ocasiones, caracteres más antiguos que $S$. etruscus (Van der Made, 2001; 2010; Van der Made et al., 2004), aunque sí hay autores que apoyan una relación antepasado - descendiente como Cigala - Fulgosi (1976), Fortelius et al., (1993) o Mazza et al., (1993).

Algo similar ocurre con S. hemitoechus. Autores como Guérin (1980) consideran esta especie descendiente de $S$. etruscus y no de $S$. hundsheimensis, aunque la mayor parte de los especialistas indican una clara relación entre $S$. hundsheimensis y $S$. hemitoechus, lo que no implica una relación directa de parentesco (Van der Made, 2010). Loose (1975), Guérin (1980, 1982a y b) y Kahle (2001) consideran que $S$. hemitoechus reemplaza a $S$. hundsheimensis en el Pleistoceno Medio, aunque la presencia de $S$. hundsheimensis en el Pleistoceno Medio final italiano sugiere un fuerte solapamiento (Fortelius et al., 1993; Sardella et al., 1998). La entrada de S. hemitoechus en Europa no está muy clara, indicando Sardella et al., (1998) una posible llegada en el Pleistoceno Inferior - Medio y Von Koenigswald y Henrich (1999) en el Pleistoceno Inferior.

Por otra parte, autores como Guérin (1980) sugieren que S. kirchbergensis entra en Europa procedente de Asia alrededor de los 0,6 y $1 \mathrm{ma}$, partiendo de los restos de Tegelen, Mosbach y Solilhac. Otros autores asignan el material de Tegelen a $S$. etruscus (Loose, 1975; Van Kolfscoten, 1989) y Van der Made (2010) indica que estos restos se asemejan métricamente a $S$. hundsheimensis. La fauna recuperada en Solilhac sitúa los restos en torno a los $600 \mathrm{ka}$, mientras que Sardella et al., (1998) sugieren una entrada en Italia poco antes del Pleistoceno Medio temprano. Otra opinión la manifiesta Azzaroli (1962), que asigna buena parte del material italiano a S. hemitoechus (Van der Made, 2010). A pesar de esto, parece ser que la entrada de este taxón se encontraría en torno a los OIS 11- 12. 
Los comentarios expuestos anteriormente reflejan la dificultad a la hora de establecer caracteres morfológicos diagnósticos, relaciones filogenéticas entre taxones, y sus rangos cronológicos. Por ello, consideramos necesario una revisión de los rinocerontes recuperados en los yacimientos del Pleistoceno Superior de la submeseta norte.

\subsubsection{Material}

El material proviene de varios yacimientos y es el siguiente:

Cueva de Valdegoba: 14 restos. Dentición (13): $1 \mathrm{D}_{2}, 1 \mathrm{D}_{3}, 1 \mathrm{D}_{4}, 1 \mathrm{D}^{1}, 2 \mathrm{D}^{2}, 1 \mathrm{D}^{3}, 1 \mathrm{D}^{4}, 1 \mathrm{P}_{3-4}$, $1 \mathrm{P}^{3-4}, 1 \mathrm{M}^{1-2}$, y $2 \mathrm{M}^{3}$. Postcraneal (1): astrágalo.

Cueva Millán: 1 maxilar: serie $\mathrm{P}^{3}-\mathrm{M}^{3}$.

Cueva del Búho: 7 restos. Dentición: dos fragmentos dentarios, 1D ${ }^{3} 1 \mathrm{P}_{2}$ y 3 fragmentos mandibulares: 1 serie $P_{2}-M_{2}$, serie $P_{3}-M_{1}$ (el cuarto premolar y el molar sólo presentan las raíces), serie $\mathrm{P}_{3}-\mathrm{P}_{4}$ (en el cuatro premolar sólo se conservan las raíces).

Peña Mudá: 3 piezas: $1 \mathrm{P}^{4}, 1 \mathrm{M}^{2}$ y $1 \mathrm{M}^{3}$.

\subsubsection{Descripción y comparación}

Las descripciones que se presentan a continuación corresponden a las piezas identificadas en los yacimientos de la Cueva de Valdegoba, Cueva Millán, la Cueva del Búho y la Peña de Mudá.

Molares deciduales inferiores (lámina V.1.1: 4) (tabla V.1.1): son dientes alargados con las coronas bajas y dos raíces, una mesial y otra distal.

$\mathbf{D}_{2}$ : esta pieza tiene el lóbulo distal más grande que el mesial. Sus cúspides principales, el protocónido y el metacónido, se encuentran a la misma altura. El paracónido y el parastílido están separados. Presenta un surco bucal, entre el protocónido y el hipocónido, muy acentuado. El valle posterior tiene forma en "V" cerrada. Carece de cíngulos mesial, lingual y vestibular, presentando, sin embargo, uno distal, algo poco frecuente en $S$. kirchbergensis (Lacombat, 2006). El sinclinal vestibular está abierto y es poco profundo.

$\mathbf{D}_{3}$ : el paralófido presenta una bifurcación en su zona lingual, lo que le diferencia del $\mathrm{D}_{4}$. El valle anterior y el posterior, en vista lingual, tienen forma de "V". Presenta cíngulos en las caras mesial y distal, algo que no suele observarse en $S$. etruscus, $S$. hundsheimensis y $S$. kirchbergensis (Lacombat, 2006). El sinclinal vestibular es poco profundo.

$\mathbf{D}_{4}$ : este diente se diferencia del tercer decidual inferior por presentar un metáconido y una prefosa más abiertas y la cara del hipolófido recta. Además, el $\mathrm{D}_{3}$ tiene también un parastilido marcado. Muestra un pequeño reborde en el extremo lingual de la postfoseta y unos valles, anterior y posterior, en forma de "V" algo que le diferencia de $S$. hundsheimensis y $S$. kirchbergensis, aunque sí que se ha registrado en $S$. etruscus (Lacombat, 2006). Presenta un cíngulo mesial poco desarrollado y uno distal más marcado lo que suele ocurrir en $S$. hundsheimensis, pero no en $S$. etruscus y S. kichbergensis. Carece de cíngulos vestibular y lingual. El sinclinal vestibular es recto y profundo.

Molares deciduales superiores (lámina V.1.1: 7 y 8 ) (tabla V.1.1): son dientes cuadrangulares, con las coronas bajas y con menos cemento que los permanentes. El 
pliegue del paracono está muy marcado y muestran un desarrollo desigual de la crista y el gancho. Son trirradiculados, con una raíz meso-bucal, una meso-distal y otra lingual.

D1: este diente se estrecha fuertemente hacia el extremo mesial. El protolofo se encuentra más marcado que el metalofo y tiene una crista muy desarrollada. Presenta un cíngulo en la cara anterior.

D2: tiene una postfoseta desarrollada lo que hace que el metalofo sea estrecho. Presenta una foseta media abierta y dividida en dos por un tabique de esmalte, algo que no suele ocurrir en S. etruscus, S. hundsheimensis y S. kirchbergensis (Lacombat, 2006). El pliegue del paracono está bien desarrollado y se encuentra proyectado mesialmente, mientras que el metastilo es corto y redondeado. El gancho se encuentra muy desarrollado y, junto a él, tiene varios pliegues secundarios. Carece de crista y antigancho, pero tiene un cíngulo en la cara mesial. Carece de constricción protoconal.

D³: el protolofo está más desarrollado que el metalofo. Tiene unos estilos poco marcados y una foseta media cerrada. El gancho está bien desarrollado y carece de crista, carácter éste muy variable en S. etruscus y S. hundsheimensis (Lacombat, 2006). No tiene antigancho y el cíngulo mesial está bien marcado.

Tabla V.1.1

Medidas tomadas en los dientes de S. hemitoechus

\begin{tabular}{|c|c|c|c|c|c|c|c|c|c|c|c|}
\hline & & & Lado & DAPo & DAP & DAPb & DTa & DTp & $\mathbf{H}$ & $\mathrm{Hci}$ & Hli \\
\hline $\mathbf{D}_{2}$ & Valdegoba & Vb-sp-3201 & $\mathrm{d}$ & & 31,8 & 29,5 & 16,0 & 17,6 & 17,2 & 13,0 & \\
\hline $\mathbf{D}_{3}$ & Valdegoba & Vb-sp-242 & $\mathrm{i}$ & & 40,2 & 39,6 & 19,3 & 21,2 & 21,1 & 16,9 & \\
\hline $\mathbf{D}_{4}$ & Valdegoba & Vb-sp-3200 & $d$ & & 38,5 & 37,4 & 21,0 & 21,5 & 20,0 & 11,2 & \\
\hline $\mathrm{D}^{2}$ & Valdegoba & Vb-sp-238 & d & & & & & 31,9 & & & \\
\hline $\mathrm{D}^{3}$ & Búho & $6495 \mathrm{Q}$ & d & & & & & 38,7 & 32,0 & & 5,0 \\
\hline$D^{3}$ & Valdegoba & Vb-sp-234 & $\mathrm{i}$ & & 37,2 & & 40,8 & 39,8 & & & \\
\hline$D^{4}$ & Valdegoba & Vb-sp-237 & d & & & 44,9 & 49,9 & 47,1 & & & \\
\hline $\mathbf{P}_{2}$ & Búho & $6496 Q$ & $\mathrm{i}$ & 27,7 & 29,3 & 26,4 & 14,5 & 17,2 & 31,8 & & \\
\hline $\mathbf{P}_{2}$ & Búho & $6514 Q$ & $d$ & & 26,1 & 26,6 & 15,8 & 19,6 & 17,7 & & \\
\hline $\mathbf{P}_{3}$ & Búho & $6511 Q$ & i & 35,1 & 34,5 & 30,1 & 20,1 & 23,8 & 24,6 & & \\
\hline $\mathbf{P}_{3}$ & Búho & $6514 Q$ & d & & & 30,5 & 20,3 & 23,3 & 20,8 & & \\
\hline $\mathbf{P}_{3}$ & Búho & $6512 Q$ & $\mathrm{i}$ & 39,4 & 39,6 & 36,5 & 24,1 & 26,0 & 35,6 & & \\
\hline $\mathbf{P}_{4}$ & Búho & $6514 Q$ & $\mathrm{~d}$ & 41,0 & 40,0 & 35,0 & 24,0 & 26,9 & 25,9 & & \\
\hline $\mathbf{P}_{3-4}$ & Valdegoba & Vb-sp-239 & $\mathrm{i}$ & & & & 20,6 & 22,1 & $>25,6$ & & \\
\hline $\mathbf{M}_{1}$ & Búho & $6514 Q$ & $d$ & 46,8 & 46,8 & 37,7 & 28,0 & 28,9 & 24,8 & & \\
\hline $\mathbf{M}_{2}$ & Búho & $6514 Q$ & $\mathrm{~d}$ & 54,3 & 54,3 & 46,0 & 28,1 & 29,5 & 25,4 & & \\
\hline $\mathbf{P}^{3}$ & Millán & CM.86.1A.9F & $\mathrm{i}$ & $(41,9)$ & $(43,9)$ & & & 47,9 & $(40,7)$ & $(14,2)$ & $(24,5)$ \\
\hline $\mathbf{P}^{4}$ & Mudá & $540 \mathrm{Q}$ & $d$ & 40,6 & 40,7 & 38,0 & 54,4 & 48,4 & 33,1 & $(16,8)$ & $(30,3)$ \\
\hline $\mathbf{P}^{4}$ & Millán & CM.86.1A.9F & $\mathrm{i}$ & $(44,4)$ & $(45,8)$ & $(44,4)$ & 53,9 & 52,3 & $(45,5)$ & $(10,2)$ & $(24,5)$ \\
\hline $\mathbf{M}^{1}$ & Millán & CM.86.1A.9F & $\mathrm{i}$ & $(58,8)$ & $(57,1)$ & $(48,2)$ & 62,5 & 57,0 & $(40,4)$ & & $(17,6)$ \\
\hline $\mathbf{M}^{2}$ & Millán & CM.86.1A.9F & i & $(64,6)$ & $(65,0)$ & $(62,8)$ & 61,5 & 54,6 & $(53,2)$ & & $(18,7)$ \\
\hline $\mathbf{M}^{2}$ & Mudá & $539 Q$ & i & 57,5 & 58,5 & 43,0 & 65,3 & 56,2 & 44,8 & 7,0 & 10,7 \\
\hline $\mathbf{M}^{1-2}$ & Valdegoba & Vb-sp-240 & d & 58,0 & & & 63,9 & $<70,7$ & $<58,5$ & & \\
\hline $\mathbf{M}^{3}$ & Millán & CM.86.1A.9F & i & $(57,0)$ & $(57,0)$ & $(43,8)$ & 47,4 & & $(59,2)$ & & \\
\hline $\mathbf{M}^{3}$ & Mudá & $542 Q$ & $\mathrm{i}$ & 45,5 & 63,3 & 62,5 & 55,8 & 51,5 & 45,9 & & 13,8 \\
\hline $\mathbf{M}^{3}$ & Valdegoba & Vb-sp-233 & d & 52,1 & & 64,6 & 58,1 & & & & \\
\hline $\mathbf{M}^{3}$ & Valdegoba & Vb-sp-235 & d & & & 52,9 & 49,4 & & & & \\
\hline
\end{tabular}

* La repetición de las siglas 6514Q y CM.86.1A.9F de la Peña de Mudá y Cueva Millán se debe a que se ha asignado un único número de registro a los maxilares en los que están incluidos dichas piezas. La nomenclatura entre paréntesis se debe a que dichas medidas son aproximadas. La notación < indica que al presentar cemento en la corona no se ha podido tomar la medida directamente en el esmalte.

D4: tiene el protolofo más desarrollado que el metalofo. Muestra una pequeña prefoseta en el protolofo. En la foseta media, cercana a la zona de apertura del extremo lingual, aparece una especie de cono secundario. La postfoseta está bien desarrollada y, en su cara 
posterior, hay una especie de cúspide. El parastilo es redondeado y está proyectado mesialmente, mientras que el metastilo es estrecho y se encuentra menos marcado. El gancho está bien desarrollado y la crista está poco marcada lo que difiere en $S$. hundsheimensis (Lacombat, 2006). Carece de antigancho y de pliegues secundarios. Tiene un cíngulo en la cara mesial.

D3-4: dentro de esta categoría se incluye uno de los dientes recuperados en la Cueva del Búho. Su morfología es cuadrangular y presenta una crista y un gancho unidos. La constricción protoconal está muy desarrollada y el parastilo está orientado mesialmente. Se trata de una pieza germinal ya que no muestra desgaste alguno y las raíces no se han desarrollado aún.

Premolares inferiores (lámina V.1.1: 2 y 5) (tabla V.1.1) (figura V.1.1): son dientes rectangulares salvo el $\mathrm{P}_{2}$, que presenta una apariencia triangular. Son similares a los molares inferiores permanentes pero tanto el paralófido como el hipolófido son más pequeños que en los molares. Tienen un valle anterior más pequeño que el posterior. Son birradiculados, con una raíz anterior y otra posterior.

$\mathbf{P}_{2}$ : difiere del resto de Stephanorhinus en que presenta un valle anterior poco marcado. El valle posterior tiene forma de "V"". Carece de cíngulos, lo que le diferencia de $S$. hundsheimensis y $S$. kirchbergensis que suelen presentar uno vestibular (Lacombat, 2006). El sinclinal vestibular es agudo. Los valores DTa y DTp son más pequeños que los registrados en $S$. kirchbergensis y $C$. antiquitatis, y se encuentran dentro del rango de $S$. hemitoechus.

$\mathbf{P}_{3}$ : tanto el valle anterior como el posterior presentan forma de "V", algo que difiere en $S$. kichbergensis que suele presentarlos en forma de "U" (Lacombat, 2006). Carece de cíngulos en todas sus caras y el sinclinal vestibular es agudo. Los DTp de la Cueva de Valdegoba y de la Cueva del Búho son los más pequeños, mientras que sus DTa están dentro del rango de $S$. hundsheimensis y $S$. hemitoechus.
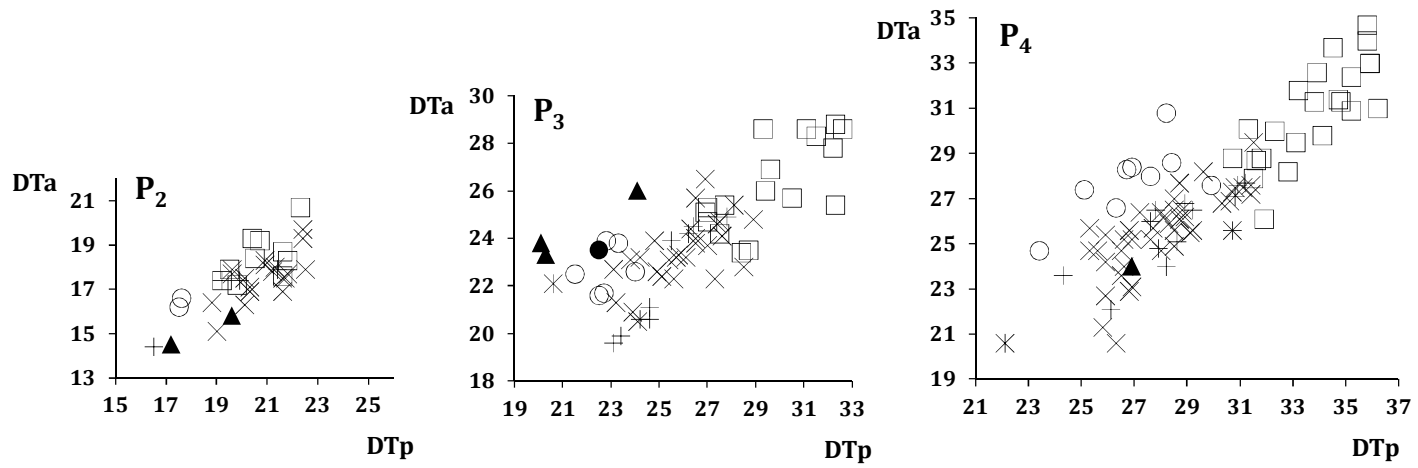

$\square$ S. kichbergensis + S. hemitoechus $\triangle$ S. hemitoechus Búho $*$ S. hemitoechus Valdegoba P3-4i $\times$ S. hundsheimensis $\circ$ C. antiquitatis $\bullet$ C. antiquitatis La Mina

Figura V.1.1. Diagramas bivariantes de los premolares inferiores: DTa (diámetro transversal anterior) y DTp (diámetro transversal posterior). S. kirchbergensis de Kirchberg, Bilzingsleben, Mobach, Steinheim, Ehrigsdorf, Taubach, Gimbsheim, Eich. S. hemitoechus de Bilzingsleben, Neumark Nord, Steinheim, Ehringsdorf, Taubach, Gimbsheim, Eich (datos aportados por J. van der Made) y Cueva del Búho. Coelodonta antiquitatis de Chlum, Steinheim, Ehringsdorf, Belvedère,. Ariendorf, Backleben, Heldrungen, Kahla, Gimbsheim, Eich (datos tomados de Van der Made, 2010), Lezika y Labeko Koba S. hundsheimensis de Voigtsted, Süssenborn, Soleilhac, Mosbach, Mauer, Ceyssaguet, Soleinac (datos aportados por J. van der Made).

$\mathbf{P}_{4}$ : ambos valles presentan forma de " $\mathrm{V}$ ", mientras que $S$. kirchbergensis suele presentarlos en forma de "U". Carece de cíngulos en todas sus caras, algo poco frecuente en S. etruscus, S. hundsheimensis y S. kirchbergensis (Lacombat, 2006). Métricamente, la pieza de la Cueva del Búho presenta unos valores de DTa y DTp similares a los registrados en $S$. hemitoechus y menores que los observados en $S$. kirchbergensis y $C$. antiquitatis. 
Molares inferiores (lámina V.1.1: 2) (tabla V.1.1) (figura V.1.2): son dientes rectangulares con dos valles bien desarrollados y dos raíces, una anterior y otra posterior.

$\mathbf{M}_{1}$ : sus valles tienen una morfología en "V" y la diferencia de altura entre ambos es muy marcada. Tiene un cíngulo en la cara distal, algo poco frecuente en $S$. etrucus, $S$. hundsheimensis y $S$. kirchbergensis (Lacombat, 2006). En vista bucal, presenta un sinclinal cerrado y agudo. Métricamente, los valores de DAP y DTp son mayores a los registrados en los premolares inferiores y menores a los observados en el $\mathrm{M}_{2}$ (tabla V.1.1). Los DTa y DTp son más pequeños que los de $S$. kirchbergensis y son similares a los de $S$. hundsheimensis y $S$. hemitoechus. El DTa es más pequeño y el DTp similar al de $C$. antiquitatis.

$\mathbf{M}_{2}$ : los dos valles tienen forma de "V" y el posterior es más profundo. El sinclinal bucal es más abierto que en el $\mathrm{M}_{1}$, pero se estrecha lingualmente. Al igual que en la pieza anterior, el valor de sus diámetros transversales es menor que en $S$. kirchbergensis, pero son similares a los de $S$. hundsheimensis y $S$. hemitoechus. C. antiquitatis tiene unos DTp similares y unos DTa más grandes.
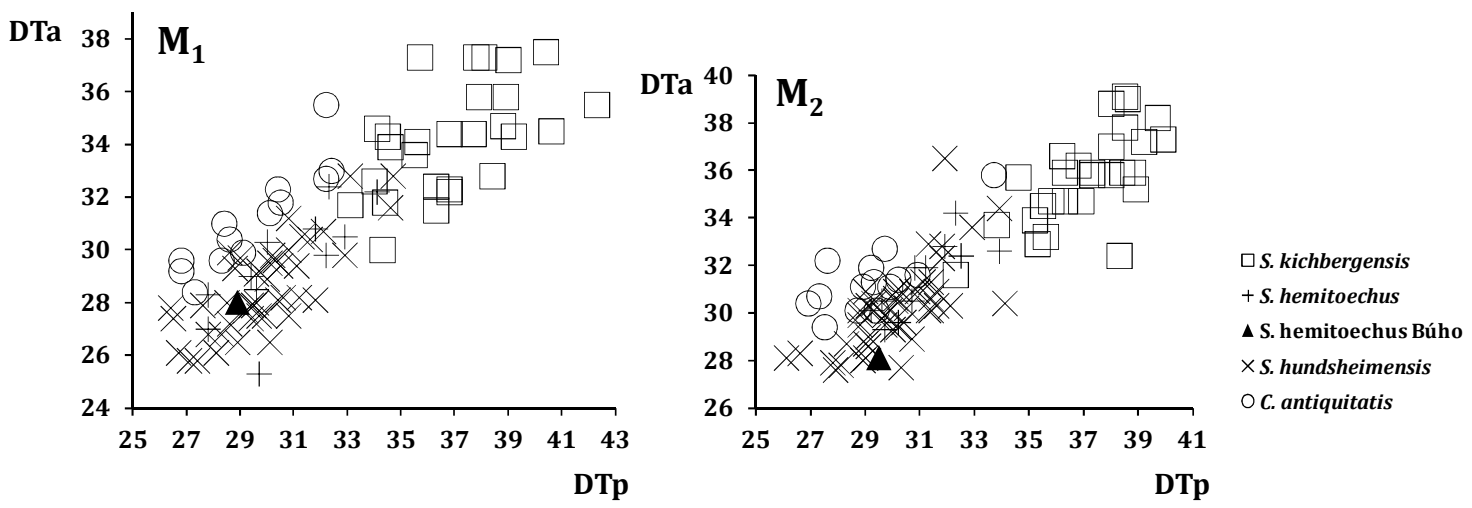

Figura V.1.2. Diagramas bivariantes de los molares inferiores permanentes: DTa (diámetro transversal anterior) y DTp (diámetro transversal posterior). S. kirchbergensis de Kirchberg, Bilzingsleben, Mobach, Steinheim, Ehrigsdorf, Taubach, Gimbsheim, Eich. S. hemitoechus de Bilzingsleben, Neumark Nord, Steinheim, Ehringsdorf, Taubach, Gimbsheim, Eich (datos aportados por J. van der Made) y Cueva del Búho. $S$. hundsheimensis de Voigtsted, Süssenborn, Soleilhac, Mosbach, Mauer, Ceyssaguet, Soleinac (datos aportados por J. van der Made). Coelodonta antiquitatis de Chlum, Steinheim, Ehringsdorf, Belvedère, Ariendorf, Backleben, Heldrungen, Kahla, Gimbsheim, Eich (datos tomados de Van der Made, 2010), Lezika y Labeko Koba.

Premolares superiores (lámina V.1.1: 1, 6 y 9) (tabla V.1.1) (figura V.1.3): dientes cuadrangulares, con esmaltes gruesos y rugosos. La superficie oclusal muestra una gran cantidad de pliegues dándole la apariencia del número $\pi$, de ahí que a estos dientes se les conozca como pilofodontos. Los estilos suelen estar menos proyectados que en los molares superiores permanentes, ocurriendo lo mismo con el pliegue del parastilo y con la constricción protoconal. Trirradiculados, con una raíz lingual y dos bucales. Sus dimensiones, por lo general, son menores que las de los molares superiores permanentes (tabla V.1.1).

P3: presenta una prefosa grande y una postfosa aislada. El hipocono se une al protocono en la zona media, cerrando el valle lingual. Este valle es más estrecho que en $S$. kirchbergensis (Van der Made, 2010). El gancho es doble y presenta una crista bien desarrollada. La constricción protoconal se encuentra muy marcada. Estos criterios se ajustan más a los observados por Lacombat (2006) en S. hundsheimensis. Sin embargo, los valores de DTa y DTp son similares a los de $S$. hemitoechus.

P4: presenta un ectolofo oblicuo y ambas fosas muy marcadas. Tanto los estilos como el pliegue del paracano están muy desarrollados, algo habitual en S. hemitoechus (Lacombat, 2006). El hipocono y la constricción protoconal no están tan desarrolladas como en el $\mathrm{P}^{3}$ y no aparece en la pieza de la Peña de Mudá. El gancho es doble y la crista está marcada pero 
no cierra la fosa media en el diente de Mudá, mientras que en el de Cueva Millán no se observa, debido a la concreción presente en la superficie oclusal. El valle lingual es más estrecho que en S. kichbergensis (Van der Made, 2010). El cíngulo mesial está bien marcado lo que le diferencia de $S$. kirchbergensis. También están desarrollados el lingual y el distal. Los valores de los diámetros transversales son similares a los de S. hemitoechus, mayores que los del C. antiquitatis de Neumark Nord y menores que los de S. kichbergensis.

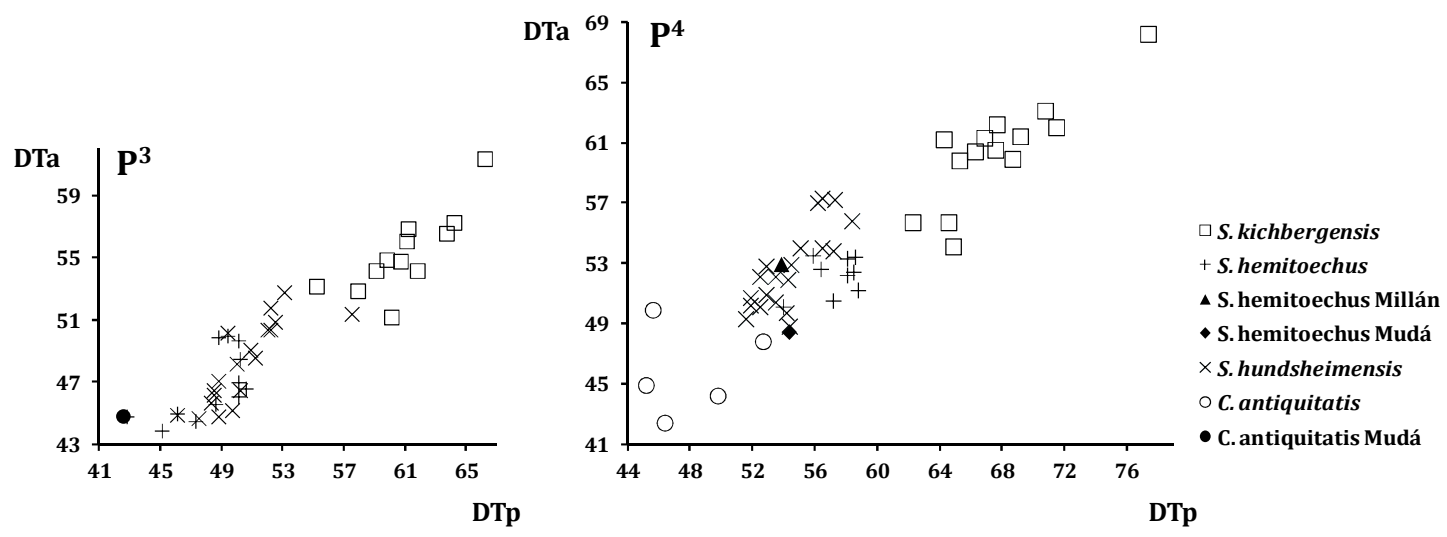

Figura V.1.3. Diagramas bivariantes de los molares superiores permanentes: DTa (diámetro transversal anterior) y DTp (diámetro transversal posterior). S. kirchbergensis de Bilzingsleben, Mobach, Steinheim, Ehrigsdorf, Taubach, Gimbsheim, Eich y Neumark Nord. S. hemitoechus de Bilzingsleben, Neumark Nord, Majolicas, Murr, Ehringsdorf, Gimbsheim, Eich (datos aportados por J. van der Made), Cueva Millán y la Peña de Mudá. S. hundsheimensis de Mauer, Süssenborn, Soleinac, Mosbach y Voigtsted (datos aportados por J. van der Made). Coelodonta antiquitatis de Bad Frankenhausen, Ehringsdorf, Ariendorf y Eich (datos aportados por J. van der Made), Lezika y la Peña de Mudá.

P3-4: en esta categoría incluimos la pieza identificada en la Cueva de Valdegoba. En este caso, y debido al avanzado estado de desgaste, no se puede observar el desarrollo ni de la crista ni del gancho, aunque sí que se puede identificar una foseta media de pequeño tamaño.

Molares superiores (lámina V.1.1: 1, 3, 10 y 11) (tabla V.1.1) (figura V.1.4): dientes similares a los premolares superiores. Presentan una morfología pilofodonta, unos estilos pronunciados y un desarrollo variable del gancho, el antigancho y la crista. Métricamente, presentan unas mayores dimensiones que los premolares.

M1: el ectolofo es oblicuo y tiene un valle lingual abierto. La foseta media no está abierta, lo que no suele ocurrir en todos los S. hundsheimensis (Lacombat, 2006). Presenta el parastilo, la crista, el gancho y la constricción protoconal muy desarrollados, siendo este último diferente en S. kirchbergensis (Van der Made, 2010). Difiere de S. etruscus y $S$. kirchbergensis por el gran desarrollo del pliegue del paracono (Lacombat, 2006). La crista y el gancho no llegan a cerrar las fosas anterior y media. El valle lingual es estrecho, a diferencia de S. kichbergensis (Van der Made, 2010). Los $\mathrm{M}^{1}$ y $^{2}{ }^{2}$ de Cueva Millán y de la Peña de Mudá presentan unos valores de DTa y DTp próximos a los de otros $S$. hemitoechus europeos, mayores que los de $C$. antiquitatis e inferiores a los de $S$. kirchbergensis.

M2: tienen el parastilo y el pliegue del paracono muy desarrollados y orientados anteroposteriormente, a diferencia de lo que ocurre en S. kirchbergenis. El metastilo se encuentra orientado hacia atrás y la postfoseta está muy desarrollada, al igual que el valle lingual. El diente de Cueva Millán carece de crista y el de la Peña de Mudá la presenta doble lo que la diferencia de $S$. etruscus, $S$. hundsheimensis y $S$. kirchbergensis (Lacombat, 2006). El antigancho está poco marcado en la pieza de Cueva Millán y en la de la Peña de Mudá no aparece. El gancho de la pieza de Cueva Millán es simple, mientras que el de la pieza de la Peña de Mudá es múltiple, uniéndose al gancho y aislando la fosa anterior de la 
media. El cíngulo anterior está bien marcado en el diente de la Peña de Mudá, prolongándose lingualmente. El cíngulo lingual está muy marcado, ocurriendo lo mismo con la constricción protoconal, aunque este carácter no se ha observado en la pieza de Mudá. Los diámetros transversales son mayores que los de $S$. hundsheimensis y $C$. antiquitatis, menores que los de S. kirchbergensis y similares a los de S. hemitoechus.

M1-2: la pieza identificada en la Cueva de Valdegoba presenta una morfología cuadrangular y un gancho desarrollado. Carece de crista y antigancho, aunque presenta una serie de tubérculos aislados. Muestra unos estilos poco pronunciados bucalmente aunque se observa un mayor desarrollo del parastilo que del metastilo.
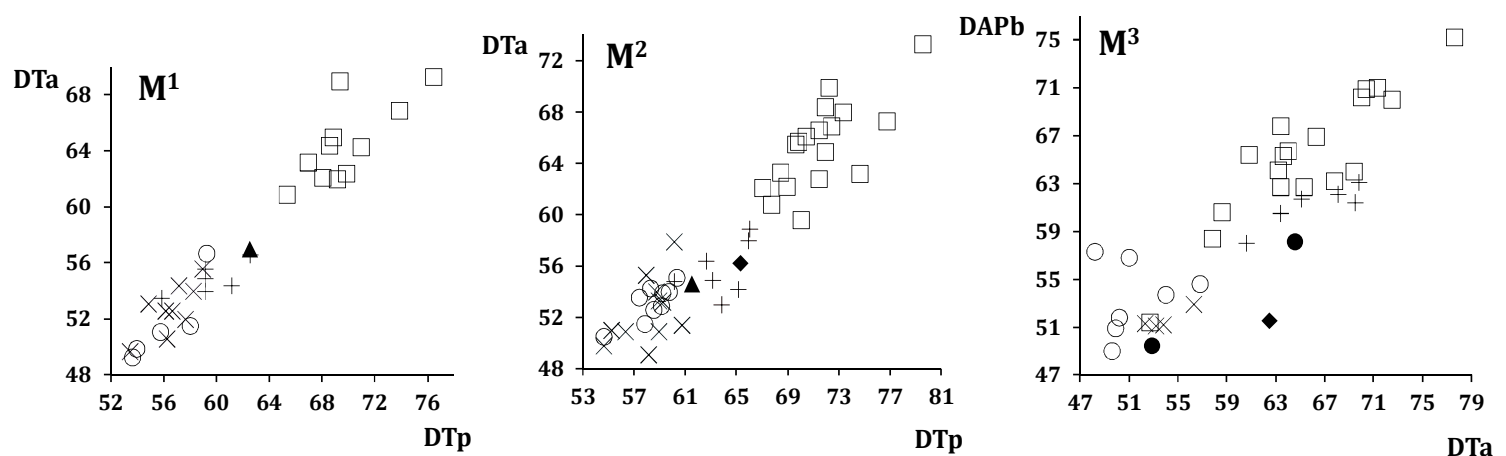

$\square$ S. kichbergensis + S. hemitoechus $\triangle$ S. hemitoechus Millán $\bullet$ S. hemitoechus Mudá $\bullet$ S. hemitoechus Valdegoba $\times$ S. hundsheimensis $\circ$ C. antiquitatis

Figura V.1.4. Diagramas bivariantes de los molares superiores permanentes: DTa (diámetro transversal anterior), DTp (diámetro transversal posterior) y DAPb (diámetro anteroposterior basal). S. kirchbergensis de Bilzingsleben, Mosbach, Steinheim, Ehrigsdorf, Taubach, Gimbsheim, Eich y Neumark Nord. S. hemitoechus de Bilzingsleben, Neumark Nord, Majolicas, Murr, Ehringsdorf, Gimbsheim, Eich (datos aportados por J. van der Made), Cueva Millán, Peña de Mudá y la Cueva de Valdegoba. S. hundsheimensis de Mauer, Süssenborn, Soleinac, Mosbach y Voigtsted (datos aportados por J. van der Made). Coelodonta antiquitatis de Bad Frankenhausen, Ehringsdorf, Ariendorf y Eich (datos aportados por J. van der Made), Lezika y Labeko Koba.

M3: su morfología es triangular debido a la convexidad del ectometalofo. Tienen gran cantidad de cemento, llegando incluso a alcanzar la superficie oclusal. La pieza de Cueva Millán se encuentra, dentro del maxilar, desplazada 45ํㅡ con respecto a su posición normal. El parastilo está poco desarrollado, a diferencia del gancho que está muy marcado. Carece de antigancho y crista, aunque la pieza de la Peña de Mudá sí que presenta esta última. El metacono está en una posición más posterior lo que hace que el ectometalofo esté más curvado que en $S$. kichbergensis (Van der Made, 2010). El cíngulo anterior se encuentra muy marcado a diferencia del lingual que apenas está desarrollado. Los valores de DTa y DTp de estas piezas están más próximos a los registrados en $C$. antiquitatis.

Figura V.1.5. Diagrama bivariante del astrágalo: Lm (longitud mínima) y Lint (longitud medial). Stephanorhinus kirchbergensis de Bilzingsleben, Ehringsdorf y Taubach, Stephanorhinus hemitoechus de Bilzingsleben, Ehringsdorf, Taubach (datos aportados por J. van der Made) y la Cueva de Valdegoba. Coelodonta antiquitatis de Zasuhino, Chlum, Wannen y Heringen (datos aportados por J. van der Made).

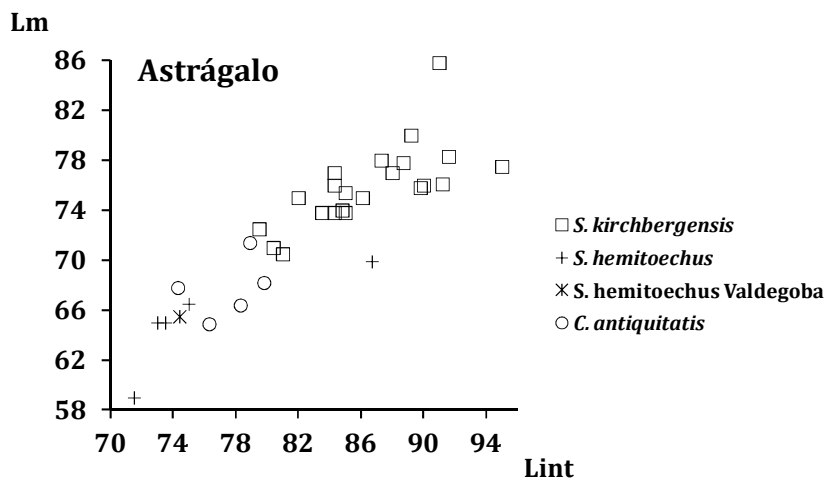

Astrágalos (lámina V.1.1: 12) (tabla V.1.2) (figura V.1.5): la pieza identificada tiene, en vista anterior, los extremos de la tróclea muy desiguales y una gran altura. En vista posterior, hay dos caras que articulan con el calcáneo, siendo la superior redondeada y la inferior ovalada. 
Tabla V.1.2

Medidas tomadas en los astrágalos de S. hemitoechus

\begin{tabular}{lcccccccccccc}
\hline & & Lado & DT & DTdf & DTpf & DTtl & Lext & Lint & Lm & Rm & Rint & DAPdf \\
\cline { 3 - 11 } Valdegoba & Vb-sp-5689 & $\mathrm{d}$ & 95,2 & 71,3 & 83,4 & 80,4 & 79,5 & 74,4 & 65,5 & 41,1 & 55,3 & 49,8 \\
\hline
\end{tabular}

Esta pieza presenta unos Lint y Lm similares a los de los $S$. hemitoechus de Bilzingsleben y menores que los de $S$. kirchbergensis y $C$. antiquitatis.

\subsubsection{Número mínimo de individuos}

El conteo de individuos se ha realizado a partir del desgaste dental, que es muy variable, sugiriendo que podrían pertenecer a ejemplares distintos. En la tabla V.1.3 se indican los individuos, las piezas empleadas y su grado de desgaste.

En la Cueva de Valdegoba se han identificado tres ejemplares. El primero se ha establecido a partir de piezas deciduales con desgastes moderados. El segundo a partir de una pieza decidual, con un desgaste máximo, y dos permanentes, con desgastes moderados. El tercer ejemplar incluye piezas permanentes con desgastes máximos. En estos dientes la corona prácticamente ha desaparecido.

Tabla V.1.3

Número mínimo de individuos de S. hemitoechus

\begin{tabular}{|c|c|c|c|c|c|c|c|c|}
\hline & \multicolumn{2}{|c|}{ Individuo 1} & \multicolumn{2}{|c|}{ Individuo 2} & \multicolumn{2}{|c|}{ Individuo 3} & Individuo 4 & \multirow[t]{2}{*}{ Total } \\
\hline \multirow{4}{*}{ Cueva de Valdegoba } & Vb-sp-3201 & $\mathrm{D}_{2}$ & Vb-sp-239 & $P_{3-4}$ & Vb-sp-244 & $\mathrm{P}^{3-4}$ & & \\
\hline & Vb-sp-242 & $\mathrm{D}_{3}$ & Vb-sp-233 & $\mathrm{M}^{3}$ & Vb-sp-240 & $\mathrm{M}^{1-2}$ & & \multirow{3}{*}{3} \\
\hline & Vb-sp-238 & $\mathrm{D}^{2}$ & Vb-sp-234 & $\mathrm{D}^{3}$ & Vb-sp-235 & $\mathrm{M}^{3}$ & & \\
\hline & Vb-sp-3200 & $\mathrm{D}_{4}$ & & & & & & \\
\hline Cueva Millán & CM.86.1A.9F & Maxilar & & & & & & 1 \\
\hline \multirow[t]{2}{*}{ Cueva del Búho } & $6495 Q$ & $\mathrm{D}^{3}$ & $6496 Q$ & $\mathrm{P}_{2}$ & $6511 Q$ & $\mathrm{P}_{3}$ & $\begin{array}{cc}6512 \mathrm{Q} & \mathrm{P}_{3} \\
6514 \mathrm{Q} & \mathrm{P}_{2}-\mathrm{M}_{2}\end{array}$ & 4 \\
\hline & $540 Q$ & $\mathrm{P}^{4}$ & & & & & & \\
\hline \multirow[t]{2}{*}{ Peña de Mudá } & $539 Q$ & $\mathrm{M}^{2}$ & & & & & & 1 \\
\hline & $542 Q$ & $\mathrm{M}^{3}$ & & & & & & \\
\hline
\end{tabular}

* Los ejemplares se han establecido empleando el grado de desgaste de las diferentes piezas. Cueva de Valdegoba: individuo 1 (desgaste moderado); individuo 2 (desgaste máximo en los deciduales y moderado en los permanentes); individuo 3 (desgaste máximo). Cueva Millán: individuo 1 (desgaste moderado). Peña de Mudá: individuo 1 (desgaste moderado). Cueva del Búho: individuo 1 (desgaste mínimo); individuo 2 (desgaste moderado); individuo 3 (desgaste marcado); individuo 4 (degaste máximo).

En Cueva Millán se ha empleado la pieza más frecuente, un maxilar, por lo tanto se ha identificado un único ejemplar. En la Cueva del Búho, el grado de desgaste de las piezas es muy desigual. Se han identificado piezas germinales, con desgaste moderado y desgastes marcados. El $\mathrm{D}^{3}$ es germinal, las raíces aún no se han desarrollado y la corona prácticamente no presenta ningún tipo de desgaste. En los permanentes, podemos observar desgastes moderados y marcados. La mandíbula 6514Q y el $\mathrm{P}_{3} 6512 \mathrm{Q}$ podrían ser asignados al mismo ejemplar ya que ambos presentan desgastes similares. Otro ejemplar comprendería la pieza 6511Q, un $\mathrm{P}_{3}$, con un desgaste marcado, mientras que el último individuo estaría definido por el $\mathrm{P}_{2}$ 6596Q, con un desgaste moderado. En dicho depósito podríamos diferenciar, por tanto, cuatro individuos, uno infantil, otro joven, definido por el $\mathrm{P}_{2}$; y otros dos adultos uno establecido a partir de las piezas 6514Q y 6512Q; y el otro por el $\mathrm{P}_{3}$ 6511Q. En la Peña de Mudá, se han identificado tres dientes diferentes con un desgaste similar lo que indica que podrían pertenecer a un único individuo. 


\subsubsection{Edad de muerte}

La asociación de ejemplares con un grado de desgaste similar ha permitido establecer diferentes rangos de edad (tabla V.1.4).

Tabla V.1.4

Rangos de edad de los individuos de $S$. hemitoechus identificados

\begin{tabular}{llcc}
\hline & & Desgaste & Edad relativa \\
\hline \multirow{2}{*}{ Cueva de Valdegoba } & Individuo 1 & Moderado & Infantil \\
& Individuo 2 & Máximo en deciduales, moderado en los permanentes & Adulto - Joven \\
& Individuo 3 & Máximo & Adulto - Viejo \\
Cueva Millán & Individuo 1 & Moderado & Adulto - Joven \\
& Individuo 1 & Mínimo & Infantil \\
Cueva del Búho & Individuo 2 & Moderado & Joven \\
& Individuo 3 & Marcado & Adulto \\
& Individuo 4 & Marcado & Adulto \\
Peña de Mudá & Individuo 1 & Marcado & Adulto \\
\hline
\end{tabular}

En la Cueva de Valdegoba, partiendo del NMI obtenido en el apartado anterior (tabla V.1.3), se puede indicar que nos encontramos con tres ejemplares: uno infantil, uno jovenadulto y otro adulto-viejo. En la primera categoría, infantil, se incluye el ejemplar con los dientes deciduales con un desgaste moderado. En el segundo, joven-adulto, se incluye un $\mathrm{D}^{3}$ con un desgaste máximo, prácticamente sin corona; un $\mathrm{P}_{3-4}$ con desgaste moderado y un $\mathrm{M}^{3}$ con poca erosión. Este individuo se diferencia claramente del tercero ya que en este último se incluyen piezas con un desgaste muy avanzado en el que sus coronas prácticamente han desaparecido.

El maxilar recuperado en Cueva Millán presenta una serie completa $\mathrm{P}^{3}-\mathrm{M}^{3}$. El desgaste del $\mathrm{M}^{3}$ es menos acentuado que el del resto de piezas. Esto podría deberse bien a la secuencia de erupción dental, bien a que se encuentra ligeramente desplazado con respecto a su posición normal dentro del maxilar. Aún así, el resto de piezas presentan un desgaste marcado, pero conservando buena parte de la corona. Por ese motivo, se puede asignar esta pieza a un ejemplar adulto - joven.

En la Cueva del Búho se han recuperado piezas con desgastes muy desiguales, aunque se han podido agrupar restos como 6512Q y 6514Q. Se ha identificado un ejemplar infantil, a partir de un $\mathrm{D}^{3}$, que presenta un desgaste mínimo. Un ejemplar joven, a partir del $\mathrm{P}_{2}$, con un desgaste moderado; y dos adultos que incluyen por un lado el grupo formado por la serie $\mathrm{P}_{2}-\mathrm{M}_{2}$ y un $\mathrm{P}_{3}$; y por el otro un $\mathrm{P}_{3}$ más, con un desgaste marcado.

Las piezas identificadas en la Peña de Mudá presentan un degaste similar, marcado. Por esta razón, podemos incluirlas en el mismo ejemplar, un adulto.

\subsubsection{Discusión}

Los restos recuperados de esta especie, salvo uno, corresponden a dientes. La altura de las coronas, la rugosidad y espesor del esmalte junto con la morfología pilofodonta de la superficie oclusal de los dientes superiores nos permite asignar dicho material a la familia Rhinocerotidae.

Como se ha comentado anteriormente, el Plio-pleistoceno de Europa occidental se caracteriza por la presencia de dos géneros de rinocerontes: Stephanorhinus y Coelodonta. La presencia, en las piezas inferiores, de lóbulos anteriores muy anchos en comparación con los posteriores y la escasa rugosidad del esmalte observada nos permite descartar a Coelodonta. La dentición superior también presenta caracteres más propios de Stephanorhinus (Van der Made, 2010) como son los esmaltes más finos, ectolofos 
rectangulares y sin una orientación anteroposterior, hipoconos grandes, valles linguales anchos, protolofos y metalofos con una orientación transversal y terceros molares superiores con una morfología triangular. Estos rasgos nos permiten descartar a Coelodonta y asignar los restos a Stephanorhinus.

El género Stephanorhinus está representado en el Pleistoceno europeo occidental por cuatro especies: $S$. etruscus, $S$. hundsheimensis, $S$. hemitoechus y $S$. kirchbergensis. Como se ha referido anteriormente, dichos taxones presentan caracteres morfométricos muy variables. Sin embargo, los estudios llevados a cabo por diversos autores (Guérin, 1980; Lacombat, 2006; Van der Made, 2010) han puesto de relieve algunas diferencias morfológicas que nos permiten concretar la clasificación de los restos identificados, aunque no todas las piezas presentan diferencias claras (Lacombat, 2006).

Los caracteres observados junto con las dimensiones comparadas nos permiten descartar a $S$. etruscus y $S$. hundsheimensis. S. hemitoechus, junto con $C$. antiquitatis, ha sido la especie característica del Pleistoceno Superior ibérico (Cerdeño, 1990; Álvarez-Lao, 2007; Van der Made y Montoya, 2007). Hay referencias de S. kirchbergensis en yacimientos de la cordillera cantábrica (Altuna, 1972; Cerdeño, 1990; Mariezkurrena-Gastearena, 2011) pero son referencias aisladas. Sin embargo, está ultima se caracteriza por la presencia de esmaltes muy finos, carácter éste que no presenta nuestro material. Además las dimensiones son más pequeñas.

A lo largo de los años, los restos asignados a $S$. hemitoechus, han recibido varios nombres: Rhinoceros lunellensis Gervais 1848-1852, Rhinoceros leptorhinus Owen 1846 o Rhinoceros hemitoechus Falconer 1859. Todos ellos han tenido poca repercusión y han sido poco utilizados en la literatura. Los primeros fósiles descritos provienen, al parecer, de de varias cavidades inglesas como las simas Bacon y Minchin Hole (Van der Made, 2010).

La dentición inferior de los rinocerontes de la Cueva del Búho, la Cueva de Valdegoba y Cueva Millán muestra unos valles linguales en " $\mathrm{V}$ " y unos $\mathrm{P}_{2}$ de pequeñas dimensiones (figura V.1.1). Lo mismo ocurre en los dientes superiores, los valles estrechos y el aspecto general del material se asemeja a los restos de las cuevas de Glamorganshire (Van der Made, 2010). Asignamos los restos descritos anteriormente a la especie S. hemitoechus.

Azzaroli (1962) describe dos subespecies dentro de $S$. hemitoechus: D. hemitoechus falconeri y $D$. hemitoechus aretinus. Guèrin (1980) indica que $D$. $h$. falconeri sería la especie propia del Pleistoceno Medio y D. h. aretinus la del Pleistoceno Final. Sin embargo, el análisis nomenclatural llevado a cabo por Van der Made (2010) indica que "aretinus" es una sinonimia de "hemitoechus" $\mathrm{y}$, al ser este último el primero en definirse, las subespecies quedarían como S. h. hemitoechus y $S$. h. falconeri. El material identificado no nos permite realizar una comparativa clara con los ejemplares tipo de estas subespecies ya que han sido descritas, en su mayor parte, a partir de material postcraneal, aunque cronológicamente corresponderían con $S$. h. hemitoechus. Aún así, y al no poder llevar a cabo comparativas morfométricas más exhaustivas, no vamos más allá de la asignación específica de los restos, $S$. hemitoechus. 

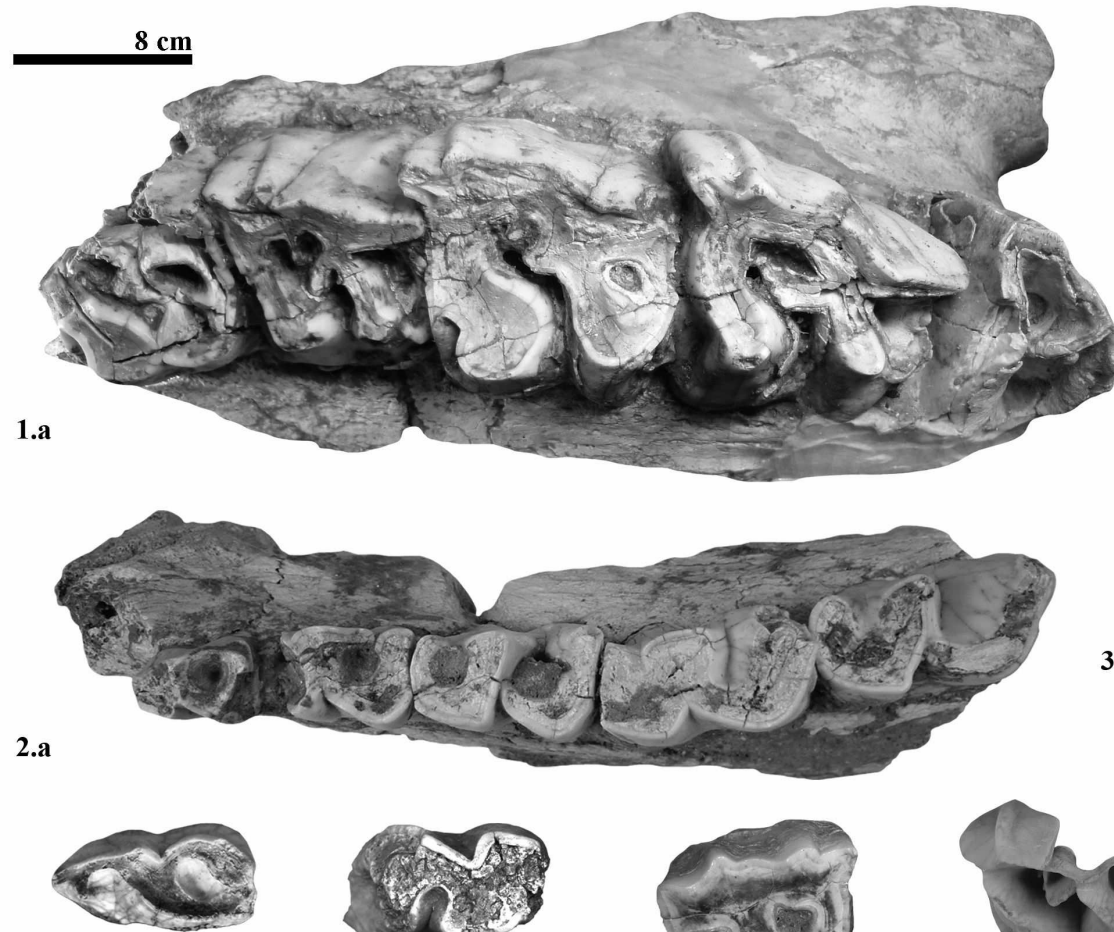

4.a
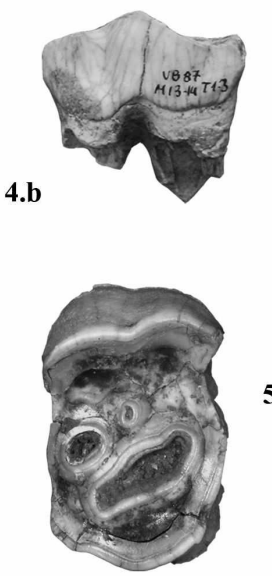

9.a

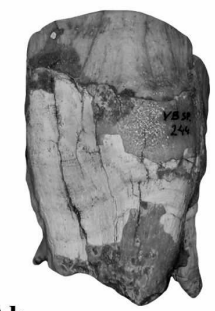

9.b

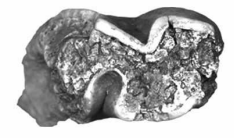

5.a

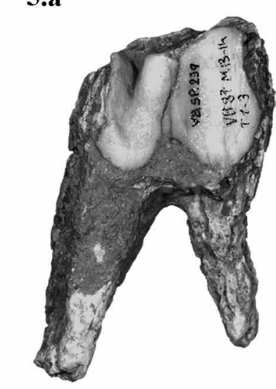

5.b

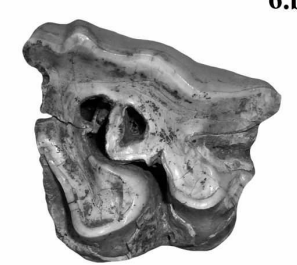

$10 . a$

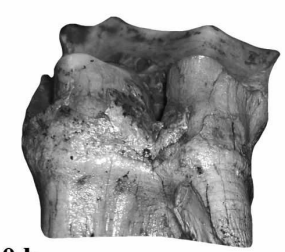

10.b

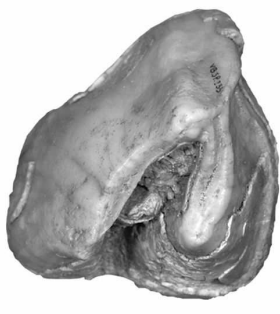

3.a

3.b
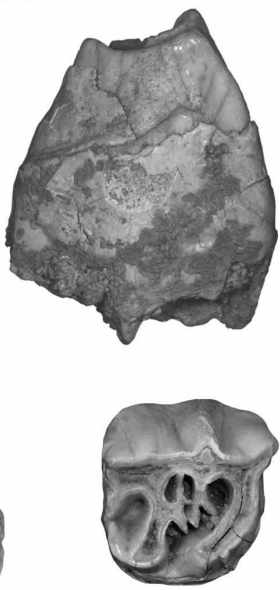

8.a

7.a

$6 . a$
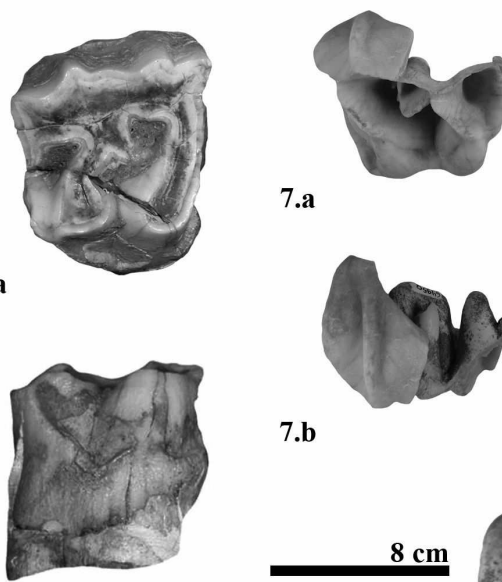

6.b
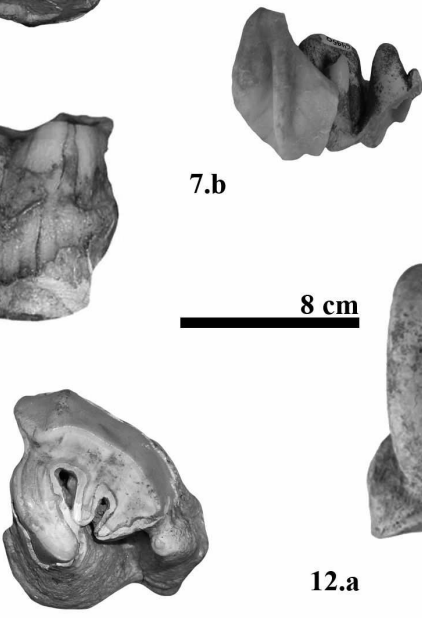

7.b

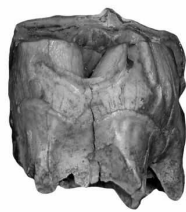

8.b

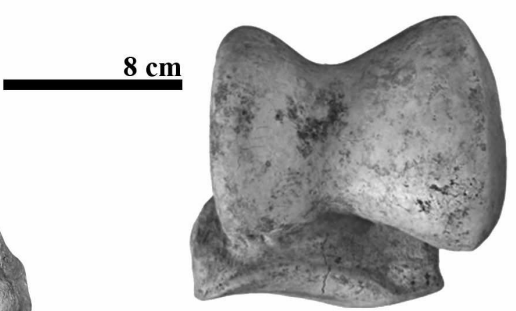

12.a

11.a

$8 \mathrm{~cm}$

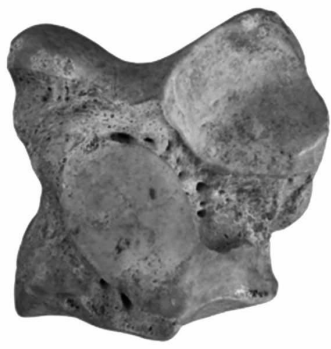

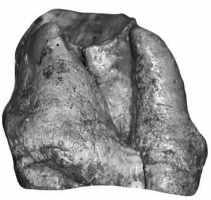

12.b

11.b

Lámina V.1.1. Stephanorhinus hemitoechus provenientes de los yacimientos de la Cueva de Valdegoba (sigla Vb), Cueva Millán (sigla CM), Cueva del Búho (sigla TCB) y la Peña de Mudá (sigla Q). 1) CM86.1A.9F dentición superior izquierda $\left(\mathrm{P}^{3}-\mathrm{M}^{3}\right)$ : 1.a vista oclusal. 2) TCB - 174b - dentición inferior derecha $\left(\mathrm{P}_{2}-\mathrm{M}_{2}\right)$ : 2.a vista oclusal. 3) Vb-sp-235 - $\mathrm{M}^{3}$ derecho: 3.a vista oclusal; 3.b vista bucal. 4) Vb-sp-3201 - $\mathrm{D}_{2}$ derecho: 4.a vista oclusal; 4.b vista lingual. 5) Vb-sp-239 - $\mathrm{P}_{3 / 4}$ izquierdo: 5.a vista oclusal; 5.b vista bucal. 6) $540 \mathrm{Q}-\mathrm{P}^{4}$ derecho: 6.a vista oclusal; 6.b vista lingual. 7) TCB-238 - D³ derecho: 7.a vista oclusal; 7.b vista bucal. 8) Vb-sp238 - D2 derecho: 8.a vista oclusal; 8.b vista lingual. 9) Vb-sp-244 - P3/4: 9.a vista oclusal; 9.b vista lingual. 10) $539 \mathrm{Q}-\mathrm{M}^{2}$ izquierdo: $10 . \mathrm{a}$ vista oclusal; 10.b vista lingual. 11) $542 \mathrm{Q}$ - $\mathrm{M}^{3}$ izquierdo: 11.a vista oclusal; 11.b vista lingual. 12) Vb-sp-5689 - Astrágalo derecho: 12.a vista anterior; 12.b vista posterior. 


\subsection{Coelodonta antiquitatis}

Orden Perissodactyla Owen, 1848

Familia Rhinocerotidae Gray, 1821

Subfamilia Rhinocerotinae Gray, 1821

Género Coelodonta Bronn, 1831

Especie Coelodonta antiquitatis (Blumenbach, 1799)

\subsubsection{Generalidades}

El primer registro de esta especie parece encontrarse en el Plioceno final en Asia. Los restos más antiguos proceden del yacimiento chino de Wucheng y fueron asignados por Kahlke (1967) a C. nihowanensis. La cronología de dicho depósito se encuentra en torno a los 2,5 m.a. (ver referencias en Álvarez-Lao, 2007) muy próxima a la registrada en el yacimiento de Togoloj, República de Bryatia, donde Beliajeva describe la especie $C$. tologoijensis (Álvarez-Lao, 2007).

Durante el Pleistoceno temprano y comienzos el Pleistoceno Medio el material de Coelodonta no es muy abundante (Álvarez-Lao, 2007). Kahlke indica que, durante este periodo, este género se expandió hacia el oeste reemplazando a las poblaciones de Stephanorhinus del este y centro de Europa. Los restos más antiguos de Europa proceden del yacimiento alemán de Bad Frankenhausen (Kahlke, 1999), fechados en 400.000 ka., así como de localidades como Bornhausen am Harz y Neuekrug am Harz (Sickenberg, 1962). A pesar de esto, no se pueden establecer fechas exactas para la entrada de Coelodonta en Europa (Alvarez-Lao, 2007). Durante el interglacial Holstein (MIS 11), las poblaciones occidentales de este género permanecen restringidas en refugios asiáticos (Kahlke, 1999), mientras que en el glaciar posterior, MIS 10 - 6, se produce una nueva migración hacia el oeste, encontrando restos en localidades del Volga y del Don (Vereschagin y Baryshnikov, 1985), así como en Rumanía, Hungría, Alemania, Suiza, Francia y Gran Bretaña (Guérin, 1973). Una nueva extinción se observa en el siguiente interglacial, volviendo a sus refugios, los cuales aún no han sido del todo localizados (Van der Made, 2010).

Su mayor expansión se produce desde finales del Eemiense y el último glaciar donde ya podemos encontrar registro en yacimientos de Gran Bretaña (Crayford, Kent) (Stuart, 1982) y en las penínsulas Itálica y Balcánica, sin alcanzar nunca el continente americano (Kalhke, 1999; Álvarez-Lao, 2007). La crisis climática de finales del Pleistoceno Tardío provoca su extinción en muy corto periodo de tiempo, encontrándose sus últimos registros en Jilin en torno al 11.000 B.P. (Kahlke, 1999; Álvarez-Lao, 2007).

En la Península Ibérica, esta especie se encuentra, restringida, en la franja cantábrica, aunque se han registrado tres depósitos en el centro, Arroyo Culebro, la Aldehuela y los Rosales, y otros dos en el este, El Toll y Arenys de Mar (Álvarez-Lao y García, 2011). Los restos más antiguos hallados en este territorio provienen del yacimiento asturiano de La Parte, $150 \mathrm{Ka}$ BP, después el material se concentra ya bien avanzado el Pleistoceno Superior (Álvarez-Lao, 2007), aunque Álvarez-Lao y García (2011) indican que las características morfológicas de los restos de Arroyo Culebro podrían corresponder a las primeras fases del Pleistoceno Tardío. Los restos más antiguos del Pleistoceno Superior se encuentran en Covacho Arenillas, 39 ka CalBP (Álvarez-Lao y García, 2010) seguidos de cerca por el material de Labeko Koba 34.215 - 31.455 BP.

Fue el primer rinoceronte en recibir un nombre específico. A lo largo del tiempo sus restos han sido clasificados bajo diversos nombres: Rhinoceros lenenensis Pallas, 1773; Rhinoceros antiquitatis Blumenbach, 1799; Rhinoceros tichorhinus Cuvier; R. pallasi Desmarest, $R$. jourdani Lortet \& Chantre o C. bojei Bronn. El nombre genérico de Tichorrhinus Brandt, 1849 también ha sido empleado y aún aparece ocasionalmente en alguna publicación (Barandiaran, 1979; Fuentes y Meijide, 1979; Charline, 1982) aunque 
es un sinónimo de Coelodonta. Sin embargo, actualmente, parece existir consenso unánime sobre la validez del nombre $C$. antiquitatis.

Son frecuentes sus representaciones en las pinturas y grabados del Paleolítico superior europeo, alcanzando su cenit en el Auriñaciense y disminuyendo en el Magdaleniense. En la Península Ibérica nos encontramos con una representación en la cueva de los Casares (Guadalajara) (Arsuaga y Aguirre, 1979) y una probable en la cueva guipuzcoana de Ekain (Corchón, 1991-1992; Acosta González, 2003).

\subsubsection{Material}

El material empleado tanto en la descripción como en la determinación de la edad de muerte proviene de los siguientes yacimientos:

La Mina: 7 restos, todos dientes aunque sólo dos identificables: $1 \mathrm{P}_{3}$ y un probable $\mathrm{M}_{1}$.

Peña de Mudá: una pieza dental, un $\mathrm{P}^{3}$.

\subsubsection{Descripción y comparación}

El material que se describe a continuación proviene de los yacimientos de La Mina y de la Peña de Mudá.

Premolar inferior (lámina V.2.1: 1) (tabla V.2.1): diente rectangular con la corona alta y dos raíces. En la superficie oclusal tiene dos fósidas más pequeñas que en los molares. Tiene el esmalte rugoso y grueso.

$\mathbf{P}_{3}$ : presenta un sinclinal abierto y profundo, un metacónido corto y estrecho, y un metalófido ancho. El entocónido está más o menos al mismo nivel que el metacónido. Este último presenta una posición anterior mientras que el metalófido está orientado hacia la parte trasera. El valle anterior es ancho y con forma de "V", al igual que el posterior. El valle posterior es más estrecho que el anterior y está orientado hacia atrás No presenta ni cíngulo mesial ni distal. Sus DAPb y DTa son menores que los del $\mathrm{M}_{1}$ recuperado (tabla V.2.1). Presenta un tamaño similar al de otros $C$. antiquitatis euroasiáticos, se solapa con $S$. hundheimensis, es más pequeño que $S$. kirchbergensis y más grande que el $S$. hemitoechus de la Cueva de Valdegoba (figura V.1.1).

Tabla V.2.1

Premolares y molares de C. antiquitatis

\begin{tabular}{|c|c|c|c|c|c|c|c|c|c|c|}
\hline & & & Lado & DAPo & DAP & DAPb & DTa & DTp & H & Hli \\
\hline $\mathbf{P}_{3}$ & La Mina & 05.40.LM.738 & $\mathrm{i}$ & 30,9 & 30,8 & 29,1 & 22,5 & 23,5 & 23,3 & 21,0 \\
\hline $\mathbf{M}_{1}$ & La Mina & 05.40.LM.759 & & $<40,3$ & $<40,7$ & $<28,4$ & $<30,6$ & & 22,2 & \\
\hline $\mathbf{P}^{3}$ & Mudá & $59 Q$ & d & 35,5 & 36,3 & 27,8 & 42,6 & 44,8 & 25,6 & 14,5 \\
\hline
\end{tabular}

* La notación < indica que, al encontrarse fragmentado, estas variables no han podido tomarse bien, por lo que las dimensiones obtenidas son una referencia.

Molar inferior permanente (lámina V.2.1: 2) (tabla V.2.1): es un diente rectangular con el esmalte grueso y rugoso. Tiene dos raíces: una anterior y otra posterior.

$\mathbf{M}_{1}$ : la pieza recuperada en La Mina no presenta un buen estado de conservación, mostrando además un desgaste muy marcado que ha erosionado prácticamente toda la superficie oclusal Sus DAPb y DTa son más grandes que los del $\mathrm{P}_{3}$ identificado (tabla V.2.1). 
Premolar superior (lámina V.2.1: 3) (tabla V.2.1): dientes cuadrangulares, con estilos poco proyectados, pliegue del parastilo poco desarrollado, esmalte grueso y gran cantidad de cemento. Trirradiculados, con una raíz lingual y dos bucales.

P3: la pieza hallada en Mudá se encuentra en buen estado de conservación, aunque el desgaste es muy elevado. Los estilos se encuentran poco proyectados, incluso el pliegue del paracono no aparece muy desarrollado. Tiene una gran cantidad de cemento, cubriendo casi por completo toda la corona y un esmalte muy rugoso. Carece de cíngulos en todas sus caras y de constricción protoconal. El parastilo es el estilo más marcado y se proyecta hacia la cara anterior. Tanto el valle lingual como la foseta media y la posterior están cerradas y aisladas. Presenta unos valores de DTa y DTp más pequeños que los de $S$. hundsheimensis y $S$. kirchbergensis. Se solapa con los valores más pequeños registrados en S. hemitoechus (figura V.1.3)

\subsubsection{Número Mínimo de Individuos}

Se ha empleado el grado de desgaste de las diferentes piezas para establecer el número mínimo de ejemplares en La Mina y la pieza más frecuente para establecerlo en la Peña de Mudá. En el depósito de La Mina, el grado de desgaste sugiere que podríamos encontrarnos ante dos ejemplares. Sin embargo, si observamos otros restos de esta misma especie, como la mandíbula de Labeko Koba (Álvarez-Lao, 2007), podemos indicar que ambos desgastes pueden ser complementarios por lo que contabilizamos un ejemplar (tabla V.1.2). En el caso de la Peña de Mudá sólo se ha recuperado un resto, un $\mathrm{P}^{3}$, por lo que sólo contabilizamos un individuo (tabla V.1.2).

\subsubsection{Edad de muerte}

Las piezas identificadas en La Mina presentan unos desgastes muy dispares. En primer lugar, el $\mathrm{P}_{3}$ tiene un desgaste marcado y el $\mathrm{M}_{1}$ un desgaste máximo, no diferenciándose ya las fosetas. Como se ha comentado anteriormente, estas dos piezas se han asignado al mismo ejemplar ya que en la mandíbula de Labeko Koba se ha registrado un desgaste similar. Álvarez-Lao (2007) asigna un rango de edad adulto-viejo para la mandíbula de Labeko Koba, incluyéndola en su grupo 3 ó 4 . Debido a la similitud existente con las piezas de La Mina, se asigna su desgaste al mismo grupo y por lo tanto la misma edad relativa, un adulto-viejo (tabla V.2.2).

Tabla V.2.2

Rangos de edad de los individuos de $C$. antiquitatis identificados

\begin{tabular}{llllccc}
\hline & & & Desgaste & Fase y Grupo de desgaste & Edad relativa \\
\hline \multirow{2}{*}{ La Mina } & Individuo 1 & 05.40.LM.738 & $\mathrm{P}_{3}$ & Marcado & Grupo 3 ó 4 & Adulto - Viejo \\
& 05.40.LM.759 & $\mathrm{M}_{1}$ & Máximo & & Fase 5 & Adulto - Viejo \\
\hline
\end{tabular}

La pieza de la Peña Mudá, el P33, se incluye en la fase 5 de Borsuk-Bialynika (1973), correspondiéndola por lo tanto una edad relativa de adulto-viejo.

\subsubsection{Discusión}

Los restos recuperados presentan una morfología típica de los rinocerontes, como los dientes superiores pilofodontos, lo que nos permite asignarlas a la familia Rhinocerotidae. En el Pleistoceno europeo nos encontramos con dos géneros de rinocerontes: Stephanorhinus y Coelodonta. 
Por lo general, Coelodonta tiene unos dientes pequeños, con el esmalte más rugoso y grueso, y unas coronas más altas. La dentición superior se caracteriza por tener unas crestas y unos ganchos grandes que tienden a aislar la foseta media de la prefoseta, por tener unos ectolofos más cuadrangulares y que además son paralelos al eje de la fila dental, metaconos más marcados en la cara bucal, unos protoconos orientados posteriormente, hipoconos más pequeños, valles linguales estrechos y poco profundos, y unas prefosas grandes y profundas. Por otra parte, los dientes inferiores, además de las coronas altas y los esmaltes gruesos, presentan unos lóbulos anteriores relativamente anchos (Van der Made, 2010). Estos caracteres permiten asignar los restos a Coelodonta antiquitatis.

Guérin (1980) reconoce dos estados evolutivos dentro de la especie. La primera y más antigua sería $C$. antiquitatis praecursor, una subespecie grácil y de mayor talla. La segunda sería $C$. antiquitatis antiquitatis, algo más pequeña y robusta. Dichos estadios han sido definidos partiendo del esqueleto postcraneal (Guérin, 1980). Sin embargo, la ausencia de este tipo de material nos impide una asignación clara por lo que no asignamos este material a un tipo particular de estadio evolutivo.

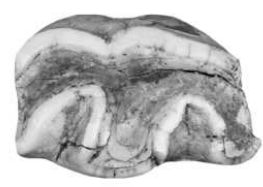

1.a

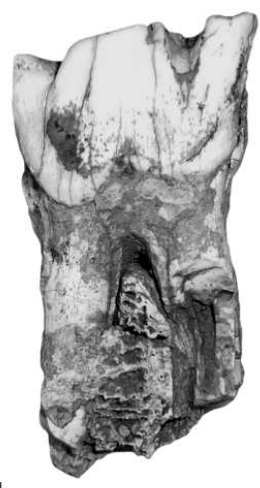

1.b

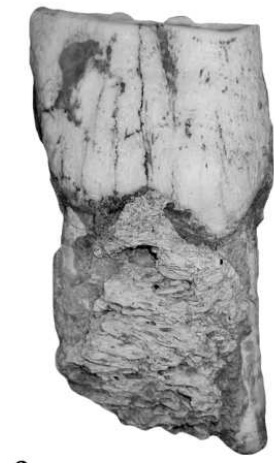

1.c

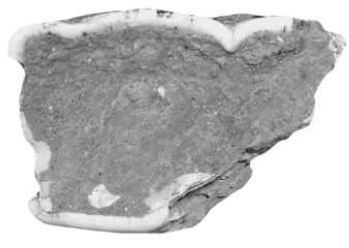

2.a
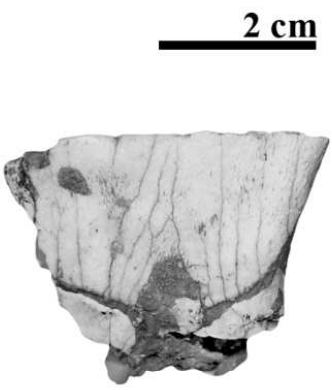

2.b

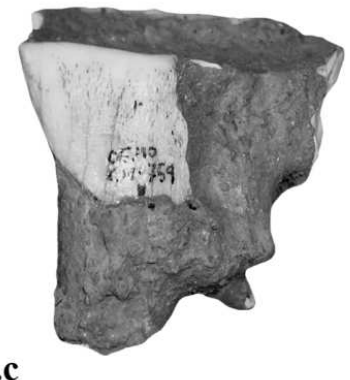

2.c

3.c

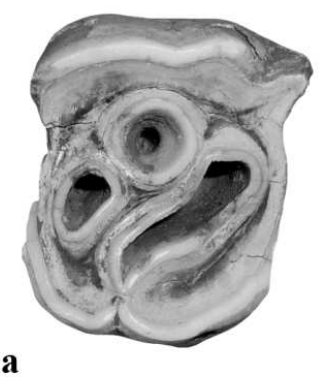

3.b
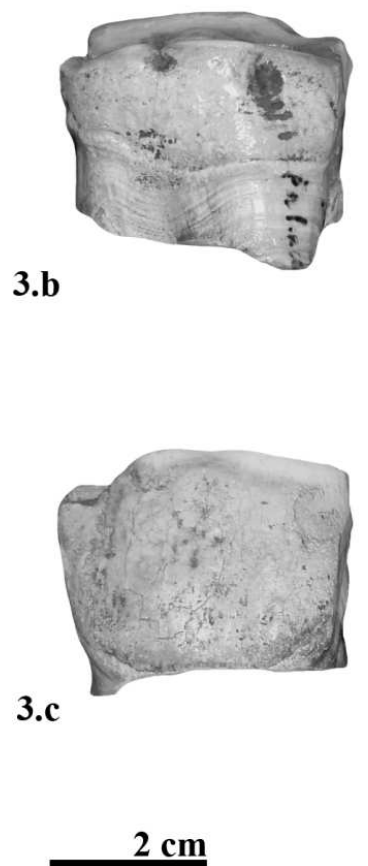

Lámina V.2.1. Coelodonta antiquitatis provenientes de los yacimientos de La Mina (sigla LM) y La Peña de Mudá (sigla Q). 1) 05.40.LM.738 - $\mathrm{P}_{3}$ izquierdo: 1.a vista oclusal; 1.b vista lingual; 1.c vista bucal. 2)

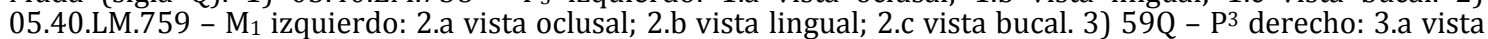
oclusal; 3.b vista lingual; 3.c vista bucal. Nota: los restos procedentes de Mudá, en concreto las figuras 3.b y 3.c presentan, en su base, una anomalía debido a que esta pieza se encontraba incluida en un molde de escayola, lo que ha impedido realizar las fotografías de una forma más aceptable. 


\title{
5.3 Rhinocerotinae indet.
}

Orden Perissodactyla Owen, 1848

Familia Rhinocerotidae Gray, 1821

Subfamilia Rhinocerotinae Gray, 1821

\subsubsection{Generalidades}

Dentro de este apartado se podrían incluir las secciones 5.1.1 y 5.2.1 ya que desconocemos tanto el género como la especie.

\subsubsection{Material}

Prado Vargas: 1 fragmento de esmalte.

\subsubsection{Descripción y comparación}

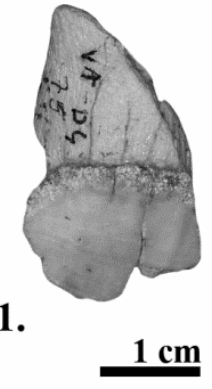

Diente (figura V.3.1): esmalte muy grueso y con una rugosidad muy marcada. Esta pieza no puede ser medida ni asignada a un diente concreto debido a su pequeño tamaño.

\author{
Figura V.3.1. Rhinocerotidae indet. proveniente del yacimiento \\ de Prado Vargas (sigla VA). 1. VA.D-4.75 - Fragmento de esmalte \\ de diente indeterminado.
}

\subsubsection{Número Mínimo de Individuos}

El número mínimo de individuos en este caso es uno, pero sin poder precisar si se trata de un ejemplar inmaduro o maduro.

\subsubsection{Discusión}

La pieza recuperada se encuentra en muy mal estado de conservación. Sin embargo el grosor y la rugosidad del esmalte sugieren que se trata de un ejemplar de grandes dimensiones. El esmalte es más grueso que el observado en otras especies de talla grande como los uros o los bisontes. Además, su rugosidad es mucho más acentuada. Por este motivo, hemos asignado este resto a un rinoceronte. Los rinocerontes del Pleistoceno europeo pertenecen todos a la subfamilia Rhinocerotidae. Como no podemos incluirlos ni en Stephanorhinus ni en Coelodonta por su mal estado, los asignamos esta subespecie. 


\subsection{Equus ferus}

Orden Perissodactyla Owen, 1848

Familia Equidae Gray, 1821

Subfamilia Equinae Gray, 1821

Género Equus Linnaeus, 1758

Especie Equus ferus Boddaert, 1785

\subsubsection{Generalidades}

La familia Equidae surge en América del Norte durante el Eoceno, siendo varias sus dispersiones hacia Eurasia (MacFadden, 1992; Franzen, 2010). Dentro de este grupo podemos diferenciar dos grandes líneas evolutivas. Por un lado, la línea "estononiana" que incluye a los asnos y cebras actuales y, por el otro, la "caballina", los verdaderos caballos (Fosten, 1988).

Los restos más antiguos identificados en Europa provienen de Rumania (Azzaroli, 1990; Maldonado, 1996), aunque la mayoría de los autores coinciden en señalar que este género llega a Europa en el Villafranquiense Medio, hace 2,6 m.a (Alberdi et al., 1997). La primera línea evolutiva, de la que se tiene registro en Europa, es la "estenoniana". A éstos pertenecen los restos de Khapry, Liventsovka, Montópoli, El Rincón y Huélago, asignados a E. livenzovensis en unos casos, a $E$. cf. bressanus (Bajguheva ,1971) en otros y por último a E. stenonis livenzovensis (Alberdi y Ruiz Bustos, 1989). En Europa, el final de esta línea no se conoce bien. Por una parte, Maldonado (1996) sugiere que los últimos estenonianos llegarían hasta el Pleistoceno Medio de manos de E. stenonis y E. altidens (Azzaroli, 1990; Alberdi et al., 1991). Otros autores incluyen a E. hydruntinus dentro de este grupo por lo que su distribución cronológica se dilataría hasta el Pleistoceno Tardío (Forsten, 1990). Por último, hay otros investigadores que sugieren una evolución hasta E. suessenbornensis (Forsten, 1999) o incluso hasta E. ferus (Prat, 1968, 1980; Alberdi y Ruiz Bustos, 1989).

Hay varias opiniones acerca de cuál pudo ser la primera forma "caballina". Por una parte, Alberdi y Ruiz Bustos (1989) incluyen al caballo de Süssenborn, E. süssenbornensis en los verdaderos caballos, mientras que Prat (1980) y Azzaroli (1985) le consideran uno de los últimos estenonianos. Otros autores como Forsten (1988) y Eisenmann (1991) sugieren que E. ferus mosbachensis podría ser el primer representante de este grupo.

El origen de Equus ferus, nombre que se aplica a las formas silvestres en lugar de $E$. caballus que queda reservado a las formas domésticas, no está del todo claro. Algunos autores como Prat (1980) lo sitúan en la línea E. bressanus - E. sussenbornesis ya que presentan dentro de su configuración dental ciertos caracteres caballinos (Prat, 1968, 1980; Alberdi y Ruiz Bustos, 1989). Sin embargo, otros como Azzaroli (1990) consideran al caballo de Süssenborn fuera de esta línea.

A partir del Pleistoceno Medio, la clasificación se complica, diferenciándose gran cantidad de subespecies, definidas a partir de los cambios en el tamaño y robustez de sus extremidades; y por la moderación o aumento de ciertos caracteres presentes en los dientes. Así, durante el MIS 11, nos encontramos con E. ferus mosbachensis en yacimientos como l'Arago, OIS 12, la Micoque, OIS 11, o Swanscombe, OIS 9. Esta subespecie es grande, robusta y tiene los dientes y los protoconos grandes. Otra subespecie, más pequeña pero más robusta, sería E. mosbachensis palustris (Bonifay, 1980). En Steinheim se registra una subespecie más pequeña y robusta que E. ferus mosbachensis, el E. steinheimensis. En la Península Ibérica, Pratt (1977) define otra nueva subespecie, pequeña y con los dientes y protoconos pequeños, E. ferus torralbae. Los caracteres arcaicos de su esqueleto postcraneal la sitúan más cerca de E. steinheimensis que de E. f. mosbachensis (Maldonado, 1996). En el yacimiento de Ea (Vizcaya), OIS5, Torres (1970) define otra subespecie, $E$. ferus eaensis. Este caballo presenta unos dientes inferiores con un tamaño similar al de $E$. steinheimensis y son muy parecidos morfológicamente a los de E. ferus taubachensis. En el 
OIS5e nos encontramos con E. ferus taubachensis (Musil, 1977). Este caballo es de talla media y tiene unos dientes y protoconos grandes. De mayores dimensiones sería E. ferus pivetaui (Prat, 1968), de finales del OIS4. Es parecido a E. f. taubachensis pero tiene los dientes algo más grandes.

En el Pleistoceno Tardío nos encontramos con un caballo pequeño, robusto, con dientes pequeños y protoconos grandes, el E. ferus germanicus. Los restos ibéricos de esta especie, identificados en yacimientos como Cova Negra, Atapuerca, Las Yedras y Villacastín, fueron reclasificados por Maldonado (1996) como E. ferus cf. germanicus. Algo posterior, pero incluida en la misma línea evolutiva, es E. ferus gallicus. Es una subespecie más pequeña y robusta, con los dientes más pequeños pero con protoconos más grandes. Eisenmann (1991) pone en duda esta subespecie; aunque acepta E. ferus arcelini Guadelli (1986), una forma más grácil, con protoconos grandes y dientes más pequeños. En la Península Ibérica se define una nueva subespecie a partir de los restos del yacimiento de Los Casares, E. ferus casarensis (Altuna, 1973). Es una forma de pequeña talla, con índices protocónicos grandes y unas extremidades gráciles. Otra subespecie ibérica sería E. ferus antunesi, definida en los yacimientos portugueses de Salemas, Fontainhas y Joäo Ramos (Cardoso y Eisenmann, 1989). Es un caballo pequeño, grácil, con dientes pequeños pero muy hipsodontos y protoconos grandes.

Todas estas clasificaciones sugieren una gran complejidad taxonómica agravada en los últimos años por diversos estudios genéticos que revelan diferencias muy significativas entre las clasificaciones morfológicas y genéticas (Weinstock et al., 2005). Estos análisis indican que, tal vez, la historia evolutiva de este género no sea tan complicada (Orlando et al., 2009) y que las clasificaciones morfológicas deberían ser profundamente revisadas (Kefena et al., 2012). Weinstock et al., (2005), empleando ADN mitocondrial, reducen los linajes a cinco grupos: caballinos, caballos de Norteamérica, Hippidion, équidos africanos y hemiones asiáticos. Orlando et al., (2008) sugieren que la variabilidad observada a nivel morfológico en los équidos pleistocenos puede deberse su gran plasticidad, lo que les permitiría adaptarse a los cambios ambientales de este periodo. Los primeros estudios genéticos los realizaron George y Ryder (1986), clasificando este grupo en: caballos, cebras y hemiones, incluyéndose en este último a los asnos. Posteriormente, otros análisis separan a los asnos de los hemiones al considerarlos diferentes genéticamente (BejaPereira et al., 2004). Estos estudios se han realizado también en especies caballinas salvajes actuales, aportando nuevos datos sobre el origen de la domesticación (Lira et al., 2009; Boyd et al., 2008; Lau et al., 2009). Los datos genéticos sugieren una profunda revisión de las líneas evolutivas de los équidos del Pleistoceno europeo.

La dificultad a la hora de establecer caracteres diagnósticos y relaciones filogenéticas claras parece algo frecuente en los últimos años. Asimismo, la presencia de gran cantidad de subespecies en la Península Ibérica durante el Pleistoceno Tardío hace difícil establecer relaciones de parentesco o bien establecer caracteres morfológicos diagnósticos en este grupo. Por lo tanto, consideramos necesario realizar una revisión de los équidos recuperados en los yacimientos del Pleistoceno Superior de la Meseta Norte.

\subsubsection{Material}

El material identificado es abundante. Los restos utilizados en cada apartado, descripción y edad de muerte, son diferentes debido, en algún caso, al estado de conservación y a la información que se puede obtener de cada uno.

En el apartado de descripción y comparación el material empleado ha sido el siguiente:

Cueva de Valdegoba: 548 restos: 1 mandíbula, 362 restos dentales y 185 postcraneales. El material dental corresponde a: $20 \mathrm{D}_{2}, 31 \mathrm{D}_{3}, 10 \mathrm{D}_{4}, 7 \mathrm{dI}_{1}, 12 \mathrm{dI}_{2}, 20 \mathrm{dI}_{3}, 4 \mathrm{I}_{1}, 9 \mathrm{I}_{2}, 14 \mathrm{I}_{3}, 7$ $\mathrm{P}_{2}, 19 \mathrm{P}_{3-4}, 24 \mathrm{M}_{1-2}, 14 \mathrm{M}_{3}, 21 \mathrm{D}^{2}, 57 \mathrm{D}^{3-4}, 3 \mathrm{C}_{\mathrm{i}}, 5 \mathrm{C}^{\mathrm{s}}, 1 \mathrm{I}^{1}, 8 \mathrm{I}^{2}, 6 \mathrm{I}^{3}, 13 \mathrm{P}^{2}, 30 \mathrm{P}^{3-4}, 19 \mathrm{M}^{1-2}$ y 16 $\mathrm{M}^{3}$. El material postcraneal, 172 identificables, se compone de: 1 axis, 1 fragmento de 
pelvis, 1 epífisis proximal de tibia, 2 fragmentos de húmero, 3 fragmentos de fémur, 2 calcáneos, 7 astrágalos, 24 fragmentos de metápodos, 3 metacarpos II, 8 metacarpos III, 3 metacarpos IV, 3 metatarsos II, 11 metatarsos III, 7 metatarsos IV, 11 falanges proximales, 9 falanges medias, 11 falanges distales, 11 carpales repartidos en 3 escafoides, 2 magnum, 2 lunares, 1 psiforme, 1 semilunar, 1 piramidal y 1 uncinato; 30 tarsales divididos en 15 naviculares, 14 cuneiformes y 1 cuboide; 20 sesamoideos y 4 sesamoideos distales.

Prado Vargas: tres restos: $1 \mathrm{P}_{2}, 1 \mathrm{P}$ 3-4; y la epífisis proximal de un fémur.

Cueva Millán: 26 piezas: 25 dientes y un resto postcraneal. Los dientes identificados son: $1 \mathrm{D}_{2}, 1 \mathrm{D}_{3}, 1 \mathrm{D}_{3-4}, 1 \mathrm{I}_{1} ; 2 \mathrm{I}_{2}, 1 \mathrm{I}_{3}, 2 \mathrm{P}_{2}, 4 \mathrm{P}_{3-4}, 2 \mathrm{M}_{1-2}, 4 \mathrm{M}_{3}, 2 \mathrm{I}^{1}, 1 \mathrm{P}^{4}$. El único resto postcraneal recuperado es un sesamoideo.

Cueva del Búho: 14 restos: 9 dentales y 5 postcraneales. De ellos se han podido identificar 2 incisivos deciduales, 4 incisivos permanentes y un canino. El material postcraneal comprende 1 astrágalo, 1 húmero, 1 escafoides y dos falanges medias. Estos restos corresponden a excavaciones antiguas (Sala, 2012).

Abrigo Vergara: 15 restos, todos ellos dientes: $1 \mathrm{P}_{3-4}, 1 \mathrm{M}_{1-2}, 1 \mathrm{D}^{3-4}, 1 \mathrm{P}^{3-4}, 1 \mathrm{M}^{1-2}$.

La Peña de Estebanvela: 45 piezas: 2 mandíbulas, 1 maxilar, 34 dientes y 8 restos postcraneales. El material se reparte en: 2 mandíbulas con series $\mathrm{D}_{3}-\mathrm{M}_{3}$ e $\mathrm{I}_{1}-\mathrm{M}_{3}, 2 \mathrm{dI}_{1}, 3$ $\mathrm{dI}_{3}, 1 \mathrm{D}_{2}, 1 \mathrm{D}_{3-4}, 2 \mathrm{I}_{1}, 3 \mathrm{P}_{2}, 2 \mathrm{P}_{3-4}, 3 \mathrm{M}_{3}, 2 \mathrm{M}_{1-2}, 1$ maxilar con la serie $\mathrm{P}^{3-\mathrm{M}^{3},}, 2 \mathrm{D}^{2}, 3 \mathrm{D}^{3-4}, 1 \mathrm{I}^{1}, 4$ $\mathrm{M}^{1-2}, 1 \mathrm{P}^{3-4}$, y $1 \mathrm{M}^{3}$. Los restos postcraneales identificados son: 2 magnum, 1 trapezoidal, 2 sesamoideos, 1 falange media y1 falange distal.

En el apartado de la edad de muerte, se emplean los dientes, debido a su buen estado de conservación. Los restos analizados son:

Cueva de Valdegoba: 92 restos: $3 \mathrm{I}_{1}, 8 \mathrm{I}_{2}, 13 \mathrm{I}_{3}, 6 \mathrm{P}_{2}, 5 \mathrm{P}_{3-4}, 6 \mathrm{M}_{1-2}, 3 \mathrm{M}_{3}, 1 \mathrm{I}^{1}, 7 \mathrm{I}^{2}, 4 \mathrm{I}^{3}, 7 \mathrm{P}^{2}$, $11 \mathrm{P}^{3-4}, 9 \mathrm{M}^{1-2}$ y $9 \mathrm{M}^{3}$.

Prado Vargas: 2 restos: $1 \mathrm{P}_{2}$ y $1 \mathrm{P}^{3-4}$.

Cueva Millán: 22 restos en tres niveles diferentes: Nivel 1A: $1 \mathrm{D}_{2}, 1 \mathrm{D}_{3}, 1 \mathrm{D}_{3-4}, 2 \mathrm{I}^{1}, 1 \mathrm{P}_{2}, 2$ $\mathrm{P}_{3-4}$ y $2 \mathrm{M}_{1-2}$. Nivel 1B: $1 \mathrm{P}_{2}$ y $1 \mathrm{P}_{3-4}$. Nivel $1 \mathrm{C}: 1 \mathrm{I}_{1}, 1 \mathrm{I}_{2} 1 \mathrm{I}_{3}, 1 \mathrm{P}_{3-4}, 2 \mathrm{P}^{3-4}$ y $4 \mathrm{M}^{3}$.

Cueva del Búho: 5 restos: $1 \mathrm{dI}_{1}, 1 \mathrm{Di}_{3}, 1 \mathrm{I}_{3}, 1 \mathrm{I}^{1}$ y $1 \mathrm{C}^{\mathrm{S}}$.

La Peña de Estebanvela: 52 restos en tres niveles: Nivel I: $1 \mathrm{dI}_{1}, 2 \mathrm{dI}_{3}, 1 \mathrm{D}_{3-4}, 1 \mathrm{D}^{2}, 2 \mathrm{D}^{3-4}, 2$ $\mathrm{I}_{1}, 1 \mathrm{P}_{2}, 1 \mathrm{M}_{3}, 2 \mathrm{I}^{1}$ y $2 \mathrm{M}^{1-2}$. Nivel II: $1 \mathrm{dI}_{1}, 1 \mathrm{D}_{2}, 1 \mathrm{D}^{2}, 1 \mathrm{D}^{3-4}, 1 \mathrm{I}_{3}, 1 \mathrm{P}_{2}, 2 \mathrm{P}_{3-4}, 2 \mathrm{M}_{3}, 1 \mathrm{P}^{3}, 1 \mathrm{P}^{4}, 1 \mathrm{P}^{3-}$ $4,1 \mathrm{M}^{1}, 1 \mathrm{M}^{2}, 1 \mathrm{M}^{1-2}$ y $1 \mathrm{M}^{3}$. Nivel III: $1 \mathrm{D}_{3}, 1 \mathrm{D}_{4}, 1 \mathrm{D}^{2}, 2 \mathrm{I}_{1}, 2 \mathrm{I}_{2}, 2 \mathrm{I}_{3}, 1 \mathrm{P}_{2}, 1 \mathrm{P}_{3}, 1 \mathrm{P}_{4}, 1 \mathrm{P}_{3-4}, 1 \mathrm{M}_{1}$, $1 \mathrm{M}_{2}, 1 \mathrm{M}_{3}, 3 \mathrm{M}_{1-2}$ y $1 \mathrm{P}^{3-4}$.

\subsubsection{Descripción y comparación}

Las descripciones corresponden a las piezas identificadas en la Cueva de Valdegoba, Prado Vargas, Cueva Millán, Cueva del Búho, Abrigo Vergara y la Peña de Estebanvela.

Incisivos deciduales (lámina V.4.1: 2) (tabla V.4.1): son similares a los permanentes pero con una hipsodoncia más atenuada. La corona se encuentra separada de la raíz por un cuello bien marcado y muestran un infundíbulo profundo en la superficie oclusal. Son más pequeños que los permanentes (tablas V.4.1 y 4). 
$\mathbf{d I}_{1}$ : tiene forma rectangular y se estrecha hacia la raíz. La superficie oclusal es más o menos recta. Su cara vestibular es convexa. En la cara distal tiene una faceta de desgaste debido al contacto con el incisivo adyacente. El borde mesial es subhorizontal. El infundíbulo está bien desarrollado. Todas las variables tomadas presentan un fuerte solapamiento en todos los incisivos (tabla V.4.1).

$\mathbf{d I}_{2}$ : su superficie oclusal está curvada lateralmente. Tiene facetas de desgaste tanto en el borde mesial como en el lateral. Sus dimensiones son similares a las del dI 3 (tabla V.4.1).

$\mathbf{d I}_{3}$ : es la pieza que se diferencia más fácilmente debido a la curvatura de la corona que es la más acentuada. Sólo presenta faceta de desgaste en el borde mesial ya que existe un diastema entre esta pieza y el canino inferior.

Tabla V.4.1

Medidas tomadas en los incisivos deciduales de E. ferus

\begin{tabular}{|c|c|c|c|c|c|c|c|}
\hline & DAP & DAP $1 / 2$ & DT & DT $1 / 2$ & H & IL & IA \\
\hline \multicolumn{8}{|l|}{$\mathrm{dI}_{\mathbf{1}}$} \\
\hline \multicolumn{8}{|l|}{ Búho } \\
\hline $\mathrm{n}=1$ & 17,7 & 15,8 & 7,2 & 7,2 & 16,2 & 13,1 & 3,5 \\
\hline \multicolumn{8}{|c|}{ Valdegoba } \\
\hline $\mathrm{n}$ & 7 & 7 & 7 & 7 & 7 & 7 & 7 \\
\hline rango & $14,4-18,7$ & $12,9-18,0$ & $6,5-7,8$ & $6,4-8,9$ & $9,9-13,6$ & $9,7-16,4$ & $2,8-4,6$ \\
\hline $\bar{x} \pm$ s.d. & $16,8 \pm 1,8$ & $15,3 \pm 1,9$ & $7,0 \pm 0,6$ & $7,6 \pm 0,9$ & $12,0 \pm 1,2$ & $13,7 \pm 2,4$ & $4,0 \pm 0,6$ \\
\hline \multicolumn{8}{|c|}{ Estebanvela } \\
\hline $\mathrm{n}$ & 2 & 2 & 2 & 2 & 2 & 2 & 2 \\
\hline rango & $15,4-16,9$ & $14,6-16,6$ & $6,6-8,2$ & $6,2-8,6$ & $12,1-18,9$ & $12,8-13,0$ & $3,2-3,6$ \\
\hline $\bar{x} \pm$ s.d. & $16,1 \pm 1,1$ & $15,6 \pm 1,4$ & $7,4 \pm 1,2$ & $7,4 \pm 1,7$ & $15,5 \pm 4,8$ & $12,9 \pm 0,2$ & $3,4 \pm 0,3$ \\
\hline \multicolumn{8}{|c|}{$\mathrm{dI}_{2}$} \\
\hline \multicolumn{8}{|c|}{ Valdegoba } \\
\hline $\mathrm{n}$ & 10 & 10 & 11 & 11 & 11 & 12 & 12 \\
\hline rango & $13,0-19,4$ & $12,0-17,6$ & $6,1-8,2$ & $6,6-9,6$ & $10,9-15,3$ & $7,4-15,2$ & $2,0-4,9$ \\
\hline$\overline{\mathrm{x}} \pm$ s.d. & $16,8 \pm 2,2$ & $15,1 \pm 1,8$ & $7,3 \pm 0,6$ & $7,7 \pm 0,9$ & $12,6 \pm 1,5$ & $12,9 \pm 2,2$ & $3,5 \pm 0,8$ \\
\hline \multicolumn{8}{|l|}{$\mathrm{dI}_{3}$} \\
\hline \multicolumn{8}{|l|}{ Búho } \\
\hline $\mathrm{n}=1$ & 17,4 & 15,2 & 7,0 & 7,9 & 19,5 & 16,0 & 4,5 \\
\hline \multicolumn{8}{|c|}{ Valdegoba } \\
\hline $\mathrm{n}$ & 14 & 17 & 14 & 17 & 18 & 15 & 17 \\
\hline rango & $8,7-19,1$ & $8,5-16,8$ & $2,5-8,3$ & $6,3-8,4$ & $8,2-16,6$ & $10,7-16,5$ & $2,4-8,2$ \\
\hline $\bar{x} \pm$ s.d. & $17,0 \pm 2,7$ & $14,3 \pm 2,1$ & $7,0 \pm 1,4$ & $7,7 \pm 0,6$ & $12,4 \pm 2,4$ & $13,5 \pm 1,5$ & $4,4 \pm 1,3$ \\
\hline \multicolumn{8}{|c|}{ Estebanvela } \\
\hline $\mathrm{n}$ & 2 & 2 & 2 & 2 & 2 & 2 & 2 \\
\hline rango & $12,1-19,2$ & $8,7-18,3$ & $5,9-8,0$ & $5,9-8,6$ & $28,6-33,8$ & $11,1-12,5$ & $3,9-8,0$ \\
\hline$\overline{\mathrm{x}} \pm$ s.d. & $15,6 \pm 5,0$ & $13,5 \pm 6,8$ & $6.9 \pm 1,5$ & $7,3 \pm 1,9$ & $31,2 \pm 3,6$ & $11,8 \pm 1,0$ & $5,9 \pm 2,9$ \\
\hline
\end{tabular}

Molares deciduales inferiores (lámina V.4.1: 4) (tabla V.4.2): son dientes subrectangulares, $\mathrm{D}_{2}$ y $\mathrm{D}_{4}$, y rectangulares, $\mathrm{D}_{3}$. Sus coronas son bajas y tienen dos raíces: una mesial y otra distal. Tienen un diámetro mesiodistal mayor y un diámetro transversal menor que los permanentes (tablas V.4.6).

Los restos recuperados presentan unos estados de conservación muy desiguales. El material de la Cueva de Valdegoba es el que está mejor conservado. De los cuatro dientes de Cueva Millán sólo se han podido describir tres $1 \mathrm{D}_{2}, 1 \mathrm{D}_{3}$ y $1 \mathrm{D}_{3-4}$. El $\mathrm{D}_{2}$ y el $\mathrm{D}_{3}$ están incluidos en una mandíbula. La pieza aislada, debido a la semejanza morfológica entre el $\mathrm{D}_{3}$ y el $\mathrm{D}_{4}$, se ha incluido en la categoría $\mathrm{D}_{3-4}$. En la Peña de Estebanvela se han recogido fundamentalmente fragmentos y su asignación a molares deciduales se debe a la altura de la corona. Dos de las piezas se han podido identificar como un $\mathrm{D}_{3} \mathrm{y}$ un $\mathrm{D}_{4}$ debido a que se encuentran en una mandíbula. 
$\mathbf{D}_{2}$ : diente subrectangular que se estrecha hacia el extremo mesial. Tiene un metacónido subtriangular; un hipocono corto y plano; y un parastílido muy desarrollado y orientado hacia el extremo anterior. El metastílido es redondeado y el doble bucle está muy abierto y tiene forma de "U". El ectofléxido es corto y no alcanza el cuello que separa el prefléxido del postfléxido en los dientes de la Cueva de Valdegoba y Cueva Millán pero sí en la pieza de la Peña de Estebanvela. El surco bucal está poco acentuado. Presentan pliegue anticaballino. Tienen unos DAP mayores, unos DT ligeramente superiores y unos KL más pequeños que los del resto de deciduales, aunque existe un solapamiento muy marcado en sus valores (tabla V.4.2).

Tabla V.4.2

Medidas tomadas en los molares deciduales inferiores de E. ferus

\begin{tabular}{|c|c|c|c|c|c|c|c|c|}
\hline & DAP & DTa & DTp & DT & $\mathbf{H}$ & Prefl. L. & Postfl. L & $\mathbf{K L}$ \\
\hline \multicolumn{9}{|l|}{$\mathbf{D}_{2}$} \\
\hline \multicolumn{9}{|c|}{ Valdegoba } \\
\hline $\mathrm{n}$ & 3 & & 3 & 3 & 2 & 2 & 2 & 4 \\
\hline rango & $29,7-31,5$ & & $8,5-11,5$ & $12,2-14,8$ & $18,6-41,6$ & $4,2-6,6$ & $14,4-14,6$ & $11,8-14,8$ \\
\hline$x \pm$ s.d. & $30,3 \pm 1,0$ & & $10,1 \pm 1,5$ & $13,2 \pm 1,4$ & $30,1 \pm 16,3$ & $5,4 \pm 1,7$ & $14,5 \pm 0,2$ & $13,5 \pm 1,3$ \\
\hline \multicolumn{9}{|l|}{ Millán } \\
\hline valor & 32,7 & 11,9 & 13,4 & 11,8 & 12,1 & 9,8 & 15,2 & 13,7 \\
\hline \multicolumn{9}{|c|}{ Estebanvela } \\
\hline$n=1$ & & & & & & 10,9 & 12,0 & \\
\hline \multicolumn{9}{|l|}{$\mathbf{D}_{3}$} \\
\hline \multicolumn{9}{|c|}{ Valdegoba } \\
\hline $\mathrm{n}$ & 13 & 11 & 9 & 15 & 12 & 10 & 11 & 14 \\
\hline rango & $25,2-31,3$ & $7,7-13,6$ & $6,2-11,5$ & $8,0-14,3$ & $10,8-31,8$ & $7,2-9,9$ & $6,6-13,1$ & $9,8-17,2$ \\
\hline$x \pm$ s.d. & $28,8 \pm 2,0$ & $10,4 \pm 2,1$ & $8,2 \pm 1,7$ & $10,6 \pm 2,0$ & $21,5 \pm 7,2$ & $9,0 \pm 1,0$ & $11,0 \pm 2,0$ & $13,6 \pm 2,3$ \\
\hline \multicolumn{9}{|l|}{ Millán } \\
\hline$n=1$ & 30,0 & 12,0 & 12,0 & 12,9 & 13,7 & 9,1 & 10,7 & 17,4 \\
\hline \multicolumn{9}{|c|}{ Estebanvela } \\
\hline $\mathrm{n}=1$ & & & 12,2 & & 7,6 & & 14,7 & \\
\hline \multicolumn{9}{|l|}{$\mathbf{D}_{3-4}$} \\
\hline \multicolumn{9}{|c|}{ Estebanvela } \\
\hline $\mathrm{n}=1$ & 27,6 & 13,8 & & 14,9 & 6 & & & \\
\hline \multicolumn{9}{|c|}{$\mathrm{D}_{4}$} \\
\hline \multicolumn{9}{|c|}{ Valdegoba } \\
\hline $\mathrm{n}$ & 3 & 4 & 3 & 5 & 2 & 1 & 2 & 5 \\
\hline rango & $29,9-32,2$ & $7,6-11,1$ & $5,5-5,9$ & $8,6-11,1$ & $23,6-26,6$ & 6,1 & $8,1-9,3$ & $11,3-13,5$ \\
\hline$x \pm$ s.d. & $31,0 \pm 1,2$ & $9,1 \pm 1,5$ & $5,7 \pm 0,2$ & $10,0 \pm 1,0$ & $25,1 \pm 2,2$ & & $8,7 \pm 0,8$ & $12,2 \pm 0,9$ \\
\hline \multicolumn{9}{|l|}{ Millán } \\
\hline$n=1$ & 31,6 & 11,8 & 10,1 & 12,3 & 23,2 & 9,1 & 11,2 & 15,3 \\
\hline \multicolumn{9}{|c|}{ Estebanvela } \\
\hline $\mathrm{n}=1$ & & & 14,2 & & 5,0 & & & \\
\hline
\end{tabular}

D ${ }_{3}$ : son piezas rectangulares, con metacónidos redondeados e hipoconúlidos anchos y planos. El parastílido está orientado lingualmente en las piezas de la Cueva de Valdegoba, mientras que en la pieza de Cueva Millán es plano. El metastílido es subtriangular y el doble bucle está abierto y presenta forma en "U". El ectofléxido es ancho y alargado, situándose entre el prefléxido y el postfléxido. El surco bucal está marcado. La pieza de Cueva Millán presenta pliegue anticaballino. Tienen unos DAP y DT más pequeños, y unos KL más grandes que los de $\mathrm{D}_{2}$ y $\mathrm{D}_{4}$ (tabla V.4.2).

$\mathbf{D}_{4}$ : pieza subrectangular que se estrecha hacia el extremo distal. Tiene el hipoconúlido acentuado y orientado mesiodistalmente. El parastílido está poco marcado. El doble bucle aparece más cerrado que en los deciduales precedentes. Presentan unos DAP más grandes y DT más pequeños que en los otros dos deciduales. Los KL son similares a los del $\mathrm{D}_{2}$ y más pequeños que los de $\mathrm{D}_{3}$ (tabla V.4.2). 
D 3-4: las piezas recuperadas tienen los metacónidos redondeados, los hipoconúlidos estrechos y redondeados, los parastílidos planos y los metastílidos subtriangulares. El doble bucle está abierto y tiene forma de "U". Los ectofléxidos son anchos y largos; y entran entre el prefléxido y el postfléxido en la pieza de la Cueva de Valdegoba, mientras que en la pieza de la Peña de Estebanvela sí que lo hace. Tienen pliegue anticaballino.

Tabla V.4.3

Medidas tomadas en los molares deciduales superiores de E. ferus

\begin{tabular}{|c|c|c|c|c|c|c|c|c|c|}
\hline & DAP & DAP1/2 & DTa & DTp & DT & DT1/2 & H & PL & PL1/2 \\
\hline \multicolumn{10}{|l|}{$\mathbf{D}^{2}$} \\
\hline \multicolumn{10}{|c|}{ Valdegoba } \\
\hline $\mathrm{n}$ & 4 & 9 & & 7 & 6 & 10 & 6 & & \\
\hline rango & $35,9-44,1$ & $31,9-44,6$ & & $13,6-19,3$ & $19,3-22,8$ & $18,9-23,4$ & $7,7-23,0$ & & \\
\hline$x \pm$ s.d. & $38,7 \pm 3,8$ & $36,4 \pm 3,8$ & & $16,0 \pm 2,3$ & $20,5 \pm 1,4$ & $20,3 \pm 1,4$ & $16,2 \pm 5,2$ & & \\
\hline \multicolumn{10}{|c|}{ Estebanvela } \\
\hline $\mathrm{n}$ & 2 & 2 & 2 & 1 & 2 & 2 & 2 & 2 & 1 \\
\hline rango & $39,4-42,0$ & $38,8-40,1$ & $18,3-22,0$ & 20,0 & $20,7-22,5$ & $21,2-23,2$ & $23,8-25,7$ & $6,3-7,5$ & 7,5 \\
\hline$x \pm$ s.d. & $40,7 \pm 1,8$ & $39,4 \pm 0,9$ & $20,1 \pm 2,6$ & & $21,6 \pm 1,2$ & $22,2 \pm 1,4$ & $24,7 \pm 1,3$ & $6,9 \pm 0,9$ & \\
\hline \multicolumn{10}{|l|}{$D^{3-4}$} \\
\hline \multicolumn{10}{|c|}{ Valdegoba } \\
\hline $\mathrm{n}$ & 7 & 24 & 8 & 8 & 17 & 24 & 11 & 21 & 22 \\
\hline rango & $28,2-33,4$ & $27,6-33,1$ & $17,8-23,5$ & $13,7-21,4$ & $18,1-23,9$ & $16,8-24,6$ & $15,5-31,8$ & $5,1-12,0$ & $7,6-20,7$ \\
\hline$x \pm$ s.d. & $31,0 \pm 2,2$ & $29,6 \pm 1,3$ & $20,0 \pm 2,1$ & $17,2 \pm 2,6$ & $21,3 \pm 1,6$ & $21,5 \pm 2,0$ & $25,0 \pm 5,0$ & $9,0 \pm 1,8$ & $10,6 \pm 2,7$ \\
\hline \multicolumn{10}{|c|}{ Estebanvela } \\
\hline $\mathrm{n}$ & 2 & 1 & 2 & 1 & 2 & 1 & 2 & 1 & \\
\hline rango & $29,6-35,2$ & 29,9 & $20,2-23,6$ & 23,6 & $21,6-23,7$ & 24,6 & $20,3-35,5$ & 12,1 & \\
\hline$x \pm$ s.d. & $32,4 \pm 3,9$ & & $21,9 \pm 2,4$ & & $22,6 \pm 1,5$ & & $27,6 \pm 10,7$ & & \\
\hline
\end{tabular}

Molares deciduales superiores (lámina V.4.1: 5) (tabla V.4.3): son dientes con una morfología variable. Tanto el $\mathrm{D}^{2}$ como el $\mathrm{D}^{4}$ presentan un aspecto triangular, mientras que el $\mathrm{D}^{3}$ es rectangular, lo que les diferencia de los premolares y molares superiores que son cuadrangulares. Sus coronas son más bajas que las de los permanentes y tienen tres raíces: una mesial, otra distal y una lingual. Presentan mayores diámetros anteroposteriores y menores transversales que los molares y premolares permanentes (tablas V.4.3 y 8).

Las piezas mejor conservadas se han recuperado en la Cueva de Valdegoba, mientras que los restos del Abrigo Vergara y de la Peña de Estebanvela están muy fragmentados por lo que su identificación, en muchos casos, se basa en su hipsodoncia. En este apartado se han establecido dos categorías, $\mathrm{D}^{2}$ y $\mathrm{D}^{3-4}$, debido a las semejanzas entre $\mathrm{D}^{3}$ y $\mathrm{D}^{4}$.

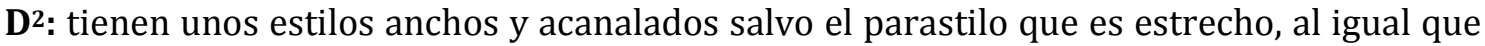
el hipocono. En vista bucal presenta dos surcos longitudinales que recorren toda la corona a diferencia del $\mathrm{D}^{3-4}$ que sólo presenta uno. Tienen unos DAP, DT y PL más grandes que los de $\mathrm{D}^{3-4}$ (tabla V.4.3).

D3-4: las piezas de la Cueva de Valdegoba presentan unos estilos anchos y acanalados, mientras que el diente del Abrigo Vergara los tienen simples y los de la Peña de Estebanvela siempre tienen acanalado el mesostilo. El parastilo está acanalado sólo en dos piezas de la Peña de Estebanvela. El surco hipoconal está acentuado y el protocono es redondeado. Las piezas de la Cueva de Valdegoba tienen unos pliegues caballinos poco acentuados mientras que el diente del Abrigo de Vergara no lo presenta y en la Peña de Estebanvela se registra en todos los casos. En una de las piezas de la Peña de Estebanvela hay un pliegue accesorio al caballino. Métricamente, presentan unos DAP y nos DT más pequeños, y unos PL más grandes que los de $\mathrm{D}^{2}$ (tabla V.4.3). 
Incisivos inferiores permanentes (lámina V.4.1: 1) (tabla V.4.4): son dientes prismáticos, con una hipsodoncia más acentuada que los deciduales. La corona y la raíz no están separadas por un cuello. La corona se curva hacia el extremo lateral, haciéndose más evidente del $\mathrm{I}_{1}$ al $\mathrm{I}_{3}$. Se diferencian de los superiores por la menor curvatura de la corona y por presentar en la cara bucal un único surco longitudinal que la recorre completamente, mientras que los superiores presentan dos. Son más grandes que los deciduales (tablas V.4.1 y 4) y entre sí presentan un fuerte solapamiento en todos los valores (tabla V.4.4).

Tabla V.4.4

Medidas tomadas en los incisivos y caninos inferiores permanentes de E. ferus

\begin{tabular}{|c|c|c|c|c|c|c|c|}
\hline & DAP & DAP 1/2 & DT & DT $1 / 2$ & $\mathbf{H}$ & IL & IA \\
\hline \multicolumn{8}{|l|}{$I_{1}$} \\
\hline \multicolumn{8}{|c|}{ Valdegoba } \\
\hline $\mathrm{n}$ & 3 & & 3 & 3 & 1 & 1 & \\
\hline rango & $9,2-11,6$ & & $9,4-14,9$ & $42,8-58,4$ & 6,8 & 2,9 & \\
\hline $\bar{x} \pm$ s.d. & $10,8 \pm 1,4$ & & $12,0 \pm 2,8$ & $52,3 \pm 8,3$ & & & \\
\hline \multicolumn{8}{|l|}{ Millán } \\
\hline$n=1$ & & & 12,8 & & & 6,7 & 4,6 \\
\hline \multicolumn{8}{|c|}{ Estebanvela } \\
\hline $\mathrm{n}$ & 3 & 1 & 2 & & 2 & 1 & \\
\hline rango & $14,8-18,3$ & 11,8 & $10,4-10,6$ & & $8,2-8,7$ & 4,2 & \\
\hline $\bar{x} \pm$ s.d. & $16,0 \pm 1,9$ & & $10,5 \pm 0,1$ & & $8,4 \pm 0,2$ & & \\
\hline \multicolumn{8}{|l|}{$\mathbf{I}_{2}$} \\
\hline \multicolumn{8}{|c|}{ Valdegoba } \\
\hline $\mathrm{n}$ & 5 & 8 & 7 & 8 & 8 & 6 & 6 \\
\hline rango & $12,5-18,2$ & $9,6-15,7$ & $8,0-10,5$ & $10,2-14,1$ & $34,8-62,8$ & $7,5-12,9$ & $2,9-5,3$ \\
\hline $\bar{x} \pm$ s.d. & $15,4 \pm 2,3$ & $11,9 \pm 2,2$ & $9,4 \pm 1,1$ & $12,3 \pm 1,2$ & $48,4 \pm 10,1$ & $10,3 \pm 2,3$ & $4,3 \pm 0,8$ \\
\hline \multicolumn{8}{|l|}{ Millán } \\
\hline $\mathrm{n}$ & 2 & & 1 & & 1 & 2 & 2 \\
\hline rango & $16,1-17,1$ & & 12,1 & & 57,8 & $9,1-10,6$ & $5,4-5,8$ \\
\hline $\bar{x} \pm$ s.d. & $17,0 \pm 0,7$ & & & & & $9,8 \pm 1,0$ & $5,6 \pm 0,3$ \\
\hline \multicolumn{8}{|c|}{ Estebanvela } \\
\hline $\mathrm{n}$ & 2 & 1 & 2 & & & 2 & 2 \\
\hline rango & $16,5-17,2$ & 13,2 & $9,0-9,6$ & & & $8,5-9,8$ & $4,0-5,2$ \\
\hline$\overline{\mathrm{x}} \pm$ s.d. & $16,8 \pm 0,5$ & & $9,3 \pm 0,4$ & & & $9,2 \pm 0,9$ & $4,6 \pm 0,9$ \\
\hline \multicolumn{8}{|l|}{$\mathbf{I}_{3}$} \\
\hline \multicolumn{8}{|l|}{ Búho } \\
\hline$n=1$ & 16 & & 7,2 & & 29,6 & 12,3 & 6,8 \\
\hline \multicolumn{8}{|c|}{ Valdegoba } \\
\hline $\mathrm{n}$ & 7 & 13 & 10 & 12 & 11 & 9 & 9 \\
\hline rango & $13,9-19,5$ & $10,4-14,6$ & $8,4-10,1$ & $11,3-14,4$ & $37,7-58,9$ & $9,9-13,4$ & $2,9-5,4$ \\
\hline$\overline{\mathrm{x}} \pm$ s.d. & $17,7 \pm 1,8$ & $12,2 \pm 1,2$ & $9,2 \pm 0,5$ & $12,6 \pm 0,8$ & $51,5 \pm 6,8$ & $11,5 \pm 1,2$ & $4,6 \pm 0,7$ \\
\hline \multicolumn{8}{|l|}{ Millán } \\
\hline$n=1$ & 20,4 & & & & & 9,8 & 5,5 \\
\hline \multicolumn{8}{|c|}{ Estebanvela } \\
\hline $\mathrm{n}$ & 2 & & 2 & & 1 & 3 & 1 \\
\hline rango & $10,6-18,0$ & & $7,2-8,7$ & & 60,7 & $8,1-14,0$ & 5,0 \\
\hline $\bar{x} \pm$ s.d. & $14,3 \pm 5,2$ & & $7,9 \pm 1,1$ & & & $10,7 \pm 3,0$ & \\
\hline \multicolumn{8}{|l|}{$\mathbf{C i}$} \\
\hline \multicolumn{8}{|c|}{ Valdegoba } \\
\hline $\mathrm{n}$ & 1 & 1 & 1 & 1 & 2 & & \\
\hline rango & 11,4 & 14,7 & 10,7 & 13,9 & $40,3-46,3$ & & \\
\hline $\bar{x} \pm$ s.d. & & & & & $43,3 \pm 4,2$ & & \\
\hline
\end{tabular}

I1: su superficie oclusal es más o menos recta. El borde mesial es rectilíneo a diferencia de los otros dos incisivos que son más curvados. La pieza de Cueva Millán se encuentra en una mandíbula, su desgaste es muy marcado y el infundíbulo apenas es visible. La pieza de la Peña de Estebanvela se encuentra en muy mal estado de conservación y se asigna a esta 
pieza debido a que la tabla de desgaste es horizontal, el borde medial es recto y a que tiene un único surco longitudinal en la cara bucal.

$\mathbf{I}_{2}$ : tiene la corona curvada lateralmente y la superficie oclusal oblicua. Presenta facetas de desgaste tanto en el borde mesial como en el lateral debido al contacto con los dientes adyacentes. El infundíbulo está más marcado que en el incisivo anterior.

$\mathbf{I}_{3}$ : su corona está muy curvada y la superficie oclusal es muy oblicua. No presenta faceta de desgaste en el borde lateral. La pieza de la Cueva del Búho es germinal y se asigna a esta pieza debido a la longitud de su corona y a la inclinación de la superficie oclusal. La pieza de Cueva Millán muestra un infundíbulo marcado y aparece junto con los otros dos incisivos en una mandíbula.

Caninos inferiores (lámina V.4.1: 7) (tabla V.4.4): son dientes cónicos, convexos y lisos en su cara lateral y cóncavos medialmente. Muestran, lingualmente, dos crestas longitudinales. Carecen de infundíbulo. Están ausentes o son rudimentarios en las hembras. Están separados del tercer incisivo por un diastema y se encuentran desplazados con respecto a los superiores por lo que el contacto con éstos no suele producirse. Difieren de los superiores por su menor curvatura y por su mayor longitud (tablas V.4.4 y 7).

Tabla V.4.5

Medidas tomadas en los premolares inferiores de E. ferus

\begin{tabular}{|c|c|c|c|c|c|c|c|c|c|}
\hline & DAP & DAP1/2 & DTa & DTp & DT & DT $1 / 2$ & Prefl. L & Postfl. L & $\mathbf{K L}$ \\
\hline \multicolumn{10}{|l|}{$\mathbf{P}_{2}$} \\
\hline \multicolumn{10}{|c|}{ Valdegoba } \\
\hline $\mathrm{n}$ & 6 & 4 & 1 & 4 & 7 & 5 & 7 & 7 & 7 \\
\hline rango & $26,5-33,2$ & $28,0-30,0$ & 12,0 & $11,3-14,1$ & $11,6-14,4$ & $12,7-16,1$ & $6,2-8,5$ & $9,7-17,0$ & $12,0-15,5$ \\
\hline $\bar{x} \pm$ s.d. & $30,1 \pm 2,6$ & $29,2 \pm 0,8$ & & $12,8 \pm 1,2$ & $13,6 \pm 1,0$ & $14,4 \pm 1,2$ & $7,2 \pm 0,9$ & $13,7 \pm 2,9$ & $13,6 \pm 1,5$ \\
\hline \multicolumn{10}{|c|}{ Prado Vargas } \\
\hline $\mathrm{n}=1$ & 31,5 & & 13,0 & 15,2 & 15,5 & & 8,6 & 15,1 & 15,5 \\
\hline \multicolumn{10}{|c|}{ Cueva Millán } \\
\hline $\mathrm{n}$ & 2 & & 2 & 2 & 2 & & 2 & 2 & 2 \\
\hline rango & $32,6-38,3$ & & $10,8-12,7$ & $13,6-17,7$ & $13,6-15,6$ & & $8,5-8,9$ & $12,1-17,6$ & $15,4-17,9$ \\
\hline $\bar{x} \pm$ s.d. & $35,5 \pm 4,0$ & & $11,7 \pm 1,4$ & $15,6 \pm 2,9$ & $14,6 \pm 1,4$ & & $8,7 \pm 0,3$ & $14,8 \pm 3,9$ & $16,7 \pm 1,8$ \\
\hline \multicolumn{10}{|c|}{ Estebanvela } \\
\hline $\mathrm{n}$ & 2 & & 2 & 3 & 3 & 1 & 1 & 1 & 3 \\
\hline rango & $32-42,6$ & & $13,2-17,2$ & $14,1-22,1$ & $15,7-22$ & 14,4 & 8,5 & 14,0 & $12,6-18,0$ \\
\hline $\bar{x} \pm$ s.d. & $37,3 \pm 7,5$ & & $15,2 \pm 2,8$ & $17,1 \pm 4,4$ & $17,5 \pm 3,9$ & & & & $15,5 \pm 2,7$ \\
\hline \multicolumn{10}{|c|}{$\mathbf{P}_{3}$} \\
\hline \multicolumn{10}{|c|}{ Valdegoba } \\
\hline $\mathrm{n}$ & 2 & & 1 & 3 & 2 & & 2 & 2 & 2 \\
\hline rango & $25,9-28,6$ & & 14,7 & $12,6-13,5$ & $14,6-15,4$ & & $8,2-9,3$ & $8,1-13,5$ & $13,0-15,5$ \\
\hline$\overline{\mathrm{x}} \pm$ s.d. & $27,3 \pm 2,0$ & & & $13,1 \pm 0,5$ & $15,0 \pm 0,6$ & & $8,8 \pm 0,8$ & $10,8 \pm 3,9$ & $14,2 \pm 1,7$ \\
\hline \multicolumn{10}{|l|}{$\mathbf{P}_{3-4}$} \\
\hline \multicolumn{10}{|c|}{ Valdegoba } \\
\hline $\mathrm{n}$ & 9 & 8 & 7 & 8 & 10 & 9 & 11 & 12 & 13 \\
\hline rango & $26,2-30,5$ & $25,4-29,1$ & $13,1-16,5$ & $9,6-16,8$ & $13,6-19,5$ & $14,7-18,2$ & $5,6-9,9$ & $8,8-15,3$ & $13,3-18,4$ \\
\hline$x \pm$ s.d. & $28,3 \pm 1,4$ & $27,8 \pm 1,1$ & $14,3 \pm 1,1$ & $12,7 \pm 2,5$ & $15,6 \pm 2,0$ & $16,9 \pm 1,2$ & $8,8 \pm 1,2$ & $12,0 \pm 1,7$ & $15,9 \pm 1,5$ \\
\hline \multicolumn{10}{|c|}{ Cueva Millán } \\
\hline $\mathrm{n}$ & 4 & 1 & 4 & 4 & 1 & & 4 & 4 & 4 \\
\hline rango & $26,8-33,1$ & 31,0 & $15,5-18,4$ & $14,2-19,4$ & 17,6 & & $9,3-10,9$ & $13,1-16,6$ & $15,6-17,7$ \\
\hline $\bar{x} \pm$ s.d. & $30,5 \pm 3,1$ & & $16,4 \pm 1,4$ & $16,6 \pm 2,1$ & $17,6 \pm 0,7$ & & $10,1 \pm 0,6$ & $14,8 \pm 1,5$ & $16,6 \pm 1,0$ \\
\hline \multicolumn{10}{|c|}{ Estebanvela } \\
\hline $\mathrm{n}=1$ & 31,0 & 28,7 & 14,2 & 17,1 & 17,7 & 17,5 & 10,1 & 13,8 & 17,1 \\
\hline \multicolumn{10}{|c|}{$\mathbf{P}_{4}$} \\
\hline \multicolumn{10}{|c|}{ Valdegoba } \\
\hline $\mathrm{n}=1$ & 24,3 & & 11,6 & 11,5 & 17,5 & & 8,1 & 11,2 & \\
\hline
\end{tabular}


Premolares inferiores (lámina V.4.1: 1) (tabla V.4.5) (figura V.4.1): son dientes molariformes, prismáticos, con coronas altas y superficies oclusales lofodónticas. El borde lingual está más elevado que el bucal. Tienen dos raíces: una mesial y otra distal. Son más anchos pero más cortos que los molares deciduales inferiores (tablas V.4.2 y 5) pero más grandes que los molares inferiores permanentes, aunque en este último caso se observan solapamientos entre sus valores (tablas V.4.5 y 6).

Los premolares inferiores se diferencian de los molares inferiores por presentar una tabla de desgaste diferente. En este caso, la superficie oclusal está inclinada hacia el extremo mesial, mientras que en los molares aparece inclinada hacia la parte posterior. Esta inclinación mesial se hace más evidente en el $\mathrm{P}_{2}$. La corona es más rectilínea que en los molares inferiores. Si observamos la superficie oclusal, vemos que, en el caso de los premolares, los bordes mesial y distal son más o menos paralelos mientras que son divergentes en los molares. Los hipoconúlidos de los premolares son anchos y cortos, mientras que los de los molares son estrechos y alargados. Los équidos tienen cuatro premolares inferiores. El $\mathrm{P}_{1}$ es el conocido como "diente de lobo" y normalmente está ausente. Se presentan dos categorías: $\mathrm{P}_{2}$ y $\mathrm{P}_{3-4}$. Esta última se define debido a la semejanza entre el $\mathrm{P}_{3}$ y el $\mathrm{P}_{4}$.

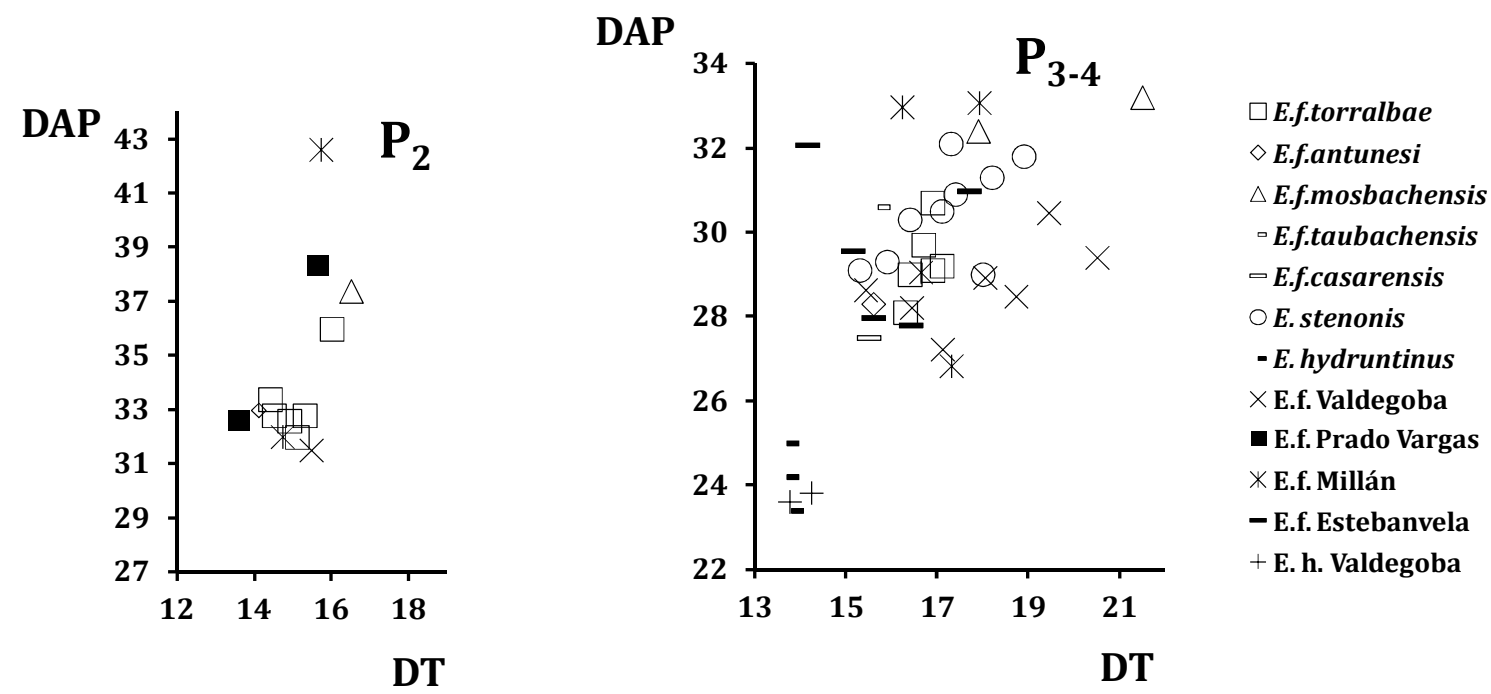

Figura V.4.1. Diagramas bivariantes de los premolares inferiores: DAP (diámetro anteroposterior) y DT (diámetro transversal). E.f.torralbae de Atapuerca, Pedraza, Las Yedras, Torralba, Pinilla del Valle, Cova Negra y Transfesa. E.f.antunesi de la Carihuela. E.f.mosbachensis de Mosbach y L'Arago. E.f.taubachensis de Taubach. E.f.casarensis de Los Casares. E. stenonis de Atapuerca, Saint Vallier, Senéze, Venta Micena, Huélago y Baza 1. E. hydruntinus de la Carihuela, Abri Suard, Arcy y Prolom (Eisenmann y Baryshnikov, 1994; Maldonado, 1996).

$\mathbf{P}_{2}$ : presenta una morfología triangular debido a la gran proyección mesial del parastilo. Tiene el hipoconúlido ancho y corto, el metacónido redondeado y el metastílido subtriangular, aunque en una de las piezas de Cueva Millán aparece redondeado. El surco bucal está poco acentuado, el ectofléxido se encuentra muy alejado del prefléxido y el postfléxido. El cuello, formado por el prefléxido y el postfléxido, se abre al metacónido. El borde lingual del protocónido y del hipocono es plano. En las piezas de Prado Vargas y Cueva Millán hay un pliegue pticostílido poco marcado. Tanto el índice del postfléxido (IPF) como el del doble bucle (IDB) de las piezas de la Peña de Estebanvela y Cueva Millán son más pequeños que los registrados en otros E. ferus. El IPF de Prado Vargas es similar al E. ferus antunesi de Salemas y se solapa con los valores medios de E. f. mosbachensis y E. $f$. torralbae (tabla V.4.9). Las piezas de la Cueva de Valdegoba son pequeñas, sus valores están próximos a los de E. f. torralbae y E. f. antunesi. El caballo de Prado Vargas presenta un tamaño similar al de E. $f$. torralbae. Tanto en Cueva Millán como en la Peña de Estebanvela hay dos piezas muy grandes, con diámetros anteroposteriores mayores que los de E. f. mosbachensis. El resto de piezas de estos dos yacimientos son similares a los de E. f. antunesi y E. f. torralbae (figura V.4.1). 
$\mathbf{P}_{3-4}$ : piezas rectangulares con un pliegue pticostílido generalmente rudimentario, al igual que E. hydruntinus y a diferencia de E. stenonis (Maldonado, 1996). El ectofléxido no penetra entre el prefléxido y el ectofléxido. El metacónido es redondeado y metastílido es subtriangular. El entofléxido tiene forma de "U" a diferencia de E. stenonis y E. hydruntinus que los tienen cerrados y agudos, en forma de "V". El pliegue anticaballino generalmente está muy marcado. El borde lingual del protocónido es plano y el del hipocónido oblicuo en tres casos de Cueva Millán, mientras que en otro presentan cierta convexidad, a diferencia de lo que ocurre en $E$. hydruntinus donde normalmente son redondeados y las paredes vestibulares cóncavas (Maldonado, 1996). El borde vestibular del metacónido es cóncavo y el del metastílido convexo. En la pieza de Cueva Millán, el parastílido es plano y no llega a alcanzar la cara lingual. Los índices del postfléxido y del doble bucle de las piezas de la Cueva de Valdegoba, Cueva Millán y la Peña de Estebanvela están dentro de los rangos de E. ferus torralbae, estando el de la Cueva de Valdegoba más próximo a los valores del E. ferus antunesi de Salemas (tabla V.4.9). El E. ferus de la Cueva de Valdegoba presenta unos dientes anchos pero con longitudes pequeñas. Los valores más pequeños están próximos a los de E. ferus torralbae. Por otra parte, el caballo de Cueva Millán presenta valores próximos al E. ferus mosbachensis aunque su DT tiende a ser menor. Los restos de la Peña de Estebanvela tienen unos valores muy variables, unos están próximos a los materiales de la Cueva de Valdegoba y otros muestran unas longitudes próximas a los ejemplares de Cueva Millán y a E.f. mosbachensis (figura V.4.1).
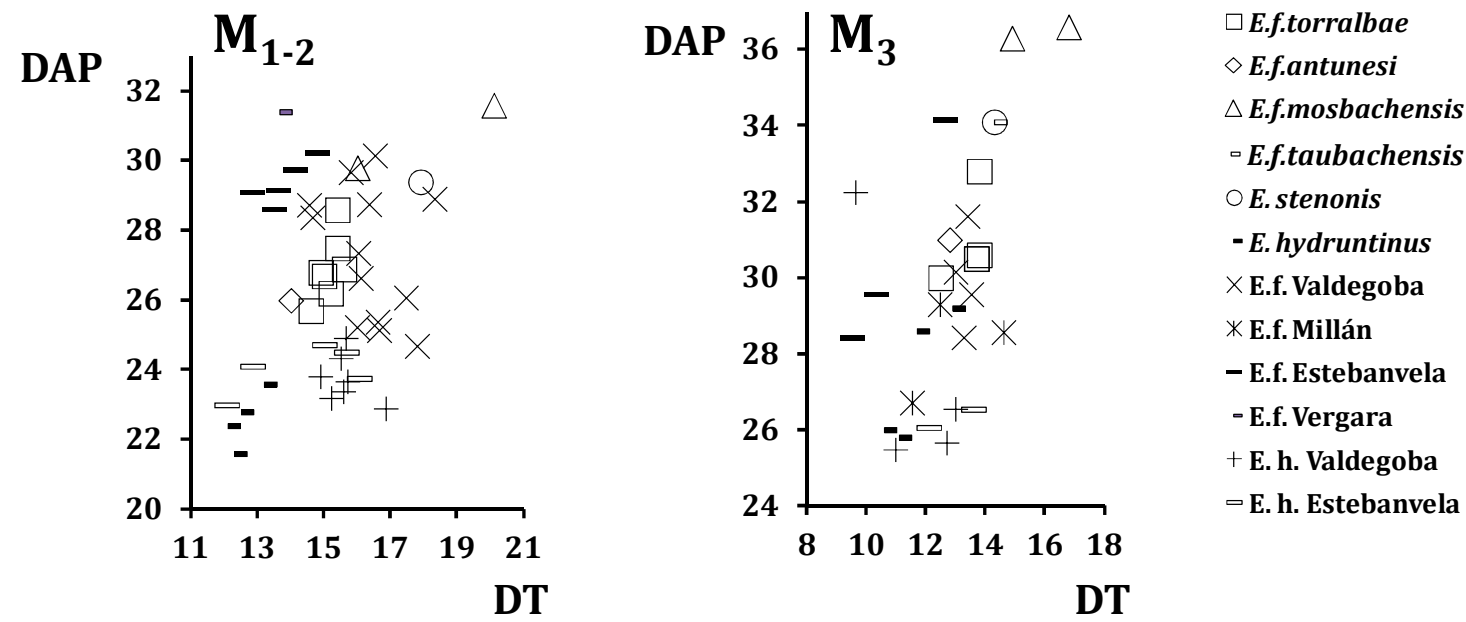

Figura V.4.2. Diagramas bivariantes de los molares inferiores permanentes: DAP (diámetro anteroposterior) y DT (diámetro transversal). E.f.torralbae de Atapuerca, Torralba, Pinilla del Valle y Transfesa. E.f.antunesi de la Carihuela. E.f.mosbachensis de Mosbach y L'Arago. E.f.taubachensis de Taubach. E. stenonis de Chatillon Saint. E. hydruntinus de la Carihuela, Arcy y Prolom (Eisenmann y Baryshnikov, 1994; Maldonado, 1996).

Molares inferiores permanentes (lámina V.4.1: 1) (tabla V.4.6) (figura V.4.2): son dientes prismáticos, con las coronas altas y morfología lofodonta. La superficie oclusal es rectangular salvo en el $\mathrm{M}_{3}$ que es subtriangular. El borde lingual está más elevado que el bucal. Tienen dos raíces, una mesial y otra distal. Difieren de los premolares inferiores en la tabla de desgaste, orientada en este caso posteriormente; por la morfología del hipoconúlido, redondeada y alargada; y por presentar los bordes mesial y distal más o menos paralelos. Son más cortos y más anchos que los molares deciduales inferiores (tablas V.4.2 y 5). Existe un fuerte solapamiento con los premolares inferiores pero hay una tendencia a que estás piezas sean más pequeñas (tablas V.4.5 y 6). Las categorías establecidas en este apartado son $\mathrm{M}_{1}, \mathrm{M}_{2}, \mathrm{M}_{3}$ y $\mathrm{M}_{1-2}$. Las dos primeras sólo se identifican en restos mandibulares y la categoría $\mathrm{M}_{1-2}$ se aplica a piezas aisladas debido a la semejanza entre el $\mathrm{M}_{1}$ y el $\mathrm{M}_{2}$.

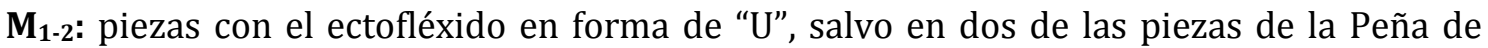
Estebanvela que tienen morfología en "V", al igual que E. stenonis y E. hydruntinus. El pliegue pticostílido presenta un desarrollo variable. El ectofléxido es largo y estrecho, 
alcanzado, en algunos casos, el cuello que separa el prefléxido del postfléxido. El entocónido es redondeado o subtriangular, al igual que el metacónido. Todas las piezas de Cueva Millán tienen las raíces rotas y, en general, muestran el prefléxido y el postfléxido sin pliegues aunque, en uno de los casos, el postfléxido tiene muchos surcos. La pieza del Abrigo Vergara aparece muy concrecionada y ha sido asignada a esta categoría debido a que la tabla de desgaste está orientada hacia atrás y a que la morfología del hipoconúlido es redondeada.

Tabla V.4.6

Medidas tomadas en los molares inferiores permanentes de E. ferus

\begin{tabular}{|c|c|c|c|c|c|c|c|c|c|}
\hline & DAP & DAP1/2 & DTa & DTp & DT & DT $1 / 2$ & Prefl. L & Postfl. L & KL \\
\hline \multicolumn{10}{|l|}{$\mathbf{M}_{1-2}$} \\
\hline \multicolumn{10}{|c|}{ Valdegoba } \\
\hline $\mathrm{n}$ & 21 & 30 & 26 & 23 & 29 & 30 & 31 & 30 & 31 \\
\hline rango & $22,6-30,7$ & $21,9-28,6$ & $10,0-16,5$ & $8,0-12,6$ & $12,4-18,3$ & $12,8-17,3$ & $5,0-9,9$ & $6,7-12,5$ & $10,9-16,5$ \\
\hline $\bar{x} \pm$ s.d. & $26,2 \pm 2,6$ & $25,1 \pm 2,6$ & $13,0 \pm 1,5$ & $10,0 \pm 1,2$ & $15,4 \pm 1,4$ & $14,6 \pm 1,2$ & $8,4 \pm 1,2$ & $9,7 \pm 1,6$ & $13,2 \pm 1,3$ \\
\hline \multicolumn{10}{|l|}{ Millán } \\
\hline $\mathrm{n}$ & 1 & 1 & 1 & 1 & 1 & 1 & 2 & 2 & 1 \\
\hline rango & 29,7 & 22,5 & 14,6 & 12,7 & 14,7 & 14,2 & $7,2-9,2$ & $7,4-12,5$ & 14,3 \\
\hline $\bar{x} \pm$ s.d. & & & & & & & $8,2 \pm 1,4$ & $10,0 \pm 3,6$ & \\
\hline \multicolumn{10}{|c|}{ Vergara } \\
\hline$n=1$ & 31,4 & & 13,8 & 11,2 & 13,7 & 14,4 & & & 12,4 \\
\hline \multicolumn{10}{|c|}{ Estebanvela } \\
\hline $\mathrm{n}$ & 2 & & 2 & 2 & 2 & 1 & & & 2 \\
\hline rango & $29,1-29,2$ & & $11,4-13,4$ & $7,3-7,6$ & $12,9-13,6$ & 15,7 & & & $14,4-14,9$ \\
\hline $\bar{x} \pm$ s.d. & $29,1 \pm 0,0$ & & $12,4 \pm 1,4$ & $7,4 \pm 0,2$ & $13,3 \pm 0,6$ & & & & $14,6 \pm 0,4$ \\
\hline \multicolumn{10}{|c|}{$M_{3}$} \\
\hline \multicolumn{10}{|c|}{ Valdegoba } \\
\hline $\mathrm{n}$ & 9 & 10 & 13 & 10 & 14 & 12 & 12 & 15 & 13 \\
\hline rango & $24,9-32,3$ & $25,1-32,8$ & $9,3-13,9$ & $5,5-10,2$ & $9,6-18,2$ & $10,8-15,3$ & $5,5-9,7$ & $6,8-12,5$ & $10,8-19,6$ \\
\hline $\bar{x} \pm$ s.d. & $28,5 \pm 2,7$ & $28,1 \pm 2,5$ & $11,6 \pm 1,4$ & $7,0 \pm 1,7$ & $13,3 \pm 2,1$ & $12,7 \pm 1,2$ & $8,0 \pm 1,1$ & $9,8 \pm 1,9$ & $12,8 \pm 2,3$ \\
\hline \multicolumn{10}{|l|}{ Millán } \\
\hline $\mathrm{n}$ & 3 & & 3 & 2 & 3 & 1 & 4 & 4 & \\
\hline rango & $26,7-29,3$ & & $12,4-13,9$ & $9,7-12,7$ & $11,5-14,6$ & 15,3 & $7,5-10,0$ & $9,7-11,4$ & \\
\hline$\overline{\mathrm{x}} \pm$ s.d. & $28,2 \pm 1,3$ & & $13,2 \pm 0,8$ & $11,2 \pm 2,1$ & $12,9 \pm 1,6$ & & $8,5 \pm 1,0$ & $10,7 \pm 0,9$ & \\
\hline \multicolumn{10}{|c|}{ Estebanvela } \\
\hline $\mathrm{n}=1$ & 28,4 & & 4,2 & 9,5 & 9,5 & & 8,4 & 11,0 & 13,0 \\
\hline
\end{tabular}

El índice del prefléxido de las piezas de la Cueva de Valdegoba y del Abrigo Vergara está en rango de E. ferus torralbae. Las piezas de Cueva Millán y de la Peña de Estebanvela, por otra parte, son más pequeñas. El índice del doble bucle, IDB, de los dientes de la Cueva de Valdegoba, Cueva Millán y de la Peña de Estebanvela está dentro del rango de E. ferus antunesi y cercano a los valores más bajos de E. ferus torralbae (tabla V.4.9). El caballo de la Cueva de Valdegoba tiene un tamaño similar a E. ferus torralbae. El material de la Peña de Estebanvela está próximo al ejemplar de Cueva Millán y se encuentra por encima de los valores registrados en E. ferus antunesi y E. ferus torralbae (figura V.4.2).

$\mathbf{M}_{3}$ : dientes triangulares debido al gran desarrollo del hipoconúlido. Tienen ectofléxidos largos, llegando casi al cuello que separa el prefléxido del postfléxido. En todas las piezas se ha observado un pliegue pticostílido bien marcado a diferencia de E. stenonis y $E$. hydruntinus. Los parastílidos son cortos. En vista bucal, se observan tres columnas, mientras que en los dos primeros molares sólo hay dos. El entocónido y el metacónido son redondeados. El postfléxido presenta gran cantidad de pliegues. En la pieza de Cueva Millán, el entofléxido se estrecha hacia el extremo bucal lo que le da una apariencia en "V". En las piezas de la Peña de Estebanvela el doble bucle tiene forma de " $U$ ", lo que difiere en E. stenonis y E. hydruntinus (Maldonado, 1996). El caballo de la Cueva de Valdegoba presenta unos valores próximos a $E$. ferus torralbae y $E$. ferus antunesi y son más pequeños que E. f. mosbachensis. Las piezas de Cueva Millán son ligeramente más pequeñas que las 
subespecies antunesi y torralbae. Por otra parte, los dientes de la Peña de Estebanvela son más estrechos que los de otros équidos, mientras que su diámetro anteroposterior es similar al registrado en E. f. torralbae (figura V.4.2).

Tabla V.4.7

Medidas tomadas en los incisivos y caninos superiores permanentes de E. ferus

\begin{tabular}{|c|c|c|c|c|c|c|c|}
\hline & DAP & DAP1/2 & DT & DT $1 / 2$ & $\mathbf{H}$ & IL & IA \\
\hline \multicolumn{8}{|l|}{$\mathbf{I}^{1}$} \\
\hline \multicolumn{8}{|c|}{ Valdegoba } \\
\hline$n=1$ & 16,8 & 13,1 & 10,4 & 11,8 & 51,9 & 10,3 & 3,3 \\
\hline \multicolumn{8}{|l|}{ Millán } \\
\hline $\mathrm{n}$ & 2 & 1 & 1 & 1 & 1 & 2 & 2 \\
\hline rango & $13,7-19,7$ & 16,9 & 10,4 & 12,3 & 54,2 & $4,2-13,2$ & $2,7-3,4$ \\
\hline $\bar{x} \pm$ s.d. & $16,7 \pm 4,2$ & & & & & $8,7 \pm 6,4$ & $3,0 \pm 0,5$ \\
\hline \multicolumn{8}{|l|}{ Búho } \\
\hline$n=1$ & & 6,8 & 5,5 & 5,1 & 39,8 & & \\
\hline \multicolumn{8}{|c|}{ Estebanvela } \\
\hline$n=1$ & 19,4 & 15,4 & 10,5 & 13,2 & 63,5 & 12,0 & 4,3 \\
\hline \multicolumn{8}{|l|}{$I^{2}$} \\
\hline \multicolumn{8}{|c|}{ Valdegoba } \\
\hline $\mathrm{n}$ & 3 & 8 & 7 & 8 & 7 & 7 & 7 \\
\hline rango & $12,9-18,8$ & $9,0-14,7$ & $6,7-12,1$ & $10,5-15,0$ & $40,7-63,8$ & $6,8-12,9$ & $3,7-5,4$ \\
\hline$\overline{\mathrm{x}} \pm$ s.d. & $15,1 \pm 3,2$ & $12,5 \pm 1,8$ & $10,0 \pm 1,7$ & $12,5 \pm 1,4$ & $52,4 \pm 7,3$ & $10,1 \pm 2,1$ & $4,5 \pm 0,7$ \\
\hline \multicolumn{8}{|c|}{$I^{3}$} \\
\hline \multicolumn{8}{|c|}{ Valdegoba } \\
\hline $\mathrm{n}$ & 5 & 6 & 5 & 6 & 6 & 6 & 6 \\
\hline rango & $15,4-21,9$ & $10,7-17,1$ & $9,0-11,8$ & $11,7-14,8$ & $37,6-63,6$ & $6,9-17,3$ & $4,1-6,8$ \\
\hline$\overline{\mathrm{x}} \pm$ s.d. & $18,7 \pm 2,4$ & $13,8 \pm 2,2$ & $10,4 \pm 1,0$ & $13,2 \pm 1,3$ & $54,4 \pm 10,7$ & $12,1 \pm 3,6$ & $5,1 \pm 1,3$ \\
\hline \multicolumn{8}{|l|}{$\mathrm{C}^{\mathrm{s}}$} \\
\hline \multicolumn{8}{|l|}{ Búho } \\
\hline$n=1$ & 14,5 & & 8,4 & & 33,1 & & \\
\hline \multicolumn{8}{|c|}{ Valdegoba } \\
\hline $\mathrm{n}$ & 3 & 4 & 3 & 4 & 5 & & \\
\hline rango & $6,7-10,4$ & $11,3-12,6$ & $2,9-7,6$ & $9,6-11,4$ & $35,0-42,3$ & & \\
\hline $\bar{x} \pm$ s.d. & $8,5 \pm 1,8$ & $12,1 \pm 0,6$ & $4,6 \pm 2,6$ & $10,2 \pm 0,8$ & $36,9 \pm 4,5$ & & \\
\hline
\end{tabular}

Incisivos superiores (lámina V.4.1: 6) (tabla V.4.7): piezas prismáticas con las coronas más largas que los deciduales. Tienen una raíz pero no poseen un cuello muy marcado. La superficie oclusal es más o menos rectangular y se inclina lateralmente a medida que avanzamos hacia el $\mathrm{I}_{3}$. Son más grandes que los deciduales y similares a los inferiores permanentes (tablas V.4.1 y 4). Son parecidos a los inferiores pero se diferencian por sus coronas más curvadas, por tener el infundíbulo en una posición más central y por presentar dos surcos longitudinales en la cara bucal. El borde medial del $\mathrm{I}^{1}$ es subhorizontal, el del $\mathrm{I}^{2}$ es oblicuo y el del $\mathrm{I}^{3}$ se encuentra fuertemente inclinado. La toma de medidas en estos dientes, tanto superiores como inferiores, es bastante complicada debido a la curvatura y el grado de desgaste. La clasificación, por tanto, se ha llevado a cabo a partir de criterios morfológicos. Métricamente existe un gran solapamiento en los valores registrados (tabla V.4.4 y 6).

Caninos superiores (lámina V.4.1: 8) (tabla V.4.7): son dientes cónicos con una raíz. Carecen de infundíbulo y presentan unos bordes agudos. Son similares a los inferiores pero son más pequeños y curvados.

Premolares superiores (lámina V.4.1: 3) (tabla V.4.8) (figura V.4.3): son dientes molariformes, prismáticos, hipsodontos y con una configuración lofodóntica. Tienen tres raíces: una lingual y dos bucales. La superficie oclusal es cuadrangular salvo en el $\mathrm{P}^{2}$, que 
es triangular debido al gran desarrollo del parastilo. Difieren de los deciduales por su menor longitud y mayor anchura (tablas V.4.3 y 8). Por otra parte, son más grandes que los molares superiores permanentes (tabla V.4.8). Las categorías que se presentan son las siguientes: $\mathrm{P}^{2}, \mathrm{P}^{3}, \mathrm{P}^{4}$ y $\mathrm{P}^{3-4}$. La última de ellas se ha aplicado a piezas aisladas debido a la gran semejanza entre el tercer y cuarto premolar. Los $\mathrm{P}^{3}$ y $\mathrm{P}^{4}$ descritos se han recuperado en maxilares por lo que su diferenciación es clara.

TablaV.4.8

Medidas tomadas en los premolares y molares superiores permanentes de E. ferus

\begin{tabular}{|c|c|c|c|c|c|c|c|c|c|}
\hline & DAP & DAP1/2 & DTa & DTp & DT & DT $1 / 2$ & $\mathbf{H}$ & PL & PL 1/2 \\
\hline \multicolumn{10}{|l|}{$\mathbf{P}^{2}$} \\
\hline \multicolumn{10}{|c|}{ Valdegoba } \\
\hline $\mathrm{n}$ & 9 & 11 & 4 & 8 & 11 & 12 & 7 & 4 & 3 \\
\hline rango & $27,2-36,4$ & $25,8-35,2$ & $20,3-25,7$ & $17,3-26,4$ & $20,5-27,7$ & $20,2-28,0$ & $20,9-54,8$ & $8,4-13,3$ & $9,8-13,3$ \\
\hline $\bar{x} \pm$ s.d. & $32,7 \pm 3,1$ & $31,5 \pm 2,7$ & $23,6 \pm 2,4$ & $21,4 \pm 2,7$ & $23,5 \pm 2,4$ & $22,6 \pm 2,4$ & $34,3 \pm 12,3$ & $11,5 \pm 2,2$ & $11,9 \pm 1,8$ \\
\hline \multicolumn{10}{|l|}{$\mathbf{P}^{3}$} \\
\hline \multicolumn{10}{|c|}{ Estebanvela } \\
\hline$n=1$ & 30,2 & & 26,1 & 26,6 & 27,9 & & & 13,5 & \\
\hline \multicolumn{10}{|l|}{$P^{4}$} \\
\hline \multicolumn{10}{|c|}{ Estebanvela } \\
\hline$n=1$ & 29,4 & & 25,3 & 25,8 & 27,4 & & 79,1 & 12,7 & \\
\hline \multicolumn{10}{|l|}{$\mathbf{P}^{3-4}$} \\
\hline \multicolumn{10}{|c|}{ Valdegoba } \\
\hline $\mathrm{n}$ & 20 & 26 & 22 & 20 & 24 & 28 & 25 & 28 & 24 \\
\hline rango & $23,5-30,8$ & $22,2-29,4$ & $17,8-27,6$ & $11,1-24,0$ & $19,4-27,5$ & $19,8-28,8$ & $21,5-81,2$ & $9,3-14,6$ & $9,5-17,6$ \\
\hline$\overline{\mathrm{x}} \pm$ s.d. & $27,1 \pm 2,3$ & $25,8 \pm 2,1$ & $22,9 \pm 1,9$ & $20,5 \pm 2,9$ & $24,2 \pm 2,0$ & $24,6 \pm 2,0$ & $57,7 \pm 17,7$ & $12,2 \pm 1,3$ & $12,3 \pm 1,8$ \\
\hline \multicolumn{10}{|l|}{ Millán } \\
\hline $\mathrm{n}$ & 2 & 1 & 2 & 2 & 2 & 1 & 2 & 2 & 1 \\
\hline rango & $29,8-32,9$ & 29 & $24,3-26,4$ & $22,2-25,1$ & $25,9-27,5$ & 27,8 & $56,1-72,0$ & $12,7-13,7$ & 12,8 \\
\hline $\bar{x} \pm$ s.d. & $31,3 \pm 2,2$ & & $25,4 \pm 1,5$ & $23,7 \pm 21$ & $26,7 \pm 1,1$ & & $64,0 \pm 11,3$ & $13,2 \pm 0,8$ & \\
\hline \multicolumn{10}{|c|}{ Estebanvela } \\
\hline $\mathrm{n}$ & 2 & & 2 & 2 & 2 & & 1 & 1 & \\
\hline rango & $30,5-31,9$ & & $25,5-26,6$ & $26,0-27,2$ & $26,3-27,6$ & & 68,6 & 13,3 & \\
\hline $\bar{x} \pm$ s.d. & $31,1 \pm 1,0$ & & $26,0 \pm 0,7$ & $26.6 \pm 0,8$ & $27,0 \pm 0,9$ & & & & \\
\hline \multicolumn{10}{|l|}{$\mathbf{M}^{1}$} \\
\hline \multicolumn{10}{|c|}{ Estebanvela } \\
\hline$n=1$ & 26,5 & 24,7 & 25 & 22 & 26 & 26,2 & 77,7 & 13 & 13,8 \\
\hline \multicolumn{10}{|l|}{$\mathbf{M}^{1-2}$} \\
\hline \multicolumn{10}{|c|}{ Valdegoba } \\
\hline $\mathrm{n}$ & 15 & 31 & 25 & 22 & 26 & 31 & 23 & 30 & 29 \\
\hline rango & $21,0-27,0$ & $20,1-30,4$ & $19,0-24,3$ & $11,7-22,0$ & $20,3-26,1$ & $11,0-26,9$ & $9,7-79,4$ & $7,9-14,2$ & $8,2-14,6$ \\
\hline$\overline{\mathrm{x}} \pm$ s.d. & $23,1 \pm 1,8$ & $23,7 \pm 2,4$ & $21,6 \pm 1,2$ & $18,2 \pm 2,2$ & $22,7 \pm 1,3$ & $23,6 \pm 2,8$ & $44,6 \pm 19,7$ & $11,2 \pm 1,5$ & $11,9 \pm 1,7$ \\
\hline \multicolumn{10}{|c|}{ Vergara } \\
\hline$n=1$ & & & & & 25,5 & 26,6 & 76,4 & & \\
\hline \multicolumn{10}{|c|}{ Estebanvela } \\
\hline $\mathrm{n}$ & 2 & 1 & 1 & 2 & 1 & & 3 & 1 & 1 \\
\hline rango & $26,1-27,3$ & 25,9 & 23,9 & $22,3-24,0$ & 26,4 & & $47,7-71$ & 11 & 13 \\
\hline$\overline{\mathrm{x}} \pm$ s.d. & $26,1 \pm 0,8$ & & & $23,0 \pm 1,2$ & & & $63,2 \pm 13,8$ & & \\
\hline \multicolumn{10}{|l|}{$\mathbf{M}^{2}$} \\
\hline \multicolumn{10}{|c|}{ Estebanvela } \\
\hline$n=1$ & 26,5 & 24,6 & 22,8 & 19,5 & 25,5 & 26,7 & 83,4 & 14,2 & 15,7 \\
\hline \multicolumn{10}{|l|}{$\mathbf{M}^{3}$} \\
\hline \multicolumn{10}{|c|}{ Valdegoba } \\
\hline $\mathrm{n}$ & 9 & 11 & 11 & 10 & 10 & 16 & 7 & 12 & 17 \\
\hline rango & $22,3-28,6$ & $24,2-29,0$ & $17,2-24,5$ & $13,8-19,7$ & $16,6-21,3$ & $18,5-25,5$ & $25,8-70,1$ & $10,4-15,1$ & $11,2-16,3$ \\
\hline $\bar{x} \pm$ s.d. & $25,5 \pm 2,1$ & $26,8 \pm 1,7$ & $20,3 \pm 2,0$ & $16,3 \pm 2,2$ & $19,8 \pm 1,7$ & $22 \pm 2,2$ & $50,8 \pm 16,2$ & $12,4 \pm 1,4$ & $13,3 \pm 1,5$ \\
\hline
\end{tabular}


P2: es un diente triangular, con estilos menos proyectados que los del $\mathrm{D}^{2}$. El mesostilo en unos casos es ancho y acanalado, y en otros es simple. La cara interestilar mesial es más plana que la distal. El protocono es corto y redondeado. Las fosas presentan pocos pliegues. Tienen un pliegue caballino desarrollado a diferencia de E. hydruntinus. El caballo de la Cueva de Valdegoba es más pequeño que las subespecies torralbae y antunesi (figura V.4.3).
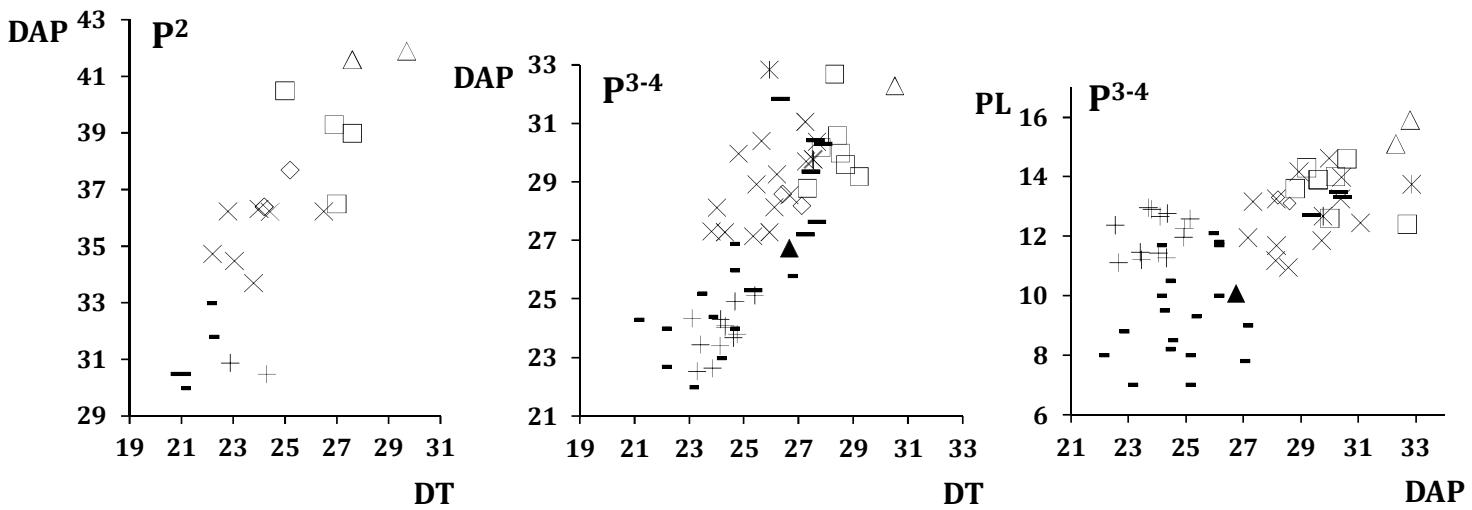

$\square$ E.f.torralbae $\diamond$ E.f.antunesi $\triangle$ E.f.mosbachensis - E. hydruntinus $\times$ E.f. Valdegoba $*$ E.f. Millán ${ }^{-}-$E.f. Estebanvela + E.h. Valdegoba $\Delta$ E.h. Millán

Figura V.4.3. Diagramas bivariantes de los premolares superiores permanentes: DAP (diámetro anteroposterior), DT (diámetro transversal) y PL (longitud del protocono). E.f.torralbae de Atapuerca, Villacastín, Las Yedras, Torralba, Pinilla del Valle, Cova Negra y Transfesa. E.f.antunesi de la Carihuela y Salemas. E.f.mosbachensis de Mosbach y L'Arago. E. hydruntinus de la Carihuela, Bourgeois Delaunay, Combe Grenal, La Ferrasie, Saint Germain la Riviere, Agios Georgios, Abric Romani, Arcy y Prolom (Eisenmann y Baryshnikov, 1994; Maldonado, 1996).

P3: tiene los estilos marcados y tanto el parastilo como el mesostilo sin acanalar, como en E. hydruntinus. El protocono es grande y está dividido en dos por un surco que recorre toda la cara lingual. Este carácter es diferente en E. hydruntinus en los que este cono es corto y redondeado (Maldonado, 1996). El pliegue caballino está bien marcado lo que le diferencia de E. hydruntinus, pero que sí que se ha observado en algunos premolares de $E$. stenonis (Maldonado, 1996). Son ligeramente más grandes que los $\mathrm{P}^{4}, \mathrm{M}^{1} \mathrm{y} \mathrm{M}^{2}$ del maxilar.

P4: muestra unos estilos poco desarrollados y simples, salvo el parastilo de Cueva Millán que sí presenta surco central. El protocono de la pieza de Cueva Millán es pequeño y no tiene surco longitudinal, mientras que en el diente de la Peña de Estebanvela ocurre lo contrario, es grande y presenta dicho surco. Tanto la prefoseta como la postfoseta presentan pocos pliegues, menos aún que los observados en E. stenonis y E. hydruntinus. Difieren también de estas dos especies por tener un pliegue caballino bien marcado (Maldonado, 1996).

P-4: la corona presenta una ligera concavidad cercana a la raíz en la cara lingual. Los estilos se encuentran proyectados bucalmente. El espacio interestilar mesial es más corto y convexo que el distal, lo que difiere de E. hydruntinus que los suele presentar planos. Las fosetas presentan menos pliegues que en E. stenonis y E. hydruntinus (Maldonado, 1996). El parastilo y el mesostilo son anchos y acanalados, mientras que el metastilo es simple y liso en las piezas de la Cueva de Valdegoba y Prado Vargas. Por otra parte, dos de las piezas de la Peña de Estebanvela tienen el parastilo y el mesostilo acanalados y otras dos no. Tienen el protocono bien marcado, presentando ambos lóbulos del mismo tamaño, con un surco longitudinal que recorre toda la cara lingual. El pliegue caballino está bien desarrollado.

Los índices del protocono de las piezas de la Cueva de Valdegoba, Cueva Millán y la Peña de Estebanvela se encuentran dentro del rango de E. ferus mosbachensis y E. ferus torralbae; además, están próximos a los valores de E. ferus antunesi (tabla V.4.9). Las piezas de la Cueva de Valdegoba presentan unos valores que abarcan a E. ferus torralbae y 
E. ferus antunesi, además tienen un tamaño similar al de los caballos de la Peña de Estebanvela pero son más pequeños que los de Cueva Millán. El tamaño del protocono, relacionado con el diámetro anteroposterior, nos aporta una clasificación similar, con unas piezas de la Cueva de Valdegoba similares a las de las subespecies antunesi, torralbae y a los dientes de la Peña de Estebanvela. Por otra parte, son más pequeñas que las de Cueva Millán y la subespecie mosbachensis (figura V.4.3).

Tabla V.4.9

Índices registrados en la dentición de los E. ferus estudiados y otros caballos euroasiáticos

\begin{tabular}{|c|c|c|c|c|c|c|c|c|c|}
\hline \multirow{2}{*}{ Especie } & \multirow{2}{*}{ Yacimiento } & \multicolumn{2}{|c|}{$\mathbf{P}_{2}$} & \multicolumn{2}{|c|}{$P_{3-4}$} & \multicolumn{2}{|c|}{$\mathbf{M}_{1-2}$} & \multirow{2}{*}{$\begin{array}{l}\mathbf{P}^{3-4} \\
\text { IPL }\end{array}$} & \multirow{2}{*}{$\begin{array}{l}\mathbf{M}^{1-2} \\
\text { IPL } \\
\end{array}$} \\
\hline & & IPF & IDB & IPF & IDB & IPF & IDB & & \\
\hline E. f. torralbae & Torralba & 48,2 & 46,7 & 49,7 & 55,9 & 43,3 & 53,0 & 47,2 & 47,7 \\
\hline E.f. mosbachensis & Mosbach & 48,4 & 49,2 & 46,0 & & & 37,2 & 46,7 & 50,9 \\
\hline E.f. mosbachensis & L'Arago & & & & & & & 48,5 & 52,4 \\
\hline E. f. mosbachensis & Villacastín & & & & & & & 47,7 & 51,5 \\
\hline E. f. mosbachensis & Transfesa & 45,6 & 47,9 & 45,8 & 54,9 & 34,8 & 34,8 & 37,9 & \\
\hline E.f.torralbae & Cova Negra & & & 49,3 & 54,8 & & & 47,7 & 48,0 \\
\hline E. f. torralbae & Las Yedras & & & & & & & 42,0 & \\
\hline E.f. torralbae & Pinilla del Valle & 50,9 & & 45,9 & & 38,1 & & 47,0 & 48,7 \\
\hline E. f. torralbae & Atapuerca TD TG & 51,4 & 50 & 46,3 & 53,4 & 40,6 & 51,4 & 47,0 & 48,9 \\
\hline E. f. torralbae & Atapuerca TE & & & 49,0 & 56,9 & 47,0 & 55,2 & & 57,1 \\
\hline E.f. torralbae & Taubach & & & 53,3 & & & & & \\
\hline E.f.torralbae & Abri Suard & & & & & & & & 54,8 \\
\hline E.f. antunesi & Salemas & & & 46,3 & 59,1 & & 53,5 & 47,2 & 54,0 \\
\hline E.f. antunesi & La Carihuela & 48,2 & 47,3 & & & & & & \\
\hline E.f. antunesi & Pedraza & & & & & 22,9 & 48,9 & & \\
\hline E.f. & Valdegoba & & & 45,5 & 57,1 & 38,4 & 51,4 & 42,8 & 46,7 \\
\hline E. f. & Prado Vargas & 47,9 & 49,1 & & & & & & \\
\hline E.f. & Cueva Millán & 41,8 & 47,0 & 48,5 & 54,6 & 33,5 & 48,0 & 42,2 & \\
\hline E.f. & Vergara & & & & & 39,4 & & & \\
\hline E.f. & Estebanvela & 37,6 & 41,5 & 51,1 & 54,4 & 33,2 & 49,8 & 43,2 & 49,1 \\
\hline
\end{tabular}

* Los valores registrados son valores medios. Los índices, salvo los correspondientes a los yacimientos analizados, provienen de Maldonado (1996).

Molares superiores permanentes (lámina V.4.1: 3) (tabla V.4.8) (figura V.4.4): dientes prismáticos, con coronas altas, morfología lofodonta y tres raíces, una lingual y dos bucales. Presentan una superficie oclusal cuadrangular, salvo el $\mathrm{M}^{3}$ que está proyectado distalmente debido al gran desarrollo del hipocono. Son más anchos pero más cortos que los deciduales superiores (tablas V.4.3 y 8). Se diferencian de los premolares superiores por su menor tamaño (tabla V.4.8) y por presentar unas tablas de desgaste orientadas hacia el borde distal. Se establecen las categorías: $\mathrm{M}^{1}, \mathrm{M}^{2}, \mathrm{M}^{3}$ y $\mathrm{M}^{1-2}$. A esta última se asignan las piezas aisladas debido a la similitud entre los dos primeros molares. Los $\mathrm{M}^{1} \mathrm{y}$ $\mathrm{M}^{2}$ se han identificado en maxilares, en este caso concreto en uno de la Peña de Estebanvela.

M1: tiene los estilos proyectados y simples. El protocono es pequeño y tiene los lóbulos del mismo tamaño. Carece de pliegue caballino. Métricamente, las piezas de la Peña de Estebanvela son iguales que las de la Cueva de Valdegoba y están próximas a E. ferus torralbae (figura V.4.4).

M2: tiene unos estilos simples y poco proyectados. Sólo una de las piezas presenta un surco central en el mesostilo. Los valores son similares a los del $\mathrm{M}^{1}$, aunque su DT es ligeramente inferior (tabla V.4.8)

M1-2: sus estilos son estrechos y carecen de surco central. Las caras interestilares presentan una ligera concavidad. Las fosas presentan pocos pliegues en las piezas de la Cueva de Valdegoba y muchos en los del Abrigo Vergara. El protocono es alargado y 
presentan un surco lingual muy marcado. Los índices del protocono, IPL, de las piezas de la Cueva de Valdegoba y de la Peña de Estebanvela están dentro del rango de E. ferus torralbae y cercanos a los valores de E. ferus antunesi (tabla V.4.9). Métricamente, las piezas de la Cueva de Valdegoba son similares a E. ferus antunesi y E. f. torralbae y a los dientes recuperados en la Peña de Estebanvela (figura V.4.4).
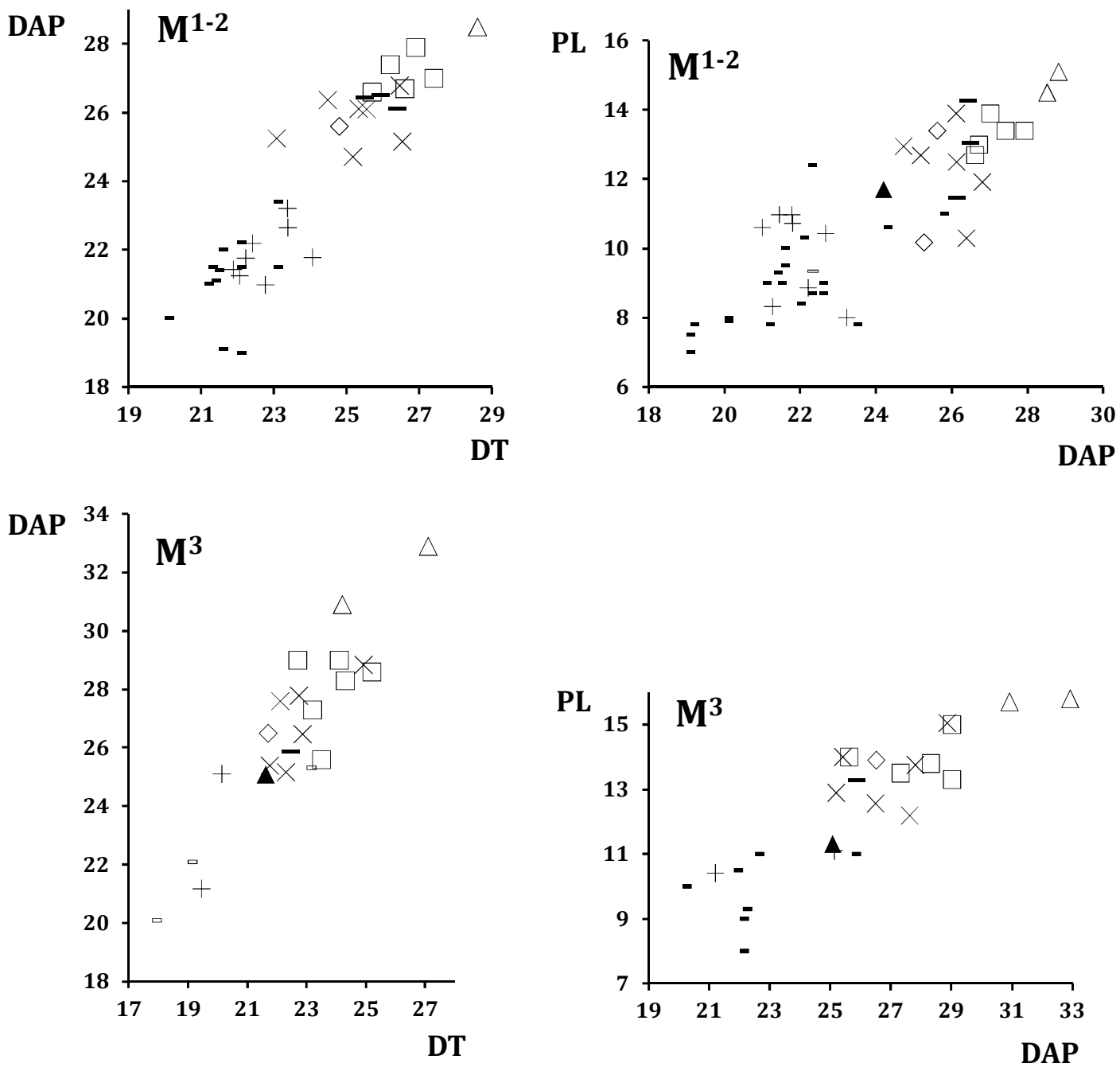

$\square$ E.f.torralbae $\diamond$ E.f.antunesi $\triangle$ E.f.mosbachensis - E. hydruntinus $\times$ E.f. Valdegoba

- E.f. Estebanvela + E.h. Valdegoba $*$ E.h. Millán - E.h. Estebanvela

Figura V.4.4. Diagramas bivariantes de los molares superiores permanentes: DAP (diámetro anteroposterior), DT (diámetro transversal) y PL (longitud del protocono). E.f.torralbae de Atapuerca, Villacastín, Torralba, Pinilla del Valle y Cova Negra. E.f.antunesi de la Carihuela. E.f.mosbachensis de Mosbach y L'Arago. E. hydruntinus de la Carihuela, Bourgeois Delaunay, Combe Grenal, La Ferrasie, Fontarnaud, Pair non Pair, Agios Georgios, Binagady y Prolom (Eisenmann y Baryshnikov, 1994; Maldonado, 1996).

M3: tienen unos estilos simples, redondeados y poco proyectados. Los espacios interestilares son aplanados. Las fosas presentan pocos pliegues. El protocono es más alargado que en el $\mathrm{M}^{1-2}$. Carecen de pliegue caballino en todos los casos. Métricamente, los dientes de la Cueva de Valdegoba y de la Peña de Estebanvela son similares a los de las subespecies antunesi y torralbae; y más pequeños que E. ferus mosbachensis (figura V.4.4).

Húmero (lámina V.4.1: 19): se ha recuperado un fragmento de la zona articular proximal, una epífisis proximal y una diáfisis. Las abrasiones presentes en sus bordes no han permitido medirlo correctamente. La epífisis proximal está formada por la cabeza, el 
cuello, dos tuberosidades y el surco intertuberal. La cabeza, región que articula con la escápula, es circular. En su extremo craneal se abre una fosa que en este caso se encuentra fragmentada. El cuello está bien definido. La tuberosidad lateral, zona donde se inserta el músculo supraespinoso y el infraespinoso, se encuentra bien marcada y separada del tubérculo intermedio por un surco intertuberal de grandes dimensiones. Más pequeño es el surco que separa dicho tubérculo del medial donde también se insertan los músculos anteriormente citados.

Astrágalo (lámina V.4.1: 20) (tabla V.4.10): la superficie proximal y dorsal, zona de articulación con la tibia, consta de dos crestas oblicuas, tróclea, con un surco profundo entre ellas. Dichas crestas son anchas. La superficie distal, que articula con el navicular o cuarto tarsal, es convexa y presenta dos morfologías diferentes en la depresión que se encuentra en esta cara pero que no suponen un carácter específico claro. El extremo anterior de esta cara tiene un pliegue bien marcado. Esta superficie distal también presenta una carilla lateral, triangular o subtriangular, que articula con el cuboide. La superficie plantar tiene cuatro carillas para la articulación con el calcáneo. La articulación de mayores dimensiones, la central, tiene una morfología ovalada con dos tipos diferentes. El primero presenta un extremo inferior convexo con una prolongación poco proyectada en un caso; mientras que en otro esta proyección es muy acusada.

Calcáneo (lámina V.4.1: 18) (tabla V.4.10): las piezas identificadas en la Cueva de Valdegoba están bien conservadas, presentando una de ellas la epífisis proximal sin fusionar. Difiere de la especie actual en la morfología de la cara articular medial que no tiene una forma ovalada y un pliegue acentuado en el extremo medial. En los restos esta cavidad, la cara más proximal presenta una morfología subcircular, mientras que en el caballo actual es ovalada. La superficie articular, inmediatamente inferior, es alargada y estrecha en el fósil mientras que en el actual es alargada y ancha. Asimismo, la cara distal presenta dos carillas articulares fusionadas. Dicha unión es más evidente en los restos de la Cueva de Valdegoba.

Tabla V.4.10

Medidas tomadas en las tibias, calcáneos y astrágalos de E. ferus de la Cueva de Valdegoba

\begin{tabular}{|c|c|c|c|c|c|c|c|c|}
\hline & GL & GB & BT & BP & DP & BD & DD & DM \\
\hline \multicolumn{9}{|l|}{ Tibia } \\
\hline $\mathrm{n}=1$ & & & & 81,4 & 57,0 & & & \\
\hline \multicolumn{9}{|c|}{ Calcáneo } \\
\hline $\mathrm{n}$ & 1 & & & 1 & 1 & 2 & 2 & \\
\hline rango & 104,2 & & & 31,6 & 49,6 & $39,2-49,7$ & $42,5-49,0$ & \\
\hline $\bar{x} \pm$ s.d. & & & & & & $44,5 \pm 7,5$ & $45,7 \pm 4,6$ & \\
\hline \multicolumn{9}{|c|}{ Astrágalo } \\
\hline $\mathrm{n}$ & 6 & 5 & 6 & & & & 6 & 6 \\
\hline rango & $55,5-59,2$ & $56,0-61,7$ & $25,9-31,9$ & & & & $30,3-36,2$ & $46,3-56,3$ \\
\hline$\overline{\mathrm{x}} \pm$ s.d. & $57,2 \pm 1,1$ & $59,0 \pm 2,0$ & $29,0 \pm 1,9$ & & & & $32,8 \pm 2,1$ & $52,4 \pm 4,1$ \\
\hline
\end{tabular}

Tibia (lámina V.4.1: 21) (tabla V.4.10): el estado de conservación de las piezas no es bueno. El resto identificado consiste en una epífisis proximal sin fusionar, cuya tuberosidad anterior no está unida a la pieza por lo que su aspecto es rectangular. El surco del extensor es redondeado y marcado. Los cóndilos medial y lateral se encuentran desarrollados aunque en este último, el surco para el tendón poplíteo está roto.

Metacarpo II (lámina V.4.1: 9) (tabla V.4.11): se han identificado tres piezas. Dos están fragmentadas, conservando sólo la epífisis proximal, y la otra está completa. Se trata de huesos de sección triangular que se estrechan hacia el extremo distal. La superficie que se fusiona con el tercer metacarpo, es plana. La superficie articular proximal es ovalada y 
tiene dos carillas para la articulación con el metacarpo III. Los restos presentan una tuberosidad, en el extremo posterior, menos acusada que en el caballo actual. Una de las piezas tiene una pequeña carilla para la articulación del primer hueso del carpo.

Metacarpo III (lámina V.4.1: 10) (tabla V.4.11) (figura V.4.5): se han recuperado seis piezas, una de ellas completa y las otras cinco conservan únicamente el extremo distal. Se trata de un hueso robusto con el cuerpo o eje semicilíndrico. La tuberosidad metacarpiana apenas está esbozada. La región que articula con el tercer carpo, el magnum, se encuentra dividida en dos partes por una depresión que atraviesa esta zona articular mediolateralmente, uniéndose a aquellas que separan las carillas articulares del cuarto carpal, uncinato, (lateral) y del segundo carpal, trapezoide, (medial). La extremidad distal, adaptada a la articulación con la falange proximal, está compuesta por dos cóndilos, siendo el medial de mayores dimensiones. Las piezas analizadas tienen un tamaño similar al de $E$. f. torralbae y E.f. antunesi; y son más pequeñas que las de E. f. germanicus y E. f. gallicus. El índice de robustez (IR) es ligeramente superior al de la forma antunesi y está dentro del rango de E. f. torralbae y E. f. mosbachensis. También se observa que esta pieza es mucho más robusta que la de E. hydruntinus (figura V.4.5).
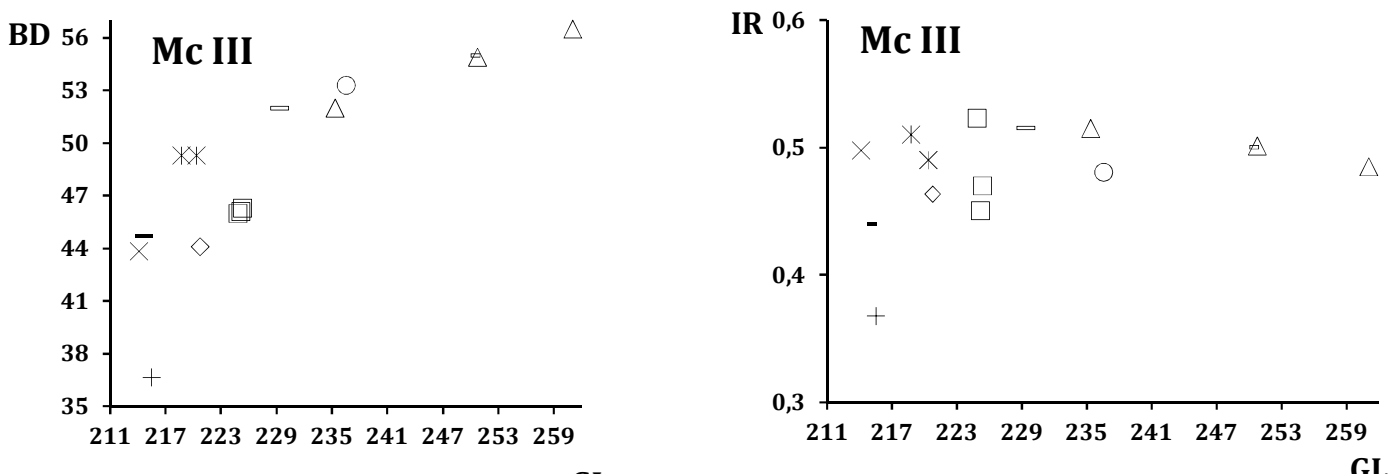

GL

GL
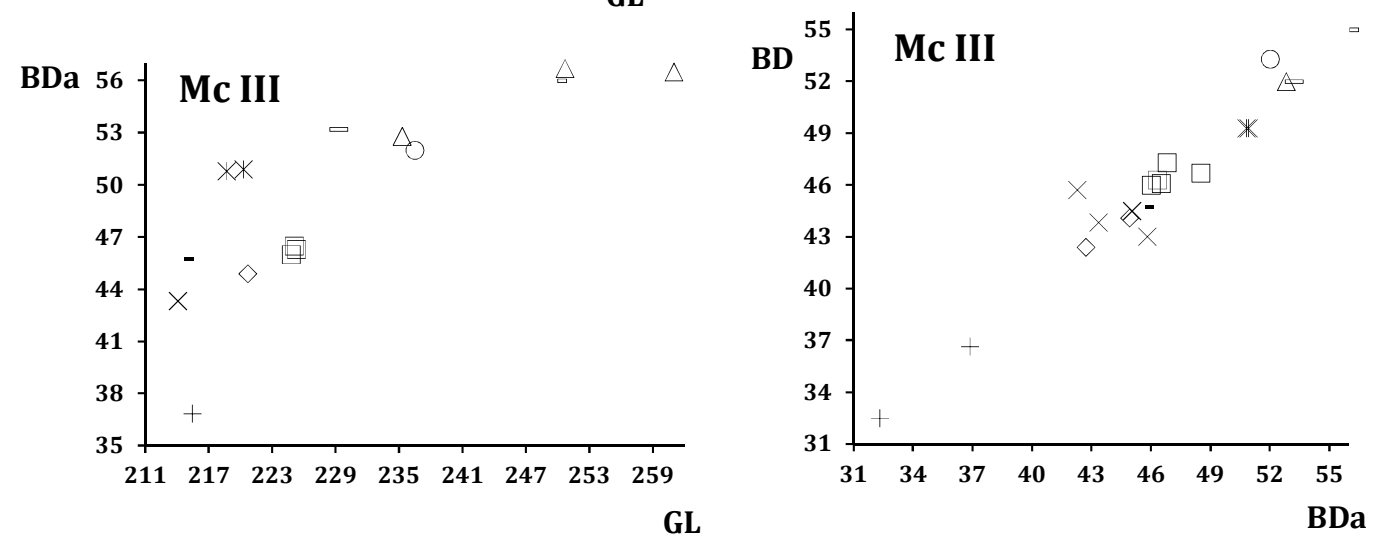

$\begin{array}{lll}\square \text { E.f.torralbae } & \diamond \text { E.f.antunesi } & \triangle \text { E.f.mosbachensis }- \text { E.f.taubachensis }=\text { E.f.germanicus } \\ * \text { E.f.gallicus } & \bigcirc \text { E.stenonis } & - \text { E.f.przewalskii } \times \text { E.f. Valdegoba }+ \text { E. h. Valdegoba }\end{array}$

Figura V.4.5. Diagramas bivariantes de los terceros metacarpos: BD (anchura epífisis distal), GL (longitud máxima), BDa (anchura articular distal), IR (índice de robustez). E.f.torralbae de Torralba, Pinilla del Valle, Atapuerca, Solana de Zamborino y Las Yedras. E.f.antunesi de la Carihuela, Salemas, Fontahinas y Jöao Ramos. E.f.mosbachensis de Mosbach, Achenheim y Lune Viel .E.f.germanicus de Pain non Pair. E.f.gallicus de Solutre y Saint Germain de la Riviere. E. stenonis de Chatillon Saint Jean. E.f.przewalskii actual (datos Maldonado, 1996).

Metacarpo IV (lámina V.4.1: 14) (tabla V.4.11): se han identificado tres piezas. Presenta una sección triangular que se va estrechando distalmente. Los restos de la Cueva de Valdegoba presentan una tuberosidad muy marcada y un pequeño pliegue en la parte posterior de la cara articular que no se encuentra en los caballos modernos. 
Tabla V.4.11

Medidas tomadas en metacarpos y metatarsos de E. ferus de la Cueva de Valdegoba

\begin{tabular}{|c|c|c|c|c|c|c|c|c|c|c|c|c|c|c|c|c|}
\hline & GL & GLm & BP & DP & SD & SDD & BSD & DM & DL & DD & BD & DPA & DAT & DAF & DAS & DPF \\
\hline \multicolumn{17}{|c|}{ Metacarpo II } \\
\hline $\mathrm{n}$ & 1 & & 3 & 3 & & & & & & & & & & & & \\
\hline rango & 116,3 & & $17,0-19,9$ & $13,4-15,2$ & & & & & & & & & & & & \\
\hline $\bar{x} \pm$ s.d. & & & $18,5 \pm 1,4$ & $14,3 \pm 0,9$ & & & & & & & & & & & & \\
\hline \multicolumn{17}{|c|}{ Metacarpo III } \\
\hline $\mathrm{n}$ & 1 & 1 & 2 & & 1 & 1 & 4 & 4 & 4 & 3 & 4 & 1 & 2 & 1 & 2 & 2 \\
\hline rango & 241,1 & 205,1 & $46,4-50,7$ & & 35,5 & 26,9 & $43,0-45,7$ & $29,6-30,6$ & $24,2-27,7$ & $34,4-35,6$ & $42,3-45,8$ & 31,4 & $38,7-42,9$ & 6,3 & $12,9-15,8$ & $6,9-7,3$ \\
\hline $\bar{x} \pm$ s.d. & & & $48,6 \pm 3,0$ & & & & $44,3 \pm 1,1$ & $29,4 \pm 1,1$ & $26,5 \pm 1,5$ & $34,9 \pm 0,7$ & $44,1 \pm 1,6$ & & $40,8 \pm 2,9$ & & $14,4 \pm 2,1$ & $6,2 \pm 1,6$ \\
\hline \multicolumn{17}{|c|}{ Metacarpo IV } \\
\hline $\mathrm{n}$ & & & 3 & 3 & & & & & & & & & & & & \\
\hline rango & & & $16,3-19,4$ & $12,3-14,4$ & & & & & & & & & & & & \\
\hline $\bar{x} \pm$ s.d. & & & $17,9 \pm 1,6$ & $13,1 \pm 1,1$ & & & & & & & & & & & & \\
\hline \multicolumn{17}{|c|}{ Metatarso II } \\
\hline $\mathrm{n}$ & & & 3 & 3 & & & & & & & & & & & & \\
\hline rango & & & $22,4-25,3$ & $11,1-14,9$ & & & & & & & & & & & & \\
\hline $\bar{x} \pm$ s.d. & & & $23,5 \pm 1,6$ & $13,5 \pm 2,1$ & & & & & & & & & & & & \\
\hline \multicolumn{17}{|c|}{ Metatarso III } \\
\hline $\mathrm{n}$ & 1 & 1 & 1 & 1 & & & 5 & 6 & 7 & 6 & 7 & 1 & & & & \\
\hline rango & 275,4 & 269,5 & 48,9 & 53,4 & & & $42,5-50,7$ & $29,5-31,3$ & $27,0-31,3$ & $34,0-51,0$ & $47,0-50,0$ & 38,2 & & & & \\
\hline $\bar{x} \pm$ s.d. & & & & & & & $45,9 \pm 3,1$ & $30,4 \pm 0,7$ & $28,9 \pm 2,5$ & $38,0 \pm 6,2$ & $484 \pm 4,1$ & & & & & \\
\hline \multicolumn{17}{|c|}{ Metatarso IV } \\
\hline $\mathrm{n}$ & 1 & & & & 7 & 7 & & & & & & & & & & \\
\hline rango & 114,8 & & & & $23,4-29,7$ & $16,9-19,3$ & & & & & & & & & & \\
\hline $\bar{x} \pm$ s.d. & & & & & $25,9 \pm 2,1$ & $18,5 \pm 0,9$ & & & & & & & & & & \\
\hline
\end{tabular}


Metatarso II (lámina V.4.1: 12) (tabla V.4.11): todas las piezas identificadas tienen su extremidad distal rota. Se diferencian del metatarso IV en que se estrechan hacia la base y son mucho menos robustos en su extremo proximal.

Metatarso III (lámina V.4.1: 13) (tabla V.4.11) (figura V.4.6): se han identificado 11 piezas, una presenta buen estado de conservación aunque tiene la superficie articular proximal fragmentada, seis tienen el extremo distal roto y cuatro la epífisis proximal abrasionada. Una de las características que permite diferenciarlo de los metacarpos es su sección casi cilíndrica. La pieza más completa no conserva la superficie articular proximal pero sí que la mantiene otra de las piezas. Esta superficie es ligeramente cóncava y presenta una depresión característica en posición central que separa las caras articulares del tercer hueso del tarso, el cuneiforme. La articulación con el cuarto tarsal, el cuboide, es más pequeña que la de los actuales E. caballus. Asimismo, la cara que articula con el cuboide, y que se encuentra en el extremo posterior, es más ancha y menos larga. Métricamente ocurre algo similar a lo que se ha comentado en los terceros metacarpos. Tiene un tamaño similar al de $E$. f. antunesi, está dentro del rango de $E$. f. torralbae y es más pequeño que $E$. f. germanicus y E. f. gallicus (figura V.4.6).
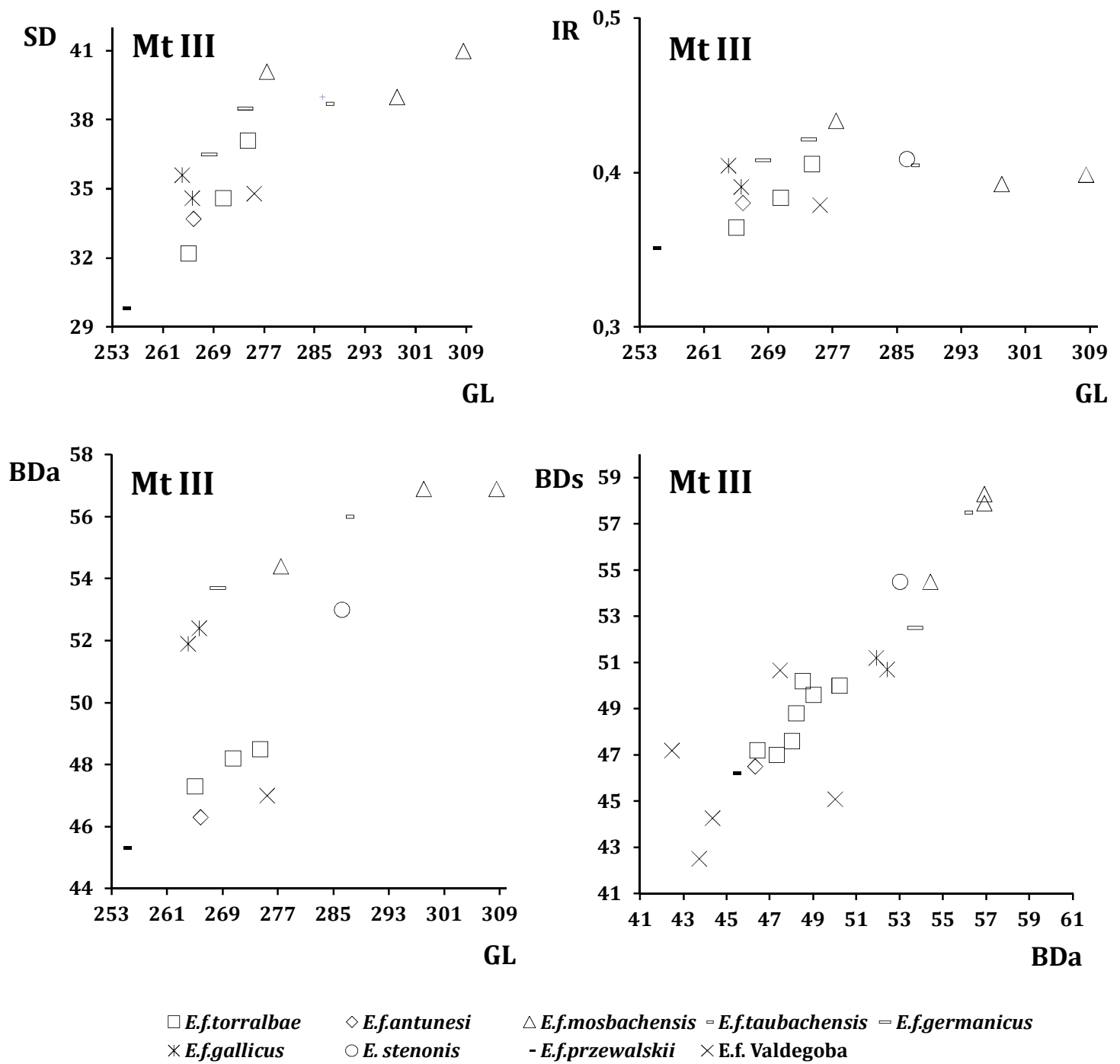

$\triangle$ E.f.mosbachensis $\circ$ E.f.taubachensis $\square$ E.f.germanicus

Figura V.4.6. Diagramas bivariantes de los terceros metatarsos: BD (anchura epífisis distal), GL (longitud máxima) y BDa (anchura articular distal), IR (índice de robustez). E.f.torralbae de Torralba, Pinilla del Valle, Atapuerca, Solana de Zamborino y Las Yedras. E.f.antunesi de la Carihuela, Salemas, Fontahinas y Jöao Ramos. E.f.mosbachensis de Mosbach, Achenheim y Lune Viel .E.f.germanicus de Pain non Pair. E.f.gallicus de Solutre y Saint Germain de la Riviere. E. stenonis de Chatillon Saint Jean. E.f.przewalskii actual (datos de Maldonado, 1996). 
Metatarso IV (lámina V.4.1: 11) (tabla V.4.11): se han analizado siete piezas, todas ellas con el extremo distal roto. Son mucho más robustos y anchos que el metatarso II (tabla V.4.10). La superficie articular proximal es ovalada y presenta un estrechamiento en la zona central para articularse con el cuarto tarsiano. Esta cara articular, en ocasiones, puede dividirse en dos, pero siempre para articularse con el cuarto tarso. La tuberosidad que presenta el extremo proximal está muy marcada, mucho más que en el caballo actual, llegando una de ellas a parecer patológica. Dorsolateralmente, muestran dos caras para la articulación con el tercer metatarso.

Falanges proximales (lámina V.4.1: 15) (tabla V.4.12): se han identificado once piezas, de las cuales cuatro no tienen la epífisis proximal fusionada. Estas falanges presentan diáfisis cortas y robustas que van perdiendo grosor hacia el extremo distal. La cara anterior es convexa mediolateralmente. La superficie posterior es plana, presentando una zona triangular para la inserción de los ligamentos sesamoideos distales. Los bordes lateral y medial son rectos, y presentan un tubérculo para la inserción del ligamento colateral. La superficie articular proximal es alargada y tiene un surco sagital, para la articulación con el tercer metápodo, que separa las dos cavidades articulares. En cada lado existe una protuberancia para la inserción de los tendones extensores. La superficie articular distal presenta un surco sagital poco desarrollado que separa los dos cóndilos articulares. El borde lateral es ligeramente más pequeño que el medial lo que permite orientar la pieza. Entre los restos recuperados se han podido identificar una falange anterior y tres posteriores. Las piezas que no tienen la epífisis proximal fusionada muestran dos morfologías diferentes. La primera de ellas, asignada a una falange anterior, es más larga y grácil y, además, presenta unas tuberosidades para la inserción de los ligamentos colaterales poco marcados. Por otra parte, la otra pieza es más pequeña y robusta, y presenta las tuberosidades mucho más marcadas en su extremidad distal. La pieza que conserva únicamente la extremidad posterior tiene estas tuberosidades muy marcadas por lo que podría pertenecer a una falange posterior. En ninguno de los casos el trigonum phalangis proximalis aparece marcado.

Falange proximal anterior: difiere de las posteriores principalmente en la superficie articular proximal. El borde anterior de esta superficie está más proyectado hacia la zona anterior, el borde medial es recto y el lateral oblicuo, el surco sagital es más profundo. Son más grandes que las posteriores (tabla V.4.12).

Falange proximal posterior: se han analizado dos piezas en buen estado que presentan diferencias con respecto a las anteriores. Su superficie articular proximal tiene un surco sagital menos profundo, un borde anterior más plano y los bordes lateral y medial oblicuos en ambos casos. Son más pequeñas que las anteriores (tabla V.4.12).

Falanges medias (lámina V.4.1: 16) (tabla V.4.13): se han analizado nueve piezas, ocho están completas y la otra no tiene la epífisis proximal fusionada. Estas falanges son más pequeñas que las proximales, diferenciándose de ellas también en la superficie articular proximal que en lugar de presentar un surco tiene un pliegue para la articulación con las proximales. Las diáfisis están aplanadas dorsoventralmente. La superficie proximal presenta dos caras articulares separadas por un surco poco marcado. El processus extensorius se encuentra bien marcado en la zona media del borde anterior. La superficie distal, que articula con la falange distal, presenta un surco más marcado que en la proximal. La cara anterior es convexa y lisa salvo en la zona distal donde existen una serie de protuberancias para la inserción de los ligamentos colaterales. La superficie posterior es lisa y plana, presentando en la parte proximal la prominencia transversa y, en la distal, los cóndilos que articulan con la falange distal. Los restos recuperados presentan dos morfologías diferentes. El estado de conservación de las piezas de la Peña de Estebanvela no permite asignarlas a anteriores o posteriores. 
Tabla V.4.12

Medidas tomadas en las falanges proximales de E. ferus de la Cueva de Valdegoba

\begin{tabular}{|c|c|c|c|c|c|c|c|c|c|c|c|c|}
\hline & GL & GLa & SD & BP & DP & BD & BFd & DD & LMS & LLS & LMI & LLI \\
\hline \multicolumn{13}{|c|}{ Anteriores } \\
\hline $\mathrm{n}=1$ & 87,0 & 77,0 & 34,6 & 52,3 & 41,2 & 44,0 & 42,6 & 24,0 & 69,7 & 68,6 & 17,1 & 16,4 \\
\hline \multicolumn{13}{|c|}{ Posteriores } \\
\hline $\mathrm{n}$ & 3 & 3 & 3 & 3 & 3 & 3 & 3 & 3 & 2 & 3 & 2 & 2 \\
\hline rango & $72,7-81,2$ & $66,-73,5$ & $30,2-31,5$ & $45,8-52,0$ & $32,5-37,2$ & $38,1-41,1$ & $38,0-40,1$ & $20,8-23,3$ & $59,2-61,6$ & $57,0-60,8$ & $14,9-17,7$ & $13,4-17,6$ \\
\hline $\bar{x} \pm$ s.d. & $77,5 \pm 4,4$ & $70,5 \pm 3,4$ & $30,9 \pm 0,6$ & $49,8 \pm 3,5$ & $35,4 \pm 2,6$ & $39,8 \pm 1,5$ & $39,4 \pm 1,2$ & $22,0 \pm 1,2$ & $60,4 \pm 1,7$ & $59,1 \pm 1,9$ & $16,3 \pm 2,0$ & $15,5 \pm 2,9$ \\
\hline
\end{tabular}

Tabla V.4.13

Medidas tomadas en las falanges medias de E. ferus de la Cueva de Valdegoba

\begin{tabular}{|c|c|c|c|c|c|c|}
\hline & GL & GLa & SD & BP & DP & BD \\
\hline \multicolumn{7}{|c|}{ F.m. anteriores } \\
\hline \multicolumn{7}{|c|}{ Valdegoba } \\
\hline $\mathrm{n}$ & 3 & 3 & 3 & 3 & 3 & 3 \\
\hline rango & $46,2-52,9$ & $35,2-38,1$ & $40,5-42,6$ & $47,8-50,7$ & $29,8-33,3$ & $42,7-48,2$ \\
\hline$\overline{\mathrm{x}} \pm$ s.d. & $48,7 \pm 3,6$ & $36,6 \pm 1,5$ & $41,6 \pm 1,1$ & $49,6 \pm 1,6$ & $31,8 \pm 1,8$ & $45,5 \pm 2,8$ \\
\hline \multicolumn{7}{|c|}{ F.m. posteriores } \\
\hline \multicolumn{7}{|c|}{ Valdegoba } \\
\hline $\mathrm{n}$ & 5 & 5 & 5 & 5 & 5 & 5 \\
\hline rango & $42,5-46,6$ & $34,3-37,0$ & $37,8-39,7$ & $44,8-46,7$ & $29,6-31,9$ & $40,2-42,5$ \\
\hline$\overline{\mathrm{x}} \pm$ s.d. & $44,6 \pm 1,5$ & $35,4 \pm 1,1$ & $38,8 \pm 0,9$ & $45,7 \pm 0,8$ & $30,7 \pm 0,8$ & $41,3 \pm 0,8$ \\
\hline \multicolumn{7}{|c|}{ Falanges medias } \\
\hline \multicolumn{7}{|c|}{ Estebanvela } \\
\hline $\mathrm{n}=1$ & 55,0 & 40,7 & & 59,2 & 35,8 & 48,2 \\
\hline
\end{tabular}


Falanges medias anteriores: muestran una superficie articular proximal con unos bordes lateral y medial ligeramente oblicuos y un surco sagital poco marcado. El surco intercondilar distal está muy desarrollado. Son más largas y anchas que las posteriores. Además, la anchura de la superficie articular proximal es más grande, aunque no ocurre los mismo con la profundidad, donde hay cierto solapamiento (tabla V.4.13).

Falanges medias posteriores: la superficie articular proximal tiene unos bordes lateral y medial curvos lo que la da una apariencia redondeada. Se diferencian de las anteriores en que el surco sagital está más marcado, por el menor desarrollo del surco que separa los dos cóndilos laterales y por ser más cortas y estrechas (tabla V.4.13).

Falanges distales (lámina V.4.1: 17) (tabla V.4.14): se han identificado diez piezas en buen estado. La superficie articular tiene dos caras articulares. La proximal, que articula con la falange media, y una más pequeña, inmediatamente por debajo, que se articula con el sesamoideo distal. A ambos lados existen dos protuberancias marcadas que actúan como lugar de inserción de los ligamentos laterales. La apófisis extensora está muy marcada. La cara anterior o parietal se encuentra inclinada dorsodistalmente y está perforada por numerosos forámenes. A ambos lados se encuentra el surco parietal cuyo desarrollo es variable. La superficie ventral presenta dos zonas bien diferenciadas separadas por la línea semilunar. La anterior es cóncava y tiene forma de media luna y, la posterior está relacionada con la inserción del tendón flexor. Cuatro de las piezas conservan las apófisis plantares muy frágiles, mientras que en el resto están erosionadas o bien fragmentadas. La pieza recuperada en la Peña de Estebanvela ha aparecido muy fragmentada por lo que no ha podido observarse ningún carácter diagnóstico.

Tabla V.4.14

Medidas tomadas en las falanges distales de E. ferus de la Cueva de Valdegoba

\begin{tabular}{|c|c|c|c|c|c|c|}
\hline & LO & Ld & GB & BF & LF & HP \\
\hline \multicolumn{7}{|c|}{ Anteriores } \\
\hline $\mathrm{n}$ & 5 & 5 & 5 & 5 & 5 & 5 \\
\hline rango & $44,8-53,5$ & $43,4-51,3$ & $50,4-54,3$ & $41,6-43,8$ & $26,5-29,2$ & $36,5-40,4$ \\
\hline$\overline{\mathrm{x}} \pm$ s.d. & $50,6 \pm 3,5$ & $48,4 \pm 3,3$ & $53,2 \pm 1,9$ & $42,4 \pm 0,9$ & $27,7 \pm 1,1$ & $38,3 \pm 1,5$ \\
\hline \multicolumn{7}{|c|}{\begin{tabular}{|l} 
Posteriores \\
\end{tabular}} \\
\hline $\mathrm{n}$ & 2 & 2 & 1 & 2 & 2 & 2 \\
\hline rango & $55,4-55,7$ & $47,2-49,4$ & 64,2 & $41,4-42,8$ & $28,1-29,2$ & $41,2-42,9$ \\
\hline$\overline{\mathrm{x}} \pm$ s.d. & $55,5 \pm 0,2$ & $48,3 \pm 1,6$ & & $42,1 \pm 1,0$ & $28,6 \pm 0,8$ & $42,0 \pm 1,2$ \\
\hline
\end{tabular}

Falanges distales anteriores: se han analizado dos piezas en buen estado de conservación. Son más compactas que las actuales. Presentan unas apófisis plantares bien marcadas. En vista ventral, la línea semilunar se encuentra en una posición posterior, haciendo que la región del casco sea más amplia. Se solapan métricamente con las posteriores (tabla V.4.13).

Falanges distales posteriores: se han identificado cinco piezas, cuatro de ellas en buen estado y otra con uno de los bordes fragmentado. Difieren de las anteriores en que la superficie que articula con la falange media es más redondeada y la superficie ventral más ovalada Las apófisis plantares no se han conservado bien, por lo que no se puede ver su desarrollo. En la superficie ventral, la línea semilunar suele encontrarse en una posición más adelantada lo que hace que la región del casco se encuentre reducida. Sus dimensiones se solapan con las de las anteriores (tabla V.4.13).

\subsubsection{Número Mínimo de Individuos}

El número mínimo de individuos (NMI) ha sido estimado empleando la pieza más frecuente y el grado de desgaste (tabla V.4.15). No se han podido determinar, en algunos 
casos, el número de ejemplares inmaduros y maduros ya que las edades de erupción abarcan ambos rangos. En estos casos sólo se indica el número total de ejemplares.

Tabla V.4.15

Número mínimo de individuos de Equus ferus

\begin{tabular}{|c|c|c|c|c|c|c|c|c|}
\hline & & Inmaduros & Maduros & Total & Infantiles & Juveniles & Adultos & Senil \\
\hline Valdegoba & & 17 & 11 & 28 & & & 5 & 1 \\
\hline Prado Vargas & & & 2 & 2 & & & 1 & 1 \\
\hline \multirow[t]{3}{*}{ Cueva Millán } & 1A & & 2 & 3 & & & 2 & \\
\hline & 1B & & & 1 & & & & \\
\hline & 1C & & & 3 & & & 3 & \\
\hline Búho & & 1 & 1 & 2 & & & 1 & \\
\hline Vergara & & 1 & & 1 & & & & \\
\hline \multirow[t]{2}{*}{ Alexandre } & & & & 1 & & & & \\
\hline & I & 1 & 1 & 2 & 1 & & 1 & \\
\hline \multirow[t]{2}{*}{ Estebanvela } & II & 1 & 1 & 2 & & & & \\
\hline & III & & 2 & 2 & & & 2 & \\
\hline
\end{tabular}

En la Cueva de Valdegoba se han identificado 28 individuos: 17 inmaduros, a partir del $\mathrm{D}^{4}$; y 11 maduros, adultos, a partir del $\mathrm{M}_{3}$ derecho, siendo uno de ellos un senil. En Prado Vargas se han identificado dos ejemplares maduros a partir del grado de desgaste de dos piezas. Uno sería un adulto, a partir de un $\mathrm{P}_{2}$ derecho; y otro sería un senil, a partir de un $\mathrm{P}^{3-4}$ izquierdo. En el nivel 1A de Cueva Millán se han identificado al menos tres ejemplares: uno de como mucho 44 meses, a partir del $\mathrm{D}_{4}$ izquierdo; y otros dos adultos, uno de entre 5 y 8 años y otro de 12 a 18, a partir del $\mathrm{I}^{1}$ derecho. En el nivel 1B hay un ejemplar, estimado a partir del $\mathrm{P}_{3-4}$ izquierdo. En el nivel $1 \mathrm{C}$ se han registrado tres ejemplares de al menos 50 meses, tres adultos, a partir $\mathrm{M}_{3}$ derecho. En la Cueva del Búho se han identificado dos ejemplares: uno inmaduro, a partir del $\mathrm{dI}_{1}$ izquierdo; y otro maduro, un adulto, a partir de un canino permanente. En el Abrigo de Vergara se ha identificado un ejemplar, un inmaduro de como mucho 44 meses, a partir del $\mathrm{D}^{3-4}$ derecho. En el Abrigo de Alexandre se ha registrado un ejemplar, no podemos especificar nada más ya que el material está muy fragmentado. En el nivel I de la Peña de Estebanvela tenemos al menos dos ejemplares. Uno de de ellos sería juvenil, estimado a partir de un $\mathrm{M}_{1-2}$ derecho; $\mathrm{y}$ otro adulto, a partir de un $\mathrm{M}_{1-2}$ izquierdo. En el nivel II tendríamos dos ejemplares, estimados a partir de los desgastes del $\mathrm{P}_{3-4}$ izquierdo; uno sería juvenil y otro sería un adulto. En el nivel III se han identificado dos ejemplares a partir de los desgastes de un $\mathrm{M}_{1}$ izquierdo y de un $\mathrm{P}^{4}$ derecho, ambos serían adultos.

\subsubsection{Edad de muerte}

Hemos empleado únicamente los dientes al ser las piezas más abundantes y que aportan más información. Se han analizado 171 piezas, siguiendo el modelo morfológico de Sisson et al. (2001) para los incisivos, el criterio métrico de Eisenmann et al., (1988) para medir las alturas de la corona, los datos de Levine (1979) para relacionar dicha altura con una edad concreta de muerte y los datos de erupción dental de Sisson et al., (2001).

Cueva de Valdegoba: los resultados son muy variables. En la dentición inferior, la mayor parte de los $\mathrm{P}_{2}$ presentan desgastes por encima del $50 \%$. Los $\mathrm{P}_{3-4}$ no han aportado piezas con desgastes inferiores al 25\%, estando la mayor parte entre el 50 y el $75 \%$ (figura V.4.7). Los molares muestran un comportamiento diferente. En los $\mathrm{M}_{1-2}$ predominan los desgastes inferiores al 25\% (figura V.4.7) y en los $\mathrm{M}_{3}$ las erosiones entre el 25 y el $75 \%$ (tablas V.4.16). 
Tabla V.4.16

Edad de muerte y rango estimado a partir de los dientes permanentes de E. ferus de Valdegoba

\begin{tabular}{|c|c|c|c|c|c|c|c|c|c|}
\hline \multicolumn{5}{|c|}{$\mathbf{P}_{2}$} & \multicolumn{5}{|c|}{$\mathbf{P}_{3-4}$} \\
\hline Sigla & $\mathbf{L}$ & Altura & Edad & Rango & Sigla & $\mathbf{L}$ & Altura & Edad & Rango \\
\hline Vb-91.M8.2 & $\mathrm{i}$ & 10,6 & $15-16$ & adulto & $\mathrm{Vb}-\mathrm{sp}-246$ & $\mathrm{i}$ & 18,4 & $19-25$ & adulto \\
\hline Vb - sp - 48 & i & 14,3 & $14-15$ & adulto & $\mathrm{Vb}-59 \mathrm{~b}$ & i & 30,3 & $15-20$ & adulto \\
\hline $\mathrm{Vb}-47$ & $\mathrm{i}$ & 33,2 & $8-9$ & adulto & $V b-59 a$ & $\mathrm{i}$ & 34,8 & $11-12$ & adulto \\
\hline $\mathrm{Vb}-49$ & d & 37,7 & $8-9$ & adulto & $\mathrm{Vb}-70$ & $\mathrm{i}$ & 55,2 & $7-9$ & adulto \\
\hline \multirow[t]{2}{*}{$\mathrm{Vb}-51$} & d & 46,4 & $8-9$ & adulto & $\mathrm{Vb}-67$ & $\mathrm{i}$ & 58,9 & $7-8$ & adulto \\
\hline & \multicolumn{3}{|c|}{$\mathbf{M}_{1-2}$} & & \multicolumn{5}{|c|}{$\mathbf{M}_{3}$} \\
\hline Sigla & $\mathbf{L}$ & Altura & Edad & Rango & Sigla & $\mathbf{L}$ & Altura & Edad & Rango \\
\hline $\mathrm{Vb}-63$ & $\mathrm{~d}$ & 41,2 & $9-11$ & adulto & $\mathrm{Vb}-81$ & $d$ & 63 & $7-8$ & adulto \\
\hline $\mathrm{Vb}-52$ & $\mathrm{i}$ & 70,2 & $5-6$ & adulto & $\mathrm{Vb}-\mathrm{sp}-81$ & d & 47,6 & $9-10$ & adulto \\
\hline $\mathrm{Vb}-\mathrm{sp}-260$ & i & 74,6 & $4-6$ & adulto & $\mathrm{Vb}-80$ & $\mathrm{~d}$ & 37,2 & $11-12$ & adulto \\
\hline Vb - sp - 5 & d & 77 & $4-5$ & adulto & & & & & \\
\hline $\mathrm{Vb}-\mathrm{sp}-9$ & $\mathrm{i}$ & 78,3 & $4-5$ & adulto & & & & & \\
\hline \multirow[t]{2}{*}{$\mathrm{Vb}-53$} & $\mathrm{i}$ & 79,1 & $4-5$ & adulto & & & & & \\
\hline & \multicolumn{3}{|c|}{$\mathbf{P}^{2}$} & & \multicolumn{5}{|c|}{$\mathbf{P}^{3-4}$} \\
\hline Sigla & $\mathbf{L}$ & Altura & Edad & Rango & Sigla & $\mathbf{L}$ & Altura & Edad & Rango \\
\hline $\mathrm{Vb}-\mathrm{sp}-123$ & $\mathrm{i}$ & 7,7 & $19-25$ & adulto & $\mathrm{Vb}-\mathrm{sp}-66$ & $\mathrm{i}$ & 24,2 & $16-25$ & adulto \\
\hline $\mathrm{Vb}-\mathrm{sp}-120$ & $d$ & 16,6 & $15-16$ & adulto & $\mathrm{Vb}-91.8$ & i & 33,1 & $12-14$ & adulto \\
\hline $\mathrm{Vb}-1$ & d & 20,9 & $13-14$ & adulto & $\mathrm{Vb}-\mathrm{sp}-15$ & $\mathrm{i}$ & 38,5 & $11-12$ & adulto \\
\hline $\mathrm{Vb}-\mathrm{sp}-256$ & i & 22,9 & $13-14$ & adulto & $\mathrm{Vb}-17$ & d & 49,8 & $9-10$ & adulto \\
\hline Vb - sp - 69 & $d$ & 29,6 & $11-12$ & adulto & $\mathrm{Vb}-87$ & i & 54,8 & $8-9$ & adulto \\
\hline $\mathrm{Vb}-\mathrm{sp}-77$ & $\mathrm{i}$ & 37,1 & $9-10$ & adulto & $\mathrm{Vb}-25$ & $\mathrm{i}$ & 59,3 & $7-8$ & adulto \\
\hline \multirow[t]{6}{*}{$\mathrm{Vb}-9$} & i & 45,5 & $8-9$ & adulto & $\mathrm{Vb}-22$ & i & 67,3 & $6-7$ & adulto \\
\hline & & & & & $\mathrm{Vb}-10$ & i & 71,4 & 5- 7 & adulto \\
\hline & & & & & $\mathrm{Vb}-19$ & $\mathrm{i}$ & 74,4 & $5-6$ & adulto \\
\hline & & & & & $\mathrm{Vb}-26$ & i & 75,8 & $5-6$ & adulto \\
\hline & & & & & $\mathrm{Vb}-21$ & $\mathrm{i}$ & 81,3 & $3-5$ & joven \\
\hline & \multicolumn{4}{|c|}{$\mathbf{M}^{1-2}$} & \multicolumn{5}{|c|}{$\mathbf{M}^{3}$} \\
\hline Sigla & $\mathbf{L}$ & Altura & Edad & Rango & Sigla & $\mathbf{L}$ & Altura & Edad & Rango \\
\hline $\mathrm{Vb}-30$ & $d$ & 53,1 & $7-9$ & adulto & $\mathrm{Vb}-45$ & i & 46,3 & $9-10$ & adulto \\
\hline $\mathrm{Vb}-\mathrm{sp}-252$ & d & 57,4 & $7-9$ & adulto & $\mathrm{Vb}-41$ & $\mathrm{i}$ & 54,2 & $8-9$ & adulto \\
\hline Vb - 92 & d & 58,9 & $7-8$ & adulto & $\mathrm{Vb}-36$ & d & 64 & $7-8$ & adulto \\
\hline $\mathrm{Vb}-31$ & d & 66,7 & $5-8$ & adulto & $\mathrm{Vb}-37$ & d & 64,2 & $7-8$ & adulto \\
\hline $\mathrm{Vb}-18$ & $d$ & 66,9 & $5-8$ & adulto & $\mathrm{Vb}-39$ & $d$ & 70,8 & $6-7$ & adulto \\
\hline $\mathrm{Vb}-34$ & d & 67,4 & $5-7$ & adulto & $\mathrm{Vb}-46$ & i & 73,8 & $6-7$ & adulto \\
\hline Vb - sp - 83 & i & 69,8 & $5-7$ & adulto & $\mathrm{Vb}-35$ & d & 75 & $5-6$ & adulto \\
\hline $\mathrm{Vb}-27$ & $\mathrm{i}$ & 74,1 & $4-6$ & joven - adulto & $\mathrm{Vb}-40$ & d & 77 & $5-6$ & adulto \\
\hline $\mathrm{Vb}-\mathrm{sp}-275$ & $\mathrm{~d}$ & 79,4 & $4-6$ & joven - adulto & $\mathrm{Vb}-44$ & $\mathrm{i}$ & 77,1 & $5-6$ & adulto \\
\hline
\end{tabular}

* Edad en años y altura en milímetros.

En los $\mathrm{P}^{2}$ predominan los desgastes superiores al $75 \%$; mientras que en los $\mathrm{P}^{3-4}$, los rangos que comprenden entre el 0 y el $50 \%$ son los que presentan mayor número de piezas (figura V.4.7). El modelo morfológico empleado en los incisivos aporta unos datos similares a los obtenidos en los dientes yugales (tabla V.4.17). Las edades de erupción de las piezas deciduales no aportan información complementaria.

Al menos cinco de los ejemplares serían maduros, empleando el $\mathrm{M}^{3}$ derecho. Aunque la pieza más frecuente para estimar la edad de muerte es el $\mathrm{P}^{3-4}$ hay que tener en cuenta que podríamos tener tanto un tercer premolar como un cuarto, por lo que, al final, el más frecuente es el $\mathrm{M}^{3}$. Sin embargo, hay piezas que aportan edades superiores a los 12 años, llegando incluso hasta los 25 por lo que también tendríamos, al menos un ejemplar senil. 

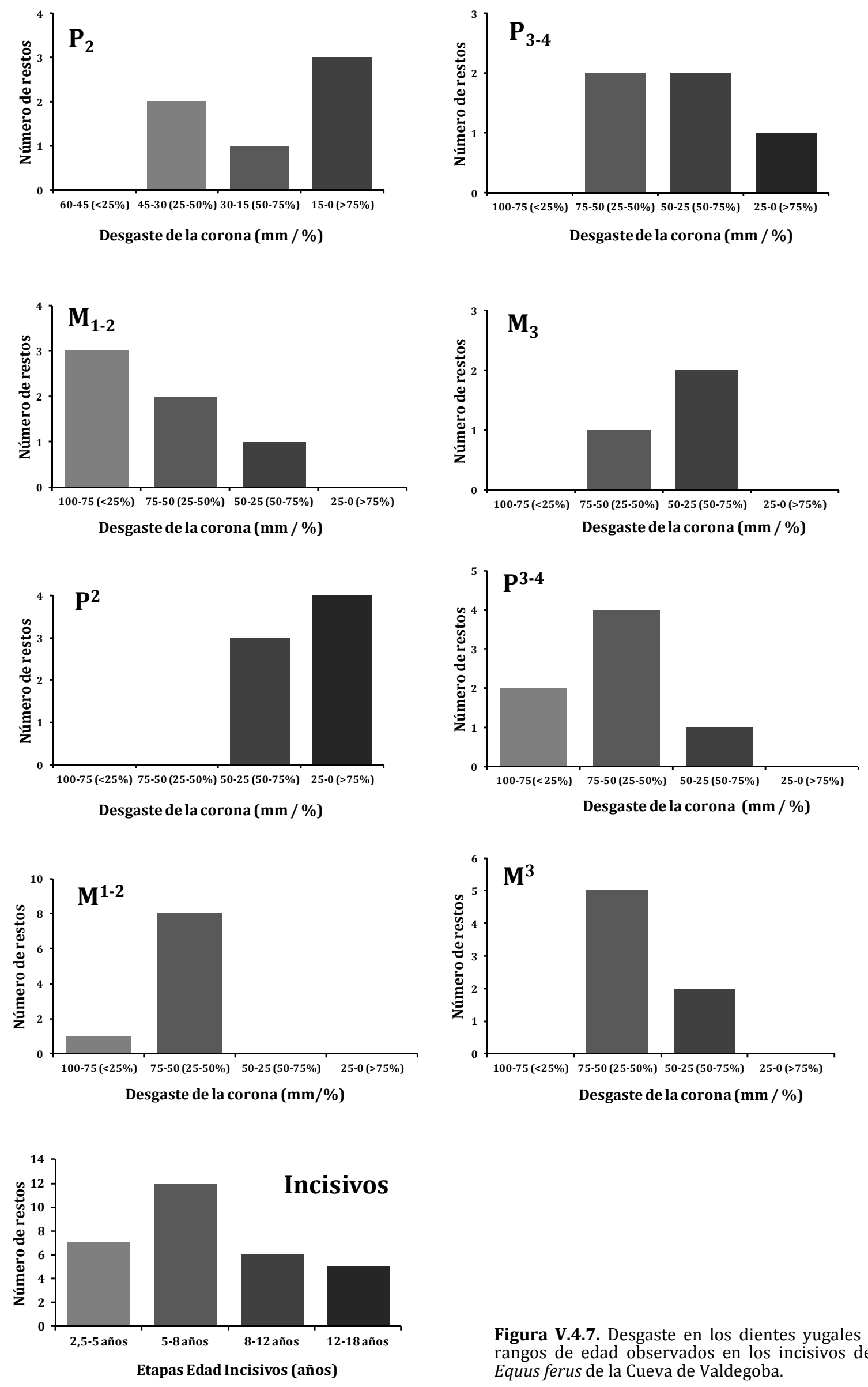

Figura V.4.7. Desgaste en los dientes yugales y rangos de edad observados en los incisivos del Equus ferus de la Cueva de Valdegoba. 
Tabla V.4.17

Caracteres morfológicos observados en los incisivos de E. ferus de Valdegoba

\begin{tabular}{|c|c|c|c|c|c|c|c|c|c|}
\hline & \multicolumn{2}{|c|}{ Infundíbulum } & \multicolumn{2}{|c|}{ Estrella dental } & \multicolumn{4}{|c|}{ Superficie oclusal } & \multirow{2}{*}{$\begin{array}{l}\text { Edad } \\
\text { Años }\end{array}$} \\
\hline & Presente & Ausente & Presente & Ausente & Ovalada & Subovalada & Subtriangular & Triangular & \\
\hline \multicolumn{10}{|l|}{$I_{1}^{1}{ }_{1}$} \\
\hline Vb-sp-143 & $\mathrm{X}$ & & & $\mathrm{X}$ & $\mathrm{X}$ & & & & $2,5-5$ \\
\hline Vb-sp-155 & $\mathrm{X}$ & & & $\mathrm{X}$ & $\mathrm{X}$ & & & & $2,5-5$ \\
\hline Vb-sp-160 & $\mathrm{X}$ & & & $\mathrm{X}$ & $\mathrm{X}$ & & & & $2,5-5$ \\
\hline Vb-sp-174 & $\mathrm{X}$ & & $\mathrm{X}$ & & & $\mathrm{X}$ & & & $2,5-5$ \\
\hline Vb-sp-145 & $\mathrm{X}$ & & $\mathrm{X}$ & & & $\mathrm{X}$ & & & $5-8$ \\
\hline Vb-sp-147 & $\mathrm{X}$ & & & $\mathrm{X}$ & & $\mathrm{X}$ & & & $5-8$ \\
\hline Vb-sp-158 & $\mathrm{X}$ & & & $\mathrm{X}$ & $\mathrm{X}$ & & & & $5-8$ \\
\hline Vb-sp-280 & & $\mathrm{X}$ & & $\mathrm{X}$ & & & & $\mathrm{X}$ & $12-18$ \\
\hline \multicolumn{10}{|l|}{$\mathbf{I}_{2}{ }_{2}$} \\
\hline Vb-sp-170 & $\mathrm{X}$ & & & $\mathrm{X}$ & $\mathrm{X}$ & & & & $2,5-5$ \\
\hline Vb-sp-49 & $\mathrm{X}$ & & & $\mathrm{X}$ & $\mathrm{X}$ & & & & $2,5-5$ \\
\hline Vb-sp-165 & $\mathrm{X}$ & & & $\mathrm{X}$ & & $\mathrm{X}$ & & & $5-8$ \\
\hline Vb-sp-156 & $\mathrm{X}$ & & $\mathrm{X}$ & & & $\mathrm{X}$ & & & $5-8$ \\
\hline Vb-sp-149 & $\mathrm{X}$ & & $\mathrm{X}$ & & & $\mathrm{X}$ & & & $5-8$ \\
\hline Vb-sp-263 & $\mathrm{X}$ & & & $\mathrm{X}$ & & $\mathrm{X}$ & & & $5-8$ \\
\hline Vb-sp-172 & $\mathrm{X}$ & & & $\mathrm{X}$ & & $\mathrm{X}$ & & & $5-8$ \\
\hline Vb-sp-171 & $\mathrm{X}$ & & & $\mathrm{X}$ & & & $\mathrm{X}$ & & $8-12$ \\
\hline Vb-sp-154 & & $\mathrm{X}$ & $\mathrm{X}$ & & & & & $\mathrm{X}$ & $12-18$ \\
\hline Vb-sp-166 & $\mathrm{X}$ & & & $\mathrm{X}$ & & & & $\mathrm{X}$ & $12-18$ \\
\hline \multicolumn{10}{|l|}{$I_{3}{ }_{3}$} \\
\hline Vb-sp-160 & $\mathrm{X}$ & & & $\mathrm{X}$ & $\mathrm{X}$ & & & & $2,5-5$ \\
\hline Vb-sp-284 & $\mathrm{X}$ & & & $\mathrm{X}$ & $\mathrm{X}$ & & & & $5-8$ \\
\hline Vb-sp-151 & $\mathrm{X}$ & & & $\mathrm{X}$ & $\mathrm{X}$ & & & & $5-8$ \\
\hline Vb-sp-148 & $\mathrm{X}$ & & & $\mathrm{X}$ & $\mathrm{X}$ & & & & $5-8$ \\
\hline Vb-sp-168 & $\mathrm{X}$ & & & $\mathrm{X}$ & $\mathrm{X}$ & & & & $5-8$ \\
\hline Vb-sp-144 & $\mathrm{X}$ & & & $\mathrm{X}$ & $\mathrm{X}$ & & & & $5-8$ \\
\hline Vb-sp-163 & $\mathrm{X}$ & & & $\mathrm{X}$ & $\mathrm{X}$ & & & & $5-8$ \\
\hline Vb-sp-161 & $\mathrm{X}$ & & & $\mathrm{X}$ & $\mathrm{X}$ & & & & $5-8$ \\
\hline Vb-sp-159 & $\mathrm{X}$ & & & $\mathrm{X}$ & $\mathrm{X}$ & & & & $5-8$ \\
\hline Vb-sp-259 & $\mathrm{X}$ & & & $\mathrm{X}$ & $\mathrm{X}$ & & & & $5-8$ \\
\hline Vb-sp-152 & & $\mathrm{X}$ & $\mathrm{X}$ & & & & $\mathrm{X}$ & & $8-12$ \\
\hline Vb-sp-264 & $\mathrm{X}$ & & & $\mathrm{X}$ & & $\mathrm{X}$ & & & $8-12$ \\
\hline Vb-sp-155 & & $\mathrm{X}$ & X & & & & & $\mathrm{X}$ & $12-18$ \\
\hline Vb-sp-157 & $\mathrm{X}$ & & $\mathrm{X}$ & & & & & $\mathrm{X}$ & $12-18$ \\
\hline Vb-sp-271 & & $\mathrm{X}$ & $\mathrm{X}$ & & & & & $\mathrm{X}$ & $12-18$ \\
\hline
\end{tabular}

Prado Vargas: se han identificado dos ejemplares a partir del desgaste dental. Uno sería adulto, a partir de un $\mathrm{P}_{2}$ derecho. Esta pieza presenta un desgaste marcado, por lo que su edad estaría alejada de su edad de erupción, 26 - 32 meses (Sisson et al., 2001). El otro sería un senil y se ha estimado a partir de un $\mathrm{P}^{3-4}$ izquierdo. Este diente tiene erosionada por completo la corona.

Cueva Millán: se analizan los tres niveles, empleando las edades de erupción dental y el desgaste.

Nivel 1A: se ha identificado, al menos, un ejemplar con una edad máxima de 44 meses, a partir un $\mathrm{D}_{4}$ izquierdo; y dos ejemplares adultos, uno de entre 5 y 8 años, y otro de entre 12 y 18 , a partir del $\mathrm{I}^{1}$ derecho.

Nivel 1B: el ejemplar identificado en este nivel tendría al menos 30 meses, edad de erupción del $\mathrm{P}_{3}$. No podemos especificar si se trataba de un ejemplar joven o de un adulto. 
Tabla V.4.18

Caracteres morfológicos observados en los incisivos de Equus ferus de Cueva Millán

\begin{tabular}{|c|c|c|c|c|c|c|c|c|}
\hline & \multicolumn{2}{|c|}{ Infundíbulum } & \multicolumn{2}{|c|}{ Estrella dental } & \multicolumn{3}{|c|}{ Superficie oclusal } & \multirow{2}{*}{$\begin{array}{l}\text { Edad } \\
\text { Años }\end{array}$} \\
\hline & Presente & Ausente & Presente & Ausente & Ovalada & Subovalada & Triangular & \\
\hline \multicolumn{9}{|l|}{$I^{1}{ }_{1}$} \\
\hline CM.86.1A.6I & $X$ & & $X$ & & & $X$ & & $5-8$ \\
\hline CM.86.1A.6J & & $\mathrm{X}$ & & $\mathrm{X}$ & & & $\mathrm{X}$ & $12-18$ \\
\hline CM.86.1C.9E & $\mathrm{x}$ & & & $\mathrm{x}$ & & $\mathrm{x}$ & & $5-8$ \\
\hline \multicolumn{9}{|l|}{$I_{2}$} \\
\hline CM.86.1C.9E & $\mathrm{X}$ & & & $\mathrm{X}$ & & $\mathrm{X}$ & & $5-8$ \\
\hline CM.86.1C.9E & $\mathrm{X}$ & & & $\mathrm{X}$ & & $\mathrm{X}$ & & $5-8$ \\
\hline \multicolumn{9}{|l|}{$I_{3}$} \\
\hline CM.86.1C.9E & $\mathrm{X}$ & & & $\mathrm{X}$ & $\mathrm{X}$ & & & $5-8$ \\
\hline
\end{tabular}

Nivel 1C: de los tres ejemplares identificados a partir del $M_{3}$ derecho, al menos uno tendría entre 9 y 10 años (tabla V.4.19). Los otros dos tendrían al menos 50 meses, edad de erupción del tercer molar inferior (Sisson et al., 2001).

Tabla V.4.19

Edad de muerte y rango estimado a partir de los dientes permanentes de E. ferus de Cueva Millán

\begin{tabular}{|c|c|c|c|c|c|c|c|c|c|}
\hline $\mathbf{M}_{3}$ & & & & & $\mathbf{P}^{3-4}$ & & & & \\
\hline Sigla & Lado & Altura & Edad (años) & Rango & Sigla & Lado & Altura & Edad (años) & Rango \\
\hline \multirow[t]{2}{*}{ CM.86.1C.9F } & d & 48,6 & $9-10$ & adulto & CM.86.1C.9G & d & 56,1 & $8-9$ & adulto \\
\hline & & & & & CM.86.1C.1F & $\mathrm{i}$ & 72,0 & $5-7$ & adulto \\
\hline
\end{tabular}

* Edad en años y altura en milímetros

Cueva del Búho: de los dos ejemplares identificados, uno tendría como mucho 30 meses, estimado a partir del $\mathrm{dI}_{1}$ izquierdo; y otro sería un adulto, a partir de un canino permanente, de más de 60 meses. La edad estimada a partir de la morfología del $I_{3}, 2,5-5$ años, está incluida en la edad obtenida a partir del canino.

Abrigo Vergara: se ha identificado un ejemplar que tendría como mucho 44 meses, a partir del $\mathrm{D}^{3-4}$ derecho.

Abrigo Alexandre: los restos están muy fragmentados por lo que no podemos identificar ninguna pieza, aunque sí que pertenecerían a dentición permanente. Por esta razón únicamente podríamos indicar, que este ejemplar, tendría al menos 10 meses, a partir del $\mathrm{M}_{1}$, el primer permanente en emerger (Sisson et al., 2001).

La Peña de Estebanvela: se han analizado las piezas de tres niveles diferentes, utilizando tanto el desgaste como la edad de erupción.

Nivel I: los datos que aporta el desgaste dental sugieren que tendríamos al menos un ejemplar de menos de dos años, un juvenil; y otro adulto, de entre 6 y 8 años. A pesar de que uno de los $\mathrm{M}_{1-2}$ es derecho y otro izquierdo, sus edades son muy diferentes por lo que consideramos que pertenecen a dos ejemplares distintos. Los incisivos aportan edades similares (tabla V.4.21). Tendríamos, por lo tanto, un ejemplar juvenil y otro adulto.

Nivel II: de los dos ejemplares identificados, uno tendría entre 3 y 4 años, un juvenil; y otro entre 7 y 9 , un adulto. Ambos han sido estimados a partir del $\mathrm{P}_{3-4}$ izquierdo. 


\section{Nivel I}
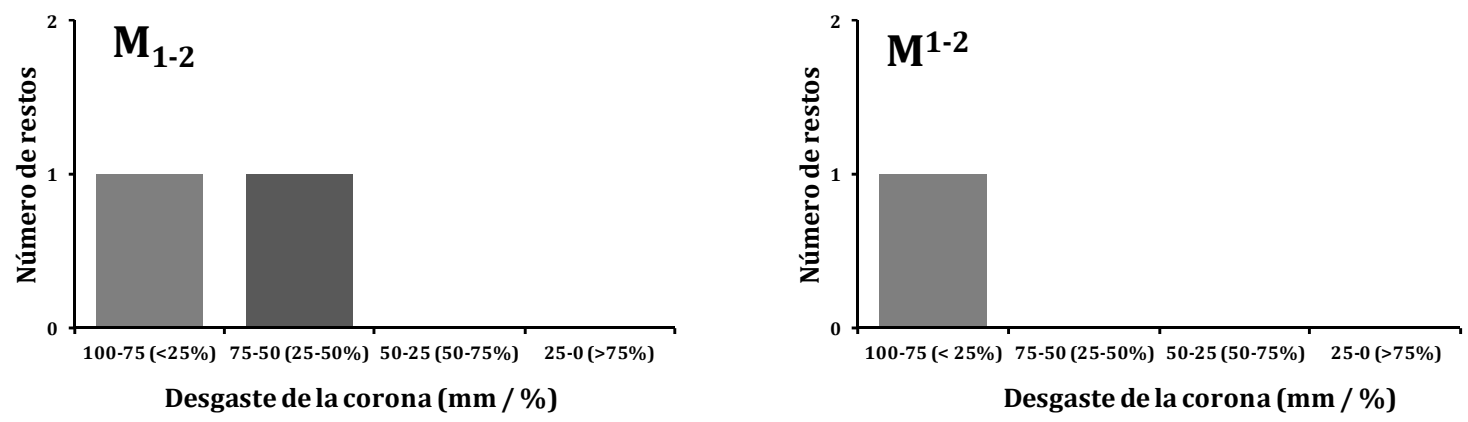

\section{Nivel II}
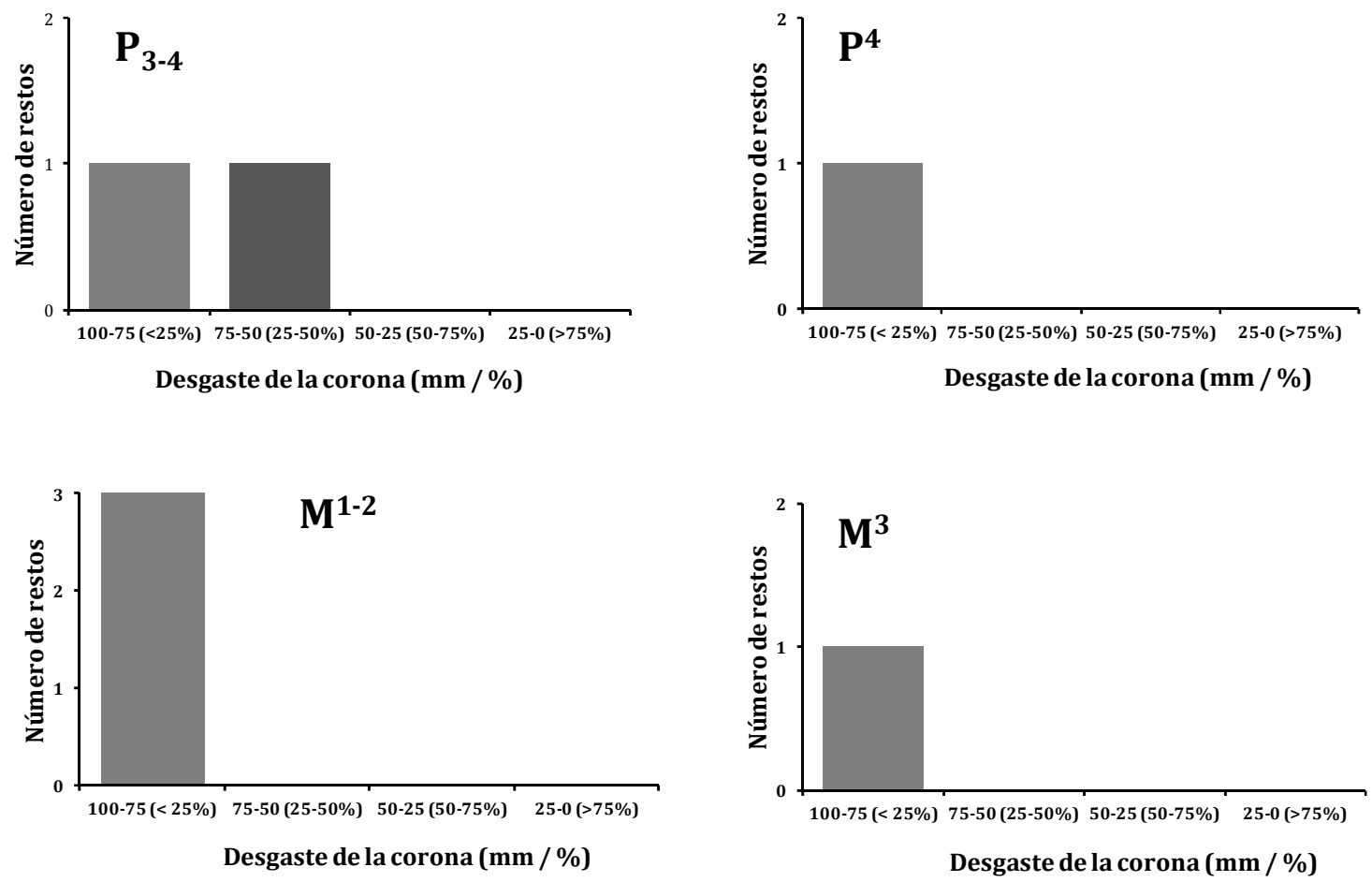

\section{Nivel III}
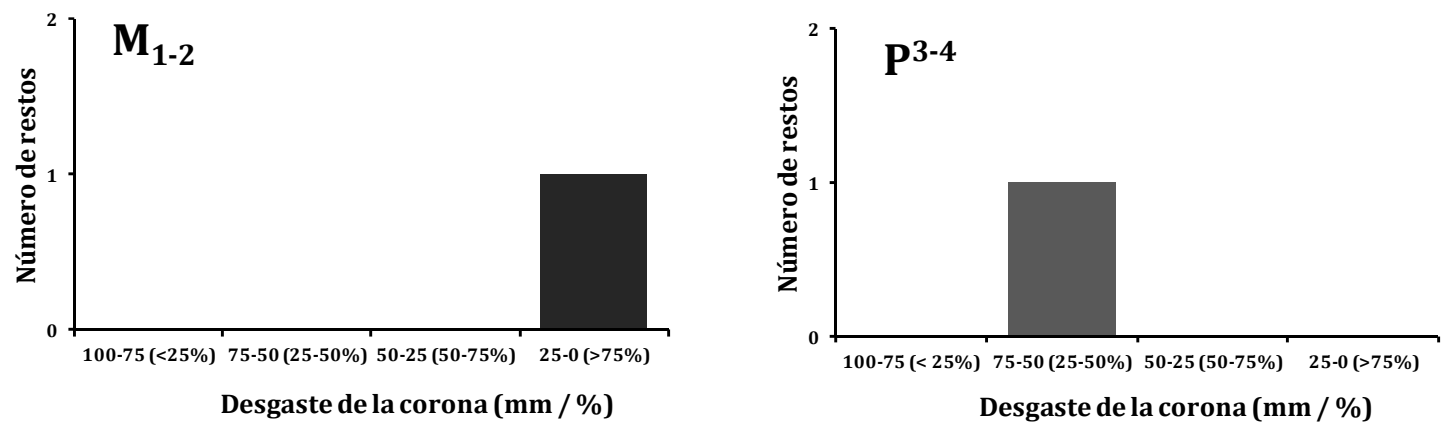

Figura V.4.8. Desgaste dental en las piezas permanentes del Equus ferus de la Peña de Estebanvela. 
Tabla V.4.20

Edad de muerte y rango estimado a partir de los dientes permanentes de E. ferus de la Peña de Estebanvela

\begin{tabular}{|c|c|c|c|c|c|c|c|c|c|}
\hline Sigla & & Altura & $\begin{array}{c}\text { Edad } \\
\text { (años) }\end{array}$ & Rango & Sigla & & Altura & $\begin{array}{c}\text { Edad } \\
\text { (años) }\end{array}$ & Rango \\
\hline \multicolumn{10}{|l|}{ Nivel I } \\
\hline $\mathbf{M}_{1-2}$ & & & & & $\mathbf{M}^{1-2}$ & & & & \\
\hline PE.02.F9-G9.NI.8 & $\mathrm{i}$ & 93,7 & $<2$ & joven & PE.09.J10.NI.7.F2284 & $\mathrm{i}$ & 83,6 & $3-5$ & jv-ad \\
\hline PE.03.F8/G8.NI.1.4 & $\mathrm{d}$ & 58,4 & $6-8$ & adulto & & & & & \\
\hline \multicolumn{10}{|l|}{ Nivel II } \\
\hline$P_{3-4}$ & & & & & $\mathbf{P}^{4}$ & & & & \\
\hline PE.02.J9.NII & $\mathrm{i}$ & 82 & $3-4$ & joven & PE.02.E11.NII.P & $\mathrm{i}$ & 79,1 & $5-6$ & adulto \\
\hline PE.03.F12/G12.NII.10 & $\mathrm{i}$ & 55,2 & $7-9$ & adulto & & & & & \\
\hline $\mathbf{M}^{1}$ & & & & & $\mathbf{M}^{2}$ & & & & \\
\hline PE.02.E11.NII.P & $\mathrm{i}$ & 77,7 & $4-5$ & jv-ad & PE.02.E11.NII.P. & $\mathrm{i}$ & 77,7 & $4-5$ & jv-ad \\
\hline $\mathbf{M}^{1-3}$ & & & & & $\mathbf{M}^{3}$ & & & & \\
\hline PE.99.D7.NII.5.2 & $\mathrm{d}$ & 71,1 & $5-7$ & adulto & PE.02.E11.NII.P. & $\mathrm{i}$ & 84,5 & $<4$ & joven \\
\hline \multicolumn{10}{|l|}{ Nivel III } \\
\hline $\mathbf{M}_{1}$ & & & & & $\mathrm{P}^{4}$ & & & & \\
\hline PE.03.E13.F13.NIII.1 & $\mathrm{i}$ & 12,6 & $19-25$ & adulto & PE.02.E11.NIII.6.7 & $\mathrm{d}$ & 68,6 & $6-7$ & adulto \\
\hline
\end{tabular}

* Altura en milímetros y edad en años.

Nivel III: en este nivel se han identificado dos ejemplares. Se han utilizado dos piezas distintas, un $\mathrm{M}^{1} \mathrm{y}$ un $\mathrm{P}^{4}$ porque los desgastes son muy desiguales por lo que suponemos que se tratan de dos ejemplares distintos. Uno tendría entre 6 y 7 años, y otro al menos 19 años (tabla V.4.20).

Tabla V.4.21

Edad de muerte y rango estimado a partir de los incisivos de E. ferus del nivel I de la Peña de Estebanvela

\begin{tabular}{lcccccc}
\hline & Infundíbulum & \multicolumn{2}{c}{ Estrella dental } & \multicolumn{2}{c}{ Superficie oclusal } & Edad \\
\hline & Presencia & Presencia & Ausencia & Ovalada & Subovalada & Años \\
\hline $\mathbf{I}_{\mathbf{1}}$ & & & & & & \\
\hline PE.02.J9.NI.4.4 & $\mathrm{X}$ & & $\mathrm{X}$ & $\mathrm{X}$ & & $2,5-5$ \\
PE.03.F9-G9.NI.13.4B & $\mathrm{X}$ & & $\mathrm{X}$ & $\mathrm{X}$ & & $2,5-5$ \\
PE.06.I9.NI.7.2 & $\mathrm{X}$ & $\mathrm{X}$ & & & $\mathrm{X}$ & $5-8$ \\
\hline
\end{tabular}

\subsubsection{Discusión}

Los caracteres morfológicos descritos anteriormente como la forma del entofléxido, el tamaño del protocono o la robustez de los metápodos nos permiten asignar estos restos a la familia Equidae. Esta familia tiene una presencia contínua en Europa desde hace unos 20 millones de años (Azzaroli, 1990; Forsten, 2010), pudiendo diferenciar en el Pleistoceno dos líneas evolutivas diferentes. Por un lado, los "estenonianos", grupo caracterizado por tener unos dientes superiores sin pligues caballinos, con unos protoconos pequeños y sin acanalar y unos estilos simples; y una dentición inferior sin pliegues pticostílidos, con entofléxidos estrechos y agudos, unos metastílidos rectangulares, y los bordes bucales del protocónido e hipocónido cóncavos. Por otra parte, la línea "caballina" está caracterizada por tener unos dientes inferiores con entofléxidos abiertos, pliegues pticostílidos marcados y los bordes vestibulares del protocónido y del hipocónido planos o ligeramente convexos. Su dentición superior, por otra parte, presenta unos estilos anchos, que tienden a desdoblarse, unas fosetas con pocos pliegues, unos espacios interestilares cóncavos y unos protoconos grandes que pueden presentar un surco longitudinal que recorre la cara lingual.

Caracteres dentales como los entofléxidos abiertos o los pliegues pticostílidos marcados de la dentición inferior; como los estilos anchos, los espacios interestilares 
cóncavos y los protoconos grandes en los dientes superiores; así como los metápodos largos y robustos nos permiten asignar los restos descritos a la línea "caballina" y a su único representante silvestre Equus ferus.

Los dientes recuperados presentan unos caracteres muy variables, que podrían encajar en E. f. torralbae y E. f. antunesi, como los protoconos grandes, las fosetas poco plegadas, los pliegues caballinos pequeños y la concavidad de los espacios interestilares. Algo similar ocurre en las comparaciones métricas. Las piezas presentan unos valores muy cercanos a ambas subespecies así como índices de robustez, protocónicos y del doble bucle que podrían encontrarse dentro del rango de variación de ambas. Por este motivo, una asignación subespecífica nos parece muy atrevida al presentar nuestros restos caracteres morfológicos y valores métricos tan próximos a ambas formas. Asignamos pues los restos a la Equus ferus. 


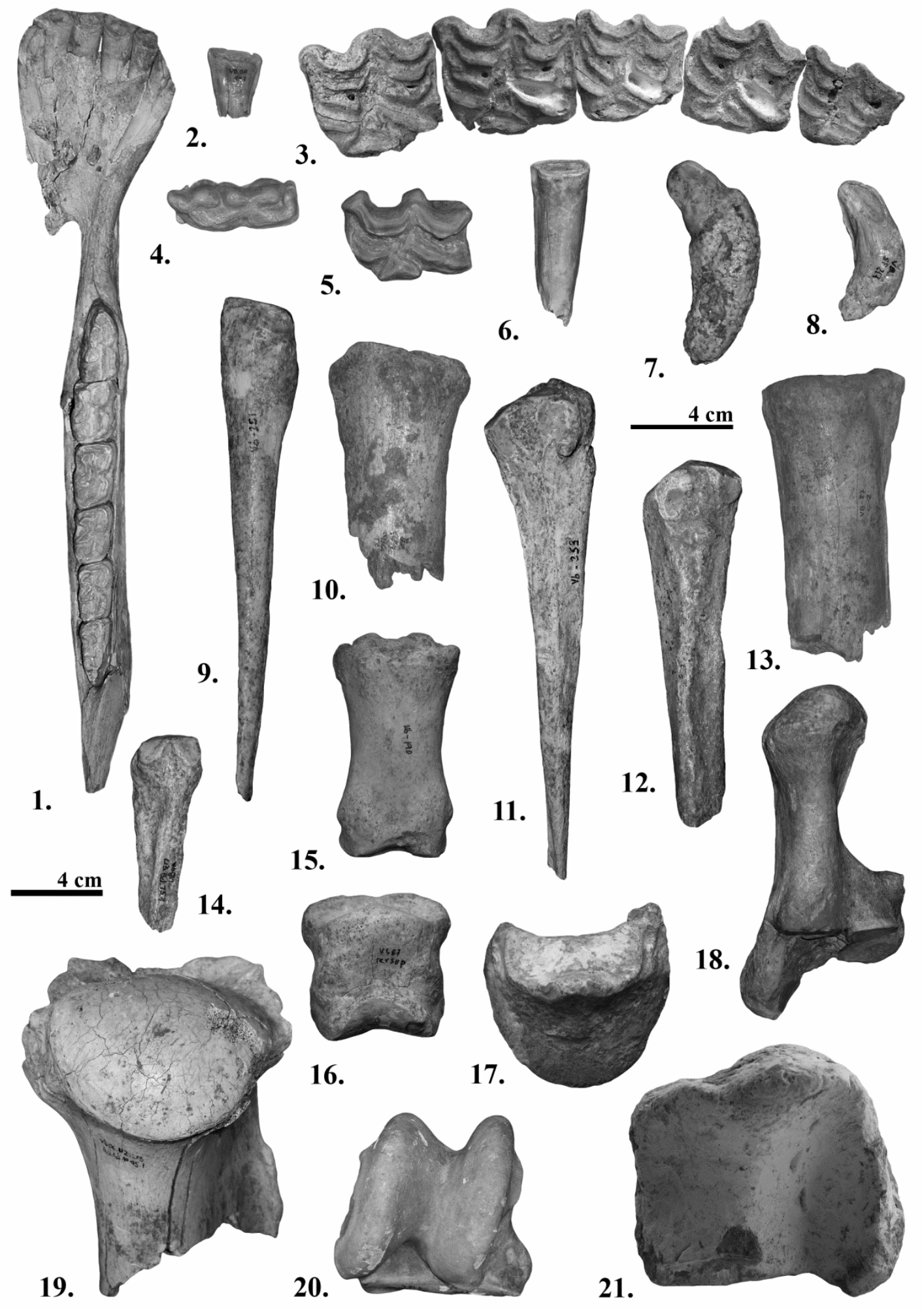

Lámina V.4.1. Equus ferus provenientes de los yacimientos de la Cueva de Valdegoba (sigla Vb), Cueva Millán (sigla CM), Cueva del Búho (sigla TCB) y La Peña de Estebanvela (sigla PE). 1) Mandíbula NIII derecha - vista oclusal. 2) Vb-sp-187 - dI 1 derecho, cara lingual. 3) PE02.E11.NII - Serie dental ( $\left.\mathrm{P}^{3}-\mathrm{M}^{3}\right)$, vista oclusal. 4) Vb138 - D $\mathrm{D}_{3-4}$ derecho, vista oclusal. 5) Vb-173 - D-4 izquierdo, vista oclusal. 6) CM86.1A.6F - I ${ }^{1}$ derecho, cara lingual. 7) Vb-sp-218 - Canino inferior, vista lingual. 8) Vb-sp-217 - Canino superior, vista lingual. 9) Vb-251 Metacarpo II derecho. 10) Vb-sp-5618 - Metacarpo III derecho. 11) Vb-253 - Metatarso IV derecho. 12) Vb249 - Metatarso II derecho. 13) Vb-178 - Metatarso III izquierdo. 14) Vb-253 - Metacarpo IV derecho. 15) Vb190 - Falange proximal izquierda. 16) Vb-194 - Falange media derecha. 17) Vb-203 - Falange distal. 18) Vb208 - Calcáneo derecho. 19) Vb06.n2.113.Aa-Ad.90-95.1 - Húmero derecho. 20) Vb91.MN8.T10.4 - Astrágalo derecho. 21) TCB-734 - Tibia izquierda. 


\subsection{Equus hydruntinus}

Orden Perissodactyla Owen, 1848

Familia Equidae Gray, 1821

Subfamilia Equinae Gray, 1821

Género Equus Linnaeus, 1758

Especie Equus hydruntinus Regalia, 1907

\subsubsection{Generalidades}

Durante Pleistoceno Superior es frecuente encontrarse, en yacimientos de toda Europa, con un équido de pequeñas dimensiones, Equus hydruntinus. Sus primeros registros aparecen en el Pleistoceno Medio, hace $350 \mathrm{ka}$, (Orlando et al., 2006), aunque su mayor distribución se alcanza durante el Pleistoceno Superior, ocupando prácticamente toda Europa y el lejano oriente (Orlando et al., 2006). Su presencia se mantiene hasta el Holoceno (Willms, 1989), aunque hay autores que sugieren que pudieron extinguirse realmente en la Edad Media (Antunes, 2006).

Su posición, dentro de los équidos, es muy discutida ya que comparte caracteres con asnos, hemiones y cebras. Así, sus extremidades son similares a las de los hemiones, la dentición superior presenta semejanzas con los asnos y cebras, mientras que los dientes inferiores son parecidos a los de los hemiones (Forsten, 1999; Burke et al., 2003). Por esta razón, en ocasiones, ha sido clasificado como una cebra (Davis, 1980), como un asno (Stehlin y Graziosi, 1935) o como un estenoniano (Forsten y Ziegler, 1995). Sin embargo, un análisis llevado a cabo por Burke et al., (2003) sugiere que Equus hydruntinus puede diferenciarse claramente de asnos y hemiones a partir de la morfología craneal, quedándose más cerca de estos últimos.

Su origen no está claro. Azzaroli (1965), en un primer momento, incluye a la especie $E$. stehlini dentro de la línea que dio lugar a los E. hydruntinus del Pleistoceno Medio y Superior, así como a los asnos y hemiones actuales. Otros autores sitúan el origen en $E$. altidens (Musil, 1969; Forsten, 1986; Alberdi et al, 1988; Azzaroli, 1990; Eisenmann, 1992; Guérin \& Patou-Mathis, 1996) en el que encuentran características compartidas con $E$. hydruntinus, asnos y hemiones. Análisis recientes llevados a cabo por Orlando et al., (2006) sugieren basarse más en datos genéticos que en morfológicos ya que el solapamiento y la semejanza entre especies es muy alta. Sus estudios sitúan esta especie en la línea E. kiang/E. hemionus/E. hydruntinus, aunque dejan el origen filogenético de esta especie abierto, a la espera de más análisis genéticos.

Prat (1968) define dos subespecies en función del tamaño del protocono: $E$. hydruntinus hydruntinus y E. hydruntinus davali. La primera muestra un protocono pequeño y aparece en yacimientos de la primera mitad del Pleistoceno Superior. La segunda, tiene un protocono ligeramente mayor y aparece en yacimientos datados en la segunda parte del Pleistoceno Superior.

La evolución de esta especie puede haber seguido dos líneas. La primera desembocaría en los asnos domésticos, E. asinus, aunque actualmente se considera descendiente de $E$. africanus, en cuyo proceso se habría producido una disminución en el tamaño de la dentición pero manteniendo las dimensiones del protocono. Una segunda nos conduciría a los hemiones, E. hemionus, lo que conllevaría un aumento del tamaño tanto de la dentición como del protocono. La gran variabilidad morfométrica que presentan, incluso a nivel intraespecífico, las diferentes especies de équidos (Maldonado, 1996; Orlando et al., 2006) justifica la revisión de este material, lo que puede aportar nuevos datos sobre los caracteres morfométricos que presenta esta especie en el norte de la Península Ibérica durante el Pleistoceno Tardío. 


\subsubsection{Material}

Los restos son escasos, siendo la mayor parte dientes. El material empleado en la descripción y comparación es el siguiente:

Cueva de Valdegoba: 65 restos: 56 dientes y 9 restos postcraneales. El material dental se reparte en: $1 \mathrm{D}_{2}, 4 \mathrm{D}_{3}, 1 \mathrm{I}_{1}, 1 \mathrm{I}^{2}, 3 \mathrm{P}_{3-4}, 9 \mathrm{M}_{1-2}, 6 \mathrm{M}_{3}, 1 \mathrm{D}^{3-4}, 2 \mathrm{P}^{2}, 16 \mathrm{P}^{3-4}, 10 \mathrm{M}^{1-2}, 2 \mathrm{M}^{3}$. El material postcraneal corresponde a: 1 astrágalo, 4 metacarpos repartidos en 1 metacarpo II, 2 metacarpos III y un metacarpo IV; 3 metatarsos compuestos de 2 metatarsos II y un metatarso IV; y por último una falange media.

Cueva Millán: 1 resto. Un maxilar con la serie $\mathrm{P}^{4}-\mathrm{M}^{3}$.

Cueva del Búho: 3 restos, todos postcraneales: un astrágalo y dos falanges medias.

La Peña de Estebanvela: 19 restos: 17 dientes y 2 postcraneales. Los dientes analizados proceden de los niveles del I al III. En el I se han recogido: $2 \mathrm{dI}_{1}, 2 \mathrm{D}_{2}, 3 \mathrm{M}_{1-2}, 1 \mathrm{M}_{3}, 1 \mathrm{M}^{1-2}$. En el II: $1 \mathrm{P}_{3-4}, 3 \mathrm{M}_{1-2}, 2 \mathrm{M}_{3}, 1 \mathrm{M}^{1-2} \mathrm{y}$, en el III: $1 \mathrm{M}_{1-2}$. El material postcraneal se ha recogido en los niveles I y II. En el I: 1 metápodo y en el II, un metatarso.

Los restos utilizados para estimar la edad de muerte son:

Cueva de Valdegoba: 28 restos: $1 \mathrm{P}_{3-4}, 3 \mathrm{M}_{1-2}, 13 \mathrm{P}^{3-4}$ y $9 \mathrm{M}^{1-2}$.

Cueva Millán: 4 dientes en el nivel 1A: $1 \mathrm{P}^{4}, 1 \mathrm{M}^{1}, 1 \mathrm{M}^{2}$ y $1 \mathrm{M}^{3}$

La Peña de Estebanvela: 14 restos. Nivel I: $1 \mathrm{Di}_{1}, 2 \mathrm{D}_{2}$ y $1 \mathrm{M}_{1-2}$. Nivel II: $1 \mathrm{P}_{3-4}, 3 \mathrm{M}_{1-2}, 1 \mathrm{M}_{3}$ y 1 M1-2. Nivel III: $1 \mathrm{M}_{1-2}$.

\subsubsection{Descripción y comparación}

Las descripciones corresponden a las piezas identificadas en la Cueva de Valdegoba, Cueva Millán, Cueva del Búho y la Peña de Estebanvela.

Tabla V.5.1

Medidas tomadas en los incisivos deciduales y permanentes de E. hydruntinus

\begin{tabular}{|c|c|c|c|c|c|c|c|}
\hline & DAP & DAP $1 / 2$ & DT & DT $1 / 2$ & $\mathbf{H}$ & IL & IA \\
\hline \multicolumn{8}{|l|}{$\mathrm{dI}_{1}$} \\
\hline \multicolumn{8}{|c|}{ Valdegoba } \\
\hline $\mathrm{n}$ & 2 & 2 & 2 & 2 & & 2 & 2 \\
\hline rango & $10,6-12,1$ & $10,0-12,0$ & $5,8-6,4$ & $5,6-6,2$ & & $3,7-10,6$ & $2,3-3,5$ \\
\hline $\bar{x} \pm$ s.d. & $11,4 \pm 1,1$ & $11,0 \pm 1,4$ & $6,1 \pm 0,4$ & $5,9 \pm 0,4$ & & $7,1 \pm 4,9$ & $2,9 \pm 0,9$ \\
\hline \multicolumn{8}{|l|}{$I_{1}$} \\
\hline \multicolumn{8}{|c|}{ Valdegoba } \\
\hline $\mathrm{n}=1$ & & 8,7 & 6,9 & 8,3 & 42,9 & 7,6 & 3,5 \\
\hline \multicolumn{8}{|c|}{$I_{2}$} \\
\hline \multicolumn{8}{|c|}{ Valdegoba } \\
\hline $\mathrm{n}=1$ & & 11,0 & 6,7 & 10,5 & 40,3 & 8,8 & 3,8 \\
\hline
\end{tabular}

Incisivos deciduales inferiores (lámina V.5.1: 1) (tabla V.5.1): son piezas de pequeño tamaño, con la superficie oclusal rectangular y un cuello bien marcado que separa la corona de la raíz. Se diferencian de los permanentes por sus menores dimensiones (tabla V.5.1) y por el cuello que en este caso está más marcado. 
dI $_{1}$ : estos dientes presentan un buen estado de conservación. Se asignan a esta pieza por la forma de la tabla de desgaste, horizontal.

Molares deciduales inferiores (lámina V.5.1: 2 y 3) (tabla V.5.2): son dientes prismáticos, con las coronas bajas, configuración lofodóntica y dos raíces: una mesial y otra distal. La forma es rectangular en el $\mathrm{D}_{3}$ y subrectangular en el $\mathrm{D}_{2}$ y el $\mathrm{D}_{4}$, debido a que se estrecha mesialmente, el primero, y distalmente el segundo. La corona es más baja que en los permanentes y suelen presentar mayor longitud y menor anchura (tablas V.5.2 y 4).

$\mathbf{D}_{2}$ : piezas subrectangulares debido al gran desarrollo del parastilo que se encuentra proyectado mesialmente. Tienen un metastílido más o menos rectangular a diferencia de E. ferus que lo tiene subtriangular. El hipoconúlido es estrecho y alargado, al igual que el entofléxido lo que le diferencia de E. ferus, en el que suele ser ancho y en forma de "U". El metacónido es alargado. El ectofléxido penetra entre el prefléxido y el postfléxido, llegando incluso a tocar la pared del entofléxido. El pliegue pticostílido está muy marcado. Son más largos pero igual de anchos que los otros deciduales inferiores (tabla V.5.2).

$\mathbf{D}_{3}$ : tiene un parastílido largo, que llega casi a la misma altura que el metacónido, que es redondeado y alargado. El hipoconúlido es estrecho y alargado. El entocónido tiene forma de "U" cerrada. El ectofléxido es largo y ancho, y penetra entre el prefléxido y el posfléxido. El pliegue pticostílido está bien desarrollado.

Tabla V.5.2

Medidas tomadas en los molares deciduales inferiores y superiores de E. hydruntinus

\begin{tabular}{|c|c|c|c|c|c|c|c|c|c|c|}
\hline & DAP & DAP $1 / 2$ & DTa & DTp & DT & DT $1 / 2$ & Prefl. L & Postfl. L & KL & PL \\
\hline \multicolumn{11}{|l|}{$\mathbf{D}_{2}$} \\
\hline \multicolumn{11}{|c|}{ Valdegoba } \\
\hline$n=1$ & 33,2 & & & 10,5 & 12,3 & & 7,4 & 13,8 & 14,3 & \\
\hline \multicolumn{11}{|c|}{ Estebanvela } \\
\hline $\mathrm{n}$ & 2 & & 2 & 2 & 2 & & 1 & 1 & & \\
\hline rango & $29,2-33,0$ & & $10,1-13,4$ & $7,3-12,7$ & $12,8-13,6$ & & 9,8 & 14,7 & & \\
\hline$\overline{\mathrm{x}} \pm$ s.d. & $31,1 \pm 2,7$ & & $11,7 \pm 2,3$ & $10,0 \pm 3,8$ & $13,2 \pm 0,6$ & & & & & \\
\hline \multicolumn{11}{|c|}{$D_{3-4}$} \\
\hline \multicolumn{11}{|c|}{ Valdegoba } \\
\hline $\mathrm{n}$ & 4 & 3 & 2 & 3 & 4 & 3 & 3 & 3 & 4 & \\
\hline rango & $25,0-30,8$ & $22,7-30,7$ & $10,2-13,2$ & $9,4-11,5$ & $13,0-16,0$ & $13,1-16,5$ & $7,3-9,5$ & $6,6-11,0$ & $13,9-17,2$ & \\
\hline$\overline{\mathrm{x}} \pm$ s.d. & $27,8 \pm 2,5$ & $27,1 \pm 4,1$ & $11,7 \pm 2,1$ & $10,2 \pm 1,1$ & $14,1 \pm 1,4$ & $14,3 \pm 1,9$ & $8,5 \pm 1,1$ & $8,7 \pm 2,2$ & $15,3 \pm 1,4$ & \\
\hline \multicolumn{11}{|c|}{$\mathrm{D}^{3-4}$} \\
\hline \multicolumn{11}{|c|}{ Valdegoba } \\
\hline $\mathrm{n}=1$ & 30,6 & 28,0 & 17,8 & 13,7 & 19,7 & 21,7 & & & & 7,4 \\
\hline
\end{tabular}

Molares deciduales superiores (lámina V.5.1: 4) (tabla V.5.2): son dientes con las coronas bajas y lofodontas. Tienen tres raíces: una lingual, una distal y otra mesial. Se diferencian de los premolares y molares superiores permanentes por su hipsodoncia más atenuada y por ser más largos pero más estrechos (tablas V.5.2 y 4).

D-4: se diferencian del $\mathrm{D}^{2}$ por presentar una morfología rectangular. Los estilos se encuentran poco proyectados. Tienen los parastilos y los mesostilos anchos, pero los primeros están acanalados y los segundos son simples y redondeados. El metastilo es simple y estrecho, y las fosas tienen pocos pliegues. No tienen pliegue caballino a diferencia de E. ferus.

Incisivos inferiores permanentes (lámina V.5.1: 5) (tabla V.5.1): dientes con las coronas altas y sin cuello. La superficie oclusal es rectangular y los infundíbulos están muy marcados y son profundos. La tabla de desgaste se inclina lateralmente. Dicha inclinación 
se hace más evidente hacia el $I_{3}$. Se diferencian de los deciduales por su hipsodoncia más acentuada, por la ausencia de cuello y por sus mayores dimensiones (tabla V.5.1).

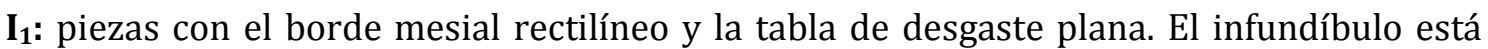
desplazado hacia la cara lingual y tiene un surco longitudinal poco acentuado en la cara bucal. Tiene un mayor DT y un menor DAP que el I $\mathrm{I}_{2}$ (tabla V.5.1).

$\mathbf{I}_{2}$ : la superficie oclusal se inclina hacia el borde lateral. El infundíbulo está cerca de la cara lingual y tiene un surco longitudinal en la cara bucal. Tiene un diámetro transversal menor y un diámetro anteroposterior mayor que el primer incisivo (tabla V.5.1).

Premolares inferiores (lámina V.5.1: 6) (tabla V.5.3) (figura V.4.1): piezas molariformes, prismáticas, lofodontas y con las coronas altas. Son birradiculados, con una raíz mesial y otra distal. Se diferencian de los molares deciduales inferiores por sus menores longitudes y sus mayores anchuras (tablas 5.5.2 y 3). Son más pequeños que los registrados en $E$. ferus y Equus stenonis (figura V.4.1). Difieren de los molares inferiores permanentes en que la faceta de desgaste presenta una orientación mesial mientras que en los molares el desgaste se orienta distalmente. El hipoconúlido es ancho y plano mientras que en los molares es estrecho y redondeado. En los premolares, los bordes anterior y posterior suelen ser más o menos paralelos mientras que en los molares son oblicuos.

Tabla V.5.3

Medidas tomadas en los premolares y molares inferiores permanentes de E. hydruntinus

\begin{tabular}{|c|c|c|c|c|c|c|c|c|c|}
\hline & DAP & DAP 1/2 & DTa & DTp & DT & DT $1 / 2$ & Prefl. L & Postfl. L & KL \\
\hline \multicolumn{10}{|l|}{$\mathbf{P}_{3-4}$} \\
\hline \multicolumn{10}{|c|}{ Valdegoba } \\
\hline $\mathrm{n}$ & 3 & 2 & 1 & 2 & 2 & 2 & 2 & 2 & 2 \\
\hline rango & $23,6-23,8$ & $22,1-22,9$ & 12,9 & $9,1-10,0$ & $13,8-14,2$ & $13,2-14,8$ & $5,5-6,5$ & $6,5-9,5$ & $13,2-13,5$ \\
\hline $\bar{x} \pm$ s.d. & $23,7 \pm 0,1$ & $22,5 \pm 0,5$ & & $9,6 \pm 0,6$ & $14,0 \pm 0,3$ & $14,0 \pm 1,1$ & $6,0 \pm 0,8$ & $8,0 \pm 2,1$ & $13,3 \pm 0,2$ \\
\hline \multicolumn{10}{|c|}{ Estebanvela } \\
\hline $\mathrm{n}=1$ & & 9,5 & & & & 16,8 & 6,5 & 8,0 & \\
\hline \multicolumn{10}{|l|}{$M_{1-2}$} \\
\hline \multicolumn{10}{|c|}{ Valdegoba } \\
\hline $\mathrm{n}$ & 8 & 11 & 9 & 8 & 10 & 11 & 10 & 10 & 11 \\
\hline rango & $22,9-27,7$ & $21,9-25,8$ & $10,8-14,1$ & $8,6-10,8$ & $12,4-16,9$ & $12,8-15,9$ & $5,0-8,9$ & $6,5-11,0$ & $11,4-13,7$ \\
\hline $\bar{x} \pm$ s.d. & $24,2 \pm 1,5$ & $23,7 \pm 1,2$ & $12,6 \pm 1,1$ & $9,8 \pm 0,8$ & $15,1 \pm 1,2$ & $14,4 \pm 1,0$ & $7,4 \pm 1,4$ & $8,4 \pm 1,4$ & $12,6 \pm 0,7$ \\
\hline \multicolumn{10}{|c|}{ Estebanvela } \\
\hline $\mathrm{n}$ & 5 & 2 & 5 & 5 & 5 & 3 & 4 & 4 & 5 \\
\hline rango & $23,0-24,8$ & $23,3-23,5$ & $13,8-15,4$ & $12,4-13,6$ & $12,1-16,1$ & $12,8-15,5$ & $7,2-8,8$ & $8,2-10,4$ & $12,3-14,3$ \\
\hline$\overline{\mathrm{x}} \pm$ s.d. & $24,0 \pm 0,7$ & $23,0 \pm 0,1$ & $14,5 \pm 0,7$ & $13,0 \pm 0,5$ & $14,3 \pm 1,8$ & $14,2 \pm 1,4$ & $7,7 \pm 0,9$ & $9,4 \pm 0,9$ & $13,3 \pm 0,9$ \\
\hline \multicolumn{10}{|l|}{$\mathbf{M}_{3}$} \\
\hline \multicolumn{10}{|c|}{ Valdegoba } \\
\hline $\mathrm{n}$ & 4 & 4 & 4 & 2 & 5 & 5 & 5 & 5 & 4 \\
\hline rango & $25,5-32,3$ & $25,5-30,1$ & $10,7-13,0$ & $6,3-6,8$ & $9,6-13,3$ & $11,2-14,0$ & $5,5-9,7$ & $6,8-12,5$ & $10,8-14,3$ \\
\hline$\overline{\mathrm{x}} \pm$ s.d. & $27,5 \pm 3,2$ & $27,9 \pm 2,1$ & $11,5 \pm 1,1$ & $6,6 \pm 0,3$ & $11,9 \pm 1,6$ & $12,8 \pm 1,2$ & $7,8 \pm 1,5$ & $9,3 \pm 2,2$ & $12,0 \pm 1,7$ \\
\hline \multicolumn{10}{|c|}{ Estebanvela } \\
\hline $\mathrm{n}$ & 2 & & 2 & 1 & 2 & & 3 & 3 & 3 \\
\hline rango & $26,1-26,5$ & & $11,1-13,0$ & 10,1 & $12,1-13,6$ & & $8,2-9,4$ & $7,7-10,6$ & $10,7-12,6$ \\
\hline $\bar{x} \pm$ s.d. & $26,3 \pm 0,3$ & & $12,0 \pm 1,2$ & & $12,8 \pm 1,1$ & & $8,9 \pm 0,6$ & $9,1 \pm 1,5$ & $11,8 \pm 0,9$ \\
\hline
\end{tabular}

$\mathbf{P}_{3-4:}$ estas piezas tienen los metastílidos alargados y los metacónidos redondeados. Los parastílidos no son tan largos como los de los molares y no alcanzan la cara lingual. El entofléxido es estrecho, con forma de "V", a diferencia de E. ferus en el que es abierto. El ectofléxido es largo y redondeado. En la cara bucal, cercana a la superficie oclusal, presenta una concavidad marcada. Carece de pliegues pticostílidos lo que le diferencia de E. ferus en los que están muy desarrollados. Son más pequeños que los molares inferiores permanentes (tabla V.5.3). Los restos de la Cueva de Valdegoba y de la Peña de 
Estebanvela tienen tamaños similares (figura V.4.1). El IPF e IDB son más pequeños que los registrados en Prolom y la Carihuela (tabla V.5.5).

Molares inferiores permanentes (lámina V.5.1: 7 y 8) (tabla V.5.3) (figura V.4.2): piezas rectangulares, salvo el $\mathrm{M}_{3}$ que está proyectado distalmente, con las coronas altas y superficies oclusales lofodontas. Presentan hipoconúlidos estrechos y alargados. Tienen dos raíces, una mesial y otra distal. Son similares a los premolares inferiores. Las diferencias se exponen en el apartado de los premolares por lo que no se repiten aquí.

$\mathbf{M}_{1-2}$ : dientes rectangulares con parastílidos cortos a diferencia de E. ferus en los que son largos. El entofléxido presenta morfologías apuntadas y redondeadas. El metacónido es redondeado, mientras que el metastílido es alargado y subtriangular. El ectofléxido es largo y se sitúa entre el prefléxido y el postfléxido en las piezas de la Cueva de Valdegoba, mientras que en los dientes de la Peña de Estebanvela no lo alcanza. El pliegue ptiscotílido apenas está esbozado mientras que en E. ferus está muy marcado. Sus dimensiones son similares a las de los premolares inferiores (tabla 5.5.3). El tamaño de los restos de la Cueva de Valdegoba y de la Peña de Estebanvela es similar, pero en general son grandes, próximos a los valores del E. ferus de la Cueva de Valdegoba (figura V.4.2). Los índices, IPF e IDB, de los restos de la Cueva de Valdegoba son más grandes que los de Prolom 2 y Arcy, similares a los de la Carihuela y más pequeños que los de la Peña de Estebanvela y Atapuerca (tabla V.5.5).

$\mathbf{M}_{3}$ : diente de apariencia triangular debido al gran desarrollo del hipoconúlido. El entofléxido es redondeado en las piezas de la Cueva de Valdegoba y de la Peña de Estebanvela. El parastílido está más desarrollado que en el anterior molar pero menos que en E. ferus. El ectofléxido, en un caso, se sitúa entre el prefléxido y el postfléxido, llegando a tocar el entofléxido, mientras que en otro caso se queda entre los fléxidos. El pliegue pticostílido aparece en dos casos en los dientes de la Cueva de Valdegoba, mientras que en los restos de la Peña de Estebanvela está ausente. Los dientes recuperados en ambos yacimientos tienen unas dimensiones similares (figura V.4.2). La pieza de la Peña de Estebanvela presenta unos índices, IPF e IDB, más grandes que los de la Carihuela y son similares que los de Atapuerca (tabla V.5.5).

Premolares superiores (lámina V.5.1: 9 y 10) (tabla V.5.4) (figura V.4.3): dientes molariformes, de coronas altas y configuración lofodonta. La superficie oclusal es cuadrangular salvo en el $\mathrm{P}^{2}$ que es triangular debido al gran desarrollo del parastilo. Son trirradiculados, con una raíz lingual, una mesial y otra distal. Tienen unas coronas más altas que los molares deciduales superiores y presentan unos menores DAP y unos mayores DT que los deciduales (tablas V.5.2 y 4). Son similares morfológicamente a los molares superiores permanentes. La diferencia más clara se encuentra en sus dimensiones que son mayores (tabla V.5.4). Debido al parecido entre los $\mathrm{P}^{3}$ y $\mathrm{P}^{4}$ se establece la categoría $\mathrm{P}^{3-4}$. El $\mathrm{P}^{4}$ analizado en Cueva Millán se ha recuperado en un maxilar con la serie $\mathrm{P}^{4}-\mathrm{M}^{3}$.

P2: tiene los estilos poco proyectados, simples y sin surcos; mientras que en E. ferus el mesostilo suele ser ancho y acanalado. Las fosetas tienen pocos pliegues. El protocono es pequeño y redondeado, y carece de surco central en la cara lingual. No tienen pliegue caballino y presenta una concavidad en la cara lingual, cercana a la superficie oclusal.

P4: piezas con los estilos simples y poco proyectados. Difiere de E. ferus por presentar protoconos pequeños, sin surco longitudinal y con ambos lados del mismo tamaño.

P3-4: tiene los estilos redondeados y sin acanalar, lo que difiere en la forma caballina. El protocono es pequeño, a diferencia de E. ferus, con la mitad anterior más pequeña que la posterior, y el borde lingual recto aunque en ocasiones puede ser ligeramente cóncavo. Carece de pliegue caballino. Los valores de estas piezas se solapan con los de $\mathrm{M}^{1-2}$ pero 
existe una tendencia a que sean mayores (tabla V.5.4). La pieza de Cueva Millán es grande, próxima a los valores del caballo de la Cueva de Valdegoba y Cueva Millán (figura V.4.3).

Tabla V.5.4

Medidas tomadas en los premolares y molares superiores permanentes de E. hydruntinus

\begin{tabular}{|c|c|c|c|c|c|c|c|c|c|}
\hline & DAP & DAP 1/2 & DTa & DTp & DT & DT $1 / 2$ & $\mathbf{H}$ & PL & PL 1/2 \\
\hline \multicolumn{10}{|l|}{$\mathbf{P}^{2}$} \\
\hline \multicolumn{10}{|c|}{ Valdegoba } \\
\hline $\mathrm{n}$ & 2 & 2 & & 1 & 2 & 2 & 1 & & \\
\hline rango & $30,5-30,9$ & $29,3-30,5$ & & 19,3 & $22,9-24,3$ & $20,9-21,2$ & 29,4 & & \\
\hline $\bar{x} \pm$ s.d. & $30,7 \pm 0,3$ & $29,9 \pm 0,9$ & & & $23,6 \pm 1,0$ & $21,1 \pm 0,3$ & & & \\
\hline \multicolumn{10}{|l|}{$\mathbf{P}^{3-4}$} \\
\hline \multicolumn{10}{|c|}{ Valdegoba } \\
\hline $\mathrm{n}$ & 13 & 13 & 15 & 14 & 14 & 15 & 13 & 16 & 12 \\
\hline rango & $22,5-25,1$ & $22,2-24,4$ & $21,0-23,7$ & $11,2-22,0$ & $23,1-25,4$ & $18,9-25,6$ & $12,4-59,7$ & $7,5-13,0$ & $8,9-12,7$ \\
\hline $\bar{x} \pm$ s.d. & $24,0 \pm 0,8$ & $23,1 \pm 0,7$ & $22,2 \pm 0,7$ & $17,6 \pm 3,0$ & $24,2 \pm 0,6$ & $23,5 \pm 1,5$ & $40,3 \pm 15,8$ & $11,6 \pm 1,3$ & $11,5 \pm 1,3$ \\
\hline \multicolumn{10}{|l|}{$\mathbf{P}^{4}$} \\
\hline \multicolumn{10}{|l|}{ Millán } \\
\hline $\mathrm{n}=1$ & 26,8 & 26,8 & 27,2 & 25,0 & 26,6 & 27,2 & 48,4 & 10,1 & 11,2 \\
\hline \multicolumn{10}{|l|}{$\mathbf{M}^{1}$} \\
\hline \multicolumn{10}{|l|}{ Millán } \\
\hline $\mathrm{n}=1$ & 24,2 & 25,8 & 25,5 & 18,7 & 25,9 & 26,7 & 45,0 & 11,7 & 12,4 \\
\hline \multicolumn{10}{|l|}{$M^{1-2}$} \\
\hline \multicolumn{10}{|c|}{ Valdegoba } \\
\hline $\mathrm{n}$ & 8 & 7 & 10 & 6 & 10 & 8 & 9 & 10 & 7 \\
\hline rango & $21,0-23,2$ & $20,5-22,1$ & $19,0-23,2$ & $15,8-20,2$ & $21,9-24,1$ & $20,6-26,1$ & $9,7-56,5$ & $8,0-11,4$ & $8,2-12,8$ \\
\hline $\bar{x} \pm$ s.d. & $21,9 \pm 0,7$ & $21,1 \pm 0,5$ & $20,9 \pm 1,3$ & $17,7 \pm 1,8$ & $22,7 \pm 0,7$ & $22,6 \pm 1,8$ & $31,9 \pm 14,8$ & $10,2 \pm 1,3$ & $10,2 \pm 1,7$ \\
\hline \multicolumn{10}{|c|}{ Estebanvela } \\
\hline $\mathrm{n}$ & 2 & 2 & 1 & 1 & 1 & 1 & 2 & 1 & 2 \\
\hline rango & $22,3-26,5$ & $21,4-26,3$ & 22,8 & 23,1 & 22,6 & 23,2 & $45,1-53,1$ & 9,3 & $7,6-9,4$ \\
\hline$\overline{\mathrm{x}} \pm$ s.d. & $24,4 \pm 3,0$ & $23,8 \pm 3,4$ & & & & & $49,1 \pm 5,7$ & & $8,5 \pm 1,2$ \\
\hline \multicolumn{10}{|l|}{$\mathbf{M}^{2}$} \\
\hline \multicolumn{10}{|l|}{ Millán } \\
\hline $\mathrm{n}=1$ & 23,8 & 24,4 & 23,6 & 17,7 & 25,5 & 26,3 & 54,7 & & 12,4 \\
\hline \multicolumn{10}{|l|}{$\mathbf{M}^{3}$} \\
\hline \multicolumn{10}{|c|}{ Valdegoba } \\
\hline $\mathrm{n}$ & 2 & 2 & 2 & 2 & 2 & 2 & 2 & 2 & 2 \\
\hline rango & $21,2-25,1$ & $24,2-25,5$ & $18,8-19,5$ & $13,8-16,8$ & $19,5-20,1$ & $18,5-18,9$ & $25,8-56,8$ & $10,4-11,1$ & $11,4-12,1$ \\
\hline $\bar{x} \pm$ s.d. & $23,1 \pm 2,8$ & $24,8 \pm 0,9$ & $19,1 \pm 0,5$ & $15,3 \pm 2,1$ & $19,8 \pm 0,5$ & $18,7 \pm 0,3$ & $41,3 \pm 21,9$ & $10,8 \pm 0,5$ & $11,7 \pm 0,5$ \\
\hline \multicolumn{10}{|l|}{ Millán } \\
\hline $\mathrm{n}=1$ & 25,07 & 25,44 & & & 21,6 & 21,8 & & 11,3 & \\
\hline
\end{tabular}

Molares superiores permanentes (lámina V.5.1: 11 y 12) (tabla V.5.4) (figura V.4.4): dientes prismáticos, con las coronas altas, lofodontas, protoconos pequeños y tres raíces: una lingual, una mesial y otra distal. La superficie oclusal es cuadrangular salvo la del $\mathrm{M}^{3}$ que es triangular debido al gran desarrollo del hipocono. Son más pequeños que los premolares y molares superiores (tabla V.5.4) de E. ferus (figura V.4.3). Se establecen las siguientes categorías: $\mathrm{M}^{1}, \mathrm{M}^{2}, \mathrm{M}^{1-2} \mathrm{y} \mathrm{M}^{3}$. El $\mathrm{M}^{1-2}$ se basa en las similitudes existentes entre los dos primeros molares. En Cueva Millán se ha recuperado un maxilar por lo que se han podido diferenciar bien $\mathrm{M}^{1} \mathrm{y} \mathrm{M}^{2}$.

M1: tiene los estilos poco proyectados y sin acanalar. El protocono es pequeño, con los dos lados del mismo tamaño y con un surco lingual. Los hipoconos son estrechos y carecen de pliegue caballino. Son más grandes que $\mathrm{M}^{2}$ y $\mathrm{M}^{3}$ pero más pequeños que $\mathrm{P}^{3-4}$ (tabla V.5.4).

M2: tiene los estilos simples. Las fosetas presentan pocos pliegues. El protocono es pequeño, con las dos partes del mismo tamaño y con un surco longitudinal en la cara 
lingual. Carece de concavidad cercana a la superficie oclusal en la cara lingual. No tiene pliegue caballino. Es más grande que el $\mathrm{M}^{3}$ pero más pequeño que $\mathrm{M}^{1}$ y $\mathrm{P}^{3-4}$ (tabla V.5.4).

Tabla V.5.5

Índices registrados en la dentición de los E. hydruntinus estudiados y otros caballos euroasiáticos

\begin{tabular}{|c|c|c|c|c|c|c|c|}
\hline \multirow{2}{*}{ Yacimiento } & \multicolumn{2}{|c|}{$P_{3-4}$} & \multicolumn{2}{|c|}{$\mathbf{M}_{1-2}$} & \multicolumn{2}{|c|}{$\mathbf{M}_{3}$} & \multirow{2}{*}{$\frac{M^{1-2}}{\text { IPL }}$} \\
\hline & IPF & IDB & IPF & IDB & IPF & IDB & \\
\hline Atapuerca TE & & & 51,0 & 60,0 & 33,8 & 46,5 & 50,7 \\
\hline Cova Negra & & & 35,1 & 52,6 & & & \\
\hline Bynagady & & & & & & & 44,8 \\
\hline Carihuela & 44,0 & 58,0 & 31,3 & 53,6 & 28,6 & 41,2 & 42,1 \\
\hline Arcy & & & 25,8 & & & & \\
\hline Prolom 2 & 42,7 & 60,3 & 31,5 & 55,1 & & 41,9 & 37,0 \\
\hline Valdegoba & 33,7 & 56,2 & 34,6 & 51,8 & & & 38,3 \\
\hline Millán & & & & & & & 48,7 \\
\hline Estebanvela & & & 39,0 & 55,6 & 34,6 & 44,8 & \\
\hline
\end{tabular}

* Los valores registrados son valores medios. Los índices, salvo los correspondientes a los yacimientos analizados, provienen de Eisenman y Barishnikov (1994 - 1995) Maldonado (1996) y Van der Made (1999). IP: índice protocónico. IPF: índice postflexídico. IDB: índice del doble bucle.

M1-2: tiene unos estilos poco proyectados, simples y sin acanalar, lo que le diferencia de $E$. ferus. Los espacios interestilares son pequeños, al igual que el protocono. Una de las piezas de Cueva Millán presenta un surco marcado en la cara lingual. Las fosetas tienen pocos pliegues. La cara lingual presenta una ligera concavidad en su parte superior y los hipoconos son estrechos. Carecen de pliegue caballino. El resto de la Cueva de Valdegoba tiene un índice del protocono pequeño, pero parecido al de Prolom 2 (tabla V.5.5).

$\mathbf{M}^{3}$ : tiene los estilos pequeños y redondeados, carentes de surco longitudinal. El protocono está más desarrollado en su parte posterior y presenta un surco longitudinal que lo recorre en la cara lingual. Uno de los ejemplares de la Cueva de Valdegoba tiene pliegue caballino y los otros dos no, la pieza de Cueva Millán tampoco presenta este pliegue. En vista lateral, tiene una concavidad cercana a la superficie oclusal en las piezas de la Cueva de Valdegoba pero no aparece en la de Cueva Millán. Son más pequeños que los molares precedentes y que los $\mathrm{P}^{3-4}$ (tabla V.5.4).

Astrágalo (lámina V.5.1: 18 y 21) (tabla V.5.6): se han recuperado dos piezas. La tróclea tiene un surco, entre las dos crestas, abierto y en forma de " $U$ ". La superficie distal, que articula con el navicular es recta. La depresión, definida por las caras articulares del cuarto tarsal, es estrecha.

Tabla V.5.6

Medidas tomadas en astrágalos de E. hydruntinus

\begin{tabular}{lccccccc}
\hline & LM & DMCM & AT & AM & AAD & PAD & PMM \\
\hline $\begin{array}{l}\text { Valdegoba } \\
\mathrm{n}=1\end{array}$ & 53,5 & 55,7 & 30,2 & 56,7 & 51,5 & 34,4 & 50,1 \\
$\begin{array}{l}\text { Búho } \\
\mathrm{n}=1\end{array}$ & & & & & & & \\
\hline
\end{tabular}

La superficie plantar, aquella que presenta las caras que articulan con el calcáneo, tiene una serie de modificaciones con respecto a la línea caballina. La cara articular lateral carece de una constricción en su zona media y además muestra, en su extremo inferior, una prolongación acusada. En el extremo proximal, la cresta lateral presenta una protuberancia doble.

Metacarpo II (lámina V.5.1: 13) (tabla V.5.7): se ha identificado una pieza en buen estado, aunque la parte distal está fragmentada. La diáfisis tiene una superficie triangular y la cara articular proximal se encuentra abrasionada. Las caras articulares proximales son estrechas y alargadas. Además, la protuberancia metacarpal posterior no está muy desarrollada. 
Tabla V.5.7

Medidas tomadas en los metacarpos y metatarsos de E. hydruntinus

\begin{tabular}{|c|c|c|c|c|c|c|c|c|c|c|c|c|c|c|c|}
\hline & GL & GLm & SD & SSD & BDS & DM & DL & DD & BDa & BP & DP & DPA & DAT & DAF & DPF \\
\hline \multicolumn{16}{|l|}{ Metacarpos } \\
\hline \multicolumn{16}{|l|}{ II } \\
\hline \multicolumn{16}{|l|}{ Valdegoba } \\
\hline $\mathrm{n}=1$ & & & & & & & & & & 16,5 & 11,5 & & & & \\
\hline \multicolumn{16}{|l|}{ III } \\
\hline \multicolumn{16}{|l|}{ Valdegoba } \\
\hline $\mathrm{n}$ & 1 & 1 & 1 & 1 & 2 & 2 & 2 & 2 & 2 & 1 & & 1 & 1 & 1 & 1 \\
\hline rango & 215,5 & 210,9 & 26,4 & 22,2 & $32,5-36,7$ & $21,9-24,1$ & $20,8-21,3$ & $24,0-26,8$ & $32,3-36,8$ & 41,5 & & 26,9 & 29,6 & 11,5 & 4,3 \\
\hline $\bar{x} \pm$ s.d. & & & & & $34,6 \pm 2,9$ & $23,0 \pm 1,5$ & $21,0 \pm 0,3$ & $25,4 \pm 2,0$ & $34,6 \pm 3,2$ & & & & & & \\
\hline \multicolumn{16}{|l|}{ IV } \\
\hline \multicolumn{16}{|l|}{ Valdegoba } \\
\hline $\mathrm{n}=1$ & & & & & & & & & & 18,1 & 10,9 & & & & \\
\hline \multicolumn{16}{|l|}{ Metatarsos } \\
\hline \multicolumn{16}{|l|}{ II } \\
\hline \multicolumn{16}{|l|}{ Valdegoba } \\
\hline $\mathrm{n}$ & 1 & & & & & & & & & 2 & 2 & & & & \\
\hline rango & $>123,5$ & & & & & & & & & $16,1-19,7$ & $11,3-11,5$ & & & & \\
\hline$\overline{\mathrm{x}} \pm$ s.d. & & & & & & & & & & $17,9 \pm 2,5$ & $11,4 \pm 0,1$ & & & & \\
\hline \multicolumn{16}{|l|}{ IV } \\
\hline \multicolumn{16}{|l|}{ Valdegoba } \\
\hline $\mathrm{n}=1$ & & & & & & & & & & 21,3 & 13,8 & & & & \\
\hline
\end{tabular}


Metacarpo III (lámina V.5.1: 15) (tabla V.5.7): se han analizado dos piezas, una de ellas completa y otra que conserva únicamente el extremo distal. La pieza que presenta el mejor estado de conservación tiene una diáfisis estrecha y grácil. La cara que articula con el uncinato es subtriangular. El extremo lateral de la superficie articular del magnum se encuentra orientada anteroposteriormente. La depresión articular, que atraviesa toda la superficie mediolateralmente, no está muy desarrollada. La tuberosidad metacarpiana no está apenas esbozada. En vista palmar, la concavidad existente por encima del cóndilo articular está muy marcada. Difieren de E. ferus por su mayor gracilidad (figura V.4.5).

Metacarpo IV (lámina V.5.1: 14) (tabla V.5.7): se han identificado dos piezas. Las caras que articulan con el tercer metacarpo están separadas. La superficie articular proximal es rectangular, presentando una protuberancia marcada en la parte posterior.

Metatarso II (lámina V.5.1: 16) (tabla V.5.7): se han analizado dos piezas, una de ellas con el extremo distal roto y una prácticamente completa que presenta la superficie articular proximal abrasionada.

Metatarso III: las piezas recuperadas en los niveles I y II de la Peña de Estebanvela han aparecido muy fragmentadas. La sección subcilíndrica de la pieza del segundo nivel hace pensar que se trata de un metatarso. Debido a su estado no se pueden realizar descripciones más exhaustivas ni la toma de medidas diagnósticas.

Metatarso IV (lámina V.5.1: 19) (tabla V.5.7): la pieza analizada tiene el extremo distal roto. La superficie articular proximal está abrasionada por lo que la morfología de las caras articulares apenas es visible. La forma ovalada de dicha superficie junto con la presencia de una protuberancia por debajo de las caras articulares laterales y la superficie lisa del extremo posterior indica que se trata de un cuatro metatarso.

Falanges medias (lámina V.5.1: 17 y 20) (tabla V.5.8): se han identificado cuatro piezas en buen estado de conservación. La superficie articular proximal tiene los bordes anterior y posterior rectos. El processus extensorius no está muy marcado al igual que el surco sagital. Los bordes lateral y medial son más o menos rectos. Las protuberancias para los ligamentos colaterales se encuentran muy marcadas, al igual que la prominencia transversa en la cara posterior. El surco que separa los cóndilos en la epífisis distal no se encuentra muy marcado. Estos caracteres hacen que se asigne esta pieza a una falange media posterior. Las inserciones de los ligamentos están muy marcadas.

Tabla V.5.8

Medidas tomadas en las falanges medias de E. hydruntinus

\begin{tabular}{lcccccc}
\hline & GL & GLa & SD & BP & DP & BD \\
\hline Valdegoba & & & & & & \\
$\mathrm{n}=1$ & 33,4 & 24,5 & 26,3 & 31,9 & 19,6 & 30 \\
Búho & 2 & 2 & 2 & 2 & 2 & 2 \\
$\mathrm{n}$ & $35,0-35,7$ & $26,4-30,4$ & $32,0-32,6$ & $31,6-37,3$ & $22,6-23,8$ & $32,1-33,5$ \\
rango & $35,3 \pm 0,5$ & $28,7 \pm 2,5$ & $32,3 \pm 0,0$ & $34,4 \pm 4,1$ & $23,2 \pm 0,9$ & $32,8 \pm 0,9$ \\
$\overline{\mathrm{x}} \pm$ s.d. & & & & & &
\end{tabular}

\subsubsection{Número Mínimo de Individuos}

El número mínimo de individuos se ha estimado teniendo en cuenta la pieza más frecuente y el desgaste dental. 
Tabla V.5.9

Número mínimo de individuos de E. hydruntinus

\begin{tabular}{|c|c|c|c|c|c|c|c|}
\hline & & Inmaduros & Maduros & Total & Juveniles & Adultos & Senil \\
\hline Valdegoba & & 2 & 3 & 5 & 2 & 1 & 2 \\
\hline Cueva Millán & $\mathbf{1 A}$ & & & 1 & & & \\
\hline \multirow[t]{2}{*}{ Búho } & & & & 1 & & & \\
\hline & I & 1 & 1 & 2 & 1 & 1 & \\
\hline \multirow[t]{2}{*}{ Estebanvela } & II & & 2 & 2 & & 2 & \\
\hline & III & & & 1 & & & \\
\hline
\end{tabular}

En la Cueva de Valdegoba se han identificado cinco ejemplares, a partir de la pieza más frecuente, el $\mathrm{P}^{3-4} \mathrm{y}$ a sus diferentes grados de desgaste (tabla V.5.10). Al menos dos ejemplares serían inmaduros, juveniles; y dos maduros, adultos. En Cueva Millán se ha recuperado únicamente un maxilar, por lo que tendríamos sólo un ejemplar de al menos 45 meses. En la Cueva del Búho hay al menos un ejemplar, estimado a partir de diferentes piezas postcraneales. En el nivel I de la Peña de Estebanvela se han identificado dos individuos a partir del desgaste del $\mathrm{M}_{1-2}$ izquierdo, uno sería juvenil y otro un adulto. En el nivel II hay al menos dos ejemplares adultos, estimados a partir de un $\mathrm{M}_{1-2}$ izquierdo y de otro derecho. En el nivel III se ha identificado un ejemplar a partir de un $\mathrm{M}_{1-2}$ izquierdo.

\subsubsection{Edad de muerte}

Se han empleado únicamente los dientes ya que son las piezas más abundantes y mejor conservadas. Se ha seguido el modelo descrito en el apartado de metodología y se han tenido en cuenta tanto el reemplazamiento como la erupción dental.
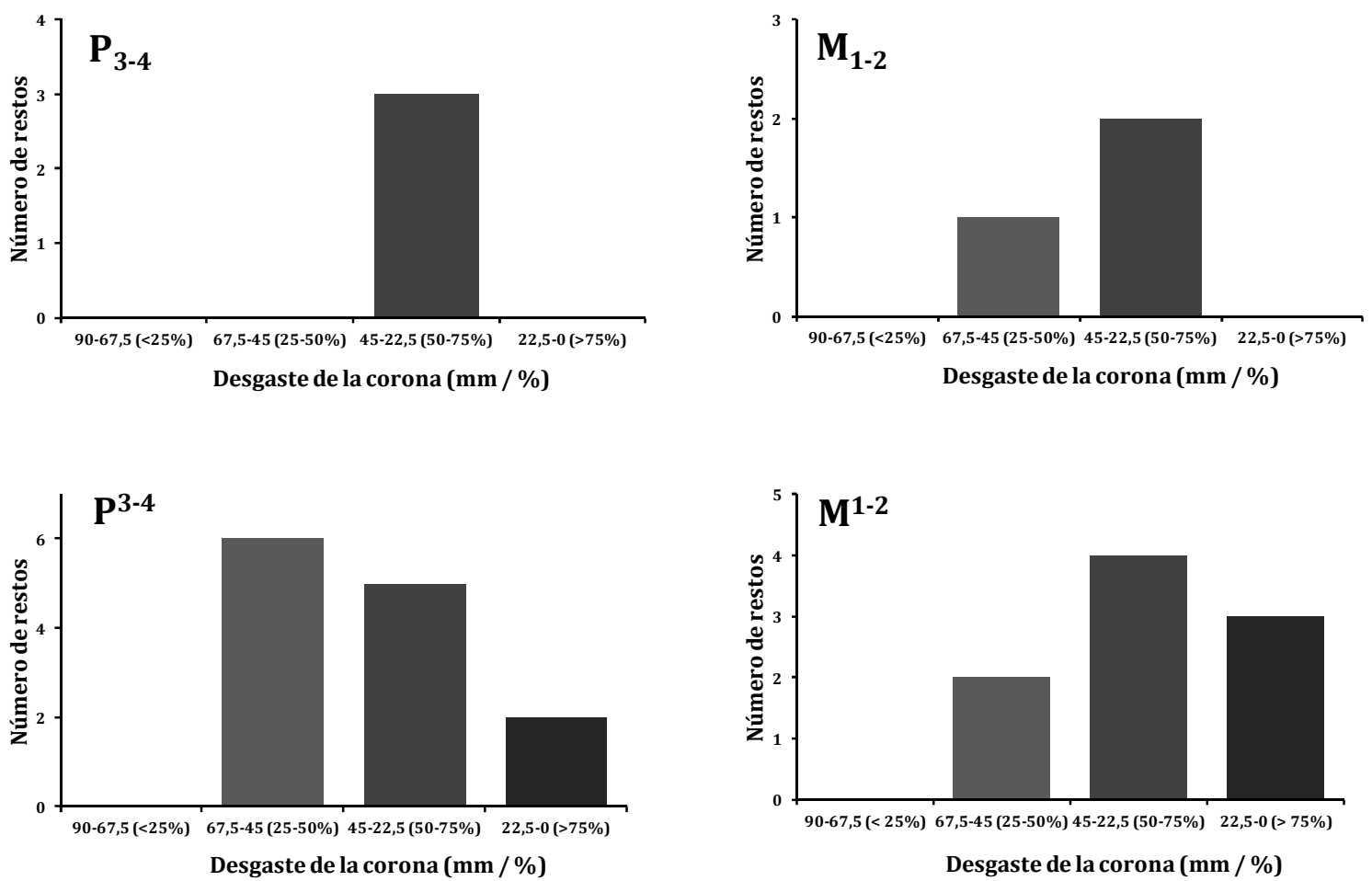

Figura V.51. Desgaste en los dientes yugales del Equus hydruntinus de la Cueva de Valdegoba.

Cueva de Valdegoba: los restos empleados en este análisis son escasos. En la dentición inferior predominan las piezas con desgastes marcados, $50-75 \%$, seguidas por aquellas 
que presentan una erosión moderada, 25 - $50 \%$. No se han recuperado restos con desgastes máximos, > $75 \%$, o poco acentuados, < $25 \%$ (figura V.5.1) (tabla V.5.9). La dentición superior presenta más variabilidad, probablemente debido al mayor número de restos. El P3-4 presenta un mayor número de efectivos con desgastes moderados, 25 - 50 $\%$; seguidos por aquellos con desgastes marcados y máximos. Los $\mathrm{M}^{1-2}$ analizados muestran unos desgastes, en su mayoría, marcados, seguidos por aquellos con erosiones superiores al $75 \%$. Aquellos con desgastes moderados son los más escasos (figura V.5.1) (tabla V.5.10).

Tabla V.5.10

Alturas de las coronas y rangos de desgaste en los dientes yugales del E. hydruntinus de la Cueva de Valdegoba

\begin{tabular}{|c|c|c|c|c|c|c|c|c|c|}
\hline & & $0-22,5$ & $\frac{22,5-45,0}{50}$ & $45,0-67,5$ & & & $0-22,5$ & $22,5-45,0$ & $45,0-67,5$ \\
\hline & & $75-100 \%$ & $50-75 \%$ & $25-50 \%$ & & & $5-100 \%$ & $50-75 \%$ & $25-50 \%$ \\
\hline $\mathbf{P}_{3-4}$ & & & & & $\mathbf{M}_{1-2}$ & & & & \\
\hline Vb-sp-230 & d & & 32,1 & & Vb-64 & d & & 28,6 & \\
\hline Vb-102 & d & & 41,7 & & Vb-96 & $\mathrm{i}$ & & 40,4 & \\
\hline Vb-94 & d & & 34,6 & & Vb-95 & $\mathrm{i}$ & & & 45,9 \\
\hline $\mathbf{P}^{3-4}$ & & & & & $\mathbf{M}^{1-2}$ & & & & \\
\hline Vb-33 & d & & & 57,0 & Vb-88 & d & & 34,8 & \\
\hline Vb-32 & d & & & 59,7 & Vb-110 & $d$ & & 24,6 & \\
\hline Vb-sp-222 & $\mathrm{i}$ & & 28,6 & & Vb-sp-220 & d & 21,3 & & \\
\hline Vb-sp-223 & $\mathrm{i}$ & & 24,7 & & Vb-84 & d & & 41,6 & \\
\hline Vb-sp-257 & $d$ & & & 59,4 & Vb-83 & i & & & 48,5 \\
\hline Vb-sp-254 & $d$ & 21,5 & & & Vb-91 & i & 21,5 & & \\
\hline Vb-85 & $\mathrm{i}$ & & & 46,4 & Vb-87 & $\mathrm{i}$ & & 28,8 & \\
\hline Vb-sp-255 & d & & & 52,5 & Vb-sp-221 & $\mathrm{i}$ & 9,7 & & \\
\hline Vb-108 & i & & 37,4 & & Vb-sp-269 & d & & & 56,5 \\
\hline Vb-sp-277 & $\mathrm{i}$ & & & 54,0 & & & & & \\
\hline Vb-107 & d & & 31,0 & & & & & & \\
\hline Vb-89 & $\mathrm{i}$ & & 38,7 & & & & & & \\
\hline Vb-sp-250 & d & 12,4 & & & & & & & \\
\hline
\end{tabular}

Si tenemos en cuenta que la pieza más frecuente, el $\mathrm{P}^{3}-4$ derecho, y sus diferentes grados de desgaste tendríamos al menos 2 ejemplares juveniles, 1 adulto y dos ejemplares seniles (tabla V.5.10).

Cueva Millán: todos los dientes tienen unos desgastes similares, entre el 25 y el $50 \%$ (tabla V.5.11). Este ejemplar tendría al menos 45 meses, edad de erupción del $\mathrm{P}^{4}$ (Sisson et al., 2001).

Tabla V.5.11

Alturas de las coronas y rangos de desgaste en los dientes yugales del E. hydruntinus de Cueva Millán

\begin{tabular}{lclc}
\hline & $\mathbf{4 5 , 0 - 6 7 , 5}$ & & $\mathbf{4 5 , 0 - 6 7 , 5}$ \\
\cline { 2 - 3 } & $\mathbf{2 5 - 5 0 \%}$ & & $\mathbf{2 5 - 5 0 \%}$ \\
\hline $\mathbf{P}^{\mathbf{4}}$ & & $\mathbf{M}^{\mathbf{2}}$ & \\
\hline CM.86.1A-9D & 48,4 & & CM.86.1A-9D \\
\hline $\mathbf{M}^{\mathbf{1}}$ & & $\mathbf{M}^{\mathbf{3}}$ & 54,68 \\
\hline CM86.1A-9D & 45,02 & CM.86.1A-9D & 52,69 \\
\hline
\end{tabular}

La Peña de Estebanvela: de las 18 piezas recuperadas únicamente han podido ser medidas 8. Se analizan por niveles.

Nivel I: se han podido analizar tres piezas: una con un desgaste mínimo $(<25 \%)$, otra con una erosión moderada (25 - $50 \%$ ) y otra con desgaste marcado $(50-75 \%)$. A partir del $\mathrm{M}_{1-2}$ podemos indicar que al menos uno de los ejemplares sería juvenil y otro sería adulto. 
Nivel II: sean podido medir tres dientes, todos con desgastes entre el 50 y el $75 \%$ (tabla V.5.12). Si tomamos el $\mathrm{M}_{1-2}$ y sus diferentes erosiones podemos indicar que tendríamos al menos dos ejemplares adultos. Las piezas PE.03.E8.NII.6 y PE.99.D7.NII.3.7 tienen unos desgastes similares por lo que podrían pertenecer al mismo ejemplar, una sería un $\mathrm{M}_{1} \mathrm{y}$ otra un $\mathrm{M}_{2}$. El otro ejemplar estaría representado por la pieza PE.00.E9/E10.NII.4.14.

\section{Nivel I}
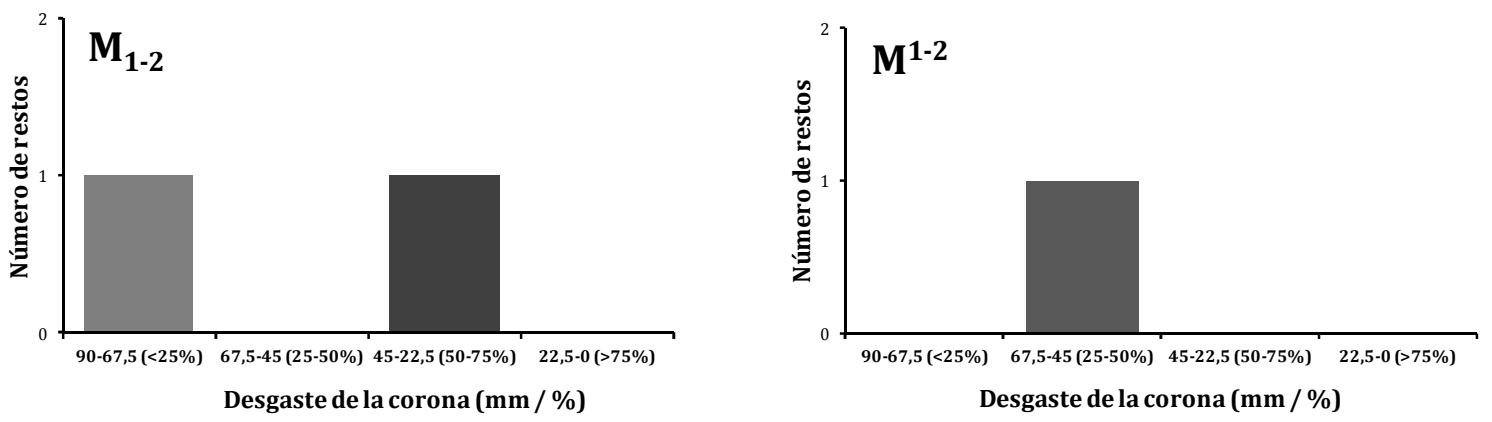

\section{Nivel II}
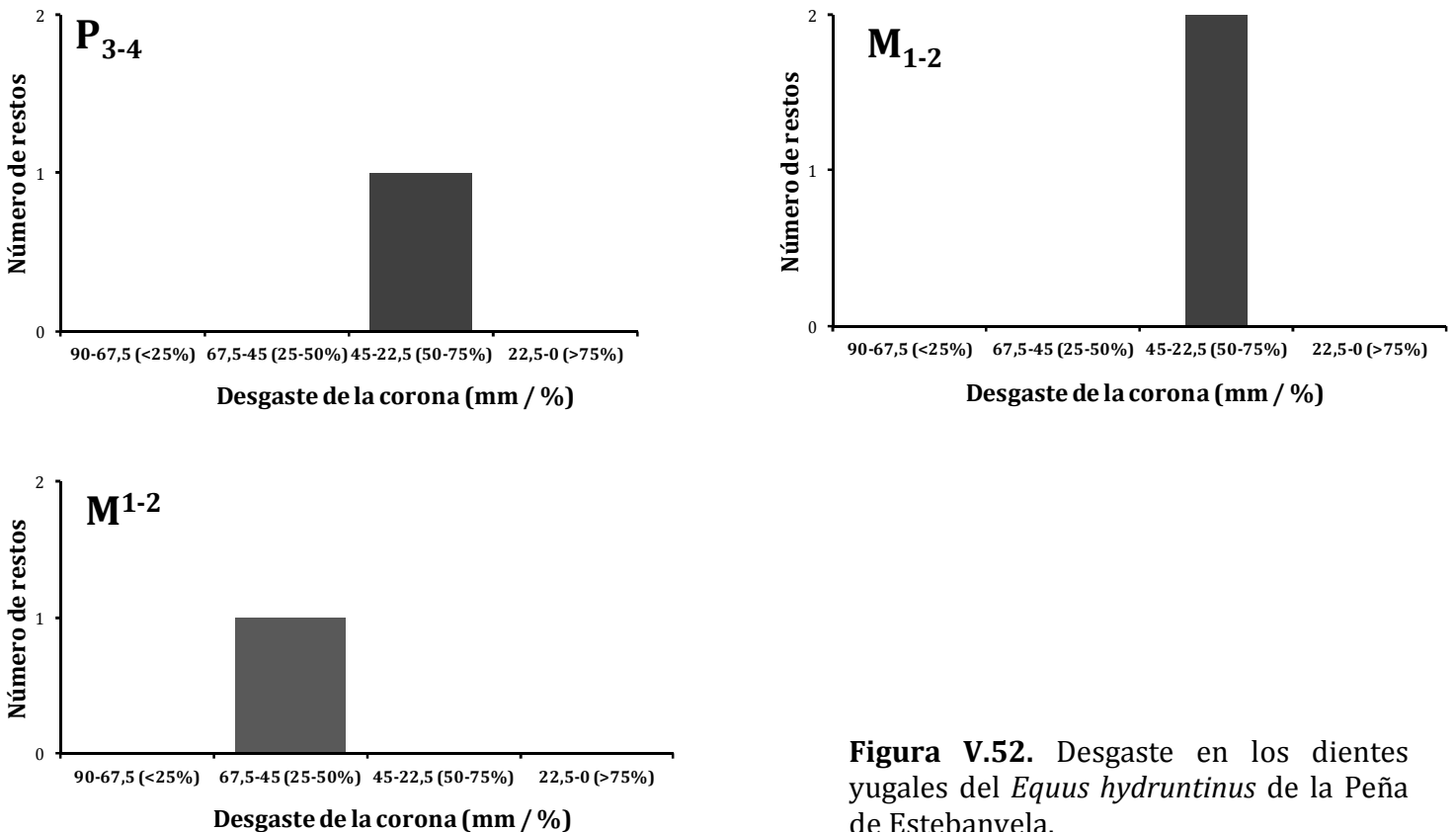

Figura V.52. Desgaste en los dientes yugales del Equus hydruntinus de la Peña de Estebanvela.

Tabla V.5.12

Alturas de las coronas y rangos de desgaste de los dientes yugales del E. hydruntinus de Estebanvela (1 ${ }^{\mathrm{a}}$ parte)

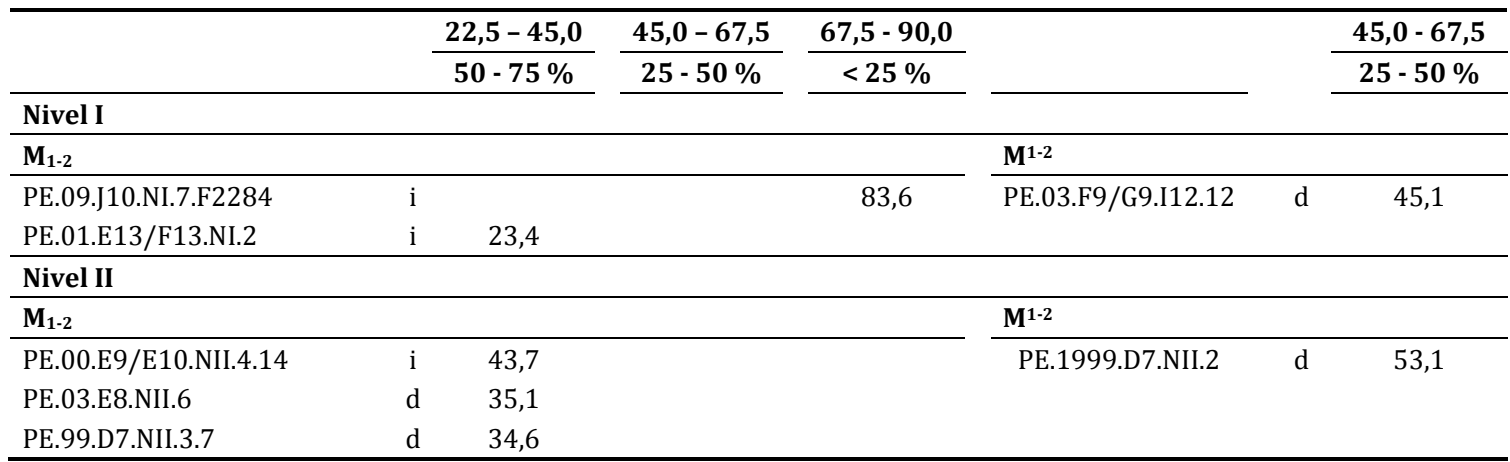


Tabla V.5.12

Alturas de las coronas y rangos de desgaste de los dientes yugales del E. hydruntinus de Estebanvela (2 $2^{\mathrm{a}}$ parte)

\begin{tabular}{|c|c|c|c|c|}
\hline & $22,5-45,0$ & $45,0-67,5$ & $67,5-90,0$ & $45,0-67,5$ \\
\hline & $50-75 \%$ & $25-50 \%$ & $<25 \%$ & $25-50 \%$ \\
\hline \multicolumn{5}{|l|}{ Nivel III } \\
\hline \multicolumn{5}{|l|}{$\mathbf{M}_{1-2}$} \\
\hline PE.03.C9.NIII.2.5 & $\mathrm{i}$ & $60,6 \mathrm{r}$ & & \\
\hline
\end{tabular}

Nivel III: la pieza recuperada, $1 \mathrm{M}_{1-2}$, tiene la base fragmentada, por lo que la altura del diente no puede medirse. Dicha variable $(\mathrm{H}=60,6 \mathrm{r})$ sugiere que el ejemplar sería al menos juvenil al no tener la corona gastada hasta el $50 \%$.

\subsubsection{Discusión}

La hipsodoncia y la configuración lofodóntica de la superficie oclusal nos permiten clasificar este material dentro de la familia Equidae. Dentro de los dos grupos evolutivos, estenoniano y caballino, descartamos el último ya que nuestro material presenta, por lo general, estilos simples, protoconos cortos, ectofléxidos estrechos, pliegues pticostílidos pequeños y carecen de pliegues caballinos o bien los tienen muy pequeños. Además, tienen unos metápodos muy gráciles, algo que nos permite diferenciarlos de E. ferus.

En los équidos, los caracteres específicos son muy raros, observándose, además, un gran solapamiento en sus dimensiones, por lo que es la combinación de caracteres lo que nos permite asignar el material a una u otra especie paleontológica. Caracteres como la gracilidad de los metápodos, la forma en "V" de los ectofléxidos, la morfología simple de los estilos, y las dimensiones registradas nos permiten asignar estos restos a $E$. hydruntinus.

Los índices protocónicos registrados en nuestros restos (tabla V.5.5) sugieren que la pieza de la Cueva de Valdegoba podría encajar bien en la subespecie $E$. h. hydruntinus, característica de las primeras fases del Pleistoceno Superior; y la de Cueva Millán en E. $h$. davili propia del Pleistoceno Superior final. Sin embargo, los valores de estos índices están muy solapados en ambas subespecies (Maldonado, 1996), encontrándose nuestros registros cercanos a los valores de las dos. Por este motivo, no consideramos ir más allá de la clasificación a nivel específico y no incluimos los restos en alguna de las subespecies descritas por Prat (1968), ya que las diferencias entre ambas se basan exclusivamente en el tamaño del protocono (Maldonado, 1996). 


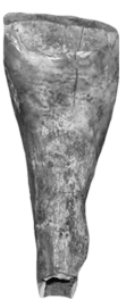

1.
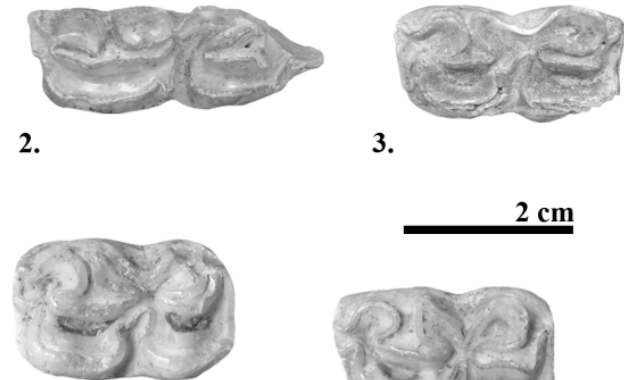

6.

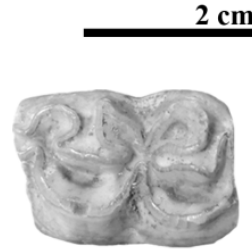

7.

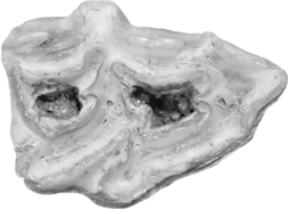

9.

10.
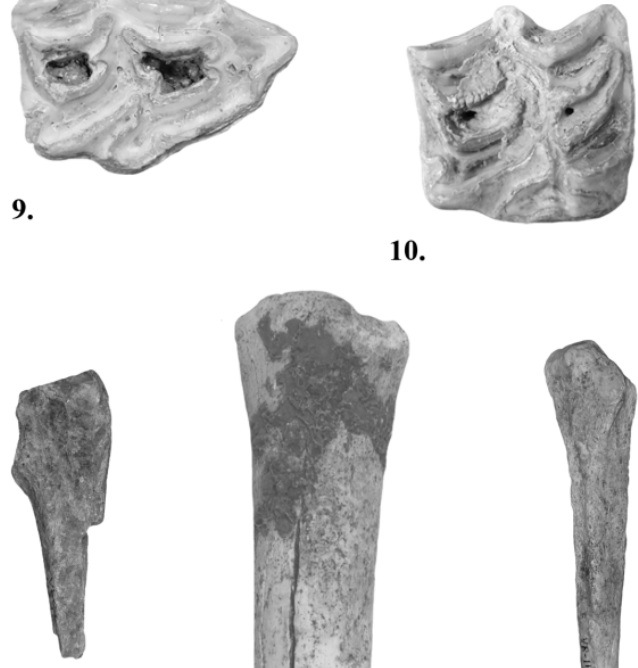

13.

14.

15.

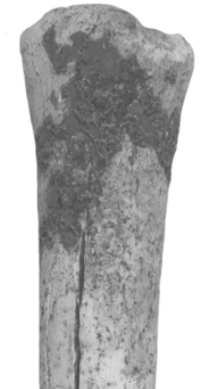

$2 \mathrm{~cm}$

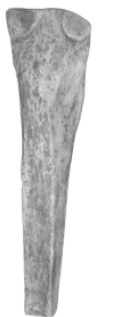

(1)

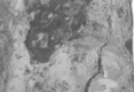

19.

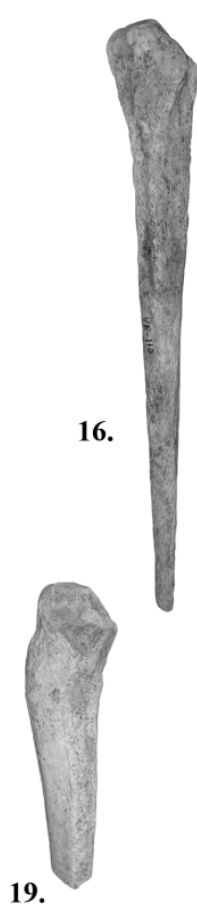

4.

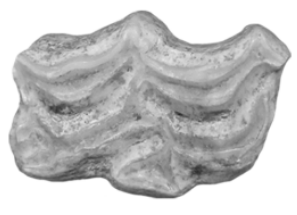

5.

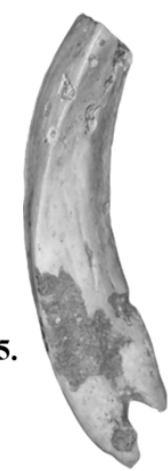

8.

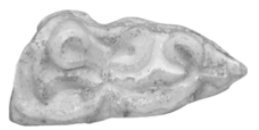

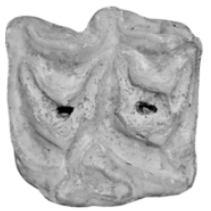

11.

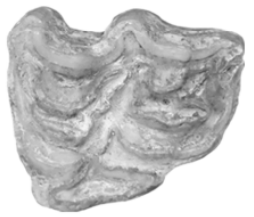

12.

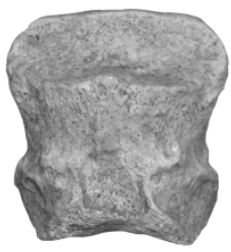

17.

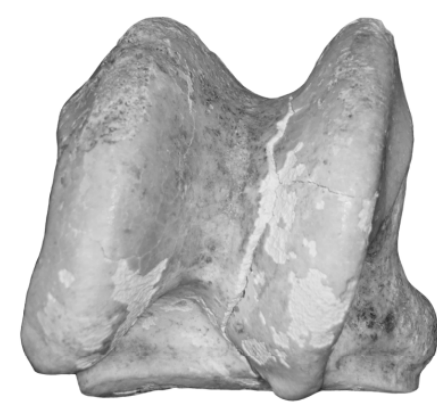

18.

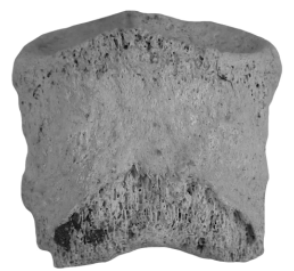

20.

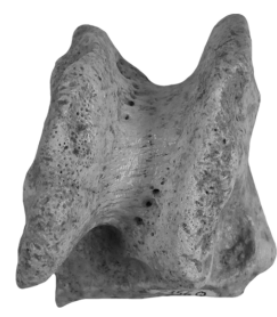

21.

Lámina V.5.1. Equus hydruntinus provenientes de los yacimientos de la Cueva de Valdegoba (sigla Vb), Cueva del Búho (sigla TCB), Cueva Millán (sigla CM) y La Peña de Estebanvela (sigla PE). 1) PE.02.F12.G12.N1.5.21 $\mathrm{dI}_{1}$ derecho, cara lingual. 2) $\mathrm{Vb}-117-\mathrm{D}_{2}$ derecho, superficie oclusal. 3) $\mathrm{Vb}$-sp-229- $\mathrm{D}_{3-4}$ derecho, superficie oclusal. 4) Vb-163 - D $\mathrm{D}^{3-4}$ derecho, superficie oclusal. 5) Vb-sp-232 - I2 izquierdo, cara lateral. 6) Vb-94 - $\mathrm{P}_{3-4}$ derecho, superficie oclusal. 7) Vb-sp-281 - M1-2 derecho, superficie oclusal. 8) Vb-104 - M3 izquierdo, superficie oclusal. 9) Vb-7 - $\mathrm{P}^{2}$ derecho, superficie oclusal. 10) Vb-sp-255 - P3-4 derecho, superficie oclusal. 11) $\mathrm{M}^{1-2}$ izquierdo, superficie oclusal. 12) $\mathrm{Vb}-42-\mathrm{M}^{3}$ izquierdo, superficie oclusal. 13) $\mathrm{Vb}-261$ - metacarpo II izquierdo. 14) Vb-247 - metacarpo IV izquierdo. 15) Vb-sp-6299 - metacarpo III derecho. 16) Vb-110 metatarso II izquierdo. 17) Vb-sp-114 - falange media derecha. 18) Vb-207 - astrágalo derecho. 19) Vb-sp4628 - metatarso IV derecho. 20) TCB-192 - falange media derecha. 21) TCB-74 - astrágalo derecho. 


\subsection{Sus scrofa}

Orden Artiodactyla Owen, 1848

Familia Suidae Gray, 1821

Subfamilia Suinae Gray, 1821

Género Sus Linnaeus, 1758

Especie Sus scrofa Linnaeus, 1758

\subsubsection{Generalidades}

Los Suidae eran abundantes en el Mioceno Medio y la primera parte del Mioceno Tardío de Europa, con géneros como Listriodon. Unas formas son bunodontas como Bunolistriodon y otras adquieren características lofodónticas como Listriodon. Su primer representante es Propotamochoerus provincialis que aparece en el Mioceno Superior en Europa occidental (Ginsburg, 1980; Van der Made y Moyà, 1989).

El primer registro de Sus data del Rusciniense (Plioceno Inferior) y se encuentra representado por Sus arvernensis (Van der Made, 1990a, b; Van der Made y Moyà, 1989). Sus strozzii es la especie característica del Pleistoceno Temprano y es reemplazado por el actual Sus scrofa en el Pleistoceno Inferior (Van der Made, 2005). Debido a su tipo de alimentación, que consiste en buscar comida en capas superficiales, su distribución se limita en Europa, durante los interglaciares, a las latitudes medias mientras que la Península Ibérica es un refugio durante las fases glaciares.

\subsubsection{Material}

El material empleado tanto en la descripción como en la determinación de la edad de muerte es el mismo y corresponde a los siguientes yacimientos:

Cueva de Valdegoba: 6 piezas: 3 dientes y 3 restos postcraneales. Los dientes son: $1 \mathrm{D}_{2} \mathrm{y}$ $2 \mathrm{D}_{4}$. El material postcraneal se compone de: 1 radio y dos falanges medias.

Prado Vargas: 2 restos: 2 falanges proximales.

Cueva del Búho: 5 restos, todos dientes: dos caninos, $1 \mathrm{P}_{2}, 1 \mathrm{P}_{3}$ y $1 \mathrm{M}^{2}$. Este material procede de las excavaciones antiguas. Los restos de las últimas campañas aparecen en Sala (2012).

La Peña de Estebanvela: 1 diente en el nivel I, un M1.

\subsubsection{Descripción y comparación}

El material descrito a continuación corresponde al recuperado en los yacimientos de la Cueva de Valdegoba, Prado Vargas, Cueva del Búho y la Peña de Estebanvela.

Molares deciduales inferiores (lámina V.6.1: 1 y 2) (tabla V.6.1): son dientes de pequeñas dimensiones, de configuración bunodonta, con las coronas bajas, sin cíngulos y con dos raíces finas y divergentes: una mesial y otra distal.

$\mathbf{D}_{2}$ : es un diente asimétrico debido a que se estrecha hacia el extremo mesial. El protocónido es la cúspide más desarrollada y se encuentra en posición central.

$\mathbf{D}_{4}$ : diente trilobulado. Los lóbulos se estrechan distalmente. Es frecuente que presente una raicilla accesoria entre las dos principales. 
Caninos (tabla V.6.1): son piezas muy desarrolladas, con las coronas cónicas. La pieza superior se curva lateral y dorsalmente. El inferior es largo, puntiagudo y cónico. El material recuperado no permite una asignación concreta a una pieza superior o inferior debido a su mal estado. Por esta razón, no se han podido tomar medidas ni realizar descripciones detalladas. Sin embargo, una de las piezas podría ser superior ya que muestra unos surcos muy marcados en la cara lingual.

Tabla V.6.1

Medidas tomadas en los dientes de S. scrofa

\begin{tabular}{|c|c|c|c|c|c|c|c|c|c|c|c|}
\hline & & & Lado & DAP & DAPb & DTa & DTp & DTpp & DT & DTb & $\mathbf{H}$ \\
\hline $\mathbf{D}_{2}$ & Valdegoba & Vb-sp-3053 & $\mathrm{d}$ & 9,8 & 9,2 & 3,4 & 4,6 & 17,2 & 3,6 & 4,6 & 6,4 \\
\hline $\mathbf{D}_{4}$ & Valdegoba & Vb-sp-3198 & $\mathrm{i}$ & 19,8 & 19,6 & 6,6 & 7,7 & 9,4 & 9,5 & 9,6 & 5,5 \\
\hline $\mathbf{D}_{4}$ & Valdegoba & Vb-sp-3177 & $\mathrm{i}$ & 20,4 & 19,1 & 6,2 & 8,0 & 9,5 & 9,2 & 9,2 & 6,2 \\
\hline $\mathbf{P}_{2}$ & Búho & TCB-181 & i & & & & 6,2 & & & & \\
\hline $\mathbf{P}_{3}$ & Búho & TCB-502 & $\mathrm{i}$ & 13,9 & 13,5 & 6,4 & 7,5 & & 5,9 & 7,5 & 9,3 \\
\hline $\mathbf{M}^{1}$ & Estebanvela & PE.02.F9-G9.NI.10 & & 15,8 & 15,2 & 9,3 & 10,7 & & 10,3 & 10,7 & 6,3 \\
\hline $\mathbf{M}^{2}$ & Búho & TCB-199 & $\mathrm{i}$ & $<22,1$ & & & 13,0 & & 13,0 & & \\
\hline
\end{tabular}

Premolares inferiores (lámina V.6.1: 3) (tabla V.6.1): son dientes de coronas altas, con morfología bunodonta, con unas cúspides cortantes a diferencia de los molares que las tienen redondeadas. Carecen de cíngulos y presentan un número variable de raíces: una el primer premolar, dos el segundo y el tercero, y tres el cuarto.

$\mathbf{P}_{2}$ : diente triangular que se estrecha hacia el extremo mesial, carece de cíngulos y el protocónido es su cúspide principal.

$\mathbf{P}_{3}$ : pieza triangular, con el protocónido en posición central. Carece de cíngulos y tiene los surcos bucales y linguales poco marcados.

Molares superiores permanentes (lámina V.6.1: 4) (tabla V.6.1): son piezas rectangulares, con coronas bajas y cuellos marcados. Su diámetro transversal disminuye distalmente. Presentan cúspides redondeadas y globulosas. Su morfología es bunodonta y tienen seis raíces.

M1: es parecido al $\mathrm{M}^{2}$, se diferencia de él por sus menores dimensiones y por el menor desarrollo de la columna interlobular y del cíngulo distal.

M2: la pieza identificada presenta el extremo posterior fragmentado. Su desgaste es marcado y tiene las raíces fragmentadas. El surco lingual está muy desarrollado al igual que el cíngulo posterior. Tanto el protocono y como el paracono están muy marcados.

Tabla V.6.2

Medidas tomadas en el radio de $S$. scrofa de la Cueva de Valdegoba

\begin{tabular}{ccccccc}
\hline & & Lado & BD & BFd & DD \\
\cline { 3 - 6 } Radio & Valdegoba & Vb-sp-3246 & i & 29,9 & 23,5 & 26,6 \\
\hline
\end{tabular}

Radio (tabla V.6.2): no tiene fusionada la epífisis distal. Conserva varias caras articulares cóncavoconvexas correspondientes a los huesos carporradial e intermediocarpiano. La cara que articula con la fíbula está proyectada más mesialmente que en el $S$. scrofa actual. Además, esta cara articular forma, con la cara articular del carpocubital y del carpo intermedio, un pliegue más desarrollado que en el jabalí moderno.

Falanges proximales (lámina V.6.1: 5) (tabla V.6.3): son huesos cortos y robustos, con la superficie interdigital plana. Las piezas recuperadas no tienen las epífisis proximales 
fusionadas y presentan dos protuberancias muy marcadas en la cara posterior. Su estado de conservación es bueno. La superficie articular distal es estrecha y presenta a ambos lados unas cavidades para la inserción de diversos ligamentos. En vista posterior, dicha superficie tiene un surco muy marcado en forma de "V". Difieren de los ciervos por su mayor robustez y por tener la superficie articular proximal más redondeada.

Tabla V.6.3

Medidas tomadas en las falanges de S. scrofa

\begin{tabular}{|c|c|c|c|c|c|c|c|c|c|c|c|c|}
\hline & & & Lado & GLP & GLpe & Hmax & DPs & DPi & BP & SD & BD & DD \\
\hline F.p. & Prado Vargas & PV06.N4.G30.80 & d & 25,1 & 25,1 & 25,3 & & 16,3 & 14,9 & 11,6 & 14,3 & 10,3 \\
\hline F.p. & Prado Vargas & PV06.N4.G30.81 & $\mathrm{i}$ & 24,3 & 24,4 & 24,8 & & 15,2 & 14,2 & 11,8 & 13,7 & 10,4 \\
\hline F.m.a & Valdegoba & Vb-sp-5674 & $\mathrm{i}$ & 20,0 & 19,7 & 22,0 & 12,0 & 15,7 & 14,2 & 12,0 & 13,7 & 14,2 \\
\hline F.m.p & Valdegoba & Vb-sp-5650 & $\mathrm{i}$ & 26,0 & 27,0 & 29,0 & 15,4 & 19,8 & 17,2 & 14,0 & 14,4 & 16,8 \\
\hline
\end{tabular}

* F.p: falanges proximales. F.m.a: falange media anterior. F.m.p: falange media posterior. Las falanges proximales corresponden a ejemplares juveniles, con las epífisis proximales sin fusionar por lo que los valores registrados son una referencia, no valores totales.

Falanges medias (lámina V.6.1: 6) (tabla V.6.3): son huesos cortos y robustos. La superficie articular proximal está dividida, por una cresta sagital, en dos cavidades glenoideas, siendo la abaxial más amplia y encontrándose en una posición más alta que la axial. El extremo anterior tiene una prominencia marcada $y$, el posterior dos protuberancias para la inserción de ligamentos. La superficie articular distal, en vista dorsal, está muy proyectada hacia arriba y curvada medialmente a diferencia de las proximales. En el lado interdigital hay una depresión marcada para la inserción del ligamento interdigital.

Falange media anterior: se diferencia de la posterior en que el extremo proximal de los cóndilos articulares está más o menos a la misma altura. Son más pequeñas que las posteriores (tabla V.6.3).

Falange media posterior: la depresión interdigital está muy marcada y los cóndilos están a alturas diferentes. Esta falange presenta una longitud, una anchura media y una anchura distal mayores que las registradas en las falanges anteriores (tabla V.6.3).

\subsubsection{Edad de muerte}

El material recuperado no nos permite obtener una edad concreta de muerte, pero sí una edad relativa a partir de la erupción y el reemplazamiento de los dientes así como de la fusión de las epífisis de las falanges.

Cueva de Valdegoba: únicamente se han empleado los dientes ya que las edades de reemplazamiento incluyen las de fusión epifisial de los radios y falanges medias. El reemplazamiento por los premolares inferiores tiene lugar en torno a los 14 - 18 meses por lo que la edad dental de los dos individuos estaría cercana al año o año y medio.

Prado Vargas: la fusión de las epífisis proximales de las primeras falanges se produce en torno a 1 - 2 meses. El ejemplar tendría menos de esa edad.

Cueva del Búho: las edades de erupción no distan mucho entre sí. Por una parte, los caninos emergen entre los 7 y 12 meses, los premolares entre los 14 y 17, y el molar superior en torno a los 13. La edad aproximada del ejemplar recuperado sería de al menos 17 meses. 
La Peña de Estebanvela: la erupción del $\mathrm{M}^{1}$ se produce en torno a los 4 - 6 meses. El desgaste de esta pieza está muy avanzado por lo que suponemos que la edad superaría con creces el medio año de edad. Sin embargo, no podemos precisar si se trataría de un ejemplar joven o de un adulto.

\subsubsection{Número Mínimo de Individuos}

El número mínimo de individuos se ha determinado a partir de la pieza más frecuente en el caso de la Cueva de Valdegoba, la Cueva del Búho y la Peña de Estebanvela. En el primero se ha identificado un ejemplar maduro, un adulto; en el segundo dos ejemplares inmaduros y en la Peña de Estebanvela un individuo joven-adulto (tabla V.6.4).

Tabla V.6.4

Número mínimo de individuos de S. scrofa

\begin{tabular}{|c|c|c|c|c|c|}
\hline & \multicolumn{2}{|c|}{ Inmaduros } & \multicolumn{2}{|r|}{ Maduros } & \multirow{2}{*}{ Total } \\
\hline & $\mathbf{n}$ & Pieza & $\mathbf{n}$ & pieza & \\
\hline Cueva de Valdegoba & 2 & $\mathrm{D}_{4}$ & & & 2 \\
\hline Prado Vargas & & Falanges & & & 1 \\
\hline Cueva del Búho & & & 1 & Dentición permanente & 1 \\
\hline Estebanvela & & & 1 & $\mathrm{M}^{1}$ & 1 \\
\hline
\end{tabular}

El caso de Prado Vargas es más complicado ya que únicamente se han identificado falanges. Hay que tener en cuenta que cada individuo tiene cuatro falanges izquierdas y otras cuatro derechas. Por esta razón, y viendo que las piezas recuperadas presentan la epífisis proximal sin fusionar, establecemos el número de ejemplares de este taxón en 1 , un ejemplar inmaduro (tabla V.6.4).

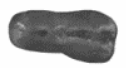

1.a

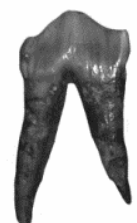

1.b

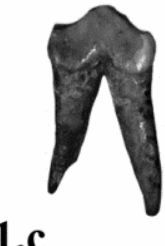

1.c

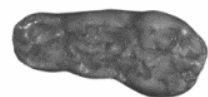

2.a

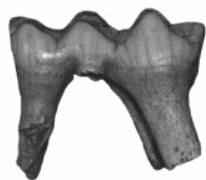

2.b

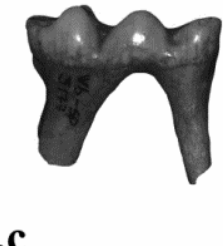

3.a
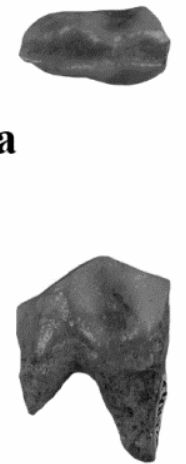

3.b

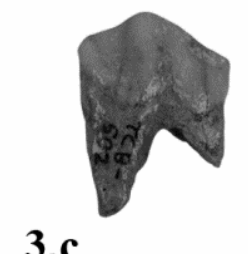

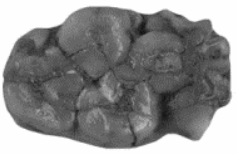

4.a

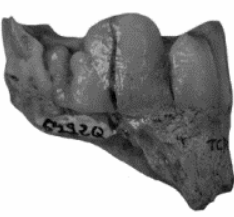

4.b

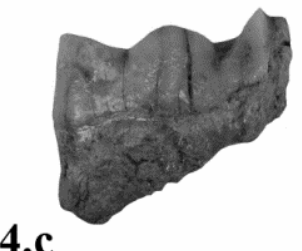

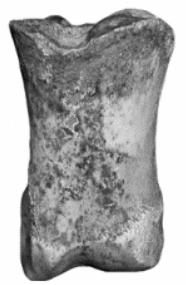

5.

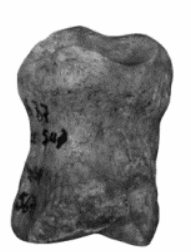

6.

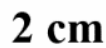

Lámina V.6.1. Sus scrofa provenientes de los yacimientos de la Cueva de Valdegoba (sigla Vb), Prado Vargas (sigla PV) y la Cueva del Búho (sigla TCB). 1) Vb-sp-3053 - D2 derecho: 1.a vista oclusal; 1.b cara lingual; 1.c cara bucal. 2) Vb-sp-3177 - $\mathrm{D}_{4}$ izquierdo: 2.a vista oclusal; 2.b cara lingual; 2.c cara bucal. 3) TCB-502 - $\mathrm{P}_{3}$ izquierdo: 3.a vista oclusal; 3.b cara lingual; 3.c cara bucal. 4) TCB-199 - $\mathrm{M}^{2}$ izquierdo: 4.a vista oclusal; 4.b cara lingual; 4.c cara bucal. 5) PV06.N4.G30.80 - Falange proximal derecha cara dorsal. 6) Vb-sp-5674 Falange media cara dorsal. 


\subsubsection{Discusión}

Las piezas recuperadas presentan una serie de modificaciones con respecto al esquema general de los artiodáctilos. La principal está en la configuración de la superficie oclusal. Nos encontramos ante dientes de coronas bajas, braquiodontas, con las cúspides redondeadas, bunodontas, que difieren del esquema selenodonto de los cérvidos y los bóvidos. Asignamos, por lo tanto, los restos a la familia Suidae.

En el Pleistoceno existen tres especies de suidos: Sus arvensis, Sus strozzii y Sus scrofa. La primera se encuentra en el Villafranquiense Inferior; la segunda se definió en el Villafranquiense Superior de Italia (Faure y Guèrin, 1984), alcanzando los inicios del Pleistoceno Medio; y ya desde este periodo nos encontramos con S. scrofa (Van der Made, 2005).

Faure (2004) describe un fragmento de $\mathrm{D}_{4}$ de $S$. strozzii recuperado en Saint-Vallier, indicando que presenta una configuración más sencilla que la de $S$. scrofa al tener menos tubérculos secundarios en la superficie oclusal. Este carácter no puede ser observado en las piezas de la Cueva de Valdegoba ya que presentan un grado de desgaste muy avanzado. Sin embargo, las medidas registradas en los ejemplares de Saint-Vallier y del Valdarno indican que nuestras piezas son más pequeñas que las registradas para el $S$. strozzii de estos yacimientos.

Los caracteres morfológicos así como las medidas y la cronología de los depósitos sugieren que el suido recuperado es $S$. scrofa. 


\subsection{Cervus elaphus}

Orden Artiodactyla Owen, 1848

Familia Cervidae Goldfuss, 1820

Subfamilia Cervinae Goldfuss, 1820

Género Cervus Linnaeus, 1758

Especie Cervus elaphus Linnaeus, 1758

\subsubsection{Generalidades}

Los cérvidos son un grupo común en Europa desde el Mioceno Temprano. Actualmente podríamos hablar de tres subfamilias: Muntiacinae, Capreolinae y Cervinae. En Capreolinae se encuentran Alces, Rangifer y Capreolus; y en Cervinae los géneros Dama, Cervus, Eucladoceros y Megaloceros.

Cervus elaphus llega a Europa hace más o menos 900 ka, a partir del evento conocido como "End Villafranchian Event" (Azzaroli, 1983), en el cual llegan, a Europa, diferentes especies desde Asia y África. A lo largo de los años han sido varios los nombres que se le han dado aunque ninguno de ellos ha sido muy utilizado. Destacan entre ellos: Cervus primigenius, Cervus intermedius, Cervus acoronatus y Cervus antiquus (Van der Made et al., 2014 y referencias incluidas en él).

Dentro de este género podemos diferenciar dos grupos en función de la presencia o ausencia de corona. Esta estructura, que apareció hace unos 500 ka (Guérin y PatouMathis, 1996; Van der Made, 2001, 2005), hace referencia a la disposición radial y no en un mismo plano de los tres o más candiles de las astas. Los Cervus de Asia y Norte América nunca han adquirido este carácter por lo que es posible que no haya existido flujo genético entre las poblaciones europeas y asiáticas al menos desde hace 500 ka (Van der Made, 2005). Esta falta de flujo genético ha llevado, en los últimos años, a hacer una revisión de la clasificación, incluyendo en la especie $C$. elaphus las poblaciones del oeste de Eurasia. Unas pequeñas poblaciones asiáticas se incluirían en $C$. walichii; y las del este de Asia y América del Norte en C. canadensis (Wilson y Mittermeier, 2011).

Muchas han sido las subespecies descritas para Cervus elaphus: C.e.acoronatus, C.e. priscus, C.e.eostephanoceros, C.e.angulatus, C.e.benindei, C.e.rianensis, C.e.intermedius, C.e.antiquus, C.e.spelaeus y C.e.simplicidens (Picket, 1844; Pohlig, 1892; Benide, 1937; Leonardi y Petronio, 1976; Di Stefano y Petronio, 1993). Éstas las podemos dividir en subespecies sin corona, con corona incipiente y con corona plenamente desarrollada. Así, en el MIS 15/16 y 21/23 nos encontramos con un ciervo de gran talla, donde no se ve ningún rastro de corona. Sus restos han sido incluidos en C. elaphus ssp., a la espera de encontrar más restos (Van der Made et al., 2014). Más tarde ya vemos indicios de corona, MIS 13/15 donde incluimos subespcies como C.e.acoronatus, C.e.priscus, C.e.eostephanoceros y C.e.reichenaui. Ciervos ya con la corona plenamente desarrollada pero de pequeñas dimensiones son el C.e.angulatus, C.e.benindei, C.e.rianensis, C.e.intermedius y C.e.antiquus y que se encuentran en los MIS 9 a 11. Del MIS 5e al 7 se encuentra C.e.spelaeus de gran porte. Del MIS 3 al 5c aparece C.esimplicidens de pequeñas dimensiones, en el MIS 2 C.e.maral, de gran tamaño y en el MIS 1 C.e.elaphus, de pequeño tamaño.

Actualmente existen seis subespecies de ciervos, siendo las más extendidas, C. elaphus elaphus, propia de todo el continente europeo y el gran C.e.maral de Anatolia, Caucaso e Irán. La subespecie europea conserva lo que se denomina corona, mientras que los otros carecen de ella (Grooves y Grubb, 2011).

Van der Made et al., (2014) hace una revisión de estas subespecies a partir del material recuperado en más de una treintena de yacimientos. En concreto, agrupa los ciervos del MIS 15/16 y 21/23 en C. elaphus ssp, a los del MIS 13/15 en C.e.acoronatus; a los del MIS 9 
-11 en C.e.angulatus, a los del MIS 5e - 7 en C.e.spelaeus, a los del MIS 5c -3 en C.e.simplicidens, los del 2 en C.e. maral y a los del 1 en C.e.elaphus.

\subsubsection{Material}

Los restos son abundantes y presentan buen estado de conservación. A continuación se presenta el material empleado en la descripción y la comparación, así como en el estudio de la edad de muerte, la estacionalidad y el dimorfismo sexual.

En el apartado de descripción y comparación el material empleado ha sido el siguiente:

Cueva de Valdegoba: 739 restos: 582 craneales y dentales; 157 postcraneales. Los craneales y dentales, de los que se han podido analizar 415 , se reparten en: 4 fragmentos de asta, $1 \mathrm{I}_{1}, 2 \mathrm{I}_{2}, 2 \mathrm{I}_{3} ; 3 \mathrm{C}_{\mathrm{i}} ; 8 \mathrm{C}^{\mathrm{s}}, 11 \mathrm{dI}_{1}, 17 \mathrm{dI}_{2}, 5 \mathrm{dI}_{3} 24 \mathrm{D}_{2}, 33 \mathrm{D}_{3}, 46 \mathrm{D}_{4}, 37 \mathrm{D}^{2}, 32 \mathrm{D}^{3}, 10 \mathrm{D}^{4} ; 5$ $\mathrm{P}_{2}, 8 \mathrm{P}_{3}, 8 \mathrm{P}_{4}, 27 \mathrm{M}_{1}, 27 \mathrm{M}_{2}, 9 \mathrm{M}_{3}, 13 \mathrm{P}^{2}, 17 \mathrm{P}^{3}, 14 \mathrm{P}^{4}, 16 \mathrm{M}^{1}, 23 \mathrm{M}^{2}$ y $17 \mathrm{M}^{3}$. El material postcraneal se divide en: 4 húmeros, 3 radios, 1 fémur, 4 tibias, 4 metacarpos, 28 metatarsos, 30 metápodos, 1 calcáneo, 6 astrágalos, 2 falanges proximales, 2 falanges medias y 3 falanges distales, 24 carpales divididos en: 7 escafoides, 5 piramidales, 4 unciformes, 1 psiforme y 7 escafocuboides; y 22 tarsales: 7 magnotrapezoidales, 9 ectocuneiformes, 6 maleolares, y por último 24 sesamoideos.

Prado Vargas: 34 restos, 29 identificables a nivel anatómico: 12 craneales y dentales, 17 postcraneales. Los restos craneales comprenden dos fragmentos de asta, $1 \mathrm{P}_{2}, 2 \mathrm{P}_{3}, 2 \mathrm{M}_{1}, 1$ $\mathrm{M}_{2}, 1 \mathrm{C}^{\mathrm{S}}, 1 \mathrm{P}^{3}, 1 \mathrm{M}^{2}$ y $1 \mathrm{M}^{3}$. El material postcraneal corresponde a 17 fragmentos de metápodos y un metacarpo.

Cueva Millán: 79 piezas: 34 dientes y 45 restos postcraneales. Los dientes son: $1 \mathrm{D}^{2} ; 1 \mathrm{dI}_{2}$, $1 \mathrm{I}_{1}, 2 \mathrm{Cs}, 2 \mathrm{P}_{2}, 3 \mathrm{P}_{3}, 4 \mathrm{P}_{4}, 3 \mathrm{P}^{2}, 1 \mathrm{P}^{3}, 3 \mathrm{M}_{1}, 1 \mathrm{M}_{1-2}, 1 \mathrm{M}_{2}, 4 \mathrm{M}_{3}, 1 \mathrm{M}^{1}, 2 \mathrm{M}^{2}$ y $4 \mathrm{M}^{3}$. Los restos postcraneales analizados incluyen: un metacarpo, una tibia, 6 sesamoideos, 3 carpales, 12 falanges proximales, 5 falanges medias y 17 falanges distales.

Cueva del Búho: 25 restos: 19 craneales y dentales; 6 postcraneales. Los craneales y dentales se reparten en: 3 fragmentos de asta, $2 \mathrm{I}_{2}, 2 \mathrm{M}_{3}, 3 \mathrm{P}^{2}, 2 \mathrm{P}^{3}, 2 \mathrm{P}^{4}, 2 \mathrm{M}^{1}, 2 \mathrm{M}^{2}, 1 \mathrm{M}^{3}$. El material postcraneal comprende: 2 astrágalos, 1 falange proximal, 1 falange media, 1 falange distal y un maleolar. El material descrito corresponde a excavaciones antiguas. El material más reciente aparece en Sala (2012).

Abrigo Vergara: 4 restos dentales: 2 fragmentos indeterminados, un molar inferior y un premolar superior.

La Peña de Estebanvela: 15 restos: 1 diente y 14 postcraneales. Se presenta el material por niveles: Nivel I: $1 \mathrm{P}_{4}, 1$ metápodo, 1 metacarpo y 2 falanges proximales. Nivel II: una falange proximal. Nivel III: un piramidal, un magnotrapezoidal, 3 falanges proximales y 3 medias. En el IV únicamente se ha recuperado un metápodo.

El material empleado en la edad de muerte es el siguiente:

Cueva de Valdegoba: 107 restos: $40 \mathrm{D}_{4}, 9 \mathrm{Cs}, 13 \mathrm{M}_{1}, 12 \mathrm{M}^{1}, 17 \mathrm{M}^{2}$ y $16 \mathrm{M}^{3}$.

Prado Vargas: 7 restos: $1 \mathrm{P}_{2}, 1 \mathrm{P}_{3}, 1 \mathrm{M}_{1}, 1 \mathrm{C}^{\mathrm{S}}, 1 \mathrm{P}^{3}, 1 \mathrm{M}^{2}$ y $1 \mathrm{M}^{3}$.

Cueva Millán: 31 restos. Nivel 1A: $1 \mathrm{dI}_{2}, 2 \mathrm{C}^{\mathrm{S}}, 2 \mathrm{P}_{2}, 2 \mathrm{P}_{3}, 3 \mathrm{P}_{4}, 2 \mathrm{M}_{1}, 5 \mathrm{M}_{3}, 1 \mathrm{P}^{2}, 2 \mathrm{M}^{2}$ y $1 \mathrm{M}^{3}$. Nivel 1B: $1 \mathrm{P}_{4}, 1 \mathrm{M}_{1}, 2 \mathrm{M}_{2}$ y $2 \mathrm{P}^{2}$. Nivel $1 \mathrm{C}: 1 \mathrm{D}^{2}, 1 \mathrm{P}^{3}, 1 \mathrm{M}^{1}$ y $1 \mathrm{M}^{3}$.

Cueva del Búho: 16 dientes: $2 \mathrm{I}_{2}, 2 \mathrm{M}_{3}, 3 \mathrm{P}^{2}, 2 \mathrm{P}^{3}, 2 \mathrm{P}^{4}, 2 \mathrm{M}^{1}, 2 \mathrm{M}^{2}$ y $1 \mathrm{M}^{3}$. 
Abrigo Vergara: 2 restos: un molar inferior y un premolar superior.

La Peña de Estebanvela: un diente, $1 \mathrm{P}_{4}$.

En el análisis de la estacionalidad no se ha utilizado el $\mathrm{M}_{3}$ debido a que su erupción es muy variable (Azorit et al., 2002). Se han empleado los siguientes dientes:

Cueva de Valdegoba: 65 restos: $37 \mathrm{D}_{4}, 11 \mathrm{M}_{1}$ y $17 \mathrm{M}_{2}$.

Prado Vargas: 2 restos: $1 \mathrm{M}_{1}, 1 \mathrm{M}_{2}$.

Cueva Millán: 6 restos. Nivel 1A: $2 \mathrm{M}_{1} 2 \mathrm{M}^{2}$. Nivel 1B: $1 \mathrm{M}_{1}$. Nivel 1C: $1 \mathrm{M}^{1}$.

Cueva del Búho: 4 dientes: $2 \mathrm{M}_{1}$ y $2 \mathrm{M}^{2}$.

En el estudio de la bimodalidad y el dimorfismo sexual no se han empleado los dientes yugales ya que, en las colecciones de referencia visitadas, estaban incluidos en mandíbulas y no ha sido posible tomar las medidas adecuadas para realizar un estudio estadístico. Asimismo, el material postcraneal está muy fragmentado. Se emplean, por lo tanto, los caninos superiores:

Cueva de Valdegoba: 9 caninos superiores: 4 derechos y 5 izquierdos.

Prado Vargas: 1 canino superior izquierdo.

Cueva Millán: 2 caninos superiores: 1 derecho y otro izquierdo.

\subsubsection{Descripción y comparación}

Estas descripciones corresponden a las piezas recuperadas en la Cueva del Búho, la Cueva de Valdegoba, Prado Vargas, Cueva Millán, Abrigo Vergara y la Peña de Estebanvela.

Astas: únicamente se han recuperado cuatro fragmentos, en concreto tres candiles y una roseta. Su estado de conservación no es muy bueno. Tienen una textura rugosa y los característicos surcos longitudinales. Su estado no permite una mayor descripción.

Incisivos deciduales (lámina V.7.1: 1) (tabla V.7.1): dientes de coronas bajas y raíces estrechas que en muchos casos aparecen fragmentadas. Presentan un cuello marcado entre la corona y la raíz; y un pequeño reborde longitudinal que recorre la corona. Ésta se inclina lateralmente, siendo la del primero más o menos recta y la del tercero muy inclinada. El $\mathrm{dl}_{1}$ tiene una corona triangular debido a que su borde medial es recto. Tienen sólo una raíz.

Molares deciduales inferiores (lámina V.7.1: 2, 3 y 4) (tabla V.7.2): piezas pequeñas, con las coronas bajas y birradiculadas, con una raíz mesial y otra distal. Son muy similares, morfológicamente, a los premolares inferiores salvo el $\mathrm{D}_{4}$, que es trilobulado. Se diferencian de éstos por presentar unas coronas más bajas, unas raíces más finas y divergentes, y por tener unos diámetros transversales más pequeños (tablas V.7.2 y 5).

$\mathbf{D}_{2}$ : diente asimétrico debido a que se estrecha mesialmente. Tiene un protocónido muy desarrollado en posición central. El surco, definido por el protocónido y el hipocónido, apenas está esbozado. El surco que hay entre el entocónido y el entostílido es más profundo que en $\mathrm{P}_{2}$. 
Tabla V.7.1

Medidas tomadas en los incisivos deciduales de C. elaphus

\begin{tabular}{|c|c|c|c|c|c|c|}
\hline & DMD & DLL & Hli & Hla & Hmes & Hdist \\
\hline \multicolumn{7}{|l|}{$\mathbf{d I}_{1}$} \\
\hline \multicolumn{7}{|c|}{ Valdegoba } \\
\hline $\mathrm{n}$ & 13 & 13 & 13 & 12 & 13 & 13 \\
\hline rango & $8,4-11,7$ & $4,1-5,9$ & $8,3-11,2$ & $7,7-11,4$ & $7,5-10,8$ & $6,6-9,8$ \\
\hline $\bar{x} \pm$ s.d. & $9,9 \pm 1,0$ & $5,1 \pm 0,5$ & $9,5 \pm 0,9$ & $9,5 \pm 1,1$ & $8,9 \pm 1,0$ & $7,9 \pm 0,9$ \\
\hline \multicolumn{7}{|c|}{$\mathrm{dI}_{2}$} \\
\hline \multicolumn{7}{|c|}{ Valdegoba } \\
\hline $\mathrm{n}$ & 2 & 2 & 2 & 2 & 2 & 2 \\
\hline rango & $4,9-5,2$ & $4,5-5,1$ & $9,7-10,1$ & $9,7-11,1$ & $8,7-10,7$ & $7,8-9,1$ \\
\hline $\bar{x} \pm$ s.d. & $5,0 \pm 0,2$ & $4,8 \pm 0,4$ & $9,9 \pm 0,3$ & $10,4 \pm 1,0$ & $9,7 \pm 1,4$ & $8,5 \pm 0,9$ \\
\hline \multicolumn{7}{|c|}{ Cueva Millán } \\
\hline $\mathrm{n}=1$ & 14,8 & 9,2 & 17,2 & 18,9 & 16,6 & 16,5 \\
\hline \multicolumn{7}{|l|}{$\mathrm{dI}_{3}$} \\
\hline $\mathrm{n}$ & 3 & 3 & 3 & 3 & 3 & 3 \\
\hline rango & $4,-4,8$ & $4,0-4,7$ & $7,9-8,8$ & $8,7-9,0$ & $9,0-9,9$ & $7,7-8,2$ \\
\hline $\bar{x} \pm$ s.d. & $4,5 \pm 0,3$ & $4,3 \pm 0,4$ & $8,3 \pm 0,4$ & $8,8 \pm 0,2$ & $9,4 \pm 0,4$ & $7,9 \pm 0,2$ \\
\hline
\end{tabular}

$\mathbf{D}_{3}$ : presenta un mayor desarrollo de las cúspides y se estrecha menos mesialmente que el $\mathrm{D}_{2}$. Tiene un pequeño cíngulo en la base de la corona en la cara bucal. Se ha observado, en ocasiones, una pequeña raicilla accesoria entre las raíces principales, algo que no se ha visto en los premolares. Se diferencian del $\mathrm{P}_{3}$ por presentar la paraprecrístida y la paraendocrístida más separadas, la hipopostcrístida y la hipoendocrístida unidas; y el surco entre el protocónido y el entocónido más profundo. Métricamente, difieren de este premolar por su menor diámetro anteroposterior basal (tablas V.7.2 y 5).

Tabla V.7.2

Medidas tomadas en los molares deciduales inferiores de C. elaphus

\begin{tabular}{|c|c|c|c|c|c|c|c|c|c|}
\hline & DAP & DAPb & DTa & DTp & DTpp & DT & DTb & На & Hр \\
\hline \multicolumn{10}{|l|}{$\mathbf{D}_{2}$} \\
\hline \multicolumn{10}{|c|}{ Valdegoba } \\
\hline $\mathrm{n}$ & 24 & 24 & 24 & 24 & & 24 & 24 & 21 & 25 \\
\hline rango & $10,0-13,4$ & $9,3-13,3$ & $3,3-5,8$ & $4,8-7,0$ & & $4,8-7,0$ & $4,9-6,9$ & $4,1-7,1$ & $3,3-6,6$ \\
\hline $\bar{x} \pm$ s.d. & $11,5 \pm 0,8$ & $11,1 \pm 1,0$ & $4,2 \pm 0,6$ & $5,9 \pm 0,5$ & & $5,9 \pm 0,5$ & $5,7 \pm 0,5$ & $5,6 \pm 0,9$ & $5,2 \pm 0,7$ \\
\hline \multicolumn{10}{|l|}{$\mathbf{D}_{3}$} \\
\hline \multicolumn{10}{|c|}{ Valdegoba } \\
\hline $\mathrm{n}$ & 68 & 66 & 67 & 69 & & 69 & 66 & 69 & 69 \\
\hline rango & $10,3-17,7$ & $10,5-17,1$ & $5,2-8,0$ & $6,5-8,6$ & & $6,5-8,6$ & $6,5-8,9$ & $4,7-11,3$ & $4,6-9,5$ \\
\hline $\bar{x} \pm$ s.d. & $16,3 \pm 1,0$ & $15,4 \pm 0,9$ & $5,8 \pm 0,5$ & $7,7 \pm 0,5$ & & $7,7 \pm 0,5$ & $7,7 \pm 0,5$ & $8,0 \pm 1,1$ & $6,9 \pm 1,1$ \\
\hline \multicolumn{10}{|l|}{$\mathbf{D}_{4}$} \\
\hline \multicolumn{10}{|c|}{ Valdegoba } \\
\hline $\mathrm{n}$ & 37 & 36 & 43 & 43 & 40 & 43 & 39 & 42 & 43 \\
\hline rango & $15,7-28,5$ & $14,7-25,7$ & $5,7-10,2$ & $7,1-11,8$ & $7,1-13,1$ & $5,9-10,5$ & $7,4-12,2$ & $7,0-14,2$ & $6,5-14,2$ \\
\hline $\bar{x} \pm$ s.d. & $25,5 \pm 3,3$ & $22,3 \pm 2,3$ & $9,0 \pm 1,0$ & $10,1 \pm 1,0$ & $11,1 \pm 1,2$ & $9,0 \pm 1,1$ & $10,7 \pm 1,0$ & $10,2 \pm 1,5$ & $10,8 \pm 1,8$ \\
\hline
\end{tabular}

$\mathbf{D}_{4}$ : diente trilobulado debido al desarrollo de un lóbulo anterior que consiste en un paracónido y un primocónido. La metapostcrístida se solapa lingualmente con la entoprecrístida. La cara bucal presenta dos columnas interlobulares de pequeño tamaño. Tiene un cíngulo de desarrollo variable en la cara bucal, tanto en la base de la parte anterior como de la posterior. Los extremos anterior y posterior de la cara lingual son divergentes. Puede presentar una pequeña raíz accesoria bucal por debajo del lóbulo central. Tiene tres lóbulos, como el $\mathrm{M}_{3}$, pero se diferencia de éste en que los lóbulos aumentan en anchura hacia el extremo distal, mientras que en el $\mathrm{M}_{3}$ es al contrario. 
Molares deciduales superiores (lámina V.7.1: 5, 6 y 7) (tabla V.7.3): dientes bilobulados, de coronas bajas y con tres raíces: una mesial, otra distal y otra lingual. En el $\mathrm{D}^{2}$ se produce, en ocasiones, la fusión de la raíz lingual y la mesial, dándole una apariencia bilobulada.

D2: pieza asimétrica debido a que se estrecha mesialmente. La cara mesial puede tener un cíngulo más o menos desarrollado que además puede prolongarse por la cara lingual. Su aspecto bilobulado se debe al surco lingual definido por el protocono y el hipocono que, además, es más profundo que en $\mathrm{P}^{2}$. La pieza de Cueva Millán tiene un cíngulo muy desarrollado en la cara mesial que se prolonga hasta la lingual. Se diferencian, además, del $\mathrm{P}^{2}$ por el menor desarrollo del surco situado entre la paraprecrístida y la parapostcrístida, por su lóbulo mesial más grande y porque son más estrechos (tablas V.7.3 y 7).

D3: diente bilobulado y fuertemente asimétrico debido a la diferencia en el diámetro transversal basal de los lóbulos mesial y distal. Tiene un cíngulo dentado en el lóbulo mesial. La raíz lingual descansa por debajo del lóbulo distal.

D4: claramente bilobulado, con el lóbulo mesial más proyectado bucalmente que el distal, como en los molares permanentes. La raíz lingual descansa sobre ambos lóbulos. Se diferencia del $\mathrm{M}^{1-2}$ por sus coronas más bajas, por el menor tamaño de las columnas interlobulares y por presentar, en vista de perfil, una oblicuidad menos acusada. Métricamente es más pequeño que el primer molar superior (tablas V.7.3 y 8).

Tabla V.7.3

Medidas tomadas en los molares deciduales superiores de C. elaphus

\begin{tabular}{|c|c|c|c|c|c|c|c|c|}
\hline & DAP & DAPb & DTa & DTp & DT & DTb & Ha & Hр \\
\hline \multicolumn{9}{|l|}{$\mathbf{D}^{2}$} \\
\hline \multicolumn{9}{|c|}{ Valdegoba } \\
\hline $\mathrm{n}$ & 35 & 35 & 34 & 34 & 35 & 35 & 36 & 35 \\
\hline rango & $15,0-18,7$ & $13,5-17,0$ & $7,8-10,5$ & $9,6-12,4$ & $6,5-10,9$ & $9,2-12,4$ & $7,3-11,9$ & $5,8-10,9$ \\
\hline $\bar{x} \pm$ s.d. & $17,1 \pm 0,8$ & $15,5 \pm 0,8$ & $9,3 \pm 0,6$ & $11,4 \pm 0,7$ & $8,6 \pm 0,9$ & $10,7 \pm 0,7$ & $10,3 \pm 1,1$ & $8,8 \pm 1,1$ \\
\hline \multicolumn{9}{|l|}{ Millán } \\
\hline $\mathrm{n}=1$ & 16,4 & 15,5 & 10,2 & 11,4 & 10 & 11,4 & 8,1 & \\
\hline \multicolumn{9}{|l|}{$\mathbf{D}^{3}$} \\
\hline \multicolumn{9}{|c|}{ Valdegoba } \\
\hline $\mathrm{n}$ & 28 & 29 & 30 & 29 & 30 & 30 & 30 & 30 \\
\hline rango & $18,3-24,0$ & $15,9-19,4$ & $10,3-13,4$ & $13,0-17,7$ & $9,5-17,2$ & $12,5-17,2$ & $6,8-13,4$ & $6,6-13,6$ \\
\hline $\bar{x} \pm$ s.d. & $21,4 \pm 1,3$ & $17,6 \pm 0,9$ & $11,7 \pm 0,7$ & $14,6 \pm 1,0$ & $11,2 \pm 1,4$ & $14,5 \pm 1,0$ & $11,2 \pm 1,4$ & $11,8 \pm 1,5$ \\
\hline \multicolumn{9}{|c|}{$\mathrm{D}^{4}$} \\
\hline \multicolumn{9}{|c|}{ Valdegoba } \\
\hline $\mathrm{n}$ & 9 & 10 & 8 & 8 & 8 & 8 & 7 & 9 \\
\hline rango & $18,1-20,6$ & $15,1-17,1$ & $14,3-16,9$ & $13,6-17,8$ & $11,6-13,3$ & $14,7-17,8$ & $12,2-14,0$ & $12,8-14,2$ \\
\hline $\bar{x} \pm$ s.d. & $19,5 \pm 0,7$ & $16,3 \pm 0,6$ & $15,7 \pm 0,9$ & $16,0 \pm 1,2$ & $12,4 \pm 0,7$ & $16,3 \pm 0,9$ & $13,2 \pm 0,8$ & $13,6 \pm 0,4$ \\
\hline
\end{tabular}

Incisivos permanentes (lámina V.7.1: 8) (tabla V.7.4): dientes con las coronas altas, espatuladas que se curvan hacia el $\mathrm{I}_{3}$, cuellos marcados y una raíz. Tienen un surco longitudinal en la cara lingual de la corona y unas raíces más gruesas que las de los deciduales. $\mathrm{El} \mathrm{I}_{1}$ se diferencia fácilmente por su aspecto triangular y por presentar el borde mesial recto. $\mathrm{El} \mathrm{I}_{2}$ y el $\mathrm{I}_{3}$ difieren, básicamente, por el menor diámetro mesiodistal de $\mathrm{I}_{3}$ con respecto a $\mathrm{I}_{2}$ y por la inclinación lateral más acentuada del $\mathrm{I}_{3}$.

Caninos inferiores (tabla V.7.4): piezas incisiviformes, con cuellos marcados y una raíz. Se diferencian del $I_{3}$ por presentar una corona más baja y redondeada debido a la ausencia de faceta de desgaste por contacto en el borde lateral. Son más pequeños que los incisivos (tabla V.7.4). 
Tabla V.7.4

Medidas tomadas en los incisivos permanentes de C. elaphus

\begin{tabular}{|c|c|c|c|c|c|c|}
\hline & DMD & DLL & Hli & Hla & Hmes & Hdist \\
\hline \multicolumn{7}{|l|}{$I_{1}$} \\
\hline \multicolumn{7}{|c|}{ Valdegoba } \\
\hline $\mathrm{n}$ & 2 & 2 & 2 & 2 & 2 & 2 \\
\hline rango & $7,7-12,8$ & $3,9-7,7$ & $7,3-13,2$ & $8,5-14,8$ & $7,3-11,5$ & $6,8-11,6$ \\
\hline $\bar{x} \pm$ s.d. & $10,2 \pm 3,6$ & $5,8 \pm 2,7$ & $10,3 \pm 4,1$ & $11,6 \pm 4,4$ & $9,4 \pm 3,0$ & $9,2 \pm 3,4$ \\
\hline \multicolumn{7}{|l|}{ Millán } \\
\hline $\mathrm{n}=1$ & 14,8 & 9,2 & 17,2 & 18,9 & 16,6 & 16,5 \\
\hline \multicolumn{7}{|l|}{$I_{2}$} \\
\hline \multicolumn{7}{|c|}{ Valdegoba } \\
\hline $\mathrm{n}$ & 22 & 22 & 14 & 19 & 15 & 15 \\
\hline rango & $6,7-8,9$ & $4,7-6,9$ & $10,9-20,3$ & $10,0-20,3$ & $7,4-21,7$ & $8,5-20,2$ \\
\hline $\bar{x} \pm$ s.d. & $7,6 \pm 0,7$ & $5,5 \pm 0,6$ & $16,2 \pm 3,1$ & $16,2 \pm 3,1$ & $15,6 \pm 4,5$ & $14,7 \pm 4,0$ \\
\hline \multicolumn{7}{|l|}{ Búho } \\
\hline $\mathrm{n}$ & 2 & 2 & 2 & 2 & 2 & 2 \\
\hline rango & $5,4-5,5$ & $4,7-4,8$ & $9,0-11,4$ & $9,0-11,6$ & $8,5-9,5$ & $7,5-9,6$ \\
\hline $\bar{x} \pm$ s.d. & $5,5 \pm 0,1$ & $4,8 \pm 0,0$ & $10,2 \pm 1,7$ & $10,3 \pm 1,9$ & $9,0 \pm 0,7$ & $8,5 \pm 1,5$ \\
\hline \multicolumn{7}{|l|}{$I_{3}$} \\
\hline \multicolumn{7}{|c|}{ Valdegoba } \\
\hline$n$ & 2 & 2 & 2 & 2 & 2 & 2 \\
\hline rango & $5,5-6,0$ & $6,0-6,2$ & $11,9-12,6$ & $12,2-13,1$ & $11,1-11,6$ & $9,5-10,0$ \\
\hline $\bar{x} \pm$ s.d. & $5,8 \pm 0,4$ & $6,1 \pm 0,1$ & $12,2 \pm 0,5$ & $12,6 \pm 0,7$ & $11,3 \pm 0,4$ & $9,7 \pm 0,3$ \\
\hline \multicolumn{7}{|l|}{$\mathrm{Ci}$} \\
\hline \multicolumn{7}{|c|}{ Valdegoba } \\
\hline$n$ & 3 & 3 & 3 & 3 & 3 & 3 \\
\hline rango & $5,1-5,5$ & $4,2-5,6$ & $8,6-12,3$ & $9,1-12,7$ & $9,9-11,2$ & $8,4-10,8$ \\
\hline $\bar{x} \pm$ s.d. & $5,3 \pm 0,2$ & $5,1 \pm 0,8$ & $10,8 \pm 2,0$ & $10,9 \pm 1,8$ & $10,5 \pm 0,7$ & $9,5 \pm 1,2$ \\
\hline
\end{tabular}

Premolares inferiores (lámina V.7.1: 9, 10 y 11) (tabla V.7.5) (figura V.7.1): dientes con las coronas altas, cuellos marcados, cíngulos y surcos de desarrollo variable, y dos raíces: una mesial y otra distal. Se diferencian de los deciduales por tener las coronas más altas, por el grosor y paralelismo de sus raíces, por la menor profundidad de los surcos bucales y por ser más anchos (tablas V.7.2 y 5).

$\mathbf{P}_{2}$ : diente asimétrico que se estrecha hacia el extremo mesial. Presenta una forma más rectangular y una protopostfoseta menos desarrollada que Haploidoceros (Sanz et al., 2014). Tiene el protocónido muy desarrollado en posición central. El surco bucal, situado entre el protocónido y el hipocónido, se encuentra muy marcado. Difiere de Dama por tener separadas la protoendocrístida y la hipoendocrístida, por tener como único elemento anterior la paraprecrístida y no el paracónido, por tener el entostílido unido a la hipopostcrístida, por tener el surco definido por la hipoendocrístida y la hipopostcrístida poco profundo, y por presentar la hipoendocrístida alineada según el eje transversal del diente y no según el eje mesiodistal (Lister, 1996). Las diferencias con el reno son más claras y se repiten en la mayor parte de las piezas. En este caso, cabe destacar el aislamiento de las cúspides principales. Bien es cierto que los cérvidos presentan este aislamiento, pero en Rangifer se da en su máxima expresión ya que se da en todas las cúspides, formando cuatro isletas claramente diferenciadas, mientras que en Dama o Cervus esta separación forma dos o como mucho tres isletas dependiendo del estado de desgaste. La pieza de Cueva Millán es muy pequeña, más que las de los gamos y renos. Por otra parte, los restos de la Cueva Valdegoba son similares a los de Prado Vargas, próximos a los valores más altos de los renos y ciervos comparados (figura V.7.1).

$\mathbf{P}_{3}$ : en esta pieza la paraprecrístida y la paraendocrístida se unen cuando el diente presenta un desgaste moderado, aunque en una de las piezas de Cueva Millán están separadas a pesar de que el desgaste es marcado, como en Dama (Lister, 1996). El metacónido es simple, unilobulado en las piezas de la Cueva de Valdegoba y Prado Vargas, 
mientras que en uno de los casos de Cueva Millán es doble. Sin embargo, en todas las piezas está separado del entocónido por un pequeño surco, a diferencia de Dama (Lister, 1996). La hipoendocrístida se encuentra orientada según el eje transversal del diente en los restos de la Cueva de Valdegoba y Prado Vargas mientras que en Cueva Millán es ligeramente oblicua. La cara bucal es convexa, y la lingual más o menos recta. Difieren de los dientes del reno por presentar un metacónido unilobulado y proyectado mesialmente, haciendo que el surco definido por esta cúspide y por la paraendocrístida no esté tan desarrollado. Los restos analizados son más grandes que los de los gamos y renos, más pequeños que los del Megaloceros de Atapuerca y similares a los de los ciervos europeos (figura V.7.1).

Tabla V.7.5

Medidas tomadas en los premolares inferiores de C. elaphus

\begin{tabular}{|c|c|c|c|c|c|c|c|}
\hline & DAP & DAPb & DTa & DTp & DT & DTb & H \\
\hline \multicolumn{8}{|l|}{$\mathbf{P}_{2}$} \\
\hline \multicolumn{8}{|c|}{ Valdegoba } \\
\hline $\mathrm{n}$ & 5 & 5 & 5 & 5 & 5 & 5 & 5 \\
\hline rango & $11,8-13,2$ & $10,7-12,9$ & $5,2-7,3$ & $6,7-7,9$ & $6,2-7,0$ & $6,7-7,9$ & $7,2-9,4$ \\
\hline $\bar{x} \pm$ s.d. & $12,4 \pm 0,5$ & $11,5 \pm 0,9$ & $6,3 \pm 0,8$ & $7,5 \pm 0,5$ & $6,7 \pm 0,3$ & $7,5 \pm 0,5$ & $8,3 \pm 0,8$ \\
\hline \multicolumn{8}{|c|}{ Prado Vargas } \\
\hline $\mathrm{n}=1$ & 13,7 & 12,2 & 7,4 & 9,5 & 6,2 & 9,5 & 9,6 \\
\hline \multicolumn{8}{|l|}{ Millán } \\
\hline $\mathrm{n}$ & 2 & 2 & 2 & 2 & 2 & 2 & 2 \\
\hline rango & $12,0-14,3$ & $11,4-12,9$ & $6,2-7,3$ & $6,6-9,1$ & $5,3-6,7$ & $6,6-9,1$ & $7,8-9,5$ \\
\hline $\bar{x} \pm$ s.d. & $13,2 \pm 1,6$ & $12,1 \pm 1,1$ & $6,7 \pm 0,7$ & $7,8 \pm 1,8$ & $6,0 \pm 1,0$ & $7,8 \pm 1,8$ & $8,7 \pm 1,2$ \\
\hline \multicolumn{8}{|l|}{$\mathbf{P}_{3}$} \\
\hline \multicolumn{8}{|c|}{ Valdegoba } \\
\hline $\mathrm{n}$ & 6 & 7 & 8 & 7 & 7 & 7 & 7 \\
\hline rango & $16,2-18,6$ & $14,2-15,8$ & $6,8-9,2$ & $8,4-10,7$ & $8,4-10,7$ & $8,6-11,1$ & $8,5-14,8$ \\
\hline $\bar{x} \pm$ s.d. & $17,4 \pm 0,9$ & $15,1 \pm 0,5$ & $8,1 \pm 0,8$ & $9,5 \pm 0,9$ & $9,5 \pm 0,9$ & $9,6 \pm 0,8$ & $10,7 \pm 2,1$ \\
\hline \multicolumn{8}{|c|}{ Prado Vargas } \\
\hline $\mathrm{n}$ & 2 & 2 & 2 & 2 & 2 & 2 & 2 \\
\hline rango & $18,3-19,2$ & $16,6-16,7$ & $8,9-9,0$ & $10,5-11,6$ & $8,0-10,5$ & $10,5-11,6$ & $11,1-14,1$ \\
\hline $\bar{x} \pm$ s.d. & $18,7 \pm 0,7$ & $16,6 \pm 0,1$ & $9,0 \pm 0,0$ & $11,0 \pm 0,8$ & $9,2 \pm 1,8$ & $11,0 \pm 0,8$ & $12,6 \pm 2,1$ \\
\hline \multicolumn{8}{|l|}{ Millán } \\
\hline $\mathrm{n}$ & 2 & 1 & 2 & 3 & 3 & 3 & 3 \\
\hline rango & $15,6-18,3$ & 15,5 & $8,1-8,8$ & $10,1-11,1$ & $7,6-8,7$ & $10,1-11,1$ & $11,1-13,8$ \\
\hline $\bar{x} \pm$ s.d. & $16,9 \pm 1,9$ & & $8,4 \pm 0,5$ & $10,5 \pm 0,6$ & $8,0 \pm 0,6$ & $10,5 \pm 0,6$ & $11,9 \pm 1,6$ \\
\hline \multicolumn{8}{|l|}{$\mathbf{P}_{4}$} \\
\hline \multicolumn{8}{|c|}{ Valdegoba } \\
\hline $\mathrm{n}$ & 3 & 5 & 5 & 5 & 5 & 3 & 5 \\
\hline rango & $17,1-19,6$ & $16,0-16,7$ & $6,1-13,6$ & $10,8-11,2$ & $10,8-11,2$ & $10,5-11,5$ & $7,4-14,0$ \\
\hline $\bar{x} \pm$ s.d. & $18,0 \pm 1,4$ & $16,3 \pm 0,3$ & $9,7 \pm 3,2$ & $11,0 \pm 0,2$ & $11,0 \pm 0,2$ & $11,0 \pm 0,5$ & $10,2 \pm 2,8$ \\
\hline \multicolumn{8}{|l|}{ Millán } \\
\hline $\mathrm{n}$ & 4 & 4 & 4 & 4 & 4 & 4 & 4 \\
\hline rango & $18,3-20,0$ & $17,9-18,9$ & $10,7-12,6$ & $10,2-12,7$ & $9,3-12,1$ & $10,7-12,7$ & $9,6-15,9$ \\
\hline$\overline{\mathrm{x}} \pm$ s.d. & $19,3 \pm 0,7$ & $18,3 \pm 0,5$ & $11,6 \pm 0,9$ & $11,6 \pm 1,2$ & $11,3 \pm 1,2$ & $10,7 \pm 0,9$ & $11,6 \pm 2,8$ \\
\hline \multicolumn{8}{|c|}{ Estebanvela } \\
\hline $\mathrm{n}=1$ & & & & 10,2 & & & 5,1 \\
\hline
\end{tabular}

$\mathbf{P}_{4}$ : presenta un metacónido bilobulado o muestra una tendencia a ello. El paracónido está bien formado. Tiene un surco bucal, entre el protocónido y el hipocónido, más profundo que $\mathrm{P}_{2}$ y $\mathrm{P}_{3}$. La metapostcrístida está bien desarrollada, al igual que la metaprecrístida, que suele cerrar la foseta anterior. Las caras bucal y lingual son menos convexas que en los premolares anteriores. Difiere de Dama por presentar la hipoendocrístida alineada según el eje transversal, el entocónido fusionado a la hipoendocrístida, el surco que separa el entocónido de la hipoendocrístida poco profundo y por tener, en ocasiones, un cíngulo anterior más o menos acentuado (Lister, 1996). Estos dos últimos caracteres permiten, 
también, diferenciarlo de Rangifer. Métricamente, los restos analizados presentan un tamaño similar al de otros Cervus elaphus europeos, son más grandes que los gamos y renos y más pequeños que el Megaloceros de Atapuerca (figura V.7.1).
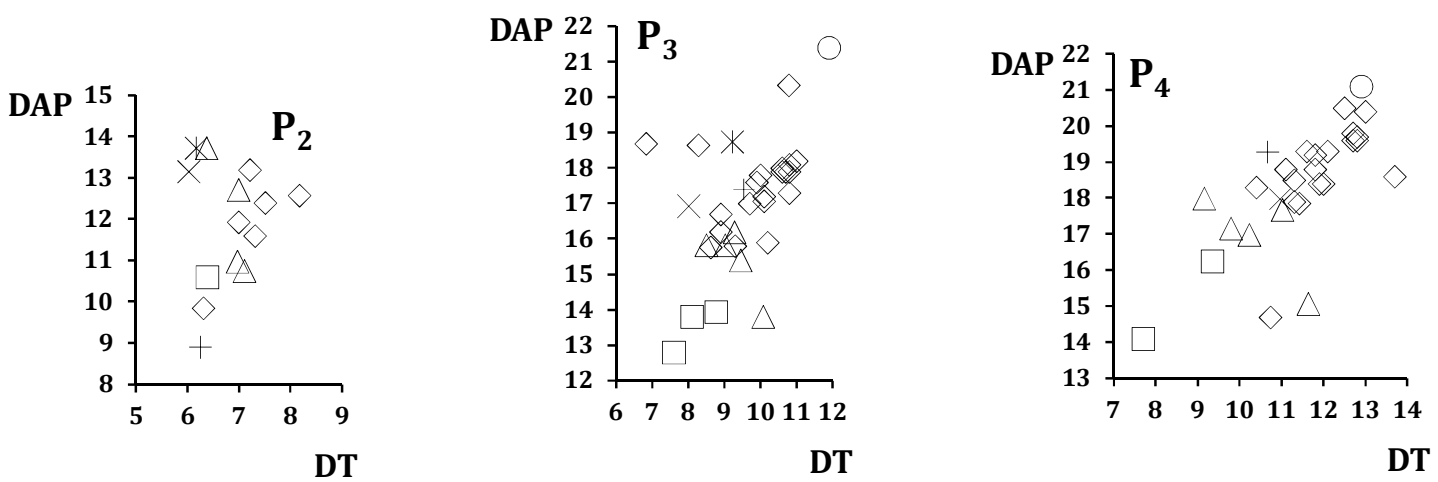

$\diamond$ C. elaphus $\square$ D.dama $\triangle$ R.tarandus $\bigcirc$ M.giganteus $\times$ C.e.Valdegoba $\quad$ C.e. Búho $\quad *$ C.e. Prado Vargas +C.e.Cueva Millán

Figura V.7.1. Diagramas bivariantes de los premolares inferiores: DAP (diámetro anteroposterior) y DT (diámetro transversal). C. elaphus de Atapuerca (TG, TE) (Van der Made, 1999), Abric Romaní (Sánchez, 1990), Majolicas (Domingo y Alberdi, 2004), Fate, Manie, Madonna (Psathi, 2003), Mendandia (Alay-Ruiz, 2006), Prince Cave (Arellano Alonso, 2004), Combe Grenal (Guadelli, 1987), La Ferrasie (Delpech, 1984), Lazaret, Orgnac, Bau l'Aubesier, Bianche St. Vaast, Tournal (Magniez, 2010), Vaufrey (Delpech, 1988), Jarama VI, Buraca Escura, Lezika y Abauntz. Dama dama de Atapuerca (TG y TE) (Van der Made, 1999) y Maltravieso. Rangifer tarandus de Atxuri, Arlanpe, Urtiagako Leizea, Armotxe y Aitzbitarte IV. Megaloceros giganteus de Atapuerca (Van der Made, 1999).

Molares inferiores permanentes (lámina V.7.1: 12, 13 y 14) (tabla V.7.6) (figura V.7.2): dientes con las coronas altas, morfología selenodonta y con una pequeña columna interlobular de desarrollo variable en la cara bucal. Son birradiculados: con una raíz mesial y otra distal. Tanto el $\mathrm{M}_{1}$ como el $\mathrm{M}_{2}$ tienen dos lóbulos, mientras que el $\mathrm{M}_{3}$, debido al desarrollo de su hipoconúlido, presenta una apariencia trilobulada. El lóbulo mesial está menos proyectado que el distal hacia la cara lingual. La metapostcrístida está solapada con la entoprecrístida. Presentan un cíngulo en la base de la corona que parte de la columna interlobular y se extiende hacia los extremos mesial y distal. Las caras bucales de los lóbulos pueden ser redondeadas o triangulares y las fósidas pueden carecer de pliegues o presentar unos pocos.

Los caracteres generales que aparecen en los tres molares y que permiten diferenciarlo de Dama, Haploidoceros y Rangifer se describen a continuación. Difieren de Dama por presentar una protopostcrístida muy próxima a la hipoprecrístida, por tener unos surcos contiguos a la metaendocrístida y la entoectocrístida más acentuados, por tener una entoectocrístida más o menos recta en la parte anterior de la base, por su hipoendocrístida recta y por presentar varios pliegues en el punto de unión de la protopostcrístida y la hipoprecrístida (Lister, 1996). Se diferencian del reno por el menor aislamiento de las cúspides, por el menor desarrollo de los cíngulos y por no presentar, en ocasiones, columnas interlobulares.

Otros caracteres son específicos de cada pieza. Por ejemplo, el $\mathrm{M}_{1}$ presenta una columna interlobular más pequeña que $\mathrm{M}_{2}$, lo que no ocurre en Dama y Haploidoceros (Lister, 1996; Sanz et al., 2014). Difiere del gamo, además, en que el cíngulo bucal está más desarrollado en $\mathrm{M}_{1}$ y $\mathrm{M}_{2}$, por la superposición más pequeña entre la metapostcrístida y la entoprecrístida en el $\mathrm{M}_{3}$. Por otra parte, la separación entre el entocónido y el hipocónido, en el $\mathrm{M}_{3}$, es mayor en Dama, Haploidoceros y Rangifer (Lister, 1996; Sanz et al., 2014). El $\mathrm{M}_{3}$ tiene un pliegue marcado en la cara lingual, entre el entocónido y el hipocónido, que no tiene el gamo; además, el ciervo presenta un cíngulo de desarrollo variable en la cara lingual del hipocónido (Lister, 1996). 
$\mathbf{M}_{1}$ : son similares al $\mathbf{M}_{2}$. Se diferencia de este diente en que el límite de la corona se encuentra más alto en la cara mesial que en la distal, mientras que en el segundo molar inferior se encuentran ambas a la misma altura. Asimismo, tiene la cara bucal más inclinada y unos diámetros transversales más pequeños que en $\mathrm{M}_{2}$ (tabla V.7.6). La columna interlobular es pequeña e incluso apenas está esbozada como en una de las piezas de Prado Vargas. Pueden presentar cíngulos en la cara bucal y mesial con un desarrollo variable. La pieza de la Cueva de Valdegoba es pequeña, similar al gamo y al reno, y más pequeña que las de otros Cervus europeos y Megaloceros (figura V.7.2).

Tabla V.7.6

Medidas tomadas en los molares inferiores permanentes de C. elaphus

\begin{tabular}{|c|c|c|c|c|c|c|c|c|c|}
\hline & DAP & DAPb & DTa & DTp & DTpp & DT & DTb & Ha & Hp \\
\hline \multicolumn{10}{|l|}{$M_{1}$} \\
\hline \multicolumn{10}{|c|}{ Valdegoba } \\
\hline $\mathrm{n}$ & 21 & 17 & 20 & 19 & & 19 & 17 & 14 & 13 \\
\hline rango & $19,7-25,5$ & $18,3-23,1$ & $11,8-14,6$ & $11,9-15,0$ & & $8,7-13,8$ & $12,0-14,6$ & $6,4-21,8$ & $6,4-21,3$ \\
\hline $\bar{x} \pm$ s.d. & $23,1 \pm 1,5$ & $20,1 \pm 1,3$ & $13,1 \pm 0,7$ & $13,5 \pm 0,7$ & & $10,6 \pm 1,4$ & $13,1 \pm 0,7$ & $17,2 \pm 4,9$ & $16,5 \pm 5,1$ \\
\hline \multicolumn{10}{|c|}{ Prado Vargas } \\
\hline $\mathrm{n}$ & & & 2 & 1 & & 1 & 1 & 1 & 1 \\
\hline rango & & & $12,5-13,3$ & 14,6 & & 14,6 & 14,6 & 13,5 & 12,5 \\
\hline $\bar{x} \pm$ s.d. & & & $12,9 \pm 0,6$ & & & & & & \\
\hline \multicolumn{10}{|l|}{ Millán } \\
\hline $\mathrm{n}$ & 3 & 1 & 3 & & & & 1 & 3 & 3 \\
\hline rango & $23,2-26,1$ & 22,3 & $14,2-16,0$ & & & & 14,2 & $14,4-20,1$ & $14,2-20,3$ \\
\hline $\bar{x} \pm$ s.d. & $24,3 \pm 1,6$ & & $15,0 \pm 0,9$ & & & & & $16,4 \pm 3,2$ & $16,4 \pm 3,4$ \\
\hline \multicolumn{10}{|c|}{$\mathbf{M}_{2}$} \\
\hline \multicolumn{10}{|c|}{ Valdegoba } \\
\hline $\mathrm{n}$ & 8 & 3 & 9 & 10 & & 9 & 7 & 7 & 8 \\
\hline rango & $22,4-25,9$ & $21,8-23,9$ & $12,1-16,5$ & $12,1-16,0$ & & $9,7-15,0$ & $12,5-16,0$ & $6,7-21,1$ & $7,5-22,2$ \\
\hline $\bar{x} \pm$ s.d. & $23,8 \pm 1,3$ & $23,1 \pm 1,1$ & $14,1 \pm 1,5$ & $14,1 \pm 1,5$ & & $12,1 \pm 2,1$ & $14,3 \pm 1,4$ & $14,9 \pm 5,1$ & $16,2 \pm 4,9$ \\
\hline \multicolumn{10}{|c|}{ Prado Vargas } \\
\hline$n=1$ & 26,9 & 26,6 & 15,7 & 17,6 & & 17,6 & & 17,4 & 17 \\
\hline \multicolumn{10}{|l|}{ Millán } \\
\hline $\mathrm{n}=1$ & 26,7 & 25 & 16,4 & 15,9 & & 12,8 & 16,4 & 22,2 & 23 \\
\hline \multicolumn{10}{|l|}{$M_{1-2}$} \\
\hline \multicolumn{10}{|l|}{ Millán } \\
\hline $\mathrm{n}=1$ & 23,6 & & 13,7 & 13,9 & & 11,9 & & & \\
\hline \multicolumn{10}{|c|}{$\mathbf{M}_{3}$} \\
\hline \multicolumn{10}{|c|}{ Valdegoba } \\
\hline $\mathrm{n}$ & 7 & 5 & 4 & 6 & 7 & 6 & 4 & 6 & 6 \\
\hline rango & $21,9-32,9$ & $30,7-33,0$ & $13,8-15,3$ & $12,4-14,7$ & $2,9-8,8$ & $8,1-14,8$ & $13,4-15,2$ & $10,4-18,0$ & $9,7-19,4$ \\
\hline$\overline{\mathrm{x}} \pm$ s.d. & $29,9 \pm 4,1$ & $31,7 \pm 1,0$ & $14,6 \pm 0,7$ & $13,7 \pm 0,8$ & $7,7 \pm 2,1$ & $12,4 \pm 2,4$ & $14,1 \pm 0,9$ & $14,5 \pm 3,1$ & $15,0 \pm 3,5$ \\
\hline \multicolumn{10}{|l|}{ Millán } \\
\hline $\mathrm{n}$ & 2 & 2 & 2 & 4 & 4 & 2 & 2 & 2 & 4 \\
\hline rango & $35,6-35,6$ & $35,5-35,5$ & $15,4-15,4$ & $14,2-15,0$ & $9,6-11,1$ & $11,9-11,9$ & $15,6-15,6$ & $25,9-25,9$ & $23,6-25,9$ \\
\hline $\bar{x} \pm$ s.d. & $35,6 \pm 0,0$ & $35,5 \pm 0,0$ & $15,4 \pm 0,0$ & $14,7 \pm 0,4$ & $10,3 \pm 0,8$ & $11,9 \pm 0,0$ & $15,6 \pm 0,0$ & $25,9 \pm 0,0$ & $25,0 \pm 1,1$ \\
\hline \multicolumn{10}{|l|}{ Búho } \\
\hline$n=1$ & 35,4 & 35,9 & 16,2 & 14,7 & 9,7 & 14,9 & 16,2 & 11,6 & 12 \\
\hline
\end{tabular}

$\mathbf{M}_{2}$ : tiene una columna interlobular más desarrollada que el $\mathrm{M}_{1}$, aunque es difícil de observar en dientes aislados. La protopostcrístida está próxima a la hipoprecrístida. Los surcos contiguos a la metaectocrístida y a la entoectocrístida están muy acentuados. La entoectocrístida no está curvada hacia la parte anterior. La protopostcrístida y la hipoprecrístida suelen presentar pliegues en el punto de unión entre ambas. El cíngulo bucal mesial está muy desarrollado en las piezas de la Cueva de Valdegoba y Cueva Millán, mientras que en una de las piezas de Prado Vargas no lo tiene. Métricamente, presentan unos valores más grandes de DTb y DAPb que el $\mathrm{M}_{1}$. Sin embargo, existe cierto solapamiento en esta última variable (tabla V.7.6). Las piezas de la Cueva de Valdegoba y 
Cueva Millán son pequeñas, cercanas a las de los renos y gamos, y más pequeñas que las registradas en Prado Vargas y otros Cervus elaphus europeos (figura V.7.2).

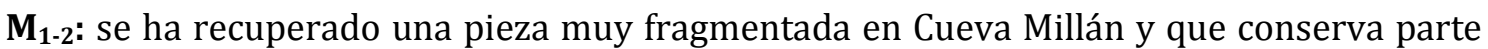
del hueso de la mandíbula pero sin los alveolos contiguos por lo que no podemos asignarla al $M_{1}$ o al $M_{2}$. Sus valores de DAP son menores que los de $\mathrm{M}_{2}$ y $\mathrm{M}_{3}$. El DT es menor que el de $\mathrm{M}_{2}$ pero similar al de $\mathrm{M}_{3}$. Lo mismo ocurre con DTa y DTp, sus valores son inferiores a los de $\mathrm{M}_{2} \mathrm{y} \mathrm{M}_{3}$ (tabla V.7.6). Las dimensiones registradas en esta pieza parecen indicar que podría pertenecer a un $\mathrm{M}_{1}$ en vez de a un $\mathrm{M}_{2}$. El estado de fragmentación no nos permite observar los caracteres morfológicos por lo que mantenemos la categoría $\mathrm{M}_{1-2}$.
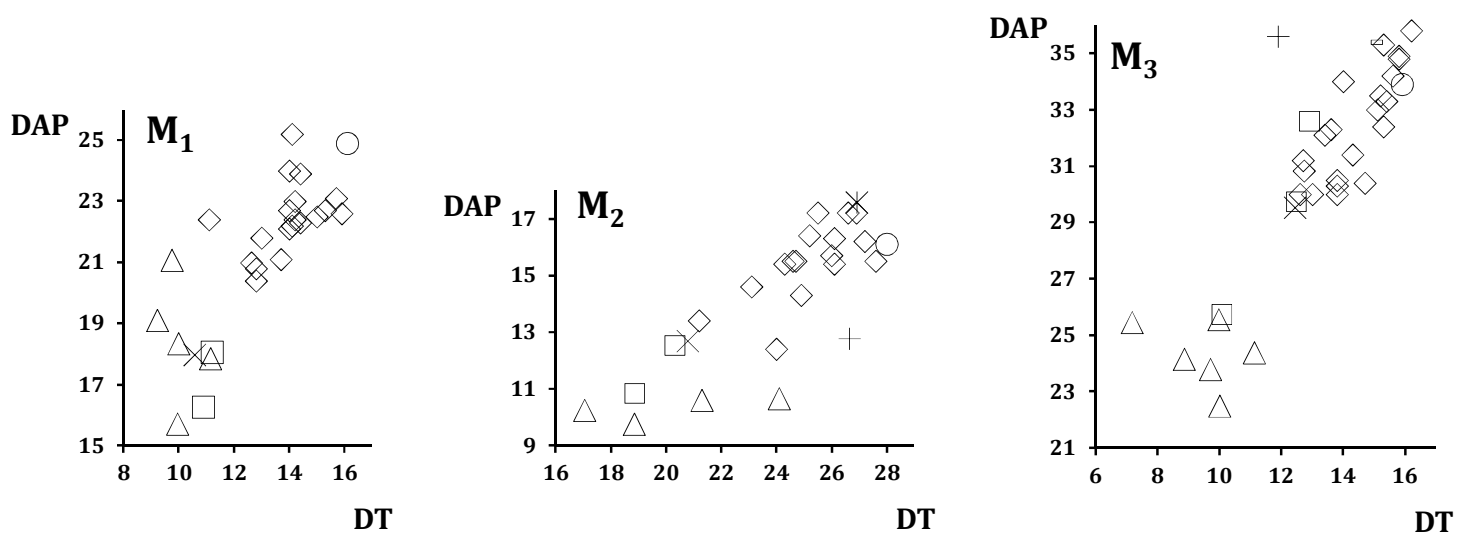

$\diamond$ C. elaphus $\square$ D.dama $\triangle$ R. tarandus $\bigcirc$ M.giganteus $\quad \times$ C.e.Valdegoba $\quad \square$ C.e.Búho $\quad *$ C.e.Prado Vargas + C.e.Cueva Millán

Figura V.7.2. Diagramas bivariantes de los molares inferiores: DAP (diámetro anteroposterior) y DT (diámetro transversal). C. elaphus de Atapuerca (TG, TE) (Van der Made, 1999), Abric Romaní (Sánchez, 1990), Majolicas (Domingo y Alberdi, 2004), Mendandia (Alday-Ruiz, 2006), Fate, Manie, Madonna (Psathi, 2003), Prince Cave (Arellano Alonso, 2004), Combe Grenal (Guadelli, 1987), La Ferrasie (Delpech, 1984), Lazaret, Orgnac, Bau l'Aubesier, Bianche St. Vaast, Tournal (Magniez, 2010), Vaufrey (Delpech, 1988), Jarama VI, Buraca Escura, Lezika y Abauntz. Dama dama de Atapuerca (TG y TE) (Van der Made, 1999) y Maltravieso. Rangifer tarandus de Atxuri, Arlanpe, Urtiagako Leizea, Armotxe y Aitzbitarte IV. Megaloceros giganteus de Atapuerca (Van der Made, 1999).

$\mathbf{M}_{3}$ : diente con apariencia trilobulada debido al gran desarrollo del hipoconúlido. Suele presentar un surco acentuado entre las crístidas anteriores. Tiene un pliegue marcado en la cara lingual, entre el entocónido y el hipocónido. La cara lingual del hipocónido tiene un cíngulo de desarrollo variable. La separación entre el entocónido y el hipocono es muy nítida. La cara bucal presenta dos columnas interlobulares con forma de espina, estando más desarrollada la mesial. El cíngulo mesial está más marcado que el distal, y en dos de las piezas de Cueva Millán apenas está esbozado. Se diferencia del $\mathrm{D}_{4}$, también trilobulado, por su mayor tamaño y por la disminución del diámetro transversal que se produce hacia el extremo distal (tablas V.7.2 y 6). Las piezas analizadas tienen un tamaño similar al de otros Cervus elaphus europeos y son más grandes que las del gamo y el reno (figura V.7.2).

Tabla V.7.7

Medidas tomadas en los caninos superiores de C. elaphus

\begin{tabular}{|c|c|c|c|c|c|c|}
\hline & DAP & DLL & Hli & Hla & Hmes & Hdist \\
\hline \multicolumn{7}{|c|}{ Valdegoba } \\
\hline $\mathrm{n}$ & 6 & 6 & 4 & 5 & 4 & 1 \\
\hline rango & $8,3-12,1$ & $4,7-9,2$ & $9,5-11,5$ & $7,2-10,2$ & $8,9-12,3$ & 5,6 \\
\hline $\bar{x} \pm$ s.d. & $10,6 \pm 2,4$ & $7,6 \pm 1,9$ & $10,7 \pm 3,4$ & $8,7 \pm 2,2$ & $11,3 \pm 3,7$ & \\
\hline \multicolumn{7}{|c|}{ Prado Vargas } \\
\hline $\mathrm{n}=1$ & 10,7 & 6,3 & 9,6 & 11,6 & 10 & 8,5 \\
\hline \multicolumn{7}{|c|}{ Cueva Millán } \\
\hline $\mathrm{n}$ & 2 & 2 & 2 & 2 & 2 & 2 \\
\hline rango & $11,0-11,7$ & $6,3-6,3$ & $9,1-13,4$ & $9,4-13,7$ & $10,9-12,2$ & $9,4-11,8$ \\
\hline $\bar{x} \pm$ s.d. & $11,4 \pm 0,4$ & $6,3 \pm 0,1$ & $11,3 \pm 3,0$ & $11,6 \pm 3,0$ & $11,6 \pm 0,9$ & $10,6 \pm 1,7$ \\
\hline
\end{tabular}


Caninos superiores (figuras V.7.13 y 14) (tabla V.7.7): dientes simples, con las coronas bajas y globulosas. Tienen un extremo distal redondeado y una raíz corta y plana. Están separados de la fila premolar - molar por un diastema lo que hace que no entren en contacto con otro diente incluso en la oclusión.

Premolares superiores (lámina V.7.1: 15, 16 y 17) (tabla V.7.8) (figura V.7.3): dientes con las coronas bajas, braquiodontas, asimétricas y con una configuración selenodonta. La asimetría se reduce del $\mathrm{P}^{2}$ al $\mathrm{P}^{4}$. Tienen un desarrollo variable de sus cíngulos, aunque por lo general no lo tienen en la cara posterior. Tienen tres raíces aunque en el $\mathrm{P}^{2}$ la lingual y la mesial pueden fusionarse.

Tabla V.7.8

Medidas tomadas en los premolares superiores de C. elaphus

\begin{tabular}{|c|c|c|c|c|c|c|c|}
\hline & DAP & DAPb & DTa & DTp & DT & DTb & $\mathbf{H}$ \\
\hline \multicolumn{8}{|l|}{$\mathbf{P}^{2}$} \\
\hline \multicolumn{8}{|c|}{ Valdegoba } \\
\hline $\mathrm{n}$ & 12 & 12 & 12 & 10 & 12 & 12 & 11 \\
\hline rango & $14,9-19,3$ & $14,5-18,5$ & $10,6-15,4$ & $14,9-17,4$ & $10,6-14,7$ & $7,4-14,8$ & $6,2-13,4$ \\
\hline $\bar{x} \pm$ s.d. & $17,3 \pm 1,3$ & $16,7 \pm 1,5$ & $12,9 \pm 1,5$ & $16,5 \pm 0,8$ & $12,8 \pm 1,6$ & $11,2 \pm 2,5$ & $9,6 \pm 2,3$ \\
\hline \multicolumn{8}{|l|}{ Millán } \\
\hline $\mathrm{n}$ & 3 & 3 & 3 & 3 & 3 & 3 & 3 \\
\hline rango & $16,1-17,9$ & $16,1-17,2$ & $14,2-16,1$ & $17,2-18,3$ & $13,5-16,6$ & $17,2-18,3$ & $8,3-10,0$ \\
\hline $\bar{x} \pm$ s.d. & $17,0 \pm 0,9$ & $16,5 \pm 0,6$ & $15,2 \pm 1,0$ & $17,7 \pm 0,5$ & $15,5 \pm 1,7$ & $17,7 \pm 0,6$ & $9,3 \pm 0,9$ \\
\hline \multicolumn{8}{|l|}{ Búho } \\
\hline $\mathrm{n}$ & 3 & 3 & 3 & 3 & 3 & 3 & 3 \\
\hline rango & $14,6-17,6$ & $13,5-17,1$ & $9,0-15,1$ & $10,1-17,5$ & $9,7-16,5$ & $10,1-17,5$ & $6,4-12,0$ \\
\hline $\bar{x} \pm$ s.d. & $16,1 \pm 1,5$ & $15,3 \pm 1,8$ & $12,3 \pm 3,1$ & $14,8 \pm 4,1$ & $13,0 \pm 3,4$ & $14,8 \pm 4,1$ & $9,1 \pm 2,8$ \\
\hline \multicolumn{8}{|l|}{$\mathbf{P}^{3}$} \\
\hline \multicolumn{8}{|c|}{ Valdegoba } \\
\hline $\mathrm{n}$ & 16 & 16 & 16 & 15 & 15 & 16 & 15 \\
\hline rango & $15,2-19,5$ & $14,1-17,0$ & $13,0-18,9$ & $16,2-20,6$ & $11,4-17,4$ & $7,8-21,0$ & $5,6-17,7$ \\
\hline $\bar{x} \pm$ s.d. & $16,9 \pm 1,2$ & $15,3 \pm 0,7$ & $16,3 \pm 1,6$ & $18,5 \pm 1,3$ & $13,8 \pm 1,6$ & $14,9 \pm 3,6$ & $11,9 \pm 3,3$ \\
\hline \multicolumn{8}{|c|}{ Prado Vargas } \\
\hline $\mathrm{n}=1$ & 17,3 & 15,9 & 17,0 & 20,9 & 20,9 & 20,9 & \\
\hline \multicolumn{8}{|l|}{ Millán } \\
\hline $\mathrm{n}=1$ & 17,6 & 16,3 & 17,8 & 18,5 & 15,3 & 18,5 & 17,4 \\
\hline \multicolumn{8}{|l|}{ Búho } \\
\hline $\mathrm{n}$ & 2 & 2 & 2 & 2 & 2 & 2 & 2 \\
\hline rango & $14,7-16,3$ & $11,9-13,8$ & $16,9-18,1$ & $17,9-18,1$ & $16,9-17,4$ & $17,9-18,1$ & $10,7-13,1$ \\
\hline $\bar{x} \pm$ s.d. & $15,5 \pm 1,1$ & $12,9 \pm 1,4$ & $17,5 \pm 0,8$ & $18,0 \pm 0,1$ & $17,2 \pm 0,3$ & $18,0 \pm 0,1$ & $11,9 \pm 1,7$ \\
\hline \multicolumn{8}{|c|}{$\mathrm{P}^{4}$} \\
\hline \multicolumn{8}{|c|}{ Valdegoba } \\
\hline $\mathrm{n}$ & 10 & 11 & 12 & 12 & 12 & 11 & 11 \\
\hline rango & $14,4-16,8$ & $11,8-15,7$ & $12,6-19,5$ & $15,1-25,6$ & $11,2-17,3$ & $6,1-17,1$ & $5,1-13,7$ \\
\hline $\bar{x} \pm$ s.d. & $15,5 \pm 0,8$ & $13,9 \pm 1,2$ & $17,0 \pm 2,4$ & $19,3 \pm 2,9$ & $15,6 \pm 1,9$ & $13,2 \pm 3,2$ & $10,7 \pm 2,7$ \\
\hline \multicolumn{8}{|l|}{ Búho } \\
\hline $\mathrm{n}$ & & & 2 & & 2 & 2 & 2 \\
\hline rango & & & $16,9-16,9$ & & $13,0-13,0$ & $17,0-17,0$ & $10,3-10,3$ \\
\hline$\overline{\mathrm{x}} \pm$ s.d. & & & $16,9 \pm 0,0$ & & $13,0 \pm 0,0$ & $17,0 \pm 0,0$ & $10,3 \pm 0,0$ \\
\hline
\end{tabular}

P2: estás piezas se estrechan mesialmente, por lo que son las que presentan mayor asimetría. La cúspide más desarrollada es el paracono. El protocono, junto con el hipocono, forma un surco que divide el diente en dos lóbulos. El paracono define dos surcos en la cara bucal que son menos acentuados que en el $\mathrm{D}^{2}$. Son más anchos que los segundos deciduales superiores (tablas V.7.3 y 8).

$\mathbf{P}^{3}$ y P4: estos dos dientes pueden confundirse con facilidad. Se diferencian básicamente por la posición de la paraectocrístida, que se encuentra en una posición mesial en el $\mathrm{P}^{3} \mathrm{y}$ 
central en el $\mathrm{P}^{4}$. Por otra parte, se ha observado que el $\mathrm{P}^{3}$ tiene más marcado el surco formado entre el protocono y el hipocono que el $\mathrm{P}^{4}$, pero es más pequeño que el del Haploidoceros (Sanz et al., 2014). Las longitudes de ambos dientes se solapan pero la anchura es mayor en el $\mathrm{P}^{4}$ (tabla V.7.8). Difieren de los renos por su morfología menos redondeada, por estar menos inclinada lingualmente, por carecer de un cíngulo en la cara posterior y por el menor desarrollo de los estilos. Los restos de la Cueva de Valdegoba y Cueva Millán están en el rango de otros Cervus elaphus europeos. El $\mathrm{P}^{3}$ de Prado Vargas es muy grande. En general, son más grandes que los de los gamos y renos (figura V.7.3).
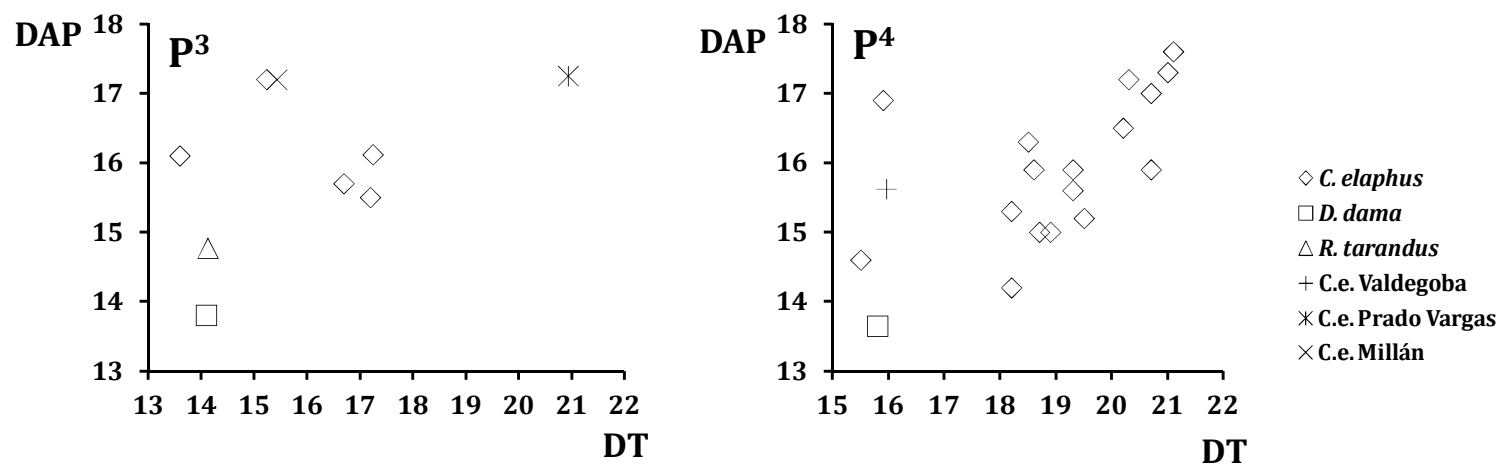

Figura V.7.3. Diagramas bivariantes de los molares inferiores: DAP (diámetro anteroposterior) y DT (diámetro transversal). C. elaphus de Atapuerca (TG, TE) (Van der Made, 1999), Abric Romaní (Sánchez, 1990), Majolicas (Domingo y Alberdi, 2004), Mendandia (Alday-Ruiz, 2006), Fate, Manie, Madonna (Psathi, 2003), Prince Cave (Arellano Alonso, 2004), Combe Grenal (Guadelli, 1987), La Ferrasie (Delpech, 1984), Lazaret, Orgnac, Bau l'Aubesier, Bianche St. Vaast (Magniez, 2010), Vaufrey (Delpech, 1988), Jarama VI, Lezika y Abauntz Dama dama de Atapuerca (TG y TE) (Van der Made, 1999) y Maltravieso. Rangifer tarandus de Bolinkoba, y Armotxe.

Molares superiores permanentes (lámina V.7.1: 18, 19 y 20) (tabla V.7.9) (figura V.7.4): dientes bilobulados, braquiodontos, con superficies oclusales selenodontas, donde el diámetro transversal del lóbulo distal disminuye con relación al del mesial a medida que nos acercamos al $\mathrm{M}^{3}$. Las cúspides están aisladas, lo que difiere de los bóvidos. Tienen una columna interlobular lingual en forma de espina que emerge de un pequeño cíngulo que rodea la base de la corona. Dicho cíngulo puede presentar más o menos desarrollo y extenderse hacia las caras mesial y distal. Los estilos presentan desarrollos variables. Son más grandes que los molares deciduales superiores (tablas V.7.3 y 9).
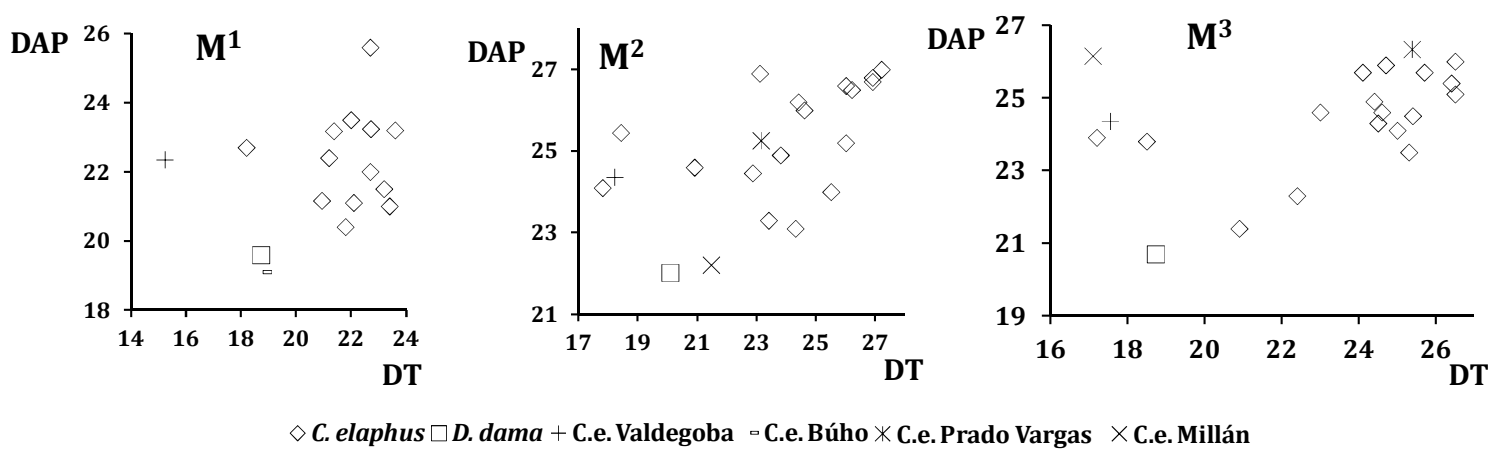

Figura V.7.4. Diagramas bivariantes de los molares superiores: DAP (diámetro anteroposterior) y DT (diámetro transversal). C. elaphus de Atapuerca (TG, TE) (Van der Made, 1999), Abric Romaní (Sánchez, 1990), Majolicas (Domingo y Alberdi, 2004), Mendandia (Alday-Ruiz, 2006), Fate, Manie, Madonna (Psathi, 2003), Prince Cave (Arellano Alonso, 2004), Combe Grenal (Guadelli, 1987), La Ferrasie (Delpech, 1984), Lazaret, Orgnac, Bau l'Aubesier, Bianche St. Vaast, (Magniez, 2010), Vaufrey (Delpech, 1988), Jarama VI, Buraca Escura, Lezika y Abauntz. Dama dama de Atapuerca (TG y TE) (Van der Made, 1999).

Difieren de los molares superiores de Dama por presentar unas columnas bucales y sus estilos adyacentes más acentuados, por carecer de pliegues en la mayor parte de los casos 
ya que sí se han observado en Prado Vargas en la proprecrista, por tener un cíngulo lingual más desarrollado y por la unión no horizontal de las columnas bucales y estilares en la base de la corona (Lister, 1996). Por otra parte, se diferencia del reno por el menor aislamiento de sus cúspides principales, por la forma menos redondeada de la superficie oclusal, por la mayor proyección de los estilos y por la forma convexa de la cara posterior de la raíz posterobucal. Asimismo, en Haploidoceros los estilos están menos proyectados (Sanz et al., 2014).

Tabla V.7.9

Medidas tomadas en los premolares superiores de C. elaphus

\begin{tabular}{|c|c|c|c|c|c|c|c|c|}
\hline & DAP & DAPb & DTa & DTp & DTpp & DTb & Ha & Hр \\
\hline \multicolumn{9}{|l|}{$\mathbf{M}^{1}$} \\
\hline \multicolumn{9}{|c|}{ Valdegoba } \\
\hline $\mathrm{n}$ & 13 & 12 & 10 & 12 & 11 & 11 & 13 & 14 \\
\hline rango & $20,8-24,0$ & $15,7-21,6$ & $19,1-23,8$ & $16,1-22,0$ & $11,8-18,5$ & $11,5-21,9$ & $8,4-20,4$ & $10,1-20,9$ \\
\hline $\bar{x} \pm$ s.d. & $22,7 \pm 0,9$ & $19,1 \pm 1,4$ & $21,0 \pm 1,3$ & $19,9 \pm 1,8$ & $15,3 \pm 1,9$ & $17,1 \pm 3,4$ & $15,6 \pm 3,6$ & $16,5 \pm 3,2$ \\
\hline \multicolumn{9}{|l|}{ Millán } \\
\hline valor & 22,4 & 20,8 & & 21,1 & & & 11,9 & 13 \\
\hline \multicolumn{9}{|l|}{ Búho } \\
\hline $\mathrm{n}$ & 2 & 2 & 2 & 2 & 2 & 2 & 2 & 2 \\
\hline rango & $18,4-19,7$ & $16,9-17,0$ & $19,7-20,8$ & $19,9-20,3$ & $17,0-20,5$ & $19,9-20,8$ & $6,7-9,4$ & $5,6-11,7$ \\
\hline $\bar{x} \pm$ s.d. & $19,1 \pm 0,9$ & $16,9 \pm 0,1$ & $20,3 \pm 0,8$ & $20,1 \pm 0,3$ & $18,8 \pm 2,5$ & $20,4 \pm 0,6$ & $8,0 \pm 1,9$ & $8,7 \pm 4,3$ \\
\hline \multicolumn{9}{|l|}{$\mathbf{M}^{2}$} \\
\hline \multicolumn{9}{|c|}{ Valdegoba } \\
\hline $\mathrm{n}$ & 20 & 21 & 22 & 21 & 20 & 22 & 20 & 19 \\
\hline rango & $22,6-27,9$ & $19,7-24,5$ & $20,5-25,7$ & $21,5-24,9$ & $13,4-21,6$ & $10,3-22,9$ & $10,0-21,5$ & $8,8-22,8$ \\
\hline $\bar{x} \pm$ s.d. & $24,4 \pm 1,3$ & $21,4 \pm 1,3$ & $23,3 \pm 1,4$ & $22,6 \pm 1,0$ & $18,2 \pm 2,4$ & $17,8 \pm 3,7$ & $16,9 \pm 3,8$ & $16,6 \pm 4,2$ \\
\hline \multicolumn{9}{|c|}{ Prado Vargas } \\
\hline$n=1$ & 25,3 & 23,1 & 26,7 & 24,9 & 23,1 & 23,1 & 16,3 & 18,9 \\
\hline \multicolumn{9}{|l|}{ Millán } \\
\hline $\mathrm{n}$ & 2 & 2 & 2 & 2 & 2 & 2 & 2 & 2 \\
\hline rango & $18,0-26,5$ & $22,5-22,5$ & $23,1-23,8$ & $22,7-23,0$ & $20,6-22,4$ & $22,7-23,0$ & $6,0-11,9$ & $6,7-13,0$ \\
\hline $\bar{x} \pm$ s.d. & $22,2 \pm 6,0$ & $22,5 \pm 0,1$ & $23,5 \pm 0,5$ & $22,8 \pm 0,3$ & $21,5 \pm 1,3$ & $22,8 \pm 0,3$ & $9,0 \pm 4,2$ & $9,8 \pm 4,4$ \\
\hline \multicolumn{9}{|l|}{ Búho } \\
\hline $\mathrm{n}$ & 2 & 2 & 2 & 2 & 2 & 2 & 2 & 2 \\
\hline rango & $23,3-24,9$ & $20,8-21,5$ & $22,9-23,0$ & $20,4-22,0$ & $16,0-19,7$ & $22,9-23,0$ & $12,5-20,2$ & $11,1-20,7$ \\
\hline $\bar{x} \pm$ s.d. & $24,1 \pm 1,1$ & $21,2 \pm 0,5$ & $22,9 \pm 0,0$ & $21,2 \pm 1,1$ & $17,8 \pm 2,6$ & $22,9 \pm 0,0$ & $16,4 \pm 5,4$ & $15,9 \pm 6,8$ \\
\hline \multicolumn{9}{|l|}{$\mathbf{M}^{3}$} \\
\hline \multicolumn{9}{|c|}{ Valdegoba } \\
\hline $\mathrm{n}$ & 15 & 14 & 14 & 14 & 13 & 15 & 15 & 15 \\
\hline rango & $22,5-25,8$ & $19,6-24,3$ & $21,4-25,4$ & $18,4-23,6$ & $15,5-20,9$ & $14,2-25,9$ & $11,7-25,9$ & $12,8-24,3$ \\
\hline $\bar{x} \pm$ s.d. & $24,3 \pm 1,0$ & $22,1 \pm 1,2$ & $23,1 \pm 1,2$ & $21,3 \pm 1,3$ & $17,6 \pm 1,8$ & $17,6 \pm 3,0$ & $16,4 \pm 3,7$ & $17,1 \pm 2,9$ \\
\hline \multicolumn{9}{|c|}{ Prado Vargas } \\
\hline$n=1$ & 26,3 & 25 & 25,4 & 23,8 & 25,4 & 25,4 & 20,1 & 21,5 \\
\hline \multicolumn{9}{|l|}{ Millán } \\
\hline $\mathrm{n}$ & 2 & 1 & 2 & 3 & 4 & 4 & 2 & 2 \\
\hline rango & $25,8-26,5$ & 22,8 & $24,3-25,6$ & $20,5-22,3$ & $15,4-19,1$ & $20,5-25,6$ & $20,5-22,2$ & $21,4-22,4$ \\
\hline $\bar{x} \pm$ s.d. & $26,2 \pm 0,5$ & & $24,9 \pm 1,0$ & $21,3 \pm 0,9$ & $17,2 \pm 1,8$ & $22,9 \pm 2,5$ & $21,4 \pm 1,2$ & $21,9 \pm 0,7$ \\
\hline \multicolumn{9}{|l|}{ Búho } \\
\hline $\mathrm{n}=1$ & 23,8 & & 25,2 & 22,3 & 18,5 & 25,2 & 15,7 & 17,1 \\
\hline
\end{tabular}

$\mathbf{M}^{1} \mathbf{y} \mathbf{M}^{2}$ : alguna de las piezas poco gastadas presenta un tetraprecónulo, formado por la tetrapostcrista. Difiere del $\mathrm{D}^{4}$ por la menor altura de la corona y por tener una convexidad en la base de la corona en la cara lingual. Difieren entre sí por las mayores dimensiones del $\mathrm{M}^{2}$ y por sus columnas interlobulares más grandes. Los $\mathrm{M}^{1}$ de la Cueva de Valdegoba están dentro del rango de los Cervus elaphus europeos. Sin embargo, la pieza de la Cueva del Búho es más pequeña (figura V.7.4). Por otra parte, los $\mathrm{M}^{2}$ de la Cueva de Valdegoba, Cueva 
Millán y Prado Vargas son similares a los de otros ciervos rojos pero el de Cueva Millán está próximo a los valores del gamo de Atapuerca (figura V.7.4).

$\mathbf{M}^{3}$ : difiere de los anteriores por presentar unos DTa y DTp muy desiguales. Tiene la columna interlobular más grande, el cíngulo lingual más marcado y carece de faceta de desgaste en la cara posterior. Los restos de la Cueva de Valdegoba, Cueva Millán y Prado Vargas son similares a las de otros Cervus elaphus europeos. Sin embargo, se observa que los de la Cueva de Valdegoba y Cueva Millán son más estrechos (figura V.7.4).

Húmero: se han identificado cuatro fragmentos. Tres de ellos corresponden a la diáfisis y uno a un fragmento de epífisis distal sin fusionar. Su estado no permite una descripción detallada ni la toma de medidas.

Radio (lamina V.7.1: 21) (tabla V.7.10): todos los restos son epífisis distales sin fusionar. El extremo medial y el borde correspondiente tiene una concavidad poco marcada El borde anterior de la cara articular medial es rectilínea.

Tabla V.7.10

Medidas de los radios del Cervus elaphus de Valdegoba

\begin{tabular}{lccc}
\hline & BD & BFd & DD \\
\hline Radios & \multicolumn{3}{c}{} \\
\hline $\mathrm{n}$ & 3 & 3 & 3 \\
rango & $37,3-43,9$ & $35,6-42,0$ & $26,6-41,7$ \\
$\overline{\mathrm{x}} \pm$ s.d. & $40,9 \pm 3,3$ & $39,3 \pm 3,3$ & $33,3 \pm 7,7$ \\
\hline Tibia & & & \\
\hline Valdegoba & & & \\
$\mathrm{n}$ & 4 & & 4 \\
rango & $39,3-46,9$ & & $30,2-36,9$ \\
$\overline{\mathrm{x}} \pm$ s.d. & $43,5 \pm 3,2$ & & $33,9 \pm 3,0$ \\
Cueva Millán & & & \\
$\mathrm{n}=1$ & 34,8 & & 29,6 \\
\hline
\end{tabular}

Fémur: el fragmento identificado, una diáfisis, no permite descripciones detalladas ni la toma de medidas.

Tibia (lámina V.7.1: 22) (tabla V.7.10): se han recuperado cuatro epífisis distales que no están fusionadas a las diáfisis. Tienen los surcos y las crestas articulares dirigidas sagitalmente. La fosa sinovial no es visible. El surco lateral está separado por una cresta aguda de la articulación del maléolo lateral. Las carillas que articulan con el maléolo están separadas por una cresta de grandes dimensiones.

La porción craneal del maléolo medial se prolonga distalmente y tiene un extremo puntiagudo. El extremo anterior es oblicuo, dirigido hacia el extremo lateral que es mucho más pequeño que el medial. Las facetas articulares del maléolo se encuentran fusionadas y tienen forma redondeada. El maléolo medial está muy pronunciado y es estrecho.

Metacarpo III-IV (lámina V.7.1: 24) (tabla V.7.11): este hueso tiene una pequeña abertura por encima de los cóndilos en la epífisis distal. En dicha región, se observa el inicio del surco que recorre longitudinalmente el hueso y que está muy marcado en los cérvidos. La sección del hueso, en media luna, nos indica que se trata de un metacarpo, descartando el metatarso cuya sección es subcilíndrica.

Metatarso III-IV (lámina V.7.1: 25) (tabla V.7.11): la mayoría son diáfisis. Tienen un surco vascular dorsal muy desarrollado.
Tabla V.7.11

Medidas tomadas en los metápodos

\begin{tabular}{lcccccc}
\hline & BP & DP & BD & PD & PL & PM \\
\hline Metacarpo & & & & & & \\
\hline Prado Vargas & & & & & & \\
$\mathrm{n}=1$ & 44,5 & 33,2 & & & & \\
Millán & & & & & & \\
$\mathrm{n}=1$ & & & 40 & 27,6 & 27,4 & 27,6 \\
Estebanvela & & & & & & \\
$\mathrm{n}=1$ & & & 43,1 & 31,2 & 30,5 & 31,2 \\
\hline Metatarso & & & & & & \\
\hline Valdegoba & & & & & & \\
$\mathrm{n}$ & 2 & 3 & & 1 & & \\
rango & $31,3-35,2$ & $34,0-36,6$ & & 19,2 & & \\
$\bar{x} \pm$ s.d. & $33,0 \pm 2,8$ & $35,0 \pm 1,4$ & & & & \\
\hline
\end{tabular}


Calcáneo (lámina V.7.1: 23): el resto identificado conserva únicamente la extremidad proximal y ha perdido toda la zona que articula con el astrágalo. En vista lateral, los extremos son más o menos rectos a diferencia de la mayoría de artiodáctilos en los que se estrechan proximalmente.

Astrágalo (lámina V.7.1: 26) (tabla V.7.12): las piezas analizadas presentan el surco de la tróclea proximal marcado. La tróclea distal está formada por dos cóndilos divididos por un surco poco desarrollado. La superficie plantar es oval y se articula con el calcáneo. Las protuberancias que presentan los cóndilos proximales en su cara plantar están muy marcadas. La superficie que articula con el calcáneo está separada de la tróclea proximal por una depresión mediolateral continua. El extremo distal de dicha cara tiene un surco marcado que se observa en dos de las piezas ya que en las otras está abrasionada.

TablaV.7.12

Medidas tomadas en los astrágalos

\begin{tabular}{lccccccc}
\hline & GLI & GLm & DL & DM & BP & BD & ATPL \\
\hline Valdegoba & \multicolumn{7}{c}{} \\
$\mathrm{n}$ & 3 & 2 & 2 & 1 & 3 & 4 & 2 \\
rango & $48,3-54,6$ & $43,2-47,6$ & $25,3-28,1$ & 24,2 & $31,5-32,0$ & $26,9-36,0$ & $30,7-31,4$ \\
$\overline{\mathbf{X}} \pm$ s.d. & $51,8 \pm 3,2$ & $45,43,1$ & $26,7 \pm 2,0$ & $24,2 \pm$ & $31,7 \pm 0,2$ & $30,7 \pm 3,9$ & $31,0 \pm 0,5$ \\
Búho & & & & & & & \\
$\mathrm{n}$ & 2 & 2 & 2 & 2 & 2 & 2 & 2 \\
rango & $50,7-54,9$ & $49,8-56,7$ & $28,4-30,2$ & $27,9-29,0$ & $32,7-33,4$ & $32,9-33,0$ & $28,0-32,0$ \\
$\overline{\mathbf{x}} \pm$ s.d. & $52,8 \pm 3,0$ & $53,3 \pm 4,9$ & $29,3 \pm 1,3$ & $28,4 \pm 0,8$ & $33,0 \pm 0,5$ & $33,0 \pm 0,1$ & $30,0 \pm 2,8$ \\
\hline
\end{tabular}

Falanges proximales (lámina V.7.1: 27) (tabla V.7.13): en las piezas de la Cueva de Valdegoba se han observado dos morfotipos diferentes que corresponden a las falanges anteriores y posteriores. En general, se trata de huesos cortos con la superficie interdigital aplanada para adaptarse a la falange anexa. En vista palmar, presenta, en su extremo proximal, dos prominencias para la inserción de los ligamentos interdigitales; y en su extremo distal, el borde de los cóndilos que articula con la falange media es recto o bien presenta un surco poco marcado. La superficie articular proximal es cóncava y presenta un surco sagital que separa los cóndilos que se articulan con el metápodo correspondiente. La superficie articular abaxial es más amplia y se encuentra más elevada que la superficie axial. Se diferencia bien del resto de los artiodáctilos en que ambos bordes son más o menos rectos, mientras que en otros taxones el borde abaxial muestra una concavidad muy marcada.

Falange proximal anterior: generalmente, se trata de piezas más pequeñas y robustas que las posteriores. Sin embargo, la falange recuperada presenta una robustez muy marcada (tabla V.7.13).

Falange proximal posterior: son más largas y estrechas que las anteriores. Sin embargo, la pieza analizada presenta un tamaño menor pero sus proporciones indican que se trata de una primera falange posterior (tabla V.7.13).

Falanges medias (lámina V.7.1: 28) (tabla V.7.13): son huesos más cortos que los proximales. La superficie articular proximal presenta una cresta sagital que la separa en dos cavidades glenoideas que articulan con los cóndilos de las falanges proximales. La cavidad abaxial es más amplia y alta que la axial. La cara palmar presenta dos prominencias para la inserción de los ligamentos interdigitales pero no están tan marcadas como las de las proximales. El borde proximal de los cóndilos distales está separado por un surco muy marcado en la cara palmar. En vista dorsal, los cóndilos distales se proyectan mucho proximalmente. Estos cóndilos están separados por un surco 
sagital marcado. A ambos lados tiene dos depresiones acentuadas para la inserción de los ligamentos interdigitales.

Tabla V.7.13

Medidas tomadas en las falanges proximales y medias de Cervus elaphus

\begin{tabular}{|c|c|c|c|c|c|c|c|c|c|c|}
\hline & GL & GLpe & Hmax & Hpost & DPs & DPi & BP & SD & BD & DD \\
\hline \multicolumn{11}{|c|}{ F.p. anteriores } \\
\hline \multicolumn{11}{|c|}{ Valdegoba } \\
\hline $\mathrm{n}=1$ & 54,7 & 54,2 & 56,8 & & 25,5 & 25,9 & 20,2 & 16,3 & 19,6 & 17,8 \\
\hline \multicolumn{11}{|c|}{ F.p. posteriores } \\
\hline \multicolumn{11}{|c|}{ Valdegoba } \\
\hline $\mathrm{n}=1$ & 46 & 45,1 & 47,4 & & 17,8 & 19,1 & 14 & 12,3 & 14,3 & 12,6 \\
\hline \multicolumn{11}{|c|}{ F.proximales } \\
\hline \multicolumn{11}{|l|}{ Millán } \\
\hline $\mathrm{n}$ & & & & & 6 & 6 & 6 & & 6 & 5 \\
\hline rango & & & & & $20,0-25,3$ & $21,1-26,3$ & $17,8-20,8$ & & $14,9-21,2$ & $13,5-23,8$ \\
\hline $\bar{x} \pm$ s.d. & & & & & $22,5 \pm 2,3$ & $24,1 \pm 2,3$ & $19,3 \pm 1,1$ & & $17,2 \pm 2,6$ & $17,0 \pm 4,1$ \\
\hline \multicolumn{11}{|l|}{ Búho } \\
\hline$n=1$ & & & & & & & & & 16,8 & 14,4 \\
\hline \multicolumn{11}{|c|}{ Estebanvela } \\
\hline $\mathrm{n}$ & & & & & 2 & 2 & 2 & & 4 & 4 \\
\hline rango & & & & & $20,4-20,5$ & $21,1-21,3$ & $18,0-19,2$ & & $17,9-23,1$ & $16,4-21,6$ \\
\hline $\bar{x} \pm$ s.d. & & & & & $20,4 \pm 0,0$ & $21,2 \pm 0,1$ & $18,6 \pm 0,9$ & & $19,7 \pm 2,4$ & $18,3 \pm 2,4$ \\
\hline \multicolumn{11}{|c|}{ F. medias } \\
\hline \multicolumn{11}{|c|}{ Valdegoba } \\
\hline valor & 39,8 & 38,5 & & 38,8 & 18 & 21 & 19 & 14 & 15,9 & 24,2 \\
\hline \multicolumn{11}{|l|}{ Millán } \\
\hline $\mathrm{n}$ & & & & & & & & & 5 & 3 \\
\hline rango & & & & & & & & & $16,7-18,3$ & $24,3-25,7$ \\
\hline $\bar{x} \pm$ s.d. & & & & & & & & & $17,4 \pm 0,6$ & $25,1 \pm 0,7$ \\
\hline \multicolumn{11}{|l|}{ Búho } \\
\hline $\mathrm{n}=1$ & & & & & 19,4 & 24,1 & 19,9 & & & \\
\hline \multicolumn{11}{|c|}{ Estebanvela } \\
\hline $\mathrm{n}$ & & & & & 2 & 1 & & & 2 & \\
\hline rango & & & & & $14,6-18,0$ & 18,8 & & & $18,6-19,0$ & \\
\hline $\bar{x} \pm$ s.d. & & & & & $16,3 \pm 2,4$ & & & & $18,8 \pm 0,2$ & \\
\hline
\end{tabular}

* F.p: falange proximal. F.m: falange media.

Falanges distales (lámina V.7.1: 29) (tabla V.7.14): son pequeñas, triangulares y están comprimidas lateralmente. Las caras laterales tienen varios forámenes de diferente tamaño. La inclinación de la superficie dorsal es marcada, continua y no presenta una escotadura proximal. La cara articular está dividida por una cresta con una dirección lateral. El borde abaxial es mayor y más alto que el axial. La cara ventral es triangular y presenta unos bordes cóncavos.
Tabla V.7.14

Medidas tomadas en las falanges distales de Cervus elaphus

\begin{tabular}{lccc}
\hline & DLS & LD & MBS \\
\hline Valdegoba & & & \\
$\mathrm{n}$ & 2 & 3 & 3 \\
rango & $36,3-49,0$ & $31,5-41,8$ & $7,3-11,6$ \\
$\overline{\mathbf{x}} \pm$ s.d. & $42,6 \pm 9,0$ & $35,8 \pm 5,3$ & $9,5 \pm 2,1$ \\
Millán & & & \\
$\mathrm{n}$ & 17 & 17 & 17 \\
rango & $41,3-52,2$ & $39,5-49,2$ & $11,1-15,8$ \\
$\overline{\mathbf{x}} \pm$ s.d. & $46,4 \pm 2,7$ & $43,3 \pm 2,9$ & $13,0 \pm 1,4$ \\
Búho & & & \\
$\mathrm{n}=1$ & & & 6,2 \\
\hline
\end{tabular}

Por debajo de las carillas articulares para la falange media tiene una carilla palmar para el sesamoideo distal. La apófisis extensora, así como la apófisis palmar lateral está poco marcada. No presenta línea semilunar como la de los équidos ya que el tendón del flexor está unido al tubérculo flexor de la superficie solar que está situado en el borde posterior. 


\subsubsection{Edad de muerte}

En este apartado se han empleado únicamente piezas dentales al ser más abundantes y al estar en mejor estado de conservación. A diferencia del resto de los artiodáctilos, se han utilizado los caninos, que además aportan datos sobre el sexo. En los dientes yugales se han utilizado las ecuaciones de Klein et al., (1984). Los resultados se comparan con los obtenidos en el modelo que hemos desarrollado que combina tanto el desgaste como la erupción dental, excluyendo datos sobre las edades concretas de erupción.

Cueva de Valdegoba: se han utilizado los caninos superiores y los dientes yugales.

Caninos superiores: el modelo morfológico sugiere un mayor número de ejemplares entre los 2 y 4 años, seguidos de aquellos con un rango entre los 8 - 19 y $10-14$ años (tabla V.7.15). El estudio métrico registra un mayor número de restos con edades comprendidas entre 1 y 4 años, seguido por aquellos entre los 8 y 13 años (tabla V.7.16).

Tabla V.7.15

Variables morfológicas registradas en los caninos superiores del Cervus elaphus de Valdegoba

\begin{tabular}{|c|c|c|c|c|c|}
\hline Sigla & DD & DR & CD & DLC & Edad (años) \\
\hline VB-sp-2286 & 1 & 2 & 0 & 0 & $2-4$ \\
\hline VB-sp-2279 & 1 & 1 & 0 & 0 & $2-4$ \\
\hline VB-sp-2339 & 1 & 1 & 1 & 0 & $2-4$ \\
\hline VB-sp-2268 & 1 & 1 & 0 & 0 & $2-4$ \\
\hline VB-sp-3178 & 1 & 1 & 0 & 0 & $2-4$ \\
\hline VB06.L13.Ad.65-70 & 3 & 3 & 1 & 0 & $8-19$ \\
\hline VB06.J12.Cc.70-75 & 3 & 2 & 1 & 0 & $8-19$ \\
\hline VB06.L13.Dad.85-90 & 4 & 3 & 1 & 1 & $10-14$ \\
\hline VB-sp-2283 & 4 & 3 & 1 & 1 & $10-14$ \\
\hline
\end{tabular}

* DD: desgaste dental. DR: desarrollo de la raíz. CD: calcificación de la cavidad pulpar. DLC: lóbulo disto lingual - cervical. Las referencias numéricas aparecen en el apartado de metodología.

Si comparamos ambos modelos observamos cierto desfase en las observaciones morfológicas por exceso. Estos resultados no encajan con los datos de erupción dental, que se estiman para esta pieza en torno a los 17 - 18 meses (Azorit et al., 2002).

Tabla V.7.16

Variables métricas tomadas en los caninos superiores del Cervus elaphus de Valdegoba

\begin{tabular}{|c|c|c|c|c|c|c|c|c|c|}
\hline & AC & AD & $\mathbf{A R}$ & EC & LC & LD & LR & Edad (meses) & Edad (años) \\
\hline Vb-sp-2286 & 11,5 & 0,0 & 10,9 & 7,9 & 9,2 & 0,0 & 10,6 & 12 & 1,0 \\
\hline Vb-sp-2339 & 11,3 & 0,0 & 10,8 & 7,8 & 9,3 & 0,0 & 10,4 & 14 & 1,1 \\
\hline Vb-sp-2279 & 10,8 & 0,0 & 10,4 & 6,9 & 8,6 & 0,0 & 11,3 & 22 & 1,8 \\
\hline Vb-sp-2268 & 9,3 & 0,0 & 8,0 & 6,1 & 7,5 & 0,0 & 11,7 & 38 & 3,2 \\
\hline Vb-sp-3178 & 8,3 & 0,0 & 6,8 & 4,8 & 7,1 & 0,0 & 11,4 & 51 & 4,2 \\
\hline Vb-sp-2283 & 10,5 & 7,8 & 10,5 & 7,5 & 6,9 & 7,6 & 10,1 & 101 & 8,4 \\
\hline Vb.06.L13.Ad.65-70 & 7,6 & 4,4 & 6,6 & 5,3 & 6,5 & 5,0 & 9,9 & 108 & 9,0 \\
\hline Vb.06.L13.Dad.85-90 & 8,5 & 5,8 & 8,7 & 7,2 & 7,2 & 10,9 & 12,0 & 135 & 11,2 \\
\hline Vb.06.J12.Cc.70-75 & 8,1 & 4,8 & 8,4 & 5,3 & 5,0 & 7,8 & 12,1 & 150 & 12,5 \\
\hline
\end{tabular}

Dientes yugales: en el modelo de desgaste y erupción, la dentición inferior analizada, tanto decidual como permanente, presenta un mayor número de efectivos con un degaste mínimo. Sólo una pequeña parte de los restos muestran una erosión superior al $50 \%$ en los $\mathrm{D}_{4}$. En el caso de los $\mathrm{M}_{1}$ se observa un único resto con un desgaste moderado y dos con una erosión marcada (figura V.7.6). La dentición superior ha proporcionado un mayor número de efectivos en buen estado por lo que se han podido analizar piezas pertenecientes a los tres molares superiores. La mayor parte de las piezas tienen unos 
desgastes comprendidos entre el 0 y el $50 \%$ en general, y en particular entre el 0 y $25 \%$, salvo el $\mathrm{M}^{3}$ que presenta ambos rangos con el mismo número de restos. Tanto $\mathrm{M}^{1}$ como $\mathrm{M}^{2}$ muestran una pieza con un desgaste marcado (figura V.7.5).
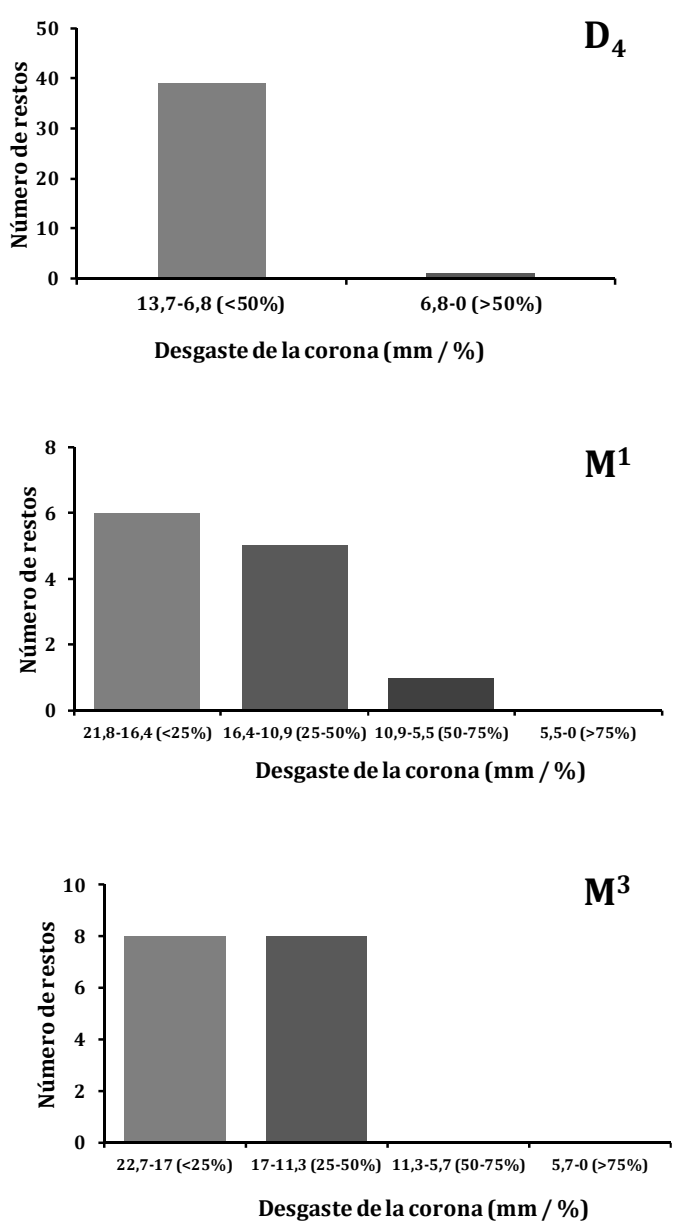
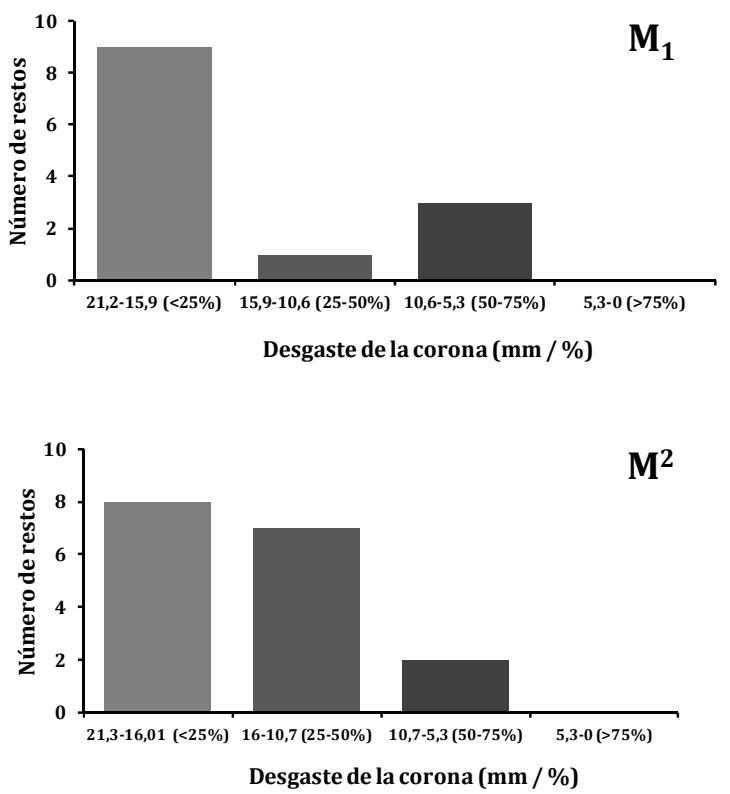

Figura V.7.5. Desgaste en los dientes yugales del Cervus elaphus de la Cueva de Valdegoba. Datos obtenidos con el modelo de desgaste y erupción.

Los resultados obtenidos a partir de las ecuaciones de Klein sugieren que los individuos infantiles, aquellos que no llegan a los 6 meses, son los más abundantes, seguidos de los juveniles, entre los 6 y 43 meses; y por último de los adultos, por encima de los 43 meses (tabla V.7.17).

Tabla V.7.17

Alturas y edades dentales estimadas en el Cervus elaphus de la Cueva de Valdegoba (1ํo parte)

\begin{tabular}{|c|c|c|c|c|c|c|c|c|c|c|c|}
\hline \multicolumn{4}{|c|}{$\mathbf{D}_{4}$} & \multicolumn{4}{|c|}{$\mathbf{M}^{1}$} & \multicolumn{4}{|c|}{$\mathbf{M}^{2}$} \\
\hline & & $\mathrm{CH}$ & Edad & & & CH & Edad & & & CH & Edad \\
\hline Vb-sp-2871 & d & 12,4 & 0 & Vb-sp-3160 & $\mathrm{i}$ & 21,8 & 6 & Vb-sp-3165 & d & 21,3 & 17 \\
\hline Vb-sp-2918 C & d & 12,0 & 0 & Vb-sp-3099 & d & 20,1 & 7 & Vb-sp-3159 & $\mathrm{i}$ & 21,3 & 17 \\
\hline Vb-sp-2934 & d & 11,8 & 0 & Vb-sp-3164 & d & 19,8 & 8 & Vb-sp-3142 & d & 20,8 & 17 \\
\hline Vb-sp-2920 & $\mathrm{d}$ & 11,5 & 0 & Vb-sp-3118 & d & 17,3 & 14 & Vb-sp-3097 & i & 20,4 & 17 \\
\hline Vb-sp-2888 & $\mathrm{i}$ & 11,6 & 0 & Vb-sp-3113 & $\mathrm{i}$ & 17,2 & 15 & Vb-sp-3121 & d & 19,7 & 18 \\
\hline Vb-sp-2917 B & i & 11,7 & 0 & Vb-sp-3149 & d & 15,8 & 20 & Vb-sp-3132 & d & 19,1 & 19 \\
\hline Vb-sp-2916 A & i & 11,5 & 0 & Vb-sp-2960 A & d & 14,9 & 25 & Vb-sp-2960 B & d & 16,9 & 24 \\
\hline Vb-sp-2924 B & d & 11,4 & 0 & Vb-sp-3162 & d & 14,6 & 26 & Vb-sp-3175 & d & 16,5 & 25 \\
\hline Vb-sp-2919 & i & 11,4 & 0 & Vb-sp-3084 & $\mathrm{i}$ & 12,8 & 38 & Vb-sp-3109 & d & 15,4 & 30 \\
\hline Vb-sp-2942 & $\mathrm{i}$ & 11,0 & 0 & Vb-sp-3158 & d & 12,7 & 38 & Vb-sp-3170 & d & 15,4 & 30 \\
\hline
\end{tabular}

* Las edades de muerte se han estimado a partir de las ecuaciones de Klein et al., (1984). CH: en milímetros. Edad: en meses. 
Tabla V.7.17

Alturas y edades dentales estimadas en el Cervus elaphus de la Cueva de Valdegoba $\left(2^{\circ}\right.$ parte $)$

\begin{tabular}{|c|c|c|c|c|c|c|c|c|c|c|c|}
\hline \multicolumn{4}{|c|}{$\mathbf{D}_{4}$} & \multicolumn{4}{|c|}{$\mathbf{M}^{1}$} & \multicolumn{4}{|c|}{$\mathbf{M}^{2}$} \\
\hline & & CH & Edad & & & CH & Edad & & & CH & Edad \\
\hline Vb-sp-2901 & $\mathrm{i}$ & 11,1 & 0 & Vb-sp-3139 & $\mathrm{i}$ & 9,3 & 68 & Vb-sp-3123 & $\mathrm{i}$ & 15,2 & 31 \\
\hline Vb-sp-2998 & $\mathrm{i}$ & 11,0 & 0 & & & & & Vb-sp-3157 & $\mathrm{i}$ & 14,8 & 33 \\
\hline Vb-sp-3012 & d & 10,8 & 0 & & & & & Vb-sp-3147 & d & 14,4 & 35 \\
\hline Vb-sp-2892 & d & 10,7 & 0 & & & & & Vb-sp-3112 & $\mathrm{i}$ & 13,8 & 38 \\
\hline Vb-sp-2983 & d & 10,6 & 1 & & & & & Vb-sp-3122 & $\mathrm{i}$ & 12,3 & 48 \\
\hline Vb-sp-2941 & d & 10,5 & 1 & & & & & Vb-sp-3137 & $\mathrm{i}$ & 9,4 & 71 \\
\hline Vb-sp-2929 & $\mathrm{i}$ & 10,5 & 1 & & & & & Vb-sp-3163 & d & 9,4 & 72 \\
\hline Vb-sp-2991 & d & 10,5 & 1 & & & & & & & & \\
\hline Vb-sp-2664 & d & 10,4 & 1 & & & & & & & & \\
\hline Vb-sp-2885 & $\mathrm{i}$ & 10,2 & 1 & & & & & & & & \\
\hline Vb-sp-2925 & d & 10,1 & 1 & & & & & & & & \\
\hline Vb-sp-2748 & d & 10,1 & 1 & & & & & & & & \\
\hline Vb-sp-2903 A & d & 10,0 & 1 & & & & & & & & \\
\hline Vb-sp-2904 & d & 9,4 & 2 & & & & & & & & \\
\hline Vb-sp-2866 & d & 9,3 & 2 & & & & & & & & \\
\hline Vb-sp-2368 & d & 9,2 & 2 & & & & & & & & \\
\hline Vb-sp-2932 & $\mathrm{i}$ & 8,7 & 2 & & & & & & & & \\
\hline Vb-sp-2923 & d & 8,7 & 2 & & & & & & & & \\
\hline Vb-sp-3009 & $\mathrm{i}$ & 8,4 & 3 & & & & & & & & \\
\hline Vb-sp-2910 & d & 8,3 & 3 & & & & & & & & \\
\hline Vb-sp-2863 & d & 8,2 & 3 & & & & & & & & \\
\hline Vb-sp-2886 & $\mathrm{i}$ & 7,8 & 4 & & & & & & & & \\
\hline Vb-sp-2889 & $\mathrm{i}$ & 7,6 & 4 & & & & & & & & \\
\hline Vb-sp-2680 & $\mathrm{i}$ & 7,6 & 4 & & & & & & & & \\
\hline Vb-sp-3005 & $\mathrm{i}$ & 7,5 & 4 & & & & & & & & \\
\hline Vb-sp-2658 & $\mathrm{i}$ & 7,0 & 5 & & & & & & & & \\
\hline Vb-sp-2876 & $\mathrm{i}$ & 6,3 & 6 & & & & & & & & \\
\hline
\end{tabular}

* Las edades de muerte se han estimado a partir de las ecuaciones de Klein et al., (1984). CH: en milímetros. Edad: en meses.

Si comparamos ambos modelos, los resultados presentan una tendencia similar. Observamos que el mayor número de piezas presentan una edad entre los 0 y 6 meses, seguidas de aquellas incluidas en el rango $6-43$ y de aquellas con más de 43 meses. Sin embargo, existe cierto desfase de piezas del segundo rango al tercero (figura V.7.7). Si tenemos en cuenta estos datos, 19 ejemplares serían infantiles (a partir del $\mathrm{D}_{4}$ derecho), 9 serían juveniles (a partir del $\mathrm{M}^{2}$ derecho) y 1 sería adulto (a partir del $\mathrm{M}^{2}$ derecho) (tabla V.7.17).
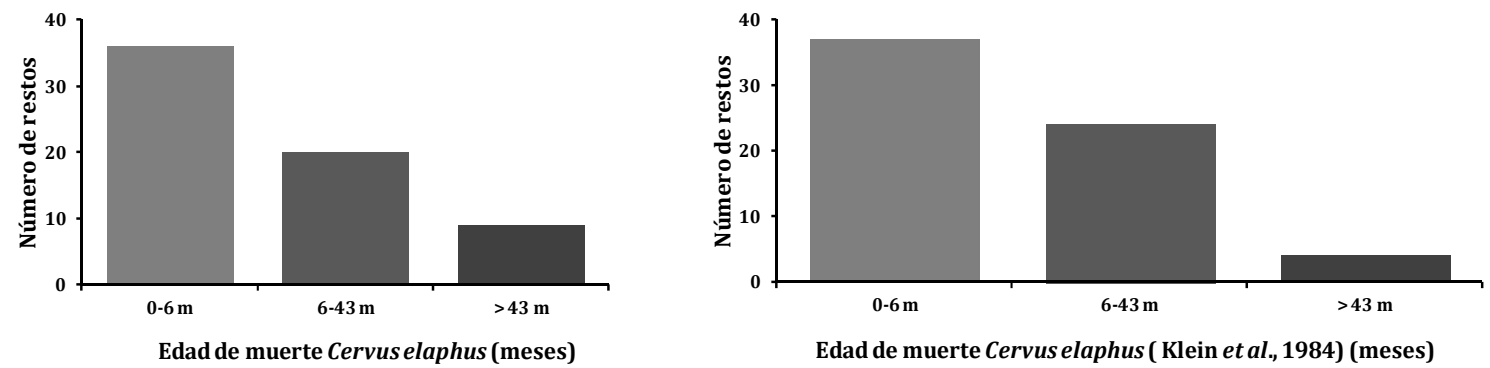

Figura V.7.6. Comparativa entre los dos modelos de estimación de la edad de muerte en los Cervus elaphus de la Cueva de Valdegoba.

Prado Vargas: se han empleado los caninos superiores y los dientes yugales. 
Caninos superiores: el análisis morfológico de la pieza sugiere una edad entre los 3 y 6 años (tabla V.1.19). No presenta un desgaste muy marcado lo que permite ver aún el lóbulo disto-lingual. Por otra parte el estudio métrico ha permitido registrar una edad de 31,8 meses, 2,6 años. Si comparamos ambos modelos, el métrico y el morfológico, vemos que existe un desfase por defecto en los resultados métricos con respecto a las observaciones morfológicas (tablas V.7.18 y 19).

Tabla V.7.18

Variables morfológicas tomadas en los caninos superiores del Cervus elaphus de Prado Vargas

\begin{tabular}{lllllll}
\hline Sigla & DD & DR & CD & DLC & & Edad (años) \\
\cline { 1 - 1 } \cline { 5 - 6 } & & & & 0 & 0 &
\end{tabular}

* DD: desgaste dental. DR: desarrollo de la raíz. CD: calcificación de la cavidad pulpar. DLC: lóbulo disto lingual - cervical. Las referencias numéricas aparecen en el apartado de metodología.

Tabla V.7.19

Variables métricas tomadas en los caninos superiores del Cervus elaphus de Prado Vargas

\begin{tabular}{|c|c|c|c|c|c|c|c|c|c|}
\hline & AC & AD & $\mathbf{A R}$ & EC & LC & LD & LR & Edad (meses) & Edad (años) \\
\hline PV.06.45.H31.208 & 10,6 & 4,8 & 7,8 & 6,3 & 8,2 & 7,0 & 14,9 & 31,8 & 2,6 \\
\hline
\end{tabular}

Dientes yugales: en el modelo de desgaste y reemplazamiento, los molares han proporcionado unos desgastes inferiores al $50 \%$. En concreto, el $\mathrm{M}_{1}$ muestra un desgaste moderado, entre el 25 y el $50 \%$; y los superiores, el $\mathrm{M}^{2}$ y el $\mathrm{M}^{3}$, unas erosiones poco o nada marcadas, inferiores al $25 \%$ (figura V.7.8).

Tabla V.7.20

Alturas y edades dentales estimadas en el Cervus elaphus de Prado Vargas

\begin{tabular}{|c|c|c|c|c|c|c|c|c|}
\hline & \multicolumn{2}{|r|}{$\mathbf{M}_{1}$} & \multicolumn{3}{|c|}{$\mathbf{M}^{2}$} & \multicolumn{3}{|c|}{$\mathbf{M}^{3}$} \\
\hline & $\mathrm{CH}(\mathrm{mm})$ & Edad (meses) & & $\mathbf{C H}$ & Edad (meses) & & CH (mm) & Edad (meses) \\
\hline $\begin{array}{l}\text { PV.06.Z78. } \\
\text { H32.73 }\end{array}$ & 13,5 & 30,5 & $\begin{array}{l}\text { PV.06.Z83. } \\
\text { H32.117 }\end{array}$ & 18,9 & 18,2 & $\begin{array}{l}\text { PV.06.Z80. } \\
\text { H32.35 }\end{array}$ & 21,4 & 43,4 \\
\hline
\end{tabular}

* Las edades de muerte se han estimado a partir de las ecuaciones de Klein et al., (1984).

Las ecuaciones de Klein han aportado unas edades muy diferentes en las tres piezas analizadas. Por un lado, el $\mathrm{M}_{1}$ ha proporcionado una edad de 30 meses, mientras que los $\mathrm{M}^{2}$ y M$^{3}$ unas fechas de 18 y 43 meses respectivamente (tabla V.7.20).

Cuando comparamos ambos modelos observamos que los resultados coinciden. Predominan los restos juveniles (6 - 43 meses), seguidos por los adultos, ( $>43$ meses) (figura V.7.7). Las edades de erupción de los premolares se encuentran entre los 27 y 30 meses (Azorit et al., 2002) por lo que al menos tendrían esta edad. La erupción dental no aporta más información. Indicamos que, al menos uno de los ejemplares, sería un juvenil.

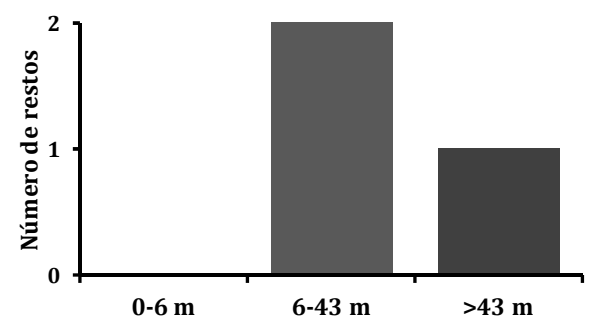

Edad de muerte Cervus elaphus (meses)

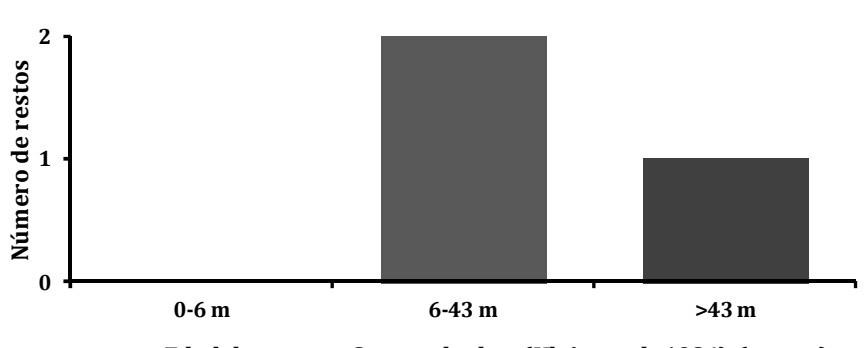

Edad de muerte Cervus elaphus (Klein et al., 1984) (meses)

Figura V.7.7. Comparativa entre los dos modelos de estimación de la edad de muerte en los Cervus elaphus de Prado Vargas. 
Cueva Millán: el análisis de este material se ha realizado por niveles. La mayor parte se encuentran en el primero, el nivel 1A, y disminuyen hacia el 1C.

Nivel 1A: se han analizado los caninos superiores y los dientes yugales.

Caninos superiores: el análisis morfológico ha sugerido unas edades dentales de entre los 3 y los 6 años (tabla V.7.21). Por otro lado, el estudio métrico confirma uno de estos resultados mientras que el otro presenta un desfase, siendo la edad estimada de $2-4$ años (tabla V.7.22). Se observa, de nuevo, un desfase por exceso en el modelo morfológico.

Tabla V.7.21

Variables morfológicas registradas en los caninos superiores del Cervus elaphus de Cueva Millán

\begin{tabular}{|c|c|c|c|c|c|}
\hline Sigla & DD & DR & CD & DLC & Edad (años) \\
\hline CM86.1A.8J & 1 & 2 & 0 & 0 & $3-6$ \\
\hline CM86.1A.8J & 1 & 2 & 0 & 0 & $3-6$ \\
\hline
\end{tabular}

* DD: desgaste dental. DR: desarrollo de la raíz. CD: calcificación de la cavidad pulpar. DLC: lóbulo disto lingual - cervical. Las referencias numéricas aparecen en el apartado de metodología.

Tabla V.7.22

Variables métricas tomadas en los caninos superiores del Cervus elaphus de Cueva Millán

\begin{tabular}{|c|c|c|c|c|c|c|c|c|c|}
\hline & AC & AD & AR & EC & LC & LD & LR & Edad (meses) & Edad (años) \\
\hline CM86.1A.8J & 11,0 & 4,2 & 6,8 & 6,3 & 9,2 & 7,0 & 10,0 & $36-72$ & $3-6$ \\
\hline CM86.1A.8J & 11,2 & 4,4 & 6,6 & 6,3 & 9,4 & 6,9 & 10,4 & $36-72$ & $2-4$ \\
\hline
\end{tabular}

Dientes yugales: el análisis de las fases de desgaste no ha proporcionado erosiones por encima del $75 \%$ de la altura de la corona (figura V.7.9).

Tabla V.7.23

Alturas y edades dentales estimadas en el Cervus elaphus de Cueva Millán

\begin{tabular}{|c|c|c|c|c|c|c|c|c|c|c|}
\hline & & \multicolumn{2}{|l|}{$M_{1}$} & \multicolumn{3}{|c|}{$\mathbf{M}^{1}$} & & & \multicolumn{2}{|l|}{$\mathbf{M}^{2}$} \\
\hline & & $\mathbf{C H}$ & Edad & & $\mathbf{C H}$ & Edad & & & $\overline{\mathrm{CH}}$ & Edad \\
\hline CM.86.1A.9F & $\mathrm{i}$ & 14,3 & 25,6 & CM.86.1C.9F d & 12,4 & 40,3 & CM.86.1A.9D & $\mathrm{d}$ & 6,3 & 103,1 \\
\hline CM.86.1A.9F & i & 20,2 & 6,3 & & & & CM.86.1A.6I & $\mathrm{i}$ & 22,3 & 40,3 \\
\hline CM.86.1B.6D & $\mathrm{i}$ & 14,7 & 23,6 & & & & & & & \\
\hline
\end{tabular}

* Las alturas han sido estimadas en milímetros y la edad en meses. Estos datos han sido obtenidos aplicando las ecuaciones de Klein et al., (1984). CH: en milímetros. Edad: en meses.

Si comparamos los resultados de ambos modelos vemos que coinciden en todos los rangos de edad (figura V.7.8). Al menos dos de los ejemplares serían juveniles, a partir del $\mathrm{M}_{1}$ izquierdo.
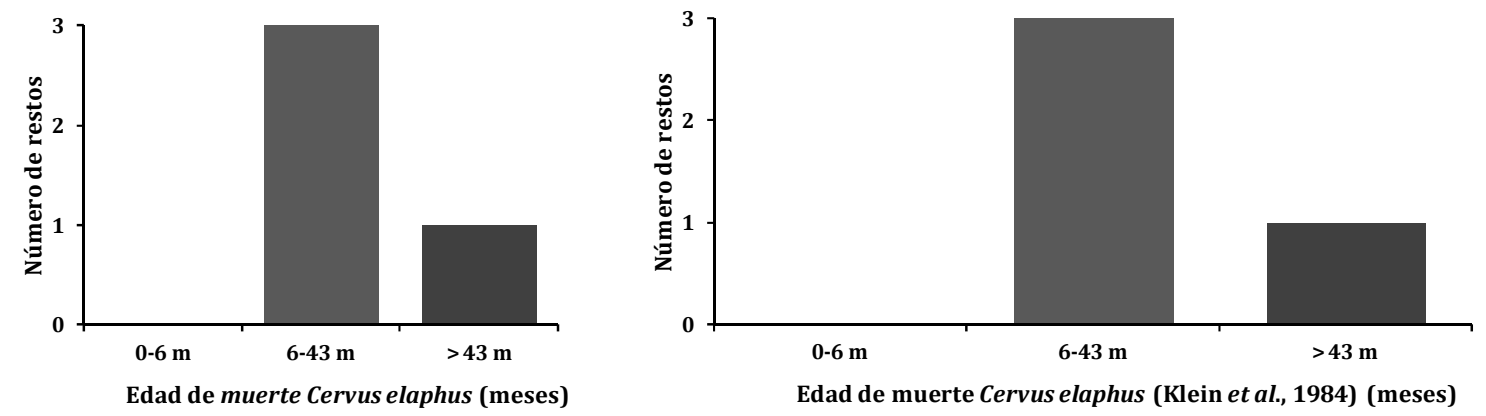

Figura V.7.8. Comparativa entre los dos modelos de estimación de la edad de muerte en los Cervus elaphus del nivel 1 A de Cueva Millán. 
Nivel 1B: sólo se ha podido analizar un $\mathrm{M}_{1}$. Su corona presenta un desgaste moderado (figura V.7.10) y su edad se encontraría en torno a los 23,6 meses, un individuo joven. Otra de las piezas, un $\mathrm{M}^{3}$ sugiere que nos encontramos con un ejemplar de más de 44 meses, su edad de erupción. Por lo tanto, tendríamos al menos un ejemplar juvenil y otro adulto.

Nivel 1C: el $\mathrm{M}^{1}$ estudiado tiene un desgaste moderado y una edad de 40,3 meses, un adulto (tabla V.7.24) (figura V.7.10).

\section{Nivel 1A}
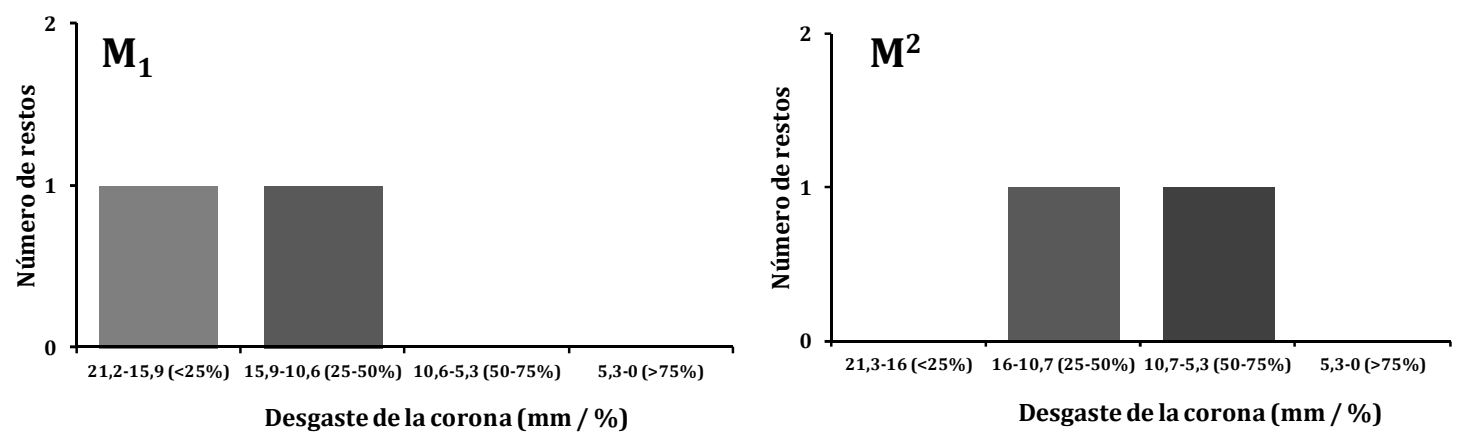

\section{Nivel 1B y 1C}
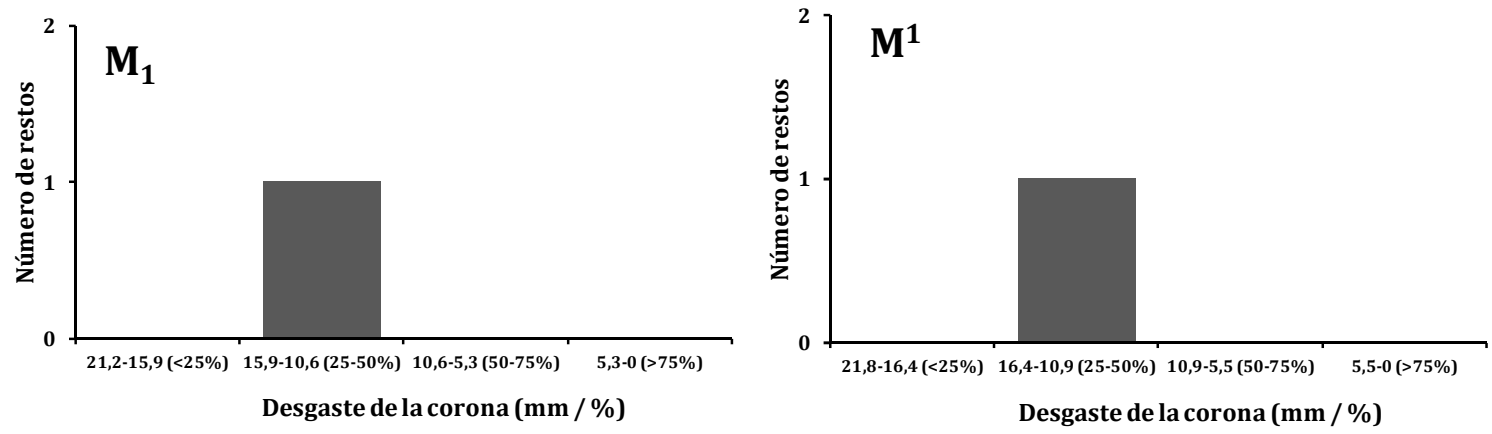

Figura V.7.9. Desgaste en los dientes yugales del Cervus elaphus de Cueva Millán. Datos obtenidos con el modelo de desgaste y erupción.

Cueva del Búho: se han incluido en este análisis los incisivos y los premolares ya que los molares son escasos. Por esta razón, combinamos el desgaste y la erupción dental. No empleamos el $\mathrm{M}^{3}$ debido a la gran variabilidad en las edades de erupción, ni el $\mathrm{M}_{3}$ ya que no se ha podido medir la altura de la corona sin desgaste.

Dientes yugales: el número de molares recuperado no permite realizar un análisis de las fases de desgaste muy exhaustivo. Los dos $\mathrm{M}^{1}$ presentan unos desgastes marcados, entre el 50 y el $75 \%$ de la altura de la corona sin erosión (tabla V.7.15). Uno de los $\mathrm{M}^{2}$ tiene un desgaste moderado y el otro inferior al $25 \%$. (figura V.7.10).

Tabla V.7.24

Alturas y edades dentales estimadas en el Cervus elaphus de la Cueva del Búho

\begin{tabular}{|c|c|c|c|c|c|c|c|}
\hline & & & $\mathbf{M}^{1}$ & & & $\mathbf{M}^{2}$ & \\
\hline & & CH (mm) & Edad (meses) & & & CH (mm) & Edad (meses) \\
\hline $6595 \mathrm{Q}$ & $\mathrm{d}$ & 10,6 & 55,4 & 6596 Q & i & 20,5 & 16,3 \\
\hline $6539 \mathrm{Q}$ & d & 6,2 & 101,9 & 6359 Q & $\mathrm{i}$ & 11,8 & 50,8 \\
\hline
\end{tabular}

* Las edades de muerte se han estimado a partir de las ecuaciones de Klein et al., (1984). 
Cuando comparamos ambos modelos vemos que los resultados coinciden. Los más abundantes serían aquellos que presentan más de 43 meses, los adultos, seguidos de los juveniles (figura V.7.10).

Las edades a partir de las ecuaciones de Klein indican que al menos un ejemplar sería juvenil y el otro un adulto (tabla V.7.24). Uno más sería infantil, sugerido a partir del $\mathrm{dI}_{2}$.
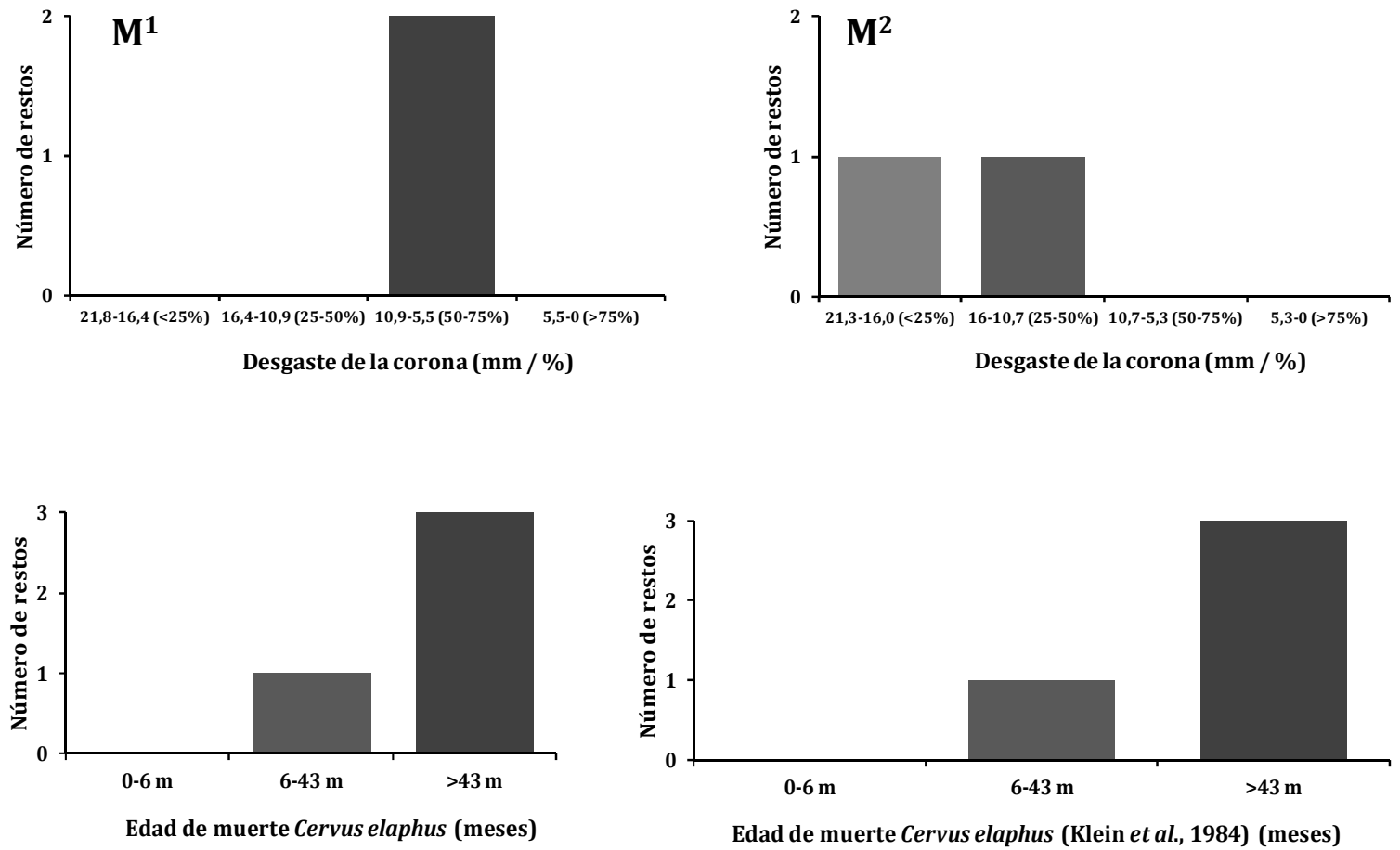

Figura V.7.10. Desgaste en los dientes yugales del Cervus elaphus de la Cueva del Búho. Modelo de desgaste y erupción. Comparativa entre los dos modelos de estimación.

Abrigo Vergara: las piezas están en mal estado y no han podido asignarse a un diente en concreto. Sólo se ha podido llegar al nivel molar inferior y premolar superior. Por lo tanto el modelo empleado se basa en la edad de erupción, que en los molares inferiores abarcan desde los 6 a los 44 meses. El ejemplar tendría al menos 6 meses.

La Peña de Estebanvela: este análisis se basa un $\mathrm{P}_{4}$ del nivel I. Esta pieza emergen entre los 27 y 30 meses por lo que este individuo tendría al menos 30 meses. No podemos especificar si se trataría de un ejemplar juvenil o de un adulto.

\subsubsection{Estacionalidad}

Estos análisis solo han podido realizarse a partir de las piezas que han aportado una edad de muerte en meses, es decir, los molares inferiores y superiores. La diferencia de resultados entre el análisis morfológico y métrico de los caninos superiores hace que no les tengamos en cuenta en este caso. El patrón social y el comportamiento de esta especie se ha tomado de Hayssen et al., (1993) y Stiner (1994), escogiendo el mes de junio como el mes de referencia para los partos.

Cueva de Valdegoba: los resultados revelan una estacionalidad muy marcada para esta especie. Las muertes ocurren principalmente en verano y son mínimas en primavera (figura V.7.11). Si hacemos un análisis por rangos de edad vemos que existe una selección 
muy marcada de ejemplares infantiles, coincidente con el periodo de partos y de lactancia, primavera y verano (Landete-Castillejos et al., 2000; Carranza et al, 2011; Gomendio et al., 2006). En otoño e invierno, predominan los juveniles. Esta estación coincide con la época de celo y con los periodos en los que los machos se separan del grupo y las hembras forman grupos con crías (Carranza et al., 2011). La acumulación de los adultos se centra en invierno y primavera, no habiéndose registrado en verano e invierno. La caza de estos ejemplares es más complicada ya que se trata de individuos más experimentados que los infantiles y los juveniles.
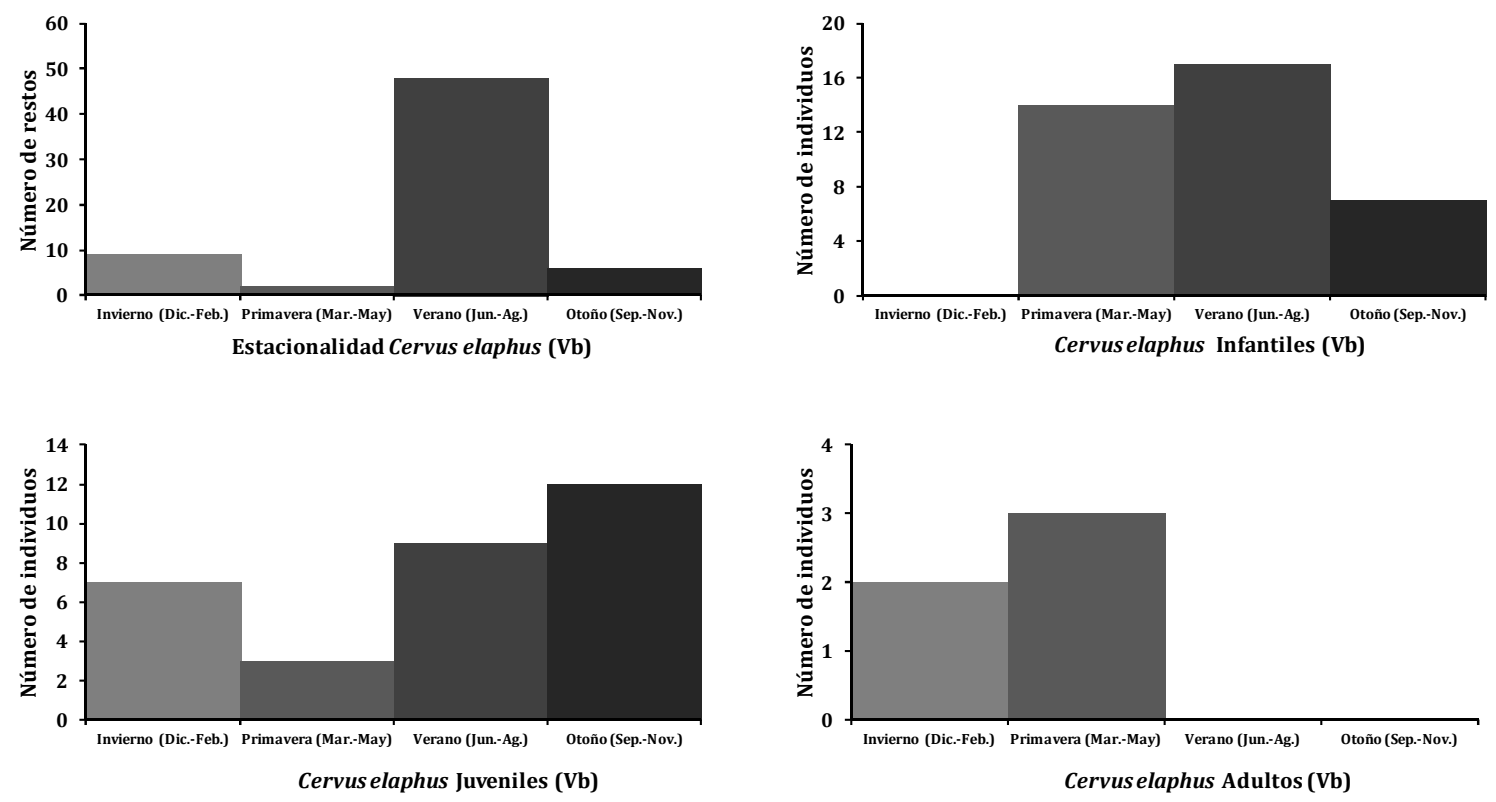

Figura V.7.11. Estacionalidad general y por rangos de edad del Cervus elaphus de la Cueva de Valdegoba.

Prado Vargas: se ha observado una fuerte estacionalidad. Todos los ejemplares fueron acumulados en invierno.

Cueva Millán: se han analizado los tres niveles aunque hay que tener cautela a la hora de interpretar los resultados ya que el número de efectivos es muy reducido. En el nivel 1A no hay una tendencia clara. Sin embargo, podemos indicar que durante la primavera no hay acumulación y que es mínima en verano y otoño. En el nivel 1B el ejemplar se depositó en verano y en el $1 \mathrm{C}$ en otoño. Llama la atención la ausencia de ejemplares en primavera, ya que mayo junto con junio, es el mes en el que se producen los partos.

Cueva del Búho: en este caso el estudio es parcial ya que no se han analizado los restos de las últimas excavaciones. Se observa una fuerte estacionalidad ya que los ejemplares fueron acumulados en otoño e invierno. Llama la atención que no se hayan registrado datos ni en primavera ni en verano, periodo que coincide con los partos y la lactancia.

\subsubsection{Bimodalidad y dimorfismo sexual}

En este apartado se analizan los caninos superiores. Se estudia la morfología y el tamaño, siguiendo el modelo de d'Errico y Vanhaeren (2002).

Cueva de Valdegoba: se ha observado una gran variabilidad morfológica entre los restos recuperados (figura V.7.12). Los caninos de los machos presentan una forma globular, que 
tiende a hacerse triangular con la edad, y unas raíces cuadradas y trapezoidales. Por otra parte, las hembras tienen caninos rectangulares con un abultamiento en la base de la corona, sus raíces son rectangulares o tienen forma de "V". Entre los restos recuperados, cinco se ajustan a la descripción de los machos y cuatro a las de las hembras (tabla V.7.25).

1.

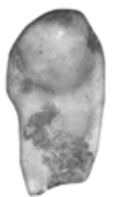

2.

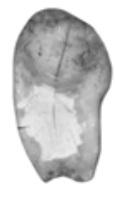

3.

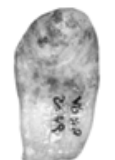

4.

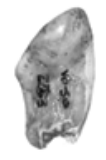

5.

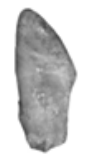

6.

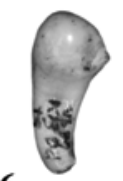

7.

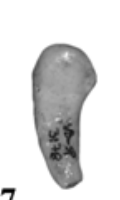

8.

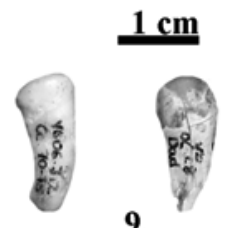

9.

Figura V.7.12. Caninos superiores de Cervus elaphus de la Cueva de Valdegoba. 1) Vb-sp-2339. 2) Vb-sp-2286. 3) Vb-sp-2279. 4) Vb-sp-2283. 5) Vb.06.L13.Dad.85-90. 6) Vb-sp-2268. 7) Vb-sp-3178. 8) Vb.06.J12.Cc.70-75. 9) Vb.06.L13.Ad.65-70.

Métricamente, los caninos de los machos difieren de los de las hembras en que la anchura de la raíz es casi siempre más del doble del espesor, mientras que en las hembras es menor (d'Errico y Vanhaeren, 2002). Esto no se cumple en todos los casos como el Vb06.L13.Ad.65-70 pero, si tenemos en cuenta los criterios morfológicos es una hembra.

Tabla V.7.25

Caracteres morfológicos y métricos de los caninos superiores del Cervus elaphus

\begin{tabular}{|c|c|c|c|c|c|c|c|c|c|}
\hline \multirow{2}{*}{ Sigla } & & \multicolumn{2}{|c|}{ Corona } & \multicolumn{2}{|c|}{ Protuberancia } & \multicolumn{4}{|c|}{ Raíces } \\
\hline & & Gb & Ap & Pr & $\mathbf{A u}$ & $\mathrm{Cd} / \mathrm{Tr}$ & Rc/"V" & AR & ER \\
\hline Vb-sp-2286 & $\mathrm{i}$ & $\mathrm{X}$ & & & $\mathrm{X}$ & $\mathrm{X}$ & & 10,9 & 3,5 \\
\hline Vb-sp-2283 & $\mathrm{d}$ & $\mathrm{X}$ & & & $\mathrm{X}$ & $\mathrm{X}$ & & 10,5 & 4,4 \\
\hline Vb-sp-2279 & $\mathrm{d}$ & $\mathrm{X}$ & & & $\mathrm{X}$ & $\mathrm{X}$ & & 10,4 & 3,7 \\
\hline Vb-sp-2339 & d & $\mathrm{X}$ & & & $\mathrm{X}$ & $\mathrm{X}$ & & 10,8 & 3,9 \\
\hline Vb06.L13.Ad.65-70 & $\mathrm{i}$ & $\mathrm{X}$ & & & $\mathrm{X}$ & $\mathrm{X}$ & & 6,6 & 4,1 \\
\hline Vb06.J12.Cc.70-75 & $\mathrm{i}$ & & $\mathrm{X}$ & $\mathrm{X}$ & & & $\mathrm{X}$ & 8,4 & 4,3 \\
\hline Vb06.L13.Dad.85-90 & d & & $\mathrm{X}$ & $\mathrm{X}$ & & & $\mathrm{X}$ & 4,7 & 3,9 \\
\hline Vb-sp-2268 & $\mathrm{i}$ & & $\mathrm{X}$ & $\mathrm{X}$ & & & $\mathrm{X}$ & 8,0 & 4,0 \\
\hline Vb-sp-3178 & $\mathrm{i}$ & & $\mathrm{X}$ & $\mathrm{X}$ & & & $\mathrm{X}$ & 6,8 & 3,9 \\
\hline PV06.45.H31.208 & $\mathrm{i}$ & & $\mathrm{X}$ & $\mathrm{X}$ & & & $\mathrm{X}$ & 7,8 & 4,0 \\
\hline CM86.1A.8J & d & & $\mathrm{X}$ & $\mathrm{X}$ & & & $\mathrm{X}$ & 6,8 & 3,2 \\
\hline CM86.1A.8J & $\mathrm{i}$ & & $\mathrm{X}$ & $\mathrm{X}$ & & & $\mathrm{X}$ & 6,6 & 3,3 \\
\hline
\end{tabular}

* Gb: globulosa. Ap: apuntada. Pr: presente. Au: ausente. Cd/Tr: cuadrada/trapezoidal. Rc/V: rectangular/forma de "V". AR: anchura raíz. ER: espesor raíz.

Prado Vargas: los resultados de ambos modelos es similar (tabla V.7.25). El ejemplar sería una hembra (figura V.7.13).

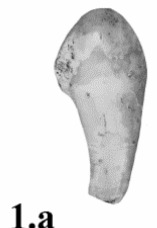

1.b

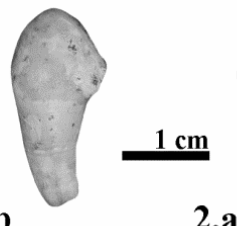

2.a

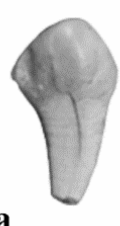

2.b

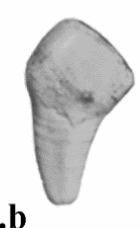

3.a

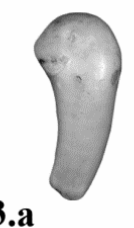

3.b

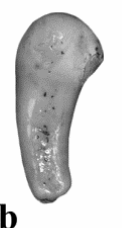

Figura V.7.13. Caninos superiores de Cervus elaphus de: 1 y 2) Cueva Millán y 3) Prado Vargas. 1 y 2) CM86.1A.8J. 3) PV06.45.H31.208.

Cueva Millán: las características morfológicas son similares en las dos piezas. Ambas tienen una corona apuntada, una protuberancia en la base de la corona marcada y unas raíces rectangulares. Morfológicamente, corresponden a una hembra (figura V.7.13), pero 
métricamente podrían corresponder a un macho, aunque los valores se encuentran en el límite que d'Errico y Vanhaeren (2002) establecen como diferencia entre machos y hembras. Los criterios morfológicos los consideramos más concluyentes por lo que indicamos que este ejemplar correspondería a una hembra.

\subsubsection{Número Mínimo de Individuos}

El número mínimo de individuos ha sido estimado a partir de los dientes. En primer lugar se han empleado los últimos deciduales en caer, los $\mathrm{D}_{4}$, y los últimos permanentes en emerger, los $\mathrm{M}_{3}$ (Azorit et al., 2002). Los primeros nos sirven para conocer el número mínimo de individuos inmaduros, aquellos en los que aún se conserva dentición decidual; y los segundos, los maduros, aquellos con la dentición permanente completamente erupcionada. En los casos en los que no se han recuperado estas piezas, los ejemplares inmaduros y maduros que se indican en la tabla V.7.26 se han estimado a partir de la edad de muerte. En los niveles II, III y IV de la Peña de Estebanvela únicamente se ha indicado el número mínimo de ejemplares ya que se ha utilizado el esqueleto postcraneal.

Tabla V.7.26

Número mínimo de individuos de Cervus elaphus

\begin{tabular}{|c|c|c|c|c|c|c|c|}
\hline & & Inmaduros & Maduros & Total & Infantiles & Juveniles & Adultos \\
\hline \multicolumn{2}{|l|}{ Cueva de Valdegoba } & 27 & 13 & 40 & 19 & 9 & 1 \\
\hline \multicolumn{2}{|l|}{ Prado Vargas } & & & 2 & & 1 & \\
\hline \multirow[t]{3}{*}{ Cueva Millán } & $1 \mathrm{~A}$ & 1 & 2 & 3 & & 1 & \\
\hline & 1B & 1 & 1 & 2 & & 1 & 1 \\
\hline & 1C & 1 & 1 & 2 & & & 1 \\
\hline \multicolumn{2}{|l|}{ Cueva del Búho } & 1 & 1 & 3 & & 1 & 1 \\
\hline \multicolumn{2}{|l|}{ Vergara } & & & 1 & & & \\
\hline \multirow{4}{*}{$\begin{array}{l}\text { La Peña } \\
\text { Estebanvela }\end{array}$} & I & & & 1 & & & \\
\hline & II & & & 1 & & & \\
\hline & III & & & 1 & & & \\
\hline & IV & & & 1 & & & \\
\hline
\end{tabular}

En la Cueva de Valdegoba hay, al menos, 27 ejemplares inmaduros, a partir del $\mathrm{D}_{4}$ izquierdo; y 13 maduros, a partir del $\mathrm{M}^{3}$ izquierdo. Al menos 19 serían infantiles, empleando el $\mathrm{D}_{4}$ derecho; 9 serían juveniles y 1 sería adulto, empleando el $\mathrm{M}^{2}$ derecho. En Prado Vargas se han identificado 2 ejemplares, a partir del $\mathrm{P}_{3}$ izquierdo, siendo al menos uno de ellos un juvenil, empleando el $\mathrm{M}_{1}$ izquierdo. En el nivel $1 \mathrm{~A}$ de Cueva Millán se han registrado 3 ejemplares. Un sería inmaduro, en concreto un juvenil, a partir del $\mathrm{M}_{1}$ izquierdo; y otros dos serían maduros, es decir, adultos, estimados a partir del $\mathrm{M}_{3}$ derecho. En el nivel 1B hay un inmaduro, un juvenil, a partir del $\mathrm{M}_{1}$ izquierdo; $\mathrm{y}$ un maduro, adulto, a partir de un $\mathrm{M}^{3}$ derecho. En el nivel $1 \mathrm{C}$ se han identificado dos ejemplares: un inmaduro, juvenil o infantil, a partir del $\mathrm{D}^{2}$ izquierdo; y un maduro, adulto, a partir del $\mathrm{M}^{1}$ izquierdo. En la Cueva del Búho se han identificado 3 ejemplares a partir del $\mathrm{P}^{2}$ derecho. Uno al menos sería juvenil y otro un adulto, estimados a partir del $\mathrm{M}^{2}$ izquierdo. En el Abrigo Vergara se ha identificado un solo ejemplar, estimado a partir de los fragmentos de un molar inferior (tabla V.7.26). En el nivel I de la Peña de Estebanvela hay un ejemplar, no sabemos si se trata de un juvenil o de un adulto ya que ha sido estimado a partir de un $\mathrm{P}_{4}$ izquierdo. En el resto de niveles, II, III y IV, hay al menos un ejemplar, aunque no podemos precisar más ya que se ha determinado a partir del esqueleto postcraneal. Todos los huesos tienen las epífisis fusionadas pero no podemos especificar si se trata de ejemplares maduros o inmaduros ya que hemos empleado como referencia el material dental (tabla V.7.26). 


\subsubsection{Discusión}

Los caracteres descritos: dientes braquidontos, selenodontos y con las cúspides aisladas sugieren que nos encontramos ante un cérvido. Esta familia es muy abundante en el Pleistoceno ibérico, estando representada por géneros como Eucladoceros, Megaloceros, Capreolus, Dama, Rangifer, Cervus y Haploidoceros (Sanz et al., 2014).

El ciervo gigante, Eucladoceros estuvo presente en la Península Ibérica durante el Pleistoceno Temprano mientras que Megaloceros pervivió en el oeste de Europa hasta hace unos 20 ka (Stuart et al., 2004; Van der Made, 2006). Las dimensiones de estos taxones están muy alejadas de las registradas en los yacimientos estudiados por lo que descartamos los géneros de grandes cérvidos. Recientemente, se ha descrito en la Península Ibérica la presencia de Haploidoceros en la Cueva del Rinoceront. Descrito por Croitor et al., (2008) a partir del material recuperado en Lune Viel, este cérvido de tamaño medio presenta unos protoconos e hipoconos separados en el $\mathrm{P}^{2}$ y $\mathrm{P}^{3}$. La morfología de sus astas difiere de las de Cervus y su tamaño general es menor (Croitor et al., 2008; Sanz et al., 2014). Estos caracteres nos permiten descartar este género. El reno, Rangifer, es un género abundante en el Pleistoceno Superior de la Península Ibérica, alcanzando su máxima expansión en el MIS 2 (Álvarez-Lao, 2007) y volviendo a sus refugios del norte al final del último máximo glaciar. En la Península Ibérica su presencia queda restringida al norte, donde se ha registrado en más cuarenta yacimientos (Gómez Olivencia et al., 2014). Sus dimensiones son intermedias entre las del gamo y el ciervo aunque las diferencias son más claras. Los caracteres que se han descrito anteriormente como el mayor aislamiento de las cúspides tanto en los premolares como en los molares, la morfología más redondeada de la dentición y su menor estatura nos permite descartar este cérvido. Más complicado es el caso de Dama ya que si bien sus dimensiones son menores, en algunos casos se ha observado un fuerte solapamiento entre ambos taxones. Los criterios definidos por Lister (1996) sugieren que los caracteres de nuestros restos difieren de los del gamo. Por esta razón, asignamos el material descrito a Cervus y en concreto a la especie Cervus elaphus.

Dentro de esta especie han sido descritas unas 12 subespecies que posteriormente Van der Made et al., (2014) reducen a 5 ya que no se limitan a incluir a todas las especies sin corona en "acoronatus". Dicha subdivisión sería la siguiente: C.e.acoronatus, C.e.angulatus, C.e.spelaeus, C.e.maral y C.e.elaphus. Los análisis métricos llevados a cabo por estos autores a partir del $\mathrm{M}_{3}$ y las falanges proximales sugieren que, a pesar de que existe un elevado solapamiento entre las variables registradas, existe una tendencia clara. C.e.acoronatus presenta un tamaño intermedio que va aumentando hacia C.e.angulatus. Posteriormente, disminuye en C.e.spelaeus, durante el Pleistoceno Superior inicial y medio para más tarde, a partir del MIS 2 aumentar en C.e.maral y los primeros C.e.elaphus. Los datos recogidos en los yacimientos de la Cueva del Búho, la Cueva de Valdegoba, Cueva Millán y la Peña de Estebanvela encajan bien en los registros que Van der Made et al., (2014) consideran C.e.spelaeus. Por otra parte, Prado Vargas no ha aportado restos en los que se puedan medir estas variables. Sin embargo, las comparaciones realizadas en la dentición, a pesar de ser en algunos casos mayores, se acercan a los valores de Cueva Millán por lo que se le asigna también esta subespecie. En Vergara, los restos obtenidos son fragmentos de difícil asignación y que además no han podido ser medidos. Por lo tanto, no es prudente asignar una subespecie y asignamos los restos de este abrigo a Cervus elaphus.

En los yacimientos del Paleolítico Medio parece existir una selección de ejemplares en función del comportamiento social de esta especie, eligiendo los periodos de mayor vulnerabilidad y a los ejemplares más vulnerables. Así, en el verano, periodo que coincide con los partos y la lactancia, se centrarían en los ejemplares infantiles; mientras que verano y otoño los ejemplares juveniles serían los predominantes. Estos últimos abandonan el núcleo familiar en esas estaciones formando grupos de machos jóvenes o permaneciendo solos hasta el celo lo que les hace más vulnerables debido a su poca experiencia. Los adultos, aunque no muy abundantes, predominan en invierno, al final del celo. 


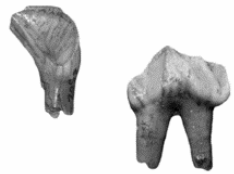

1.

2.

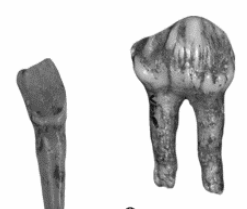

9.

8.

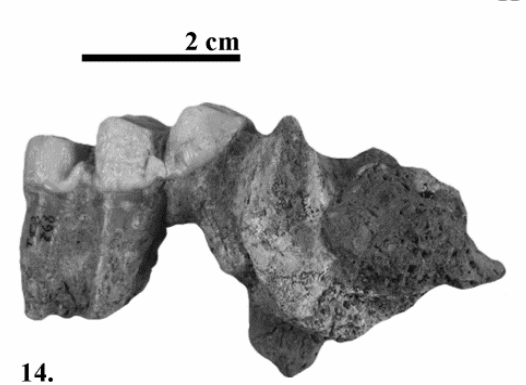

14.

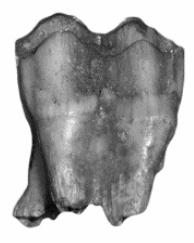

18.

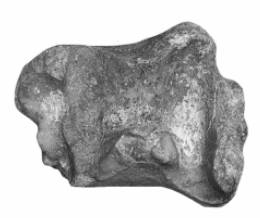

22.

23.

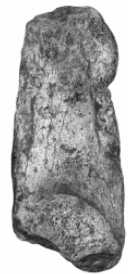

3.

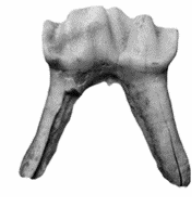

4.

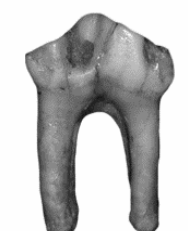

10.

11
19.

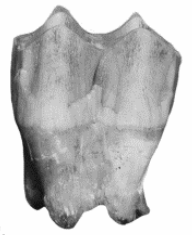

24.

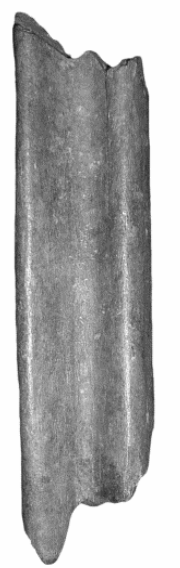

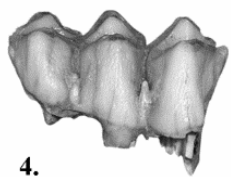

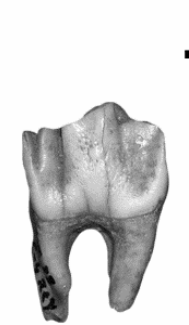

12.

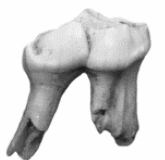

5.

$2 \mathrm{~cm}$

6.
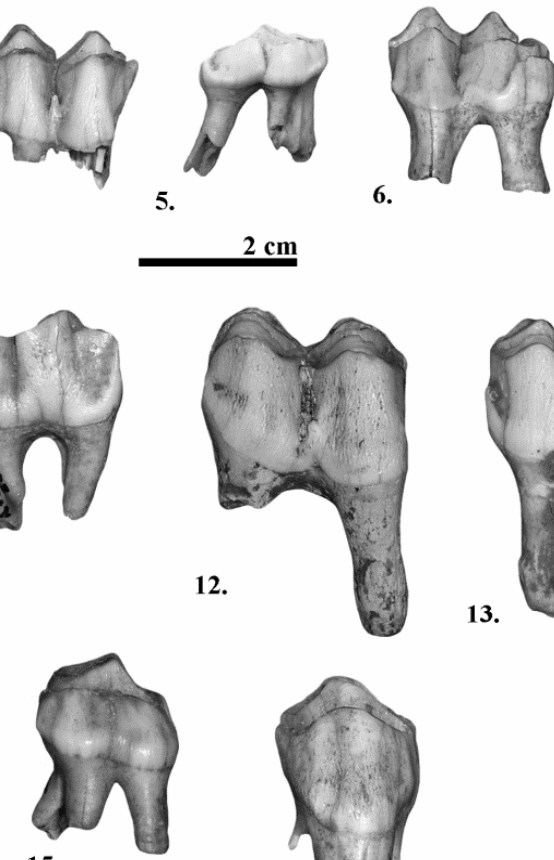

15.

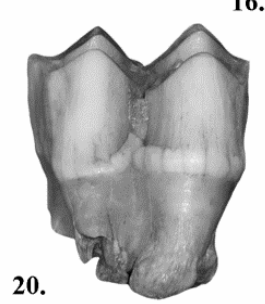

16.

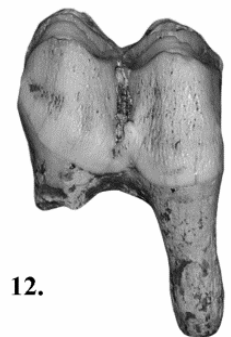

13.
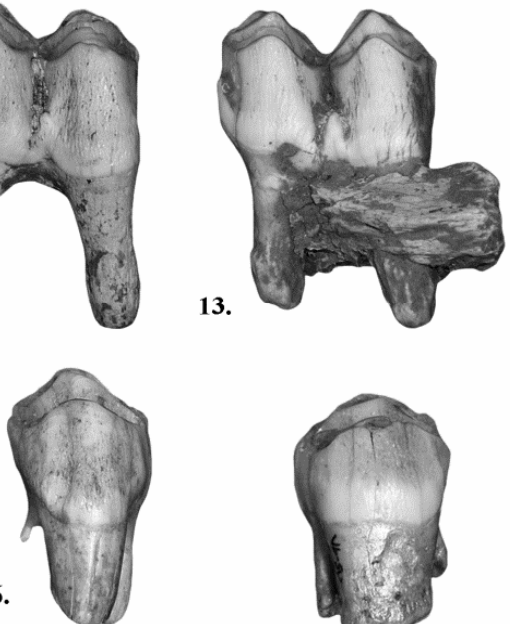

17.
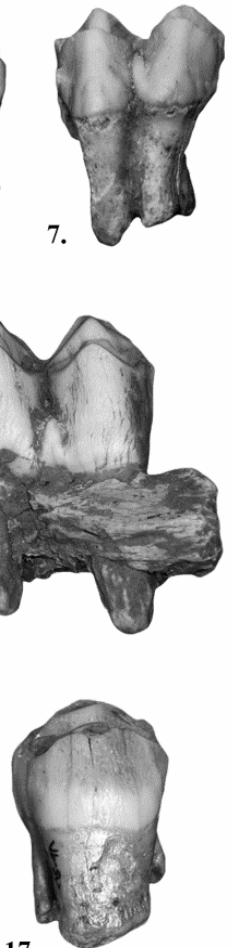

7.
21.

20.

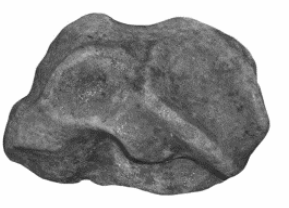

25.

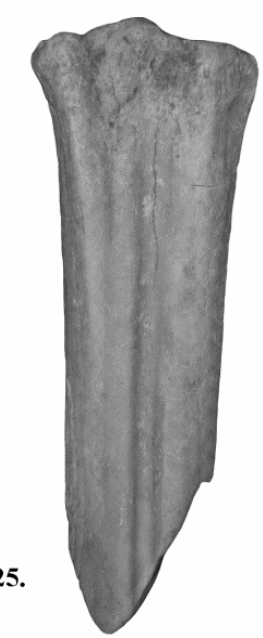

28.

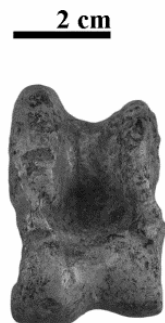

27.
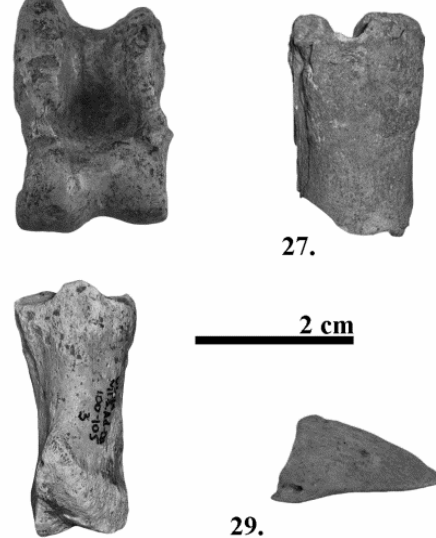

$2 \mathrm{~cm}$

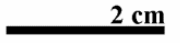

29.

Lámina V.7.1. Cervus elaphus provenientes de los yacimientos de la Cueva de Valdegoba (sigla Vb), Prado Vargas (sigla PV), Cueva Millán (sigla CM), Cueva del Búho (sigla TCB) y La Peña de Estebanvela (sigla PE). 1) $\mathrm{Vb}-\mathrm{sp}-2302$ - dI $\mathrm{d}_{1}$ izquierdo: cara lingual. 2) Vb-sp-2905 - $\mathrm{D}_{2}$ izquierdo: cara lingual. 3) Vb-sp-2875 - $\mathrm{D}_{3}$ derecho: cara lingual. 4) Vb-sp-3009 - $\mathrm{D}_{4}$ izquierdo: cara bucal. 5) Vb-sp-2668 - $\mathrm{D}^{2}$ izquierdo: cara lingual. 6) Vb-sp-3010 - D ${ }^{3}$ derecho: cara lingual. 7) Vb-sp-2970 - D4 derecho: cara lingual. 8) TCB-213 - I2 izquierdo: cara lingual. 9) Vb-sp-3063 - $\mathrm{P}_{2}$ izquierdo: cara lingual. 10) Vb-sp-2961 - $\mathrm{P}_{3}$ derecho: cara lingual . 11) Vb-sp2963 - $\mathrm{P}_{4}$ izquierdo: cara lingual. 12) PV06 45 H32 73 - M $\mathrm{M}_{1}$ izquierdo: cara bucal. 13) PV06 45 H31 $88-\mathrm{M}_{2}$ izquierdo: cara bucal. 14) TCB 268 - $\mathrm{M}_{3}$ derecho: cara bucal. 15) Vb-sp-3001 - P2 izquierdo: cara lingual. 16) Vb-sp-3128 - $\mathrm{P}^{3}$ izquierdo: cara lingual. 17) Vb-sp-3085 - $\mathrm{P}^{4}$ izquierdo: cara lingual. 18) Vb-sp-3158 - $\mathrm{M}^{1}$ derecho: cara lingual. 19) CM86 1A 6I - M² izquierdo: cara lingual. 20) Vb-sp-3175 - $\mathrm{M}^{3}$ derecho: cara lingual. 21) Vb sp 5338 - Radio derecho. 22) CM.86.1A.10F - Tibia izquierda. 23) Vb sp 5564 - Calcáneo derecho. 24) Vb-sp-5372 - Metacarpo. 25) Vb-sp-5251 - Metatarso. 26) TCB447 - Astrágalo derecho. 27) PE07.E8.NIIIII.6.43 - Falange proximal derecha. 28) Vb06.M13.Ad.100-105.3 - Falange media izquierda. 29) TCB203 Falange distal derecha. 


\subsection{Capreolus capreolus}

Orden Artiodactyla Owen, 1848

Familia Cervidae Goldfuss, 1820

Subfamilia Capreolinae Brookes, 1828 (incl. Odocoileinae, Pocock, 1923)

Género Capreolus Gray, 1821

Especie Capreolus capreolus Linnaeus, 1758

\subsubsection{Generalidades}

Los corzos son los cérvidos más pequeños del Pleistoceno europeo (Guérin y PatouMathis, 1996). Han estado presentes en Europa desde el Mioceno Tardío, representados por Procapreolus. Su descendiente, Capreolus, entra en Europa, procedente de Asia, hace 1 m.a. (Visloboka et al., 1995). Su clasificación ha sido un tema discutido. Por un lado, Lister (1996) asigna la mayor parte del material fósil a C. capreolus mientras que Pfeiffer (1998) los clasifica en tres especies: $C$. suessenbornensis, $C$. priscus y $C$. capreolus. Más tarde, Kahlke (2001) añade a la lista $C$. cusanoides después de analizar el material de Untermassfeld. Esta clasificación se debe fundamentalmente a las adaptaciones al medio que se observan en las extremidades. Así, la mayor talla y las proporciones de las extremidades anteriores, más largas, en relación con las posteriores, más cortas, de $C$. suessenbornensis le permitiría vivir en medios abiertos mientras que el menor tamaño y la mayor robustez de $C$. priscus sería más característica de medios cerrados.

Van der Made (2005) considera que las tres especies de Pfeiffer (1998) forman parte de la misma línea evolutiva, que estaría caracterizada por una disminución del tamaño y un aumento de la robustez de sus extremidades. Así, Van der Made et al., (2014) consideran que $C$. suessenbornensis sería característica del Pleistoceno Inferior y comienzos del Pleistoceno Medio; C. priscus del Pleistoceno Medio e inicios del Pleistoceno Superior y $C$. capreolus estaría presente desde el Pleistoceno Tardío en Europa.

En la actualidad persisten dos especies de corzos: C. capreolus y C. pygargus. La primera habita en Europa, Anatolia, el Caucaso y el norte de Irán; y la segunda estaría restringida a Asia (Wilson y Mittermeier, 2011).

\subsubsection{Material}

Los restos son escasos. El material empleado en la descripción y la comparación es el siguiente:

Cueva de Valdegoba: 68 restos: 56 dientes y 12 piezas postcraneales. Los dientes se dividen en: $2 \mathrm{I}_{2}, 5 \mathrm{I}_{3}, 6 \mathrm{C}, 24 \mathrm{dC}, 1 \mathrm{P}_{3}, 1 \mathrm{P}_{4}, 2 \mathrm{M}_{1}, 2 \mathrm{M}_{2}, 3 \mathrm{M}_{3}, 2 \mathrm{P}^{2}, 4 \mathrm{M}^{1}, 2 \mathrm{M}^{2}, 2 \mathrm{M}^{3}$. Los restos postcraneales se reparten en: 5 astrágalos, 1 calcáneo, 1 metatarso, 4 falanges medias y 1 falange distal.

Cueva del Búho: un resto, $1 \mathrm{D}^{3}$.

Las piezas utilizadas para estimar la edad de muerte son los dientes debido a su abundancia y a su mejor conservación.

\subsubsection{Descripción y comparación} Búho.

En este apartado se describen los restos de la Cueva de Valdegoba y de la Cueva del 
Caninos deciduales (tabla V.8.1): dientes incisiviformes, con el cuello marcado y una raíz. La corona es redondeada y no tiene faceta de desgaste en el borde lateral. Presentan una pequeña cresta en la cara lingual. Son más pequeños que los permanentes (tabla V.8.1).

Molares deciduales superiores (tabla V.8.2): dientes con las coronas bajas, braquiodontas y esquema selenodonto. Tienen tres raíces: una mesial, otra distal y una lingual.

D²: esta pieza se caracteriza por presentar el lóbulo mesial más estrecho que el distal, una excepción en las piezas superiores. Tiene un cíngulo muy marcado en la cara mesial. Tanto los estilos como la columna interlobular están muy marcados.

Incisivos permanentes (lámina V.8.1: 11) (tabla V.8.1): dientes de pequeño tamaño, con las coronas bajas, cuellos marcados y una raíz. Su corona se inclina hacia el extremo lateral y tienen un surco en su cara lingual. La inclinación es más marcada en el $\mathrm{I}_{3}$. Se diferencian de los caninos inferiores por presentar una corona más cuadrangular y por tener una faceta de desgaste en la cara lateral. Se diferencian de los del ciervo por sus menores dimensiones (tablas V.7.4 y V.8.1).

Caninos permanentes (lámina V.8.1: 12) (tabla V.8.1): dientes incisiviformes, con coronas bajas y una raíz. Carecen de faceta de desgaste en el borde lateral a diferencia de los incisivos de los que se diferencian también por la forma redondeada de la corona. Son más pequeños que los incisivos permanentes y más grandes que los caninos deciduales (tablas V.8.1 y 2).

Tabla V.8.1

Medidas de los incisivos y caninos deciduales y permanentes del C. capreolus de la Cueva de Valdegoba

\begin{tabular}{|c|c|c|c|c|c|c|}
\hline & DMD & DLL & Hli & Hla & Hmes & Hdist \\
\hline \multicolumn{7}{|l|}{$\mathbf{I}_{2}$} \\
\hline $\mathrm{n}$ & 2 & 2 & 1 & 2 & 1 & 2 \\
\hline rango & $6,7-6,8$ & $4,6-4,9$ & 11,7 & $13,1-21,1$ & 10,2 & $10,6-17,0$ \\
\hline 国 \pm s.d. & $6,8 \pm 0,1$ & $4,7 \pm 0,2$ & & $17,1 \pm 5,6$ & & $13,8 \pm 4,5$ \\
\hline \multicolumn{7}{|l|}{$I_{3}$} \\
\hline $\mathrm{n}$ & 5 & 5 & 5 & 5 & 4 & 5 \\
\hline rango & $3,9-5,4$ & $4,2-4,5$ & $8,4-10,5$ & $8,3-11,7$ & $9,4-10,4$ & $6,2-10,1$ \\
\hline to \pm s.d. & $4,6 \pm 0,6$ & $4,3 \pm 0,1$ & $9,2 \pm 0,8$ & $10,0 \pm 1,2$ & $9,9 \pm 0,4$ & $7,9 \pm 1,4$ \\
\hline \multicolumn{7}{|l|}{$\mathbf{C}$} \\
\hline $\mathrm{n}$ & 6 & 6 & 6 & 6 & 6 & 6 \\
\hline rango & $3,7-4,4$ & $3,2-3,6$ & $5,7-9,3$ & $5,1-10,0$ & $5,1-9,1$ & $4,3-8,6$ \\
\hline t \pm s.d. & $4,1 \pm 0,3$ & $3,4 \pm 0,2$ & $7,5 \pm 1,4$ & $7,7 \pm 1,9$ & $7,5 \pm 1,6$ & $6,7 \pm 1,6$ \\
\hline \multicolumn{7}{|l|}{ dC } \\
\hline $\mathrm{n}$ & 24 & 24 & 24 & 24 & 24 & 24 \\
\hline rango & $2,5-4,6$ & $2,1-3,3$ & $4,9-8,3$ & $4,1-8,5$ & $4,3-7,9$ & $3,9-7,4$ \\
\hline 国 \pm s.d. & $3,4 \pm 0,7$ & $2,7 \pm 0,3$ & $6,3 \pm 0,7$ & $6,0 \pm 0,9$ & $5,9 \pm 0,8$ & $5,6 \pm 1,0$ \\
\hline
\end{tabular}

Premolares inferiores (lámina V.8.1: 1, 2, 10, 13) (tabla V.8.2): dientes de pequeñas dimensiones, con coronas braquiodontas, esquema selenodonto, cúspides aisladas y dos raíces: una mesial y otra distal. Difieren de los ciervos por sus menores dimensiones (tablas V.7.5 y V.8.2)

$\mathbf{P}_{3}$ : estas piezas tienen un metacónido redondeado, una hipopostfoseta apenas visible por la pequeña distancia existente entre la hipoendocrístida y la hipopostcrístida, y un surco bucal entre el protocónido y el hipocónido menos acentuado que en el $\mathrm{P}_{4}$. Difieren del ciervo por presentar la paraprecrístida y la paraendocrístida menos separadas. 
$\mathbf{P}_{4}$ : la paraprecrístida y la paraendocrístida se encuentran fusionadas. El metacónido es bilobulado. La metaprecrístida aparece muy desarrollada y se une bucalmente con la paraendocrístida. Se diferencia del ciervo por tener la protoendocrístida separada del metacónido.

Molares inferiores permanentes (lámina V.8.1: 3, 4, 5, 10 y 13) (tabla V.8.2): dientes braquiodontos, selenodontos y con dos raíces: una mesial y otra distal. Son bilobulados, salvo el $\mathrm{M}_{3}$ que debido al desarrollo del hipoconúlido presenta una apariencia trilobulada. El lóbulo mesial está menos proyectado que el distal en la cara bucal. Tienen cíngulos de desarrollo variable en las caras anterior y bucal. Difieren de los caprinos por presentar un aislamiento de las cúspides en la superficie oclusal, por sus coronas más bajas y por tener una columna interlobular marcada.

$\mathbf{M}_{1}$ y $\mathbf{M}_{2}$ : estas piezas carecen de cíngulos y tienen los bordes bucales de los lóbulos apuntados. Se diferencian entre sí por el menor desarrollo de la columna interlobular en $\mathrm{M}_{1}$ y por la diferencia entre los diámetros transversales, que es mayor en $\mathrm{M}_{2}$ (tabla V.8.2)

Tabla V.8.2

Medidas tomadas en los premolares y molares deciduales y permanentes de $C$. capreolus

\begin{tabular}{|c|c|c|c|c|c|c|c|c|c|c|c|c|c|}
\hline & & & Lado & DAP & DAPb & DTa & DTp & DTpp & DT & DTb & $\mathbf{H}$ & $\mathrm{Ha}$ & Hр \\
\hline$D^{3}$ & Búho & $6528 Q$ & $\mathrm{i}$ & 11,7 & 9,0 & 6,7 & 8,0 & & 5,8 & 7,8 & & 6,8 & 6,0 \\
\hline $\mathbf{P}_{3}$ & Valdegoba & Vb-sp-2578 A & $\mathrm{i}$ & 10,8 & 10,0 & 5,5 & 7,2 & & 7,2 & 6,9 & 4,7 & & \\
\hline $\mathbf{P}_{3}$ & Valdegoba & Vb-sp-2582 A & $\mathrm{i}$ & 10,1 & 8,9 & & & & 5,1 & 5,7 & 7,7 & & \\
\hline $\mathbf{P}_{3}$ & Valdegoba & Vb-sp-1029 & d & 11,0 & 9,7 & 4,3 & 6,3 & & 5,9 & 6,1 & 6,2 & & \\
\hline $\mathbf{P}_{4}$ & Valdegoba & Vb-sp-3038 & d & 11,5 & 10,2 & 7,0 & 7,1 & & 6,2 & 7,0 & 9,2 & & \\
\hline $\mathbf{M}_{1}$ & Valdegoba & Vb-sp-3056 & $\mathrm{i}$ & 12,3 & 11,1 & 8,3 & 8,5 & & 7,6 & 8,0 & & 8,9 & 8,9 \\
\hline $\mathbf{M}_{1}$ & Valdegoba & Vb-sp-2778 & $\mathrm{d}$ & 12,9 & 12,1 & 8,2 & 8,6 & & 7,4 & 8,1 & & 7,8 & 8,0 \\
\hline $\mathbf{M}_{2}$ & Valdegoba & Vb-sp-3065 & d & 12,8 & 12,2 & 8,6 & 9,3 & & 8,3 & 8,8 & & 5,9 & 5,9 \\
\hline $\mathbf{M}_{2}$ & Valdegoba & Vb-sp-3050 & $\mathrm{d}$ & 12,9 & 11,5 & 8,2 & 9,2 & & 7,0 & 9,0 & & 11,1 & 10,6 \\
\hline $\mathbf{M}_{3}$ & Valdegoba & Vb-sp-1028 & $\mathrm{i}$ & 16,2 & 15,5 & 8,2 & 8,3 & 5,8 & 8,3 & 8,3 & & 7,5 & 6,9 \\
\hline $\mathbf{M}_{3}$ & Valdegoba & Vb-sp-3191 & $\mathrm{i}$ & 16,1 & 16,1 & 7,6 & 8,0 & 5,6 & 7,6 & 7,9 & & 9,5 & 9,0 \\
\hline $\mathbf{M}_{3}$ & Valdegoba & Vb-sp-3199 & $\mathrm{d}$ & 17,0 & 16,8 & 8,2 & 8,2 & 6,1 & 8,1 & 8,1 & & 7,4 & 6,8 \\
\hline
\end{tabular}

$\mathbf{M}_{3}$ : tiene las columnas interlobulares bucales pequeñas y con forma de espina. El metaprestilo está menos proyectado lingualmente que en Cervus, por lo que la metaprecrístida no define un surco mesiodistal.

Premolares superiores (lámina V.8.1: 6) (tabla V.8.3): dientes braquiodontos y selenodontos. Tienen tres raíces aunque el $\mathrm{P}^{2}$ puede tener fusionadas la mesial y la bucal. Se diferencian de los del ciervo por su menor tamaño (tabla V.7.8 y V.8.3).

P2: se estrecha hacia el extremo mesial, por lo que es muy asimétrico. El paracono es la cúspide más desarrollada. Carece de cíngulos. Difiere del ciervo por tener una prefoseta más estrecha y el surco posterobucal más cóncavo y el lingual menos marcado.

Molares superiores permanentes (lámina V.8.1: 7, 8 y 9) (tabla V.8.3): dientes con las coronas bajas, braquiodontas y con esquema selenodonto. Tienen dos lóbulos y pueden presentar cíngulos de desarrollo variable en las caras mesial y lingual. Tienen tres raíces: una lingual, una mesial y otra distal. Se diferencian entre sí en que el solapamiento entre la parapostcrístida y la metaprecrístida disminuye hacia el $\mathrm{M}^{3}$; y en que la diferencia entre los diámetros transversales de ambos lóbulos aumenta hacia el tercer molar (tabla V.8.3). Se diferencian de los caprinos por el menor tamaño de las coronas, por el aislamiento de las cúspides principales y por tener una columna interlobular. Difieren de los del ciervo, básicamente, por sus menores dimensiones (tablas V.7.9 y V.8.3). 
M1: las piezas analizadas se diferencian del $\mathrm{M}^{2}$ por la presencia de un tetrapostcónulo, por tener la columna interlobular más pequeña, un cíngulo distal más marcado y por ser más pequeños (tabla V.8.3).

M2: carece de tretrapostcónulo y de cíngulos en todas sus caras. La columna interlobular es grande y tiene forma de espina.

Tabla V.8.3

Medidas de los incisivos y caninos deciduales y permanentes del C. capreolus de la Cueva de Valdegoba

\begin{tabular}{lllcccccccccc}
\hline & & & Lado & DAP & DAPb & DTa & DTp & DT & DTb & H & Ha & Hp \\
\cline { 5 - 11 } $\mathbf{P}^{2}$ & Valdegoba & Vb-sp-3041 & $\mathrm{d}$ & 10,0 & 10,6 & 7,4 & 10,4 & 6,7 & 8,9 & 8,6 & & \\
$\mathbf{P}^{2}$ & Valdegoba & Vb-sp-3064 & $\mathrm{i}$ & 11,8 & 10,7 & 7,3 & 10,6 & 9,4 & 9,3 & 5,9 & & \\
$\mathbf{M}^{1}$ & Valdegoba & Vb-sp-3046 & $\mathrm{d}$ & 12,4 & 11,3 & 11,7 & 10,8 & 9,9 & 11,6 & & 7,6 & 8,1 \\
$\mathbf{M}^{2}$ & Valdegoba & Vb-sp-3055 & $\mathrm{d}$ & 12,7 & 11,3 & 12,8 & 12,2 & 10,3 & 12,7 & & 9,0 & 9,2 \\
$\mathbf{M}^{2}$ & Valdegoba & Vb-sp-1913 & $\mathrm{d}$ & 13,4 & 12,0 & 13,0 & 12,8 & 11,9 & 12,9 & & 8,1 & 7,5 \\
$\mathbf{M}^{1}$ & Valdegoba & Vb-sp-1940 & $\mathrm{d}$ & 12,4 & 10,0 & 11,5 & 11,2 & 9,4 & 11,9 & & 9,8 & 10,1 \\
$\mathbf{M}^{1}$ & Valdegoba & Vb-sp-2935 & $\mathrm{i}$ & 11,6 & 10,8 & 11,1 & 11,1 & 9,8 & 11,9 & & 5,2 & 5,2 \\
$\mathbf{M}^{1}$ & Valdegoba & Vb-sp-1401 & $\mathrm{d}$ & 13,2 & 10,7 & 11,8 & & & & & 8,4 & 8,4 \\
$\mathbf{M}^{3}$ & Valdegoba & Vb-sp-3045 & $\mathrm{i}$ & 11,8 & 10,7 & 12,5 & 11,0 & 8,6 & 11,7 & & 9,1 & 9,0 \\
$\mathbf{M}^{3}$ & Valdegoba & Vb-sp-3049 & $\mathrm{d}$ & 11,6 & 10,7 & 12,1 & 11,1 & 9,3 & 11,5 & & 8,5 & 8,5 \\
\hline
\end{tabular}

$\mathbf{M}^{3}$ : carecen de tetrapostcónulo al igual que $\mathrm{M}^{2}$ y a diferencia de $\mathrm{M}^{1}$. Presenta un borde distobucal casi recto. No tiene cíngulo lingual y presenta un lóbulo distal mucho más pequeño que el mesial. Este carácter permite diferenciarlo de los dos molares anteriores.

Astrágalo (lámina V.8.1: 15) (tabla V.8.4): se han analizado cinco piezas, tres de ellas maduras y dos inmaduras. Estas últimas presentan mayores proporciones de tejido esponjoso. Las piezas estudiadas tienen la tróclea proximal separada de la distal por una depresión ovalada bien marcada. Por debajo de ella, hay una depresión que en unos casos es contínua y en otras apenas es visible. A ambos lados de esta depresión, existen unas protuberancias para la inserción de ligamentos que están más desarrolladas que en los caprinos, sobretodo la lateral. En vista palmar, la tróclea proximal tiene una serie de protuberancias siendo la lateral la más grande, aunque es más estrecha que en los caprinos. La cara que articula con el calcáneo presenta unos bordes oblicuos. Proximalmente, está separado de la tróclea proximal por una depresión contínua y que, distalmente, tiene un surco que en unos casos está muy marcado y en otros apenas se encuentra esbozado. La carilla que articula con el escafoides es alargada y su borde proximal es redondeado. En vista lateral, la carilla distal, que articula con el calcáneo, es corta y ancha a diferencia de los caprinos en los que es alargada y estrecha.

Tabla V.8.4

Medidas tomadas en los astrágalos del C. capreolus de la Cueva de Valdegoba

\begin{tabular}{lcccccccc}
\hline & Lado & GLl & GLm & DL & DM & BP & BD & ATPL \\
\hline Maduro & & & & & & & & \\
\hline Vb-91.6.M6.T1-2.1 & i & 24,5 & 23,0 & 12,8 & 13,4 & 17,1 & 15,8 & 15,9 \\
Vb-06.M13.Da-A.5 & i & 30,4 & 29,1 & 15,9 & 17,7 & 21,1 & 19,1 & 17,1 \\
Vb-sp-3516 & d & 26,5 & 25,1 & 13,9 & 14,8 & 16,7 & 16,7 & 16,8 \\
\hline Inmaduro & & & & & & & & \\
\hline Vb-91.6.N7.T5,7 & i & 21,2 & 20,2 & 11,6 & 10,6 & 14,7 & 13,0 & 13,4 \\
Vb-91.6.N7.T3.6 & d & 20,3 & 19,1 & 12,0 & 10,9 & 15,2 & 13,6 & 13,2 \\
\hline
\end{tabular}

Calcáneo (lámina V.8.1: 14): la pieza analizada rotas la tuberosidad calcánea y la cara que articula con el maleolo lateral. La diáfisis es más alargada y más estrecha que en los caprinos. La cara que articula con el astrágalo es estrecha y su borde dorsal tiene un surco marcado. Se diferencia bien de la de los caprinos porque es más ancha y presenta surcos 
tanto en el borde anterior como en el lateral. La carilla que articula con el maléolo es corta y ancha a diferencia de los caprinos en los que es alargada y estrecha. La carilla que articula con el escafoides es convexa, alargada y se proyecta distalmente. El surco para la inserción del flexor digital profundo es ancho, corto y fuertemente curvado hacia atrás.

Metatarso III+IV (lámina V.8.1: 16): sólo se ha identificado un fragmento de la cara dorsal de la diáfisis. Su asignación a un cérvido en lugar de a un caprino se debe al gran desarrollo del surco vascular. Su tamaño hace que se asigne a Capreolus en lugar de a Cervus o Dama.

Falanges medias (lámina V.8.1: 17 y 18) (tabla V.8.5): son huesos cortos y muy comprimidos lateralmente lo que permite diferenciarlos de otros artiodáctilos de tamaño similar como el rebeco. Las falanges de los cérvidos se caracterizan por tener la tróclea distal con una superficie articular que se proyecta mucho proximalmente en la cara dorsal, terminando en punta y no de forma redondeada como se observa en los caprinos. La superficie articular proximal está comprimida lateralmente lo que hace que dorsopalmarmente parezca más alargada. La superficie articular, al igual que en el resto de artiodáctilos, se encuentra dividida por una cresta sagital en dos pequeñas carillas siendo la abaxial más amplia que la axial. Dorsalmente existe una prominencia más marcada que en los caprinos y que carece de una protuberancia en la cara dorsal para la inserción de ligamentos. En el borde palmar hay dos prominencias, también para la inserción de ligamentos, que se encuentran más desarrolladas que en los caprinos. La diáfisis es muy estrecha. La epífisis distal presenta una protuberancia muy profunda, a cada lado, para la inserción de los ligamentos interdigitales. La superficie articular distal se proyecta mucho dorsalmente a diferencia de los caprinos. En la cara palmar, la tróclea es más o menos recta a diferencia de los caprinos en los que se puede observar un surco más o menos amplio.

Falange media anterior: son más cortas y estrechas que las posteriores (tabla V.8.5). Se han identificado dos piezas. Se caracterizan por su menor longitud y su mayor anchura en el punto medio de la diáfisis. A nivel morfológico, los caracteres que pueden diferenciarlas de las posteriores son bastante escasos ya que a diferencia de los caprinos las inserciones musculares y ligamentosas están igual de desarrolladas en ambos casos. A simple vista, se diferencian en la superficie articular proximal, más amplia en las anteriores, y por la mayor profundidad en el punto central de la diáfisis, lo que les da un aspecto más robusto.

Falange media posterior: es más larga y más ancha que las anteriores. El desarrollo de las inserciones musculares y ligamentosas es similar. La superficie articular proximal no es tan amplia como en las anteriores y la profundidad de la diáfisis es menor.

Tabla V.8.5

Medidas tomadas en las falanges del C. capreolus de la Cueva de Valdegoba

\begin{tabular}{llcccccccccccccc}
\hline & & Posición & Lado & GL & GLpe & Hpost & DPs & DPi & BP & SD & BD & DD & DLS & LD & MBS \\
\hline Vb-sp-5701 & F.m. & P & i & 29,3 & 30,5 & 31,1 & 11,2 & 15,4 & 11,3 & 8,2 & 8,3 & 13,6 & & & \\
Vb-sp-5719 & F.m. & A & d & 25,2 & 28,7 & 28,3 & 8,9 & 15,5 & 10,7 & 7,0 & 8,1 & 14,2 & & \\
Vb06.L13.N2.2 & F.m. & A & d & 23,1 & 23,9 & 24,4 & 10,1 & 11,4 & 8,8 & 6,4 & 7,0 & 12,7 & & & \\
Vb-sp-5703 & F.d. & & d & & & & & & & & & & 27,2 & 25,3 & 6,1 \\
\hline
\end{tabular}

* F.m.: falange media. F.d.: falange distal. A: anterior. P: posterior.

Falanges distales (lámina V.8.1: 19) (tabla V.8.5): la pieza recuperada es triangular y está comprimida lateralmente. Tiene una línea de forámenes muy marcada en la cara lateral. La cara articular está dividida por una cresta poco marcada. La superficie que articula con el sesamoideo distal es una pequeña protuberancia. La apófisis extensora está poco 
desarrollada, haciendo que la cara dorsal carezca de la depresión que caracteriza a las falanges distales de los caprinos

\subsubsection{Edad de muerte}

En este apartado se han empleado únicamente los dientes, al ser más abundantes y al estar en mejor estado de conservación. No se han utilizado los métodos de desgaste debido a que no tenemos datos de coronas sin erosión. Se sigue, por lo tanto, la erupción y el reemplazamiento dental.

Cueva de Valdegoba: todas las piezas están desgastadas por lo que su edad estaría alejada de la edad de erupción. Se han recuperado dos mandíbulas, una conserva la serie $\mathrm{P}_{4}-\mathrm{M}_{3}$ y la otra la secuencia $\mathrm{P}_{3}-\mathrm{M}_{2}$. Pertenecen a ejemplares distintos, ambas son izquierdas, y tienen desgastes diferentes. La primera tiene un desgaste menos marcado y en la segunda las coronas prácticamente han desaparecido. Al tener ambas los premolares emergidos, su edad sería superior a los 12 - 13 meses. Sin embargo, la primera podría ser asignada a un individuo adulto mientras que la segunda, al presentar un degaste máximo, podría pertenecer a un individuo senil. Si tenemos en cuenta la edad reemplazamiento de los caninos deciduales, 8 - 12 meses, al menos tendríamos diez ejemplares infantiles o juveniles.

Cueva del Búho: la edad de erupción del $\mathrm{P}^{3}$ se estima entre los 12 y 13 meses, por lo que el ejemplar identificado tendría al menos esa edad y podría tratarse de un ejemplar infantil o de un juvenil (tabla IV.2.9).

\subsubsection{Número Mínimo de Individuos}

El MNI se ha estimado a partir la pieza más frecuente, la erupción y el desgaste dental.

Tabla V.8.6

Número mínimo de individuos de Capreolus capreolus

\begin{tabular}{|c|c|c|c|c|c|c|}
\hline & Inmaduros & Maduros & Total & Infantiles-Juvenil & Adultos & Seniles \\
\hline Valdegoba & 10 & 2 & 12 & 10 & 1 & 1 \\
\hline Búho & 1 & & 1 & 1 & & \\
\hline
\end{tabular}

En la Cueva de Valdegoba se han identificado al menos 10 ejemplares inmaduros, infantiles o juveniles, a partir de los caninos deciduales izquierdos; y dos maduros, dos adultos, a partir de dos mandíbulas izquierdas. Su desgaste nos permite indicar que al menos uno sería un adulto y otro un ejemplar senil. Aunque la pieza más frecuente sería el M1 derecho, su edad de erupción, 4 - 5 meses (Daujeard, 2008) estaría incluida en los juveniles y adultos por lo que creemos más prudente no tener en cuenta esta pieza ya que podríamos duplicar individuos. En la Cueva del Búho se ha identificado un ejemplar a partir del $\mathrm{D}^{3}$ izquierdo. La edad de erupción sugiere que podría tratarse de un ejemplar infantil o de un juvenil.

\subsubsection{Discusión}

El material recuperado en la Cueva del Búho y en la Cueva de Valdegoba presenta caracteres propios de la familia Cervidae. Así, los dientes tienen las coronas braquiodontas, selenodontas, con columnas interlobulares y con un aislamiento claro de las cúspides principales. Estas características contrastan con las observadas en los caprinos, grupo con el que estos restos podrían confundirse principalmente por sus 
dimensiones. Los caprinos carecen de columnas interlobulares y las cúspides principales se encuentran fusionadas. Estos caracteres junto con los observados en el esqueleto postcraneal permiten asignar estos restos a la familia Cervidae.

El material recuperado pertenece a un cérvido mucho más pequeño que Dama, Rangifer, Cervus y por supuesto de Megaloceros. Los cérvidos más pequeños del Pleistoceno europeo pertenecen al género Capreolus, asignamos los restos a este género.

Los corzos del Pleistoceno Medio y Superior han sido clasificados en cuatro especies: $C$. cusanoides, C. suessenbornensis, C. priscus y C. capreolus (Pfeiffer, 1998; Kahlke, 2001). Sus dimensiones han ido disminuyendo con el tiempo a la vez que aumentaba su robustez, probablemente por una adaptación a medios más cerrados. Van der Made et al., (2014) llevan a cabo un estudio métrico de estas especies, tomando como referencia el material recuperado en más de treinta yacimientos. Estos autores han observado que, a pesar del fuerte solapamiento existente en las variables analizadas, existe una tendencia a la disminución de los $\mathrm{M}_{3}$ del $C$. suessenbornensis al $C$. capreolus actual, así como un aumento de la robustez de sus extremidades.

El material recuperado en buen estado de conservación y que nos permite una comparación clara es bastante escaso. Por esta razón, no podemos comparar los datos de robustez de Van der Made et al., (2014) ya que no hemos recuperado falanges proximales. Sin embargo, los terceros molares inferiores encajan bien con los recogidos en otros yacimientos como Abric Romani, Kafzeh y Kamieneczyk. Por otra parte, son más pequeños que los recuperados en Taubach, Ehringsdirf, Steinheim, Orgnac 3, Schöningen y Bilzingsleben y que han sido asignados a C. priscus. Los datos recogidos en la Cueva de Valdegoba encajan bien con la tendencia observada por Van der Made et al., (2014) referentes a la disminución del tamaño corporal, no así con los datos de robustez ya que no tenemos el material suficiente. Asignamos el material de la Cueva de Valdegoba a Capreolus capreolus. Por otra parte, el diente de la Cueva del Búho no permite unas comparaciones muy exhaustivas. Además, la cronología manejada para este yacimiento se encuentra próxima a la de transición entre C. priscus y C. capreolus. La falta de datos y de material nos impide ir más allá de la asignación genérica. Asignamos los restos de la Cueva del Búho a Capreolus sp. 


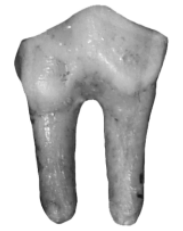

1.

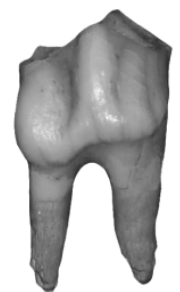

2.

6.

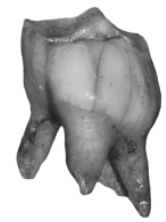

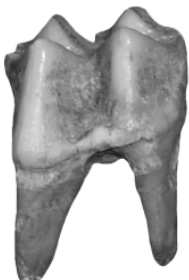

3.

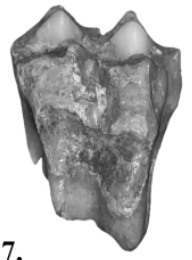

7.

8.
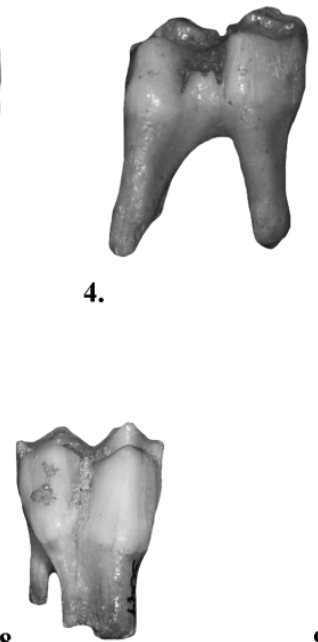

4.

5.

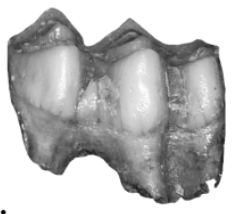

$1 \mathrm{~cm}$

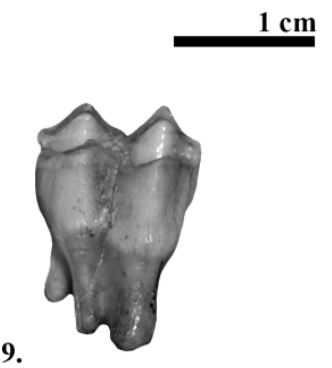

9.

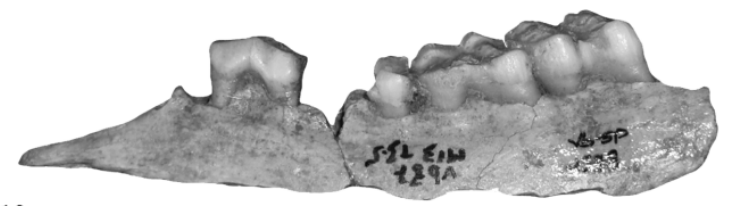

10.

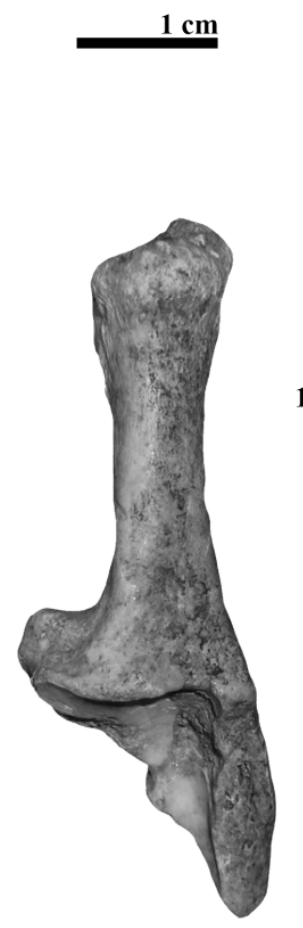

14.

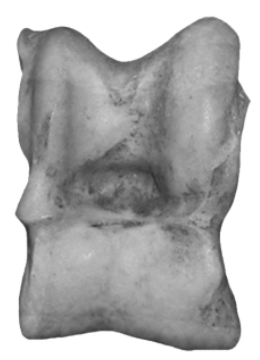

15.

16.

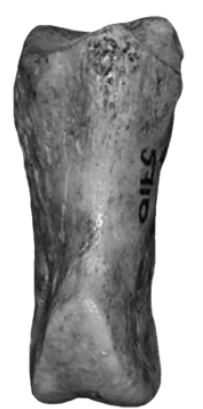

17.

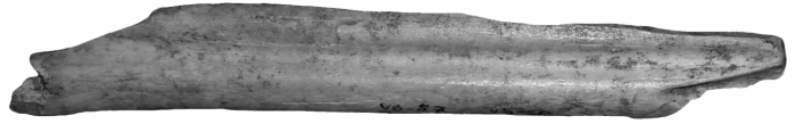

18.
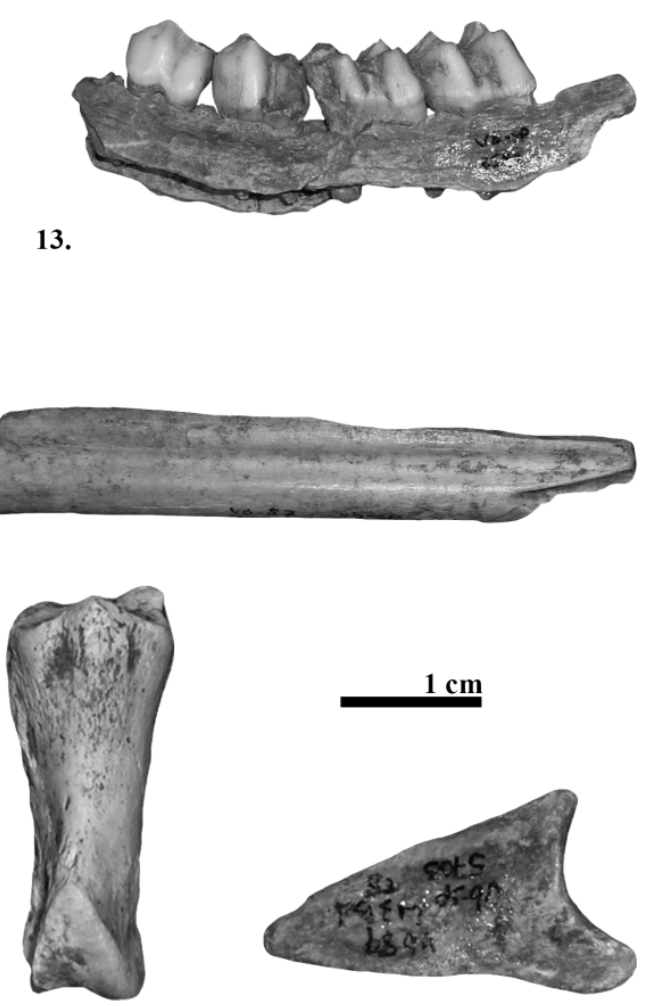

13.

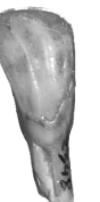

11.

12.
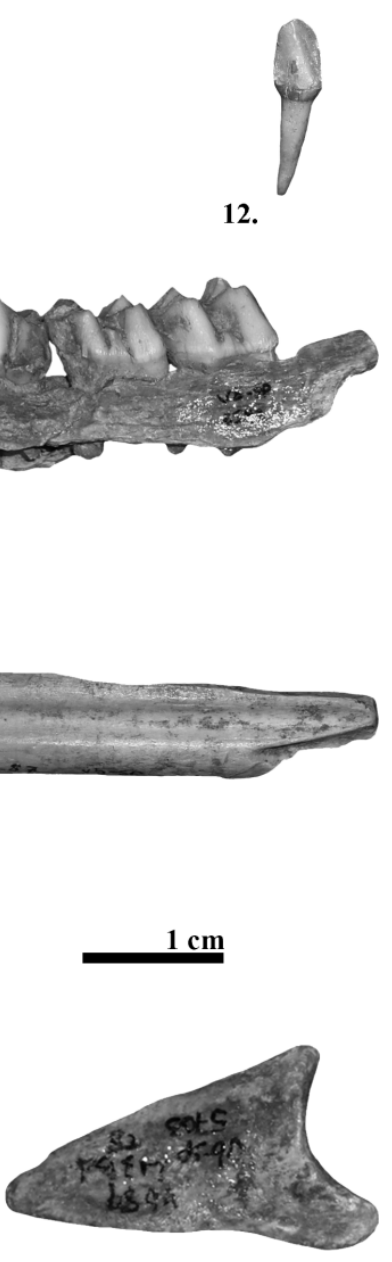

19.

Lámina V.8.1. Capreolus capreolus proveniente del yacimiento de la Cueva de Valdegoba (sigla Vb). 1) Vb-sp1029 - P3 derecho: cara lingual. 2) Vb-sp-3038 - P $_{4}$ derecho: cara bucal. 3) Vb-sp-3056 - M 1 derecho: cara bucal. 4) $\mathrm{Vb}$-sp-3065 - $\mathrm{M}_{2}$ derecho: cara bucal. 5) Vb-sp-1028 - $\mathrm{M}_{3}$ derecho: cara bucal. 6) Vb-sp-3041 - $\mathrm{P}^{2}$ derecho: cara lingual. 7) Vb-sp-3046 - M11 derecho: cara lingual. 8) Vb-sp-3049 - $\mathrm{M}^{2}$ derecho: cara lingual. 9) Vb-sp-3055 - $\mathrm{M}^{3}$ derecho: cara lingual. 10) Vb-sp-2578 - Mandíbula $\left(\mathrm{P}_{4}-\mathrm{M}_{3}\right)$ izquierda: cara bucal. 11) Vb-sp-2348 - $\mathrm{I}_{2}$ izquierdo: cara lingual. 12) Vb sp 1584 -Canino permanente izquierdo: cara lingual. 13) Vb-sp-2582 Mandíbula $\left(\mathrm{P}_{3}-\mathrm{M}_{2}\right)$ izquierda: cara bucal. 14) Vb-sp-3713 - Calcáneo izquierdo. 15) Vb.91.6.M6.T1-2 Astrágalo izquierdo. 16) Vb-sp-5368 - Metatarso. 17) Vb-sp-5719 - Falange media anterior izquierda. 18) Vbsp-5710 - Falange media posterior izquierda. 19) Vb-sp-5710 - Falange distal. 


\title{
5.9 Rupicapra pyrenaica
}

\author{
Orden Artiodactyla Owen, 1848 \\ Familia Bovidae Gray, 1821 \\ Subfamilia Caprinae Gray, 1821 \\ Género Rupicapra Blainville, 1816 \\ Especie Rupicapra pyrenaica Bonaparte, 1845
}

\subsubsection{Generalidades}

Los rebecos, género Rupicapra, son muy abundantes en Europa desde el Pleistoceno Medio. Los primeros fósiles de esta subfamilia, correspondientes al Mioceno, son escasos y están muy dispersos por lo que las relaciones filogenéticas y el origen de esta especie es difícil de establecer (Gentry, 2000). La mayor parte de los investigadores sugieren un origen asiático a partir de Procamptoceras, el cual pudo sobrevivir en el este de Europa hasta el Pleistoceno Medio (Domínguez Sanjurjo et al., 2009).

El mal estado de conservación de los restos así como la falta de datos sobre la filogenia han provocado continuos cambios en la clasificación de esta especie. Sin embargo, se ha sugerido que $R$. pyrenaica se habría expandido en primer lugar, llegando hasta las penínsulas Ibérica e Itálica durante el Pleistoceno Medio; y más tarde entraría $R$. rupicapra, provocando el aislamiento de las poblaciones de $R$. pyrenaica que posteriormente darían lugar a $R$. p. parva en la Cordillera Cantábrica y a $R$. p. pyrenaica en los Pirineos, pudiendo desplazarse, en el Pleistoceno Superior final, hacia los Apeninos donde dieron lugar a $R$. p. ornata (Crégut-Bonnoure, 2006). Los restos más antiguos de Europa han sido asignados a $R$. cf. pyrenaica (Rivals, 2002) y provienen de los yacimientos franceses de l'Arago, OIS 12, (aparece como $R$. aff. pyrenaica en Moigne et al., 2006) y Orgnac 3, 0IS 9, (considerado por Youcef, (2009) como R. rupicapra). Más modernos son los registros de Les Conques (Moigne, 2003), Tournal (Magniez, 2010), Le Portel-Ouest, la Cova de l'Arbreda (considerados por Kacimi (2003) como R. rupicapra) y la Grotte de Castel 2, todos ellos anteriores al OIS 6 (Rivals, 2002). Ya asignados a $R$. pyrenaica nos encontramos rebecos en la Niche, Montmaurin, Cap de la Bielle y Nestier (OIS 6) (Rivals, 2002; Magniez, 2010). $R$ r rupicapra aparece a comienzos de la última glaciación en Les Cèdres (OIS 5). Esta especie protagoniza una segunda migración proveniente del este de Europa. Los trabajos de Crègut-Bonnoure (1992a, 2006) sobre las migraciones han sugerido que $R$. rupicapra nunca alcanzó la Península Ibérica, siendo el sarrio ibérico el único representante en este territorio. Sin embargo, tradicionalmente, el rebeco fósil del Pleistoceno Superior ibérico ha sido asignado a $R$. rupicapra (Altuna, 1972, Alférez et al., 1980-1981).

La clasificación de esta especie ha estado sometida a continuas revisiones a lo largo del siglo pasado, definiéndose una, dos e incluso tres especies (Pérez et al., 2013). Debido a su semejanza con las cabras, Linnaeus los incluyó en la especie Capra rupicapra. Posteriormente, Blainville crea, para este grupo, un nuevo género, dándoles una entidad propia (Domínguez Sanjurjo et al., 2009) y los incluyó en la especie Rupicapra rupicapra. Años más tarde, Charles Lucien Bonaparte separa, de este grupo, a los rebecos pirenaicos, creando la especie $R$. pyrenaica. En 1913, Lydekker agrupa a todas las poblaciones en $R$. rupicapra y, un año después Camerano las separa en tres: $R$. pyrenaica en la Península Ibérica, $R$. ornata en los Apeninos y $R$. rupicapra en el resto de Eurasia. Más tarde, una nueva revisión llevada a cabo por Couturier (1938) las vuelve a incluir a todas en $R$. rupicapra, definiendo, además, diez subespecies distintas. Una nueva revisión, realizada por Lovari (1987) y Nascetti et al., (1985) las reagrupa en dos especies: R. pyrenaica en el suroeste de Europa y $R$. rupicapra en el resto de Europa y el Cáucaso; y las divide a su vez en diez subespecies, cada una distribuida en un sistema montañoso (Domínguez Sanjurjo et al., 2009). Una de las últimas revisiones realizada a partir de estudios genéticos, morfológicos y de distribución sugiere a la existencia de siete especies (Groves y Grubb, 2011). En esta clasificación se incluyen $R$. parva, $R$. pyrenaica, $R$. ornata, $R$. rupicapra (con 
los rebecos de los Alpes, Tatra y Chartreuse), $R$. carpatica, $R$. balcanica y $R$. asiatica (con las poblaciones de Turquía y el Cáucaso). Otros autores, siguiendo este esquema, incluyen el rebeco de los Balcanes en $R$. rupicapra (Valdez, 2011).

Los análisis filogenéticos basados en estudios del ADNmt, cromosoma Y y microsatélites aportan datos que difieren mucho de los análisis realizados por Groves y Grubb (2011), y por Valdez (2011), y vuelven a clasificar a los rebecos en una, dos o tres especies (Pérez et al., 2013). Así, el ADNmt, el más usado para diagnosticar especies (Domínguez, com. pers.) forma tres clados: uno para las poblaciones del oeste de Europa (R. pyrenaica. parva y $R$. pyrenaica pyrenaica), otro para los grupos de Europa central $(R$. pyrenaica ornata y $R$ rupicapra cartusiana) y el último para las poblaciones del oeste de Europa (las otras seis poblaciones) (Rodríguez et al., 2010). Por otra parte, el análisis de microsatélites separa tres grupos: $R$. pyrenaica, $R$. rupicapra y $R$. ornata. El último, el cromosoma Y, divide las poblaciones en las dos especies conocidas: $R$. pyrenaica y $R$. rupicapra, incluyendo a R. ornata en $R$. pyrenaica (Pérez et al., 2011).

Las clasificaciones morfológicas y los análisis genéticos realizados en los últimos años revelan una gran complejidad taxonómica. Los estudios genéticos chocan, en muchos casos, con las clasificaciones morfológicas. En este texto tenemos en cuenta las dos especies que se han clasificado tradicionalmente, $R$. pyrenaica y $R$ rupicapra, y que aparecen en todas las revisiones realizadas hasta la fecha (Domínguez Sanjurjo et al., 2009; Pérez et al., 2013) y en la diferente bibliografía que trata a este taxón en el Pleistoceno (Rivals, 2002; Moigne et al., 2006; Magniez, 2010; Arceredillo et al., 2011). Tradicionalmente, se ha considerado que los restos de los rebecos del Pleistoceno Superior de la Península Ibérica pertenecían a $R$ rupicapra, cuando no se reconocía aún a $R$. pyrenaica. Los estudios de distribución y los recientes análisis genéticos chocaban con esta asignación por lo que se ha considerado necesario llevar a cabo un análisis morfológico exhaustivo para aportar datos sobre la especie recuperada en los diferentes yacimientos de la Meseta Norte.

\subsubsection{Material}

El material empleado en la descripción y la comparación es el siguiente:

La Cueva de Valdegoba: 4482 restos identificados, 3857 analizados: 2680 craneales y dentales; 1177 postcraneales. El material craneal se compone de 77 núcleos óseos de cuernos y 2603 dientes: $21 \mathrm{dI}_{1}, 52 \mathrm{dI}_{2}, 50 \mathrm{dI}_{3}, 89$ caninos de leche, $12 \mathrm{D}_{2}, 57 \mathrm{D}_{3}, 47 \mathrm{D}_{4}, 33$ $\mathrm{D}^{2}, 56 \mathrm{D}^{3}, 62 \mathrm{D}^{4}, 122 \mathrm{I}_{1}, 80 \mathrm{I}_{2}, 73 \mathrm{I}_{3}, 50$ caninos permanentes, $233 \mathrm{M}_{1}, 153 \mathrm{M}_{2}, 173 \mathrm{M}_{3}, 118$ $\mathrm{P}^{2}, 121 \mathrm{P}^{3}, 126 \mathrm{P}^{4}, 228 \mathrm{M}^{1}, 187 \mathrm{M}^{2}$ y $169 \mathrm{M}^{3}$. El material postcraneal se compone de 23 fragmentos de escápulas, 47 tibias, 55 metacarpos (III + IV), 44 metatarsos (III + IV), 63 metápodos, 49 radios, 74 húmeros, 88 astrágalos, 46 calcáneos, 16 ulnas, 19 patellas, 284 falanges proximales, 219 falanges medias y 150 falanges distales.

Prado Vargas: 4 restos: 3 dientes y un resto postcraneal. Los dientes son: $2 \mathrm{M}_{1}, 1 \mathrm{M}_{2}$ y un fragmento de $\mathrm{P}^{4}$. El hueso es una falange proximal.

Cueva Millán: 87 piezas: 54 dientes y 33 restos postcraneales. En el Nivel 1A: $1 \mathrm{D}_{3}, 1 \mathrm{P}_{2}, 2$ $\mathrm{P}_{3}, 2 \mathrm{P}_{4}, 6 \mathrm{M}_{1}, 4 \mathrm{M}_{2}, 4 \mathrm{M}_{3}, 1 \mathrm{D}^{4}, 1 \mathrm{P}^{2}, 1 \mathrm{P}^{3}, 1 \mathrm{P}^{4}, 3 \mathrm{M}^{1}, 2 \mathrm{M}^{2}, 2 \mathrm{M}^{3}, 5$ falanges proximales, 8 falanges medias y 3 falanges distales. En el Nivel 1B: $1 \mathrm{P}_{2}, 1 \mathrm{P}^{4}, 2 \mathrm{M}_{1}$ y una falange distal. En el Nivel 1C: $2 \mathrm{P}_{4}, 1 \mathrm{P}^{4}, 2 \mathrm{M}_{1}$ y una falange distal. A estos hay que añadir dos falanges proximales recuperadas en el nivel superficial.

Abrigo Alexandre: 1 diente, $1 \mathrm{D}^{2}$.

La Peña de Estebanvela: 33 piezas: 18 restos craneales y dentales; 15 postcraneales. Se ha recuperado una mandíbula en el nivel revuelto. En el nivel I: $1 \mathrm{D}_{2}, 1 \mathrm{D}_{3}, 1 \mathrm{D}^{3}, 2 \mathrm{I}_{1}, 1 \mathrm{C}, 1$ $\mathrm{P}_{3}, 1 \mathrm{P}_{4}, 2 \mathrm{P}^{2}, 1 \mathrm{M}_{1}, 1 \mathrm{M}_{3}, 1 \mathrm{M}^{1}, 1 \mathrm{M}^{2}, 1$ húmero, 1 radio, 1 astrágalo, 2 sesamoideos, 1 falange 
proximal y 1 falange media. En el nivel II: 1 navicular, 1 astrágalo, 1 semilunar y 1 radio. En el nivel III: $1 \mathrm{I}_{2}, 1 \mathrm{P}^{4}, 1 \mathrm{M}^{2}, 1$ piramidal, 1 falange proximal y una falange media; por último en el nivel IV se ha identificado una falange proximal.

Los restos empleados para estimar la edad de muerte son todos dientes debido a su mayor número y su mejor estado de conservación.

La Cueva de Valdegoba: 349 restos: $19 \mathrm{D}_{4}, 99 \mathrm{M}_{1}, 68 \mathrm{M}_{2}, 94 \mathrm{M}^{1}$ y $81 \mathrm{M}^{2}$.

Prado Vargas: 3 dientes: $2 \mathrm{M}_{1}$ y $1 \mathrm{M}_{2}$.

Cueva Millán: 19 restos. Nivel 1A: $6 \mathrm{M}_{1}, 4 \mathrm{M}_{2}, 3 \mathrm{M}^{1}$ y $2 \mathrm{M}^{2}$. Nivel 1B: $2 \mathrm{M}_{1}$. Nivel 1C: $2 \mathrm{P}_{4}$.

Abrigo de Alexandre: 1 resto: $1 D^{2}$.

La Peña de Estebanvela: 5 restos: Nivel I: $1 \mathrm{D}_{2}, 1 \mathrm{D}_{3}, 1 \mathrm{D}_{4}, 1 \mathrm{M}_{1}$, Nivel: $1 \mathrm{M}$ 1.

En la estacionalidad se han utilizado los dientes que han permitido obtener la edad en meses. Además, se ha empleado la pieza más frecuente para, de esta manera, determinar la estacionalidad en individuos. Los restos son los que siguen:

La Cueva de Valdegoba: $99 \mathrm{M}_{1}$ izquierdos.

Prado Vargas: 2 restos: $2 \mathrm{M}_{1}$ izquierdos.

Cueva Millán: 6 dientes: Nivel 1A: $5 \mathrm{M}_{1}$ izquierdos. Nivel 1B: $1 \mathrm{M}_{1}$ izquierdo.

La Peña de Estebanvela: 1 diente en el Nivel I, $1 \mathrm{M}_{1}$ izquierdo.

El estudio de la bimodalidad sexual se ha llevado a cabo únicamente en la Cueva de Valdegoba. El material empleado es el siguiente:

La Cueva de Valdegoba: 105 restos: 31 radios, 31 metacarpos, 27 tibias y 16 metatarsos.

\subsubsection{Descripción y comparación}

El material que se describe a proviene de la Cueva de Valdegoba, Prado Vargas, Cueva Millán, Abrigo Alexandre y la Peña de Estebanvela.

Núcleos óseos de cuernos: se han analizado 77 restos, la mayor parte fragmentos que conservan parte del hueso parietal. Cinco de ellos pertenecen a ejemplares infantiles ya que consisten en protuberancias que sobresalen del hueso.

Incisivos deciduales (lámina V.9.1: 7) (tabla V.9.1): dientes pequeños, con los cuellos marcados y una raíz. Difieren de los permanentes por sus menores dimensiones (tablas V.9.1 y 4) y por tener los cuellos más marcados. Métricamente no se diferencian mucho entre sí, aunque los $\mathrm{dI}_{1}$ tienden a ser más anchos y los $\mathrm{dI}_{3}$ más estrechos (tabla V.9.1).

$\mathbf{d I}_{1}$ : es un diente con una forma triangular y con un borde medial recto. Difiere del resto de deciduales por presentar la corona recta, menos inclinada hacia el borde lateral, y por ser ligeramente más anchos. 
$\mathbf{d I}_{2}$ : tiene la corona curvada lateralmente, más que en el $\mathrm{dI}_{1}$ pero menos que en el $\mathrm{dI}_{3}$.

$\mathbf{d I}_{3}$ : presenta una corona más curvada hacia el borde lateral y son más pequeños que los incisivos precedentes. Presentan una faceta de desgaste, en el borde lateral, y la corona más o menos rectangular, lo que permite diferenciarlo del canino decidual.

Caninos deciduales (lámina V.9.1: 10) (tabla V.9.1): dientes incisiviformes, con las coronas bajas y una raíz. Difieren de los incisivos deciduales por tener una corona más redondeada y por carecer de una faceta de desgaste en el borde lateral. Sus dimensiones se solapan con las de los incisivos deciduales y son más pequeños que los caninos permanentes (tabla V.9.1 y 4).

Tabla V.9.1

Medidas tomadas en los caninos e incisivos deciduales de R. pyrenaica

\begin{tabular}{|c|c|c|c|c|c|c|}
\hline & DMD & DLL & Hli & Hla & Hmes & Hdist \\
\hline \multicolumn{7}{|l|}{$\mathrm{dI}_{1}$} \\
\hline \multicolumn{7}{|c|}{ Valdegoba } \\
\hline $\mathrm{n}$ & 21 & 21 & 21 & 21 & 21 & 21 \\
\hline rango & $3,3-5,6$ & $2,9-4,6$ & $5,5-8,5$ & $5,0-9,5$ & $4,4-7,6$ & $3,9-7,6$ \\
\hline $\bar{x} \pm$ s.d. & $4,5 \pm 0,6$ & $3,5 \pm 0,6$ & $7,0 \pm 0,8$ & $7,1 \pm 1,0$ & $6,2 \pm 1,0$ & $6,0 \pm 1,0$ \\
\hline \multicolumn{7}{|l|}{ Millán } \\
\hline $\mathrm{n}=1$ & 3,5 & 3,9 & 3,8 & 6,2 & 5,7 & 5,4 \\
\hline \multicolumn{7}{|c|}{$\mathrm{dI}_{2}$} \\
\hline \multicolumn{7}{|c|}{ Valdegoba } \\
\hline $\mathrm{n}$ & 52 & 52 & 52 & 52 & 52 & 52 \\
\hline rango & $2,2-5,0$ & $1,8-4,0$ & $4,5-8,7$ & $4,1-9,4$ & $3,6-8,4$ & $4,1-8,4$ \\
\hline$\overline{\mathrm{x}} \pm$ s.d. & $3,8 \pm 0,6$ & $3,2 \pm 0,5$ & $6,8 \pm 0,9$ & $7,0 \pm 1,2$ & $6,6 \pm 1,1$ & $6,1 \pm 1,1$ \\
\hline \multicolumn{7}{|l|}{ Millán } \\
\hline $\mathrm{n}$ & 2 & 2 & 2 & 2 & 2 & 2 \\
\hline rango & $3,4-4,2$ & $3,3-3,5$ & $5,9-7,6$ & $5,9-7,9$ & $4,8-7,6$ & $5,1-7,6$ \\
\hline $\bar{x} \pm$ s.d. & $3,8 \pm 0,6$ & $3,4 \pm 0,2$ & $6,7 \pm 1,2$ & $6,9 \pm 1,4$ & $6,2 \pm 2,0$ & $6,3 \pm 1,7$ \\
\hline \multicolumn{7}{|l|}{$\mathrm{dI}_{3}$} \\
\hline \multicolumn{7}{|c|}{ Valdegoba } \\
\hline $\mathrm{n}$ & 50 & 50 & 50 & 50 & 50 & 50 \\
\hline rango & $2,0-4,6$ & $2,0-3,9$ & $4,5-8,8$ & $4,1-9,3$ & $4,3-8,7$ & $3,9-8,1$ \\
\hline $\bar{x} \pm$ s.d. & $3,7 \pm 0,6$ & $3,1 \pm 0,5$ & $6,8 \pm 1,0$ & $6,9 \pm 1,3$ & $6,5 \pm 1,0$ & $5,9 \pm 1,0$ \\
\hline \multicolumn{7}{|l|}{$\mathrm{dC}$} \\
\hline \multicolumn{7}{|c|}{ Valdegoba } \\
\hline $\mathrm{n}$ & 85 & 85 & 85 & 85 & 85 & 85 \\
\hline rango & $2,8-5,1$ & $2,7-4,0$ & $5,2-9,8$ & $4,7-10,3$ & $3,6-9,8$ & $3,9-8,7$ \\
\hline $\bar{x} \pm$ s.d. & $4,0 \pm 0,4$ & $3,3 \pm 0,3$ & $6,7 \pm 1,0$ & $6,8 \pm 1,2$ & $6,3 \pm 1,1$ & $5,9 \pm 1,0$ \\
\hline
\end{tabular}

Molares deciduales inferiores (lámina V.9.1: 2) (tabla V.9.2): dientes con las coronas bajas y dos raíces: una mesial y otra distal. Carecen de cíngulos y columnas interlobulares. Difieren de los premolares inferiores permanentes por sus mayores longitudes y sus menores anchuras, aunque puede haber un gran solapamiento en estas variables. Asimismo, las raíces son más divergentes y finas que en los premolares. Son más pequeños que los de Capra pyrenaica (tablas V.9.2 y V.10.2).

$\mathbf{D}_{2}$ : diente que se estrecha mesialmente. El protocónido es su cúspide principal, está muy desarrollado y se encuentra en posición central. La cara bucal apenas es convexa. El surco posterobucal, situado entre el protocónido y el hipocónido, está apenas esbozado a diferencia del $\mathrm{P}_{2}$.

$\mathbf{D}_{3}$ : en las piezas poco gastadas el hipocónido y el entocónido están separados por una foseta, constituyendo un lóbulo posterior pequeño. El surco lingual, situado entre el 
paracónido y el metacónido, está muy marcado y tiende a la bilobularización. El surco bucal, entre el protocónido y el hipocónido, es más profundo que en el $\mathrm{P}_{3}$.

$\mathbf{D}_{4}$ : diente de apariencia trilobulada, carente de columnas interlobulares y cíngulos. Suele tener una raíz accesoria entre la mesial y la distal. Difiere del $\mathrm{M}_{3}$ por sus menores dimensiones (tablas V.9.2 y 6) y porque su DT aumenta hacia el lóbulo distal.

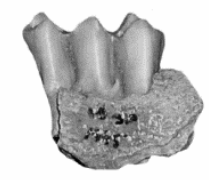

1.

2.

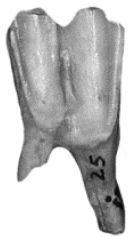

3.

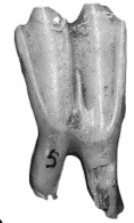

4.
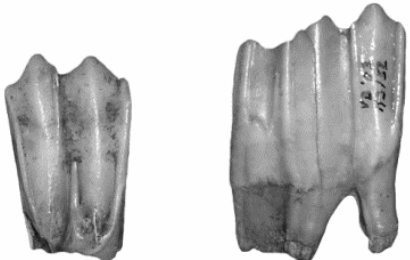

5.

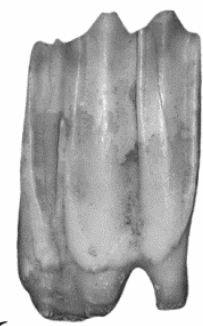

6.

$2 \mathrm{~cm}$

Figura V.9.1. Dientes inferiores del $R$. pyrenaica de la Cueva de Valdegoba que presentan una columna accesoria. 1) Vb-sp-1995 - D4 izquierdo: cara bucal. 2) Vb-sp-1884 - M 1 derecho: cara lingual. 3) Vb-sp-1885 M1 derecho: cara lingual. 4) Vb-sp-1886 - M2 derecho: cara lingual. 5) Vb-03 M3 32 - M3 derecho: cara lingual. 6) Vb.03.M3.18 - $\mathrm{M}_{3}$ derecho: cara lingual.

En la Cueva de Valdegoba se han recuperado dos morfologías (figura V.9.1). La primera, la típica de Rupicapra: dientes trilobulados, con las caras lingual y bucal rectilíneas, estilos poco marcados y birradiculados. Sin embargo, en la segunda, podemos añadir la presencia de una pequeña columna accesoria de desarrollo variable en la cara lingual, entre los lóbulos distal y medio (figura V.9.1). Las dimensiones de estas piezas no difieren de las de las piezas normales de Rupicapra (tabla V.9.2).

Tabla V.9.2

Medidas tomadas en los molares deciduales inferiores de $R$. pyrenaica

\begin{tabular}{|c|c|c|c|c|c|c|c|c|c|c|}
\hline & DAP & DAPb & DTa & DTp & DTpp & DT & DTb & $\mathbf{H}$ & $\mathrm{Ha}$ & Hp \\
\hline \multicolumn{11}{|l|}{$\mathrm{D}_{2}$} \\
\hline \multicolumn{11}{|c|}{ Valdegoba } \\
\hline $\mathrm{n}$ & 14 & 14 & 14 & 14 & & 14 & 14 & 14 & & \\
\hline rango & $4,7-5,7$ & $3,6-5,1$ & $1,9-3,3$ & $2,4-3,8$ & & $2,3-7,7$ & $2,4-3,3$ & $3,3-6,2$ & & \\
\hline$\overline{\mathrm{x}} \pm$ s.d. & $5,1 \pm 0,3$ & $4,5 \pm 0,4$ & $2,6 \pm 0,4$ & $3,1 \pm 0,5$ & & $3,4 \pm 1,3$ & $2,9 \pm 0,2$ & $4,9 \pm 0,8$ & & \\
\hline \multicolumn{11}{|c|}{ Estebanvela } \\
\hline $\mathrm{n}=1$ & 4,5 & 4,5 & 2,7 & 3,3 & & 3,3 & 4,1 & 2,9 & & \\
\hline \multicolumn{11}{|l|}{$\mathbf{D}_{3}$} \\
\hline \multicolumn{11}{|c|}{ Valdegoba } \\
\hline $\mathrm{n}$ & 50 & 41 & 43 & 44 & & 57 & 39 & 51 & & \\
\hline rango & $6,5-9,9$ & $5,5-7,7$ & $1,8-4,2$ & $3,2-5,4$ & & $3,2-5,6$ & $3,2-4,5$ & $3,1-9,8$ & & \\
\hline$\overline{\mathrm{x}} \pm$ s.d. & $8,3 \pm 0,7$ & $6,7 \pm 0,5$ & $3,3 \pm 0,4$ & $4,4 \pm 0,5$ & & $4,3 \pm 0,5$ & $3,7 \pm 0,4$ & $5,3 \pm 1,6$ & & \\
\hline \multicolumn{11}{|l|}{ Millán } \\
\hline$n=1$ & 8,6 & 6,3 & 3,6 & 4,6 & & 4,4 & 4,7 & 5,4 & & \\
\hline \multicolumn{11}{|c|}{ Estebanvela } \\
\hline $\mathrm{n}=1$ & & & & & & 6,8 & 7,1 & 9,9 & & \\
\hline \multicolumn{11}{|l|}{$\mathrm{D}_{4}$} \\
\hline \multicolumn{11}{|c|}{ Valdegoba* } \\
\hline $\mathrm{n}$ & 8 & 6 & 9 & 9 & 9 & 9 & 7 & & 7 & 7 \\
\hline rango & $12,8-15,6$ & $10,4-12,2$ & $3,7-5,0$ & $4,4-5,8$ & $4,7-6,5$ & $4,5-6,1$ & $4,4-6,5$ & & $4,4-9,3$ & $6,3-11,3$ \\
\hline$\overline{\mathrm{x}} \pm$ s.d. & $14,5 \pm 0,9$ & $11,1 \pm 0,6$ & $4,2 \pm 0,5$ & $5,1 \pm 0,5$ & $5,7 \pm 0,6$ & $5,2 \pm 0,5$ & $5,6 \pm 0,6$ & & $6,9 \pm 1,5$ & $8,0 \pm 1,7$ \\
\hline \multicolumn{11}{|c|}{ Valdegoba } \\
\hline $\mathrm{n}$ & 27 & 16 & 24 & 23 & 23 & 34 & 14 & & 25 & 29 \\
\hline rango & $11,3-19,9$ & $9,1-13,2$ & $3,8-5,6$ & $4,5-6,4$ & $4,9-6,8$ & $4,7-6,6$ & $4,9-6,5$ & & $2,2-9,6$ & $3,0-9,8$ \\
\hline $\bar{x} \pm$ s.d. & $14,3 \pm 1,9$ & $11,0 \pm 1,2$ & $4,5 \pm 0,4$ & $5,4 \pm 0,4$ & $5,9 \pm 0,5$ & $5,6 \pm 0,5$ & $5,5 \pm 0,4$ & & $5,6 \pm 1,8$ & $6,2 \pm 1,9$ \\
\hline
\end{tabular}

* Hace referencia a las piezas que presentan una columna interlobular. 
Molares deciduales superiores (lámina V.9.1: 6) (tabla V.9.3): dientes con las coronas bajas, bilobulados, con las cúspides fusionadas, sin islote central de esmalte, estilos proyectados, sin columnas interlobulares y tres raíces: una mesial, una distal y otra lingual. Difieren de los de Capra pyrenaica por sus menores dimensiones y por tener las coronas más bajas (tablas V.9.3 y V.10.3).

D2: diente fuertemente asimétrico debido a que se estrecha hacia el extremo mesial. El surco lingual está poco desarrollado pero le da una apariencia bilobulada. Se diferencia de los $\mathrm{P}^{2}$ por sus coronas más bajas y por ser, en general, más estrechos pero algo más largos (tablas V.9.3 y 7). Son más pequeños que los de Capra y, además el borde mesial es convexo mientras que en las cabras es recto o cóncavo.

$D^{3}$ : dientes bilobulados, con el lóbulo mesial menos proyectado que el distal lo que permite diferenciarlos de $\mathrm{D}^{4} \mathrm{y}$ de los molares superiores permanentes. Se diferencian de los de Capra por tener la corona más baja, los estilos más proyectados, el surco lingual más profundo y por ser más pequeños (tablas V.9.3 y V.10.3). Además, la raíz lingual, en Rupicapra, parte de ambos lóbulos mientras que en Capra surge sólo del lóbulo distal.

D4: dientes bilobulados, con el lóbulo mesial más proyectado lingualmente que el distal. La pieza de Cueva Millán tiene un islote central de esmalte. Son parecidos al $\mathrm{M}^{1}$ pero se diferencian por tener las coronas más bajas y convexas, unos estilos más proyectados, por carecer de un abultamiento en la base de la corona en la cara lingual y por su menor tamaño (tablas V.9.3 y 8). Se diferencian de los de Capra por sus menores dimensiones y porque la raíz lingual parte de ambos lóbulos mientras que en las cabras sólo parte de la región distal del lóbulo mesial.

Tabla V.9.3

Medidas tomadas en los molares deciduales superiores de R. pyrenaica

\begin{tabular}{|c|c|c|c|c|c|c|c|c|c|}
\hline & DAP & DAPb & DTa & DTp & DT & DTb & $\mathbf{H}$ & Ha & Hр \\
\hline \multicolumn{10}{|l|}{$\mathbf{D}^{2}$} \\
\hline \multicolumn{10}{|c|}{ Valdegoba } \\
\hline $\mathrm{n}$ & 40 & 34 & 36 & 36 & 44 & 35 & & 37 & 41 \\
\hline rango & $5,4-9,0$ & $5,1-7,9$ & $3,2-4,5$ & $4,0-5,4$ & $3,7-6,3$ & $3,5-5,2$ & & $2,2-8,8$ & $2,5-6,7$ \\
\hline $\bar{x} \pm$ s.d. & $7,2 \pm 0,8$ & $6,3 \pm 0,6$ & $4,0 \pm 0,3$ & $4,6 \pm 0,3$ & $4,5 \pm 0,6$ & $4,2 \pm 0,4$ & & $4,7 \pm 1,5$ & $4,7 \pm 1,1$ \\
\hline \multicolumn{10}{|c|}{ Alexandre } \\
\hline $\mathrm{n}=1$ & 6,5 & 6,3 & 4,8 & 5,1 & 5,3 & 4,7 & 5,7 & & \\
\hline \multicolumn{10}{|l|}{$\mathbf{D}^{3}$} \\
\hline \multicolumn{10}{|c|}{ Valdegoba } \\
\hline $\mathrm{n}$ & 50 & 33 & 40 & 39 & 62 & 29 & & 56 & 57 \\
\hline rango & $7,4-13,2$ & $6,7-10,5$ & $4,8-6,9$ & $6,3-8,2$ & $5,5-9,0$ & $5,3-8,2$ & & $3,0-13,7$ & $3,7-13,2$ \\
\hline $\bar{x} \pm$ s.d. & $10,7 \pm 1,3$ & $8,2 \pm 0,8$ & $5,8 \pm 0,4$ & $7,2 \pm 0,5$ & $7,1 \pm 0,6$ & $6,9 \pm 0,6$ & & $7,1 \pm 2,1$ & $7,3 \pm 2,0$ \\
\hline \multicolumn{10}{|c|}{ Estebanvela } \\
\hline $\mathrm{n}=1$ & 7,6 & 7,6 & 5,8 & 7,1 & 7,1 & 7,1 & & 2,5 & 1,9 \\
\hline \multicolumn{10}{|l|}{$\mathrm{D}^{4}$} \\
\hline \multicolumn{10}{|c|}{ Valdegoba } \\
\hline $\mathrm{n}$ & 50 & 30 & 37 & 36 & 62 & 31 & & 52 & 51 \\
\hline rango & $9,6-14,7$ & $7,2-9,3$ & $8,2-10,6$ & $7,7-9,4$ & $6,6-9,7$ & $8,1-9,5$ & & $4,8-21,4$ & $5,5-21,9$ \\
\hline $\begin{array}{l}\bar{x} \pm \text { s.d. } \\
\text { Millán }\end{array}$ & $11,7 \pm 1,1$ & $8,0 \pm 0,7$ & $9,0 \pm 0,5$ & $8,6 \pm 0,4$ & $8,2 \pm 0,7$ & $8,8 \pm 0,4$ & & $8,2 \pm 2,7$ & $9,3 \pm 2,6$ \\
\hline$n=1$ & 12,4 & & 9,5 & 10,3 & 9 & 10,3 & & 9,3 & \\
\hline
\end{tabular}

Incisivos permanentes (lámina V.9.1: 9) (tabla V.9.4): son dientes de pequeño tamaño, con las coronas bajas, con cuellos marcados, con un pliegue longitudinal en la cara lingual y una raíz. Son muy parecidos entre sí, pero su corona se curva lateralmente. Dicha curvatura aumenta del $\mathrm{I}_{1}$ al $\mathrm{I}_{3}$. Métricamente existe un gran solapamiento en todas las variables (tabla V.9.4), aunque tienden a disminuir de tamaño hacia el $\mathrm{I}_{3}$. Se diferencian de los caninos permanentes por tener las coronas menos redondeadas y una faceta de 
desgaste en el borde lateral. Son más grandes que los deciduales (tablas V.9.1 y 4). Se diferencian de los de Capra por tener las coronas más bajas, los cuellos más marcados y por ser, por lo general, más pequeños (tablas V.9.4 y V.10.4).

Caninos permanentes (lámina V.9.1: 8) (tabla V.9.4): dientes incisiviformes, con las coronas bajas y muy curvadas, sin faceta de desgaste en el borde lateral, tienen un pliegue en la cara lingual de la corona y una raíz. Se diferencian de los incisivos permanentes por tener la corona más redondeada y curvada lateralmente, por carecer de faceta de desgaste y por ser más pequeños (tabla V.9.4).

Tabla V.9.4

Medidas tomadas en los incisivos y caninos inferiores permanentes de $R$. pyrenaica

\begin{tabular}{|c|c|c|c|c|c|c|}
\hline & DMD & DLL & Hli & Hla & Hmes & Hdist \\
\hline \multicolumn{7}{|l|}{$I_{1}$} \\
\hline \multicolumn{7}{|c|}{ Valdegoba } \\
\hline $\mathrm{n}$ & 149 & 151 & 150 & 150 & 150 & 150 \\
\hline rango & $3,8-6,8$ & $3,1-5,2$ & $5,0-12,4$ & $5,2-14,0$ & $3,3-11,5$ & $3,3-11,1$ \\
\hline $\bar{x} \pm$ s.d. & $5,6 \pm 0,7$ & $4,3 \pm 0,4$ & $8,6 \pm 1,3$ & $9,5 \pm 1,7$ & $7,6 \pm 1,6$ & $7,6 \pm 1,5$ \\
\hline \multicolumn{7}{|l|}{ Millán } \\
\hline $\mathrm{n}$ & 2 & 2 & 2 & 2 & 2 & 2 \\
\hline rango & $4,6-4,9$ & $4,2-4,7$ & $5,4-6,6$ & $5,5-7,2$ & $3,6-6,0$ & $3,4-5,7$ \\
\hline $\bar{x} \pm$ s.d. & $4,7 \pm 0,2$ & $4,5 \pm 0,4$ & $6,0 \pm 0,9$ & $6,4 \pm 1,2$ & $4,8 \pm 1,7$ & $4,5 \pm 1,6$ \\
\hline \multicolumn{7}{|c|}{ Estebanvala } \\
\hline $\mathrm{n}$ & 1 & 2 & 2 & 2 & 1 & 2 \\
\hline rango & 6,8 & $4,5-4,7$ & 12 & $12,9-13,1$ & 10,5 & $10,6-11,1$ \\
\hline $\bar{x} \pm$ s.d. & & $4,6 \pm 0,2$ & $12,0 \pm 0,0$ & $13,0 \pm 0,2$ & & $10,9 \pm 0,3$ \\
\hline \multicolumn{7}{|c|}{$\mathbf{I}_{2}$} \\
\hline \multicolumn{7}{|c|}{ Valdegoba } \\
\hline $\mathrm{n}$ & 99 & 98 & 98 & 98 & 98 & 97 \\
\hline rango & $3,1-6,0$ & $2,8-5,0$ & $5,2-10,4$ & $4,8-12,0$ & $3,9-10,0$ & $3,4-9,9$ \\
\hline$\overline{\mathrm{x}} \pm$ s.d. & $5,0 \pm 0,7$ & $4,1 \pm 0,5$ & $8,0 \pm 1,2$ & $8,8 \pm 1,6$ & $7,5 \pm 1,4$ & $7,1 \pm 1,4$ \\
\hline \multicolumn{7}{|l|}{ Millán } \\
\hline $\mathrm{n}$ & 7 & 7 & 7 & 7 & 7 & 7 \\
\hline rango & $4,0-6,1$ & $3,4-4,9$ & $7,3-6,8$ & $6,6-11,8$ & $6,3-10,4$ & $5,8-10,0$ \\
\hline$\overline{\mathrm{x}} \pm$ s.d. & $4,7 \pm 0,7$ & $3,9 \pm 0,6$ & $8,6 \pm 1,3$ & $9,1 \pm 1,7$ & $8,4 \pm 1,5$ & $7,9 \pm 1,6$ \\
\hline \multicolumn{7}{|c|}{ Estebanvela } \\
\hline $\mathrm{n}=1$ & 4,9 & 3,2 & 9,1 & 9,2 & 8,1 & 7,7 \\
\hline \multicolumn{7}{|l|}{$I_{3}$} \\
\hline \multicolumn{7}{|c|}{ Valdegoba } \\
\hline $\mathrm{n}$ & 80 & 80 & 80 & 80 & 80 & 80 \\
\hline rango & $2,8-6,2$ & $3,1-4,9$ & $0,6-10,5$ & $6,1-12,0$ & $5,6-11,4$ & $0,2-10,1$ \\
\hline$\overline{\mathrm{x}} \pm$ s.d. & $4,8 \pm 0,5$ & $4,1 \pm 0,4$ & $8,4 \pm 1,3$ & $9,1 \pm 1,4$ & $8,4 \pm 1,3$ & $7,4 \pm 1,4$ \\
\hline \multicolumn{7}{|c|}{ C } \\
\hline \multicolumn{7}{|c|}{ Valdegoba } \\
\hline $\mathrm{n}$ & 50 & 50 & 50 & 50 & 49 & 50 \\
\hline rango & $3,9-5,1$ & $3,2-4,3$ & $0,3-9,7$ & $6,2-10,8$ & $5,9-9,9$ & $5,2-9,1$ \\
\hline$\overline{\mathrm{x}} \pm$ s.d. & $4,6 \pm 0,3$ & $3,8 \pm 0,2$ & $7,6 \pm 1,3$ & $8,3 \pm 1,1$ & $7,5 \pm 1,0$ & $7,1 \pm 1,0$ \\
\hline \multicolumn{7}{|c|}{ Estebanvela } \\
\hline $\mathrm{n}=1$ & 3,1 & 3,1 & 6,8 & 8,0 & 7,0 & 6,2 \\
\hline
\end{tabular}

Premolares inferiores (lámina V.9.1: 1) (tabla V.9.5): son dientes de pequeño tamaño, con las coronas bajas, sin cíngulos y dos raíces: una mesial y otra distal. Son parecidos a los molares deciduales inferiores pero se diferencian por el mayor grosor y paralelismo de sus raíces, por presentar unas coronas más altas y por ser más grandes (tablas V.9.2 y 5). Son más pequeños que los de Capra pyrenaica, aunque los valores más bajos de alguna de sus variables pueden solaparse con los más altos de Rupicapra (tablas V.9.5 y V.10.5). 
$\mathbf{P}_{2}$ : diente asimétrico debido a que se estrecha hacia el extremo mesial. El protocónido es su cúspide principal y está en posición central. La profoseta, definida por el paracónido y el protocónido, está muy marcada en la cara lingual. La hipopostfoseta está muy desarrollada. Los surcos de la cara lingual son mucho más profundos que en el $\mathrm{D}_{2}$. Carece de surco bucodistal, entre el protocónido y el hipocónido. La cara bucal es convexa y la mesial oblicua. En vista lingual, los bordes mesial y distal son divergentes.

Tabla V.9.5

Medidas tomadas en los premolares inferiores de $R$. pyrenaica

\begin{tabular}{|c|c|c|c|c|c|c|c|}
\hline & DAP & DAPb & DTa & DTp & DT & DTb & H \\
\hline \multicolumn{8}{|l|}{$\mathbf{P}_{2}$} \\
\hline \multicolumn{8}{|c|}{ Valdegoba } \\
\hline $\mathrm{n}$ & 110 & 115 & 120 & 120 & 124 & 113 & 115 \\
\hline rango & $3,7-6,3$ & $2,9-5,0$ & $2,0-3,5$ & $2,4-4,4$ & $2,2-8,1$ & $1,9-4,4$ & $2,0-8,2$ \\
\hline $\bar{x} \pm$ s.d. & $5,2 \pm 0,5$ & $3,8 \pm 0,4$ & $2,9 \pm 0,3$ & $3,3 \pm 0,4$ & $3,3 \pm 0,6$ & $2,6 \pm 0,4$ & $3,1 \pm 0,7$ \\
\hline \multicolumn{8}{|l|}{ Millán } \\
\hline $\mathrm{n}$ & 2 & 2 & 2 & 2 & 2 & 2 & 2 \\
\hline rango & $5,3-7,7$ & $4,3-4,3$ & $3,8-4,4$ & $4,6-5,3$ & $3,9-5,1$ & $3,2-3,5$ & $6,1-7,5$ \\
\hline $\bar{x} \pm$ s.d. & $6,5 \pm 1,7$ & $4,3 \pm 0,1$ & $4,1 \pm 0,4$ & $5,0 \pm 0,5$ & $4,5 \pm 0,9$ & $3,4 \pm 0,2$ & $6,8 \pm 1,0$ \\
\hline \multicolumn{8}{|c|}{ ( } \\
\hline \multicolumn{8}{|c|}{ Valdegoba } \\
\hline $\mathrm{n}$ & 117 & 119 & 160 & 160 & 156 & 118 & 127 \\
\hline rango & $6,2-9,1$ & $4,7-7,2$ & $2,3-6,4$ & $3,6-7,0$ & $3,3-6,0$ & $2,9-6,5$ & $2,4-10,7$ \\
\hline $\bar{x} \pm$ s.d. & $7,3 \pm 0,5$ & $5,6 \pm 0,4$ & $3,3 \pm 0,5$ & $4,7 \pm 0,5$ & $4,4 \pm 0,5$ & $3,7 \pm 0,6$ & $5,0 \pm 1,4$ \\
\hline \multicolumn{8}{|l|}{ Millán } \\
\hline $\mathrm{n}$ & 2 & 2 & 2 & 2 & 2 & 2 & 2 \\
\hline rango & $7,3-9,0$ & $5,5-5,7$ & $3,7-5,5$ & $4,5-5,7$ & $4,0-5,6$ & $4,5-4,6$ & $7,8-7,9$ \\
\hline$\overline{\mathrm{x}} \pm$ s.d. & $8,2 \pm 1,2$ & $5,6 \pm 0,1$ & $4,6 \pm 1,2$ & $5,1 \pm 0,8$ & $4,8 \pm 1,1$ & $4,5 \pm 0,1$ & $7,8 \pm 0,0$ \\
\hline \multicolumn{8}{|c|}{ Estebanvela } \\
\hline $\mathrm{n}=1$ & 8,1 & 7,0 & 3,6 & 4,8 & 4,3 & 4,8 & 7,6 \\
\hline \multicolumn{8}{|c|}{$\mathbf{P}_{4}$} \\
\hline \multicolumn{8}{|c|}{ Valdegoba } \\
\hline $\mathrm{n}$ & 101 & 96 & 160 & 149 & 151 & 99 & 139 \\
\hline rango & $7,0-10,2$ & $6,1-8,3$ & $1,9-5,3$ & $4,1-6,7$ & $3,9-7,9$ & $3,8-6,1$ & $1,5-11,5$ \\
\hline$\overline{\mathrm{x}} \pm$ s.d. & $8,5 \pm 0,6$ & $7,1 \pm 0,5$ & $3,7 \pm 0,6$ & $5,3 \pm 0,4$ & $5,2 \pm 0,5$ & $4,7 \pm 0,5$ & $6,9 \pm 2,0$ \\
\hline \multicolumn{8}{|l|}{ Millán } \\
\hline $\mathrm{n}$ & 4 & 3 & 4 & 4 & 4 & 4 & 4 \\
\hline rango & $6,7-10,4$ & $7,8-8,3$ & $5,2-7,6$ & $5,4-7,7$ & $5,2-7,6$ & $4,8-5,2$ & $6,6-15,0$ \\
\hline $\bar{x} \pm$ s.d. & $8,9 \pm 1,6$ & $8,1 \pm 0,2$ & $6,4 \pm 1,0$ & $6,7 \pm 1,1$ & $6,3 \pm 1,1$ & $5,0 \pm 0,2$ & $10,3 \pm 4,4$ \\
\hline \multicolumn{8}{|c|}{ Estebanvela } \\
\hline $\mathrm{n}=1$ & 9,2 & 7,0 & 4,5 & 5,6 & 5,4 & 5,6 & 8,3 \\
\hline
\end{tabular}

$\mathbf{P}_{3}$ : su metacónido, unilobular, está separado del protocónido por un pequeño valle en los dientes con poco desgaste, aunque pueden unirse cuando la erosión está más avanzada. La paraendocrístida está unida a la paraprecrístida. El surco que se encuentra entre el protocónido y el hipocónido es poco profundo, a diferencia del que se encuentra entre el protocónido y el metacónido que es profundo y triangular. Son más cortos que los $\mathrm{D}_{3}$ pero presentan una anchura similar (tablas V.9.2 y 5 ).

$\mathbf{P}_{4}$ : presenta cuatro cúspides visibles en los dientes poco o nada gastados. Las cúspides distales se sitúan en una posición más baja que las mesiales y están separadas por una foseta poco profunda. Se fusionan pronto y forman un lóbulo distal poco profundo. El paracónido y el metacónido se unen para formar un dentículo mesiolingual tan desarrollado como el mesiovestibular. Los surcos bucodistales definidos entre el protocónido y el hipocónido, y entre el metacónido y el entocónido son profundos lo que hace que el diente presente una apariencia bilobulada. Menos profundo es el surco mesiolingual situado entre el paracónido y el metacónido. 
Tabla V.9.6

Medidas tomadas en los molares inferiores permanentes de R. pyrenaica

\begin{tabular}{|c|c|c|c|c|c|c|c|c|c|}
\hline & DAP & DAPb & DTa & DTp & DTpp & DT & DTb & Ha & Hp \\
\hline \multicolumn{10}{|l|}{$\mathbf{M}_{1}$} \\
\hline \multicolumn{10}{|c|}{ Valdegoba* } \\
\hline $\mathrm{n}$ & 20 & 18 & 20 & 20 & & 22 & 19 & 18 & 18 \\
\hline rango & $10,4-13,3$ & $8,5-10,7$ & $5,7-6,8$ & $6,6-7,7$ & & $5,2-7,3$ & $6,2-7,4$ & $5,4-20,2$ & $5,2-20,2$ \\
\hline $\bar{x} \pm$ s.d. & $11,8 \pm 0,9$ & $9,4 \pm 0,6$ & $6,3 \pm 0,3$ & $7,2 \pm 0,3$ & & $6,1 \pm 0,5$ & $6,6 \pm 0,4$ & $12,4 \pm 3,6$ & $13,5 \pm 3,9$ \\
\hline \multicolumn{10}{|c|}{ Valdegoba } \\
\hline $\mathrm{n}$ & 147 & 125 & 147 & 147 & & 200 & 124 & 186 & 185 \\
\hline rango & $8,7-15,0$ & $8,3-12,1$ & $5,3-8,6$ & $5,8-11,3$ & & $4,8-8,8$ & $5,9-11,3$ & $1,6-26,3$ & $2,9-24,8$ \\
\hline $\bar{x} \pm$ s.d. & $11,7 \pm 1,2$ & $9,6 \pm 0,7$ & $6,3 \pm 0,5$ & $7,2 \pm 0,7$ & & $6,2 \pm 0,6$ & $6,8 \pm 0,8$ & $10,8 \pm 4,8$ & $11,7 \pm 5,2$ \\
\hline \multicolumn{10}{|c|}{ Prado Vargas } \\
\hline $\mathrm{n}$ & 2 & 1 & 2 & 2 & 2 & 2 & 2 & 2 & \\
\hline rango & $10,8-13,5$ & 12,2 & $6,9-7,3$ & $7,8-8,5$ & $7,5-8,0$ & $7,8-8,5$ & $12,3-21,6$ & $12,3-22,5$ & \\
\hline$\overline{\mathrm{x}} \pm$ s.d. & $12,1 \pm 1,8$ & & $7,1 \pm 0,3$ & $8,2 \pm 0,5$ & $7,8 \pm 0,4$ & $8,2 \pm 0,5$ & $16,9 \pm 6,6$ & $17,4 \pm 7,2$ & \\
\hline \multicolumn{10}{|l|}{ Millán } \\
\hline $\mathrm{n}$ & 8 & 6 & 7 & 8 & & 8 & 7 & 6 & 6 \\
\hline rango & $10,6-13,8$ & $8,8-11,7$ & $6,4-8,2$ & $5,9-9,7$ & & $5,5-9,1$ & $6,9-7,3$ & $2,0-26,9$ & $2,6-27,5$ \\
\hline $\bar{x} \pm$ s.d. & $12,3 \pm 1,1$ & $10,5 \pm 1,3$ & $7,3 \pm 0,7$ & $7,6 \pm 1,2$ & & $7,1 \pm 1,4$ & $7,1 \pm 0,1$ & $13,7 \pm 9,2$ & $14,2 \pm 9,0$ \\
\hline \multicolumn{10}{|c|}{ Estebanvela } \\
\hline$n=1$ & 11,5 & 9,8 & 7,3 & 8,6 & & 7,5 & 8,6 & 11,1 & 12,2 \\
\hline \multicolumn{10}{|l|}{$\mathbf{M}_{2}$} \\
\hline \multicolumn{10}{|c|}{ Valdegoba * } \\
\hline $\mathrm{n}=1$ & 13,4 & & 6,2 & 6,3 & & 5,4 & & & \\
\hline \multicolumn{10}{|c|}{ Valdegoba } \\
\hline $\mathrm{n}$ & 97 & 85 & 91 & 98 & & 153 & 86 & 144 & 144 \\
\hline rango & $9,3-14,7$ & $8,5-11,9$ & $5,4-8,2$ & $5,2-8,5$ & & $4,6-8,6$ & $5,3-8,9$ & $4,4-25,4$ & $4,1-25,6$ \\
\hline $\bar{x} \pm$ s.d. & $12,8 \pm 0,9$ & $10,6 \pm 0,6$ & $6,9 \pm 0,4$ & $7,5 \pm 0,5$ & & $6,4 \pm 0,7$ & $7,2 \pm 0,6$ & $13,2 \pm 5,7$ & $14,8 \pm 6,2$ \\
\hline \multicolumn{10}{|c|}{ Prado Vargas } \\
\hline $\mathrm{n}=1$ & 12,9 & 10,8 & 6,7 & 6,9 & 6,1 & 6,9 & 18,3 & 20,0 & \\
\hline \multicolumn{10}{|l|}{ Millán } \\
\hline $\mathrm{n}$ & 3 & 1 & 2 & 2 & & 4 & 1 & 1 & 1 \\
\hline rango & $13,4-14,0$ & 11,6 & $6,8-8,4$ & $6,7-8,8$ & & $6,1-8,8$ & 8,8 & 20,0 & 21,4 \\
\hline $\bar{x} \pm$ s.d. & $13,6 \pm 0,3$ & & $7,6 \pm 1,1$ & $7,7 \pm 1,5$ & & $7,1 \pm 1,2$ & & & \\
\hline \multicolumn{10}{|l|}{$\mathbf{M}_{3}$} \\
\hline \multicolumn{10}{|c|}{ Valdegoba * } \\
\hline $\mathrm{n}$ & 22 & 20 & 21 & 21 & 22 & 21 & 19 & 20 & 20 \\
\hline rango & $15,3-19,6$ & $6,9-19,2$ & $6,6-8,0$ & $6,1-7,4$ & $3,7-5,8$ & $5,5-6,9$ & $5,9-7,6$ & $15,2-26,8$ & $17,7-27,2$ \\
\hline $\bar{x} \pm$ s.d. & $17,5 \pm 1,0$ & $16,1 \pm 2,5$ & $7,2 \pm 0,4$ & $6,9 \pm 0,4$ & $4,8 \pm 0,6$ & $6,2 \pm 0,4$ & $6,6 \pm 0,5$ & $20,0 \pm 3,5$ & $20,5 \pm 3,5$ \\
\hline \multicolumn{10}{|c|}{ Valdegoba } \\
\hline $\mathrm{n}$ & 104 & 90 & 117 & 126 & 111 & 148 & 84 & 144 & 148 \\
\hline rango & $15,6-19,8$ & $16,2-18,6$ & $4,6-7,8$ & $4,5-7,7$ & $1,7-6,6$ & $2,6-7,6$ & $3,8-7,7$ & $5,3-24,8$ & $5,3-25,7$ \\
\hline $\bar{x} \pm$ s.d. & $17,5 \pm 0,7$ & $16,5 \pm 1,1$ & $7,0 \pm 0,5$ & $6,7 \pm 0,5$ & $4,4 \pm 0,7$ & $6,2 \pm 0,8$ & $6,5 \pm 0,6$ & $14,3 \pm 6,0$ & $14,6 \pm 6,3$ \\
\hline \multicolumn{10}{|l|}{ Millán } \\
\hline $\mathrm{n}$ & 4 & 1 & 3 & 3 & 3 & 5 & 2 & 2 & 1 \\
\hline rango & $17,3-18,1$ & 16,8 & $6,9-7,6$ & $6,8-7,3$ & $3,6-4,2$ & $5,3-7,2$ & $6,8-7,0$ & $13,1-22,9$ & 23,9 \\
\hline$\overline{\mathrm{x}} \pm$ s.d. & $17,7 \pm 0,3$ & & $7,2 \pm 0,4$ & $7,1 \pm 0,3$ & $4,0 \pm 0,3$ & $6,0 \pm 0,7$ & $6,9 \pm 0,2$ & $18,0 \pm 6,9$ & \\
\hline
\end{tabular}

* Hace referencia a las piezas que presentan una columna interlobular.

Molares inferiores permanentes (lámina V.9.1: 1) (tabla V.9.6) (figura V.9.2): dientes con las coronas bajas, selenodontas, con estilos de desarrollo variable y con las cúspides fusionadas. Carecen de islote central de esmalte, de columna interlobular y de cíngulos. Tienen dos raíces: una mesial y otra distal. Son bilobulados, salvo el $\mathrm{M}_{3}$ que tiene apariencia trilobulada debido al gran desarrollo del hipoconúlido. El lóbulo mesial está menos proyectado que el distal. Los valores más grandes de esta especie se solapan con los más pequeños de C. pyrenaica (tablas V.9.6 y V.10.6). 
En la Cueva de Valdegoba se han identificado dos morfologías distintas en cada uno de los molares (figura V.9.1). La primera encaja bien con el esquema general de Rupicapra; y la segunda es similar, pero añadiendo una pequeña columna de desarrollo variable en la cara lingual. Ambas morfologías no se diferencian métricamente (tabla V.9.6).
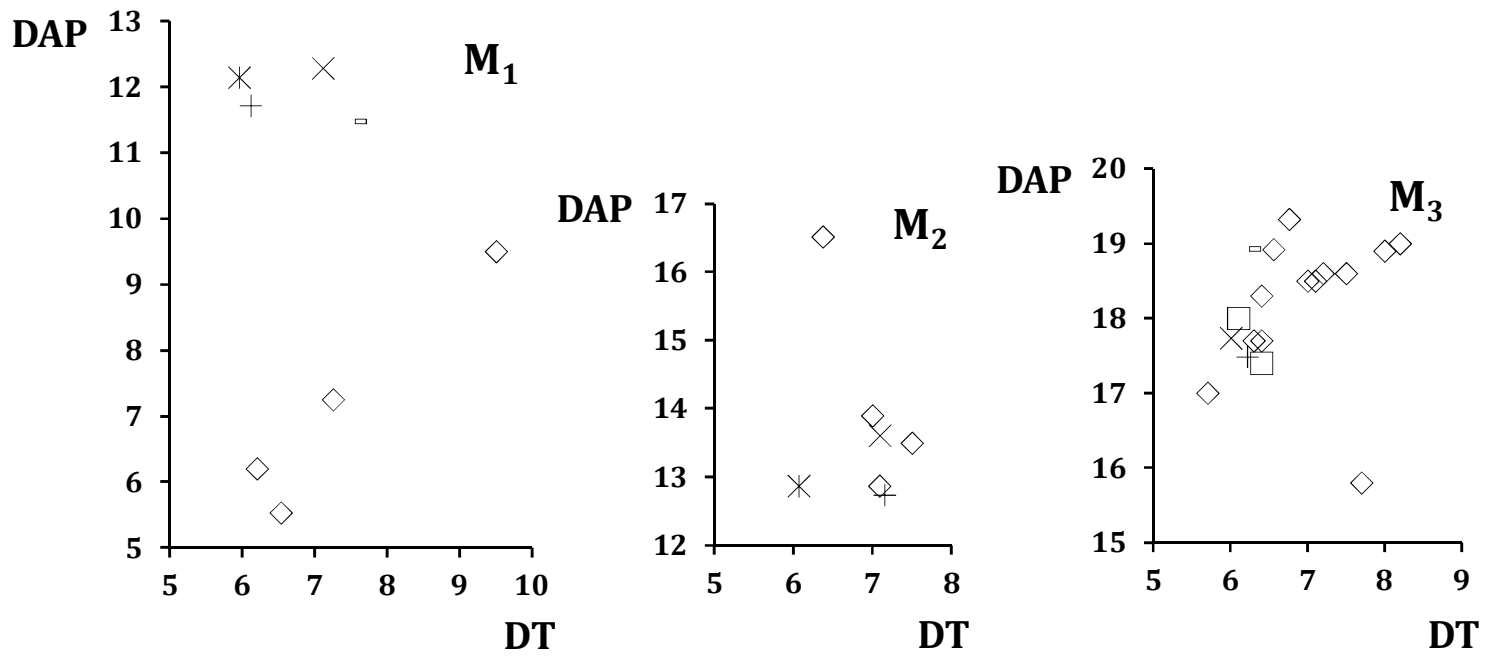

$\diamond$ R. pyrenaica $\square$ R. rupicapra + R.p. Valdegoba $*$ R.p. Prado Vargas $\times$ R.p. Millán ${ }^{\circ}$ R.p. Estebanvela

Figura V.9.2. Diagramas bivariantes de los molares inferiores permanentes: DAP (diámetro anteroposterior) y DT (diámetro transversal). R. pyrenaica de Orgnac 3, Le Portel (Fernández y Crégut-Bonnoure, 2007), Erralla, Arlanpe, Jarama VI. R. rupicapra de Abric Romani (Sánchez, 1990), Nacimiento (Álferez et al., 1980 - 1981), Abauntz, Lezika, Lezikako Koba (Castaños et al., 2009), La Riera (Straus et al., 1986), Le Gras (Fernández y Crégut-Bonnoure, 2007).

$\mathbf{M}_{1}$ y $\mathbf{M}_{2}$ : son dientes muy parecidos. Se diferencian en que en el $\mathrm{M}_{1}$ los bordes mesial y distal divergen hacia la superficie oclusal mientras que en el $M_{2}$ se hacen paralelos a medida que nos acercamos a esta superficie. El punto de contacto entre la raíz y la corona está más alto en la cara mesial que en la distal en el $\mathrm{M}_{1}$ mientras que en el $\mathrm{M}_{2}$ están a la misma altura. El segundo molar tiene el lóbulo posterior más pequeño en relación con el lóbulo anterior. Métricamente, se solapan en todas las variables (tabla V.9.6). El M $\mathrm{M}_{1}$ de la Cueva de Valdegoba tiene un tamaño similar al de Prado Vargas, Cueva Millán y al de la Peña de Estebanvela; y son más grandes que los de otros rebecos europeos (figura V.9.1). En el $\mathrm{M}_{2}$ no ocurre lo mismo, ya que su tamaño es similar al de otros sarrios de Europa (figura V.9.1). En el $\mathrm{M}_{3}$ vemos que los restos de la Cueva de Valdegoba y Cueva Millán presentan el mismo tamaño, son parecidos a los $R$. rupicapra de Abric Romaní y Nacimiento, son más pequeños que los de la Peña de Estebanvela y están dentro del rango de R. pyrenaica (figura V.9.1).

$\mathbf{M}_{3}$ : dientes con apariencia trilobulada en el que el diámetro transversal disminuye del mesial al distal. Este carácter permite diferenciarlos de los $\mathrm{D}_{4}$.

Premolares superiores (lámina V.9.1: 4) (tabla V.9.7): dientes de pequeño tamaño, asimétricos, unilobulados, con las coronas altas, sin cíngulos, con los estilos de desarrollo variable, sin surco lingual y con tres raíces, aunque el $\mathrm{P}^{2}$ puede tener fusionadas dos de ellas. Se diferencian de los deciduales por sus coronas más altas y por ser más cortos pero más anchos (tablas V.9.3 y 7). Difieren de los de Capra por sus menores dimensiones (tabla V.9.7 y V.10.7) aunque los rangos de diversas variables pueden solaparse.

P2: dientes asimétricos debido a que se estrechan hacia el extremo mesial. El paracono es la cúspide más desarrollada. Carece de surco lingual entre el paracono y el hipocono. Las caras lingual y bucal son ligeramente convexas. 
P3: diente cuadrangular con el paracono muy desarrollado. La paraectocrista está desplazada mesialmente lo que le da un aspecto asimétrico y, además está menos desarrollada que en el $\mathrm{P}^{4}$. Carece de surco lingual al igual que el $\mathrm{P}^{2}$. Las caras lingual y bucal son rectas o ligeramente convexas. Los bordes mesial y distal son divergentes. Son más estrechos que los $\mathrm{P}^{4}$.

P4: diente simétrico ya que la paraectocrístida está situada en una posición central. Tanto los estilos como la paraectocrista están muy proyectados. Son más anchos que los $\mathrm{P}^{3}$.

Tabla V.9.7

Medidas tomadas en los premolares superiores de $R$. pyrenaica

\begin{tabular}{|c|c|c|c|c|c|c|c|}
\hline & DAP & DAPb & DTa & DTp & DT & DTb & $\mathbf{H}$ \\
\hline \multicolumn{8}{|l|}{$\mathbf{P}^{2}$} \\
\hline \multicolumn{8}{|c|}{ Valdegoba } \\
\hline $\mathrm{n}$ & 115 & 107 & 119 & 115 & 126 & 109 & 54 \\
\hline rango & $4,9-7,3$ & $4,4-6,5$ & $4,0-7,1$ & $3,6-7,0$ & $4,2-6,6$ & $4,1-6,9$ & $4,0-12,7$ \\
\hline$\overline{\mathrm{x}} \pm$ s.d. & $5,8 \pm 0,5$ & $5,3 \pm 0,4$ & $4,8 \pm 0,6$ & $5,3 \pm 0,6$ & $5,1 \pm 0,5$ & $5,0 \pm 0,5$ & $7,2 \pm 1,9$ \\
\hline \multicolumn{8}{|l|}{ Millán } \\
\hline$n=1$ & 5,6 & 5,0 & 4,8 & 5,5 & 4,9 & 5,5 & 5,1 \\
\hline \multicolumn{8}{|c|}{ Estebanvela } \\
\hline $\mathrm{n}$ & 2 & 2 & 2 & 2 & 2 & 2 & 2 \\
\hline rango & $5,7-7,5$ & $5,6-6,2$ & $5,8-9,2$ & $6,1-8,9$ & $6,1-8,2$ & $6,1-8,9$ & $4,4-9,5$ \\
\hline $\bar{x} \pm$ s.d. & $6,6 \pm 1,3$ & $5,9 \pm 0,4$ & $7,5 \pm 2,4$ & $7,5 \pm 2,0$ & $7,1 \pm 1,5$ & $7,5 \pm 2,0$ & $6,9 \pm 3,6$ \\
\hline \multicolumn{8}{|l|}{$\mathbf{P}^{3}$} \\
\hline \multicolumn{8}{|c|}{ Valdegoba } \\
\hline $\mathrm{n}$ & 100 & 92 & 91 & 89 & 122 & 80 & 101 \\
\hline rango & $5,6-8,3$ & $4,4-7,2$ & $5,5-8,2$ & $5,8-8,2$ & $5,0-7,4$ & $5,1-7,6$ & $2,8-13,2$ \\
\hline$\overline{\mathrm{x}} \pm$ s.d. & $7,1 \pm 0,5$ & $5,8 \pm 0,4$ & $6,6 \pm 0,6$ & $7,0 \pm 0,5$ & $6,1 \pm 0,5$ & $6,4 \pm 0,5$ & $7,2 \pm 2,0$ \\
\hline \multicolumn{8}{|l|}{ Millán } \\
\hline$n=1$ & 7,8 & 6,2 & 6,8 & 7,3 & 6,7 & 7,3 & 8,2 \\
\hline \multicolumn{8}{|l|}{$\mathbf{P}^{4}$} \\
\hline \multicolumn{8}{|c|}{ Valdegoba } \\
\hline $\mathrm{n}$ & 100 & 85 & 88 & 86 & 128 & 88 & 103 \\
\hline rango & $5,2-8,7$ & $4,1-6,7$ & $5,1-9,0$ & $4,4-9,1$ & $5,0-10,0$ & $5,2-9,1$ & $3,7-13,3$ \\
\hline$\overline{\mathrm{x}} \pm$ s.d. & $7,3 \pm 0,6$ & $5,8 \pm 0,4$ & $7,9 \pm 0,6$ & $8,1 \pm 0,8$ & $7,3 \pm 0,8$ & $7,7 \pm 0,5$ & $8,3 \pm 2,3$ \\
\hline \multicolumn{8}{|c|}{ Prado Vargas } \\
\hline$n=1$ & & & & & & & 15,5 \\
\hline \multicolumn{8}{|l|}{ Millán } \\
\hline rango & $6,9-7,8$ & $4,8-5,6$ & $6,6-8,7$ & $7,4-9,1$ & $6,3-8,6$ & $7,4-9,1$ & $9,9-13,1$ \\
\hline$\overline{\mathrm{x}} \pm$ s.d. & $7,4 \pm 0,7$ & $5,2 \pm 0,5$ & $7,7 \pm 1,5$ & $8,2 \pm 1,3$ & $7,4 \pm 1,6$ & $8,2 \pm 1,3$ & $11,5 \pm 2,3$ \\
\hline \multicolumn{8}{|c|}{ Estebanvela } \\
\hline$n=1$ & 6,7 & 6,4 & 9,4 & 8,7 & 7,9 & 9,4 & 7,4 \\
\hline
\end{tabular}

Molares superiores permanentes (lámina V.9.1: 4) (tabla V.9.8) (figura V.9.3): son dientes de pequeño tamaño, con las coronas bajas y dos lóbulos. Tienen las cúspides fusionadas y una morfología selenodonta. Los estilos pueden presentar un desarrollo variable pero carecen de cíngulos y columnas interlobulares. Tienen un islote central de esmalte y tres raíces: una mesial, una distal y otra lingual. El lóbulo mesial está más proyectado que el distal. Se diferencian de los de Capra por sus menores dimensiones (tablas V.9.8 y V.10.8), por la menor proyección de sus estilos y por tener un islote central de esmalte. Difieren de los de Capreolus por tener las cúspides fusionadas y por carecer de columna interlobular.

$\mathbf{M}^{1}$ y $\mathbf{M}^{2}$ : son dientes muy similares. Se diferencian en que en el $\mathrm{M}^{1}$ el paraprestilo y el metapostilo divergen hacia la superficie oclusal mientras que en el $\mathrm{M}^{2}$ son más o menos paralelos. Son más pequeños que los $\mathrm{M}^{2}$, aunque los valores de algunas variables pueden solaparse (tabla V.9.8). Métricamente, las piezas de la Cueva de Valdegoba, Cueva Millán y 
la Peña de Estebanvela son similares pero, son más estrechas que las de otros rebecos europeos (figura V.9.3).

Tabla V.9.8

Medidas tomadas en los molares superiores permanentes de $R$. pyrenaica

\begin{tabular}{|c|c|c|c|c|c|c|c|c|}
\hline & DAP & DAPb & DTa & DTp & DT & DTb & Ha & Hp \\
\hline \multicolumn{9}{|l|}{$\mathbf{M}^{1}$} \\
\hline \multicolumn{9}{|c|}{ Valdegoba } \\
\hline $\mathrm{n}$ & 186 & 157 & 174 & 177 & 219 & 146 & 210 & 210 \\
\hline rango & $11,1-15,0$ & $6,2-12,3$ & $7,5-12,6$ & $6,5-11,7$ & $5,6-13,8$ & $9,3-13,1$ & $2,6-26,6$ & $4,3-26,8$ \\
\hline $\bar{x} \pm$ s.d. & $12,0 \pm 1,3$ & $9,0 \pm 0,7$ & $10,4 \pm 0,8$ & $9,8 \pm 0,9$ & $9,1 \pm 0,9$ & $10,5 \pm 0,5$ & $11,5 \pm 4,1$ & $12,9 \pm 4,1$ \\
\hline \multicolumn{9}{|l|}{ Millán } \\
\hline $\mathrm{n}$ & 3 & 1 & 2 & 2 & 3 & 2 & 2 & 2 \\
\hline rango & $11,0-13,6$ & 9,6 & $9,3-10,1$ & $9,8-10,1$ & $8,3-8,9$ & $9,8-10,1$ & $1,1-12,4$ & $13,5-15,1$ \\
\hline $\bar{x} \pm$ s.d. & $12,4 \pm 1,3$ & & $9,7 \pm 0,6$ & $9,9 \pm 0,2$ & $8,5 \pm 0,3$ & $9,9 \pm 0,2$ & $11,8 \pm 0,9$ & $14,3 \pm 1,1$ \\
\hline \multicolumn{9}{|c|}{ Estebanvela } \\
\hline$n=1$ & 11,7 & 8,7 & 11,2 & 10,6 & 8,8 & 11,2 & 15,2 & 16,4 \\
\hline \multicolumn{9}{|l|}{$\mathbf{M}^{2}$} \\
\hline \multicolumn{9}{|c|}{ Valdegoba } \\
\hline $\mathrm{n}$ & 167 & 143 & 161 & 157 & 196 & 139 & 178 & 181 \\
\hline rango & $10,6-33,1$ & $8,7-12,2$ & $6,2-12,7$ & $6,5-13,6$ & $4,3-11,7$ & $9,5-12,5$ & $4,2-26,1$ & $4,9-27,3$ \\
\hline $\bar{x} \pm$ s.d. & $13,4 \pm 1,7$ & $10,1 \pm 0,7$ & $10,8 \pm 1,0$ & $10,1 \pm 1,1$ & $9,0 \pm 0,9$ & $10,8 \pm 0,6$ & $16,1 \pm 4,8$ & $17,2 \pm 4,7$ \\
\hline \multicolumn{9}{|l|}{ Millán } \\
\hline $\mathrm{n}$ & 2 & 2 & 2 & 2 & 2 & 2 & 2 & 2 \\
\hline rango & $12,3-14,6$ & $9,1-10,1$ & $10,5-10,7$ & $10,2-10,4$ & $9,2-9,2$ & $10,5-10,7$ & $13,9-23,6$ & $15,4-23,2$ \\
\hline $\bar{x} \pm$ s.d. & $13,4 \pm 1,6$ & $9,6 \pm 0,7$ & $10,6 \pm 0,1$ & $10,3 \pm 0,1$ & $9,2 \pm 0,0$ & $10,6 \pm 0,1$ & $18,7 \pm 6,8$ & $19,3 \pm 5,4$ \\
\hline \multicolumn{9}{|c|}{ Estebanvela } \\
\hline $\mathrm{n}=1$ & 12,9 & 11,0 & 10,8 & 10,8 & 9,3 & 10,8 & 15,2 & 17,5 \\
\hline \multicolumn{9}{|c|}{$\mathbf{M}^{3}$} \\
\hline \multicolumn{9}{|c|}{ Valdegoba } \\
\hline $\mathrm{n}$ & 154 & 120 & 148 & 145 & 172 & 122 & 158 & 155 \\
\hline rango & $11,7-17,1$ & $9,5-15,5$ & $7,0-12,2$ & $6,1-11,7$ & $1,7-10,8$ & $8,5-12,5$ & $4,5-31,2$ & $5,1-30,1$ \\
\hline $\bar{x} \pm$ s.d. & $13,7 \pm 0,9$ & $11,9 \pm 1,2$ & $10,4 \pm 0,7$ & $9,1 \pm 0,8$ & $8,4 \pm 1,2$ & $10,1 \pm 0,7$ & $16,3 \pm 3,6$ & $17,0 \pm 3,7$ \\
\hline \multicolumn{9}{|l|}{ Millán } \\
\hline $\mathrm{n}$ & 2 & 1 & & 1 & 2 & 1 & & \\
\hline rango & $13,5-15,4$ & 13,0 & & 8,3 & $7,5-7,7$ & 9,1 & & \\
\hline$\overline{\mathrm{x}} \pm$ s.d. & $14,4 \pm 1,4$ & & & & $7,6 \pm 0,2$ & & & \\
\hline
\end{tabular}
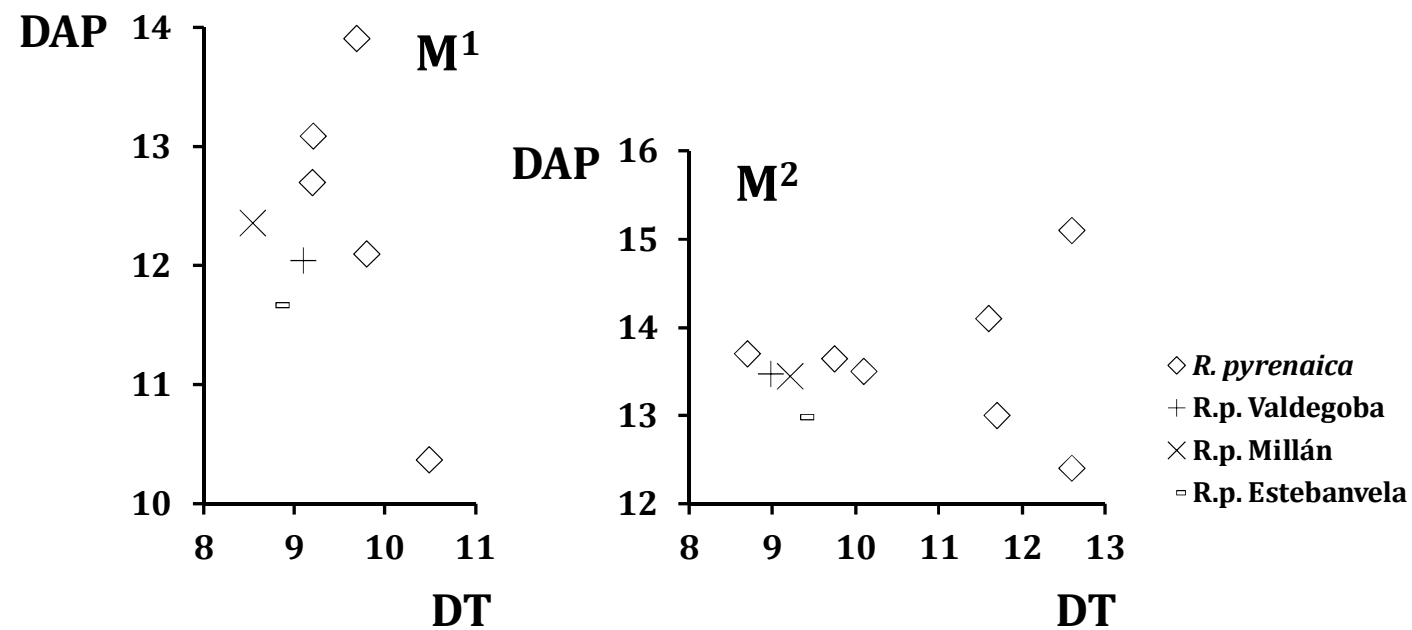

Figura V.9.3. Diagramas bivariantes de los molares superiores: DAP (diámetro anteroposterior) y DT (diámetro transversal). R. pyrenaica de Arlanpe, Jarama VI, Buraca Escura, Arago, Portel (Fernández y CrégutBonnoure, 2007), Abri Marcq (Rivals, 2002) y Salemas (Álferez et al., 1980 - 1981). 
$\mathbf{M}^{3}$ : se separa bien de los dos anteriores por la mayor diferencia de tamaño del lóbulo distal en relación al mesial y porque el metapostilo está más desarrollado. Una de las piezas de Cueva Millán no tiene islote central de esmalte, probablemente por su escasa erosión. En la base del borde posterolingual pueden tener un ligero abultamiento. Son más grandes que $\mathrm{M}^{1} \mathrm{y} \mathrm{M}^{2}$ (tabla V.9.8).

Escápula (lámina V.9.1: 15) (tabla V.9.9) (figura V.9.4: 1 y 2): es un hueso triangular con una apófisis espinosa muy marcada que define una fosa supraspinosa estrecha. La espina es sinuosa y se encuentra inclinada caudalmente en la porción media y ventralmente en la rostral. Se proyecta ventralmente, terminando en el acromion donde se inserta el deltoides. La cavidad glenoidea es casi circular y no tiene ningún tipo de escotadura. Se han recuperado 23 fragmentos, conservando 14 de ellos parte de su superficie articular. Ninguna de ellas tiene el acromion. La tuberosidad supraglenoidea está muy marcada. La cavidad glenoidea es cóncava y redondeada, uniéndose a la tuberosidad suplaglenoidea mediante una cresta ancha. Las líneas musculares de la fosa infraespinosa no están muy desarrolladas.

Tabla V.9.9

Medidas tomadas en las escápulas del R. pyrenaica de la Cueva de Valdegoba

\begin{tabular}{lccc}
\hline & GLP & GL & BG \\
\hline $\mathrm{n}$ & 5 & 6 & 10 \\
rango & $29,6-34,2$ & $20,8-27,0$ & $18,3-22,6$ \\
$\overline{\mathrm{x}} \pm$ s.d. & $31,6 \pm 2,1$ & $25,3 \pm 2,4$ & $20,6 \pm 1,2$ \\
\hline
\end{tabular}

Difiere del corzo por el gran desarrollo de la apófisis espinosa, por la cresta ancha y marcada que une la tuberosidad supraglenoidea con la cavidad glenoidea, por la proyección de la fosa supraespinosa y por el desarrollo de las líneas musculares en esta zona. Se diferencia de $R$. rupicapra por tener la cavidad glenoidea más redondeada y por presentar la tuberosidad glenoidea más proyectada (figura V.9.4).

Tabla V.9.10

Medidas tomadas en los húmeros del R. pyrenaica de la Cueva de Valdegoba

\begin{tabular}{lcc}
\hline & BT & BD \\
\hline $\mathrm{n}$ & 5 & 7 \\
rango & $13,7-30,3$ & $28,8-33,0$ \\
$\overline{\mathrm{x}} \pm$ s.d. & $17,6 \pm 7,1$ & $30,9 \pm 1,8$ \\
\hline
\end{tabular}

Húmero (lámina V.9.1: 25) (tabla V.9.10) (figura V.9.4: 3 y 4): la mayoría de los restos son epífisis distales de individuos maduros. La superficie articular distal o cóndilo es muy oblicuo y los surcos y crestas están muy marcados. La fosa olecranoidea es profunda y presenta una morfología triangular. La fosa radial es profunda y ancha. El epicóndilo lateral está poco marcado. Las áreas de inserción de los músculos extensor y flexor están poco desarrolladas.

Estas piezas son prácticamente iguales en ambas especies de rebecos. La única diferencia observada en la epífisis distal se encuentra en que $R$. pyrenaica tiene menos marcada la fosa radial (figura figura V.9.4).

Radios (lámina V.9.1: 5) (tabla V.9.11) (figura V.9.4: 5 y 6): huesos largos, anchos y ligeramente oblicuos. La superficie articular proximal tiene una fosa sinovial bien marcada. El borde lateral de esta fosa es más o menos redondeado mientras que el anterior tiene dos pliegues. El primero corresponde con una depresión que recorre anteroposteriormente la superficie articular proximal, mientras que el segundo coincide con la concavidad de la cara articular situada más lateralmente. La cara anterior es plana. 


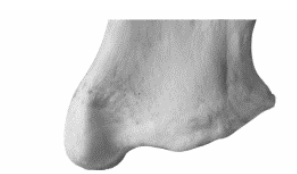

1.a

1.b

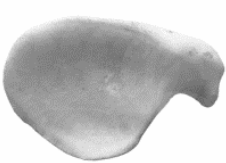

$2 \mathrm{~cm}$

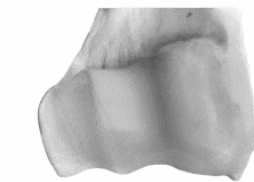

3.a
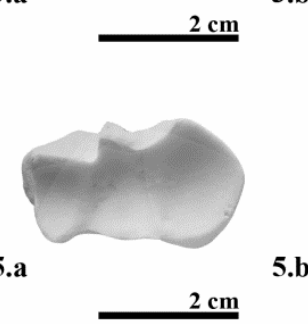

$5 . \mathbf{b}$

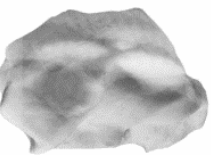

b

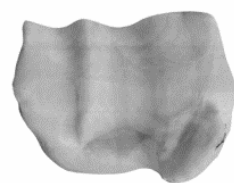

3.b

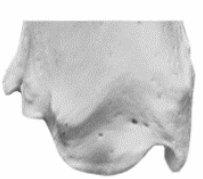

7.a

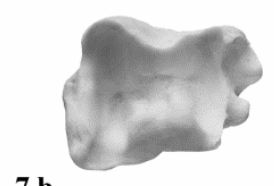

7.b

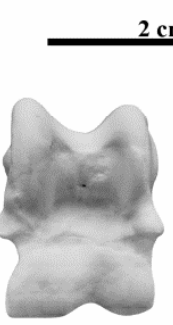

9.a

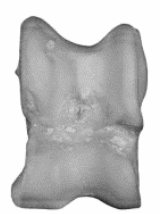

10.a

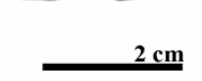

$10 . b$

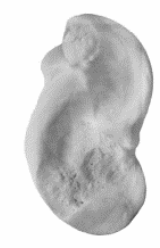

9.b

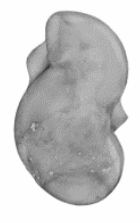

10.

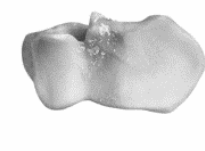

6.a

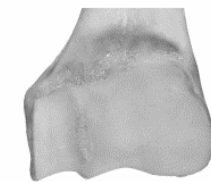

4.a

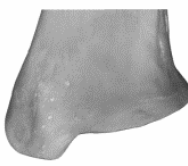

2.a

2.b
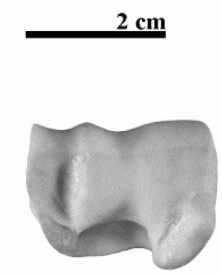

4.b
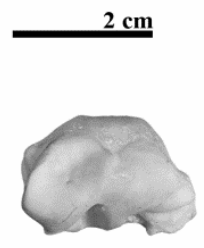

6.b

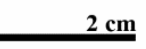

8.a

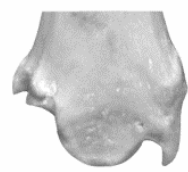

8.b
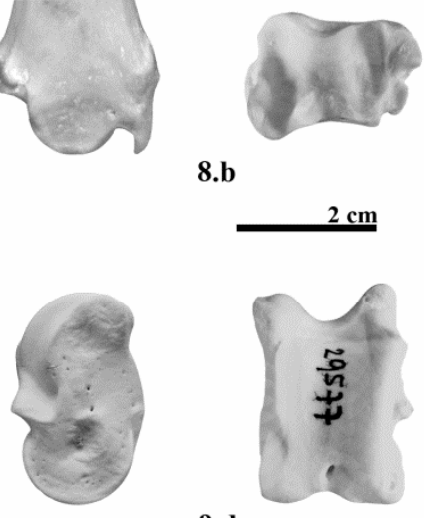

9.c

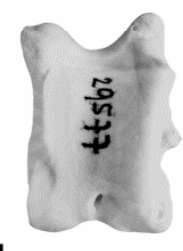

9.d

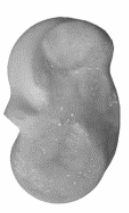

10.d
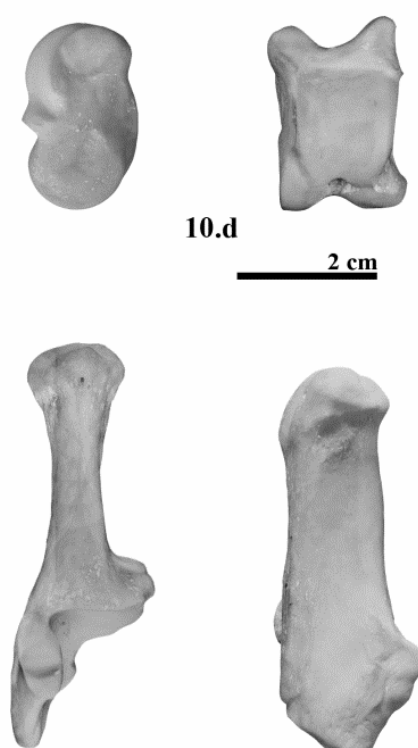

12.a

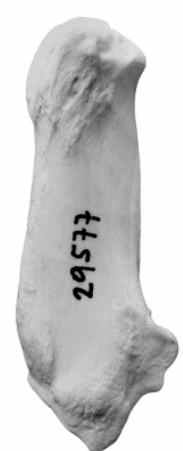

11.b

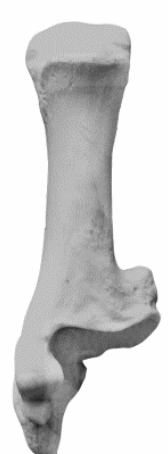

11.a

Figura V.9.4. Diferencias observadas en las escápulas, húmeros, radios, tibias, astrágalos y calcáneos de: 1$) R$. rupicapra ( 异 actuales $(1,3,5,7,9$ y 11). 2) $R$. pyrenaica ( 异 actuales $(2,4,6,8,10$ y 12$)$. 
El borde medial tiene una protuberancia radial muy marcada. La cara palmar tiene, en la región proximal, unas protuberancias muy marcadas para la inserción de diferentes músculos, formando una superficie triangular. La superficie articular distal presenta varias carillas articulares para la fila proximal del carpo. La carilla del navicular es estrecha y fuertemente oblicua, aunque se ensancha hacia la cara anterior. Dicha cara se encuentra separada de la carilla del semilunar por una cresta marcada, también oblicua. Esta cara es amplia proximalmente y estrecha distalmente. Está separada por un pequeño pliegue de la carilla articular del piramidal. La cara que articula con la ulna es grande y está situada en la cara palmar. Difieren de R. rupicapra por la menor profundidad de las caras articulares y por tener las regiones de inserción muscular más pequeñas (figura V.9.4).

Tabla V.9.11

Medidas tomadas en los radios de R. pyrenaica

\begin{tabular}{|c|c|c|c|c|c|c|c|c|}
\hline & GL & BP & BFp & DP & SD & BD & DD & BFd \\
\hline \multicolumn{9}{|c|}{ Maduros } \\
\hline \multicolumn{9}{|c|}{ Valdegoba } \\
\hline $\mathrm{n}$ & & 19 & 19 & 20 & & 7 & 6 & 6 \\
\hline rango & & $28,1-38,9$ & $28,1-37,6$ & $8,3-16,5$ & & $24,7-28,3$ & $17,0-21,8$ & $24,7-28,2$ \\
\hline $\bar{x} \pm$ s.d. & & $30,6 \pm 2,3$ & $30,4 \pm 2,1$ & $15,2 \pm 1,8$ & & $27,1 \pm 1,3$ & $19,2 \pm 1,7$ & $26,3 \pm 1,2$ \\
\hline \multicolumn{9}{|c|}{ Estebanvela } \\
\hline $\mathrm{n}=1$ & & 27,3 & & 15 & & & & \\
\hline \multicolumn{9}{|c|}{ Inmaduros } \\
\hline \multicolumn{9}{|c|}{ Valdegoba } \\
\hline $\mathrm{n}$ & 2 & 3 & 2 & 3 & 2 & 10 & 11 & 9 \\
\hline rango & $124,1-126,3$ & $24,6-30,5$ & $25,3-30,5$ & $12,5-15,9$ & $14,5-16,5$ & $21,6-29,3$ & $16,0-22,1$ & $23,0-29,3$ \\
\hline $\bar{x} \pm$ s.d. & $125,2 \pm 1,5$ & $26,8 \pm 3,2$ & $27,9 \pm 3,6$ & $13,9 \pm 1,8$ & $15,5 \pm 1,4$ & $26,9 \pm 2,7$ & $19,3 \pm 1,8$ & $26,7 \pm 2,0$ \\
\hline
\end{tabular}

Metacarpo III + IV (lámina V.9.1: 19) (tabla V.9.12) (figura V.9.5: 1 y 3): huesos largos con la superficie dorsal redondeada y, a diferencia de los cérvidos, con el surco vascular poco marcado. La superficie palmar es plana aunque en los extremos proximal y distal se distinguen dos surcos para la inserción de diferentes ligamentos. El extremo proximal tiene dos caras articulares ligeramente cóncavas para articularse con los huesos de la fila proximal del carpo. La cara medial es más grande y está separada de la lateral por una depresión profunda que se abre en la cara palmar, formando un surco marcado en dicha cara y que en algunos casos puede dividirse en dos depresiones. El borde medial tiene unas tuberosidades apenas visibles en los bordes dorsal y palmar. El borde dorsal tiene la tuberosidad metacarpiana apenas esbozada. La superficie articular distal presenta dos cóndilos para la articulación con las dos falanges proximales. Estos cóndilos están separados por una escotadura sagital, denominada inserción intertroclear que termina en punta. El contacto entre la diáfisis y la epífisis es muy marcado originando unos bordes medial y lateral fuertemente convexos.

Tabla V.9.12

Medidas tomadas en los metacarpos y metatarsos de R. pyrenaica

\begin{tabular}{|c|c|c|c|c|c|c|c|c|}
\hline & GL & BP & DP & SD & BD & DD & PL & PM \\
\hline \multicolumn{9}{|c|}{ Metacarpos III + IV } \\
\hline \multicolumn{9}{|c|}{ Valdegoba } \\
\hline $\mathrm{n}$ & 6 & 20 & 20 & 6 & 20 & 3 & 3 & 3 \\
\hline rango & $144,6-168,1$ & $18,5-26,0$ & $14,6-18,5$ & $15,2-17,3$ & $24,3-28,4$ & $15,1-18,1$ & $15,0-17,4$ & $14,9-18,5$ \\
\hline $\bar{x} \pm$ s.d. & $156 \pm 9,8$ & $23,6 \pm 1,7$ & $16,7 \pm 1,0$ & $16,0 \pm 0,8$ & $26,7 \pm 1,0$ & $16,4 \pm 1,5$ & $15,9 \pm 1,3$ & $16,5 \pm 1,8$ \\
\hline \multicolumn{9}{|l|}{ Millán } \\
\hline $\mathrm{n}=1$ & & 23,4 & 16,5 & & & & & \\
\hline \multicolumn{9}{|c|}{ Metatarsos III + IV } \\
\hline \multicolumn{9}{|c|}{ Valdegoba } \\
\hline $\mathrm{n}$ & 3 & 16 & 15 & 3 & 10 & 13 & 13 & 14 \\
\hline rango & $161,3-178,2$ & $20,7-26,6$ & $20,4-24,4$ & $13,1-15,8$ & $23,1-30,7$ & $16,0-18,8$ & $15,7-18,2$ & $16,2-19,4$ \\
\hline $\bar{x} \pm$ s.d. & $169,7 \pm 8,4$ & $22,8 \pm 1,4$ & $22,0 \pm 1,1$ & $14,5 \pm 1,3$ & $28,3 \pm 2,2$ & $17,3 \pm 0,9$ & $16,9 \pm 0,8$ & $17,6 \pm 1,0$ \\
\hline
\end{tabular}


Estos restos se diferencian de los del rebeco alpino por tener una superficie articular proximal más redondeada, unas zonas de inserción muscular más pequeñas, unos tubérculos distales más prominentes y por ser más gráciles (figura V.9.5).

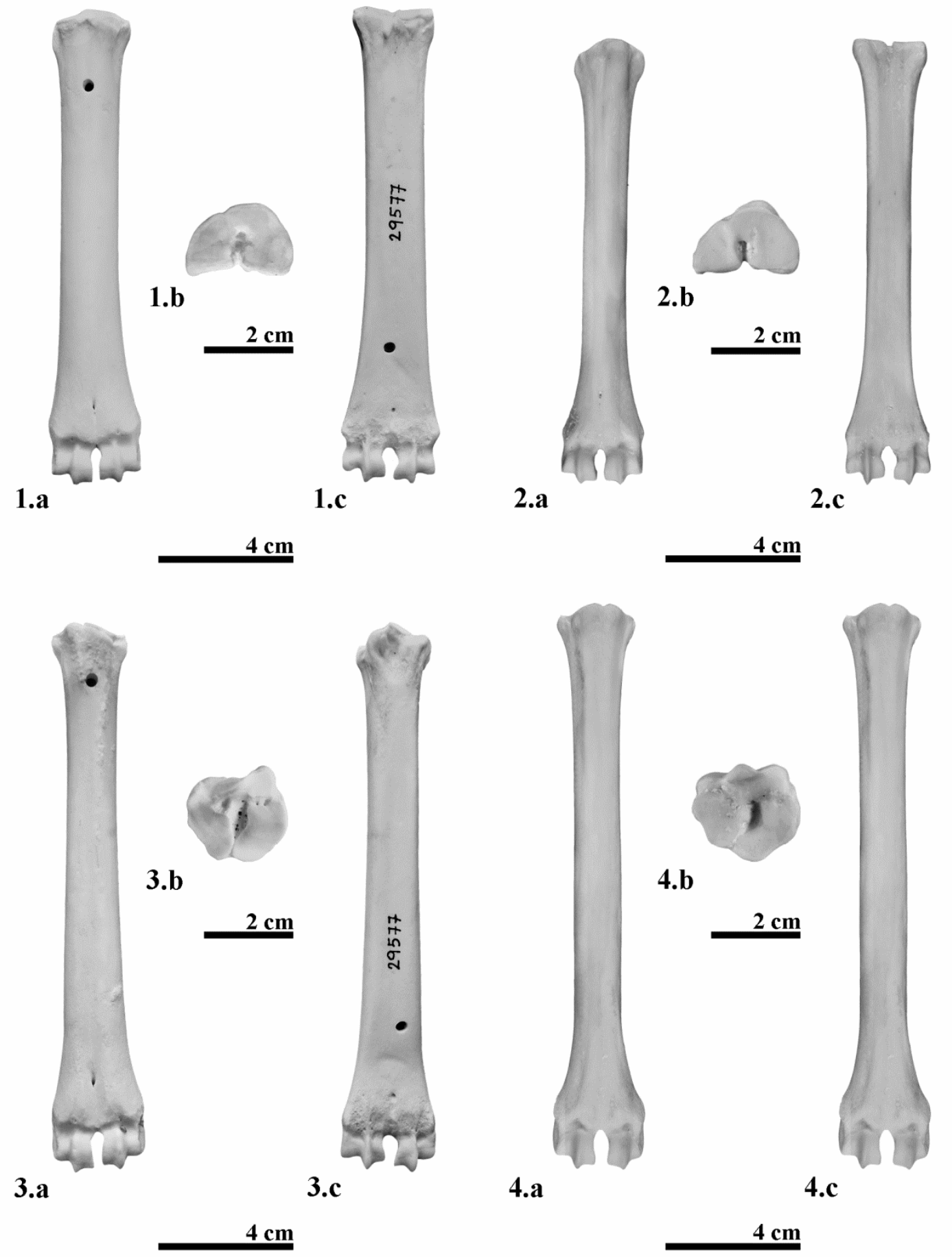

Figura V.9.5. Diferencias observadas en metacarpos y metatarsos de: 1) R. rupicapra ( 9 actuales $(1,3)$. 2) $R$. pyrenaica $($ fo actuales $(2,4)$.

Patella (lámina V.9.1: 18) (tabla V.9.13): hueso corto, estrecho y grueso. Se estrecha distalmente lo que le da una apariencia triangular. La cara anterior es convexa y rugosa, mientras que la posterior es cóncava. El borde medial es más recto que el lateral. La apófisis cartilaginosa está muy marcada en el borde proximal, lo que difiere en el corzo. 
Tabla V.9.13

Medidas tomadas en las patellas del R. pyrenaica de la Cueva de Valdegoba

\begin{tabular}{lccc}
\hline & GL & BM & DM \\
\hline $\mathrm{n}$ & 10 & 14 & 14 \\
rango & $22,4-32,4$ & $13,8-21,2$ & $11,7-20,0$ \\
$\overline{\mathrm{x}} \pm$ s.d. & $27,6 \pm 3,1$ & $18,5 \pm 1,9$ & $15,6 \pm 2,2$ \\
\hline
\end{tabular}

Tibias (lámina V.9.1: 26) (tabla V.9.14) (figura V.9.4: 7 y 8): la mayor parte de las piezas son epífisis distales, de las cuales once pertenecen a ejemplares inmaduros. Los surcos articulares y la cresta intermedia tienen una orientación sagital. El maleolo medial apenas se encuentra desarrollado. El surco lateral está muy marcado y es continuo. Las líneas de inserción muscular de la cara caudal apenas están marcadas.

Tabla V.9.14

\begin{tabular}{|c|c|c|c|}
\hline & SD & BD & DD \\
\hline \multicolumn{4}{|c|}{ Maduros } \\
\hline \multicolumn{4}{|c|}{ Valdegoba } \\
\hline $\mathrm{n}$ & 3 & 23 & 22 \\
\hline rango & $15,2-15,9$ & $23,2-28,5$ & $18,1-20,9$ \\
\hline$\overline{\mathrm{x}} \pm$ s.d. & $15,5 \pm 0,3$ & $26,6 \pm 1,3$ & $19,6 \pm 0,8$ \\
\hline \multicolumn{4}{|c|}{ Inmaduro } \\
\hline $\mathrm{n}$ & & 10 & 8 \\
\hline rango & & $24,7-27,9$ & $18,1-21,2$ \\
\hline$\overline{\mathrm{x}} \pm$ s.d. & & $26 \pm 1,1$ & $19,6 \pm 1,0$ \\
\hline
\end{tabular}

Difieren del corzo en que la fosa sinovial apenas se encuentra marcada y en que las caras articulares del maléolo lateral están conectadas por un pequeño cuello. Difieren de $R$. rupicapra en la forma del borde dorsal de la epífisis distal que es menos oblicua (figura V.9.4).

Astrágalo (lámina V.9.1: 13) (tabla V.9.15) (figura V.9.4: 9 y 10): es un hueso estrecho y aplanado dorsoventralmente que presenta una tróclea en cada extremo. Los surcos y crestas de ambas trócleas siguen una dirección sagital. La tróclea proximal presenta una cresta lateral más ancha que la medial que articula tanto con la tibia como con la fíbula. La cara palmar tiene una depresión que separa la tróclea proximal de la distal, presentando una morfología más o menos rectangular. La parte inferior de esta tróclea tiene dos protuberancias para la inserción de ligamentos. Por debajo de ellas, hay un surco que separa la tróclea proximal de la distal y que va desde la cara lateral a la medial. La cara plantar presenta dos caras articulares. La más grande, y que ocupa la mayor parte de la superficie, es la que articula con el calcáneo. Su borde proximal está separado de la tróclea proximal por una pequeña depresión que no se abre ni lateral ni medialmente. Tanto el borde lateral como el medial son ligeramente oblicuos. En su parte distal, está separada de la cara que articula con el escafocuboides por una cresta poco marcada que continúa con un surco muy desarrollado en dirección proximal que, en algunos casos, no se aprecia muy bien. La cara articular del escafoides es estrecha y alargada y, en algunos casos, se proyecta hasta la mitad de la cara plantar, terminando en forma redondeada o apuntada. En vista medial, la tróclea proximal tiene una protuberancia poco marcada y redondeada. Las piezas recuperadas tienen los dos extremos de la tróclea proximal muy separados y más o menos a la misma altura. La cresta lateral es más ancha que la medial. La tróclea distal tiene una convexidad acentuada. La cara palmar es rectangular y tiene una depresión que separa la tróclea proximal de la distal. Difieren de $R$. rupicapra por el menor desarrollo de la trócela distal y por el mayor desarrollo de las zonas de inserción muscular. 
Tabla V.9.15

Medidas tomadas en los astrágalos de R. pyrenaica

\begin{tabular}{|c|c|c|c|c|c|c|c|}
\hline & GLI & GLm & DL & DM & BP & BD & ATPL \\
\hline \multicolumn{8}{|c|}{ Maduros } \\
\hline \multicolumn{8}{|c|}{ Valdegoba } \\
\hline $\mathrm{n}$ & 72 & 73 & 72 & 70 & 69 & 68 & 72 \\
\hline rango & $28,2-32,5$ & $26,2-31,1$ & $14,9-19,2$ & $15,3-19,3$ & $16,1-21,3$ & $15,4-22,2$ & $16,0-22,6$ \\
\hline$\overline{\mathrm{x}} \pm$ s.d. & $30,5 \pm 0,9$ & $28,9 \pm 1,0$ & $17,0 \pm 0,9$ & $17,6 \pm 0,9$ & $19,2 \pm 1,0$ & $19,5 \pm 1,2$ & $18,3 \pm 1,1$ \\
\hline \multicolumn{8}{|c|}{ Estebanvela } \\
\hline $\mathrm{n}$ & 2 & 2 & 2 & 1 & & 2 & \\
\hline rango & $28,9-29,4$ & $26,2-28,0$ & $15,9-16,1$ & 17,8 & & $19,3-19,5$ & \\
\hline$\overline{\mathrm{x}} \pm$ s.d. & $29,1 \pm 0,3$ & $27,1 \pm 1,2$ & $16,0 \pm 0,1$ & & & $19,4 \pm 0,2$ & \\
\hline \multicolumn{8}{|c|}{ Inmaduros } \\
\hline \multicolumn{8}{|c|}{ Valdegoba } \\
\hline $\mathrm{n}$ & 4 & 4 & 4 & 4 & 3 & 4 & 4 \\
\hline rango & $22,4-29,5$ & $20,5-27,8$ & $11,8-15,4$ & $9,1-16,4$ & $15,0-18,5$ & $12,7-17,6$ & $11,8-17,3$ \\
\hline $\bar{x} \pm$ s.d. & $25,4 \pm 3,4$ & $24,5 \pm 3,2$ & $13,4 \pm 1,7$ & $12,3 \pm 3,3$ & $16,7 \pm 1,7$ & $15,3 \pm 2,5$ & $14,4 \pm 2,4$ \\
\hline
\end{tabular}

Calcáneo (lámina V.9.1: 12) (tabla V.9.16) (figura V.9.4: 11 y 12): es un hueso alargado, estrecho y comprimido lateralmente en su región distal. Tiene tres carillas articulares, dos para el astrágalo y otra para el maleolo. Las caras que articulan con el astrágalo son: una horizontal, más o menos redondeada, y otra vertical, alargada y estrecha. Están separadas por una pequeña depresión. La cara que articula con el maléolo está dividida en dos: la superior es corta y ancha; y la inferior tiene un borde distal redondeado. La cara que articula con el escafocuboides es alargada, estrecha y curvada.

Tabla V.9.16

Medidas tomadas en los calcáneos del R. pyrenaica de la Cueva de Valdegoba

\begin{tabular}{lcc}
\hline & GL & GB \\
\hline Maduros & & 30 \\
\hline $\mathrm{n}$ & 26 & $19,8-25,4$ \\
rango & $58,6-69,3$ & $21,8 \pm 1,1$ \\
$\overline{\mathrm{x}} \pm$ s.d. & $64,9 \pm 2,4$ & \\
\hline Inmaduros & & 4 \\
$\mathrm{n}$ & 3 & $19,5-21,2$ \\
rango & $51,3-56,9$ & $20,1 \pm 0,8$ \\
$\overline{\mathrm{x}} \pm$ s.d. & $54,9 \pm 3,1$ & \\
\hline
\end{tabular}

Se diferencian de $R$. rupicapra en que la superficie que articula con el maléolo tiene una cresta menos marcada.

Ulna (lámina V.9.1: 17) (tabla V.9.17): hueso alargado, plano en su parte distal y que articula con el húmero y con el radio. El olecranon es grande y tiene una tuberosidad redondeada. El extremo distal está fusionado con el radio y se proyecta distalmente, formando la apófisis deltoides de la ulna, donde se articula el carpo cubital. La apófisis ancónea es redondeada y lisa. Tiene una escotadura troclear circular. La cara que articula con el húmero tiene un borde anterior oblicuo y unos bordes lateral y medial rectos. Tiene, además, una fosa sinovial muy marcada que incluso puede llegar a dividir esta cara articular en dos partes. La cara que articula con el radio, en su extremo más proximal, está divida en dos partes, una orientada lateralmente y otra medialmente. La que está orientada medialmente es más o menos cuadrangular y la otra es más ancha, con un borde medial convexo y uno lateral cóncavo. La otra parte, que articula con el radio, no es una verdadera cara articular sino una protuberancia que se fusiona a lo largo de la vida del animal. Entre las dos caras se desarrolla un surco que es muy acentuado. 
Tabla V.9.17

Medidas tomadas en las ulnas del R. pyrenaica de la Cueva de Valdegoba

\begin{tabular}{lcccc}
\hline & LO & DPA & SDO & BPC \\
\hline $\mathrm{n}$ & 1 & 6 & 1 & 11 \\
rango & 40,6 & $24,6-30,9$ & 22,4 & $15,1-23,3$ \\
$\overline{\mathrm{x}} \pm$ s.d. & & $27,8 \pm 2,2$ & & $16,5 \pm 2,4$ \\
\hline
\end{tabular}

Metatarso III + IV (lámina V.9.1: 20) (tabla V.9.12) (figura V.9.5: 3 y 4): hueso largo con una sección subcilíndrica. El surco vascular está más marcado que en el metacarpo pero menos que los metatarsos de los cérvidos. La cara palmar suele ser plana o presentar un surco apenas esbozado. En la superficie articular proximal existe un foramen de pequeñas dimensiones que atraviesa oblicuamente el hueso y se abre en la parte proximal de la cara palmar. La mayor parte de los restos corresponden a la superficie articular distal. Al igual que en los metacarpos, la inserción intertroclear termina en forma apuntada. La unión entre la epífisis distal y la diáfisis forma unos bordes medial y lateral fuertemente convexos. La superficie articular proximal tiene un borde palmar más o menos recto. Las caras articulares del escafocuboides y del ectocuneiforme están conectadas por una cresta bien marcada lo que hace que la depresión central no se abra a la cara caudal. La cara articular del escafocuboides es fuertemente cóncava y su borde lateral es más o menos recto. En su parte posterior, existe una depresión que llega a alcanzar el borde medial. La cara articular del ectocuneiforme es más baja y también es cóncava. La carilla articular del pequeño cuneiforme está separada por una pequeña depresión de las caras articulares del ectocuneiforme.

Difieren de $R$. rupicapra en que las protuberancias que hay entre la diáfisis y la epífisis distal están menos marcadas, por el menor desarrollo del surco vascular, por el menor tamaño del foramen, por carecer de un surco en la cara articular del escafocuboides, por el menor tamaño de la cara que articula con el ectocuneiforme, por el menor desarrollo del borde palmar de la cara que articula con el primer tarso y por ser más gráciles (figura V.9.5).

Falanges proximales (lámina V.9.1: 21 y 22) (tabla V.9.18): son huesos cortos y estrechos, con la superficie interdigital aplanada y la palmar con dos prominencias para la inserción de los ligamentos interdigitales. La epífisis proximal es cóncava dorsopalmarmente y está dividida por un surco sagital. Este surco divide la superficie articular en dos zonas, una más alta grande y convexa, la abaxial y otra más baja, pequeña y recta, la axial. Palmar a estas dos caras articulares hay dos prominencias para la articulación de los huesos sesamoideos proximales, que son más o menos redondeadas y que se extienden hacia la cara palmar. La que se encuentra en posición medial es ovalada y mantiene toda su superficie en la cara proximal. La cara palmar tiene dos protuberancias separadas por una depresión muy marcada. La tróclea, extremidad distal, está dividida, por un surco sagital en dos caras convexas. A cada lado, existen dos depresiones para la inserción de ligamentos.

Son más cortas, estrechas y menos comprimidas que las de los ciervos y corzos (tablas V.7.13, V.8.5 y V.9.18) y a diferencia de éstos la escotadura que separa los cóndilos articulares distales no está muy marcado.

Falanges proximales anteriores: son más cortas que las posteriores. La superficie articular distal, en vista palmar, tiene un borde proximal oblicuo. En la diáfisis, más o menos en la zona media, hay dos zonas rugosas para la inserción de ligamentos, estando más marcados las proximales donde se insertan los ligamentos interdigitales. Dichas protuberancias definen un surco proximal, que en este caso está muy marcado. En vista ventral, los bordes dorsal y palmar de la epífisis distal no son paralelos. Son más pequeñas que las posteriores pero tienen unas anchuras similares (tabla V.9.18). 
Falanges proximales posteriores: son más largas que las anteriores. En vista palmar, el borde proximal de la tróclea no es tan desigual como en las anteriores, Las protuberancias de la diáfisis no se encuentran tan marcadas como en las precedentes, al igual que las prominencias para la inserción de los ligamentos interdigitales de la zona proximal. En vista ventral, y a diferencia de lo que ocurre en las falanges anteriores, los bordes dorsal y palmar no son paralelos. Son más largas pero igual de anchas (tabla V.9.18).

Tabla V.9.18

Medidas tomadas en las falanges proximales y medias de $R$. pyrenaica

\begin{tabular}{|c|c|c|c|c|c|c|c|c|}
\hline & GL & GLpe & DPs & DPi & BP & SD & BD & DD \\
\hline \multicolumn{9}{|c|}{ Falange proximal anterior } \\
\hline \multicolumn{9}{|c|}{ Valdegoba } \\
\hline $\mathrm{n}$ & 90 & 90 & 93 & 93 & 93 & 97 & 97 & 97 \\
\hline rango & $40,7-58,6$ & $40,1-55,7$ & $12,0-17,8$ & $13,3-19,9$ & $11,4-18,3$ & $6,0-11,5$ & $7,8-13,8$ & $8,2-15,1$ \\
\hline$\overline{\mathrm{x}} \pm$ s.d. & $25,8 \pm 2,9$ & $45,8 \pm 2,9$ & $14,6 \pm 1,0$ & $15,2 \pm 1,0$ & $13,4 \pm 0,8$ & $9,2 \pm 0,8$ & $12,1 \pm 0,9$ & $10,9 \pm 1,0$ \\
\hline \multicolumn{9}{|c|}{ Falange proximal posterior } \\
\hline \multicolumn{9}{|c|}{ Valdegoba } \\
\hline $\mathrm{n}$ & 83 & 84 & 85 & 84 & 85 & 88 & 87 & 87 \\
\hline rango & $41,9-63,2$ & $42,3-59,2$ & $13,6-19,7$ & $13,0-21,3$ & $12,2-19,8$ & $6,6-12,6$ & $10,8-14,1$ & $7,8-11,8$ \\
\hline$\overline{\mathrm{x}} \pm$ s.d. & $49,0 \pm 3,1$ & $48,5 \pm 2,9$ & $15,3 \pm 1,1$ & $15,8 \pm 1,2$ & $13,6 \pm 1,1$ & $9,3 \pm 0,7$ & $12,0 \pm 0,6$ & $10,2 \pm 0,6$ \\
\hline \multicolumn{9}{|c|}{ Falange proximal } \\
\hline \multicolumn{9}{|c|}{ Prado Vargas } \\
\hline$n=1$ & & & & & & & 13,1 & 11,8 \\
\hline \multicolumn{9}{|l|}{ Millán } \\
\hline $\mathrm{n}$ & 4 & 4 & 4 & 5 & 4 & 4 & 5 & 5 \\
\hline rango & $40,3-44,8$ & $39,6-44,1$ & $13,5-17,0$ & $12,8-17,1$ & $12,7-14,3$ & $7,8-11,6$ & $11,1-13,1$ & $10,1-11,9$ \\
\hline$\overline{\mathrm{x}} \pm$ s.d. & $43,1 \pm 2,0$ & $42,0 \pm 2,2$ & $15,3 \pm 1,8$ & $15,2 \pm 1,8$ & $13,4 \pm 0,8$ & $9,5 \pm 1,7$ & $12,0 \pm 0,7$ & $10,8 \pm 0,7$ \\
\hline \multicolumn{9}{|c|}{ Estebanvela } \\
\hline $\mathrm{n}=1$ & & & & & & & 13,0 & 15,6 \\
\hline \multicolumn{9}{|c|}{ Falange media anterior } \\
\hline \multicolumn{9}{|c|}{ Valdegoba } \\
\hline $\mathrm{n}$ & 93 & 93 & 92 & 92 & 93 & 94 & 94 & 93 \\
\hline rango & $26,7-32,5$ & $18,0-32,1$ & $9,4-13,8$ & $11,8-16,6$ & $11,5-14,8$ & $6,6-10,0$ & $8,1-11,3$ & $9,6-13,4$ \\
\hline$\overline{\mathrm{x}} \pm$ s.d. & $29,9 \pm 1,3$ & $29,0 \pm 1,7$ & $11,2 \pm 0,7$ & $14,5 \pm 0,9$ & $12,8 \pm 0,7$ & $8,1 \pm 0,6$ & $9,7 \pm 0,6$ & $11,8 \pm 0,8$ \\
\hline \multicolumn{9}{|c|}{ Falange media posterior } \\
\hline \multicolumn{9}{|c|}{ Valdegoba } \\
\hline $\mathrm{n}$ & 91 & 92 & 91 & 89 & 92 & 92 & 92 & 89 \\
\hline rango & $28,1-34,1$ & $26,1-33,4$ & $9,3-13,3$ & $11,4-15,5$ & $11,2-14,4$ & $6,6-9,7$ & $8,3-10,5$ & $9,4-12,9$ \\
\hline$\overline{\mathrm{x}} \pm$ s.d. & $30,8 \pm 1,3$ & $30,2 \pm 1,3$ & $10,8 \pm 0,7$ & $13,6 \pm 1,0$ & $12,5 \pm 0,7$ & $7,7 \pm 0,5$ & $9,4 \pm 0,5$ & $11,2 \pm 0,8$ \\
\hline \multicolumn{9}{|c|}{ Falange media } \\
\hline \multicolumn{9}{|c|}{ Millán } \\
\hline $\mathrm{n}$ & 10 & 11 & 11 & 11 & 11 & 10 & 9 & 10 \\
\hline rango & $27,0-29,1$ & $24,8-28,4$ & $10,1-14,4$ & $13,1-17,2$ & $11,5-15,9$ & $7,3-12,5$ & $8,4-12,4$ & $10,0-14,5$ \\
\hline$\overline{\mathrm{x}} \pm$ s.d. & $28,1 \pm 0,9$ & $26,9 \pm 1,2$ & $12,0 \pm 1,3$ & $14,7 \pm 1,1$ & $13,5 \pm 1,5$ & $9,8 \pm 1,9$ & $10,4 \pm 1,5$ & $12,5 \pm 1,5$ \\
\hline \multicolumn{9}{|c|}{ Estebanvela } \\
\hline $\mathrm{n}$ & 1 & 2 & 4 & 4 & 4 & 2 & 1 & 1 \\
\hline rango & 30,3 & $26,1-28,7$ & $12,9-14,3$ & $15,1-16,4$ & $15,5-16,7$ & $11,8-12,9$ & 13,6 & 14,9 \\
\hline$\overline{\mathrm{x}} \pm$ s.d. & & $27,4 \pm 1,8$ & $13,6 \pm 0,6$ & $16,0 \pm 0,6$ & $15,9 \pm 0,5$ & $12,3 \pm 0,8$ & & \\
\hline
\end{tabular}

Se han recuperado 52 falanges inmaduras: 35 anteriores y 17 posteriores. Los caracteres de la diáfisis y la región articular distal son similares a los descritos anteriormente. No tienen fusionada la epífisis proximal.

Falanges medias (lámina V.9.1: 23 y 24) (tabla V.9.18): huesos cortos y estrechos. La superficie articular proximal tiene una cresta sagital que la divide en dos cavidades glenoideas, siendo la abaxial más amplia y alta que la axial. Presenta una prominencia en su zona central y dos tubérculos en la cara palmar. La superficie articular se proyecta 
mucho proximalmente en la cara dorsal y palmar, y está dividida por un surco sagital. En la cara interdigital de la tróclea, hay unas depresiones para la inserción de diversos ligamentos. Son más pequeñas que las proximales y están menos comprimidas que las de los corzos (tablas V.8.5 y V.9.18).

Falanges medias anteriores: difieren de las posteriores por el mayor desarrollo de las regiones de inserción muscular que hay en la cara palmar, por tener los bordes lateral y medial de la diáfisis paralelos y por su menor longitud y mayor anchura (tabla V.9.18).

Tabla V.9.19

Medidas tomadas en las falanges distales de R. pyrenaica

\begin{tabular}{|c|c|c|c|}
\hline & DLS & LD & MBS \\
\hline \multicolumn{4}{|c|}{ Maduras } \\
\hline \multicolumn{4}{|c|}{ Valdegoba } \\
\hline $\mathrm{n}$ & 96 & 94 & 108 \\
\hline rango & $24,3-40,0$ & $18,5-32,8$ & $5,6-8,5$ \\
\hline$\overline{\mathrm{x}} \pm$ s.d. & $33,8 \pm 2,8$ & $28,2 \pm 2,6$ & $7,2 \pm 0,7$ \\
\hline \multicolumn{4}{|l|}{ Millán } \\
\hline $\mathrm{n}$ & 5 & 5 & 5 \\
\hline rango & $29,1-36,3$ & $23,9-29,9$ & $5,4-8,0$ \\
\hline $\bar{x} \pm$ s.d. & $33,2 \pm 2,8$ & $26,8 \pm 2,3$ & $6,6 \pm 0,9$ \\
\hline \multicolumn{4}{|c|}{ Inmaduras } \\
\hline \multicolumn{4}{|c|}{ Valdegoba } \\
\hline $\mathrm{n}$ & 20 & 20 & 20 \\
\hline rango & $17,0-29,8$ & $14,6-25,2$ & $3,9-7,5$ \\
\hline $\bar{x} \pm$ s.d. & $24,1 \pm 3,7$ & $20,8 \pm 2,8$ & $6,1 \pm 1,0$ \\
\hline
\end{tabular}

Falanges medias posteriores: son más largas y tienen las zonas de inserción muscular de la cara palmar menos marcadas que en las precedentes. Se han identificado diez piezas inmaduras, 5 anteriores y 5 posteriores.

Falanges distales (lámina V.9.1: 16) (tabla V.9.19): hueso triangular, comprimido lateralmente, con una fila de forámenes en la cara lateral y con la apófisis extensora redondeada y muy marcada. La cara parietal está menos inclinada que en los cérvidos, sobre todo cerca de la cara ventral.

\subsubsection{Edad de muerte}

Se han utilizado sólo los dientes ya que son los restos más abundantes y mejor conservados. Aplicamos el modelo de desgaste y erupción dental (figura V.9.12); y las ecuaciones de Klein et al., (1984). Al final comparamos ambos modelos. No se tienen en cuenta los $\mathrm{M}_{3}$ y $\mathrm{M}^{3}$ debido a la variabilidad de sus periodos de erupción (Pérez-Barbería y Palacios, 2009). La comparativa sólo se realiza con los dientes inferiores debido a que Klein et al., (1984) emplea estas piezas.

Tabla V.9.20

Edad dental estimada en los $\mathrm{D}_{4}$ y $\mathrm{M}_{1}$ del $R$. pyrenaica de la Cueva de Valdegoba (1 ${ }^{\mathrm{a}}$ parte)

\begin{tabular}{|c|c|c|c|c|c|c|c|c|}
\hline & $\mathbf{C H}$ & Edad (meses) & & CH & Edad (meses) & & CH & Edad (meses) \\
\hline \multicolumn{9}{|l|}{$\mathbf{D}_{4}$} \\
\hline Vb-sp-2610 & 8,8 & 0,0 & Vb-sp-2580 C & 5,9 & 3,0 & Vb-sp-1925 & 4,0 & 8,2 \\
\hline Vb-sp-1941 & 8,7 & 0,0 & Vb-sp-1293 & 5,2 & 4,8 & Vb-sp-1427 & 3,5 & 10,0 \\
\hline Vb-sp-336 B & 6,7 & 1,7 & Vb-sp-1412 & 5,1 & 4,8 & Vb-sp-1300 & 3,5 & 10,1 \\
\hline Vb-sp-2583 B & 6,5 & 1,9 & Vb-sp-417 B & 5,1 & 5,0 & Vb-sp-326 A & 3,1 & 11,9 \\
\hline Vb-sp-1995 & 6,4 & 2,2 & Vb-sp-406 C & 5,0 & 5,1 & Vb-sp-1298 & 2,6 & 14,0 \\
\hline Vb-sp-306 B & 6,3 & 2,2 & Vb-sp-1914 & 4,1 & 8,0 & Vb-sp-1316 & 1,6 & 18,8 \\
\hline \multicolumn{9}{|l|}{$\mathbf{M}_{1}$} \\
\hline Vb-sp-1151 & 23,0 & 3,0 & Vb-sp-1157 & 12,5 & 65,0 & Vb-sp-1387 & 8,4 & 123,3 \\
\hline Vb-sp-1152 & 20,8 & 5,6 & Vb-sp-1344 & 12,4 & 65,9 & Vb-sp-1378 & 8,3 & 124,8 \\
\hline Vb-sp-784 & 20,0 & 8,1 & Vb-sp-1333 & 12,3 & 66,9 & Vb-sp-1367 & 8,1 & 127,2 \\
\hline Vb-sp-1352 В & 20,1 & 10,1 & Vb-sp-769 & 12,3 & 67,4 & Vb-sp-386 B & 7,7 & 133,7 \\
\hline Vb-sp-543 & 13,4 & 55,2 & Vb-sp-1338 & 12,1 & 70,1 & Vb-sp-306 C & 7,7 & 133,9 \\
\hline Vb-sp-1144 & 19,0 & 11,8 & Vb-sp-432 & 12,0 & 70,2 & Vb-sp-394 B & 7,7 & 134,9 \\
\hline Vb-sp-1245 & 18,3 & 12,5 & Vb-sp-1342 & 12,1 & 70,3 & Vb-sp-313 D & 7,5 & 137,5 \\
\hline Vb-sp-1150 & 18,1 & 16,4 & Vb-sp-764 & 11,9 & 71,7 & Vb-sp-1291 & 7,5 & 138,1 \\
\hline
\end{tabular}

* Las edades de muerte se han estimado a partir de las ecuaciones de Klein et al., (1984). CH: en milímetros. 
Tabla V.9.20

Edad dental estimada en los $\mathrm{D}_{4}$ y $\mathrm{M}_{1}$ del R. pyrenaica de la Cueva de Valdegoba (2 ${ }^{\mathrm{a}}$ parte)

\begin{tabular}{|c|c|c|c|c|c|c|c|c|}
\hline & $\mathbf{C H}$ & Edad (meses) & & $\mathbf{C H}$ & Edad (meses) & & $\mathbf{C H}$ & Edad (meses) \\
\hline \multicolumn{9}{|c|}{ cuad (meses) } \\
\hline Vb-sp-336 C & 17,6 & 19,6 & Vb-sp-32 & 11,5 & 72,3 & Vb-sp-384 C & 7,5 & 138,2 \\
\hline Vb-sp-843 & 17,5 & 20,2 & Vb-sp-1328 A & 11,7 & 74,2 & Vb-sp-383 B & 7,3 & 142,1 \\
\hline Vb-sp-1336 & 17,5 & 20,3 & Vb-sp-1353 & 11,7 & 74,6 & Vb-sp-339 D & 7,1 & 144,6 \\
\hline Vb-sp-1346 & 16,7 & 25,4 & Vb-sp-1331 & 11,4 & 78,4 & Vb-sp-417 C & 6,9 & 148,0 \\
\hline Vb-sp-1363 & 16,7 & 25,6 & Vb-sp-1351 & 10,9 & 84,9 & Vb-sp-326 B & 6,9 & 148,3 \\
\hline Vb-sp-1328 B & 16,4 & 27,5 & Vb-sp-1354 & 10,7 & 85,4 & Vb-sp-307 C & 6,8 & 150,5 \\
\hline Vb-sp-1136 & 15,6 & 34,1 & Vb-sp-1359 & 10,8 & 86,2 & Vb-sp-390 C & 6,6 & 153,8 \\
\hline Vb-sp-1349 & 15,6 & 34,2 & Vb-sp-1297 & 10,4 & 91,7 & Vb-sp-1358 & 6,6 & 154,5 \\
\hline Vb-sp-931 & 15,4 & 34,3 & Vb-sp-1458 & 10,3 & 92,3 & Vb-sp-331 A & 6,3 & 158,8 \\
\hline Vb-sp-775 & 14,9 & 39,4 & Vb-sp-1298 & 10,2 & 94,5 & Vb-sp-396 B & 6,2 & 161,1 \\
\hline Vb-sp-1373 & 14,7 & 41,6 & Vb-sp-1345 & 10,1 & 95,9 & Vb-sp-372 A & 6,2 & 161,2 \\
\hline Vb-sp-1582 & 14,3 & 42,3 & Vb-sp-1375 A & 10,1 & 96,4 & Vb-sp-1365 & 6,2 & 161,2 \\
\hline Vb-sp-1366 & 14,4 & 44,5 & Vb-sp-399 C & 10,1 & 96,8 & Vb-sp-320 C & 6,0 & 165,3 \\
\hline Vb-sp-1326 & 14,2 & 46,4 & Vb-sp-1381 & 10,1 & 97,1 & Vb-sp-1368 & 6,0 & 166,2 \\
\hline Vb-sp-1356 & 14,1 & 47,2 & Vb-sp-198 & 9,9 & 100,1 & Vb-sp-1362 & 5,9 & 168,0 \\
\hline Vb-sp-1392 & 13,9 & 49,3 & Vb-sp-132 & 9,6 & 102,0 & Vb-sp-1100 & 5,8 & 168,7 \\
\hline Vb-sp-1892 & 13,8 & 49,4 & Vb-sp-405 A & 9,7 & 102,3 & Vb-sp-1364 A & 5,8 & 169,6 \\
\hline Vb-sp-1332 & 13,9 & 49,6 & Vb-sp-1391 & 9,6 & 103,4 & Vb-sp-1357 & 5,5 & 174,6 \\
\hline Vb-sp-412 & 13,9 & 49,6 & Vb-sp-1361 & 9,6 & 103,5 & Vb-sp-310 & 5,5 & 175,3 \\
\hline Vb-sp-1386 B & 13,8 & 50,4 & Vb-sp-395 C & 9,5 & 105,0 & Vb-sp-347 C & 5,0 & 185,3 \\
\hline Vb-sp-1372 & 13,5 & 53,4 & Vb-sp-1339 & 9,5 & 105,2 & Vb-sp-403 A & 4,9 & 186,0 \\
\hline Vb-sp-1355 & 13,3 & 56,2 & Vb-sp-1377 & 9,4 & 107,6 & Vb-sp-1395 A & 4,8 & 189,4 \\
\hline Vb-sp-1154 & 13,2 & 57,1 & Vb-sp-1350 & 9,3 & 108,4 & Vb-sp-1382 & 4,7 & 190,8 \\
\hline Vb-sp-1390 & 12,7 & 62,4 & Vb-sp-329 B & 9,1 & 111,8 & Vb-sp-1383 & 4,5 & 195,4 \\
\hline Vb-sp-1352 & 12,7 & 62,4 & Vb-sp-1389 & 9,0 & 113,5 & Vb-sp-1347 & 3,7 & 212,2 \\
\hline Vb-sp-1335 & 12,7 & 63,1 & Vb-sp-1371 & 8,7 & 117,1 & & & \\
\hline \multicolumn{9}{|l|}{$\mathbf{M}_{2}$} \\
\hline Vb-sp-326 C & 21,2 & 6,4 & Vb-sp-1129 & 17,2 & 34,0 & Vb-sp-1163 & 7,9 & 140,3 \\
\hline Vb-sp-320 D & 21,0 & 8,8 & Vb-sp-1142 & 17,2 & 34,1 & Vb-sp-1138 & 7,8 & 142,0 \\
\hline Vb-sp-313 E & 20,8 & 11,2 & Vb-sp-1125 B & 16,9 & 35,7 & Vb-sp-313 E & 7,7 & 143,4 \\
\hline Vb-sp-1124 B & 23,7 & 12,0 & Vb-sp-1337 & 16,7 & 37,1 & Vb-sp-407 B & 7,7 & 144,2 \\
\hline Vb-sp-1135 & 23,7 & 12,0 & Vb-sp-1168 & 15,7 & 45,2 & Vb-sp-372 B & 7,5 & 147,2 \\
\hline Vb-sp-1147 & 22,9 & 12,4 & Vb-sp-1386 A & 15,7 & 45,5 & Vb-sp-417 D & 7,5 & 147,2 \\
\hline Vb-sp-1148 & 22,3 & 13,1 & Vb-sp-1161 & 15,4 & 47,4 & Vb-sp-394 C & 7,5 & 147,7 \\
\hline Vb-sp-1167 B & 22,1 & 13,4 & Vb-sp-1130 & 15,0 & 51,2 & Vb-sp-358 A & 7,2 & 152,2 \\
\hline Vb-sp-1146 & 22,1 & 13,4 & Vb-sp-1132 & 14,6 & 54,3 & Vb-sp-397 D & 7,1 & 153,0 \\
\hline Vb-sp-307 D & 20,5 & 13,6 & Vb-sp-1128 & 14,2 & 58,9 & Vb-sp-1159 & 7,0 & 155,0 \\
\hline Vb-sp-1160 & 21,6 & 14,5 & Vb-sp-1133 & 12,3 & 79,1 & Vb-sp-1385 & 7,0 & 155,1 \\
\hline Vb-sp-1162 & 21,3 & 15,2 & Vb-sp-1369 & 10,0 & 108,4 & Vb-sp-326 C & 7,0 & 155,5 \\
\hline Vb-sp-1145 A & 21,1 & 15,6 & Vb-sp-362 & 9,9 & 110,5 & Vb-sp-331 в & 6,8 & 159,0 \\
\hline Vb-sp-305 D & 20,3 & 16,0 & Vb-sp-395 D & 9,5 & 115,8 & Vb-sp-386 C & 6,7 & 160,1 \\
\hline Vb-sp-413 & 20,8 & 16,5 & Vb-sp-320 D & 8,8 & 126,5 & Vb-sp-390 D & 6,6 & 163,0 \\
\hline Vb-sp-1156 & 20,7 & 16,6 & Vb-sp-391 A & 8,7 & 127,1 & Vb-sp-378 B & 6,5 & 163,3 \\
\hline Vb-sp-1149 & 20,7 & 16,8 & Vb-sp-384 D & 8,7 & 127,4 & Vb-sp-382 D & 6,4 & 165,4 \\
\hline Vb-sp-1164 & 20,3 & 18,1 & Vb-sp-329 C & 8,6 & 129,9 & Vb-sp-1384 & 6,3 & 168,2 \\
\hline Vb-sp-1137 & 20,2 & 18,4 & Vb-sp-368 A & 8,3 & 134,2 & Vb-sp-1067 & 6,2 & 170,1 \\
\hline Vb-sp-1141 & 19,5 & 21,0 & Vb-sp-385 A & 8,1 & 136,5 & Vb-sp-396 C & 6,0 & 172,7 \\
\hline Vb-sp-1167 A & 18,8 & 24,4 & Vb-sp-403 B & 8,0 & 138,7 & Vb-sp-305 D & 5,5 & 183,0 \\
\hline Vb-sp-1143 & 18,8 & 24,6 & Vb-sp-307 D & 7,9 & 140,2 & Vb-sp-365 A & 4,8 & 195,4 \\
\hline Vb-sp-383 C & 17,6 & 31,5 & Vb-sp-405 B & 7,9 & 140,2 & & & \\
\hline
\end{tabular}

* Las edades de muerte se han estimado a partir de las ecuaciones de Klein et al., (1984). CH: en milímetros.

La Cueva de Valdegoba: en este depósito, y debido a la abundancia del material, todos los restos analizados son izquierdos, por lo que se analiza la edad de muerte de diferentes 
ejemplares. Si tenemos en cuenta la dentición inferior, observamos que los $\mathrm{D}_{4}$ más abundantes son aquellos cuyas erosiones superan el $50 \%$ de la altura de la corona (figura V.9.6). El $\mathrm{M}_{1}$ tiene un mayor número de efectivos con desgastes marcados (50 - $75 \%$ ), seguidos por aquellos con erosiones moderadas (25-50\%), máximas ( $>75 \%$ ) y mínimas (<25\%). En $\mathrm{M}_{2}$, al igual que el $\mathrm{M}_{1}$, predominan los desgastes marcados, pero seguido en este caso por aquellos con erosiones muy bajas; los menos abundantes serían los que tienen unos desgastes máximos (tabla V.9.20).
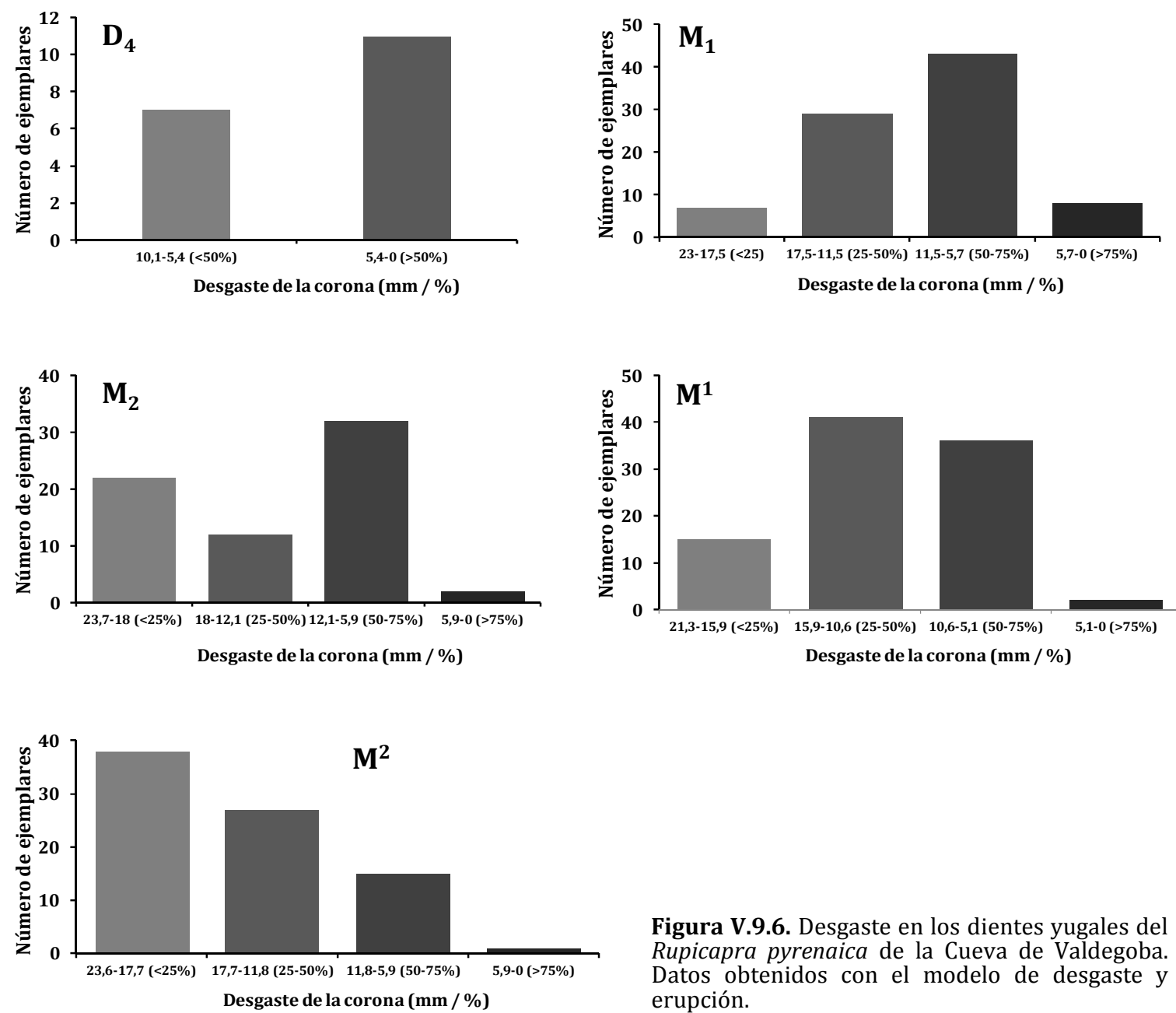

Figura V.9.6. Desgaste en los dientes yugales del Rupicapra pyrenaica de la Cueva de Valdegoba. Datos obtenidos con el modelo de desgaste y erupción.

Cuando comparamos ambos modelos observamos (figura V.9.7) que el patrón es similar en los dos, con un mínimo de ejemplares con edades entre los 0 y 3 meses y un máximo en aquellos con más de 41. Existe un cierto desplazamiento de ejemplares del rango intermedio a aquel que representa los ejemplares adultos en el modelo de Klein.
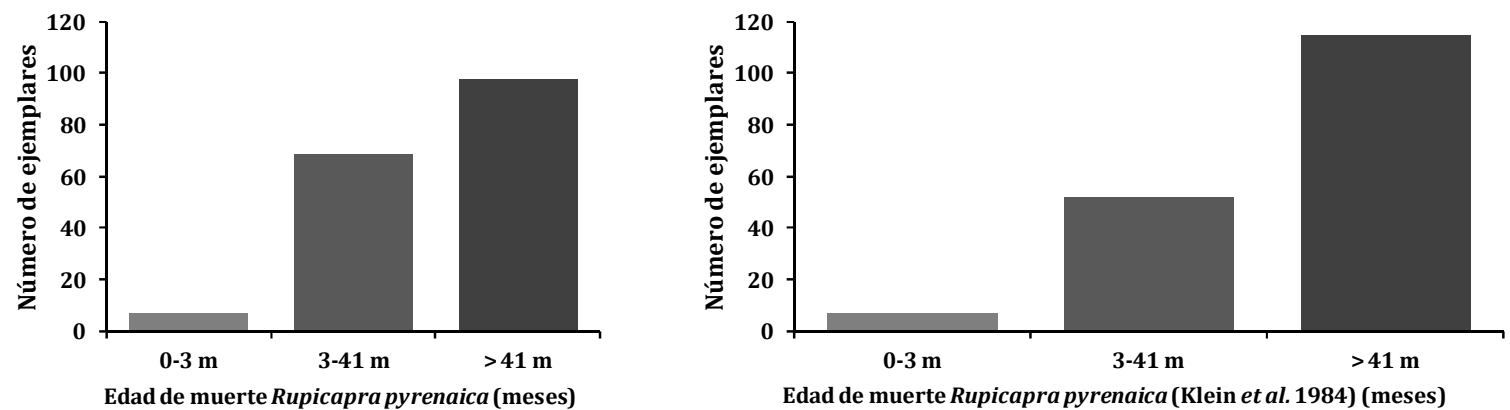

Figura V.9.7. Comparativa entre los dos modelos de estimación de la edad de muerte en el Rupicapra pyrenaica de la Cueva de Valdegoba. 
Los resultados obtenidos anteriormente sugieren, a partir del $\mathrm{M}_{1}$ izquierdo, que al menos habría un ejemplar infantil, 16 juveniles y 82 adultos (tabla V.9.20).

Prado Vargas: predominan las piezas con erosiones mínimas ( $<25 \%$ ), aunque un $\mathrm{M}_{1}$ tiene un desgaste moderado, (25 - 50 \%) (figura V.9.15). Las ecuaciones de Klein et al., (1984) aportan unas edades entre los 10 y 68 meses para los $\mathrm{M}_{1}$; y de 13,5 para el $\mathrm{M}_{2}$ (tabla V.9.21).

Tabla V.9.21

Edad dental estimada en el R. pyrenaica de Prado Vargas

\begin{tabular}{|c|c|c|c|c|c|c|}
\hline & & \multicolumn{2}{|l|}{$\mathbf{M}_{1}$} & \multicolumn{3}{|c|}{$\mathbf{M}_{2}$} \\
\hline & & $\mathrm{CH}(\mathrm{mm})$ & Edad (meses) & & $\mathrm{CH}(\mathrm{mm})$ & Edad (meses) \\
\hline PV.06.Z90.G30.148 & $\mathrm{i}$ & 12,3 & 67,3 & VA. $\alpha 1-4-201$ i & 22,4 & 13,5 \\
\hline VA. $\alpha 2-4-349$ & $\mathrm{i}$ & 19,3 & 10,8 & & & \\
\hline
\end{tabular}

Cuando comparamos los resultados vemos que hay un desfase hacia los ejemplares con más de 41 meses con las ecuaciones. A pesar de esta diferencia, el rango predominante es el comprendido entre los 3 y los 41 meses (figura V.5.8).
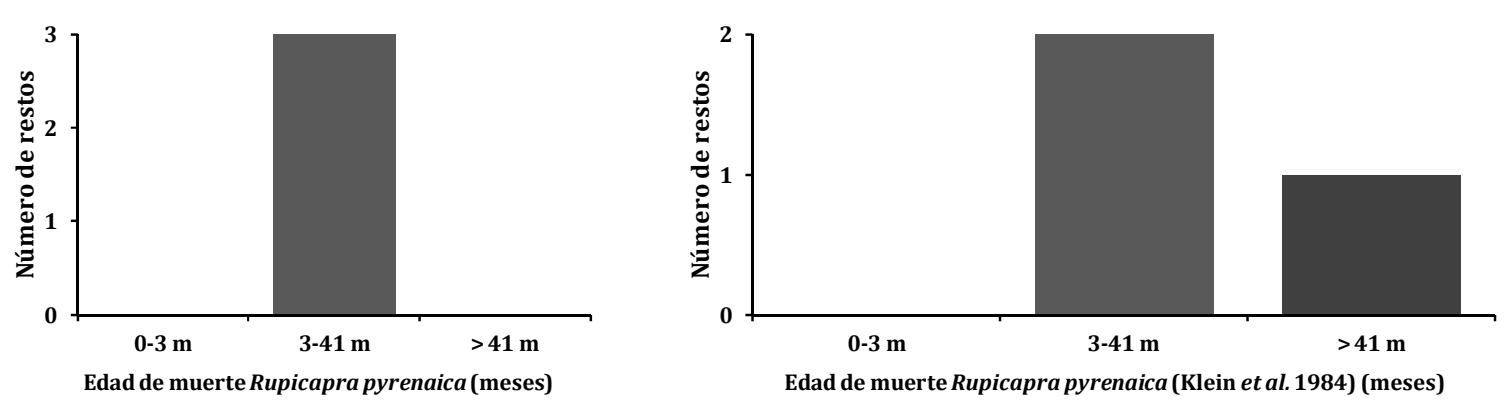

Figura V.9.8. Comparativa entre los dos modelos de estimación de la edad de muerte en el Rupicapra pyrenaica de Prado Vargas.

Teniendo en cuenta el $\mathrm{M}_{1}$ izquierdo, la pieza más frecuente, un ejemplar sería juvenil y otro un adulto (tabla V.9.21).

Cueva Millán: se analizan las edades de muerte por niveles.

Tabla V.9.22

Edad dental estimada en el R. pyrenaica de Cueva Millán

\begin{tabular}{|c|c|c|c|c|c|c|}
\hline \multicolumn{4}{|l|}{$\mathbf{M}_{1}$} & \multicolumn{3}{|l|}{$\mathbf{M}_{2}$} \\
\hline & & $\mathrm{CH}(\mathrm{mm})$ & Edad (meses) & & $\mathrm{CH}(\mathrm{mm})$ & Edad (meses) \\
\hline CM.86.1A.6I & $\mathrm{i}$ & 20,5 & 6,4 & CM.86.1A.9G d & 20,7 & 16,7 \\
\hline CM.86.1A.7D & $\mathrm{i}$ & 27,2 & 12,9 & & & \\
\hline CM.86.1A.8C & $\mathrm{i}$ & 11,0 & 83,8 & & & \\
\hline CM.86.1A.6J & $\mathrm{i}$ & 7,2 & 144,0 & & & \\
\hline CM.86.1A.10F & $\mathrm{i}$ & 2,3 & 244,3 & & & \\
\hline CM.86.1B.9E & $\mathrm{i}$ & 15,6 & 38,0 & & & \\
\hline \multirow[t]{2}{*}{$\mathbf{M}^{1}$} & & & & $\mathbf{M}^{2}$ & & \\
\hline & & CH (mm) & Edad (meses) & & CH (mm) & Edad (meses) \\
\hline CM.86.1A.7D & $\mathrm{i}$ & 13,7 & 40,5 & CM.86.1A.9F d & 23,4 & 12,0 \\
\hline CM.86.1A.8C & $\mathrm{d}$ & 12,3 & 55,7 & СM.86.1A.8C i & 14,7 & 53,2 \\
\hline
\end{tabular}

* Las alturas han sido estimadas en milímetros y la edad en meses. Estos datos han sido obtenidos aplicando las ecuaciones de Klein et al., (1984). CH: en milímetros. Edad: en meses. 
Nivel 1A: los $M_{1}$ analizados presentan todas las fases de desgaste (figura V.9.9) y el $M_{2}$ sólo desgastes mínimos. En los molares superiores se han registrado erosiones moderadas en el $\mathrm{M}^{1} \mathrm{y}$ de mínimas a moderadas en el $\mathrm{M}^{2}$. Los datos obtenidos a partir de las ecuaciones de Klein indican que la mayor parte de las piezas presentan más de dos años de edad (tabla V.9.22). De los molares analizados sólo dos aportan valores inferiores a los 12 meses, 6 entre los 12 y los 83 meses, y dos por encima de los 100 meses de edad.
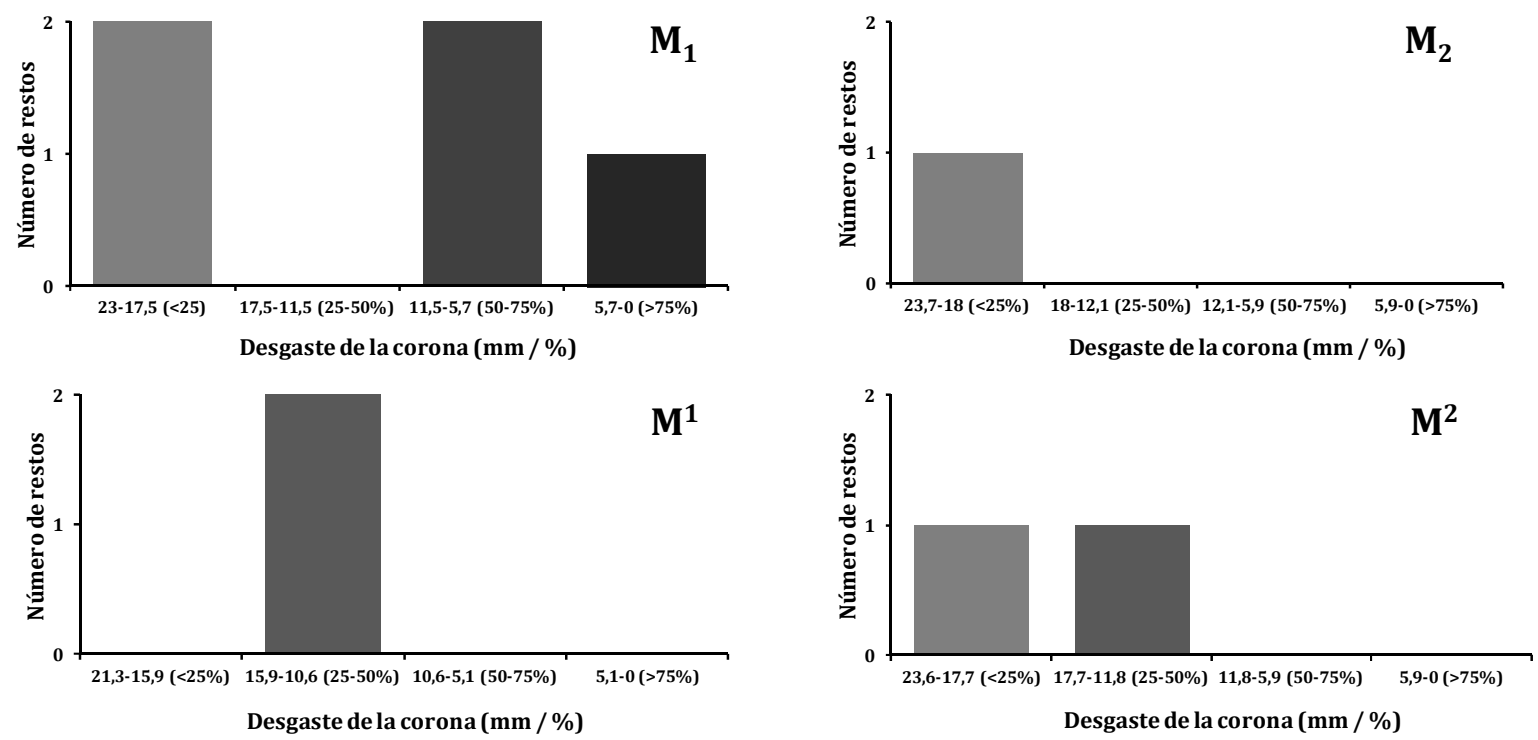

Figura V.9.9. Desgaste en los dientes yugales del Rupicapra pyrenaica del nivel 1A de Cueva Millán. Datos obtenidos con el modelo de desgaste y erupción.

Si comparamos ambos modelos (figura V.9.10) existe un desfase en los resultados, ya que la mitad de los restos incluidos en el rango (3-41) del modelo de desgaste se encuentran en el rango de más de 41 meses del modelo de Klein et al., (1984). Si tenemos en cuenta los $\mathrm{M}_{1}$ izquierdos, al menos tendríamos dos ejemplares juveniles y tres adultos, uno de ellos de más de 12 años (tabla V.9.22).
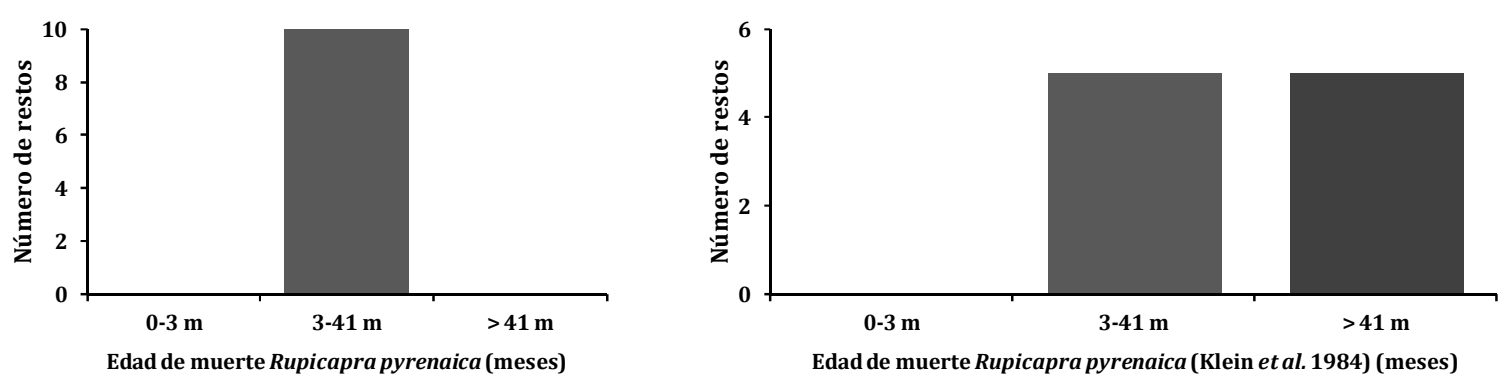

Figura V.9.10. Comparativa entre los dos modelos de estimación de la edad de muerte en el Rupicapra pyrenaica del nivel 1 A de Cueva Millán.

Nivel 1B: el resto analizado en este nivel registra un desgaste moderado (25 - $50 \%)$. Tras aplicar las ecuaciones de Klein et al. (1984) la edad estimada para esta pieza es de 38 meses (tabla V.9.23). Los resultados coinciden en ambos modelos de estimación, siendo el ejemplar un individuo joven.

Nivel 1C: en este nivel se ha identificado un ejemplar maduro, un adulto, a partir del $\mathrm{P}^{4}$, último permanente en emerger según lo observado en las mandíbulas de la Cueva de Valdegoba. 
Abrigo de Alexandre: se ha identificado un solo diente, un $\mathrm{D}^{2}$, por lo que el ejemplar sería inmaduro. Al presentar un desgaste muy avanzado, estaría próximo a ser reemplazado por el $\mathrm{P}^{2}$, por lo que podríamos indicar que se trataría de un juvenil.

La Peña de Estebanvela: se analiza el material por niveles. El modelo se basa en la erupción y en el desgaste.

Nivel I: en este nivel se ha podido medir un $\mathrm{M}_{1}$. Las ecuaciones de Klein indican una edad de 77 meses y el desgaste es marcado (50 - $75 \%$ ). Los $\mathrm{D}_{2}$ y $\mathrm{D}_{3}$ son remplazados a los 25 29 meses. En este nivel, tendríamos al menos dos ejemplares: un inmaduro, infantil o juvenil, de cómo mucho 29 meses; y un adulto.

Nivel III: en este nivel se ha identificado un ejemplar maduro, un adulto, a partir del $\mathrm{P}^{4}$ izquierdo.

\subsubsection{Estacionalidad}

Se ha analizado en aquellos casos en los que la edad de muerte se ha estimado en meses. No se han tenido en cuenta los terceros molares debido a la variabilidad en la erupción. El comportamiento social de la especie se ha tomado de Pérez-Barbería (1994) y la fecha de partos, el mes de mayo, de Hayssen et al., (1993).

La Cueva de Valdegoba: se han empleado las piezas inferiores izquierdas, es decir, el número de ejemplares. No se ha observado estacionalidad en esta especie ya hay una acumulación durante todo el año. Existe un ligero pico en verano, seguido de la primeva y el otoño. Los ejemplares acumulados durante el invierno son los más escasos aunque la diferencia no es muy grande.
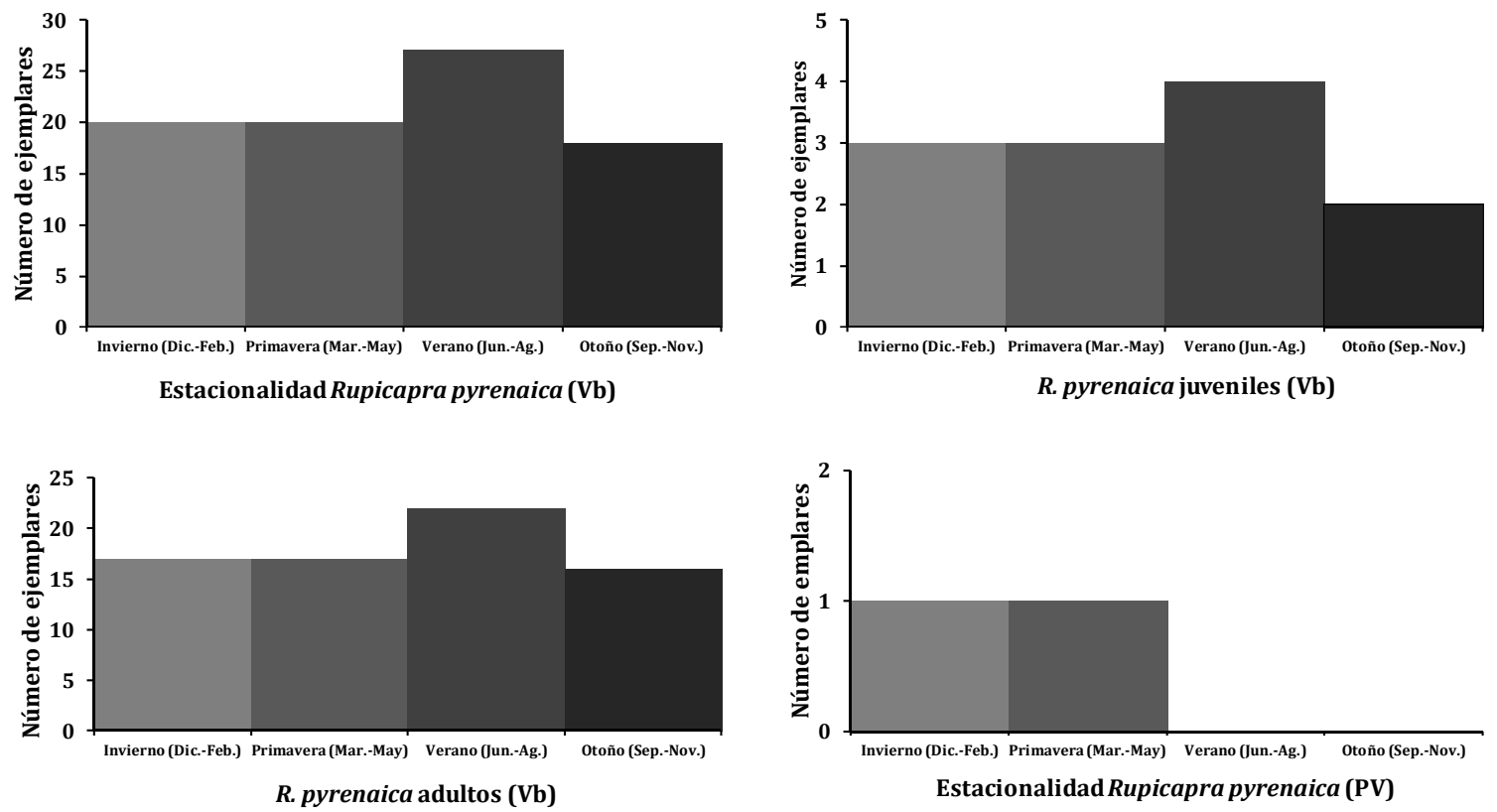

Figura V.9.11 Estacionalidad general y por rangos de edad del Rupicapra pyrenaica de la Cueva de Valdegoba (Vb) y Prado Vargas (PV).

Si hacemos un estudio por rangos de edad, teniendo en cuenta el $\mathrm{M}_{1}$ izquierdo, vemos que sigue sin haber una estacionalidad clara. Existe un pico en verano en los tres rangos, el infantil es acumulado en agosto, periodo que coincide con la parte final de los partos y con 
la lactancia. La acumulación se mantiene constante en invierno, primavera y otoño (figura V.9.11).

Prado Vargas: si tenemos en cuenta individuos, a partir del $\mathrm{M}_{1}$ izquierdo (tabla V.9.22) vemos que hay estacionalidad. Los dos ejemplares estudiados, un juvenil y otro adulto, son acumulados en primavera e invierno respectivamente. La primavera coincide con la época de partos y diciembre con el final del celo (Pérez-Barbería, 1994).

Cueva Millán: analizamos el material por niveles y por individuos, a partir del $\mathrm{M}_{1}$ izquierdo. En el nivel 1A, la acumulación se centra en la primavera y disminuye en el verano y el otoño. Si analizamos estos resultados por rangos de edad, vemos que los jóvenes son acumulados en primavera y en otoño. Los adultos, por otra parte, son depositados en primavera y verano. En el segundo nivel, el ejemplar juvenil fue acumulado en verano (figura V.9.12). El número de ejemplares analizados no es muy grande por lo que inferir un comportamiento es complicado. Sin embargo, parece que esta especie fue acumulada principalmente en los periodos de partos y lactancia.
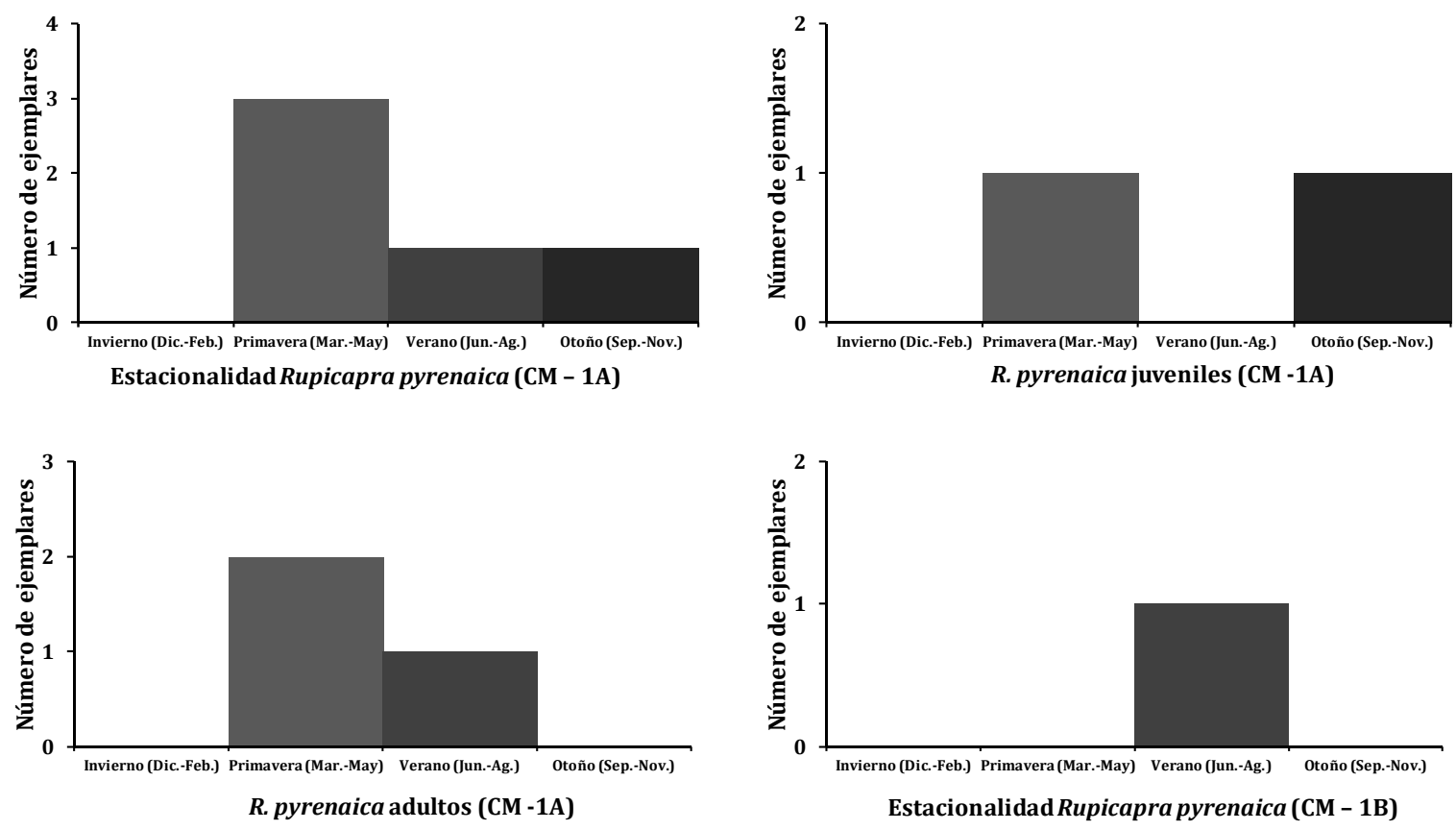

Figura V.9.12. Estacionalidad general y por rangos de edad del Rupicapra pyrenaica de los niveles $1 \mathrm{~A}$ y $1 \mathrm{~B}$ de Cueva Millán.

La Peña de Estebanvela: el único diente que ha podido ser medido, un $\mathrm{M}_{1}$ izquierdo, sugiere que este ejemplar, un adulto, fue acumulado en otoño, periodo que coincide con el celo de esta especie y en el que los machos pueden permanecer aislados o formando pequeños grupos.

\subsubsection{Bimodalidad sexual}

En este apartado sólo se ha analizado el material de la Cueva de Valdegoba debido a su mayor abundancia y su mejor estado de conservación. Se ha empleado únicamente el material postcraneal ya que en las colecciones de referencia consultadas, los dientes estaban incluidos en las mandíbulas y maxilares por lo que no se han podido tomar medidas diagnósticas.

En primer lugar, se han comparado diferentes modelos estadísticos sobre una muestra de sexo conocido. Se han analizado varios huesos, seleccionados en función de si 
posteriormente se pueden estudiar en el yacimiento. No se han empleado los calcáneos ni los astrágalos ya que, a pesar de ser muy abundantes en la muestra fósil, no permiten saber si se trata de individuos juveniles o adultos en el yacimiento. Tampoco se han empleado ni la escápula ni el fémur debido a que los fósiles están muy fragmentados. Se han tomado 49 medidas; posteriormente, se escogen aquellas variables que aportan diferencias significativas; y por último se aplica, a la muestra fósil, el método que ha dado mejores resultados en la muestra moderna.

Tabla V.9.23

Resultados previos Test Wilcoxon/Mann-Whitney en las extremidades del R. p. parva de la muestra moderna

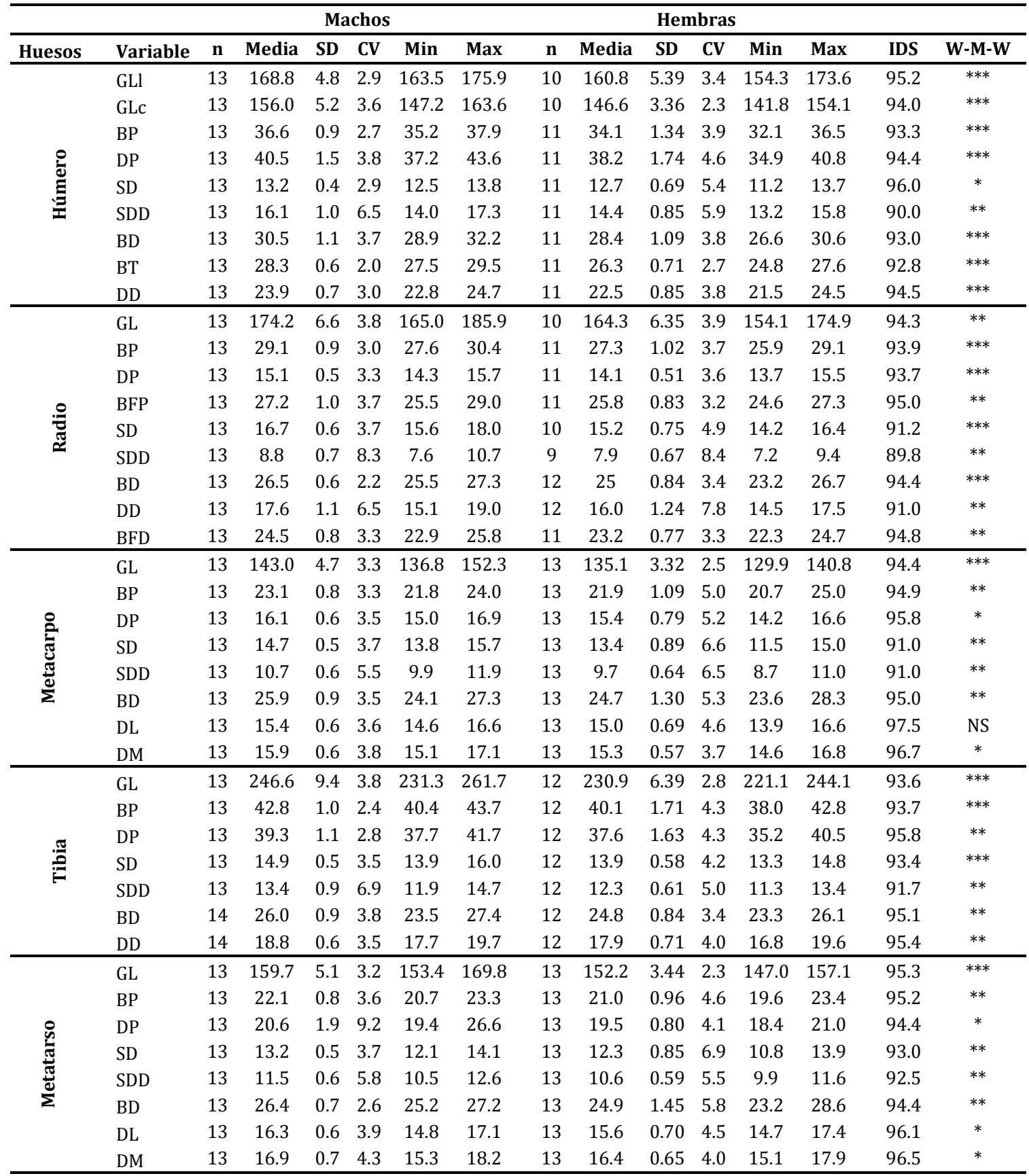

* Estadística descriptiva, índice de dimorfismo sexual (IDS) y test de Wilcoxon/Mann-Whitney (W-M-W). Resultados para todos los huesos de las extremidades de la muestra moderna de Rupicapra pyrenaica parva. SD: desviación estándar; CV: coeficiente de variación; Min: valor mínimo; Max: valor máximo; n: número de individuos de la muestra; IDS: índice de dimorfismo sexual (media de las hembras/media de los machos * 10; W-M-W: resultados del test Wilcoxon/Mann-Whitney $\left({ }^{*}: \mathrm{p}<0,05 ;{ }^{* *}\right.$ : $\mathrm{p}<0,01 ;{ }^{* *}$ : $\left.\mathrm{p}<0,001\right)$. 


\section{Muestra moderna}

En la muestra moderna se han llevado a cabo los siguientes análisis estadísticos:

Test Wilcoxon/Mann-Whitney (tabla V.9.23): se llevo a cabo sobre el húmero, el radio, el metacarpo, la tibia y el metatarso (Arceredillo y Gómez Olivencia, 2009) para determinar que variables presentaban diferencias significativas entre los sexos. La única variable que las ha aportado es el DL del metacarpo (tabla V.9.23).

Tabla V.9.24

Resultados obtenidos tras aplicar los tres métodos a la extremidad anterior de la muestra moderna

\begin{tabular}{|c|c|c|c|c|c|c|c|c|c|c|}
\hline \multirow[t]{2}{*}{ Hueso } & \multirow[t]{2}{*}{ Variables } & \multirow{2}{*}{$\begin{array}{c}\text { Variables } \\
\text { Análisis } \\
\text { Multivariante }\end{array}$} & \multirow{2}{*}{$\begin{array}{c}\text { Mixture } \\
\text { Analyisis } \\
\text { Clásico }\end{array}$} & \multicolumn{3}{|c|}{ Análisis Cluster Jerárquico } & \multicolumn{2}{|c|}{ K-medias } & \multicolumn{2}{|c|}{$\begin{array}{c}\text { Análisis de } \\
\text { Componentes } \\
\text { Principales }\end{array}$} \\
\hline & & & & Ward & Complete & Average & Clásico & Robusto & Clásico & Robusto \\
\hline \multirow{10}{*}{ 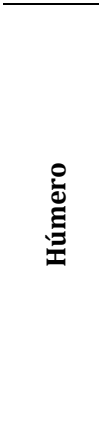 } & GLl & $\mathrm{N}$ & 60 & 60 & $\underline{92 * *}$ & 60 & 72 & 64 & & \\
\hline & GLc & S & $\underline{76}$ & 68 & $\underline{88^{*}}$ & 68 & $\underline{76}$ & $\underline{80 *}$ & & \\
\hline & BP & S & $\underline{76}$ & $\underline{76}$ & $\underline{84^{*}}$ & 64 & $\underline{92 * *}$ & $\underline{84^{*}}$ & & \\
\hline & DP & S & $\overline{68}$ & $\underline{80^{*}}$ & $\underline{80^{*}}$ & $\mathrm{X}$ & $\underline{80 *}$ & $\underline{80^{*}}$ & & \\
\hline & SD & $\mathrm{N}$ & 56 & 72 & $\underline{76}$ & $\mathrm{X}$ & 72 & 72 & & \\
\hline & SDD & S & $\underline{80 *}$ & $\underline{80 *}$ & $\underline{80^{*}}$ & $\underline{80 *}$ & $\underline{76}$ & $\underline{76}$ & & \\
\hline & $\mathrm{BD}$ & S & $\overline{80^{*}}$ & $\overline{72}$ & $\underline{88^{*}}$ & $\overline{72}$ & $\underline{80^{*}}$ & $\underline{84^{*}}$ & & \\
\hline & $\mathrm{BT}$ & S & $\underline{96 * *}$ & $\underline{96^{* *}}$ & $\underline{84 *}$ & $\underline{96^{* *}}$ & $\underline{96^{* *}}$ & $96^{* *}$ & & \\
\hline & $\mathrm{DD}$ & $\mathrm{N}$ & 68 & $\underline{84}$ & $\underline{84^{*}}$ & $84^{*}$ & $\underline{80^{*}}$ & 72 & & \\
\hline & $\begin{array}{l}\mathrm{GLC}+\mathrm{BP}+\mathrm{DP}+ \\
\mathrm{CD}+\mathrm{BD}+\mathrm{BT}\end{array}$ & - & $\underline{92^{* *}}$ & - & $\underline{92^{* *}}$ & - & $\underline{96^{* *}}$ & $\underline{96^{* *}}$ & $\underline{96^{* *}}$ & $\underline{96^{* *}}$ \\
\hline \multirow{10}{*}{ 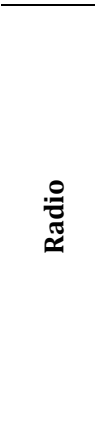 } & $\mathrm{GL}$ & $\mathrm{N}$ & 64 & $\underline{76}$ & 64 & 64 & $\underline{76}$ & $\underline{76}$ & & \\
\hline & $\mathrm{BP}$ & S & $\underline{80 *}$ & $\underline{84^{*}}$ & $\underline{76}$ & $\underline{84^{*}}$ & $\underline{84^{*}}$ & $\underline{84^{*}}$ & & \\
\hline & DP & S & $\underline{80 *}$ & 68 & $\underline{80 *}$ & $\underline{80^{*}}$ & $\underline{80^{*}}$ & $\underline{80^{*}}$ & & \\
\hline & BFP & $\mathrm{N}$ & $\overline{72}$ & 68 & 68 & $\bar{x}$ & $\underline{80^{*}}$ & $\underline{76}$ & & \\
\hline & SD & S & $\underline{80^{*}}$ & $\underline{88^{*}}$ & $\underline{88^{*}}$ & $\underline{88^{*}}$ & $\underline{88^{*}}$ & $\underline{84^{*}}$ & & \\
\hline & SDD & $\mathrm{N}$ & 52 & $\underline{84 *}$ & $\underline{84^{*}}$ & 52 & 60 & $\underline{84^{*}}$ & & \\
\hline & $\mathrm{BD}$ & S & $\underline{80^{*}}$ & $\underline{80^{*}}$ & $\underline{88^{*}}$ & $\mathrm{X}$ & $\underline{84^{*}}$ & $\underline{84^{*}}$ & & \\
\hline & $\mathrm{DD}$ & $\mathrm{N}$ & $\overline{68}$ & $\overline{72}$ & $\overline{72}$ & 72 & $\overline{72}$ & $\overline{72}$ & & \\
\hline & BFD & $\mathrm{N}$ & 72 & $\underline{80 *}$ & 72 & $\underline{80}$ & $\underline{80}$ & $\underline{84^{*}}$ & & \\
\hline & $\begin{array}{l}\mathrm{BP}+\mathrm{DP}+ \\
\mathrm{SD}+\mathrm{BD}\end{array}$ & - & $\underline{88^{*}}$ & - & $\underline{88^{*}}$ & - & $\underline{88^{*}}$ & $\underline{88^{*}}$ & $\underline{84^{*}}$ & $\underline{88^{*}}$ \\
\hline \multirow{9}{*}{ 营 } & GL & S & 69,23 & $\underline{84,6^{*}}$ & 69,23 & 69,2 & 73,1 & $\underline{80,8^{*}}$ & & \\
\hline & $\mathrm{BP}$ & S & $\underline{80,8^{*}}$ & $\underline{76,9}$ & $\underline{76,9}$ & 69,2 & $\underline{80,8^{*}}$ & $\underline{80,8^{*}}$ & & \\
\hline & DP & $\mathrm{N}$ & $\overline{69,2}$ & $\overline{61,5}$ & $\overline{61,5}$ & 61,5 & $\overline{69,2}$ & $\underline{80,8^{*}}$ & & \\
\hline & SD & S & $\underline{76,9}$ & $\underline{80,8^{*}}$ & $\underline{84,6^{*}}$ & $\mathrm{X}$ & $\underline{80,8^{*}}$ & $\underline{80,8^{*}}$ & & \\
\hline & SDD & S & 73,1 & $80,8^{*}$ & $80,8^{*}$ & 61,5 & $\underline{76,9}$ & $\underline{76,9}$ & & \\
\hline & $\mathrm{BD}$ & S & $\underline{80,8}$ & $\overline{65,4}$ & $\overline{84,6}$ & 73,1 & $\underline{84,6}$ & $\underline{84,6}$ & & \\
\hline & DL & $\mathrm{N}$ & $\mathrm{X}$ & 65,3 & 65,4 & X & 57,7 & 57,7 & & \\
\hline & $\mathrm{DM}$ & $\mathrm{N}$ & 61,5 & 69,2 & 69,23 & 69,23 & 69,23 & 69,23 & & \\
\hline & $\begin{array}{l}\mathrm{GL}+\mathrm{BP}+ \\
\mathrm{SD}+\mathrm{CD}+\mathrm{BD}\end{array}$ & - & $\underline{84,6^{*}}$ & - & $\underline{76,9}$ & - & $\underline{84,6^{*}}$ & $\underline{80,8^{*}}$ & $\underline{(80.8}$ & $\underline{88,5^{*}}$ \\
\hline
\end{tabular}

* Porcentaje de clasificaciones correctas para todas las variables, utilizando los diferentes métodos estadísticos. Los porcentajes por encima de un 75\% están subrayados; los valores similares o iguales al $80 \%$ también están marcados con un asterisco; y los valores iguales o por encima del $90 \%$ tienen dos asteriscos.

Análisis de componentes principales (ACP) (tabla V.9.24 y 25): aunque el ACP no es un método de clasificación en sí mismo, en nuestros datos, se ve que la mayor parte de los individuos de cada sexo, muestran valores positivos o negativos en la primera componente principal (CP), la cual tienen en cuenta la mayor parte de la variación de los datos. Así, de este modo, el cómputo de los resultados de las variables seleccionadas se puede emplear para una clasificación simple y efectiva de los datos. Aunque la representación de las CPs es valiosa, su cálculo es suficiente para los propósitos de clasificación. El análisis de componentes principales ha proporcionado unos porcentajes de clasificación muy altos (tabla V.9.24 y 25). Sin embargo, su aplicación al registro fósil es limitada debido a que en 
la mayor parte de los casos los restos se encuentran fragmentados no pudiendo medirse todas las variables en todos los huesos.

Tabla V.9.25

Resultados obtenidos tras aplicar los tres métodos a la extremidad posterior de la muestra moderna

\begin{tabular}{|c|c|c|c|c|c|c|c|c|c|c|}
\hline \multirow[t]{2}{*}{ Hueso } & \multirow[t]{2}{*}{ Variables } & \multirow{2}{*}{$\begin{array}{c}\text { Variables } \\
\text { Análisis } \\
\text { Multivariante }\end{array}$} & \multirow{2}{*}{$\begin{array}{l}\text { Mixture } \\
\text { Analyisis } \\
\text { Clásico }\end{array}$} & \multicolumn{3}{|c|}{ Análisis Cluster Jerárquico } & \multicolumn{2}{|c|}{ K-medias } & \multicolumn{2}{|c|}{$\begin{array}{c}\text { Análisis de } \\
\text { Componentes } \\
\text { Principales }\end{array}$} \\
\hline & & & & Ward & Complete & Average & Clásico & Robusto & Clásico & Robusto \\
\hline \multirow{9}{*}{ 离 } & GL & $\mathrm{N}$ & 64 & $\underline{84 *}$ & 64 & 64 & $\underline{88 *}$ & $\underline{88^{*}}$ & \multirow{9}{*}{$\underline{84^{*}}$} & \multirow{9}{*}{$\underline{88 *}$} \\
\hline & GLC & S & 64 & $\underline{80 *}$ & 64 & 64 & $\underline{88^{*}}$ & 68 & & \\
\hline & $\mathrm{BP}$ & S & 68 & $\underline{84^{*}}$ & $\underline{88^{*}}$ & $\mathrm{X}$ & $\underline{88^{*}}$ & $\underline{88^{*}}$ & & \\
\hline & DC & $\mathrm{N}$ & 56 & $\overline{64}$ & $\overline{64}$ & $\mathrm{X}$ & $\overline{64}$ & $\overline{64}$ & & \\
\hline & SD & $\mathrm{N}$ & 56 & 56 & 56 & 56 & 52 & 52 & & \\
\hline & SDD & $\mathrm{N}$ & 64 & 64 & 64 & $\mathrm{X}$ & 64 & 72 & & \\
\hline & $\mathrm{BD}$ & S & 68 & $\underline{80^{*}}$ & $\underline{80 *}$ & 68 & $\underline{80^{*}}$ & $\underline{84^{*}}$ & & \\
\hline & $\mathrm{DD}$ & S & $\underline{84^{*}}$ & $80^{*}$ & $\underline{80^{*}}$ & $\mathrm{X}$ & $84^{*}$ & $\underline{80 *}$ & & \\
\hline & $\begin{array}{l}\mathrm{GLC}+\mathrm{BP}+ \\
\mathrm{BD}+\mathrm{DD}\end{array}$ & - & 72 & $\underline{80^{*}}$ & $\underline{80^{*}}$ & - & $\underline{80^{*}}$ & $\underline{80 *}$ & & \\
\hline \multirow{8}{*}{$\stackrel{\frac{\pi}{2}}{3}$} & GL & $S$ & 65,4 & $\underline{88,5^{*}}$ & $\underline{88,5^{*}}$ & 65,4 & 69,2 & $\underline{88,5^{*}}$ & & \\
\hline & BP & S & $\underline{80,8^{*}}$ & $\overline{80,8^{*}}$ & $\overline{80,8^{*}}$ & $\underline{80,8^{*}}$ & $\underline{80,8^{*}}$ & $\overline{80,8^{*}}$ & & \\
\hline & DP & $S$ & $\underline{80,8^{*}}$ & $\underline{80,8^{*}}$ & $80,8^{*}$ & $x$ & $\underline{76,9}$ & $\underline{76,9}$ & & \\
\hline & SD & S & $\underline{76,9}$ & $\underline{76,9}$ & $\underline{76,9}$ & $\underline{76,9}$ & $\underline{76,9}$ & $\underline{76,9}$ & & \\
\hline & SDD & $\mathrm{N}$ & 69,2 & 69,2 & 69,2 & 69,2 & 73,1 & 73,1 & & \\
\hline & $\mathrm{BD}$ & S & $\underline{76,9}$ & $\underline{80,8^{*}}$ & $\underline{76,9}$ & $\mathrm{X}$ & $\underline{80,8^{*}}$ & $\underline{80,8^{*}}$ & & \\
\hline & $\mathrm{DD}$ & S & 57,7 & $\overline{65,4}$ & $\underline{76,9}$ & 65,4 & $80,8^{*}$ & 65,4 & & \\
\hline & $\begin{array}{l}\mathrm{GL}+\mathrm{BP}+\mathrm{DP}+ \\
\mathrm{SD}+\mathrm{BD}+\mathrm{DD}\end{array}$ & - & $\underline{84,6^{*}}$ & - & $\underline{84,6^{*}}$ & - & $\underline{84,6^{*}}$ & $\underline{88,5^{*}}$ & $\underline{88,5^{*}}$ & $\underline{88,5^{*}}$ \\
\hline \multirow{9}{*}{ 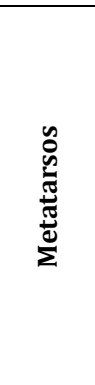 } & GL & $S$ & 73,1 & $\underline{76,9}$ & $\underline{76,9}$ & $\underline{76,9}$ & $\underline{76,9}$ & $\underline{76,9}$ & & \\
\hline & $\mathrm{BP}$ & S & 73,1 & 61,5 & 76,9 & $\overline{57,7}$ & $\overline{80,8^{*}}$ & $\overline{80,8^{*}}$ & & \\
\hline & DP & $\mathrm{N}$ & 53,8 & $\mathrm{X}$ & $\bar{x}$ & $\mathrm{X}$ & $\overline{53,8}$ & $\overline{53,8}$ & & \\
\hline & SD & S & 65,4 & $\underline{76,9}$ & 65,4 & $\underline{76,9}$ & $\underline{76,9}$ & 73,1 & & \\
\hline & SDD & S & $\underline{76,9}$ & $\underline{\overline{76,9}}$ & $\underline{76,9}$ & $\underline{\overline{76,9}}$ & $\overline{73,1}$ & 69,2 & & \\
\hline & $\mathrm{BD}$ & S & $\overline{76,9}$ & $\overline{80,8^{*}}$ & $\overline{80,8^{*}}$ & $\overline{80,8^{*}}$ & 73,1 & 69,2 & & \\
\hline & DL & $\mathrm{N}$ & 69,2 & 73,1 & $\overline{69,2}$ & $\overline{73,1}$ & 69,2 & 69,2 & & \\
\hline & $\mathrm{DM}$ & $\mathrm{N}$ & 73,1 & 69,2 & 73,2 & X & 73,1 & 73,1 & \multirow[b]{2}{*}{$\frac{84.6}{(88.5)^{*}}$} & \multirow[b]{2}{*}{$\underline{88,5^{*}}$} \\
\hline & $\begin{array}{l}\mathrm{GL}+\mathrm{BP}+ \\
\mathrm{SD}+\mathrm{CD}+\mathrm{BD}\end{array}$ & - & 73,1 & - & 69,2 & - & $\underline{88,5^{*}}$ & $\underline{80,8^{*}}$ & & \\
\hline
\end{tabular}

* Porcentaje de clasificaciones correctas para todas las variables utilizando los diferentes métodos estadísticos. Los porcentajes por encima de un 75\% están subrayados; los valores similares o iguales al $80 \%$ también están marcados con un asterisco; y los valores iguales o por encima del $90 \%$ tienen dos asteriscos.

Análisis de mixturas (mixture analysis) (MA) (tabla V.9.24 y 25): este modelo es el que ha aportado peores datos. Sin embargo, se observa que al igual que los análisis cluster, los mejores resultados se obtienen en las epífisis y en las anchuras de las diáfisis.

Análisis cluster (AC) (tabla V.9.24, 25 y 26): este método proporciona mejores resultados que el análisis de mixturas. Las diferentes opciones del Cluster Hierático Aglomerativo (Agglomerative Hierarchical Cluster Analysis), aportan resultados distintos, dependiendo del método aglomerativo empleado. Las técnicas "Ward" y "Complete" arrojan los mejores resultados mientras que el "Average" no es tan bueno (tabla V.9.24 y 25). Los análisis kmedias, tanto el clásico como el robusto, aportan resultados similares, con una ligera mejora en el clásico. El rendimiento entre el "Complete" y el k-medias clásico es muy similar, pero con resultados algo mejores en el k-medias. Por todo ello, será este método, el k-medias, el que se desarrollará en la muestra fósil. Los porcentajes de clasificación más altos se obtienen con el húmero, seguidos por el radio, el metacarpo, el fémur, la tibia y el metatarso. Así, se puede indicar que las mejores clasificaciones se obtienen en la extremidad anterior (tabla V.9.24) aunque el método se aplica en los huesos de ambas extremidades (tabla V.9.24, 25 y 26). 
TablaV.9.26

Estadística descriptiva e Índice de dimorfismo sexual para el k-medias de la muestra de la Cueva de Valdegoba (Vb) comparada con la muestra moderna (Md)

\begin{tabular}{|c|c|c|c|c|c|c|c|c|c|c|c|c|}
\hline \multirow{2}{*}{ Hueso } & \multirow{2}{*}{ Variable } & \multirow{2}{*}{ Muestra } & \multirow{2}{*}{ Método } & \multicolumn{4}{|c|}{ Machos } & \multicolumn{4}{|c|}{ Hembras } & \multirow{2}{*}{ IDS } \\
\hline & & & & $\mathbf{n}$ & $\overline{\mathbf{x}}$ & rango & s.d. & $\mathbf{n}$ & $\overline{\mathbf{x}}$ & rango & s.d. & \\
\hline \multirow{12}{*}{$\underset{\pi}{\stackrel{乛}{\pi}}$} & \multirow[t]{4}{*}{ BP } & $\mathrm{Vb}$ & K-medias (a) & 12 & 31,3 & $28,8-38,9$ & 2.54 & 7 & 28,6 & $24,6-30,7$ & 2,0 & 91,2 \\
\hline & & $\mathrm{Vb}$ & K-medias (b) & 8 & 31,3 & $28,8-38,9$ & 3.16 & 4 & 27,8 & $24,6-29,9$ & 2,2 & 88,7 \\
\hline & & $\mathrm{Md}$ & K-medias & 12 & 29,4 & $28,4-30,4$ & 0.65 & 12 & 27,3 & $25,9-29,1$ & 0,8 & 92,9 \\
\hline & & $\mathrm{Md}$ & Muestra moderna & 13 & 29,1 & $27,6-30,4$ & 0.87 & 11 & 27,3 & $25,9-29,1$ & 1,0 & 93,9 \\
\hline & \multirow[t]{4}{*}{ DP } & $\mathrm{Md}$ & K-medias (a) & 12 & 15,8 & $15,5-16,5$ & 0.30 & 7 & 15,0 & $13,4-15,6$ & 0,7 & 94,8 \\
\hline & & $\mathrm{Md}$ & K-medias (b) & 8 & 15,9 & $15,5-16,5$ & 0.33 & 4 & 14,8 & $13,4-15,6$ & 0,9 & 93,5 \\
\hline & & $\mathrm{Md}$ & K-medias & 12 & 15,3 & $14,6-15,7$ & 0.39 & 12 & 14,1 & $13,7-14,6$ & 0,2 & 92,2 \\
\hline & & $\mathrm{Md}$ & Muestra moderna & 13 & 15,1 & $14,3-15,7$ & 0.50 & 11 & 14,1 & $13,7-15,5$ & 0,5 & 93,7 \\
\hline & \multirow[t]{4}{*}{ BD } & $\mathrm{Vb}$ & K-medias (a) & 8 & 28,1 & $27,0-29,3$ & 0.71 & 4 & 24,4 & $23,0-25,1$ & 0,9 & 86,8 \\
\hline & & $\mathrm{Vb}$ & K-medias (b) & 6 & 28,2 & $27,0-29,3$ & 0.76 & 3 & 24,9 & $24,7-25,1$ & 0,2 & 88,1 \\
\hline & & $\mathrm{Md}$ & K-medias & 11 & 26,7 & $26,0-27,3$ & 0.38 & 14 & 25,0 & $23,2-25,8$ & 0,7 & 93,6 \\
\hline & & $\mathrm{Md}$ & Muestra moderna & 13 & 26,5 & $25,5-27,3$ & 0.59 & 12 & 24,9 & $23,2-26,7$ & 0,8 & 94,4 \\
\hline \multirow{8}{*}{ 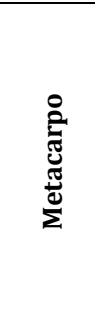 } & \multirow[t]{4}{*}{ BP } & $\mathrm{Vb}$ & K-medias (a) & 11 & 24,7 & $23,5-26,0$ & 0.83 & 8 & 22,1 & $18,5-23,2$ & 1,5 & 89,5 \\
\hline & & $\mathrm{Vb}$ & K-medias (b) & 7 & 24,8 & $23,8-25,7$ & 0.67 & 5 & 21,8 & $18,5-23,2$ & 1,9 & 87,6 \\
\hline & & $\mathrm{Md}$ & K-medias & 12 & 23,4 & $22,6-25,0$ & 0.68 & 14 & 21,6 & $20,7-22,4$ & 0,5 & 92,2 \\
\hline & & Md & Muestra moderna & 13 & 23,1 & $21,8-24,0$ & 0.76 & 13 & 21,9 & $20,7-25,0$ & 1,1 & 94,9 \\
\hline & \multirow[t]{4}{*}{ BD } & $\mathrm{Vb}$ & K-medias (a) & 12 & 27,9 & $26,8-29,4$ & 0.70 & 5 & 25,4 & $23,1-26,5$ & 1,4 & 91,0 \\
\hline & & $\mathrm{Vb}$ & K-medias (b) & 6 & 27,9 & $26,8-29,4$ & 0.86 & 3 & 26,3 & $25,8-26,5$ & 0,4 & 93,9 \\
\hline & & $\mathrm{Md}$ & K-medias & 13 & 26,3 & $24,4-28,3$ & 1.01 & 13 & 24,4 & $23,6-25,5$ & 0,6 & 92,7 \\
\hline & & $\mathrm{Md}$ & Muestra moderna & 13 & 25,9 & $24,1-27,3$ & 0.90 & 13 & 24,7 & $23,6-28,3$ & 1,3 & 95,0 \\
\hline \multirow{8}{*}{$\stackrel{\frac{\pi}{3}}{\stackrel{3}{=}}$} & \multirow[t]{4}{*}{$\mathrm{BD}$} & $\mathrm{Vb}$ & K-medias (a) & 17 & 27,1 & $26,1-28,5$ & 0.76 & 10 & 24,9 & $23,2-25,8$ & 0,9 & 91,8 \\
\hline & & $\mathrm{Vb}$ & K-medias (b) & 13 & 27,2 & $26,2-28,5$ & 0.77 & 5 & 24,6 & $23,2-25,8$ & 1,1 & 90,7 \\
\hline & & $\mathrm{Md}$ & K-medias & 17 & 26,1 & $25,2-27,4$ & 0.68 & 9 & 24,2 & $23,3-25,1$ & 0,7 & 93,0 \\
\hline & & $\mathrm{Md}$ & Muestra moderna & 14 & 26,0 & $23,5-27,4$ & 0.99 & 12 & 24,8 & $23,3-26,1$ & 0,8 & 95,1 \\
\hline & \multirow[t]{4}{*}{ DD } & $\mathrm{Vb}$ & K-medias (a) & 17 & 19,9 & $19,0-20,9$ & 0.48 & 10 & 18,6 & $18,0-19,7$ & 0,5 & 93,1 \\
\hline & & $\mathrm{Vb}$ & K-medias (b) & 13 & 20,0 & $19,0-20,9$ & 0.53 & 5 & 18,7 & $18,0-19,7$ & 0,6 & 93,2 \\
\hline & & $\mathrm{Md}$ & K-medias & 17 & 18,9 & $18,1-19,7$ & 0.57 & 9 & 17,6 & $16,8-18,0$ & 0,4 & 93,2 \\
\hline & & $\mathrm{Md}$ & Muestra moderna & 14 & 18,8 & $17,7-19,7$ & 0.65 & 12 & 17,9 & $16,8-19,6$ & 0,7 & 95,4 \\
\hline \multirow{4}{*}{ 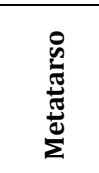 } & \multirow[t]{4}{*}{ BP } & $\mathrm{Vb}$ & K-medias (a) & 7 & 23,9 & $22,9-26,6$ & 1.25 & 9 & 21,6 & $20,6-22,5$ & 0,7 & 90,4 \\
\hline & & $\mathrm{Vb}$ & K-medias (b) & 5 & 23,9 & $22,9-26,6$ & 1.52 & 5 & 21,6 & $20,6-22,5$ & 0,7 & 90,1 \\
\hline & & $\mathrm{Md}$ & K-medias & 14 & 22,3 & $21,5-23,4$ & 0.65 & 12 & 20,6 & $19,6-21,2$ & 0,5 & 92,6 \\
\hline & & $\mathrm{Md}$ & Muestra moderna & 13 & 22,1 & $20,7-23,3$ & 0.79 & 13 & 21,0 & $19,6-23,4$ & 0,9 & 95,2 \\
\hline
\end{tabular}

* Estadística descriptiva, índice de dimorfismo sexual y relación entre los valores obtenidos en la muestra moderna y la fósil aplicando el K-medias. A: k-medias aplicado a toda la muestra; b: k-medias aplicado a los huesos derechos excepto en el Bp del metatarso de las hembras en el que se ha tenido en cuenta el lado izquierdo. s.d: desviación estándar; Min: valor mínimo; Max: valor máximo; n: número de individuos; IDS: índice de dimorfismo sexual (media hembras/media machos * 100).

Los resultados indican que las variables más fiables son aquellas que miden el valor medio-lateral de las epífisis. En el caso del húmero, hueso que ha proporcionado los mejores resultados, la mejor variable es la que mide la tróclea (BT) en lugar de toda la epífisis (BD). Sin embargo, en el caso del radio, los mejores resultados los proporciona toda la epífisis (BD) en vez de la superficie articular (BFD). Los resultados de las longitudes máximas (GL, GLl y GLc) son variables y más fiables en las extremidades posteriores. En algún caso, la longitud fisiológica (GLc) del húmero aporta mejores resultados cuando lo comparamos con la longitud máxima (GLI). Finalmente, los resultados de las variables tomadas en las diáfisis son bastante irregulares. 
Tabla V.9.27

Resultados del K-medias en la muestra de R. pyrenaica de la Cueva de Valdegoba

\begin{tabular}{|c|c|c|c|c|c|c|c|c|c|c|}
\hline & \multicolumn{2}{|c|}{$\begin{array}{c}\text { \% clasificaciones } \\
\text { correctas }^{\mathrm{a}}\end{array}$} & \multicolumn{4}{|c|}{ Machos } & \multicolumn{3}{|c|}{ Hembras } & \multirow{2}{*}{$\begin{array}{c}\text { Relación } \\
\mathbf{M} / \mathbf{H}\end{array}$} \\
\hline & $\begin{array}{l}\text { K-medias } \\
\text { clásico }\end{array}$ & $\begin{array}{c}\text { K-medias } \\
\text { robusto }\end{array}$ & $\mathbf{N}$ & Izquierdo & Derecho & Total & Izquierdo & Derecho & Total & \\
\hline \multicolumn{11}{|l|}{ Radio } \\
\hline $\mathrm{BP}+\mathrm{DP}$ & $87,5^{b}$ & $87,5^{b}$ & 19 & 4 & 8 & 12 & 3 & 4 & 7 & $8 / 4=2$ \\
\hline BD & 84,0 & 84,0 & 12 & 2 & 6 & 8 & 1 & 3 & 4 & $6 / 3=2$ \\
\hline \multicolumn{11}{|c|}{ Metacarpo } \\
\hline $\mathrm{BP}$ & 80,7 & 80,7 & 19 & 4 & 7 & 11 & 3 & 5 & 8 & $7 / 5=1,4$ \\
\hline BD & 84,6 & 84,6 & 17 & 6 & 6 & 12 & 2 & 3 & 5 & $6 / 3=2$ \\
\hline \multicolumn{11}{|l|}{ Tibia } \\
\hline $\mathrm{BD}+\mathrm{DD}$ & $80,7^{c}$ & $80,7^{c}$ & 28 & 4 & 14 & 18 & 5 & 5 & 10 & $14 / 5=2,8$ \\
\hline \multicolumn{11}{|c|}{ Metatarso } \\
\hline $\mathrm{BP}$ & 80,7 & 80,7 & 16 & 2 & 5 & 7 & 5 & 4 & 9 & $5 / 5=1$ \\
\hline
\end{tabular}

* Resultados del K-means en la muestra de la Cueva de Valdegoba. aBasado en la la muestra moderna; bEl análisis bivariante ha proporcionado mejores resultados que las variables por separado; cEl análisis bivariante ha proporcionado resultados similares a los aportados por el análisis univariante. Izq: izquierdo. Drch: derecho.

Tabla V.9.28

Diferencias en el dimorfismo sexual de los R. pyrenaica actuales y los de la Cueva de Valdegoba

\begin{tabular}{|c|c|c|c|c|c|c|c|}
\hline & \multicolumn{4}{|c|}{ Wilcoxon/Mann-Whitneyq } & \multirow{2}{*}{\multicolumn{2}{|c|}{$\begin{array}{l}\text { Diferencia } \\
\text { en IDS }\end{array}$}} & \multirow[b]{3}{*}{$\begin{array}{c}\text { DS } \\
\text { Sexual } \\
\text { en } \\
\text { Valdegoba }^{\mathrm{d}}\end{array}$} \\
\hline & \multicolumn{2}{|r|}{ Machos } & \multicolumn{2}{|c|}{ Hembras } & & & \\
\hline & p-valor & $\begin{array}{c}\text { Tamaño } \\
\text { de la muestra } \\
\text { de Valdegoba } \\
\text { comparada } \\
\text { con la } \\
\text { moderna }\end{array}$ & p-valor & $\begin{array}{c}\text { Tamaño } \\
\text { de la muestra } \\
\text { de Valdegoba } \\
\text { comparada } \\
\text { con la moderna }\end{array}$ & $\begin{array}{c}\text { IDS }^{\mathbf{b}} \\
\text { Md-Vb }\end{array}$ & $\begin{array}{c}\text { IDS }^{\mathbf{b}} \\
\text { Md-Vb }\end{array}$ & \\
\hline \multicolumn{8}{|l|}{ Radio } \\
\hline $\mathrm{BP}$ & 0.0052 & + & 0.3952 & $=$ & 4.2 & 5.2 & + \\
\hline DP & 0.0004 & + & 0.2632 & $=$ & -1.3 & 0.2 & ? \\
\hline BD & 0.0007 & + & 0.5126 & $=$ & 5.5 & 6.3 & + \\
\hline \multicolumn{8}{|c|}{ Metacarpo } \\
\hline $\mathrm{BP}$ & 0.0004 & + & 0.3233 & $=$ & 4.6 & 7.3 & + \\
\hline BD & 0.0007 & + & 0.0429 & $\neq ?$ & -1.2 & 1.1 & $?$ \\
\hline \multicolumn{8}{|l|}{ Tibia } \\
\hline BD & 0.0033 & + & 0.7919 & $=$ & 2.3 & 4.4 & + \\
\hline DD & 0.0001 & + & 0.0571 & $=$ ? & 0 & 2.2 & $?$ \\
\hline \multicolumn{8}{|c|}{ Metatarso } \\
\hline $\mathrm{BP}$ & 0.0028 & + & 0.1984 & $=$ & 2.5 & 5.1 & + \\
\hline
\end{tabular}

* Diferencias en el dimorfismo sexual de los rebecos de la Cueva de Valdegoba (Vb) y los sarrios actuales (Md). Resultados del test de Wilcoxon/Mann-Whitney entre la muestra moderna y la fósil. a En la muestra de machos la hipótesis alternativa es $\mathrm{H}_{0}$ : Valdegoba=Moderna; $\mathrm{H}_{1}$ : Valdegoba>Moderna. En la muestra de hembras la hipótesis alternativa es $\mathrm{H}_{0}$ : Valdegoba=Moderna; $\mathrm{H}_{1}$ : Valdegoba $\neq$ Moderna. ${ }^{\mathrm{b}}$ La muestra moderna es aquella en la que se ha aplicado el k-medias y la muestra de la Cueva de Valdegoba es aquella en la que se ha calculado el NMI. c La muestra moderna es la muestra actual y la de la Cueva de Valdegoba es aquella que se ha utilizado para calcular el NMI. d Comparación con la muestra moderna. Se han tenido en cuenta aquellas variables en las que: 1) los machos de la Cueva de Valdegoba son significativamente más grandes que los machos modernos; 2 ) las hembras de ambos grupos son similares en tamaño; 3) las diferencias en IDS son de al menos dos en ambas columnas.

\section{Muestra fósil}

Se han aplicado el K-medias clásico y el robusto ya que son los que han aportado los mejores resultados en la muestra moderna. Los resultados obtenidos en la muestra fósil son similares (tabla V.9.27). 
El grupo con las medias más grandes ha sido asignado a los machos y el grupo con las medias más pequeñas a las hembras. Se han dividido los resultados de acuerdo con el lado, para no replicar los individuos y se ha utilizado el lado con mayor cantidad de huesos para calcular el ratio macho-hembra. Este ratio varía entre 1 y 2,8 dependiendo del hueso y la variable seleccionada (media $=1,87$; mediana $=2$ ). Así, hay dos machos por cada una de las hembras en el yacimiento (tabla V.9.28). Esto contrasta con la distribución actual de esta especie en la que las hembras duplican el número de machos (Cano et al., 2009).

La estadística descriptiva ha sido calculada utilizando todos los huesos de la muestra y sólo se han tenido en cuenta aquellas implicadas en el ratio sexual así como en el índice de dimorfismo sexual (IDS) (tabla V.9.28). La comparación de los valores medios y del IDS de la muestra de la Cueva Valdegoba y la muestra moderna sugieren que los machos de la Cueva de Valdegoba eran más grandes que los modernos, mientras que las hembras de ambos grupos son similares en tamaño. Esta observación ha sido confirmada por el test Wilcoxon/Mann-Whitney y mediante la comparación entre los IDS (tabla V.9.28). Estos resultados sugieren que al menos cinco de las ocho variables muestran mayor dimorfismo sexual en la Cueva de Valdegoba debido al mayor tamaño de los machos.

\subsubsection{Número Mínimo de Individuos}

El número mínimo de individuos se ha estimado a partir de las piezas más frecuentes y la edad de muerte. Se han determinado, en primer lugar, los ejemplares inmaduros y maduros. Los inmaduros, que incluyen los infantiles y juveniles, se han estimado a partir del $\mathrm{D}_{4}$; y los maduros a partir del $\mathrm{P}_{4}$. En segundo lugar, se indica el número de ejemplares infantiles, juveniles y adultos, a partir de los datos obtenidos en la edad de muerte. En los casos en los que no se hayan recuperado ni el $\mathrm{D}_{4}$ ni el $\mathrm{P}_{4}$, el número de ejemplares inmaduros y maduros se ha estimado a partir de los resultados de la edad de muerte.

Tabla V.9.29

Número mínimo de individuos de Rupicapra pyrenaica

\begin{tabular}{|c|c|c|c|c|c|c|c|}
\hline & & Inmaduros & Maduros & Total & Infantiles & Juveniles & Adultos \\
\hline Cueva de Valdegoba & & 26 & 88 & 114 & 1 & 16 & 82 \\
\hline Prado Vargas & & 1 & 1 & 2 & & 1 & 1 \\
\hline \multirow[t]{3}{*}{ Cueva Millán } & $\mathbf{1 A}$ & 2 & 3 & 5 & & 2 & 3 \\
\hline & 1B & 1 & & 1 & & 1 & \\
\hline & 1C & & 1 & 1 & & & 1 \\
\hline \multirow[t]{2}{*}{ Alexandre } & & 1 & & 1 & & 1 & \\
\hline & I & 1 & 1 & 2 & & & 1 \\
\hline \multirow[t]{3}{*}{ Estebanvela } & II & & & 1 & & & \\
\hline & III & & 1 & 1 & & & 1 \\
\hline & IV & & & 1 & & & \\
\hline
\end{tabular}

En la Cueva de Valdegoba se han identificado 26 ejemplares inmaduros, a partir del $\mathrm{D}_{4}$ izquierdo; y 88 maduros, a partir del $\mathrm{P}_{4}$ izquierdo. De los inmaduros, al menos 1 sería infantil y 16 serían juveniles. De los maduros, al menos 82 serían adultos (tabla V.9.30). En Prado Vargas se han registrado dos ejemplares a partir del $\mathrm{M}_{1}$ izquierdo. La edad de muerte estimada a partir de las ecuaciones de Klein nos indica que uno sería juvenil, es decir inmaduro; y otro sería un adulto, un maduro. En el nivel 1A de Cueva Millán se han identificado dos ejemplares juveniles, inmaduros; y otros tres maduros, adultos, a partir del $\mathrm{M}_{1}$ izquierdo. En el 1B, se han registrado al menos un ejemplar inmaduro, un juvenil a partir del $\mathrm{M}_{1}$ izquierdo. En el 1C, se ha identificado un ejemplar maduro, es decir, adulto, a partir de un $\mathrm{P}_{4}$ derecho. En el Abrigo de Alexandre el ejemplar identificado, un inmaduro, se ha estimado a partir del $\mathrm{D}^{2}$ izquierdo. Debido a su grado de desgaste, muy avanzado, estaría próximo a ser reemplazado por el $\mathrm{P}^{2}$, por lo que podríamos indicar que se trata de un juvenil. En el nivel I de la Peña de Estebanvela tendríamos al menos un ejemplar inmaduro, a partir del $\mathrm{D}_{3}$ derecho; y un maduro, es decir un adulto, a partir del $\mathrm{M}_{1}$ 
izquierdo. En el nivel II, se ha identificado un ejemplar, empleando un astrágalo, sin poder especificar nada más. En el nivel III hay al menos un ejemplar maduro, un adulto, estimado a partir del $\mathrm{P}^{4}$ izquierdo. En el nivel IV hay un ejemplar. Debido a que se ha identificado a partir de una falange proximal no podemos indicar si se trata de un ejemplar inmaduro o de un maduro.

\subsubsection{Discusión}

Los caracteres descritos anteriormente: dientes selenodontos y con las cúspides fusionadas nos permiten descartar a los cérvidos. Estas características son frecuentes en los bóvidos pero los restos recuperados, tanto los craneales como los postcraneales, son pequeños, permitiéndonos descartar a los bovinos y decantarnos por los caprinos. Dentro de este grupo, los dientes inferiores con los estilos marcados e hipoconúlidos rectos; y los superiores con los estilos muy proyectados y con islotes centrales de esmalte; así como las pequeñas dimensiones de ambos; la mayor gracilidad de los metápodos y el menor tamaño de los restos postcraneales y de los núcleos óseos de los cuernos nos permiten descartar al género Capra. Desde el Pleistoceno Medio existe en Europa un caprino de pequeño tamaño, aunque no tanto como los actuales (Arceredillo et al., 2011), cuyas características encajan bien con esta descripción, Rupicapra. Asignamos los restos a este género.

Las nuevas clasificaciones junto con los nuevos estudios de dispersión nos han obligado a realizar un análisis morfológico detallado de los fósiles. A nivel dental, ambas especies son muy similares. Sin embargo, hay que tener en cuenta que el material de referencia, al estar incluido en mandíbulas y maxilares, es de difícil estudio aunque sería interesante llevar a cabo un análisis dental para poder contrastar los datos observados en el esqueleto postcraneal. Los caracteres registrados en el postcráneo como la forma redondeada de la cavidad glenoidea y la proyección de la tuberosidad glenoidea de la escápula; la menor proyección de la fosa radial de la epífisis distal del húmero; el menor desarrollo de las áreas de inserción muscular del radio y de los metápodos; el borde dorsal menos oblicuo de la epífisis distal de la tibia y el menor desarrollo de la tróclea distal de los astrágalos nos permiten asignar los restos a R. pyrenaica (figura V.9.4 y 5).

En la actualidad, el rebeco, Rupicapra pyrenaica, está distribuido en dos núcleos en la Península Ibérica: uno en la cordillera cantábrica cuyo representante es $R$. p. parva, y otro en los Pirineos, con $R$. p. pyrenaica. Durante el Pleistoceno Tardío su distribución era mayor, habiéndose encontrado restos en Portugal (Salemas) (Cardoso y Antunes, 1989), la Comunidad de Madrid (Pinilla del Valle) (Arsuaga et al., 2010) e incluso en Córdoba (El Pirulejo) (Riquelme Cantal, 2008). Esto sugiere que durante el Pleistoceno Superior ocuparon hábitats más diversos ya que hoy en día se encuentran restringidos fundamentalmente en zonas de alta montaña. Los yacimientos estudiados, aunque se encuentran en lugares con abundantes roquedos, están distribuidos tanto en el norte como en el sur de la meseta por lo que podemos inferir una distribución más o menos continua desde el norte hasta, al menos, el centro peninsular. Las poblaciones actuales parecen haber sufrido un retroceso, probablemente debido a un aumento de la presión humana, o a la reintroducción o entrada especies competidoras. 

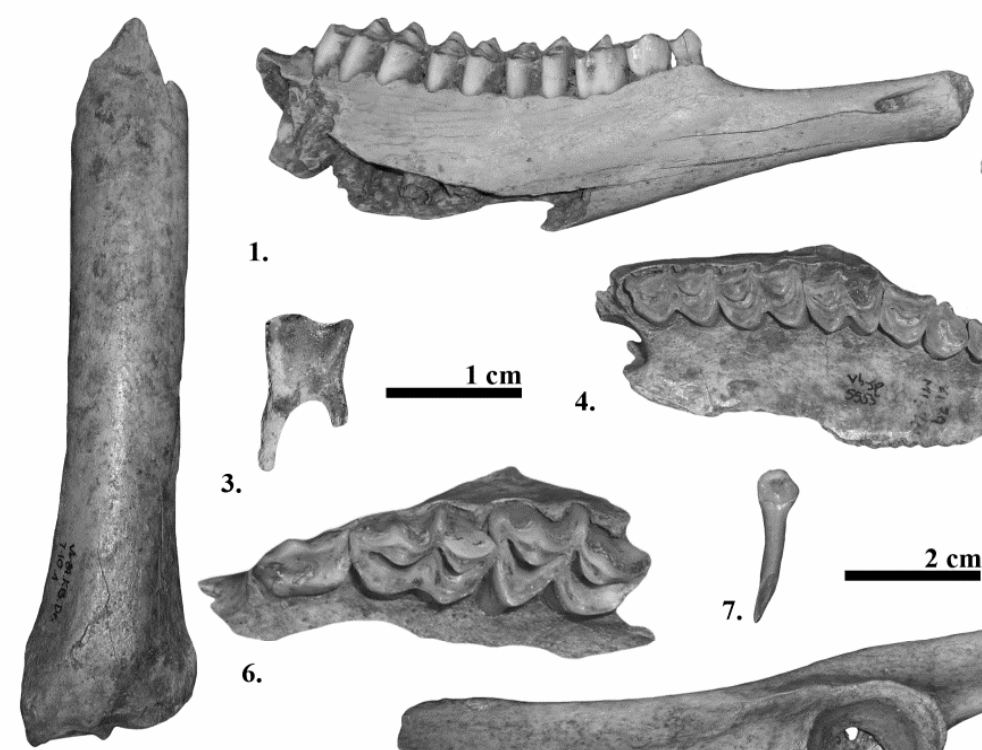

1.

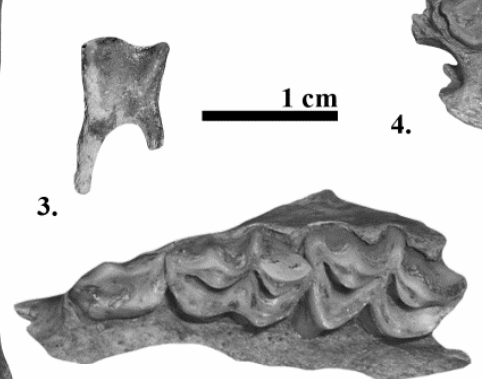

6.

,
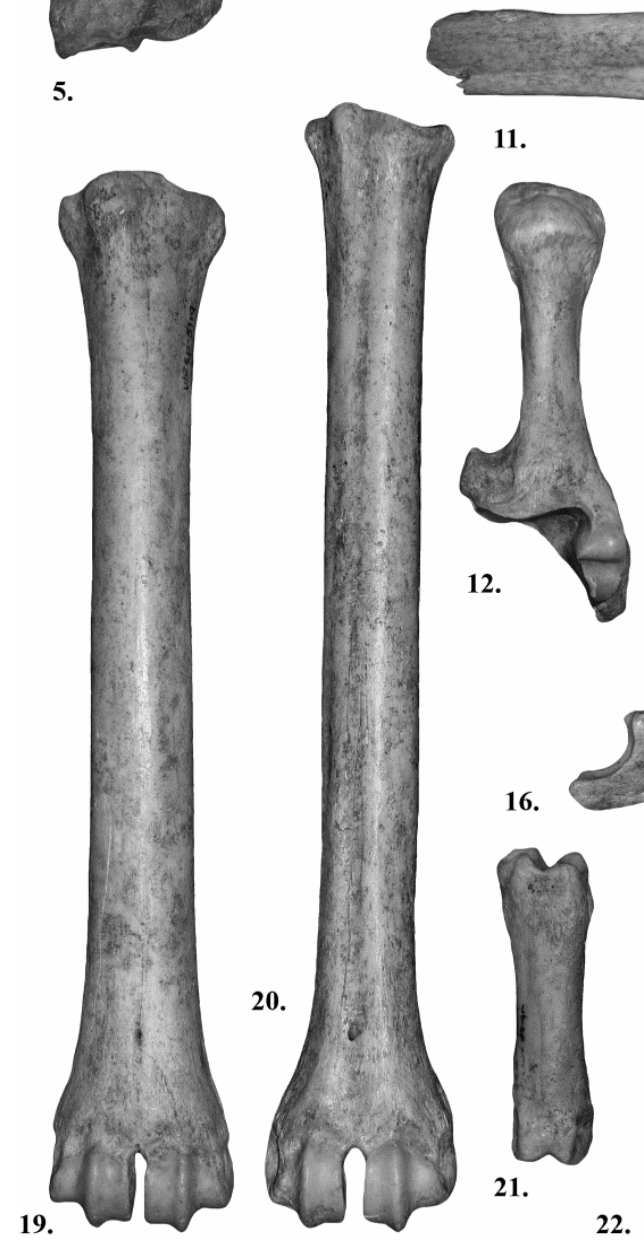

16.
20.

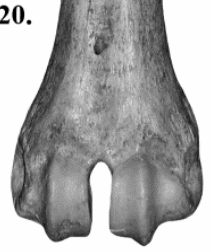

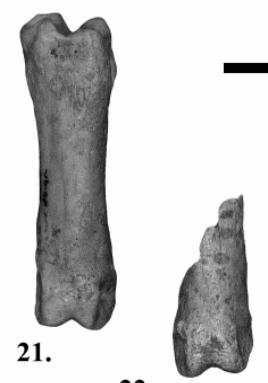

22.
15.

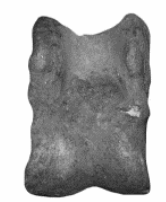

13.
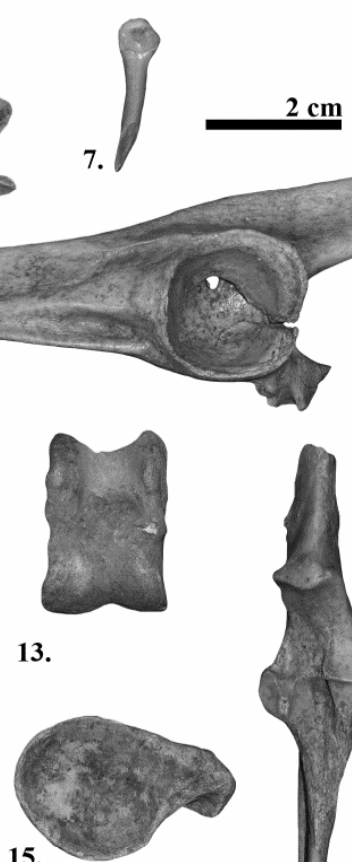

8.

2.
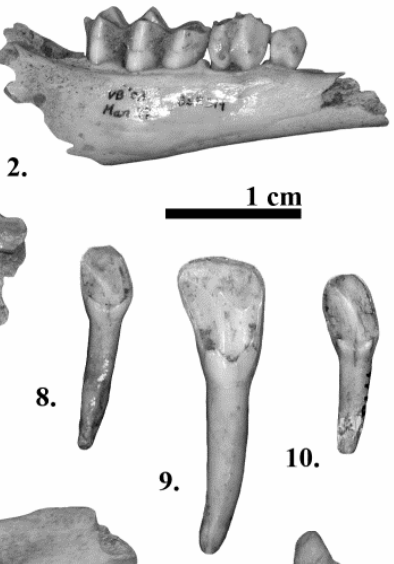

$1 \mathrm{~cm}$

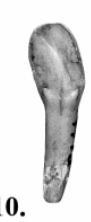

10.

14.
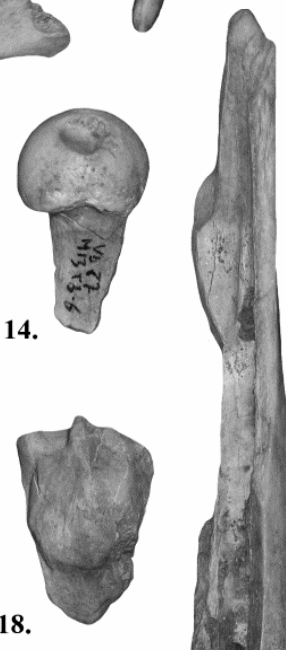

18.

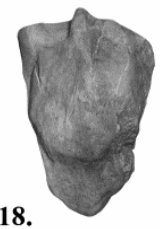

$2 \mathrm{~cm}$

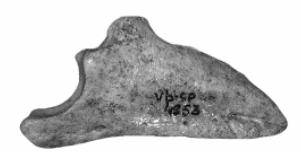

17.

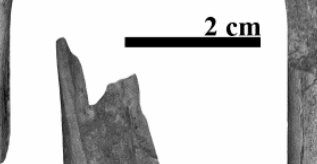

$2 \mathrm{~cm}$

24.

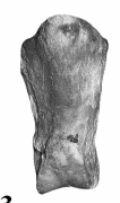

23.

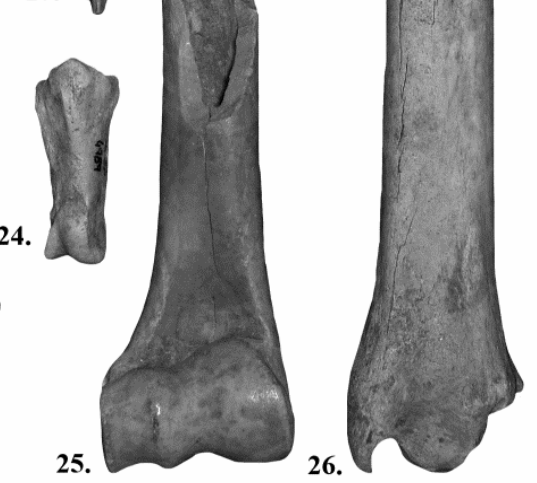

Lámina V.9.1. Rupicapra pyrenaica provenientes de los yacimientos de la Cueva de Valdegoba (sigla Vb), Prado Vargas (PV), Cueva Millán (sigla CM), Abrigo Alexandre (sigla AL) y La Peña de Estebanvela (sigla PE). 1) Vb-sp-5921 - Mandíbula $\left(\mathrm{P}_{2}-\mathrm{M}_{3}\right)$ derecha: cara bucal. 2) Vb-sp-319 - Mandíbula $\left(\mathrm{D}_{2}-\mathrm{D}_{4}\right)$ derecha: cara bucal. 3) 97.13.AL.10C.15.162 - $\mathrm{D}^{2}$ izquierdo: cara bucal. 4) Vb-sp-5535 - Maxilar ( $\left.\mathrm{P}^{2}-\mathrm{M}^{3}\right)$ derecho: superficie oclusal. 5) Vb.89.K13.Dc.T10.1 - Radio izquierdo. 6) Vb-sp-1908 - Maxilar (D2 - D ${ }^{4}$ izquierdo: superficie oclusal. 7) Vb-sp-5730 - dI2 izquierdo: cara lingual. 8) Vb-sp-2045 - Canino permanente izquierdo: cara lingual. 9) Vb-sp-1505: I I izquierdo: cara lingual. 10) Vb-sp-1778 - Canino decidual izquierdo. 11) Vb-sp-4741- Pelvis izquierda. 12) Vb-sp-3506 - Calcáneo izquierdo. 13) PE.02.F9.G9.NI.6 - Astrágalo derecho. 14) Vb.87.M13.T3. 6

- Fémur derecho. 15) Vb-sp-4738 - Escápula derecha. 16) Vb-sp-4853 - Falange distal derecha. 17) Vb-sp-3502 - Ulna derecha. 18) Vb-sp-3763 - Patella izquierda. 19) Vb-sp-5119 - Metacarpo izquierdo. 20) Vb-sp-3224 Metatarso derecho. 21) Vb-sp-4573 - Falange proximal derecha. 22) PV06.N4.H31.87 - Falange proximal derecha. 23) CM.86.1C.72 - Falange media derecha. 24) Vb-sp-4989 - Falange media izquierda. 25) Vb-sp-5163 - Húmero derecho. 26) Vb-sp-5216 - Tibia izquierda. 


\subsection{Capra pyrenaica}

Orden Artiodactyla Owen, 1848

Familia Bovidae Gray, 1821

Subfamilia Caprinae Gray, 1821

Género Capra Linnaeus, 1758

Especie Capra pyrenaica Schintz, 1838

\subsubsection{Generalidades}

La subfamilia Caprinae incluye a los bóvidos adaptados a climas extremos y terrenos difíciles. Los registros fósiles se encuentran mal documentados pero el primer grupo apareció durante el Mioceno Tardío (Guèrin y Patou-Mathis, 1996). La subfamilia Caprinae comprende 13 géneros divididos en tres tribus: Caprini, Rupicaprini y Ovibovini. La tribu Caprini comprende a las cabras, Capra, a las ovejas, Ovis, y a géneros supuestamente relacionados como Ammotragus, Hemitragus y Pseudois (Crégut-Bonnoure, 2006).

La evolución del genero Capra es difícil de rastrear debido a la escasez de restos y a su difícil ubicación taxonómica, aunque se considera que su origen se encuentra en Asia (Schaffer y Reed, 1972). El número de especies actuales ha variado mucho, desde la única reconocida por Herre y Röhrs (1955) hasta las nueve descritas por Lydekker (1913). En los últimos años, se han ido recuperando fósiles anteriores al Pleistoceno Medio en yacimientos como Fonelas P-1 (Arribas y Garrido, 2008), asignados a Capra baetica; como Dmanisi (Bukhsianidze y Vekua, 2006), descritos como C. dalii; como Aïn-Brimba (Arambourg, 1979), Venta Micena (Moyà-Solà, 1987) y Quibas (Montoya et al., 1999; Carlos-Calero et al., 2006; Arribas y Garrido; 2008) pertenecientes a C. alba, aunque autores como Crégut-Bonnoure (1999) incluyen este material en Hemitragus y Van der Made et al., (2008) indican que podría tratarse de un nuevo género de Caprini. Sin embargo, los restos procedentes de depósitos del Pleistoceno Medio son mucho más abundantes y hasta hace poco tiempo considerados como los más antiguos de Europa (Crégut- Bonnoure, 2006).

Una de las hipótesis sobre la entrada de este género en Europa la propone Crégut Bonnoure (1992a, 2006). Esta autora sugiere dos oleadas sucesivas. La primera tendría lugar hace unos 300.000 años dando lugar a $C$. ibex, y la segunda, ya en el Pleistoceno Tardío, hace 80.000 años, derivaría en C. pyrenaica. Otro escenario lo desarrollan Manceau et al., (1999), a partir de análisis de ADN mitocrondrial, sugiriendo una única oleada a partir de la cual surgirían los dos taxones actuales. Estas migraciones han permitido proponer varias hipótesis sobre el origen de C. pyrenaica. La primera propone como antepasado a $C$. ibex, la cual pudo cruzar los Pirineos en algún momento cercano al OIS 5e y diferenciarse en la Península Ibérica (Pérez et al., 2002). Otra hipótesis sugiere como antepasado a C. caucasica praepyrenaica, la cual cruzaría los Pirineos hace unos 80.000 años dando lugar más tarde a la cabra montés ibérica (Pérez et al., 2002). Por otra parte, Manceau et al (1999) proponen una única oleada protagonizada por Capra spp., diferenciándose posteriormente las dos especies europeas. Lo que sí parece claro es que durante el Paleolítico Superior y el Neolítico, esta especie ocupaba casi toda la Península Ibérica (Alados, 1985).

Los descubrimientos recientes llevados a cabo en el norte de África y en el sur de Europa cuestionan los estudios sobre la filogenia y las migraciones de estos bóvidos. Los descubrimientos realizados en Fonelas P-1 (Arribas y Garrido, 2008), Venta Micena (Moyà-Solà, 1987) y Quibas (Carlos-Calero et al., 2006) sugieren un escenario más complejo que debería ser analizado con más detalle en los próximos años debido a la importancia de este género en los depósitos del Pleistoceno Europeo. 


\subsubsection{Material}

El material empleado en la descripción y en la comparación proviene de los siguientes yacimientos:

La Cueva de Valdegoba: 584 restos identificados, 385 analizados: 282 restos craneales y dentales; y 103 postcraneales. Los restos craneales y dentales se reparten en: 6 fragmentos de cuernas, $3 \mathrm{dI}_{1}, 1 \mathrm{dI}_{2}, 1 \mathrm{dI}_{3}, 11 \mathrm{D}_{2}, 6 \mathrm{D}_{3}, 10 \mathrm{D}_{4}, 12 \mathrm{D}^{2}, 20 \mathrm{D}^{3}, 10 \mathrm{D}^{4}, 8 \mathrm{I}_{1}, 15 \mathrm{I}_{2}, 6$ $\mathrm{I}_{3}, 16$ caninos permanentes, $\mathrm{M}_{1}, 23 \mathrm{M}_{2}, 15 \mathrm{M}_{3}, 6 \mathrm{P}^{2}, 16 \mathrm{P}^{3}, 16 \mathrm{P}^{4}, 15 \mathrm{M}^{1}, 20 \mathrm{M}^{2}$ y $13 \mathrm{M}^{3}$. Los restos postcraneales se dividen en 2 radios, 2 tibias, 1 ulna, 4 húmeros, 7 astrágalos, 22 calcáneos, 2 metápodos, 17 falanges proximales, 25 falanges medias y 22 falanges distales.

Prado Vargas: 10 dientes: $1 \mathrm{I}_{1}, 1 \mathrm{P}_{3} 1 \mathrm{P}_{4}, 1 \mathrm{M}_{3}, 1 \mathrm{P}^{4}, 3 \mathrm{M}^{2}, 2 \mathrm{M}^{3}$.

Cueva Millán: 37 restos: 26 dientes y 11 piezas postcraneales. Nivel 1A: $5 \mathrm{I}_{1}, 5 \mathrm{I}_{2}, 1 \mathrm{C}, 1 \mathrm{P}_{2}$, $3 \mathrm{M}_{3}, 2 \mathrm{M}_{2}, 1 \mathrm{M}^{2}, 1 \mathrm{M}^{3}, 1$ astrágalo, 3 falanges proximales y 3 falanges distales. Nivel 1B: $2 \mathrm{I}_{1}$, $1 \mathrm{P}_{4}$ y 1 astrágalo. Nivel 1C: $1 \mathrm{I}_{1}, 1 \mathrm{M}_{1}, 1 \mathrm{P}^{4}, 1$ escafocuboides, 1 metacarpo y una falange distal. Se han identificado dos piezas: $1 \mathrm{M}^{1}$ y $1 \mathrm{M}^{2}$ cuyas siglas no indican ningún nivel (CM 865700 y CM 865701 respectivamente) por lo que no se tienen en cuenta en el análisis.

La Peña de Estebanvela: 42 restos: 20 dientes y 22 restos postcraneales. En el nivel I: 2 $\mathrm{dI}_{2}, 1 \mathrm{D}^{3}, 1 \mathrm{I}_{2}, 1 \mathrm{M}_{1}, 1 \mathrm{M}_{2}, 2 \mathrm{M}^{3}, 1$ húmero, 1 astrágalo, 1 calcáneo, 1 sesamoideo, 3 falanges proximales y 1 falange media. En el nivel II: $1 \mathrm{I}_{2}$ y 1 astrágalo. En el nivel III: $1 \mathrm{P}_{2}, 1 \mathrm{M}_{2}, 1$ $\mathrm{M}_{3}, 1 \mathrm{P}^{2}, 1 \mathrm{P}^{4}, 2 \mathrm{M}^{1}, 1 \mathrm{M}^{2}, 1 \mathrm{M}^{3}, 1$ astrágalo, 1 metapodio, 5 falanges proximales, 2 falanges medias y 2 falanges distales. En el nivel IV: $1 \mathrm{M}^{2}, 1 \mathrm{M}^{3}, 1$ astrágalo y 1 falange media.

En el análisis de la edad de muerte se han empleado los siguientes restos:

La Cueva de Valdegoba: 35 restos: $8 \mathrm{D}_{4}, 16 \mathrm{M}_{1}$ y $11 \mathrm{M}_{2}$.

Prado Vargas: 1 resto: $1 \mathrm{M}^{2}$.

Cueva Millán: 3 restos. Nivel 1A: 1 M2. Nivel 1B: 1 P4. Nivel 1C: 1 P4.

La Peña de Estebanvela: 6 restos. Nivel I: $2 \mathrm{dI}_{2}, 1 \mathrm{M}_{1}$ y $1 \mathrm{M}_{2}$. Nivel II: $1 \mathrm{I}_{2}$. Nivel III: $1 \mathrm{P}_{2}$ y 1 $\mathrm{M}_{2}$. Nivel IV: $1 \mathrm{M}_{3}$.

En la estacionalidad se han utilizado los siguientes dientes:

La Cueva de Valdegoba: $10 \mathrm{M}_{1}$ derechos.

Cueva Millán: $1 \mathrm{M}_{2}$ izquierdo.

La Peña de Estebanvela: 3 restos: Nivel I: $1 \mathrm{M}_{1}$ izquierdo y $1 \mathrm{M}_{2}$ izquierdo. Nivel III: $1 \mathrm{M}_{2}$ derecho.

\subsubsection{Descripción y comparación}

Los restos descritos provienen de los yacimientos de la Cueva de Valdegoba, Prado Vargas, Cueva Millán y la Peña de Estebanvela. Estas piezas podrían confundirse con las de Ovis, Hemitragus y Saiga. Empleamos los criterios que Halstead y Collins (2002) utilizaron para diferenciar Capra de Ovis pero aplicadas también a los otros dos géneros. Asimismo, se emplean los criterios de Crégut-Bonnoure (1992a) para compararlos con otras cabras europeas. Esta autora define dos líneas evolutivas diferentes, la línea $C$. caucasica $-C$. cylindricornis, que daría lugar a $C$. pyrenaica y la línea $C$. ibex, que daría lugar al íbice alpino 
(figuras V.10.2 y 3). Asimismo en el esqueleto postcraneal utilizamos los criterios de Boessneck et al. (1964) y Crègut-Bonnoure (1987) para comparar el material con el de Ovis y Hemitragus.

Núcleos óseos de cuernos: todos los restos han aparecido muy fragmentados. Ninguno conserva la zona de unión con el hueso parietal. Se descarta a Rupicapra por el gran diámetro de la pieza. Debido a su estado no se han podido tomar medidas ni realizar estudios sobre dimorfismo sexual.

Incisivos deciduales (lámina V.10.1: 1) (tabla V.10.1): son dientes de pequeño tamaño, con las coronas bajas y una raíz. Tienen un relieve longitudinal en la cara lingual de la corona, que está menos desarrollado que en los permanentes. El cuello no está muy marcado, a diferencia de Rupicapra. El dI 1 tiene un borde medial rectilíneo, lo que permite diferenciarlo del resto de incisivos. $\mathrm{El} \mathrm{dI}_{2} \mathrm{y} \mathrm{dI}_{3}$ muestran una gran curvatura en la corona, siendo más marcada en el $\mathrm{dI}_{3}$. Métricamente son muy similares entre sí (tabla V.10.1) pero son más pequeños que los permanentes (tablas V.10.1 y 4).

Tabla V.10.1

Medidas tomadas en los incisivos deciduales de C. pyrenaica

\begin{tabular}{|c|c|c|c|c|c|c|}
\hline & DMD & DLL & Hli & Hla & Hmes & Hdist \\
\hline \multicolumn{7}{|l|}{$\mathrm{dI}_{\mathbf{1}}$} \\
\hline \multicolumn{7}{|c|}{ Valdegoba } \\
\hline $\mathrm{n}$ & 4 & 4 & 4 & 4 & 4 & 4 \\
\hline rango & $5,1-5,6$ & $3,0-4,5$ & $7,6-8,7$ & $8,2-9,7$ & $6,5-8,1$ & $5,4-7,7$ \\
\hline $\bar{x} \pm$ s.d. & $5,2 \pm 0,2$ & $3,6 \pm 0,6$ & $7,9 \pm 0,5$ & $9,0 \pm 0,7$ & $7,3 \pm 0,7$ & $6,4 \pm 1,1$ \\
\hline \multicolumn{7}{|l|}{$\mathrm{dI}_{2}$} \\
\hline \multicolumn{7}{|c|}{ Valdegoba } \\
\hline $\mathrm{n}$ & 4 & 4 & 4 & 4 & 4 & 4 \\
\hline rango & $4,1-5,4$ & $3,2-3,7$ & $5,8-8,1$ & $5,1-9,9$ & $4,1-8,2$ & $4,5-8,8$ \\
\hline $\bar{x} \pm$ s.d. & $4,6 \pm 0,6$ & $3,5 \pm 0,2$ & $7,2 \pm 1,0$ & $7,9 \pm 2,0$ & $6,6 \pm 1,8$ & $7,0 \pm 1,8$ \\
\hline \multicolumn{7}{|c|}{ Estebanvela } \\
\hline $\mathrm{n}$ & 2 & 2 & 1 & & 1 & \\
\hline rango & $6,6-7,0$ & $3,1-4,2$ & 14,0 & & 11,8 & \\
\hline $\bar{x} \pm$ s.d. & $6,8 \pm 0,3$ & $3,6 \pm 0,8$ & & & & \\
\hline \multicolumn{7}{|l|}{$\mathrm{dI}_{3}$} \\
\hline \multicolumn{7}{|c|}{ Valdegoba } \\
\hline $\mathrm{n}$ & 2 & 2 & 2 & 2 & 2 & 2 \\
\hline rango & $4,2-4,2$ & $3,2-4,3$ & $7,4-9,7$ & $7,5-8,9$ & $7,1-9,7$ & $6,6-9,5$ \\
\hline$\overline{\mathrm{x}} \pm$ s.d. & $4,2 \pm 0,0$ & $3,7 \pm 0,7$ & $8,5 \pm 1,6$ & $8,2 \pm 1,0$ & $8,4 \pm 1,8$ & $8,1 \pm 2,1$ \\
\hline
\end{tabular}

Molares deciduales inferiores (lámina V.10.1: 2, 3 y 4) (tabla V.10.2): son dientes de pequeño tamaño, con las coronas bajas, sin cíngulos ni islotes centrales de esmalte y con dos raíces: una mesial y otra distal. El $\mathrm{D}_{4}$ puede presentar una o dos raicillas accesorias centrales. Morfológicamente son parecidos a los premolares inferiores, salvo el $\mathrm{D}_{4}$ que es trilobulado, pero tienen las coronas más bajas y las raíces más finas y divergentes. Son más estrechos que los premolares inferiores y más pequeños que los molares deciduales inferiores de Rupicapra (tablas V.9.2 y V.10.2).

$\mathbf{D}_{2}$ : tiene el protocónido muy desarrollado en posición central. Es asimétrico debido a que se estrecha hacia el extremo medial. Las caras lingual y bucal son convexas. Difiere del $\mathrm{P}_{2}$ por tener la protoprecrístida más larga y el surco, definido por la protoprecrístida y la protopostcrístida, más profundo.

$\mathbf{D}_{3}$ : el protocónido no está tan desarrollado como en el $\mathrm{D}_{2}$. Difiere del $\mathrm{P}_{3}$ por tener una paraprecrístida y un paracónido menos desarrollado, unos metacónidos y entocónidos 
unidos, un surco lingual más profundo y unas raíces más finas y divergentes. Son más estrechos y su longitud se solapa con las de los $\mathrm{P}_{3}$ (tablas V.10.2 y 5).

$\mathbf{D}_{4}$ : tiene el hipoconúlido muy desarrollado, dándole una apariencia trilobular. Los surcos de la cara lingual son poco profundos. Se diferencia del $\mathrm{M}_{3}$ por su menor tamaño y porque su diámetro transversal aumenta hacia el extremo distal.

Tabla V.10.2

Medidas tomadas en los molares deciduales inferiores de C. pyrenaica de la Cueva de Valdegoba

\begin{tabular}{|c|c|c|c|c|c|c|c|c|c|c|}
\hline & DAP & DAPb & DTa & DTp & DTpp & DT & DTb & $\mathbf{H}$ & Ha & Hр \\
\hline \multicolumn{11}{|l|}{$\mathbf{D}_{2}$} \\
\hline $\mathrm{n}$ & 11 & 11 & 11 & 11 & & 11 & 11 & 11 & & \\
\hline rango & $5,4-6,4$ & $4,7-5,7$ & $2,6-3,8$ & $3,1-4,2$ & & $3,3-4,1$ & $3,4-4,1$ & $2,9-5,2$ & & \\
\hline $\bar{x} \pm$ s.d. & $5,9 \pm 0,3$ & $5,2 \pm 0,3$ & $3,2 \pm 0,3$ & $3,7 \pm 0,4$ & & $3,7 \pm 0,2$ & $3,7 \pm 0,2$ & $3,7 \pm 0,6$ & & \\
\hline \multicolumn{11}{|l|}{$\mathbf{D}_{3}$} \\
\hline $\mathrm{n}$ & 5 & 5 & 3 & 3 & & 5 & 5 & 5 & & \\
\hline rango & $8,8-9,9$ & $7,5-7,9$ & $3,4-4,0$ & $4,9-5,5$ & & $4,1-5,2$ & $4,1-4,8$ & $3,5-8,8$ & & \\
\hline$\overline{\mathrm{x}} \pm$ s.d. & $9,3 \pm 0,5$ & $7,6 \pm 0,2$ & $3,7 \pm 0,3$ & $5,3 \pm 0,3$ & & $4,7 \pm 0,5$ & $4,6 \pm 0,3$ & $5,8 \pm 2,2$ & & \\
\hline \multicolumn{11}{|l|}{$\mathrm{D}_{4}$} \\
\hline $\mathrm{n}$ & 14 & 10 & 10 & 11 & 11 & 13 & 11 & & 11 & 11 \\
\hline rango & $15,2-19,3$ & $11,9-15,0$ & $4,9-5,5$ & $5,7-6,9$ & $6,4-7,7$ & $4,9-7,1$ & $6,3-7,4$ & & $7,0-12,3$ & $7,1-14,1$ \\
\hline$\overline{\mathrm{x}} \pm$ s.d. & $17,9 \pm 1,5$ & $13,7 \pm 1,0$ & $5,3 \pm 0,2$ & $6,3 \pm 0,3$ & $7,1 \pm 0,3$ & $6,1 \pm 0,6$ & $6,9 \pm 0,4$ & & $9,7 \pm 1,9$ & $11,0 \pm 2,6$ \\
\hline
\end{tabular}

Molares deciduales superiores (lámina V.10.1: 9, 10 y 11) (tabla V.10.3): dientes de pequeño tamaño, selenodontos, con las cúspides aisladas y coronas bajas. Son bilobulados, no tienen columnas interlobulares ni islotes centrales de esmalte. Los estilos están poco proyectados y tienen tres raíces: una mesial, otra distal y otra lingual. El $\mathrm{D}^{2}$ puede tener fusionadas la lingual y la mesial. Son más pequeños que los premolares y molares superiores permanentes pero más grandes que los de Rupicapra (tablas V.9.3 y V.10.3).

Tabla V.10.3

Medidas tomadas en los molares deciduales superiores de C. pyrenaica

\begin{tabular}{|c|c|c|c|c|c|c|c|c|c|}
\hline & DAP & DAPb & DTa & DTp & DT & DTb & H & $\mathrm{Ha}$ & Hр \\
\hline \multicolumn{10}{|l|}{$\mathbf{D}^{2}$} \\
\hline \multicolumn{10}{|c|}{ Valdegoba } \\
\hline $\mathrm{n}$ & 14 & 14 & 14 & 14 & 14 & 14 & 14 & & \\
\hline rango & $7,8-9,1$ & $7,1-8,5$ & $3,9-5,5$ & $4,4-6,0$ & $4,2-5,9$ & $4,3-5,9$ & $3,3-11,6$ & & \\
\hline $\bar{x} \pm$ s.d. & $8,5 \pm 0,5$ & $7,7 \pm 0,4$ & $4,9 \pm 0,6$ & $5,4 \pm 0,5$ & $5,1 \pm 0,6$ & $5,2 \pm 0,5$ & $6,7 \pm 2,1$ & & \\
\hline \multicolumn{10}{|l|}{$D^{3}$} \\
\hline \multicolumn{10}{|c|}{ Valdegoba } \\
\hline $\mathrm{n}$ & 19 & 17 & 18 & 20 & 24 & 19 & & 15 & 15 \\
\hline rango & $11,2-14,7$ & $7,4-11,3$ & $5,8-7,9$ & $7,1-10,0$ & $5,1-9,5$ & $4,8-9,5$ & & $4,8-9,5$ & $3,2-12,2$ \\
\hline$\overline{\mathrm{x}} \pm$ s.d. & $12,9 \pm 1,0$ & $9,8 \pm 0,9$ & $6,9 \pm 0,5$ & $8,7 \pm 0,7$ & $7,6 \pm 0,9$ & $7,6 \pm 0,9$ & & $8,5 \pm 1,2$ & $9,0 \pm 2,7$ \\
\hline \multicolumn{10}{|c|}{ Estebanvela } \\
\hline $\mathrm{n}=1$ & 14,9 & 11,9 & 8,9 & 10,0 & 9,2 & 10,0 & 14,0 & 13,2 & 14,9 \\
\hline \multicolumn{10}{|c|}{$\mathrm{D}^{4}$} \\
\hline \multicolumn{10}{|c|}{ Valdegoba } \\
\hline $\mathrm{n}$ & 9 & 4 & 11 & 11 & 11 & 5 & & 8 & 7 \\
\hline rango & $8,2-14,7$ & $10,6-11,0$ & $5,2-11,4$ & $6,3-11,2$ & $6,3-10,5$ & $8,5-11,2$ & & $4,4-12,7$ & $4,4-14,0$ \\
\hline$\overline{\mathrm{x}} \pm$ s.d. & $11,8 \pm 2,5$ & $10,8 \pm 0,2$ & $9,2 \pm 2,2$ & $9,3 \pm 1,8$ & $8,5 \pm 1,6$ & $10,3 \pm 1,1$ & & $8,6 \pm 3,1$ & $9,3 \pm 3,1$ \\
\hline
\end{tabular}

D2: diente asimétrico ya que se estrecha hacia el extremo mesial. El metacono está muy desarrollado. El surco, definido por el protocono y el hipocono, es profundo, dándole una apariencia bilobular. La parapostcrísta es poco profunda y el parastilo está poco desarrollado. Son más estrechos que los $\mathrm{P}^{2}$ pero pueden tener longitudes similares (tablas V.10.3 y 7). 
D3: diente bilobulado, con el lóbulo anterior más estrecho que el posterior. Este carácter es diferente en el $\mathrm{D}^{4} \mathrm{y}$ en el resto de molares superiores permanentes. No tiene cíngulo en la cara mesial.

D4: diente bilobulado con los estilos muy proyectados. Difieren del $\mathrm{M}^{1}$ por su menor tamaño (tablas V.10.3 y 8).

Incisivos inferiores permanentes (lámina V.10.1: 12) (tabla V.10.4): dientes con las coronas altas y cuellos poco marcados,. La altura se atenúa y la curvatura aumenta del $\mathrm{I}_{1} \mathrm{al}$ $\mathrm{I}_{3}$. Tienen un relieve longitudinal en la cara lingual. Los tres incisivos presentan un tamaño similar (tabla V.10.4). Son más grandes que los deciduales (tablas V.10.1 y 4). Se diferencian de los caninos inferiores por tener la corona menos redondeada y por carecer de faceta de desgaste en la cara lateral. Difieren de los de Rupicapra por su mayor tamaño (tabla V.9. 4 y V.10.4) y por la ausencia de cuello entre la corona y la raíz.

Tabla V.10.4

Medidas tomadas en los incisivos permanentes de C. pyrenaica

\begin{tabular}{|c|c|c|c|c|c|c|}
\hline & DMD & DLL & Hli & Hla & Hmes & Hdist \\
\hline \multicolumn{7}{|l|}{$I_{1}$} \\
\hline \multicolumn{7}{|c|}{ Valdegoba } \\
\hline $\mathrm{n}$ & 17 & 16 & 11 & 15 & 14 & 15 \\
\hline rango & $3,8-8,8$ & $3,4-5,9$ & $5,9-20,4$ & $6,0-25,7$ & $4,9-21,7$ & $5,1-22,2$ \\
\hline $\bar{x} \pm$ s.d. & $6,5 \pm 1,5$ & $4,9 \pm 0,8$ & $14,2 \pm 5,1$ & $17,9 \pm 6,6$ & $15,6 \pm 5,9$ & $14,9 \pm 5,5$ \\
\hline \multicolumn{7}{|c|}{ Prado Vargas } \\
\hline $\mathrm{n}=1$ & 6,5 & 3,8 & 16 & 20,6 & 15,9 & 16 \\
\hline \multicolumn{7}{|l|}{ Millán } \\
\hline $\mathrm{n}$ & 8 & 8 & 8 & 7 & 8 & 8 \\
\hline rango & $5,0-7,8$ & $5,2-6,0$ & $3,7-19,1$ & $6,7-21,4$ & $4,3-20,5$ & $3,2-20,1$ \\
\hline $\bar{x} \pm$ s.d. & $6,3 \pm 1,1$ & $5,5 \pm 0,3$ & $14,2 \pm 6,1$ & $15,0 \pm 6,2$ & $13,5 \pm 6,0$ & $12,7 \pm 6,7$ \\
\hline \multicolumn{7}{|l|}{$\mathbf{I}_{2}$} \\
\hline \multicolumn{7}{|c|}{ Valdegoba } \\
\hline $\mathrm{n}$ & 20 & 19 & 12 & 16 & 11 & 11 \\
\hline rango & $4,9-8,3$ & $4,0-5,8$ & $10,9-20,3$ & $11,3-23,9$ & $10,6-19,3$ & $8,6-18,4$ \\
\hline $\bar{x} \pm$ s.d. & $6,9 \pm 1,0$ & $5,0 \pm 0,4$ & $15,8 \pm 3,0$ & $18,2 \pm 4,1$ & $14,5 \pm 3,2$ & $14,0 \pm 3,5$ \\
\hline \multicolumn{7}{|l|}{ Millán } \\
\hline $\mathrm{n}$ & 5 & 5 & 4 & 3 & 4 & 4 \\
\hline rango & $5,5-7,1$ & $4,9-6,0$ & $12,5-20,2$ & $13,5-22,1$ & $11,4-19,9$ & $9,6-18,0$ \\
\hline$\overline{\mathrm{x}} \pm$ s.d. & $6,3 \pm 0,7$ & $5,4 \pm 0,4$ & $15,1 \pm 3,6$ & $17,1 \pm 4,5$ & $14,4 \pm 3,8$ & $12,6 \pm 3,7$ \\
\hline \multicolumn{7}{|c|}{ Estebanvela } \\
\hline $\mathrm{n}$ & 2 & 2 & 2 & 2 & 2 & 2 \\
\hline rango & $5,4-6,2$ & $4,3-5,6$ & $11,0-12,7$ & $11,2-13,2$ & $9,5-11,6$ & $8,2-10,1$ \\
\hline$\overline{\mathrm{x}} \pm$ s.d. & $5,8 \pm 0,9$ & $5,0 \pm 0,9$ & $11,8 \pm 1,2$ & $12,2 \pm 1,4$ & $10,6 \pm 1,5$ & $9,1 \pm 1,3$ \\
\hline \multicolumn{7}{|l|}{$I_{3}$} \\
\hline \multicolumn{7}{|c|}{ Valdegoba } \\
\hline $\mathrm{n}$ & 9 & 9 & 7 & 7 & 7 & 7 \\
\hline rango & $3,7-6,9$ & $3,3-5,2$ & 8,1 - 19,1 & $7,8-22,1$ & $6,0-19,0$ & $6,6-18,4$ \\
\hline$\overline{\mathrm{x}} \pm$ s.d. & $5,7 \pm 1,2$ & $4,5 \pm 0,6$ & $13,3 \pm 4,0$ & $14,4 \pm 5,2$ & $12,3 \pm 4,4$ & $11,7 \pm 4,2$ \\
\hline \multicolumn{7}{|l|}{ C } \\
\hline \multicolumn{7}{|c|}{ Valdegoba } \\
\hline $\mathrm{n}$ & 15 & 15 & 13 & 12 & 11 & 10 \\
\hline rango & $5,0-7,0$ & $3,5-5,7$ & $10,5-17,3$ & $11,0-18,9$ & $9,8-15,9$ & $7,7-15,9$ \\
\hline$\overline{\mathrm{x}} \pm$ s.d. & $6,2 \pm 0,5$ & $4,6 \pm 0,6$ & $13,6 \pm 2,1$ & $15,3 \pm 2,7$ & $12,9 \pm 1,9$ & $11,6 \pm 2,0$ \\
\hline \multicolumn{7}{|l|}{ Millán } \\
\hline$n=1$ & 6,5 & 4,3 & 11,9 & & & \\
\hline
\end{tabular}

Caninos permanentes (lámina V.10.1: 13) (tabla V.10.4): dientes incisiviformes, con las coronas bajas, sin cuello que separe la corona de la raíz y unirradiculados. Difieren de los 
incisivos permanentes por tener las coronas redondeadas y una faceta de desgaste en el borde lateral. Su tamaño es similar al de los incisivos (tabla V.10.4) y son más grandes que los caninos de Rupicapra (tablas V.9.4 y V.10.4).

Premolares inferiores (lámina V.10.1: 5, 14 y 15) (tabla V.10.5) (figuras V.10.1, 2 y 3): dientes con las coronas bajas, sin cíngulos ni islotes centrales de esmalte. Tienen las fosetas profundas y unos surcos de desarrollo variable. Son birradiculados, con una raíz mesial y otra distal. Difieren de los deciduales por su mayor anchura (tablas V.10.2 y 5). Son más grandes que los premolares inferiores de Rupicapra (tablas V.9.5 y V.10.5).

$\mathbf{P}_{2}$ : tiene el protocónido muy desarrollado en posición central. Carece de cíngulos y tiene los bordes bucal y lingual rectos. Difiere del $\mathrm{D}_{2}$ por tener la protoprecrístida más grande y los surcos linguales y bucales menos desarrollados.

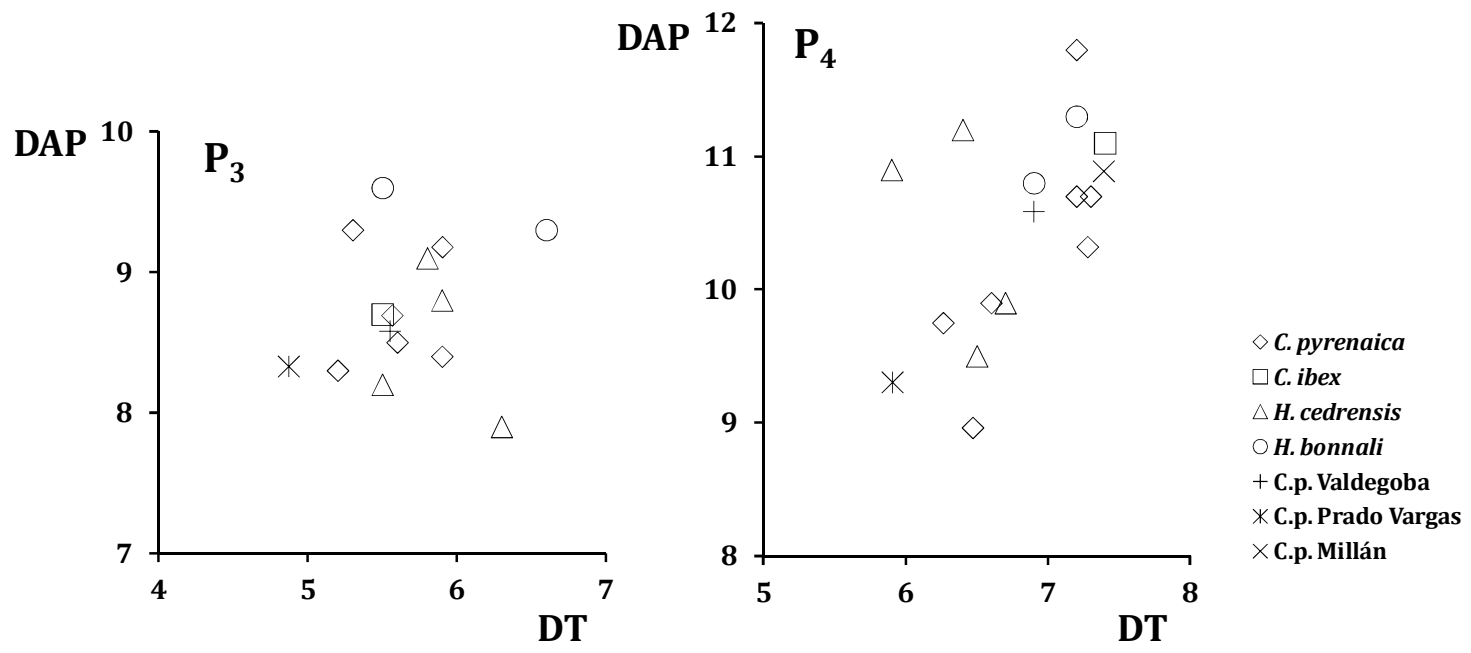

Figura V.10.1. Diagramas bivariantes de los premolares inferiores: DAP (diámetro anteroposterior) y DT (diámetro transversal). C. pyrenaica de Arlanpe, Buraca Escura, Jarama VI, Abric Romani (Sánchez, 1990), Tournal y Le Portel (Crégut-Bonnoure, 1992b). C. ibex de Adaouste (Rivals, 2006). H. cedrensis de l'Arago, les Cèdres (Rivals, 2006) y Bau de l'Aubesier (Rivals y Blasco, 2008). H. bonali de l'Arago (Rivals, 2006) y les Cèdres (Rivals, 2006).

$\mathbf{P}_{3}$ : tiene el paracónido separado del metacónido por un valle muy amplio y el entocónido proyectado hacia el extremo mesial. El surco bucodistal, definido por el protocónido y el hipocónido, es poco profundo. El surco lingual, entre el paracónido y el metacónido, tiene forma de "U". El paracónido es ancho en su parte anterior y se junta en la base del metacónido para formar un saliente en forma de "V". En dientes poco o nada gastados, el metacónido se encuentra ligeramente dilatado en su tercio superior, formando una especie de columna. En las piezas más gastadas, el metacónido no está dilatado sino que, prácticamente aislado, se une al entocónido formando una superficie plana. Difiere del $\mathrm{D}_{3}$ por el menor desarrollo de la paraprecrístida. Métricamente, se observa un fuerte solapamiento en los diámetros transversales y anteroposteriores de Capra y Hemitragus. La pieza de Prado Vargas es más pequeña y la de la Cueva de Valdegoba está próxima a los valores tanto de C. ibex como de C. pyrenaica (figura V.10.1).

Difieren de Ovis por no tener el surco, entre el paracónido y el metacónido ( $\left.\mathrm{P}_{3} .1\right)$, muy profundo, aunque este carácter no se ha observado en todos los casos. El surco distobucal, entre el protocónido y el hipocónido, está menos acentuado en Capra y el borde mesiobucal en Capra forma un ángulo obtuso $\left(\mathrm{P}_{3} .2\right)$. Se diferencian de Hemitragus por estar menos comprimidos anteroposteriormente y más mesiolateralmente; por tener el surco, definido por el paracónido y el metacónido, mucho más marcado $\left(\mathrm{P}_{3} .1\right)$ y por tener el borde mesiobucal formando un ángulo menos abierto $\left(\mathrm{P}_{3} .2\right)$. Este borde, en su extremo posterior, tiene un pliegue marcado que no presenta Capra. La morfología general del 
diente es cuadrangular en ambos géneros $\left(\mathrm{P}_{3} .3\right)$. Sin embargo, en Capra, la relación entre el diámetro anteroposterior y el transversal es mayor que en Hemitragus, dándole un aspecto más rectangular.

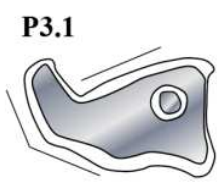

P3.2

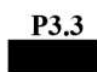

2.

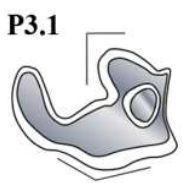

P3.2

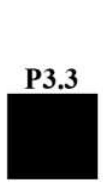

3.

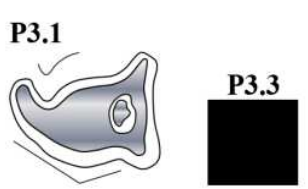

P3.2

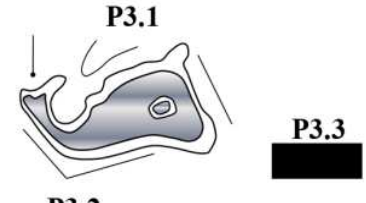

4.

Figura V.10.2. Diferencias observadas en los $\mathrm{P}_{3}$ de: 1) Ovis (actual). 2) Capra (Cueva de Valdegoba). 3) Hemitragus (l'Escale). 4) Saiga (actual).

Los $\mathrm{P}_{3}$ de Saiga son más rectangulares $\left(\mathrm{P}_{3} .3\right)$. Los surcos linguales están muy marcados, son redondeados y se proyectan en un borde lingual que es oblicuo y termina en una hipopostcrístida muy marcada y orientada posteriormente $\left(\mathrm{P}_{3} .1\right)$. La cara bucal forma un ángulo más abierto que en Capra $\left(\mathrm{P}_{3} .2\right)$, aunque el surco distal está más desarrollado en la cabra. El borde posterior es oblicuo, a diferencia de Capra que lo tiene más o menos recto. Los restos recuperados se diferencian de la línea de $C$. ibex por tener un valle lingual abierto, en forma de "U"; por presentar más desarrollado el surco posterolingual; por tener el surco bucal menos desarrollado y porque el entocónido forma un pequeño bucle cuyo eje buco-lingual es perpendicular al anteroposterior.

Tabla V.10.5

Medidas tomadas en los premolares inferiores de C. pyrenaica

\begin{tabular}{|c|c|c|c|c|c|c|c|}
\hline & DAP & DAPb & DTa & DTp & DT & DTb & $\mathbf{H}$ \\
\hline \multicolumn{8}{|l|}{$\mathbf{P}_{2}$} \\
\hline \multicolumn{8}{|c|}{ Valdegoba } \\
\hline $\mathrm{n}$ & 26 & 26 & 25 & 25 & 26 & 26 & 27 \\
\hline rango & $5,0-7,3$ & $4,2-5,7$ & $3,2-4,5$ & $4,2-5,9$ & $3,6-5,7$ & $4,1-5,7$ & $3,3-8,6$ \\
\hline$\overline{\mathrm{x}} \pm$ s.d. & $5,8 \pm 0,5$ & $4,9 \pm 0,4$ & $4,0 \pm 0,3$ & $4,9 \pm 0,5$ & $4,7 \pm 0,5$ & $4,6 \pm 0,3$ & $6,5 \pm 1,0$ \\
\hline \multicolumn{8}{|l|}{ Millán } \\
\hline$n=1$ & 5,4 & 4,4 & 4,0 & 4,9 & 3,1 & 4,9 & 7,1 \\
\hline \multicolumn{8}{|c|}{ Estebanvela } \\
\hline $\mathrm{n}=1$ & 5,6 & 4,9 & 3,6 & 4,2 & 3,6 & 4,2 & 9,5 \\
\hline \multicolumn{8}{|l|}{$\mathbf{P}_{3}$} \\
\hline \multicolumn{8}{|c|}{ Valdegoba } \\
\hline $\mathrm{n}$ & 21 & 22 & 21 & 21 & 25 & 22 & 21 \\
\hline rango & $7,8-9,7$ & $6,8-7,6$ & $3,4-5,6$ & $3,3-7,4$ & $4,1-7,1$ & $5,0-7,2$ & $3,7-14,6$ \\
\hline$\overline{\mathrm{x}} \pm$ s.d. & $8,6 \pm 0,5$ & $7,2 \pm 0,2$ & $4,7 \pm 0,5$ & $6,3 \pm 1,0$ & $5,6 \pm 0,8$ & $5,9 \pm 0,7$ & $9,4 \pm 2,4$ \\
\hline \multicolumn{8}{|l|}{$\mathbf{P}_{4}$} \\
\hline \multicolumn{8}{|c|}{ Valdegoba } \\
\hline $\mathrm{n}$ & 27 & 25 & 26 & 26 & 33 & 27 & 27 \\
\hline rango & $8,9-15,0$ & $8,1-10,2$ & $3,1-7,4$ & $5,9-8,0$ & $5,9-8,1$ & $5,1-8,0$ & $5,5-25,0$ \\
\hline$\overline{\mathrm{x}} \pm$ s.d. & $10,6 \pm 1,4$ & $9,0 \pm 0,6$ & $6,4 \pm 0,9$ & $7,1 \pm 0,6$ & $7,0 \pm 0,5$ & $6,8 \pm 0,8$ & $13,5 \pm 5,4$ \\
\hline \multicolumn{8}{|c|}{ Prado Vargas } \\
\hline$n=1$ & 9,8 & 9,7 & 6,3 & 6,4 & 6,4 & 6,7 & 15,8 \\
\hline \multicolumn{8}{|l|}{ Millán } \\
\hline$n=1$ & 10,9 & 10,4 & 7,6 & 7,9 & 7,4 & 7,9 & 13,8 \\
\hline
\end{tabular}

$\mathbf{P}_{4}$ : tiene las cúspides distales más pequeñas que las mesiales. Las distales están separadas por un valle poco profundo y se fusionan pronto formando un único lóbulo distal. El paracónido y el metacónido se unen para formar un dentículo mesiolingual tan desarrollado como el mesiobucal del que está separado por una profunda foseta. La columna del paracónido está bien marcada al igual que la del entocónido. El parastílido es muy saliente. La pieza de Prado Vargas es la más pequeña, muy alejada de los valores de la 
Cueva de Valdegoba y Cueva Millán que tienen un tamaño similar al de C. ibex, C. pyrenaica y H. bonnali (figura V.10.3).

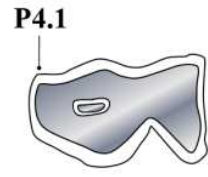

1.

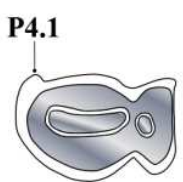

2.
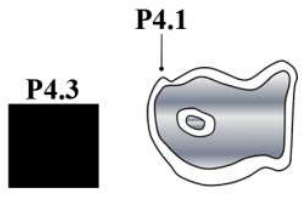

3.

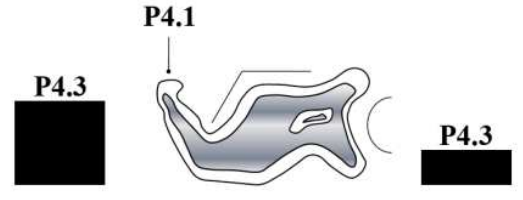

4.

Figura V.10.3 Diferencias observadas en los $\mathrm{P}_{4}$ de 1) Ovis (actual). 2) Capra (Cueva de Valdegoba). 3) Hemitragus (l'Escale). 4) Saiga (actual).

Se diferencian de Ovis por tener el borde mesiobucal más abierto, por no presentar un pliegue en este borde que sí que está muy desarrollado en las ovejas $\left(\mathrm{P}_{4} .1\right)$ y por ser más anchos ( $\left.\mathrm{P}_{4} .3\right)$. Difieren de Hemitragus por estar más comprimidos lateralmente $\left(\mathrm{P}_{4} .3\right)$, por tener un pliegue en el borde mesiolingual más marcado, por presentar un surco bucal más desarrollado y por ser más rectangulares $\left(\mathrm{P}_{3} .3\right)$. Por otra parte, Saiga tiene, en la cara lingual, un surco de grandes dimensiones; la paraprecrístida orientada lingualmente ( $\mathrm{P}_{4.1}$ ); la cara posterior redondeada y un aspecto más rectangular que el de Capra $\left(\mathrm{P}_{4} .3\right)$.

Molares inferiores permanentes (lámina V.10.1: 6, 7 y 8) (tabla V.10.6) (figuras V.10.4, 5 y 6): dientes de coronas bajas, selenodontas con las cúspides fusionadas, estilos de desarrollo variable y con dos lóbulos salvo el $\mathrm{M}_{3}$. El lóbulo distal está menos proyectado hacia la cara lingual que el mesial. Carecen de islotes centrales de esmalte, columnas interlobulares y cíngulos. Tienen dos raíces: una mesial y otra lingual. Son más grandes que los de Rupicapra (tabla V.9.6 y V.10.6).

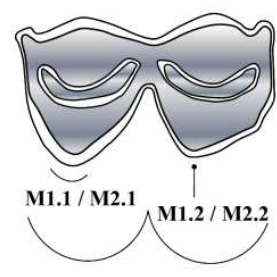

1.

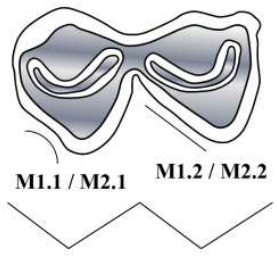

2.

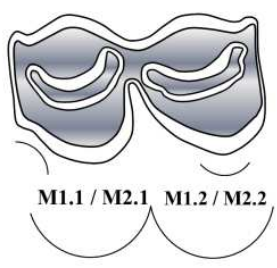

M1.3 / M2.3

3.

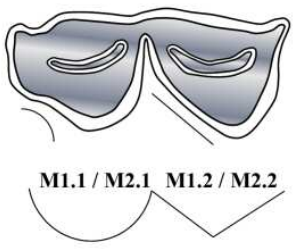

4.
M1.3 / M2.3

Figura V.10.4. Diferencias observadas en los $\mathrm{M}_{1}$ y $\mathrm{M}_{2}$ de 1) Ovis (actual). 2) Capra (Cueva de Valdegoba). 3) Hemitragus (l'Escale). 4) Saiga (actual).

$\mathbf{M}_{1}$ y $\mathbf{M}_{2}$ : son difíciles de separar ya que presentan una morfología semejante. El $\mathrm{M}_{1}$ difiere del $\mathrm{M}_{2}$ en que la zona de contacto entre la corona y la raíz está más alta en la cara mesial que en la distal. Ambos tienen el surco lingual, entre el protocónido y el hipocónido, ancho y redondeado. Métricamente se solapan mucho (tabla V.10.6). Los $\mathrm{M}_{1}$ de la Cueva de Valdegoba tienen un tamaño similar a los de otros $C$. pyrenaica europeos, son más grandes que los dientes de Cueva Millán y más pequeños que los registrados en C. caucasica. Los $\mathrm{M}_{2}$ de la Cueva de Valdegoba y la Peña de Estebanvela tienen un tamaño parecido, son más grandes que los de Cueva Millán, similares al de otras $C$. pyrenaica europeas, y son más pequeños que $C$. ibex y C. caucasica.

Difieren de Ovis en que el borde mesial del lóbulo anterior es cóncavo ( $\mathrm{M}_{1-2.1}$ ) y en que el borde mesial del lóbulo distal es recto $\left(\mathrm{M}_{1-2.2}\right.$ ) (figura V.10.4). Se diferencia de Hemitragus en que son menos redondeados $\left(\mathrm{M}_{1-2.1}-3\right)$. Los estilos están más marcados en Hemitragus (figura V.10.4). Difieren de Saiga en que los estilos están menos desarrollados y en que las caras bucales de ambos lóbulos son apuntadas ( $\mathrm{M}_{1-2.1}$ - 4) (figura V.10.4). 
Tabla V.10.6

Medidas tomadas en los molares inferiores permanentes de C. pyrenaica

\begin{tabular}{|c|c|c|c|c|c|c|c|c|c|}
\hline & DAP & DAPb & DTa & DTp & DTpp & DT & DTb & $\mathrm{Ha}$ & Hp \\
\hline \multicolumn{10}{|l|}{$M_{1}$} \\
\hline \multicolumn{10}{|c|}{ Valdegoba } \\
\hline $\mathrm{n}$ & 29 & 21 & 28 & 26 & & 33 & 21 & 21 & 20 \\
\hline rango & $11,7-17,2$ & $10,2-15,0$ & $6,7-9,4$ & $6,5-9,6$ & & $6,1-9,9$ & $6,9-9,6$ & $7,1-33,6$ & $7,1-34,0$ \\
\hline$\overline{\mathrm{x}} \pm$ s.d. & $14,6 \pm 1,4$ & $12,6 \pm 1,2$ & $8,0 \pm 0,7$ & $8,4 \pm 0,7$ & & $7,8 \pm 1,0$ & $7,9 \pm 0,7$ & $24,7 \pm 6,1$ & $24,7 \pm 5,9$ \\
\hline \multicolumn{10}{|l|}{ Millán } \\
\hline$n=1$ & 12,7 & & 8,2 & 9,6 & & 9,5 & & & \\
\hline \multicolumn{10}{|c|}{ Estebanvela } \\
\hline$n=1$ & & & 7,1 & 9,0 & 8,1 & 9,0 & & 14,0 & 16,7 \\
\hline \multicolumn{10}{|l|}{$\mathbf{M}_{2}$} \\
\hline \multicolumn{10}{|c|}{ Valdegoba } \\
\hline $\mathrm{n}$ & 24 & 15 & 23 & 23 & & 28 & 18 & 14 & 14 \\
\hline rango & $15,6-19,7$ & $13,1-15,8$ & $7,8-10,7$ & $7,6-10,7$ & & $6,6-9,6$ & $8,5-10,3$ & $24,4-43,7$ & $23,7-42,7$ \\
\hline$\overline{\mathrm{x}} \pm$ s.d. & $17,5 \pm 1,2$ & $14,5 \pm 0,8$ & $9,4 \pm 0,7$ & $9,4 \pm 0,7$ & & $8,1 \pm 0,8$ & $9,2 \pm 0,5$ & $36,0 \pm 5,4$ & $35,7 \pm 5,3$ \\
\hline \multicolumn{10}{|l|}{ Millán } \\
\hline $\mathrm{n}$ & 3 & 1 & 1 & 1 & & 3 & 1 & 1 & 1 \\
\hline rango & $14,3-17,5$ & 13,1 & 9,2 & 10,4 & & $8,7-10,3$ & 10,4 & 9,2 & 10 \\
\hline$\overline{\mathrm{x}} \pm$ s.d. & $16,4 \pm 1,8$ & & & & & & & & \\
\hline \multicolumn{10}{|c|}{ Estebanvela } \\
\hline $\mathrm{n}$ & 2 & 2 & 2 & 2 & 2 & 2 & & 2 & 1 \\
\hline rango & $15,7-19,1$ & $15,0-15,2$ & $9,2-9,6$ & $9,5-10,1$ & $7,5-8,9$ & $9,5-10,1$ & & $22,5-39,5$ & 39,8 \\
\hline$\overline{\mathrm{x}} \pm$ s.d. & $17,0 \pm 2,4$ & $15,0 \pm 0,1$ & $9,4 \pm 0,3$ & $9,8 \pm 0,5$ & $8,2 \pm 1,0$ & $9,8 \pm 0,5$ & & $31,0 \pm 12,0$ & \\
\hline \multicolumn{10}{|l|}{$\mathbf{M}_{3}$} \\
\hline \multicolumn{10}{|c|}{ Valdegoba } \\
\hline $\mathrm{n}$ & 15 & 8 & 15 & 13 & 9 & 14 & 7 & 7 & 7 \\
\hline rango & $20,4-30,0$ & $24,2-29,9$ & $8,2-10,4$ & $7,8-10,2$ & $4,0-7,5$ & $6,5-9,5$ & $7,5-9,5$ & $29,5-53,3$ & $25,0-50,2$ \\
\hline$\overline{\mathrm{x}} \pm$ s.d. & $26,0 \pm 2,6$ & $26,5 \pm 2,2$ & $9,4 \pm 0,5$ & $9,0 \pm 0,7$ & $5,7 \pm 1,0$ & $8,4 \pm 0,8$ & $8,5 \pm 0,7$ & $36,8 \pm 8,2$ & $35,0 \pm 7,7$ \\
\hline \multicolumn{10}{|c|}{ Prado Vargas } \\
\hline valor & & & 7,9 & & 7,6 & & & & \\
\hline \multicolumn{10}{|l|}{ Millán } \\
\hline$n=1$ & 28,9 & & & 9,5 & 6,4 & 10,0 & 9,5 & & 24,9 \\
\hline
\end{tabular}

$\mathbf{M}_{3}$ : tiene una apariencia trilobular debido al desarrollo del hipoconúlido. Difiere del $\mathrm{D}_{4}$ en que la anchura de los lóbulos disminuye del anterior al posterior. El borde anterior de la cúspide centrobucal es recto y está orientada hacia el extremo posterior. El lóbulo anterior es triangular y el posterior es redondeado. El borde bucal del hipoconúlido es redondeado, mientras que el posterior agudo. El diente de Cueva Millán es grande, próximo a los valores de $C$. ibex y $C$. caucasica. Las piezas de la Cueva de Valdegoba son más grandes que las de H. cedrensis y están dentro del rango de C. pyrenaica (figura V.10.6).

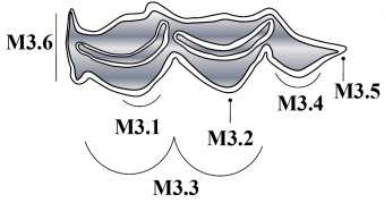

Figura V.10.5. Diferencias observadas en los $\mathrm{M}_{3}$ de 1) Ovis (actual). 2) Capra (Cueva de Valdegoba). 3) Hemitragus (l'Escale). 4) Saiga (actual).

Se diferencian de Ovis en que el borde bucal de la cúspide mesiobucal es cóncavo o recto $\left(\mathrm{M}_{3} .1\right)$, en que el borde bucal de la cúspide centrobucal puede estar orientado posteriormente $\left(\mathrm{M}_{3} .2\right)$ y en que el borde bucal de los lóbulos mesial y central son más o menos triangulares $\left(\mathrm{M}_{3} .3\right)$ (figura V.10.5). El borde distal del hipoconúlido es estrecho con un borde bucal redondeado ( $\mathrm{M}_{3} .4$ y 5 ), mientras que en Ovis es estrecho y redondeado. Por 
otra parte, el $\mathrm{M}_{3}$ de Hemitragus tiene los bordes bucales de ambos lóbulos y del hipoconúlido redondeados, mientras que Capra los tiene apuntados $\left(\mathrm{M}_{3.1} 1-4\right)$. El borde posterior del hipoconúlido tiene un pequeño pliegue orientado hacia atrás que está más desarrollado que en Capra. Además, el borde anterior es más ancho en Capra (figura V.10.5). Se diferencia de Saiga en que no está tan comprimido lateralmente, en que tiene unos estilos más proyectados y en que la protuberancia presente en el hipoconúlido está menos marcada $\left(\mathrm{M}_{3} .5\right)$ (figura V.10.5).

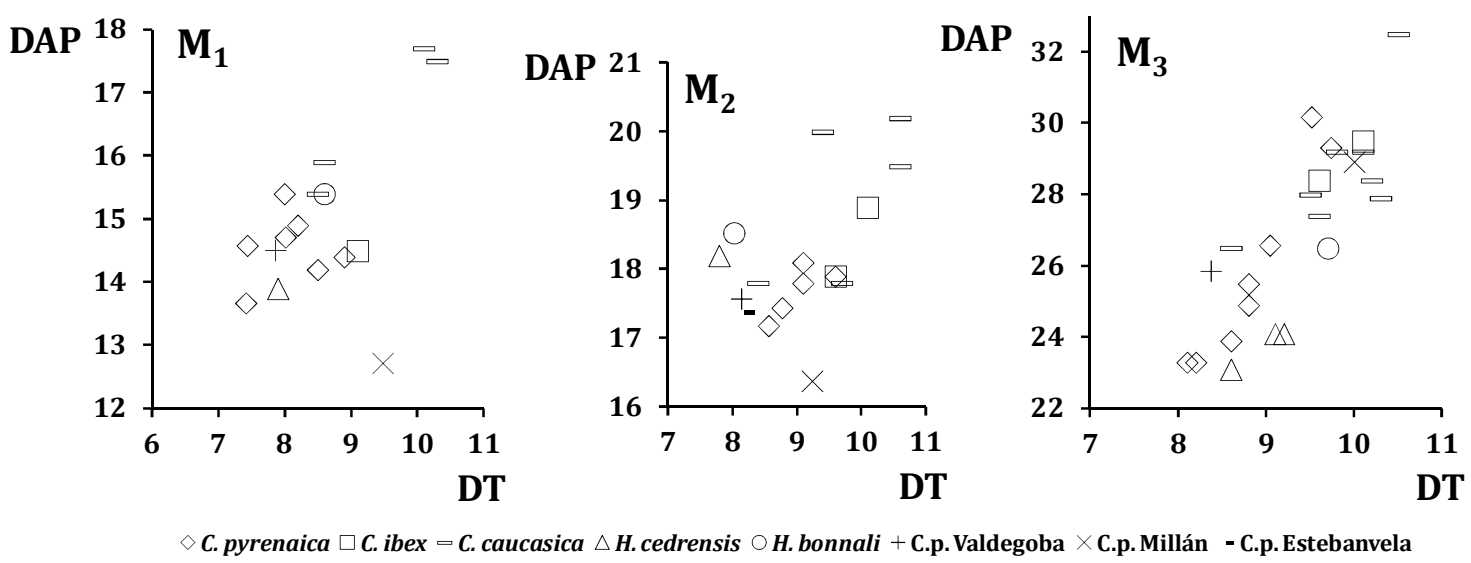

Figura V.10.6. Diagramas bivariantes de los molares inferiores permanentes: DAP (diámetro anteroposterior) y DT (diámetro transversal). C. pyrenaica de Abric Romani (Sánchez, 1990), Tournal, Le Portel (CrégutBonnoure, 1992b), Buraca Escura y Jarama VI. C. ibex de Adaouste y Petralona (Rivals, 2006). C. caucasica de Kozarnika, Koudaro I y III, Ortvala (Fernández y Crègut-Bonnoure, 2007), Sakajia, Tsutskhavati, l'Arago, Le Portel, Baume Moula-Guercy, Saint Marcel y Dzudzuana (Rivals, 2006). H. cedrensis de Les Cèdres, Bau de l'Aubesier y Rigabe (Rivals, 2006). H. bonnali de l'Escale y l'Arago (Rivals, 2006).

Premolares superiores (lámina V.10.1: 18, 19 y 20) (tabla V.10.7) (figura V.10.7): dientes con las coronas bajas, unilobulados, con estilos poco marcados, sin cíngulos ni islotes centrales de esmalte, y tres raíces: una mesial, otra distal y otra lingual. El P2 puede tener fusionadas las dos primeras. Son más anchos y más cortos que los deciduales superiores (tablas V.10.3 y 7). Son más grandes que los de R. pyrenaica (tablas V.9.7 y V.10.7).

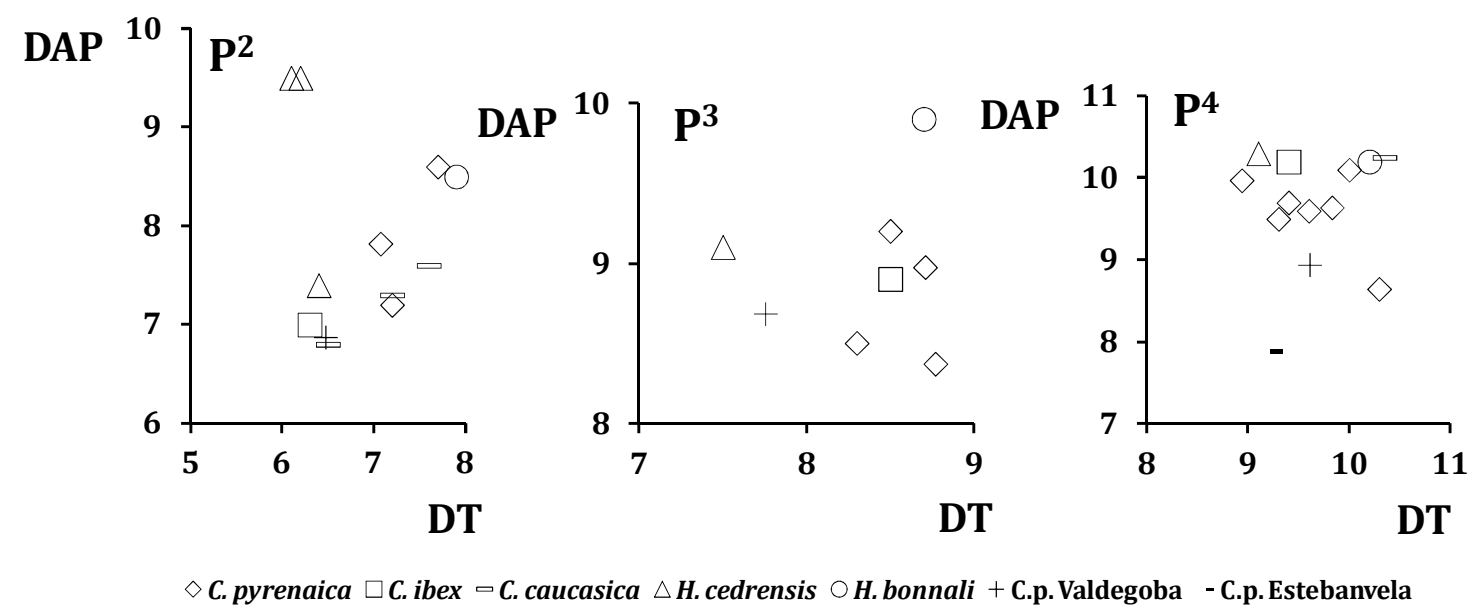

Figura V.10.7. Diagramas bivariantes de los premolares superiores: DAP (diámetro anteroposterior) y DT (diámetro transversal). C. pyrenaica de Abric Romani (Sánchez, 1990), Tournal, Le Portel (Crégut-Bonnoure, 1992) y Buraca Escura. C. ibex de Adaouste (Rivals, 2006). C. caucasica de l'Arago (Rivals, 2002), Kozarnika y Koudaro I y III (Fernández y Crègut-Bonnoure, 2007). H. cedrensis de Les Cèdres, Bau de l'Aubesier y Bolomor (Rivals, 2006; Rivals y Blasco, 2008). H. bonnali de l'Escale (Rivals, 2006).

$\mathbf{P}^{2}$ : es un diente fuertemente asimétrico que se estrecha hacia el extremo mesial. El paracono es la cúspide principal. Difiere del $\mathrm{D}^{2}$ por tener la corona más alta y el surco, 
entre el paracono y el metacono, más marcado. Las piezas de la Cueva de Valdegoba tienen un tamaño similar al de $C$. ibex y $C$. caucasica. Son más pequeñas que las de Hemitragus y $C$. pyrenaica (figura V.10.7).

P3: es un diente unilobulado en el que el paracono es la cúspide principal. Carecen de surco bucal entre el paracono y el metacono. Se diferencian del $\mathrm{P}^{4}$ en que la paraectocrístida está desplazada mesialmente. Las dimensiones de esta pieza están dentro del rango de $C$. pyrenaica y son más pequeñas que las de H. bonnali y C. ibex (figura V.10.7).

P4: es similar al tercer premolar superior. Se diferencian de él por tener la paraectocrístida en posición central y las caras bucal y lingual rectas. Las piezas de la Cueva de Valdegoba son más grandes que las de la Peña de Estebanvela, están dentro del rango de C. pyrenaica y son más pequeñas que las de C. ibex, C. caucasica y Hemitragus (figura V.10.7).

Tabla V.10.7

Medidas tomadas en los premolares superiores de $C$. pyrenaica

\begin{tabular}{|c|c|c|c|c|c|c|c|}
\hline & DAP & DAPb & DTa & DTp & DT & DTb & $\mathbf{H}$ \\
\hline \multicolumn{8}{|l|}{$\mathbf{P}^{2}$} \\
\hline \multicolumn{8}{|c|}{ Valdegoba } \\
\hline $\mathrm{n}$ & 7 & 6 & 7 & 7 & 8 & 6 & 3 \\
\hline rango & $5,9-7,3$ & $5,6-6,7$ & $5,9-7,5$ & $5,7-8,8$ & $5,2-8,2$ & $5,8-8,8$ & $9,6-14,1$ \\
\hline$\overline{\mathrm{x}} \pm$ s.d. & $6,9 \pm 0,5$ & $6,3 \pm 0,4$ & $6,4 \pm 0,5$ & $6,5 \pm 1,0$ & $6,5 \pm 0,9$ & $6,5 \pm 1,1$ & $11,6 \pm 2,3$ \\
\hline \multicolumn{8}{|c|}{ Estebanvela } \\
\hline $\mathrm{n}=1$ & 7,1 & 7,2 & 6,9 & 7,6 & & & 6,1 \\
\hline \multicolumn{8}{|l|}{$\mathbf{P}^{3}$} \\
\hline \multicolumn{8}{|c|}{ Valdegoba } \\
\hline $\mathrm{n}$ & 12 & 9 & 10 & 9 & 15 & 8 & 10 \\
\hline rango & $7,6-10,3$ & $7,1-8,6$ & $4,9-9,6$ & $5,1-9,9$ & $6,3-9,1$ & $7,9-9,3$ & $4,6-22,9$ \\
\hline $\bar{x} \pm$ s.d. & $8,8 \pm 1,6$ & $7,8 \pm 3,0$ & $8,3 \pm 2,3$ & $8,6 \pm 2,1$ & $7,8 \pm 3,8$ & $8,5 \pm 0,7$ & $11,9 \pm 7,7$ \\
\hline \multicolumn{8}{|l|}{$\mathbf{P}^{4}$} \\
\hline \multicolumn{8}{|c|}{ Valdegoba } \\
\hline $\mathrm{n}$ & 14 & 11 & 14 & 14 & 17 & 10 & 13 \\
\hline rango & $8,0-10,3$ & $7,2-8,0$ & $8,9-11,6$ & $9,2-11,8$ & $8,3-11,3$ & $9,6-10,8$ & $4,5-24,7$ \\
\hline$\overline{\mathrm{x}} \pm$ s.d. & $8,9 \pm 0,7$ & $7,6 \pm 0,2$ & $10,3 \pm 0,7$ & $10,5 \pm 0,7$ & $9,7 \pm 0,8$ & $10,3 \pm 0,4$ & $13,0 \pm 5,1$ \\
\hline \multicolumn{8}{|l|}{ Millán } \\
\hline $\mathrm{n}=1$ & 9,6 & 7,0 & 11,0 & 11,0 & 9,8 & 11 & 25,3 \\
\hline \multicolumn{8}{|c|}{ Estebanvela } \\
\hline $\mathrm{n}=1$ & 7,9 & 6,6 & 9,1 & 9,6 & 9,2 & 9,6 & 13 \\
\hline
\end{tabular}

Molares superiores permanentes (lámina V.10.1: 16, 17 y 21) (tabla V.10.8) (figura V.10.8 y 9): dientes con las coronas bajas, configuración selenodonta, cúspides fusionadas, bilobulados, con el lóbulo mesial más proyectado hacia la cara lingual que el mesial, estilos poco marcados, sin islote central de esmalte ni columna interlobular y con tres raíces: una mesial, otra distal y otra lingual. Son más grandes que los deciduales superiores (tablas V.10.3 y 8) y que los molares superiores permanentes de Rupicapra pyrenaica (tablas V.9.8 y V.10.8).

$\mathbf{M}^{1}$ y $\mathbf{M}^{2}$ : son dientes muy parecidos. Sin embargo, en el $\mathbf{M}^{1}$, los bordes, en vista lingual, divergen hacia la superficie oclusal, mientras que en el $\mathrm{M}^{2}$ son más o menos paralelos. El borde lingual del lóbulo mesial es triangular y el del distal es redondeado. Métricamente, la diferencia en el DTb con respecto al DAPb es más acusada en $\mathrm{M}^{1}$ que en $\mathrm{M}^{2}$ pero este carácter es, en ocasiones, difícil de diferenciar. Los $\mathrm{M}^{1}$ de la Cueva de Valdegoba son más grandes que los recuperados en la Peña de Estebanvela y más pequeños que los de Cueva Millán. En general, las piezas analizadas son más pequeñas, salvo el caso de Cueva Millán, que las de Hemitragus y C. ibex y están dentro del rango de C. pyrenaica y C. caucasica (figura V.10.8). Por otra parte, los $\mathrm{M}^{2}$ de la Cueva de Valdegoba son más grandes que los de 
Cueva Millán y Prado Vargas. Están dentro del rango de Hemitragus cedrensis y $C$. pyrenaica, y son más pequeños que los de C. ibex (figura V.10.8).

Tabla V.10.8

Medidas tomadas en los molares superiores permanentes de C. pyrenaica

\begin{tabular}{|c|c|c|c|c|c|c|c|c|}
\hline & DAP & DAPb & DTa & DTp & DT & DTb & $\mathbf{H a}$ & Нp \\
\hline \multicolumn{9}{|l|}{$\mathbf{M}^{1}$} \\
\hline \multicolumn{9}{|c|}{ Valdegoba } \\
\hline $\mathrm{n}$ & 15 & 13 & 15 & 13 & 17 & 13 & 15 & 13 \\
\hline rango & $11,5-17,3$ & $10,2-11,6$ & $11,2-13,5$ & $10,1-11,7$ & $9,5-13,1$ & $12,0-13,1$ & $7,0-39,5$ & $9,9-38,8$ \\
\hline $\bar{x} \pm$ s.d. & $14,5 \pm 1,7$ & $11,0 \pm 0,4$ & $12,2 \pm 0,7$ & $11,2 \pm 0,5$ & $11,4 \pm 1,2$ & $12,4 \pm 0,4$ & $19,1 \pm 10,2$ & $21,1 \pm 9,9$ \\
\hline \multicolumn{9}{|l|}{ Millán } \\
\hline $\mathrm{n}=1$ & 16,9 & 10 & 11,8 & 11,8 & 10,5 & 11,8 & 33,9 & 34,3 \\
\hline \multicolumn{9}{|c|}{ Estebanvela } \\
\hline $\mathrm{n}$ & 2 & 2 & 2 & 2 & 2 & 2 & 2 & 2 \\
\hline rango & $11,8-14,0$ & $10,0-10,3$ & $9,9-11,2$ & $9,6-11,2$ & $9,7-11,2$ & $9,9-11,2$ & $10,2-12,9$ & $11,5-12,9$ \\
\hline $\bar{x} \pm$ s.d. & $12,9 \pm 1,5$ & $10,1 \pm 0,2$ & $10,5 \pm 1,0$ & $10,4 \pm 1,2$ & $10,4 \pm 1,1$ & $10,5 \pm 1,0$ & $11,5 \pm 1,9$ & $12,2 \pm 1,0$ \\
\hline \multicolumn{9}{|l|}{$\mathbf{M}^{2}$} \\
\hline \multicolumn{9}{|c|}{ Valdegoba } \\
\hline $\mathrm{n}$ & 21 & 14 & 19 & 18 & 20 & 14 & 13 & 14 \\
\hline rango & $14,8-18,9$ & $12,5-15,3$ & $10,5-14,7$ & $9,9-13,6$ & $9,5-14,6$ & $13,1-14,7$ & $8,8-42,4$ & $8,8-43,1$ \\
\hline$\overline{\mathrm{x}} \pm$ s.d. & $17,4 \pm 1,0$ & $13,8 \pm 0,8$ & $13,3 \pm 1,4$ & $12,0 \pm 0,8$ & $11,5 \pm 1,5$ & $13,8 \pm 0,5$ & $30,9 \pm 10,7$ & $31,1 \pm 10,4$ \\
\hline \multicolumn{9}{|c|}{ Prado Vargas } \\
\hline $\mathrm{n}$ & 3 & 2 & 2 & 2 & 2 & 2 & 2 & 2 \\
\hline rango & $15,6-18,5$ & $14,1-14,6$ & $10,9-12,5$ & $10,2-14,5$ & $10,7-13,1$ & $10,9-14,5$ & $25,8-30,5$ & $25,2-32,4$ \\
\hline$\overline{\mathrm{x}} \pm$ s.d. & $16,9 \pm 1,5$ & $14,3 \pm 0,3$ & $11,7 \pm 1,2$ & $12,3 \pm 3,0$ & $11,9 \pm 1,7$ & $12,7 \pm 2,5$ & $28,1 \pm 3,3$ & $28,8 \pm 5,0$ \\
\hline \multicolumn{9}{|l|}{ Millán } \\
\hline $\mathrm{n}$ & 2 & & 2 & 2 & 2 & 1 & & \\
\hline rango & $15,8-17,4$ & & $12,1-12,5$ & $10,9-11,1$ & $10,8-12,3$ & 12,5 & & \\
\hline$\overline{\mathrm{x}} \pm$ s.d. & $16,6 \pm 1,2$ & & $12,3 \pm 0,3$ & $11,0 \pm 0,1$ & $11,6 \pm 1,0$ & & & \\
\hline \multicolumn{9}{|c|}{ Estebanvela } \\
\hline $\mathrm{n}$ & 2 & 2 & 2 & 2 & & 2 & 2 & 2 \\
\hline rango & $17,2-18,9$ & $12,8-13,3$ & $13,4-13,5$ & $11,9-12,7$ & & $13,4-13,5$ & $21,4-31,0$ & $19,9-31,2$ \\
\hline$\overline{\mathrm{x}} \pm$ s.d. & $18,0 \pm 1,2$ & $13,0 \pm 0,4$ & $13,4 \pm 0,1$ & $12,3 \pm 0,6$ & & $13,4 \pm 0,1$ & $26,2 \pm 6,8$ & $25,5 \pm 8,0$ \\
\hline \multicolumn{9}{|l|}{$\mathbf{M}^{3}$} \\
\hline \multicolumn{9}{|c|}{ Valdegoba } \\
\hline $\mathrm{n}$ & 14 & 9 & 16 & 16 & 16 & 12 & 11 & 10 \\
\hline rango & $18,9-25,9$ & $14,3-23,5$ & $11,5-14,8$ & $10,4-12,9$ & $9,3-13,8$ & $12,6-14,9$ & $16,0-41,2$ & $18,1-38,9$ \\
\hline$\overline{\mathrm{x}} \pm$ s.d. & $22,3 \pm 2,1$ & $21,3 \pm 2,8$ & $13,4 \pm 1,1$ & $11,8 \pm 0,7$ & $11,7 \pm 1,4$ & $14,1 \pm 0,7$ & $29,4 \pm 9,3$ & $27,3 \pm 7,7$ \\
\hline \multicolumn{9}{|c|}{ Prado Vargas } \\
\hline $\mathrm{n}=1$ & 17,9 & & & & & & & \\
\hline \multicolumn{9}{|c|}{ Estebanvela } \\
\hline $\mathrm{n}$ & 4 & 2 & 4 & 2 & 3 & 3 & 3 & 3 \\
\hline rango & $17,0-22,7$ & $22,0-23,4$ & $10,9-14,0$ & $12,7-12,9$ & $11,2-13,6$ & $12,7-14,0$ & $26,6-42,7$ & $25,5-37,3$ \\
\hline$\overline{\mathrm{x}} \pm$ s.d. & $22,4 \pm 3,8$ & $22,7 \pm 1,0$ & $13,1 \pm 1,5$ & $12,8 \pm 0,2$ & $12,5 \pm 1,2$ & $13,6 \pm 0,8$ & $36,1 \pm 8,4$ & $31,6 \pm 5,9$ \\
\hline
\end{tabular}

M3: el lóbulo mesial es triangular y el distal es redondeado. El metastilo está muy desarrollado. Los espacios interestilares presentan diferente longitud, el distal es mucho más grande que el mesial. El parastilo es redondeado, el mesostilo aparece en todos los casos muy proyectado y el metastilo diverge hacia la base. Es más grande que los dos molares precedentes. El ala hipostilar presenta un desarrollo variable. Las piezas de la Cueva de Valdegoba y de la Peña de Estebanvela son más anchas que las de $C$. caucasica, más pequeñas que las de C. ibex y más grandes que las de Hemitragus cedrensis y H. bonnali (figura V.10.8).

Crégut-Bonnoure (1992b) describe dos líneas evolutivas en Capra empleando, entre otros restos, los $\mathrm{M}^{3}$. El material recuperado presenta unos estilos estrechos y unos espacios estilares con la misma longitud. Estos caracteres permiten diferenciarlos de la 
línea $C$. ibex y los acerca a la línea caucasica-cilindricornis. Sin embargo, el desarrollo del ala metastilar, aspecto diferencial para Crégut, presenta un elevado polimorfismo en los restos recuperados ya que puede presentar diferentes grados de desarrollo en la base de la corona (figura V.10.9)
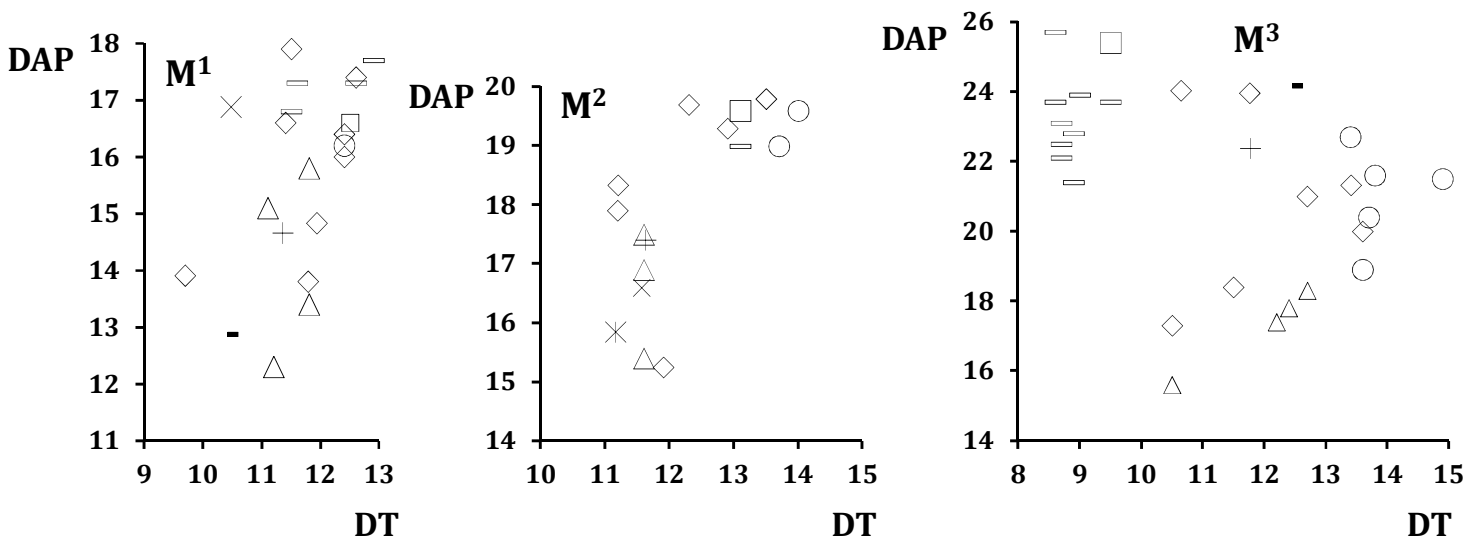

$\diamond$ C. pyrenaica $\square$ C. ibex $\triangle$ C. caucasica $\triangle$ H. cedrensis $\bigcirc$ H. bonnali + C.p. Valdegoba $*$ C.p. Prado Vargas $\times$ C.p. Millán - C.p. Estebanvela

Figura V.10.8. Diagramas bivariantes de los molares superiores: DAP (diámetro anteroposterior) y DT (diámetro transversal). C. pyrenaica de Abric Romani (Sánchez, 1990), Tournal, Le Portel (Crégut-Bonnoure, 1992), Jarama VI y Buraca Escura. C. ibex de Adaouste (Rivals, 2006). C. caucasica de l'Arago (Rivals, 2002), Kozarnika, Koudaro I y III, Ortvala (Fernández y Crègut-Bonnoure, 2007) y Sakajia (Rivals, 2006). H. cedrensis de Les Cèdres, Bau de l'Aubesier y Bolomor (Rivals, 2006; Rivals y Blasco, 2008). H. bonnali de l'Escale (Rivals, 2006).

1.

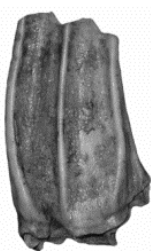

2.

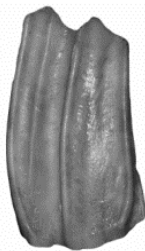

3.

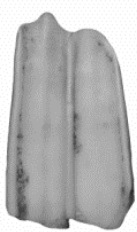

4.

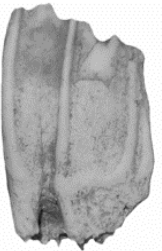

5.

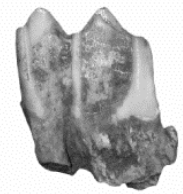

6.

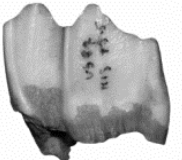

$2 \mathbf{c m}$

Figura V.10.9. Polimorfismo observado en las alas metastilares del M33. 1) Vb-sp-2652. 2) Vb-sp-2650. 3) PV06 45 H32 76 3. 4) PE.02.E11.NIII.6. 5) Vb-sp-2635. 6) Vb-sp-2662.

Húmeros (lámina V.10.1: 27) (tabla V.10.9): hueso largo y robusto con una fosa oleocranoidea alta y subtriangular en los adultos y subcircular en los jóvenes. Tiene una fosa radial alargada y poco profunda. El epicóndilo lateral está muy marcado al igual que el capitulum que además es profundo. La tróclea distal, en vista craneal, tiene una morfología oblicua y poco comprimida. El epicóndilo medio está poco desarrollado y se proyecta distalmente. Difieren de Ovis por su mayor gracilidad; por tener la región articular distal, en vista dorsal, más baja; un epicóndilo lateral y medial menos desarrollado y la fosa oleocranoidea más estrecha.

Radios (lámina V.10.1: 29) (tabla V.10.9): son huesos largos y estrechos con una fosa sinovial amplia y poco marcada en la superficie articular proximal. En esta superficie, la cara lateral, donde se articula con la ulna, es ovalada y tiene un surco muy marcado en el borde distal. En ejemplares adultos de Capra ibex la ulna y el radio están fusionados en su región proximal. Este carácter ya aparece en la C. ibex de Petralona, 300 - 400 ka (Van der Made com pers.). En Hemitragus no aparece esta fusión sino que ambas están articuladas (Van der Made, 1999). Los huesos que se han recuperado en la Cueva de Valdegoba muestran la superficie proximal sin rastros de rotura ni fragmentos de la ulna por lo que podríamos indicar que en estos individuos la ulna y el radio estarían articulados. El borde lateral es redondeado y el medial plano. El borde anterior tiene dos pliegues, siendo el 
lateral el que está más marcado y que además recorre sagitalmente la superficie articular proximal. Además tiene una faceta proximal que sobresale mucho del borde medial de la diáfisis.

Tabla V.10.9

Medidas tomadas en los húmeros, radios, tibias y calcáneos de C. pyrenaica

\begin{tabular}{|c|c|c|c|c|c|c|c|}
\hline & BT & BD & BP & DP & BFp & GL & GB \\
\hline \multicolumn{8}{|c|}{ Húmero } \\
\hline \multicolumn{8}{|c|}{ Valdegoba } \\
\hline $\mathrm{n}$ & 3 & 4 & & & & & \\
\hline rango & $36,1-40,2$ & $35,2-38,8$ & & & & & \\
\hline $\bar{x} \pm$ s.d. & $38,1 \pm 2,0$ & $36,6 \pm 1,6$ & & & & & \\
\hline \multicolumn{8}{|c|}{ Estebanvela } \\
\hline$n=1$ & 35,6 & 36,3 & & & & & \\
\hline \multicolumn{8}{|l|}{ Radio } \\
\hline \multicolumn{8}{|c|}{ Valdegoba } \\
\hline $\mathrm{n}$ & & & 2 & 2 & 2 & & \\
\hline rango & & & $31,0-38,0$ & $16,7-16,9$ & $31,1-37,2$ & & \\
\hline $\bar{x} \pm$ s.d. & & & $34,5 \pm 4,9$ & $16,8 \pm 0,1$ & $34,2 \pm 4,3$ & & \\
\hline \multicolumn{8}{|l|}{ Tibia } \\
\hline \multicolumn{8}{|c|}{ Valdegoba } \\
\hline $\mathrm{n}$ & & 2 & & 2 & & & \\
\hline rango & & $25,2-27,8$ & & $19,1-22,2$ & & & \\
\hline$\overline{\mathrm{x}} \pm$ s.d. & & $26,5 \pm 1,9$ & & $20,6 \pm 2,1$ & & & \\
\hline \multicolumn{8}{|c|}{ Calcáneo } \\
\hline \multicolumn{8}{|c|}{ Valdegoba } \\
\hline $\mathrm{n}$ & & & & & & 13 & 14 \\
\hline rango & & & & & & $58,3-71,4$ & $19,1-27,1$ \\
\hline $\bar{x} \pm$ s.d. & & & & & & $64,5 \pm 4,3$ & $21,5 \pm 1,9$ \\
\hline \multicolumn{8}{|c|}{ Estebanvela } \\
\hline $\mathrm{n}=1$ & & & & & & 78,4 & 23,4 \\
\hline
\end{tabular}

Ulna (lámina V.10.1: 32): tiene la apófisis ancónea convexa y rugosa. La escotadura troclear es circular. La cara que articula con el húmero es ancha y alargada. Esta cara está separada, de las que articulan con el radio, por una depresión marcada. El estado de conservación de la pieza no es bueno por lo que nos e han podido tomar medidas.

Tabla V.10.10

Medidas tomadas en los metápodos de C. pyrenaica

\begin{tabular}{lcccccccc}
\hline & GL & BP & DP & SD & BD & DD & PL & PM \\
\hline Metacarpo & & & & & & & & \\
\hline Valdegoba * & & & & & & & & \\
$\mathrm{n}=1$ & 79,6 & 25,9 & 14,9 & 14 & 21,4 & 13,7 & & \\
Millán & & & & & & & & \\
$\mathrm{n}=1$ & & & & & 31,4 & & 19,2 & 27,6 \\
\hline Metatarso & & & & & & & \\
\hline Valdegoba & & & & & & & & \\
$\mathrm{n}=1$ & & & & & 26,8 & 19,2 & 15,6 & 19,2 \\
\hline
\end{tabular}

* El metacarpo de la Cueva de Valdegoba no tiene fusionada la epífisis distal.

Metacarpos (lámina V.10.1: 30 y 31) (tabla V.10.10): huesos largos, con una sección ovalada. La superficie articular proximal tiene un surco que separa la cara medial de la lateral. La depresión definida por ambas caras articulares es estrecha. El surco longitudinal que recorre la diáfisis no está muy desarrollado, aunque el foramen distal es grande y profundo. Tiene unos tubérculos suprarticulares bien marcados y los bordes mediales de los cóndilos convergen hacia la diáfisis. Son más robustos que los de 
Rupicapra y Ovis. Asimismo se diferencian también de las ovejas por tener las caras articulares de la epífisis proximal menos profundas y por presentar la zona de contacto entre la diáfisis y la epífisis distal con unas protuberancias mucho más marcadas (Boessneck et al., 1964).

Tibias (lámina V.10.1: 34) (tabla V.10.9): la epífisis distal es cuandragular. La cresta, que separa las caras que articulan con el astrágalo y con el maléolo lateral, es recta, marcada y muy sinuosa. La fosa sinovial no es grande y las caras que articulan con el maléolo están unidas por un surco poco profundo.

Tabla V.10.11

Medidas tomadas en los astrágalos de C. pyrenaica

\begin{tabular}{|c|c|c|c|c|c|c|c|}
\hline & GLI & GLm & DL & DM & BP & BD & ATPL \\
\hline \multicolumn{8}{|c|}{ Valdegoba } \\
\hline $\mathrm{n}$ & 7 & 7 & 7 & 7 & 7 & 7 & 7 \\
\hline rango & $36,4-42,4$ & $34,6-38,9$ & $20,2-23,2$ & $20,2-23,8$ & $21,9-26,7$ & $22,9-27,6$ & $25,0-28,2$ \\
\hline$\overline{\mathrm{x}} \pm$ s.d. & $39,7 \pm 2,1$ & $37,1 \pm 1,5$ & $22,0 \pm 1,3$ & $22,2 \pm 1,4$ & $24,9 \pm 1,8$ & $25,5 \pm 1,8$ & $26,9 \pm 1,2$ \\
\hline \multicolumn{8}{|l|}{ Millán } \\
\hline $\mathrm{n}$ & 2 & 2 & 2 & 2 & 2 & 2 & 2 \\
\hline rango & $30,6-35,0$ & $28,7-32,7$ & $17,2-19,0$ & $19,6-29,0$ & $19,3-22,0$ & $20,8-22,7$ & $17,5-23,1$ \\
\hline$\overline{\mathrm{x}} \pm$ s.d. & $32,8 \pm 3,1$ & $30,7 \pm 2,8$ & $18,1 \pm 1,3$ & $24,3 \pm 6,7$ & $20,7 \pm 1,9$ & $21,7 \pm 1,4$ & $20,3 \pm 4,0$ \\
\hline \multicolumn{8}{|c|}{ Estebanvela } \\
\hline $\mathrm{n}$ & 4 & 4 & 4 & 2 & 4 & 4 & 4 \\
\hline rango & $30,7-35,0$ & $29,7-32,3$ & $17,1-19,2$ & $18,6-18,7$ & $18,7-22,1$ & $19,2-22,5$ & $19,3-21,7$ \\
\hline $\bar{x} \pm$ s.d. & $33,7 \pm 2,0$ & $31,5 \pm 1,2$ & $18,3 \pm 0,9$ & $18,7 \pm 0,1$ & $20,8 \pm 1,5$ & $21,2 \pm 1,5$ & $20,9 \pm 1,1$ \\
\hline
\end{tabular}

Astrágalos (lámina V.10.1: 28) (tabla V.10.11): es un hueso estrecho y comprimido dorsoventralmente. La tróclea proximal tiene una cresta lateral más ancha que la medial y articula tanto con la tibia como con la fíbula. Los bordes de la tróclea proximal están más o menos a la misma altura. La cara palmar tiene un surco, ovalado o subcircular, que separa la tróclea proximal de la distal. La región inferior de esta tróclea presenta dos protuberancias para la inserción de ligamentos, que se proyectan poco hacia los laterales. Por debajo de la misma, hay un surco que separa la tróclea proximal de la distal pero no es continuo. La cara plantar tiene dos caras articulares. La que articula con el calcáneo, la más grande, presenta unos bordes más o menos paralelos y cóncavos. Está separado de la tróclea proximal por una depresión marcada muy estrecha. Su borde distal tiene un surco muy marcado. La cara que articula con el escafocuboides está separada de la del calcáneo por una cresta poco marcada. Difieren de Ovis por sus mayores dimensiones y por presentar, en vista dorsal una proyección mucho más marcada en la cara medial que prácticamente está ausente en las ovejas. Asimismo, la cara que articula con el calcáneo tiene un borde medial más recto que en Ovis (Boessneck et al., 1964). Difiere de Hemitragus en varios aspectos como en que el borde lateral de la cara que articula con el calcáneo no se cierra en la base y en que el borde medial de esta articulación está en una posición más interna, creando una zona sin articulación. Asimismo, Capra carece de región sinovial lateral y presenta, en la cara lateral de la tróclea superior, una tuberosidad que no tiene Hemitragus, que tiene una ligera concavidad.

Calcáneos (lámina V.10.1: 33) (tabla V.10.9): son huesos estrechos y alargados, con la parte distal comprimida lateralmente. La tuberosidad calcánea está muy marcada. Tiene dos caras que articulan con el astrágalo y una con el maléolo. Esta última está dividida en dos partes, una más elevada que la otra. La más baja presenta un borde distal alargado. La superior es ovalada y ancha. En vista medial, el surco donde se inserta el flexor digital profundo está muy marcado. En vista lateral, la cara que articula con el maléolo tiene un surco muy desarrollado. La cara que articula con el escafocuboides es alargada, estrecha y muy curvada. Siete de las piezas identificadas no tienen la epífisis distal fusionada. 
Difieren de Ovis en que son más largos y estrechos, en que la faceta para el maléolo es estrecha y en que las dos caras que articulan con el astrágalo están unidas. Difieren de Hemitragus por ser más cortos y estrechos y por tener, la cara que articula con el maléolo, más ancha

Metatarso (tabla V.10.10): la pieza sólo conserva el extremo distal. La sección subcircular y el desarrollo del surco vascular la diferencian del metacarpo. Tiene un foramen dorsal muy desarrollado. El surco que separa los cóndilos es estrecho y triangular. Difieren de Rupicapra y Ovis en que son más robustos.

Tabla V.10.12

Medidas tomadas en las falanges proximales y falanges medias de C. pyrenaica

\begin{tabular}{|c|c|c|c|c|c|c|c|c|}
\hline & GL & GLpe & DPs & DPi & BP & SD & BD & DD \\
\hline \multicolumn{9}{|c|}{ F.p. anteriores } \\
\hline \multicolumn{9}{|c|}{ Valdegoba } \\
\hline $\mathrm{n}$ & 7 & 7 & 5 & 6 & 7 & 8 & 8 & 8 \\
\hline rango & $43,0-48,3$ & $42,0-47,6$ & $17,3-20,1$ & $17,5-19,6$ & $13,6-16,6$ & $11,3-13,1$ & $12,7-15,3$ & $10,6-14,0$ \\
\hline $\bar{x} \pm$ s.d. & $46,2 \pm 1,8$ & $45,0 \pm 1,9$ & $18,1 \pm 1,2$ & $18,3 \pm 0,8$ & $15,2 \pm 1,2$ & $12,3 \pm 0,6$ & $13,9 \pm 0,8$ & $12,2 \pm 1,0$ \\
\hline \multicolumn{9}{|c|}{ F.p. posteriores } \\
\hline \multicolumn{9}{|c|}{ Valdegoba } \\
\hline $\mathrm{n}$ & 6 & 4 & 4 & 4 & 5 & 6 & 6 & 5 \\
\hline rango & $43,6-51,1$ & $43,2-49,9$ & $14,4-16,5$ & $15,2-16,6$ & $12,6-14,1$ & $8,9-10,8$ & $10,2-14,2$ & $9,6-12,2$ \\
\hline $\bar{x} \pm$ s.d. & $46,7 \pm 2,5$ & $46,1 \pm 2,8$ & $15,6 \pm 0,9$ & $16,0 \pm 0,6$ & $13,6 \pm 0,6$ & $9,6 \pm 0,7$ & $12,2 \pm 1,4$ & $10,8 \pm 1,1$ \\
\hline \multicolumn{9}{|c|}{ Falanges proximales } \\
\hline \multicolumn{9}{|c|}{ Millán } \\
\hline $\mathrm{n}$ & 1 & 1 & 3 & 3 & 3 & 1 & 1 & 1 \\
\hline rango & 48,6 & 48,1 & $17,0-18,3$ & $16,9-19,4$ & $13,8-18,1$ & 14,6 & 17,5 & 15,5 \\
\hline$\overline{\mathrm{x}} \pm$ s.d. & & & $17,9 \pm 0,7$ & $18,4 \pm 1,4$ & $15,5 \pm 2,2$ & & & \\
\hline \multicolumn{9}{|c|}{ Estebanvela } \\
\hline $\mathrm{n}$ & 1 & 2 & 3 & 3 & 3 & 1 & 6 & 1 \\
\hline rango & 41,4 & $18-40,4$ & $16,5-17,4$ & $17,1-17,8$ & $13,7-13,9$ & 13,4 & $14,1-15,1$ & 11,8 \\
\hline $\bar{x} \pm$ s.d. & & $29,3 \pm 15,9$ & $16,9 \pm 0,3$ & $17,5 \pm 0,5$ & $13,9 \pm 0,4$ & & $13,4 \pm 0,9$ & \\
\hline \multicolumn{9}{|c|}{ F.m. anteriores } \\
\hline \multicolumn{9}{|c|}{ Valdegoba } \\
\hline $\mathrm{n}$ & 14 & 13 & 15 & 15 & 15 & 14 & 13 & 13 \\
\hline rango & $22,8-32,0$ & $23,9-30,2$ & $11,4-14,6$ & $14,2-17,5$ & $10,7-17,1$ & $8,6-12,9$ & $8,4-12,2$ & $11,9-14,9$ \\
\hline $\bar{x} \pm$ s.d. & $28,6 \pm 2,3$ & $27,0 \pm 1,8$ & $13,2 \pm 0,9$ & $15,7 \pm 1,0$ & $14,8 \pm 1,5$ & $11,1 \pm 1,2$ & $11,2 \pm 1,1$ & $13,1 \pm 1,1$ \\
\hline \multicolumn{9}{|c|}{ F.m. posteriores } \\
\hline \multicolumn{9}{|c|}{ Valdegoba } \\
\hline $\mathrm{n}$ & 9 & 9 & 8 & 8 & 10 & 9 & 9 & 8 \\
\hline rango & $27,7-34,5$ & $26,3-32,9$ & $11,8-15,9$ & $14,7-17,2$ & $12,7-15,6$ & $7,7-11,8$ & $10,1-12,3$ & $12,4-14,4$ \\
\hline $\bar{x} \pm$ s.d. & $31,7 \pm 2,3$ & $30,2 \pm 2,2$ & $13,2 \pm 1,3$ & $15,5 \pm 0,9$ & $14,3 \pm 1,1$ & $10,4 \pm 1,3$ & $11,0 \pm 0,9$ & $13,4 \pm 0,7$ \\
\hline \multicolumn{9}{|c|}{ Falanges medias } \\
\hline \multicolumn{9}{|c|}{ Estebanvela } \\
\hline $\mathrm{n}$ & 1 & 2 & 4 & 4 & 4 & 2 & 1 & 1 \\
\hline rango & 30,3 & $26,1-28,7$ & $12,9-14,3$ & $15,1-16,4$ & $15,5-16,7$ & $11,8-12,9$ & 13,6 & 14,9 \\
\hline $\bar{x} \pm$ s.d. & & $27,4 \pm 1,8$ & $13,6 \pm 0,6$ & $16,0 \pm 0,6$ & $15,9 \pm 0,5$ & $12,3 \pm 0,8$ & & \\
\hline
\end{tabular}

* F.p: falanges proximales. F.m: falanges distales.

Falanges proximales (lámina V.10.1: 23 y 24) (tabla V.10.12): son huesos cortos y robustos. Tienen una superficie interdigital aplanada. La cara palmar presenta dos protuberancias para la inserción de los ligamentos interdigitales. La superficie articular proximal está dividida en dos caras por un surco muy profundo, siendo la abaxial más alta y más grande que la axial. En la cara palmar tiene dos carillas que articulan con los huesos sesamoideos proximales. Una de ellas tiene una morfología cuadrangular y un pliegue muy marcado. Difieren de Rupicapra por sus menores dimensiones (tablas V.9.18 y V.10.12), 
por tener los bordes de la superficie articular proximal cóncavos y un surco muy marcado en la cara palmar de forma triangular. Se diferencian de Ovis por el mayor tamaño de las regiones de inserción muscular, por el mayor tamaño de las superficies de articulación con los sesamoideos y por tener el surco que divide la superficie articular proximal más profundo, algo que es más evidente en vista posterior. En vista posterior, la región articular distal tiene el surco, que separa las caras axial y abaxial, más profundo. En vista de perfil, en la región proximal, las zonas articulares presentan una mayor concavidad que en Ovis (Boessneck et al.,1964)..

Falanges proximales anteriores: son más cortas, aunque puede existir solapamiento en la longitud, y más anchas que las posteriores (tabla V.10.12). El borde de la tróclea, en vista ventral, es oblicuo, a diferencia de las posteriores en el que es recto. Las protuberancias presentes en la cara palmar de la diáfisis están más marcadas que en las posteriores. Dichas protuberancias definen un surco proximal marcado. Las zonas donde se insertan los ligamentos interdigitales no están tan marcadas como en las posteriores.

Falanges proximales posteriores: son más largas, puede haber solapamiento en la longitud, y más estrechas que las anteriores, son más gráciles. En vista ventral, los bordes de la tróclea son más o menos paralelos, a diferencia de las anteriores en las que divergen. Las protuberancias para la inserción de los ligamentos interdigitales están menos marcadas que en las anteriores.

Falanges medias (lámina V.10.1: 22 y 25) (tabla V.10.12): son huesos cortos y anchos. Esta falange es más corta que la proximal. La superficie proximal tiene una cresta sagital que la divide en dos cavidades, siendo la abaxial más amplia y alta que la axial. En el borde anterior de dicha superficie tiene un saliente muy proyectado, y distal a él muestra una pequeña depresión para la inserción de ligamentos. En la cara palmar, hay dos crestas bien marcadas para la inserción de ligamentos. La superficie articular se proyecta mucho proximalmente en la cara dorsal y menos en el lado palmar. Difieren de Rupicapra por tener los bordes lateral y medial, de la superficie articular proximal, muy cóncavos, por tener un surco muy marcado en la cara palmar de la superficie articular distal y por ser más grandes (tablas V.9.18 y V.10.12). Difieren de Ovis en que las áreas de inserción muscular están más desarrolladas y en que la superficie articular distal presenta los extremos axial y abaxial mucho más desiguales que en las ovejas.

Tabla V.10.13

Medidas tomadas en las falanges distales de C. pyrenaica

\begin{tabular}{lccc}
\hline & DLS & LD & MBS \\
\hline Valdegoba & & & \\
$\mathrm{n}$ & 15 & 14 & 15 \\
rango & $28,1-43,5$ & $22,4-32,4$ & $6,2-9,1$ \\
$\overline{\mathrm{x}} \pm$ s.d. & $35,3 \pm 4,3$ & $26,0 \pm 2,7$ & $7,6 \pm 0,8$ \\
Millán & & & \\
$\mathrm{n}$ & 4 & 4 & 4 \\
rango & $40,7-42,9$ & $33,4-42,4$ & $7,3-13,1$ \\
$\overline{\mathrm{x}} \pm$ s.d. & $42,3 \pm 1,1$ & $36,9 \pm 4,1$ & $10,4 \pm 2,9$ \\
Estebanvela & & & \\
$\mathrm{n}$ & 2 & 2 & 2 \\
rango & $33,6-39,7$ & $27,3-28,1$ & $8,2-10,4$ \\
$\overline{\mathrm{x}} \pm$ s.d. & $36,6 \pm 4,3$ & $27,7 \pm 0,5$ & $9,3 \pm 1,5$ \\
\hline
\end{tabular}

Falanges medias anteriores: difieren de las posteriores por tener unas regiones de inserción muscular más marcadas, por tener los bordes de la superficie articular proximal más paralelos y por su menor longitud y mayor anchura (tabla V.10.12).

Falanges medias posteriores: son más largas, puede existir solapamiento en la longitud, y más estrechas que las anteriores.

Falanges distales (lámina V.10.1: 26) (tabla V.10.13): huesos triangulares, comprimidos lateralmente y sin surcos en la región distal de la superficie parietal. La apófisis extensora está muy marcada, es redondeada y se encuentra separada de la cara articular por una depresión muy desarrollada. Dicha depresión muestra dos forámenes de grandes dimensiones. La superficie articular está separada en dos partes. La primera, la más 
grande, que articula con la falange media, está dividida en dos partes por una cresta proximodistal muy inclinada. La segunda, representada por una pequeña carilla articular, está situada por debajo y es donde se articula el sesamoideo distal. La superficie solar es estrecha y recta. Difiere de Ovis en que la superficie plantar es más apuntada y en que el processus extensorius que está menos marcado.

\subsubsection{Edad de muerte}

Se han analizado únicamente los dientes ya que son los restos más abundantes. Las piezas completas son escasas por lo que también se emplean las edades de erupción y reemplazamiento dental. En aquellas piezas en las que se ha podido medir la altura se utilizan el modelo de desgaste y las ecuaciones de Klein et al., (1984). Al final se comparan los resultados de ambos modelos métricos.
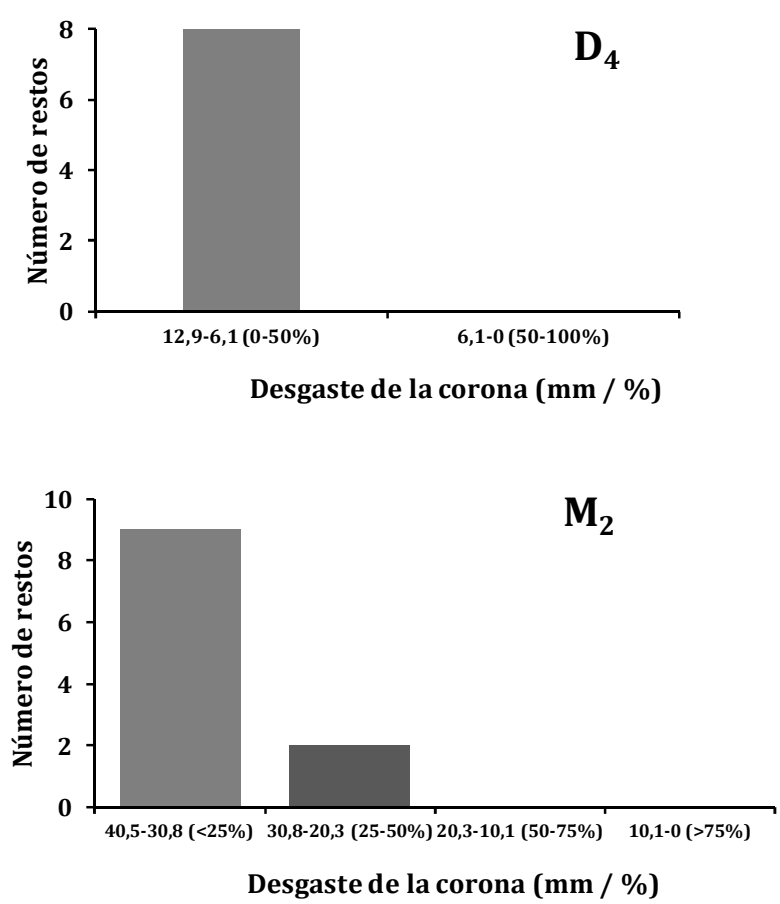

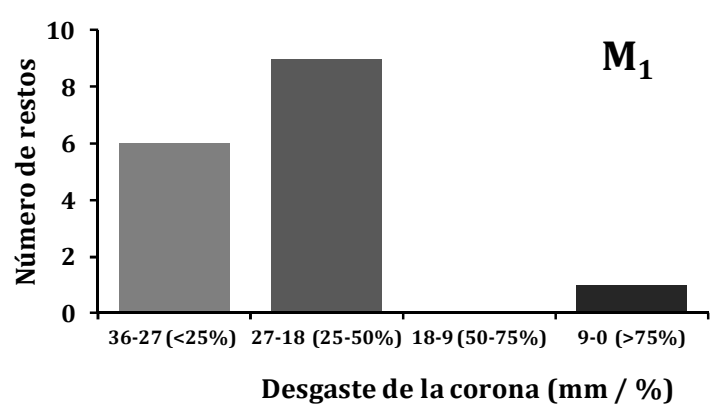

Figura V.10.10. Desgaste en los dientes yugales de la Capra pyrenaica de la Cueva de Valdegoba. Datos obtenidos con el modelo de desgaste y erupción.

La Cueva de Valdegoba: el desgaste indica que existe un mayor número de piezas con desgastes entre el 0 y el $50 \%$. En el $\mathrm{D}_{4}$ predominan los desgastes por debajo del $50 \%$. En el $\mathrm{M}_{1}$, aquellos con erosiones entre el 25 y el $50 \%$ son los más abundantes, seguidos por aquellos con desgastes inferiores al $25 \%$ y por aquellos con desgastes máximos (> $75 \%$ ). En el $\mathrm{M}_{2}$ predominan aquellos con desgastes inferiores al $25 \%$ (figura V.10.10).

Tabla V.10.14

Edad dental estimada en los $\mathrm{D}_{4}, \mathrm{M}_{1}$ y $\mathrm{M}_{2}$ de $C$. pyrenaica (1 ${ }^{\mathrm{a}}$ parte)

\begin{tabular}{|c|c|c|c|c|c|c|c|c|c|c|c|}
\hline \multicolumn{4}{|c|}{$\mathbf{D}_{4}$} & \multicolumn{4}{|c|}{$\mathbf{M}_{1}$} & \multicolumn{4}{|c|}{$\mathbf{M}_{2}$} \\
\hline & & CH & Edad & & & $\mathrm{CH}$ & Edad & & & $\mathrm{CH}$ & Edad \\
\hline Vb-sp-1943 & $\mathrm{d}$ & 11,6 & 0,0 & Vb-sp-2561 & $\mathrm{i}$ & 34,4 & 3,0 & Vb-sp-2650 B & $\mathrm{i}$ & 44,5 & 13,0 \\
\hline Vb-sp-1395 & $\mathrm{i}$ & 10,8 & 0,1 & Vb-sp-2500 & d & 32,6 & 3,0 & Vb-sp-2624 & i & 42,4 & 13,4 \\
\hline Vb-sp-1296 & d & 10,3 & 0,3 & Vb-sp-2623 & i & 32,5 & 3,7 & Vb-sp-2646 B & $\mathrm{i}$ & 40,3 & 14,9 \\
\hline Vb-sp-1393 & $\mathrm{i}$ & 8,4 & 1,9 & Vb-sp-2478 & i & 29,1 & 8,2 & Vb-sp-2570 C & d & 39,8 & 15,3 \\
\hline Vb-sp-2596 & d & 8,3 & 2,0 & Vb-sp-1155 & i & 27,7 & 11,1 & Vb-sp-2615 & d & 39,5 & 15,6 \\
\hline Vb-sp-1295 & $\mathrm{d}$ & 8,2 & 2,1 & Vb-sp-2564 & $\mathrm{d}$ & 27,0 & 12,8 & Vb-sp-2619 & d & 38,1 & 17,2 \\
\hline Vb-sp-2580 & $\mathrm{i}$ & 6,5 & 4,8 & Vb-sp-2549 & $\mathrm{i}$ & 26,4 & 14,5 & Vb-sp-2631 & $\mathrm{i}$ & 36,9 & 18,9 \\
\hline
\end{tabular}

* Las edades de muerte se han estimado a partir de las ecuaciones de Klein et al., (1984). CH: en milímetros. Edad: en meses. 
Tabla V.10.14

Edad dental estimada en los $\mathrm{D}_{4}, \mathrm{M}_{1}$ y $\mathrm{M}_{2}$ de C. pyrenaica (2 ${ }^{\mathrm{a}}$ parte)

\begin{tabular}{|c|c|c|c|c|c|c|c|c|c|c|c|}
\hline \multicolumn{4}{|c|}{$\mathbf{D}_{4}$} & \multicolumn{4}{|c|}{$\mathbf{M}_{1}$} & \multicolumn{4}{|c|}{$\mathbf{M}_{2}$} \\
\hline & & CH & Edad & & & CH & Edad & & & $\mathrm{CH}$ & Edad \\
\hline \multirow{9}{*}{\multicolumn{2}{|c|}{ Vb-sp-2575 C }} & 6,2 & 5,4 & Vb-sp-1207 & d & 26,1 & 15,6 & Vb-sp-2654 & d & 33,9 & 24,6 \\
\hline & & & & Vb-sp-1204 & d & 25,6 & 17,1 & Vb-sp-2521 & d & 32,3 & 28,3 \\
\hline & & & & Vb-sp-2551 & $\mathrm{i}$ & 24,2 & 21,8 & Vb-sp-2423 & d & 29,9 & 34,8 \\
\hline & & & & Vb-sp-2647 & d & 23,5 & 24,4 & Vb-sp-2644 B & $\mathrm{i}$ & 25,6 & 49,5 \\
\hline & & & & Vb-sp-1086 & d & 23,4 & 25,0 & & & & \\
\hline & & & & Vb-sp-1179 & d & 21,4 & 33,4 & & & & \\
\hline & & & & Vb-sp-2544 & d & 20,1 & 39,9 & & & & \\
\hline & & & & Vb-sp-1185 & d & 19,8 & 41,5 & & & & \\
\hline & & & & Vb-sp-2579 C & d & 7,1 & 136,9 & & & & \\
\hline
\end{tabular}

Cuando comparamos los dos modelos existe una tendencia similar (figura V.10.11), predominando las edades de entre 3 y 52 meses, seguidas de aquellas de menos de 3 y por las de más de 52 meses. Sin embargo, a pesar de que la tendencia es similar, el número de restos no lo es. Las piezas, que en el modelo de desgaste, están en el primer y último rango, pasan al intermedio en el modelo de Klein et al., (1984).

Si tenemos en cuenta la pieza más frecuente, el $\mathrm{M}_{1}$ derecho, al menos uno de los ejemplares sería infantil, 8 serían juveniles y uno sería adulto.
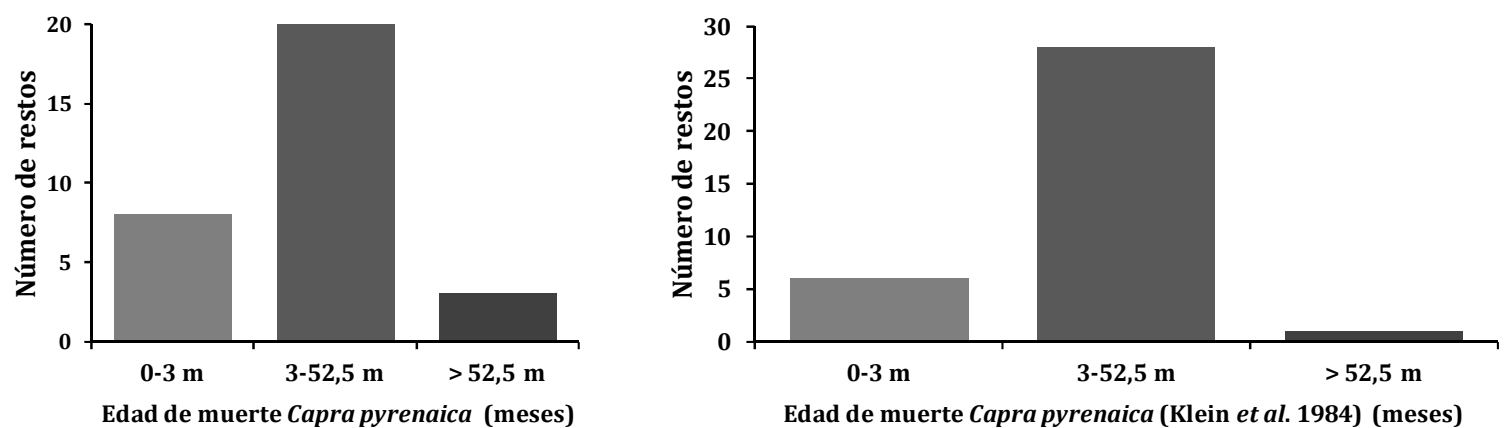

Figura V.10.11. Comparativa entre los dos modelos de estimación de la edad de muerte en la Capra pyrenaica de la Cueva de Valdegoba.

Prado Vargas: en este depósito se han empleado las edades de erupción. Al menos uno de los ejemplares tendría por lo menos 25 meses, edad de erupción del $\mathrm{P}_{4}$ (Vigal y Marchordom, 1985) y otro 13, edad de erupción del M².

Cueva Millán: analizamos el material por niveles:

Nivel 1A: la pieza analizada, un $\mathrm{M}_{2}$ izquierdo, presenta desgaste marcado y su edad estaría entorno a los 128 meses. Esta edad encaja bien con la de erupción del canino por lo que este ejemplar sería un adulto.

Nivel 1B: se ha empleado la edad de erupción del $\mathrm{P}_{4}$. El ejemplar tendría al menos 25 meses. No se puede especificar si se trata de un ejemplar juvenil o de un adulto.

Nivel 1C: al menos uno de los ejemplares tendría 25 meses, a partir del $\mathrm{P}^{4}$. No se puede indicar si se trata de un juvenil o de un adulto.

La Peña de Estebanvela: se ha analizado la edad por niveles. 
Nivel I: se han podido medir dos piezas. En uno de los casos, un $\mathrm{M}_{2}$, el desgaste es moderado (25 y $50 \%$ ), y en la otra, un $\mathrm{M}_{1}$, marcado (50 - $75 \%$ ). Las ecuaciones de Klein et al., (1984) aportan una edad de 51 meses para el primero y de 72 a la segundo. Los resultados de ambos modelos son similares. Asimismo, en este nivel se han identificado 2 $\mathrm{dI}_{2}$. Esta pieza es reemplazada por el $\mathrm{I}_{2}$ en torno a los 30 meses (Vigal y Marchordom, 1985), por lo que un ejemplar tendría al menos esa edad. Por lo tanto, dos de los individuos serían adultos y otro no alcanzaría los 30 meses.

Nivel II: al menos uno de los ejemplares tendría 30 meses. Esta edad ha sido estimada a partir de la erupción del $\mathrm{I}_{2}$. No se puede indicar si es juvenil o adulto.

Nivel III: se ha podido medir la altura de un $\mathrm{M}_{2}$. Esta pieza presenta un desgaste inferior al $25 \%$ y ha aportado una edad de 13,2 meses, un ejemplar joven. Se ha recuperado un $\mathrm{P}_{2}$. La erupción de esta pieza se produce en torno a los 30 meses (Vigal y Marchordom, 1985) por lo que, junto con el ejemplar joven, tendríamos otro de al menos 30 meses.

Nivel IV: el individuo identificado tendría al menos 25 meses, edad de erupción del $\mathrm{M}_{3}$ (Vigal y Marchordom, 1985).

\subsubsection{Estacionalidad}

Se ha analizado en aquellos casos en los que la edad de muerte se ha estimado en meses. El comportamiento social de la especie se ha tomado de Vigal y Fandos (1989), de Fandos et al., (1992) y de Alados y Escós (2003). La fecha de partos, el mes de mayo, se ha tomado de Hayssen et al., (1993).
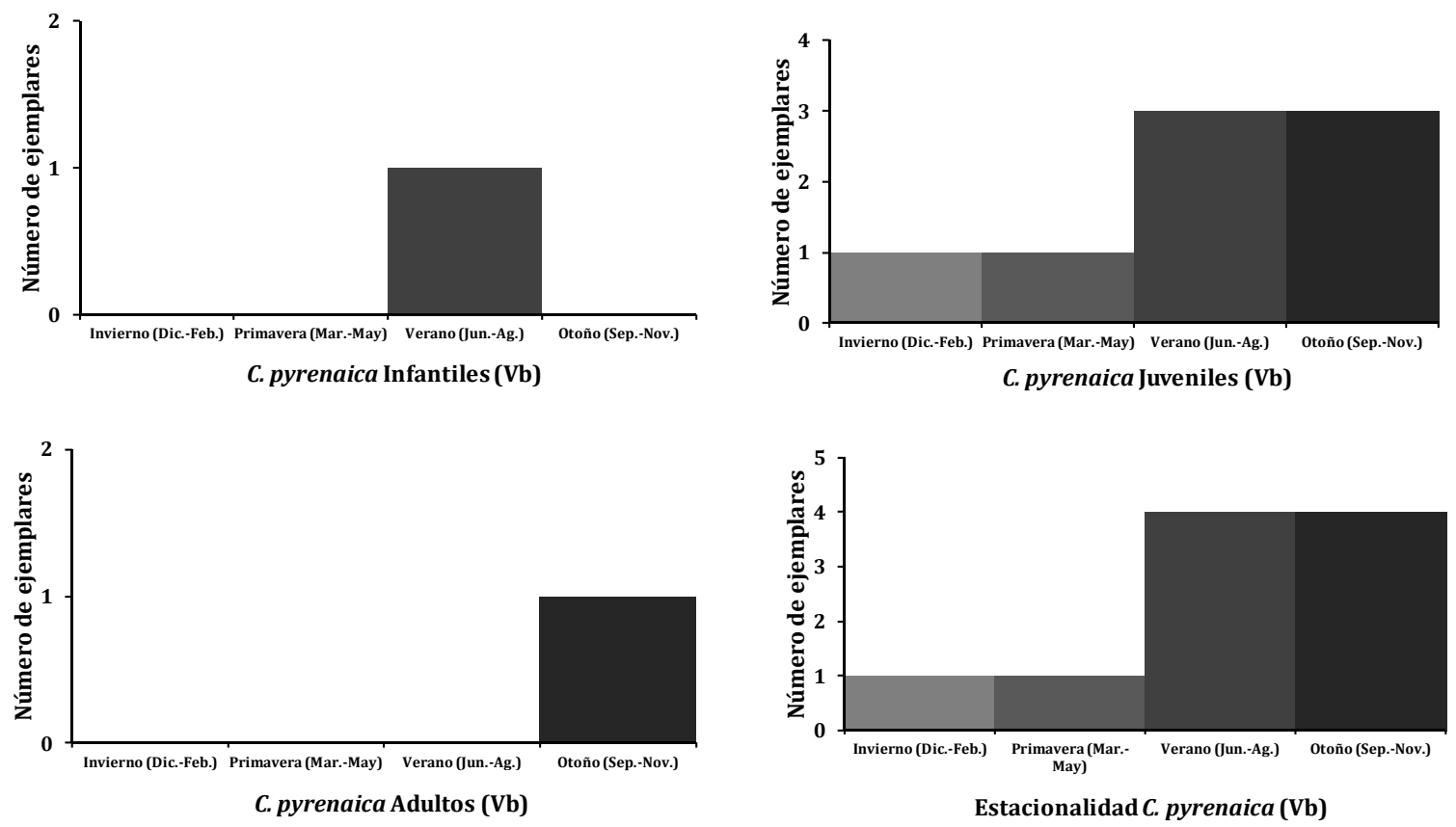

Figura V.10.12. Estacionalidad general y por rangos de edad de Capra pyrenaica en la Cueva de Valdegoba.

La Cueva de Valdegoba: los resultados obtenidos en la edad de muerte sugieren que sí que existe estacionalidad. Las capturas predominan en verano y en otoño. Si la analizamos por rangos de edad, vemos que el ejemplar infantil fue acumulado en verano, los juveniles en verano y otoño, y el adulto en otoño. Hay dos ejemplares que fueron depositados en invierno y primavera. Los periodos de acumulación coinciden la lactancia y el celo (figura V.10.12). 
Cueva Millán: la pieza que ha podido analizarse en el nivel 1A, un $\mathrm{M}_{2}$ izquierdo, indica que este individuo adulto fue depositado en invierno, periodo en el que estos ejemplares permanecen aislados o forman pequeños grupos con machos (Alados y Escós, 2003).

La Peña de Estebanvela: se han podido analizar dos niveles:

Nivel I: se han analizado dos piezas, $1 \mathrm{M}_{1}$ izquierdo y $1 \mathrm{M}_{2}$ izquierdo. Ambas piezas dan resultados similares e indican que se depositaron en primavera, la época de partos.

Nivel III: el $\mathrm{M}_{2}$ derecho sugiere el verano como periodo de acumulación. El ejemplar, un juvenil, fue acumulado en el periodo de lactancia.

\subsubsection{Número Mínimo de Individuos}

Para determinar el MNI se ha empleado la pieza más frecuente. Asimismo para indicar si los ejemplares son infantiles, juveniles o adultos se ha tenido en cuenta la pieza más frecuente analizada en la edad de muerte (tabla V.10.15). En primer lugar se establece el número de ejemplares maduros e inmaduros y posteriormente se les clasifica en infantiles, juveniles y adultos.

Tabla V.10.15

Número mínimo de individuos de Capra pyrenaica

\begin{tabular}{|c|c|c|c|c|c|c|c|}
\hline & & Inmaduros & Maduros & Total & Infantiles & Juveniles & Adultos \\
\hline Cueva de Valdegoba & & 10 & 8 & 18 & 1 & 8 & 1 \\
\hline Prado Vargas & & & & 2 & & & \\
\hline \multirow[t]{4}{*}{ Cueva Millán } & $1 \mathrm{~A}$ & & 1 & 5 & & & 1 \\
\hline & 1B & & & 1 & & & \\
\hline & 1C & & & 1 & & & \\
\hline & I & 2 & 2 & 4 & & & 2 \\
\hline \multirow[t]{3}{*}{ Estebanvela } & II & & & 1 & & & \\
\hline & III & 1 & & 2 & & 1 & \\
\hline & IV & & & 1 & & & \\
\hline
\end{tabular}

En la Cueva de Valdegoba se han identificado 18 ejemplares: 10 inmaduros a partir del $\mathrm{D}_{4}$ derecho y 8 maduros a partir del canino derecho. De éstos, al menos uno sería infantil, ocho serían juveniles y uno sería adulto, a partir del $\mathrm{M}_{1}$ derecho. En Prado Vargas habría al menos dos ejemplares, estimados a partir del $\mathrm{M}^{2}$ derecho. En el nivel $1 \mathrm{~A}$ de Cueva Millán se han identificado cinco ejemplares a partir del $\mathrm{I}_{2}$ izquierdo, siendo al menos uno de ellos adulto, a partir del $\mathrm{M}_{2}$ izquierdo. En el nivel 1B habría al menos un ejemplar de al menos 25 meses, a partir de un $\mathrm{P}_{4}$ izquierdo. En el 1C, habría otro al menos de 25 meses, a partir de un $\mathrm{P}^{4}$ izquierdo. En el nivel I de la Peña de Estebanvela se han identificado 4 ejemplares: dos inmaduros de cómo mucho 30 meses a partir del $\mathrm{dI}_{2}$ izquierdo; y dos maduros, a partir de un $\mathrm{M}_{1}$ y un $\mathrm{M}_{2}$ izquierdos. En el nivel 1B habría al menos un ejemplar de 30 meses, a partir de un $\mathrm{I}_{2}$ derecho. En el nivel III se han identificado dos ejemplares: un inmaduro, juvenil, a partir de un $\mathrm{M}_{2}$ derecho; y un ejemplar de al menos 30 meses, a partir de un $\mathrm{P}_{2}$ derecho. En el nivel IV tendríamos al menos un ejemplar de 25 meses, a partir de un $\mathrm{M}_{3}$ derecho.

\subsubsection{Discusión}

Los restos de la Cueva de Valdegoba, Prado Vargas, Cueva Millán y la Peña de Estebanvela presentan afinidades con el género Capra, y permiten descartar a otros géneros de caprinos y antílopes como Rupicapra, Ovis, Hemitragus, Ammotragus y Saiga (figuras V.10.2, 3,4 y 5). Entre estos caracteres destacan la morfología de los lóbulos, la 
ausencia de islotes centrales de esmalte o el diferente desarrollo de los estilos en la dentición inferior y superior. Asimismo la mayor o menor robustez de los huesos largos, la diferencia en el desarrollo de las áreas de inserción muscular así como la morfología de las diferentes regiones articulares nos permiten asignar los restos al género Capra.

Las hipótesis sobre la llegada de este género a Europa son diversas e influyen en las relaciones filogenéticas de las diferentes especies en los últimos 500 ka. Así, CrégutBonnoure (2006) sugiere una migración independiente de C. ibex y C. pyrenaica, mientras que Pérez et al., (2002) proponen una relación entre ambas especies, siendo C. ibex la antepasada directa de C. pyrenaica. Las diferencias entre ambas especies son sutiles Crégut-Bonnoure (1992b). Para esta autora, las diferencias entre los íbices del Pleistoceno Superior europeo no se encuentran únicamente en el esqueleto postcraneal sino que también aparecen manifestadas a nivel dental. Describe una serie de caracteres diferenciales a partir de los restos recuperados en Bouxès, Le Portel, Pêcheurs y Adaouste, sugiriendo dos líneas evolutivas diferentes. La primera, línea caucasica-cylindricornis, daría lugar a C. pyrenaica; y la segunda, línea $C$. ibex, derivaría en el íbice alpino $C$. ibex. El mayor número de diferencias se encuentran en el $\mathrm{P}_{3}$ y en el $\mathrm{M}^{3}$. En relación al $\mathrm{M}^{3}$, se ha observado que el ala metastilar presenta en todos los casos una fuerte proyección hacia la base de la corona. Este carácter no parece coincidir con los criterios de Crégut-Bonnoure (1992b) en los que sugiere que en la línea caucasica-cilindricornis este ala no está tan proyectada como en la línea C. ibex. El material recuperado presenta un gran polimorfismo con respecto a este carácter por lo que no lo consideramos diferencial (figura V.10.9). Sin embargo, el resto de caracteres descritos anteriormente, así como la diferencia de tamaño observado nos permiten asignar los restos a Capra pyrenaica. 


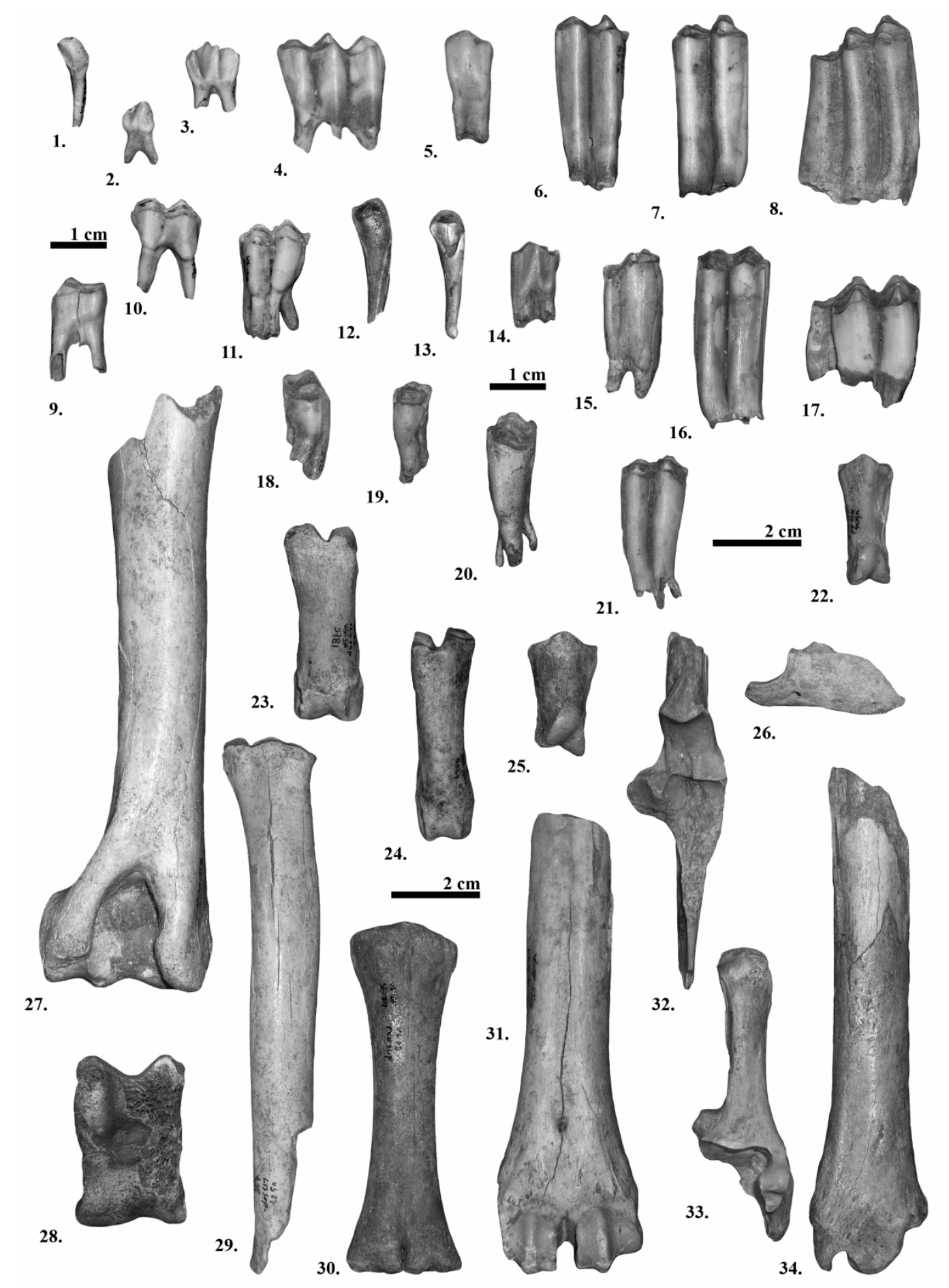

Lámina V.10.1. Capra pyrenaica provenientes de los yacimientos de la Cueva de Valdegoba (sigla Vb), Prado

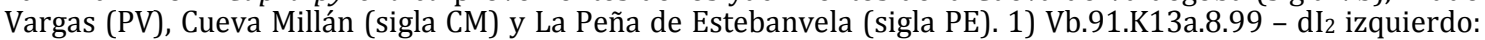
cara lingual. 2) 36 - D izquierdo: cara lingual. 3) Vb-sp-921 - $D_{3}$ derecho: cara lingual. 4) Vb-sp-5923 - $D_{4}$ izquierdo: cara bucal. 5) Vb-sp-2699 - $\mathrm{P}_{2}$ derecho: cara bucal. 6) Vb-sp-2561 - M $\mathrm{M}_{1}$ izquierdo: cara bucal. 7) Vbsp-6026 - M2 izquierdo: cara bucal. 8) Vb-sp-1027 - M3 izquierdo: cara bucal. 9) Vb-sp-1430 - D2 izquierdo: cara lingual. 10) Vb-sp-2476 - $\mathrm{D}^{3}$ derecho: cara lingual. 11) Vb-sp-590 - $\mathrm{D}^{4}$ derecho: cara lingual. 12) PV.06.45.G30.387 - $I_{1}$ izquierdo: cara lingual. 13) CM.861A.8C - Canino izquierdo: cara lingual. 14) Vb-sp-2530 - $\mathrm{P}_{3}$ izquierdo: cara lingual. 15) Vb.89.L13.Cd.8.10 - $\mathrm{P}_{4}$ derecho: cara bucal. 16) Vb-sp-2538 - M2 izquierdo: cara lingual. 17) Vb-sp-2635 - $\mathrm{M}^{3}$ derecho: cara lingual. 18) Vb-sp-2775 - $\mathrm{P}^{2}$ derecho: cara lingual. 19) Vb-sp-905 $\mathrm{P}^{3}$ izquierdo: cara lingual. 20) Vb-sp-901 - $\mathrm{P}^{4}$ derecho: cara lingual. 21) Vb-sp-5915 - $\mathrm{M}^{1}$ izquierdo: cara lingual. 22) Vb.06.M13.Ad.65.70.3 - Falange media posterior izquierda. 23) Vb-sp-5781 - Falange proximal anterior izquierda. 24) Vb-sp-4549 - Falange proximal posterior izquierda. 25) Vb-sp-5795 - Falange media anterior izquierda. 26) CM.86.1A.10F - Falange distal izquierda. 27) Vb-sp-5572 - Húmero izquierdo. 28) PE.07.B7.NVI.10.1433 - Astrágalo derecho. 29) Vb-sp-3254 - Radio derecho. 30) Vb-sp-5879 - Metacarpo inmaduro izquierdo. 31) Vb-sp-5566 - Metacarpo derecho. 32) Vb-sp-5842 - Ulna derecha. 33) Vb-sp-6289 Calcáneo izquierdo. 34) Vb-sp-5675 - Tibia izquierda. 


\subsection{Bos primigenius}

Orden Artiodactyla Owen, 1848

Familia Bovidae Gray, 1821

Subfamilia Bovinae Gray, 1821

Género Bos Linnaeus, 1758

Especie Bos primigenius Bojanus, 1827

\subsubsection{Generalidades}

Los Bovidae son rumiantes en los que los machos, y en algunas especies las hembras, tienen cuernos. Los Bovinae incluyen formas grandes, como bisontes y vacas domésticas. Se trata de un grupo con una tendencia a que los cuernos se sitúen en una posición progresivamente más atrasada, llegando al extremo en el género Bos. La clasificación dentro de esta subfamilia es complicada. Autores como Gentry (1978) o Groves (1981) consideran a Bos, Bibos y Bison como subgéneros de Bos; e incluso Brugal (1985) y MoyàSolà (1987) sugieren que el género Leptobos podría estar incluido también dentro de Bos.

El origen de este género, habitual en las faunas del Pleistoceno Medio y del Holoceno, no está del todo claro. Por un lado Van Vuure (2005) sugiere un posible origen asiático a partir de formas como Bos acutifrons y Bos planifrons; mientras que Martínez-Navarro et al., $(2007,2014)$ proponen un origen africano, siendo un posible ancestro el género Pelorovis de finales del Plioceno y comienzos del Pleistoceno. Según estos autores (Martínez Navarro et al., 2014), el primer representante africano sería Bos turkanensis y las primeras evidencias europeas se encontrarían en Ponte Galeria, 0,7 - 0,8 Ma., asignados a B. galerianus, aunque posteriormente fueron incluidos en Hemibos galerianus. Por otra parte, Turner et al., (1996) proponen su presencia en el yacimiento alemán de Miesenheim, $464 \mathrm{Ka}$, aunque en una revisión posterior (Turner, 2000) indica únicamente la presencia probable de Bison schoetensacki en este depósito.

Martinez-Navarro et al., (2010) realizan una distribución de este género en el Pleistoceno. Las formas del Pleistoceno Temprano estarían incluidas en Bos turkanensis; las del Pleistoceno Inicial de África y del Corredor Levantino en B. oldowayensis; y las formas del Pleistoceno Medio - Holoceno en B. primigenius. Los primeros restos identificados de Bos primigenius se encuentran en el yacimiento africano de Gesher Benot Yakov, datado en torno a los 0,8 Ma. (Martínez-Navarro et al., 2011, 2014).

La filogenia de Bos y Bison es muy discutida, habiéndose realizado estudios tanto genéticos como morfológicos y varias propuestas sobre sus relaciones filogenéticas. Por un lado, el análisis morfológico realizado por Bohlken (1961) sugiere una separación clara entre Bison bison y B. bonasus por un lado, y de Bos taurus y B. grunniens por otro. Algo similar lo propone Groves (1981) a partir del análisis de diferentes elementos craneales, donde no tiene en cuenta a B. grunniens, y deja por un lado a B. taurus y por otro a los bisontes. Otro estudio lo realiza Geraads (1992), sugiriendo un origen parafilético para Leptobos e incluyendo a Leptobos etruscus en el género Smertiobos y a su vez dentro de Bovinae junto con Bos y Bison. Duvernois (1990) sugiere un origen común para ambos géneros cuyo representante sería el género Leptobos, distinguiendo posteriormente dos líneas dentro de este género. La primera protagonizada por Leptobos elatus y la segunda por Leptobos etruscus. Las diferencias recaen en la longitud, curvatura y la posición de sus cuernos. Este autor propone la primera línea como el posible ancestro de los géneros Bison y Bos del Pleistoceno. Otra hipótesis la desarrollan Wall et al., (1992) a partir de estudios de ADN nuclear. Estos autores sugieren una relación mucho más estrecha entre $B$. grunniens, Bison bonasus y B. taurus, divergiendo de un mismo nodo y sin estar relacionados con Bos gaurus ni Bos javanicus. El análisis del citocromo b oxidasa realizado por Janecek et al., (1996) propone que Bison y Bos serían grupos hermanos, aunque indican que Bison podría tener un origen parafilético. Por otra parte, los estudios de ADN mitocondrial llevados a cabo por Douglas et al., (2011) sugieren un análisis más 
exhaustivo de las poblaciones actuales para poder explicar el origen de ambos géneros de grandes bóvidos.

Los estudios morfológicos y genéticos no dejan claro el origen de este taxón y ponen en cuestión muchas de las clasificaciones realizadas hasta la fecha, creando nuevos géneros y modificando clasificaciones previas. En este sentido, un estudio morfológico de los grandes bóvidos recuperados en la Meseta Norte puede aportar datos acerca de la presencia de uno u otro género en esta región y así completar la distribución de estos taxones en el Pleistoceno Tardío.

\subsubsection{Material}

El material descrito y comparado proviene de los siguientes yacimientos:

Cueva de Valdegoba: 46 piezas: 28 dientes y 17 postcraneales. Los dientes son $6 \mathrm{M}_{1}, 2 \mathrm{P}^{2}$, $3 \mathrm{P}^{3}, 4 \mathrm{P}^{4}, 2 \mathrm{M}^{1}, 2 \mathrm{M}^{2}, 3 \mathrm{M}^{1-2}$ y $6 \mathrm{M}^{3}$. Los restos postcraneales se componen de: 5 calcáneos, 1 tibia, 7 astrágalos, 2 metacarpos y 2 metatarsos.

Cueva del Búho: 18 restos: 9 dentales y 9 postcraneales. Los dientes recuperados son: 1 $\mathrm{P}^{2}, 2 \mathrm{P}^{3}, 1 \mathrm{M}^{1}, 1 \mathrm{M}^{2}, 2 \mathrm{M}^{1-2}$ y $2 \mathrm{M}^{3}$. Los restos postcraneales son: 1 tibia, 1 astrágalo, 1 calcáneo, 3 metacarpos y 3 metatarsos.

\subsubsection{Descripción y comparación}

Los restos descritos a continuación provienen de los yacimientos de la Cueva del Búho y de la Cueva de Valdegoba. Se emplean los criterios que aparecen en Jaubert et al., (1990) y Sala et al., (2010) para poder comparar los restos de Bison con los de Bos.

Molares inferiores permanentes (lámina V.11.1: 1) (tabla V.11.1) (figura V.11.1): se trata de dientes con las coronas altas, selenodontas, con las cúspides fusionadas y sin islotes centrales de esmalte ni cíngulos. Tienen unas columnas interlobulares de grandes dimensiones y dos raíces: una mesial y otra distal. Los $\mathrm{M}_{1}$ y $\mathrm{M}_{2}$ son bilobulados y el $\mathrm{M}_{3}$ tiene una apariencia trilobulada debido al gran desarrollo del hipoconúlido. Debido a la semejanza entre los dos primeros molares se define la categoría $\mathrm{M}_{1-2}$. Difieren de Bison priscus en que la columna interlobular es alta y en que el surco lingual es ancho y convexo en la base. Por lo contrario, Bison tiene la columna interlobular baja y el surco lingual profundo y estrecho (Jaubert et al., 1990).

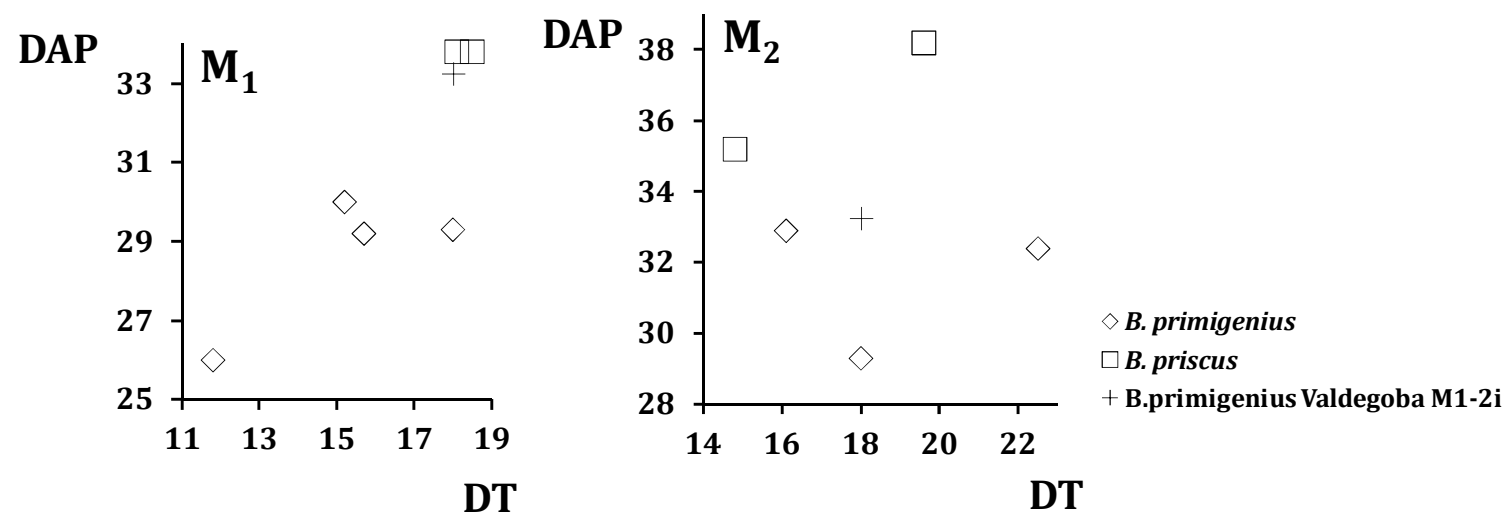

Figura V.11.1. Diagramas bivariantes de los molares inferiores: DAP (diámetro anteroposterior) y DT (diámetro transversal). Bos primigenius de Mendandia (Alday Ruiz, 2006), Biache-Saint-Vaast (Auguste, 1995), Bau de l'Aubesier (Fernández, 2001), Livernon (Slott-Moller 1990), Abri Marcq (Crégut-Bonnoure, 1993) y Chinchon 2 (Crégut-Bonnoure, 1992c). Bison priscus de Nestier (Clot y Marsan, 1986), Jaurens, I'l skaya (Guèrin y Valli, 2000) y Marcamps (Slott-Moller 1990). 
M-2: las piezas recuperadas tienen los estilos poco pronunciados. Los bordes mesial y distal de la cara lingual son más o menos paralelos. Tienen una columna interlobular bien desarrollada. El ectostílido, o columna interlobular, es alta. El surco lingual, definido por el protocónido y el hipocónido, es ancho y convexo en la base. La pieza de la Cueva de Valdegoba tiene un tamaño similar al de los $\mathrm{M}_{1}$ de Bison priscus y es más grande que los de Bos primigenius. Sin embargo, cuando los comparamos con los $\mathrm{M}_{2}$ están dentro del rango del uro y son más pequeños que los del bisonte (figura V.11.1).

Premolares superiores (lámina V.11.1: 4) (tabla V.1.11) (figura V.11.2): dientes con las coronas altas, selenodontas y unilobuladas. No tienen cíngulos y los estilos presentan un desarrollo variable. Las fosetas son simples y su esmalte es rugoso. Tienen tres raíces: una mesial, una distal y otra lingual. Difieren de Bison en que los bordes lingual y bucal son subparalelos, mientras que son divergentes en Bison (Jaubert et al., 1990).

P2: esta pieza tiene el parastilo poco desarrollado pero un metastilo fuertemente proyectado hacia atrás. En la cara bucal hay dos surcos, uno mesial y otro distal. El mesial se encuentra muy marcado y tiene forma de "V" mientras que el distal no está muy desarrollado. No tiene surcos en la cara lingual.

P3: el paracono está muy desarrollado y la paraectocrista está proyectada mesialmente, dándole el aspecto asimétrico que permite diferenciarlo del $\mathrm{P}^{4}$. Tanto el parastilo como el metastilo están muy desarrollados. Carecen de surco lingual entre el protocono y el hipocono. Las piezas de la Cueva del Búho y de la Cueva de Valdegoba son más pequeñas que las de Bison priscus y están dentro del rango de Bos primigenius (figura V.11.2).
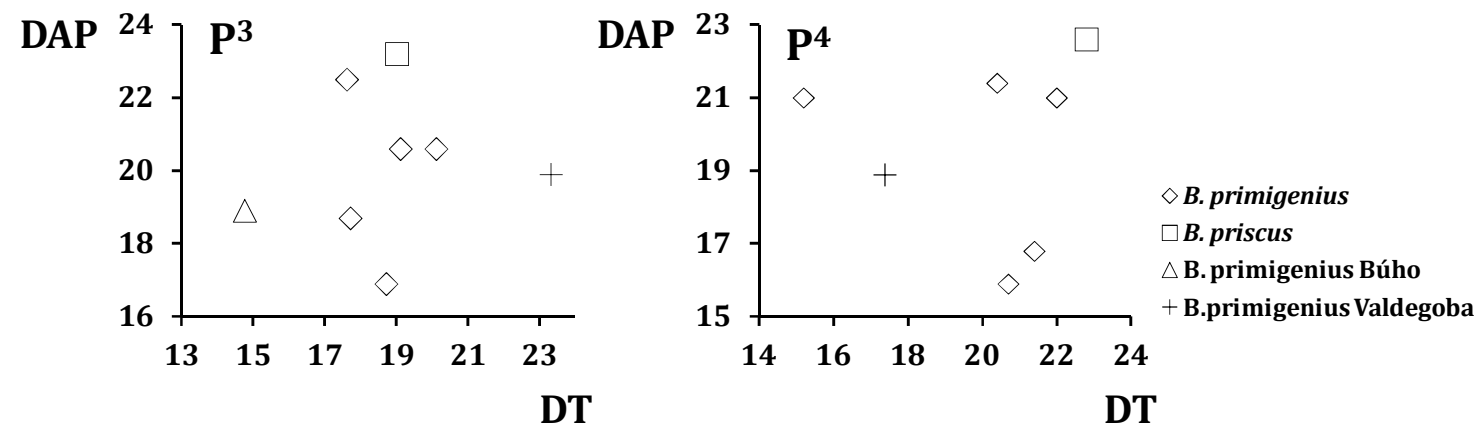

Figura V.11.2. Diagramas bivariantes de los premolares superiores: DAP (diámetro anteroposterior) y DT (diámetro transversal). Bos primigenius de Biache-Saint-Vaast (Auguste, 1995), Bau de l'Aubesier (Fernández, 2001), Livernon (Slott-Moller 1990), Chinchon 2 (Crégut-Bonnoure, 1992c) y Combe Grenal (Guadelli, 1987). Bison priscus de Jaurens (Guérin y Valli, 2000), Marcamps (Slott-Moller 1990), I'l skaya (Guérin y Valli, 2000) y Ènlène (Lalande, 1986).

P4: la paraectocrista está situada en una posición central, dándole un aspecto simétrico. No tiene un surco entre el protocono y el hipocono en la cara lingual. Esta cara es, además, más convexa que en el $\mathrm{P}^{3}$. Son más anchos pero tienen unas longitudes similares a las de los otros premolares superiores (tabla V.11.1). Son más pequeños que los del bisonte y tienen un tamaño similar al de otros uros (figura V.11.2).

Molares superiores permanentes (lámina V.11.1: 2 y 5) (tabla V.1.11) (figuras V.11.3): son dientes con las coronas altas, esmalte rugoso, dos lóbulos, cúspides fusionadas y configuración selenodonta. El lóbulo mesial está más proyectado que el distal hacia la cara lingual. Los estilos presentan un desarrollo variable. Tienen una columna interlobular muy desarrollada en la cara lingual. Carece de cíngulos en todas sus caras. Son trirradiculados, con una raíz mesial, una distal y otra lingual. Difieren de Bison en que la zona de contacto entre la corona y la raíz es rectangular; en que, en ocasiones, puede tener un islote de 
esmalte en la superficie oclusal en las piezas muy gastadas; en que la columna interlobular, el entostilo, es larga, puede llegar a la base de la corona y puede tener una cierta convexidad próxima a la superficie oclusal; y en que en vista bucal, el mesostilo tiene una convexidad más o menos marcada en la parte superior (Jaubert et al., 1990). Asimismo, la sección a nivel del cuello es cuadrangular en Bos y trapezoidal en Bison (Castaños, 1988). Las categorías empleadas en este caso son: $\mathrm{M}^{1-2}, \mathrm{M}^{1}, \mathrm{M}^{2}$ y $\mathrm{M}^{3}$.

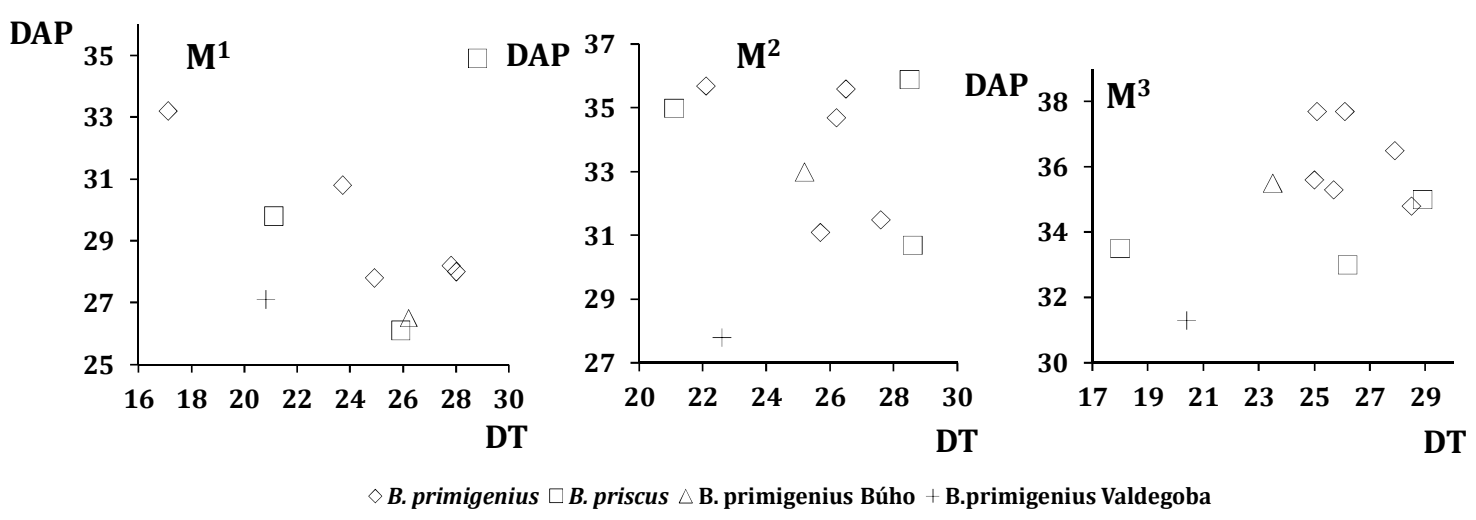

Figura V.11.3. Diagramas bivariantes de los molares superiores permanentes: DAP (diámetro anteroposterior) y DT (diámetro transversal). Bos primigenius de Biache-Saint-Vaast (Auguste, 1995), Bau de l'Aubesier (Guadelli, 1987; Fernández, 2001), Livernon (Slott-Moller 1990), Chinchon 2 (Crégut-Bonnoure, 1992c) y Combe Grenal (Guadelli, 1987). Bison priscus de Jaurens (Guérin y Valli, 2000), Marcamps (SlottMoller 1990), I’l skaya (Guérin y Valli, 2000) y Ènlène (Lalande, 1986).

M1: en vista bucal, los bordes anterior y posterior son paralelos. En el borde posterior, la zona de contacto entre la corona y la raíz forma un ángulo agudo que no presenta el segundo molar superior. Son más pequeños que los otros dos molares aunque el DTa es parecido al del $\mathrm{M}^{3}$ (tabla V.1.11). La columna interlobular es larga, más que en el $\mathrm{M}^{2}$, alcanza la base de la corona y es fuertemente convexa en la zona cercana a la superficie oclusal. Los bordes bucal y lingual son subparalelos. Las piezas de la Cueva del Búho tienen un tamaño similar a la del Bison priscus de Marcamps pero, al igual que los restos de la Cueva de Valdegoba, están dentro del rango de Bos primigenius (figura V.11.3).

M2: tiene los estilos marcados y las columnas interestilares largas y que alcanzan la base de la corona. Cerca de la superficie oclusal, esta columna, presenta una convexidad acentuada. Tiene los bordes lingual y bucal subparalelos. Carecen de islote central de esmalte. Métricamente, son más grandes que los $\mathrm{M}^{1}$ pero más pequeños que el $\mathrm{M}^{3}$ (tabla V.11.1). El resto de la Cueva del Búho está dentro del rango del uro. Por otra parte, la pieza de la Cueva de Valdegoba es más pequeña que las registradas en otros B. priscus y $B$. primigenius (figura V.11.3).

M1-2: se han recuperado dos piezas. Tienen la columna interlobular larga y alcanza la base de la corona. Los bordes lingual y bucal son subparalelos. La sección transversal del diente es cuadrangular.

M3: tienen los estilos y las columnas estilares bien marcadas. El metastilo se encuentra proyectado hacia el extremo posterior al no tener contacto con ningún diente en esta zona. En vista bucal, vemos que el diente tiene una apariencia más rectangular que los otros dos molares superiores. El metastilo forma una curva hacia la raíz que no presentan los otros dos molares. En vista lingual, la columna interlobular se encuentra fragmentada en su parte inferior en uno de los casos, mientras que en el otro aparece completa y muy desarrollada, alcanzando la base de la corona. Son más grandes que los otros dos molares (tabla V.11.1). El diente de la Cueva de Valdegoba es más pequeño que el de otros uros y bisontes. Por otro lado, la pieza de la Cueva del Búho está dentro del rango de Bos primigenius y es más largo pero más estrecho que el de los Bison priscus comparados (figura V.11.3). 
Tabla V.11.1

Medidas tomadas en los dientes de Bos primigenius

\begin{tabular}{|c|c|c|c|c|c|c|c|c|c|c|c|c|}
\hline & & & Lado & DAP & DAPb & DTa & DTp & DT & DTb & $\mathbf{H}$ & Ha & Hp \\
\hline $\mathbf{M}_{1-2}$ & Valdegoba & Vb-sp-286 & $\mathrm{i}$ & 33,0 & & 23,3 & 24,2 & 17,0 & & & & \\
\hline $\mathbf{M}_{1-2}$ & Valdegoba & Vb-sp-299 & d & 34,5 & & & & & & & & \\
\hline $\mathbf{M}_{1-2}$ & Valdegoba & Vb-sp-295 & d & 32,9 & 29,8 & 20,2 & 20,9 & 18,5 & 20,8 & & 35,2 & 40,0 \\
\hline $\mathbf{M}_{1-2}$ & Valdegoba & Vb-sp-292 & d & 33,0 & 26,5 & 19,3 & 20,4 & 17,7 & 18,1 & & 32,8 & 35,4 \\
\hline $\mathbf{M}_{1-2}$ & Valdegoba & Vb-sp-285 & $\mathrm{i}$ & 32,8 & 24,0 & 24,0 & 24,9 & 19,0 & & & 48,0 & 45,5 \\
\hline $\mathbf{M}_{1-2}$ & Valdegoba & Vb-sp-298 & d & 34,5 & & & 22,3 & 17,9 & & & & \\
\hline $\mathbf{P}^{2}$ & Valdegoba & Vb-sp-3183 & d & 14,7 & 13,4 & 9,8 & 11,2 & 10,9 & 11,3 & 17,5 & & \\
\hline $\mathbf{P}^{2}$ & Valdegoba & Vb-sp-3195 A & $\mathrm{i}$ & & & & & 10,3 & & & & \\
\hline $\mathbf{P}^{2}$ & Cueva del Búho & 6618Q & d & 19,3 & 19,1 & 12,1 & 17,2 & 14,2 & 17,2 & 22,8 & & \\
\hline $\mathbf{P}^{3}$ & Valdegoba & Vb-sp-309 & $\mathrm{i}$ & 20,0 & 16,2 & 18,9 & 21,9 & 17,5 & 16,1 & 20,0 & & \\
\hline $\mathbf{P}^{3}$ & Valdegoba & Vb-sp-302 & d & 18,7 & & 24,0 & 24,6 & & 21,5 & 11,9 & & \\
\hline $\mathbf{P}^{3}$ & Valdegoba & Vb-sp-3180 & d & 17,8 & 14,2 & 11,8 & 15,5 & 12,0 & 13,2 & 25,2 & & \\
\hline $\mathbf{P}^{3}$ & Cueva del Búho & $6616 Q$ & d & 20,3 & 13,3 & 21,4 & 21,9 & 20,3 & 21,9 & 17,8 & & \\
\hline $\mathbf{P}^{3}$ & Cueva del Búho & $6621 Q$ & $\mathrm{i}$ & 19,5 & 15,7 & 21,6 & 24,9 & 26,4 & 24,9 & 15,0 & & \\
\hline $\mathbf{P}^{4}$ & Valdegoba & Vb-sp-303 & d & 17,1 & 15,3 & 20,7 & 21,6 & 20,5 & 20,1 & & & \\
\hline $\mathbf{P}^{4}$ & Valdegoba & Vb-sp-3182 & d & 15,9 & 16,2 & 16,1 & 16,3 & 11,3 & 16,7 & 24,7 & & \\
\hline $\mathbf{P}^{4}$ & Valdegoba & Vb-sp-3194 & d & 19,5 & 17,3 & 11,4 & 19,1 & 17,6 & 16,7 & & & \\
\hline $\mathbf{P}^{4}$ & Valdegoba & Vb-sp-3190 & d & 23,1 & & 21,8 & 21,4 & 20,2 & & & & \\
\hline $\mathbf{M}^{1}$ & Valdegoba & Vb-sp-3184 A & d & & & & & 17,0 & & & & \\
\hline $\mathbf{M}^{1}$ & Valdegoba & Vb-sp-3196 & $\mathrm{i}$ & 27,4 & 20,2 & 20,7 & 19,3 & 16,9 & 21,0 & & 38,1 & 38,4 \\
\hline $\mathbf{M}^{1}$ & Cueva del Búho & $6503 Q$ & $\mathrm{i}$ & 26,5 & 20,8 & 26,2 & 26,2 & 21,5 & 26,2 & & 24,7 & 22,4 \\
\hline $\mathbf{M}^{2}$ & Valdegoba & Vb-sp-3184 B & d & 26,5 & & & & 16,3 & & & & \\
\hline $\mathbf{M}^{2}$ & Valdegoba & Vb-sp-3188 & d & 27,6 & 21,5 & 22,5 & 21,2 & 15,8 & 22,4 & & 47,3 & 46,1 \\
\hline $\mathbf{M}^{2}$ & Cueva del Búho & 6503Q & $\mathrm{i}$ & 33,0 & 27,9 & & & 25,2 & & & & \\
\hline$M^{1-2}$ & Valdegoba & Vb-sp-290 & $\mathrm{i}$ & 27,9 & 25,6 & 25,9 & 24,7 & 23,8 & 24,6 & & 15,9 & 17,5 \\
\hline $\mathbf{M}^{1-2}$ & Valdegoba & Vb-sp-285 & d & 32,8 & 24,2 & 24,5 & 24,2 & 23,2 & 23,8 & & 46,7 & 47,5 \\
\hline $\mathbf{M}^{1-2}$ & Valdegoba & Vb-sp-286 & d & 33,0 & & 24,2 & & 23,3 & 24,0 & & 50,1 & \\
\hline $\mathbf{M}^{1-2}$ & Cueva del Búho & $6617 Q$ & $\mathrm{i}$ & 23,0 & 22,4 & 22,8 & 24,6 & 20,8 & 24,6 & & 10,1 & 12,4 \\
\hline$M^{1-2}$ & Cueva del Búho & $6505 Q$ & $\mathrm{i}$ & 33,4 & 25,1 & 24,9 & 19,9 & 20,6 & 25,3 & & 47,1 & 46,5 \\
\hline $\mathbf{M}^{3}$ & Valdegoba & Vb-sp-288 & $\mathrm{i}$ & 35,8 & 36,9 & 29,4 & 28,7 & 24,5 & 28,8 & & 46,7 & 47,6 \\
\hline $\mathbf{M}^{3}$ & Valdegoba & Vb-sp-289 & $\mathrm{i}$ & 35,4 & & 30,1 & 28,0 & 19,1 & 29,7 & & & 53,4 \\
\hline $\mathbf{M}^{3}$ & Valdegoba & Vb-sp-306 & d & 34,9 & & & & 19,6 & & & & \\
\hline $\mathbf{M}^{3}$ & Valdegoba & Vb-sp-3184 C & d & 24,4 & & 21,6 & 18,2 & 15,6 & 22,4 & & & \\
\hline $\mathbf{M}^{3}$ & Valdegoba & Vb-sp-3186 & $\mathrm{i}$ & 25,1 & 26,5 & 21,3 & 18,7 & 14,6 & 21,7 & & 47,7 & 44,3 \\
\hline $\mathbf{M}^{3}$ & Valdegoba & Vb-sp-299 & d & 34,9 & & & & & & & 47,7 & 44,3 \\
\hline $\mathbf{M}^{3}$ & Cueva del Búho & $6504 Q$ & d & 37,5 & 38,2 & 27,8 & 27,7 & 25,6 & 27,7 & & 50,5 & 48,1 \\
\hline $\mathbf{M}^{3}$ & Cueva del Búho & $6503 Q$ & $\mathrm{i}$ & 33,6 & 33,8 & 27,4 & 25,0 & 21,5 & 27,4 & & 45,9 & 45,3 \\
\hline
\end{tabular}

Metacarpos (lámina V.11.1: 9) (tabla V.11.2): por lo general, estas piezas están muy fragmentadas o con un grado de concreción muy alto por lo que no se pueden observar muchas características. Sin embargo, tienen la superficie articular proximal con una depresión medial muy marcada. Presentan un tubérculo medial marcado y, la superficie que articula con el unciforme, tiene una forma cuadrangular que además presenta una ligera concavidad en el borde lateral. El borde medial es recto. Difieren de Bison por la continuidad que se observa entre la epífisis y la diáfisis. En Bos, este límite, es recto, es decir que no hay cambio de dirección (Sala et al., 2010 y referencias incluidas en él).

Tabla V.11.2

Medidas tomadas en los metápodos de Bos primigenius (1aㅡ parte)

\begin{tabular}{|c|c|c|c|c|c|c|c|c|c|c|c|c|}
\hline & & & Lado & GL & BP & DP & SD & SDD & BD & DD & DL & DM \\
\hline Metacarpo & Valdegoba & Vb-sp-4668 & $\mathrm{d}$ & & 75,1 & 50,2 & & & & & & \\
\hline Metacarpo & Valdegoba & Vb-89.L13.Ca.T6.1 & d & & 71,7 & 42,3 & & & & & & \\
\hline Metacarpo & Búho & $6635 Q$ & $d$ & & 76,1 & 45,4 & 42,8 & 34,6 & & & & \\
\hline Metacarpo & Búho & 6420Q & $\mathrm{i}$ & & & & & & 87,7 & 48,3 & 45,6 & 48,3 \\
\hline Metacarpo & Búho & $6421 Q$ & d & & 75,9 & 47,3 & & & & & & \\
\hline
\end{tabular}


Tabla V.11.2

Medidas tomadas en los metápodos de Bos primigenius (2 2 parte)

\begin{tabular}{|c|c|c|c|c|c|c|c|c|c|c|c|c|}
\hline & & & Lado & GL & BP & DP & SD & SDD & BD & DD & DL & DM \\
\hline Metatarso & Valdegoba & Vb-sp-4692 & & & 67,9 & & & & & & & \\
\hline Metatarso & Valdegoba & Vb-06.N2.J12.Ca-Co.85-90.6 & $d$ & 284,3 & 62,3 & & 40,7 & 43,8 & 75,4 & 35,9 & & \\
\hline Metatarso & Búho & $6422 Q$ & $\mathrm{~d}$ & & 74,0 & 68,5 & & & & & & \\
\hline Metatarso & Búho & $6425 Q$ & d & & 60,1 & 62,7 & & & & & & \\
\hline Metatarso & Búho & 66380 & $\mathrm{i}$ & 282,1 & 67,9 & 62,0 & 49,7 & 46,6 & 72,0 & 42,5 & 39,5 & 42,5 \\
\hline
\end{tabular}

Tibias (lámina V.11.1: 7) (tabla V.11.3): la superficie articular distal tiene dos surcos separados por una cresta marcada. Estos surcos son paralelos y siguen una orientación anteroposterior a diferencia de los caballos. El borde medial tiene dos carillas que articulan con el maléolo. Dichas carillas están conectadas entre sí, siendo la anterior estrecha y plana y, la posterior más o menos redondeada. Difieren de Bison priscus por presentar las carillas articulares del maléolo unidas, planas y estrechas mientras que en el bisonte están separadas y son más o menos circulares (Sala et al., 2010).

Tabla V.11.3

Medidas tomadas en las tibias de Bos primigenius

\begin{tabular}{llccccc}
\hline & & Lado & SD & CD & BD & DD \\
\cline { 3 - 7 } Valdegoba & Vb-sp-5578 & d & & & 73,5 & 56,9 \\
Cueva del Búho & $6641 Q$ & $\mathrm{i}$ & 70,8 & 48,5 & 94,2 & 77,8 \\
\hline
\end{tabular}

Astrágalos (lámina V.11.1: 3) (tabla V.11.4): del surco plantar, que separa las superficies articulares del calcáneo y del escafocuboides, forma un ángulo de $90^{\circ}$ en la zona plantar y media del hueso. Carecen de la carilla que articula con el escafocuboides, algo que sí que tiene Bison (Sala et al., 2010). La faceta articular lateral, para el calcáneo, es más larga próximo-distalmente. Los resultados del índice de la faceta articular lateral (IFAL) y de la tróclea distal (ITD) se solapan. En Bos, para el primero, Bibikova (1958), Stampfli (1963), Altuna (1972) y Buitrago (1972) establecen un rango de entre los 43,3 y 69,4. Para el segundo, proponen unos valores comprendidos entre 81,2 y 122,7. Por otra parte, Bibikova (1958) y Stampfli (1963) establecen unos rangos para estos índices en Bison de 41,6 a 56,6 en el primero y de 73,3 a 100,0 en el segundo. En la pieza de la Cueva del Búho el índice de la faceta articular lateral está dentro del rango de Bos y el índice de la trócela distal lo está dentro del rango tanto de los bisontes como de los uros. En las piezas de la Cueva de Valdegoba el índice de la faceta articular lateral y el de la tróclea distal presentan una gran variabilidad. Ambos muestran unos valores que se encuentran dentro de los rangos de Bos y de Bison, salvo el Vb-06.N2.J12.Ca-Cd.95-100.5, Vb-91.C3.N8.T11-12.5 y Vb-sp-4671 en los que únicamente están dentro de los de Bos primigenius.

Tabla V.11.4

Medidas tomadas en los astrágalos de Bos primigenius

\begin{tabular}{llcccccccccc}
\hline & & Lado & GLl & GLm & DL & DM & BP & BD & ATPL & IFAL & ITD \\
\cline { 3 - 10 } Valdegoba & Vb-sp-4673 & $\mathrm{i}$ & 90,8 & 84,1 & 51,6 & 56,0 & 62,5 & 62,5 & 62,4 & 43,3 & 98,7 \\
Valdegoba & Vb-sp-4679 & $\mathrm{d}$ & 94,3 & 87,8 & 56,2 & 54,8 & 62,5 & 65,2 & 58,1 & & 88,8 \\
Valdegoba & Vb-sp-4671 & $\mathrm{d}$ & 89,1 & 8,1 & 51,8 & 51,2 & 55,8 & 56,8 & 52,2 & & 107,5 \\
Valdegoba & Vb-06.N2.J12.Ca-Cd.95-100.5 & $\mathrm{d}$ & 89,0 & 84,2 & 50,3 & 56,7 & 62,7 & 66,5 & & 61,0 & 89,3 \\
Valdegoba & Vb-06.N2.J12.Ca-Cd.85-90.3 & $\mathrm{d}$ & 93,1 & 83,7 & 50,4 & 56,7 & 60,2 & 65,8 & 59,8 & 47,8 & 91,5 \\
Valdegoba & Vb-91.C3.N8.T11-12.5 & $\mathrm{d}$ & 92,4 & 83,8 & 53,5 & 54,7 & 62,1 & 65,1 & 54,7 & 57,4 & 89,7 \\
Cueva del Búho & 6647Q & $\mathrm{i}$ & 88,7 & 82,8 & 49,1 & 50,1 & 56,9 & 57,4 & 55,6 & 61,8 & 93,3 \\
\hline
\end{tabular}

Calcáneos (lámina V.11.1: 10) (tabla V.11.5): la morfología de la cara que articula con el escafocuboides se estrecha en la parte superior y en la inferior a diferencia de otros bovinos como Bison. 
Los valores del índice de la longitud articular externa (ILAE) y de la anchura articular externa (IAAE) están en Bos primigenius, entre 70,9 y 80,9 para el primero y 80,0 y 118,1 para el segundo (Lehmann, 1949; Stampli, 1963). Para Bison priscus, los rangos para los mismos índices se situarían entre 80,3 y 96,9 para el primero y 64,0 y 100,0 para el segundo (Lehmann, 1949; Stampli, 1963). La pieza de la Cueva del Búho tiene unos valores similares a los de Bos primigenius. Por otra parte, las de la Cueva de Valdegoba tienen los valores de ambos índices incluidos dentro de los rangos de Bos primigenius, salvo $\mathrm{Vb}$-sp4687 que se encuentra también dentro de los valores de Bison priscus.

Tabla V.11.5

Medidas tomadas en los calcáneos de Bos primigenius

\begin{tabular}{llccccc}
\hline & & Lado & GL & GB & ILAE & IAAE \\
\cline { 3 - 7 } Valdegoba & Vb-sp-4687 & $\mathrm{d}$ & 205,6 & 85,6 & 83,5 & 80,5 \\
Valdegoba & Vb-sp-4675 & $\mathrm{d}$ & & 83,1 & 79,9 & 81,0 \\
Valdegoba & Vb-sp-5258* & $\mathrm{d}$ & 119,1 & 44,7 & 78,0 & 89,6 \\
Valdegoba & Vb-sp-5622* & $\mathrm{i}$ & & 63,9 & & \\
Cueva del Búho & $6413 \mathrm{Q}$ & $\mathrm{d}$ & 127,7 & 53,2 & 79,6 & 90,1 \\
\hline
\end{tabular}

* Piezas que no tienen la epífisis proximal fusionada.

Metatarsos (lámina V.11.1: 8) (tabla V.11.2): en la epífisis proximal, las facetas que articulan con el gran cuneiforme y con el escafocuboides están separadas. Carece de un tubérculo medial en el borde posterior medial. El límite lateral, entre la diáfisis y la epífisis distal, es continuo lo que permite diferenciarlo de Bison (Sala et al., 2010).

\subsubsection{Edad de muerte}

La mayor parte de los restos corresponden a piezas dentales. Sin embargo, no se han recuperado dientes sin desgaste por lo que no podemos aplicar ni las ecuaciones de Klein et al., (1984) ni el modelo de desgaste. Se han empleado la edades de erupción dental, utilizando eso sí, datos de la especie actual Bos taurus (Wegrzyn et al, 1984).

Cueva de Valdegoba: se han localizado dos maxilares (Vb-sp3184 y Vb-sp-3196), ambos con la serie $\mathrm{M}^{1}-\mathrm{M}^{3}$. La edad estimada es de al menos 24 meses, fecha de erupción del $\mathrm{M}_{3}$. No se puede indicar si se trata de ejemplares juveniles o de adultos.

Cueva del Búho: al menos uno de los ejemplares tendría 13 meses, edad de erupción del $\mathrm{M}^{2}$. Otro de los individuos tendría por lo menos 30 meses, a partir del $\mathrm{P}^{4}$. No podemos especificar si se trataría de ejemplares juveniles o adultos.

\subsubsection{Número Mínimo de Individuos}

Para estimarlo se ha empleado la pieza más frecuente. En la Cueva de Valdegoba se han identificado 6 individuos, a partir de los astrágalos derechos. En la Cueva del Búho se han registrado al menos 2 individuos a partir de los M $^{1-2}$ izquierdos, también se ha recuperado $1 \mathrm{M}^{1}$ y $1 \mathrm{M}^{2}$ izquierdo.

\subsubsection{Discusión}

El material recuperado en la Cueva del Búho y en la Cueva de Valdegoba presenta características de la subfamilia Bovinae como los dientes de coronas altas, selenodontos, cúspides aisladas, columnas interlobulares de gran tamaño y carentes de cíngulos. La definición del género resulta complicada debido a la ausencia de restos tradicionalmente diagnósticos como cráneos y los núcleos óseos de los cuernos. Sin embargo, se han 
desarrollado una serie de manuales que nos permiten separar los dos grandes géneros de bóvidos, Bos y Bison. Estas referencias emplean tanto el material dental (Jaubert et al., 1990) como, en mayor medida, restos postcraneales (Schertz, 1936; Bibikova, 1958; Altuna, 1972; Brugal, 1984; Buitrago, 1992; Gee, 1993; Álvarez-Lao, 2007 y Sala et al., 2010). Caracteres como el gran tamaño de las columnas interlobulares en los molares superiores e inferiores; los bordes linguales y bucales subparalelos de los premolares superiores; el no presentar un cambio de dirección entre la epífisis y la diáfisis en los metápodos; la fusión de las caras que articulan con el maléolo en las tibias y la forma estrecha de la cara que articula con el maléolo en los calcáneos nos permiten descartar a Bison priscus y asignar los restos a Bos primigenius. 


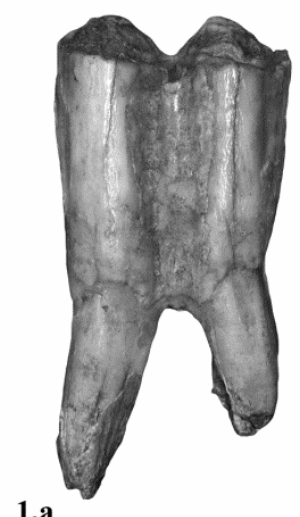

1.a

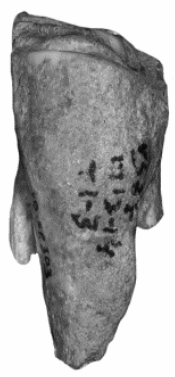

4.a

4.b

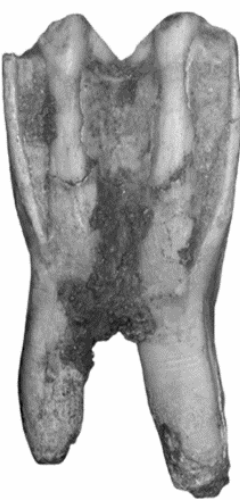

1.b

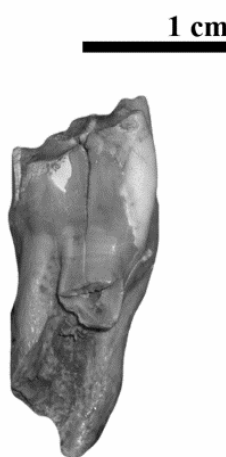

5.

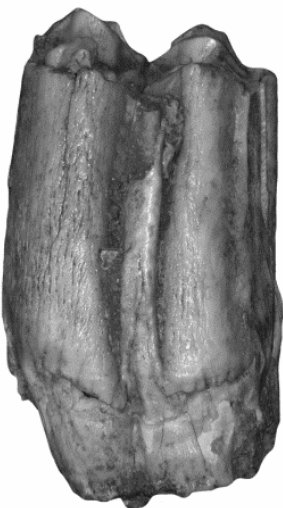

2.
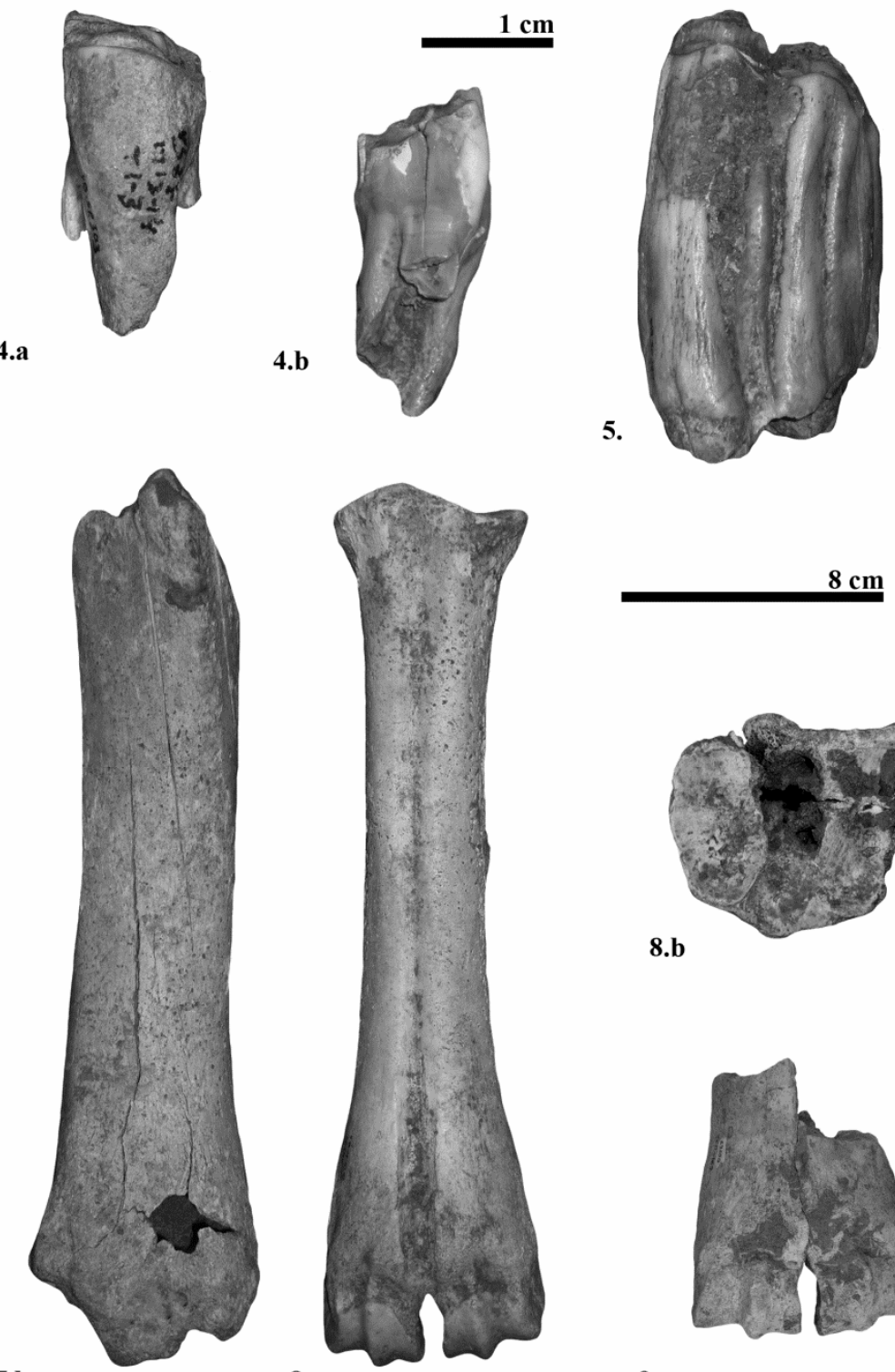

7.b

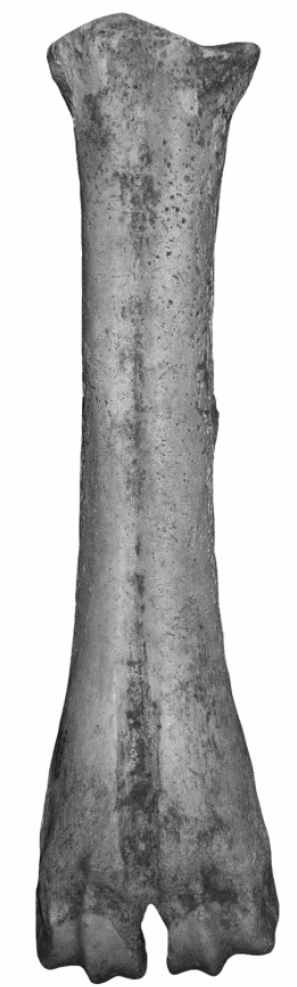

8.a

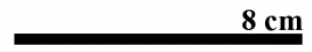

8.b

9.

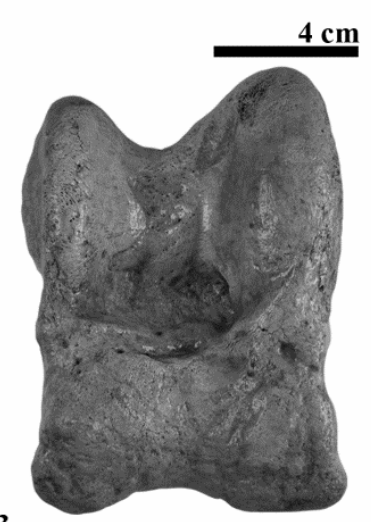

3.

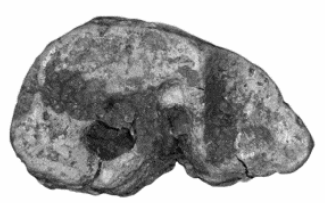

6.
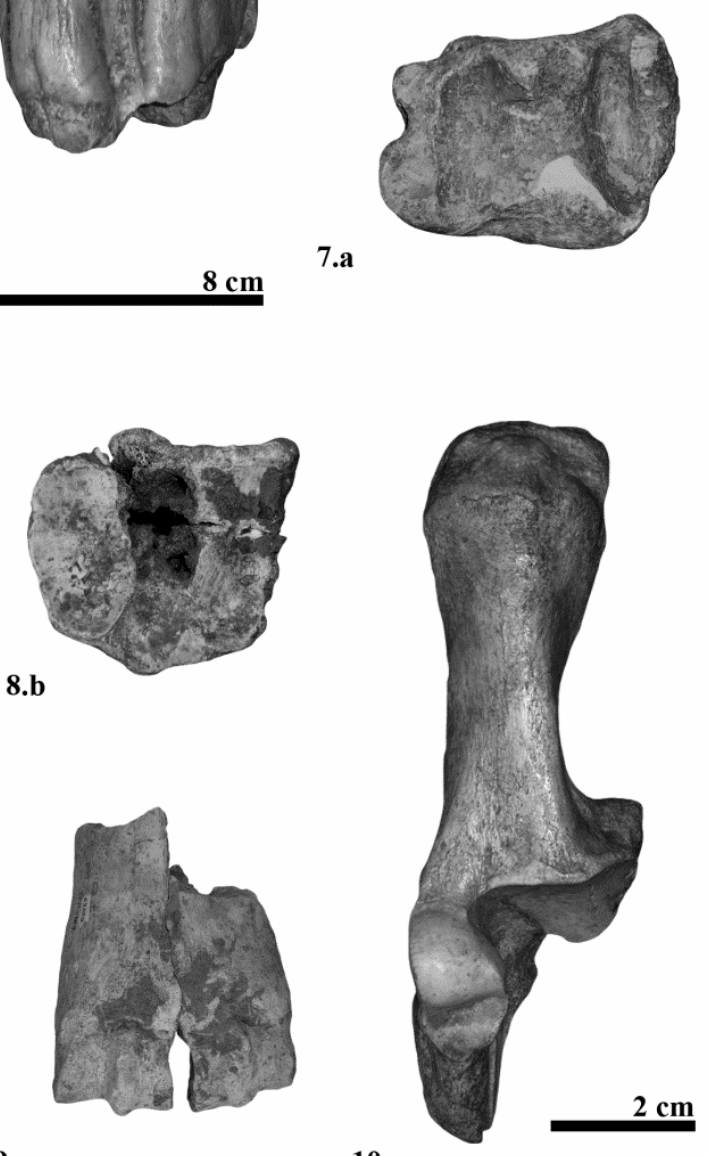

10.

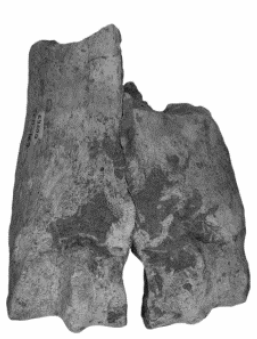

Lámina V.11.1. Bos primigenius proveniente de los yacimientos de la Cueva de Valdegoba (sigla Vb) y la Cueva del Búho (sigla Q). 1) Vb-sp-292 - M $\mathrm{M}_{1-2}$ derecho: 1.a cara bucal; 1.b cara lingual. 2) Vb-sp-288 - M³ izquierdo cara lingual. 3) 6647Q - Astrágalo izquierdo. 4) Vb-sp-303 - P4 derecho: 4.a cara lingual; 4.b cara mesial. 5) Vbsp-289 - M³ izquierdo cara lingual. 6) Vb89.L13.Ca.T6.1 - Metacarpo derecho. 7) Vb-sp-5578 - Tibia derecha: 7.a superficie articular distal; 7.b cara anterior. 8) Vb06.N2.J12.Ca-Cb.85-90.6 - Metatarso derecho: 8.a cara anterior; 8.b superficie articular proximal. 9) 6420Q - Metacarpo izquierdo. 10) Vb-sp-4687 - Calcáneo derecho. 


\subsection{Bison priscus}

Orden Artiodactyla Owen, 1848

Familia Bovidae Gray, 1821

Subfamilia Bovinae Gray, 1821

Género Bison Smith, 1827

Especie Bison priscus Bojanus, 1827

\subsubsection{Generalidades}

La tribu Bovini incluye los géneros europeos Leptobos, Bubalus, Bos y Bison, estando estas dos últimas presentes en Europa durante el Pleistoceno Medio y Tardío de manos de Bos primigenius, Bison shoetensacki y Bison priscus. Los uros, B. primigenius, y el bisonte, $B$. priscus, sobreviven hasta el Holoceno.

Bibi $(2007,2009)$ sugiere un origen asiático para la tribu, que posteriormente se dispersaría primero hacia África y después hacia Europa. El registro africano más antiguo se encuentra en Toros-Menalla (Vignaud et al., 2002), alrededor de los 7 Ma; y el europeo en el Plioceno Temprano (Gromolard, 1980). Durante el Plioceno Tardío, entra en Europa occidental Leptobos, reemplazando a Parabos (Garrido, 2008). Este género parece estar representado por dos líneas: la primera, la línea L. etruscus, caracterizada por unos cuernos orientados posteriormente; y la segunda, la línea L. elatus, caracterizada por unos cuernos proyectados hacia afuera (Garrido, 2008).

El primer representante del género Bison en Europa es B. degiulii, presente ya en Pirro Nord hace 1,2 Ma. Esta especie tiene unos frontales grandes y unos metápodos relativamente robustos (De Giuli et al., 1987). Este taxón evoluciona, probablemente, hacia B. schoetensacki, ya conocido en Vallonnet (subcron Jaramillo; Van der Made, 2001). Bison menneri es una especie grande, con los metápodos gráciles (Sher, 1997) que ya aparecen en Untermassfel. Bison voigtstedtensis podría ser un descendiente más pequeño. Van der Made et al., (2013) sugiere la presencia de un gran bóvido, probablemente Bison, en el TE 9 de la Sima del Elefante, Atapuerca. Este bóvido, más grande que B. degiulii y Leptobos, podría tratarse de un nuevo taxón, por lo que la diversidad de este género en torno al millón de años sería mayor de lo que se pensaba hasta ahora. Bison priscus entra en Europa en el Pleistoceno Medio y ya está presente en l'Arago, Mosbach y Taubach (Magniez, 2010), alcanzando su mayor distribución en el Pleistoceno Tardío, cuando también aparecen restos en América del Norte (Zazula et al., 2009).

\subsubsection{Material}

El material empleado en la descripción y en la comparación es el siguiente:

Cueva de Valdegoba: 2 restos: 1 tibia y 1 metacarpo.

Cueva del Búho: 7 piezas: 1 tibia, 2 astrágalos y 4 metatarsos.

\subsubsection{Descripción y comparación}

Se describen a continuación los restos recuperados en la Cueva de Valdegoba y en la Cueva del Búho. Se emplean los criterios que aparecen en Sala et al., (2010) para poder comparar los restos de Bison con los de Bos.

Metacarpos (lámina V.12.1: 2) (tabla V.12.1): este hueso tiene una sección subcilíndrica lo que permite asignarla a un metacarpo y no a un metatarso. El borde lateral de esta región 
no es continuo con el de la diáfisis, sino que se observa un cambio de dirección, esto permite diferenciarlo de Bos.

Tibias (lámina V.12.1: 1) (tabla V.12.1): la orientación de los surcos presentes en la superficie articular distal es anteroposterior lo que nos permite diferenciarlas de las de los équidos. Difieren de Bos en que las caras que articulan con el maléolo están separadas.

Astrágalos (lámina V.12.1: 3) (tabla V.12.1): las dos piezas identificadas tienen el surco plantar ligeramente arqueado y termina en el borde lateral formando un ángulo de entre 100 a $110^{\circ}$ lo que permite diferenciarlo de Bos en el que no suele superar los $90^{\circ}$. La carilla que articula con el escafocuboides separa las superficies articulares del calcáneo y del escafocuboides. La cara que articula con el calcáneo en el borde lateral es más larga anteroposteriormente, mientras que en Bos es más larga próximo-distalmente.

Tabla V.12.1

Medidas tomadas en Bison priscus

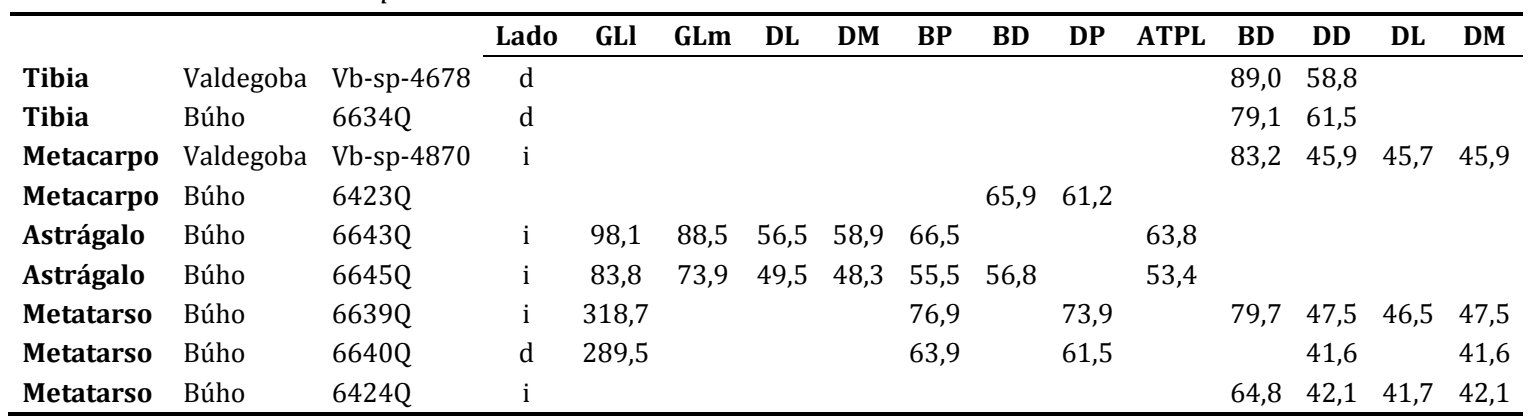

Metatarsos (lámina V.12.1: 4) (tabla V.12.1): las piezas que conservan la epífisis proximal tienen, en la superficie articular proximal, las carillas que articulan con el gran cuneiforme y con el escafocuboides, simétricas y unidas, a diferencia de Bos donde están separadas. El borde lateral de la diáfisis y de la epífisis distal tienen orientaciones diferentes, mientras que en Bos son continuas (Sala et al., 2010).

\subsubsection{Edad de muerte}

En este caso no se puede determinar la edad ya que todos los restos, salvo los astrágalos, están fragmentados, no pudiéndose observar si las epífisis están fusionadas o no. El astrágalo no se utiliza ya que es difícil diferenciar si es una pieza inmadura o madura.

\subsubsection{Número Mínimo de Individuos}

Para determinarlos se han empleado las piezas más frecuentes. Todos corresponderían a ejemplares maduros. En la Cueva de Valdegoba sería 1, a partir de la tibia. En la Cueva del Búho, el MNI es 2 y se han determinado a partir de los metatarsos izquierdos.

\subsubsection{Discusión}

Los restos recuperados en los yacimientos de La Cueva del Búho y de la Cueva de Valdegoba presentan características propias de los artiodáctilos como los surcos distales con una orientación anteroposterior en las tibias o unos metápodos con dos cóndilos distales. Asimismo, los grandes surcos anteriores presentes en los metápodos y la 
robustez de estas piezas nos permiten asignarlos a la familia Bovidae. Los grandes bóvinos presentes en Europa occidental en el Pleistoceno Tardío corresponden a Bos y Bison. Caracteres como la separación de las caras que articulan con el maléolo en las tibias; el borde lateral alargado anteroposteriormente en la cara que articula con el calcáneo en el astrágalo; y el cambio de orientación entre la diáfisis y la epífisis distal en los metatarsos (Sala et al., 2010 y referencias incluidas en él) nos permiten descartar a Bos y asignar los restos a Bison priscus.

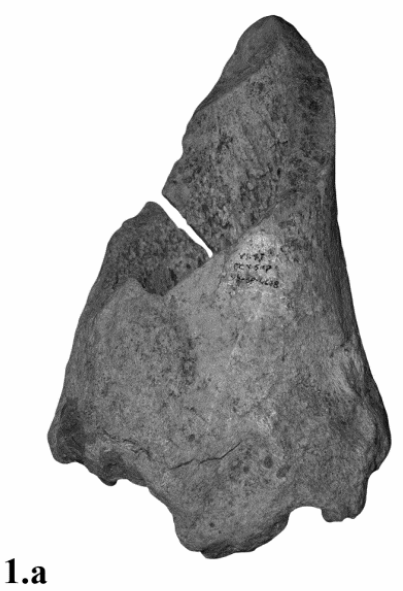

2.b

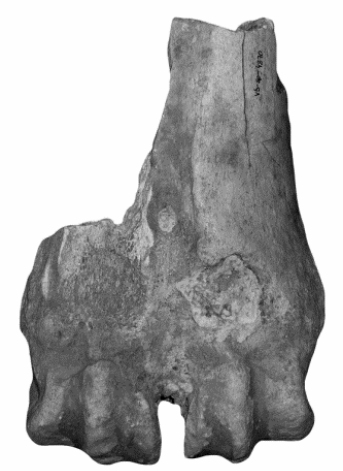

2.a

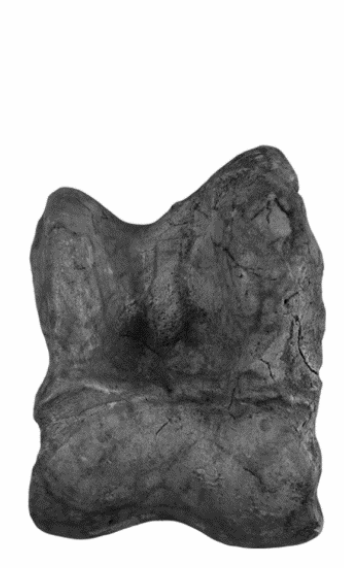

3.

$4 \mathrm{~cm}$

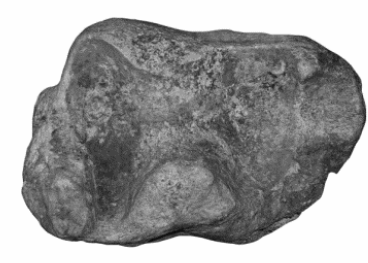

1.b
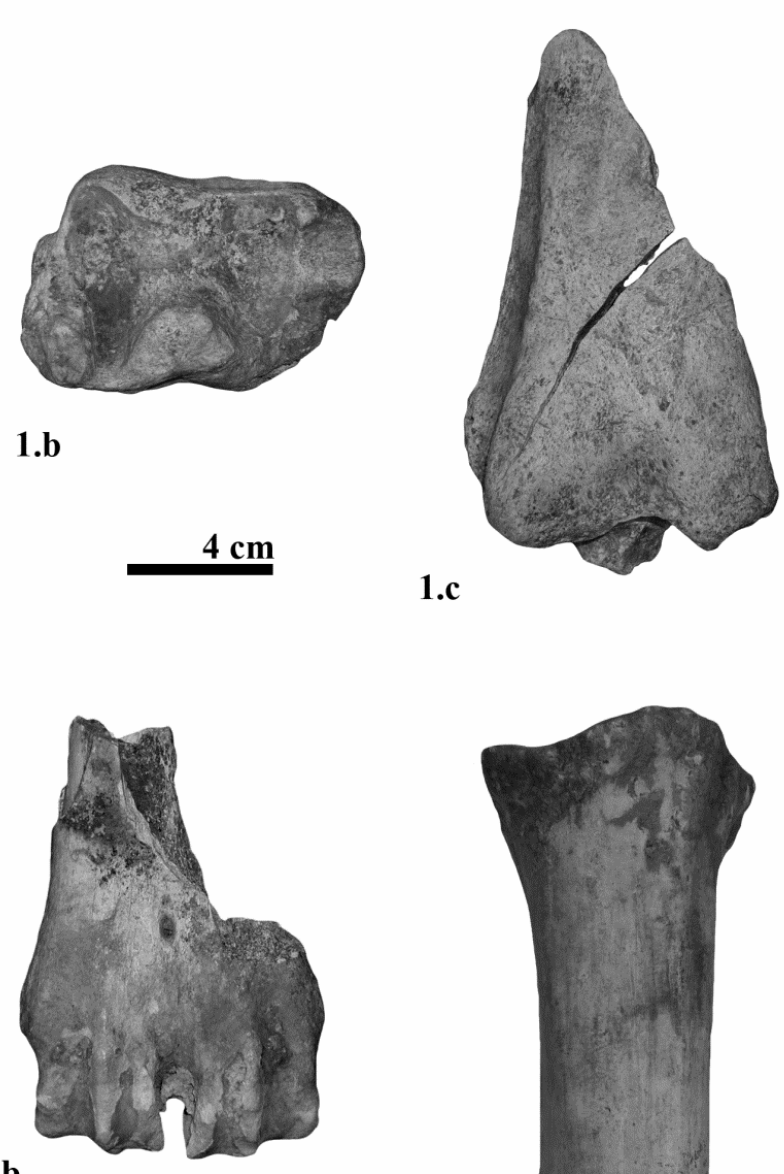

1.c

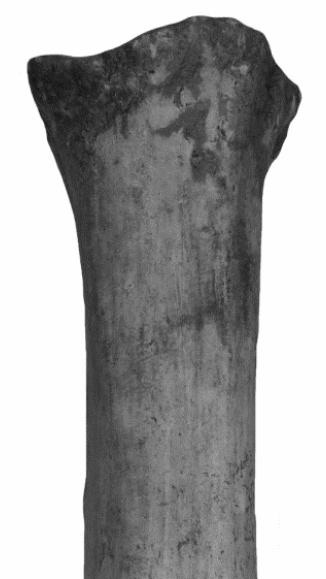

$4 \mathrm{~cm}$

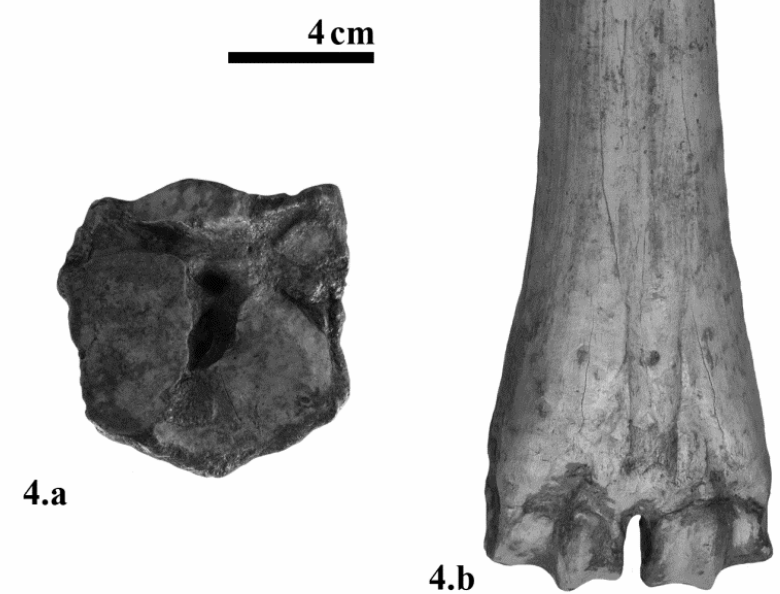

4.b

Lámina V.12.1. Bison priscus proveniente de los yacimientos de la Cueva del Búho (sigla Q) y de la Cueva de Valdegoba (sigla Vb). 1) Vb-sp-4678 - Tibia derecha: 1.a cara anterior; 1.b superficie articular distal; 1.c cara lateral. 2) Vb-sp-4870 - Metacarpo izquierdo: 2.a cara anterior; 2.b cara posterior. 3) 6645Q - Astrágalo izquierdo. 4) $6639 \mathrm{Q}$ - Metatarso izquierdo: 4.a superficie articular proximal; 4.b cara anterior. 


\subsection{Bos/Bison sp.}

Orden Artiodactyla Owen, 1848

Familia Bovidae Gray, 1821

Subfamilia Bovinae Gray, 1821

Género Bos/Bison sp.

\subsubsection{Generalidades}

La información aparece en los capítulos 5.11.1 y 5.12.1 por lo que no se repite aquí.

\subsubsection{Material}

En este apartado se han incluido todos los restos asignados a la familia Bovinae y que no han podido ser incluidos ni en Bos primigenius ni en Bison priscus. Los restos empleados en la descripción provienen de los yacimientos de la Cueva de Valdegoba, Cueva Millán y la Cueva del Búho.

Cueva de Valdegoba: 29 restos: 18 craneales y dentales y 11 postcraneales. Los craneales son: 3 fragmentos de cuernos, $1 \mathrm{dI}_{1}, 1 \mathrm{D}_{3}, 4 \mathrm{D}_{4}, 3 \mathrm{D}^{3}, 6 \mathrm{D}^{4}$. Los postcraneales incluyen: 2 metacarpos, 2 metatarsos, 2 falanges proximales, 2 falanges medias y 3 distales.

Cueva Millán: 2 restos: dos falanges proximales.

Cueva del Búho: 23 restos: 12 dientes y 11 postcraneales. Los dientes incluyen: $1 \mathrm{D}_{4}, 2 \mathrm{D}^{2}$, $1 \mathrm{D}^{4}, 3 \mathrm{I}_{1}, 1 \mathrm{I}_{2}$, un incisivo inferior sin identificar, $1 \mathrm{P}_{2}, 1 \mathrm{P}_{3}$ y un fragmento de molar inferior. Los restos postcraneales son: 2 metacarpos, 2 tibias, 1 astrágalo, 3 calcáneos y una falange proximal.

\subsubsection{Descripción}

El material descrito proviene de los yacimientos de la Cueva del Búho, la Cueva de Valdegoba y Cueva Millán.

Núcleos óseos de cuernos (lámina V.13.1: 1): los restos están muy fragmentados y no se han podido tomar medidas ni observar caracteres diagnósticos como la morfología de los surcos o de la base.

\section{Tabla V.13.1}

Medidas tomadas en los incisivos deciduales y permanentes de Bos/Bison sp.

\begin{tabular}{|c|c|c|c|c|c|c|c|c|c|}
\hline & & & Lado & DMD & DLL & Hli & Hla & Hmes & Hdist \\
\hline $\mathrm{dI}_{1}$ & Valdegoba & Vb-sp-2300 & $\mathrm{d}$ & 14,4 & 7,8 & 14,4 & 16,3 & 12,9 & 13,8 \\
\hline $\mathbf{I}_{1}$ & Búho & $6612 Q$ & $\mathrm{i}$ & 11,1 & 8,6 & 13,0 & 12,1 & 11,2 & 9,6 \\
\hline $\mathbf{I}_{1}$ & Búho & $6614 Q$ & d & 12,8 & 9,8 & 15,1 & 14,7 & 14,1 & 11,6 \\
\hline $\mathbf{I}_{1}$ & Búho & $6603 Q$ & $\mathrm{i}$ & 8,4 & 8,2 & 9,3 & 6,6 & 6,5 & 6,6 \\
\hline $\mathbf{I}_{2}$ & Búho & $6606 \mathrm{Q}$ & d & 11,0 & 9,1 & 14,3 & 12,5 & 10,8 & 9,9 \\
\hline
\end{tabular}

Incisivos deciduales (lámina V.13.1: 2) (tabla V.13.1): se trata de dientes con las coronas bajas y con forma de "pala". Están muy curvados lateralmente, carecen de surco en la cara lingual, tienen un cuello marcado y una raíz. La superficie oclusal está fragmentada por lo que no se pueden observar los caracteres morfológicos que nos permiten diferenciar Bos de Bison como las coronas más bajas y redondeadas de Bison con respecto a Bos (Jaubert et al., 1990). 
dI ${ }_{1}$ : se ha identificado una pieza que presenta el borde medial recto y la corona más o menos triangular lo que permite diferenciarlo de los otros dos incisivos deciduales.

Molares deciduales inferiores (lámina V.13.1: 3 y 4) (tabla V.13.2): dientes con las coronas bajas, cuellos marcados, sin cíngulos y con dos raíces: una mesial y otra distal que son finas y divergentes. El $\mathrm{D}_{2}$ y el $\mathrm{D}_{3}$ son similares a los permanentes pero, por lo general, son más largos y más estrechos (tablas V.13.2 y 4). El $\mathrm{D}_{4}$ tiene una apariencia trilobular debido al gran desarrollo del hipoconúlido. Se diferencia del $\mathrm{M}_{3}$ en que el diámetro transversal aumenta del lóbulo anterior al posterior.

Tabla V.13.2

Medidas tomadas en los molares deciduales inferiores de Bos/Bison sp.

\begin{tabular}{|c|c|c|c|c|c|c|c|c|c|c|c|c|c|}
\hline & & & Lado & DAP & DAPb & DTa & DTp & DTpp & DT & DTb & H & Ha & Нp \\
\hline $\mathrm{D}_{3}$ & Valdegoba & Vb-sp-3027 & d & 20,8 & 19,4 & 8,9 & 11,7 & 11,7 & 9,6 & 11,6 & 11,8 & & \\
\hline $\mathbf{D}_{4}$ & Valdegoba & Vb-sp-1322 & d & 39,9 & 32,2 & 13,6 & 15,0 & 16,0 & 11,8 & 15,6 & & 24,0 & \\
\hline$D_{4}$ & Valdegoba & Vb-sp-1321 & i & & & 9,8 & 11,0 & & & & & & \\
\hline $\mathbf{D}_{4}$ & Valdegoba & Vb-sp-1323 & d & 31,6 & 24,7 & 10,7 & 12,4 & 13,6 & 12,1 & 13,3 & & 17,0 & 19,8 \\
\hline $\mathbf{D}_{4}$ & Valdegoba & Vb-sp-1325 & d & 36,3 & 28,5 & 12,1 & 13,9 & 13,9 & 10,0 & 13,6 & & 24,0 & 28,0 \\
\hline $\mathbf{D}_{4}$ & Búho & $6505 Q$ & d & 42,5 & 31,9 & 13,0 & 14,6 & 14,8 & 10,3 & 14,9 & & 19,5 & 25,2 \\
\hline
\end{tabular}

D $_{3}$ : tiene un surco bucodistal muy marcado lo que le da una apariencia bilobulada. El protocónido está muy desarrollado y el paracónido se encuentra separado del parastilo por la paraprecrístida que define un pequeño surco en la cara bucal. El metacónido está unido al entocónido por la metapostcrístida. Por otra parte, está separado del metastílido por una hipopostfoseta de pequeño tamaño.

D4: sus coronas presentan una morfología selenodonta. Tiene las cúspides fusionadas lo que nos permite diferenciarlo de los cérvidos. Los estilos están poco marcados salvo en el lóbulo posterior en el que están muy proyectados. Tiene dos columnas interlobulares muy desarrolladas al igual que las columnas estilares de la cara lingual. Algunas piezas presentan una raicilla accesoria en posición central.

Tabla V.13.3

Medidas tomadas en los molares deciduales superiores de Bos/Bison sp.

\begin{tabular}{|c|c|c|c|c|c|c|c|c|c|c|c|c|}
\hline & & & Lado & DAP & DAPb & DTa & DTp & DT & DTb & H & Ha & Нp \\
\hline$D^{2}$ & Búho & 6377Q & $\mathrm{d}$ & 20,5 & & 11,1 & 12,5 & 10,6 & 12,5 & 17,4 & & \\
\hline $\mathbf{D}^{2}$ & Búho & $6624 Q$ & d & 23,6 & 20,7 & 13,8 & & 10,5 & 13,8 & 17,8 & & \\
\hline $\mathrm{D}^{3}$ & Valdegoba & Vb-sp-1324 & d & 28,0 & 24,3 & 15,8 & 19,3 & 16,5 & 18,9 & & 22,1 & 23,0 \\
\hline $\mathrm{D}^{3}$ & Valdegoba & Vb-sp-3195 B & $\mathrm{i}$ & & & & & 15,5 & & & 11,6 & 8,9 \\
\hline $\mathrm{D}^{4}$ & Búho & $6623 Q$ & $\mathrm{i}$ & 31,3 & & 22,3 & & 15,7 & 22,3 & & 26,2 & 26,4 \\
\hline $\mathrm{D}^{4}$ & Valdegoba & Vb-sp-287 & d & 30,8 & 22,7 & 16,6 & 16,7 & 18,2 & 24,0 & & 24,7 & 30,3 \\
\hline $\mathrm{D}^{4}$ & Valdegoba & Vb-sp-296 & i & 28,8 & & 19,8 & 17,8 & 15,8 & & & & \\
\hline $\mathrm{D}^{4}$ & Valdegoba & Vb-sp-297 & $\mathrm{i}$ & 30,8 & 24,7 & 24,2 & 23,8 & 18,4 & 24,5 & & 25,0 & 31,8 \\
\hline $\mathrm{D}^{4}$ & Valdegoba & Vb-sp-1320 & $\mathrm{i}$ & 29,7 & 20,9 & & 20,0 & 17,8 & & & & \\
\hline $\mathrm{D}^{4}$ & Valdegoba & Vb-sp-3181 & d & 20,8 & 19,0 & 19,0 & 18,8 & 16,8 & 19,5 & & 10,2 & 11,6 \\
\hline $\mathrm{D}^{4}$ & Valdegoba & Vb-sp-3195 C & $\mathrm{i}$ & & & & & 16,8 & & & 12,0 & 11,7 \\
\hline
\end{tabular}

Molares deciduales superiores (lámina V.13.1: 5) (tabla V.13.3): dientes con las coronas bajas, las cúspides fusionadas y morfología selenodonta. Tienen dos lóbulos, salvo el $\mathrm{D}^{2}$. Presentan estilos de desarrollos variables y tienen tres raíces: una mesial, una distal y otra lingual, aunque el $\mathrm{D}^{2}$ puede tener fusionadas la mesial y la lingual.

D2: piezas fuertemente asimétricas debido a que se estrechan mesialmente. El paracono y el metastilo están muy marcados. El surco lingual, definido por el protocono y el hipocono, está poco desarrollado. El surco bucal, entre el metacono y el paracono, está muy marcado. 
D3: diente fuertemente asimétrico debido a que el diámetro anteroposterior del lóbulo mesial es mayor que el del lóbulo distal. Además, el distal está más proyectado lingualmente lo que permite diferenciarlo del $\mathrm{D}^{4} \mathrm{y}$ del resto de molares superiores permanentes. Tiene una columna interlobular desarrollada. No tiene cíngulo en la cara anterior y la raíz lingual descansa sobre ambos lóbulos.

D4: tienen los estilos y las columnas interlobulares muy desarrolladas, llegando a alcanzar estas últimas la superficie oclusal. El metastilo está muy proyectado posteriormente. Los bordes mesial y distal no son paralelos. Difieren del $\mathrm{M}^{1}$ en que los bordes anterior y posterior convergen hacia la base de la corona.

Incisivos permanentes (tabla V.13.1): son dientes con las coronas altas, con forma de pala, sin surcos en la cara lingual, con cuellos marcados, una cara bucal fuertemente convexa y una raíz. La curvatura de la corona aumenta del $\mathrm{I}_{1}$ al $\mathrm{I}_{3}$. El $\mathrm{I}_{1}$ tiene una corona triangular y el borde mesial más o menos recto. El $\mathrm{I}_{2}$ está más curvado lateralmente. Jaubert et al., (1990) observan que las piezas de Bison tienen unas coronas más pequeñas y redondeadas que las de Bos. Estos caracteres no han podido ser observados.

Premolares inferiores (lámina V.13.1: 7) (tabla V.13.4): son dientes con las coronas altas, con los estilos y surcos de desarrollo variable, carecen de cíngulos, tienen cuellos marcados y dos raíces: una mesial y otra distal.

$\mathbf{P}_{2}$ : tiene el protocónido muy desarrollado en posición central. La paraprecrístida está poco desarrollada a diferencia de la hipopostcrístida que sí está marcada. La profoseta está poco marcada al igual que los surcos lingual y bucal.

$\mathbf{P}_{3}$ : tiene el paracónido separado del metacónido por un valle ancho. El entocónido está proyectado bucalmente. El metacónido es unilobulado. El surco, definido por la protopostcrístida y la hipoendocrístida, está muy marcado en la cara bucal. La hipopostfoseta está muy desarrollada, En vista bucal, el surco posterior está muy marcado.

Tabla V.13.4

Medidas tomadas en los premolares de Bos/Bison sp.

\begin{tabular}{|c|c|c|c|c|c|c|c|c|c|c|}
\hline & & & Lado & DAP & DAPb & DTa & DTp & DT & DTb & $\mathbf{H}$ \\
\hline $\mathbf{P}_{2}$ & & 6611 & d & 14,9 & 13,9 & 7,7 & 10,5 & 8,1 & 10,5 & 13,8 \\
\hline $\mathbf{P}_{3}$ & Cueva del Búho & $6611 Q$ & d & 22,4 & 18,9 & 9,0 & 13,4 & 10,9 & 13,4 & 15,3 \\
\hline
\end{tabular}

Metápodos (lámina V.13.1: 6) (tabla V.13.5): tanto los metacarpos como los metatarsos están muy fragmentados. La morfología de la superficie articular proximal es la típica de los artiodáctilos. Se ha asignado a un bovino debido a sus grandes dimensiones pero la abrasión presente en la superficie articular proximal no nos permite asignarlo a un género concreto-

Tibias (lámina V.13.1: 8): las piezas identificadas en la Cueva del Búho aparecen muy fragmentadas. Su asignación a un bovino se debe a la orientación de los surcos articulares de la superficie articular distal que permite diferenciarlos de los équidos.

Astrágalo (lámina V.13.1: 9): la pieza recuperada en la Cueva del Búho, 6644Q, está muy concrecionada. El surco plantar está roto. El borde mesial está muy abrasionado lo que no permite ver bien la faceta articular del calcáneo. Debido a la abrasión y a la concreción presente en algunas zonas no se han tomado medidas de esta pieza. 
Calcáneo (lámina V.13.1: 11) (tabla V.13.5): las caras que articulan con el escafocuboides y con el astrágalo están rotas o bien concrecionadas. No se han podido observar caracteres diagnósticos en las tres piezas de la Cueva del Búho.

Tabla V.13.5

Medidas tomadas en los metápodos y calcáneos de Bos/Bison sp.

\begin{tabular}{|c|c|c|c|c|c|c|c|c|c|c|}
\hline & & & Lado & GL & GB & BP & DP & SD & BD & DD \\
\hline Metacarpo & Valdegoba & Vb-sp-4672 & $\mathrm{d}$ & & & 66,6 & & & & \\
\hline Metacarpo & Valdegoba & Vb-sp-4668 & $\mathrm{d}$ & & & 75,3 & & & & \\
\hline Metacarpo & Valdegoba & Vb-sp-4672 & $d$ & & & 64,8 & & & & \\
\hline Metacarpo & Búho & $6631 Q^{*}$ & $\mathrm{i}$ & 234,7 & & 79,8 & 51,8 & 47,0 & 77,2 & 49,0 \\
\hline Metatarso & Valdegoba & Vb-89.K13.Cd.T10.1 & i & & & 77,3 & & & & \\
\hline Calcáneo & Búho & $6414 Q$ & $\mathrm{i}$ & & 62,5 & & & & & \\
\hline Calcáneo & Búho & $6632 Q$ & $\mathrm{~d}$ & 136,6 & 53,0 & & & & & \\
\hline
\end{tabular}

* La pieza de la Cueva del Búho corresponde a un ejemplar inmaduro. No tiene la epífisis distal fusionada

Falanges proximales (lámina V.13.1: 10) (tabla V.13.6): las piezas identificadas han aparecido muy abrasionadas y fragmentadas. Aún así se han podido tomar medidas.

Tabla V.13.6

Medidas tomadas en las falanges de Bos/Bison sp.

\begin{tabular}{|c|c|c|c|c|c|c|c|c|c|c|c|c|c|c|}
\hline & & & Lado & GL & GLpe & DPs & DPi & BP & SD & BD & DD & DLS & LD & MBS \\
\hline F.proximal & Valdegoba & Vb-sp-5581 & $\mathrm{d}$ & 80,8 & 79,7 & 41,8 & 49,2 & 48,6 & 44,3 & 41,6 & 33,3 & & & \\
\hline F.proximal & Valdegoba & Vb-sp-4685 & d & 76,6 & 75,4 & & & 39,4 & 37,6 & 39,5 & 27,3 & & & \\
\hline F.proximal & Millán & СM.86.1A.5 & d & & & & & & & 20,4 & & & & \\
\hline F.proximal & Millán & CM.86.1A.6I & i & & & & & & & 19,5 & 17,6 & & & \\
\hline F.proximal & Búho & $6579 Q$ & $\mathrm{i}$ & 75,3 & & 36,9 & & 39,6 & 37,0 & 36,7 & 27,3 & & & \\
\hline F.m.anterior & Valdegoba & Vb-sp-4676 & d & 54,4 & 49,6 & 34,6 & 41,2 & 44,5 & 39,2 & 35,8 & 37,2 & & & \\
\hline F.m.posterior & Valdegoba & Vb-sp-4686 & i & 54,0 & 52,5 & 32,8 & 43,8 & 42,2 & 31,9 & 35,0 & 39,9 & & & \\
\hline F.distal & Valdegoba & Vb-sp-4682 & $\mathrm{i}$ & & & & & & & & & 66,4 & 51,4 & 27,6 \\
\hline F.distal & Valdegoba & Vb-sp-4707 & d & & & & & & & & & 55,4 & 44,7 & 21,2 \\
\hline F.distal & Valdegoba & Vb-sp-4681 & i & & & & & & & & & 69,3 & 60,6 & 27,2 \\
\hline
\end{tabular}

Falanges medias (lámina V.13.1: 13) (tabla V.13.6): estas falanges tienen la superficie articular proximal dividida por una cresta sagital, que la atraviesa anteroposteriormente, en dos partes. El borde lateral es recto mientras que el medial es curvo. Ambos bordes terminan en una prominencia central muy marcada aunque no tanto como en los cérvidos. En la cara palmar presentan dos tubérculos para la inserción de ligamentos. Dichos tubérculos definen una depresión muy marcada y rugosa que coincide con el borde posterior de la epífisis proximal. La tróclea es más pequeña que la de las proximales. Se encuentra divida en dos por un surco sagital bien marcado. A ambos lados existen unas depresiones para la inserción de los ligamentos interdigitales siendo más marcado el que se encuentra en posición lateral. La superficie articular penetra mucho en la superficie dorsal de la pieza.

Falange media anterior: son más robustas que las posteriores. La región proximal, en su cara palmar, tiene unos tubérculos más marcados que en las posteriores. La superficie articular proximal es más redondeada. Los bordes de la diáfisis son rectos a diferencia de las posteriores en las que presentan una curvatura marcada. En vista palmar, la superficie articular distal tiene un surco más marcado que en la posterior.

Falange media posterior: son más gráciles que las anteriores. Su superficie articular proximal es más cuadrangular y sus bordes son más o menos rectos. Las protuberancias de la cara palmar no están tan marcadas con en las anteriores. Los bordes de la diáfisis son 
curvos y la tróclea, en la cara palmar, no presenta un surco tan marcado en su borde proximal.

Falanges distales (lámina V.13.1: 12) (tabla V.13.6): tiene una apariencia triangular. La superficie parietal tiene, en su región más distal, una hilera de forámenes que se reducen de tamaño hacia la zona anterior. También hay forámenes cerca de la apófisis extensora que en el caso de las piezas maduras se encuentra muy desarrollada mientras que en las inmaduras es aún una prominencia. En vista de perfil, presenta una fuerte pendiente y un cambio en el tercio superior, terminando en la apófisis extensora. La superficie articular es estrecha y está inclinada. Está dividida por una cresta en dos partes siendo, de nuevo, la abaxial la mayor. Distal e inferior a esta cara, que articula con la segunda falange, hay una carilla que articula con el sesamoideo distal, siendo ovalada en todos los casos. La superficie solar, ventral, es estrecha, cóncava y se estrecha hacia el extremo anterior.

\subsubsection{Número Mínimo de Individuos}

En la Cueva del Búho y en la Cueva de Valdegoba no se tiene en cuenta este análisis ya que los individuos identificados a partir de este material podrían pertenecer tanto a Bos primigenius como a Bison priscus. Otro caso distinto es el de Cueva Millán ya que no se han identificado ni uros ni bisontes. El número mínimo de ejemplares en este depósito y en concreto del nivel $1 \mathrm{~A}$ es de 2 , un ejemplar sería inmaduro y otro maduro, a partir de dos falanges proximales.

\subsubsection{Discusión}

El material recuperado consiste en restos fragmentados o abrasionados y piezas dentales de difícil asignación. La disposición de los surcos articulares de las tibias, la morfología selenodonta de la superficie oclusal de los deciduales así como la forma de los astrágalos nos permiten incluir estos restos en la familia Bovidae. Su asignación a un género determinado es más complicado. Los criterios descritos por Jaubert et al., (1990) y por Sala et al., (2010) como la morfología de la superficie articular proximal de los metápodos y de las diferentes estructuras dentales como las columnas interlobulares no han podido ser observados. Se asignan estos restos a Bos/Bison sp. 


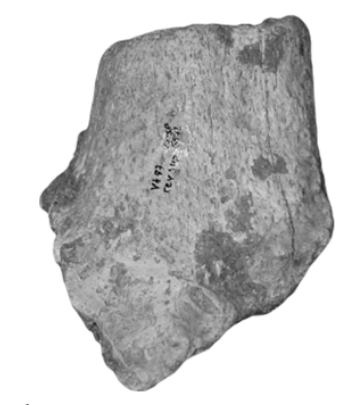

1.

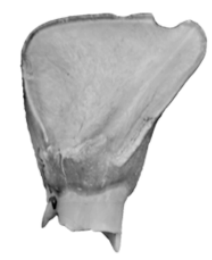

2.a

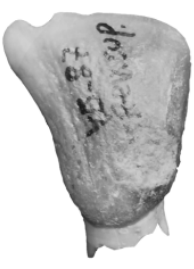

2.b

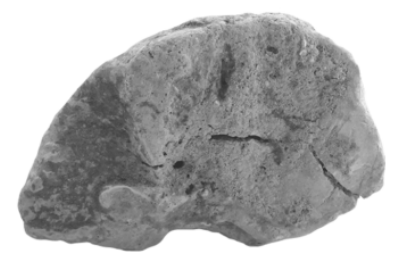

6. $2 \mathrm{~cm}$

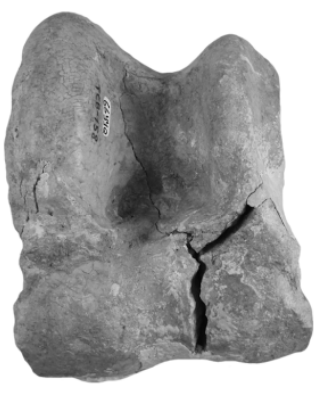

9. $4 \mathrm{~cm}$

7.

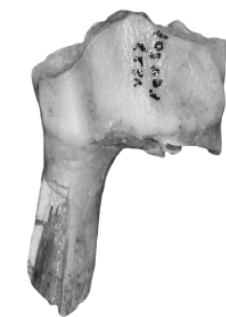

3.a

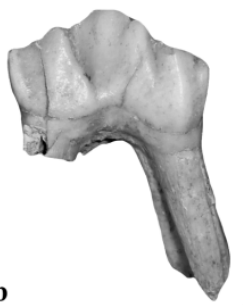

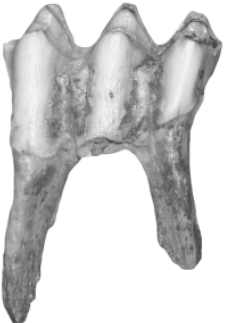

4.a

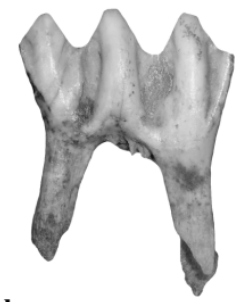

4.b

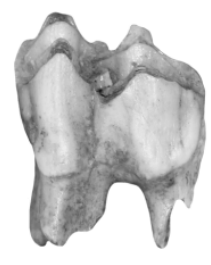

5.a

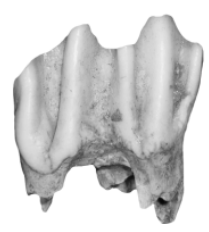

5.b

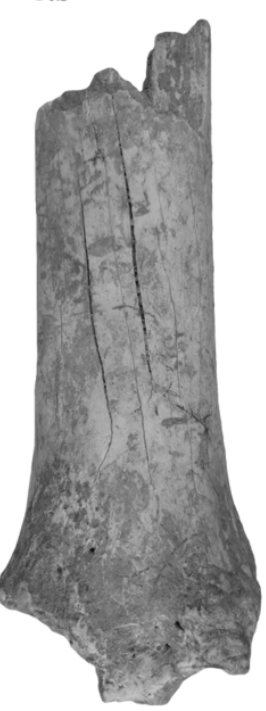

8.

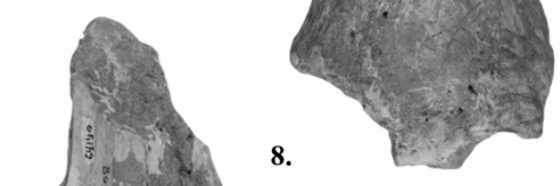

11.

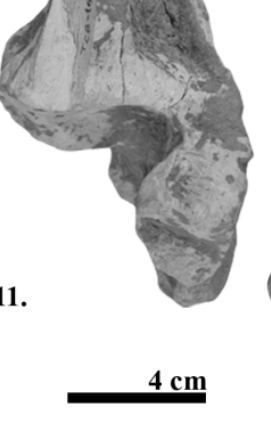

13.

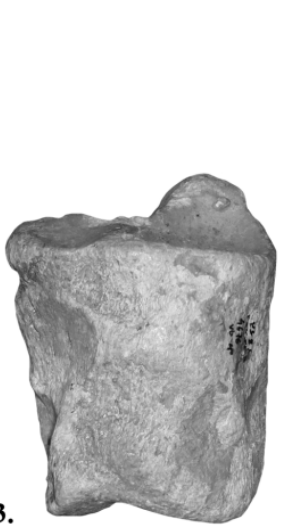

12.

10.

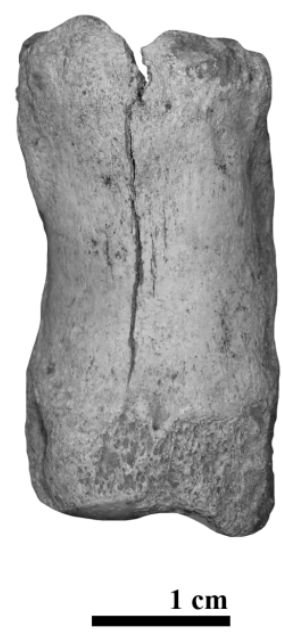

Lámina V.13.1. Bos/Bison sp. provenientes de los yacimientos de la Cueva del Búho (sigla Q) y de la Cueva de Valdegoba (sigla Vb). 1) Vb-sp-5642- Cuernos. 2) Vb-sp-2300 - Incisivo decidual derecho: 2.a cara lingual; 2.b cara bucal. 3) Vb-sp-3027 - D 3 derecho: 3.a cara bucal: 3.b cara lingual. 4) Vb-sp-1323 - D derecho: 4.a cara bucal; 4.b cara lingual. 5) Vb-sp-1324 - $\mathrm{D}^{3}$ derecho: 5.a cara lingual; 5.b cara bucal. 6) 6631Q - Metacarpo izquierdo. 7) 6611Q - Mandíbula $\left(\mathrm{P}_{2}-\mathrm{P}_{3}\right)$ derecha, cara lingual. 8) 6515Q - Tibia izquierda. 9) 6644Q Astrágalo derecho. 10) Vb-sp-4685 - Falange proximal derecha. 11) 6414Q - Calcáneo izquierdo. 12) Vb-sp4681 - Falange distal izquierda. 13) Vb-sp-4676 - Falange media izquierda. 


\subsection{Análisis de cada depósito}

El análisis por especies nos permite tener una visión particular de cada una de ellas. Sin embargo, en un yacimiento nos encontramos varias por lo que es necesario realizar un resumen de lo recuperado en cada depósito (tabla V.14.1). Los ejemplares de talla grande incluyen a los rinocerontes, uros y bisontes; los de talla media a los caballos, encebros ( $E$. hydruntinus) y ciervos; y los de talla pequeña a los jabalís, corzos, rebecos y cabras monteses.

En La Mina se ha tenido en cuenta sólo el resto del rinoceronte lanudo, Coelodonta antiquitatis, ya que el depósito ha aparecido revuelto y este resto es el que ha aportado la única datación (Diez et al., 2008). Pertenece a un ejemplar adulto - viejo, no pudiéndose precisar más. No se puede establecer un agente acumulador claro ya que se han recuperado tanto instrumentos líticos como coprolitos de carnívoros lo que sugiere una alternancia ocupacional (Díez et al., 2008).

En la Cueva de Valdegoba se han identificado diez taxones: Stephanorhinus hemitoechus, Equus ferus, Equus hydruntinus, Sus scrofa, Cervus elaphus, Capreolus capreolus, Rupicapra pyrenaica, Capra pyrenaica, Bos primigenius y Bison priscus. En la acumulación participaron tanto carnívoros como homínidos aunque parece que estos últimos ocuparon más intensamente la cavidad y que su acceso a las presas fue primario (Díez, 2006). Predominan, con un 63,7\%, los ejemplares de talla pequeña; seguidos por los talla media, con un $31,8 \%$; y por los de talla grande, con un 4,4\%. Destaca la presencia de rebeco, con un $50 \%$ del total de ejemplares identificados. En los individuos de talla pequeña y grande predominan los adultos y en los de talla media los infantiles. Parece ser que los habitantes de la cavidad se especializaron en las especies de talla pequeña, en los que el rebeco sería la principal presa, en concreto los machos adultos que fueron acumulados durante todo el año. Sin embargo, la mayor parte de las capturas, si incluimos todas las tallas, se produce en verano. En esta estación es cuando se concentra la acumulación de ejemplares de talla media. No despreciaban otras presas como las especies de talla grande, aunque no se ha podido precisar el periodo de su acumulación ya que no se ha podido estimar la estacionalidad.

En resumen, los habitantes de la cavidad se especializaron en la captura de rebecos durante todo el año y se centraban en otras especies cuando eran más vulnerables, en la época de partos y la lactancia.

En Prado Vargas se han recuperado seis taxones: Rhinocerotidae indet., Equus ferus, Sus scrofa, Cervus elaphus, Rupicapra pyrenaica y Capra pyrenaica. Este depósito se ha interpretado como un alto de caza, siendo muy pocas las evidencias de carnívoros (Navazo et al., 2005). Predominan las especies de talla pequeña, con un $50 \%$ de los efectivos; seguidas de los taxones de talla media, con un $40 \%$; y por el $10 \%$ de los de talla grande.

Parece existir una preferencia por los ejemplares de talla pequeña, y por su acumulación en invierno y primavera, periodos en los que especies rupícolas como los rebecos y las cabras monteses bajan de las montañas y se refugian en zonas forestales.

En Cueva Millán podemos hacer un estudio por niveles: En el primero, 1A, se han identificado siete taxones: Stephanorhinus hemitoechus, Equus ferus, Equus hydruntinus, Cervus elaphus, Rupicapra pyrenaica, Capra pyrenaica y Bos/Bison sp. Tanto la presencia como las evidencias de actividad de carnívoros son muy bajas por lo que el principal agente de acumulador sería humano (Díez et al., 2008). Predominan los ejemplares de talla pequeña, 50\%; seguidos de los de talla media, $35 \%$; y talla grande, $15 \%$. Predominan 
los adultos en todas ellas. La cavidad estuvo ocupada en todas las estaciones pero con una mayor intensidad en primavera y verano, coincidiendo con el principio de los partos y la lactancia. En el nivel 1B se han registrado cuatro especies: Equus ferus, Cervus elaphus, Rupicapra pyrenaica y Capra pyrenaica, siendo igual de abundantes los ejemplares de talla media que los de pequeña. Fueron acumulados en verano, coincidiendo con el final de los partos y con la lactancia. En el nivel 1C se han identificado cuatro taxones: Equus ferus, Cervus elaphus, Rupicapra pyrenaica y Capra pyrenaica. Predominan los ejemplares de talla media, que fueron acumulados en otoño, periodo que coincide con el celo.

Parece ser, que en este depósito, la intensidad de ocupación aumenta del nivel 1C al 1A. Se centran principalmente, salvo en el 1C, en especies de talla pequeña, siendo su presión más marcada en verano y otoño.

En la Cueva del Búho se han identificado ocho taxones: Stephanorhinus hemitoechus, Equus ferus, E. hydruntinus, Sus scrofa, Cervus elaphus, Capreolus capreolus, Bos primigenius y Bison priscus. Este depósito ha sido interpretado como un cubil de hienas con una clara ausencia de intervención antrópica (Sala, 2012). Predominan los ejemplares de talla grande con un $50 \%$, seguidos por los de talla media con un $37,5 \%$, y por los de talla pequeña con sólo un 12,5\%. En todas ellas predominan los ejemplares adultos, seguidos por los juveniles y los infantiles. Los periodos de adquisición serían el otoño y el invierno, al menos en los ejemplares de talla media, periodos en los que los machos y las hembras se reúnen en el celo; y en el que los machos permanecen aislados, lo que les haría más vulnerables. Sin embargo, estos resultados son parciales ya que sólo incluyen las excavaciones antiguas y sería necesario realizar un análisis de toda la colección.

En el Abrigo de Alexandre se han identificado dos especies: Equus ferus y Rupicapra pyrenaica. Su origen es antrópico, como así lo sugiere la gran cantidad de material lítico y la ausencia de actividad de otros predadores (Utrilla et al., 1999). No podemos precisar mucho más ya que no se ha podido establecer un periodo de acumulación. Sin embargo, el diente decidual de rebeco nos indica que el ejemplar no habría alcanzado su desarrollo y que pudo haber sido acumulado en verano o durante el otoño.

En el Abrigo de Vergara se ha detectado la presencia de Equus ferus y Cervus elaphus. Sus restos, muy fragmentados no nos aportan más información.

Los habitantes de estos abrigos se especializaron en la caza de ejemplares de talla media y, en concreto, de ejemplares adultos.

En la Peña de Estebanvela, todas las especies fueron aportadas por el ser humano. Así lo sugieren la gran cantidad de marcas de aprovechamiento, ligadas a procesos de desollado, descarnado y desarticulado (Yravedra, 2013). En el nivel I se han identificado seis especies: Equus ferus, E. hydruntinus, Sus scrofa, Cervus elaphus, Rupicapra pyrenaica y Capra pyrenaica. Los ejemplares de talla pequeña y media aparecen en la misma proporción, destacando en ambas los adultos. La cavidad estuvo ocupada desde finales de la primavera a principios del otoño. En el nivel II se han registrado cinco taxones: E. ferus, $E$. hydruntinus, $C$. elaphus, $R$. pyrenaica y $C$. pyrenaica. Predominan los ejemplares de talla media, seguidos de los de talla pequeña, y en ambos casos los ejemplares adultos. En el nivel III se han identificado los mismos taxones que en el nivel precedente. Predominan los individuos de talla media, seguidos por los de talla pequeña que fueron acumulados en verano. En el nivel IV se reduce el número de taxones. Se han identificado tres: C. elaphus, $R$. pyrenaica y $C$. pyrenaica, predominando los ejemplares de talla pequeña. En este nivel no se ha podido hacer un estudio de estacionalidad. 
Tabla V.14.1

Resumen de los resultados obtenidos en cada yacimiento (1 1 a parte)

\begin{tabular}{|c|c|c|c|c|c|c|c|c|c|c|c|c|c|c|}
\hline & & \multirow{2}{*}{ NMI } & \multicolumn{6}{|c|}{ Edad de muerte } & \multicolumn{4}{|c|}{ Estacionalidad } & \multicolumn{2}{|c|}{ Bimodalidad y Dimorfismo } \\
\hline & & & infantil & juvenil & adulto & senil & inmaduro & maduro & Invierno & Primavera & Verano & Otoño & Machos & Hembras \\
\hline \multirow[t]{8}{*}{ Cueva del Búho } & S. hemitoechus & 4 & 1 & 1 & 2 & & & & & & & & & \\
\hline & E.ferus & 2 & & & 1 & & 1 & 1 & & & & & & \\
\hline & E. hydruntinus & 1 & & & & & & & & & & & & \\
\hline & S. scrofa & 1 & & & & & & 1 & & & & & & \\
\hline & C. elaphus & 3 & & 1 & 1 & & & 1 & $\mathrm{X}$ & & & $\mathrm{X}$ & & \\
\hline & C. capreolus & 1 & (1) & & & & 1 & & & & & & & \\
\hline & B. primigenius & 2 & & & & & & & & & & & & \\
\hline & B. priscus & 2 & & & & & & & & & & & & \\
\hline La Mina & C. antiquitantis & 1 & & & (1) & & & & & & & & & \\
\hline \multirow[t]{10}{*}{ Cueva de Valdegoba } & S. hemitoechus & 3 & 1 & (1) & & (1) & & & & & & & & \\
\hline & E.ferus & 28 & & & 5 & 1 & 17 & 11 & & & & & & \\
\hline & E. hydruntinus & 5 & & 2 & 1 & 2 & 2 & 3 & & & & & & \\
\hline & S. scrofa & 2 & & & & & 2 & & & & & & & \\
\hline & C. elaphus & 40 & 19 & 9 & 1 & & 27 & 13 & $\mathrm{X}$ & $\mathrm{X}$ & $\mathrm{X}$ & $\mathrm{X}$ & 5 & 4 \\
\hline & C. capreolus & 12 & (10) & & 1 & 1 & 10 & 2 & & & & & & \\
\hline & R. pyrenaica & 114 & 1 & 16 & 82 & & 26 & 88 & $\mathrm{X}$ & $\mathrm{X}$ & $\mathrm{X}$ & $\mathrm{X}$ & 16 & 8 \\
\hline & C. pyrenaica & 18 & 1 & 8 & 1 & & 10 & 8 & $\mathrm{X}$ & $\mathrm{X}$ & $\mathrm{X}$ & $\mathrm{x}$ & & \\
\hline & B. primigenius & 6 & & & & & & & & & & & & \\
\hline & B. priscus & 1 & & & & & & & & & & & & \\
\hline \multirow[t]{6}{*}{ Prado Vargas } & Rhinocerotidae indet. & 1 & & & & & & & & & & & & \\
\hline & E. ferus & 2 & & & 1 & 1 & & 2 & & & & & & \\
\hline & S. scrofa & 1 & & & & & 1 & & & & & & & \\
\hline & C. elaphus & 2 & & 1 & & & 1 & & $\mathrm{X}$ & & & & & 1 \\
\hline & R. pyrenaica & 2 & & 1 & 1 & & 1 & 1 & $\mathrm{X}$ & $\mathrm{X}$ & & & & \\
\hline & C. pyrenaica & 2 & & & & & & & & & & & & \\
\hline
\end{tabular}

* La referencia (1) o (10) indica que el ejemplar podría ser en: S. hemitoechus: un joven-adulto o un adulto-viejo; C. antiquitatis: un adulto-viejo; C. capreolus diez infantiles-juveniles. 
Tabla V.14.1

Resumen de los resultados obtenidos en cada yacimiento ( $2^{\mathrm{a}}$ parte)

\begin{tabular}{|c|c|c|c|c|c|c|c|c|c|c|c|c|c|c|c|}
\hline & & & \multirow[t]{2}{*}{ NMI } & \multicolumn{6}{|c|}{ Edad de muerte } & \multicolumn{4}{|c|}{ Estacionalidad } & \multicolumn{2}{|c|}{ Bimodalidad y Dimorfismo } \\
\hline & & & & infantil & juvenil & adulto & senil & inmaduro & maduro & Invierno & Primavera & Verano & Otoño & Machos & Hembras \\
\hline \multirow[t]{15}{*}{ Cueva Millán } & $1 \mathrm{~A}$ & S. hemitoechus & 1 & & & & & & & & & & & & \\
\hline & & E.ferus & 3 & & & 2 & & 1 & 2 & & & & & & \\
\hline & & E. hydruntinus & 1 & & & & & & & & & & & & \\
\hline & & C. elaphus & 3 & & 1 & 2 & & 1 & 2 & & & $\mathrm{X}$ & $\mathrm{X}$ & & 2 \\
\hline & & R. pyrenaica & 5 & & 2 & 3 & & 2 & 3 & & $\mathrm{x}$ & $\mathrm{x}$ & $\mathrm{x}$ & & \\
\hline & & C. pyrenaica & 5 & & & 1 & & & 1 & $\mathrm{x}$ & & & & & \\
\hline & & Bos/Bison sp. & 2 & & & 1 & & 1 & 1 & & & & & & \\
\hline & $1 \mathrm{~B}$ & E. ferus & 1 & & & & & & 1 & & & & & & \\
\hline & & C. elaphus & 2 & & 1 & 1 & & 1 & 1 & & & $\mathrm{x}$ & & & \\
\hline & & R. pyrenaica & 1 & & 1 & & & 1 & & & & $\mathrm{x}$ & & & \\
\hline & & C. pyrenaica & 1 & & & & & & & & & & & & \\
\hline & $1 \mathrm{C}$ & E. ferus & 3 & & & & & & 3 & & & & & & \\
\hline & & C. elaphus & 2 & & & 1 & & 1 & 1 & & & & $\mathrm{X}$ & & \\
\hline & & R. pyrenaica & 1 & & & 1 & & & 1 & & & & & & \\
\hline & & C. pyrenaica & 1 & & & & & & & & & & & & \\
\hline \multirow[t]{19}{*}{ Peña de Estebanvela } & I & E. ferus & 2 & 1 & & 1 & & 1 & 1 & & & & & & \\
\hline & & E. hydruntinus & 2 & & 1 & 1 & & 1 & 1 & & & & & & \\
\hline & & S. scrofa & 1 & & & 1 & & & 1 & & & & & & \\
\hline & & C. elaphus & 1 & & & & & & & & $\mathrm{x}$ & & & & \\
\hline & & R. pyrenaica & 2 & & & 1 & & 1 & 1 & & & & $\mathrm{X}$ & & \\
\hline & & C. pyrenaica & 4 & & & 2 & & 2 & 2 & & & & & & \\
\hline & II & E. ferus & 2 & & & & & 1 & 1 & & & & & & \\
\hline & & E. hydruntinus & 2 & & & 2 & & & 2 & & & & & & \\
\hline & & C. elaphus & 1 & & & & & & & & & & & & \\
\hline & & R. pyrenaica & 1 & & & & & & & & & & & & \\
\hline & & C. pyrenaica & 1 & & & & & & & & & & & & \\
\hline & III & E.ferus & 2 & & & 2 & & & 2 & & & & & & \\
\hline & & E. hydruntinus & 1 & & & & & & & & & & & & \\
\hline & & C. elaphus & 1 & & & & & & & & & & & & \\
\hline & & R. pyrenaica & 1 & & & 1 & & & 1 & & & & & & \\
\hline & & C. pyrenaica & 2 & & 1 & & & 1 & & & & $\mathrm{X}$ & & & \\
\hline & IV & C. elaphus & 1 & & & & & & & & & & & & \\
\hline & & R. pyrenaica & 1 & & & & & & & & & & & & \\
\hline & & C. pyrenaica & 1 & & & & & & & & & & & & \\
\hline
\end{tabular}


Tabla V.14.1

Resumen de los resultados obtenidos en cada yacimiento ( $3^{\text {a }}$ parte)

\begin{tabular}{|c|c|c|c|c|c|c|c|c|c|c|c|c|c|c|}
\hline & & \multirow[t]{2}{*}{ NMI } & \multicolumn{6}{|c|}{ Edad de muerte } & \multicolumn{4}{|c|}{ Estacionalidad } & \multicolumn{2}{|c|}{ Bimodalidad y Dimorfismo } \\
\hline & & & infantil & juvenil & adulto & senil & inmaduro & maduro & Invierno & Primavera & Verano & Otoño & Machos & Hembras \\
\hline \multirow[t]{2}{*}{ Peña Mudá } & S. hemitoechus & 1 & & & 1 & & & & & & & & & \\
\hline & C. antiquitantis & 1 & & & & & & 1 & & & & & & \\
\hline \multirow[t]{2}{*}{ Abrigo Alexandre } & E. ferus & 1 & & & & & & & & & & & & \\
\hline & R. pyrenaica & 1 & & 1 & & & 1 & & & & & & & \\
\hline \multirow[t]{2}{*}{ Abrigo Vergara } & E. ferus & 1 & & & & & 1 & & & & & & & \\
\hline & C. elaphus & 1 & & & & & & & & & & & & \\
\hline
\end{tabular}

Tabla V.14.2

Número mínimo de individuos y porcentajes de tallas en los depósitos del Paleolítico Medio y Superior

\begin{tabular}{|c|c|c|c|c|c|}
\hline & & \multicolumn{2}{|c|}{ Paleolítico Medio } & \multicolumn{2}{|c|}{ Paleolítico Superior } \\
\hline & & NMI & $\%$ & MNI & $\%$ \\
\hline \multirow[t]{5}{*}{ Talla grande } & S. hemitoechus & 4 & 5,8 & & \\
\hline & Rhinocerotidae indet. & 1 & & & \\
\hline & Bos primigenius & 6 & & & \\
\hline & Bison priscus & 1 & & & \\
\hline & Bos/Bison sp. & 9 & & & \\
\hline \multirow[t]{3}{*}{ Talla media } & E. ferus & 34 & 25,5 & 12 & 64,7 \\
\hline & E. hydruntinus & 5 & & 5 & \\
\hline & C. elaphus & 53 & & 5 & \\
\hline \multirow[t]{4}{*}{ Talla pequeña } & C. capreolus & 13 & 68,7 & & \\
\hline & S. scrofa & 3 & & & 35,5 \\
\hline & R. pyrenaica & 187 & & 7 & \\
\hline & C. pyrenaica & 45 & & 5 & \\
\hline
\end{tabular}


En la Peña de Mudá se han identificado dos especies de rinocerontes: Stephanorhinus hemitoechus y Coelodonta antiquitatis. Del resto de los ungulados recuperados en este yacimiento, y que se encuentran depositados en el Museo Geominero, se desconoce su contexto por lo que no podemos aportar más información.

Llama la atención el mayor número de yacimientos del Paleolítico Medio con respecto a los del Paleolítico Superior. En el primer grupo se encontrarían la Cueva del Búho, La Mina, la Cueva de Valdegoba, Cueva Millán y Prado Vargas. También estaría incluida La Ermita, cuyos restos no han sido analizados en este trabajo. En el segundo estarían los abrigos de Vergara y Alexandre; y la Peña de Estebanvela. Si excluimos los yacimientos de la Cueva del Búho, cuyo origen es no antrópico; y La Mina donde no se puede inferir un agente acumulador concreto, podemos ver algunas diferencias (tabla 5.14.2). Se observa una menor variedad de presas en los yacimientos del Paleolítico Superior, en los que ni siquiera se han registrado ejemplares de talla grande, y donde predominan los ejemplares de talla media. En cambio, los depósitos del Paleolítico medio muestran una mayor variedad de presas, predominando los ejemplares de talla pequeña. Podemos inferir que los habitantes del Paleolítico Medio se especializaron en los ejemplares de talla pequeña, fundamentalmente en especies rupícolas como el rebeco o la cabra montés. No despreciaban a los individuos de talla media, tanto a los ciervos como a los caballos y lo que menos consumían eran especies de talla grande. Durante el Paleolítico Superior cambian las preferencias, centrándose en ejemplares de talla media y abandonando la caza de presas de talla grande. 


\section{Discusión}


En este capítulo se excluye la discusión referente a la identificación de cada una de las especies, que ya se ha expuesto en los apartados 5.1 - 13. Este capítulo se ha divido en dos partes. En la primera se discute la elección de cada uno de los métodos empleados para estimar la edad de muerte, la estacionalidad y el dimorfismo sexual y se comparan con modelos similares. En la segunda, se presentan las especies y se discuten los resultados sobre la edad de muerte, la estacionalidad y el dimorfismo.

La Meseta Norte, por su situación geográfica, fue un lugar adecuado para el poblamiento humano desde hace al menos un millón de años (Díez y Rodríguez, 2009). Sin embargo, la ocupación de este territorio durante el Paleolítico Medio y Superior ha sido considerada tradicionalmente residual, en comparación con regiones próximas como Asturias, Cantabria o el País Vasco. Esto empieza a cambiar a principios del siglo XX con la labor de estudiosos como el Abate Breuil, Hernández Pacheco, los padres Íbero y Carballo y Hugo Obermaier. Estos investigadores realizan las primeras incursiones en la Meseta, localizando y publicando los primeros depósitos (Breuil, 1918-1919; Obermaier, 1925). Posteriormente, la labor de diferentes universidades, centros de investigación y asociaciones científicas nos han dado a conocer la riqueza arqueopaleontológica de esta región. Hoy en día, gracias a todos estos investigadores la Meseta Norte se considera un lugar muy frecuentado por los humanos desde hace más de un millón de años, demostrándose por la gran cantidad de depósitos que abarcan periodos culturales que van desde el Paleolítico Inferior al Paleolítico Superior (Bermúdez de Castro et al., 1997; Santonja y Pérez González, 2000 - 2001; Delibes de Castro y Díez Martín, 2006; Carbonell et al., 2008; Díez y Rodríguez, 2009; Arsuaga et al., 2014).

Este trabajo se centra en los fósiles de ungulados de los depósitos del Paleolítico Medio y Superior, periodos culturales encuadrados en el Pleistoceno Superior. De este estudio se han excluido los restos fuera de contexto procedentes de depósitos cuya localización a día de hoy es complicada como los de la zona de Oña (Burgos) o aquellos que aún están siendo estudiados como los de la Cueva de la Zarzamora (Segovia) (Sala, 2012), la Loma (Rodríguez com. pers.) y Cueva Corazón (Palencia) (Díez Martín et al., 2011; Sánchez Yustos et al., 2011). El yacimiento de la Ermita no se ha estudiado debido a que, en el momento de análisis del material, las colecciones no estaban disponibles. Por tanto, en este estudio se analizan la Cueva de Valdegoba, Prado Vargas, La Mina, Cueva Millán, la Cueva del Búho, el Abrigo de Alexandre, el Abrigo de Vergara, la Peña de Estebanvela y la Peña de Mudá.

La naturaleza de algunos yacimientos arqueopaleontológicos hace difícil y en ocasiones imposible establecer el agente de acumulación o definir la combinación o contribución de diferentes agentes (Klein y Cruz-Uribe, 1984; Twiss, 2008). Afortunadamente, hay algunos yacimientos donde la asociación de objetos y los caracteres presentes en los huesos pueden apuntar a un agente primario de acumulación (Klein y Cruz-Uribe, 1984). Algunos de los métodos más utilizados en arqueología para determinar este origen son el estudio de la edad de muerte, la estacionalidad y el dimorfismo sexual.

\subsection{Discusión metodológica}

\section{Edad de muerte}

Los restos paleontológicos que nos permiten realizar la determinación de la edad de muerte son los dientes (tanto su erupción como su desgaste) y el grado de desarrollo de los huesos. El desarrollo de las astas, la fusión y el desarrollo de los huesos craneales son también métodos válidos (Klein y Cruz-Uribe, 1984; Greenfield et al., 2008) pero poco habituales en esta disciplina, debido a la escasez y a la mala conservación de este material. Las técnicas más frecuentes son el estudio de la fusión epifisial y el análisis de la erupción y del desgaste dental. La fusión epifisial tiene, por otro lado, una serie de limitaciones como son, por ejemplo, la dificultad a la hora de identificar especies a partir de huesos inmaduros, la escasa conservación tanto de epífisis como de diáfisis en individuos 
infantiles así como la poca información que aportan, ya que sólo se pueden establecer dos clases de edad: antes de la fusión y después de la misma, y que además cambian con el tipo de hueso y la especie (Klein y Cruz-Uribe, 1984). Por ello, el material dental es el más común en estos estudios (Habermehl, 1961; Schmid, 1972; Silver, 1969). Su composición los hace más resistentes, los procesos tafonómicos los afectan en menor medida, se puede seguir su desgaste a lo largo de toda la vida del animal, son muy abundantes, son buenos marcadores biocronológicos y su asignación específica es más clara (Payne, 1973; Spinage, 1973; Grant, 1982; Hillson, 2005; Greenfield et al., 2008). Además, su uso está muy extendido en herbívoros debido a su gran hipsodoncia dental (Spinage, 1973; Klein et al., 1981; O'Connor, 2000; Munson et al, 2003; Greenfield et al., 2008). Este hecho hace que las variaciones morfológicas y métricas puedan ser observadas y cuantificadas con facilidad.

Existen varios métodos que nos permiten establecer la edad de muerte a partir de los dientes pero los más empleados son la cementocronología, la erupción y el desgaste (Spinage, 1973; Klein et al., 1981; 1983; 1984; Levine, 1982; Pike-Tay et al., 2000; O'Connor, 2000; Steele, 2002, 2004). Cada uno de estos métodos tiene sus ventajas pero también encierran una serie de inconvenientes. Por una parte, la cementocronología, que mide el incremento de cemento en la corona, tiene un efecto muy invasivo y sus resultados dependen de la calidad de las láminas delgadas. Es un buen modelo pero su aplicación en paleontología es limitada. Los métodos más empleados son el de la erupción y el desgaste dental, pero también tienen problemas de aplicación. Así, en la erupción dental destacamos la falta de colecciones de referencia en mamíferos fósiles o la escasa mineralización en los individuos infantiles que dificulta la obtención de radiografías de buena calidad. Asimismo, la erupción puede verse afectada por las diferencias en el desarrollo ontogenético, la alimentación y por diferentes enfermedades (Hillson, 2005). Por otra parte, definir el concepto erupción siempre ha sido complicado ya que asociar una erupción con el desgaste concreto de una pieza no siempre es fácil (Hillson, 2005; Greenfield et al., 2008). Por último, otro de los problemas es elegir el tipo de tablas a utilizar a la hora de establecer la edad de erupción ya que algunos autores como Habermehl (1961), Schmid (1972) o Silver (1969) usan tablas basadas en estudios del siglo XIX mientras que Halstead (1985) y Hambleton (1999) usan datos del siglo XX.

Por esta razón, en paleontología, hay siempre algo de incertidumbre a la hora de escoger una población de referencia. La exactitud del método incrementa cuando los rangos son similares a los de las poblaciones actuales pero en muchos casos los datos se basan en poblaciones domésticas y/o asilvestradas. El acceso a datos, provenientes de poblaciones salvajes, referentes a la de erupción dental con un número de individuos significativo no es fácil. Por suerte, estos trabajos han proliferado en suidos (Rolett y Chiu, 1994), cérvidos (Azorit et al., 2002; Daujeard, 2008), caprinos (Pérez-Barbería, 1994; Vigal y Machordom, 1985) y bovinos (Wegrzyn y Serwatka, 1984; St. Clair, 2005). Por otra parte, el desgaste dental se aplica de dos maneras: morfológica y métricamente. Existen dos grandes "sistemas" para registrar la edad de muerte a partir de los cambios morfológicos de la superficie oclusal en los dientes de los artiodáctilos. El primero es el modelo de Payne (1973), orientado principalmente a ovejas y cabras; y ampliado posteriormente a las vacas por Halstead (1985). El segundo, desarrollado por Grant (1975), se centra en las ovejas, cabras, vacas y cerdos. Ambos modelos combinan las técnicas de erupción dental, tanto en dentición decidual como permanente, y el desgaste de la corona desde un punto de vista morfológico. A partir de varias fases de erosión construyen una etapa de desgaste a la cual asignan una edad (Greenfield et al., 2008). Una de las diferencias entre ambos reside en las poblaciones control utilizadas. Grant (1975) se basó en poblaciones arqueológicas de Gran Bretaña, mientras que Payne (1973) utilizó material arqueológico turco y referencias históricas. Otras diferencias radican en el número de rangos de edad definidos, en cómo se representan, en la variación de edad y en la relación con la edad absoluta (Greenfield et al., 2008). Más tarde, Hambleton (1999) convirtió el modelo de Grant (1982) al de Payne (1973), por el que se evitan duplicidades y solapamientos entre los métodos. Aún así, podemos ver que las técnicas basadas en los cambios morfológicos encierran cierta subjetividad y que incluso han sido modificadas por los mismos autores a lo largo del tiempo (Payne, 1973, 1987). Este método ha sido 
ampliamente utilizado por muchos investigadores. Sin embargo, las ilustraciones, dibujos y fotografías que se presentan en alguna de las publicaciones (Payne, 1973; Grant, 1975) pueden hacer que el investigador intente incluir sus restos en alguna de las categorías definidas por el autor a pesar de que la morfología no sea similar. Este hecho, junto con la subjetividad a la hora de llevar a cabo estas ilustraciones, puede conducirnos a un error evitable, que podría corregirse eligiendo una técnica basada en variables métricas.

El modelo métrico se basa en el desgaste que experimenta la corona a lo largo de la vida del animal. Las medidas varían de un grupo a otro, aunque hay un cierto consenso a la hora de elegir la bibliografía a utilizar. Este método es a menudo la única alternativa práctica para el material paleontológico (Levine, 1982, 1983; Hillson, 2005) ya que permite un análisis no invasivo y además no destructivo. Una de las primeras aproximaciones a este tipo de estudios lo realizó Spinage (1972) y posteriormente se fue afianzado con los modelos de Klein y Cruz-Uribe (1984). Sin embargo, el modelo de Klein encierra también problemas como la necesidad de emplear datos basados en poblaciones actuales para poder completar las variables de sus ecuaciones. Autores como Pike-Tay et al. (2000) indican que pequeñas diferencias en las alturas iniciales de la corona pueden provocar desviaciones muy grandes en la edad de los ejemplares, y sugieren cambios en varios de los términos como AGEpel por AGEmax (esperanza media de vida de la especie; o edad de muerte natural), aunque esto también ha sido criticado por Enloe y Turner (2002) que indican que este cambió puede proporcionar edades más bajas.

El desgaste dental también presenta una serie de inconvenientes que podrían afectar a los resultados. Entre ellos podríamos destacar el uso de poblaciones control actuales, las posibles diferencias en la dieta, la diferente velocidad de desgaste y su variación a lo largo de la vida del animal, las diferencias entre los sexos o considerar que una clase de edad tenga siempre asociada la misma altura de la corona. Todos estos problemas influyen, en cierta medida, en los modelos empleados tradicionalmente como las ecuaciones de Klein y Cruz-Uribe (1984) y las tablas de Payne (1973) y Grant (1975). Por este motivo, y con la finalidad de reducir, en cierta medida, algunos de estos problemas, hemos tomado como población control la propia población paleontológica. La Cueva de Valdegoba ha aportado un registro muy bien conservado de dientes de rebeco, cabra y ciervo; incluyendo varios sin desgaste en los que se ha aplicado esta técnica. Este hecho ha permitido tomar la propia asociación como control e incluir estos datos en la variable CHo (altura de la corona sin desgaste). Esto ha evitado tomar esta variable de poblaciones actuales en las que se han demostrado cambios en el tamaño de los ejemplares a lo largo del tiempo (Altuna, 1978; Maldonado, 1996; Arceredillo et al., 2011; Van der Made et al., 2014).

La elección de la asociación fósil como grupo control nos permite reducir problemas asociados al tipo de dieta, ya que se considera más o menos homogénea; disminuir la diferencia de desgaste asociada al sexo, ya que los restos son aleatorios y no se ha determinado el dimorfismo a partir de los dientes; y también conocer la secuencia de erupción. Sin embargo, esto también podría ser objeto de críticas ya que es cierto que para llevar a cabo un buen estudio de la edad de muerte, reduciendo lo máximo posible la variabilidad, sería necesario encontrar en cada yacimiento dientes sin desgaste. Sin embargo, las ventajas de escoger una asociación fósil, a pesar de encontrarse separada de otra miles de años, en este caso, son mayores que las desventajas asociadas.

Con la finalidad de reducir lo máximo posible esta variabilidad, además de aplicar el modelo de Klein y Cruz-Uribe (1984), hemos propuesto un método que incluye únicamente las edades de erupción y el desgaste dental, evitando, en la medida de lo posible, incluir datos basados en poblaciones actuales.

Si comparamos ambos modelos vemos que, por lo general, los patrones son similares, habiéndose observado comportamientos diferentes únicamente en dos de los siete casos en los que se ha analizado. Lo que varía es únicamente el número de ejemplares o restos que se incluyen en cada rango. Por esta razón, se podrían utilizar para conocer patrones 
aunque no para determinar el número mínimo de ejemplares que se encuentra en un rango u en otro.

Sí que es cierto que escogemos dos modelos morfológicos, uno basado en los cambios que tienen lugar en la superficie oclusal de los incisivos de los équidos y el otro en los caninos superiores de los ciervos. Estos modelos han sido seleccionados por su poca utilización en la bibliografía con la finalidad de comprobar si en un estudio amplio, basado en dientes yugales, podrían complementarse sus resultados. El análisis de los incisivos de los équidos ha revelado resultados interesantes ya que, a diferencia de los dientes yugales, sí que se observan cambios significativos en la superficie oclusal con el desgate y los resultados se complementan con los obtenidos en los yugales. No ocurre lo mismo con los caninos superiores de los ciervos, donde se ha registrado un fuerte desfase entre los resultados obtenidos con el modelo métrico y con el modelo morfológico y que no coinciden con los resultados de los yugales. Esto podría deberse a la dificultad a la hora de observar los cambios de forma y en la toma de medidas de estas piezas, así como a la especial situación de estas piezas con respecto a la fila premolar-molar. Por esta razón, estas piezas son de difícil uso.

\section{Estacionalidad}

La estimación de la estacionalidad es un complemento a los resultados obtenidos en la edad de muerte. El patrón social y el comportamiento de los diferentes taxones nos pueden aportar datos acerca de las variaciones estacionales, rangos de edad o sexos. En este caso, y debido a la falta de información acerca de especies extintas, utilizamos datos basados en poblaciones actuales silvestres de la Península Ibérica.

El patrón social y la etología de los ungulados estudiados son muy similares, variando únicamente en las edades y en la composición y el tamaño relativo de los grupos pero siguiendo el mismo patrón general. El número de crías suele ser de 1, exceptuando el caso del S. scrofa que puede presentar hasta ocho jabatos (Fernández - Llario, 2006), los partos dobles son raros y las observaciones que se realizan de más de una cría se deben en muchos casos a individuos "adoptados". En general, son especies en las que los machos o bien forman grupos de pequeño tamaño o bien son solitarios. Las hembras por otra parte, suelen formar grupos bien con sus descendientes directos bien con otras hembras con la finalidad de proteger a las crías de manera más efectiva. En todos los casos, los machos abandonan la unidad familiar entre el primer y segundo año de vida, aunque en algunas especies este hecho puede producirse más tempranamente, como en el corzo, o más tarde, como en el ciervo. En las hembras no ocurre lo mismo, pudiendo permanecer en el grupo matriarcal, o formar uno propio pero no muy alejado de su grupo original.

Sin embargo, los patrones básicos de actividad y el uso del espacio pueden verse afectados por las interacciones ecológicas que los individuos de una especie mantienen con el medio en el que se desenvuelven, así como por las relaciones que tienen con otros miembros de la misma especie que incluyen los recursos alimenticios, los depredadores o la presencia de otras especies competidoras. Por todo esto, tanto las diferencias entre sexos y edades como la forma de enfrentarse y resolver estas interacciones varían en cada individuo y cada especie, de modo que resulta difícil generalizar y no hablar, a menudo, de situaciones excepcionales. En el caso concreto de los ungulados de la Península Ibérica, el uso del espacio se encuentra fuertemente afectado por la actividad humana, ya sea para sus propios propósitos, como la creación de pastos o lugares de ocupación, o bien para influir directamente en sus poblaciones a través de la caza (Carranza, 2000). Así, por ejemplo, la época de celo y por lo tanto la de partos de las poblaciones de ungulados estudiadas pueden verse afectadas por la disponibilidad de alimentos o las condiciones físicas de las hembras. La época de partos en el jabalí, S. scrofa, puede producirse durante todo el año en algunas regiones de la península (Markina et al., 2003). Las hembras de los ciervos pueden permanecer con la madre hasta que ellas tienen una cría de un año y después formar su propio grupo, asimismo en la época de celo se suelen distribuir en 
función de la disponibilidad de la comida y los machos se desplazan hacia las zonas donde hay más hembras (Carranza y Valencia, 1999). El celo en el corzo está muy dilatado en las poblaciones ibéricas (Mateos-Quesada, 1998) aunque no afecta a la época de partos. En los rebecos, los grupos de hembras con crías son de mayor tamaño en las áreas desprovistas de terreno de escape (Pérez-Barbería y García-González, 2004), de lo contrario se impediría una huida eficiente. La formación de grupos no es constante en la especie, habiéndose observado en la subespecie pyrenaica que el grupo más estable es el de la madre con una cría. La formación de clanes de mayor tamaño en los sarrios pirenaicos se cree debida a la unión de grupos que migran juntos pero sin una cohesión prolongada en el tiempo (Pérez-Barbería y García-González, 2004). Las cabras monteses presentan una fuerte estacionalidad en el periodo de partos con el fin de garantizar la supervivencia de las crías (Alados y Escós, 2003). El número de partos gemelares en esta especie alcanza el $10 \%$. Durante la época de celo el número de machos despeñados se incrementa debido a las carreras por controlar o proteger el harén (Pérez-Barbería y García-González, 2004).

Con todo esto queremos indicar que si bien el modelo social y el comportamiento de las diferentes especies analizadas muestra un patrón general, existen muchas excepciones no sólo a nivel específico sino también en función de la distribución de las diferentes poblaciones en el territorio. Este análisis sólo ha podido llevarse a cabo en aquellas especies en las que la edad ha sido estimada en meses y únicamente en aquellas que han aportado una edad concreta. No se tienen en cuenta, por tanto, las edades registradas en años y las recogidas a partir de las edades de erupción y reemplazamiento dental.

También es importante asociar los diferentes periodos de actividad con la latitud, ya que el patrón social puede variar en función de la temperatura. Así, Hayssen et al., (1993) observa ciertas diferencias en las poblaciones europeas en función de su distribución. Esto, en un periodo glaciar, en el que se encuentran muchos de nuestros yacimientos, hace pensar que quizás el comportamiento reproductivo de las especies estudiadas podría modificarse con la finalidad de que las crías pudieran alcanzar el tamaño suficiente para poder sobrevivir a los periodos de mayor escasez. Esto podría modificar los periodos de parto, lactancia y celo, y por lo tanto condicionar nuestros resultados. Esta variable tiene difícil solución pero habría que tenerla en cuenta en posibles estudios futuros sobre estacionalidad ya que condiciona los periodos en los que una cavidad pudo estar ocupada.

\section{Bimodalidad y dimorfismo sexual}

El sexo, junto con la edad y el peso son fuentes importantes de información sobre la etología y la biología de las especies y es vital para el estudio de la dinámica de una población (Pérez-Barbería y Pérez-Fernández, 2009). En yacimientos paleontológicos, el sexo de las especies recuperadas puede hacernos entender la composición del grupo y el posible origen de la acumulación (Speth, 1983; Klein y Cruz-Uribe, 1984; Monchot, 1999). Por otra parte, en yacimientos arqueológicos, el sexo junto con la edad de muerte de las presas puede proporcionar importantes datos acerca de las estrategias de caza y subsistencia de las poblaciones prehistóricas de cazadores recolectores (Speth, 1983; Klein y Cruz-Uribe, 1984; Stiner, 1990; Monchot, 1999). Los métodos de observación directa aplicados en neontología no pueden ser empleados directamente a yacimientos arqueológicos y paleontológicos. Además, estos yacimientos presentan normalmente una dificultad añadida, la naturaleza fragmentada de muchos de los restos acumulados, y la ausencia, en ocasiones, de material diagnóstico que hacen de la determinación del sexo algo complicado.

La determinación del sexo basada en material osteológico es posible cuando hay diferencias esqueléticas entre los machos y las hembras de una especie, bien a nivel morfológico, bien a nivel métrico. En este contexto, los animales más dimórficos o bimodales son los que se sexan con más facilidad. Tradicionalmente, los estudios dedicados a sexar se han basado en el aspecto externo del animal. La otra alternativa, la 
bimodalidad, mide fundamentalmente las diferencias en el tamaño corporal (Klein y CruzUribe, 1984).

Habitualmente, las diferencias basadas en la forma y en el tamaño se suelen confundir. Estas diferencias pueden ser expresadas en forma (dimorfismo) o tamaño (bimodalidad). La forma puede ser variable en términos de población, especie, cronología etc. Hay que tener en cuenta que, en ocasiones, las diferencias de tamaño pueden inducir diferencias en la forma, lo que se denomina alometría, lo que no se considera realmente un dimorfismo sexual. En este contexto, los animales más dimórficos o bimodales son los que se sexan con más facilidad.

Tradicionalmente, los estudios dedicados a sexar mamíferos actuales se han basado en el aspecto externo del animal (Alados y Escós, 2003; Carranza, 2011; Fernández-Llario, 2006; Mateos-Quesada, 2011; Pérez-Barbería et al., 2010). En muchos taxones, algunas partes del esqueleto difieren entre los sexos, aunque no ocurre lo mismo con los dientes que a pesar de ser los restos más abundantes en la mayoría de los depósitos, no muestran diferencias significativas entre los sexos (Dong, 1997) a excepción de los caninos en équidos, suidos y cérvidos (d'Errico y Vanhaeren, 2002). En los équidos, por ejemplo, las mandíbulas de los machos normalmente presentan caninos, mientras que en las hembras están ausentes o son vestigiales. Algo similar ocurre en algunos bóvidos en los que las hembras carecen de cuernos o, en el caso en que las presenten, son más pequeñas que los de los machos (Klein y Cruz-Uribe, 1984). En los carnívoros, el pene normalmente presenta un hueso denominado "baculum" que no lo tienen las hembras. En los seres humanos, la pelvis de las hembras difiere significativamente de la de los machos debido al canal del parto, algo que ocurre también por ejemplo en los cérvidos y los caprinos (Boessneck, 1969).

La otra alternativa a la hora de sexar especies, la bimodalidad, se refiere a las diferencias en el tamaño corporal (Klein y Cruz-Uribe, 1984, Van der Made, 1991). Los machos tienden a ser más grandes que las hembras en la mayoría de los mamíferos (Boessneck y Von den Driesch, 1978) por lo que se pueden emplear métodos estadísticos para demostrar las diferencias en el tamaño y medir su variación; y una vez detectadas emplearlas para sexar los huesos. Una de las ventajas de la bimodalidad es que se puede aplicar a gran cantidad de huesos, al menos en los que abundan en los yacimientos arqueológicos. Además, no hay indicios de que pueda existir una selección de sexos sobre estas piezas en los procesos postdeposicionales (Klein y Cruz-Uribe, 1984). Este método es, claramente, el más útil cuando lo aplicamos a elementos esqueléticos donde la diferencia de tamaños entre sexos es conocida. Normalmente, estos estudios han empleado análisis bivariantes o distribuciones univariantes (Altuna, 1978; Cuggiani, 1981; Chaix y Desse, 1983; Herrera, 1988; David y Enloe, 1993; Weinstock, 2000; Fernández, 2001; Zeder, 2001). Sin embargo, existen una serie de problemas asociados a estos métodos como, por ejemplo, el establecimiento de una frontera entre machos y hembras, sobre todo en especies con un solapamiento acentuado; y la valoración en la anchura de los histogramas (Dong, 1997; Monchot y Lechelle, 2002). Algunos autores sugieren elegir alguna dimensión en concreto y sexar a partir de ella. Por ejemplo, Klein y Cruz-Uribe (1984) indican que las epífisis de los huesos largos son una buena opción ya que sostienen el peso del animal, siendo, por lo tanto, mayores en los machos. Normalmente, estos estudios se aplican en huesos en los que las epífisis están ya fusionadas y por tanto han terminado ya su crecimiento, lo que evita registrar diferencias de tamaño que se deben al crecimiento y no al dimorfismo sexual per se (Klein y Cruz-Uribe, 1984). Por lo tanto, si los sexos difieren en tamaño y si ambos están bien representados en la muestra y, además, ésta es lo suficientemente grande, en una representación gráfica es esperable que los sexos ocupen distintos espacios. Los individuos grandes serán machos y los pequeños a las hembras.

Hay varios problemas intrínsecos a este método (Klein y Cruz-Uribe, 1984). El primero es que se excluye a individuos con un crecimiento incompleto, aunque en muchas muestras son muy comunes, lo cual reduce enormemente el número de restos sobre los 
que se puede aplicar la técnica. Otra dificultad recae en las colecciones de referencia, ya que en algunas muestras domésticas, los machos pueden aparecer castrados afectando esto a su tamaño (Chaplin, 1971), aunque no es el caso aquí. En los últimos años han proliferado diferentes metodologías que han tratado de dejar los modelos uni y bivariantes atrás y han sido aplicados tanto a homínidos (Arsuaga et al., 1997; Dong, 1997; Rehg y Leigh, 1999; Rosas et al., 2002; Gómez - Olivencia et al., 2007), como a carnívoros (Monchot y Gendron, 2010) y herbívoros (Boessneck et al., 1964; Altuna, 1978; Mariezkurrena y Altuna, 1983; Monchot, 1999; Fernández y Monchot, 2007; Van Asperen, 2010). No obstante, los modelos empleados en los herbívoros se han basado tradicionalmente en especies muy dimórficas como la cabra montés (Altuna, 1978; Monchot, 1999; Fernández y Monchot, 2007), consiguiendo por lo tanto buenos resultados en sus comparaciones. Sin embargo, hay que tener en cuenta que hay especies que no presentan esos grados de bimodalidad y en las que el solapamiento entre sexos es marcado.

El cambio en el tamaño medio de las poblaciones puede ser atribuido a la domesticación (Davis, 1981), a cambios climáticos (Kurten, 1959, 1965; Klein, 1975), a presiones predatorias (Klein, 1979; Klein et al., 1983) o a la calidad de los pastos (Klein y Cruz-Uribe, 1984). Por otra parte, se sabe que el dimorfismo sexual en grandes primates está relacionado con su organización social y su comportamiento (Alexander et al., 1979; Clutton-Brock, 1985). Por ejemplo, cuanto más dimórfica es una especie existe una mayor tendencia a que éstas sean poligínicas, con un macho dominante; mientras que cuanto menos dimórfica es una especie más monogínica es, pudiendo establecer núcleos familiares. Por otra parte, la determinación del sexo permite conocer el sex ratio (índice entre el número de machos y hembras) de una población. Esto puede hacerse en especies con un dimorfismo y una bimodalidad determinables. Obtenerlo es sencillo si conocemos el sexo de cada uno de los ejemplares, pudiendo aportar importantes datos acerca de la biología y el comportamiento de las poblaciones, sobre las apetencias del/ de los responsable/s de la acumulación (Dong, 1997) o establecer inferencias sobre tendencias evolutivas y dinámicas de una población (Dong, 1997).

Los caracteres métricos y morfológicos definidos por d'Errico y Vanhaeren (2002) han permitido desarrollar un modelo para determinar el dimorfismo sexual y la bimodalidad sexual a partir del análisis de los caninos superiores de Cervus elaphus. La escasez de estudios sobre dimorfismo a partir del análisis de estas piezas puede deberse a diferentes causas, entre las que sobresale un patrón de desgaste diferencial. Sexar los restos a partir de estos dientes no debería ser complicado ya que las diferencias morfológicas son notables y más evidentes que en los dientes yugales. Las diferencias morfométricas entre machos y hembras permiten una estimación del sexo aceptable. El material utilizado es escaso por lo que sacar conclusiones acerca del origen o de los agentes de acumulación no sería del todo correcto. Sin embargo, los resultados pueden complementarse con aquellos obtenidos a partir del análisis de los dientes yugales. Un estudio conjunto puede fortalecer los resultados, así como aportar datos sobre la selección sexual.

Otro caso diferente es el del rebeco. Debido a la escasez de material actual y paleontológico, y por el elevado grado de solapamiento que existe entre los sexos, esta especie no ha sido utilizada en estudios de dimorfismo y bimodalidad sexual, siendo el único del que tenemos constancia el presentado en esta memoria, y que fue recientemente publicado (ver Arceredillo et al., 2011). Sin embargo, es la especie que ha aportado el mayor número de restos a este estudio. El rebeco es una especie moderadamente bimodal, lo que quiere decir que presenta un fuerte solapamiento de talla entre sexos, especialmente cuando es comparado con especies más dimórficas como la cabra montés (Pérez-Barbería y Pérez-Fernández, 2009). A nivel metodológico, cuando se quiere determinar qué métodos estadísticos son más efectivos a la hora de sexar, el uso de animales con un marcado dimorfismo sexual no es recomendable ya que todos los métodos darán buenos resultados con lo que no es posible discernir cuál es más apropiado. Animales con menos dimorfismo/bimodalidad son, en cambio, más apropiados 
para hacer estas pruebas metodológicas. En este estudio se ha seleccionado el rebeco, como un buen ejemplo para comprobar la efectividad de distintos métodos estadísticos.

Como referencia se ha utilizado el sarrio ibérico, en concreto a su variedad cantábrica, R. pyrenaica parva. La elección de esta subespecie se debe a dos motivos muy particulares. El primero, que es la subespecie con mayor colección de referencia, lo que nos permite realizar unos cálculos estadísticos más precisos. Por otro lado, como el objetivo era usar después esos métodos en el yacimiento de la Cueva de Valdegoba, se ha elegido la subespecie más cercana geográficamente. Es necesario señalar que la subespecie pyrenaica es ligeramente mayor que la cantábrica, hecho que hace que no sea recomendable mezclar material de ambos grupos. Asimismo, en la muestra control se han seleccionado, los ejemplares adultos para evitar que los resultados se viesen afectados por diferencias de tamaño de origen ontogenético.

En este estudio se ha demostrado que el método k-medias en particular, y los diferentes análisis cluster en general han proporcionado mejores resultados que el análisis de mixturas (mixture analysis). El método de análisis de mixturas había sido muy difundido por Monchot (Monchot, 1999; Quiles y Monchot, 2004; Fernández y Monchot, 2007), pero no se había testado de manera cuantitativa respecto a otros métodos. Sin embargo, una de las ventajas que presenta el análisis de mixturas frente al k-medias es la posibilidad de obtener la probabilidad a posteriori de pertenecer a un grupo u a otro. De esta forma, es posible conocer la clasificación de aquellos individuos más dudosos. Para detectar individuos problemáticos, en el k-medias, las distancias pueden ser calculadas al centroide del cluster en todos los casos. Sin embargo, aquellos individuos que muestren distancias similares a esos centroides podrían ser considerados más problemáticos en la determinación. Por otro lado, el k-medias presenta una serie de ventajas frente al análisis discriminante. Las funciones discriminantes procedentes de una muestra de sexo conocido no pueden ser aplicadas directamente al registro fósil, debido a que no se pueden contabilizar los potenciales cambios de tamaño en las poblaciones del pasado (Munro et al., 2011). Por el contrario, el k-medias se puede aplicar directamente a dicho registro, y los resultados obtenidos en una muestra no determinan los resultados en otra.

En resumen, aunque la literatura relacionada con las aplicaciones del análisis de mixturas es muy abundante (Monchot, 1999; Quiles y Monchot, 2004; Fernández y Monchot, 2007), el k-medias ha aportado mejores resultados en los rebecos, una especie menos bimodal y más difícil de sexar. Por lo tanto, consideramos que la aplicación del kmedias para animales más bimodales aporta excelentes resultados. Adicionalmente, esta metodología no presenta los inconvenientes del análisis discriminante, en los que la aplicación directa al registro fósil es complicada. Además, el k-medias ha sido aplicado previamente, en arqueología, al análisis espacial (Kintigh y Ammerman, 1982), al estudio de restos líticos (Ríos, 2010) y probablemente puede ser útil en estudios taxonómicos como los realizados por Monchot y Gendron (2010).

Sin embargo, soy consciente de que, incluso, aunque las muestras analizadas aquí son las más grandes tanto en el caso de la actual como en la fósil, el número de individuos implicado es aún bajo y esto podría ser el punto de partida para futuros trabajos. Además, sería interesante, en futuros análisis, aumentar la muestra de rebeco fósil, estudiar su dimorfismo, relacionarlo con las oscilaciones climáticas del Pleistoceno y con las posibles presiones cinegéticas de las poblaciones humanas de este periodo en la Península Ibérica.

\section{Número mínimo de individuos}

El criterio para calcular el número mínimo de individuos difiere del empleado en (Arceredillo, 2008). En dicho trabajo se empleaban únicamente los dientes y se clasificaban los individuos en inmaduros y maduros. Los primeros a partir de los dientes deciduales y los segundos a partir de las piezas permanentes. En el presente estudio, este sistema no puede aplicarse ya que, al determinar la edad de muerte, podemos crear un 
sesgo debido a que los inmaduros incluyen ejemplares infantiles y juveniles, y los maduros a los adultos y seniles por lo que podríamos contabilizar dos veces los mismos individuos. El número de ejemplares se ha reducido con respecto a los expuestos en Arceredillo (2008) pero los porcentajes se mantienen sin muchos cambios.

\subsection{Paleobiología}

Los caracteres descritos en apartados anteriores nos han permitido asignar los restos de los rinocerontes de la Cueva de Valdegoba, Cueva Millán, la Cueva del Búho y uno de los identificados en la Peña de Mudá a Stephanorhinus hemitoechus. Esta especie es frecuente en las faunas del Pleistoceno Europeo. A pesar de que la entrada de esta especie en Europa no está muy clara (Guérin, 1980; Sardella et al., 1998; Kahlke, 2001) parece que ya se encuentra Europa occidental, en l'Arago, en torno al OIS 12 (Van der Made et al., 2010), aunque ya hay registros en Alemania en el OIS 15 (Van der Made, 2005). Su presencia es común en toda Europa a partir de ese momento, apareciendo en la Península Ibérica desde el Pleistoceno Medio y alcanzando su mayor distribución en el Pleistoceno Tardío (Cerdeño, 1990). Uno de sus últimos registros se encuentra en el yacimiento de La Ventana, en la transición del Pleistoceno y el Holoceno (Sánchez et al., 2003). Parece que esta especie presenta un aumento de la robustez desde las formas del Pleistoceno Medio a las presentes en el Pleistoceno Superior (Van der Made, 2010). Este autor indica la presencia de un $S$. hemitoechus grácil en yacimientos como l'Arago, Bilzingsleben, Heppenloch, Orgnac 3 y Steinheim; y de uno más robusto en depósitos como La Fage, Ehringsdorf, Neumark Nord, Barrington, Taubach, Burgtonna, Crayford, Can Rubau, Abric Romaní, Arroyo Culebro y La Ventana. Los datos obtenidos en el astrágalo de la Cueva de Valdegoba, única pieza postcraneal recuperada, se encuentran próximos a los valores de la forma grácil de Bilzingsleben y a la robusta de Taubach; pero alejados de otras formas robustas como Neumark Nord o Ehringsdorf (Van der Made, 2010: figura 35). La falta de material postcraneal no nos permite incluir a estos ejemplares en uno u otro grupo ya que tampoco el material dental nos aporta datos concluyentes.

El rinoceronte lanudo, Coelodonta antiquitatis, se ha identificado en la Peña de Mudá y en La Mina. El material de Mudá fue incluido, en primer lugar, en Rhinoceros merckii (= Stephanorhinus kirchbergensis) y posteriormente en C. antiquitatis por Álvarez-Lao (2007). La falta de datos sobre el depósito, localización y dataciones, nos impiden situarlo en un contexto concreto. Los restos de La Mina, clasificados en un primer momento como Stephanorhinus hemitoechus (Díez et al., 2008), han aportado la única datación del depósito, 52,5 Ka., lo que implica que son los más antiguos del Pleistoceno Tardío ibérico, sólo superados por el yacimiento del Pleistoceno Medio de La Parte (Álvarez-Lao y García, 2006). Sesé y Soto (2002) apuntan a que también pudiera pertenecer al Pleistoceno Medio el yacimiento de Los Rosales y Álvarez-Lao y García $(2011,2014)$ incluyen los restos de Arroyo Culebro en el Pleistoceno Superior Temprano. Sin embargo, ni Los Rosales ni Arroyo Culebro han aportado dataciones absolutas por lo que el resto de La Mina es, a día de hoy, el más antiguo del Pleistoceno Tardío ibérico, sugiriendo una entrada más temprana en este periodo.

La Mina añade un nuevo yacimiento, con Coelodonta, a los 24 descritos por Álvarez-Lao y García (2011) y Álvarez-Lao (2014); y una nueva datación a las 8 ya realizadas (ÁlvarezLao y García, 2011; Álvarez-Lao, 2014). Este descubrimiento plantea dos nuevos aspectos, no sólo en lo referente a la distribución de este género sino también a las posibles vías de acceso a la Meseta Norte durante el Paleolítico. Álvarez-Lao y García (2011) hablan de tres entradas detectadas, una durante el Pleistoceno Medio y dos durante el Pleistoceno Superior (tres si incluyéramos Arroyo Culebro): la primera entre los 36 y $41 \mathrm{Ka}$. con yacimientos como Labeko Koba y Covacho Arenillas; y la segunda entre los 32 y $20 \mathrm{Ka}$. con depósitos como Leguintxiki, Abauntz, Cueva del Cuco y Lezetxiki (Álvarez-Lao y García, 2010). El nuevo registro y las nuevas dataciones retrasan la entrada de este taxón en la península al menos $10 \mathrm{Ka}$., al MIS 3, un periodo algo más cálido que los otros dos, que 
corresponden a eventos fríos y a la expansión de las estepas (Álvarez-Lao y García, 2011). La posible ausencia de material entre los 50 y los $100 \mathrm{Ka}$. podría deberse bien a la ausencia de esta especie en la península o bien a que estamos fuera del límite del carbono lo que limita las dataciones en algunos casos. Sin embargo, hay que tener en cuenta la incertidumbre que dan las dataciones de racemización de aminoácidos que incluyen rangos muy amplios, por lo que sería interesante aplicar más métodos, como el $\mathrm{C}^{14} \mathrm{o}$ el OSL, para poder concretar un poco más la edad del depósito. Álvarez-Lao y García (2014) indican que lo que sí que parece posible es que la presencia de este taxón en la Península Ibérica responde a entradas esporádicas provenientes de Europa más que a una presencia estable.

Hasta este momento 20 de los 23 yacimientos con restos de rinoceronte lanudo se han localizado en el norte de la Península Ibérica: 18 en la región cantábrica y 2 en Cataluña. Los otros tres se encuentran en el centro, en Madrid. Según Delpech (1983) las poblaciones de rinoceronte lanudo, frecuentes en el sur de Francia durante el Pleistoceno Tardío, entraron en la península, atravesando los Pirineos por sus márgenes occidental y oriental, ocupando las regiones cantábrica y catalana respectivamente. Estas rutas de acceso han sido tenidas en cuenta también por Arrizabalaga y Ríos-Garaizar (2012), añadiendo que, una vez atravesados estos lugares, la fauna se movería libremente ocupando otros territorios pero siempre siguiendo los mismos ejes geográficos. Estos autores proponen varios pasos de montaña entre la costa cantábrica, la llanada alavesa y el valle del Ebro que posteriormente tendrían conexión con la Meseta. Estos pasos fueron muy empleados por los grupos humanos y podrían ser también aptos para el paso de fauna ya que muchos de estos grupos se movían siguiendo las manadas y establecían sus asentamientos en lugares de paso. Estos autores definen la denominada "encrucijada vasca" que actuaría como un nudo de comunicaciones entre la región cantábrica, la Meseta Norte e incluso la región mediterránea. Podríamos, por lo tanto, a partir de la entrada por el oeste de los Pirineos, inferir tres posibles rutas de acceso a la Meseta: por el oeste, por el alto Valle del Ebro; por el este, por los valles del Egea y Arga; y por el sur, a través de la Rioja alavesa y de Navarra.

Estas tres posibilidades podrían explicar la presencia de rinoceronte lanudo en la Meseta y también de los restos localizados en el centro de la Península. A estas tres opciones, podríamos añadir una cuarta, el acceso a través de la cordillera Cantábrica por puertos como los de la Palombera, San Glorio, Piedrasluengas, el Escudo, Estacas de Trueba, la Lunada o la Sía. Estos pasos quedan próximos a los depósitos de Prado Vargas y de la Peña de Mudá. Díez y Navazo (2005, fig. 7) sugieren pasos a través de esta cadena montañosa, manteniéndose durante el Paleolítico Superior (La Palomera, Ojo Guareña, Penches, La Blanca etc.) y en tiempos históricos. Esto podría explicar la presencia de la pieza de la Peña de Mudá, abriendo más posibilidades a la población de la Meseta. Sin embargo, estos dos yacimientos se encuentran muy alejados de la Comarca del Arlanza y el paso a través de la encrucijada vasca sería el más viable. A pesar de esto, no podemos descartar esta posibilidad.

Equus ferus es una especie bien representada y aparece en casi todos los depósitos que se han estudiado. Su clasificación a lo largo de los años ha ido cambiando mucho, principalmente por la descripción de nuevas subespecies (Maldonado, 1996). Los últimos datos genéticos sugieren que no son más que el reflejo de una gran variabilidad debida a su gran plasticidad (Orlando et al., 2008; 2009). Esta variabilidad morfológica no aparece reflejada en la genética y en muchos casos, los índices empleados para separar subespecies cronológicamente muy próximas se solapan mucho (Maldonado, 1996). En este sentido, los estudios paleogenéticos están aportando nuevos datos acerca de la evolución de este taxón a lo largo de todo el Pleistoceno.

Maldonado (1996) observa una disminución progresiva en el tamaño de los dientes que va desde el E.f.mosbachensis del OIS 12 hasta los caballos actuales. Esta disminución también se observa en el tamaño del protocono (figura VI.1.1). 


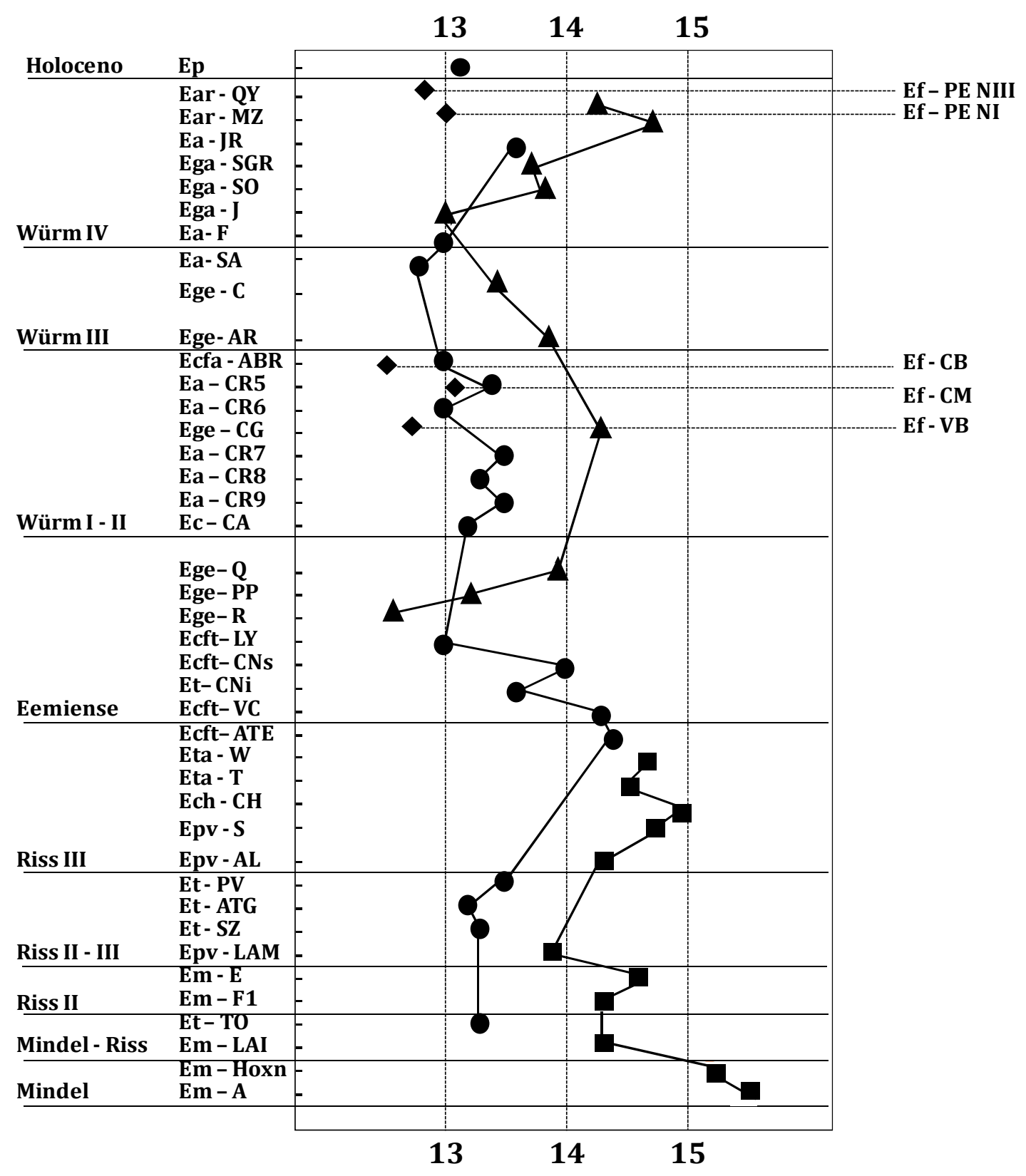

Figura VI.1.1. Variación del tamaño del protocono (PL) de la dentición superior (dientes yugales centrales $\mathrm{P}^{3}$ a $\mathrm{M}^{2}$ ). Valores medios. Especies: Ear: Equus caballus arcelini. Ea: E. caballus antunesi. Ega: E. caballus gallicus. Ege: E. caballus germanicus. Ecfa: E. caballus cf. antunesi. Ec: E. caballus casarensis. Ecft: E. caballus cf. torralbae. Et: E. caballus torralbae. Eta: E. caballus taubachensis. Ech: E. caballus chosaricus. Epv: E. caballus pivetaui. Em: E. caballus mosbachensis. Ef: E. ferus. Yacimientos: QY: Le Queroy. MZ: Mezine. JR: Joao Ramos. SGR: St. Germain la Riviere. SO: Solutre. J: Jaurens. F: Fontahinas. SA: Salemas. AR: Arcy. ABR: Abric Romani. CR: La Carihuela. CG: Combe Grenal. CA: Los Casares. Q: La Quina. PP: Pair non Pair. R: Remagen. LY: Las Yedras. CN: Cova Negra. VC: Villacastín. ATE: Atapuerca Trinchera Elefante nivel 9. W: Weimar. T: Taubach. CH: Toungouze. S: Abri Suard. AL: yacimientos ingleses antewürnienses. PV: Pinilla del Valle. ATG: Atapuerca Galería. SZ: Solana Zamborino. LAM: Achenheim loess medio. E: Ehringsdorf. F1: La Fage. T0: Torralba. LAI: Achenheim loess inferior. Hoxn: yacimientos ingleses del Mindel Riss. A: l'Arago (datos y terminología tomada de Maldonado, 1996; gráfico 24). VB: la Cueva de Valdegoba. CM: Cueva Millán. CB: la Cueva del Búho. PE: la Peña de Estebanvela. $\mathbf{A}$ grupo germanicus-gallicus. Ogrupo torralbae-antunesi. :

Nuestros datos corroboran este patrón tras actualizar los datos de Maldonado con las nuevas dataciones de la Cueva de Valdegoba, que sitúan los restos entre los caballos de los niveles 6 y 7 de la Carihuela. El material de Cueva Millán pertenece completamente al nivel 1c, un nivel sin dataciones, aunque sería más antiguo de los $43 \mathrm{Ka}$., fecha registrada en el nivel previo. El tamaño de estas piezas sigue el patrón de disminución, presentando unos valores cercanos al caballo del Abric Romaní, al igual que los restos de la Cueva del Búho, y 
encontrándose entre los caballos con protoconos pequeños del OIS 3. Los datos recogidos en la Peña de Estebanvela corroboran también esta disminución de tamaño, siendo más grandes los del nivel III y más pequeños los del nivel I, que están cerca ya de los valores de los caballos actuales. Por lo general, podemos indicar que los restos de E. ferus recuperados en los yacimientos de la Meseta Norte confirman la disminución de tamaño en este taxón desde el OIS 12 hasta la actualidad.

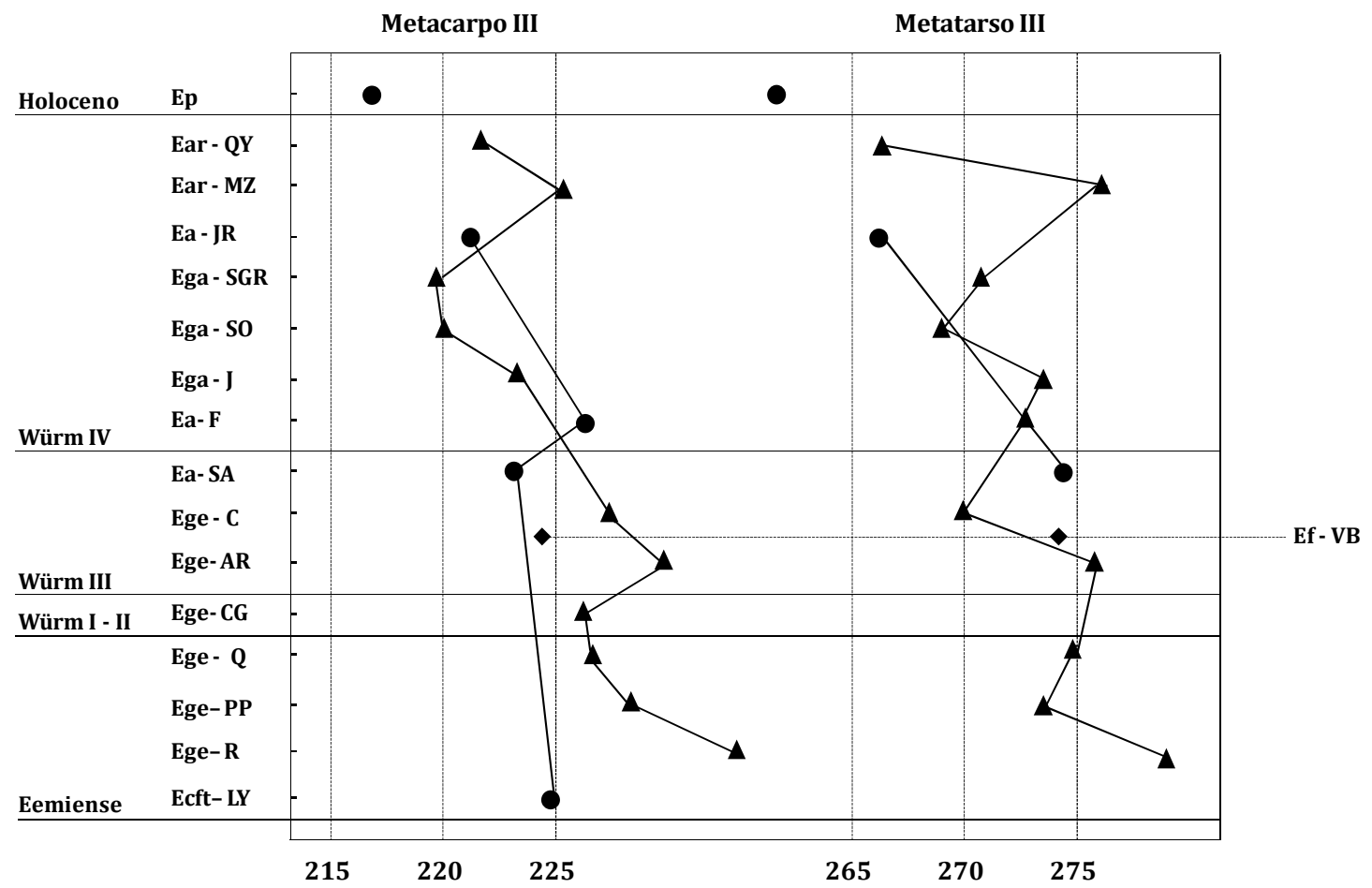

Figura VI.1.2. Variación de la longitud de los metápodos (GL) en Equus ferus. Especies: Ep: Equus caballus przewalskii actual. Ear: E. caballus arcelini. Ea: E. caballus antunesi. Ega: E. caballus gallicus. Ege: E. caballus germanicus. Ecft: E. caballus cf. torralbae. Ef: E. ferus. Yacimientos: QY: Le Queroy. MZ: Mezine. JR: Joao Ramos. SGR: St. Germain la Riviere. SO: Solutre. J: Jaurens. F: Fontahinas. SA: Salemas. AR: Arcy. CG: Combe Grenal. Q: La Quina. PP: Pair non Pair. R: Remagen. LY: Las Yedras (datos y terminología tomada de Maldonado, 1996; gráfico 24). VB: la Cueva de Valdegoba. $\mathbf{A}$ grupo germanicus-gallicus. Ogrupo torralbae-antunesi.

Algo similar ocurre con los metápodos. Maldonado (1996) registra un acortamiento de los metacarpos y metatarsos desde el OIS 12 hasta los caballos actuales. Los valores registrados en los metacarpos y metatarsos de la Cueva de Valdegoba siguen este patrón (figura VI.1.2), colocándose entre los caballos de Salemas y Combe Grenal. Podemos indicarque los caballos de la Meseta Norte siguen el patrón de otros caballos europeos del Pleistoceno Tardío.

La especie E. hydruntinus está bien representada en el Pleistoceno Tardío de la Meseta Norte. Presentan una dentición inferior similar a la de otros E. hydruntinus centroeuropeos aunque la superior es ligeramente más grande. Algunos autores como Prat (1968) lo achacan a adaptaciones a condiciones ambientales diferentes. Por lo general, se aprecian pocas variaciones en el tamaño corporal lo que hace que resulte un grupo muy homogéneo (Maldonado, 1996) y los restos estudiados en esta memoria se enmarcan dentro de esta tendencia (figura V.1.3).

El ciervo, Cervus elaphus, está bien representado en la Meseta. Van der Made (2011b) y Van der Made et al., (2014) hacen un análisis de la evolución del tamaño de esta especie, desde el OIS 20, utilizando el diámetro transversal del lóbulo anterior del $\mathrm{M}_{3}$, la anchura de la articulación proximal de las falanges proximales y la longitud lateral de los astrágalos (figura VI.1.4). En los tres casos se observa una disminución desde el Cervus elaphus spp. 
(MIS 12 - 15) hasta el C. elaphus actual con un pequeño incremento en el C. elaphus angulatus. En estos trabajos, el material de la Cueva de Valdegoba se sitúa en el OIS5, y no en el OIS3 como indican las nuevas dataciones. Sin embargo, y a diferencia de lo que ocurre en el caballo, cuando trasladamos los datos a su nueva ubicación, la tendencia no sufre un gran cambio. Nuestros datos, tanto los tomados en el $\mathrm{M}_{3}$ como en los astrágalos y en las falanges, encajan bien en esta disminución de tamaño registrada por Van der Made (2011b) y Van der Made et al. (2014).

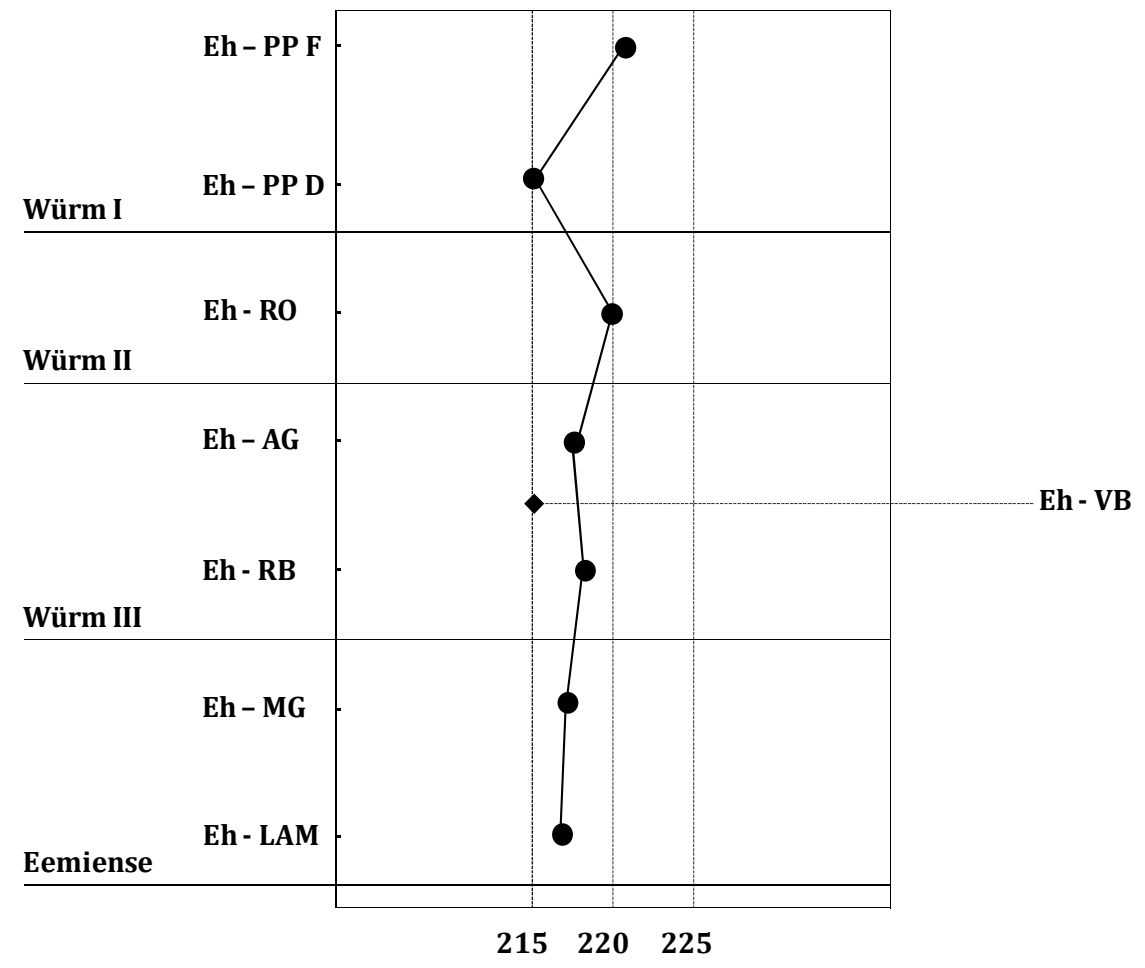

Figura VI.1.3. Variación de la longitud de los metápodos (GL) en E. hydruntinus. Yacimientos: PP F: Pair non Pair nivel F. PP D: Pair non Pair nivel D. RO: Romanelli. AG: Agios Georgios. RB: Roter Berg. MG: Montgaudier. LAM: Achenheim loess medio (datos y terminología tomada de Maldonado, 1996; gráfico 24). VB: Cueva de Valdegoba.

Si nos fijamos en la edad de muerte, en los depósitos del Pleistoceno Medio no vemos una tendencia clara en la adquisición de un tipo u otro de rangos de edad (figuras V.7.5, 7, 8 y 9). Por lo general, en los yacimientos del Paleolítico Medio predominan los ejemplares infantiles (0-6 meses) seguidos de los juveniles (6-43) y de los adultos (>43). En los yacimientos del Paleolítico Superior abundan los ejemplares juveniles aunque hay que tener en cuenta que el número de depósitos es significativamente menor.

En cuanto a la estacionalidad, los resultados de la Cueva del Búho no se han tenido en cuenta ya que su acumulación no es de origen antrópico (Sala, 2012). En la Cueva de Valdegoba se observa una fuerte estacionalidad en los ejemplares infantiles y adultos, pero no en los juveniles que son depositados durante todo el año. La acumulación se centra en la época de partos, donde capturan tanto a infantiles, juveniles como adultos. En estas épocas tanto las hembras como las crías recién nacidas suelen ser más vulnerables.

Los infantiles disminuyen en otoño, a favor de los juveniles. Éstos abandonan el grupo donde han nacido en torno a los dos años, tienen menos experiencia, son más vulnerables y podrían permanecer solos durante cierto tiempo. No ocurre lo mismo con los adultos en los que no se recogen datos en otoño, época que coincide con el celo, cuando son más agresivos. 

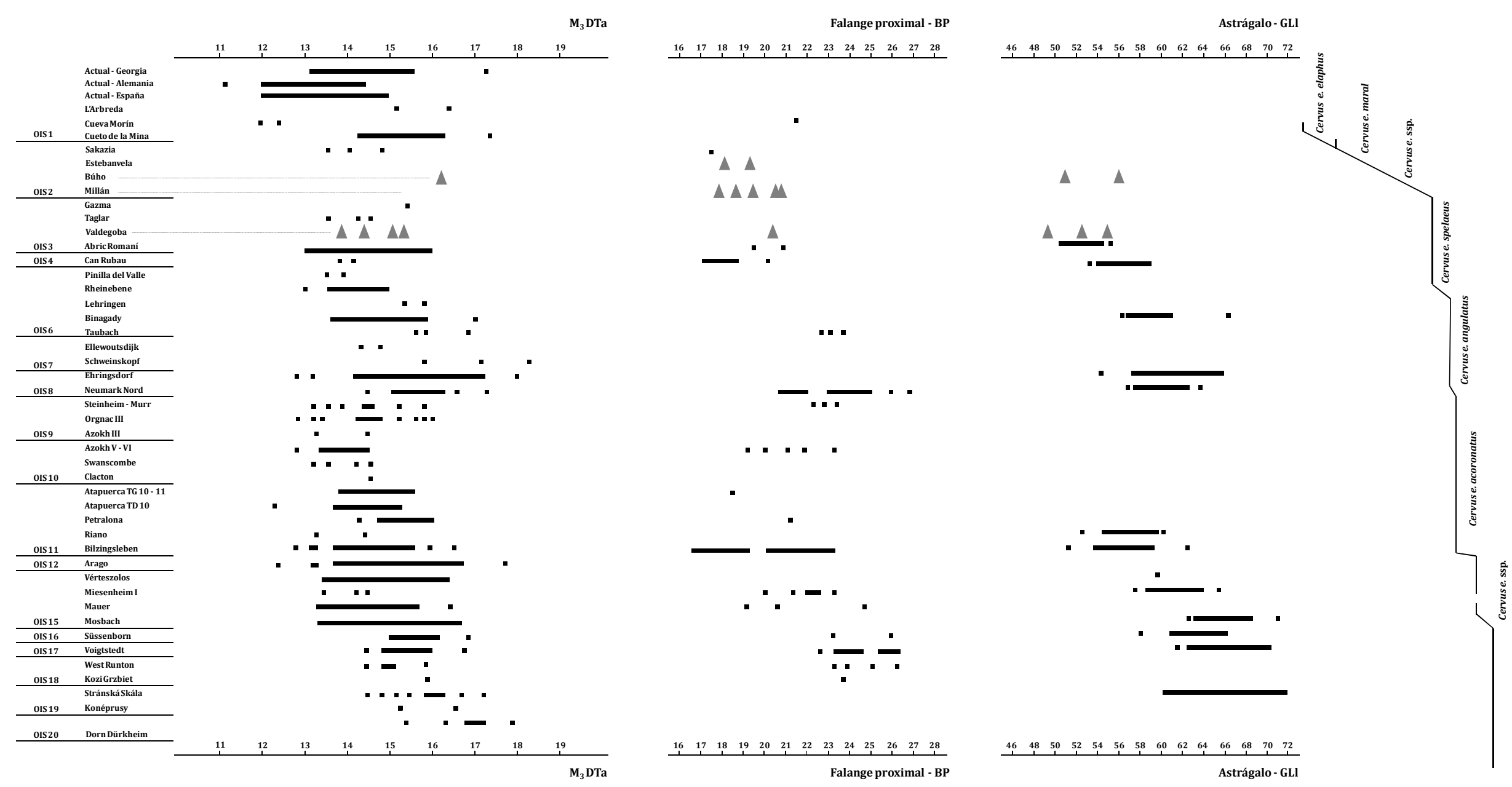

Figura VI.1.4. Variación de tamaño en el ciervo, Cervus elaphus, tomando la anchura del primer lóbulo (DTa) del M3, la anchura proximal (BP) de las falanges proximales y la longitud lateral del astrágalo (GLl). Los datos de la Cueva de Valdegoba, Cueva Millán, la Cueva del Búho y la Peña de Estebanvela se han añadido a las tablas de Van der Made (2011b) y Van der Made et al., (2014). 
Parece ser que la caza de esta especie coincide con los periodos de mayor vulnerabilidad. Los infantiles serían acumulados fundamentalmente en los periodos de parto y lactancia; los juveniles cuando abandonan el grupo en el que han nacido y los adultos cuando termina el celo y pueden permanecer aislados o formar pequeños grupos.

Los caninos superiores han demostrado ser unos buenos marcadores sexuales. Sin embargo, en los yacimientos de la Meseta son escasos y su análisis no aporta muchos datos acerca de una posible selección sexual de las presas. Por esta razón, sería interesante realizar estos análisis en otros yacimientos en los que estas piezas son más abundantes debido a su uso como elementos decorativos (Vanhaeren y d'Errico, 2003; Peñalver Iribarren, 2005; Vidal Encinas et al., 2010).

El corzo, Capreolus capreolus, no es muy abundante en los depósitos de la Meseta Norte. Se ha observado una disminución de tamaño desde sus primeros representantes, $C$. cusanoides y C. suessenbornensis, hasta las poblaciones actuales (Van der Made et al., 2014). El material de la Cueva de Valdegoba encaja bien en esta tendencia (figura VI.1.5).

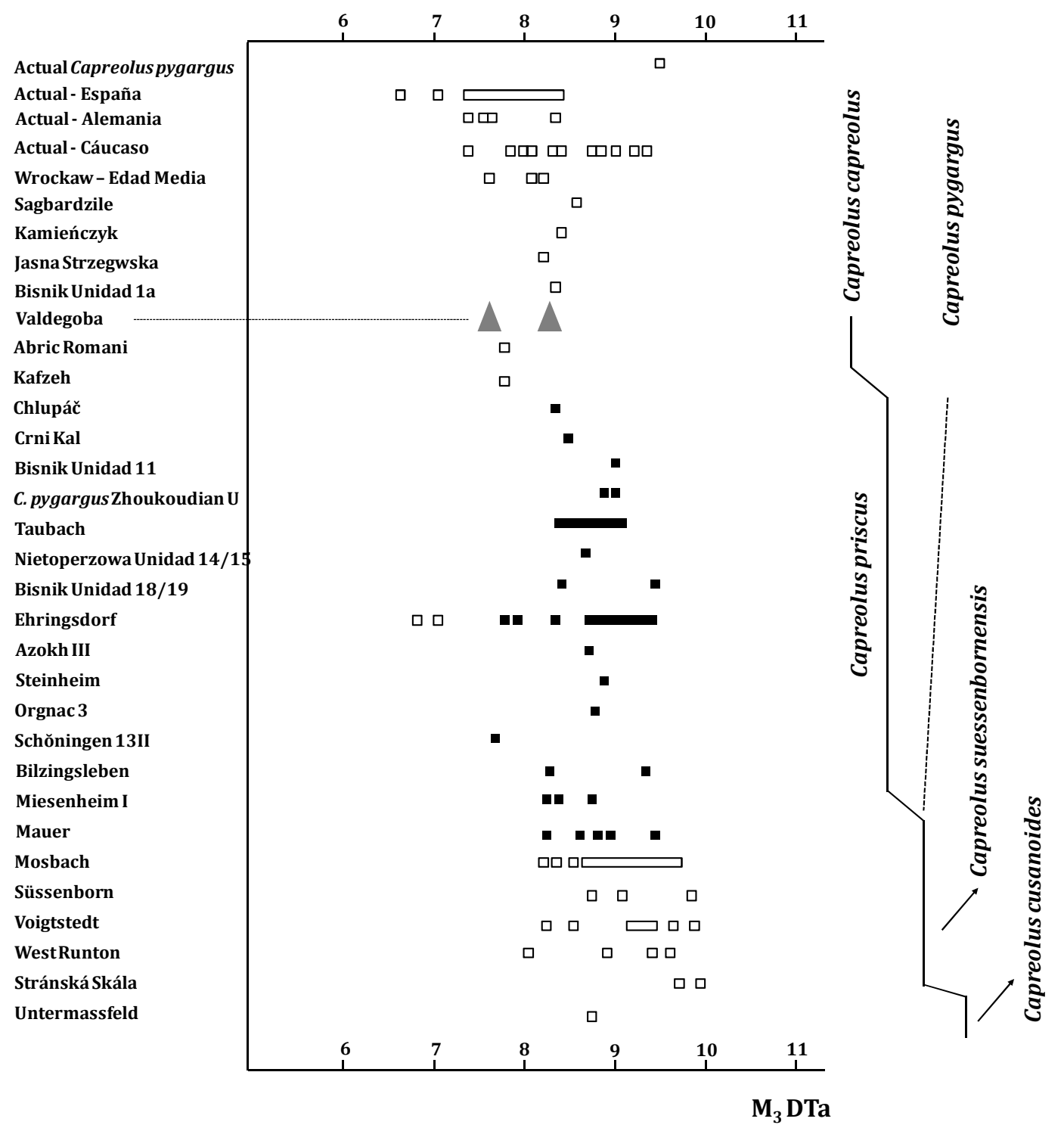

Figura VI.1.5. Variación de tamaño en el corzo, Capreolus capreolus, tomando la anchura del primer lóbulo (DTa) del M3. Los datos de la Cueva de Valdegoba se han añadido a las tablas de Van der Made et al., (2014). Datos y terminología tomada de Van der Made et al., 2014; figuras 2 y 6. Los yacimientos están ordenados de más moderno (arriba) a más antiguo (abajo). 
El rebeco, Rupicapra pyrenaica, es la especie mejor representada debido, fundamentalmente, a la gran abundancia que presenta en la Cueva de Valdegoba (Arceredillo et al., 2011). Esta asociación es la segunda en abundancia de la Península Ibérica tras la del yacimiento guipuzcoano de Amalda (Altuna 1990b). El análisis de los restos postcraneales y el empleo de las últimas revisiones taxonómicas y migratorias nos han permitido reasignar los restos de la Cueva de Valdegoba, Prado Vargas, Cueva Millán y de la Peña de Estebanvela a la especie $R$ pyrenaica. Anteriores trabajos incluían este material en R. rupicapra (Quam et al., 2001; Navazo et al., 2005; Díez et al., 2008) aunque según Crégut-Bonnoure (2006) R. rupicapra nunca consiguió atravesar los Pirineos. La asignación de los rebecos fósiles ibéricos a la especie $R$. rupicapra se debe a que muchas de las listas faunísticas se realizaron antes de la publicación de Nascetti et al., (1988) en la empiezan a diferenciar a nivel genético ambas especies. Observar una tendencia en este taxón es complicado ya que sus restos, salvo excepciones no son muy abundantes (Altuna, 1972; Rivals, 2002, Youcef, 2009; Magniez, 2010). Los nuevos estudios filogenéticos, así como los recientes estudios sobre su dispersión en Europa han condicionado mucho la clasificación de este pequeño caprino en los yacimientos europeos, clasificándose, en algunos casos, los mismos restos como $R$. rupicapra o como $R$. pyrenaica. Por este motivo, establecer un patrón sería muy aventurado ya que al no haber accedido a dichas colecciones podríamos incluir, en el análisis, datos referentes a cualquiera de las dos. Sería necesario por tanto, un estudio monográfico de esta especie a nivel europeo para así confirmar datos tanto filogenéticos como migratorios.

En cuanto a la edad de muerte, observamos que en los depósitos del Paleolítico Medio predominan los adultos, seguidos de los juveniles y de los infantiles. Algo similar ocurre en los yacimientos del Paleolítico Superior, en los que los adultos también predominan. Si tenemos en cuenta la estacionalidad, observamos que en los yacimientos del Paleolítico Medio no parece existir un periodo concreto de acumulación ya que se han recuperado ejemplares en todas las estaciones. Esto, claro, si tenemos en cuenta todos los depósitos en su conjunto. Si hacemos un análisis por yacimientos vemos que en la Cueva de Valdegoba tanto los juveniles como los adultos se acumulan durante todo el año, aunque existen picos en verano, coincidiendo con el final del periodo de partos y con el periodo de lactancia. En Prado Vargas, por el contrario, prefieren el invierno y la primavera. Llama la atención la acumulación en invierno ya que es un periodo en el que los sarrios suelen permanecer en zonas boscosas y alejados de las cumbres. El invierno, es el único periodo en el que no se acumulan sarrios en Cueva Millán. En esta cavidad hay un pico en primavera y disminuye hasta el invierno. Los juveniles son acumulados en el periodo de partos y en el celo, mientras que los adultos durante el parto y la lactancia. Por otra parte, en la Peña de Estebanvela el ejemplar se depositó en otoño, periodo que coincide con el celo.

La presencia de marcas de corte, en los huesos recuperados en la Cueva de Valdegoba, sugiere que los Neandertales tenían un acceso primario a los sarrios (Díez, 2006). Cuando lo comparamos con las poblaciones modernas, esta asociación destaca por dos razones. La primera, por el relativamente pequeño número de individuos inmaduros representado en comparación a una población viva de la actualidad. La preferencia por los adultos puede deberse a la mayor cantidad de carne fresca que aportan. En segundo lugar, los resultados sugieren que los machos fueron acumulados en mayor proporción que las hembras. Habría múltiples explicaciones para este patrón y soy consciente de que los resultados se basan en un número reducido de individuos y mi interpretación podría ser parcial. Sin embargo, podemos sugerir que dicha tendencia podría ser una extensión de la preferencia previa por animales más grandes. Alternativamente, Pérez-Barbería (1994) y PérezBarbería y Pérez-Fernández (2009) encontraron un patrón en el que los machos tienden a ocupar zonas forestales más frecuentemente que las hembras. Así, de este modo, la caza en zonas forestales podría, al menos parcialmente, explicar la mayor proporción de machos en la muestra de la Cueva de Valdegoba.

Finalmente, cuando combinamos estos resultados con los obtenidos en la edad de muerte (Arceredillo y Díez, 2009) se observa una posible preferencia por los adultos. La caza de estos machos sería más sencilla debido a su falta de experiencia una vez que 
alcanzan la madurez y abandonan el grupo matriarcal. También son las presas favoritas en el yacimiento de Amalda (Guipuzcoa). Este sitio ha aportado la mayor acumulación de rebecos de la Península Ibérica con un total de 4830 restos divididos en cuatro niveles (VII: Musteriense; VI y V: Gravetiense; IV: Solutrense). En todos ellos, los rebecos son los herbívoros más abundantes ( 40 - 68\%), basándose en el NMI. En todos estos niveles el número de individuos adultos (en total para los cuatro niveles NMI =97) supera al de no adultos (total para los cuatro niveles NMI $=29$ ) (Altuna 1990b).

Volviendo a la Cueva de Valdegoba, los rebecos son más abundantes en el nivel VI, cuando la ocupación de la cueva por parte de los Neandertales es más intensa. El nivel V, cronológicamente más antiguo, ha proporcionado menos instrumentos líticos, relacionado con una ocupación menos intensa de la cavidad. Además, en este nivel, los carnívoros son tan abundantes como los herbívoros; disminuyendo los rebecos su proporción frente a los grandes bóvidos y caballos (Quam et al., 2001). Además, en un reciente análisis isotópico, los grandes bóvidos de la Cueva de Valdegoba han aportado valores muy altos de $\delta^{13} \mathrm{C}$, indicando que pastaban en lugares abiertos; mientras que los sarrios presentaban un rango más amplio del mismo isótopo, reflejando un nicho ecológico muy amplio (Feranec et al., 2010). El cambio en la composición de las faunas de herbívoros de los niveles V y VI ha sido interpretado por Quam et al., (2001) como el resultado de cambios en los hábitos cinegéticos. Estos cambios podrían estar relacionados con el tamaño del grupo y la intensidad de ocupación de la cavidad.

Basándonos en las medidas de las epífisis analizadas mediante el k-medias, los machos son más grandes que los actuales pero, en cambio, las hembras presentan un tamaño similar a las modernas. Esto implica que los rebecos del Pleistoceno de la Cueva de Valdegoba presentaban mayor bimodalidad sexual que los actuales sarrios de la muestra analizada. La longitud máxima de los huesos de la Cueva de Valdegoba no ha sido utilizada en el análisis k-medias debido al bajo número de especímenes conservados que permitían medirlas. Sin embargo, el metacarpo más corto de Valdegoba es ligeramente superior $(144,6 \mathrm{~mm})$ a la media de las hembras modernas; y el más largo (168,0 mm) está 5,3 desviaciones típicas por encima de la muestra de machos modernos; y algo similar ocurre con el metatarso. Esta evidencia favorece la idea de que los machos son más grandes que los de la muestra moderna.

La cabra montés, Capra pyrenaica, es el otro caprino representado en los yacimientos estudiados. De mayor tamaño que el sarrio, se diferencia bien de otros caprinos como Capra ibex, Hemitragus, Ovis y Ammotragus. En los yacimientos del Paleolítico Medio predominan los ejemplares juveniles, seguidos de los infantiles y de los adultos. En cambio, en los depósitos del Paleolítico Superior nos encontramos con una cierta paridad entre los juveniles y los adultos. El estudio de la estacionalidad sugiere que no hay un periodo concreto de acumulación, ya que hay ejemplares en todas las estaciones. Sí que es cierto que predomina la adquisición en verano y otoño, periodos que coinciden con la lactancia y el celo.

El uro, Bos primigenius, es una especie escasa y cuyos restos no presentan buen estado de conservación. Tradicionalmente, los restos empleados para diferenciar al uro del bisonte son los cuernos y los terceros molares inferiores. En ninguno de los depósitos se han identificado estas piezas. Además, los dientes no son elementos muy empleados en la comparación y el material postcraneal no ha aparecido bien conservado por lo que no se han incluido en un patrón de desarrollo de la especie.

En el bisonte, Bison priscus, ocurre lo mismo que en el uro. El material es escaso y su estado de conservación no permite llevar a cabo una comparativa clara. 
Los yacimientos del Paleolítico Medio y Superior de la Meseta Norte analizados en la presente memoria se han identificado en cavidades o abrigos abiertos hacia los valles. Esta localización permite un gran aprovechamiento de los ecosistemas de ribera, media ladera y media montaña; así como el acceso rápido a los animales tanto a los que acceden al agua como a aquellos que utilizan estas zonas como paso en sus migraciones (Díez y Navazo, 2005). Estas zonas atraen a los homínidos. Los yacimientos estudiados salvo la Cueva del Búho (Sala, 2012) y la Peña de Mudá han sido interpretados como campamentos, vivacs o cazaderos tanto de Neandertales como de humanos anatómicamente modernos (Quam et al., 2001; Navazo et al., 2005; Utrilla et al., 2006; Yravedra, 2006; Díez et al., 2008; Cacho, 2013). Todos ellos corresponden a lo que se ha conocido tradicionalmente como lugares estratégicos, que podrían emplearse de forma temporal, como altos de caza o bien de una manera más o menos intensa lo que parece sugerir ciertas estrategias de desplazamiento. El descubrimiento de emplazamientos al aire libre sugiere que las anteriores localizaciones no pueden considerarse un modelo para estos periodos (Díez y Navazo, 2005 ) ya que revelan una presencia intensa en las terrazas fluviales y en el entorno de los cañones y valles, aunque alguno de ellos puede haber desaparecido por acciones erosivas. Sin embargo, a partir del registro actual, podemos inferir que la mayor parte de las ocupaciones parecen encontrarse en estos valles, cañones y en su entorno cercano (Delibes de Castro y Díez Martín, 2006; Díez y Rodríguez, 2008). Por otra parte, sería interesante saber si estas ocupaciones se deben a la búsqueda de unos microhábitats concretos donde la variedad faunística permitiera un acceso a una gran cantidad de recursos o bien a la elección de un lugar en función de la estacionalidad debido a la migración o dispersión de determinados taxones. Esto podría explicar si estas ocupaciones se deberían a la preferencia por un determinado lugar o bien serían concentraciones dentro de un paisaje social, un territorio dominado por un grupo que se movería en función del desplazamiento de las especies.

El estudio de estacionalidad nos permite inferir que en los depósitos del Paleolítico Medio parece existir una ocupación muy intensa, con un gran aprovechamiento de los recursos, especializándose principalmente en los taxones de talla pequeña, y acumulando los taxones de talla media y grande en los momentos en los que eran más vulnerables. Este hecho revela unas preferencias alimenticias y un posible conocimiento del patrón social y reproductivo de las especies muy desarrollado en el caso de que el agente acumulador sea un grupo humano como en la Cueva de Valdegoba, Prado Vargas y Cueva Millán (Navazo et al., 2005; Díez, 2006; Díez et al., 2008).

Según Díez y Navazo (2005), la gran variedad de depósitos registrados en los últimos años parece indicar que no existe una preferencia por un medio en concreto y que la ocupación de esos lugares responde a un uso complejo del espacio tanto por los pobladores del Paleolítico Medio como por los del Paleolítico Superior. Los depósitos de ambos periodos se emplazan en zonas rocosas con corrientes permanentes de agua que han permitido el desarrollo de un ecosistema mixto. Estos lugares favorecen la presencia de especies rupícolas como el rebeco o la cabra montés; de especies forestales como el jabalí, el ciervo o el corzo; y de taxones adaptados a zonas abiertas, como los équidos o los grandes bóvidos. Especies generalistas como el caballo, el burro salvaje (Equus hydruntinus) o los grandes bóvidos aparecen asociadas frecuentemente, en yacimientos del Pleistoceno Tardío ibérico, a especies alpinas como el rebeco o la cabra montés (Altuna, 1972; Daura et al., 2005; Yravedra, 2006b; Álvarez-Lao, 2007; Arceredillo et al., 2014). También es frecuente, dentro de esta asociación, la presencia del rinoceronte de las estepas, S. hemitoechus (Cerdeño, 1990) lo que indica unas condiciones frías. La presencia de rinoceronte lanudo sugiere una mezcla interesante de fauna fría y templada, y que se da a menudo en otros yacimientos del norte peninsular (Álvarez-Lao y García, 2014). La ausencia de otros taxones de clima frío, como Rangifer, Ovibos o Saiga, es más difícil de explicar, aunque en el caso del reno es posible que las preferencias ecológicas sean la causa como sugieren Gómez-Olivenza et al., (2014). Por otra parte, Balbín y Alcolea (1994) señalan la existencia de representaciones de reno en Siega Verde (Zamora) lo que podría sugerir su presencia en la Meseta, aunque hay dudas sobre esta asignación (Gómez Olivencia et al., 2014). 
Llama la atención el escaso número de yacimientos del Paleolítico Superior en relación con los del Paleolítico Medio y el Holoceno (Navazo, 2006; Marcos Saiz, 2014). Este hecho, además de darse en depósitos de abrigo y cuevas, parece repetirse al aire libre (Delibes y Martín, 2006; Díez y Rodríguez, 2009) y contrasta con el gran número de depósitos del Paleolítico Superior presentes en la región cantábrica (Altuna, 1972; Corchón, 1999; De la Rasilla y Straus, 2004; Ríos et al., 2013). El escaso número de depósitos del Paleolítico Superior en la Meseta ha sido un tema discutido en los últimos años (Delibes y Martín, 2006), pudiendo deberse a varios factores como a una despoblación o a una ocupación menos intensa del territorio, a una falta de estudios y prospecciones en esta región o como también sugiere Van der Made $(2011,2014)$ a una menor tasa de sedimentación o a una mayor erosión. Un mayor número de prospecciones deberían llevarse a cabo, con la finalidad de explicar mejor esta ausencia no sólo en abrigos y cavidades sino también al aire libre. 


\section{Conclusiones}


Este apartado se ha dividido en tres partes. La primera, las conclusiones paleontológicas, incluye la identificación taxonómica, la reclasificación de alguna de las especies estudiadas y los resultados del dimorfismo sexual. La segunda, se centra en cada uno de los yacimientos, en la lista de ungulados, las tallas más abundantes, sus rangos de edad, los periodos de acumulación y las diferencias entre los depósitos del Paleolítico Medio y del Paleolítico Superior. Por último, la tercera, incluye las conclusiones metodológicas de los modelos utilizados tanto en la determinación de la edad de muerte como en el dimorfismo y la bimodalidad sexual.

\subsection{Conclusiones paleontológicas}

1. Se han identificado once especies de ungulados en los yacimientos del Pleistoceno Superior de la Meseta Norte: Stephanorhinus hemitoechus, Coelodonta antiquitatis, Equus ferus, Equus hydruntinus, Sus scrofa, Cervus elaphus, Capreolus capreolus, Rupicapra pyrenaica, Capra pyrenaica, Bos primigenius, y Bison priscus.

2. Se han reasignado los restos del rinoceronte de La Mina, antes clasificados como Stephanorhinus hemitoechus, a la especie Coelodonta antiquitatis.

3. Se han reasignado los restos del sarrio a la especie Rupicapra pyrenaica, adaptando la clasificación a los nuevos datos taxonómicos y biogeográficos de esta especie.

4. En el Abrigo de Alexandre se han reasignado los restos de Cervus elaphus a Rupicapra pyrenaica.

5. El análisis del dimorfismo sexual del rebeco de la Cueva de Valdegoba ha revelado que los machos eran más grandes que los actuales rebecos cantábricos mientras que las hembras presentan el mismo tamaño. Podemos concluir, por tanto, que presentaban un mayor dimorfismo sexual.

\subsection{Conclusiones relativas a cada uno de los yacimientos estudiados}

1. En La Mina se ha registrado el rinoceronte lanudo Coelodonta antiquitatis, cuyos restos pertenecen a un ejemplar adulto-viejo. Se trata del registro más antiguo del Pleistoceno Superior ibérico. Además, su situación geográfica permite sugerir una entrada a la Meseta por los pasos del noreste, por la denominada "encrucijada vasca", y sugerir, de alguna manera, un acceso por el Sistema Central hacia zonas más meridionales.

2. En la Cueva de Valdegoba se han recuperado diez taxones: Stephanorhinus hemitoechus, Equus ferus, E. hydruntinus, Sus scrofa, Cervus elaphus, Capreolus capreolus, Rupicapra pyrenaica, Capra pyrenaica, Bos primigenius y Bison priscus Predominan las especies de talla pequeña $(63,7 \%)$, seguidas por las de talla media $(31,8 \%)$ y grande $(4,4 \%)$.

Los habitantes de la cavidad se especializaron en especies de talla pequeña en los que el rebeco sería la presa principal, en concreto los machos adultos. Los adultos predominan también en los taxones de talla grande y en otras especies de talla pequeña; y los infantiles en los de talla media. Aunque existe acumulación en todas las estaciones, existe un pico en el verano, durante el periodo de partos y lactancia.

3. En Prado Vargas se han identificado seis taxones: Rhinocerotidae indet., Equus ferus, Sus scrofa, Cervus elaphus, Rupicapra pyrenaica y Capra pyrenaica. Predominan los taxones de talla pequeña (50\%) frente a los de talla media (40\%) y grande $(10 \%)$. 
Los habitantes de esta cavidad se especializaron en taxones de talla pequeña y permanecieron en ella al menos durante el invierno y la primavera, coincidiendo con el momento en el que las especies rupícolas ocupan las áreas forestales.

4. En Cueva Millán, en el nivel 1A se han recuperado: Stephanorhinus hemitoechus, Equus ferus, E. hydruntinus, Cervus elaphus, Rupicapra pyrenaica, Capra pyrenaica y un bóvido de gran tamaño (Bos/Bison sp.). Predominan las especies de talla pequeña (50\%), seguidas por las de talla media (35\%) y grande (15\%). Predominan los adultos en los taxones de talla pequeña y grande; y los juveniles en la talla media. Fueron acumulados fundamentalmente en primavera y verano, aunque se han recuperado ejemplares en todas las estaciones. En el nivel 1B se han identificado: E. ferus, C. elaphus, $R$. pyrenaica y $C$. pyrenaica. Las especies de talla pequeña y media se acumulan por igual y sobre todo en verano. En el nivel 1C se han localizado: E. ferus, $C$. elaphus, $R$. pyrenaica y $C$. pyrenaica. Predominan los taxones de talla media y fueron acumulados en otoño.

En este depósito, los habitantes se centraron en los taxones de talla media, y se ocupó fundamentalmente en verano y otoño.

5. En la Cueva del Búho se han identificado ocho taxones: Stephanorhinus hemitoechus, Equus ferus, E. hydruntinus, Sus scrofa, Cervus elaphus, Capreolus capreolus, Bos primigenius y Bison priscus. Al menos las especies de talla pequeña y media se acumularon en otoño e invierno. Estos datos son parciales ya que corresponden a las excavaciones antiguas.

6. En el Abrigo de Alexandre se han identificado dos especies: Equus ferus y Rupicapra pyrenaica. Predominan los caballos, todos ellos adultos; mientras que el rebeco es inmaduro.

7. En el Abrigo Vergara se ha registrado la presencia de Equus ferus y Cervus elaphus.

Los habitantes de los abrigos sorianos se centraron en el consumo de especies de talla media y en concreto de ejemplares adultos.

8. En el nivel I de la Peña de Estebanvela se han identificado seis especies: Equus ferus, E. hydruntinus, Sus scrofa, Cervus elaphus, Rupicapra pyrenaica y Capra pyrenaica. Los taxones de talla pequeña y media aparecen en la misma proporción, destacando en ambos los adultos. La cavidad estuvo ocupada en primavera y otoño. En el nivel II se han localizado cinco especies: E. ferus, E. hydruntinus, $C$. elaphus, $R$. pyrenaica y $C$. pyrenaica. Predominan los taxones de talla media (75\%), seguidos por los de talla pequeña (25\%). En ambos casos los adultos son los más abundantes. En el nivel III se han identificado cinco especies: E. ferus, E. hydruntinus, C. elaphus, R. pyrenaica y C. pyrenaica. Predominan los taxones de talla media y su acumulación ocurrió en verano. En el nivel IV se han registrado tres especies: C. elaphus, R. pyrenaica y C. pyrenaica y predominan los ejemplares de talla pequeña.

En este depósito hay una preferencia por la adquisición de taxones de talla media, fundamentalmente adultos, existiendo ocupaciones en todas las estaciones salvo en invierno.

9. Los habitantes de las cavidades del Paleolítico Medio se especializaron en el consumo de especies de talla pequeña, fundamentalmente rupícolas y, aunque podían ocupar las cavidades durante todo el año, centraban su adquisición en el verano, coincidiendo con los periodos de partos y lactancia. 
10. Durante el Paleolítico Superior, las poblaciones se centran en especies de talla media como los caballos y los ciervos, abandonando el consumo de especies de talla grande. La variedad disminuye al igual que el número de ocupaciones, que es significativamente menor que las detectadas en el Paleolítico Medio. Estas cavidades y abrigos fueron ocupados desde finales de la primavera hasta los inicios del otoño, coincidiendo también con los periodos de partos y lactancia.

\subsection{Conclusiones metodológicas}

\section{Edad de muerte}

1. El modelo que se ha desarrollado en este estudio ha proporcionado resultados similares a los de las ecuaciones de Klein y Cruz Uribe (1984). Sin embargo, existe un intercambio de ejemplares entre unos rangos y otros, por lo que sería conveniente emplearlo únicamente para establecer patrones en los que se quiera conocer qué rango es más abundante y no el número de ejemplares que aparece en cada uno de ellos.

\section{Dimorfismo sexual}

1. La comparación de varios modelos estadísticos ha demostrado que los métodos cluster en general y el método k-medias en particular aportan los mejores resultados para conocer el sexo de especies poco dimórficas. Ofrece ventajas frente a otros métodos como que puede ser aplicado al material fósil ya que no se ven influenciados por posibles cambios de tamaño en las especies paleontológicas y, por lo tanto los resultados de una muestra no condicionan los resultados de la otra. Los buenos resultados obtenidos en especies poco dimórficas hace que su aplicación en especies más bimodales sea de gran interés.

2. De este método derivan una serie de recomendaciones para determinar la bimodalidad sexual, al menos en el rebeco, Rupicapra pyrenaica, en particular, aunque pueden ser extrapolados a los ungulados en general:

2.1 La extremidad anterior es la que aporta mejores resultados, fundamentalmente las anchuras de los huesos de la articulación del codo (BT para el húmero y BP para el radio).

2.2. Las medidas de la epífisis (especialmente aquellas con una orientación mediolateral) son mejores que aquellas tomadas en la diáfisis.

\subsection{Los análisis multivariantes son preferibles a los univariantes.}

2.4. Los resultados indican que las variables más fiables son aquellas que miden el valor medio-lateral de las epífisis. En el caso del húmero, hueso que ha proporcionado los mejores resultados, la mejor variable es la que mide la tróclea (BT) en lugar de toda la epífisis (BD). Sin embargo, en el caso del radio, los mejores resultados los proporciona toda la epífisis (BD) en vez de la superficie articular (BFD). Los resultados de las longitudes máximas (GL, GLl y GLc) son variables y más fiables en las extremidades posteriores. En algún caso, la longitud fisiológica (GLc) del húmero aporta mejores resultados cuando lo comparamos con la longitud máxima (GLI). Finalmente, los resultados de las variables tomadas en las diáfisis son bastante irregulares. 


\section{Referencias}


Acosta González, A., 2003. Los grabados de la Cueva de los Casares (Riba de Saelices, Guadalajara, ediciones Guadalajara.

Alados, C. L., 1985. Distribution and status of the Spanish ibex (Capra pyrenaica Schinz), en: Lovari, S. (Ed.), The biology and management of mountain ungulates. Groom Helm, London, pp. 204 211.

Alados, C. L., Escós, J., 2003. Cabra montés - Capra pyrenaica, en: Carrascal, L. M., Salvador, A. (Eds.), Enciclopedia virtual de los vertebrados españoles. Madrid, Museo de Ciencias Naturales. Madrid.

Alberdi, M. T., Caloi, L., Palombo, M. R., 1988. The Quaternary of Venosa: Equids. Bull. Mus. Anthrop. Préhist. Mónaco. 31, 5 - 39.

Alberdi, M. T., Ruiz Bustos, A., 1989. Taxonomía y bioestratigrafía de Equidae (Mammalia, Perissodactyla) en la Cuenca de Guadix - Baza (Granada). Trabajos sobre el Neógeno Cuaternario. M.N.C.N. Madrid. pp. 239 - 271.

Alberdi, M. T., Caloi, L., Palombo, M. R., 1991. Pleistocene equids from Western Europe their biostratigraphic and palaeoecological characteristics. Paleontology "Ongules / Ungulates 91". $31-35$.

Alberdi, M. T., Cerdeño, E., López-Martínez, N., Morales, J., Soria, M. D., 1997. La fauna villafranquiense de El Rincón-1 (Albacete, Castilla-La Mancha). Estudios Geológicos. 53 (1-2), $69-93$.

Alday-Ruiz, A., 2006. El legado arqueológico de Mendandia. Los modos de vida de los últimos cazadores en la Prehistoria de Treviño. Valladolid, Consejería de Turismo y Cultura. Junta de Castilla y León. Arqueología en Castilla y León. Memorias, 15, pp. 676.

Alexander, R. M., Jayes, A. S., Maloiy, G. M. O., Wathuta, E. M., 1979. Allometry of the limb bones of mammals from shrews (Sorex) to elephant (Loxodonta). Journal of Zoology. 189 (3), 305 314.

Alférez, F., Molero, G., Bustos, V., 1980 - 1981. Los restos fósiles más meridionales de Rupicapra rupicapra hallados en Europa. Coloquios de Paleontología. 36, 53 - 59.

Alonso, A., 1981. El Cretácico de la provincia de Segovia (Borde Norte del Sistema Central). Facultad de Ciencias Geológicas, CSIC-UCM. Madrid, pp. 271.

Altuna, J., 1972. Fauna de mamíferos de los yacimientos prehistóricos de Guipúzcoa. Con catálogo de los mamíferos cuaternarios del Cantábrico y del Pirineo occidental. Munibe XXIV, pp. 464.

Altuna, J., 1973. Fauna de mamíferos del yacimiento prehistórico de los Casares (Guadalajara). Excavaciones Arqueológicas en España. 76, 97-116.

Altuna, J., 1978. Dimorphisme sexuel dans le squelette postcephalique de Capra pyrenaica pendant le Würm final. Munibe. 4, 201 - 214.

Altuna, J., 1990. Caza y alimentación procedente de macromamíferos durante el Paleolítico de Amalda, en: Altuna, J., Baldeón, A., Mariezkurrena, K. (Eds.), La cueva de Amalda. Sociedad de Estudios Vascos/Sociedad de Ciencias Aranzadi, San Sebastián.

Altuna, J., 2002. Los animales representados en el arte rupestre de la Península Ibérica. Frecuencias de los mismos. Munibe. 54, 21 - 33.

Álvarez, M. T., Morales, A., Sesé, C., 1992. Mamíferos del yacimiento del Pleistoceno Superior de Cueva Millán (Burgos, España). Estudios Geológicos. 48, 193-204.

Álvarez-Lao, D., 2007. Revisión paleontológica de los macromamíferos indicadores de clima frío en el Pleistoceno de la Península Ibérica. Tesis Doctoral. Universidad de Oviedo, pp. 421.

Álvarez-Lao, D., 2014. The Jou Puerta cave (Asturias, NW Spain): A MIS3 large mammal assemblage with mixture of cold and températe elements. Palaeogeography, Palaeoclimatology, Palaeoecology. 393, 1 - 19.

Álvarez-Lao, D., García, N., 2006. A new site from the Spanish Middle Pleistocene with cold-resistant faunal elements: La Parte (Asturias, Spain). Quaternary International. 142 - 143, 107 - 118. 
Álvarez-Lao, D., García, N., 2010. Chronological distribution of Pleistocene cold-adapted large mammal faunas in the Iberian Peninsula. Quaternary International. 212 (2), 120 - 128.

Álvarez-Lao, D., García, N., 2011. Southern dispersal and Palaeoecological implications of woolly rhinoceros (Coelodonta antiquitatis): review of the Iberian occurrences. Quaternary Science Reviews. 30, 2002 - 2017.

Antunes M. T., 2006. The Zebro (Equidae) and its extinction in Portugal, with an Appendix on the noun zebro and the modern zebra, en: Mashkour, M. (Ed.), Equids in Time and Space. OxbowBooks, Oxford.

Aparicio, M. T., 2013. La fauna malacológica continental del yacimiento de La Peña de Estebanvela (Segovia). Proyecto de investigación 2006-2009, en: Cacho, C. (Ed.), Ocupaciones magdalenienses en el interior de la Península Ibérica. La Peña de Estebanvela (Ayllón, Segovia), Junta de Castilla y León, CSIC, 127 - 131.

Arambourg, C., 1979. Vertébrés villafranchiens d'Afrique du Nord (Artiodactyles, Carnivores, Primates, Reptiles et Oiseaux). Foundation Singer Polignac, pp. 141.

Arceredillo, D., 2008a. Estudio Paleontológico de los Herbívoros de la Cueva de Valdegoba (Huérmeces, Burgos), Tesis de Licenciatura, Departamento de Geología, Facultad de Biología. Universidad de Salamanca, pp. 297.

Arceredillo, D., 2008b. Morphometric differences among the equids of the upper Pleistocene from Valdegoba (Burgos, Spain). Bull. Int. Assoc. Paleodont. 2 (2), 21 - 26.

Arceredillo, D., 2010. Los macromamíferos del yacimiento del Pleistoceno Superior de Prado Vargas (Burgos, España). Seminario de Paleontología de Zaragoza. 9, 63 - 65.

Arceredillo, D., 2013. Los ungulados de La Peña de Estebanvela (Ayllón, Segovia), en: Cacho, C. (Ed.), Ocupaciones magdalenienses en el interior de la Península Ibérica. La Peña de Estebanvela (Ayllón, Segovia). Junta de Castilla y León, CSIC, pp. 183-209.

Arceredillo, D., Díez, C., 2009. Age of Death and Seasonality based on Ungulate tooth remains from the Upper Pleistocene Site of Valdegoba (Burgos, Spain). Journal of Taphonomy. 7 (2-3), 75 91.

Arceredillo, D., Gómez-Olivencia, A., 2009. Sex determination in fossil caprines: k-means applied to the Rupicapra postcranial remains from the upper pleistocene site of Valdegoba (Burgos, Spain). V World Conference on Mountain Ungulates. Granada, Consejería de Medio Ambiente. Junta de Andalucía, Granada, pp. 224 - 225.

Arceredillo, D., Diez, C., 2010. Edad de muerte y dimorfismo sexual del Cervus elaphus de tres yacimientos del Pleistoceno Superior a partir del estudio de sus caninos superiores. Seminario de Paleontología de Zaragoza. 9, 67-70.

Arceredillo, D., Gómez-Olivencia, A., García-Pérez, A., 2011. Three statistical methods for sex determination in extant and fossil caprines: assessment of the Rupicapra long bones. Journal of Archaeological Sciences. 38, 2450 - 2460.

Arceredillo, D., Gómez-Olivencia, A., San Pedro, Z., 2013. La fauna de macromamíferos de los niveles pleistocenos de la Cueva de Arlanpe (Lemoa, Bizkaia), en: Ríos-Garaizar, J., Gárate-Maidagan, D., Gómez-Olivencia, A. (Eds.), La Cueva de Arlanpe (Lemoa): Ocupaciones humanas desde el Paleolítico Medio Antiguo hasta la Prehistoria Reciente. Kobie Serie Bizkaiko Arkeologi Indusketar - Excavaciones Arqueológicas en Bizkaia. 3, 123 - 160.

Arellano Alonso, A., 2004. Etude paléontologique des Elephantidés, Equidés, grands Bovidés et Cervidés des niveaux du Pléistocene supérieur des grottes de Grimaldi (Vintimille, Italie). Comparaison avec d"autres sites de Ligurie, d"Europe et du Caucase. Données archéozoologiques. Centre Europeen de Recherches Prehistoriques de Tautavel, Université de Perpignan, France.

Arribas, A., Garrido, G., 2008. Los representantes más antiguos del género Capra (Bovide, Artiodactyla, Mammalia) en el registro euroasiático (Fonelas P-1, Cuenca de Guadix, España), en: Arribas, A. (Ed.), Vertebrados del Plioceno superior terminal en el suroeste de Europa: Fonelas P-1 y el Proyecto Fonelas. Instituto Geológico y Minero de España, serie Cuadernos del Museo Geominero, Madrid, 10, pp. 461 - 474.

Arrizabalaga, A., Ríos-Garaizar, J., 2012. The first human occupation of the basque crossroads. Journal of World Prehistory. 25, 157 - 181. 
Arsuaga, P. M., Aguirre, E., 1979. Rinoceronte lanudo en la provincia de Madrid (Coelodonta antiquitatis Blumenbach). Boletín de la Real Sociedad Española de Historia Natural (Geol.). 77, 23-59.

Arsuaga, J. L., Martínez, I., Gracia, A., Carretero, J. M., Lorenzo, C., García, N., Ortega, A. I., 1997. Sima de los Huesos (Sierra de Atapuerca, Spain). The site. Journal of Human Evolution. 33 (2-3), $109-127$.

Arsuaga , J. L., Baquedano, E., Pérez González, A., Sala, M. T. N., García, N., Álvarez Lao, D., Laplana Conesa, C., Huguet, R., Sevilla García, P., Blain, H., A., Quam, R., Ruiz Zapata, M. B., Sala, P., Gil García, M. J., Uzquíano Ollero, P., Pantoja Pérez, A., 2010. El yacimiento kárstico del Pleistoceno Superior de la Cueva del Camino en el Calvero de la Higuera (Pinilla del Valle, Madrid), en: Baquedano, E., Rosell, J. (Eds.), Actas de la 1a Reunión de científicos sobre cubiles de hiena (y otros grandes carnívoros) en los yacimientos arqueológicos de la Península Ibérica. Museo Arqueológico Nacional, Alcalá de Henares, pp. 349 - 368.

Arsuaga, J. L., Martínez, I., Arnold, L. J., Aranburu, A., Gracia-Téllez, A., Sharp, W. D., Quam, R. M., Falguères, C., Pantoja-Pérez, A., Bischoff, J., Poza-Rey, E., Parés, J. M., Carretero, J. M., Demuro, M., Lorenzo, C., Sala, N., Martinón-Torres, M., García, N., Alcázar de Velasco, A., CuencaBescós, G., Gómez-Olivencia, A., Moreno, D., Pablos, A. ,Shen, C. C., Rodríguez, L., Ortega, A. I., García, R., Bonmatí, A., Bermúdez de Castro, J. M., Carbonell, E., 2014. Neandertal roots: Cranial and chronological evidence from Sima de los Huesos. Science. 344, 1358 - 1363.

Auguste, P., 1995. Cadres biostratigraphiques et paléoécologiques du peuplement humain dans la France septentrionale durant le Pléistocène. Apports de l'étude paléontologique des grands mammifères du gisement de Biache-Saint-Vaast (Pas-de-Calais). Thèse de doctorat, Muséum National d'Histoire Naturelle de Paris, France. pp. 724.

Azorit, C., Analla, M., Carrasco, R., Calvo, J. A., Muñoz-Cobo, J., 2002. Teeth eruption pattern in red deer (Cervus elaphus hispanicus) in southern Spain. Anales de Biología. 24, 107 - 114.

Azorit, C., Analla, M., Muñoz-Cobo, J., 2003. Variation of mandible size in red deer Cervus elaphus hispanicus from southern Spain. Acta Theriologica. 48 (2), 221 - 222.

Azzaroli, A., 1962. Validita della specie Rhinoceros hemitoechus Falconer. Paleontographia Italica. 61(26), $21-34$.

Azzaroli, A., 1965. On the two Villafranchian horses of the Upper Valdarno. Palaeontolographia Italica. 59, 1 - 12.

Azzaroli, A., 1979. On a late Pleistocene ass from Tuscany; with notes on the History of Asses. Palaeontographia Italica. Vol. LXXI, pp. 26 - 66.

Azzaroli, A., 1983. Quaternary mammals- the "end Villafranchiaan" dispersal event- a turning point in the history of Eurasia. Paleogeography, Paleoclimatology, Paleoecology. 66, 77 - 100.

Azzaroli, A., 1985. On some vertebrate remains of middle Pleistocene age in the Upper Valdarno and Val di Chiana, Tuscany. Palaeontographia. 73, $104-115$.

Azzaroli, A., 1990. The genus Equus in Europe. European Neogene Mammal Chronology, pp. 339356.

Bajguheva, V. S., 1971. Iskopaemaja Teriofauna Levenzovskigo Karera (Severo Vostochnoe Priazovie). Materialy po faunam Antropogena SSSR. Akad. Nauk. SSSR, Trudy Zoologiecheskogo Instituta. 49, 5 - 28.

Balbín, R., Alcolea, J. J., 1994. Arte paleolítico de la Meseta Española. Complutum. 5, 97 - 138.

Barandiarán, I., 1979. El glotón (Gulo gulo L.) en el Arte Paleolítico. Zephyrus XXV, 177 - 196.

Barone, R., 1966. Anatomie comparée des mammifères domestiques. Laboratoire d’Anatomie, École Vétérinaire de Lyon., Lyon.

Beja-Pereira, A., England, P. R., Ferrand, N., Jordan, S., Bakhiet, A. O., Abdalla, M. A., Mashkour, M., Jordana, J., Taberlet, P., Luikart, G., 2004. African origins of the domestic donkey. Science. $304,1781$.

Beninde, J., 1937. Über die Edelhirschformen von Mosbach, Mauer und Steinheim a.d. Murr. Palaeontologische Zeitschrift. 19, 79 - 116. 
Bermúdez de Castro, J. M., Arsuaga, J. L., Carbonell, E., Rosas, A., Martínez, I., Mosquera, M., 1997. A hominid from the lower Pleistocene of Atapuerca, Spain: possible ancestor to Neandertals and modern humans. Science. 276 (5317), 1392 - 1395.

Bibi, F., 2007. Origin, paleoecology and paleobiogeography of early Bovini. Palaeogeography Palaeoclimatology Palaeoecology. 248, $60-72$.

Bibi, F., Bukhsianidze, M., Gentry, A. W., Geraads, D., Kostopoulos, D., Vrba, E. S., 2009. The fossil record and evolution of Bovidae: state of the field. Palaeontologia Electronica. 12 (3), 1 - 10.

Bibikova, V. I., 1958. Some distinguishing features in the bones of the genera Bison and Bos. Bull. Mosk. Obschtschestwa Isp Privoda NS Otdel Biol. 63 (6), 23 - 35.

Boessneck, J., 1969. Osteological differences between sheep (Ovis aries Linne) and goats (Capra hircus Linne), en: Brothwell, E., Higgs, E. (Eds.), Science in archaeology. London, Thames and Hudson, pp. 331 - 358.

Boessneck, J., Muller, H-H., Teichert, M., 1964. Osteologische Unterscheidungsmerkmale zwischen Schaf (Ovis aries Linné) und Ziege (Capra hircus Linné). Kühn-Archiv. 78, 1 - 129.

Boessneck, J., Von den Driesch, A., 1978. The significance of measuring animal bones form archaeological sites. Peabody Museum of Archaeology Bulletin. Harvard University 2, 25 - 39.

Bohlken, H., 1961. Haustiere und Zoologische systematik. Z. Tier. Zuchtungsbiol. 76, 107 - 113.

Bonifay, M. F., 1980. Le cheval du Pléistocene moyen des Grottes de Lunel - Viel (Hérault) Equus mosbachensis palustris nov. ssp. Gallia Préhistoire. 23 (2), 233 - 281.

Borsuk Bialynicka M., 1973. Studies on the Pleistocene rhinoceros Coelodonta antiquitatis (Blumenbach). Paleontologia Polonica, 29, 1-95.

Boyd, L., Zimmermann, W., King, S.R.B., 2008. Equus ferus ssp. przewalskii. IUCN 2010. IUCN Red List of Threatened Species. Version 2010.1. www.iucnredlist.org.

Braza, F., San José, C., Aragón, S., Delibes, J. R., 1998. La reproducción del corzo morisco. Revista de la Sociedad Gaditana de Historia Natural. 1, 11 - 15.

Breuil, H., 1918 - 1919. Les peintures rupestres de la Péninsule Iberique IX. La vallée peinte des Batuecas (Salamanca). X, Roches peintes de Garcibuey (Salamanca). L’Anthropologie. XXIX, 1 -21 .

Brugal, J. P., 1984. Le Bos primigenius Boj., 1827 du Pléistocène moyen des grottes de Lunel-Viel (Hérault). Bulletin du Musée d'Anthropologie Préhistorique de Monaco. 28, 7 - 62.

Brugal, J. P., 1985. Le Bos primigenius Boj., 1827 du Pléistocène moyen des grottes de Lunel-Viel (Hérault). Bulletin du Musée d'Anthropologie Préhistorique de Monaco. 28, 7 - 62.

Brugal, J. P., 1999. Etude de populations de grands Bovidés européens : intérêt pour la connaissance des comportements humains au Paléolithique, en : Brugal J.P., David F., Enloe J.G., Jaubert J. (Eds.), Le Bison: Gibier et moyen de subsistance des Hommes du Paléolithique aux paléoindiens des grandes plaines. Actes du colloque international de Toulouse, 1995, APDCA Editions, 84 - 103.

Buitrago, A. M., 1992. Estudio de los Artiodáctilos del yacimiento del Pleistoceno medio de Pinilla del Valle (Madrid). Tesis doctoral. Universidad Complutense de Madrid. Madrid.

Bukhsianidze, M., Vekua, A., 2006. Capra dalii nov. sp. (Caprinae, Bovidae, Mammalia) at the limit of Plio-Pleistocene from Dmanisi (Georgia). Courier Fouschungs - Insttitut Senckenberg. 256, $1136-1138$.

Burke, A., Eisenmann, V., Ambler, G. K., 2003. The systematic position of Equus hydruntinus an extinct species of Pleistocene equid. Quaternary Research. 59, 459 - 469.

Cacho Quesada, C., Ripoll López, S., Jordá Pardo, J. F., Muñoz Ibañez, F., Yravedra Sainz de los Terreros, J., Maicas Ramos, R., 2003. Ocupaciones Magdalenienses en la Meseta Norte. La Peña de Estebanvela (Segovia). Zephyrus. 56, 19 - 37.

Cacho Quesada, C., Muñoz Ibáñez, F., Martos Romero, J. A., 2006. Industria lítica de la Peña de Estebanvela (Segovia), en: Cacho Quesada, C., Ripoll López, S., Muñoz Ibáñez, F. (Eds.), Estudio tecnológico y tipológico. La Peña de Estebanvela (Estebanvela-Ayllón, Segovia). 
Grupos Magdalenienses en el Sur del Duero, Valladolid, Consejería de Turismo y Cultura, Junta de Castilla y León, Arqueología en Castilla y León. Memorias, 17, pp. 239 - 394.

Cacho Quesada, C., Yravedra Sainz de los Terreros, J., Jordá Pardo, J. F., Ripoll López, S., Muñoz Ibánez, F. J., 2006. La Peña de Estebanvela: Reconstrucción Paleoambiental, Recursos Alimenticios, Cronología y Contexto del Registro Arqueológico. Contactos con la Cornisa Cantábrica y el Ámbito Pirenaico. La Peña de Estebanvela (Estebanvela-Ayllón, Segovia). Grupos Magdalenienses en el Sur del Duero. Array. Valladolid, Consejería de Cultura y Turismo de la Junta de Castilla y León. 1, pp. 427 - 444.

Cacho, C., 2013, Ocupaciones magdalenienses en el interior de la Península Ibérica. La Peña de Estebanvela (Ayllón, Segovia). Monografías. Valladolid. Consejería de Cultura y Turismo de la Junta de Castilla y León.

Calderón, S., 1876. Enumeración de los Vertebrados fósiles de España. Anales de la Sociedad Española de Historia Natural. 5, 3 - 35.

Cano, M., García-Rovés, P., González-Quirós, P., Nores, C., 2009. Assessment of population estimates in the Cantabrian chamois (Rupicapra pyrenaica parva) in the Cantabrian Mountains (North of Spain), en: Pérez-Barbería, F. J., Palacios, B. (Eds.), El Rebeco Cantábrico Rupicapra pyrenaica parva. Conservación y Gestión de sus poblaciones, Organismo Autónomo Parques Nacionales. Ministerio de Medio Ambiente y Medio Rural y Marino, Madrid, pp. 416 - 447.

Carbonell, E., Bermúdez De Castro, J. M., Parés, J. M., Pérez-González, A., Cuenca-Bescós, G., Ollé, A., Mosquera, M., Huguet, R., Van der Made, J., Rosas, A., Sala, R., Vallverdú, J., García, N., Granger, D. E., Martinón-Torres, M., Rodríguez, X. P., Stock, G. M., Vergès, J. M., Allué, E., Burjachs, F., Cáceres, I., Canals, A., Benito, A., Díez, C., Lozano, M., Mateos, A., Navazo, M., Rodríguez, J., Rosell, J., Arsuaga, J. L., 2008. The first hominin of Europe. Nature. 452, 465 - 469.

Cardoso, J., 1996. Les grands mammifères du Pléistocène supérieur du Portugal. Essai de synthèse. Geobios. 29, 235 - 250.

Cardoso, J. L., Antunes, M. T., 1989. Rupicapra rupicapra (Mammalia) in the Late Pleistocene of Portugal. Ciencias da Terra (UNL) 10: 81 - 96.

Cardoso, I. L., Eisenmann, V., 1989. Eauus caballus antunesi, nouvelle sousespèce quaternaire du Portugal. Palaeovertebrata. 19 (2), 47 - 72.

Carlos-Calero, J. A., Van der Made, J., Mancheño, M. A., Montoya, P., Romero, G., 2006. Capra alba Moyà-Solà, 1987 del Pleistoceno inferior de la Sierra de Quibas (Murcia, España). Estudios Geológicos. 62 (1-2), 571 - 578.

Carranza, J., 2000. Environmental effects on the evolution of mating systems in endotherms, en: Apollonio, M., Festa-Bianchet, M., Mainardi, D., Vertebrate Mating Systems. World Scientific, pp. $106-139$.

Carranza, J., 2011. Ciervo - Cervus elaphus, en: Carrascal, L.M., Salvador, A. (Eds.), Enciclopedia virtual de los Vertebrados Españoles, Museo Nacional de Ciencias Naturales. Madrid.

Carranza, J., Valencia, J., 1999. Red deer females collect on male clumps at mating areas. Behavioral Ecology. 10 (5), 525 - 532.

Castaños, P., 2006. Estudio arqueozoológico de la fauna de Mendandia (Sáseta, Treviño), en: AldayRuiz, A. (Ed.), El legado arqueológico de Mendandia. Los modos de vida de los últimos cazadores en la Prehistoria de Treviño. Valladolid, Consejería de Turismo y Cultura. Junta de Castilla y León. Arqueología en Castilla y León. Memorias, 15, 435 - 455.

Castaños, P., Murelaga, X., Bailon, S., Castaños J., Sáez de Lafuente, X., Suarez, O., 2009. Estudio de los vertebrados del yacimiento de Lezikako koba (Kortezubi, Vizkaya). Kobie. XXVIII, 25 - 50.

Cerdeño, E., 1987. Presencia de Rinoceronte en la fauna de Cueva Millán. Geogaceta. 2, 9 - 10.

Cerdeño, E., 1990. Stephanorhinus hemitoechus (Falc.) (Rhinocerotidae, Mammalia) del Pleistoceno Medio y Superior de España. Estudios Geológicos. 6, 465 - 479.

Chaix, L., Desse, J., 1983. Les bouquetins de l'Observatoire (Monaco) et des Baoussé Roussé (Grimaldi, Italie). Prèmiere partie: cranium, atlas, epistropheus. Bulletin du Musée d'Anthropoligie préhistorique de Monaco. 26, 41 - 74.

Chaplin, R. E., 1971. The study of animal bones from archaeological sites. New York, Seminar Press. 
Charline, J., 1982. El Cuaternario: la historia humana y su entorno. Ediciones AKAI. pp. 316.

Cigala-Fulgosi, F., 1976. Dicerorhinus hemitoechus (Falconer) del post-Villafranchiano fluviolacustre del T. Stirone (Salsomaggiore, Palma). Boll. Soc. Paleont. Ital. 15, 59 - 72.

Clot, A., Marsan, G., 1986. La grotte du Cap de la Bielle à Nestier (Hautes-Pyrénées). Fouilles M. Debeaux, 1960. Paleontologie des grands mammiferes. Gallia Préhistoire. 29 (1), 53 - 64.

Clutton-Brock, J., Harvey, P. H., 1985. Life history variation in primates. Evolution. 39 (3), 559 - 581.

Corchón, M. S. 1991 - 1992. Representaciones de fauna fría en el Arte mueble de la Cueva de Caldas (Asturias, España). Significación e implicaciones en el Arte parietal. Zephyrus.44 - 45, 35 - 64.

Corchón, M. S., 1997. La cueva de la Griega de Pedraza. Memorias de Arqueología en Castilla y León 3. Junta de Castilla y León. Zamora.

Corchón, M. S., 1999. Solutrense y Magdaleniense del oeste de laCornisa Cantábrica: dataciones 14C (calibradas) y marco cronológico. Zephyrus. LII, pp. 3 - 32.

Corchón, M.S., Valladas, H., Bécares, J., Arnold, M., Tisnerat, N., Cachier, H., 1996. Datación de las pinturas y revisión del arte paleolítico de Cueva Palomera (Ojo Guareña, Burgos, España). Zephyrus. 49, pp. $47-60$.

Couturier, M. A. J., 1938. Le Chamois. Arthaud, Grenoble.

Crégut-Bonnoure, E., 1992a. Pleistocene Tahrs, Ibexes and Chamois of France. Ongulés/Ungulates 91, en: Spitz G.J.F., González, G., Aulagnier, S. (Eds.), Tolouse, S.F.E.P.M. - I.R.G.M. 1, 49-56.

Crégut-Bonnoure, E. 1992b, Intérêt biostratigraphique de la morphologie dentaire de Capra (Mammalia, Bovidae). Ann. Zool. Fennici. 28, 272 - 290.

Crégut-Bonnoure, E., 1992c. La faune de mammifères de Chinchon II (Saumane-de-Vaucluse, Vaucluse). Bulletin Archéologique de Provence. 21, 9 - 13.

Crégut-Bonnoure, E., 1999. Les petits Bovidae de Venta Micena (Andalousie) et de Cueva Victoria (Murcia), en: Gibert, J., Sánchez, F., Gibert, L., Ribot, F. (Eds.), The Hominids and their environment during the lower and middle Pleistocene of Eurasia, Proceedings of the International Conference of Human Palaeontology, Orce, 1995, 191- 228.

Crégut-Bonnoure, E., 1993. La faune de grands mammifères de l'Abri Marcq (Sorgues, Vaucluse). Bull. Soc. Et. Sci. Nat. Vaucluse, 39 - 52.

Crégut-Bonnoure, E., 2006. European Ovibovini, Ovini and Caprini (Caprinae, Mammalia) from the Plio-Pleistocene: new interpretations. Cour. Forsch.-Inst. Senckenberg. 256, 139 - 158.

Croitor, R., Bonifay, M. F., Brugal, J. P., 2008. Systematic revision of the endemic deer Haploidoceros n. gen. mediterraneus (Bonifay, 1967) (Mammalia, Cervidae) from the Middle Pleistocene of Southern France. Paläontologische Zeitschrift. 82 (3), 325 - 346.

Cuggiani, M. C., 1981. Studio biometrico sulle ossa lunghe Della popolazione di Ursus spelaeus Della grotta di Equi (Toscana). Bolletino del Servizio Geologico d'Italia. 11, 173 - 188.

Dalen, L., Orlando, L., Shapiro B., Brandstrom-Durling, M., Quam, R., Gilbert, M. T. P., FernándezLomana, J. C., Willerslev, E., Arsuaga, J. L. Gotherstrom, A., 2012. Partial Genetic Turnover in Neandertals: Continuity in the East and Population Replacement in the West. Mol. Biol. Evol. DOI: 10.1093.

Dalmau Bueno, A., 2005. Comportamiento social y de alimentación del rebeco pirenaico (Rupicapra pyrenaica pyrenaica). Universitat Autonoma de Barcelona. Barcelona.

Daujeard, C., 2008. Exploitation du milieu animal par les Néander- thaliens dans le sud-est de la France. Ph.D. dissertation, Université Lumière-Lyon 2.

Daura, J., Sanz, M., Subirá, M. E., Quam, R., Fullola, J. M., Arsuaga, J. L. 2005. A Neandertal mandible from the Cova del Gegant (Sitges, Barcelona, Spain). Journal of Human Evolution. 49, 56 - 70.

David, F., Enloe, J. G., 1993. L'exploitation des animaux sauvages à travers le temps, XIIIe Reconres Internationale d'Archéologie et d'Histoire d'Antibes, Ed. ADPCA, Juan-les-Pins, 29 - 47. 
Davis, S. J. M., 1980. Late Pleistocene and Holocene equid remains from Israel. Zoological Journal of the Linnean Society. 70, 289 - 312.

Davis, S. J .M., 1981. The effects of temperature change and domestication on the body size of late Pleistocene to Holocene mammals of Israel. Paleobiology. 7, 101 - 114.

De la Rasilla, M., Straus, L. G., 2004. El poblamiento en la región Cantábrica en torno al Último Máximo Glacial: Gravetiense y Solutrense", en: FANO, M. A. (Ed.), Las sociedades del Paleolítico en la Región Cantábrica. Bilbao, Bizkaiko Foru Aldundia- Diput. Foral de Bizkaia, pp. $209-242$.

Delibes de Castro, G., Diez Martín, F., 2006. ¿Una meseta desolada? Estado actual de la investigación sobre Paleolítico superior en las regiones interiores de la Península Ibérica, en: Delibes de Castro, G., Diez Martín, F. (Eds.), El Paleolítico superior en la Meseta Norte española. Studia Archaeologica, Universidad de Valladolid, Fundación Duques de Soria, 94, pp. 11 - 39.

Delpech, F., 1983. Les faunes du Paleolithique Superieur dans le Sud-Ouest de La France. Cahiers du Quaternaire 6. Editions du Centre National de la Recherche Scientifique, 1 - 453.

Delpech, F., 1984. Les Ongulés en Périgord et Nord-Ouest du Quercy durant le Würm III. Chronoclimatologie, Paléobiogéographie, Palethnologie. Geobios. 17 (5), 531 - 548.

Delpech, F., 1988. Les grands mammifères de la grotte Vaufrey, à l'exception des Ursidés, en: Rigaud, J.P. (Ed.), La grotte Vaufrey à Cénac et Saint-Julien (Dordogne): paléoenvironnements, chronologie et activités humaines. Mémoires de la Société Préhistorique Fraçaise, 19. 213 - 289.

Dempster, A. P., Laird, N. M., Rubin, D. B., 1977. Maximum likelihood from incomplete data viea the EM algorithm. J. Roy. Stat. Soc. Series B 39, 1 - 38.

d'Errico, F., Vanhaeren, M., 2002. Criteria for identifying red deer (Cervus elaphus) age and sex from their canines. Application to the study of Upper Palaeolothic and Mesolithic ornaments. Journal of Archaeological Science. 29, 211 - 232.

Díez, J. C., 1990. La cueva del Pleistoceno Superior de Valdegoba. Raña. 9, 39 - 40.

Díez, J. C., 2006. Huellas de descarnado en el Paleolítico Medio: la cueva de Valdegoba (Burgos). Zona Arqueológica. 7, 305 - 316.

Díez, J. C., García, M. A., Gil, E., Jordá Pardo, J. F., Ortega, A. I., Sánchez, A., Sánchez, B., 1988-1989. La Cueva de Valdegoba (Burgos). Primera Campaña de Excavaciones. Zephyrus. 41 - 42, 55 - 74.

Díez, J. C., Navazo, M., 2005, Apuntes sociales y geográficos a partir de los yacimientos del Paleolítico Medio en la zona noroiental de la Meseta castellano leonesa, en: Montes Barquín, R., Lasheras Corruchaga J. A. (Eds.), Neandertales Cantábricos, Estado de la Cuestión. Santillana del Mar, Museo Nacional y Centro de Investigación de Altamira, 20, 39 - 54.

Díez, C., Navazo, M., Alonso, R., 2008. La Gestión de los Recursos en los Asentamientos Musterienses de la Ermita y Millán (Hortigüela, Burgos), en: Lario, J., Silva, P.G. (Eds.), Contribuciones al Estudio del Periodo Cuaternario. Ávila, Aequa. 1, pp. 103 - 104.

Díez, C., Alonso, R., Bengoechea, A., Colina, A., Jordá, F. J., Navazo, M., Ortiz, J. E., Pérez, S., Torres. T., 2008. El Paleolítico Medio en el Valle del Arlanza (Burgos): Los Sitios de La Ermita, Millán y La Mina. Cuaternario y Geomorfología. 22(3 - 4), 135 - 157.

Díez, J. C., Rodríguez Marcos, J. A., 2009. Las raíces de nuestra historia. De Atapuerca al Neolítico, Caja Círculo, Burgos, pp. 207.

Díez, J. C., Jordá, J., Arceredillo, D., 2014. El yacimiento Paleolítico de Valdegoba (Huérmeces, Burgos), en: Sala, R. (Ed.), Los cazadores recolectores del Pleistoceno y del Holoceno en Iberia y el Estrecho de Gibraltar. Estado actual del conocimiento del registro arqueológico, $608-610$.

Díez Martín, F., Sánchez Yustos, P., Gómez González J. A., Gómez de la Rúa, D., Yravedra Sáinz de los Terreros, J. Díaz Muñoz, I., 2011. La ocupación neandertal en el Cañón de la Horadada (Mave, Palencia, España): Nuevas perspectivas arqueológicas en Cueva Corazón. Munibe. 62, 65 85.

Di Stefano, G., Petronio, C., 1993. A new Cervus elaphus subspecies of Middle Pleistocene age. Neues Jahrbuch für Geologie und Paläontologie Abhandlungen 190, 1 - 18. 
Domingo, M. S., Alberdi, M. T., 2004. Fauna de mamíferos del Pleistoceno Superior del yacimiento de las Majolicas (Granada). Estudios Geológicos. 60, 169 - 178.

Domínguez Sanjurjo, A., Rodríguez Vázquez, F., Albornoz Pons, J., Pérez Méndez, T., 2009. El rebeco cantábrico, filogeografía e historia evolutiva, en: Pérez-Barbería, F., Palacios, B. (Eds.), El Rebeco Cantábrico (Rupicapra pyrenaica parva): Conservación y Gestión de sus Poblaciones. Naturaleza y Parques. Serie Técnica, pp. 70 - 102.

Dong, Z., 1997. Mixture Analysis and its Preliminary Application in Archaeology. Journal of Archaeological Science. 24, 141 - 161.

Douglas, K. C., Halbert, N. D., Kolenda, C., Childers, C., Hunter, D. L., Derr, J. N., 2011. Complete mitochondrial DNA sequence analysis of Bison bison and bison-cattle hybrids: function and phylogeny. 11, $166-175$.

Duvernois, M. P., 1990. Les Leptobos (Mammalia, Artiodactyla) du Villafranchien d'Europe occidentale. Systématique, évolution, biostratigraphie, paeléoécologie. Documents Lyon. 113, $1-213$.

Eisenmann, V., 1991. Les chevaux quaternaires européens (Mammalia, Perissodactyla). Courier biostratigraphie et taxonomie. Geobios. 24, 747 - 759.

Eisenmann. V., 1992. Origins, dispersals and migrations of Equus (Mammalia, Perissodactyla). Courier Forsch. - Inst. Senckenberg, Frankfurt am Main. 153, 161 - 170.

Eisenmann, V., Alberdi, M. T., De Giuli, C., Staesche, C., 1988. Collected papers after the "New York International Hipparion Conference, 1981", en: Woodburne, M., Sondaar, P. (Eds.), Studying fossil horses. 1 Methodology, 1 - 7.

Eisenmann, V., Baryshnikov, G. F., 1994. Equus cf. taubachensis et E. hydruntinus de la grotte de Prolom 2 (Crimée, Ukraine). Bull. Mus. Nat. Hist. Nat. Paris. 16(4), 329-347.

Enloe, J. G., Turner, E., 2002. Methodological problems and biases in age determinations: a View from the Magdalenian, en: Ruscillo D. (Ed.), Recent advances in ageing and sexing animal bones. $9^{\text {th }}$ ICAZ Conference, Durham.

Esteban, M., Sanchiz, B., 1990. Sobre la presencia de Rana iberica en el Pleistoceno burgalés. Revista Española de Herpetología, 5, 93 - 99.

Fandos, P., Aranda, Y., Orueta, J. F., 1992. Tamaño y tipo de grupo en la cabra montés (Capra pyrenaica). Relación con el ciclo reproductivo. Etología. 2, 65 - 70.

Faure, M., 2004. Le Sus strozzii du Pliocène final de Saint-Vallier (Drôme). The Middle Villafranchian Suid of the Saint-Vallier site (Drôme, France). Geobios. 37, 189 - 190.

Faure, M., Guèrin, C., 1984. Sus strozzii et Sus scrofa, deux mammiferes artiodactyles, marqueurs des paleoenvironnements. Palaeogeography, Palaeoclimatology, Palaeoecology. 48, 215 - 228.

Feranec, R., García, N., Díez, J. C. y Arsuaga, J. L., 2010. Understanding the ecology of mammalian carnivorans and herbivores from Valdegoba cave (Burgos, northern Spain) through stable isotope analysis. Palaeogeogr., Palaeoclim., Palaeoecol. 297, 263 - 272.

Fernández, H., 2001. Ostéologie compare des petits ruminants eurasiatiques sauvages et domestiques (genres Rupicapra, Ovis, Capra et Capreolus): diagnose différentielle du squelette appendiculaire. PhD thesis, Université de Genève.

Fernández, P., Legrende, S., 2003. Mortality curves for horses from the Middle Palaeolithic site of Bau de l'Aubesier (Vaucluse, France): methodological, palaeo-ethnological, and palaeoecological approaches. Journal of Archaeological Science. 30, 1577 - 1598.

Fernández, P., Crégut-Bonnoure, E., 2007. Les Caprinae (Rupicaprini, Ovibovini, Ovini et Caprini) de la séquence pléistocène de Kozarnika (Bulgarie du Nord): morphométrie, biochronologie et implications phylogéniques. Revue de Paléobiologie. 26, 425 - 503.

Fernández, H., Monchot, H., 2007. Sexual dimorphism in limb bones of Ibex (Capra ibex L.): mixture analysis applied to modern and fossil data. Intern. J. Osteoarch. 17, 479 - 491.

Fernández-Llario, P., 2006. Jabalí - Sus scrofa, en: Carrascal, L. M., Salvador, A. (Eds.), Enciclopedia Virtual de los Vertebrados Españoles. Madrid, Museo Nacional de Ciencias Naturales. 
Fernández-Llario, P., Mateos-Quesada, P., 2005. Udder preference in wild board piglets. Acta Ethologica. 8, 51 - 55.

Fierro, Y., Gortazar, C., Landete-Castillejos, T., Vicente, J., García, A., Gallego, L., 2002. Baseline values for cast antlers of Iberian red deer (Cervus elaphus hispanicus). Zeitschrift fur Jagdwissenschaft. 48 (4), 244 - 251.

Forsten, A., 1986. A review of the Süsssenborn Horses and the origin of Equus hydruntinus Regalia. Quartärpaläontologie, Berlín, 6, 43 - 52.

Forsten, A., 1988. Middle Pleistocene replacement of Stenoid horses by Caballoid horses Ecological implications. Palaeogeography, Palaeoclimatology, Palaeoecology. 65, 23 - 33.

Forsten, A., 1990. Old World “Asses”. Quartärpaläontologie. 8, 71 - 78.

Forsten, A., 1999. A review of Equus stenonis Cocchi (Perissodactyla, Equidae) and related forms. Quaternary Science Reviews. 18, 1373 - 1408.

Forsten, A., Ziegler, R., 1995. The horses (Mammalia, Equidae) from the early Wurmian of Villa Seckendorff, Stuttgart-Bad Cannstadt, Germany. Stuttgarteer Beitrage zur Naturkunde, Series B (Geologie une paläeontologie). 224, 1 - 22.

Fortelius, M., Mazza, P., Sala, B., 1993. Stephanorhinus (Mammalia: Rhinocerotidae) of the western European Pleistocene, with a revision of $S$. etruscus (Falconer, 1868). Paleontographia Italica. $80,63-155$.

Fortelius, M., Solounias, N., 2000. Functional characterization of ungulate molars using the abrasion-attrition wear gradient: a new method for reconstructing palaeodiets. American Museum Novitates. 3301, 1 - 36.

Franzen, J. L., 2010. The rise of horses. The Johns Hopkins University Press, Baltimore, Maryland.

Fuentes, C., Meijide, M., 1979. El rinoceronte lanudo (Rhinocerus tichorhinus Cuvier = Coelodonta antiquitatis Blumenbach) de la Cueva del Nando (Ajo, Santander). Cuadernos de espeleología. $(9-10), 87-88$.

García-González, R., Barandalla, I., 2002. Sexual dimorphism of pyrenean chamois (Rupicapra p. pyrenaica) based on skull morphometry. Pirineos. 157, 25 - 37.

García-Pérez, A., 2008a. Estadística aplicada con R. Universidad Nacional de Educación a Distancia. UNED Varia, PB 352, pp. 132.

Garrido, G., 2008. Generalidades sobre los artiodáctilos del Villafranquiense Superior en relación con el registro fósil de Fonelas P-1, en: Arribas, A (Ed.). Vertebrados del Plioceno superior terminal en el suroeste de Europa: Fonelas P-1 y el Proyecto Fonelas. Cuadernos del Museo Geominero, no 10, Instituto Geológico y Minero de España, pp. 279 - 335.

Gee, H., 1993. The distinction between postcranial bones of Bos primigenius Bojanus, 1827 and Bison priscus Bojanus, 1827 from the British Pleistocene and the taxonomic status of Bos and Bison. Journal of Quaternary Science. 8 (1), 79 - 92.

Gentry, A. W., 1978. Bovidae, en: Maglio, J. V., Cooke, H. B. S. (Eds.), Evolution of African Mammals. Harvard Univ. Press, pp. 264 - 278.

George, M. J., Ryder, O. A., 1986. Mitochondrial DNA evolution in the genus Equus. Mol. Biol. Evol. 3, $535-546$.

Geraads, D., 1992. Phylogenetic analysis of the tribe Bovini (Mammalia. Artiodactyla). Zoological Journal of the Linnean Society. 104, $193-207$.

Ginsburg, L., 1980. Xenohyus venitor, suidé nouveau (Mammalia, Artiodactyla) du Miocène Inferieur de France. Geobios. 13, 861 - 877.

Gomendio, M., Malo, A. F., Soler, A. J., Fernández-Santos, M. R., Esteso, M. C., García, A. J., Roldán, E.R.S., Garde, J., 2006. Male fertility and sex ratio at birth in red deer. Science. 314 (5804), 1445 - 1447.

Gómez-Olivencia, A., Carretero, J. M., Arsuaga, J. L., Rodríguez-García, L., García-González, R., Martínez, I., 2007. Metric and morphological study of the Upper cervical spine from the Sima 
de los Huesos site (Sierra de Atapuerca, Burgos, Spain). Journal of Human Evolution. 53, 6 25.

Gómez-Olivencia, A., Arceredillo, D., Álvarez-Lao, D.J., Garate, D., San Pedro, Z., Castaños, P., RíosGaraizar, J. (2014). New evidence for the presence of reindeer (Rangifer tarandus) on the Iberian Peninsula in the Pleistocene: an archaeopalaeontological and chronological reassessment. Boreas. 43 (2), $286-308$.

Grant, A., 1975. The use of tooth wear as a guide to the age of domestic animals, en: Cunliffe, B. (Ed.), Excavations at Portchester Castle: I Roman. Reports of the Research Committee of the Society of Antiquaries of London, 32. London: Thames \& Hudson, pp. 437 - 450.

Grant, A., 1982. The use of tooth wear as a guide to the age of domestic ungulates. Ageing and sexing animal bones from archaeological sites, en: Wilson, B. G, Grigson, C., Payne, S. (Eds.), Oxford: British Archaeological Reports. 109, pp. 91 - 108.

Greenfield, H. J., Arnold, E. R., 2008. Absolute age and tooth eruption and wear sequences in sheep and goat: determining age-at-death in zooarchaeology using a modern control sample. Journal of Archaeological Science. 35, 836 - 849.

Greer, K. P., Yeager, H. W., 1967. Sex and age indications from upper canine teeth of Elk (Wapiti). Journal of Wildlife Managementet. 31(3), 408 - 417.

Gromolard, C. 1980. Une nouvelle interprétation des grands Bovidae (Artiodactyla, Mammalia) du Pliocène d'Europe occidentale classés jusqu' à présent dans le genre Parabos: Parabos cordieri (de Christol) emend.,? Parabos boodon (Gervais) et Alephis lyrix n. gen., n. sp. Géobios. 13, 767 - 775.

Groves, G. B., 1981. Systematic relationship of the Bovini (Artiodactyla, Bovidae). Z. Zool. Syst. Evol. $4,264-278$.

Groves, C., Grubb, P., 2011. Ungulate Taxonomy. Johns Hopkins University Press, Baltimore.

Guadelli, J. L., 1986. Revisión de la sous-espèce Equus caballus gallicus : contribution du Cheval à la connaissance des paléoenvironnements. 1 ème Réunion des Sciences de la Terre. ClermontFerrand, Soc. Géol. Fr. édit. 85.

Guadelli, J. L., 1987. Contribution a l'étude des zoocenoses préhistoriques en Aquitaine (Würm ancient et interstade würmien). Thesis. Université de Bordeaux. pp. 568.

Guérin, C., 1980. Les Rhinoceros (Mammalia, Perissodactyla) du Miocène terminal au Pléistocène Supérieur en Europe occidentale. Comparaison avec les espèces actuelles. Documents des Laboratoires de Géologie Lyon. 79, 1 - 1185.

Guérin, C., 1983a. Le gisement pléistocène supérieur de la Grotte de Jaurens a Nespouls, Corrèze, France: Les Rhinocerotidae (Mammalia, Perissodactyla). Nouv. Arch. Mus. Hist. nat. 21, 65 85.

Guérin, C., 1983b. Les Rhinocéros (Mammalia, Perissodactyla) du gisement Pléistocene Moyen de Vergranne (Doubs). Annales Scientifiques de l'Université de Franche-Comté. 5 (4), 47 - 67.

Guérin, C., Patou- Mathis, M., 1996. Les grands mammifères Plio-Pléistocènes d'Europe. Masson.

Guérin, C., Valli, A., 2000. Le gisement pléistocène supérieur de la grotte de JaurensàNespouls, Corrèze: les Bovidae (Mammalia, Artiodactyla). Cahiers scientifiques du Muséum d'Histoire naturelle de Lyon. 1, 7 - 39.

Habermehl, L., 1961. Die altersbestimmung bei haustieren. Pelztieren und beim jagdbaren wild. Hamburgo.

Halstead, P., 1985. A study of mandibular teeth form Romano-British contexts at Maxey, en: Pryor, F., French, C., Crowther, D., Gurney, D., Simpson, G., Taylor, M. (Eds.), The Fenland Project: Archaeology and Environment in the Lower Welland Valley Cambridgeshire. 1. 27 The Fenland Project Committee, Cambridgeshire Archaeological Commitee East Anglican Archaeology Report, pp. 219 - 224.

Halstead, P., Collins, P., 2002. Sorting the sheep from the goats: morphological distinctions between the mandibles and mandibular teeth of adult Ovis and Capra. Journal of Archaeological Science. 29, 545 - 553. 
Hambleton, E., 1999. Animal husbandry regimes in Iron Age Britain: a comparative study of faunal assemblages from British Iron Age sites. Oxford, British Archaeological Reports, 282, British Series, BAR.

Hammer, Ø., Harper, D. A. T., 2006. Paleontological data analysis. Wiley-Blackwell, Malden.

Hayssen, V., Van Tienhoven, A., Van Tienhoven, A., Asdell, S. A., 1993. Asdell's patterns of mammalian reproduction. A compendium of species -specific data. New York, Corner University Press.

Hernández Pacheco, E., 1917. Los grabados de la Cueva de Penches (Burgos). C.I.P.P. 17. Madrid.

Herre, W. y Röhrs, M., 1955. Ubre die formenmennigfaltigkeit des gehorns der caprini Simpson 1945. Zool. Gart. 22, 85 - 110.

Herrera, P. L., 1988. Contribution à l'étude morphologique et biométrique de la dentition et du squelette post-crânien de cerf élaphe (Cervus elaphus) du néolihique de Suisse occidentle. Travail de Diplôme de la Facult'des Sciences, Université de Genéve.

Herrero, J., 2002. Adaptación funcional del jabalí (Sus scrofa L.) a un ecosistema forestal y a un sistema agrario intensivo en Aragón. Tesis Doctoral. Universidad de Alcalá. Alcalá de Henares.

Hewinson, A. J. M., Vicent, J. P., Angibault, J. M., Delorme, D., Van Laere, G., Gaillard, J. M., 1999. Test of estimation of age from tooth wear on roe deer o known age: variation within and among populations. Canadian Journal of Zoology. 77 (1), 58 - 67.

Hillson, S., 2005. Teeth. New York, Cambridge University Press, pp. 373.

Iñigo, C., 1995. El Rinoceronte del Pleistoceno Superior de la Cueva del Búho (Segovia). Boletín Geológico y Minero. 106 (2), 3 - 6.

Iñigo, C., Molero, G., Maldonado, E., 1998. Los carnívoros del yacimiento pleistoceno de Cueva del Búho (Segovia, España) y sus huellas de actividad. Estudios Geológicos. 54, 65 - 73.

Janecek, L. L., Honeycutt, R. L., Adkins, R. M., Davis, S. K., 1996. Mitochondrial gene sequences and the molecular systematics of the artiodactyl subfamily Bovinae. Molecular Phylogenetics and Evolution. 6 (1), 107 - 119.

Jaubert, J., Lorblanchet, M., Laville, H., Slott-Moller, R., Turq, A., Brugal, J. P., 1990. Les chasseurs d'Aurochs de La Borde. París, Éditions de la Maison des Sciences de l’Homme. D.A.F. no 27.

Jequier, J. P., 1963. Seeberg Burgäschisee Süd Teil 3. Die Tierreste. Acta Bernensia. 1 - 209.

Jimeno Martínez, A., Fernández Moreno, J. J., 1988. Una placa de arte mueble paleolítico en la provincia de Soria. Trabajos de Prehistoria. 45, 235 - 241.

Jordá Pardo, J. F., 2006a. La malacofauna del yacimiento de la Peña de Estebanvela (Segovia), en: Cacho Quesada, C., Ripoll López, S., Muñoz Ibáñez, F. (Eds.), La Peña de Estebanvela (Estebanvela-Ayllón, Segovia). Grupos Magdalenienses en el Sur del Duero, Valladolid, Consejería de Cultura y Turismo, Arqueología en Castilla y León, Memorias 17, pp. 107 - 125.

Jordá Pardo, J. F. 2006b. La Peña de Estebanvela (Ayllón, Segovia). Estudio Geoarqueológico, en: Cacho Quesada, C., Ripoll López, S., Muñoz Ibáñez, F. (Eds.), La Peña de Estebanvela (Estebanvela, Ayllón, Segovia). Grupos Magdalenienses en el Sur del Duero, Valladolid, Consejería de Cultura y Turismo de la Junta de Castilla y León 1, pp. 43 - 89.

Jordá Pardo, J., Cacho, C., 2013. Radiocarbono y cronoestratigrafía del registro arqueológico pleistoceno de La Peña de Estebanvela (Ayllón, Segovia, España), en: Cacho, C. (Ed.), Ocupaciones magdalenienses en el interior de la Península Ibérica. La Peña de Estebanvela (Ayllón, Segovia), Junta de Castilla y León, CSIC, 75 - 92.

Kahlke, H. D., 1967. Der Weg des Eiszeitnashorns, en: Kahlke, H. D. (Ed.), Ausgrabungen auf vier Kontinenten. Urania, Leipzig, Jena, Berlin, pp. 28 - 32.

Kahlke, H. D., 1999. The history of the origin, evolution and dispersal of the Late Pleistocene Mammauthus-Coelodonta faunal complex in Eurasia (large mammals). Mammoth Site of Hot Springs. 
Kahlke, H. D., 2001. Neufunde von Cerviden-Resten aus dem Unterpleistozän von Untermassfeld, en: Kahlke, R.D. (Ed.), Das Pleistozän von Untermassfeld bei Meinigen (Thüringen), Teil 2, Römisch Germanisches Zentralmuseum Forschungsinstitut für Vor- und Frühgeschichte, Monographiën, 40 (2), 461 - 482.

Kahlke, R. D., Kaiser, T. M., 2011. Generalism as a subsistence strategy: advantages and limitations of the highly flexible feeding traits of Pleistocene Stephanorhinus hundsheimensis (Rhinocerotidae, Mammalia). Quaternary Science Reviews. 30, 2250 - 2261.

Kamici, S., 2003. Les grands bovidés au Pléostocène en Languedoc-Roussillon et en Catalogne. Etude paléontologique, biostratigraphique, archéozoologique et paléoécologique. Thèse de doctorat de l'Université de Perpignan. pp. 267.

Kaufman, L., Rosseeuw, P. J., 1990. Finding Groups in Data: An Introducction to Cluster Analysis. John Wiley \& Sons, New York.

Kefena, E., Mekasha, Y., Han, J. J., Rosenborn, S., Haile, A., Dessie, T., Beja-Pereira, A., 2012. Discordances between morphological systematics and molecular taxonomy in the stem line of equids: A review of the case of taxonomy of genus Equus. Lifestock Science. 143, 105 - 115.

Kintigh, K. W., Ammerman, A. J., 1982. Approaches to spatial analysis in Archaeology. Am. Antiquity $47,31-63$.

Kirillova, I. V., Shidlovskiy, F. K., 2010. Estimation of individual age and season of death in woolly rhinoceros, Coelodonta antiquitatis (Blumenbach, 1799) from Sakha-Yakutia, Russia. Quaternary Science Reviews. 29 (23/24), 3106 - 3114

Klein, R. G., 1975. Paleoanthropological implications of the nonarcheological bone assemblage from Swartklip 1, South-Western Cape Province, South Africa. Quaternary Research. 5, 275 - 288.

Klein, R. G., 1979. Stone age exploitation of animals in southern Africa. American Scientist. 67, 151 160.

Klein, R. G., Wolf, C., Freeman, L. G., Allwarden, K., 1981. The Use of Dental Crown Heights for Constructing Age Profiles of Red Deer and Similar Species in Archaeological Samples. Journal of Archaeological Science. 8, 1 - 32.

Klein, R. G., Allwarden, K., Wolf, C., 1983. The calculation and interpretation of ungulate age profiles from dental crown heights, en: Bailey, G. (Ed.), Hunter-gatherer Economy in Prehistory: a European Perspective. Cambridge, United Kingdom, Cambridge University Press, pp. 47 - 57.

Klein, R G., Cruz-Uribe, K., 1984. The Analysis of Animal Bones from Archaeological Sites. University of Chicago Press. Chicago. pp. 273.

Kurten, B., 1959. Rates of evolution in fossil mammals. Cold Spring Harbor Symposia on Quantitative Biology. 24, 205 - 215.

Kurten, B.,1965. The carnivora of the Palestine Caves. Acta Zoologica Fennica. 107, 1 - 74.

Lacombat, P. F., 2006. Morphological and biometrical differentiation of the teeth from Pleistocene species of Stephanorhinus (Mammalia, Perissodactyla, Rhinocerotidae) in Mediterranean Europe and the Massif Central, France. Paleontographica Abt. A. 274, 71 - 111.

Lalande, B., 1986 Contribution à l'étude des faunes magdaléniennes de la grotte d'Enlène (Ariège); les grands mammifères de la Salle du Fond, fouilles anciennes. D.E.S.S. Université de Bordeaux I Institut du Quaternaire. pp. 239.

Lau, A. N., Peng, L., Goto, H., Chemnick, L., Ryder, O.A., Makova, K. D., 2009. Horse domestication and conservation genetics of Przewalski's horse inferred from sex chromosomal and autosomal sequences. Mol. Biol. Evol. 26, 199 - 208.

Leonardi, G., Petronio, C., 1976. The fallow deer of European Pleistocene. Geologica Romana 15, 1 67.

Levine, M. A., 1979. Archaeo-zoological analysis of some Upper Pleistocene horse bone assemblages in Western Europe. Tesis Doctoral, Cambridge University.

Levine, M. A., 1982. The use of crown height measurements and eruption wear sequence to age horse teeth, en: Wilson, B., Grigson, C., S. Payne, S. (Eds.), Ageing and sexing from archaeological sites. Oxford, BAR. 109. 
Levine, M. A., 1983. Mortality models and the interpretation of horse population structure, en: Bailey, G. (Ed.), Hunter Gatherer Economy in Prehistory. Cambridge, Cambridge University Press.

Lister, A. M., 1996. The morphological distinction between bones and teeth of fallow deer (Dama dama) and red deer (Cervus elaphus). International Journal of Osteoarchaeology. 6, 119 - 143.

Lira, J., Linderholm, A., Olaria, C., Brandstrom - Durling, M., Gilbert, M. T. Ellegren, H., Willerslev, E., Lidén, K., Arsuaga, J. L. y Götherström, A., 2009. Ancient DNA reveals traces of Iberian Neolithic and Bronze Age lineages in modern Iberian horses. Molecular Ecology. 19, 64 - 78.

Lovari, S., 1987. Evolutionary aspects of the biology of Chamois, Rupicapra spp. (Bovidae, Caprinae), en: Soma, H. (Ed.), The Biology and Management of Capricornis and Related Mountain Antelopes. Croom Helm. London, pp. 51 - 61.

Lydekker, R., 1913. Catalogue of the Ungulate Mammals of British Museum (Natural History. London. (Cit. por Massini and Lovari, 1988).

MacFadden, B. J., 1992. Fossil Horses: Systematics, Paleobiology, and Evolution of the Family Equidae, Cambridge University Press, New York.

Magniez, P., 2010. Etude paléontologique des Artiodactyles de la grotte Tournal (Bize-Minervois, Aude, France). Etude taphonomique, archéozoologique et paléoécologique des grands mammifères dans leur cadre biostratigraphique et paléoenvironnemental. Thèse de doctorat, University of Perpignan, pp. 791.

Manceau, V., Crampe, J. P., Boursot, P., Taberlet, P., 1999. Identification of evolutionary significant units in the Spanish wildgoat Capra pyrenaica (Mammalia, Artiodactyla). Animal Cons. 2, 33 39.

Maldonado, E., 1996. Revisión de los équidos del Pleistoceno Medio y Superior de España. Tesis Doctoral. Universidad Complutense. Madrid.

Marcos Saiz, J. M., 2014. El entorno de la sierra de Atapuerca en el Neolítico, Calcolítico y Edad del Bronce: Tecnología Lítica, sistemas de Información Geográfica (SIG) y patrones de asentamiento.Tesis Doctoral. Universidad de Burgos.

Mariezkurrena, K., Altuna, J., 1983. Contribución al conocimiento del desarrollo de la dentición y el desarrollo del esqueleto postcraneal de Cervus elaphus. Munibe. 35, 149 - 202.

Mariezkurrena-Gastearena, K., 2011. Hallazgos de macromamíferos poco frecuentes en yacimientos arqueológicos y paleontológicos del Pleistoceno de la región cantábrica. Kobie (Serie Paleoantropología). 83 - 110.

Markina, F. A., Sáez-Royuela, C., De Garnica, R., 2003. Fenología reproductiva del jabalí (Sus scrofa L.) en las Montañas Cantábricas (Álava, Norte de España). Galemys. 15, 145 - 155.

Martín Merino, M. A., 1978. Cavidades de los alrededores de San Pedro de Arlanza. Kaite. Estudios de Espeleología Burgalesa, Caja de Ahorros Municipal de Burgos, Diputación de Burgos 1, 27 $-61$.

Martínez-Navarro, B., Pérez-Claros, J. A., Palombo, M. R., Rook, L., Palmqvist, P., 2007. The Olduvai buffalo Pelorovis and the origin of the Bos. Quaternary Research. 68, 220 - 226.

Martínez-Navarro, B., Rook, L., Papini, M., Libsekal, Y., 2010. A new species of bull from the Early Pleistocene paleoanthropological site of Buia (Eritrea): Parallelism on the dispersal of the genus Bos and the Acheulian culture. Quaternary International. 212, 169 - 175.

Martínez-Navarro, B., Rabinovich, R., 2011. The fossil Bovidae (Artiodactyla, Mammalia) from Gesher Benot Ya'aqov, Israel: Out of Africa during the Early-Middle Pleistocene transition. Journal of Human Evolution. 60, 375 - 386.

Martínez-Navarro, B., Karoui-Yaakoub, N., Oms, O., Amri, L., López-García, J. M., Zerai, K., Blain, H. A., Mtimet, M. S., Espigares, M. P., Haj Ali, N. B., Ros-Montoya, S., Boughdiri, M., Agustí, J., KhayatiAmmar, H., Maalaoui, K., Om El Khir, M., Sala, R., Othmani, A., Hawas, R., Gómez-Merino, G., Solè, A., Carbonell, E. y Palmqvist, P., 2014. The early Middle Pleistocene archeopaleontological site of Wadi Sarrat (Tunisia) and the earliest record of Bos primigenius. Quaternary Science Reviews. 90, 37 - 46. 
Masini, F., Lovari, S., 1988. Systematics, Phylogenetic Relationships and Dispersal of the Chamois (Rupicapra spp.). Quaternary Research. 30, 339 - 349.

Mateos-Quesada, P., 1998. Parámetros poblacionales y sistema de apareamiento del corzo en las Villuercas. Tesis Doctoral, Universidad de Extremadura. Cáceres.

Mateos-Quesada, P., 2005. Densidad poblacional y uso del espacio del corzo en el centro de la Península Ibérica. Galemys. 17 (1-2), 3-12.

Mateos-Quesada, P., 2011. Corzo - Capreolus capreolus, en: Salvador, A., Cassinello, J. (Eds.), Enciclopedia Virtual de los Vertebrados Españoles. En: Madrid, Museo Nacional de Ciencias Naturales.

Moigne, A. M., Palombo. A. R., Belda, V., Heriech-Briki, D., Lacombat, F., Lumley, M.A., Moutoussamy, J., Rivals, F., Quilès, J., Testu, A., 2006. Les faunes de grands mammifères de la Caune de l'Arago (Tautavel) deans le cadre biochronologique des faunes du Pléistocène moyen italien. L'Anthropologie. 110, 778 - 831.

Monchot, H., 1999. Mixture Analysis and Mammalian Sex Ratio Among Middle Pleistocene Mouflon of Arago Cave, France. Quaternary Research. 52, 259 - 268.

Monchot, H., Léchelle, J., 2002. Statistical nonparametric methods for the study of fossil populations. Paleobiol. 28, 55-69.

Monchot, H., Gendron, D., 2010. Disentangling long bones of foxes (Vulpes vulpes and Alopex lagopus) from arctic archaeological sites. Journal of Archaeological Science. 37, 799-806.

Montané, L., Bourdelle, E., Bressou, C., 1949. Anatomie régionale des animaux domestiques: Equidés (cheval, âne, mulet). Fascicule II, Tête et encolure, Baillière Edit, Paris.

Montoya, P., Alberdi, M. T., Blázquez, A. M., Barbadillo, L. J., Fumanal, M. P., Van der Made, J., Marín, J. M., Molina, A., Morales, J., Murelaga, X., Peñalver, E., Robles, F., Ruiz Bustos, A., Sánchez, A., Sanchiz, B., Soria, D., Szyndlar, Z., 1999. La fauna del Pleistoceno inferior de la Sierra de Quibas (Abanilla, Murcia). Estudios Geol. 55, 107 - 206.

Molero, G., Iñigo, C., Maldonado, E., Sánchez, F. L., Diez, A., 1989. El yacimiento del Pleistoceno Superior de la Cueva del Búho (Perogordo, Segovia) y su fauna de vertebrados. Resúmenes V Jornadas de Paleontología. Valencia, pp. 101 - 102.

Moran, N. C., O'Connor, T. P. 1994. Age attribution in domestic sheep by skeletal and dental maturation: a pilot study of available sources. International Journal of Osteoarchaeology. 4, $267-286$.

Mosquera, M., Ollé, A., Pérez-González, A., Rodríguez Álvarez, X. P., Vaquero, M., Vergès, J. M. Carbonell, E., 2007. Valle de las Orquídeas: un yacimiento al aire libre del Pleistoceno Superior en la Sierra de Atapuerca (Burgos). Trabajos de Prehistoria. 64 (2), 143 - 155.

Moure Romanillo, J. A., 1983. Radiocarbon datin of the Musterian in Cueva Millán (Hortigüla, Burgos, Spain). Current Anthropology. 19 (2), 155 - 157.

Moure Romanillo, J. A., García Soto, E., 1982. Datación radiocarbónica del Musteriense de Cueva Millán (Hortigüela, Burgos). Boletín del Seminario de Estudios de Arte y Arqueología. XLVIII, 71 - 72 .

Moure Romanillo, J. A., García Soto, E., 1983. Cueva Millán y La Ermita. Dos yacimientos musterienses en el valle medio del Arlanza. Seminario de Estudios de Arte y Arqueología. 49, $5-30$.

Moyà-Solà, S., 1987. Los bóvidos (Artiodactyla, Mammalia) del yacimiento del Pleistoceno inferior de Venta Micena (Orce, Granada, España). Paleontología i Evolució. mem. Esp. 1, 181 - 235.

Munson, P. J., Garniewicz, R. C., 2003. Age-mediated Survivorship of Ungulate Mandibles and Teeth in Canid-ravaged Fanal Assemblages. Journal of Archaeological Science. 30, 405 - 416.

Munro, N. D., Bar-Oz, G., Hill, A. C., 2011. An exploration of character traits and linear measurements for sexing mountain gazelle (Gazella gazella) skeletons. Journal of Archaeological Science. 38, 1253 - 1265.

Musil, R., 1969. Die Pferdereste der Lokalität Stranska Skala. Anthropos. 20, pp. 204. 
Musil, R., 1977. Die Equidensreste aus dem Travertinen von Taubach. Quartärpaläont. 2, 237 - 264.

Nascetti, G., Lovari, S., Lanfranchi, P., Berducou, C., Matiucci, S., Rossi, L., Bullini, L., 1985. Electrophoretic studies semonstrating species distinction of chamois populations of the Alps from those of the Apennines and Pyrenees, en: Lovari, S. (Ed.), Revision of Rupicapra Genus. III, The Biology and Management of Mountain Ungulates. Croom Helm, London, pp. 56 - 62.

Navazo, M., 2006. Sociedades cazadoras-recolectoras en la sierra de Atapuerca durante el Paleolítico Medio: patrones de asentamiento y estrategias de movilidad. Tesis Doctoral. Universidad de Burgos. Burgos.

Navazo, M., Díez, J. C., Torres, T., Colina, A., Ortiz, J. E., 2005. La cueva de Prado Vargas. Un yacimiento del Paleolítico Medio en el sur de la Cordillera Cantábrica, en: Montes Barquín, R., Lasheras Corruchaga J. A. (Eds.), Neandertales Cantábricos, Estado de la Cuestión. Santillana del Mar, Museo Nacional y Centro de Investigación de Altamira. 20, 151 - 166.

Navazo, M. Díez, J. C. 2008. Prado Vargas y la variabilidad tecnológica a finales del Paleolítico Medio en la Meseta Norte. Treballs d'Arqueologia. 14, 121 - 139.

Lehmann, U., 1949. Der Ur Dilivium Deutschlands und seine Verbreitung. Neues Jahrbuch f. Mineralogie. Geologie und Paläontologie. 90, 163 - 266.

Lemppenau, U., 1964. Geschlechts und Gattungsunterschiede am Becken mitteleuropaischer Wiederkäuer. Dissertation. Universität München.

Loose, H., 1975. Pleistocene Rhinocerotidae of W. Europe with reference to the recent two-horned species of Africa and S.E.Asia. Scripta Geologica. 33, 1 - 59.

Obermaier, H., 1925. El hombre fossil (2aㅡ edición). Memoria 9. Comisión de Investigaciones Prehistóricas y Protohistóricas. Madrid. Museo Nacional de Ciencias Naturales. Madrid.

O'Connor, T., 2000. The Achaeology of Animal Bones. Sutton Publishing Limited.

Orlando, L., Mashkour, M., Burke, A., Douady C. J., Eisenmann, V., Hänn, C., 2006. Geographic distribution of an extinct equid (Equus hydruntinus: Mammalia, Equidae) revealed by morphological and genetical analyses of fossils. Molecular Ecology. 15 (8), 2083 - 2093.

Orlando, L., Male, D., Alberdi, M. T., Prado, J. L., Prieto, A., Cooper, A., Hanni, C., 2008. Ancient DNA clarifies the evolutionary history of American late Pleistocene equids. J. Mol. Evol. 66, 533 538.

Orlando, L., Metcalf, J. L., Alberdi, M. T., Telles-Antunes, M., Bonjean, D., Otte, M., Martin, F., Eisenmann, V., Mashkour, M., Morello, F., Prado, J. L., Salas- Gismondi, R., Shockey, B. J., Wrinn, P. J., Vasilev, S. K., Ovodov, N. D., Cherry, M. I., Hopwood, B., Male, D., Austin, J. J., Hanni, C., Cooper, A., 2009. Revising the recent evolutionary history of equids using ancient DNA. Proc. Natl. Acad. Sci. U. S. A. 106, 21,754 - 21,759.

Pales, L., García, M. A., 1981. Atlas ostéologique des mamiféres. CNRS. Paris.

Payne, S., 1973. Kill-off patterns in sheep and goats. The mandibles form Assban Kale. Annatolian Studies. 23, 281 - 303.

Payne, S., 1987. Reference codes for wear states in the mandibular cheek teeth of sheep and goats. Journal of Archaeological Science. 14, 609 - 614.

Peñalver Iribarren, X., 2005. Orígenes. Txalaparta, pp. 376.

Perea, S., Doabrio, I., 2013. Restos ictiofaunísticos del Pleistoceno superior del yacimiento de La Peña de Estebanvela (Ayllón, Segovia), en: Cacho, C. (Ed.), Ocupaciones magdalenienses en el interior de la Península Ibérica. La Peña de Estebanvela (Ayllón, Segovia), Junta de Castilla y León, CSIC, 133 - 148.

Pérez, T., Albornoz, J., Domínguez, A., 2002. Phylogeography of chamois (Rupicapra spp.) inferred from microsatellites. Molecular Phylogenetics and Evolution. 25 (3): 524 - 534.

Pérez, T., Hammer, S. E., Albornoz, J., Domínguez, A., 2011. Y-chromosome phylogeny in the evolutionary net of chamois (genus Rupicapra). BMC Evol. Biol. 11, 272. 
Pérez, T., Essler, S., Palacios, B., Albornoz, J., Domínguez, A., 2013. Evolution of the melanocortin-1 receptor gene (MC1R) in chamois (Rupicapra spp.). Molecular Phylogenetics and Evolution. $67,621-625$.

Pérez-Barbería, F. J., 1994. Biología, ecología y caracterización genética del rebeco cantábrico (Rupicapra pyrenaica parva). Tesis Doctoral. Universidad de Oviedo. Oviedo.

Pérez-Barbería, J., García-González, R., 2004. Rebeco - Rupicapra pyrenaica, en: Carrascal, L. M., Salvador, A. (Eds.), Enciclopedia Virtual de los Vertebrados Españoles. Museo Nacional de Ciencias Naturales. Madrid.

Pérez-Barbería, F. J., Pérez-Fernández, E., 2009. Identificación, biología y ecología del rebeco cantábrico, en: Pérez-Barbería, F. J., Palacios, B. (Eds.), El rebeco cantábrico Rupicapra pyrenaica parva. Conservación y gestión de sus poblaciones, Organismo Autónomo Parques Nacionales/Ministerio de Medio Ambiente y Medio Rural y Marino, Madrid, pp. 26 - 69.

Pérez-Barbería, F. J., García-González R., Palacios, B., 2010. Rebeco - Rupicapra pyrenaica, en: Salvador, A., Cassinello, J. (Eds.), Enciclopedia Virtual de los Vertebrados Españoles. Madrid, Museo Nacional de Ciencias Naturales.

Pérez-Legido, B., Cerdeño, E., 1992. Los Macromamíferos del Pleistoceno Superior de Cueva Millán (Burgos). Estudios Geológicos. 48, 187 - 192.

Pérez Romero, A., 2009. Protohistoria e historia en el Portalón de Cueva Mayor, Sierra de Atapuerca (Burgos). Tesis de Licenciatura. Departamento de Ciencias Históricas y Geografía. Facultad de Humanidades y Educación. Universidad de Burgos. Burgos.

Pfeiffer, T., 1998. Capreolus suessenbornensis Kahlke 1956 (Cervidae, Mammalia) aus den MosbachSanden (Wiesbaden, Biebrich). Mainzer naturwissenschaftliches Archiv. 36, 47 - 76.

Pflieger, R., 1982. Le chamois son identification et sa vie. Gerfaut Club-Princesse.

Pictet, F. J., 1844. Traité de Paléontologie, tome premier. Imprimeri de Jules-Guillaume Fick, Genève.

Pike-Tay, A., Morcomb, C. A., 2000. Reconsidering the Quadratic Crown Height Method of age estimation for Rangifer from archaeological sites. Archaeozoologia. XI, 145 - 174.

Pohlig, H., 1892. Monographie der Elephas antiquus Falc. fürhenden Travertine Thüringens, ihrer Fauna und Flora. II, en: Stück (Ed.), Die Cerviden des thüringischen Diluvial-Travertines mit Beiträgen über andere diluviale und über recente Hirschformen. E. Schweizerbart'sche Verlagshandlung, Stuttgart, pp. 215 - 262.

Ponti, F., 1992. Il patrimonio camoscio, en: C. Lorenzini (Ed.), Torreano di Mastignacco. Italy.

Prado, C., 1864. Descripción física y geológica de la Provincia de Madrid. Junta General de estadística, pp. 219.

Prat, F., 1968. Reserches sur les équidés pléistocènes en France. Thesis. Univ. Bordeaux, pp. 662.

Prat, F., 1977. L'Equide du gisement de Torralba (Soria, Espagne) Equus caballus torralbae, nov. Subespec. Suplement and Bull. AFEQ I, $33-46$.

Prat, F., 1980. Les Equidés Villafranchiens en France. Genre Equus. Cahiers du Quaternarie 2 Inst. Du Quat. Unv. De Bordeaux.

Prummel, W., Frisch, H-J., 1986. A guide for distinction of species, sex and body size in bones of sheep and goats. Journal of Archaeological Science. 13, 567 - 577.

Psathi, E., 2003. Les sites moustériens de la Caverna delle Fate et de l'Arma delle Manie (Ligurie, Italie): Étude paléontologique et archéozoologique des faunes des grands mammifères. Thèse de Doctorat, Museum National d'Histoire Naturelle de Paris, France.

Quam, R. M., Arsuaga, J. L., Bermudez de Castro, J. M., Lorenzo, C., Carretero, J. M., García, N., Ortega, A. I., 2001. Human remains from Valdegoba Cave (Huérmeces, Burgos). Journal of Human Evolution. 41, 385 - 435.

Quiles, J., Monchot, H., 2004. Sex-ratio et analyse des mélanges d'Ursus spelaeus (Carnivora, Ursidae) du gisement pléistocène supérieur de Fate (Ligurie, Italie). Implications paléobiologiques. Annales de Paléontologie. 90, 115 - 133. 
Rehg, J. A., Leigh, S. R., 1999. Estimating sexual dimorphism and size differences in the fossil record: A test of methods. American Journal of Physical Anthropology. 110 (1), 95 - 104.

Rencher, A. C., 2002. Methods of Multivariante Analyisis. Wiley-Interscience, New York.

Rios, J., 2010. Organización económica de las sociedades Neandertales: el caso del nivel VII de Amalda (Zestoa, Gipuzkoa). Zephyrus. LXV, 15 - 37.

Ríos-Garaizar, J., Gárate Maidagan, D., Gómez Olivencia, A., Arceredillo Alonso, D., Iriarte Avilés, E., García Moreno, A., Garrido Pimentel, D., San Pedro Calleja, Z., 2013. El final del Solutrense en el Oriente cantábrico a través de las ocupaciones de la cueva de Arlanpe (Lemoa, Vizcaya). Zephyrus. LXXII, 15 - 38.

Ripoll, S., Municio, L., 1999. Domingo García. Arte paleolítico al aire libre en la meseta castallana. Memorias de Arqueología en Castilla y León 8. Junta de Castilla y León. Salamanca.

Riquelme Cantal, J. A., 2008. Estudio de los restos óseos de mamíferos de El Pirulejo. Los niveles paleolíticos. Antiquitas. 20, $199-212$.

Rivals, F., 2002. Les petits Bovidés pléistocènes dans le bassin méditerranéen et le Caucase. Etude paléontologique, taphonomique, archéozoologique et paléoécologique. Thèse de Doctorat, Université de Perpignan. pp. 417.

Rivals, F., 2006. Découverte de Capra caucasica et d'Hemitragus cedrensis (Mammalia, Bovidae) dans les niveaux du Pléistocène supérieur de la Caune de l'Arago (Tautavel, France): implication biochronologique dans le contexte du Bassin Méditerranéen. Geobios. 39, 85 102.

Rivals, F., Blasco, R., 2008. Presence of Hemitragus aff. cedrensis (Mammalia, Bovidae) in the Iberian Peninsula: Biochronological and biogeographical implications of its discovery at Bolomor Cave (Valencia, Spain). Systematic Paleontology (Vertebrate Paleontology). 7, 391 - 399.

Rodríguez, J., 1997. Análisis de la estructura de las comunidades de mamíferos del Pleistoceno de la Sierra de Atapuerca. Revisión de metodologías. Tesis Doctoral. Universidad Autónoma de Madrid. Madrid, pp. 353.

Rolett, B. V., Chiu, M. Y., 1994. Age estimation of prehistoric pisgs (Sus scrofa) by molar eruption and attrition. Journal of Archaeological Science. 21, 377 - 386.

Rosas, A., Bastir, M., Martínez-Maza, C., Bermúdez de Castro, J. M., 2002. Sexual dimorphism in the Atapuerca-SH hominids: the evidence from the mandibles. Journal of Human Evolution. 42, $451-474$.

Rosell, C., 1998. Biología i ecologia del senglar (Sus scrofa L., 1758) a dues poblacions del nordest ibèric. Aplicació a la gestió. Tesis Doctoral. Universidad de Barcelona. Barcelona.

Roselló Izquierdo, E., 1992. La ictiofauna Musteriense de Cueva Millán (Burgos): Consideraciones de índole biológica y cultural contrastadas con ictiocenosis paleolíticas cantábricas. Estudios Geológicos. 48, 79-83.

Sáez-Royuela, C., 1987. Biología y ecología del jabalí. Tesis Doctoral. Universidad Complutense. Madrid.

Sala, M. T. N., 2012. Tafonomía de yacimientos kársticos de carnívoros en el Pleistoceno. Tesis Doctoral. Universidad Complutense de Madrid.

Sala, M. T. N., Algaba, M., Aranburu, A., Pantoja, A., García, N., Berreteaga, A., Arsuaga, J. L. 2009. Estudio preliminar del yacimiento del Pleistoceno Superior de la Cueva de la Zarzamora (Segovia, España). VII Reuniao do Quaternário Ibérico, Faro.

Sala, M. T. N., Pantoja, A., Arsuaga, J. L., Algaba, M. 2010. Presencia de bisonte (Bison priscus Bojanus, 1827) y uro (Bos primigenius Bojanus, 1827) en las cuevas del Búho y de la Zarzamora (Segovia, España). Munibe. 61, 43 - 55.

Sánchez, A., Fraile, S., Van der Made, J., Morales, J., Quiralte, V., Salesa, M. J., Sánchez, I. M., Sanchiz, B., Soria, D., Jiménez, J., Barbadillo, L. J., Laplana, C., Szyndlar, Z., 2003. Primeros datos faunísticos del Neolítico madrileño: la cueva de La Ventana (Torrelaguna, Madrid), en: Arias Cabal, P., Ontañón Peredo, R., García-Moncó Piñeiro, C. (Eds.), III Congreso del Neolítico en la Península Ibérica. Monografias del Instituto Internacional de Investigaciones Prehistóricas de Cantabria. 1, 155-165. 
Sánchez, B., 1990. La fauna de mamíferos del Pleistoceno Superior del Abric Romaní (Capellades, Barcelona). Actas de Paleontología. 68, 331 - 347.

Sánchez Marco, A., 2013. Avifauna finipleistocena de La Peña de Estebanvela (Segovia), en: Cacho, C. (Ed.). Ocupaciones magdalenienses en el interior de la Península Ibérica. La Peña de Estebanvela (Ayllón, Segovia), Junta de Castilla y León, CSIC, 149 - 155.

Sánchez Yustos, P., Díez Martín, F., Díaz Muñoz, I., Gómez de la Rúa, D., Gómez González J. A., 2011. Estrategias de talla en Cueva Corazón (Mave, Palencia). Un yacimiento del Musteriense antiguo en las estribaciones meridionales de la Cordillera Cantabrica. Trabajos de Prehistoria. 68 (1), 51 - 63.

Sanchiz, B., Bailon, S., 2013. Nuevos datos sobre la herpetofauna tardiglaciar deLa Peña de Estebanvela (Segovia), en: Cacho, C. (Ed.), Ocupaciones magdalenienses en el interior de la Península Ibérica. La Peña de Estebanvela (Ayllón, Segovia), Junta de Castilla y León, CSIC, $141-148$.

Santonja, M., Pérez-González, A., 2000-2001. El Paleolítico inferior en el interior de la Península Ibérica. Un punto de vista desde la geomorfología. Zephyrus. LIII - LIV, 27 - 77.

Santos, P., Fernández-Llario, P., Fonseca, C., Monzón, A., Bento, P., Soares, A. M. V. M., MateosQuesada, P., Petruci-Fonseca, F., 2006. Habitat and reproduive phenology of wild boar (Sus scrofa) in the western Iberian Peninsula. European Journal of Wildlife Research. 52 (3), 207 212.

Sánz, M., Daura, J., Brugal, J. P., 2014. First occurrence of the extinct deer Haploidoceros in the Iberian Peninsula in the Upper Pleistocene of the Cova del Rinoceront (Castelldefels, Barcelona). C. R. Palevol. 13 (1), 27 - 40.

Sardella, R., Caloi, L., Di Stefano, G., Palombo, M. R., Petronio, C., Abbazzi, L., Azzaroli, A., Ficcarelli, G., Mazza, P., Mezzabotta, C., Rook, L., Torre, D., Argenti, P., Cappasso Barbato, L., Kotsakis, T., Gliozzi, E., Masini, F., Sala, B., 1998. Mammal faunal turnover in Italy from the Middle Pliocene to the Holocene, en: van Kolfschoten, T., Gibbard, P. L. (Eds.), The Dawn of the Quaternary. Haarlem: Mededelingen Nederlands Instituut voor Toegepaste Geowetenschappen. pp. 499 - 512.

Schaffer, W. M., Reed, C. A., 1972. The coevolution of social behaviour and cranial morphology in sheep and goats (Bovidae, Caprini). Fieldiana Zoology. 61, 1 - 88.

Schertz, E., 1936. Zur Unterscheidung von Bison priscus Bojanus, 1827 und Bos primigenius Bojanus 1827. an Metapodien und Astragalus. Senckenbergiana. 18, 37 - 71.

Schmid, E., 1972. Atlas of Animal Bones._Amsterdam-London-New York, Elsevier Publishing Company.

Sesé, C., 2013. Nuevos datos sobre los micromamíferos del yacimiento de La Peña de Estebanvela (Segovia), en: Cacho, C. (Ed.). Ocupaciones magdalenienses en el interior de la Península Ibérica. La Peña de Estebanvela (Ayllón, Segovia), Junta de Castilla y León, CSIC, 157 - 182.

Sese, C., Soto, E., 2002. Vertebrados del Pleistoceno del Jarama y Manzanares, en: Bifaces y Elefantes. La investigacion del Paleol 337.

Sickenberg, O., 1962. Die Säugetierreste aus den elsterzeitlichen Kiesen (Pleistozän) von Bornhausen am Harz. Geologisches Jahrbuch. 79, 707 - 736.

Silver, I. A., 1969. The Ageing of Domestic Animals. Science in Archaeology, en: Brothwell, D., London, H.B. (Eds.), Thames and Hudson, pp. 283 - 302.

Sisson, S., Grossman, J. P., 2001. Anatomía de los animales domésticos. Tomo I. Masson. Barcelona.

Slott-Moller, R., 1990. La Faune, en: Jaubert J., Lorblanquet M., Laville L., Slott-Moller R., Turq, A., Brugal, J. P. (Eds), Les Chasseures d'Aurochs de La Borde. Un site du Paléolithique moyen, (Livernon, Lot). Documents d'Archéologie Française. Editions de la Maison des Sciences de l'Homme Paris. 27, 33 - 68.

Speth, J. D., 1983. Bison kills and bone counts: decision making by ancient hunters. University of Chicago Press, Chicago.

Spinage, C. A., 1972. Age estimation of zebra. East African Wildlife Journal. 10, 273 - 277. 
Spinage, C. A., 1973. A review of the age determination of mammals by means of teeth, with special reference to Africa. East African Wildlife Journal. 11, 165 - 187.

St. Clair, L. E., 2005. Sistema digestivo de los ruminates, en: Sisson, S., Grossman, J.D. (Eds.), Anatomía de los animales dométicos. Tomo I. Masson. Barcelona.

Stampfli, H. R., 1963. Wisent, Bison bonasus (Linné) 1758, Ur, Bos primigenius Bojanus, 1827, und Hausrind, Bos taurus (Linné), 1758. Acta Bernensia, Beiträge zur prähistorischen, klassischen und jüngeren Archäologie. 2, 117 - 196.

Steele, T. E., 2002. Accuracy of Age Determinations from Tooth Crown Heights: a Test Using and Expanded Sample of Known Age Red Deer (Cervus elaphus). Recent Advances in Ageing and Sexing Animal Bones, en: Ruscillo, D. (Ed.), Durham, pp. 119 - 128.

Steele, T. E., 2004. Variation in Mortality Profiles of Red Deer (Cervus elaphus) in Middle Palaeolithic Assemblages from Western Europe. International Journal of Osteoarchaeology. 14, 307 - 320.

Steele, T. E., 2005. Comparing Methods for Analysisng Mortality Profiles in Zooarchaeological and Palaeontological Samples. International Journal of Osteoarchaeology. 15, 404 - 420.

Stehlin, H. G., Graziosi, P., 1935. Ricerche sugli Asinidi fossili d'Europa. Memoires de la Societe Paleontologique Suisse. 56, 1 - 73.

Stiner, M. C., 1990. The use of mortality patterns in archeological studies of hominid predatory adaptations. J. Anthropol. Archaeol. 9, 305 - 351.

Stiner, M. C., 1994. Honor among thieves: a zooarchaeological study of Neandertal ecology. Princeton, Princeton University Press.

Straus, L. G., Clark, G. A., 1986. La Riera Cave. Stone age hunter-gatherer adaptations in northern Spain. Arizona State University. Anthropological Research Papers. 36.

Stuart, A. J., Kosintsev, P. A., Higham, T. F. G., Lister, A. M., 2004. Pleistocene to Holocene extintion dynamics in giant deer and woolly mammoth. Nature. 431, 684 - 689.

Torres, T., 1970. Un caballo microdonte del Pleistoceno medio de Vizcaya. Boletín Geológico y Minero. LXXXI-4, Madrid, 569 - 585.

Torres, T., Rodríguez, B., González, P., 1989. Excavación en el yacimiento de la cueva de Prado Vargas, Merindad de Sotoscueva (Cornejo, Burgos). Memoria Científica, Junta de Castilla y León, pp. 1-116.

Torres, T., Rodríguez, B., González, P., 1993. Excavación de la cueva de Prado Vargas, Cornejo (Burgos, España). Actas de la Segunda Reunión del Cuaternario Ibérico 1989, Madrid, I.T.G.E. 1 , pp. $281-289$.

Trancho, G. J., Robledo, B., 2006. Restos humanos de la Peña de Estebanvela (Segovia), en: Cacho Quesada, C., Ripoll López, S., Muñoz Ibáñez, F. (Eds.), La Peña de Estebanvela (EstebanvelaAyllón, Segovia). Grupos Magdalenienses en el Sur del Duero, Valladolid, Consejería de Turismo y Cultura, Junta de Castilla y León. Arqueología en Castilla y León. Memorias. 17, pp. $217-224$.

Turner, E., 2000. Miesenheim I Excavations at a Lower Palaeolithic site in the Central Rhineland of Germany. Römisch-Germanisches Zentralmuseum, Monographs 44, Verlag RGZM. pp. 151.

Twiss, K. C., 2008. An Assessment of the Archaeological Applicability of Faunal Ageing Methods Based on Dental Wear. International Journal of Osteoarchaeology. 18 (4), 329 -351.

Utrilla, P., González, P., Ferrer, C., Blasco, F., 1999. La ocupación magdaleniense del valle del río Henar: los asentamientos de Cetina (Zaragoza) y Deza (Soria). Geologia i Quaternari litoral. Memorial M.P. Fumanal. 283 - 296.

Utrilla, P., Blasco, F., 2000. Dos asentamientos Magdalenienses en Deza, Soria. Boletín del Seminario de estudios de Arte y Arqueología, BSAA .66, 9 - 64.

Utrilla, P., Blasco, F., Rodanés, J. M., 2006. Entre el Ebro y la Meseta: el Magdaleniense en la Cuenca del Jalón y la Placa de Villalva, en: Delibes de Castro, G., Díez Martín, F. (Eds.), El Paleolítico Superior en la Meseta Norte Española. Universidad de Valladolid. Serie Studia Archaeologica. $94,173-213$. 
Van Asperen, E. N., 2010. Implications of age variation and sexual dimorphism in modern Equids for middle Pleistocene Equid taxonomy. International Journal of Osteoarchaeology. 23 (1), 1 12.

Vandebroeck, G., 1961. The comparative anatomy of the teeth of lower and non specialized Mammals. Paleis der Academiën.

Vandebroeck, G., 1969. Evolution des vertebres de leur origine à l'homme. Masson et Cie., Ed., París, pp. 583.

Vanhaeren, M., d'Errico, F., 2003. Le mobilier funéraire de la Dame de Saint-Germain-la-Rivière (Gironde) et l'origene palólithique des inégalités. Paleo. 15, 195 - 238.

Van Kolfschoten, T., 1989. De pleistocene neushoorns van Nederland. Cranium. 6 (2), 19 - 32

Van Kolfschoten, T., Tuner, E., 1996. Early Middele Pleistocene mammalian faunas from Kärlich and Miesenheim I and their biostratigraphical implications, en: Turner, E. (Ed.), The early Middle Pleistocene in Europe, Balkema, Rotterdam, pp. 227 - 253.

Valdez, R., 2011. Genus Rupicapra, en: Wilson, D. E., Mittermeier, R. A. (Eds.), Handbook of the Mammals of the World, Hoofed Mammals, 2. Lynx Editions, Barcelona, pp. 741-743.

Van der Made, J., 1989. The bovid Pseudotragus seegrabensis nov. gen., nov. sp. from the Aragonian (Miocene) of Seegraben near Leoben (Austria). Proceedings of the Royal Society B. 92 (3), $215-240$.

Van der Made, J., 1990a. Iberian Suoidea. Paleontologia i Evolució. 23, 83 - 97.

Van der Made, J., 1990b. A range chart for European Suidae and Tayassuidae. Paleontologia I Evolució. 23, $99-104$.

Van der Made, J., 1991. Sexual bimodality in some recent pig populations and application of the findings to the study of fossils. Z. Säugetierkunde. 56, 81 - 87.

Van der Made, J., 1996. Listriodontinae (Suidae, Mammalia) their evolution, systematic and distribution in time and space. Contributions to Tertiary and Quaternary. Geology. 33 (1 - 4), $3-254$.

Van der Made, J., 1999. Artiodactyla del yacimiento mesopleistoceno de Galería (Sierra de Atapuerca), en: Carbonell, E., Rosas, A., Díez, J. C. (Eds.), Atapuerca: Ocupaciones humanas y paleoecologia del yacimiento de Galería. Monografías arqueológicas. Junta de Castilla y León, pp.143 - 167.

Van der Made, J., 2001. Les ongulés d'Atapuerca. Stratigraphie et biogéographie. L'Antropologie. $105,95-113$.

Van der Made, J., 2005. La fauna del Pleistoceno europeo, en: Carbonell, E. (Ed.), Homínidos: las primeras ocupaciones de los continentes, Ariel, pp. $394-432$.

Van der Made, J., 2006. The evolution and biogeography of the Pleistocene giant deer Megaloceros giganteus (Cervidae, Mammalia). Courier Forschungs-institut Senckenberg. 256, 117 - 129.

Van der Made, J., 2010. The rhinos from the middle Pleistocene of Neumark Nord (Saxony-Anhalt). Veröffentlichungen des landesamtes für denkmalpflege und_archäologie. 62, 434 - 527.

Van der Made, J., 2011a. Biogeography and climatic change as a context to human dispersal out of Africa and within Eurasia. Quaternary Science Reviews. 30, 1353 - 1367.

Van der Made, J., 2011b. Observations on the fauna from Terra Amata, en: de Lumley, H. (Ed.), Terra Amata, Nice, Alpes-Maritimes, France. Tome II. Palynologie, Anthracologie, Faunes des vertébrés, Molusques, Paléoenvironnements, Paléoanthroplogie. CNRS Éditions, Paris, pp. $277-284$.

Van der Made, J., 2014. Late Pleistocene European and Late Miocene African acceleration of faunal change in relation to climate and as a background to human evolution. Quaternary International. $326-327,431$ - 447.

Van der Made, J., Moyà-Solà, S., 1989. European Suinae (Artiodactyla) from Late Miocene onwards. Bolletino de la Società Paleontologica Italiana. 28 (2/3), 329 - 339. 
Van der Made, J., Aguirre, E., Bastir, M., Fernández Jalvo, Y., Huguet, R., Laplana, C., Márquez, B., Martínez, C., Martinón, M., Rosas, A., Rodríguez, J., Sánchez, A., Sarmiento, S., Bermúdez de Castro, J. M., 2003. El registro paleontológico y arqueológico de los yacimientos de la Trinchera del Ferrocarril en la Sierra de Atapuerca. Coloquios de Paleontología. 1, 345 - 372.

Van der Made, J., Montoya, P., 2007. Rinocerontes del Pleistoceno de El Baradello, Plaça de la República y El Molinar en Alcoy, España. Recerques del Museu d'Alcoi. 16, 7 - 18.

Van der Made, J., Carlos Calero, J. A., Mancheño, M. A., 2008. New material of the goat Capra alba from the Lower Pleistocene of Quibas (Spain) - notes on sexual dimorphism, stratigraphic distribution and systematic. Bolletino della Società Paleontologica Italiana. 47 (1), 13 - 23.

Van der Made, J., Stefaniak, K., Marciszak, A., 2014. The Polish fossil record of the wolf Canis and the deer Alces, Capreolus, Megaloceros, Dama y Cervus in an evolutionary perspective. Quaternary International. 326 - 327, 406 - 430.

Van Vuure, C., 2005. Retracing the Aurochs. History, morphology and ecology of an extinct wild ox. Pensoft, pp. 432.

Venables, W. N., Ripley, B. D., 2002. Modern Applied Statistics with S. Springer, New York.

Vereschagin, N. K., Barysnikov, G. F., 1985. Vymiranie mlekopitaûŝih v četvertičnom periode Severnoj Evrazii. Trudy Zoologicheskogo Instituta Akademii Nauk SSSR. 131, 3 - 38.

Vidal Encinas, J. M., Prada Marcos, E., Fernández Rodríguez, C., Fuertes Prieto, M. N., 2010. Los hombres mesolíticos de la cueva de la Braña-Arintero (Valdelugueros, León), en: Vidal Encinas J. M., Prada Marcos M. E. (Eds), Junta de Castilla y León, Consejería de Cultura y Turismo, Museo de León, pp. 16 - 61.

Vigal, C. R., Fandos, P., 1989. Estimación de la edad de los fetos y de los periodos de celo y parto en la cabra montés de Gredos. Graellsia. 45, 31 - 34.

Vigal, C. R., Machordom, A., 1985. Tooth eruption and replacement in the Spanish wild goat. Acta Theriologica. 30 (19), 305 - 320.

Vignaud, P., Duringer, P., Mackaye, H. T., Likius, A., Blondel, C., Boisserie, J. R., de Bonis, L., Eisenmann, V., Etienne, M. E., Geraads, D., Guy, F., Lehmann, T., Lihoreau, F., Lopez-Martinez, N., Mourer-Chauviré, C., Otero, O., Rage, J. C., Schuster, M., Viriot, L., Zazzo, A., Brunet, M., 2002. Geology and palaeontology of the Upper Miocene Toros-Menalla hominid locality, Chad. Nature. 418, 152 - 155.

Vislobokova, I., Dmitrieva, E., Kalmykov, N., 1995. Artiodactyls from the Late Pliocene of Udunga, western Trans-Baikal, Russia. Journal of Vertebrate Paleontology. 15, 146 - 159.

Von den Driesch, A., 1976. A guide to measurement for animals bones from archaeoogical sites, Harvard University Peabody Museum of Archaeology an Ethnology.

Wall, D. A., Davis, S. K., Read, B. M., 1992. Phylogenetic relationships in the subfamily Bovinae (Mammalia: Artiodactyla) based on ribosomal DNA. J. Mammal. 73, $262-275$.

Wegrzyn, M., Serwatka, S., 1984. Teeth eruption in the European Bison. Acta Theriologica. 29 (9), $111-121$.

Weinstock, J., 2000. Osteometry as a source of refined demographic information: sex-ratios of reindeer hunting srategies, and herd control in the late glacial site of Stellmoor, Norhtern Germany. Journal of Arahaeological Science. 27, 1187 - 1195.

Weinstock, J., Willerslev, E., Sher, A., Tong, W., Ho, S. Y. W., Rubenstein, D., Storer, J., Burns, J., Martin, L., Bravi, C., Prieto, A., Froese, D., Scott, E., Xulong, L., Cooper, A., 2005. Evolution, systematics, and phylogeography of Pleistocene horses in the New World: a molecular perspective. PLoS Biol. 3, e241.

Willms, C., 1989. Zum Aussterben des europaischen Wildesels. Germania. 67, 143 - 148.

Wilson, D. E., Mittermeier, R. A., 2011. Handbook of the Mammals of the World, 2. Lynx Edicions, Barcelona,. Hoofed mammals. pp. 885

Youcef, S., 2009. Etude paléontologique, archéozoologique et taphonomique des grands mammifères du site Pléistocène moyen d'Orgnac 3 (Ardèche, France). Thèse de Doctorat, Université de Perpignan. pp. 301. 
Yravedra Sainz de los Terreros, J., 2006. Zooarqueología y tafonomía de los macromamíferos y lagomorfos de la Peña de Estebanvela (Segovia), en: Cacho, C., Ripoll, S., Muñoz, F. (Eds.). La Peña de Estebanvela (Estebanvela-Ayllón, Segovia). Grupos Magdalenienses en el Sur del Duero. Valladolid, Consejería de Turismo y Cultura. Junta de Castilla y León. Arqueología en Castilla y León. Memorias. 17, 167 - 216.

Yravedra Sáinz de los Terreros, J., 2006b. Acumulaciones biológicas en yacimientos arqueológicos: Amalda VII y Esquilleu III-IV. Trabajos de Prehistoria. 63 (2), 55 - 78.

Yravedra Sáinz de los Terreros, J., 2013. Estrategias de subsistencia entre los grupos magdalenienses de la Peña de Estebanvela (Ayllón, Segovia), en: Cacho, C. (Ed.), Ocupaciones magdalenienses en el interior de la Península Ibérica. La Peña de Estebanvela (Ayllón, Segovia), Junta de Castilla y León, CSIC, 211 - 244.

Yravedra Sáinz de los Terreros, J., Díez Martín, F., Sánchez Yustos, P., Gómez de la Rúa, D., Díaz Muñoz, I., Gómez González, J. A., 2013. Estrategias de subsistencia durante el Paleolítico medio en la Submeseta norte. La Cueva Corazón (Mave, Palencia). Zephyrus. LXXI, 45 - 60.

Zazula, G. D., MacKay, G., Andrews, T. D., Shapiro, B., Letts, B., Brock, F., 2009. A late Pleistocene steppe bison (Bison priscus) partial carcass from Tsiigehtchic, Northwest Territories, Canada. 28 (25 - 26), $2734-2742$.

Zeder, M. A., 2001. A metrical analysis of a collection of modern goats (Capra hircus aegagrus and Capra hircus hircus) from Iran and Iraq: implications for the study of caprine domestication. Journal of Archaeological Science. 28, 61-79. 


\section{Y ANALYSES PALÉOBIOLOGIQUES DES ONGULÉS DU PLÉISTOCĖNE
SUPÉRIEUR DU PLATEAU NORD DES ONGULÉS DU PLÉISTOCĖNE
SUPÉRIEUR DU PLATEAU NORD}




\section{Indice}




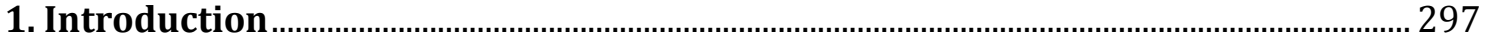

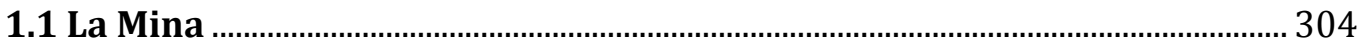

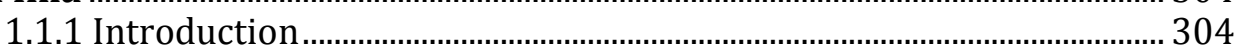

1.1.2 Géologie et Stratigraphie ............................................................................ 304

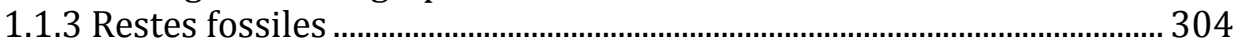

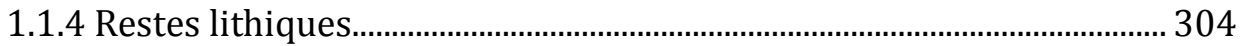

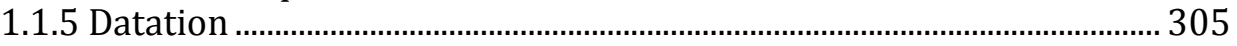

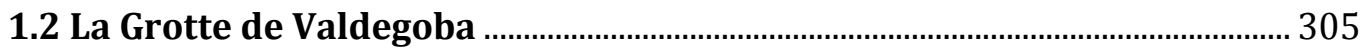

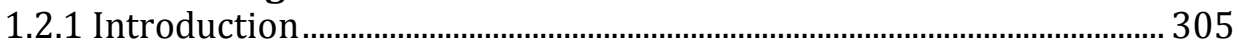

1.2.2 Géologie et Stratigraphie ..............................................................................305

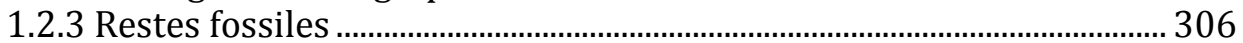

1.2.4 Restes lithiques............................................................................................ 306

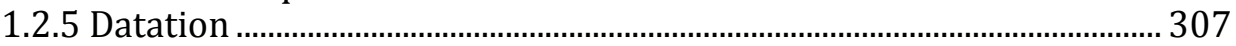

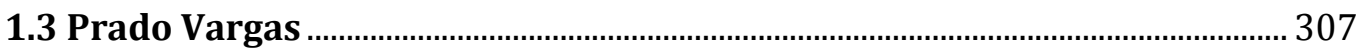

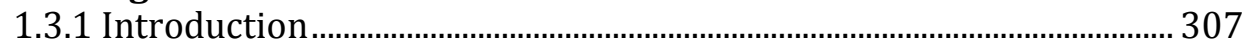

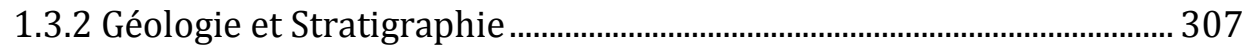

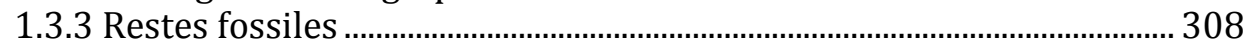

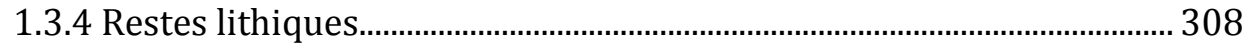

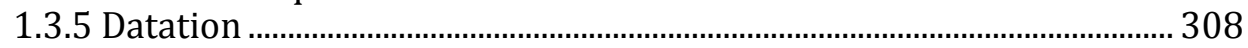

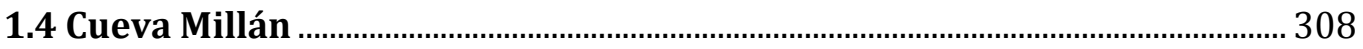

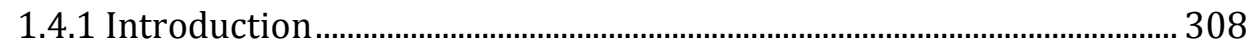

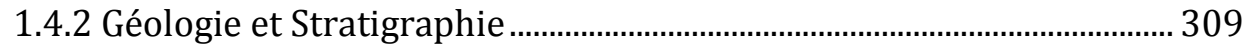

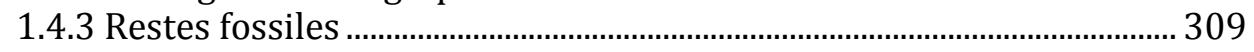

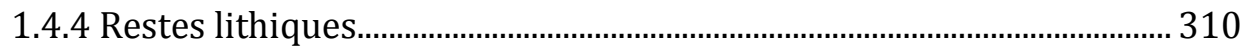

1.4.5 Restes palynologiques ............................................................................... 310

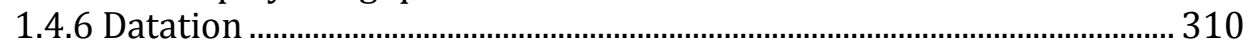

1.5 La Grotte du Búho / Grotte de la Zarzamora ....................................................... 310

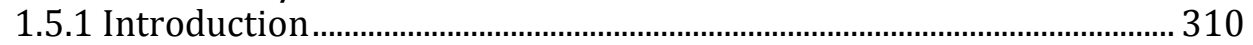

1.5.2 Géologie et Stratigraphie .......................................................................... 311

1.5.3 Restes fossiles ........................................................................................ 311

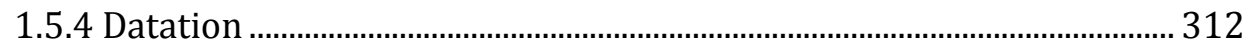

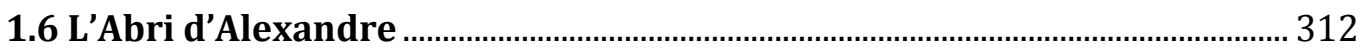

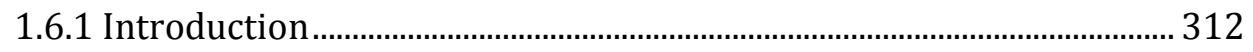

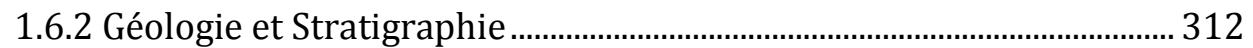

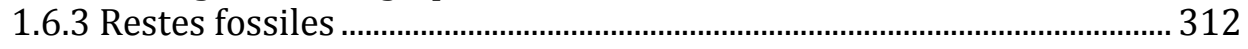

1.6.4 Restes lithiques....................................................................................... 313

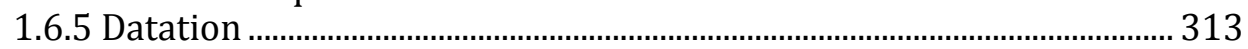

1.7 L'Abri de Vergara ..................................................................................................... 313

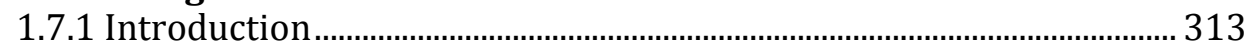

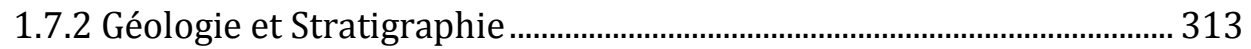

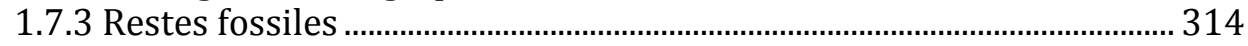

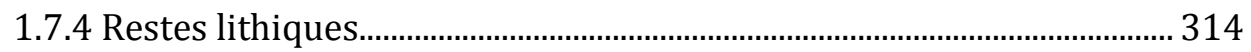

1.7.5 Datation …………………………………………………………………… 314

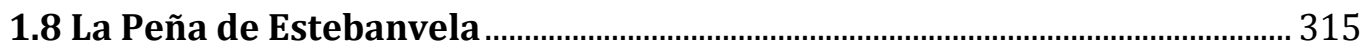

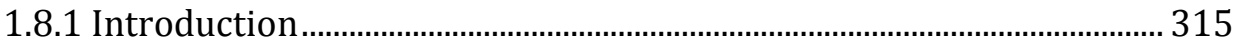

1.8.2 Géologie et Stratigraphie ........................................................................ 315

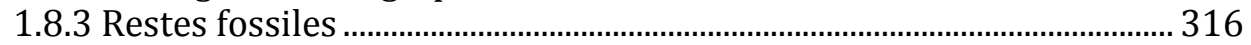

1.8.4 Restes lithiques et osseues .............................................................................. 316

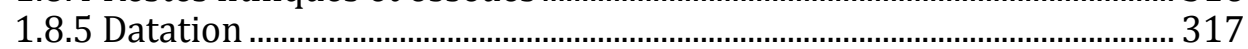

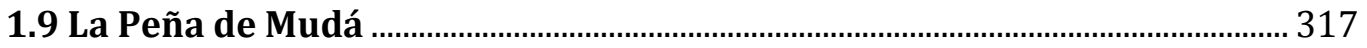

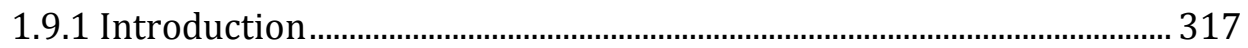

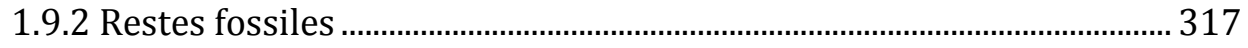

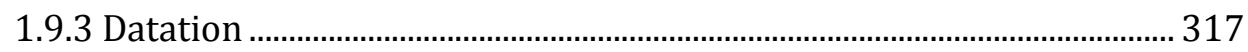

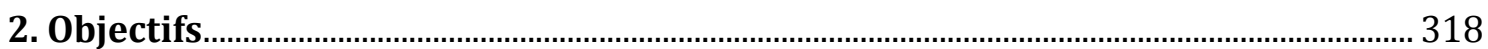

2.1 Objectifs paléobiologiques …………………........................................................... 319

2.2 Objectifs archéologiques .................................................................................... 319

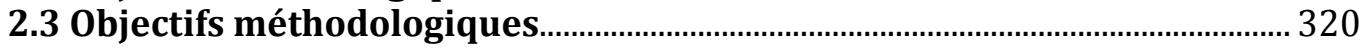




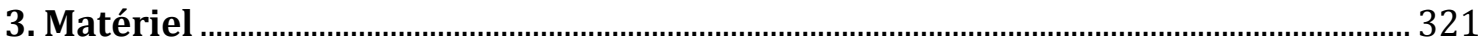

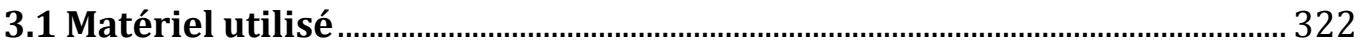

3.2 Matériel de comparaison actuel et fossile ............................................................. 322

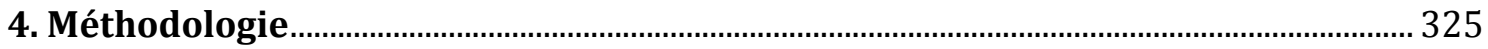

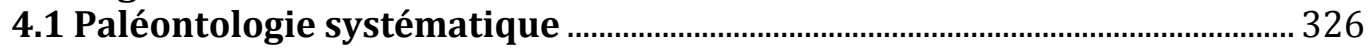

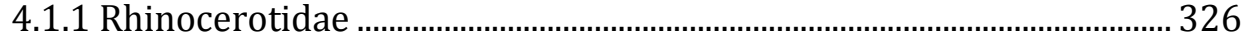

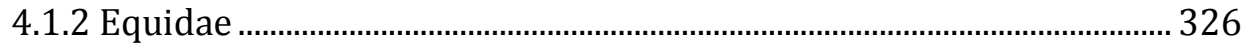

4.1.3 Suidae, Cervidae et Bovidae ....................................................................... 328

4.1.4 Nombre mínimum d'individus ..................................................................... 330

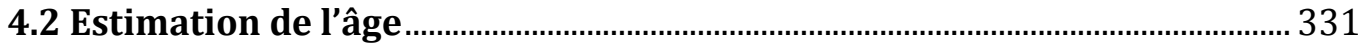

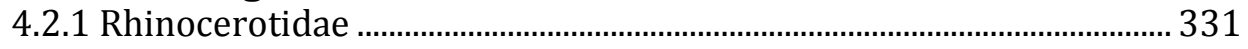

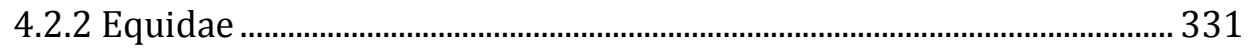

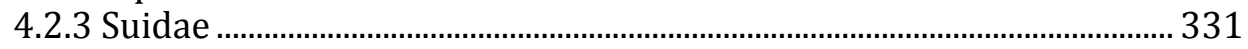

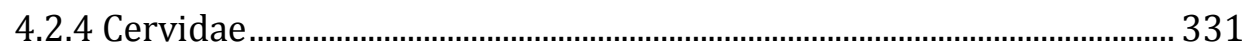

4.2.5 Caprinae................................................................................................... 331

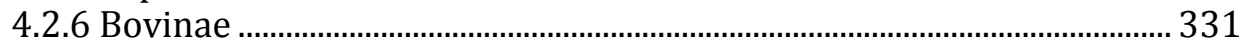

4.3 Estimation de la saison de mortalité …………………………………………….... 331

4.4 Détermination du sexe .......................................................................................... 332

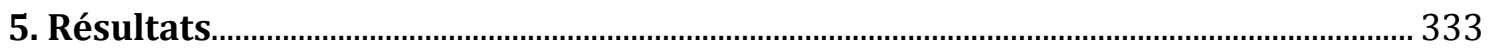

6. Conclusions

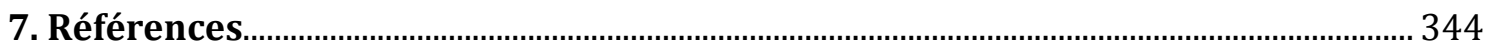

Figure I.1.1. Situation des sites étudiés dans ce travail.............................................................. 303

Table III.1.1. Matériel utilisé pour chaque site étudié et dans chaque chapitre...................322

Table V.1.1. Résumé des résultats obtenus dans chaque site...................................................336

Table V.1.2. Nombre minimum d'individus et pourcentages des tailles dans les dépôts du

Paléolithique Moyen et Supérieur .............................................................................................. 338 
1. Introduction 
L'étude des ongulés provenant de gisements archéopaléontologiques est un sujet traité depuis longtemps. Leur analyse a fourni de nombreuses données sur deux niveaux fondamentaux: un niveau paléontologique et un autre archéologique. Le niveau paléontologique offre des informations paléobiologiques des espèces, dans certains cas disparues, et les données paléoécologiques d'un grand intérêt comme la composition des groupes, les interactions entre les différents taxons ou leur présence et/ou l'absence dans certaines périodes. L'intégration de ces données avec d'autres comme les données paléopalynologiques nous permettraient de connaître comment pourraient être les écosystèmes dans une certaine période et si les habitats ou les niches de ces espèces peuvent avoir changé au fil du temps. Au niveau archéologique, de nombreux gisements sont d'origine anthropique, ce qui fait que ces analyses, intégrées aux études taphonomiques, reflètent des données intéressantes sur les chasseurs-cueilleurs, les périodes d'occupations des cavités, les préférences alimentaires de ses occupants et leur relation aux autres prédateurs.

Le peuplement du Plateau Nord a été un thème très discuté depuis le début du $20^{\mathrm{e}}$ siècle. L'absence de dépôts en comparaison avec les régions proches telles que les Asturies, les Cantabres et le Pays Basque a attiré l'attention des chercheurs. Cependant dans le premier tiers de siècle, le travail de noms illustres tels que l'Abbé Breuil, Hernández Pacheco et les pères Ibero et Carballo a mis au jour les premières évidences d'occupations dans ce territoire. Un bon recensement de noms apparait dans l'oeuvre d'Obermaier "El hombre fósil", employée comme livre de chevet par les chercheurs durant plusieurs années. Néanmoins et malheureusement beaucoup de restes apparaissant dans ces oeuvres (Breuil, 1918 - 1919; Obermaier, 1925) ont été perdus ou les fouilles ne furent pas réalisées selon une méthodologie adécuate et sont difficiles à attribuer à une période concrète. Les études menées à bien dans cette région comprennent trois périodes: le Paléolithique Inférieur, le Moyen et le Supérieur. Ce travail se concentre sur les dépôts avec ongulés fossiles du Plateau Nord, en particulier dans les gisements de la Communauté Autonome de Castilla y León, dans le cas précis des gisements limités à la couverture du Pléistocène Supérieur qui sont inclus dans le Paléolithique Moyen et aussi dans le Paléolithique Supérieur.

\section{Le Paléolitique Moyen dans le Plateau Nord}

À l'intérieur du premier, le Paléolitique Moyen, nous pouvons parler des dépôts à l'air libre et des sites en grottes ou abris sous roche. Les premiers sont les plus abondants et se trouvent répartis dans les provinces de Burgos, Valladolid, Segovia et Soria, Ucero I étant le seul dépôt à ciel ouvert localisé dans cette dernière. La plus grande concentration avec environ 43 sites, se trouve à Páramo de Corcos, à la limite des provinces de Burgos, Valladolid et Segovia, et qui de plus ont été attribués aux alentours du Paléolithique Inférieur (Díez et Rodríguez, 2009). À Segovia il existe des références confuses en relation avec des découvertes faites à Pradales et Honrubia de la Cuesta et à Cuéllar quelques restes ont été localisés. Un autre grand ensemble se trouve aux alentours de la Sierra d'Atapuerca. Plus d'une trentaine de gisements (Navazo, 2006) ont été localisés, grâce aux prospections réalisées par l'Université de Burgos, qui complètent les lacunes présentent dans les cavités de la Sierra. La province de Burgos est la zone qui possède le plus grand nombre de dépôts de ce type dans tout le Plateau. En marge des gisements localisés aux alentours d'Atapuerca, ont été localisés des gisements dans la vallée de l'Ebro, les Merindades, dans les vallées des fleuves Urbel, Arlanza, Arlanzón et Pico. Sont incluses également dans ce type là les terrasses fluviales de Villagonzalo -Arenas, Villatoro, Ubierna, Villalonquejar, la Moneda, Villimar, Villacienzo et Cortes. Aucun de ces dépôts n'a fourni de restes fossiles (Díez et Rodríguez, 2009).

Les gisements en grotte sont bien représentés faisant ressortir de nouveau la province de Burgos avec cinq dépôts: la grotte de Valdegoba (Díez et al., 1988-1989; Quam et al., 2001), Prado Vargas (Torres et al., 1989; Navazo et al., 2005), La Mina (Díez et al., 2008), Cueva Millán et La Ermita (Moure Romanillo et al., 1982; Moure Romanillo et al., 1983). 
Tous ces sites ont fourni aussi bien des restes lithiques que des fossiles complétant et améliorant l'information obtenue dans les gisements à l'air libre. Dans la province de Palencia, nous mettons en relief les dépôts des grottes Corazón et Guantes. La première découverte en 1978 et étudiée par les universités de Valladolid et la Complutense de Madrid, a apporté un riche ensemble osseux et lithique (Díez Martín et al., 2011; Sánchez Yustos et al., 2011). Les deux autres, Villanueva 1 et la grotte de Guantes, sont encore étudiés et analysés par une équipe du Centre National de Recherche sur l'Évolution Humaine (CENIEH), parce que beaucoup de leurs restes sont d'ongulés (Rodríguez com. pers.).

Les gisements de Cañón de Río Lobos méritent une brève mention. Les abris et cavités apparaissent dans les citations de l'abbé Breuil et d'Hugo Obermaier au début du siècle passé. Dans leurs textes ils citent des sites tels que ceux d'Arganza ou l'abri de Barranco (Obermaier, 1925). Aujourd'hui au jour beaucoup de ces gisements et les pièces qui y ont été récupérées n'ont pas pu être localisés. Dans la même zone, en 2004, le Pôle de Préhistoire de l'Université de Burgos, fouille dans la grotte de la Máquina et del Polvorista, sans trouver de restes d'occupation paléolithique (Navazo com. pers.).

\section{Le Paléolitique Supérieur dans le Plateau Nord}

Le Paléolithique Supérieur, période qui comprend en Europe des chronologies allant de 40.000 à 9.500 ans, n'a pas fourni autant de gisements mais l'abondance et la variété des restes font que dans l'ensemble, ils sont plus complets. Dans de nombreux cas des problèmes existent au moment d'attribuer chronologiquement les dépôts surtout pour le manque de datations absolues et par la réutilisation des cavités dans des périodes postérieures comme le Néolithique et l'âge du Bronze (Díez et Rodríguez, 2009). Les dépôts pourraient être classés selon Díez et Rodríguez (2009) en cinq grands groupes: gisements à l'air libre avec une utilisation comme atelier; gisements à l'air libre avec des représentations artistiques; gisements en grotte avec occupations; gisements en grotte avec représentations artistiques et gisements en grotte avec occupations et manifestations graphiques.

Dans le premier groupe, les sites à l'air libre avec une utilisation comme atelier, nous pourrions inclure les gisements de Valladolid de Palomar (Mucientes) (Delibes de Castro et Díez Martín, 2006) et celui de Burgos de la Vallée des Orquídeas (Mosquera et al., 2007) et Fuente Mudarra (Cardeñuela del Río Pico). Aucun des deux n'a founi de restes fossiles, seulement des instruments lithiques de facture très homogène (Navazo com. pers).

Le second groupe, les gisements à l'air libre avec représentations artistiques, est plus réduit. Y sont inclus les gisements de Domingo García (Santa María de Nieva, Segovia) (Ripoll et Municio, 1999) et le site isolé de Villaba de Almazán (Soria), la Placa de Villalba (Jimeno et Fernández, 1988). Le premier qui de plus, présente les représentations les plus abondantes et en meilleur état de conservation, comprend une aire de plus de $40 \mathrm{~km}^{2}$. Y ont été identifiées des gravures représentant des chevaux, bouquetins, bovidés, chiens, cerfs, anthropomorphes et zoomorphes (Díez et Rodríguez, 2009). La pièce isolée de Villaba, la Placa, est apparue sans contexte stratigraphique clair. Dessus figurent des gravures des deux côtés, huit chevaux et dix huit bouquetins. Son attribution au Magdalénien se doit à la typologie des figures (Jimeno et Fernández, 1988).

Le groupe avec le plus de représentations est le troisième, les gisements en grotte avec occupations. Díez et Rodríguez (2009) incluent dans ce groupe les dépôts de la province de Burgos de El Níspero (Orbaneja del Castillo), La Blanca et El Caballón (Oña), La Aceña (Lara), El Portalón et El Mirador (Ibeas de Juarros). D'un autre côté, à Soria, sont mis en relief les abris d'Alexandre et Vergara (Deza) (Utrilla et al., 1999). Les restes d'El Níspero se trouvent très fragmentés bien qu'ils aient été attribués à des restes de cerfs, bouquetins et chevaux. Le gisement de La Blanca a fourni des restes en mauvais état de bouquetins, cerfs, chevaux et lynx. À El Caballón, il a été récupéré un important ensemble 
archéologique et un bâton de commandement, aujourd'hui disparu, duquel il ne reste seulement qu'un dessin avec ce qui apparaît être une gravure d'une tête de ruminant. Dans La Aceña (Obermaier, 1925), il a été identifié une collection de fossiles très rare et de plus, la localisation tant des restes que de l'abri est inconnue (Díez et Rodríguez, 2009). Dans les campagnes récentes de la Sierra d'Atapuerca, ont été localisés des niveaux de transition entre le Pléistocène et l'Holocène dans les gisements de Portalón (Pérez Romero, 2009), la grotte de Silo et la grotte d'El Mirador (Díez et Rodríguez, 2009), même si dans ce dernier il manque à realiser des datations plus précises dans les niveaux inférieurs du sondage commencé en 2002. Dans la province de León, nous incluons les dépôts d’El Espertín, La Uña, La Cantera et El Castro. Les restes qui y ont été récupérés ne sont pas très abondants et sont apparus très fragmentés (Delibes de Castro et Díez Martín, 2006). Les abris de Soria, ont donné en proportion plus de restes en meilleur état, nous en reparlerons un peu plus tard.

Dans le groupe des dépôts en grotte avec manifestations artistiques, nous dénombrons trois sites, deux à Burgos et l'autre à Segovia. Ceux de Burgos se situent dans la zone nord et sont La Palomera (Cueva de Sotoscueva), et la grotte de Los Moros à Peches (Barcina de los Montes) (Hernández Pacheco, 1917; Corchón et al., 1988 - 1989). La cavité de Ségovie, La Griega, se trouve à Pedraza (Corchón, 1997). La Palomera, dans l'ensemble karstique de Ojo Guareña, présente, dans la dite salle des peintures, 93 représentations d'aurochs, de cerfs, d'anthropomorphes, triangles noirs, bâtonnets et un possible mammouth (Díez et Rodríguez, 2009). À Penches, découverte par les jésuites d'Oña, ont été identifiés sept bouquetins, un équidé, un bovidé et un possible anthropomorphe schématique (Corchón, 1988 - 1989). Cependant, il n'y a pas de datations absolues de ces dites représentations malgré sa similitude avec d'autres gisements magdaléniens et sa ressemblance, tant par le style, avec d'autres figures de la région cantabrique permettent de les attribuer au Paléolitique Supérieur même si certains chercheurs suggèrent une attribution postpaléolithique (Díez et Rodríguez, 2009). La grotte de La Griega présente un important ensemble de gravures d'animaux tels que chevaux, cerfs, aurochs, sangliers, ours, félins, poissons, motifs géométriques et anthropomorphes (Corchón, 1997). Sa chronologie a été déterminée par des raisons stylistiques et se place dans le Solutréen et le Magdalénien Inférieur (Díez et Rodríguez, 2009).

Dans le dernier groupe, le plus complet celui qui comprend les occupations en grotte ou abris sous roche avec représentations artistiques, existe seulement qu'un dépôt la Peña de Estebanvela. À part la collection de fossiles d'ongulés, de laquelle nous parlerons après il a été trouvé un important ensemble d'industrie lithique et osseuse et 35 éléments artistiques qui comprend des plaquettes et galets de pierre avec des motifs décoratifs qui présentent des figures géométriques abstraites. Les peintures et gravures rupestres dans le Plateau Nord sont très abondantes, elles se trouvent tant à l'air libre qu'en abris sous roche et en grotte. Beaucoup d'entre eux n'ont pas été bien diffusés et leur accès tout comme leur étude n'est pas facile. Pour mieux les connaître, puisque dans cette introduction nous faisons seulement référence aux plus connus, il est intéressant de consulter le travail de Corchón et al., (1988 - 1989) et Altuna (2002) et les références qui apparaissent ici.

Enfin, même si sa découverte n'est pas récente les premières références datent de 1864, nous trouvons la Peña de Mudá (Mudá, Palencia). Ses fossiles n’ont été étudiés que très récemment (Álvarez-Lao, 2007). Même si des datations absolues n'ont pas été obtenues, les espèces identifiées le situent dans une des phases froides du Pléistocène Supérieur.

\section{Études précédentes de la faune du Plateau Nord avec une préférence particulière pour les ongulés}

L'étude des ongulés du Pléistocène Supérieur du Plateau Nord est allée de pair avec l'analyse d'autres restes archéopaléontologiques, peut-être même plus valorisés, comme 
ceux des hominidés, des carnivores ou de l'industrie lithique (Cacho et al., 2006; Navazo et al., 2005; Quam et al., 2001).

L'analyse des restes récupérés dans ces gisements peut se diviser en deux périodes: les premières années du 20 e siècle et à partir de la décade des années 70 du siècle passé. Dans la première période, caractérisée par les premières incursions de préhistoriens dans la région, se distinguent les travaux et découvertes de chercheurs tels que l'abbé Breuil, Hugo Obermaier, le père Saturio et différents religieux anonymes des monastères de Silos et de San Salvador de Oña. L'inventaire qu'ils réalisèrent en début de siècle (Obermaier, 1925) fut la base pour les préhistoriens postérieurs. La méthodologie employée dans ces premières années, basée fondamentalement dans les blancs archéologiques, c'est-à-dire dans une sélection de pièces concrètes a fait que beaucoup de gisements n'ont pas pu être localisés et que le peu de restes qui peuvent encore se trouver apparaissent en dehors de leur contexte et cela empêche donc de les attribuer à une époque concrète.

Tout cela change à partir des années 70 du siècle passé, quand la méthodologie actuelle a été introduite. Avec elle entre en scène, le travail multidisciplinaire intégrant différentes disciplines et spécialités qui donnent de l'importance à tout le registre pour pouvoir comprendre et interpréter les découvertes. La bibliographie de cette période pourrait se diviser en deux types bien différenciés. D'un côté, les études générales dans lesquelles se présentent les dépôts, en incluant la localisation, la géologie, la stratigraphie et les listes faunistiques (Moure Romanillo et García Soto, 1983; Molero et al., 1989; Torres et al., 1989; Díez, 1990; Utrilla et Blasco, 2000; Quam et al., 2001; Navazo et al., 2005; Cacho et al., 2006; Díez et al., 2008; Sala et al., 2009), et les études plus concrètes qui se centrent dans un groupe déterminé. Ainsi par exemple, nous mettons en relief les travaux, dans les dépôts du bassin d'Arlanza à Burgos, de Pérez Legido et Cerdeño (1992) et Álvarez et al., (1992) sur les macromammifères, et de Roselló Izquierdo (1992) sur l'ichtyofaune. Beaucoup de ces travaux excepté ceux qui se réfèrent à une espèce concrète comme Cerdeño (1987), qui décrit le rhinocéros de Cueva Millán et l'attribut au Dicerohinus hemitoechus, ne présentent pas de descriptions très détaillées, se centrant fondamentalement dans le nombre de restes, nombre minimum d'individus et des mesures basiques. L'ichtyofaune, d'autre part, inclut aussi une analyse de la saisonnalité et compare les espèces récupérées avec celles prises dans d'autres gisements de la péninsule nord où ces restes se trouvent être les plus abondants. Un autre gisement dans lequel des études plus détaillées sont réalisées est celui de la grotte du Búho. Dans ce dépôt il s'est mené à terme une analyse générale des carnivores de la part d'Iñigo et al. (1998) et deux plus concrètes, une sur le rhinocéros et l'autre sur les bovidés, qui ont permis d'attribuer le matériel tant au Stephanorhinus hemitoechus (Iñigo, 1995) comme au Bos primigenius et au Bison priscus (Sala et al., 2010). En ce qui concerne les ongulés, la grotte de Valdegoba, avec Prado Vargas et la Peña de Estebanvela sont les gisements qui présentent les travaux les plus détaillés. Ainsi, dans le premier, il existe des références sur les équidés (Arceredillo, 2008b), l'âge de mort des artiodactiles (Arceredillo et Díez, 2009) et le dimorphisme sexuel des isards (Arceredillo et al., 2011). À Prado Vargas des analyses générales de ce groupe ont été réalisées (Arceredillo, 2010) ainsi que sur l'âge de mort des cerfs (Arceredillo et Díez, 2010). Les ongulés de la Peña de Estebanvela ont été étudiés par Yravedra (2006) et Arceredillo (2013), présentant pour le premier une liste faunistique très détaillée et pour le deuxième une analyse plus exhaustive du matériel.

D’autre part, dans les dernières années, il a été identifié des groupes qui n'avaient pas été décrits dans le Plateau Nord pour la période du Pléistocène Supérieur comme le rhinocéros laineux Coelodonta antiquitatis (Álvarez-Lao, 2007) et des genres qui n'avaient pas été localisés dans la Péninsule Ibérique pour le Pléistocène comme Hemitragus (Van der Made et al., 2003; Rivals et Blasco, 2008). De même, il y a eu des avancées dans la classification de certains taxons très représentatifs comme Equus caballus (Maldonado, 1996). Dans ce travail l'évolution de ce genre est analysée et sont décrites une part des sous espèces qui jusqu'à présent n'ont pas été incluses dans les travaux précédents. Quelque chose de similaire se passe avec Equus hydruntinus, espèce peu connue par le 
manque de fossiles mais mieux étudiée maintenant grâce à des travaux comme celui de Davis (1980).

Une des espèces les plus communes au début du Pléistocène Supérieur et maintenant entrant dans l'Holocène est le chamois Rupicapra (Altuna, 1972). Traditionnellement, cette espèce a été considérée dans les gisements ibériques comme $R$. rupicapra (Altuna, 1972; Alférez et al., 1980-1981), parce qu'à cette époque là était seulement reconnue l'existence de cette espèce. Cependant, après la publication de Nascetti et al., (1985), la présence de deux espèces est acceptée: $R$. rupicapra et $R$. pyrenaica, la première présente dans le sud-ouest de l'Europe et la deuxième distribuée dans le reste de l'Europe et du Caucase. Malgré cela, les travaux qui parlent de $R$. pyrenaica sont encore très rares (Cardoso, 1996; Fernández, 2001; Rivals, 2002; Moigne et al., 2006; Magniez, 2010). Cette nouvelle classification fait qu'il était nécessaire de réviser le matériel de cette espèce qui non seulement affectait l'attribution taxonomique mais aussi les données employées dans les analyses postérieures. Cette information touche les périodes de naissance, allaitement, rut et gestation; comme aux indices d'usure et aux dates de remplacement et éruption dentaire (Couturier, 1938; Pérez-Barbería, 1994). Quelque chose de similaire a lieu avec les bouquetins Capra pyrenaica. Traditionnellement, les restes de ce caprin ibérique ont été inclus dans l'espèce Capra pyrenaica. Néanmoins, il a été observé, dans certaines références, le taxon Capra ibex comme dans le gisement de La Blanca à Burgos (Delibes de Castro et Díez Martín, 2006). Crégut-Bonnoure (1992b) définit certains critères diagnostiques dans la dentition inférieure des deux caprinés qui seront employés ultérieurement. Il faut signaler que ces dits restes sont abondants dans les gisements analysés, justifiant sa révision.

Il en va de même pour les aurochs et les bisons, Bos primigenius et Bison priscus. De nombreux restes sont normalement attribués à Bos/Bison sp. Dû à l'absence de matériel diagnostique comme les cornes et la troisième molaire inférieure. Cependant, existent des travaux dans lesquels on tente de différencier les deux genres et qui utilisent du matériel postcrânial Schertz (1936), Bibikova (1958), Brugal (1984), Buitrago (1992), Gee (1993), Álvarez-Lao (2007) et Sala et al., (2010). Dans nos dépôts, les critères observés par ces chercheurs ne peuvent pas être utilisés pour la plupart des restes à cause de l'origine anthropique des différentes accumulations, ce matériel apparaît très fragmenté. D'un autre côté, Jaubert et al. (1994) développe une analyse de la dentition des deux genres, incluant des pièces distinctes de la troisième molaire inférieure ce qui rend son utilisation très intéressante dans les gisements archéopaléontologiques.

D'une manière générale, les données enregistrées sur les ongulés dans les gisements du Pléistocène Supérieur du Plateau Nord constituent la majeure partie du matériel récupéré dans ces mêmes gisements. Sauf dans un des cas de la grotte du Búho, La Mina et la Peña de Mudá, le reste des dépôts a eu une origine fondamentalement anthropique (Utrilla et al., 2006; Díez, 2006; Díez et al., 2008; Yravedra, 2013), même s'il est sûr qu'il existe des références de l'utilisation occasionnelle de ces cavités par des carnivores de plus ou moins grande taille (Torres et al., 1989, Navazo et al., 2005, Díez, 2006). Les analyses taphonomiques et les études archéozoologiques réalisées dans ces gisements ont permis de connaître tant l'origine de ces accumulations comme les activités qui y ont été réalisées. Cependant, ces travaux n'apportent pas d'informations sur les périodes d'occupation ni sur une possible sélection des proies par l'âge ou le sexe. Pour cette raison, et dû à l'importance du matériel obtenu, l'identification correcte des taxons, la détermination de l'âge de mort, la saison et le dimorphisme sexuel apportent d'importantes informations sur les occupations.

L'emplacement et la situation de ce territoire associé aux peu de gisements localisés a posé une série d'incertitudes aux chercheurs le considérant très souvent comme un lieu isolé et non habité comparé aux régions proches. Les récentes découvertes ainsi que l'obtention de ces grandes collections nous permettent de connaître les différentes routes d'accès au Plateau de la part des populations du Pléistocène Supérieur ainsi que de déterminer les périodes durant lesquelles elles occupaient les cavités, si elles furent 
utilisées de manière continue ou durant des saisons précises. D’autre part, la saisonnalité peut être mise en relation avec les comportements sociaux et migrateurs des espèces identifiées, nous aidant à comprendre l'occupation d'un lieu déterminé durant une saison concrète.

De même, l'analyse de ces pièces peut nous aider à différencier les préférences de consommation de deux espèces qui peuplèrent ce territoire durant le Paléolithique Supérieur, Homo neanderthalensis et $H$. sapiens, savoir s'il existait une différence entre les espèces, âges et genres, et s'ils occupaient le territoire et les grottes avec la même intensité et durant la même période de l'année.

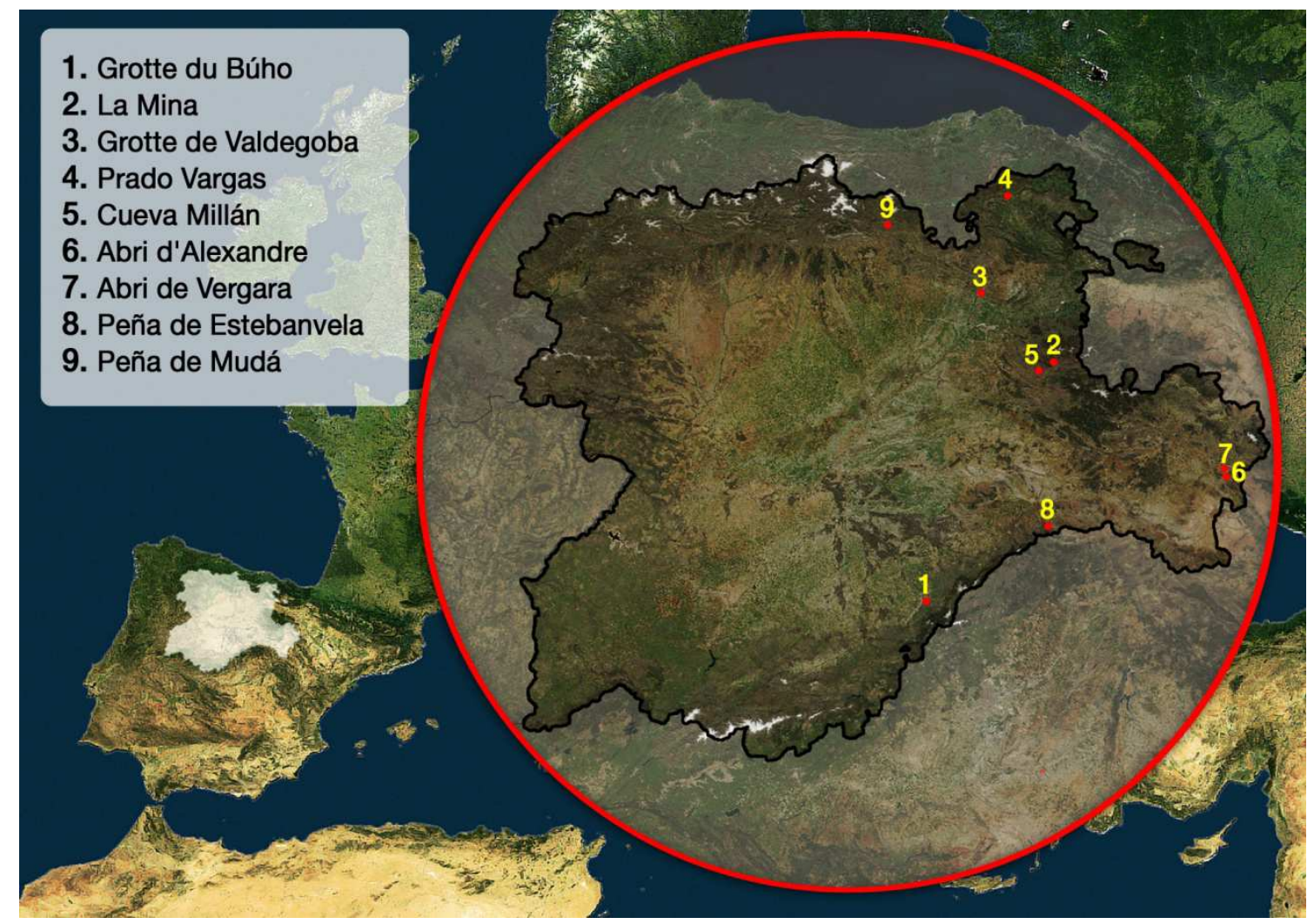

Figure I.1.1. Situation des sites étudiés dans ce travail.

De plus, l'importance du matériel récupéré peut également nous aider à savoir si la taille de ces espèces a changé avec le temps et si cela pourrait influencer les modèles de consommation de ces populations humaines. Les études préalables de ces gisements ont été menées à bien de façon indépendante par différents groupes d'investigation (Moure Romanillo et García Soto, 1982; Díez et al., 1988-1989; Navazo et al., 2005; Utrilla et al., 2006; Álvarez -Lao, 2007; Cacho et al., 2006). Une analyse globale de ces mêmes ongulés peut nous offrir une vision plus détaillée et obtenir des conclusions générales qui nous indiquent l'intensité des différentes occupations de la part des populations humaines qui occupèrent ce territoire durant le Pléistocène Supérieur. Avec tout cela et en valorisant bien évidemment le travail réalisé par les scientifiques précédents nous résumons brièvement les gisements sujets de cette étude. 


\subsection{La Mina}

\subsubsection{Introduction}

Le gisement de La Mina est un des trois gisements situés dans le cours moyen du fleuve Arlanza. Il se situe à la limite municipale d'Hortigüela (Burgos), à 970 mètres au-dessus du niveau de la mer, dans une vallée transversale du fleuve Arlanza, d'où coule le fleuve Valparaiso (Díez et al., 2008). La grotte est étudiée pour la première fois en 2006 par l'équipe du Dr. Carlos Díez de l'Université de Burgos. Quatre sondages ont été réalisés où il était certain que le dépôt était complètement bouleversé. Ils identifient une petite matrice d'argiles contenant des indices d'une occupation paléolithique (Díez et al., 2008), arrivant à la conclusion qu'il pourrait exister deux occupations durant le Pléistocène.

\subsubsection{Géologie et Stratigraphie}

La cavité se trouve dans le Secteur Oricedo. Dans sa structure il existe des évidences d'une forte diaclase qui se manifeste dans le développement de la grotte avec des directions de galeries E-O (dominantes) et NO-SE secondaires joint à sa galerie conjointe NE-SO. La grotte possède un développement de 105 mètres, se terminant par un petit passage de deux mètres. Tant la largeur que la hauteur varient entre un et deux mètres (Díez et al., 2008).

Une séquence stratigraphique n'a pas pu être établie du fait que le dépôt fut l'objet de réactivations karstiques continues et d'interventions furtives (Díez et al., 2008). À partir de cela deux possibles ensembles ont été identifiés même s'ils ne sont pas définis comme niveaux "sensu stricto", ils peuvent nous donner une idée sur les possibles occupations de la grotte. Le premier ensemble inclut cinquante-cinq restes osseux entourés de morsures de carnivores. Le groupe n'a fourni aucun reste archéologique. La majeure partie des fossiles correspondent à des diaphyses fragmentées d'herbivores de taille moyenne à grande. Le second ensemble est représenté par 493 fossiles et quatre pièces lithiques. Il a été aussi récupérer des coprolythes de carnivores et des os digérés.

\subsubsection{Restes fossiles}

Dans les 548 restes récupérés d'attribution pléistocène, 19 taxons ont été identifiés (Díez et al., 2008). Les micromammifères incluent: Eurotestudo sp., Oryctolagus cuniculus, Lepus sp. et Hystrix sp. Les macromammifères comprennent: Ursus arctos, Canis sp., Vulpes vulpes, Panthera sp., Lynx pardina, Felis sylvestris, Crocuta crocuta spelaea, Meles meles, Coelodonta antiquitatis, Equus ferus, Equus hydruntinus, Sus scrofa, Cervus elaphus, Rupicapra pyrenaica et Bos/Bison sp.

Dans ce travail nous changeons l'attribution du rhinoceros. Au début, il a été identifié comme Stephanorhinus hemitoechus (Díez et al., 2008). Dans cette étude nous le classifions comme Coelodonta antiquitatis.

\subsubsection{Restes lithiques}

Les matières premières se composent fondamentalement de silex et quartzite. Le silex présente des caractéristiques macroscopiques similaires à celles de la Ermita et Cueva Millán, sauf une lame qui paraît être réalisée avec du matériel allochtone. Ont été récupérés des nucléus avec une exploitation ortogonale, très épuisés, des couteaux à dos naturel, des lames Levallois, de nombreux denticulés, une pointe retouchée en quartzite et un racloir latéral droit sur dos naturel. Du fait que les outils aient été récuperés dans un sédiment remué, leur attribution culturelle est difficile à définir. En tenant compte des 
processus technologiques ils pourraient être attribués au Pléistocène Supérieur (Díez et al., 2008).

\subsubsection{Datation}

La méthodologie employée fut la racémisation des acides aminés. Elle est menée à bien à partir d'une dent de rhinocéros. Le résultat révéla un âge approximatif de 52,5 Ka. BP. (Díez et al., 2008). Du fait que le dépôt soit remué et que la datation a été obtenue grâce à une dent de rhinocéros, seuls les restes de ce taxon sont analysés.

\subsection{La Grotte de Valdegoba}

\subsubsection{Introduction}

Le gisement de la Grotte de Valdegoba se trouve situé à $28 \mathrm{~km}$ au nord-ouest de la ville de Burgos, à 930 mètres au-dessus du niveau de la mer et à 35 mètres au-dessus du cours haut du fleuve Urbel (Díez, 1990; Díez et al., 1989; Quam et al., 2001; Arceredillo, 2008a). Il appartient à la municipalité de Huérmeces, même si les localités les plus importantes de la zone sont Montorio et Santibánez de Zarzaguda. La grotte est connue depuis 1980 grâce aux travaux réalisés par le groupe de spéléologie de Burgos Edelweiss (Díez, 1990). Quatre campagnes ont été réalisées entre 1987 et 1991, et en 2006 un sondage pour faire des études sur des matières et la paléovégétation de la part de l’Université de Burgos.

\subsubsection{Géologie et Stratigraphie}

Le gisement s'ouvre dans un affleurement de calcaires du Crétacique Supérieur, sur le côté le plus méridional de la bordure Mésozoique de la Cordillère Cantabrique (I.G.M.E., 1970) (Díez et al., 1988-1989). Ceux-ci apparaissent proche de la localité de Huérmeces sur les dépôts terciaires du bassin du Duero, suivant une orientation $135^{\circ} \mathrm{N}-140^{\circ} \mathrm{E}$ et une pente de $38^{\circ}$. Au pied de l'entrée, le fleuve Urbel rentre pour s'ouvrir postérieurement dans la plaine tertiaire du bassin du Duero. La grotte est située sur le côté nord de l'affleurement et à l'est du canyon du fleuve, au pied duquel apparaissent des dépôts avec une grande pente (Díez et al., 1988-1989; Quam et al., 2001).

Le système karstique est de type pluvial, avec une alimentation autochtone par infiltration gravitationnelle d'eau superficielle, facilitée par la grande quantité de diaclases existentes dans la zone. Le complexe est formé par trois cavités, constituant actuellement un karst mort. Des trois, celle qui présente un registre archéopaléontologique est la plus ancienne d'entre elles et se trouve en position centrale (Díez, 1990; Díez et al., 19881989). L'entrée donne accès à un vestibule orienté vers la vallée, avec une morphologie d'abri et où se trouve la plus grande hauteur de la grotte. Dans l'extrême sud-ouest s'ouvre une galerie ascendante en direction nord-sud qui se resserre progressivement. Les dimensions de la grotte ne sont pas très grandes, présentant une longueur de 21 mètres, une largeur maximale de 14 mètres et une minimale de 6 mètres dont la hauteur varie entre les 4 à 5 mètres dans l'entrée et 0,5 mètres dans le fond (Díez 1990).

Une bonne partie des dépôts apparaissent altérés dû à des réactivations et à l'action de clandestins (Díez, 2006). La grotte se trouve partiellement remplie par des argiles et des galets dispersés lesquels arrivèrent à colmater la cavité et qui postérieurement furent vidés par érosion et remués par l'action de clandestins (Díez, 1990). Seul un des sondages réalisés a permis le dégagement d'une colonne lithostratigraphique favorable à l'obtention de résultats géologiques puisque à l'intérieur d'elle les matériaux se trouvèrent "in situ". 
Cette séquence fut développée par J. Jordá (Quam et al., 2001), différenciant huit niveaux qui du mur à la voûte sont les suivants:

Niveau I: Concrétion stalagmitique de base. Stérile.

Niveau II: $40 \mathrm{~cm}$ d'argiles rouges avec limons et sables avec un sous niveau de concrétion carbonaté. Stérile.

Niveau III: $10 \mathrm{~cm}$ d'argiles marrons avec limons et sables. Concrétion stalagmitique en superficie. Stérile.

Niveau IV: Argiles marrons avec des blocs calcaires d'épaisseurs non supérieures à $50 \mathrm{~cm}$. Érosion visible en superficie. Industrie lithique et fossiles.

Niveau V: $20 \mathrm{~cm}$ d'argiles marrons avec de nombreux blocs calcaires. Contact érosif avec le niveau IV. Industrie lithique, fossiles de faune et d'hominidés.

Niveau VI: Brèche calcaire au moins couverte de $20 \mathrm{~cm}$ de blocs calcaires, instruments lithiques et fossiles. En continuité avec le niveau V. Seule la cimentation de la brèche permet sa distinction.

Niveau VII: Une concrétion stalagmitique laminaire ferme le niveau 6. Cette concrétion est unie à divers endroits aux parois et à la voûte. Elle présente du matériel archéologique. C'est un reflet clair du point de colmatation qu'arrive à avoir la cavité.

Niveau VIII: $60 \mathrm{~cm}$ d'argiles en contact avec le niveau VII. Il contient un mélange de matériaux Paléolithiques et Holocènes ainsi que des restes humains. Ce mélange reflète une altération dûe à l'action des furtifs.

\subsubsection{Restes fossiles}

Les fouilles menées à bien depuis 1987 ont fourni un important ensemble de restes faunistiques qui incluent des primates carnivores, périssodactyles, artiodactyles, oiseaux, rongeurs et lagomorphes. Les macromammifères incluent: Homo sapiens, Homo neanderthalensis, Ursus arctos, Ursus spelaeus, Canis lupus, Vulpes vulpes, Crocuta crocuta, Panthera pardus, Felis silvestris, Lynx pardina, Meles meles, Lutra lutra, Martes sp., Stephanorhinus hemitoechus, Equus ferus, Equus hydruntinus, Sus scrofa, Cervus elaphus, Capreolus capreolus, Rupicapra pyrenaica, Capra pyrenaica, Bos primigenius, Bison priscus et Bos/Bison sp. (Díez et al., 1989). Les micromammifères incluent: Sorex sp., Neomys sp., Oryctolagus cuniculus, Microtus nivalis, Microtus arvalis-agrestis, Pliomys lenki, Apodemus cf. sylvaticus, Arvicola sp., Marmota cf. marmota, Hystrix cf. vinogradovii et Castor fiber. L'avifaune comprend: Anas sp., Aegypius monachus, Falco tinnunculus, Columba sp., Athene noctua, Alectoris sp., Coturnix coturnix, Turdus sp. et Pyrrhocorax graculus (Díez et al., 1989).

Les restes qui se distinguent le plus déjà qu'ils sont les seuls découverts jusqu'au moment de ceux de Castilla y León correspondent à l'hominidé Homo neanderthalensis. De cette espèce ont été récupérés un fragment mandibulaire qui conserve neuf pièces dentaires, une phalange et deux métatarses. Ont été également obtenus divers restes attribués à $H$. sapiens qui nous indiquent une occupation holocène de la cavité (Díez et al., 1988-1989).

Dans ce travail nous changeons l'attribution du chamois à l'espèce Rupicapra pyrenaica et des restes d'auroch Bos primigenius au bison Bison priscus.

\subsubsection{Restes lithiques}

L'industrie lithique est abondante, quelques 2.500 pièces produites principalement à partir de silex et quartzite, même si apparaissent aussi des pièces fabriquées à partir de grés et quartz. Le matériel provient d'affleurements proches au gisement, les quartzites se 
trouvent dans le fleuve Urbel, le silex provient tant du fleuve en forme de blocs néogènes, comme de nodules crétaciques de l'affleurement où se trouve la grotte (Díez et al., 19881989; Quam et al., 2001). Les nucléus centripètes, les extractions longitudinales, les racloirs et les denticulés sont abondants (Díez, 2006).

\subsubsection{Datation}

Deux types de datations ont été menées à bien. Les premières, réalisées par James Bischoff, basées sur la méthodologie U/Th, apportèrent des résultats peu concluants. Trois échantillons ont été pris; un dans la croûte stalagmitique base du niveau I et deux autres dans la brèche superficielle du niveau VII (Arceredillo, 2008a). La premier apporte une date $>350 \mathrm{Ka}$ et les deux autres ne donnèrent pas de résultats concluants puisqu'ils apparaissèrent contaminés avec un thorium détritique (Díez, 2006), donnant pour autant des chronologies plus anciennes, $95 \pm 8 \mathrm{Ka}$ et $73 \pm 5 \mathrm{Ka}$. D'autre part, l'équipe de Trinidad Torres, en 2005, a employé la racémisation des acides aminés et a obtenu les dates à partir de restes osseux variés du niveau IV: 121,86 Ka BP; du niveau V: 72,59 et $138 \mathrm{Ka} \mathrm{BP;} \mathrm{et} \mathrm{du}$ niveau VI: 93,26 Ka et 106,02 Ka (Díez et al., 2014). Enfin, deux os du niveau V ont été envoyés à l'Université d'Oxford (ORAU). Un os ne peut pas être daté et un autre, par le protocole d'ultrafiltration, a donné une date non calibrée de 48, $400 \pm 3,300$ BP (OxA21970) (Dalen et al., 2012).

\subsection{Prado Vargas}

\subsubsection{Introduction}

La grotte de Prado Vargas se trouve dans la Merindad de Sotoscueva, seulement à 500 mètres de la localité de Cornejo, au nord de Burgos (Torres et al., 1993; Navazo et al., 2005). Elle prend part dans l'ensemble karstique de Ojo Guareña, se présentant comme une ancienne résurgence, aujourd'hui inactive, située à 20 mètres au-dessus du cours actuel du fleuve Trema. Cette grotte se situe sur un passage naturel entre la région Cantabrique et le Plateau Nord et présente une morphologie d'abri naturel (Torres et al., 1989). Son potentiel paléontologique est connu depuis les années 70 du siècle passé. Ce fut lorsque le groupe de spéléologues Edelweiss trouva un crâne d'Ursus spelaeus déposé dans le Musée Provincial de Burgos. Il a été analysé par Trinidad Torres qui après une étude préalable, décide de réaliser une intervention unique en 1986. Durant cette campagne s'ouvrirent quatre sondages pour définir la stratigraphie et observer sa corrélation récupérant diverses pièces lithiques et fossiles (Torres et al., 1989; Navazo et al., 2005). L'activité repris en 2006 de la part de l'Université de Burgos, sous la direction de Marta Navazo et Carlos Díez, avec la réouverture du sondage de la zone la plus proche de l'entrée et un à l'extérieur proche du porche. Durant cette intervention une grande quantité de matériel lithique a été récupéré ainsi que des restes osseux et dentaires.

\subsubsection{Géologie et Stratigraphie}

La grotte s'ouvre sur les matériaux carbonatés du Crétacique Supérieur du flanc nordoriental du sinclinal de Villarcayo et plus concrètement dans le secteur dénommé "zone plissée du fleuve Trema", au pied d'un petit escarpement calcaire, fermant un pré à forte pente et à peu d'extention (Torres et al., 1989; Díez et Rodríguez, 2009). Il s'agit d'une grotte à faible développement, seulement 120 mètres, suivant une galerie rectiligne interrelationnée avec une diaclase (Torres et al., 1989) avec une direction nordouest/sud-est (Navazo et al., 2005) et une série de petites ramifications de direction nordouest/sud-est. La grotte se divise en trois sections bien différenciées: 1: proche de la sortie avec une longueur de 30 mètres et une hauteur maximale de trois; 2) un couloir de six 
mètres de longueur; 2) la partie finale avec un parcours de 50 mètres et deux mètres de haut dans sa partie la plus élevée (Navazo et al., 2005). La grotte s'ouvre à la vallée par l'intermédiaire d'une forte pente alluviale qui se termine dans le fleuve Trema, et à ce niveau s'ouvrent les actuels affluents du fleuve. Durant la campagne de 1986 fut établie la stratigraphie des dépôts. Dans ce travail le matériel du sondage alpha a été analysé concentré en grande part dans le niveau quatre. Cinq niveaux furent différenciés qui de la voûte au mur sont les suivants:

Niveau 1: Terre libre et remuée. Stérile.

Niveau 2: Matière fine avec galets calcaires. Matériel archéologique "in situ". Différents fragments de céramique d'origine du Haut Moyen-Âge ont été récupérés ainsi que les restes d'un artiodactyle jeune (agneau ou chèvre).

Niveau 3: Paquet d'argile rouge compacte de 40-50 cm d'épaisseur. Stérile.

Niveau 4: Matière argileuse mélangée avec des gravillons, gravier et sable calcaires. Dans ce niveau apparaît quasiment tout le matériel archéologique et paléontologique.

Niveau 5: Composé de gravillons et de gros sable calcaire. Stérile.

\subsubsection{Restes fossiles}

Les campagnes menées à bien ont apporté peu de restes. La majeure partie de ces restes apparaît très fragmentée et son identification est impossible. Même les sédiments n'ont pas été criblés parce que l'enregistrement tant des micromammifères que de l'avifaune n'a même pas été analysé. Les macromammifères incluent: Canis lupus, Panthera pardus, Ursus spelaeus, Rhinocerotidae indet., Equus ferus, Sus scrofa, Cervus elaphus, Capreolus capreolus, Rupicapra pyrenaica, Capra pyrenaica et Oryctolagus sp.

Dans ce travail s'ajoute à l'inventaire réalisé par Torres et al., (1989) et Navazo et al., (2005) le reste de rhinocéros et se réattribut l'isard à l'espèce Rupicapra pyrenaica à la place de R. rupicapra.

\subsubsection{Restes lithiques}

Prédominent les lames faisant ressortir une petite portion de nucléus et la présence de, au minimum, deux burins. Les matières premières employées furent le silex, la quartzite, le calcaire silicieux et la lutite (Navazo et al., 2005). La plupart de ces matériaux se localisèrent dans le sondage proche de l'entrée de la grotte, étant rare dans le sondage interne (Torres et al., 1993, Navazo et al., 2005; Navazo et Díez, 2008).

\subsubsection{Datation}

La technique employée pour dater le gisement fut la racémisation des acides aminés. Pour cela il a été utilisé un $\mathrm{P}_{2}$ droit de cheval (Navazo et al., 2005). Les résultats reflétèrent une chronologie proche des 46,4 Ka.

\subsection{Cueva Millán}

\subsubsection{Introduction}

L'abri de Cueva Millán se situe à la frontière municipale de Hortigüela, à environ 50 kilomètres de la ville de Burgos et à 985 mètres au-dessus du niveau de la mer (Díez et al., 
2008). Il se situe dans une petite vallée transversale, tributaire du fleuve Arlanza, dans un lieu connu comme "Los Riscos del Estillín" (Moure Romanillo et al., 1983; Álvarez et al., 1992; Roselló Izquierdo, 1992).

La première référence fut réalisée par Martín Merino (1978), membre du groupe de spéléologie Edelweiss du Conseil Provincial de Burgos. Cette mention parle de Cueva Millán comme "...possédant un extraordinaire atelier de silex" (Moure Romanillo et al., 1982; Moure Romanillo et al., 1983). Avant les fouilles menées à bien par une équipe de la UCM, des membres du Collectif Archéologique Salense visitent la cavité et récupèrent 1.165 pièces lithiques en surface (Díez et al., 2008). Des membres du Département de Préhistoire de l'Université Complutense de Madrid, au travers d'une visite précédente d'où ils récupérèrent un matériel lithique abondant en surface, décident de mener à bien une série d'interventions dans le gisement. Ces dernières se réalisèrent en quatre campagnes, trois d'entre elles de manière consécutive en 1980, 1981 et 1982 (Moure Romanillo et al., 1983; Álvarez et al., 1992) et la dernière durant l’année 1986 (Pérez Legido et Cerdeño, 1992).

\subsubsection{Géologie et Stratigraphie}

Le gisement se trouve dans le cours moyen du fleuve Arlanza, lequel communique avec la Sierra de la Demanda avec le troisième du Plateau. Il suit une direction ouest sauf dans la zone de Hortigüela, où il prend une direction sud qui forme une large vallée (Díez et al., 2008). Tant Cueva Millán que la Ermita et La Mina participent à un environnement géomorphologique et paysage similaire: espaces ouverts et vallées, versants généralement prononcés avec abondance de parois verticales, et grand développement de zones hautes (Díez et al., 2008). L'abri s'ouvre dans les calcaires crétaciques du Turonien Inférieur qui affleurent dans cette zone proche de la localité d'Hortigüela (Álvarez et al., 1992).

La stratigraphie se définit à partir des coupes présentes dans cinq carrés situés à différents endroits de l'abri. Elle fut réalisée par l'équipe d'Enrique García Soto durant la première campagne de fouilles. La séquence est assez claire dû à la faible altération des dépôts. Ont été définis quatre niveaux sédimentologiques (Moure Romanillo et al., 1983; Álvarez et al., 1992):

Niveau 1: Superficiel très fin, formé quasiment dans sa totalité par des sédiments végétaux. Il présente du matériel lithique et fossile.

Niveau 1a: Niveau avec le meilleur potentiel de toute la séquence, formé par de l'argile et de petits galets uniformes de calcaire. Avec fossiles et matériel lithique.

Niveau 1b: Argile jaunâtre avec des galets calcaires de plus grande taille que ceux du niveau précédent. Fertile archéologiquement.

Niveau 1c: Argile rouge et de plus grands galets calcaires qu'en 1a et 1b. Fertile archéologiquement.

\subsubsection{Restes fossiles}

Les fouilles menées à bien durant les quatre campagnes ont apporté un important ensemble de fossiles. Malgré cela, seule une petite partie a pu être identifiée (Álvarez et al., 1992) dû au fait que le niveau de fragmentation des fossiles est très élevé.

La collection de micromammifères se compose de: Ortyctolagus cuniculus, Myotis myotis, Castor fiber, Eliomys quercinus, Pliomys lenkii, Microtus arvalis/agrestis, Microtus nivalis-minuta, Pitymys duodecimcostatus, Arvicola cf. terrestris et Apodemus sp. Les macromammifères incluent: Canis lupus, Vulpes vulpes, Mustela nivalis, Stephanorhinus hemitoechus, Equus ferus, Equus hydruntinus, Cervus elaphus, Capreolus capreolus, 
Rupicapra pyrenaica, Capra pyrenaica et Bos/Bison sp. L'abondance du lapin ressort, suivit des ariodactiles, des périssodactyles et enfin des carnivores.

Capra est le genre qui compte le plus grand nombre de restes identifiés, suivit du cerf, de l'isard et du cheval (Pérez Legido et Cerdeño, 1992; Díez et al., 2008). Le plus grand nombre de restes et d'individus se trouvent dans le premier niveau ce qui est logique si nous prenons en compte qu'il s'agit de la zone la plus largement fouillée (Pérez Legido et Cerdeño, 1992). La bibliographie n'est pas précise sur la présence et/ou absence d'espèces déterminées comme Equus hydruntinus et Capreolus capreolus surtout qu'ils apparaissent dans certaines publications et pas d'en d'autres. E. hydruntinus n'est pas mentionné dans l'analyse menée à bien par Pérez-Legido et Cerdeño (1992) au travers de la révision du matériel des macromammifères tandis que Díez et al., (2008) le cite. D’autre part, Moure Romanillo et al., (1983) et Álvarez et al., (1992) indiquent la présence de chevreuil mais ni Pérez Legido et Cerdeño (1992) ni Díez et al., (2008) ne le comptent dans leurs révisions.

Les restes correspondants à l'ichtyofaune sont importants (279 restes), desquels ont pu être identifiées trois espèces: Salmo trutta, Anguila anguila et Chondrostoma polylepis (Moure Romanillo et al., 1983; Álvarez et al., 1992). De même, Esteban et al. (1990) cite la présence de la grenouille ibérique, Rana iberica.

\subsubsection{Restes lithiques}

Il a été récupéré un total de 1.165 pièces en surface. La matière première utilisée est autochtone et est principalement composée de silex et quartzite. Le fait de trouver la chaîne opératoire complète, des indices de recyclage du matériel et divers systèmes opératoires suggère un profit intensif des matières premières (Díez et al., 2008). Dans les trois niveaux suivants, l'industrie paraît être assez homogène tant en composition qu'en distribution. En plus du silex et de la quartzite, ont été récupérées des pièces de quartz, grés et calcaire (Moure Romanillo et al., 1983). Faisant ressortir les racloirs et les denticulés dans les trois niveaux (Moure Romanillo et al., 1983; Díez et al., 2008).

\subsubsection{Restes palynologiques}

L'analyse pollinique détecta la présence de trois espèces d'arbres: le pin, Pinus sp., le chêne, Quercus sp., le bouleau, Betula sp.; et de huit herbacées parmis lesquelles s'observe Ninphaceae (Moure Romanillo et al., 1983).

\subsubsection{Datation}

Les dates s'obtinrent à partir de la technique ${ }^{14} \mathrm{C}$ (Moure Romanillo et al., 1983, Díez et al., 2008). Les deux furent prises dans des fragments d'os non identifiés des niveaux 1a et 1b (Moure Romanillo et al., 1982; Moure Romanillo et al., 1983). L'échantillon calibré du niveau 1a apporta des dates de 43.130 - 41.290 calBP. et celui du 1 b $43.010-41.250$ calBP. Les chronologies situent le dépôt dans une période comprise entre le OIS2 et le OIS3.

\subsection{La Grotte du Búho / Grotte de la Zarzamora}

\subsubsection{Introduction}

Les dépôts quaternaires de la Grotte du Búho et la Grotte de la Zarzamora (Perogordo, Segovia) se trouvent à seulement deux kilomètres au sud-ouest de la cité de Segovia, à côté 
de l'un des affluents du ruisseau Tejadilla (Molero et al., 1989; Maldonado, 1996; Sala et al., 2009; Sala et al., 2010).

Les premières études ont été réalisées par Guillermo Molero et son équipe (Iñigo et al., 1998; Sala et al., 2009). Ces interventions ont été realisées dans trois parties différentes: la Grotte du Búho, le Sondage Extérieur qui est situé sur le sol d'une ancienne galerie colmatée et la Grotte Annexe (maintenant la Grotte de la Zarzamora). En 2008, une équipe de spécialistes de l'Université Complutense de Madrid et du Centre UCM-ISCIII d'Evolution et Comportement Humain a repris le travail dans cette cavité. Ils ont récupéré des niveaux fertiles seulement dans la Grotte de la Zarzamora (Sala et al., 2009, 2010) dont le matériel est encore à l'étude.

La présence de jeunes individus et de coprolithes de hyène ainsi que la grande quantité de marques laissées par les carnivores laissent penser qu'il pourrait s'agir d'une tanière de hyènes (Sala, 2012).

\subsubsection{Géologie et Stratigraphie}

La cavité s'ouvre sur le versant nord du Système Central, dans un affleurement de calcaires et de dolomies (dolomies de Castrojimeno) (Alonso, 1981; Sala, 2012) du Crétacique Supérieur (Santoniense) appartenant à la Sierra de Guadarrama. Certains outils apparaissent coupés par le système fluvial du ruisseau Tejadilla et de plus ils présentent des cristaux de dolomite avec des grains de quartz.

La grotte se situe dans un système de cavités karstiques. Elle présente un développement subhorizontal d'un mètre de haut et deux mètres de large avec une direction nord-sud. La section indique une évolution depuis des conditions phréatiques jusqu'à des conditions dans lesquelles a eu lieu la sédimentation.

L'activité des hyènes et l'action de l'eau a empêché dans beaucoup de cas la création d'une colonne stratigraphique complète. Cependant, Sala et al., (2009) divise le remplissage sédimentaire en trois niveaux qui de la voûte au mur sont:

Niveau 1-2: $45 \mathrm{~cm}$ de potentialité. Matériel détritique de composition carbonatée qui arrive pratiquement jusqu'à la voûte. En plus des galets de dolomie il englobe les fossiles de macrovertébrés et des coprolithes de hyène. La plupart des fossiles présentent une concrétion carbonatée. La nomenclature est due au fait que dans un premier temps deux niveaux ont été établis mais des études postérieures ne justifièrent pas la subdivision.

Niveau 3: $30 \mathrm{~cm}$ de potentialité. Des blocs anguleux et tabulaires de dolomie altérée, englobés dans une matrice de cristaux de dolomie. Riche en fossiles et avec une concrétion mineure.

Niveau 4: $15 \mathrm{~cm}$ de potentialité. Argiles plastiques, homogènes et stériles.

\subsubsection{Restes fossiles}

L'activité prédatrice des hyènes a produit un important mélange de restes fossiles, se trouvant dans les niveaux remués comme conséquence tant de l'activité de ces prédateurs que de l'action d'érosion des eaux dans le système karstique. Les macromammifères présents sont: H. sapiens, Canis lupus, Vulpes vulpes, Meles meles, Crocuta crocuta spelaea, Panthera cf. pardus, Lynx sp., Stephanorhinus hemitoechus, Equus ferus antunesi, Equus hydruntinus, Sus scrofa, Cervus elaphus, Bos primigenius et Bison priscus. Les micromammifères identifiés dans ce dépôt incluent: Myotis sp., Oryctolagus cuniculus, Lepus capensis, Erinaceus europaeus, Crocidura cf. rusula, Microtus cf. cabrerae, Microtus duodecimcostatus, Apodemus silvaticus, Castor fiber et Eliomys quercinus (Molero et al., 1989; Iñigo, 1995; Maldonado, 1996; Iñigo et al., 1998 et Sala et al., 2010). 


\subsubsection{Datation}

La datation par radiocarbone d'un fossile du niveau 1-2 a fourni une date de $32.510 \pm$ 240 BP, mais selon Sala (2012) cette donnée doit être considérée avec prudence, dû au fait qu'il ne pouvait pas être répété avec le protocole d'ultrafiltation par l'absence de collagène. Une autre date a été obtenue dans le sondage extérieur, dans le niveau 2. La datation obtenue à partir de ${ }^{14} \mathrm{C}$ est $>44.400 \mathrm{BP}$ (Sala, 2012).

\subsection{L'Abri d'Alexandre}

\subsubsection{Introduction}

Cet abri est situé sur le versant ouest de la Peña del Manto, dans un endroit appelé Fuentes de San Roquillo, sur la rive gauche de la rivière Henar du territoire communal de Deza (Soria) (Utrilla et al., 2000). Il est situé à 960 mètres au-dessus du niveau de la mer et s'ouvre à 500 mètres au-dessus de l'Abri de Vergara (Utrilla et al., 2006). Ce gisement a été découvert en 1995 par Vicente Alexandre, un résident de la ville de Deza (Soria) (Utrilla et al., 2006). Après les permis pertinents, Pilar Utrilla réalisa une campagne de fouilles en 1997 (Utrilla et al., 2006). L'intervention a consisté en la réalisation d'un sondage pour prendre des prélèvements palynologiques et sédimentologiques. En plus, ils prirent des prélèvements pour réaliser les premières analyses radiocarboniques. Les restes de faune sont rares. L'industrie lithique et l'abondance relative d'outils retouchés leur firent penser que cet endroit fut utilisé comme un habitat (Utrilla et al., 2000).

\subsubsection{Géologie et Stratigraphie}

L'abri est situé dans une zone de tufs calcaires et stromatolitiques qui présentent une structure fibreuse. En général, ces dépôts présentent une karstification postérieure qui provoque la précipitation du carbonate. L'origine de l'unité semble être dans un drainage des reliefs du Mésozoïque qui a été provoqué par des changements brusques de température (Utrilla et al., 2000). L'abri est très profond, il s'agit presque d'une grotte. La précipitation de l'eau sur les dépôts a permis leur préservation. Trois niveaux ont été détectés dans le sondage (Utrilla et al., 2006):

Niveau I: terre grisâtre, détachée, avec des plaques horizontales dans la base. Les sables et les limons avec des graviers arrondis. $20 \mathrm{~cm}$ d'épaisseur.

Niveau II: tufs rouges ou blancs procédant de la désintégration du plafond. Il a été divisé en deux sub-niveaux: Ia: avec des tufs rougeâtres dans une matrice argileuse et $20 \mathrm{~cm}$ d'épaisseur. IIb: avec tufs blancs et $50 \mathrm{~cm}$ d'épaisseur.

Niveau III: texture fine et de couleur grise dans un sédiment rougeâtre très compact. Il est fertile et a été divisé en trois sub-niveaux: IIIa: des limons rougeâtres avec des charbons dispersés. IIIb: gris foncé avec des cailloux anguleux et des cendres. Il a des industries lithiques mais les restes de faune sont rares. IIIc: rougeâtre, texture sableuse avec des cailloux arrondis.

\subsubsection{Restes fossiles}

Ces restes sont rares et quelques fragments de dents d'équidés et une dent de Rupicapra pyrenaica ont été récupérés. Dans ce travail nous attribuons une dent de Cervus elaphus qui apparaissait dans Utrilla et al., (2000) au chamois, R. pyrenaica. 


\subsubsection{Restes lithiques}

Bien que seulement un sondage ait été réalisé, la collection d'industrie lithique est importante. L'ensemble inclut des grattoirs, des burins et des lames (Utrilla et al., 2000). Leur forme leur permettent de rejeter un usage comme atelier et ils suggèrent l'utilisation comme lieu d'habitation (Utrilla et al., 2006).

\subsubsection{Datation}

Ils ont daté un charbon originaire du sub-niveau IIIb. Il a apporté une chronologie de $15.370 \pm 110$ BP (Utrilla et al., 2000; 2006). Cette date a situé l'abri dans les dernières phases du Pléistocène Tardif.

\subsection{L'Abri de Vergara}

\subsubsection{Introduction}

L'abri est ouvert sur le versant ouest de la Peña du Manto, un affleurement de calcaire sur la route actuelle qui raccorde Deza avec Cihuela (Soria) (Utrilla et al., 1999; 2006). Il est situé à seulement 120 mètres au-dessous de l'Abri d'Alexandre et à 860 mètres audessus du niveau de la mer.

Ce dépôt a été découvert par Daniel Vergara quand il participa à des prospections archéologiques qu'organisa l'Université de Salamanque dans la région. Ils ont réalisé deux campagnes de fouilles en 1996 et 1997, dirigées par Pilar Utrilla et Fernanda Blasco, la première étant un sondage d'urgence (Utrilla et al., 2000). Le travail suggère une utilisation du site comme atelier à cause des caractéristiques typologiques du matériel (Utrilla et al., 2000).

\subsubsection{Géologie et Stratigraphie}

L'Abri de Vergara et l'Abri d'Alexandre sont situés dans le même affleurement calcaire (Utrilla et al., 2000), par conséquent l'explication de la géologie et de la stratigraphie est similaire et se situe dans la section de la géologie et de la stratigraphie de l'Abri d'Alexandre.

Le gisement est situé dans la partie centrale du corridor rocheux qui cerne la partie inférieure de la Peña du Manto, sous un grand mur rocheux incliné. Cette visière a permis la préservation d'une petite partie du dépôt. Á l'origine, cette visière pouvait être plus grande quand il y avait les grands blocs sur le versant.

Le gisement archéologique est petit, présentant quatre mètres de longueur, un mètre de large et un mètre d'épaisseur. Ils ont identifié cinq niveaux qui du plafond à la base sont (Utrilla et al., 1999, 2000):

Niveau a: niveau de sables avec argiles et limons de couleur gris. L'épaisseur maximale est de $30 \mathrm{~cm}$ (vers l'intérieur du mur) et de $15 \mathrm{~cm}$ dans le bord du sondage. Il y a un peu de restes lithiques, principalement des restes de taille. Ils ont identifié deux sub-niveaux: a2: niveau de sables avec argiles et limons de nature lenticulaire mais riche dans les nodules carbonatés. Il est situé dans la région centrale mais déplacé vers un côté. a3: niveau de plaques d'entre 15 et $20 \mathrm{~cm}$ de longueur. 
Niveau b: avec des cailloux de couleur jaune-rougeâtre, de $25 \mathrm{~cm}$ d'épaisseur. Il recouvre un grand bloc qui est tombé de la visière. Il existe des restes d'industries dans la base, près du niveau c.

Niveau c: des limons de $20 \mathrm{~cm}$ d'épaisseur maximale. Dans la base, présence de grands blocs qui sont tombés de la visière. Un niveau de plaquettes est en contact avec le niveau d.

Niveau d: avec des limons de couleur marron-grisâtre avec une épaisseur de $12 \mathrm{~cm}$. Il remplit une petite cuvette fouillée dans le niveau inférieur. Il possède un peu de cailloux, anguleux et altérés par le feu. C'est le niveau le plus fertile. Ils ont identifié deux subniveaux:1d: limons-argiles avec des sables de couleur marron-jaunâtre et des cailloux anguleux. 2d: limons de couleur marron avec un peu de cailloux. Il y a quelques plaques planes et plaquettes abondantes qui sont tombées du plafond. Le niveau s'inclinent vers l'intérieur de l'abri et a une épaisseur maximale de $27 \mathrm{~cm}$. Il présente des industries lithiques et des restes de faune.

Niveau e: avec des sables et argiles ayant une distribution homogène de couleur ocrerougeâtre, très compact et dur, sans pierres ni blocs. Il présente des fractions fines de couleur jaune-rougeâtre, avec quelques cailloux et graviers plus abondants vers la base. A la base, le niveau est plus granuleux avec des calcaires anguleux. Il n'y a pas de restes archéologiques bien que dans la base il y ait des restes de charbon de bois.

\subsubsection{Restes fossiles}

Ils sont rares. Ils sont apparus très fragmentés et se situent dans le niveau d (Utrilla et al., 2000, 2006). La plupart sont les restes dentaires d'herbivores: Equus ferus et Cervus elaphus. D'autre part, ils ont récupéré les restes d'un bivalve: Pecten maximus.

\subsubsection{Restes lithiques}

Le matériel lithique est abondant et diversifié. 7390 pièces ont été récupérées, dont 7189 correspondent aux restes de taille et les autres 181 pièces sont retouchées. La plupart se trouvent en contact entre les niveaux "c" et " $d$ ". Les micro-éclats et les microlames sont prédominants. Dans les niveaux "a" et " $b$ " ressortent les micro-éclats (Utrilla et al., 2000, 2006). Dans les deux niveaux avec la plupart des outils (c et d) ont été identifiés les grattoirs, les perforateurs, les burins, les pointes de gravette, les micro-gravettes, les pièces avec troncature, les denticulés, les racloirs, les pièces avec encoches, les feuilles retouchées et les feuilles à dos (Utrilla et al., 2000, 2006).

La matière première est principalement le silex autochtone, obtenu dans les dépôts Oligocènes et dans les marnes de limonite du bassin du Miocène d'Almazán qui appartient au bassin de la rivière Henar (Utrilla et al., 2000, 2006).

\subsubsection{Datation}

Trois niveaux ont été datés par la méthode du ${ }^{14} \mathrm{C}$. Dans le niveau "d", ils ont utilisé un os, révélant un âge de $7.800 \pm 50 \mathrm{BP}$. Dans ce cas, le laboratoire qui fit la datation nota ses doutes sur l'âge dû au peu de collagène présent dans la pièce (Utrilla et al., 2000).

Dans le niveau " $d$ " et plus précisément dans le sub-niveau " $2 \mathrm{~d}$ ", une dent de cheval a été datée, donnant du $14.000 \pm 100 \mathrm{BP}$. Enfin, un charbon récupéré dans le niveau "e" a démontré une date de $>38.750 \mathrm{BP}$. (Utrilla et al., 2000. 2006). La dernière date semble provenir d'un remplissage d'une petite cuvette qui ne semble pas être in situ (Utrilla et al., 2000). 


\subsection{La Peña de Estebanvela}

\subsubsection{Introduction}

L'abri de La Peña de Estebanvela (Peña de la Grieta) est situé dans le bord méridional du secteur sud-est du bassin du Duero (Cacho et al., 2003), à 1000 mètres de la localité d'Estebanvela au nord-ouest de la Province de Segovia. Le gisement se situe à 1085 mètres au-dessus du niveau de la mer et à 20 mètres sur le cours actuel de la rivière Aguisejo, un des affluents de la rivière Riaza (Jordá, 2006a).

Le dépôt a été découvert après la rédaction de la Carte Archéologique de la Province de Segovia en 1992. L'équipe de prospection dirigée par Fernando López Ambite récupère divers matériaux du Paléolithique Supérieur dans un abri sur le bord droit de la rivière Aguisejo. Le site s'appelle, dans un premier temps, l'Estebanvela 3. L'équipe de recherche actuelle l'appelle La Peña de Estebanvela, changeant le toponyme de "Peña de la Grieta" pour le différencier d'autres gisements de la Péninsule qui ont déjà ce nom. En 1998, le premier projet de recherche de la Direction Générale du Patrimoine Culturel et de Promotion du Ministère de l'Education et de la Culture de la Junta de Castilla et León a demandé et concéda le projet: "El poblamiento de la cuenca alta del Duero durante el Paleolítico Superior y el Epipaleolítico" qui après s'appella: "El Pleistoceno Superior Final y la transición al Holoceno en las estribaciones de la Sierra de Guadarrama" (Cacho et al., 2003).

\subsubsection{Géologie et Stratigraphie}

Le gisement est situé sur l'extrémité sud du secteur sud-est du bassin du Duero dans le bord sud du corridor d'Aranda de Duero - Burgo de Osma (Jordá, 2006a), en contact avec l'extrémité nord du Système Central, représenté par la Sierra de Ayllón. À l'ouest, la Sierra de Pradales-Honrubia et à l'est le bassin de Almazán. L'abri s'ouvre dans les conglomérats du Miocène du bassin du Duero (Jordá, 2006a). La rivière a formé un petit canyon qui se trouve à l'endroit du gisement.

La formation de la grotte est due à un processus karstique d'un tronçon de conglomérats, avec une matrice d'argiles partiellement remplacée par une carbonatation secondaire (Jordá, 2006a). La grotte a une profondeur de six mètres, avec de petites coupoles et des murs irréguliers. La grotte est totalement remplie par des dépôts subhorizontaux de différents types. Six unités ont été identifiées dans la coupe extérieure (Jordá, 2006a):

Niveau 0: 0-50 cm de fragments de roches de nature conglomératique englobés dans une matrice de couleur orange. Il ferme l'abri et est en contact avec la voûte.

Niveau I: 40-140 cm des conglomérats, des sables et des argiles de couleur orange. Il forme un léger angle vers l'ouest et varie sur plusieurs niveaux intercalés. Le premier est formé par $25-100 \mathrm{~cm}$ d'argile rouge avec des limons et des sables qui ont des galets autochtones. Ce niveau est stérile. Le deuxième, avec $25-50 \mathrm{~cm}$ d'épaisseur, est formé par des sables et des cailloutis. Parfois, il contient des galets et cailloutis autochtones. Dans les derniers $10-15 \mathrm{~cm}$, il y a alternance des matériels fins de couleur rouge avec de gros sables et graviers de couleur grise. Ce sub-niveau contient des restes fossiles et des industries lithiques.

Niveau II: $18-50 \mathrm{~cm}$ de lutites de couleur grise avec des galets et des blocs de quartzite autochtones, des galets et des ardoises allochtones très anguleux d'origine anthropique. Il existe des intrusions du niveau précédant provoquées par des processus de crioturbation. Dans la partie interne et vers la base, des sables et graviers fins passant ensuite à des limons rouges. Vers l'extérieur, présence de cailloux et de graviers autochtones. Ce niveau est riche en matériel archéologique. 
Niveau III: 35 - $40 \mathrm{~cm}$ de dépôt de couleur marron et rouge clair. Il est formé par des sables fins et des limons. Il y a des galets autochtones vers la voûte. Avec matériel archéologique abondant.

Niveau IV: $25-30 \mathrm{~cm}$ de conglomérats avec une matrice lutitique orange. Nous y trouvons des graviers, des cailloux, des quartzites et des quartzs. Dans la partie interne il y a des laminages de différentes granulométries. Vers la voûte, un dépôt rouge, formé par un conglomérat de matrice sableuse-limoneuse, très carbonaté de $10 \mathrm{~cm}$ d'épaisseur. En dessous, des sables fins avec les limons ocres et jaunâtres avec des cailloux autochtones. Peu de restes archéologiques.

Niveau V: $30 \mathrm{~cm}$ de sables limoneux marrons avec cailloux et blocs autochtones. Nous avons des blocs de conglomérats. Il contient peu de restes archéologiques.

Niveau VI: $<40 \mathrm{~cm}$ de sables et de graviers avec argiles de couleur rouge et cailloux autochtones. La partie inférieure a de grands blocs de conglomérats.

\subsubsection{Restes fossiles}

La Peña de Estebanvela est un gisement avec une grande richesse taxonomique. 51 taxons ont été identifiés jusqu'à présent. Ils comprennent des groupes comme les primates, les oiseaux, les lagomorphes, les rongeurs, les carnivores, les ongulés, l'ichtyofaune, la malacofaune, et l'herpétofaune.

Ce gisement a apporté un important ensemble de restes humains qui appartiennent à Homo sapiens. Ils sont tous postcrâniens et ressortent en quantité les côtes, les humérus, les métacarpiens, les tibias, les fémurs et les coxaux. Ont été identifiés au moins deux individus (Trancho et al., 2006). Dans la macro-faune ressortent: Canis lupus, Vulpes vulpes, Felix silvestris, Lynx pardina, Equus ferus, Sus scrofa, Cervus elaphus, Capreolus capreolus, Rupicapra pyrenaica et Capra pyrenaica.

La micro-faune inclut: Oryctolagus cuniculus, Eliomys quercinus, Arvicola sapidus, Microtus arvalis-agrestis, Microtus oeconomus, Microtus duodecimcostatus, Apodemus sylvaticus, Chionomys nivalis, Talpa sp., Sorex minutus, Erinaceus europeus, Crocidura russula, Plecotus auritus-austriacus, Plecotus autriacus, Barbastella barbastellus, Myotis myotis et Rhinolophus ferrumequinum (Sesé, 2013). En plus, une importante collection d'oiseaux a été récupérée: Aquila sp., Alectoris rufa, Perdix perdix, Coturnix coturnix, Hirudo rustica, Anthus campestris, Emberiza citrinella, Petronia petronia, Turdus sp. et Corvus monedula (Sánchez Marco, 2013). Aussi, un important ensemble de malacofaune a été identifié: Theodoxus fluviatilis, Melanopsis sp., Helicella unifasciata, Jaminia quadridens, Candidula camporroblensis, Vallonia costata, Gastropoda indet., Littorina obtusata, Trivia árctica, Columbella rustica, Nassarius reticulatus, Cyclope neritea et Pecten maximus (Jordá, 2006b; Aparicio, 2013). L'ichtyofaune est totalement consacrée à Salmo trutta (Perea et Doabrio, 2013). Plusieurs restes de reptiles et d'amphibiens ont été decouverts (Sanchiz et al., 2013): Timon lepidus, Rhinechis scalaris, Malpolon monspessulanus, Vipera latasti, Coronella sp., Epidalea calamita et Alytes sp.

Dans ce travail nous n'avons pas identifié le chevreuil bien que cette espèce ait été citée par Yravedra (2006 et 2013) et nous avons attribué les restes du chamois à Rupicapra pyrenaica.

\subsubsection{Les industries lithiques et osseuses}

Le silex est la principale matière première du site, présentant une grande variété de types. Aussi sont présents, le quartz, le cristal de roche, la quartzite et le calcaire. Les instruments comprennent des grattoirs, des perçoirs, des racloirs, des perforateurs et des burins (Cacho et al., 2006). Plusieurs pièces d'industrie osseuse ont été récupérées comme des javelots, des poinçons, des spatules et des aiguilles. D’autre part, nous avons récupéré 
des pièces d'art mobilier comme quelques coquilles ou canines de cerf perforées et des plaquettes de schiste et ardoise décorées avec motifs géométriques et faunistiques. Ont été aussi identifiées, quelques plaques de grès avec perforations (Cacho et al., 2006).

\subsubsection{Datation}

Jusqu'à présent, 16 datations radiocarboniques utilisent la méthodologie AMS sauf une qui emploie le système radiométrique traditionnel, ont été appliquées (Jordá Pardo et Cacho, 2013). Le niveau I a apporté des datations entre 12.700 et 13.580 calBP., le niveau II entre 13.610 et 13.800 calBP., le niveau III entre 14.290 et 15.010 calBP, le niveau IV entre 14.810 et 15.210 calBP. et le niveau $V$ entre 17.610 et 17.840 calBP.

\subsection{La Peña de Mudá}

\subsubsection{Introduction}

La Peña de Mudá est située dans la Province de Palencia, dans la ville de Mudá. La première citation correspond à Prado (1864). Ce chercheur obtient plusieurs dents de rhinocéros, une canine d'ours et d'autres restes qui n'ont pas été identifiés (Álvarez-Lao, 2007). Quelques années plus tard, Calderón (1876) attribua les restes de rhinocéros à Stephanorhinus merckii. Récemment, Álvarez-Lao (2007), dans sa thèse sur les macromammifères indicateurs de climat froid, attribut une des dents à Coelodonta antiquitatis.

\subsubsection{Les restes fossiles}

Le matériel est rare. Prédominent les grands herbivores comme: Stephanorhinus hemitoechus, Coelodonta antiquitatis, Equus ferus et Bos/Bison sp. Les restes des carnivores consistent en quelques dents d'ours. Álvarez-Lao (2007) suggère un possible mélange de matériel depuis son dépôt dans le Musée Géologique et Minier. La différence dans l'état de fossilisation des restes de rhinocéros et d'autres taxons semble l'indiquer. Pour cette raison, nous analysons seulement les restes des rhinocéros.

\subsubsection{Datation}

L'association d'espèces le situe dans quelques phases du Pléistocène Supérieur. Les rhinocéros laineux se trouvent, dans la Péninsule Ibérique, presque entièrement limitée à la zone cantabrique dans cette période. Cependant, Ảlvarez-Lao et García (2006) ont attribué les restes au gisement de La Parte, du Pléistocène Moyen des Asturies, à Coelodonta antiquitatis. Pour cette raison, nous ne pouvons pas indiquer un âge pour ce dépôt. 


\section{Objectifs}


Cette étude tente d'apporter des données sur les ongulés du Pléistocène Supérieur du Plateau Nord, en particulier de la Communauté Autonome de Castilla y León. Cette période comprend le Paléolithique Moyen et une partie du Paléolithique Supérieur, qui sont caractérisés par la présence de deux espèces: l'Homo neanderthalensis et l'H. sapiens. Les ongulés peuvent nous donner des informations sur les ressources alimentaires de ces deux espèces et par leurs comparaisons permettent de définir différentes stratégies d'occupation et d'obtention de ressources. Pour atteindre ce but, nous avons dressé trois types d'objectifs: paléobiologiques, archéologiques et méthodologiques.

Les paléobiologiques comprennent aussi bien l'identification que l'analyse du dimorphisme sexuel. La première, l'identification, part de la description anatomique des différents éléments ainsi que de la réalisation de statistiques de base qui nous permettent de faire des comparaisons avec d'autres espèces similaires de la même période. Ainsi, nous adaptons les listes faunistiques aux nouvelles classifications et elles nous permettent de comparer nos taxons avec les espèces qui, jusqu'à présent, n'avaient pas été récupérées dans les dépôts du Pléistocène Tardif dans cette région. De la même manière, l'analyse du dimorphisme sexuel nous permet de savoir si le sexe a changé avec le temps.

Les seconds, les archéologiques, incluent la détermination de l'âge de mort, les périodes d'accumulation (de saisonnalité) et le sexe-ratio. Ces analyses sont essentielles pour l'identification correcte des espèces puisque les comportements biologiques et sociaux changent avec le temps. La réalisation de ces objectifs, paléobiologiques et archéologiques, nous permet, avec d'autres disciplines, de connaître l'origine de l'accumulation et les préférences alimentaires de chaque espèce d'hominidés pour plus tard les comparer.

Enfin, les objectifs méthologiques. Dans ce travail, une série de procédures qui nous permettent d'identifier chaque taxon, de déterminer l'âge de mort et le dimorphisme sexuel ont été développées, éliminant l'incertitude qu'introduisent les méthodologies actuelles.

Pour résumer, nous présentons schématiquement les différents objectifs à atteindre dans chacune des sections.

\subsection{Objectifs paléobiologiques}

L'objectif à atteindre dans cette section est d'examiner les restes d'ongulés des dépôts du Pléistocène Supérieur de Castilla y León, adapter cette classification aux plus récentes découvertes et changements taxonomiques. Pour cela, nous suivons les étapes suivantes:

- Présenter le matériel identifiable de chaque site.

- Décrire les différents éléments morphologiques récupérés.

- Afficher les statistiques de base des éléments décrits.

- Justifier l'attribution spécifique basée sur les caractères morphologiques observés.

- Connaître la bimodalité et le dimorphisme sexuel des spécimens dont les restes permettent la séparation des sexes.

\subsection{Objectifs archéologiques}

À partir de l'information obtenue antérieurement qui nous permet d'utiliser des données du comportement social et biologique de chaque taxon, nous essayerons de connaître les préférences alimentaires de la population qui occupait la cavité. À cette occasion, nous avons essayé de: 
- Dresser l'âge de mort de chaque spécimen lorsque cela est possible.

- Déterminer la saisonnalité de l'accumulation du taxon dans laquelle il a été possible de connaître l'âge de mort en mois.

- Mettre en relation le comportement social de chaque taxon avec les périodes d'occupation des cavités.

- Comparer les données obtenues dans les sites du Paléolithique Moyen avec celles enregistrées dans les dépôts du Paléolitique Supérieur.

\subsection{Objectifs méthodologiques}

Pour atteindre les objectifs précédents nous développons des méthodes qui permettent d'une part d'attributer correctement le matériel à un taxon, de connaître l'âge de mort et de déterminer la bimodalité et le dimorphisme sexuel. Ces modèles tentent de:

- Évaluer les caractères morphologiques qui nous permettent de différencier les taxons similaires.

- Développer un nouveau modèle pour déterminer l'âge de mort ou nous remplacions les variables qui utilisent des données d'espèces actuelles par les données de populations fossiles. Comparer cette méthode avec les précédentes.

Comparer les différentes méthodes statistiques pour déterminer le sexe des spécimens avec peu de dimorphisme sexuel. 
3. Matériel 


\subsection{Matériel utilisé}

Les restes proviennent des dépôts du Pléistocène Supérieur du Plateau Nord, en particulier ceux qui sont situés dans la Communauté Autonome de Castilla y León. Les restes de la Grotte de Valdegoba et La Mina sont déposés à l'Université de Burgos; les restes de Cueva Millán au Musée Provincial de Burgos; le matériel de la Peña de Estebanvela au Musée de Segovia; les fossiles des Abris de Vergara et Alexandre au Musée Numantino de Soria; et les restes de la Peña de Mudá dans le Musée Géologique et Minier de Madrid. Les fossiles de l'Ermita n'ont pas été analysés parce que les collections ne sont pas disponibles pour le renouvellement du Musée Archéologique National de Madrid. Il en va de même pour le matériel des Grottes Corazón et Guantes, Palencia, qui n'a pas encore été étudié. Les restes des grottes de León, Espertín, l'Uña, la Cantera et le Castro sont plus fragmentés et ceux des différents sites du Cañon del Río Lobos (Burgos - Soria) récupérés au début du 20e siècle n'ont pas été analysés parce qu'ils ne peuvent pas être inclus dans un contexte particulier.

L'état de conservation des pièces ne dispose toujours pas d'identification. Nous présentons le matériel utilisé dans chaque section (tableau III.1.1).

Tableau III.1.1

Matériel utilisé pour chaque site étudié et dans chaque chapitre

\begin{tabular}{lccccccc}
\hline & \multicolumn{2}{c}{ Paléontologie systématique } & \multicolumn{2}{c}{ Détermination de l'âge } & Saisonnalité & \multicolumn{2}{c}{ Dimorphisme sexuel } \\
\cline { 2 - 7 } La Mina & Crânien & Postcrânien & Dentaire & Postcrânien & Dentaire & Dentaire & Postcrânien \\
\cline { 2 - 7 } Valdegoba & 7 & & 2 & & & & \\
Prado Vargas & 4151 & 1668 & 461 & & 160 & 9 & 105 \\
Millán & 35 & 20 & 10 & 2 & 4 & 1 & \\
Búho & 167 & 90 & 50 & & 13 & 2 & \\
Alexandre & 76 & 38 & 22 & & 4 & & \\
Vergara & 1 & & & & & & \\
Estebanvela & 19 & & 13 & & & & \\
Mudá & 129 & 59 & 1 & & & &
\end{tabular}

\subsection{Matériel de comparaison actuel et fossile}

Les comparaisons ont été faites avec des matériaux déposés dans plusieurs institutions scientifiques. Ce matériel est principalement postcrânien parce que le matériel dentaire est inclus dans les mandibules et les maxillaires et nous ne pouvons pas prendre des mesures diagnostiques qui ne varient pas avec l'usure. D'autres informations sont prises de sources documentaires qui comprennent des espèces de sites ibériques et du reste de l'Europe.

Les spécimens actuels sont pris des institutions suivantes:

Cervus elaphus: Musée National des Sciences Naturelles (Madrid), Musée Anatomique de l'Université de Valladolid (Valladolid), Musée d'Histoire Naturelle de Vienne (Vienne).

Capreolus capreolus: Musée Anatomique de l'Université de Valladolid (Valladolid).

Rangifer tarandus: Société des Sciences Aranzadi (San Sebastián), Centre de Gestion et Garde des Collections Archéologiques et Paléontologiques de Guipuzcoa (San Sebastián), Musée Anatomique de l'Université de Valladolid (Valladolid), Musée d'Histoire Naturelle de Vienne (Vienne).

Rupicapra rupicapra: Musée d'Histoire Naturelle de Vienne (Vienne).

Rupicapra pyrenaica: Musée National des Sciences Naturelles (Madrid), Societé des Sciences Aranzadi (San Sebastián), Centre de Gestion et Garde des Collections Archéologiques et Paléontologiques de Guipúzcoa (San Sebastián). 
Capra pyrenaica: Musée National des Sciences Naturelles (Madrid).

Capra ibex: Musée d'Histoire Naturelle de Vienne (Vienne).

Bison bonasus: Musée National des Sciences Naturelles (Madrid), Musée d'Histoire Naturelle de Vienne (Vienne).

Hemitragus jemlaicus: Musée d'Histoire Naturelle de Vienne (Vienne).

Saiga tatarica: Musée d'Histoire Naturelle de Vienne (Vienne).

Dans les espèces fossiles, la littérature utilisée est la suivante:

Stephanorhinus hemitoechus: Bilzingsleben, Neumark Nord, Steinheim, Ehringsdorf, Taubach, Gimbsheim, Eich (Van der Made, 2010); Majolicas (Cerdeño, 1990).

Stephanorhinus kirchbergensis: Kirchberg, Bilzingsleben, Mosbach, Steinheim, Ehrigsdorf, Taubach, Gimbsheim, Eich (Van der Made, 2010).

Stephanorhinus hunsheimensis: Voigtsted, Süssenborn, Soleilhac, Mosbach, Mauer, Ceyssaguet, Soleinac (informations apportées par J. van der Made).

Coelodonta antiquitatis: Bad Frankenhausen, Chlum, Wannen, Heringen, Steinheim, Ehringsdorf, Belvedère, Ariendorf, Backleben, Heldrungen, Zasuhino, Kahla, Gimbsheim, Eich (Van der Made, 2010); Lezika, Labeko Koba (Arkeologi Museoa, Bilbao).

Equus ferus torralbae: Atapuerca (TG), Villacastín, Pedraza, Las Yedras, Solana de Zamborino, Torralba, Pinilla del Valle, Cova Negra, Transfesa (Eisenmann et Baryshnikov, 1994; Maldonado, 1996).

Equus ferus antunesi: la Carihuela, Fontahinas, Jöao Ramos, Salemas (Maldonado, 1996).

Equus ferus mosbachensis: Mosbach, Achenheim, Lune Viel, l'Arago (Maldonado, 1996).

Equus ferus taubachensis: Taubach (Maldonado, 1996).

Equus ferus casarensis: Los Casares (Maldonado, 1996).

Equus ferus germanicus: Pair non Pair (Maldonado, 1996).

Equus ferus gallicus: Solutree et Saint Germain de la Rivière (Maldonado, 1996).

Equus stenonis: Atapuerca, Saint Vallier, Senéze, Venta Micena, Chatillon Saint Jean, Huélago, Baza 1 (Eisenmann et Baryshnikov, 1994; Maldonado, 1996)

Equus hydruntinus: la Carihuela, Bourgeois Delaunay, Combe Grenal, La Ferrasie, Saint Germain la Rivière, Agios Georgios, Fontarnaud, Pair non Pair, Binagady, Abric Romani, Abri Suard, Arcy et Prolom (Eisenmann et Baryshnikov, 1994; Maldonado, 1996).

Sus scrofa y Sus strozii: Saint Vallier (Faure, 2004).

Cervus elaphus: Atapuerca (TG, TE) (Van der Made, 1999); Abric Romaní (Sánchez, 1990); Majolicas (Domingo et Alberdi, 2004); Fate, Manie, Madonna (Psathi, 2003); Prince Cave (Arellano Alonso, 2004); Combe Grenal (Guadelli, 1987); Vaufrey, La Ferrasie (Delpech, 1984); Lazaret, Orgnac, Bau l'Aubesier, Bianche St. Vaast, Tournal (Magniez, 2010); Vaufrey (Delpech, 1988); Jarama VI; Buraca Escura (Parque Arqueológico do Vale do Côa (Portugal); Lezika y Abauntz (Arkeologi Museoa, Bilbao).

Dama dama: Atapuerca (TG, TE) (Van der Made, 1999); et Atapuerca (TE) (Centre National de Recherche sur l'Évolution Humaine CENIEH, Burgos).

Rangifer tarandus: Atxuri, Arlanpe, Urtiagako Leizea, Bolinkoba, Armotxe, Aitzbitarte IV (Arkeologi Museoa, Bilbao).

Haploidoceros mediterraneus: Cova del Rinoceront (Sanz et al., 2014); et Lunel Viel (Croitor et al., 2008).

Rupicapra pyrenaica: Orgnac 3, l'Arago, Le Portel (Fernández y Crégut-Bonnoure, 2007); Abri Marq (Rivals, 2002); Salemas (Álférez et al., 1980-1981); Jarama VI; Buraca Escura 
(Parque Arqueológico do Vale do Côa (Portugal); Erralla et Arlanpe (Arkeologi Museoa, Bilbao).

Rupicapra rupicapra: Abric Romani (Sánchez, 1990); Nacimiento (Álferez et al., 19801981); Abauntz, Lezika, Lezikako Koba (Castaños et al., 2009); La Riera (Straus et al., 1986); et Le Gras (Fernández et Crégut-Bonnoure, 2007).

Capra pyrenaica: Abric Romani (Sánchez, 1990); Tournal, Le Portel (Crégut-Bonnoure, 1992b); Buraca Escura (Parque Arqueológico do Vale do Côa, Portugal), Jarama VI (révision faite à l'Université de Burgos); et Arlanpe (Arkeologi Museoa, Bilbao).

Capra caucasica: Kozarnika, Koudaro I et III, Ortvala (Fernández y Crègut-Bonnoure, 2007); Sakajia, Tsutskhavati, Le Portel, Baume Moula-Guercy, Saint Marcel, Dzudzuana (Rivals, 2006); et l'Arago (Rivals 2002, 2006).

Capra ibex: Adaouste et Petralona (Rivals, 2006).

Hemitragus cedrensis: l'Arago, les Cèdres, Rigabe, Bolomor (Rivals, 2006); et Bau de l'Aubesier (Rivals et Blasco, 2008).

Hemitragus bonali: l'Escale, l'Arago (Rivals, 2006); et les Cèdres (Rivals, 2006).

Bos primigenus: Biache-Saint-Vaast (Auguste, 1995); Bau de l'Aubesier (Fernández, 2001); Livernon (Slott-Moller 1990); Abri Marcq (Crégut-Bonnoure, 1993); Chinchon 2 (Crégut-Bonnoure, 1992c); et Combe Grenal (Guadelli, 1987).

Bison priscus: Nestier (Clot y Marsan, 1986); Jaurens, I'l skaya (Guérin et Valli, 2000); Marcamps (Slott-Moller 1990); et Ènlène (Lalande, 1986).

Dans la section sur le dimorphisme sexuel, nous avons utilisé divers spécimens comme groupe contrôle. Ils correspondent à des restes postcrâniens de Rupicapra pyrenaica parva. Les institutions où nous avons ramassé ce matériel sont: Musée National des Sciences Naturelles

(Madrid): mâles:14292/U.Z.A.1982.06.03.02(2),14253.U.Z.A.1982.06.04.01(3),14267/U.Z.A.1982.06. 05.01(3),14267/U.Z.A.1982.06.30.04(12),14264/U.Z.A.1982.08.10.01(16),14254/U.Z.A.19 82.0.10.02(17),14271/U.Z.A.1982.08.11.01(19),14265/U.Z.A.1982.08.24.01(21),14283/U. Z.A.1982.12.17.03(28),14256/U.Z.A.1982.12.21.05(31),14261/U.Z.A.1983.01.26.01(35),1 4287/U.Z.A.1983.06.01.01(36),14269/U.Z.A.1983.06.09.04(47),14293/U.Z.A.1983.06.09.0 5(48);femâles:14288/U.Z.A.1982.06.04.02(4),14282/U.Z.A.1982.06.30.03(11),14292/U.Z. A.1982.08.10.03(18),14279/U.Z.A.1982.08.08.01(13),14280/U.Z.A.1982.08.25.01(23),142 90/U.Z.A.1982.08.25.02(24),14291/U.Z.A.1982.12.16.01(25),14283/U.Z.A.1982.12.17.01( 26),14285/U.Z.A.1982.12.21.03(29),14278/U.Z.A.1983.06.02.03(39),14289/U.Z.A.1983.0 6.03.01(40),14258/U.Z.A.1983.06.03.03(42),14286/U.Z.A.1983.06.09.02 (45). Société des Sciences Aranzadi (San Sebastián): mâles: 674, 619.13. femâles: 673,11. Collection privée Altuna-Mariezkurrena: mâle: A-138. 


\section{Méthodologie}


La méthodologie utilisée dans ce travail combine des procédures pour chacun des chapitres. Le choix d'une terminologie et des critères métriques appropiés sont essentiels pour développer une bonne détermination des taxons dans le premier cas et la caractérisation de l'espèce dans le deuxième. Un bon choix fait que le travail peut être comparé par d'autres chercheurs avec une prolongation dans le temps.

\subsection{Paléontologie systématique}

Dans cette section, nous présentons des critères descriptifs et morphométriques qui utilisent les dents et les restes postcrâniens.

\section{Les restes dentaires}

Dans ce travail, nous utilisons la terminologie proposée par Osborn - Gregory en 1907. Dans la dentition supérieure, les cuspides principales sont identifiées par le préfixe proto (antérielinguale), para - (antérielabiale), meta - (postérielabiale) et hypo (postérielinguale). Sur la face linguale, sont présentent des cuspides secondaires, les styles: le parastyle, le métastyle et le mésostyle. Dans les dents inférieures, les préfixes sont similaires mais change le suffixe de -cône à - conide: protoconide, métaconide, paraconide, hypoconide et protoconide. De ces cuspides sortent des crêtes qui délimitent des dépressions appelées fosses ou des vallées dont le nom dépend des cuspides et de la direction d'où elles commencent.

\section{Les restes postcrâniens}

La terminologie apparaît dans plusieurs atlas de morphologie (Barone, 1966; Pales et García, 1981).

\subsubsection{Rhinocerotidae}

La nomenclature que nous avons utilisé pour les rhinocéros est celle proposée par Guérin (1980) et les critères métriques apparaissent dans Van der Made (2010) (figure IV.1.1, 2 et 3).

Les mesures prises dans le matériau dentaire sont les suivantes: DAP: diamètre maximal antéro-postérieur. DAPb: diamètre antéro-postérieur à la base. DAPo: diamètre antéro-postérieur dans la surface de la dent. DTa: diamètre antéro-postérieur du lobe postérieur. DTp: diamètre transverse du lobe antérieur. H: hauteur maximale de la couronne. Hci: hauteur entre le cordon de la base de la couronne et le bord le plus haut de la couronne. Hli: hauteur du bord inférieur de la couronne jusqu'à la vallée linguale.

Le matériel postcrânien est rare. Nous avons seulement identifié un talus. Les mesures indiquées sont les suivantes: DAPdf: diamètre antéro-postérieur de la surface articulaire distale. DT: diamètre maximal transverse. DTdf: diamètre transverse de la surface articulaire distale. DTpf: diamètre transverse de la trochlée. DTtl: diamètre transverse de la région articulaire. Lext: longueur de la face latérale. Lint: longueur de la face médiane. Lm: longueur minimale. Rint: diamètre de la trochlée. $\mathbf{R m}$ : diamètre minimal de la trochlée.

\subsubsection{Equidae}

La terminologie et les mesures utilisées dans cette famille apparaissent dans Eisenmann et al., 1988) (figure IV.1.1, 4 et 5). 
Les mesures prises dans les restes dentaires sont les suivantes (figure IV.1.4): DAP: diamètre maximal antéro-postérieur. DAP $1 / 2$ : diamètre antéro-postérieur à la mi- hauteur de la couronne. DT: diamètre maximal transverse. DT 1/2: diamètre transverse à la mihauteur de la couronne. DTa: diamètre transverse antérieur. DTp: diamètre transverse postérieur. H: hauteur maximale de la couronne. IA: diamètre transverse de l'infundibulum dans les incisives. IL: diamètre transverse de l'infundibulum dans les incisives. KL: longueur de la double boucle dans la dentition inférieure. PL : longueur du protocône dans la dentition supérieure. PL 1/2: longueur du protocône sur la hauteur moyenne de la couronne. Postfl. L.: longueur du «postflexid» dans les dents inférieures. Prefl. L.: longueur du « preflexid » dans la dentition inférieure.

Les mesures utilisées dans les matériaux postcrâniens sont les suivantes (figure IV.1.5):

Métacarpien II (figure IV.1.5: 1.a, 1.b): BP: largeur maximale de l'extrémité proximale. DP: profondeur de l'extrémité proximale. GL: longueur maximale de l'os.

Métacarpien III (figure IV.1.5: 2.a, 2.b, 2.c): BD: largeur maximale de l'extrémité distale. BP: largeur maximale de l'extrémité proximale. DAF: diamètre maximal de la face antérieure du quatrième carpien. DAT: diamètre maximal de la facette articulaire du troisième carpien. DAS: diamètre de la facette articulaire du deuxième carpien. DD: profondeur maximale du condyle latéral. DPA: profondeur de la facette articulaire. DPF: diamètre de la facette postérieure du quatrième carpien. GL: longueur maximale de l'os. GLM: longueur médiane. SD: diamètre transversal du milieu de la diaphyse. SDD: profondeur du milieu de la diaphyse.

Métacarpien IV (figure IV.1.5: 3.a, 3.b): BP : largeur maximale de l'extrémité proximale. DP: profondeur de l'extrémité proximale.

Tibia (figure IV.1.5: 4): BP: largeur maximale de l'extrémité proximale. DP: profondeur de l'extrémité proximale.

Talus (figure IV.1.5: 9.a, 9.b, 9.c): BT: largeur de la trochlée. DD: profondeur de l'articulation distale. DM: la profondeur moyenne maximale. GB: longueur maximale. GL: longueur maximale de l'os.

Calcanéum (figure IV.1.5: 8.a, 8.b): BD: largeur maximale de l'extrémité distale. BP: largeur maximale de l'extrémité proximale. DD: profondeur du condyle latéral. DP: profondeur de l'extrémité proximale. GL: longueur maximale de l'os.

Métatarsien II (figure IV.1.5): BP: largeur maximale de l'extrémité proximale. DP: profondeur de l'extrémité proximale.

Métatarsien III (figure IV.1.5: 6.a, 6.b, 6.c): BD: largeur maximale de l'extrémité distale. BP: largeur maximale de l'extrémité proximale. DD: profondeur de l'extrémité distale. DL: profondeur maximale du condyle latéral. DM: profondeur maximale du condyle interne. DP: profondeur maximale de l'extrémité proximale. GL: longueur maximale de l'os. GLM: longueur médiane. SD: diamètre transversal du milieu de la diaphyse.

Première phalange (antérieur et postérieur) (figure IV.1.5 : 10.a, 10.b, 10.c, 10.d): BD: largeur maximale de l'extrémité distale. BFD: largeur de l'articulation distale. BP: largeur maximale de l'extrémité proximale. DD: profondeur de l'extrémité distale. DP: profondeur de l'extrémité proximale. GL: longueur maximale de l'os. GLa: longueur antérieure. LLi: longueur de l'infratubérosité latérale. LLS: longueur de la supratubérosité latérale. LMI: longueur de l'infratubérosité médiane. LMS: longueur de la supratubérosité médiane. SD: diamètre transversal du milieu de la diaphyse.

Deuxième phalange (antérieur et postérieur) (figura IV.1.5: 12.a, 12.b): BD: largeur maximale de l'extrémité distale. BP: largeur maximale de l'extrémité proximale. DP: 
profondeur de l'extrémité proximale. GL: longueur maximale de l'os. GLa: longueur antérieure. SD: diamètre transversal du milieu de la diaphyse.

Troisième phalange (figure IV.1.5: 11.a, 11.b, 11.c): GB: largeur maximale. HP: hauteur maximale. LD: longueur antérieure. LF: largeur articulaire. LO: longueur de la surface articulaire postérieure.

Nous utilisons les indices suivants:

Indice du «postflexid» (IPF):

$$
\mathrm{IPF}=\frac{100 \times \text { Postfl. L. }}{\text { DAP }}
$$

Indice du double bucle (IDB):

$$
\mathrm{IDB}=\frac{\text { DAPo } \times 100 \times \mathrm{KL}}{\mathrm{DAP}}
$$

Indice du protocône (IP):

$$
\mathrm{IP}=\frac{100 \times \mathrm{LP}}{\mathrm{DAP}}
$$

Indice de robustesse (IR):

$$
\mathrm{IR}=\frac{\text { SD diáfisis } \times 100}{\text { GL longitud total }}
$$

\subsubsection{Suidae, Cervidae et Bovidae}

La terminologie que nous avons utilisé apparaît dans Van der Made $(1989,1996)$ (figure IV.1.6). Dans les mesures, nous avons utilisé deux critères. Pour les dents, le modèle de Van der Made $(1989,1996)$ et pour le matériel postcrânien le modèle de Von den Driesch (1976) et Sala et al., (2010) (figures IV.1.8).

Les mesures prises dans les restes dentaires sont les suivantes (figure IV.1.7): DAP: diamètre maximal antéro-postérieur. DAPb: diamètre antéro-postérieur dans la base. DLL: diamètre antéro-postérieur dans les incisives et les canines. DT: diamètre maximal transverse. DTa: diamètre transverse antérieur. DTb: diamètre transverse dans la base. DTp: diamètre transverse postérieur. DTpp: diamètre transverse de l'hypoconulide. $\mathbf{H}$ : hauteur maximale de la couronne. Ha: hauteur du lobe antérieur. Hdist: hauteur distale de la couronne dans les incisives et les canines. Hla: hauteur labiale de la couronne dans les incisives et les canines. Hli: hauteur linguale de la couronne dans les incisives et les canines. Hmes: hauteur mésiale de la couronne dans les incisives et les canines. Hp: hauteur du lobe postérieur.

Les mesures utilisées dans les matériaux postcrâniens sont les suivantes (figure IV.1.8):

Scapula (figure IV.1.8: 1): BG: largeur de la cavité glénoide. GL: longueur de la cavité glénoide. GLP: longueur maximale du processus glénoide. 
Humérus (figure IV.1.8: 2): BD: largeur maximale de l'extrémité distale. BT: largeur de la surface articulaire.

Radius (figure IV.1.8: 3.a, 3.b, 3.c): BD: largeur maximale de l'extrémité distale. BFd: diamètre transverse de la surface articulaire antérieure. BFp: diamètre transverse de la surface articulaire distale. BP: largeur maximale de l'extrémité proximale. DD: profondeur de l'extrémité distale. DP: profondeur de l'extrémité proximale. GL: longueur maximale. SD: diamètre transversal du milieu de la diaphyse.

Ulna (figure IV.1.8: 4.a, 4.b): BPC: largeur de la surface articulaire proximale. DPA: profondeur dans le processus anconaeus. LO: longueur du oleocraneon. SDO: profondeur minimale du oleocraneon.

Métacarpien III + IV (figure IV.1.8: 5.a, 5.b, 5.c): BD: largeur maximale de l'extrémité distale. BP: largeur maximale de l'extrémité proximale. DD: profondeur de l'extrémité distale. DP: profondeur de l'extrémité proximale. GL: longueur maximale. PM: profondeur du condyle médial. PL: profondeur du condyle latéral. SD: diamètre transversal du milieu de la diaphyse.

Patella (figure IV.1.8: 6.a, 6.b): BM: largeur maximale. DM: profondeur maximale. GL: longueur maximale.

Tibia (figure IV.1.8: 7): BD: largeur maximale de l'extrémité distale. DD: profondeur de l'extrémité distale. SD: diamètre transversal du milieu de la diaphyse.

Métatarsien III + IV (figure IV.1.8: 10): BD: largeur maximale de l'extrémité distale. BP: largeur maximale de l'extrémité proximale. DD: profondeur de l'extrémité distale. DP: profondeur de l'extrémité proximale. GL: longueur maximale. PM: profondeur du condyle médial. PL: profondeur du condyle latéral. SD: diamètre transversal du milieu de la diaphyse.

Talus (figure IV.1.8: 8.a, 8.b, 8.c): ATPL: hauteur de la trochlée proximale-latérale. BD: largeur maximale de l'extrémité distale. BP: largeur maximale de l'extrémité proximale. DM: profondeur de la partie médiane. DL: profondeur de la partie latérale. GLm: longueur maximale de la partie médiale. GLl: longueur maximale de la partie latérale. LAP: longueur antéro-postérieure de la surface articulaire latérale du calcanéum. LPD: longueur proximale-latérale de la surface articulaire latérale du calcanéum.

Calcanéum (figure IV.1.8: 9.a, 9.b): AEA: largeur de la surface articulaire externe pour le talus. AEE: largeur de la surface articulaire externe pour le scaphoide. GB: largeur maximale. GL: longueur maximale. LEA: longueur de la surface articulaire externe pour le talus. LEE: longueur de la surface articulaire externe pour le scaphoide.

Première phalange (antérieur et postérieur) (figure IV.1.8: 11.a, 11.b, 11.c): BD: largeur maximale de l'extrémité distale. BP: largeur maximale de l'extrémité proximale. DD: profondeur de l'extrémité distale. DP: profondeur de l'extrémité proximale. DPi: profondeur de l'extrémité proximale dans la région d'insertion musculaire. DPs: profondeur de l'extrémité proximale dans la région articulaire. GL: longueur maximale dans l'extrême axial. GLpe: longueur maximale dans l'extrême abaxial. Hmax: hauteur maximale. SD: diamètre transversal du milieu de la diaphyse.

Deuxième phalange (antérieur et postérieur) (figura IV.1.8: 12.a, 12.b, 12.c): BD: largeur maximale de l'extrémité distale. BP: largeur maximale de l'extrémité proximale. DD: profondeur de l'extrémité distale. DP: profondeur de l'extrémité proximale. DPi: profondeur de l'extrémité proximale dans la région d'insertion musculaire. DPs: profondeur de l'extrémité proximale dans la région articulaire. GL: longueur maximale dans l'extrême axial. GLpe: longueur maximale dans l'extrême abaxial. Hmax: hauteur 
maximale. Hpost: hauteur de la partie postérieure. SD: diamètre transversal du milieu de la diaphyse.

Troisième phalange (figure IV.1.8 : 13.a, 13.b, 13.c): DLS: diamètre antéro-postérieur de la sole plantaire. LD: longueur de la surface dorsale. MBS: largeur de la région médiale de la face sole.

Pour différencier les genres Bos et Bison, nous avons utilisé les références suivantes: Schertz (1936), Bibikova (1958), Altuna (1972), Brugal (1984), Jaubert et al., (1990), Buitrago (1992), Gee (1993), Álvarez-Lao (2007) et Sala et al., (2010). De plus, nous avons employé les indices suivants:

Dans le talus:

Indice de la surface articulaire pour le calcanéum:

$$
\mathrm{IFAL}=\frac{\text { longueur proximale }- \text { latérale }(\mathrm{LPD})}{\text { longueur antéro }- \text { postérieure }(\mathrm{LAP})} \times 100
$$

Indice de la trochlée distale:

$$
\text { AMTD }=\frac{\text { largeur mésiale de la trochlée distale (AMD) }}{\text { largeur latérale de la trochlée distale (ALD) }} \times 100
$$

Dans le calcanéum:

Indice de la longueur des surfaces articulaires externes pour le talus et le scaphoide:

$$
\text { ILAE }=\frac{\text { longueur de la surface articulaire externe pour le talus (LEA) }}{\text { longueur de la surface articulaire externe pour le scaphoide (LEE) }} \times 100
$$

Indice de la largeur des surfaces articulaires externes pour le talus et le scaphocuboide:

$$
\text { IAAE }=\frac{\text { largeur de la surface articulaire externe pour le talus (AEA) }}{\text { largeur de la surface articulaire externe pour le scaphoide (AEE) }} \times 100
$$

\subsubsection{Nombre minimum d'individus}

Le NMI correspond à un nombre minimal d'individus précisément identifiables dans un ensemble de fossiles. Une première méthode consiste à déterminer les restes les plus fréquents en tenant compte de la latéralité. Une autre méthode consiste en l'utilisation de l'usure dentaire parce que cette usure peut indiquer qu'ils appartiennent à individus différents. 


\subsection{Estimation de l'âge}

Les modèles utilisés dans cette analyse sont basés sur la morphologie et les mesures prises dans les dents.

\subsubsection{Rhinocerotidae}

La méthode utilisée pour Stephanorhinus hemitoechus est basée sur l'usure des dents et l'éruption. Nous avons défini des rangs d'âge relatif qui vont des individus les plus jeunes aux vieux individus (Álvarez-Lao, 2007). Pour le Coelodonta antiquitatis nous avons utilisé la méthode qu'emploie Álvarez-Lao (2007) qui utilise les dents (figure IV.2.1).

\subsubsection{Equidae}

Nous avons identifié deux espèces: Equus ferus et Equus hydruntinus. Dans la première, E. ferus, a été utilisée une méthodologie morphométrique: l'observation des changements dans la forme de la surface occlusale des incisives selon la méthode de Sisson et Grossman (2001); et l'usure et l'éruption des dents (Sisson et Grossman, 2001). Dans la deuxième, $E$. hydruntinus, nous avons utilisé seulement un modèle métrique (figure IV.2.3).

\subsubsection{Suidae}

Dans cette espèce nous avons utilisé l'âge d'éruption dentaire (Rolett et Chiu, 1994).

\subsubsection{Cervidae}

Dans cette famille ont été analysés les changements morphométriques dans les canines supérieures selon la méthode d'Errico et Vanhaeren (2002), et l'usure dans les molaires inférieures et supérieures de Cervus elaphus utilisant les équations de Klein et Cruz Uribe (1984). Dans Capreolus capreolus nous avons seulement utilisé l'éruption dentaire.

\subsubsection{Caprinae}

Dans cette sous-famille, dans les genres Rupicapra et Capra, ont été utilisées les dents et la méthode métrique décrite dans la famille des cervidés. Les résultats des équations de Klein et Cruz Uribe (1984) ont été comparés avec une méthode qui utilise uniquement l'éruption et l'usure dentaire.

\subsubsection{Bovinae}

Dans ce cas, et à cause de l'absence de dents sans l'usure, nous avons utilisé l'éruption dentaire. Pour le genre Bos les données de St. Clair (2005) et pour le genre Bison ces de Wegrzyn et al., (1984) (table IV.2.6).

\subsection{Estimation de la saison de mortalité}

Pour réaliser cette étude afin d'obtenir plus d'informations sur les préférences alimentaires des groupes qui occupaient les cavités étudiées, il est important de comprendre la biologie des espèces identifiées. Ces données incluent les époques de la naissance, la maturité sexuelle, le rut et les périodes de gestation et de lactation (table 
IV.3.1). Les données pour chaque taxons sont les suivantes: Sus scrofa (Sáez-Royuela, 1987; Hayssen et al., 1993; Rossell, 1998; Herrero, 2002; Markina et al., 2003; FernándezLlario et Mateos-Quesada, 2005; Santos et al., 2006), C. elaphus (Hayssen et al., 1993; Stiner, 1994). C. capreolus (Braza et al., 1998; Mateos-Quesada, 1998). R pyrenaica (Hayssen et al., 1993; Pérez-Barbería, 1994; Dalmau, 2005). C. pyrenaica (Vigal et Fandos, 1989; Fandos et al., 1992; Hayssen et al., 1993; Alados et Escós, 2003).

\subsection{Détermination du sexe}

Dans ce travail, nous avons utilisé deux modèles appliqués à deux espèces différentes: Cervus elaphus et Rupicapra pyrenaica. Pour la première, nous employons la méthode d'Errico et Vanhaeren (2002) qui utilise les canines supérieures. Pour la deuxième, nous employons les restes postcrâniens et différentes analyses statistiques. Nous développons une nouvelle méthode qui utilise les données de l'espèce actuelle, $R$. pyrenaica, appliquant après les modèles statistiques comme: l'analyse en composantes principales, l'analyse cluster et l'analyse de mixtures. 
5. Résultats 
Dans cette section nous présentons un résumé des ongulés récupérés dans chaque dépôts (tableau V.1.1). Les spécimens de grande taille comprennent les aurochs et les bisons; de taille moyenne les chevaux, les ânes sauvages (Equus hydruntinus) et les cerfs; de petite taille les sangliers, les chevreuils, les chamois et les bouquetins.

Dans La Mina nous avons seulement étudié le rhinocéros laineux Coelodonta antiquitatis, parce que ce dépôt est troublé et ce reste est ce qui a été daté (Díez et al., 2008). Il appartient à un adulte - vieux et nous ne pouvons pas être plus précis. Nous ne pouvons pas indiquer un agent d'accumulation clair puisque aussi bien des outils en pierre que des coprolithes de carnivores ont été récupérés, suggérant une alternance dans l'occupation (Díez et al., 2008).

Dans la Grotte de Valdegoba nous avons identifié dix taxons: Stephanorhinus hemitoechus, Equus ferus, Equus hydruntinus, Sus scrofa, Cervus elaphus, Capreolus capreolus, Rupicapra pyrenaica, Capra pyrenaica, Bos primigenius et Bison priscus. Dans l'accumulation participaient aussi bien les carnivores que les hominidés bien que ces derniers eurent plus d'importance et leur accès aux proies furent primaire (Díez, 2006). Prédominent, avec $63,7 \%$, les spécimens de petite taille; suivent les taxons de taille moyenne avec 31,8 \%; et enfin ceux de grande taille avec 4,4\%. Ce qui en ressort est la présence de chamois, avec $50 \%$ de tous les spécimens identifiés. Dans les taxons de petite et grande taille prédominent les adultes; et, dans ceux de taille moyenne, les infantiles, les chamois sont les plus abondants, concrètement les mâles adultes qui ont été accumulés pendant toute l'année. Cependant, la plupart des captures, se produisent en été. À cette saison, les captures de spécimens de taille moyenne sont plus importantes. Cependant, ils ne méprisèrent pas les proies de grande taille, bien que nous ne pouvons pas préciser la période d'accumulation parce que la saisonnalité ne peut pas être estimée.

En résumé, les habitants de la cavité se spécialisèrent dans la capture de chamois durant toute l'année et ils capturèrent d'autres espèces quand elles étaient plus vulnérables, principalement au moment des mises bas et de l'allaitement.

Dans Prado Vargas, six taxons ont été récupérés: Rhinocerotidae indet., Equus ferus, Sus scrofa, Cervus elaphus, Rupicapra pyrenaica et Capra pyrenaica. Ce dépôt a été interprété comme un refuge de chasseurs, les évidences des carnivores sont rares (Navazo et al., 2005). Prédominent les espèces de petite taille, avec $50 \%$ du total; suivies par les taxons de taille moyenne, avec $40 \%$, et celles de grande taille avec $10 \%$.

Une préférence pour un des spécimens de petite taille paraît exister par leur accumulation en hiver et au printemps, les périodes où les espèces de roche comme les chamois et les chèvres se cachent dans les zones forestières.

Dans Cueva Millán nous pouvons faire une étude par niveaux: dans le premier, 1A, sept espèces ont été identifiées: Stephanorhinus hemitoechus, Equus ferus, Equus hydruntinus, Cervus elaphus, Rupicapra pyrenaica, Capra pyrenaica et Bos/Bison sp. La présence et l'activité des carnivores est très courte par conséquent le principal agent d'accumulation serait humain (Díez et al., 2008). Prédominent les espèces de petite taille, $50 \%$; suivies par celle de taille moyenne, $35 \%$, et par celle de grande taille, $15 \%$. Dans toutes les tailles prédominent les adultes. La cavité fut occupée à toutes les saisons mais avec plus d'intensité au printemps et en été, coïncidant avec le début des mises bas et de l'allaitement. Dans le niveau 1B, quatre taxons ont été enregistrés: Equus ferus, Cervus elaphus, Rupicapra pyrenaica et Capra pyrenaica, étaient égal en abondance les spécimens de petite et moyenne taille. Ces taxons furent accumulés en été, coïncidant avec la fin des mises bas et avec l'allaitement. Dans le niveau 1C, nous avons identifié quatre espèces: Equus ferus, Cervus elaphus, Rupicapra pyrenaica et Capra pyrenaica. Les spécimens de moyenne taille prédominent et furent accumulés en automne, coïncidant avec le rut. 
Dans ce dépôt, l'intensité d'occupations accroît du niveau 1C au 1A. Les habitants de la cavité se concentrent sur les espèces de petite taille, la consommation est plus marquée en été et en automne.

Dans la Grotte du Búho, huit espèces ont été identifiées: Stephanorhinus hemitoechus, Equus ferus, E. hydruntinus, Sus scrofa, Cervus elaphus, Capreolus capreolus, Bos primigenius et Bison priscus. Ce dépôt a été interprété comme une tanière de hyènes avec une absence évidente d'une intervention humaine (Sala, 2012). Les spécimens de grande taille prédominent avec $50 \%$; suivis par ceux de moyenne taille, 37,5\% et par les taxons de petite taille avec seulement $12,5 \%$. Dans toutes les tailles, les spécimens adultes prédominent, suivis par les jeunes et les petits. Les périodes d'acquisition seraient en automne et en hiver, au moins pour les spécimens de taille moyenne, les périodes où les mâles et les femelles se rassemblent pendant le rut; et où les mâles restent isolés, ce qui les rend plus vulnérables. Cependant, ces résultats sont partiels parce qu'ils incluent seulement les fouilles anciennes et il serait nécessaire d'analyser toute la collection.

Dans l'Abri d'Alexandre nous avons identifié deux espèces : Equus ferus et Rupicapra pyrenaica. Son origine est anthropique, comme suggère la grande quantité de matériel en pierre et l'absence d'activité d'autres prédateurs (Utrilla et al., 1999). Nous ne pouvons pas en dire plus parce qu'une période d'accumulation n'a pas pu être établie. Cependant, la dent de lait de chamois nous indique que ce spécimen était immature et qu'il a pu être accumulé en été ou en automne.

Dans l'Abri de Vergara nous avons détecté la présence d'Equus ferus et de Cervus elaphus. Ces restes, plus fragmentés ne nous ont pas donné plus d'informations.

Les habitants de ces abris se spécialisaient dans la consommation de spécimens de moyenne taille et, plus concrètement, d'adultes.

Dans la Peña de Estebanvela, toutes les espèces ont été accumulées par les humains comme le suggèrent la grande quantité de marques d'usage, de dépouillement, d'enlèvement de viande et de désarticulation (Yravedra, 2013). Dans le niveau I, nous avons identifié six espèces: Equus ferus, E. hydruntinus, Sus scrofa, Cervus elaphus, Rupicapra pyrenaica et Capra pyrenaica. Les spécimens de petite et moyenne taille apparaissent en même proportion, faisant ressortir les adultes dans les deux tailles. Dans le niveau II, cinq taxons ont été enregistrés: E. ferus, E. hydruntinus, C. elaphus, $R$. pyrenaica et $C$. pyrenaica. Prédominent les espèces de moyenne taille, suivies par celle de petite taille. Dans les deux cas prédominent les adultes. Dans le niveau III, nous avons identifié les mêmes taxons que dans le niveau précédent. Les spécimens de moyenne taille sont les plus nombreux, suivis par ceux de petite taille qui ont été accumulés en été. Dans le niveau IV trois espèces ont été enregistrées: $C$. elaphus, $R$. pyrenaica et $C$. pyrenaica. Ressortent les spécimens de petite taille. Dans ce niveau, nous ne pouvons pas faire une étude de la saisonnalité. 
Tableau V.1.1

Résumé des résultats obtenus dans chaque site (partie 1)

\begin{tabular}{|c|c|c|c|c|c|c|c|c|c|c|c|c|c|c|}
\hline & & \multirow{2}{*}{ NMI } & \multicolumn{6}{|c|}{ L'âge de la mort } & \multicolumn{4}{|c|}{ Saisonnalité } & \multicolumn{2}{|c|}{ Bimodalité et Dimorphisme } \\
\hline & & & petit & juvénile & adulte & sénile & immature & mature & hiver & printemps & été & automne & mâles & femelles \\
\hline \multirow[t]{8}{*}{ Grotte du Búho } & S. hemitoechus & 4 & 1 & 1 & 2 & & & & & & & & & \\
\hline & E.ferus & 2 & & & 1 & & 1 & 1 & & & & & & \\
\hline & E. hydruntinus & 1 & & & & & & & & & & & & \\
\hline & S. scrofa & 1 & & & & & & 1 & & & & & & \\
\hline & C. elaphus & 3 & & 1 & 1 & & & 1 & $\mathrm{X}$ & & & $\mathrm{X}$ & & \\
\hline & C. capreolus & 1 & (1) & & & & 1 & & & & & & & \\
\hline & B. primigenius & 2 & & & & & & & & & & & & \\
\hline & B. priscus & 2 & & & & & & & & & & & & \\
\hline La Mina & C. antiquitantis & 1 & & & (1) & & & & & & & & & \\
\hline \multirow[t]{10}{*}{ Grotte de Valdegoba } & S. hemitoechus & 3 & 1 & (1) & & (1) & & & & & & & & \\
\hline & E.ferus & 28 & & & 5 & 1 & 17 & 11 & & & & & & \\
\hline & E. hydruntinus & 5 & & 2 & 1 & 2 & 2 & 3 & & & & & & \\
\hline & S. scrofa & 2 & & & & & 2 & & & & & & & \\
\hline & C. elaphus & 40 & 19 & 9 & 1 & & 27 & 13 & $\mathrm{X}$ & $\mathrm{x}$ & $\mathrm{X}$ & $\mathrm{X}$ & 5 & 4 \\
\hline & C. capreolus & 12 & $(10)$ & & 1 & 1 & 10 & 2 & & & & & & \\
\hline & R. pyrenaica & 114 & 1 & 16 & 82 & & 26 & 88 & $\mathrm{X}$ & $\mathrm{X}$ & $\mathrm{X}$ & $\mathrm{X}$ & 16 & 8 \\
\hline & C. pyrenaica & 18 & 1 & 8 & 1 & & 10 & 8 & $\mathrm{x}$ & $\mathrm{x}$ & $\mathrm{X}$ & $\mathrm{x}$ & & \\
\hline & B. primigenius & 6 & & & & & & & & & & & & \\
\hline & B. priscus & 1 & & & & & & & & & & & & \\
\hline \multirow[t]{6}{*}{ Prado Vargas } & Rhinocerotidae indet. & 1 & & & & & & & & & & & & \\
\hline & E. ferus & 2 & & & 1 & 1 & & 2 & & & & & & \\
\hline & S. scrofa & 1 & & & & & 1 & & & & & & & \\
\hline & C. elaphus & 2 & & 1 & & & 1 & & $\mathrm{x}$ & & & & & 1 \\
\hline & R. pyrenaica & 2 & & 1 & 1 & & 1 & 1 & $\mathrm{x}$ & $\mathrm{X}$ & & & & \\
\hline & C. pyrenaica & 2 & & & & & & & & & & & & \\
\hline
\end{tabular}

* La référence (1) ou (10) indique que le spécimen pourrait être en: $S$. hemitoechus: un juvénile-adulte ou un adulte-sénile; C. antiquitatis: un adulte-sénile; C. capreolus: dix petitsjuvéniles. 


\section{Tableau V.14.1}

Résumé des résultats obtenus dans chaque site (partie 2)

\begin{tabular}{|c|c|c|c|c|c|c|c|c|c|c|c|c|c|c|c|}
\hline & & & \multirow[t]{2}{*}{ NMI } & \multicolumn{6}{|c|}{ L'âge de la mort } & \multicolumn{4}{|c|}{ Saisonnalité } & \multicolumn{2}{|c|}{ Bimodalité et Dimorphisme } \\
\hline & & & & petit & juvénile & adulte & sénile & immature & mature & hiver & printemps & été & automne & mâles & femelles \\
\hline \multirow[t]{15}{*}{ Cueva Millán } & $1 \mathrm{~A}$ & S. hemitoechus & 1 & & & & & & & & & & & & \\
\hline & & E. ferus & 3 & & & 2 & & 1 & 2 & & & & & & \\
\hline & & E. hydruntinus & 1 & & & & & & & & & & & & \\
\hline & & C. elaphus & 3 & & 1 & 2 & & 1 & 2 & & & $\mathrm{X}$ & $\mathrm{X}$ & & 2 \\
\hline & & R. pyrenaica & 5 & & 2 & 3 & & 2 & 3 & & $\mathrm{X}$ & $\mathrm{X}$ & $\mathrm{X}$ & & \\
\hline & & C. pyrenaica & 5 & & & 1 & & & 1 & $\mathrm{X}$ & & & & & \\
\hline & & Bos/Bison sp. & 2 & & & 1 & & 1 & 1 & & & & & & \\
\hline & 1B & E. ferus & 1 & & & & & & 1 & & & & & & \\
\hline & & C. elaphus & 2 & & 1 & 1 & & 1 & 1 & & & $\mathrm{X}$ & & & \\
\hline & & R.pyrenaica & 1 & & 1 & & & 1 & & & & $\mathrm{X}$ & & & \\
\hline & & C. pyrenaica & 1 & & & & & & & & & & & & \\
\hline & $1 \mathrm{C}$ & E. ferus & 3 & & & & & & 3 & & & & & & \\
\hline & & C. elaphus & 2 & & & 1 & & 1 & 1 & & & & $\mathrm{X}$ & & \\
\hline & & R. pyrenaica & 1 & & & 1 & & & 1 & & & & & & \\
\hline & & C. pyrenaica & 1 & & & & & & & & & & & & \\
\hline \multirow[t]{19}{*}{ Peña de Estebanvela } & I & E. ferus & 2 & 1 & & 1 & & 1 & 1 & & & & & & \\
\hline & & E. hydruntinus & 2 & & 1 & 1 & & 1 & 1 & & & & & & \\
\hline & & S. scrofa & 1 & & & 1 & & & 1 & & & & & & \\
\hline & & C. elaphus & 1 & & & & & & & & $\mathrm{X}$ & & & & \\
\hline & & R. pyrenaica & 2 & & & 1 & & 1 & 1 & & & & $\mathrm{X}$ & & \\
\hline & & C. pyrenaica & 4 & & & 2 & & 2 & 2 & & & & & & \\
\hline & II & E. ferus & 2 & & & & & 1 & 1 & & & & & & \\
\hline & & E. hydruntinus & 2 & & & 2 & & & 2 & & & & & & \\
\hline & & C. elaphus & 1 & & & & & & & & & & & & \\
\hline & & R. pyrenaica & 1 & & & & & & & & & & & & \\
\hline & & C. pyrenaica & 1 & & & & & & & & & & & & \\
\hline & III & E. ferus & 2 & & & 2 & & & 2 & & & & & & \\
\hline & & E. hydruntinus & 1 & & & & & & & & & & & & \\
\hline & & C. elaphus & 1 & & & & & & & & & & & & \\
\hline & & R. pyrenaica & 1 & & & 1 & & & 1 & & & & & & \\
\hline & & C. pyrenaica & 2 & & 1 & & & 1 & & & & $\mathrm{X}$ & & & \\
\hline & IV & C. elaphus & 1 & & & & & & & & & & & & \\
\hline & & R. pyrenaica & 1 & & & & & & & & & & & & \\
\hline & & C. pyrenaica & 1 & & & & & & & & & & & & \\
\hline
\end{tabular}


Tableau V.1.1

Résumé des résultats obtenus dans chaque site (partie 3)

\begin{tabular}{|c|c|c|c|c|c|c|c|c|c|c|c|c|c|c|}
\hline & & \multirow[t]{2}{*}{ NMI } & \multicolumn{5}{|c|}{ L'âge de la mort } & \multirow[b]{2}{*}{ mature } & \multicolumn{4}{|c|}{ Saisonnalité } & \multicolumn{2}{|c|}{ Bimodalité et Dimorphisme } \\
\hline & & & petit & juvénile & adulte & sénile & immature & & hiver & printemps & été & automne & mâles & femelles \\
\hline \multirow[t]{2}{*}{ Peña Mudá } & S. hemitoechus & 1 & & & 1 & & & & & & & & & \\
\hline & C. antiquitantis & 1 & & & & & & 1 & & & & & & \\
\hline \multirow[t]{2}{*}{ Abri d'Alexandre } & E. ferus & 1 & & & & & & & & & & & & \\
\hline & R. pyrenaica & 1 & & 1 & & & 1 & & & & & & & \\
\hline \multirow[t]{2}{*}{ Abri de Vergara } & E. ferus & 1 & & & & & 1 & & & & & & & \\
\hline & C. elaphus & 1 & & & & & & & & & & & & \\
\hline
\end{tabular}

Tableau V.1.2

Nombre minimum d'individus et pourcentages des tailles dans les dépôts du Paléolitique Moyen et Supérieur

\begin{tabular}{|c|c|c|c|c|c|}
\hline & & \multicolumn{2}{|c|}{ Paléolithique Moyen } & \multicolumn{2}{|c|}{ Paléolithique Supérieur } \\
\hline & & NMI & $\%$ & MNI & $\%$ \\
\hline \multirow[t]{5}{*}{ Grande taille } & S. hemitoechus & 4 & 5,8 & & \\
\hline & Rhinocerotidae indet. & 1 & & & \\
\hline & Bos primigenius & 6 & & & \\
\hline & Bison priscus & 1 & & & \\
\hline & Bos/Bison sp. & 9 & & & \\
\hline \multirow[t]{3}{*}{ Moyenne taille } & E. ferus & 34 & 25,5 & 12 & 64,7 \\
\hline & E. hydruntinus & 5 & & 5 & \\
\hline & C. elaphus & 53 & & 5 & \\
\hline \multirow[t]{4}{*}{ Petite taille } & C. capreolus & 13 & 68,7 & & \\
\hline & S. scrofa & 3 & & & 35,5 \\
\hline & R. pyrenaica & 187 & & 7 & \\
\hline & C. pyrenaica & 45 & & 5 & \\
\hline
\end{tabular}


Dans la Peña de Mudá, nous avons identifié deux espèces de rhinocéros: Stephanorhinus hemitoechus et Coelodonta antiquitatis. Parmi les restes d'ongulés récupérés dans ce gisement, et ceux qui sont dans le Musée Géologique et Minier, nous ne connaissons pas le contexte donc nous ne pouvons pas apporter plus d'information.

La chose qui a attiré notre attention est le grand nombre de sites du Paléolithique Moyen et du Paléolithique Supérieur. Dans le premier groupe nous trouvons: La Mina, Grotte du Buho, Grotte de Valdegoba, Cueva Millán et Prado Vargas. Aussi pourrions nous inclure La Ermita, bien que nous n'ayons pas analysé ses restes. Le deuxième groupe inclut les Abris d'Alexandre et de Vergara, et la Peña de Estebanvela. Dans cette analyse nous excluons la Grotte du Búho parce que son origine n'est pas anthropique; ainsi que La Mina parce que nous ne pouvons pas définir d'origine vu que le dépôt est troublé (tableau V.1.2). Une plus petite gamme de proies se trouvent dans les sites du Paléolithique Supérieur, où nous n'avons pas identifié des espèces de grande taille et où prédominent les spécimens de moyenne taille. D'un autre côté, les dépôts du Paléolithique Moyen montrent une plus grande variété de proies, où dominent les espèces de petite taille. Nous pouvons conclure que les habitants du Paléolithique Moyen se spécialisèrent dans des petits spécimens, particulièrement en taxons rupicoles comme Rupicapra pyrenaica et Capra pyrenaica. Ils ne méprisèrent pas les espèces de moyenne taille comme les cerfs et les chevaux, bien que les espèces les moins consommées furent celle de grande taille. Durant le Paléolithique Supérieur, les préférences se modifièrent, se concentrant sur les spécimens de moyenne taille et abandonnant la consommation de proies de grande taille. 


\section{Conclusions}


Cette partie est divisée en trois paragraphes. Le premier, les résultats paléontologiques, qui comprennent l'identification taxonomique, le reclassement de certaines espèces étudiées et les résultats du dimorphisme sexuel. Le deuxième se concentre sur chacun des sites, dans la liste des ongulés, la taille plus abondante, leurs tranches d'âge, les périodes d'accumulation et les différences entre les dépôts du Paléolithique Moyen et du Paléolithique Supérieur. Enfin, le troisième comprend les conclusions méthodologiques des modèles utilisés dans la détermination de l'âge de la mort et du dimorphisme et bimodalité sexuels.

\section{Conclusions paléontologiques}

1. Nous avons identifié onze espèces d'ongulés dans les gisements du Pléistocène Supérieur du Plateau Nord: Stephanorhinus hemitoechus, Coelodonta antiquitatis, Equus ferus, Equus hydruntinus, Sus scrofa, Cervus elaphus, Capreolus capreolus, Rupicapra pyrenaica, Capra pyrenaica, Bos primigenius et Bison priscus.

2. Nous avons attribué les restes du rhinocéros de La Mina, avant identifié comme Stephanorhinus hemitoechus, à l'espèce Coelodonta antiquitatis.

3. Nous avons redéterminé les restes de chamois à l'espèce Rupicapra pyrenaica, et nous les avons adapté à la nouvelle classification taxonomique et aux nouvelles données biogéographiques de cette espèce.

4. À l'Abri d'Alexandre, nous avons attribué les restes de Cervus elaphus à Rupicapra pyrenaica.

5. L'analyse du dimorphisme sexuel du chamois de la Grotte de Valdegoba a révélé que les mâles étaient plus grands que les actuels chamois cantabriques, tandis que les femelles avaient la même taille. Nous pouvons conclure que les chamois du Pléistocène Supérieur eurent plus de dimorphisme sexuel.

\section{Conclusions sur chacun des sites étudiés}

1. Dans le gisement de La Mina, nous avons trouvé le rhinocéros Coelodonta antiquitatis. Ses restes appartiennent à un spécimen adulte-vieux. Ils sont les plus anciens du Pléistocène Supérieur. En plus, sa situation géographique permet de proposer une entrée dans le Plateau au travers de passages du nord à l'est; et de suggérer un nouveau accès pour le Système Central aux régions du sud.

2. Dans la Grotte de Valdegoba ont été récupérées dix espèces: Stephanorhinus hemitoechus, Equus ferus, E. hydruntinus, Sus scrofa, Cervus elaphus, Capreolus capreolus, Rupicapra pyrenaica, Capra pyrenaica, Bos primigenius et Bison priscus. Les espèces de petite taille $(63,7 \%)$ dominent, suivies par celles de taille moyenne $(31,8 \%)$ et de grande taille $(4,4 \%)$.

Les habitants de la grotte se spécialisèrent en espèces de petite taille surtout le chamois et particulièrement sur les adultes mâles. Les adultes prédominent aussi en taxons de grande taille et les petits dans la classe moyenne. Bien qu'il y ait une accumulation dans toutes les saisons il existe une pointe en été, lors des saisons de naissance et d'allaitement.

3. Dans Prado Vargas ont été identifiées six espèces: Rhinoceros indet., Equus ferus, Sus scrofa, Cervus elaphus, Rupicapra pyrenaica et Capra pyrenaica. Les espèces de petite taille (50\%) dominent, suivies par celles de taille moyenne (40\%) et par celles de grande taille $(10 \%)$. 
Les habitants de cette cavité étaient spécialisés en taxons de petite taille. Ils occupèrent la grotte surtout l'hiver et au printemps, quand ces espèces occupaient les zones forestières.

4. Dans le premier niveau, $1 \mathrm{~A}$, de Cueva Millán nous avons identifié: Stephanorhinus hemitoechus, Equus ferus, E. hydruntinus, Cervus elaphus, Rupicapra pyrenaica, Capra pyrenaica et d'un grand bovidé (Bos / Bison sp.). Dominent les espèces de petite taille (50 $\%$ ), suivies par celles de taille moyenne (35\%) et grande (15\%). Les adultes sont les plus abondants dans la petite taille et les jeunes dans la moyenne. Ces spécimens se sont accumulés surtout au printemps et en été. Dans le niveau 1B ont été identifiés: $E$. ferus, $C$. elaphus, $R$. pyrenaica et $C$. pyrenaica. Les espèces prédominantes sont les petites et furent déposées en été. Dans le niveau $1 \mathrm{C}$ ont été localisés: $E$. ferus, $C$. elaphus, $R$. pyrenaica et $C$. pyrenaica. Les espèces de petite et moyenne taille sont de prédominances égales et se sont accumulées pendant l'automne.

Dans cette cavité, les résidents préférèrent les taxons de moyenne taille qui ont été accumulés pendant l'été et l'automne.

5. Dans la Grotte del Búho ont été identifiés huit taxons: Stephanorhinus hemitoechus, Equus ferus, E. hydruntinus, Sus scrofa, Cervus elaphus, Capreolus capreolus, Bos primigenius et Bison priscus. Les espèces de petite et moyenne taille ont au moins été déposées pendant l'automne et l'hiver. Cette information est partielle parce que ces restes se trouvent dans les anciennes fouilles.

6. Dans l'Abri d'Alexandre nous avons identifié deux espèces: Equus ferus et Rupicapra pyrenaica. Les chevaux adultes sont prédominants et le chamois est jeune.

7. Dans l'Abri Vergara nous avons enregistré Equus ferus et Cervus elaphus.

Les habitants de ces abris consommaient des espèces de taille moyenne et des adultes.

8. Dans le premier niveau, I, de Peña de Estebanvela, nous avons identifié six taxons: Equus ferus, E. hydruntinus, Sus scrofa, Cervus elaphus, Rupicapra pyrenaica et Capra pyrenaica. Les taxons de petite et moyenne taille sont en même proportion. Les adultes sont prédominants. La cavité a été occupée pendant le printemps et l'automne. Dans le niveau II nous avons localisé cinq espèces: E. ferus, E. hydruntinus, C. elaphus, $R$. pyrenaica et $C$. pyrenaica. Les taxons de petite taille prédominent $(75 \%)$, suivis par les espèces de petite taille (25\%). Dans les deux cas prédominent les spécimens adultes. Le niveau III comprend cinq taxons: E. ferus, E. hydruntinus, C. elaphus, $R$. pyrenaica et $C$. pyrenaica. Les espèces de moyenne taille sont prédominantes et ont été déposées pendant l'été. Dans le niveau IV nous avons identifié trois espèces: $C$. elaphus, $R$. pyrenaica et $C$. pyrenaica et les spécimens de petite taille sont les plus abondants.

Dans cette cavité nous notons une préférence pour les taxons de moyenne taille, surtout adultes, avec une accumulation durant toute l'année.

9. Les habitants des cavités du Paléolitique Moyen spécialisés dans la chasse d'espèces de petite taille, principalement caprines, bien qu'ils pouvaient occuper les cavités tout au long de l'année, centrèrent la chasse en été, coïncidant avec des périodes de naissance et d'allaitement. 
10. Pendant le Paléolithique Supérieur, les populations se concentrent sur les espèces de taille moyenne comme les chevaux et les cerfs, abandonnant la chasse de taxons de grande taille. La variété diminue au fil du nombre d'occupations, qui sont nettement inférieures à celles présentes dans le Paléolithique Moyen. Ces cavités et abris ont été occupés à partir de la fin du printemps jusqu'au début de l'automne, ce qui coïncide avec les périodes de naissance et d'allaitement.

\section{Conclusions méthodologiques}

\section{Estimation de l'âge}

1. Le modèle développé dans cette étude a donné des résultats similaires aux équations de Klein et Uribe (1984). Cependant, il existe un changement de spécimens entre certains groupes et d'autres, pour cela il serait préférable d'employer seulement cette méthode pour connaître l'abondance de chaque groupe d'âge et non pour connaître le nombre de spécimens qu'il y a dans chacun de ces groupes.

\section{Détermination du dimorphisme sexuel}

1. La comparaison des différents modèles statistiques a montré que les méthodes cluster en général et particulièrement la méthode k-means apportent les meilleurs résultats pour estimer le dimorphisme sexuel. Cette méthode offre des avantages sur d'autres méthodes comme le fait qu'elle puisse être appliquée aux fossiles car elle n'est pas influencée par les possibles variations de taille des espèces paléontologiques et par conséquent, les résultats d'un prélèvement ne déterminent pas le résultat d'un autre. Les bons résultats obtenus dans certaines espèces un peu dimorphes font que ces méthodes peuvent être appliquées à des espèces plus bimodales.

2. Cette méthode suggère une recommandation pour déterminer la bimodalité sexuelle, au moins pour le chamois, Rupicapra pyrenaica, en particulier, mais elle peut être utilisée pour d'autres ongulés.

2.1. L'extrémité antérieure est ce qui apporte les meilleurs résultats, surtout la largeur des os de l'articulation du coude (BT pour l'humérus et BP pour le radius).

2.2. Les mesures de l'épiphyse (en particulier ceux avec une orientation médio-latérale) sont meilleurs que ceux pris dans la diaphyse.

\subsection{Les analyses multivariées sont préférables à une analyse univariable}

2.4 Les résultats indiquent que les variables les plus fiables sont celles qui mesurent la valeur demi-latérale de l'épiphyse. Dans le cas de l'humérus, os qui a fourni les meilleurs résultats, la meilleure variable est la largeur de la trochlée (BT) au lieu de la largeur de l'épiphyse (BD). Cependant, dans le cas de la radio, les meilleurs résultats se trouvent dans la largeur de toute l'épiphyse (BD) au lieu de la surface articulaire (BFD). Les résultats des longueurs maximales (GL, GLl et GLc) sont variables et plus fiables dans les membres postérieurs. Dans tous les cas, la longueur physiologique (GLc) de l'humérus apporte de meilleurs résultats que la longueur maximale (GLL). Enfin, les résultats des variables prises dans les diaphyses sont très irréguliers. 


\section{Références}


Alados, C. L., Escós, J., 2003. Cabra montés - Capra pyrenaica, en: Carrascal, L. M., Salvador, A. (Eds.), Enciclopedia virtual de los vertebrados españoles. Madrid, Museo de Ciencias Naturales. Madrid.

Alférez, F., Molero, G., Bustos, V., 1980 - 1981. Los restos fósiles más meridionales de Rupicapra rupicapra hallados en Europa. Coloquios de Paleontología. 36, 53 - 59.

Alonso, A., 1981. El Cretácico de la provincia de Segovia (Borde Norte del Sistema Central). Facultad de Ciencias Geológicas, CSIC-UCM. Madrid, pp. 271.

Altuna, J., 1972. Fauna de mamíferos de los yacimientos prehistóricos de Guipúzcoa. Con catálogo de los mamíferos cuaternarios del Cantábrico y del Pirineo occidental. Munibe XXIV, pp. 464.

Altuna, J., 2002. Los animales representados en el arte rupestre de la Península Ibérica. Frecuencias de los mismos. Munibe. 54, 21 - 33.

Álvarez, M. T., Morales, A., Sesé, C., 1992. Mamíferos del yacimiento del Pleistoceno Superior de Cueva Millán (Burgos, España). Estudios Geológicos. 48, 193-204.

Álvarez-Lao, D., 2007. Revisión paleontológica de los macromamíferos indicadores de clima frío en el Pleistoceno de la Península Ibérica. Tesis Doctoral. Universidad de Oviedo, pp. 421.

Aparicio, M. T., 2013. La fauna malacológica continental del yacimiento de La Peña de Estebanvela (Segovia). Proyecto de investigación 2006-2009, en: Cacho, C. (Ed.), Ocupaciones magdalenienses en el interior de la Península Ibérica. La Peña de Estebanvela (Ayllón, Segovia), Junta de Castilla y León, CSIC, 127 - 131.

Arceredillo, D., 2008a. Estudio Paleontológico de los Herbívoros de la Cueva de Valdegoba (Huérmeces, Burgos), Tesis de Licenciatura, Departamento de Geología, Facultad de Biología. Universidad de Salamanca, pp. 297.

Arcedillo, D., 2008b. Morphometric differences among the equids of the upper Pleistocene from Valdegoba (Burgos, Spain). Bull. Int. Assoc. Paleodont. 2 (2), 21 - 26.

Arceredillo, D., 2010. Los macromamíferos del yacimiento del Pleistoceno Superior de Prado Vargas (Burgos, España). Seminario de Paleontología de Zaragoza. 9, 63 - 65.

Arceredillo, D., Díez, C., 2009. Age of Death and Seasonality based on Ungulate tooth remains from the Upper Pleistocene Site of Valdegoba (Burgos, Spain). Journal of Taphonomy. 7 (2-3), 75 91.

Arceredillo, D., Diez, C., 2010. Edad de muerte y dimorfismo sexual del Cervus elaphus de tres yacimientos del Pleistoceno Superior a partir del estudio de sus caninos superiores. Seminario de Paleontología de Zaragoza. 9, 67-70.

Arceredillo, D., Gómez-Olivencia, A., García-Pérez, A., 2011. Three statistical methods for sex determination in extant and fossil caprines: assessment of the Rupicapra long bones. Journal of Archaeological Sciences. 38, 2450 - 2460.

Arceredillo, D., Gómez-Olivencia, A., San Pedro, Z., 2013. La fauna de macromamíferos de los niveles pleistocenos de la Cueva de Arlanpe (Lemoa, Bizkaia), en: Ríos-Garaizar, J., Gárate-Maidagan, D., Gómez-Olivencia, A. (Eds.), La Cueva de Arlanpe (Lemoa): Ocupaciones humanas desde el Paleolítico Medio Antiguo hasta la Prehistoria Reciente. Kobie Serie Bizkaiko Arkeologi Indusketar - Excavaciones Arqueológicas en Bizkaia. 3, 123 - 160.

Barone, R., 1966. Anatomie comparée des mammifères domestiques. Laboratoire d'Anatomie, École Vétérinaire de Lyon., Lyon.

Bibikova, V. I., 1958. Some distinguishing features in the bones of the genera Bison and Bos. Bull. Mosk. Obschtschestwa Isp Privoda NS Otdel Biol. 63 (6), 23 - 35.

Braza, F., San José, C., Aragón, S., Delibes, J. R., 1998. La reproducción del corzo morisco. Revista de la Sociedad Gaditana de Historia Natural. 1, 11 - 15.

Breuil, H., 1918 - 1919. Les peintures rupestres de la Péninsule Iberique IX. La vallée peinte des Batuecas (Salamanca). X, Roches peintes de Garcibuey (Salamanca). L'Anthropologie. XXIX, 1 $-21$.

Brugal, J. P., 1984. Le Bos primigenius Boj., 1827 du Pléistocène moyen des grottes de Lunel-Viel (Hérault). Bulletin du Musée d'Anthropologie Préhistorique de Monaco. 28, 7 - 62. 
Buitrago, A. M., 1992. Estudio de los Artiodáctilos del yacimiento del Pleistoceno medio de Pinilla del Valle (Madrid). Tesis doctoral. Universidad Complutense de Madrid. Madrid.

Cacho Quesada, C., Ripoll López, S., Jordá Pardo, J. F., Muñoz Ibañez, F., Yravedra Sainz de los Terreros, J., Maicas Ramos, R., 2003. Ocupaciones Magdalenienses en la Meseta Norte. La Peña de Estebanvela (Segovia). Zephyrus. 56, 19 - 37.

Cacho Quesada, C., Muñoz Ibáñez, F., Martos Romero, J. A., 2006. Industria lítica de la Peña de Estebanvela (Segovia), en: Cacho Quesada, C., Ripoll López, S., Muñoz Ibáñez, F. (Eds.), Estudio tecnológico y tipológico. La Peña de Estebanvela (Estebanvela-Ayllón, Segovia). Grupos Magdalenienses en el Sur del Duero, Valladolid, Consejería de Turismo y Cultura, Junta de Castilla y León, Arqueología en Castilla y León. Memorias, 17, pp. 239 - 394.

Cacho Quesada, C., Yravedra Sainz de los Terreros, J., Jordá Pardo, J. F., Ripoll López, S., Muñoz Ibánez, F. J., 2006. La Peña de Estebanvela: Reconstrucción Paleoambiental, Recursos Alimenticios, Cronología y Contexto del Registro Arqueológico. Contactos con la Cornisa Cantábrica y el Ámbito Pirenaico. La Peña de Estebanvela (Estebanvela-Ayllón, Segovia). Grupos Magdalenienses en el Sur del Duero. Array. Valladolid, Consejería de Cultura y Turismo de la Junta de Castilla y León. 1, pp. 427 - 444.

Cardoso, J., 1996. Les grands mammifères du Pléistocène supérieur du Portugal. Essai de synthèse. Geobios. 29, 235 - 250.

Cerdeño, E., 1987. Presencia de Rinoceronte en la fauna de Cueva Millán. Geogaceta. 2, 9 - 10.

Corchón, M. S. 1991 - 1992. Representaciones de fauna fría en el Arte mueble de la Cueva de Caldas (Asturias, España). Significación e implicaciones en el Arte parietal. Zephyrus.44 - 45, 35 - 64.

Corchón, M. S., 1997. La cueva de la Griega de Pedraza. Memorias de Arqueología en Castilla y León 3. Junta de Castilla y León. Zamora.

Couturier, M. A. J., 1938. Le Chamois. Arthaud, Grenoble.

Crégut-Bonnoure, E. 1992b, Intérêt biostratigraphique de la morphologie dentaire de Capra (Mammalia, Bovidae). Ann. Zool. Fennici. 28, 272 - 290.

Dalen, L., Orlando, L., Shapiro B., Brandstrom-Durling, M., Quam, R., Gilbert, M. T. P., FernándezLomana, J. C., Willerslev, E., Arsuaga, J. L. Gotherstrom, A., 2012. Partial Genetic Turnover in Neandertals: Continuity in the East and Population Replacement in the West. Mol. Biol. Evol. DOI: 10.1093.

Dalmau Bueno, A., 2005. Comportamiento social y de alimentación del rebeco pirenaico (Rupicapra pyrenaica pyrenaica). Universitat Autonoma de Barcelona. Barcelona.

Davis, S. J. M., 1980. Late Pleistocene and Holocene equid remains from Israel. Zoological Journal of the Linnean Society. 70, 289 - 312.

Delibes de Castro, G., Díez Martín, F., 2006. ¿Una meseta desolada? Estado actual de la investigación sobre Paleolítico superior en las regiones interiores de la Península Ibérica, en: Delibes de Castro, G., Diez Martín, F. (Eds.), El Paleolítico superior en la Meseta Norte española. Studia Archaeologica, Universidad de Valladolid, Fundación Duques de Soria, 94, pp. 11 - 39.

d'Errico, F., Vanhaeren, M., 2002. Criteria for identifying red deer (Cervus elaphus) age and sex from their canines. Application to the study of Upper Palaeolothic and Mesolithic ornaments. Journal of Archaeological Science. 29, 211 - 232.

Díez, J. C., 1990. La cueva del Pleistoceno Superior de Valdegoba. Raña. 9, 39 - 40.

Díez, J. C., 2006. Huellas de descarnado en el Paleolítico Medio: la cueva de Valdegoba (Burgos). Zona Arqueológica. 7, 305 - 316.

Díez, J. C., García, M. A., Gil, E., Jordá Pardo, J. F., Ortega, A. I., Sánchez, A., Sánchez, B., 1988-1989. La Cueva de Valdegoba (Burgos). Primera Campaña de Excavaciones. Zephyrus. 41 - 42, 55 - 74.

Díez, C., Navazo, M., Alonso, R., 2008. La Gestión de los Recursos en los Asentamientos Musterienses de la Ermita y Millán (Hortigüela, Burgos), en: Lario, J., Silva, P.G. (Eds.), Contribuciones al Estudio del Periodo Cuaternario. Ávila, Aequa. 1, pp. 103 - 104.

Díez, J. C., Rodríguez Marcos, J. A., 2009. Las raíces de nuestra historia. De Atapuerca al Neolítico, Caja Círculo, Burgos, pp. 207. 
Díez Martín, F., Sánchez Yustos, P., Gómez González J. A., Gómez de la Rúa, D., Yravedra Sáinz de los Terreros, J. Díaz Muñoz, I., 2011. La ocupación neandertal en el Cañón de la Horadada (Mave, Palencia, España): Nuevas perspectivas arqueológicas en Cueva Corazón. Munibe. 62, 65 85.

Eisenmann, V., Alberdi, M. T., De Giuli, C., Staesche, C., 1988. Collected papers after the "New York International Hipparion Conference, 1981", en: Woodburne, M., Sondaar, P. (Eds.), Studying fossil horses. 1 Methodology, 1 - 7.

Esteban, M., Sanchiz, B., 1990. Sobre la presencia de Rana iberica en el Pleistoceno burgalés. Revista Española de Herpetología, 5, 93 - 99.

Fandos, P., Aranda, Y., Orueta, J. F., 1992. Tamaño y tipo de grupo en la cabra montés (Capra pyrenaica). Relación con el ciclo reproductivo. Etología. 2, 65 - 70.

Fernández, H., 2001. Ostéologie compare des petits ruminants eurasiatiques sauvages et domestiques (genres Rupicapra, Ovis, Capra et Capreolus): diagnose différentielle du squelette appendiculaire. PhD thesis, Université de Genève.

Fernández-Llario, P., Mateos-Quesada, P., 2005. Udder preference in wild board piglets. Acta Ethologica. 8, 51 - 55.

Gee, H., 1993. The distinction between postcranial bones of Bos primigenius Bojanus, 1827 and Bison priscus Bojanus, 1827 from the British Pleistocene and the taxonomic status of Bos and Bison. Journal of Quaternary Science. 8 (1), 79 - 92.

Hayssen, V., Van Tienhoven, A., Van Tienhoven, A., Asdell, S. A., 1993. Asdell's patterns of mammalian reproduction. A compendium of species -specific data. New York, Corner University Press.

Hernández Pacheco, E., 1917. Los grabados de la Cueva de Penches (Burgos). C.I.P.P. 17. Madrid.

Herrero, J., 2002. Adaptación funcional del jabalí (Sus scrofa L.) a un ecosistema forestal y a un sistema agrario intensivo en Aragón. Tesis Doctoral. Universidad de Alcalá. Alcalá de Henares.

Iñigo, C., 1995. El Rinoceronte del Pleistoceno Superior de la Cueva del Búho (Segovia). Boletín Geológico y Minero. 106 (2), 3 - 6.

Iñigo, C., Molero, G., Maldonado, E., 1998. Los carnívoros del yacimiento pleistoceno de Cueva del Búho (Segovia, España) y sus huellas de actividad. Estudios Geológicos. 54, 65 - 73.

Jaubert, J., Lorblanchet, M., Laville, H., Slott-Moller, R., Turq, A., Brugal, J. P., 1990. Les chasseurs d'Aurochs de La Borde. París, Éditions de la Maison des Sciences de l’Homme. D.A.F. no 27.

Jimeno Martínez, A., Fernández Moreno, J. J., 1988. Una placa de arte mueble paleolítico en la provincia de Soria. Trabajos de Prehistoria. 45, 235 - 241.

Jordá Pardo, J. F., 2006a. La malacofauna del yacimiento de la Peña de Estebanvela (Segovia), en: Cacho Quesada, C., Ripoll López, S., Muñoz Ibáñez, F. (Eds.), La Peña de Estebanvela (Estebanvela-Ayllón, Segovia). Grupos Magdalenienses en el Sur del Duero, Valladolid, Consejería de Cultura y Turismo, Arqueología en Castilla y León, Memorias 17, pp. 107 - 125.

Jordá Pardo, J. F., 2006b. La Peña de Estebanvela (Ayllón, Segovia). Estudio Geoarqueológico, en: Cacho Quesada, C., Ripoll López, S., Muñoz Ibáñez, F. (Eds.), La Peña de Estebanvela (Estebanvela, Ayllón, Segovia). Grupos Magdalenienses en el Sur del Duero, Valladolid, Consejería de Cultura y Turismo de la Junta de Castilla y León 1, pp. 43 - 89.

Jordá Pardo, J., Cacho, C., 2013. Radiocarbono y cronoestratigrafía del registro arqueológico pleistoceno de La Peña de Estebanvela (Ayllón, Segovia, España), en: Cacho, C. (Ed.), Ocupaciones magdalenienses en el interior de la Península Ibérica. La Peña de Estebanvela (Ayllón, Segovia), Junta de Castilla y León, CSIC, 75 - 92.

Klein, R G., Cruz-Uribe, K., 1984. The Analysis of Animal Bones from Archaeological Sites. University of Chicago Press. Chicago. pp. 273.

Magniez, P., 2010. Etude paléontologique des Artiodactyles de la grotte Tournal (Bize-Minervois, Aude, France). Etude taphonomique, archéozoologique et paléoécologique des grands mammifères dans leur cadre biostratigraphique et paléoenvironnemental. Thèse de doctorat, University of Perpignan, pp. 791. 
Maldonado, E., 1996. Revisión de los équidos del Pleistoceno Medio y Superior de España. Tesis Doctoral. Universidad Complutense. Madrid.

Markina, F. A., Sáez-Royuela, C., De Garnica, R., 2003. Fenología reproductiva del jabalí (Sus scrofa L.) en las Montañas Cantábricas (Álava, Norte de España). Galemys. 15, 145 - 155.

Martín Merino, M. A., 1978. Cavidades de los alrededores de San Pedro de Arlanza. Kaite. Estudios de Espeleología Burgalesa, Caja de Ahorros Municipal de Burgos, Diputación de Burgos 1, 27 $-61$.

Mateos-Quesada, P., 2005. Densidad poblacional y uso del espacio del corzo en el centro de la Península Ibérica. Galemys. 17 (1-2), 3-12.

Moigne, A. M., Palombo. A. R., Belda, V., Heriech-Briki, D., Lacombat, F., Lumley, M.A., Moutoussamy, J., Rivals, F., Quilès, J., Testu, A., 2006. Les faunes de grands mammifères de la Caune de l'Arago (Tautavel) deans le cadre biochronologique des faunes du Pléistocène moyen italien. L'Anthropologie. 110, 778 - 831.

Molero, G., Iñigo, C., Maldonado, E., Sánchez, F. L., Diez, A., 1989. El yacimiento del Pleistoceno Superior de la Cueva del Búho (Perogordo, Segovia) y su fauna de vertebrados. Resúmenes V Jornadas de Paleontología. Valencia, pp. 101 - 102.

Mosquera, M., Ollé, A., Pérez-González, A., Rodríguez Álvarez, X. P., Vaquero, M., Vergès, J. M. Carbonell, E., 2007. Valle de las Orquídeas: un yacimiento al aire libre del Pleistoceno Superior en la Sierra de Atapuerca (Burgos). Trabajos de Prehistoria. 64 (2), 143 - 155.

Moure Romanillo, J. A., 1983. Radiocarbon datin of the Musterian in Cueva Millán (Hortigüla, Burgos, Spain). Current Anthropology. 19 (2), 155 - 157.

Moure Romanillo, J. A., García Soto, E., 1982. Datación radiocarbónica del Musteriense de Cueva Millán (Hortigüela, Burgos). Boletín del Seminario de Estudios de Arte y Arqueología. XLVIII, $71-72$.

Moure Romanillo, J. A., García Soto, E., 1983. Cueva Millán y La Ermita. Dos yacimientos musterienses en el valle medio del Arlanza. Seminario de Estudios de Arte y Arqueología. 49, $5-30$.

Nascetti, G., Lovari, S., Lanfranchi, P., Berducou, C., Matiucci, S., Rossi, L., Bullini, L., 1985. Electrophoretic studies semonstrating species distinction of chamois populations of the Alps from those of the Apennines and Pyrenees, en: Lovari, S. (Ed.), Revision of Rupicapra Genus. III, The Biology and Management of Mountain Ungulates. Croom Helm, London, pp. 56 - 62.

Navazo, M., 2006. Sociedades cazadoras-recolectoras en la sierra de Atapuerca durante el Paleolítico Medio: patrones de asentamiento y estrategias de movilidad. Tesis Doctoral. Universidad de Burgos. Burgos.

Navazo, M., Díez, J. C., Torres, T., Colina, A., Ortiz, J. E., 2005. La cueva de Prado Vargas. Un yacimiento del Paleolítico Medio en el sur de la Cordillera Cantábrica, en: Montes Barquín, R., Lasheras Corruchaga J. A. (Eds.), Neandertales Cantábricos, Estado de la Cuestión. Santillana del Mar, Museo Nacional y Centro de Investigación de Altamira. 20, 151 - 166.

Navazo, M. Díez, J. C. 2008. Prado Vargas y la variabilidad tecnológica a finales del Paleolítico Medio en la Meseta Norte. Treballs d'Arqueologia. 14, 121 - 139.

Obermaier, H., 1925. El hombre fossil (2 ${ }^{a}$ edición). Memoria 9. Comisión de Investigaciones Prehistóricas y Protohistóricas. Madrid. Museo Nacional de Ciencias Naturales. Madrid.

Pales, L., García, M. A., 1981. Atlas ostéologique des mamiféres. CNRS. Paris.

Perea, S., Doabrio, I., 2013. Restos ictiofaunísticos del Pleistoceno superior del yacimiento de La Peña de Estebanvela (Ayllón, Segovia), en: Cacho, C. (Ed.), Ocupaciones magdalenienses en el interior de la Península Ibérica. La Peña de Estebanvela (Ayllón, Segovia), Junta de Castilla y León, CSIC, 133 - 148.

Pérez-Barbería, F. J., 1994. Biología, ecología y caracterización genética del rebeco cantábrico (Rupicapra pyrenaica parva). Tesis Doctoral. Universidad de Oviedo. Oviedo.

Pérez-Legido, B., Cerdeño, E., 1992. Los Macromamíferos del Pleistoceno Superior de Cueva Millán (Burgos). Estudios Geológicos. 48, 187 - 192. 
Pérez Romero, A., 2009. Protohistoria e historia en el Portalón de Cueva Mayor, Sierra de Atapuerca (Burgos). Tesis de Licenciatura. Departamento de Ciencias Históricas y Geografía. Facultad de Humanidades y Educación. Universidad de Burgos. Burgos.

Quam, R. M., Arsuaga, J. L., Bermudez de Castro, J. M., Lorenzo, C., Carretero, J. M., García, N., Ortega, A. I., 2001. Human remains from Valdegoba Cave (Huérmeces, Burgos). Journal of Human Evolution. 41, 385 - 435.

Ripoll, S., Municio, L., 1999. Domingo García. Arte paleolítico al aire libre en la meseta castallana. Memorias de Arqueología en Castilla y León 8. Junta de Castilla y León. Salamanca.

Rivals, F., 2002. Les petits Bovidés pléistocènes dans le bassin méditerranéen et le Caucase. Etude paléontologique, taphonomique, archéozoologique et paléoécologique. Thèse de Doctorat, Université de Perpignan. pp. 417.

Rivals, F., Blasco, R., 2008. Presence of Hemitragus aff. cedrensis (Mammalia, Bovidae) in the Iberian Peninsula: Biochronological and biogeographical implications of its discovery at Bolomor Cave (Valencia, Spain). Systematic Paleontology (Vertebrate Paleontology). 7, 391 - 399.

Rolett, B. V., Chiu, M. Y., 1994. Age estimation of prehistoric pisgs (Sus scrofa) by molar eruption and attrition. Journal of Archaeological Science. 21, 377 - 386.

Rosell, C., 1998. Biología i ecologia del senglar (Sus scrofa L., 1758) a dues poblacions del nordest ibèric. Aplicació a la gestió. Tesis Doctoral. Universidad de Barcelona. Barcelona.

Roselló Izquierdo, E., 1992. La ictiofauna Musteriense de Cueva Millán (Burgos): Consideraciones de índole biológica y cultural contrastadas con ictiocenosis paleolíticas cantábricas. Estudios Geológicos. 48, 79-83.

Sáez-Royuela, C., 1987. Biología y ecología del jabalí. Tesis Doctoral. Universidad Complutense. Madrid.

Sala, M. T. N., 2012. Tafonomía de yacimientos kársticos de carnívoros en el Pleistoceno. Tesis Doctoral. Universidad Complutense de Madrid.

Sala, M. T. N., Algaba, M., Aranburu, A., Pantoja, A., García, N., Berreteaga, A., Arsuaga, J. L. 2009. Estudio preliminar del yacimiento del Pleistoceno Superior de la Cueva de la Zarzamora (Segovia, España). VII Reuniao do Quaternário Ibérico, Faro.

Sala, M. T. N., Pantoja, A., Arsuaga, J. L., Algaba, M. 2010. Presencia de bisonte (Bison priscus Bojanus, 1827) y uro (Bos primigenius Bojanus, 1827) en las cuevas del Búho y de la Zarzamora (Segovia, España). Munibe. 61, 43 - 55.

Sánchez Marco, A., 2013. Avifauna finipleistocena de La Peña de Estebanvela (Segovia), en: Cacho, C. (Ed.). Ocupaciones magdalenienses en el interior de la Península Ibérica. La Peña de Estebanvela (Ayllón, Segovia), Junta de Castilla y León, CSIC, 149 - 155.

Sánchez Yustos, P., Díez Martín, F., Díaz Muñoz, I., Gómez de la Rúa, D., Gómez González J. A., 2011. Estrategias de talla en Cueva Corazón (Mave, Palencia). Un yacimiento del Musteriense antiguo en las estribaciones meridionales de la Cordillera Cantabrica. Trabajos de Prehistoria. 68 (1), 51 - 63.

Sanchiz, B., Bailon, S., 2013. Nuevos datos sobre la herpetofauna tardiglaciar deLa Peña de Estebanvela (Segovia), en: Cacho, C. (Ed.), Ocupaciones magdalenienses en el interior de la Península Ibérica. La Peña de Estebanvela (Ayllón, Segovia), Junta de Castilla y León, CSIC, $141-148$.

Santos, P., Fernández-Llario, P., Fonseca, C., Monzón, A., Bento, P., Soares, A. M. V. M., MateosQuesada, P., Petruci-Fonseca, F., 2006. Habitat and reproduive phenology of wild boar (Sus scrofa) in the western Iberian Peninsula. European Journal of Wildlife Research. 52 (3), 207 212.

Schertz, E., 1936. Zur Unterscheidung von Bison priscus Bojanus, 1827 und Bos primigenius Bojanus 1827. an Metapodien und Astragalus. Senckenbergiana. 18, 37 - 71.

Sesé, C., 2013. Nuevos datos sobre los micromamíferos del yacimiento de La Peña de Estebanvela (Segovia), en: Cacho, C. (Ed.). Ocupaciones magdalenienses en el interior de la Península Ibérica. La Peña de Estebanvela (Ayllón, Segovia), Junta de Castilla y León, CSIC, 157 - 182.

Sisson, S., Grossman, J. P., 2001. Anatomía de los animales domésticos. Tomo I. Masson. Barcelona. 
St. Clair, L. E., 2005. Sistema digestivo de los ruminates, en: Sisson, S., Grossman, J.D. (Eds.), Anatomía de los animales dométicos. Tomo I. Masson. Barcelona.

Stiner, M. C., 1994. Honor among thieves: a zooarchaeological study of Neandertal ecology. Princeton, Princeton University Press.

Torres, T., Rodríguez, B., González, P., 1989. Excavación en el yacimiento de la cueva de Prado Vargas, Merindad de Sotoscueva (Cornejo, Burgos). Memoria Científica, Junta de Castilla y León, pp. 1-116.

Torres, T., Rodríguez, B., González, P., 1993. Excavación de la cueva de Prado Vargas, Cornejo (Burgos, España). Actas de la Segunda Reunión del Cuaternario Ibérico 1989, Madrid, I.T.G.E. 1, pp. $281-289$.

Trancho, G. J., Robledo, B., 2006. Restos humanos de la Peña de Estebanvela (Segovia), en: Cacho Quesada, C., Ripoll López, S., Muñoz Ibáñez, F. (Eds.), La Peña de Estebanvela (EstebanvelaAyllón, Segovia). Grupos Magdalenienses en el Sur del Duero, Valladolid, Consejería de Turismo y Cultura, Junta de Castilla y León. Arqueología en Castilla y León. Memorias. 17, pp. $217-224$.

Utrilla, P., González, P., Ferrer, C., Blasco, F., 1999. La ocupación magdaleniense del valle del río Henar: los asentamientos de Cetina (Zaragoza) y Deza (Soria). Geologia i Quaternari litoral. Memorial M.P. Fumanal. 283 - 296.

Utrilla, P., Blasco, F., 2000. Dos asentamientos Magdalenienses en Deza, Soria. Boletín del Seminario de estudios de Arte y Arqueología, BSAA .66, 9 - 64.

Utrilla, P., Blasco, F., Rodanés, J. M., 2006. Entre el Ebro y la Meseta: el Magdaleniense en la Cuenca del Jalón y la Placa de Villalva, en: Delibes de Castro, G., Díez Martín, F. (Eds.), El Paleolítico Superior en la Meseta Norte Española. Universidad de Valladolid. Serie Studia Archaeologica. $94,173-213$.

Van der Made, J., 1989. The bovid Pseudotragus seegrabensis nov. gen., nov. sp. from the Aragonian (Miocene) of Seegraben near Leoben (Austria). Proceedings of the Royal Society B. 92 (3), $215-240$.

Van der Made, J., 1996. Listriodontinae (Suidae, Mammalia) their evolution, systematic and distribution in time and space. Contributions to Tertiary and Quaternary. Geology. 33 (1 - 4), $3-254$.

Van der Made, J., 2010. The rhinos from the middle Pleistocene of Neumark Nord (Saxony-Anhalt). Veröffentlichungen des landesamtes für denkmalpflege und_archäologie. 62, 434 - 527.

Van der Made, J., Aguirre, E., Bastir, M., Fernández Jalvo, Y., Huguet, R., Laplana, C., Márquez, B., Martínez, C., Martinón, M., Rosas, A., Rodríguez, J., Sánchez, A., Sarmiento, S., Bermúdez de Castro, J. M., 2003. El registro paleontológico y arqueológico de los yacimientos de la Trinchera del Ferrocarril en la Sierra de Atapuerca. Coloquios de Paleontología. 1, 345 - 372.

Vigal, C. R., Fandos, P., 1989. Estimación de la edad de los fetos y de los periodos de celo y parto en la cabra montés de Gredos. Graellsia. 45, 31 - 34.

Wegrzyn, M., Serwatka, S., 1984. Teeth eruption in the European Bison. Acta Theriologica. 29 (9), $111-121$.

Yravedra Sainz de los Terreros, J., 2006. Zooarqueología y tafonomía de los macromamíferos y lagomorfos de la Peña de Estebanvela (Segovia), en: Cacho, C., Ripoll, S., Muñoz, F. (Eds.). La Peña de Estebanvela (Estebanvela-Ayllón, Segovia). Grupos Magdalenienses en el Sur del Duero. Valladolid, Consejería de Turismo y Cultura. Junta de Castilla y León. Arqueología en Castilla y León. Memorias. 17, 167 - 216.

Yravedra Sainz de los Terreros, J., 2013. Estrategias de subsistencia entre los grupos magdalenienses de la Peña de Estebanvela (Ayllón, Segovia), en: Cacho, C. (Ed.), Ocupaciones magdalenienses en el interior de la Península Ibérica. La Peña de Estebanvela (Ayllón, Segovia), Junta de Castilla y León, CSIC, 211 - 244. 